UNIVERSIDAD NACIONAL DE LA PLATA

Facultad de Ciencias Naturales y Museo

\title{
Movilidad y Utilización del Ambiente en Poblaciones Cazadoras-Recolectoras del Sur de la Región Pampeana: la Cuenca del Arroyo Chasicó como Caso de Estudio
}

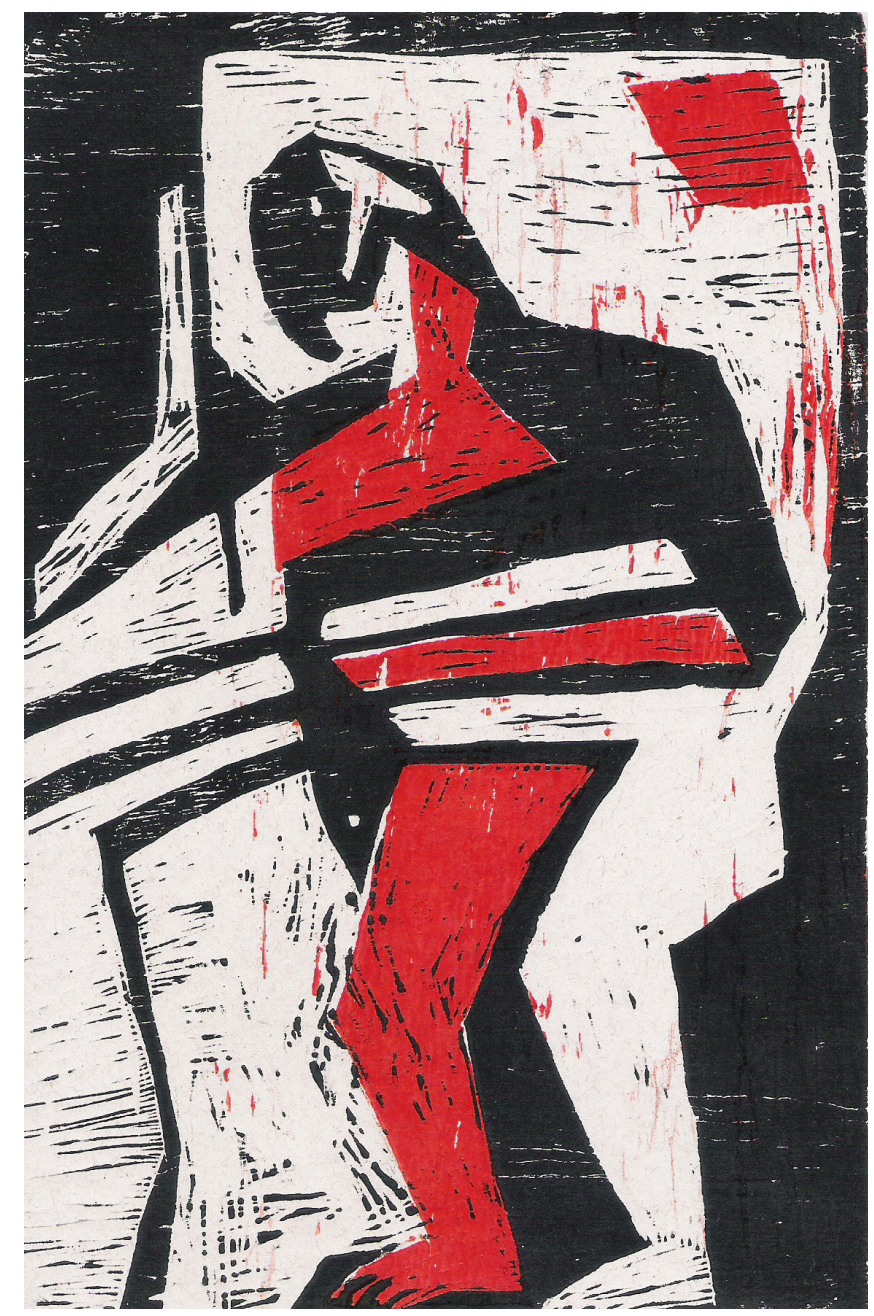

\section{Luciana Catella}

Director: Dr. Gustavo Barrientos

Trabajo de Tesis para optar por el título de Doctor en Ciencias Naturales Julio de 2014 
A Avi y Tati 


\section{Agradecimientos}

Muchas fueron las personas que de una u otra forma me ayudaron a poder llevar a cabo esta investigación y hoy, después de varios años de trabajo, algunos de sus nombres seguramente se me olviden. Sin embargo vale la pena hacer el intento y tratar de mencionar a la mayor parte de ellos. En primer lugar quiero agradecerles a Fernando Oliva y Gustavo Barrientos, quienes me acompañaron y guiaron desde el primer momento, haciendo caso omiso de mi, demasiado frecuente, "poca onda", especialmente durante el último tiempo. Desde dos lugares diferentes y con perspectivas bastante distintas orientaron mis trabajos y se tomaron el tiempo para discutir, leer, corregir y volver a discutir. A ellos dos muchas gracias, ya que sin su ayuda nunca hubiese podido realizar este trabajo.

El Consejo Nacional de Investigaciones Científicas y Tecnológicas y la Universidad Nacional de La Plata me otorgaron las becas que me permitieron llevar a cabo este doctorado. Además conté con el subsidio a tesistas de la Facultad de Ciencias Naturales y Museo (UNLP) y subsidios a Jóvenes Investigadores de la Universidad Nacional de La Plata.

Mi reconocimiento al Organismo Provincial para el Desarrollo Sustentable (OPDS), en particular al personal del Parque Provincial E. Tornquist y de la Reserva Natural de Objetivos Definidos Laguna Chasicó, así como a la Cooperadora Chapalcó y a los municipios de Tornquist y Villarino por apoyar estas investigaciones brindándome alojamiento, facilitando los traslados y realizando todo tipo de apoyo logístico. También al Centro de Registro Arqueológico y Paleontológico del Instituto Cultural de la Provincia de Buenos Aires especialmente a Laura Lisboa, Mariano Arregui, Lucas Martínez, Verónica Lirusso y Delia Cocconi. A Mariano del Papa de la División Antropología y a Gabriel Alarcón y Jorge Kraideberg por su asistencia durante el análisis de las colecciones arqueológicas y bioarqueológicas depositadas en el Museo de La Plata.

Al personal del INGEIS, muy especialmente a Augusto Tessone por el procesamiento de las muestras para la obtención de valores isotópicos. También al NSF Arizona AMS Facility, The University of Arizona por los descuentos otorgados en la realización de las dataciones radiocarbónicas.

Con Jorge San Cristóbal y Marcelo Manassero discutí sobre diversos aspectos geológicos, particularmente acerca de la procedencia de las rocas utilizadas en la confección de artefactos. Jorge además me permitió revisar sus muestras geológicas del sur de Buenos Aires y La Pampa, entre mates, galletitas y charlas sobre ciencia y geología.

A Leonardo García San Juan por recibirme en la Universidad de Sevilla donde pude realizar una pasantía. Con él y Joaquín Márquez Pérez discutí algunos de los temas aquí presentados. También a los compañeros de laboratorio durante esos días, Luis, Miriam, Daniela, Cristina y Marisa. A la Universidad Nacional de La Plata por financiar parcialmente esta estancia. 
Los trabajos de campo y análisis de colecciones particulares fueron posibles gracias a la enorme hospitalidad de muchas personas. Mi reconocimiento a Nora Cinquini y su familia, quienes me abrieron las puertas de su casa para que pudiera estudiar las colecciones arqueológicas. A Inés de la Estancia La Sofía y a Cristina de La Taba y a Carmén y Héctor. En Chapalcó quiero agradecerles a Silvina, Leticia Samosiuk, Adrián Olaverría, Luis Egea y sus hijos, Flia Wendorff, Fausto, Peluso y personal del establecimiento El Oasis, El Vizcacha, Puchuca, Angel y Bruno Schinchirimini, Pesquero Los Médanos, Ariel Rule y el personal de Chapalcó Ray, Angel Guette, Estancia Ibarburen, Establecimiento Los Mellizos, especialmente a Sandra Maurici y sus hijos (los mellizos), Rodolfo Cisneros y al pueblo de Chapalcó en general. Todos ellos me recibieron muy amablemente y me ayudaron durante mis estancias en la laguna, llevándome y trayéndome, compartiendo mates, comidas, contándome sobre los lugares en los que habían visto materiales y permitiéndome analizar los materiales que algunos de ellos tenían en sus casas.

A Marcelo Sánchez Peressi, Fabrizio Piantanida, Isabel Garmedia, Aníbal Areco, Daniel Porte, Patricia González y Juanjo Navarro por su constante apoyo durante las tareas de campo desarrolladas en la laguna Chasicó y el Parque Tornquist, pero especialmente por las largas charlas y asados compartidos.

A quienes iniciaron conmigo esta investigación Leonardo Mudry, David Ávila, Mariela Gallego, María Pía Ayuso, con ellos realicé los primeros análisis y viajes a Chasicó. También a quienes vinieron en los viajes posteriores: Valentina Aviani, Catalina Vicente y Linda Miguez.

Mi mayor agradecimiento a quienes compartieron el laboratorio durante los últimos años. A Natalia Morales por su eterna paciencia y ayuda en las tareas de campo y laboratorio, particularmente en el análisis de los elementos óseos faunísticos. A Jorge Moirano con quien realizamos las prospecciones en la cuenca superior y discutimos muchos de los temas relacionados con aprovisionamiento lítico. A él le debo también la mayor parte de las fotografías de materiales. A María Cecilia Panizza por todas las horas compartidas, el constante intercambio de ideas y bibliografía y, sobre todo, por sus exquisitas tortas. A Camila Oliva, Anabella Sfeir y Gimena Devoto por su ayuda en los momentos finales. A Miguel Delgado Burbano por el tiempo compartido en el laboratorio de Barrientos. También a Mariana Algraín y Diana Tamburini quienes son el apoyo rosarino.

Al equipo del Museo de Historia Natural de San Rafael por su hospitalidad durante los cursos de postgrado realizados en esa localidad y por prestarme su biblioteca. Realizar cursos en San Rafael siempre fue un enorme placer.

A los docentes de los cursos de postgrado, quienes a través de sus comentarios y discusiones aportaron a lo volcado en este trabajo: Pilar Babot, Nora Franco, Gustavo Neme, Adolfo Gil, Ailén Capparelli, Barbara Balesta, María Gutiérrez, Juan Bautista Belardi. Colaboraron también con este trabajo, respondiendo a mis consultas, facilitándome bibliografía y realizando comentarios y préstamos varios, Virginia Lynch, Laura Miotti, Lucía Magnin, Leire Carrascosa, Eduardo Llambías, Ana María Sato, Arturo Giordano, Gabriela Zavalía

A los amigos, Elina Albarrán, Gabriela Ameri, Celeste Isasmendi, Dario Hermo, Miguel Giardina, Rocío Fernández, Magali Sánchez, Brenda Mira, Paola Mansilla, Gastón Reale, Facundo Castiñeira, Mariángeles Güerci, Florencia Paganini, por preguntar (y entender cuándo no preguntar), por bancarme, ayudarme de cuanta manera pudieron, escucharme siempre y, fundamentalmente, alentarme para que 
termine, de una buena vez, la tesis. A mis ahijados Igor y Matías, por tantas visitas postergadas. A Florencia Paganini quiero agradecerle también su ayuda con el diseño y las imágenes. A Mariángeles Güerci por la impresión de la tesis. Y a Miguel Giardina por la determinación de los elementos óseos correspondientes a aves. También a su familia, especialmente a "la Mary" y a Naty por alojarme en sus casas durante los cursos realizados en San Rafael. A Pepe por tantos cursos compartidos.

Por último, a mi familia, a quienes les debo el trabajo completo. Por acompañarme y apoyarme siempre, incondicionalmente. A mis hermanos Facundo y Valeria, a Iván, a mi Tío, Margarita, Nico, a mis abuelos. También a la familia Raverta, Horacio, Mónica, Paula, Luka y Julia y su familia. Por su constante interés y aliento. Los aportes de mis padres han sido infinitos, inclusive participaron de alguna prospección en la laguna Chasicó. La imagen de tapa es una xilografía realizada especialmente por mi madre para ilustrar este trabajo. A ella le debo también los dibujos de la cerámica.

A mi tía Nata por sus paseos por las salas del museo que fueron mi primer contacto con la arqueología.

Sin todos ustedes esta investigación no hubiera sido posible. Muchas Gracias! 


\section{Resumen}

En esta tesis se presentan los resultados de una investigación arqueológica realizada en la cuenca del arroyo Chasicó, un área de aproximadamente $3800 \mathrm{~km}^{2}$, localizada en el sector sur de la denominada Área Ecotonal Húmedo-Seca Pampeana (AEHSP), más precisamente en la zona de transición entre las regiones Pampeana y Patagónica, abarcando tanto ambientes de transición, como ambientes con características propias de ambas regiones. Dichas investigaciones estuvieron orientadas a aportar información sobre las pautas de movilidad y utilización de los recursos implementadas por las sociedades cazadoras-recolectoras del Holoceno. De este modo, se realiza un aporte a la arqueología regional ya que se integran diversas líneas de evidencia a partir de estudios cuali-cuantitativos y espaciales de datos primarios (i.e. generados por la autora) y secundarios (i.e. información previamente existente en la literatura), ordenados según diversas escalas de análisis.

En este marco, los objetivos específicos se orientaron a: 1) establecer la estructura del registro arqueológico regional, 2) identificar tendencias en la manufactura y uso de artefactos y ecofactos, principalmente del instrumental lítico, 3) evaluar la incidencia de los principales agentes y procesos postdepositacionales que actúan en la formación del registro arqueológico a nivel regional, 4) sistematizar la información ambiental y paleoambiental disponible y 5) discutir la información obtenida desde el punto de vista de los modelos teóricos disponibles acerca de la movilidad de los cazadores-recolectores, en relación con la estructura de los recursos y con otros factores de naturaleza ecológica, social y cultural.

La información analizada procede de la realización de prospecciones en los diferentes sectores de la cuenca (superior, medio e inferior) y en algunas áreas vecinas (salinas Chicas, salitral de la Vidriera, río Sauce Chico y arroyo Napostá), del análisis de materiales arqueológicos -procedentes de excavaciones, recolecciones superficiales y colecciones de museo- y del relevamiento y sistematización de información édita regional. A partir de esta información se analizó: 1) la distribución espacial del registro arqueológico y de los recursos acerca de los cuales hay evidencias de su utilización -real y/o potencial- por parte de los grupos humanos, 2) las características en el diseño y uso de los artefactos líticos y cerámicos así como las tendencias en la distribución de las materias primas utilizadas en la fabricación de las principales categorías de ítems ergológicos, 3) la diversidad taxonómica, los patrones de representación anatómica y las pautas de procesamiento inferibles a través de estudios arqueofaunísticos, 4) los patrones de variación espacial -a diferentes escalas- en los valores de isótopos estables del carbono y nitrógeno de muestras humanas y animales, 5) los patrones de diversidad a nivel del registro bioarqueológico y 6) la distribución espacial y temporal de los fechados radiocarbónicos.

La información arqueológica obtenida, generalmente en localizaciones puntuales o sitios fue integrada espacialmente, a nivel de la mesoescala (v.g. la cuenca del arroyo Chasicó) y de la macroescala (v.g. sur de la Región Pampeana y NE de Patagonia; $36^{\circ}$ y $42^{\circ}$ de lat. Sur y $57^{\circ}$ y $68^{\circ}$ de long. Oeste), con los datos ambientales y paleoambientales disponibles, mediante el uso de Sistemas de Información Geográfica (SIG) y de estadísticas descriptivas, aplicadas a la distribución de valores cuantitativos. 
De este modo se generaron modelos estadísticos, espaciales y cronológicos a partir de los cuales se identificaron tendencias informativas acerca de las pautas de movilidad y estrategias de uso del paisaje y los recursos.

Los resultados obtenidos permiten proponer que el Holoceno tardío inicial es el momento en que ocurren las primeras evidencias de ocupación en el área estudiada (probablemente como consecuencia de sesgos tafonómicos y/o de muestreo), iniciándose la secuencia en $c a .4000$ años AP., con una mayor intensidad de la señal arqueológica a partir de $c a .3000$ años AP. Durante este período, en el sur de la Región Pampeana y NE de Patagonia, la distribución de algunos ítems arqueológicos (isótopos estables del carbono y del nitrógeno, frecuencias relativas de las materias primas líticas y características de la pasta cerámica), muestran un patrón de distribución parcelado, que se corresponden con la disponibilidad local de recursos. Estas tendencias no parecen corresponderse con rangos de acción de gran escala, sino con la utilización de áreas relativamente acotadas compatibles, en principio, con las dimensiones de los rangos de acción esperables en función de la latitud, es decir entre ca. $2000 \mathrm{~km}^{2}$ y $12000 \mathrm{~km}^{2}$. El acceso a los recursos se habría realizado, principalmente, por medio de movilidad residencial, con patrones de actividad espacialmente continuos, no territoriales, donde las fronteras o límites no habrían estado claramente definidos. El abastecimiento lítico refleja un uso prioritario de rocas inmediatamente locales y estrategias en las que se priorizó el aprovisionamiento de los individuos por medio de artefactos transportables, principalmente instrumentos terminados y lascas. Las estrategias de aprovisionamiento de lugares se relacionan con la reocupación de sectores particulares del paisaje a los fines de procesar recursos predecibles en el tiempo y el espacio. Por último, la evidencia analizada indica dietas basadas, fundamentalmente, en el consumo de recursos terrestres, tanto vegetales (mayoritariamente $\mathrm{C}_{3}$ ) como animales (mayoritariamente consumidores de vegetales $\mathrm{C}_{3}$ ), donde, el guanaco habría sido la principal fuente de proteínas, acompañado por venado de las pampas, ñandú y animales menores (v.g. mara, armadillos), a lo que se agrega un componente aportado por los recursos vegetales, particularmente leguminosas del Espinal. 


\section{Abstract}

This dissertation explores prehistoric hunters-gatherers' mobility strategies and resource use patterns in the Chasicó Basin, an area of about $3800 \mathrm{~km}^{2}$ localized in the southern of the Humid-Dry Panpean Ecotonal Area (AEHSP), specifically in the transition between the Pampean and Patagonian regions. It represents a contribution to regional Archaeology since it integrates quali-quantitative and spatial studies of primary (i.e. generated during this research) and secondary (i.e. pre-existing on literature) data, sorted by different scales of analyses.

The specific goals of this research are: 1) to set the structure of regional archaeological records, 2) to identify tendencies in the manufacture and use of artifacts and ecofacts, especially among lithic tools, 3) to evaluate the manner in which the main post-depositional processes and agents affect the archaeological record in a regional scale, 4) to systematize environmental and paleo-environmental information and 5) to discuss the archaeological evidence in relation with theoretical models of resource structure and hunters-gatherers' mobility.

Information has been obtained from surface surveys conducted in different sectors of the Chasicó basin (upper, medium and lower) and in neighboring areas (Chicas and de la Vidriera Salt Flats and Sauce Chico and Napostá rivers), as well as from the study of archaeological items -stratigraphy and surface collected- and from the survey and systematization of edited data. This information was used to analyzed: 1) the spatial distribution of archaeological record and resources with evidence of have been used -actual or potential- by human groups, 2) design and use characteristics of lithic and ceramic artifacts, as well as trends on raw material distribution, 3) taxonomic diversity and anatomical representation patterns, through archaeofaunistic analysis, 4) spatial variation patterns -at different scales- in stable isotopic values of carbon and nitrogen of human and animal samples, 5) diversity patterns on bioarchaeological record and 6) spatial and temporal distribution of radiocarbon datings.

The archaeological information, usually obtained in individual and isolated sites, was spatially integrated on a mesoscale (v.g. the Chasicó basin) and macroscale level (v.g. South of the Pampean Region and Northeast of Patagonia; $36^{\circ}$ y $42^{\circ} \mathrm{S}$ and $57^{\circ}$ y $68^{\circ} \mathrm{W}$ ) and with the environmental and paleoenvironmental data. Data were integrated with GIS and descriptive statistic help, creating spatial and chronological models from distributions of quantitative data. These models show the information in a more coherent manner in order to identify informative tendencies and patterns.

The initial late Holocene is the moment when the first evidence of human occupation appears in the study area (probably because of taphonomic and sampling biases). The sequence starts about 4000 years BP, increasing the archaeological signal after 3000 years BP. During this period, in the South of Pampean Region and NE of Patagonia, the distribution of some archaeological items (carbon and nitrogen stable isotopes, relative frequencies of lithic raw material, and characteristics of the pottery paste) shows a patchy pattern corresponding with local resources availability. This trends do not seem to correspond with large home ranges, but wirh the use of relatively small areas, with dimensions similar to those expected based on the latitude (i.e. between $c a .2000 \mathrm{~km}^{2}$ and $12000 \mathrm{~km}^{2}$ ). 
Resource access seems to be obtained, mainly, through residential mobility in a spatially continuous activity area with poorly defined boundaries. Lithic procurement prioritized the provisioning of individuals with local rocks. Supplying places, with large and heavy artifacts from distant sources, were secondarily and related with re-occupation of particular places to process predictable resources. The analized evidence shows diets based on the consumed of terrestrial resources, both vegetables (mainly $\mathrm{C}_{3}$ ) and animals (mainly consumers of $\mathrm{C}_{3}$ vegetables). Lama guanicoe would be the main protein source, complemented with Ozotoceros bezoarticus, Rhea sp and small animals. Vegetables were also consumed, especially legumes of the Espinal province. 


\section{Índice General}

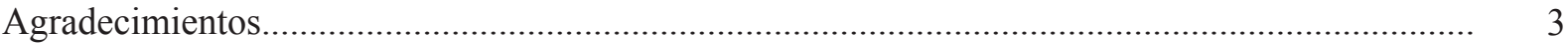

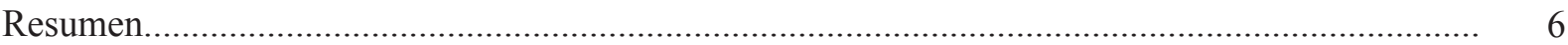

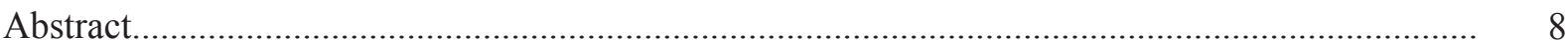

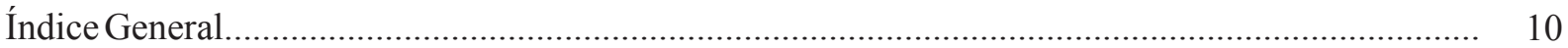

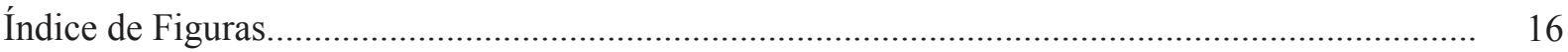

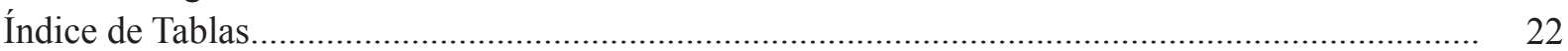

\section{PRESENTACIÓN DEL TEMA Y ÁREA DE ESTUDIO}

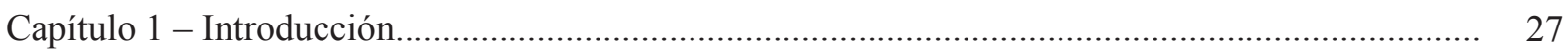

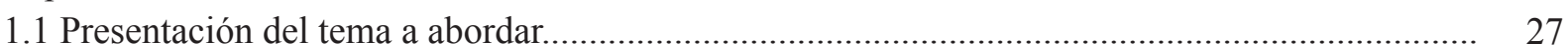

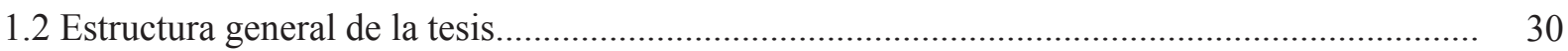

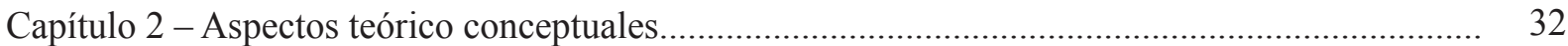

2.1 La movilidad ntre grupos cazadores-recolectores y el uso de grandes ambientes....................... 32

2.2 El ambiente y la movilidad en las sociedades cazadoras-recolectoras......................................... 34

2.2.1 Cómo se utilizan los recursos: modelos de amplitud de dieta, de selección de parcelas y

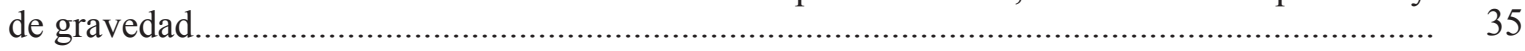

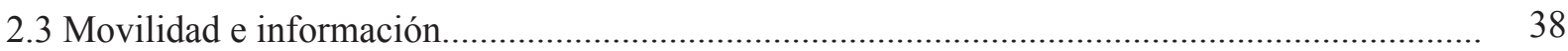

2.4 El concepto de riesgo y su relación con la movilidad y el uso del ambiente.............................. 39

2.5 Aproximaciones teóricas para el abordaje de la relación entre movilidad, uso de los recursos y registro arqueológico

2.6 Indicadores arqueológicos que aportan información sobre los patrones de movilidad y el uso de los recursos

2.6.1 La tecnología como indicador de las estrategias de movilidad y uso de los recursos......... 41

2.6.2 El concepto de estilo tecnológico $\quad 42$

2.6.3 La movilidad de los individuos a través de su "huella" isotópica...................................... 43

2.6.4 Los modelos espaciales y el análisis de tendencias y patrones en los datos......................... 43

Capítulo 3 - Antecedentes 46

3.1 Las investigaciones arqueológicas en el Sur de la Región Pampeana y NE de Patagonia.......... 46

3.1.1 El interés inicial por los materiales arqueológicos........................................................ 46

3.1.2. Cambian las preguntas y se genera nueva información..................................................... 47

3.1.3. El desarrollo de modelos explicativos............................................................................. 49

3.1.3.1 Prácticas mortuorias, salud y nutrición....................................................................... 49

3.1.3.2 Aproximaciones a la subsistencia y el uso de los recursos: su variabilidad espacial y temporal..................................................................................................... 50

3.1.3.2.1 El uso de los recursos animales y vegetales..................................................... $\quad 50$

3.1.3.2.2 El uso de los recursos minerales: los artefactos líticos y cerámicos.................. 52

3.1.3.2.3 Intensificación y diversificación durante el Holoceno tardío.............................. 54

3.1.3.3 La movilidad grupal y el uso del espacio.............................................................. 55

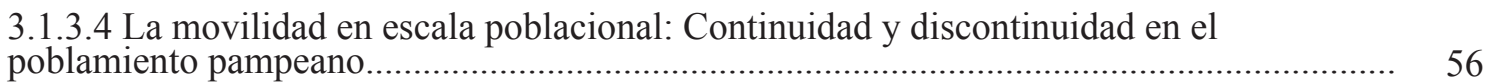

3.1.3.5 La incorporación de los aspectos sociales y simbólicos a las interpretaciones sobre

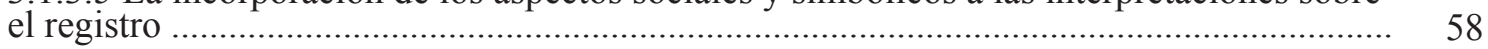

3.2 Las investigaciones arqueológicas en el Sistema Serrano de Ventania y sus inmediaciones....... 59 
3.3 Investigaciones previas en la cuenca del Arroyo Chasicó........................................................... 64

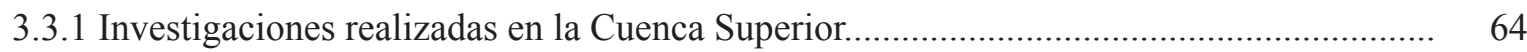

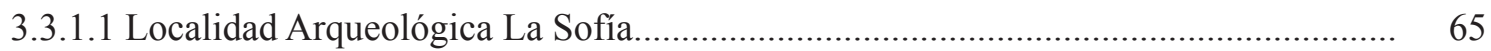

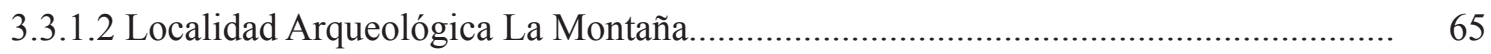

3.3.1.3 Afloramientos de La Mascota............................................................................ 66

3.3.1.4 Localidad arqueológica Los Chilenos................................................................... 67

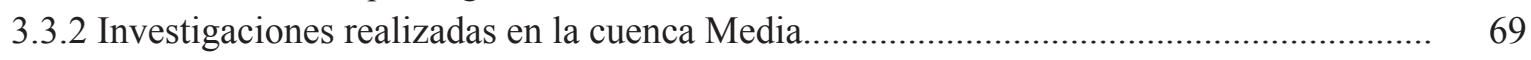

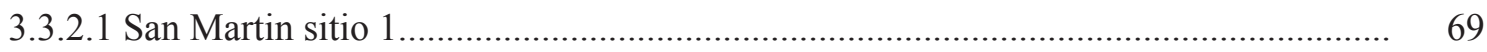

3.3.3 Investigaciones realizadas en la cuenca Inferior........................................................ 70

Capítulo 4 - Características Ambientales del Área de Estudio...................................................... 71

4.1 Caracterización ambiental del sur de la Región Pampeana y NE de Patagonia.......................... 71

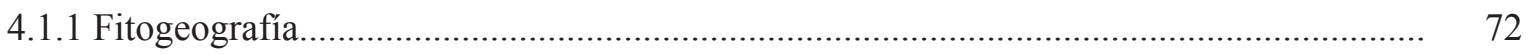

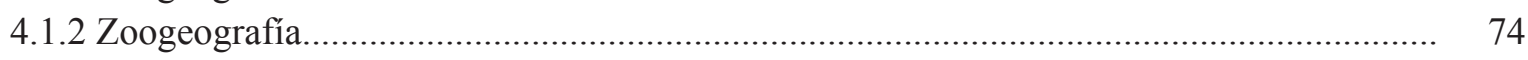

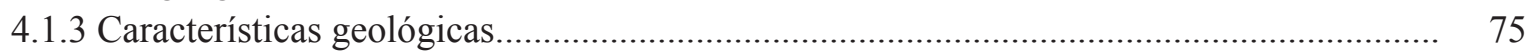

4.2 Las características ambientales de la cuenca del arroyo Chasicó y el área de Ventania.............. 78

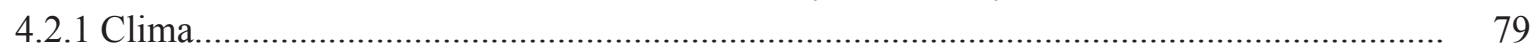

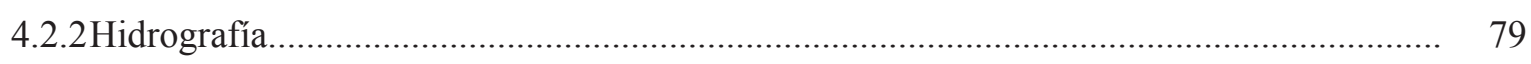

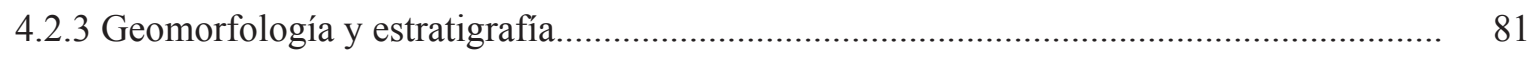

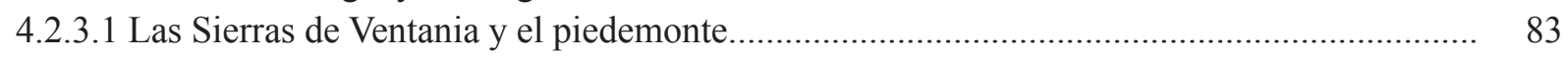

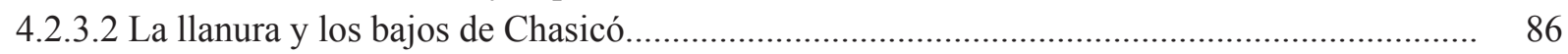

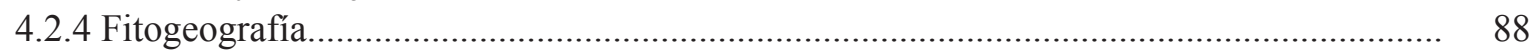

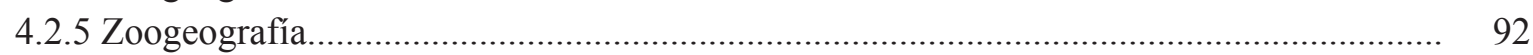

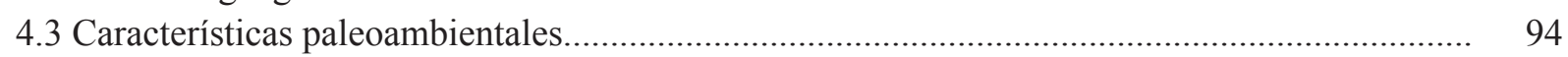

\section{GENERACIÓN DE MODELOS ESPACIALES}

Capítulo 5. Derivación de Expectativas Arqueológicas para la Cuenca del Arroyo Chasicó sobre la base del Análisis e Integración de Información Preexistente..

5.1. Los datos secundarios: sus potencialidades y limitaciones................................................. 101

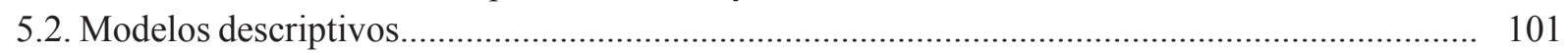

5.2.1. Factores directa o indirectamente involucrados en la generación del registro................. 102

5.2.1.1. Modelo acerca de la estructura regional de los recursos........................................... 102

5.2.1.1.1. Mapeo de recursos vegetales.................................................................... 102

5.2.1.1.2. Mapeo de recursos animales..................................................................... 104

5.2.1.1.3. Mapeo de recursos líticos............................................................................. 104

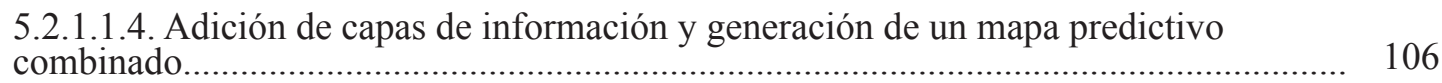

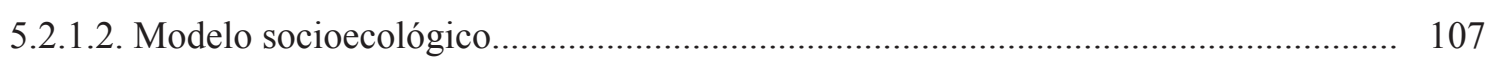

5.2.2. Patrones distribucionales (espaciales y temporales) de diferentes aspectos del registro arqueológico del sur de la Región Pampeana y NE de Patagonia.................................................. 115

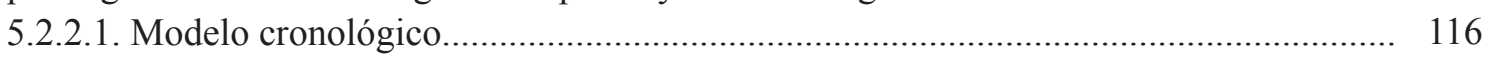

5.2.2.2. Modelos distribucionales de la variación tecnológica............................................. 119

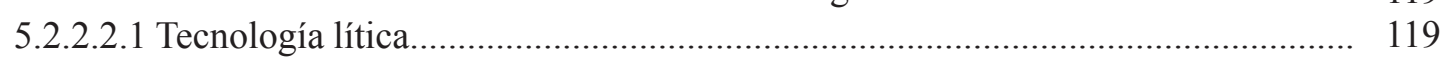

5.2.2.2.1.1 Materias primas representadas en artefactos........................................ 119

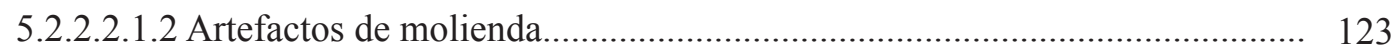

5.2.2.2.2 Tecnología cerámica................................................................................... 124

5.2.2.3. Modelos distribucionales acerca de la dieta (isótopos estables del C y N).............. 126

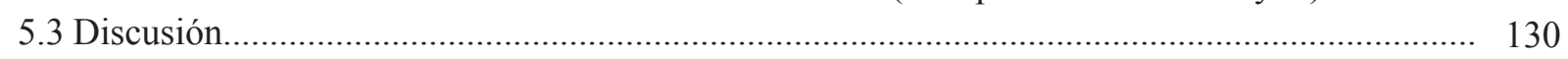




\section{RESULTADOS}

Capítulo 6 - Prospecciones, Sondeos y Excavaciones Arqueológicas.

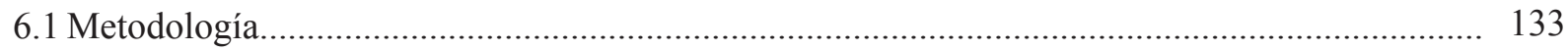

6.1.1 Relevamiento de la disponibilidad de materias primas líticas.......................................... 133

6.1.2 Relevamiento de la distribución del registro arqueológico.............................................. 135

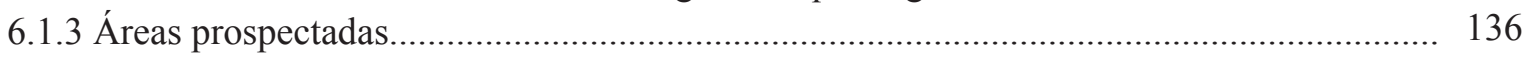

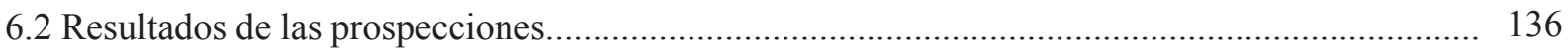

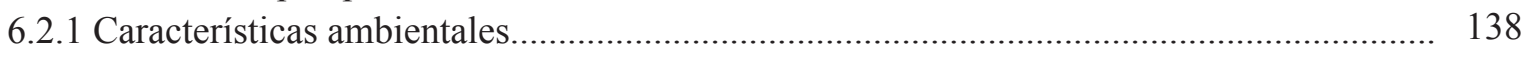

6.2.1.1 Variaciones geomorfológicas y ecológicas............................................................ 138

6.2.1.2 Disponibilidad de materias primas líticas................................................................. 138

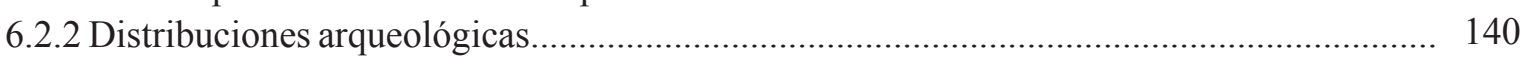

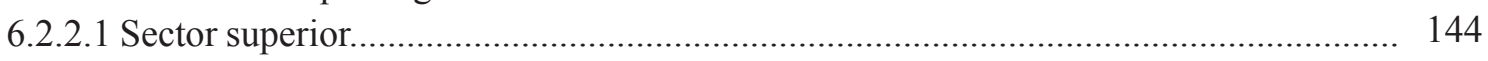

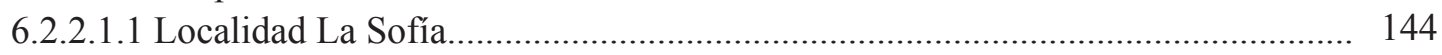

6.2.2.1.2 La Montaña sitio 1.................................................................................... 145

6.2.2.1.3 Localidad Arqueológica Arroyo Saudade......................................................... 145

6.2.2.1.4 Localidad arqueológica Laguna Los Chilenos.................................................... 146

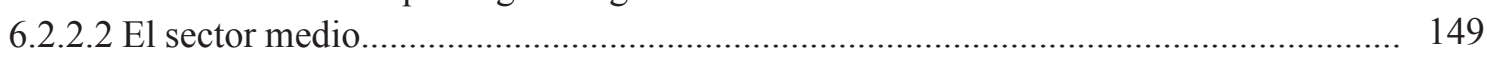

6.2.2.2.1 Colección San Martín (Museo Regional Chasicó)........................................... 150

6.2.2.2.2 San Martín sitio 1........................................................................................ 150

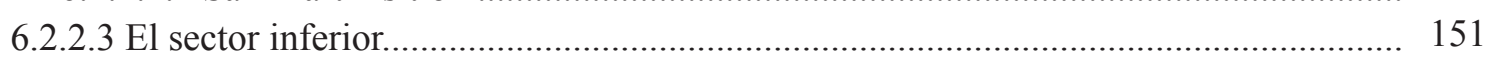

6.2.2.3.1 Arroyo Chasicó....................................................................................... 152

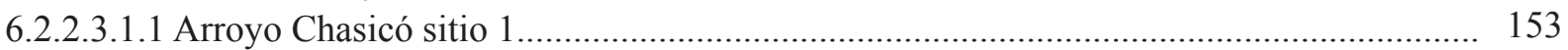

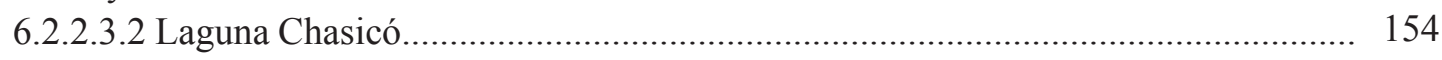

6.2.2.3.2.1 Laguna Chasicó sitio 1...................................................................... 154

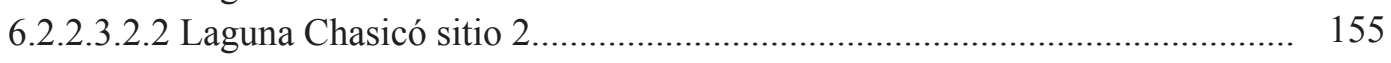

6.2.2.3.2.3 Laguna Chasicó sitio 3 ...................................................................... 157

6.2.2.3.2.4 Laguna Chasicó sitio 4....................................................................... 158

6.2.2.3.2.5 Laguna Chasicó sitios 5, 6 y 13 ............................................................. 159

6.2.2.3.2.6 Laguna Chasicó sitio 7 ..................................................................... 160

6.2.2.3.2.7 Laguna Chasicó sitio 8 ..................................................................... 160

6.2.2.3.2.8 Laguna Chasicó sitios 9 y 10............................................................. 161

6.2.2.3.2.9 Hallazgos aislado.............................................................................. 162

6.2.2.3.3 Áreas adyacentes a la cuenca inferior................................................................ 162

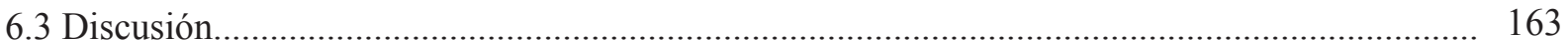

Capítulo 7 - Marco Cronológico.

7.1 Marco cronológica de la cuenca del arroyo Chasicó............................................................. 165

7.2 La cronología de la cuenca del arroyo Chasicó en relación con las áreas vecinas....................... 165

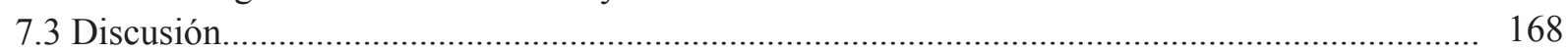

Capítulo 8 - El Registro Arqueofaunístico.

8.1 Algunos conceptos teóricos sobre el registro arqueofaunístico y los procesos post- $\quad 172$ depositacionales que lo afectan.

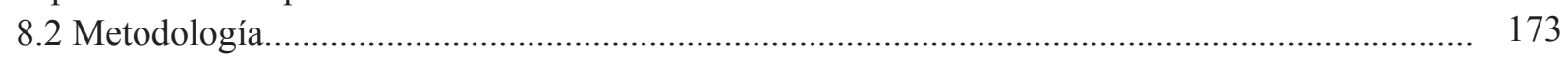

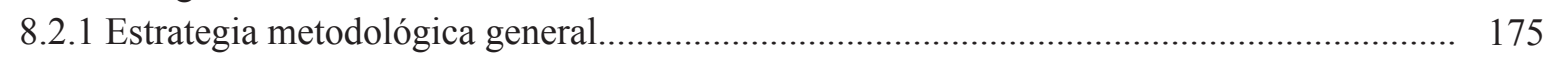

8.2.1.1 Generación de un modelo regional de agentes y procesos post-depositacionales: $\quad 175$ identificación de áreas con expectativas diferenciales de preservación del registro óseo........

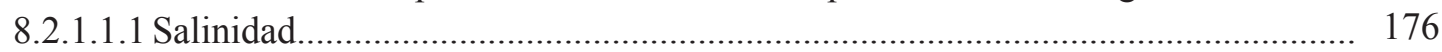

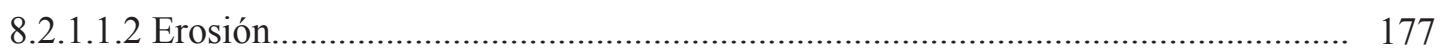


8.2.1.1.4 Probabilidad de desarrollo de cubierta vegetal.................................................... 181

8.2.1.1.5 pH promedio de los depósitos sedimentarios.................................................... 182

8.2.1.1.6 Modelo regional de agentes y procesos post-depositacionales........................... 184

8.2.1.2 Metodología empleada en el análisis de los elementos arqueofainístios..................... 186

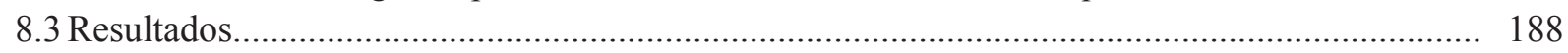

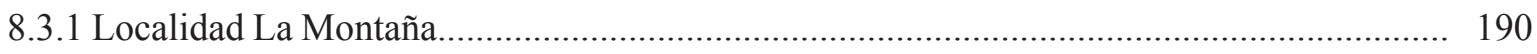

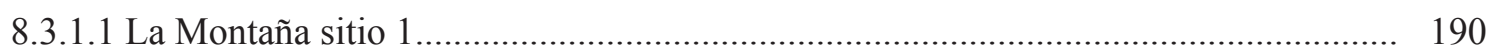

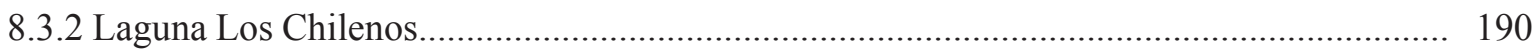

8.3.2.1 Los Chilenos sitio 2 2...................................................................................... 193

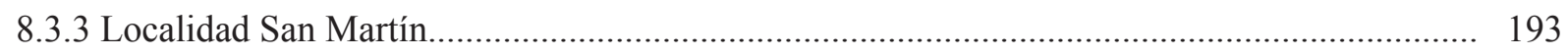

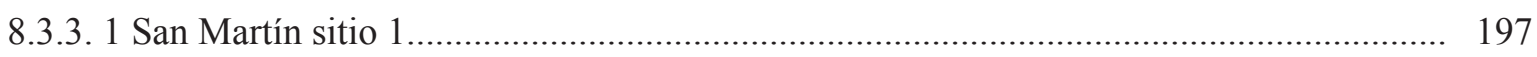

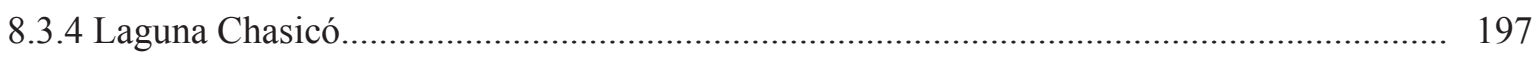

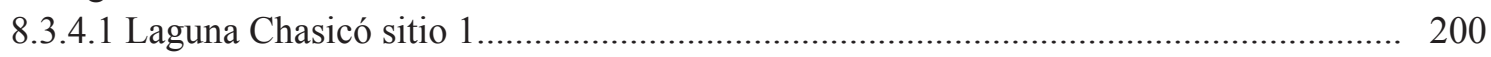

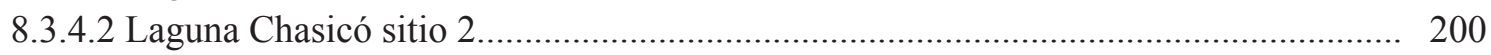

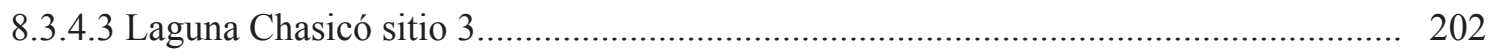

8.3.4.4 Laguna Chasicó sitio 4 ......................................................................................... 203

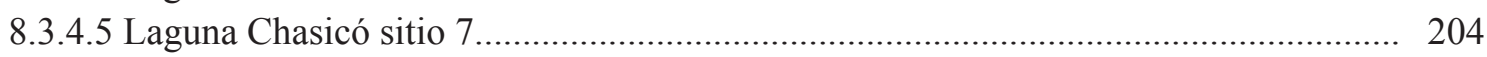

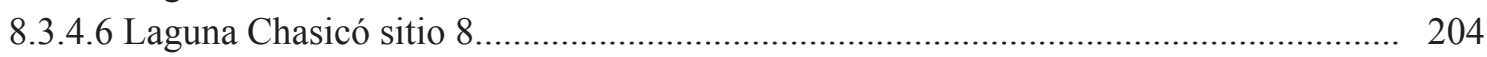

8.4 El registro arqueofaunístico en la cuenca del arroyo Chasicó.................................................. 206

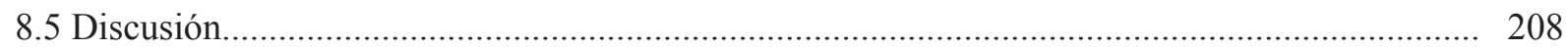

212

Capítulo 9 - Tecnología Cerámica.

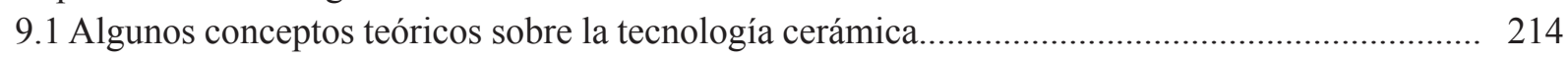

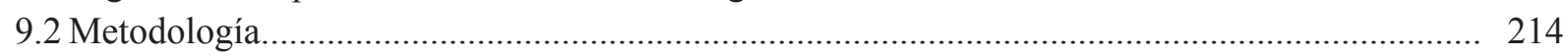

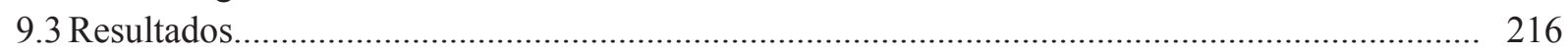

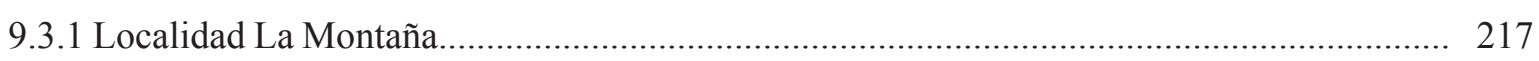

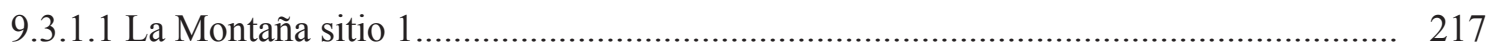

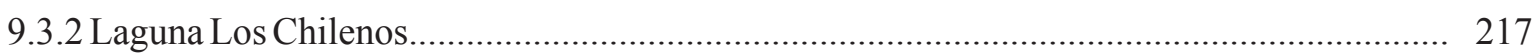

9.3.3 Localidad San Martín.............................................................................................. 220

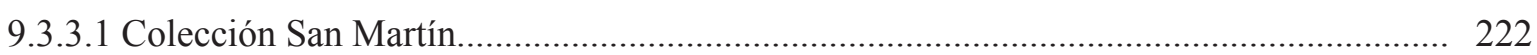

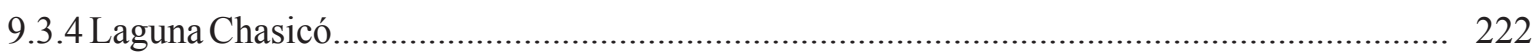

9.4 La tecnología cerámica en la cuenca del arroyo Chasicó........................................................... 223

9.5 La tecnología cerámica en el contexto del sur de la Región Pampeana y el NE de Patagonia.... 227

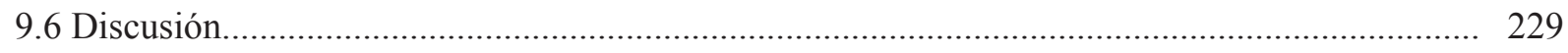

232

Capítulo 10 - Tecnología Lítica.

10.1 Algunos conceptos teóricos sobre la tecnología lítica y su relación con la movilidad y el uso 234 de los recursos: los artefactos tallados y los confeccionados por picado, abrasión y/o pulido...........

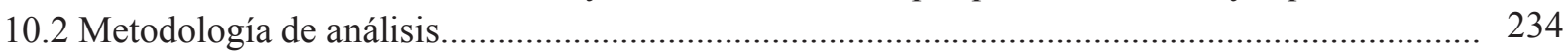

10.2.1 Estrategia metodológica general........................................................................... 239

10.2.1.1 Metodología empleada en el análisis de los materiales confeccionados por técnica 239 de talla.

10.2.1.2 Metodología empleada en el análisis de los artefactos modificados por uso o por $\quad 240$ picado, abrasión y/o pulido.

10.2.1.3 Identificación de materias primas...................................................................... 241

10.2.1.3.1 Criterios empleados en la clasificación de las materias primas........................ 241

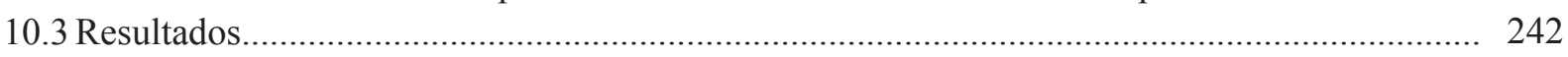

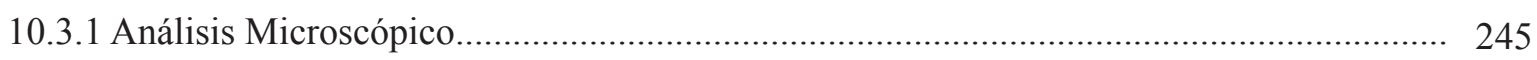

10.3.1.1 Análisis petrográfico sobre muestras geológicas................................................. 245 
10.3.1.2 Análisis petrográfico sobre muestras arqueológicas.............................................. 245

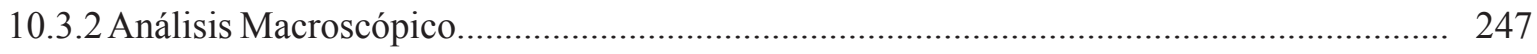

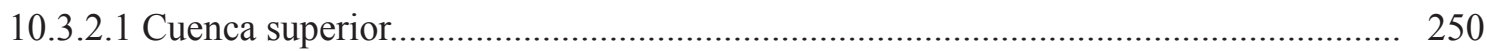

10.3.2.1.1 Localidad arqueológica Arroyo Saudade (AS).......................................... 250

10.3.2.1.2 La Montaña sitio 1(LM1) ........................................................................ 250

10.3.2.1.3 Localidad arqueológica La Sofía (LS)...................................................... 252

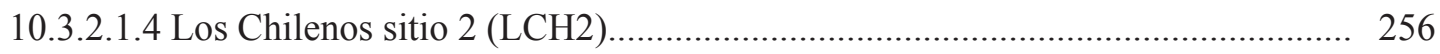

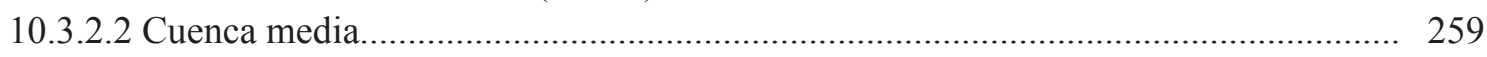

10.3.2.2.1 Localidad Arqueológica San Martín (SM)................................................... 264

10.3.2.2.2 Colecciones Museo Regional Chasicó............................................................ 264

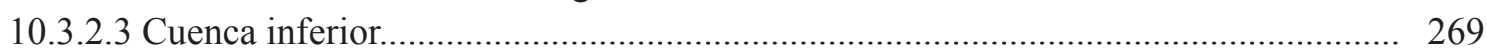

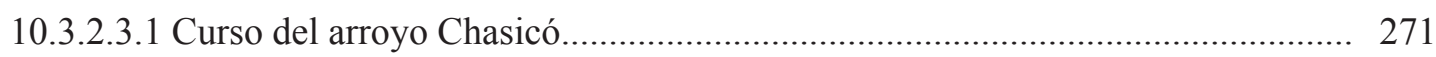

10.3.2.3.1.1 Hallazgos aislados sobre el Arroyo Chasicó............................................. 271

10.3.2.3.1.2 Arroyo Chasicó sitio 1 (ACHA1) ....................................................... 271

10.3.2.3.2 Laguna Chasicó (LCHA)....................................................................... 272

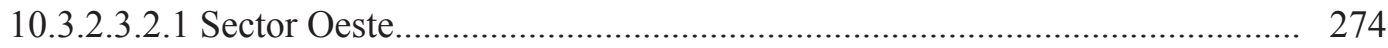

10.3.2.3.2.1.1 Laguna Chasicó sitio 1 (LCHA1) ................................................. 274

10.3.2.3.2.1.2 Laguna Chasicó sitio 2 (LCHA2)................................................. 274

10.3.2.3.2.1.3 Laguna Chasicó sitio 3 (LCHA3)............................................... 278

10.3.2.3.2.1.4 Hallazgos aislados y pequeñas concentraciones del Sector Oeste.... 282

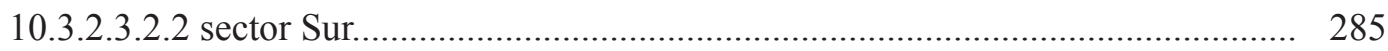

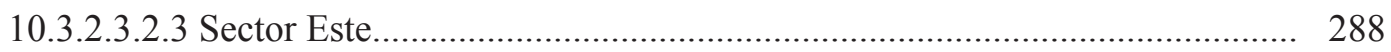

10.3.2.3.2.3.1 Laguna Chasicó sitio 7 (LCHA7),................................................. 291

10.3.2.3.2.4 Sector Norte............................................................................... 291

10.3.2.3.2.4.1 Laguna Chasicó 4 (LCHA4)........................................................ 295

10.3.2.3.2.4.2 Laguna Chasicó sitio 8 (LCHA8)................................................. 295

10.3.2.3.3 Salinas Chicas (SCH)........................................................................... 297

10.4 La tecnología lítica en la cuenca del arroyo Chasicó: aprovisionamiento y circulación de rocas 298

10.5 El paisaje lítico en el contexto del sur de la Región Pampeana y NE de Patagonia.................. 300

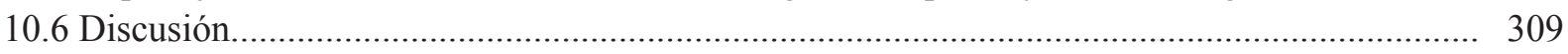

Capítulo 11 - El Registro Bioarqueológico: Tipos de Entierro e Isótopos Estables...... 314

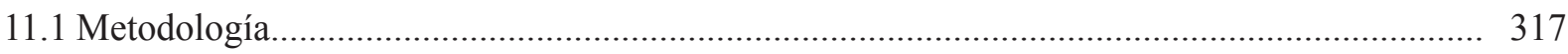

11.2 Estructura espacial y temporal del registro bioarqueológico de la cuenca del arroyo Chasicó. 318

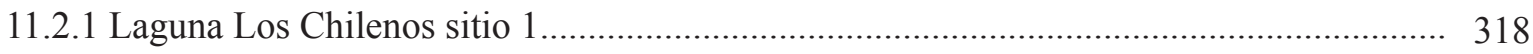

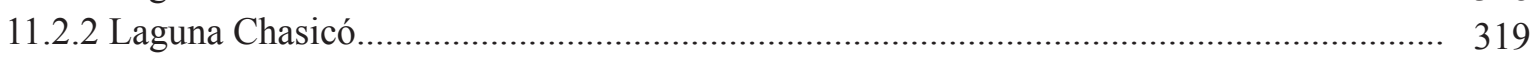

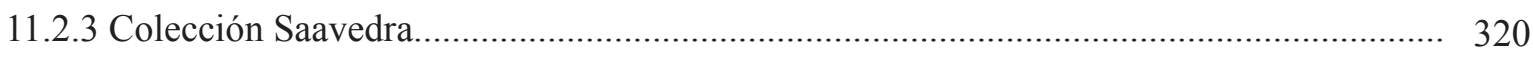

11.3 Indicadores de movilidad y uso de recursos a escala individual y grupal............................... 320

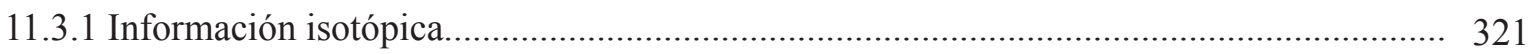

11.3.1.1 Variabilidad en la dieta en el sur de Sudamérica.................................................. 321

11.3.1.2 Isótopos estables en la cuenca del arroyo Chasicó.................................................. 321

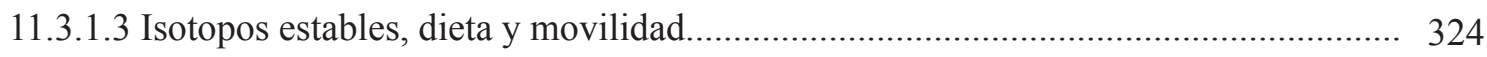

11.4 Indicadores de movilidad y uso de recursos a escala poblacional......................................... 331

11.4.1 Entierros secundarios en el SE de la Región Pampeana y NE de Patagonia...................... 333

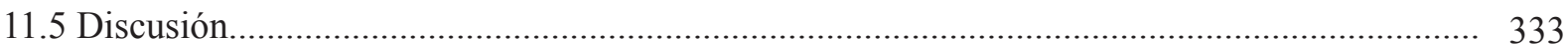


Capítulo 12 - Discusión

12.1. Tendencias generales en la cuenca del arroyo Chasicó: movilidad y uso de recursos

12.1.1 ¿Cuál es la profundidad temporal de las ocupaciones del área?

12.1.2 ¿Cuáles fueron los recursos aprovechados y qué importancia tuvo cada uno de ellos? ¿Cómo fueron utilizados?

12.1.3 ¿Cuáles fueron los recursos con mayor incidencia y de qué manera influyeron en los patrones de uso del espacio?

12.1.4 ¿Qué amplitud tuvieron los rangos de acción de las poblaciones que habitaron la cuenca del Arroyo Chasicó?

12.1.5 ¿Cuál fue el tipo (residencial o logístico) y el grado (frecuencia de los movimientos) de 343 movilidad predominante de esas poblaciones?.

12.2 La cuenca del arroyo Chasicó en el contexto del sur de la Región Pampeana y el NE de

12.2.1 ¿Pueden identificarse diferencias entre las características (e.g. tecnológicas, morfológicas y/o decorativas) de los conjuntos arqueológicos de la cuenca del arroyo Chasicó y las de áreas vecinas (Ventania, Interserrana, cuenca del río Colorado, Pampa Seca, Tandilia)?....

12.2.3 ¿Cómo varían los patrones observables en el registro arqueológico al aplicar diferentes escalas de análisis?

Capítulo 13- Conclusiones y Futuras Líneas de Investigación.

BIBLIOGRAFÍA

ANEXO: Cortes Petrográficos 


\section{Índice de Figuras}

Figura 1.1. Sector centro-oriental de la República Argentina..................................................... 30

Figura 3.1. Sitios arqueológicos investigados por otros autores desde fines del siglo XIX.......... $\quad 61$

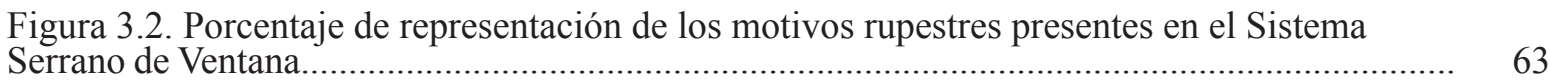

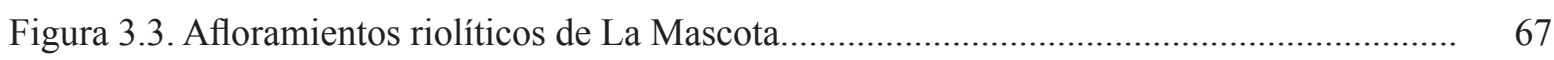

Figura 4.1. Sector centro-oriental de la República Argentina..................................................... 72

Figura 4.2. Fitogeografía del sector central de la República Argentina........................................ 73

Figura 4.3. Zoogeografía del sector central de la República Argentina......................................... 74

Figura 4.4. Distribución potencial, durante el Holoceno tardío, de: A) Lama guanicoe y B)

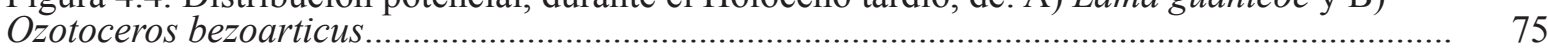

Figura 4.5. Distribución de las principales rocas en el centro-este de Argentina.......................... 77

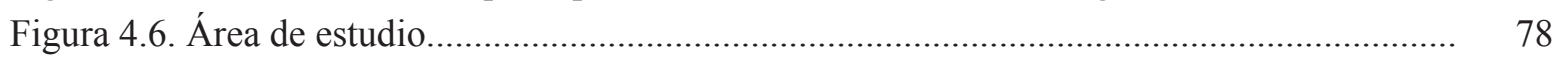

Figura 4.7. Hidrografía de la cuenca superior del arroyo Chasicó............................................ 80

Figura 4.8. Hidrografía de las cuencas media e inferior del arroyo Chasicó................................. 81

Figura 4.9. Perfil longitudinal de la cuenca del arroyo Chasicó ................................................. 82

Figura 4.10. Formaciones geológicas del Sistema Serrano de Ventania....................................... 84

Figura 4.11. Formaciones geológicas del sector occidental del Sistema Serrano de Ventania...... 85

Figura 4.12. Distribución de las regiones fitogeográficas....................................................... 89

Figura 4.13. Vegetación presente en los distintos sectores de la cuenca del arroyo Chasicó........ 91

Figura 4.14. Vegetación en la cuenca inferior (provincia del Espinal)........................................ 92

Figura 4.15. Guanacos en el Parque Provincial Ernesto Tornquist (Sierra de la Ventana)........... 93

Figura 4.16. Tendencias paleoclimáticas en la Región Pampeana según diferentes proxies de

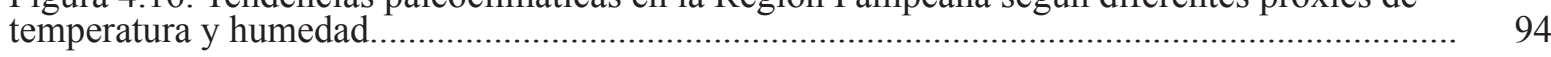

Figura 5.1. Distribución de la provincia fitogeográfica del Espinal.............................................. 103

Figura 5.2. Mapas modificados a partir de Politis et al. (2011b), en los que se expresan zonas de distribución potencial moderna de. A- Lama guanicoe; B- Ozotoceros bezoarticus.................. 104

Figura 5.3. Distribución de materias primas líticas clasificadas según su aptitud para la confección de instrumentos por técnica de talla, de picado, abrasión y/o pulido o de ambas....... 105

Figura 5.4. Mapa representando las áreas con mayor abundancia de recursos ............................ 106

Figura 5.5. Localización de los grupos cazadores-recolectores de Australia y Norteamérica ...... 108

Figura 5.6. Mapa modificado a partir de Morello (2002), donde se realiza una comparación entre los ambientes de América del Sur y América del Norte...

Figura 5.7. Gráfico ternario que muestra la dispersión de los valores porcentuales de caza, recolección y pesca.

Figura 5.8. Diagrama de dispersión múltiple que muestra la relación entre densidad poblacional y composición de la dieta

Figura 5.9. Diagrama de contorno 3D que muestra la relación entre densidad poblacional, porcentaje de recolección y movilidad para la muestra total

Figura 5.10. Distribución espacial de los fechados considerados para generar el modelo cronológico

Figura 5.11. Curvas de probabilidades sumadas de los fechados radiocarbónicos calibrados .....

Figura 5.12. Distribución espacial de los fechados más tempranos registrados en cada sitio o localidad

Figura 5.13. Modelo espacial continuo de la distribución de frecuencias relativas de RSO en la forma de artefactos 
Figura 5.14. Modelo espacial continuo de la distribución de frecuencias relativas de rocas cuarcitica en la forma de artefactos

Figura 5.15. Modelo espacial continuo de la distribución de frecuencias relativas de calcedonia en la forma de artefactos

Figura 5.16. Modelo en el que se representa la distribución espacial de materias primas representadas con valores superiores al $20 \%$.

Figura 5.17. Distribución de los artefactos de molienda en relación con los artefactos de filo ...

Figura 5.18. Modelado de la frecuencia de aparición de material cerámico.

Figura 5.19. Distribución de valores isotópicos $\delta^{13} \mathrm{C}$ en muestras humanas.

Figura 5.20. Distribución de valores isotópicos $\delta^{15} \mathrm{~N}$ en muestras humanas.

Figura 5.21. Distribución de paleodietas humanas obtenidas a partir de la reclasificación y

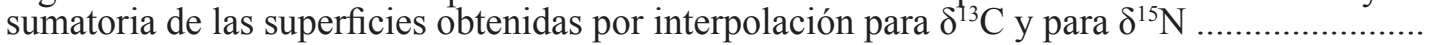

Figura 6.1 Áreas donde se llevaron a cabo las prospecciones.

Figura 6.2. Muestreos realizados en la cuenca del arroyo Chasicó y áreas vecinas...

Figura 6.3. Transectas realizadas en la cuenca superior del arroyo Chasicó y áreas adyacentes..

Figura 6.4. Transectas realizadas en la cuenca inferior, sector inferior de la cuenca media y las áreas adyacentes de Salinas Chicas y Salitral de la Vidriera.

Figura 6.5. Variabilidad en la visibilidad en los distintos sectores de la cuenca......

Figura 6.6. Distribución de rodados en los diferentes sectores de la cuenca superior .

Figura 6.7. Rodados cuarcíticos en la cuenca media e inferior del arroyo Chasicó.

Figura 6.8. Perfil topográfico de la cuenca del arroyo Chasicó y boxplot representando la media geométrica de los rodados cuarcíticos.

Figura 6.9. Materias primas disponibles en la laguna Chasicó.

Figura 6.10. Cuenca superior: localización de los sitios estudiados en esta tesis..

Figura 6.11. Localización de los sitios que conforman la localidad arqueológica La Sofía.

Figura 6.12. Planta del sitio La Montaña 1 y localización espacial de los tres sitios que conforman la localidad.

Figura 6.13. Localización de los sitios que conforman la localidad Arroyo Saudades.

Figura 6.14. Imagen satelital mostrando la ubicación de los sitios estudiados, muestreos de los bancos de rodados y localización de los hallazgos aislados recolectados y de la zona, fuera del sitios 2, con mayor concentración de materiales en superficie.

Figura 6.15. Vista del sitio 2 y detalle de uno de los muestreos realizados..

Figura 6.16. Afloramiento 1

Figura 6.17. Laguna Los Chilenos, Imagen satelital mostrando la ubicación de los sitios 1 y 2 $\mathrm{y}$ detalle de las actividades desarrolladas en el sitio 2 .

Figura 6.18. Localización del sitio San Martín 1 y de las recolecciones realizadas por N. Cinquini en sus inmediaciones.

Figura 6.19. Plantas del sitio San Martín 1

Figura 6.20. Distribución de materiales arqueológicos (sitios y hallazgos aislados) en la cuenca inferior.

Figura 6.21. Arroyo Chasicó sitio 1.......

Figura 6.22. Variaciones en el nivel de base de la laguna Chasicó.

Figura 6.23. Laguna Chasicó sitio 1. Planta de la isla donde se detalla la evolución de la línea de costa y las áreas donde se desarrollaron las recolección y sondeos.......

Figura 6.24. Laguna Chasicó sitio 2. Planta del área de costa donde se desarrollaron las recolección y sondeos.

Figura 6.25. Laguna Chasicó sitio 3. Planta del área de costa donde se desarrollaron las recolección y localización de los sondeos realizados.

Figura 6.26. Laguna Chasicó sitio 4. Planta del voladero donde se desarrollaron las recolección. 
Figura 6.27. Laguna Chasicó sitio 7. Planta del sector de playa donde se desarrollaron las recolecciones.

Figura 6.28. Laguna Chasicó sitio 8. Planta del sector de donde se desarrollaron las recolección...

Figura 7.1. Distribución de los fechados más tempranos

Figura 7.2 Distribución de los fechados en el conjunto de las áreas consideradas y en cada una de las áreas que la componen.

Figura 8.1. Suelos con mayor concentración de sales.

Figura 8.2. Concentración de cloruros en las aguas subterráneas..

Figura 8.3. Generación de la cobertura de concentración de sales.

Figura 8.4. Áreas con mayor susceptibilidad a la erosión.

Figura 8.5. Textura predominante de los suelos.

Figura 8.6. Probabilidad de desarrollo de cubierta vegetal de pastos.

Figura 8.7. $\mathrm{pH}$ promedio estimado de los suelos.

Figura 8.8. Generación de una cobertura en la que se sectoriza la cuenca en función de los agentes y procesos post-depositacionales actuantes sobre el registro óseo

Figura 8.9. Reclasificación de la cobertura raster de agentes y procesos en función de la cantidad que actúa en un mismo sector.....

Figura 8.10. Cantidad de especímenes óseos por nivel estratigráfico en el sitio La Montaña $1 \ldots$

Figura 8.11. Principales modificaciones producto de la acción de agentes y procesos postdepositacionales, representadas en los especímenes óseos procedentes del sitio La Montaña 1 ..

Figura 8.12. Estado de conservación de la muestra ósea procedente del sitio La Montaña 1.......

Figura 8.13. Cantidad de especímenes óseos por nivel estratigráfico en el sitio Los Chilenos 2 estratigrafía....

Figura 8.14. Principales modificaciones producto de la acción de agentes y procesos postdepositacionales, representadas en los especímenes óseos procedentes del sitio Los Chilenos 2 estratigrafía..

Figura 8.15. Estado de conservación de la muestra ósea procedente del sitio Los Chilenos 2 estratigrafía.....

Figura 8.16. Principales modificaciones producto de la acción de agentes y procesos postdepositacionales, representadas en los especímenes óseos procedentes del sitio Los Chilenos 2 superficie.....

Figura 8.17. Estado de conservación de la muestra ósea procedente del sitio Los Chilenos 2 superficie.

Figura 8.18. Cantidad de especímenes óseos por nivel estratigráfico en el sitio San Martín 1.....

Figura 8.19. Marcas presentes sobre las superficies óseas de los conjuntos del sitio San Martín 1..

Figura 8.20. Estado de conservación de la muestra ósea procedente del sitio San Martín 1.........

Figura 8.21. Principales modificaciones producto de la acción de agentes y procesos postdepositacionales, representadas en los especímenes óseos procedentes del sitio San Martín 1....

Figura 8.22. Principales modificaciones producto de la acción de agentes y procesos postdepositacionales, representadas en los especímenes óseos procedentes del sitio Laguna Chasicó 1 .

Figura 8.23. Principales modificaciones producto de la acción de agentes y procesos postdepositacionales, representadas en los especímenes óseos procedentes del sitio Laguna Chasicó 2.

Figura 8.24. Principales modificaciones producto de la acción de agentes y procesos postdepositacionales, representadas en los especímenes óseos procedentes del sitio Laguna Chasicó 3.

Figura 8.25. Principales modificaciones producto de la acción de agentes y procesos postdepositacionales, representadas en los especímenes óseos procedentes del sitio Laguna Chasicó 4.

Figura 8.26. Instrumento óseo (punzón) manufacturado sobre el extremo distal de un metapodio de $O$. bezoarticus, recuperado en el sitio Laguna Chasicó....... 
Figura 8.27. Principales modificaciones producto de la acción de agentes y procesos postdepositacionales, representadas en los especímenes óseos procedentes del sitio Laguna Chasicó 7

Figura 8.28. Principales modificaciones producto de la acción de agentes y procesos postdepositacionales, representadas en los especímenes óseos procedentes del sitio Laguna Chasicó 8.

Figura 8.29. Diversidad taxonómica representada en los sitios arqueológicos.

Figura 8.30. Grado de fragmentación y densidad de los especímenes óseos faunísticos.

Figura 8.31. Estado de los conjuntos óseos faunísticos. A- alteración estructural; B- marcas......

Figura 8.32. Estado de los conjuntos óseos faunísticos. A- mineralización; B- abrasión.

Figura 8.33. Falange recuperada en superficie en las Salinas Chicas, altamente degradada como consecuencia de la exposición al ambiente salino.

Figura 9.1 Histograma de los valores de espesor de los fragmentos cerámicos procedentes de La Montaña sitio 1 .

Figura 9.2. La Montaña sitio 1. Distribución de colores en corte fresco.

Figura 9.3. Tratamiento de las superficies interna y externa de los fragmentos cerámicos recuperados en La Montaña sitio 1.

Figura 9.4 Diseños decorativos presentes en la cerámica del sitio La Montaña 1.

Figura 9.5. Histograma de los valores de espesor de los fragmentos cerámicos procedentes de Los Chilenos.

Figura 9.6. Distribución de colores en corte fresco de los fragmentos cerámicos del la localidad arqueológica Los Chilenos

Figura 9.7. Tratamiento de las superficies interna y externa de los fragmentos cerámicos recuperados en la localidad arqueológica Los Chilenos.

Figura 9.8. Distribución de colores en corte fresco de los fragmentos cerámicos de la colección San Martín.

Figura 9.9. Tratamiento de las superficies interna y externa de los fragmentos cerámicos de la colección San Martín.

Figura 9.10. Espesor de los fragmentos cerámicos procedentes de la laguna Chasicó.

Figura 9.11. Distribución de colores en corte fresco de los fragmentos cerámicos de la colección San Martín.

Figura 9.12. Reconstrucción de la forma de la vasija.

Figura 9.13. Cerámica decorada recolectada por el Sr. Peluso en la laguna Chasicó.

Figura 9.14. Box plot representando la dispersión en espesores en las localidades arqueológicas de la cuenca del arroyo Chasicó..

Figura 9.15. Modelado de la frecuencia de aparición de material cerámico.

Figura 9.16.Análisis cluster entre muestras procedentes de las áreas Interserrana, Tandilia, Sur y Ventania...

Figura 10.1. Representación esquemática de la estructura de un paisaje lítico.

Figura 10.2. Muestras de chert tomadas por Jorge San Cristóbal.

Figura 10.3. Caracterización de la disponibilidad de materias primas líticas en la cuenca del arroyo Chasicó....

Figura 10.4. Rodados procedentes de los arroyos que drenan las sierras de Ventania..

Figura 10.5. Cuarcitas G3.

Figura 10.6 Cuarcitas representadas en artefactos de los sitios arqueológicos de la cuenca del arroyo Chasicó.

Figura 10.7. Proporción de materias primas presentes en los artefactos de la localidad arqueológica Arroyo Saudades, considerando su peso y frecuencia.

Figura 10.8. Proporción de materias primas presentes en los artefactos del sitio La Montaña 1, considerando su peso y frecuencia...

Figura 10.9. Proporción de materias primas presentes en los artefactos de la localidad La 
Figura 10.10. Proporción de materias primas presentes en los artefactos del sitio Los Chilenos 2 estratigrafía, considerando su peso y frecuencia.....

Figura 10.11. Proporción de materias primas presentes en los artefactos del sitio Los Chilenos 2 superficie, considerando su peso y frecuencia.

Figura 10.12. Proporción de materias primas presentes en los artefactos del sitio San Martín 1 estratigrafía, considerando su peso y frecuencia..

Figura 10.13. Proporción de materias primas presentes en los artefactos del sitio San Martín 1 superficie, considerando su peso y frecuencia.

Figura 10.14. Proporción de materias primas presentes en los artefactos del sitio Arroyo Chasicó 1, considerando su peso y frecuencia.....

Figura 10.15. Proporción de materias primas presentes en los artefactos del sitio Laguna Chasicó 1, considerando su peso y frecuencia.

Figura 10.16. Proporción de materias primas presentes en los artefactos del sitio Laguna Chasicó 2, considerando su peso y frecuencia.

Figura 10.17. Proporción de materias primas presentes en los artefactos del sitio Laguna Chasicó 3, considerando su peso y frecuencia..

Figura 10.18. Proporción de materias primas presentes en los artefactos del sector oeste de la laguna Chasicó, considerando su peso y frecuencia..

Figura 10.19. Proporción de materias primas presentes en los artefactos del sector sur de la laguna Chasicó, considerando su peso y frecuencia.

Figura 10.20. Mortero con decoración incisa geométrica en su borde, elaborado en una riolita ignimbrítica.

Figura 10.21. Proporción de materias primas presentes en los artefactos del sitio Laguna Chasicó 7 , considerando su peso y frecuencia.

Figura 10.22. Proporción de materias primas presentes en los artefactos del sitio Laguna Chasicó 4 , considerando su peso y frecuencia...

Figura 10.23. Proporción de materias primas presentes en los artefactos del sitio Laguna Chasicó 8 , considerando su peso y frecuencia.

Figura 10.24. Proporción de materias primas presentes en los artefactos de Salinas Chicas, considerando su peso y frecuencia

Figura 10.25. Curvas de frecuencia relativa de las materias primas más representadas en los sitios de la cuenca del arroyo Chasicó...

Figura 10.26. Curvas del índice de corteza de las materias primas más representadas en los sitios de la cuenca del arroyo Chasicó......

Figura 10.27. Curvas de frecuencia relativa de cuarcita G2, cuarcita G3 y riolita.

Figura 10.28. Variaciones en las proporciones de materias primas de los sitios arqueológicos de la cuenca del arroyo Chasicó en relación con la disponibilidad local de materias primas líticas.

Figura 10.29. Índice de bifacialidad por materia prima en filos

Figura 10.30. Modelo espacial continuo de la distribución de frecuencias relativas de RSO en la forma de artefactos en el sur de la Región Pampeana y NE de Patagonia.

Figura 10.31. Modelo espacial continuo de la distribución de frecuencias relativas de rocas cuarcíticas en la forma de artefactos en el sur de la Región Pampeana y NE de Patagonia...........

Figura 10.32. Modelo espacial continuo de la distribución de frecuencias relativas de calcedonias en la forma de artefactos en el sur de la Región Pampeana y NE de Patagonia........

Figura 10.33. Modelo generado a partir de datos extraídos de las figuras 10.30 a 10.32 en el que se representa la distribución espacial de materias primas representadas con valores superiores al $20 \%$.

10.34 Curvas de disminución de la frecuencia de RSO y cuarcitas..

Figura 10.35. Distribución de los artefactos de molienda en relación con los artefactos de filo...

Figura 11.1. Distribución de entierros humanos en la cueca del arroyo Chasicó y sus inmediaciones. 
Figura 11.2. Distribución de valores isotópicos de $\delta^{13} \mathrm{C}$ y $\delta^{15} \mathrm{~N}$ en el extremo sur de Sudamérica y su relación con la probable composición de la dieta de las paleo-poblaciones humanas.

Figura 11.3. Modelos espaciales de abundancia relativa actual de pastos $\mathrm{C}_{3} \mathrm{y}_{4} \mathrm{y}$ de arbustos (Epstein et al. 2002)

Figura 11.4. Distribución de las áreas utilizadas por las 16 principales especies depredadoras...

Figura 11.5. Valores isotópicos para nitrógeno y carbono de muestras humanas procedentes del área de Ventania

Figura 11.6. Diagrama de dispersión de los valores isotópicos del nitrógeno y el carbono.

Figura 11.7. Valores $\delta^{13} \mathrm{C}$ y $\delta^{15} \mathrm{~N}$ de muestras humanas y recursos con mayor probabilidad de haber sido consumidos

Figura 11.8. Distribución de valores isotópicos $\delta^{13} \mathrm{C}$ en muestras óseas de L. guanicoe, clasificados manualmente considerando rangos de valor dietario (Schoeninger y Moore 1992)..

Figura 11.9. Distribución de valores isotópicos $\delta^{13} \mathrm{C}$ en muestras humanas, clasificados de manera manual considerando rangos de valor dietario (Pate 1995).

Figura 11.10. Distribución de valores isotópicos $\delta^{15} \mathrm{~N}$ en muestras humanas, clasificados de manera manual considerando rangos de nivel trófico (Barrientos 2010).

Figura 11.11. Distribución de paleodietas humanas obtenidas a partir de la reclasificación y sumatoria de las superficies obtenidas por interpolación para $\delta^{13} \mathrm{C}$ (ver Figura 11.9) y para $\delta 15 \mathrm{~N}$ (ver Figura 11.10).....

Figura 11.12. Distribución de paleodietas humanas en relación con las características de la estructura vegetal.

Figura 11.13. Comparación del MAU\% entre el entierro secundario del sitio 1 de Laguna Los Chilenos (Barrientos 1997) y la colección Saavedra

Figura 11.14. Distribución de entierros humanos en NE Patagonia, Pampa Seca, Interserrana, Tandilia y Ventania.. 


\section{Índice de Tablas}

Tabla 4.1. Distribución y usos de las principales especies presentes en la provincia fitogeográfica del Espinal.

Tabla 5.1. Estadísticas descriptivas para diferentes variables cuantitativas relevadas a partir de Binford (2001), correspondientes a 21 sociedades etnográficas norteamericanas móviles del O. de California y de la Gran Cuenca (Grupo I).

Tabla 5.2. Estadísticas descriptivas para diferentes variables cuantitativas relevadas a partir de Binford (2001), correspondientes a 4 sociedades etnográficas norteamericanas sedentarias o semisedentarias del O. de California y de la Gran Cuenca (Grupo II)......

Tabla 5.3. Estadísticas descriptivas para diferentes variables cuantitativas relevadas a partir de Binford (2001).

Tabla 7.1. Detalle de las dataciones radiocarbónicas efectuadas en la cuenca del arroyo Chasicó.....

Tabla 8.1. Medición del pH de las muestras de sedimento tomadas en las distintas unidades estratigráficas de los sitios y cálculo del $\mathrm{pH}$ promedio de cada uno de ellos......

Tabla 8.2. Diversidad taxonómica representada en el sitio La Montaña 1.

Tabla 8.3. Diversidad taxonómica representada en el sitio Los Chilenos 2............................. 194

Tabla 8.4. Diversidad taxonómica representada en el sitio San Martín 1

Tabla 8.5. Modificaciones de las superficies óseas presentes en el sitio San Martín 1 diferenciadas por agente efector y por taxón en que se encuentran......

Tabla 8.6. Diversidad taxonómica representada en el sitio Laguna Chasicó 1

Tabla 8.7. Diversidad taxonómica representada en el sitio Laguna Chasicó 2

Tabla 8.8. Diversidad taxonómica representada en el sitio Laguna Chasicó 3

Tabla 8.9. Diversidad taxonómica representada en el sitio Laguna Chasicó 4.

Tabla 8.10. Diversidad taxonómica representada en el sitio Laguna Chasicó 7

Tabla 8.11. Diversidad taxonómica representada en el sitio Laguna Chasicó 8

Tabla 10.1. Características petrográficas de muestras de rodados obtenidas en el cauce superior de los principales cursos fluviales que drenan el sector sud-occidental de las sierras de Ventania.

Tabla 10.2. Características petrográficas de muestras de cuarcitas procedentes de la localidad Arroyo Saudades.

Tabla 10.3. Tipos de materiales recuperados en los diferentes sectores muestreados.

Tabla 10.4. Tamaño en las diferentes materias primas representadas en artefactos de la localidad Arroyo Saudade.

Tabla 10.5. Remanente de corteza en las diferentes materias primas representadas en artefactos de la localidad Arroyo Saudade.

Tabla 10.6. Principales características de los artefactos formatizados por talla en la localidad arqueológica Arroyo Saudade.....

Tabla 10.7. Principales características de los núcleos recuperados en la localidad arqueológica Arroyo Saudade.....

Tabla 10.8. Tamaño en las diferentes materias primas representadas en artefactos del sitio La Montaña 1 .....

Tabla 10.9. Remanente de corteza en las diferentes materias primas representadas en artefactos del sitio La Montaña 1.

Tabla 10.10. Principales características de los artefactos formatizados por talla en artefactos del sitio La Montaña 1.

Tabla 10.11. Principales características de los núcleos recuperados en el sitio La Montaña 1.....

Tabla 10.12. Principales características de los artefactos modificados por uso y formatizados por picado, abrasión y/o pulido en el sitio La Montaña 1. 
Tabla 10.13. Tamaño en las diferentes materias primas representadas en artefactos de la localidad La Sofía.

Tabla 10.14. Remanente de corteza en las diferentes materias primas representadas en artefactos de la localidad La Sofía.....

Tabla 10.15. Principales características de los artefactos formatizados por talla de la localidad La Sofía...

Tabla 10.16. Principales características de los núcleos recuperados en la localidad La Sofía......

Tabla 10.17. Tamaño en las diferentes materias primas representadas en artefactos del sitio

Los Chilenos 2 estratigrafía....

Tabla 10.18. Remanente de corteza en las diferentes materias primas representadas en artefactos del sitio Los Chilenos 2 estratigrafía.

Tabla 10.19. Principales características de los artefactos formatizados por talla del sitio Los Chilenos 2 estratigrafía.

Tabla 10.20. Principales características de los núcleos recuperados en el sitio Los Chilenos 2 estratigrafía.....

Tabla 10.21. Tamaño en las diferentes materias primas representadas en artefactos de Los Chilenos 2 superficie.

Tabla 10.22. Tamaño en las diferentes materias primas representadas en artefactos del sitio Los Chilenos 2 superficie.

Tabla 10.23. Principales características de los artefactos formatizados por talla Los Chilenos 2 superficie.

Tabla 10.24. Principales características de los núcleos recuperados en el sitio Los Chilenos 2 superficie.

Tabla 10.25. Tamaño en las diferentes materias primas representadas en artefactos del sitio San Martín 1 estratigrafía.

Tabla 10.26. Remanente de corteza en las diferentes materias primas representadas en artefactos del sitio San Martín 1 estratigrafía

Tabla 10.27. Principales características de los artefactos formatizados por talla del sitio San Martín 1 estratigrafía....

Tabla 10.28. Tamaño en las diferentes materias primas representadas en artefactos del sitio San Martín 1 superficie.

Tabla 10.29. Remanente de corteza en las diferentes materias primas representadas en artefactos del sitio San Martín 1 superficie.

Tabla 10.30. Principales características de los artefactos formatizados por talla del sitio San Martín 1 superficie.

Tabla 10.31. Principales características de los núcleos recuperados en superficie en el sitio San Martín 1 superficie

Tabla 10.32. Tamaño en las diferentes materias primas representadas en artefactos de las colecciones San Martín (Museo Regional Chasicó).

Tabla 10.33. Remanente de corteza en las diferentes materias primas representadas en artefactos de las colecciones San Martín (Museo Regional Chasicó).

Tabla 10.34. Tamaño en las diferentes materias primas representadas en artefactos de la colección Bastán (Museo Regional Chasicó).

Tabla 10.35. Remanente de corteza en las diferentes materias primas representadas en artefactos de la colección Bastán (Museo Regional Chasicó).....

Tabla 10.36. Tamaño en las diferentes materias primas representadas en artefactos del sitio Arroyo Chasicó 1

Tabla 10.37. Remanente de corteza en las diferentes materias primas representadas en artefactos del sitio Arroyo Chasicó 1

Tabla 10.38. Principales características de los artefactos formatizados por talla del sitio Arroyo Chasicó 1

Tabla 10.39. Tamaño en las diferentes materias primas representadas en artefactos del sitio Laguna Chasicó 1 
Tabla 10.40. Remanente de corteza en las diferentes materias primas representadas en artefactos del. Sitio Laguna Chasicó 1.

Tabla 10.41. Principales características de los artefactos formatizados por talla del sitio Laguna Chasicó 1.

Tabla 10.42. Principales características de los núcleos recuperados en el sitio Laguna Chasicó 1.. 277

Tabla 10.43. Principales características de los artefactos modificados por uso y formatizados por picado, abrasión y/o pulido en el sitio Laguna Chasicó 1 .

Tabla 10.44. Tamaño en las diferentes materias primas representadas en artefactos de talla del sitio Laguna Chasicó 2 .

Tabla 10.45. Remanente de corteza en las diferentes materias primas representadas en artefactos de talla del sitio Laguna Chasicó 2 .

Tabla 10.46. Principales características de los artefactos formatizados por talla del sitio Laguna Chasicó 2 .

Tabla 10.47. Principales características de los núcleos, nucleiformes y nódulos recuperados en el sitio Laguna Chasicó 2 .

Tabla 10.48. Principales características de los artefactos modificados por uso y formatizados por picado, abrasión y/o pulido en el sitio Laguna Chasicó 2 .

Tabla 10.49. Tamaño en las diferentes materias primas representadas en artefactos del sitio Laguna Chasicó 3.

Tabla 10.50. Remanente de corteza en las diferentes materias primas representadas en artefactos del sitio La Montaña 1.

Tabla 10.51. Principales características de los artefactos formatizados por talla del sitio La Montaña 1 ......

Tabla 10.52. Principales características de los núcleos recuperados en el sitio Laguna Chasicó $3 .$.

Tabla 10.53. Principales características de los artefactos modificados por uso y formatizados por picado, abrasión y/o pulido en el sitio Laguna Chasicó 3 .

Tabla 10.54. Tamaño en las diferentes materias primas representadas en artefactos del sector oeste de la laguna Chasicó..

Tabla 10.55. Remanente de corteza en las diferentes materias primas representadas en artefactos del sector oeste de la laguna Chasicó.

Tabla 10.56. Principales características de los artefactos formatizados por talla del sector oeste de la laguna Chasicó...

Tabla 10.57. Principales características de los núcleos recuperados en el sector oeste de la laguna Chasicó.....

Tabla 10.58. Tamaño en las diferentes materias primas representadas en artefactos del sector sur de la laguna Chasicó.

Tabla 10.59. Remanente de corteza en las diferentes materias primas representadas en artefactos del sector sur de la Laguna Chasicó.

Tabla 10.60. Principales características de los artefactos formatizados por talla del sector sur de la Laguna Chasicó.

Tabla 10.61. Principales características de los artefactos modificados por uso y formatizados por picado, abrasión y/o pulido del sector sur de la Laguna Chasicó.

Tabla 10.62. Tamaño en las diferentes materias primas representadas en artefactos del sitio Laguna Chasicó 7.

Tabla 10.63. Remanente de corteza en las diferentes materias primas representadas en artefactos del sitio Laguna Chasicó 7.

Tabla 10.64. Principales características de los artefactos formatizados por talla del sitio Laguna Chasicó 7.

Tabla 10.65. Principales características de los núcleos recuperados en el sitio Laguna Chasicó 7.. 294

Tabla 10.66. Principales características de los artefactos modificados por uso y formatizados por picado, abrasión y/o pulido en el sitio Laguna Chasicó 7.

Tabla 10.67. Tamaño en las diferentes materias primas representadas en artefactos del sitio Laguna Chasicó 4. 
Tabla 10.68. Remanente de corteza en las diferentes materias primas representadas en artefactos del sitio Laguna Chasicó 4

Tabla 10.69. Principales características de los artefactos formatizados por talla del sitio Laguna Chasicó 4.

Tabla 10.70. Tamaño en las diferentes materias primas representadas en artefactos del sitio Laguna Chasicó 8 .

Tabla 10.71. Remanente de corteza en las diferentes materias primas representadas en artefactos del sitio Laguna Chasicó 8

Tabla 10.72. Principales características de los artefactos formatizados por talla del sitio Laguna Chasicó 8.

Tabla 10.73. Tamaño en las diferentes materias primas representadas en artefactos de Salinas Chicas.

Tabla 10.74. Remanente de corteza en las diferentes materias primas representadas en artefactos de Salinas Chicas.

Tabla 10.75. Principales características de los artefactos formatizados por talla en Salinas Chicas.

Tabla 11.2. Valores isotópicos obtenidos sobre muestras óseas humanas..

Tabla 11.3 Valores isotópicos obtenidos sobre muestras óseas de Lama guanicoe. 


\section{PRESENTACIÓN DEL TEMA Y ÁREA DE ESTUDIO}

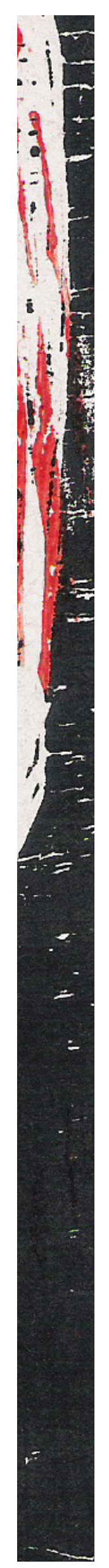




\section{I Introducción}

\subsection{Presentación del tema a abordar}

En el presente trabajo de tesis se exponen los resultados obtenidos a partir de investigaciones arqueológicas desarrolladas en la cuenca del arroyo Chasicó (3764 km2; Bonorino et al. 1989). Estos estudios tuvieron como objetivo general abordar el análisis de los patrones de movilidad y utilización de los recursos implementados por las sociedades cazadoras-recolectoras del Holoceno, en un área localizada en el sector sur de la denominada Área Ecotonal Húmedo-Seca Pampeana (AEHSP, sensu Oliva 2006), más precisamente en la zona de transición entre las regiones Pampeana y Patagónica.

En las sociedades cazadoras-recolectoras, la movilidad representa un fenómeno multidimensional (Grove 2009; Kelly 1992) que sirve a múltiples propósitos, tanto "utilitarios" como "no utilitarios" (sensu Whallon 2006, 2011). Como tal forma parte, entre otras cosas, de estrategias orientadas a la utilización de recursos distribuidos -espacial y/o temporalmente- de manera heterogénea, involucrando una serie de movimientos, residenciales y/o logísticos (Binford 1980, 1982, 2001; Kelly 1992, 1995), llevados a cabo dentro de rangos de acción individuales o grupales (Hamilton et al. 2007: 4765). A su vez, la movilidad también puede ser utilizada como una estrategia para disminuir los niveles de conflicto bajo condiciones de saturación del espacio y aumento en la densidad demográfica o para disminuir el stress en situaciones de deterioro ambiental, involucrando en este caso la migración de los miembros de una población hacia áreas localizadas a mediana o larga distancia (v.g. Gat 2000; Kelly 1992; Morgan 2009; Sellet et al. 2006; Stojanowski y Knudson 2014; entre otros). Durante el desarrollo de esta tesis se discutirán ambos aspectos, aunque con un claro énfasis en el primero de ellos.

Los estudios abordados en esta investigación surgen en el contexto del desarrollo -durante los últimos 30 años- de las investigaciones en el sur de la Región Pampeana y el NE de Patagonia, particularmente en Ventania y la desembocadura de los ríos Negro y Colorado. En estas regiones, el interés por los temas vinculados con el uso, manejo y ocupación de los distintos ambientes por parte de las sociedades cazadoras-recolectoras, ha estado presente en las investigaciones arqueológicas desarrolladas desde sus inicios en el siglo XIX (ver Politis 2008; Politis y Madrid 2001). En el Sistema Serrano de Ventania y la llanura circundante, los estudios fueron esporádicos durante gran parte del siglo XX (Austral 1968; Castro 1983; Gradín 1978; Holmberg 1884; Madrazo 1967; Pérez Amat et al. 1985), pero a partir de mediados de la década de 1980 adquirieron mayor sistematicidad, intensidad y continuidad (Barrientos et al. 1997; Bayón et al. 1999, 2006; Catella et al. 2010, 2013; Moirano et al. 2007; Oliva 2006; Oliva y Moirano 1997, 2001; Oliva y Algraín 2004; Oliva et al. 2004 entre otros). En el NE de Patagonia se realizan numerosas investigaciones hacia la primera mitad del siglo XX (Outes 1908, 1926; Torres 1922; Vignati 1931; entre otros), las que crecen en número y sistematicidad a partir de la década de 1990 (v.g. Eugenio y Aldazábal 2004; Favier Dubois et al. 2009; Martínez et al. 2007; Martínez, Zangrando y Prates 2009; Martínez 2004, 2010; Sanguinetti de Bórmida et al. 1999). En ambas subregiones, las investigaciones 
mencionadas permitieron obtener información sobre la organización tecnológica, prácticas mortuorias, sistema de asentamiento, subsistencia, movilidad y cronología. La franja de territorio transicional entre la Región Pampeana y el NE de Patagonia -en donde se sitúa nuestra área de estudio-, sin embargo, cuenta con escasos antecedentes arqueológicos, limitados a la investigación de sitios puntuales (Austral 1972; Austral y García Cano 1999; Barrientos et al. 1997, 2002; Oliva et al. 1991b) o trabajos sobre aspectos específicos (Catella 2004; Moirano 1999).

La cuenca del arroyo Chasicó (Figura 1.1), abarca tanto ambientes de transición como ambientes con características propias de la Región Pampeana y el NE de Patagonia. En este sentido, vincula el Sistema Serrano de Ventania, donde predominan los recursos bióticos relacionados con la Pampa Húmeda, con los bajos ocupados por la laguna Chasicó y las salinas Chicas, al sur de los cuales se desarrollan los paisajes patagónicos de meseta con zonas bajas, de salares o salitrales y recursos propios de las provincias fitogeográficas del Monte y Espinal, con abundantes especies arbóreas y arbustivas. La cuenca del arroyo Chasicó surca transversalmente lo que puede ser considerado un área ecotonal pampeano-patagónica, donde se encuentra una amplia diversidad de microambientes que pudieron ser explotados de manera diferencial por las poblaciones que la habitaron. En este marco, la presente tesis espera constituirse en un aporte a la arqueología regional, ya que plantea una integración de diversas líneas de evidencia a partir de estudios cuali-cuantitativos y espaciales de datos primarios (i.e. generados por la autora) y secundarios (i.e. información previamente existente en la literatura), ordenados según diversas escalas de análisis, con el fin de realizar inferencias acerca de la movilidad, de los patrones de ocupación del espacio y de la utilización de los recursos de las sociedades cazadoras-recolectoras que ocuparon la cuenca, así como zonas colindantes, durante el Holoceno.

Para el cumplimiento del objetivo general enunciado, se plantearon los siguientes objetivos específicos:

a) Establecer la estructura del registro arqueológico regional, medida en términos de su composición y distribución espacial y temporal, a partir de la integración de información preexistente -édita e inédita- y la obtenida durante el desarrollo de esta investigación.

b) Identificar tendencias en la manufactura y uso de artefactos y ecofactos, principalmente del instrumental lítico.

c) Evaluar la incidencia de los principales agentes y procesos post-depositacionales que actúan en la formación del registro arqueológico a nivel regional.

d) Sistematizar la información ambiental y paleoambiental disponible, principalmente en relación con la distribución actual (observada) y pasada (inferida) de los recursos acerca de los cuales hay evidencias de su utilización real y/o potencial por parte de los grupos humanos que habitaron el área.

e) Discutir la información obtenida desde el punto de vista de los modelos teóricos disponibles acerca de la movilidad de los cazadores-recolectores, en relación con la estructura de los recursos y con otros factores de naturaleza ecológica, social y cultural. 
Teniendo en cuenta los objetivos arriba expresados y el estado actual del conocimiento acerca del poblamiento humano del sur de la Región Pampeana y NE de Patagonia, las preguntas que guiaron esta investigación fueron las siguientes:

¿Cuál es la profundidad temporal de las ocupaciones del área?

¿Cuáles fueron los recursos aprovechados y qué importancia tuvo cada uno de ellos? ¿Cómo fueron utilizados?

¿Cuáles fueron los recursos con mayor incidencia y de qué manera influyeron en los patrones de uso del espacio?

¿Qué amplitud tuvieron los rangos de acción de las poblaciones que habitaron la cuenca del Arroyo Chasicó?

¿Cuál fue el tipo (residencial o logístico) y el grado (frecuencia de los movimientos) de movilidad predominante de esas poblaciones?

¿Pueden identificarse diferencias entre las características (tecnológicas, morfológicas y/o decorativas) de los conjuntos arqueológicos de la cuenca del arroyo Chasicó y las de áreas vecinas (Ventania, Interserrana, cuenca del río Colorado, Pampa Seca, Tandilia)?

¿Cómo varían los patrones observables en el registro arqueológico al aplicar diferentes escalas de análisis?

Las líneas de evidencia empleadas para alcanzar los objetivos propuestos y buscar respuestas a las preguntas planteadas, fueron: a) modelos espaciales acerca de la distribución de recursos, b) la distribución espacial y temporal del registro arqueológico, c) las características en el diseño y uso de los artefactos líticos y cerámicos, d) las tendencias en la distribución de las materias primas utilizadas en la fabricación de las principales categorías de ítems ergológicos, e) la diversidad taxonómica y los patrones de representación anatómica, f) los patrones de variación espacial -a diferentes escalas- en los valores de isótopos estables del carbono y nitrógeno de muestras humanas y animales y g) los patrones de diversidad a nivel del registro bioarqueológico. Estas líneas se llevaron a cabo empleando tres escalas de análisis diferentes, a) la del sitio o sector -en el caso de materiales aislados o concentraciones pequeñas (i.e. microescala; sensu Delcourt y Delcourt 1988; Dincauze 2000)- donde se obtuvo la información primaria discutida; b) la de la cuenca del arroyo Chasicó (i.e. mesoescala; sensu Delcourt y Delcourt 1988; Dincauze 2000), en la que se puso en relación la información arqueológica y ambiental, con el objetivo de identificar patrones recurrentes y diferenciales en sus distintos ambientes; c) la región (i.e, macroescala; sensu Delcourt y Delcourt 1988; Dincauze 2000), donde el espacio considerado se amplió a los fines de evaluar los tendencias identificadas en la cuenca en relación con aquellas emergentes (a partir de la información generada por diferentes equipos de investigación) para el sur de la Región Pampeana y el NE de Patagonia (entre $36^{\circ}$ y $42^{\circ}$ de lat. Sur y $57^{\circ}$ y $68^{\circ}$ de long. Oeste). 
La integración a diferentes escalas de la información arqueológica y los datos ambientales y paleoambientales disponibles, se llevó a cabo mediante el uso de Sistemas de Información Geográfica (SIG), que permitieron visualizar, por medio de la generación de modelos espaciales, patrones y tendencias generales en los datos. Este es un recurso metodológico que hasta ahora no ha sido implementado en forma intensiva en las investigaciones arqueológicas regionales del centro-este de Argentina, por lo que se espera de este modo contribuir al desarrollo de esta línea de investigación.

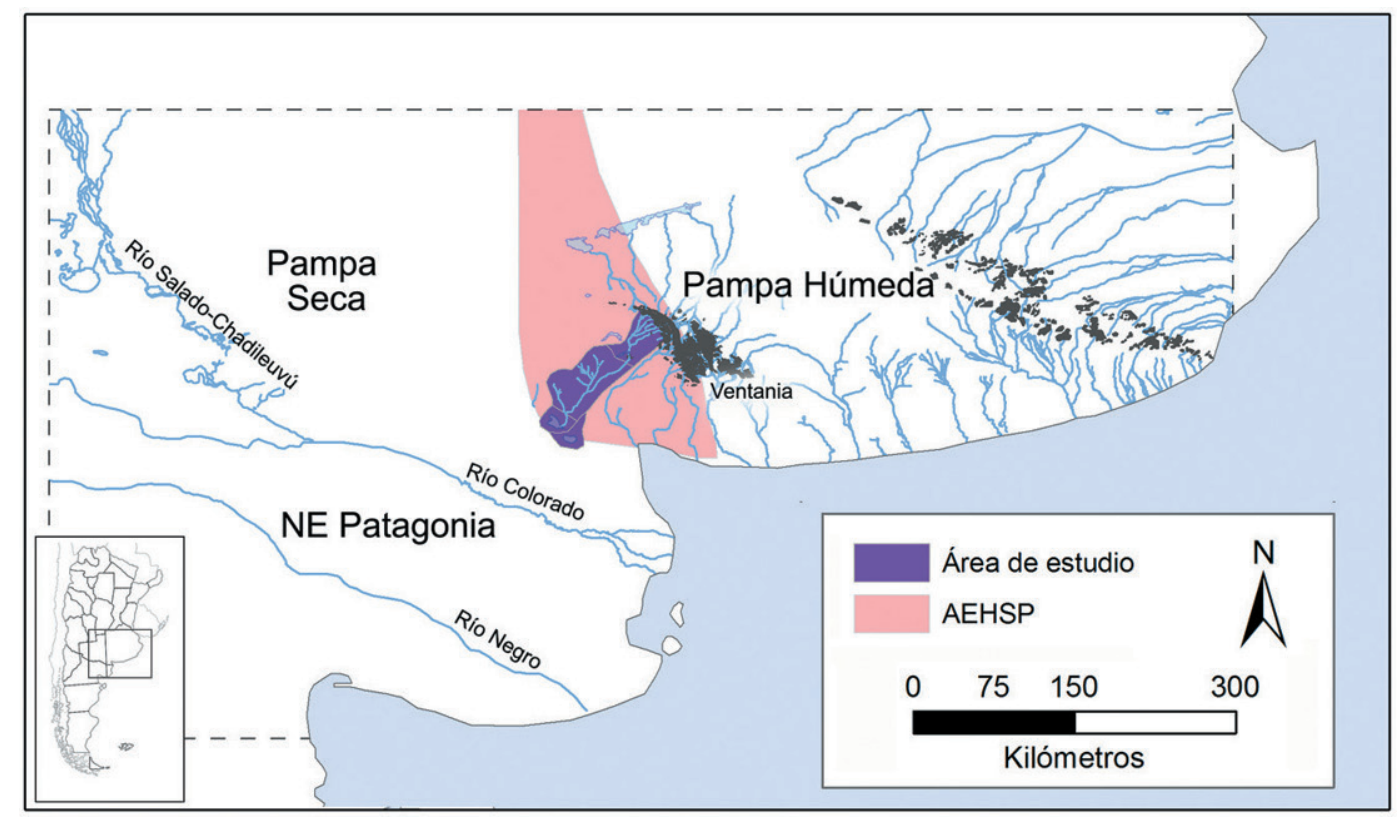

Figura 1.1. Sector centro-oriental de la República Argentina. Resaltada en violeta el área de estudio. La línea punteada comprende el sur de la Región Pampeana y NE de Patagonia.

\subsection{Estructura general de la tesis}

El presente trabajo se organiza en 13 capítulos, distribuidos en cuatro secciones. La primera sección, además de esta introducción, comprende los capítulos 2 a 4 . En el capítulo 2 se desarrollan los conceptos teóricos generales sobre movilidad y uso de recursos en sociedades cazadoras-recolectoras, la interacción entre el ambiente y las preferencias culturales en este tipo de sociedades, así como los correlatos arqueológicos esperables en diferentes contexto. En el capítulo 3 se discuten las investigaciones arqueológicas realizadas en el sur de la Región Pampeana y el NE de Patagonia, analizándose los objetivos y resultados alcanzados en diferentes momentos y desde distintas perspectivas teóricas. Se discuten los principales modelos arqueológicos acerca de la movilidad y del uso del espacio propuestos para estas regiones, con especial énfasis en las investigaciones llevadas a cabo con posterioridad a 1980. En el capítulo 4 se describen las características geológicas, climáticas, fitogeográficas, zoogeográficas e hidrográficas generales del sur de la Región Pampeana y NE de Patagonia (entre $36^{\circ}$ y $42^{\circ}$ de lat. Sur y $57^{\circ}$ y $68^{\circ}$ de long. Oeste); luego, se analizan con mayor detalle las particularidades de la cuenca del arroyo Chasicó como área de transición entre las regiones pampeana y patagónica y, finalmente, se sintetiza la información paleoambiental generada para el sur de la Región Pampeana y NE de Patagonia en general y para la cuenca del arroyo Chasicó y sus inmediaciones en particular. 
La segunda sección está conformada por el capítulo 5, en el que se formulan modelos estadísticos, espaciales y cronológicos que permitan derivar expectativas específicas acerca del contenido y distribución de aspectos relevantes del registro arqueológico de la cuenca del arroyo Chasicó y de sus mecanismos de formación. Dichos modelos son generados sobre la base del análisis e integración de información preexistente (i.e. datos secundarios), mediante herramientas derivadas de sistemas de información geográfica (SIG) y el uso de estadísticas descriptivas, aplicadas a la distribución de valores cuantitativos.

En la tercera sección (capítulos 6 a 10) se presenta la metodología implementada en los análisis de diferentes tipos de evidencia realizados durante el desarrollo de esta tesis, así como los resultados alcanzados. En el capítulo 6 se describen las prospecciones, relevamientos, recolecciones y sondeos llevados a cabo en la cuenca y algunas áreas adyacentes. En el capítulo 7 se presentan nuevos datos radiocarbónicos y se analiza esta información en relación con la preexistente, tanto para los sitios de la cuenca como para las áreas vecinas, a los fines de obtener un marco cronológico apropiado para la discusión de los datos. En el capítulo 8 se generan, a partir de la información ambiental disponible, expectativas tafonómicas regionales en relación con las cuales se interpretan los resultados obtenidos en el análisis del material óseo faunístico. En los capítulos 9 y 10 se exponen los estudios realizados sobre materiales cerámicos y líticos, respectivamente, y se discute su distribución espacial. En el capítulo 11 se presenta información sobre los restos óseos humanos del área, así como análisis sobre la estructuración espacial de los valores de isótopos estables del carbono y nitrógeno resultantes del análisis de muestras humanas y faunísticas (guanacos).

En la cuarta y última sección (capítulos 12 y 13), se realiza una discusión global de la información presentada y se proponen posibles líneas futuras de investigación. En el capítulo 12, específicamente, se evalúan los objetivos propuestos a la luz de los resultados presentados en la tercera sección y en relación con los modelos propuestos en el capítulo 5. Por último, en el capítulo 13 se plantean los nuevos interrogantes surgidos a partir del desarrollo de esta tesis y se identifican las líneas de investigación que podrían abordarse a futuro para darles una adecuada respuesta. 


\section{I Aspectos Teórico-Conceputales}

En este capítulo se discuten algunos conceptos teóricos útiles para el estudio de los patrones de movilidad y uso del espacio, particularmente en vinculación con la tecnología y el uso de los recursos, por parte de las poblaciones cazadoras-recolectoras. Dichos conceptos son empleados como herramientas para la construcción de modelos que permiten derivar hipótesis que puedan ser contrastadas con el registro arqueológico. En particular, se analizan las diferentes escalas de la movilidad, distinguiendo entre aquella orientada a la utilización de recursos y la vinculada con procesos de migración y ocupación de nuevos espacios. Debido al énfasis de este trabajo en la primera de ellas, la discusión se centra en los conceptos de rango de acción y territorio, las escalas espaciales relevantes para su análisis y la relación entre la estructura de los recursos y las estrategias de movilidad y uso implementadas. En este sentido se presentan los modelos de amplitud de dieta (diet breadth), de selección de parcelas de hábitat (patch models) y de gravedad o gravitación (gravity models), como herramientas para analizar la toma de decisiones, y se analiza el rol de la movilidad en la obtención y circulación de información. Por último se discute la necesidad de emplear escalas de análisis amplias y el modo en que indicadores arqueológicos como la señal isotópica y la tecnología pueden aportar información interpretable en términos de movilidad y uso de los recursos.

\subsection{La movilidad entre grupos cazadores-recolectores y el uso de grandes espacios}

La movilidad, en las sociedades cazadoras-recolectoras, es un concepto amplio que incluye el movimiento de personas, grupos y poblaciones a diferentes escalas y con el fin de alcanzar múltiples objetivos. Pueden diferenciarse dos tipos de movilidad, la movilidad individual y grupal, que normalmente se resuelve a nivel de la micro o mesoescala espacial (Delcourt y Delcourt 1988; Dincauze 2000), encontrándose en relación con lo que usualmente se denominan "rangos de acción" (Hamilton et al. 2007; Sellet 2006) y la movilidad poblacional, que normalmente se resuelve a nivel de la meso o macroescala espacial (Delcourt y Delcourt 1988; Dincauze 2000), comprendiendo fenómenos tales como la dispersión y la migración a mediana y larga distancia de los miembros de una población (v.g. Anthony 1990; Bettinger y Baumhoff 1982; Lahr y Foley 1994; Rockman y Steele 2003).

La movilidad individual o grupal se realiza con el objetivo de obtener los recursos diarios para la subsistencia, recopilar información, intercambiar objetos, mantener lazos sociales y encontrar pareja, entre otros (Binford 1980, 1983; Kelly 1983; MacDonald y Hewllett 1999; Mithen 1990; Whallon 2011). La misma involucra múltiples dimensiones del movimiento de un grupo, entre las que se incluyen el tamaño del rango de acción, la frecuencia y distancia de los movimientos y quiénes son los integrantes del grupo que se mueven y con qué objetivos lo hacen (Jones et al. 2003). Es así como los grupos cazadores-recolectores transitan a través de los distintos paisajes mediante una inmensa variabilidad 
de combinaciones de movimientos (individuales, partidas de tareas, traslado de grupos residenciales enteros), que pueden realizarse por razones diversas y durante los cuales se adquieren, transportan y descartan restos materiales en distintas frecuencias (Bamforth 2009; Binford 1983).

A partir de estudios etnográficos y etnoarquelógicos, diversos investigadores han propuesto que el área utilizada por un grupo cazador-recolector conforma su rango de acción o territorio. Este abarca zonas de dimensiones variables, en las que se realizan actividades diferenciales. El concepto de territorio ha sido definido, desde la ecología -particularmente desde la ecología evolutiva-, como un área ocupada de manera más o menos exclusiva, ya sea por un individuo o por un grupo de individuos, dentro de la cual los recursos son defendidos a través de la manifestación de un comportamiento agresivo o de alguna otra forma de comunicación ${ }^{1}$ (Cashdan 1992; Dyson-Hudson y Smith 1978; Krebs y Davies 1993). Debido a que un componente clave de esta noción ecológica de territorio -el uso exclusivo de un determinado sector del espacio- no ocurre en cualquier contexto sino en uno muy específico en el cual un espacio es económicamente defendible (i.e. cuando los recursos son tanto abundantes como predecibles; Brown 1964), resulta preferible el concepto de rango de acción, ya que no depende de un contexto específico de aplicación. Dentro del rango de acción de un individuo o de un grupo pueden encontrarse zonas diferenciadas en función de la configuración de los recursos (su variabilidad, densidad, tamaño de la agregación, movilidad, etc.), del tipo de actividades desarrolladas y el tiempo que el individuo o grupo pasa en ellas, las que podrán modificarse en función de la localización de tales agentes (Binford 1982, 1983).

El modelo arqueológico más antiguo que emplea implícitamente la noción de rango de acción, es el de área de captación de un sitio o site catchment (Vita-Finzi y Higgs 1970; ver Grove 2009; Renfrew y Bahn 2004). Elaborando en mayor o menor medida sobre este modelo y con aportes de la ecología y de la etnoarqueología, diferentes autores (v.g. Binford 1983; Jochim 1976; Mac Donald y Hewlett 1999; Sampson 1988) han definido, tomando como referencia un lugar focal de actividad (típicamente un campamento base), un área circundante de aproximadamente $10 \mathrm{~km}$ de radio (foraging radius), dentro del cual se obtienen la mayor cantidad de los recursos utilizados diariamente, principalmente aquellos de baja movilidad, por medio de micro-movimientos que no consumen más de un día de marcha. Más allá de los $10 \mathrm{~km}$ se encuentra el radio logístico (logistic radius), explotado por partidas que pasan fuera del campamento residencial al menos una noche, obteniendo aquellos recursos de mayor movilidad como la caza mayor (Binford 1980, 1982, 1983). Las áreas regularmente utilizadas de modo residencial y logístico durante un ciclo estacional anual conforman el rango anual (annual range) (Binford 1983), cuya ubicación varía en el largo plazo, con el objeto de evitar la reducción en el número de opciones para localizar el campamento residencial. Dentro de este rango anual se realizan viajes a distancias intermedias, o meso-movimientos (Mac Donald y Hewlett 1999), a los fines de afianzar lazos con amigos y parientes, encontrar pareja, visitar lugares sagrados y explorar el territorio. Finalmente, más allá de las tierras ocupadas dentro de los rangos de acción cotidianos puede encontrarse lo que Binford (1983) denomina como rango extendido (extended range), sectores que son visitados más esporádicamente, hacia el interior de las cuales también pueden realizarse viajes educativos, de monitoreo y partidas de caza por parte de algunos individuos del grupo, a través de macro-movimientos que permiten actualizar la información y explorar sitios exóticos en busca de recursos potencial o especialmente escasos (Binford

1 Para concepciones diferentes acerca de la noción de territorio ver, entre otros, Ingold (1987), Layton (1986). 
1983; Mac Donald y Hewlett 1999). Particularmente para el caso de los nunamiut, L. Binford (1983) observa que es con este rango extendido con el que los miembros del grupo local mantienen relaciones de identidad o pertenencia.

La movilidad poblacional, por otra parte, implica procesos de dispersión hacia un nuevo espacio, de toda una población o de una fracción de ella, que pueden responder, entre otras causas, a aumentos en la densidad poblacional o cambios en la estructura de los recursos (Binford 1983; Morgan 2009; Stojanowski y Knudson 2014; Veth 2005). Estos movimientos, suelen realizarse preferencialmente siguiendo las rutas de menor resistencia (Borrero 1994-1995), es decir, sectores del paisaje con topografía más suave y mayor disponibilidad de agua dulce, recursos vegetales y animales y, en muchos casos, materias primas líticas, como las cuencas de ríos o arroyos que, de esta manera, se convierten en corredores de acceso a la nueva área. Estas migraciones pueden realizarse hacia espacios conocidos previamente, o bien hacia ambiente desconocidos, sobre los que se dispone de poca o ninguna información (para un tratamiento de este problema en diversas situaciones, ver contribuciones en Rockman y Steele 2003). Las diferencias en la información disponible implicarán, a su vez, grados variables de riesgo y, por lo tanto, particulares estrategias de uso del nuevo espacio. Muchas veces las nuevas regiones a ocupar presentan una menor jerarquía, respecto a otras regiones cercanas, en cuanto a abundancia y distribución de los recursos críticos utilizados, constituyendo áreas marginales (Borrero 1989-1990; Gil 2002), es decir, áreas que son pobladas mas tardíamente y presentan, frecuentemente, vacíos arqueológicos que reflejan momentos de abandono del área. En estos casos es factible que esta no se encuentre poblada y, por lo tanto, no se produzcan situaciones de conflicto y/o competencia. Sin embargo, también puede suceder que la migración se produzca hacia una zona habitada por otras poblaciones, desarrollándose, en este caso, una amplia variabilidad de procesos de competencia, lucha y/o integración (Bettinger 2001; Bettinger y Baumhoff 1982; Binford 1983).

\subsubsection{El ambiente y la movilidad grupal en las sociedades cazadoras-recolectoras}

Las estrategias de movilidad y uso del espacio en las sociedades cazadoras-recolectoras se encuentran estrechamente vinculadas con la distribución espacial y temporal de los recursos, la tecnología disponible y aspectos sociales e ideacionales, estableciéndose una continua interacción entre estos diferentes componentes. De particular importancia es la manera en que se estructuran determinados elementos del paisaje, como aquellos recursos considerados atractores, entre los que pueden mencionarse fuentes estables de agua y áreas ecotonales (Dincauze 2000; Jochim 1981, Jones et al. 2003, Mithen 1990, Wandsnider 1998). En este sentido, y dado que la localización de los recursos (agua, rocas, plantas, animales) puede ser incongruente, la movilidad será una de las principales herramientas utilizadas a los fines de realizar un aprovechamiento exitoso de los mismos, reduciendo a su vez, el impacto que un consumo excesivo y espacialmente restringido podría generar (Binford 1983). Sobre la base de lo expuesto puede resumirse, en palabras de L. Binford, que la distribución y agrupación de las personas en el espacio se relaciona con: 1- la distribución relativa de los recursos, 2- las relaciones sociales entre las personas y 3- las relaciones culturalmente específicas entre personas y espacios geográficos o recursos per se (Binford 1983). 
La calidad del ambiente y la estructura de los recursos, son algunos de los principales factores que influyen sobre las características de los patrones de movilidad implementados por una sociedad (Jochim 1976; Kelly 1995; Wandsnider 1998). La calidad del ambiente se evalúa, habitualmente, en términos de variables tales como la temperatura efectiva y la producción primaria. La temperatura efectiva (Bailey 1960) es una medida de la intensidad y distribución anual de la radiación solar en un área, considerando la temperatura al comienzo y al final de la estación de crecimiento de los vegetales (Bailey 1960; Binford 1980; Kelly 1995). La producción primaria (vegetal), por otra parte, se estima en función de la precipitación efectiva y la radiación solar (ver Kelly 1995). La estructura de los recursos, por otra parte, se refiere a la heterogeneidad u homogeneidad en su distribución espacial y/o temporal (Binford 1980; Jochim 1976;). Las decisiones sobre el uso de los recursos tienden a estructurar la configuración espacial y demográfica de las poblaciones cazadoras-recolectoras (Jochim 1976). En tal sentido, L. Binford establece un continuum entre ambientes con recursos homogéneamente distribuidos y ambientes con una distribución discontinua o heterogénea de los recursos críticos (i.e. aquellos que limitan la ocupación de un área, tales como el agua o el combustible), en lo que serán esperables estrategias de movilidad diferentes. En tanto en los primeros la mejor opción para su aprovechamiento es una estrategia forager, en la que los consumidores se mueven hacia los recursos mediante desplazamientos residenciales frecuentes, en los segundos será esperable una estrategia de tipo collector, que implica una menor cantidad de desplazamientos residenciales y en la que se transportan los recursos hacia los consumidores mediante viajes especiales realizados por pequeñas partidas, en lo que configura un manejo logístico del espacio y sus recursos (Binford 1980). De manera similar, Kelly (1983; 1995) observa que los grupos cazadores-recolectores se mueven más frecuentemente en ambientes con alta biomasa primaria, donde los niveles de vegetales comestibles son bajos pero donde tales recursos se encuentran homogéneamente distribuidos.

La configuración de los recursos también se relaciona con el tamaño del rango de acción de un grupo, ya que los ambientes ricos y predecibles en la cantidad y/o variedad de recursos posibilitarán rangos más pequeños que aquellos ambientes donde su cantidad y/o variedad es menor, incrementándose, a su vez, el tamaño del rango de acción al aumentar la dependencia en la caza (Bamforth 2009; Binford 1983; Grove 2009; Kelly 1995; Whallon 2006). Las características ambientales, por otra parte, se conjugan con otras variables como el tipo de organización social y la demografía, influyendo en el tipo de recursos seleccionados por un grupo, el modo en que éstos son utilizados, el tiempo que se mantiene un campamento residencial, la distancia a la que se localiza el próximo campamento residencial y, finalmente, el tamaño del rango de acción (Binford 1982, 1983; Grove 2009).

\subsection{Cómo se utilizan los recursos: modelos de amplitud de dieta, de selección de parcelas y de gravedad}

Si aceptamos que las decisiones sobre el uso de los recursos tienden a estructurar la configuración espacial y demográfica de las poblaciones cazadoras-recolectoras, algunas de las herramientas teóricas desarrolladas por la ecología del comportamiento humano (ECH), pueden ayudar a detectar regularidades que permitan identificar relaciones adaptativas entre la población y los recursos. Entre estas herramientas se encuentra la teoría de la toma de decisiones (general decision-making theory), desde la cual el sistema de subsistencia y asentamiento se considera como el resultado de comportamientos tendientes 
a la solución de problemas relacionados con preguntas tales como qué tipo de recursos pueden ser utilizados, en qué cantidad, cuándo y dónde adquirirlos y cuántas personas deben intervenir en las tareas de obtención (Jochim 1976).

Los presupuestos de los modelos de la $\mathrm{ECH}$, al igual que los de la ecología evolutiva de la cual deriva, proceden de la microeconomía, según la cual el comportamiento económico implica la toma de decisiones por parte de individuos racionales que tratan de maximizar su utilidad o beneficio mediante elecciones basadas en la información disponible, ya sea ésta total o parcial. Esta teoría considera que los individuos toman la mayor parte de sus decisiones económicas (entre las que se incluyen aquellas relacionadas con la subsistencia y el asentamiento), considerando los costos y beneficios de cada una de las opciones posibles. En este sentido, el comportamiento de subsistencia y asentamiento de un grupo cazador-recolector es visto como producto de elecciones conscientes, racionales y no oportunísticas, cuyo objetivo es resolver de manera óptima problemas relacionados, principalmente, con la satisfacción de las necesidades calóricas de la población y la obtención de materias primas para la manufactura de utensilios, limitando el esfuerzo y minimizando el riesgo (Jochim 1976). Se entiende por "óptimo" a la mejor situación o estado de cosas posible de acuerdo con algún objetivo explícito y respecto de algún estándar preciso de evaluación. En este contexto teórico, los modelos de depredación óptima, generados dentro de la $\mathrm{ECH}$, proponen que maximizar la tasa de adquisición de nutrientes, ya sea por un aumento en la cantidad obtenida o por una disminución en el tiempo empleado para incorporarlos, mejorará la adaptabilidad.

Otros modelos ampliamente utilizados para analizar el comportamiento de las sociedades cazadorasrecolectoras son el modelo de amplitud de dieta y el de selección de parcelas, los cuales predicen, respectivamente, el tipo de recursos que serán incorporados y el tiempo que se invertirá en la utilización de cada parcela de hábitat (Bird y O`Connell 2006; Jochim 1976; Lupo 2007). A estos se agrega el de gravedad, empleado para analizar la atracción ejercida por recursos (e.g. fuentes de materias primas) o ambientes diferenciados sobre los agentes humanos (Wilson 2007).

En el modelo de amplitud de dieta, se evalúa el costo de búsqueda (o tasa de encuentro) y el costo de procesamiento. Los recursos son jerarquizados en función de su costo de procesamiento, donde aquellos con menor costo de procesamiento estarán mejor posicionados en el ranking y serán incorporados antes que aquellos con mayor costo de procesamiento. Este modelo asume que la inclusión de un recurso no dependerá, únicamente, de su propia densidad, sino de la densidad de los recursos mejor jerarquizados, es decir, que el forrajeador al momento de elegir un recurso evaluará, sobre la base de su conocimiento, la calidad, densidad y costo de procesamiento de los otros recursos potencialmente disponibles (Kelly 1995).

El modelo de elección de parcela asume que los recursos no se distribuyen homogéneamente, sino que se encuentran agrupados en parcelas que pueden ser clasificadas, al igual que en el modelo anterior, en relación con el retorno energético obtenible por unidad de tiempo pero, en este caso, considerando también el tiempo de traslado entre ellas. De esta manera, basándose en el teorema del valor marginal (Charnov 1976), predice que una parcela de recursos será abandonada en el momento en que su tasa de retorno, es decir la utilidad obtenida del mismo, caiga por debajo del promedio del ambiente local conocido (Kelly 1995).

Los modelos de gravedad o de gravitación, se basan en la analogía con la atracción gravitacional entre dos cuerpos celestes. Dentro de las ciencias sociales, estos modelos han sido desarrollados para 
analizar la distribución y tamaño de los asentamientos y el flujo de personas e información entre áreas (Haynes y Fotheringham 1984). En arqueología, los modelos de gravedad han sido aplicados para simular la interacción entre actividades dentro de sitios o entre sitios dentro de sistemas. En relación con el tema que nos ocupa, estos modelos permiten predecir la atracción de los distintos recursos sobre un asentamiento, particularmente, entender los comportamientos involucrados en la obtención de aquellos recursos estables en el paisaje, como las fuentes de materias primas. Para esto, se analizan los factores que pueden influir en la elección de la fuente, como facilidad de acceso, densidad, facilidad de obtención, extensión, etc., a partir de los cuales se calcula el poder de atracción de la fuente. De esta manera, los valores de atracción de cada fuente comparados con los de las fuentes vecinas permiten predecir qué fuentes tendrán mayor importancia y cuáles serán sus áreas de influencia (Browne y Wilson 2011; Wilson 2007).

Prácticamente desde el comienzo de la aplicación de estos modelos el presupuesto de toma de decisión racional y óptima ha sido objeto de crítica desde diferentes disciplinas y posturas teóricas, cuestionándose la validez de este estándar individualista de evaluación. Estos modelos también han sido criticados internamente, tanto en el campo de la economía como de la ecología del comportamiento y la arqueología (e.g. Bettinger 1987; Bird y O'Connell 2006; Borgerhoff Mulder y Schacht 2012; Gremillion 2002; Henrich 2002; Henrich et al. 2005; Kelly 1995; Mithen 1989; Smith 2005; Winterhalder et al. 1988). En particular, se ha propuesto la necesidad de reducir la dependencia respecto del modelo de toma de decisiones, basado en la lógica del costo-beneficio, e incorporar una comprensión, cognitivamente informada, acerca del aprendizaje social, la transmisión cultural y el procesamiento de información (Henrich 2002). A este respecto, cabe considerar que resulta poco probable que los patrones de comportamiento humano sean, ante todo, un producto de consideraciones de costo-beneficio porque: 1) los datos de laboratorio muestran que el procesamiento de información está tan cargado de errores, prejuicios y fallas de calibración que, si este fuera nuestro principal modo de adaptación o de lograr objetivos individuales, deberíamos observar patrones sistemáticos de comportamientos maladaptativo, y 2) los datos etnográficos muestran que las personas, con frecuencia, carecen del tipo de información requerida por los modelos de costo-beneficio típicos y que las elecciones de las personas frecuentemente se desvían en forma sustancial respecto de aquellas que podrían maximizar sus ganancias materiales inmediatas (Henrich et al. 2005; Smith 2005).

En general, la respuesta a la crítica ha sido integrar los cuestionamientos a los principios de los modelos de elección racional, con el fin de lograr una mayor realidad y precisión. A este respecto, cabe señalar que el objetivo de los modelos de la ECH no ha sido nunca duplicar la realidad, sino modelarla con un nivel de complejidad y especificidad variable en función de los objetivos de la investigación y del estado del conocimiento (Kelly 1995; Smith 1983). Estos modelos, debido a su simplicidad son útiles a los fines de generar hipótesis sobre el comportamiento de actores individuales bajo condiciones específicas (Bird y O'Connell 2006). Permiten predecir qué recursos serán utilizados y de qué manera ciertos rasgos ambientales afectarán a su selección (Kelly 1995; Winterhalder et al. 1988), brindando herramientas para evaluar las tensiones generadas entre el comportamiento desarrollado en el contexto de normas e ideas culturales y las decisiones individuales (Bettinger 1987). De esta manera, su principal valor es heurístico, al aportar un marco de referencia que permite comprender el modo en que los humanos -particularmente aquellos organizados en sociedades de pequeña escala- utilizaron el 
ambiente, evaluando las ventajas y desventajas de las diferentes estrategias empleadas (Bird y O 'Connell 2006; Jochim 1976; Lupo 2007). En este trabajo, para el tratamiento de algunos problemas, tomaremos elementos de estos modelos (e.g. las características de las fuentes y de las en la selección de ellas), sin intentar su desarrollo formal con fines predctivos, debido a la falta de información de la cantidad y calidad requerida para tal fin.

\subsection{Movilidad e información}

Otro componente importante de la movilidad es la información, definida como el conocimiento, de tipo ambiental, técnico y social (Whallon 2011), que un individuo adquiere y actualiza mediante observaciones personales efectuadas, generalmente, durante los traslados realizados para cazar, recolectar, trasladar el campamento y visitar personas y/o lugares. Dado que la información es adquirida diferencialmente por los individuos y grupos, la movilidad permite a su vez que esta información circule, transmitiéndose de manera verbal y no verbal, en este último caso, tanto por medio de la imitación como a través de la utilización de signos, símbolos o estilos compartidos (Gamble 1990; Hegmon y Fisher 1991; Mithen 1990; Whallon 2011).

Las estrategias de movilidad por otra parte, son planificadas en función de la información previa disponible, pero para que dicha información sea útil debe ser adquirida y transmitida lo más precisamente posible. En este sentido, su exactitud aumenta al aumentar la frecuencia con la que es actualizada y disminuye cuando se incrementa el número de vínculos a través de los cuales pasa en el curso de su circulación (Gamble 1990; Hegmon y Fisher 1991; Mithen 1990; Whallon 2011). De esta manera, se la puede dividir en: 1-Información de corto plazo, que incluye el estado y disponibilidad de los recursos más variables, como agua, plantas y animales, así como información sobre posibles amenazas y sobre la posición, tamaño y composición de otros grupos de personas; esta información debe ser actualizada frecuentemente y circula principalmente dentro del territorio de captación de recursos de la banda mínima local, aunque también puede circular a nivel de bandas máximas extendidas, involucrando el intercambio de bienes materiales; 2- Información de largo plazo, que incluye aquella referente a factores que no necesitan ser monitoreados, como la topografía y ciclos de larga duración en la disponibilidad de los recursos (Hegmon y Fisher 1991). Este tipo de información circula interregionalmente por medio de viajes a larga distancia relacionados con el fortalecimiento de las redes sociales, la búsqueda de pareja, las obligaciones religiosas y el acceso a recursos lejanos y en los que suele realizarse el intercambio de ítems con significado social (Bamforth 2009; Binford 1983; Whallon 2006, 2011).

Es así como, el establecimiento y mantenimiento de relaciones a través de la movilidad, crea derechos y obligaciones que funcionan como una red de seguridad, generando un flujo de información actualizado y preciso que podrá ser utilizado cuando los recursos escaseen, para decidir no sólo dónde se encuentran disponibles, sino también cuáles son los grupos dispuestos a compartirlos. Cuanto más grande y más crítica para sobrevivir a una crisis sea la red, más extensa y más frecuente será la movilidad, sirviendo como un reaseguro en ambientes de alto riesgo. La homogeneidad ambiental también influye en la escala de movilidad necesaria para establecer y mantener una red de seguridad adecuada, debiendo ser más amplia en aquellos ambientes más homogéneos (Fitzhugh et al. 2011; Whallon 2006, 2011). Estas estrategias de flujo de información a través de grandes regiones pueden ser costosas de mantener, 
y estarán orientadas a cumplir objetivos parcialmente diferentes dependiendo de la predictibilidad ambiental y el costo de interacción (Fitzhugh et al. 2011).

\subsection{El concepto de riesgo y su relación con la movilidad y el uso del ambiente}

En este punto cabe desarrollar un concepto relacionado con el uso de los recursos y los patrones de movilidad en sus diferentes escalas y que ha sido mencionado en el apartado anterior: el riesgo. El riesgo puede ser definido como la probabilidad de que ocurra una pérdida de tipo económica, vinculada, principalmente, a la posibilidad de no contar con la cantidad suficiente de un recurso crítico (generalmente alimento, pero también puede tratarse de agua o materias primas), necesaria para permitir la supervivencia del grupo. Se encuentra supeditado a dos factores, por un lado la falla total o parcial en la adquisición del recurso, donde inciden la frecuencia y duración con que una falla ocurre, el tamaño y homogeneidad del área afectada y la severidad de la escasez (Bousman 1993; Halstead y O' Shea 1989), por otra parte la información que una población o individuo posee acerca de estas variaciones ambientales o, mejor dicho, la falta de esta información, a lo que se llama incertidumbre (Bettinger 2001; Bousman 1993; Fitzhugh et al. 2011; Lovis y Donahue 2011).

Una de las maneras de amortiguar los efectos del riesgo es mediante la implementación de cambios en los patrones de movilidad, a partir del abandono o uso esporádico de los lugares menos favorables y la incorporación de nuevas áreas, cuando esto sea posible. También podrá modificarse la base del sistema de subsistencia, explotando un rango más amplio de especies, lo que implica la incorporación de recursos de mayor costo o una mayor variedad de áreas, y/o realizando un uso más intensivo de ellas, proceso llamado por algunos autores diversificación (Halstead y O' Shea 1989) y por otros intensificación (Brouhgton 1994). Por último, el establecimiento de sistemas de reciprocidad con grupos que explotan ambientes diferentes, permite establecer obligaciones que puedan ser empleadas en aquellos casos en que se dan condiciones locales de escasez pero regionales de abundancia (Cashdan 1985), pudiendo verse reflejado en el intercambio de bienes "raros" a través de grandes distancias.

\subsection{Aproximaciones teóricas para el abordaje de la relación entre movilidad, uso de los recursos y registro arqueológico}

Dado que la movilidad implica la utilización de espacios amplios, su estudio requiere de una perspectiva regional dentro de la cual se incluyan análisis a diferentes escalas, que permitan acceder a los patrones de distribución en el espacio y uso del paisaje de las poblaciones pasadas. Muchos estudios han enfatizado en los materiales procedentes de "sitios arqueológicos", definidos estos como conjuntos de artefactos (ítems y rasgos), habitualmente en un contexto estratigráfico, con determinado grado de concentración (Binford 1982). A estas agregaciones deben sumarse los restos superficiales dispersos, con grados variables de densidad artefactual. Esto lleva a analizar algunos de los postulados planteados por las arqueologías distribucionales, del tipo "non-site sampling" (Thomas 1975), "offsite" (Foley 1981) y "site-less survey" (Dunnell y Dancey 1983), desde las cuales se considera que la mayor proporción del descarte ocurre fuera del asentamiento. En tal sentido, ciertos aspectos como el uso de la tierra, el patrón de asentamiento y la utilización de los recursos, pueden comprenderse mejor si se analizan las distribuciones de los artefactos y sus densidades sobre grandes áreas, a una escala regional. 
De esta manera se incorporan los materiales superficiales, considerándose al registro arqueológico como una distribución más o menos continua de artefactos con densidades altamente variables. Desde esta perspectiva, los "sitios" representan sólo aquellos sectores del registro con mayor densidad artefactual, donde la variabilidad en la densidad no responde a diferencias cualitativas, sino al carácter y frecuencia de las actividades desarrolladas, diferenciales pero distribuidas de manera continua (Dunnell y Dancey 1983; Ebert 1992; Foley 1981; Tainter 1998 y en nuestro país Belardi 2005; Magnín 2010).

Desde una perspectiva distribucional, Foley (1981) propuso que la unidad de análisis pertinente para el estudio del comportamiento humano es el rango de acción (o home range), estrechamente relacionado en cuanto a su estructura, tamaño y continuidad espacial con la distribución y densidad de los recursos y requerimientos de subsistencia. Desde una perspectiva arqueológica sin embargo, el concepto de rango de acción no se asocia con el de un conjunto de asentamientos funcionando sincrónicamente como parte de un sistema cultural. Por el contrario, este concepto queda conformado por la sumatoria de múltiples estrategias de uso del espacio, desarrolladas en una escala temporal larga, diferentes procesos naturales (geológicos, tafonómicos) y variadas técnicas de muestreo y análisis (Barrientos et al. 2014; Belardi 2005; Borrero et al. 1991; Holdaway et al. 2004).

Analizar la estructura del registro arqueológico como espacialmente continua y en una escala amplia, tiene la ventaja de permitir documentar patrones que brindan información en relación con aspectos tales como tamaño y estructura del rango de acción, uso y modificación del paisaje, patrón de asentamiento, adaptación ecológica y utilización de recursos que, de otra manera, no podrían ser evaluados claramente (Dunnell y Dancey 1983; Tainter 1998). Este tipo de enfoques permite analizar al registro arqueológico en términos de sistema adaptativo (Borrero 1989-1990), centrando la atención en la distribución de las poblaciones cazadoras recolectoras en tiempo y espacio así como en los cambios en la organización social, densidad poblacional y tecnologías disponibles (Clarkson 2008; Schalenger 1992; Wandsnider 1992).

2.6 Indicadores arqueológicos que aportan información sobre los patrones de movilidad y el uso de los recursos

Como ha sido desarrollado previamente, la movilidad involucra diferentes dimensiones, que abarcan desde movimientos individuales hasta poblacionales y desde traslados de unos pocos kilómetros hasta relocalizaciones a grandes distancias, realizados a los fines de cumplir con un amplio espectro de objetivos. Como consecuencia, el correlato arqueológico de estos comportamientos también incluye una amplia variedad de indicadores. Las materias primas representadas en los sitios de cazadoresrecolectores, han sido consideradas una representación, al menos parcial, de la escala de movilidad del grupo (Amick 1999; Shackley 1985). La identificación de su lugar de procedencia, permite acercarse a los posibles lugares por donde transitaron los individuos o grupos de individuos. Sin embargo, entre estos elementos, aquellos que se encuentran en muy baja proporción y son considerados como "exóticos" o "raros" pueden formar parte de sistemas de alianzas que facilitan el flujo de información y proveen redes de seguridad ante situaciones de stress (Whallon 2006). Por otra parte, a partir del análisis de las características tecnológicas de los conjuntos artefactuales pueden realizarse inferencias acerca del tipo de recursos consumidos, su importancia relativa y el modo en que fueron utilizados, así como las estrategias de movilidad empleadas para resolver los problemas planteados por las variaciones, en tiempo 
y espacio, de la estructura del paisaje (Bright y Ugan 1999; Khun 1994; Nelson 1991; Nelson y Lippmeier 1993; Simms et al. 1997; Skibo et al. 1989; Torrence 1989). Finalmente, los análisis isotópicos aportan información sobre la alimentación de los individuos, variaciones en las estrategias de subsistencia y, dependiendo de cómo los alimentos se distribuyan en el espacio, también sobre las áreas visitadas durante cierto período de tiempo (Eerkens et al. 2013; Price et al. 2006; Schoeninger y Moore 1992).

En este punto, es necesario resaltar que las sociedades cazadoras-recolectores no utilizan el espacio de una manera estable, sino que reconfiguran sus rangos de acción y patrones de movilidad en relación con diversos factores. Por esta razón al analizar la distribución en el espacio de los indicadores mencionados, no se están observando rangos de acción, sino registros promediados de las distintas configuraciones espaciales adoptadas a lo largo del tiempo (Binford 1983).

\subsubsection{La tecnología como indicador de las estrategias de movilidad y uso de los recursos}

Las estrategias tecnológicas son procesos de solución de problemas que responden a las condiciones creadas por la interacción entre los seres humanos y su ambiente (Nelson 1991). Dado que la tecnología juega un rol dinámico en constante interacción con otros aspectos del sistema social, será esperable observar como correlato arqueológico de variaciones en la movilidad, la subsistencia, el manejo del riesgo, la demografía, la organización social y otros aspectos del comportamiento humano, variaciones en las estrategias tecnológicas y consecuentemente variaciones en las características, frecuencia y distribución de los artefactos representados (Babot 2004; Odell 1996; Rice 1987).

El diseño de las herramientas, en términos de tiempo invertido en su confección, cantidad de funciones que pueden llevar a cabo, posibilidad de reconfiguración y transportabilidad de las mismas, así como su distribución en el espacio, también aporta información sobre cómo se utilizó el paisaje, ya sea en el tipo de recursos utilizados, la intensidad con que se los procesó y las estrategias de movilidad implementadas para afrontar la heterogeneidad en tiempo y espacio (Nelson 1991). Las variaciones en la composición de los conjuntos, en términos de, por ejemplo, tipo de artefactos representados, vida útil remanente, peso y tamaño, puede, aportar información sobre la duración de los asentamientos y la reocupación de determinados sectores. Una mayor estabilidad en la ocupación de determinados espacios tendrá como correlato el acondicionamiento a través del equipamiento del área con, por ejemplo, núcleos no agotados, caches de herramientas versátiles y artefactos de molienda. La presencia de estos artefactos en lugares puntuales del paisaje, actúa, a su vez, como un factor positivo que favorece su reocupación a través del tiempo (Dewar y McBride 1992). Este tipo de registro sugiere patrones de movilidad estables y recursos predecibles que justifican la inversión de energía realizada en anticipar futuras visitas (Nelson y Lippmeier 1993; Smith y Mc Knees 1999). Una mayor duración y regularidad de ocupación por otra parte, generará un conjunto artefactual con diferencias en los remanentes de vida útil, evidencias de abundante mantenimiento, técnicas de administración del desgaste (generación de nuevas superficies de molienda o rotación de la pieza horizontal o verticalmente a los fines de conservar las formas confortables), una elevada proporción de artefactos agotados y/o rotos y evidencias de reutilización o reclamación, reciclaje y uso secundario de artefactos agotados (Adams 1996; Babot 2004; Binford 1979; Holdaway et al. 2010). 
Por otra parte, se ha propuesto que a medida que aumenta la variedad de recursos incorporados y, como consecuencia, también los costos de procesamiento, la complejidad de la tecnología disminuye, utilizándose un repertorio limitado de herramientas multipropósito, con diseños flexibles y versátiles (sensu Nelson 1991) o bien una mayor proporción de materias primas fácilmente obtenibles para, de esta manera, reducir los costos de procesamiento. (Bettinger 2001; Bousman 1993; Jeske 1992). Por otra parte, las modificaciones en la dieta también podrán verse acompañadas por la incorporación y modificación de herramientas que permiten la explotación de nuevos recursos y/o un aprovechamiento más efectivo de estos. En este último caso, particularmente cuando las tareas realizadas insuman una gran cantidad de tiempo, la tecnología se tornará más elaborada, confeccionando diseños más cómodos y eficaces (Babot 2004). La reducción en la movilidad por último, podrá generar cambios en las características tecnológicas de los conjuntos y el aumento en la proporción de materias primas locales (Amick 1999; Eerkens et al. 2007; Holdaway et al. 2004, 2010; MacDonald 2007; Nelson 1991; Nelson y Lippmeier 1993; Shackley 1985).

\subsubsection{El concepto de estilo tecnológico}

Un concepto interesante al momento de evaluar la movilidad poblacional y la interacción entre poblaciones y los procesos de continuidad/discontinuidad poblacional, es el de estilo tecnológico, considerado este como "la manera de hacer", es decir, el conjunto de elecciones que se realizan durante la elaboración de un artefacto. El estilo estaría conformado por el conjunto de procedimientos cuya selección es dictada por la tradición tecnológica dentro de la cual han sido aprendidos, encontrándose presente en toda variación formal y debiendo compartir necesariamente esta variación con la función (Sackett 1985, 1990). De esto se deriva que los aspectos menos salientes y más cotidianos de la cultura material serían tan pertinentes para estudiar los límites sociales como aquellos visibles y supuestamente cargados de manera consciente de información social (Gosselain 2000).

Según Gosselain (2000), aquellas etapas más visibles, como la decoración y la forma de los artefactos, serían fácilmente transmisibles en la interacción posterior al aprendizaje, pudiendo tener mayor tendencia a fluctuar a través del tiempo y a ser transmitidos ampliamente a través del espacio, por lo que reflejarían mas superficialmente facetas situacionales y temporarias de la identidad, en tanto la técnica de construcción sería más estable a lo largo del tiempo reflejando mejor aspectos como identidad social, lenguaje, género y divisiones de clase (Gosselain 2000). Por esto, se ha considerado que, debido a que muchas de las opciones técnicas pueden ser funcionalmente equivalentes, las cadenas operativas no deberían ser vistas, únicamente, como orientadas funcionalmente, sino como consecuencia de procesos socialmente aprendidos. Esto significa que, si bien hay interdependencia entre los diferentes estadios, esta puede ser pequeña, es decir, que una elección hecha en un nivel no condiciona automáticamente las elecciones que se harán en otros niveles (Gosselain 2000; Sackett 1990), sino que la selección de una u otra opción se realiza en base a una tradición tecnológica aprendida en la interacción con los miembros del grupo social de pertenencia (Gosselain 2000; Sackett 1985, 1990). De esta manera, no sólo la forma o determinados rasgos considerados no funcionales (Wiessner 1983), pueden brindar información sobre la identidad de un grupo social, sino cada una de las elecciones realizadas durante la elaboración de un artefacto (Gosselain 2000; Sackett 1985, 1990). Desde una perspectiva evolutiva, también se ha planteado que las similitudes entre dos o más rasgos pueden responder a causas históricas (homologías), producto 
de una continuidad en la transmisión cultural, o funcionales (analogías), consecuencia de limitaciones impuestas a la variación por factores ambientales. Sólo las primeras pueden ser consideradas como evidencia de continuidad poblacional, siendo la distinción entre unas y otras sólo posible a partir de la identificación de procesos tecnológicos similares (ver discusión en Barrientos 2009). Es por esto que, al considerar que estilo y función se encuentran presentes simultáneamente en la forma artefactual, es necesario ser cuidadoso al realizar interpretaciones acerca de cómo y en qué medida las variaciones entre conjuntos reflejan diferentes grupos sociales, diferentes actividades desarrolladas o el aprovechamiento de ambientes diferentes (Sackett 1990).

\subsubsection{La movilidad de los individuos a través de su "huella" isotópica}

La particularidad de los análisis isotópicos consiste en la posibilidad de obtener información a nivel del individuo. Particularmente en el caso de los isótopos estables del carbono y el nitrógeno, estos permiten determinar la dieta de un individuo durante los últimos años de su vida, pero con menor nivel de especificidad que otros análisis (v.g. identificación anatómica y taxonómica de especies vegetales y/o animales). Los valores isotópicos resultan de un promedio de los alimentos ingeridos durante los últimos años de vida, entre 10 y 20 años en el caso de los elementos óseos, obteniéndose así categorías amplias acerca de las proporciones con las que se incluyeron alimentos de variado origen -marinos vs. terrestres; vegetales vs. animales; $\mathrm{C}_{3}$ vs. $\mathrm{C}_{4}-($ Schoeninger y Moore 1992). De este modo, si bien no de manera directa, ya que múltiples factores influyen en la composición isotópica de los tejidos de un individuo (v.g. edad, stress hídrico y nutricional, procesos diagenéticos, nivel trófico), los análisis de isótopos estables permiten realizar reconstrucciones acerca de la composición de la dieta y, en algunos casos, también de la movilidad de un individuo. Esto se debe a que los valores isotópicos de los tejidos se correlacionan positivamente con aquellos de los alimentos consumidos (Schoeninger y Moore 1992). En los casos en que se observen variaciones espaciales en los valores isotópicos de diferentes ambientes, podrán establecerse vinculaciones entre la señal isotópica de un individuo y el área donde este obtuvieron los recursos que formaron parte de su alimentación. El mapeo de de estos valores permite la delimitación de rangos de acción (en el sentido arqueológico arriba desarrollado) y/o estrategias particulares de obtención de recursos (v.g. Barberena 2005; Eerkens et al. 2013).

Los valores isotópicos también pueden reflejar migraciones a mayor distancia, como es el caso de individuos que presentan diferencias en los valores isotópicos de sus dientes con respecto a los elementos óseos, o bien valores isotópicos diferentes a los esperables para el ambiente en que se encuentran, por ejemplo en estroncio y oxígeno. Algunos isótopos como los del azufre y el estroncio, varían espacialmente de manera significativa, por lo que es factible identificar las áreas de nacimiento en personas que migraron de adultas (Price et al. 2006; Schoeninger y Moore 1992). Si bien el análisis de estos isótopos no ha tenido mayor desarrollo en argentina, recientemente han comenzado a realizarse algunos avances en esta vía (Berón et al. 2012; Gil et al. 2011).

\subsubsection{Los modelos espaciales y el análisis de tendencias y patrones en los datos}

El análisis de la distribución, en la meso y/o la macro escala espacial, de los ítems arqueológicos mencionados, permitirá reconocer su estructura espacial e identificar así patrones que no pueden ser 
distinguidos cuando se analizan los materiales de forma aislada. La estructura espacial del registro arqueológico consiste en un patrón organizado, no al azar, de objetos que se localizan sobre, o inmediatamente debajo, de la superficie terrestre (Barrientos et al. 2014). Dichos patrones responden a múltiples factores, entre los que se incluyen aspectos organizativos de las sociedades, procesos pre y post-depositacionales y sesgos relacionados con las metodologías de muestreo y procesamiento de los datos (Barrientos et al. 2014).

Los Sistemas de Información Geográfica (SIG), son herramientas que facilitan el manejo de grandes cantidades de información geográfica (e.g. arqueológica, ambiental y paleoambiental), permitiendo la identificación de relaciones, patrones y tendencias, mejorando así la comprensión de la estructura espacial del registro arqueológico (Hodder y Orton 1976). También permiten generar mapas predictivos de diversos aspectos del registro, como la probable localización de los sitios o características esperables en la integridad y resolución de los conjuntos (Conolly y Lake 2006; Verhagen y Whitley 2012; Wheatley y Gillings 2002). Estos análisis se realizan por medio de dos sistemas de almacenamiento de información, cada uno de ellos con potencialidades y limitaciones propias. Los sistemas raster, consistentes en una matriz de celdas y los vectoriales, conformados por objetos geométricos definidos en términos de su localización y coordenadas (Wheatley y Gillings 2002). Por medio de estos dos sistemas, los SIG permiten transformar datos espaciales, generar nuevos datos y desarrollar modelos desde los cuales derivar hipótesis y obtener información que o no era evidente o no estaba presente originalmente (Connoly y Lake 2006; Lloyd y Atkinson 2003; Wheatley y Gillings 2002).

Una de las principales herramientas utilizadas para caracterizar la variación espacial y realizar predicciones y simulaciones es la geoestadística (Lloyd y Atkinson 2003). Esta se basa en el principio de la dependencia espacial o autocorrelación (aunque puede ser utilizada siempre que los datos muestren alguna estructura y no una distribución al azar), según el cual, los datos espacialmente más cercanos tenderán a ser más semejantes entre sí que con respecto a los más lejanos (Lloyd y Atkinson 2003). Entre los procedimientos geoestadísticos, se encuentran las técnicas de interpolación geoestadística, como el kriging, las cuales permiten estimar el valor de una variable en un punto no muestreado, a partir de valores observados en sus cercanías, teniendo en consideración el semivariograma o, en otras palabras, el grado de dependencia espacial de la variable de interés (Lloyd y Atkinson 2003). A través de la interpolación, se generan superficies continuas, partiendo de datos cuantitativos puntuales, obtenidos en muestreos aislados y heterogéneamente distribuidos. Estas superficies, facilitan el examen y análisis de los datos, volviendo más inteligible la información que de otra manera se visualiza de forma fragmentada e inconexa. A diferencia de otras técnicas de interpolación no geoestadísticas, como la ponderación de distancia inversa (inverse distance weighting o IDW) y splines, los métodos geoestadísticos brindan la posibilidad de realizar análisis exploratorios de los datos a los fines de conocer el carácter de la autocorrelación, detectar y compensar limitaciones relacionadas con la distribución de los datos (e.g. anisotropías, agrupamientos) y estimar el grado de incertidumbre del mapa resultante (Márquez Pérez 2012).

Entre las principales limitaciones de estos modelos puede mencionarse que procesos distintos pueden dar como resultado patrones espaciales similares (i.e. equifinalidad), por lo que la identificación de estos, o el establecimiento de relaciones, no necesariamente proporciona información sobre su origen (Hodder y Orton 1976). Por otra parte, la calidad de los datos (i.e. su precisión y exactitud) influirá 
sobre la confiabilidad del modelo generado. Problemas de este tipo podrán producirse especialmente en aquellos casos en que se trabaja con escalas espaciales amplias, donde los datos utilizados son recolectados con objetivos diferentes y mediante estrategias de investigación heterogéneas desarrolladas en diferentes momentos y por diversos investigadores (Wheatley y Gillings 2002). A su vez, cuando se trabaja en espacios amplios, la erosión, la destrucción y las diferencias en la intensidad del trabajo de campo también distorsionarán la distribución de los datos, afectando la fortaleza de los modelos (Hodder y Orton 1976).

Entre los principales medios para evaluar la confiabilidad de los mapas, se encuentra el análisis del grado de ajuste de nuevos datos a las tendencias observadas y la variedad de herramientas geoestadísticas brindadas por los SIG para medir el grado de distorsión de los mapas (Verhagen y Whitley 2012). Por otra parte, es esperable que los factores que afectan a los conjuntos arqueológicos (e.g. tafonómicos, de muestreo) actúen con variado grado de intensidad sobre el modelado de la variable de interés. En tal sentido, el análisis de indicadores diversos, que aportan información con variable nivel de resolución (e.g. acerca del individuo en el caso de valores isotópicos, sobre el grupo, o grupos, cuando se trata de conjuntos de artefactos arqueológicos) permite, a través de la yuxtaposición de los patrones emergentes en estos modelos y de la comparación de unos con otros y con información ambiental y/o paleoambiental, la identificación de relaciones reciprocas, patrones y tendencias que aporten información relevante acerca de la movilidad y uso de los recursos. 


\section{I Antecedentes}

Las preguntas que guiaron el desarrollo de esta tesis surgen a partir de las investigaciones llevadas a cabo, desde fines del siglo XIX, en las diferentes áreas de la Región Pampeana y el NE de Patagonia. Por tal motivo se exponen brevemente los desarrollos particulares de cada una de dichas regiones, considerando como límite meridional el río Negro en la provincia homónima y, como límite septentrional, el río Salado en la provincia de Buenos Aires, para luego centrar la discusión en los estudios previos efectuados en el Sistema Serrano de Ventania y en la llanura ubicada al sudoeste del mismo. Dado que el análisis exhaustivo de todas las investigaciones llevadas a cabo en la región Pampeana y el NE de Patagonia excede los intereses de este trabajo, se analizarán particularmente los modelos e hipótesis propuestos, considerando el orden cronológico en que fueron desarrolladas las investigaciones y enfatizando, principalmente, en aquellas realizadas con posterioridad a 1980. La razón de este recorte se debe a que los estudios llevados a cabo con anterioridad a esa fecha ya han sido analizados en profundidad, y desde diferentes perspectivas, por varios investigadores (v.g. Barrientos 1997; Bonomo 2002; Boschín 1991-1992; Podgorny y Politis 1990-1992; Politis 1984, 1988; Prates 2008). Por otra parte, a partir de la década de 1980, aumenta exponencialmente la cantidad de investigadores y, consecuentemente, de los temas analizados -desde perspectivas afines a este trabajo- proponiéndose modelos interpretativos generales sobre la movilidad, economía y organización social de aquellas sociedades.

\subsection{Las investigaciones arqueológicas en el Sur de la Región Pampeana y NE de Patagonia}

\subsubsection{El interés inicial por los materiales arqueológicos}

Las descripciones iniciales sobre el registro arqueológico de la Regiones Pampeana y el NE de Patagonia corresponden a las realizadas por viajeros, religiosos, militares y naturalistas durante los siglos XVIII y XIX, (Burmeister 1883-1891; Cardiel 1930; Claraz [1865-1866] 1988; Darwin [1845] 2007; Holmberg 1884; Lista [1879] 1975; Moreno 1874, 1876; Strobel 1867, 1868). Sin embargo, el primer momento de intensa investigación y discusión arqueológica se produce a partir de los trabajos desarrollados por Ameghino (1909; 1910, 1915) y posteriormente por Outes (1909), Hrdlicka (1912) y Willis (1912) quienes discuten la antigüedad de la presencia humana en el continente americano, considerada como muy temprana por el primer autor (Ameghino 1909, 1910, 1915) y con una antigüedad no mayor a un siglo, por el segundo grupo de investigadores (ver discusión en Politis et al. 2011a).

Luego de un período de menor intensidad en las investigaciones (ver discusión en Barrientos 1997; Bonomo 2002), hacia mediados del siglo XX, estas se reanudan bajo la influencia de la Escuela HistóricoCultural (Boschín 1991-1992; Boschin y Llamazares 1984; Politis 1988), con el foco en la estimación de cronologías y la definición de industrias a partir de detallados estudios tipológicos. Durante este momento surgen las primeras referencias a la movilidad de las sociedades, pero principalmente, en su aspecto 
poblacional, siendo empleada la migración de poblaciones como uno de los principales mecanismos explicativos de los cambios observados en el registro arqueológico (Bórmida s/f, 1960, 1962, 1969; Menghin 1963; Menghin y Bórmida 1950; ver también Boschin y Llamazares 1984; Boschín 19911992; Politis 1988). Durante las décadas de 1960 y 1970 se introducen nuevos conceptos teóricos y, consecuentemente, nuevas técnicas y preguntas, iniciándose a su vez, los trabajos en la subregión Pampa Seca, (Austral 1965; 1971; 1972 Gradín 1975; Gradin y Aguerre 1984; Zetti y Casamiquela 1967).

Hacia principios de la década de 1970, Madrazo introduce conceptos derivados de la ecología (Madrazo 1973, 1979), analizando el registro arqueológico en relación con su contexto ambiental. Dicho autor discute muchos de los postulados previos, como la antigüedad de las ocupaciones y la migración como principal explicación al cambio y propone un nuevo modelo basado en aspectos ecológicos y económicos. De esta manera caracteriza los desarrollos culturales pampeanos en función de tres tipos de subsistencia: 1- un nicho, más antiguo, de cazadores inferiores de fauna pleistocénica, al que le siguieron, 2- un nicho de cazadores de venado, al norte del río Salado y 3- un nicho de cazadores de guanaco, al sur de dicho río. Es durante este momento que se inician los trabajos de excavación y recolección en las sierras de Ventania y su llanura adyacente, generándose los primeros datos sistemáticos sobre esta región (ver detalle más adelante; Austral 1965, 1966, 1967-1968; Madrazo 1967).

Durante este período, las investigaciones en el NE de Patagonia mostraron tendencias teóricas similares a las descriptas para la región Pampeana, pero fueron más escasas y limitadas, principalmente, al área de Bahía San Blas y la desembocadura del Río Negro (Bórmida 1969; Outes 1908; Torres 1922; Vignati 1931;). En estos trabajo se propuso que dicha área constituiría una "zona de transición entre las llanuras pampeanas y las mesetas patagónicas” (Torres 1922: 477) y un “...lugar de convergencia de elementos étnicos diferentes... que ha determinado la adyacencia de culturas diversas que, a veces, aparecen aisladas y, otras, se encuentran mezcladas" (Vignati 1931:19).

\subsubsection{Cambian las preguntas y se genera nueva información}

Durante la década de 1980 y principio de la de 1990 se produce un progresivo aumento en la cantidad de investigadores trabajando en la Región Pampeana, acompañado a su vez de la incorporación de nuevos conceptos teóricos derivados, primero, de la arqueología procesual y, posteriormente, de la ecología evolutiva. Como consecuencia se sistematizan las investigaciones en áreas hasta ese momento poco investigadas (Pampa Seca y sierras de Ventania) y se intensifican los estudios en las sierras de Tandilia y el área Interserrana. En este contexto surgen nuevas preguntas relacionadas con los modos en que las sociedades cazadoras-recolectoras se relacionaron con el ambiente, por un lado, y con los procesos que intervienen en la formación de los conjuntos arqueológicos, por otro (v.g. Flegenheimer 1991; Madrid y Salemme 1991; Oliva et al. 1991a, 1991b; Politis 1984; Politis y Madrid 1988; Salemme 1987). Se investigan sistemáticamente varios de los sitios más tempranos de la región, se caracteriza el proceso de poblamiento y se establece una secuencia cronológica, basada en fechados radiocarbónicos, que le asigna una profundidad temporal de más de 12000 años AP a las ocupaciones en la llanura Interserrana y las sierras de Tandilia y de $c a .8600$ años AP a aquellas ocurridas en la Pampa Seca (un sistematización de esto puede encontrarse en Berón 2004; Politis y Madrid 2001). 
La influencia de los conceptos teóricos procesuales y el consecuente interés en la relación entre el hombre y su entorno llevó a incorporar el estudio de materiales hasta ese momento no considerados, o sólo brevemente descriptos, como es el caso de los restos óseos faunísticos, los desechos de talla y la cerámica no decorada, comenzando a implementarse técnicas de análisis novedosas e investigaciones interdisciplinarias (Carbonari et al. 1982; Fidalgo et al. 1986; Madrid y Salemme 1991; Madrid y Politis 1991; Nieto y Prieto 1986; Salemme 1987). En este contexto se realizan los primeros análisis microscópicos de huellas de utilización (Castro 1987-1988), se caracterizan algunos sitios de aprovisionamiento lítico (Flegenheimer 1991; Lozano 1991) y se llevan a cabo los primeros estudios orientados a evaluar las estrategias de aprovisionamiento, producción y circulación de artefactos líticos sobre la base de su análisis tecnomorfológicos y de su distribución en el paisaje (Flegenheimer 1988; Franco 1990). Comienzan a desarrollarse estudios interdisciplinarios, zooarqueológicos, palinológicos, estratigráficos y geomorfológicos, a partir de los cuales se obtiene información sobre las características paleoambientales del área y, en relación con esto, el tipo de recursos disponibles, el modo en que estos fueron aprovechados y los factores que habrían influido en la formación del registro arqueológico (Nieto y Prieto 1986; Páez y Prieto 1993; Politis y Madrid 1988; Salemme 1990). No se abandonan completamente, sin embargo, los anteriores conceptos de tradición y fase, los que son utilizados en la sistematización de las secuencias culturales. En tal sentido, Politis (1984) propuso la presencia, en la llanura Interserrana, de una tradición de igual nombre que se desarrolló desde el Holoceno temprano hasta el tardío, caracterizándose tecno-morfológicamente por:

"a-utilización preferencial de la cuarcita para la confección de instrumentos "conservados" $y$ uso en porcentajes menores de calcedonia, sílex y rodados costeros; $b$ - predominio de instrumentos formatizados sobre lascas con retoque marginal unifacial; c-empleo del retoque unifacial extendido y bifacial marginal; d- técnica bipolar para la confección de instrumentos en porcentajes de entre 3\% y 10\%; d-extracción de lascas que se caracteriza por la producción de núcleos poliédricos con lascados multidireccionales y piramidales; $f$-representación de láminas y hojas en porcentajes menores al 5\%, ya sea como forma base de instrumentos o como desechos de talla; g- elementos formatizados por abrasión con terminación de pulido, probablemente vinculados a la molienda; $h$ - los instrumentos recurrentemente utilizados incluyen: raedera doble convergente biconvexa, de filo lateral y de filo frontal, raspadores de filo frontal "piéce esquillée" y cepillos de filo perimetral" (Politis 1986: 27).

Este autor incorpora en su definición los recursos consumidos, y propone tres fases en relación con modificaciones en la utilización de dichos recursos y la aparición de nuevos elementos culturales: Fase Arroyo Seco CI, caracterizada por la explotación del guanaco y complementariamente otras especies, entre las que se incluye fauna extinta. Arroyo Seco CM, en la que se incorporan puntas de proyectil bifaciales triangulares medianas, y se explota principalmente el guanaco y complementariamente otras especies actuales (como el venado y distintas especies de dasipódidos). Fase Zanjón Seco, en la que se encuentra presente "alfarería, puntas triangulares bifaciales pequeñas y medianas, lanceolada bi-punta y base de lanceolada", rodados costeros sin modificaciones antrópicas e instrumentos de hueso (Politis 1986:30). Politis realiza a su vez, una división de la Región Pampeana en siete áreas denominadas Norte, Depresión del Salado, Tandilia, Interserrana, Ventania, Oeste y Sur, las que presentan diferencias ambientales y en el registro arqueológico, que interpreta como posible consecuencia de distintas estrategias adaptativas (ver también capitulo 4). De esta manera, incorpora en su análisis la variabilidad 
intersitio como producto de la explotación diferencial de los recursos, su utilización estacional, la distancia y disponibilidad de las materias primas o la posición dentro de un sistema de intercambio y propone que la subsistencia de los grupos interserranos habría estado basada en la explotación de los recursos de la costa, la llanura, el área periserrana y los sistemas serranos de Tandilia y Ventania (Politis 1984).

Los conceptos teóricos derivados de la escuela Histórico-Cultural dejan de ser utilizados, definitivamente, en la organización de la información arqueológica, durante la década de 1990, cuando la secuencia temporal comienza a ser estructurada en función de grandes bloques caracterizados en relación con variaciones paleoambientales (Pleistoceno final-Holoceno temprano, Holoceno medio y Holoceno tardio), que a su vez se relacionan con cambios observados en el registro arqueológico. Durante estos momentos los estudios procesuales cobran cada vez más relevancia, incorporándose también investigaciones desarrolladas desde una perspectiva ecológico-evolutiva, en las que el interés se centra en explicar procesos y establecer las causas de la variación observada (Barrientos 1997; Martínez 2002; Politis y Madrid 2001; Politis 2008).

\subsubsection{El desarrollo de modelos explicativos}

Hacia fines del siglo XX e inicios del tercer milenio, la realización de un número cada vez mayor de tesis doctorales y la incorporación de los avances producidos en otras áreas de la ciencia, como los sistemas de información geográfica, la microscopía, óptica y electrónica, y los estudios arqueométricos entre otras, promovieron el desarrollo de investigaciones específicas principalmente sobre restos óseos, humanos y faunísticos, artefactos líticos y, en menor medida, cerámicos, orientadas a generar información acerca de la organización tecnológica, subsistencia, movilidad, uso del espacio y características biológicas de las poblaciones y procesos de formación de los sitios (Barrientos 1997; Flegenheimer y Bayón 2002; Gutiérrez 2004; Leipus 2006; Madrid 1997; Martínez 1999). En este contexto, aumenta exponencialmente la información arqueológica sobre la Región Pampeana y se re-inician, hacia fines de la década de 1990, las investigaciones en el norte de Patagonia, particularmente en la Bahía de San Blas (Eugenio y Aldazábal 2004), la cuenca media del río Negro (Prates 2008), y la cuenca inferior del río Colorado (Bayón et al. 2004).

\subsubsection{Prácticas mortuorias, salud y nutrición}

Uno de los modos de aproximación a las características de las poblaciones humanas, su estado de salud y nutrición, su dieta y las variaciones de estos aspectos en el espacio y el tiempo, se realizó a través del estudio de los restos óseos humanos (Barrientos 1997; Barrientos y Pérez 2002; L'Heureux 2000; Luna 2008; Scabuzzo 2010).

Barrientos (1997) identificó variaciones temporales y espaciales tanto en las características de los entierros como en el tipo de deformación craneana de los individuos que los conforman. Según este autor, en la Región Pampa húmeda (al sur del río Salado) con anterioridad a ca. 3000 años AP predominan los entierros primarios de individuos sin deformación craneana o con deformación circular, en tanto durante el Holoceno tardío, aumenta la frecuencia de entierros secundarios y se observan variaciones en el tipo de deformación craneal, encontrándose individuos con deformación tabular oblicua a inicios del período 
e individuos con deformación tabular erecta durante momentos finales del mismo. Este autor también distingue entre entierros secundarios constituidos por los cráneos y los huesos largos, con muy baja o nula representación de otras unidades anatómicas (Tipo I) y entierros compuestos por casi la totalidad de las partes esqueletarias en frecuencias variables (Tipo II). Este último tipo de entierros se distribuye desde el río Negro hasta el área Interserrana pero temporalmente acotados a ca. 2000 - 400 años AP (Barrientos 1997; Madrid y Barrientos 2000).

Un patrón de variabilidad similar es descripto para Nordpatagonia, donde se registran exclusivamente modalidades primarias entre 3000 y 800 años AP y entierros primarios y/o secundarios entre 500250 años AP, momento para el que también se registran áreas exclusivas de inhumación (Mariano 2008; Martínez et al. 2012). Para la Pampa Seca, los estudios desarrollados por Berón y su equipo de investigación indican un incremento en la complejidad de la manipulación de los cuerpos entre $400 \mathrm{y}$ 320 años AP, dada por la presencia de entierros primarios, secundarios y, los llamados, disposiciones (esqueletos parcialmente articulados con unidades anatómicas reorganizadas). Para esta sub-región se registra la presencia de un área formal de entierro, el sitio Chenque 1, en el que se describen dos niveles de entierros generados entre 1030 y 370 años AP, momento en el que se encuentran también una mayor frecuencia de signos de conflicto y violencia (Berón 2007; Luna 2008).

El estudio del estado de salud y nutrición de las poblaciones, se realizó a través de indicadores como hipoplasias del esmalte dental, líneas de Harris, hiperostósis porótica y evidencias de procesos infecciosos, a partir de las que Barrientos (1997) concluye que entre fines del Holoceno tempranocomienzos del Holoceno medio y momentos inmediatamente previos a la llegada de los europeos, la incidencia de factores estresantes habría sido baja o nula. Recientemente, en una línea de investigación similar, Scabuzzo (2010) propuso, a partir del análisis de los patrones generales de desgaste y patologías de las articulaciones y de la robusticidad de los restos óseos, que para los individuos masculinos habría tenido mayor importancia la actividad ambulatoria.

\subsubsection{Aproximaciones a la subsistencia y el uso de los recursos: su variabilidad espacial y temporal}

\subsection{El uso de los recursos animales y vegetales}

Bajo la influencia teórica del procesualismo y la ecología evolutiva, el tipo de recursos consumidos $\mathrm{y}$, en consecuencia, las estrategias tecnológicas implementadas para obtenerlos y procesarlos fueron centrales en las investigaciones del sur de la Región Pampeana y NE de Patagonia. La mayor parte de la información sobre estos temas se obtuvo a partir de dos líneas de investigación principales, los análisis zooarqueológicos y los estudios sobre la tecnología lítica, complementados con estudios puntuales de microrrestos vegetales y ácidos grasos.

Los estudios zooarqueológicos, se orientaron a identificar el tipo de especies aprovechadas y el modo en que estas fueron utilizadas. A partir de estos estudios, se propuso que en la Región Pampeana, las estrategias económicas habrían variado desde una economía regional generalizada durante el Pleistoceno final/Holoceno temprano, caracterizada por la explotación de un amplio espectro de recursos que incluyó la megafauna extinta (Martínez y Gutiérrez 2004; Politis et al. 2004), hacia una economía especializada, en mayor o menor grado, en el guanaco durante el Holoceno medio. La subsistencia, finalmente se habría diversificado en el Holoceno tardío por medio de la incorporación a la dieta de recursos de 
tamaño pequeño como roedores, dasipódidos, réptiles y peces entre otros (Gutierrez y Martínez 2008; Martínez y Gutiérrez 2004; Politis y Madrid 2001; Quintana y Mazzanti 2001). Esta tendencia temporal general sin embargo, presenta variaciones espaciales particulares. En el área de Tandilia, Mazzanti y Quintana (2001) sugieren que, para momentos tempranos, la dieta no habría incorporado la utilización de megafauna extinta, en tanto para el Holoceno medio observan una mayor variabilidad en la fauna consumida, incorporándose, al consumo del guanaco, recursos secundarios como venado, armadillos, coypo, vizcacha y huevos de ñandú. En la costa atlántica, las evidencias de consumo intensivo de recursos marinos, particularmente otarios, durante el Holoceno medio muestra que al menos algunos integrantes de las poblaciones incorporaron también este tipo de recursos (Bayón y Politis 1996; Bayón et al. 2012; Politis et al. 2009). En las cuencas de los ríos Negro y Colorado, los estudios zooarqueológicos han revelado un patrón general de subsistencia basado en la explotación del guanaco complementada con ciervo, ñandú y recursos vegetales. Este patrón se diversifica hacia el Holoceno tardío final (1000250BP), incorporando una mayor proporción de armadillos y peces, con un uso más intensivo de los recursos vegetales de las provincias fitogeográficas del espinal y el monte. Esta información, junto a la de los valores isotópicos, lleva a los investigadores a proponer un uso integrado de las áreas costeras y del interior (Aldazabal et al. 2011; Fernández et al. 2011; Martínez et al. 2006, 2009; Prates y Acosta Hospitaleche 2010; Stoessel 2007).

Considerando las variaciones descriptas, Politis (2008) propuso que, durante el Holoceno tardío, se habrían dado en la Región Pampeana tres sistemas de subsistencia diferentes, dos de ellos en el sur. El primero, representado en los sitios de la subregión Pampa Seca (e.g. Casa de Piedra, Tapera Moreira y sitios de la cuenca inferior del río Colorado), se orientó a la explotación del bosque xerófilo y al consumo del guanaco y, secundariamente, venado de las pampas, armadillos y Rhea, con la incorporación de peces en el río Colorado. El segundo sistema de subsistencia involucra la explotación de la estepa de pastos abierta e incluye los dos sistemas serranos de la provincia de Buenos Aires y la llanura localizada entre ellos, donde el guanaco también habría sido el principal recurso consumido, complementado por venado de las pampas, armadillos y Rhea (Politis 2008). Las variaciones, temporales y espaciales, en los recursos explotados, han sido relacionadas, entre otras cosas, con cambios en la densidad demográfica y organización de las poblaciones y con variaciones en la disponibilidad de recursos. En tal sentido, Politis et al. (2011b) han planteado fluctuaciones en la distribución de las especies de mayor porte, particularmente del guanaco, el cual habría experimentado una retracción hacia el oeste y sur de la Región Pampeana durante el Holoceno tardío.

El uso de los recursos vegetales ha sido objeto de una menor cantidad de estudios, debido a las dificultades que las características ambientales y depositacionales de la Región Pampeana presentan para la conservación de sus macro y microrrestos. Su utilización ha sido inferida a través de evidencia indirecta y, más recientemente a partir de estudios de fitolitos, almidones y ácidos grasos. Entre las evidencias indirectas, los estudios funcionales realizados en artefactos del área Interserrana y serrana de Ventania, mostraron rastros de uso correspondientes al trabajo de madera (Leipus y Oliva 1999; Leipus 2006; Leipus y Mansur 2007; Pal 2012). Se ha inferido, a su vez, una mayor incorporación a la dieta de alimentos vegetales durante el Holoceno tardío, debido a un aumento en la representación de artefactos de molienda durante este momento, así como a una mayor proporción de caries (Barrientos 1997; L'Heureux 2000; ver discusión en Barrientos 2001). Los análisis sobre microfósiles presentes en estos artefactos avalan su uso, al menos parcial, para el procesamiento de recursos vegetales entre los que 
han podido identificar gramíneas, Prosopis sp. y Celtis sp. (Babot et al. 2007; Musaubach et al. 2010; Tassara y Osterrieth 2008). En otros casos, la molienda de recursos vegetales no pudo corroborarse, vinculándose estos artefactos con el procesamiento de sustancias minerales como pigmentos (Zucol y Bonomo 2008). Por último, el uso de vegetales también queda evidenciado a partir de microrrestos de gramíneas y, en menor cantidad, Prosopis sp., Cucurbitaceae Phaseolus sp y Zea mays en tiestos cerámicos y en el tártaro dental de individuos de los sitios Chenque 1 en Pampa Seca (Musaubach 2012) y Gascón 1 en el AEHSP (Menéndez et al. 2009).

Finalmente, una de las líneas que ha tomado importancia en los últimos años, es el estudio isotópico de los restos óseos humanos. Estos estudios han aportado información sobre el tipo de recursos consumidos por los individuos y, en algunos casos, también sobre la movilidad de algunos de ellos. Los primeros estudios sobre valores isotópicos fueron realizados por Barrientos (1997), quien interpreta los valores $\delta^{13} \mathrm{C}$ obtenidos a partir de fechados AMS realizados sobre restos óseos humanos y faunísticos de la Pampa Húmeda, proponiendo que las poblaciones humanas habrían tenido una dieta básicamente continental basada en el consumo de plantas y/o animales consumidores de plantas $\mathrm{C}_{3}$, con algunos aportes de alimentos de origen marino (Barrientos 1997). Recientemente se realizaron nuevos estudios de $\delta^{13} \mathrm{C}$, a los que se incorporaron los análisis de $\delta^{15} \mathrm{~N}$, no sólo en la Pampa Húmeda, sino también en el NE de Patagonia y La Pampa Seca. Estos valores indican, para todas las áreas, una dieta basada principalmente en el consumo de platas $\mathrm{C}_{3}$ o animales consumidores de $\mathrm{C}_{3}$, pero con variaciones espaciales e interindividuales. Para elárea interserrana, se propone que la presencia de algunos individuos (especialmente hombres) en los que la señal isotópica indica el consumo de importantes cantidades de proteínas marinas, podría responder a diferencias en la movilidad, a la presencia de tabúes alimentarios o bien a la existencia de un patrón residencial matrilocal (Politis et al. 2009). En el cauce inferior del río Colorado Martínez et al. $(2005,2009)$ consideran que los valores de $\delta^{15} \mathrm{~N}$ son indicadores del consumo regular de animales acuáticos por parte de algunos individuos que se habrían movido a lo largo de un eje costa-interior. Para la Pampa Seca por otra parte, Berón et al. (2009) identifica variaciones en los valores isotópicos, entre 1000 y 300 años AP, que estarían sugiriendo cambios importantes en la subsistencia. En esta misma línea, Berón y Luna (2011) realizaron recientemente análisis de $\delta^{18} \mathrm{O}$, observando que dos de los individuos presentes en el sitio Chenque 1 presentan valores considerablemente más empobrecidos que el resto, pudiendo tratarse de individuos procedentes de ambientes cordilleranos o de la vertiente pacífica.

\subsection{El uso de los recursos minerales: los artefactos líticos y cerámicos}

Los estudios sobre los artefactos líticos se enmarcaron, principalmente, dentro del análisis de la organización de la tecnología, evaluándose las estrategias de abastecimiento, producción, mantenimiento y circulación de rocas y su utilidad como indicadores de rangos de acción, y de estrategias de uso del espacio y los recursos. Es así como se intensificaron los estudios en sitios de aprovisionamiento, a los fines de precisar las fuentes y evaluar los modos de obtención y circulación de materias primas (Barros y Messineo 2004; Colombo 2013; Flegenheimer et al. 1996; Flegenheimer y Bayón 2002, 2004; Valverde 2002). En las sierras de Tandilia, se investigaron sitios de extracción y formatización primaria de artefactos en afloramientos de cuarcita, ftanita, dolomía silicificada, y ópalo ocráceo (entre otros Barros y Messineo 2004; Colombo 2011, 2013; Flegenheimer 1991; Flegenheimer et al. 1996; Flegenheimer 
y Bayón 2002; Mazzanti 1997; Messineo 2008; Paulides 2007a, 2007b), en Ventania se localizaron fuentes de aprovisionamiento de riolita y cuarcita (ver detalle más adelante Oliva y Barrientos 1988; Oliva y Moirano 1997) y en la provincia de La Pampa se localizó, en el oeste, una cantera-taller sobre los afloramientos primarios de chert de la Meseta del Fresco y, en el sur, afloramientos del manto Tehuelche con evidencias de explotación (entre otros Berón 2006; Berón y Curtoni 2002).

A partir de análisis petrográficos de rocas cuarcíticas de Tandilia y Ventania, Bayón et al. (1999), diferenciaron entre metacuarcitas, propias de Ventania, y ortocuarcitas, características de Tandilia, proponiendo que aquellas de mejor calidad para la talla corresponden a las ortocuarcitas del Grupo Sierras Bayas, aflorantes de manera localizada en las sierras de Tandilia. A su vez, y considerando la representación de materias primas en los sitios arqueológicos establecieron que las rocas con mayor importancia arqueológica local y regional, son las ortocuarcitas Sierras Bayas. Las metacuarciticas características de Ventania habrían sido utilizadas mayoritariamente a escala areal, encontrándose regionalmente sólo en forma secundaria, en tanto otras materias primas riolita, ftanita, dolomía silicificada y ortocuarcitas de menor calidad, habrían sido utilizadas en forma mayoritariamente local (Bayón et al 1999; Flegenheimer y Bayón 2002; Messineo et al. 2004). Esta caracterización llevó a considerar que las sociedades cazadoras-recolectoras habrían obtenido las rocas de mejor calidad en el Sistema de Tandilia, en tanto en el Sistema de Ventania únicamente se habrían obtenido metacuarcitas, de inferior calidad para la talla (Bayón et al. 2004; Berón 2006; Valverde 2002).

En cuanto a la circulación de rocas en el paisaje, Franco (1994) propuso la presencia de estrategias de maximización de los recursos líticos en el área interserrana y, posteriormente, Martínez (1999) observó variaciones temporales en el modo de aprovisionamiento y traslado de las rocas en el curso medio del río Quequén Grande. Según este autor, a finales del Holoceno medio, habría predominado el aprovisionamiento de los individuos, en un contexto de escasa densidad poblacional, grupos pequeños y movilidad frecuente, en tanto a inicios del Holoceno tardío, comenzaron a implementarse estrategias de aprovisionamiento de los lugares con núcleos y artefactos sub-explotados en un proceso de "litificación del paisaje" (Martínez 1999, 2002; Martínez y Mackie 2003-2004). Este proceso, reflejado también por un aumento en la frecuencia de artefactos de molienda, es interpretado como consecuencia de una menor movilidad y mayor redundancia ocupacional, con campamentos diferenciados internamente y ocupados durante períodos prolongados por agregaciones importantes de personas (Martínez 1999). En las desembocaduras de los ríos Colorado y Negro, se propuso el uso predominante de materias primas locales, pero con bajas proporciones, de rocas procedentes de las sierras pampeanas, la Pampa Seca y otras áreas de Nordpatagonia (cuarcitas, sílices, calcedonias) obtenidas, probablemente, a través de redes sociales amplias (Martínez 2010). Por otra parte, se postuló que hacia ca 1000 y 250 años AP se produce un aumento en la diversidad, flexibilidad, estandarización y formalidad de los instrumentos (Armentano 2004a, 2004b). Esto es acompañado también por un incremento en el número y estandarización de los artefactos de molienda interpretado como consecuencia de la intensificación en el uso de recursos vegetales, particularmente del espinal (Armentano 2004a, 2004b; Martínez 2004; Prates 2004, 2010).

Los trabajos realizados para caracterizar a la tecnología cerámica y sus funciones han sido considerablemente menores, debido, probablemente, a la poca representación que este tipo de registro muestra en los contextos del sur de la Región Pampeana y NE de Patagonia. Esta tecnología fue incorporada hacia inicios del Holoceno tardío, ca. 2500-3000 años AP (Politis et al. 2001) en un proceso 
de cambios organizativos que se detallan en el siguiente apartado. Su frecuencia es considerablemente mayor al norte del río Salado, donde también se encuentran evidencias de manufactura local y mayor diversidad en cuanto a sus formas y diseños decorativos (Aldazabal 1991; González 2005; Politis et al 2001), si bien, la cerámica de las diferentes áreas muestra similitudes estilísticas (Aldazabal 1999; González 2005). La similitud entre los conjuntos cerámicos, fue interpretada como producto de la continuidad de un sistema de información (Aldazabal 1999), donde la mayor abundancia de alfarería y diversidad de formas y de motivos decorativos en los sitios al norte de la depresión del Salado fue considerada como posible indicador de un origen alóctono en circuitos de intercambio y circulación de bienes (Politis et al. 2001). Por otra parte, estudios orientados a la caracterización tecnológica de sitios de las áreas interserrana y serranas de Ventania y Tandilia, en la Región Pampeana y de la Bahía de San Blas, en el NE de Patagonia, muestran variaciones en la frecuencia de los distintos tipos de inclusiones, sus tamaños y asociaciones, así como cierta correspondencia con los sedimentos locales, lo que estarían indicando el uso de fuentes de aprovisionamiento de arcillas de distinto origen (Eugenio y Aldazábal 2013; González de Bonaveri et al. 2000; Madrid 1997; Mazzanti y Porto López 2007), proponiéndose una producción local a baja escala (Eugenio y Aldazábal 2013; Mazzanti y Porto López 2007).

\subsection{Intensificación y diversificación durante el Holoceno tardio}

Los mencionados cambios en las estrategias de aprovisionamiento lítico, la diversificación en los recursos faunísticos consumidos, así como la introducción de nuevas tecnologías como la cerámica y el arco y la flecha, sumado a un aumento en el número de artefactos de molienda, ha sido interpretado como evidencia de un proceso de intensificación ocurrido durante el Holoceno tardío. En tal sentido, el incremento tanto en el número como en el tamaño de los artefactos de molienda, fue relacionado con un aumento en los costos de procesamiento consecuencia de un incremento en el componente vegetal de la dieta, particularmente de los frutos característicos de la provincia del Espinal (Armentano 2004a, 2004b; Martínez 1999, 2002, 2004; Politis et al. 2001). La presencia de sitios de actividades múltiples redundantemente ocupados, en los que se encuentran pesados artefactos de molienda junto a materias primas sub-explotadas (grandes núcleos e instrumentos líticos), así como la aparición de áreas formales de entierro re-utilizadas a través de períodos más o menos largos de tiempo, como el sitio Chenque 1 en La Pampa y el Túmulo de Malacara en la costa atlántica, son considerados indicadores de un momento de ocupación efectiva del espacio regional, con disminución del rango de movilidad y un probable comportamiento territorial (Barrientos 1997; Bayón et al. 2004; Madrid y Barrientos 2000; Martínez 1999, 2010; Martínez et al. 2005, 2006; Politis y Madrid 2001; Prates 2007; Prates et al. 2006). En este contexto, se ha propuesto que las áreas de entierros actuarían como demarcadores territoriales legitimando, por medio de la presencia de los ancestros, el uso y control de los recursos críticos (Berón 2004; Berón et al. 2000; Madrid y Barrientos 2000).

Politis et al. (2001) proponen que la incorporación de la tecnología cerámica para la fabricación de contenedores se produce $c a .3000$ años AP, en el marco de este proceso de intensificación, facilitando el almacenamiento y permitiendo un aprovechamiento más intensivo de los recursos, mediante la técnica de hervir los alimentos (Politis et al. 2001). Para este momento varios autores han propuesto, que se produce la ampliación de las redes sociales y de las alianzas entre grupos de distintas regiones, generándose una compleja red de intercambio de objetos, información y lazos matrimoniales que tendría 
como correlato arqueológico la presencia de materiales exóticos y/o con contenido simbólico (Politis y Madrid 2001). Entre ellos se mencionan las piezas cerámicas con motivos decorativos y/o procedente de lugares lejanos, como es el caso de cerámica chilena vergel-valdivia en la provincia de la Pampa (Berón 2004; Politis et al. 2001;), adornos labiales y auriculares (Austral 1971; Crivelli Montero et al. 1997), placas grabadas (Austral 1968; Berón 2004; Crivelli Montero 1991; Oliva 2006), valvas de Volutidae y adornos manufacturados sobre valvas, puntas pedunculadas y materias primas alóctonas (Bayón et al. 2004; Berón 1997; Bonomo 2004, 2005; Martínez 2010; Martínez et al. 2005, 2006; Prates 2007; Prates et al. 2006) presentes en el sur de la Región pampeana y NE de Patagonia.

\subsubsection{La movilidad grupal y el uso del espacio}

Desde principios del siglo XX, una de las principales preguntas que guió las investigaciones fue de qué manera se movieron las poblaciones a través del paisaje y en qué medida las variaciones observadas en el registro arqueológico responden a una única población utilizando de manera diferencial los espacios y recursos disponibles o si, en cambio, son consecuencia de grupos con rasgos culturales diferentes. En tal sentido, Politis y Madrid (2001) postularon que las diferencias observadas en el registro faunístico representado en sitios del área interserrana y sitios de Tandilia sería producto de su utilización, por parte de una misma población, en momentos diferentes. El área interserrana durante momentos de agregación de varias bandas para el desarrollo de actividades cooperativas como la caza de megafauna, y los abrigos rocosos de Tandilia en periodos de fisión y el desarrollo de tareas individuales. Las investigaciones desarrolladas por Bonomo desde fines de la década de 1990 también estuvieron orientadas a discutir si fueron los mismos grupos humanos los que generaron los contextos costeros y los del interior, concluyendo que no existió una adaptación costera, sino que este ambiente fue utilizado, por las mismas poblaciones que ocuparon el interior, para la obtención de recursos específicos como materias primas líticas, moluscos marinos y recursos faunísticos como otáridos (Bonomo 2004, 2011).

En el NE de Patagonia, las investigaciones tuvieron entre sus principales objetivos, evaluar si el área ocupada por el cauce de los ríos Negro y Colorado, fue simultánea o alternativamente ocupada por poblaciones procedentes de Pampa y Patagonia o si, por el contrario, se desarrolló un patrón de adaptación específico. En este sentido, se generó un marco cronológico y se analizó la utilización de los ecosistemas marino y de estepa en relación con la adaptación y evolución de las sociedades cazadoras-recolectoras, teniendo en cuenta su organización tecnológica, prácticas mortuorias, sistema de asentamiento, subsistencia y movilidad entre otros (Aldazabal y Eugenio 2006; Armentano 2004a; Bayón et al. 2004; Eugenio y Aldazabal 2004; Martínez y Figuerero Torres 2000; Martínez 2004; Prates et al. 2006; Sanguinetti de Bórmina et al. 1999). A partir de estas investigaciones, Martínez y Prates (2007) consideran que en las cuencas de los ríos Negro y Colorado se habrían generado adaptaciones específicas que produjeron correlatos materiales particulares, idiosincrásicos, que no son directamente asimilables a aquello establecido como propio de lo Pampeano y/o Patagónico (Martínez 2010). A su vez, Prates (2008) sostiene que el río Negro podría haber funcionado como un límite entre distintas poblaciones, que se ve reflejado en una representación diferencial de las puntas de proyectil, encontrándose preponderancia de puntas triangulares pequeñas apedunculadas en la ribera norte de dicho rio, en tanto en la ribera sur predominan las puntas triangulares pedunculadas. 


\subsubsection{La movilidad en escala poblacional: Continuidad y discontinuidad en el poblamiento pampeano.}

A partir de la información obtenida en las investigaciones mencionadas, y en otras que por una cuestión de espacio no han podido ser incorporadas, fueron postulados dos modelos sobre el poblamiento y la evolución cultural del sur de la Región Pampeana, que incorporan en su explicación también al NE de Patagonia. El primero de estos modelos se basa en la continuidad de algunos patrones tecnológicos y de subsistencia, así como en el uso redundante de ciertos espacios, particularmente algunos lugares de entierro, y propone que el proceso de poblamiento y evolución cultural sería fundamentalmente continuo, abarcando desde el Pleistoceno tardío hasta el inicio del contacto con poblaciones europeas (Martínez 1999, 2002; Politis 1984, 1988, 2008; Politis y Madrid 2001). El segundo modelo considera que la evidencia disponible en estas dos regiones, particularmente las secuencias de fechados radiocarbónicos y el registro bioarqueológico, no permite rechazar la existencia de un poblamiento regional discontinuo, caracterizado por probables extinciones locales, recolonizaciones y reemplazos poblacionales (Barrientos 1997, 2001; Barrientos y Pérez 2002, 2005; Barrientos et al. 2005; Pérez 2006).

Por una parte, la idea de continuidad poblacional puede observarse al menos desde la década de 1950, con la definición de la tradición Tandiliense (Menghin y Bórmida 1950) y, posteriormente, el de tradición Interserrana (Politis 1984). Politis (1984) argumenta que la evidencia arqueológica muestra continuidad entre las poblaciones del Holoceno temprano y medio observándose únicamente diferencias intra-regionales, que podrían ser producto de procesos evolutivos e históricos particulares que dieron como resultado patrones adaptativos diferentes. Los cambios ocurridos en el Holoceno medio (como una mayor especialización en la dieta o el registro de puntas triangulares medianas y artefactos de molienda) son explicados como resultado de transformaciones producidas dentro de las poblaciones del Holoceno temprano. De manera similar, el proceso de diferenciación regional propuesto para el Holoceno tardío, tendría raíces más profundas, habiendo comenzado a hacerse visible durante el Holoceno medio. El fundamento a esta propuesta se basa principalmente en la larga secuencia de reocupación de algunos sitios como Arroyo Seco 2 y en que, en las áreas Interserrana y serranas de Tandilia y Ventania, la tecnología lítica está representada por un tool-kit unifacial básico de cuarcita y calcedonia que no presenta variaciones mayores a través del tiempo. A esto se agrega que la explotación de los recursos faunísticos también presenta cierta continuidad desde comienzos del Holoceno medio hasta el tardío, siendo el guanaco el principal recurso explotado. En este contexto, el mayor cambio, tanto tecnológico como económico, se produciría durante el Holoceno tardío como consecuencia del proceso de intensificación y diversificación mencionado, cuyo origen se encontraría hacia fines del Holoceno medio (Martínez y Gutiérrez 2004; Politis 2008), cuando "bajo nuevas condiciones ambientales..., lo que quizás aumente es el promedio de innovaciones conductuales debido a que las sanciones sociales y el peso de la tradición son aún muy débiles debido al tamaño pequeño y a la menor complejidad de los grupos" (Martínez 2002: 143). Esta nueva situación habría propiciado una amplia variedad de trayectorias históricas y patrones adaptativos específicos, en un escenario social que habría dado lugar a la interacción y coexistencia entre los grupos residentes en el área y aquellos de áreas aledañas (Martínez 2010).

En contraposición a la idea de que la región pampeana haya sido habitada por una misma población durante los 12000 años de evolución y sobre la base de datos arqueológicos, secuencias de fechados radiocarbónicos y, principalmente, evidencia bioarqueológica, G. Barrientos y colaboradores han planteado que en el área se habrían producido al menos dos eventos de reemplazo poblacional e ingreso de poblaciones preexistentes, posiblemente vinculados con cambios ambientales y la consecuente alteración 
de la estructura de los recursos. El primero de estos eventos se habría producido durante el Holoceno medio (Barrientos 1997; Barrientos y Pérez 2002, 2005; Barrientos et al. 2005), en tanto el segundo habría ocurrido hacia finales del Holoceno tardío (Barrientos 1997; Barrientos y Pérez 2004; Barrientos et al. 2005). Estos autores se basan en que la secuencia de fechados radiocarbónicos en el sudeste de la Región Pampeana, Pampa Seca, Payunia y Atuel-Diamante, muestra una señal arqueológica muy débil para el lapso 7000-4500 años cal AP, con un hiato entre $c a 5000$ y 4800 años cal AP, al que se asocian a su vez cambios morfométricos no graduales en los rasgos craneofaciales de las muestras situadas a ambos lados del hiato. Los estudios morfométricos por ellos realizados, muestran una mayor diferencia entre la muestra del Holoceno temprano/medio y la correspondiente al Holoceno tardío inicial, lo cual no les permite rechazar, "la hipótesis que vincula el hiato en la secuencia de fechados radiocarbónicos con una discontinuidad poblacional ocasionada por un despoblamiento subsecuente a una contracción demográfica y/o geográfica de la población o por una extinción local seguida por una recolonización por parte de otra población" (Barrientos 2009: 204).

Por otra parte, G. Barrientos e I. Pérez encuentran una mayor similitud entre las muestras del Holoceno temprano/medio y las del Holoceno tardío final. Esta similitud es interpretada como consecuencia de un proceso en el que poblaciones relacionadas con la primera (aquella correspondiente al Holoceno temprano/medio) habrían subsistido en regiones vecinas, ingresando luego a las llanuras pampeanas durante el Holoceno tardío final, reintroduciendo así, miembros de la metapoblación original en el área. Este nuevo ingreso de población, se relacionaría con un proceso de aumento en la densidad poblacional y en la saturación del espacio, incremento en la diferenciación cultural o étnica y en los niveles de competencia, asociado a hábitats más controlados y territorios más reducidos. Dicho proceso habría tenido como consecuencia la expansión de una población humana desde el sector inferior de las cuencas de los ríos Negro y Colorado y costa sur pampeana hacia el Sistema Serrano de Ventania y las llanuras adyacentes. La distribución de los entierros secundarios Tipo II y de la deformación tabular erecta podría estar mapeando, al menos parcialmente, la extensión del mencionado proceso (Barrientos 1997, 2001, 2009; Barrientos y Pérez 2002, 2004).

Como ha sido observado por Barrientos (2009), ambas posturas se basan en tipos de evidencia diferentes y, por ende, reflejarán de modo diferencial las continuidades o discontinuidades poblacionales. Si bien un conjunto de rasgos tecnológicos y económicos del registro arqueológico del sudeste pampeano presentan similitudes formales a través del tiempo, las mismas podrían estar reflejando las limitaciones impuestas a la variación por factores ambientales. En relación con esto, Barrientos (2009) propone que, para poder evaluar la continuidad o discontinuidad en la distribución temporal de los rasgos y relacionar esta con una continuidad biológica, es necesario desarrollar una metodología orientada al reconocimiento de homologías y homoplasias artefactuales, es decir, a distinguir entre aquellas similitudes debidas a verdaderas conexiones históricas y aquellas debidas a causas meramente funcionales (Barrientos 2014).

A estos probables eventos de movilidad poblacional ocurridos con anterioridad al contacto hispanoindígena, se agrega un tercero, producido durante el período hispano indígena, si bien sus raíces pueden encontrarse en momentos previos (Berón 2004). Este incluyó la ocupación de las Pampas Argentinas hacia fines del siglo XVIII, por parte de poblaciones provenientes del NO de Patagonia y Chile (Martínez Sarasola 1992). Arqueológicamente, este proceso se ve evidenciado por la presencia en la Región Pampeana de dos emplazamientos con características similares a las descriptas para la provincia de 
Neuquén. Se trata del sitio Gascón 1 y la localidad Amalia, ambos asignados cronológicamente al siglo XVIII (Cabanillas y Oliva 2004; Mazzanti y Quintana 2010). El sitio Gascón 1, localizado en el partido de Adolfo Alsina, consiste en un área de entierro, con similitudes formales (i.e. posición y orientación de los entierros, tipo y diversidad de ajuar funerario) (Oliva et al. 2007) con el sitio Caepe Malal localizado al norte de la provincia de Neuquén (Hajduk 1991; Hajduk y Biset 1996). Amalia por otra parte, consiste en áreas de actividades múltiples, donde se recuperaron cuentas de collar y fragmentos cerámicos con características similares a los recuperados en Gascón 1 y en Caepe Malal 1 y que, a su vez, se diferencian de la cerámica y cuentas de collar descriptas para la Región Pampeana en momentos previos al contacto Hispano-Indígena (Mazzanti 1999; Oliva y Lisboa 2006; Oliva et al 2007).

\subsubsection{La incorporación de los aspectos sociales y simbólicos a las interpretaciones sobre el registro arqueológico}

A partir de los últimos años de la década de 1990, si bien continúan desarrollándose un gran número de investigaciones enmarcadas en las corrientes teóricas procesual y ecológico evolutiva, se incorporan también conceptos derivados del post-procesualismo, la arqueología cognitiva y la arqueología del paisaje. Estos estudios utilizan datos etnohistóricos de Pampa y Patagonia así como trabajos antropológicos, realizados en diferentes partes del mundo, como fuentes de información a partir de las cuales generar interpretaciones acerca del significado social y simbólico de ciertos bienes materiales o motivos gráficos y del modo en que el paisaje fue construido por las sociedades del pasado (Bonomo 2006, 2007; Curtoni 2006; Oliva y Algraín 2004, 2005, Politis 1998; Politis et al. 2005). Son objeto de este tipo de estudios principalmente aquellos rasgos del registro a los que es difícil asignarles una función dentro de la esfera económica o de subsistencia, considerándose la ausencia, o escasez, de valor económico como indicador de su vinculación con esferas simbólicas, religiosas, estéticas y/o ideológicas.

Uno de los primeros trabajos en esta línea fue realizado por Flegenheimer y Bayón (1999), quienes incluyeron en los estudios de aprovisionamiento lítico la variable color, hasta ese momento no considerado como un factor relevante. Estas autoras observaron que, en tanto en los afloramientos y talleres de ortocuarcitas del Grupos Sierras Bayas predomina el color blanco, en los sitios arqueológicos tempranos las cuarcitas de color marrón, rojo, rosa, amarillo, gris y moteado, al menos duplican a las blancas. Esta selección de cuarcitas coloreadas habría implicado una inversión adicional de energía para su obtención. Dado que ambos tipos de roca presentan la misma calidad para la talla, su selección no se relacionaría con cuestiones utilitarias, sino que debió haber una recompensa de otro tipo como cuestiones sociales, simbólicas y/o estéticas (Flegenheimer y Bayón 1999).

Un estudio orientado a evaluar el probable valor simbólico de ciertos objetos materiales fue desarrollado por Bonomo $(2006,2007)$, quien, a partir del análisis del contexto de hallazgo de los elementos, de fuentes etnohistóricas y de bibliografía antropológica sobre religión propone que ciertos elementos, como unidades anatómicas de carnívoros, dientes de tiburón blanco, huesos mineralizados, pigmentos y caracoles marinos, presentes en algunos de los sitios pampeanos, podrían ser derivados materiales de los aspectos simbólicos incluidos en la esfera ideacional de los cazadores-recolectores pampeanos. Particular atención reciben los caracoles marinos, presentes en numerosos sitios de la Región Pampeana, los que son considerados como ítems de un marcado significado simbólico (Bonomo 
2007). De modo similar, se interpretaron los materiales depositados en el sitio Calera, como producto de conductas diversas pero vinculadas mayormente actos ofrendatorios y/o ceremoniales y de la basura generada durante los mismos (Messineo y Politis 2007).

También se trató de acceder a las esferas simbólica e ideacional de las sociedades del pasado a través del estudio del arte y su relación con el paisaje. Curtoni (2006) propone que durante el Holoceno tardío habría existido una cosmovisión u orden de racionalidad común que tendría relación de origen con la macro escala espacial del centro de Argentina y que, hacia el Holoceno tardío final, comenzarían a expresarse más intensamente sentidos de exclusividad areal/territorial. Oliva (2000) y Mazzanti (2006) analizan la relación entre las pinturas rupestres y su emplazamiento en el paisaje, encontrando relaciones con ciertos rasgos particulares como fuentes de agua y puntos de mayor visibilidad que los llevan a proponer su función como demarcadores territoriales o de recursos críticos. Los trabajos de Algraín en esta misma línea, analizan el contexto de producción de este tipo de representaciones, proponiendo su generación bajo estados modificados de conciencia y su vinculación con el chamanismo (Oliva et al. 2010b).

\subsection{Las investigaciones arqueológicas en el Sistema Serrano de Ventania y sus inmediaciones}

En el Sistema Serrano de Ventania los primeros trabajos se remontan a los estudios realizados por E. Holmberg a fines del siglo XIX, quién desde una perspectiva naturalista llega a las sierras de la Ventana con el objetivo de realizar estudios geológicos y biológicos y, especialmente, "de los antecedentes que queden de las razas humanas extinguidas". Durante su viaje visita la llamada Gruta del esqueleto, donde encuentra en superficie un esqueleto y, junto a él, un ejemplar de molusco del género Voluta, dos rodados de calcedonia semejantes a los del río Negro y un pedazo de tierra mal cocida. Releva también la Gruta de los Espíritus, donde describe "gran cantidad de figuras de color rojo,... aparte de toda intención simbólica se ha querido representar caras humanas, aunque privadas del importantísimo órgano llamado nariz" y reproduce 12 de las figuras, mencionando la presencia de más representaciones con motivos repetidos (Holmberg 1884).

Luego de estas primeras menciones, no se realizan investigaciones hasta la década de 1960, cuando A. Austral y G. Madrazo comienzan a realizar sus estudios. A. Austral prospectó diferentes sectores de la sierra y la llanura y llevó a cabo sondeos en la Gruta de los Espíritus y excavaciones extensivas en los partidos de Coronel Pringles, Saavedra y Villarino (Austral 1966, 1967-1968, 1968). En la localidad arqueológica Paso Mayor, ubicada en el cauce del Río Sauce Grande, partido de Coronel Pringles, recuperó un rodado alargado, decorado con incisiones y pintura roja, artefactos líticos y múltiples restos óseos humanos cubiertos con pintura roja correspondientes a un entierro secundario (Austral 1968; Scabuzzo 2010). Más recientemente, sobre la base de las investigaciones realizadas en los sitios SA17AV (Avestruz) y Los Flamencos I, ubicados cronológicamente entre 3280 y 3100 años ${ }^{14} \mathrm{C}$ AP, propone la existencia durante estos momentos de "una hipotética Formación Arqueológica Avestruz" caracterizada por la ausencia de puntas de proyectil bifaciales y cerámica, el predominio de actividades de caza, centradas en el guanaco, y la escasa o nula incidencia de las actividades de molienda (Austral y García Cano 1999). También investiga los sitios cerámicos Puente de Fierro (localizado sobre la margen izquierda del río Sauce Grande), para el que obtiene una datación de $2000 \pm 80$ años ${ }^{14} \mathrm{C}$ AP y Paso 
Vanoli (sobre la margen derecha del arroyo Napostá Grande), fechado en $630 \pm 60$ años ${ }^{14} \mathrm{C} A \mathrm{P}$ (Austral y García Cano 1999).

G. Madrazo realizó recolecciones superficiales en sitios ubicados en la estancia La Bonanza y en las lagunas Encadenadas, ubicadas al sur de las sierras (Madrazo 1967, 1979). En estancia La Bonanza recuperó piezas de cuarcita blanca y roja, a las que describió como de aspecto grosero, formatizadas mediante técnica unifacial con dos elementos, sin encontrar cerámica ni otros objetos indicadores de influencias "neolitizantes" (Madrazo 1967, 1979). En Las Encadenadas estudió los materiales donados al museo etnográfico de Olavarría por el paleontólogo J. Zetti, consistentes en artefactos de cuarcita de morfología muy tosca y mayor tamaño que aquellos correspondientes al blancagrandense, que tipológicamente parece constituir un antecedente de la serie de Sierra de la Ventana. Dada la tosquedad de las piezas, considera que "podrían indicar el foco originario de la tradición lítica pampeana, lo que remarca la importancia del sector situado al sur de la sierra de la ventana y entre los ríos colorado y negro" (Madrazo 1979: 55-56). Incluye a Ventania, y los territorios al sur, junto con Tandilia dentro del aspecto serrano, definido como “...la región que ofrece manifestaciones más puras y quizás más antiguas" (Madrazo 1979: 62).

Hacia fines de la década de 1970 comienzan a realizarse algunos estudios sobre el arte rupestre local y su relación con las representaciones de otras áreas. En este sentido, Gradín (1975) considera que las Sierras Australes de la provincia de Buenos Aires componen un horizonte de motivos geométricos simples con el sur de Mendoza y San Luis. Posteriormente M. Pérez Amat, D. Scheines y C. Bayón describen las pinturas rupestres presentes en los abrigos rocosos del establecimiento Santa Marta en inmediaciones del río Sauce Chico (Pérez Amat et al. 1985) y a principios de la década de 1980 Castro (1983) realiza prospecciones y sondea en la caverna El Abra o cueva de Las Víboras, obteniendo un fechado de $6230 \pm 90$ años AP. sobre carbón vegetal, que ubica cronológicamente a este sitio como el más temprano en el área de Ventania. Otro posible sitio temprano sería Los Flamencos II, localizado sobre las márgenes de la laguna Las Encadenadas, para el que Austral (1987) plantea el registro de material lítico en asociación con placas de Glyptodon sp., sin embargo esta asociación no ha sido corroborada por estudios más detallados.

Luego de estos esporádicos estudios, hacia mediados de la década de 1980 las investigaciones adquirieron una mayor continuidad y sistematicidad, generándose un conjunto de información novedosa en relación con sistemas productivos y disponibilidad de recursos, patrones de entierro y características del arte rupestre (Barrientos et al. 1997, 2014; Bayón y Zavala 1997; Bayón et al. 1999, Catella et al. 2010, 2013; Consens y Oliva 1999; Flegenheimer y Bayón 2002; Madrid y Oliva 1994; Oliva 1996, 2000; Oliva y Moirano 1997, 2001; Oliva y Algraín 2004, 2005; Oliva et al. 1991a, 1991b, 2004; Vecchi et al. 2013).

Se realizaron múltiples prospecciones, que permitieron detectar 34 abrigos rocosos con representaciones rupestres (Oliva y Panizza 2012) y numerosos sitios, tanto de actividades múltiples como específicas, distribuidos en la zona serrana, intraserrana y de llanura adyacente, principalmente sobre las márgenes de lagunas y arroyos localizados al sudoeste de las sierras (Figura 3.1). Oliva (2006) relacionó el registro arqueológico localizado en esta área, particularmente aquel al que se le pueden asignar significados simbólicos, con el localizado en áreas ambientalmente similares y propuso que en inmediaciones del meridiano $62^{\circ}$ y entre los paralelos $39^{\circ}$ y $33^{\circ}$, se encuentra un espacio ecotonal 
donde se hallan recursos correspondientes tanto a la Pampa Húmeda como a la Pampa Seca (AEHSP), conformando un sector con una mayor concentración de recursos respecto de las áreas vecinas, que lo convierte en un espacio atractivo que habría sido recurrentemente ocupado por las sociedades cazadorasrecolectoras. Considera que la importancia que el área habría tenido para las sociedades del pasado se ve reflejada en una mayor proporción, en comparación con áreas vecinas, de "bienes fuertemente valorados", que en el caso de estudio están representados por caches, placas grabadas, manos de molienda faliformes, sitios con entierros humanos, arte rupestre huevos de ñandú grabados, caracoles marinos y elementos de molienda decorados (Oliva 2006).

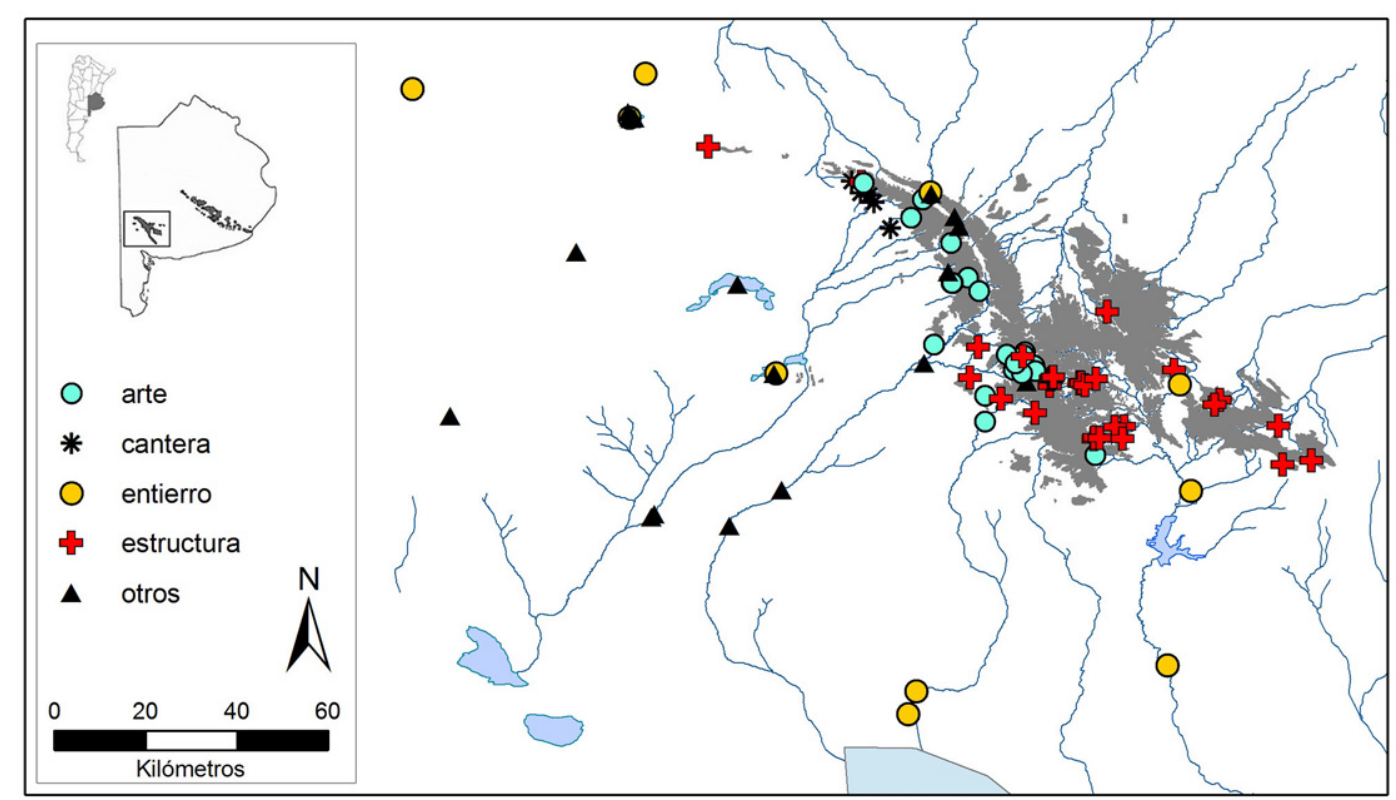

Figura 3.1. Sitios arqueológicos investigados por otros autores desde fines del siglo XIX en las sierras de Ventania y la llanura adyacente al sudoeste.

El registro arqueológico del área de Ventania e inmediaciones, se ubica cronológicamente entre fines del Holoceno medio y momentos de contacto hispano-indígena. Entre los sitios más tempranos se encuentran el sitio San Martín 1 localizado sobre la margen izquierda del arroyo Chasicó (ver descripción en el siguiente apartado) y el sitio Laguna de Puán 1. En este último se recuperaron restos óseos de Lama guanicoe, con un NMI= 3 y restos óseos humanos correspondientes a un individuo masculino adulto datado en $c a$. 3300 años AP. Se recuperó a su vez material lítico, predominantemente productos de talla, sobre cuarcita, riolita y calcedonia y un cache de riolita, conformado por un núcleo, 8 artefactos formatizados y 4 nódulos con incrustaciones de arenisca ferruginosa, al que se agrega un segundo cache de cuarcita recuperado por pobladores locales (Oliva et al. 1991a). La presencia de estos cache ha sido interpretado como evidencia de la implementación de estrategias de uso del espacio y del tiempo que implican una planificación de las actividades a realizar en un futuro, incluyendo la reutilización de determinados sectores del paisaje (Oliva y Pérez 2008). Por otra parte, Oliva y Pérez (2008) observan que muchos de los caches registrados para la Región Pampeana se distribuyen en concordancia con el AEHSP, por lo que proponen que su funcionalidad pudo haber estado relacionada 
con el aprovechamiento de las madera, recurso propio de la provincia fitogeográfica del Espinal (Oliva y Pérez 2008). Esta interpretación se ve apoyada a su vez, por estudios funcionales realizados por M. Leipus, que evidenciaron que algunos de los instrumentos que conforman los cache habrían sido utilizados en el trabajo de madera (Leipus 2006; Oliva y Leipus 1999).

Correspondientes a finales del Holoceno tardío pueden mencionarse los sitios La Montaña 1 y Laguna Los Chilenos 1, ambos localizados en la cuenca del arroyo Chasicó, por lo que serán tratado más adelante. Finalmente para momentos posteriores al contacto hispano-indígena se excavó el sitio Gascón 1 , donde se recuperaron cinco entierros primarios individuales de distinto sexo y edad, dispuestos con un eje de orientación NE-SO con los cráneos en dirección al poniente. En asociación con los individuos, a modo de ajuar, se hallaron argollas de metal, un freno de caballo, vasijas cerámicas, concreciones de carbonato de calcio, cuartos delanteros y costillas de oveja y cuentas de vidrio y metal (Oliva et al. 2007). El análisis de muestras correspondientes al área abdominal de un individuo y a una vasija cerámica asociada, permitió observar en estas muestras, una mayor representación de fitolitos correspondientes a gramíneas (subfamilias pooideae, chloridoideae y panicoideae), que los presentes en sedimentos externos al sitio arqueológico, lo que podría indicar su utilización (Menéndez et al. 2009).

Los estudios realizados en el área sobre materiales líticos identifican a la cuarcita como la materia prima más utilizada, en directa relación con la abundancia regional del recurso, la riolita como segunda en representatividad, seguida por la calcedonia y la limolita silicificada (Oliva y Moirano 2001). A partir del análisis de artefactos confeccionados por picado, abrasión y/o pulido, recuperados en recolecciones y excavaciones sistemáticas, pero principalmente presentes en colecciones particulares, J. Ávila describe para su elaboración, el uso predominante de materias primas locales, especialmente rodados presentes en los arroyos, encontrándose representadas también, aunque en menor proporción, granitos, presentes solo en afloramientos puntuales, que habrían implicado su traslado por distancias en algunos casos superiores a los 30 km activa (Ávila 2003, 2004, 2009; Ávila y Catella 2005). Este autor observa que predominan los artefactos activos por sobre los pasivos y lo relaciona con la posible utilización de madera para la confección de bases (Ávila 2003, 2004, 2009). Entre los sitios de aprovisionamiento de materias primas registrados, se encuentran los afloramientos primarios de riolita (ver más adelante; Oliva y Moirano 1997) y bloques de cuarcita con evidencias de extracción por canteado en la Laguna de Puán y en las nacientes del arroyo Napostá (Oliva y Barrientos 1988; Oliva y Moirano 2001), habiéndose propuesto también, que muchas de las rocas utilizadas, especialmente cuarcitas, pudieron haber sido obtenida a partir del aprovisionamiento de rodados presentes en el cauce de los ríos y arroyos del área (Oliva y Moirano 2001).

Por último, muchas de las investigaciones realizadas se centraron en el análisis del arte rupestre representado en las sierras. Las expresiones gráficas identificadas fueron descriptas predominantemente como geométrico-abstractas, con un menor porcentaje de motivos figurativos (Figura 3.2), generalmente de color rojo, aunque también se han hallado en tonalidades naranja y amarillo-ocre. La presencia de un fechado radiocarbónico de $c a .1600$ años AP aproximadamente asociado a las pinturas de Cueva La Sofía 4 y la representación de una embarcación en Cueva Florencio llevaron a proponer que este tipo de representaciones fueron realizadas al menos durante ese lapso temporal (Oliva 2000). 


\begin{tabular}{|l|c|c|}
\hline \multicolumn{1}{|c|}{ Motivos } & $\begin{array}{c}\text { Cantidad de } \\
\text { sitios }\end{array}$ & Ejemplos \\
\hline $\begin{array}{l}\text { Abstractos } \\
\text { puntiformes, lineales } \\
\text { y de cuerpo lleno }\end{array}$ & $\begin{array}{l}29 \\
(97 \%)\end{array}$ \\
\hline $\begin{array}{l}\text { Representativos } \\
\text { naturalistas } \\
\text { biomorfos }\end{array}$ & 2 & \\
\hline $\begin{array}{l}\text { Representativos } \\
\text { esquemáticos } \\
\text { biomorfos }\end{array}$ & $(6,6 \%)$ & \\
\hline $\begin{array}{l}\text { Representativos } \\
\text { esquemáticos } \\
\text { objetos }\end{array}$ & $(13,3 \%)$ \\
\hline $\begin{array}{l}\text { Representativos } \\
\text { esquemáticos } \\
\text { escenas }\end{array}$ & $11 \%$ \\
\hline
\end{tabular}

Figura 3.2. Porcentaje de representación de los motivos rupestres presentes en el Sistema Serrano de Ventana, modificado de Oliva et al. (2010b). Porcentajes calculados a partir de un total de 30 abrigos rocosos con representaciones rupestres.

Una de las líneas de investigación desarrolladas interpreta que ciertos motivos geométricos podrían ser producto de visiones shamánicas generadas durante estados alterados de conciencia producto del uso de enteógenos, como plantas y hongos con potencial psicodélico presente en la región (Oliva y Algraín 2004; Oliva et al. 2010b). Según esta perspectiva, durante la primera etapa de un estado modificado de conciencia se generan patrones geométricos, como puntos, cuadrículas, líneas paralelas y en zig zag, a las que luego se les busca sentido mediante asociaciones con objetos de la memoria, pudiendo relacionarse el predominio de motivos geométricos con la existencia de patrones culturales comunes, compartidos por las sociedades que habitaron la región (Oliva y Algraín 2004). Las representaciones rupestres también son analizadas desde una perspectiva semiótica, entendiéndolas como un sistema estructurado de comunicación gráfica, que habría actuado en el proceso de transmisión y/o almacenamiento de información. Estos análisis identifican marcas (unidades mínimas) y atractores (combinación de unidades) que permiten definir los mundos semióticos posibles para estas expresiones gráficas, a los fines de obtener una aproximación al significado que pudieron tener para las sociedades responsables de su ejecución (Panizza 2008, 2010). En este tipo de sitios también fueron realizados estudios tendientes a identificar los procesos y agentes que afectan la conservación del arte rupestre, por medio de observaciones 
controladas en diferentes momentos del año, que permiten obtener un mejor conocimiento sobre estos agentes y delinear acciones de protección (Gallego y Oliva 2005). Considerando las distintas vías de análisis, el arte rupestre fue considerado como producto de una estrategia de monumentalización del paisaje, donde este tipo de representaciones pudieron: 1- formar parte de un sistema territorial mayor; 2- funcionar como indicadores de ciertos recursos críticos, 3- representar un sistema de mensajes que pudiese ser interpretado por diferentes grupos a través del tiempo y/o 4- ser producto de actividades desarrolladas en un contexto de trance shamánico (Oliva 2000; Oliva y Panizza 2012).

Recientemente, el arte rupestre comenzó a ser analizado, en conjunto con las estructuras de piedra presentes en Ventanaia, como parte de un "registro monumental". Las estructuras de piedra, consisten en alineamientos de piedras paradas y pircados, que fueron descriptas de forma preliminar durante la década de 1980 y actualmente están siendo objeto de estudios tendientes a realizar una clasificación en función de su morfología, analizar las técnicas de construcción y evaluar espacialmente su distribución en relación con otros rasgos del paisaje mediante el uso de herramientas derivadas de los Sistemas de Información Geográfica (SIG) (ver síntesis en Oliva y Panizza 2012). Otros antecedentes importante en el uso de herramientas SIG, consisten en la determinación de las cuencas visuales de algunos de los sitios con representaciones rupestres (Oliva et al. 2013) y el análisis de la distribución de los sitios arqueológicos en relación con los ambientes serrano, intraserrano, periserrano y de llanura, proponiéndose una mayor densidad en el ambiente intraserrano, en probable correspondencia con una mayor concentración de recursos (Oliva et al. 2004).

\subsection{Investigaciones previas en la cuenca del Arroyo Chasicó}

Varios de los sitios localizados en la cuenca del arroyo Chasicó y considerados en el desarrollo de esta tesis, fueron investigados, inicialmente, en el marco de los proyectos de investigación, de carácter regional, dirigidos por F. Oliva desde mediados de la década de 1980 y a los que la autora se incorporó hacia fines de la década de 1990. Estos proyectos tuvieron como objetivo general aportar conocimiento sobre las sociedades cazadoras-recolectoras que habitaron el sudeste de la Región Pampeana, realizándose para ello, prospecciones y excavaciones sistemáticas, principalmente en el sector superior de la cuenca y, en menor proporción, en el sector medio (Barrientos et al. 1997, 2002; Oliva y Moirano 1997; Oliva et al. 1991, 2000, 2006). A partir de estas investigaciones se plantea la necesidad de intensificar los estudios en los sectores medio e inferior, a los fines de obtener información relevante sobre el uso del espacio en ambientes con características ecológicas diferentes (i.e. ambientes de mayor aridez y menor disponibilidad de materias primas líticas) y evaluar las particularidades de un área transicional entre las regiones pampeana y patagónica.

\subsubsection{Investigaciones realizadas en la Cuenca Superior}

En el sector serrano fueron descriptos ocho abrigos rocosos con representaciones rupestres sobre sus paredes y/o techo. En las nacientes del arroyo Agua Blanca, a menos de $100 \mathrm{~m}$ de su cauce, F. Oliva relevó el sitio Abra Agua Blanca, donde describe varios motivos geométricos (en forma de "V", líneas cruzadas, puntos) en color rojo desvaído (Oliva 2000; Oliva et al. 2010b). Sobre la margen izquierda de una de las nacientes del arroyo Cochenleufú Chico este mismo autor releva otro sitio con arte al que 
denomina Cueva arroyo Cochenleufú Chico, donde describe un posible motivo antropomorfo y motivos geométricos (Oliva 2000, 2014; Oliva et al. 2010b). Los restantes sitios con arte se localizan todos en el abra de La Sofía, conformando, junto con otro sitio a cielo abierto la Localidad arqueológica La Sofía.

\subsubsection{Localidad Arqueológica La Sofía}

La localidad arqueológica La Sofía se encuentra localizada en el Abra de la Sofía, en el cordón serrano de Curamalal. Se trata de seis abrigos rocosos que presentan pinturas en sus paredes, cinco localizados en las nacientes del arroyo Cochenleufú Grande (La Sofía sitios 1, 2, 3, 4, 6) y uno en las nacientes del río Sauce Chico (La Sofía sitio 7 o valle Intraserrano cueva 3), a los que se suma un sitio de superficie a cielo abierto (La Sofía sitio 5). Las investigaciones en el área estuvieron orientadas principalmente al relevamiento del arte rupestre presente en los abrigos rocosos del abra Sofía, sin embargo, en algunos de ellos también se realizaron sondeos y recolecciones a partir de los cuales se recuperó material arqueológico que será tratado en esta tesis (Oliva 2000, 2014).

La Sofía 1, localizada a $100 \mathrm{~m}$ de la margen derecha de una de las nacientes del arroyo Cochenleufí Grande, presenta en una de sus paredes una concentración de motivos curvilíneos y rectilíneos que podrían corresponder a un motivo figurativo biomorfo esquematizado. Los sitios 2, 3 y 4 consisten en tres abrigos rocosos localizados sobre la margen izquierda de una de las nacientes del arroyo Cochenleufú Grande, a entre 40 y $150 \mathrm{~m}$ uno del otro y a poco más de $150 \mathrm{~m}$ del curso de agua. El sitio 2 presenta, en sus paredes y parcialmente en el techo, 10 motivos aislados y cuatro concentraciones de motivos pintados en rojo desvaído consistentes en líneas paralelas y manchas y motivos lineales indeterminables en las paredes (Oliva 2000, 2014). El sitio 3 presenta sólo algunos motivos lineales indeterminables aislados en color rojo desvaído, en tanto el sitio 4 presenta una concentración de líneas paralelas y motivos aislados también en rojo desvaído. En este sitio F. Oliva obtuvo un fechado 1595 \pm 70 (AA19290) para restos óseos de Lama guanicoe asociados a un fragmento de roca de base con restos de pintura roja desvaída en su superficie, razón por la cual se interpretó que las pinturas rupestres habrían sido realizadas con anterioridad a dicho fechado (Oliva 2000, 2014).

\subsubsection{Localidad Arqueológica La Montaña}

La localidad arqueológica la Montaña fue investigada por F. Oliva desde principios de la década de 1990. Se localiza en la estancia La Montañita, ubicada en las últimas estribaciones, hacia el noroeste, de las sierras de Curamalal, en inmediaciones de los afloramientos de riolita de La Mascota. Se trata de tres sitios arqueológicos y gran cantidad de materiales dispersos que fueron recolectados por los propietarios del establecimiento y hoy forman parte de las colecciones del museo privado Coyug Curá ubicado en esa misma estancia. Estos sitios no se encuentra estrictamente dentro de la cuenca del arroyo Chasicó, pero dado que están a menos de $3 \mathrm{~km}$ de sus nacientes, fueron considerados, a los fines de esta tesis, como formando parte de la misma (Oliva 2014).

Los primeros estudios consistieron en un análisis preliminar de los materiales de la colección Coyug Curá y prospecciones en el área donde fueron recolectados la mayor parte de estos materiales. Luego de estos análisis preliminares, F. Oliva realizó excavaciones en las que recuperó, entre otros materiales, dos puntas de proyectil triangulares pequeñas, fragmentos cerámicos y elementos óseos asignables a Lama 
guanicoe y Ozotoceros bezoarticus sobre los cuales se obtuvo un fechado de 385 \pm 80 AA-19298 (Catella 2004; Oliva 1996, 2000 2014; Oliva et al. 2000). Sobre la base de esta información, F. Oliva postuló que se trataría de un sitio de actividades múltiples ubicado cronológicamente en momentos finales de la ocupación indígena (Oliva 2000; Oliva et al. 2000).

El sitio 1 se encuentra relacionado espacialmente con otros dos sitios ubicados sobre las laderas de un cerro llamado Las Plantas. En la ladera sudoeste se encuentran tres estructuras de piedra de forma subrectangular, a las que se las denominó como sitio 2 , y en la ladera este se localiza un pequeño alero en el que se registraron motivos abstractos pintados en rojo desvaído y un posible motivo figurativo (líneas paralelas, líneas entrecruzadas, líneas aisladas, alineación de puntos), al que se llamó sitio 3 (Oliva 2000, 2014).

Por otra parte, F. Oliva, J. Moirano y J. Ávila analizaron en diferentes ocasiones la colección recuperada en inmediaciones del sitio 1, conformada principalmente por artefactos de molienda y material lítico tallado. Un estudio preliminar fue realizado por F. Oliva y luego continuado por J. Moirano, quien analizó una muestra conformada por 176 artefactos obtenidos por técnica de talla. Considerando como principales variables materia prima, grosor, tamaño, módulo ancho-espesor, grupo tipológico, serie técnica y forma base, observa que predominan los instrumentos (raspadores, raederas y artefactos de formatización sumaria) por sobre las lascas, confeccionados en cuarcita $(60 \%)$ y en menor proporción riolita (20\%), con tamaños mediano-grande. Describe a su vez, un posible escondrijo conformado por dos artefactos bifaciales confeccionados sobre riolita, de características similares a los descriptos en el escondrijo recuperado en la laguna de Puán, e identifica la presencia de artefactos de menores dimensiones confeccionados sobre calcedonia. Este autor concluye que los altos porcentajes de riolita responderían a un fenómeno exclusivo (en principio) del sector occidental del sistema serrano de Ventania. Considera a su vez, y que la calcedonia, dado que se encuentra presente en la mayor parte de las colecciones del área, pudo haber sido obtenida en las sierras de Ventania (Moirano 1999). Por su parte, Ávila (2009) se centró en los artefactos confeccionados por picado, abrasión y/o pulido, analizando, macroscópicamente, una muestra conformada por 22 manos de mortero que representa, aproximadamente, el 10\% de la muestra total de artefactos de molienda. A partir del análisis de estos materiales y de otros artefactos de molienda depositados en colecciones particulares del área, propone que el aprovisionamiento de las materias primas utilizadas para su confección habría sido principalmente local y relacionado con la disponibilidad y accesibilidad de este recurso en el paisaje. Por otra parte, basándose en datos etnográficos, etnohistóricos y en las características de las maderas disponibles en el área, considera que el predominio de artefactos activos (manos) en todas las colecciones podría responder al uso de maderas para la confección de su contraparte pasiva o base (Ávila 2009).

\subsubsection{Afloramientos de La Mascota}

En el sector suroccidental de la sierra de Curamalal Oliva y Moirano (1997) realizaron prospecciones en los afloramientos primarios de riolita y en el cauce de los arroyos del área, a los fines de obtener información sobre las posibles estrategias empleadas por las sociedades cazadoras-recolectoras en el aprovisionamiento y circulación de esta materia prima. A partir de estas prospecciones detectaron un total 
de 12 afloramientos primarios de riolita en un área restringida de aproximadamente $45 \mathrm{~km}^{2}$, localizada entre las localidades de Saavedra y Pigüé. A partir del relevamiento de los materiales líticos en superficie observan que siete de los afloramientos (LM 2, LM 3, LM 4, LM 6, LM 7, LM 9, y LM 11) presentan evidencias de extracción y realización de las primeras etapas de formatización (Figura 3.3). Estas actividades no se habrían desarrollado de manera uniforme, sino que algunos afloramiento muestran mayor concentración de artefactos en sectores particulares evidenciando un uso más intensivo de ellos. Estos autores proponen que la utilización de sólo algunos de los afloramientos estaría relacionada con la variabilidad en la calidad para la talla de las riolitas aflorantes, mejor en aquellos afloramientos con evidencia de extracción y talla. Los artefactos recuperados en el área, consistentes en lascas, artefactos de formatización sumaria, núcleos y algunos percutores e instrumentos formatizados, en su gran mayoría de tamaño muy grande y espesores medios, con alta proporción de corteza, los lleva a caracterizar a este sector del paisaje como un área cantera-taller, donde se habrían llevado a cabo, predominantemente, tareas relacionadas con el aprovisionamiento de riolita, la reducción inicial de nódulos y la formatización sumaria de instrumentos (Oliva y Moirano 1997). Por otra parte, evalúan la disponibilidad de rodados riolíticos en el cauce de los arroyos próximos a los afloramientos, observando que su representación es de escasa importancia, por lo que el aprovisionamiento de esta materia prima en estos sectores no habría sido significativo, sino que se habría centrado en la utilización de los afloramientos primarios (Oliva y Moirano 1997).

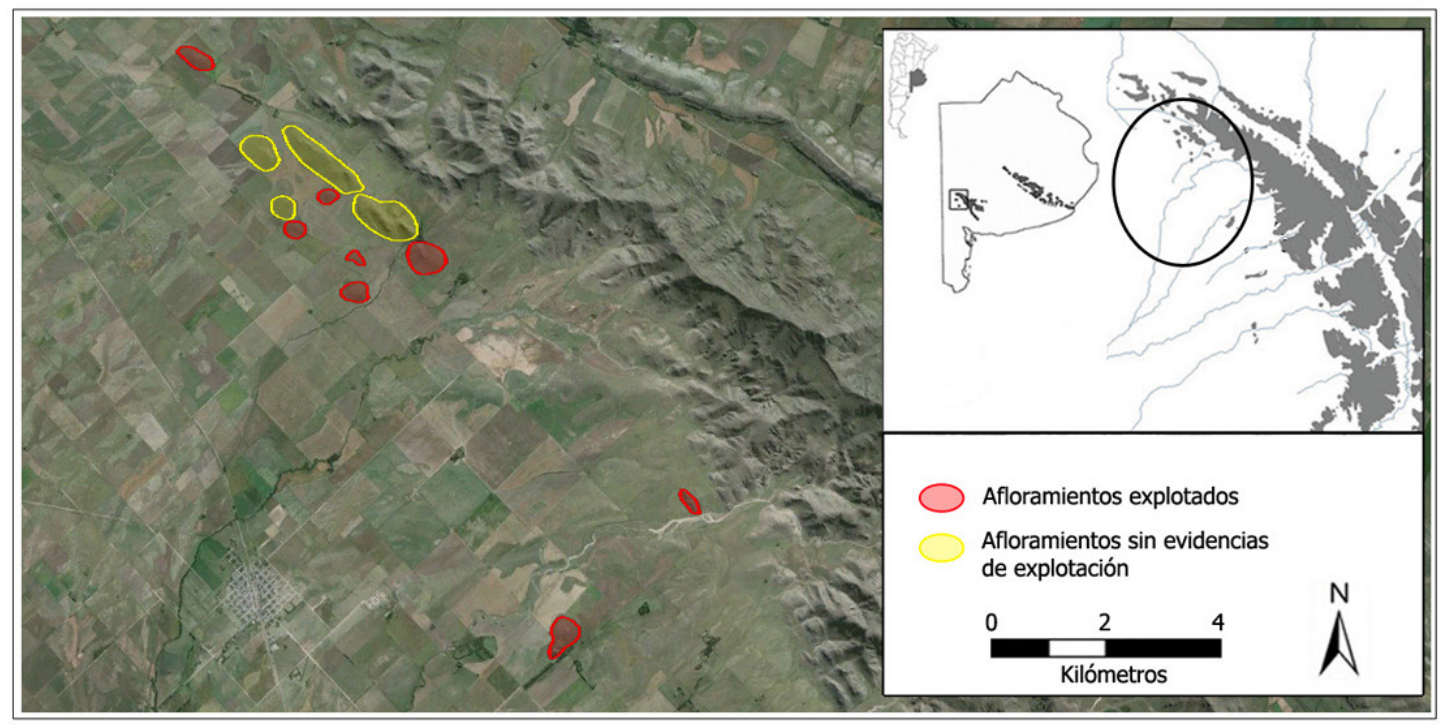

Figura 3.3. Afloramientos riolíticos de La Mascota.

\subsubsection{Localidad arqueológica Los Chilenos}

En la laguna Los Chilenos, los trabajos arqueológicos realizados por G. Barrientos y F. Oliva, les permitieron identificar dos sitios en estratigrafía (Los Chilenos sitios 1 y 2) y materiales arqueológicos distribuidos en superficie, en el sector de playa localizado entre ambos (Barrientos et al. 1997, 2002; Oliva 2014). En el sitio 1, estos autores realizan excavaciones extensivas a partir de las cuales recuperan tres entierros, dos primarios y uno secundario, numerosos elementos óseos humanos dispersos, escasos 
artefactos y ecofactos, entre los que se encuentran tiestos cerámicos, cuentas circulares de valva, un fragmento de valva de Adelomelon sp. y artefactos líticos, además de elementos óseos correspondientes a Ovis aries (en las unidades superiores), Ctenomys sp. y Dasipodidae sp. (Barrientos 1997; Barrientos et al. 2002).

El sitio fue asignado a momentos finales del Holoceno tardío, a partir de una datación realizada sobre el entierro secundario, que arrojó una fecha de $470 \pm 40$ años ${ }^{14} \mathrm{C}$ AP (LP 501). Los análisis realizados sobre dicho entierro permitieron identificar un NMI de 14 individuos, representados por la casi totalidad de los elementos óseos esqueletarios pero en distinta frecuencia (Barrientos et al. 2002). Barrientos (1997) describe que las unidades anatómicas con mayor representación son el cráneo, las diáfisis de huesos largos, las clavículas, el íleon y el isquion, gran parte de ellos pintados de rojo y amarillo. En base a la articulación de partes esqueletarias, presencia y frecuencia de epífisis no fusionadas asociadas a las diáfisis, este autor infiere que gran parte de los individuos habrían ingresado al sitio con parte de los tejidos blandos adheridos, especialmente tendones y ligamentos. A su vez, la presencia de marcas de corte poco profundas, distribuidas preferencialmente en los extremos distales y proximales de los huesos largos y en la parte media de la diáfisis, con una orientación oblicua o paralela a su eje mayor, le sugieren la realización de actividades de descarne. Los entierros primarios, por otra parte, corresponden a un individuo masculino y otro a uno femenino, ambos adultos, que fueron recolectados por aficionados, con excepción de uno de los cráneos, debido a que habían sido expuestos por acción erosiva de la laguna. A estos entierros se suman un NMI de 7 individuos, 5 adultos y 2 subadultos recuperados en la playa. (Barrientos 1997; Barrientos et al. 1997, 2002)

A partir de los análisis descriptos, de la escasa presencia de artefactos y ecofactos y de la ausencia de elementos óseos faunísticos de importancia económica, como guanaco o venado, este sitio fue interpretado como un área formal de entierros humanos, con una intensa modificación postdepositacional producto de la acción de roedores, pisoteo y erosión y re-depositación hídrica (Barrientos 1997; Barrientos et al. 2002).

Hacia el sudoeste del sitio 1, también sobre la costa, las prospecciones realizadas por el equipo de investigación permitieron identificar otra concentración de materiales a la que denominaron sitio 2 , conformado por materiales en estratigrafía y re-depositados sobre la playa. Las actividades realizadas en este sitio, consistentes en recolecciones superficiales y la excavación de dos sondeos sobre la barranca, les permitieron recuperar restos óseos humanos desarticulados, restos óseos de guanaco, venado y vaca, valvas de Adelomelon, fragmentos cerámicos y artefactos líticos. Entre estos últimos, describen la presencia de materias primas locales, cuyas fuentes se ubican a menos de $10 \mathrm{~km}$, no locales, obtenidas a más de $10 \mathrm{~km}$ e indeterminadas y de un artefacto en pumicita con sus caras incisas conformando un damero similar a las placas grabadas de origen patagónico. Este sitio ha sido interpretado como producto de ocupaciones sucesivas que se superpusieron en diversos sectores del paisaje, o bien como resultado de ocupaciones, únicas o sucesivas, de carácter agregacional (Barrientos et al. 1997). 


\subsubsection{Investigaciones realizadas en la cuenca Media}

\subsubsection{San Martin sitio 1}

El sitio San Martín fue investigado por F. Oliva, quien realiza excavaciones, desde fines de la década de 1980, sobre margen izquierda del arroyo Chasicó, en un sector donde la Prof. N. Cinquini había recolectado numerosos materiales arqueológicos. A partir de estas excavaciones se recuperaron elementos óseos con marcas de corte asignables a guanaco (NMI de 5), venado de las pampas (NMI de 2), ñandú (NMI de 1) y otras especies de menor porte, placas de dasipódidos, cáscaras de huevo de ñandú y una hemimandíbula de comadrejita patagónica (Lestodelphis halli; Oliva et al. 1991b), un marsupial presente en climas más áridos que los existentes actualmente en el área (Tonni 1985; Voglino y Pardiñas 2005). También se recuperaron artefactos líticos confeccionados principalmente sobre cuarcita, calcedonia y riolita, fragmentos de pigmento mineral, caracoles marinos de la especie Adelomelon brasiliana y cuentas de collar confeccionadas sobre mica y valva. Sobre la base del análisis de estos materiales, se ha propuesto que en el sitio se habrían desarrollado actividades de formatización de cuentas e instrumentos y reactivación de filos, vinculadas a tareas de faenamiento y probable consumo de presas (Oliva 2014; Oliva et al. 1991b; Oliva y Lisboa 2006).

Cronológicamente, el sitio fue asignado a fines del Holoceno medio o inicios del Holoceno tardío, a partir de un fechado radiocarbónico realizado sobre material malacológico presente en el sedimento (Austroborus sp. y Succinea sp.), el que proporcionó una edad de $2890 \pm 80$ años ${ }^{14} \mathrm{C}$ AP (LP-624). La realización del fechado sobre este tipo de material se debió a que las muestras óseas de guanaco procesadas en laboratorios nacionales y extranjeros, no rindieron la cantidad suficiente de colágeno (Oliva y Lisboa 2006; Oliva et al. 2010a).

Basándose en la distribución de los materiales arqueológicos, los cuales se concentran en el sector sur de las cuadrículas, en la UE. B, se propuso que al menos una parte del sitio (sector norte) habría sido erosionada por una cárcava (Oliva et al. 1991b). En posteriores estudios sobre los procesos de formación actuantes, se analizó el perfil de meteorización de los elementos óseos, las marcas y huellas representadas, el tipo de fractura y la representación de partes esqueletarias de Lama guanicoe (MAU\%) en relación con los valores de densidad mineral ósea (DMO) propuestos para los distintos elementos (Elkin 1995; Miotti et al. 1999) y se planteó que el sitio habría tenido un origen fundamentalmente antrópico, generándose durante la/s ocupación/es de lo que en ese momento ya era una antigua planicie de inundación pero con incidencia, también, de otros agentes bióticos como roedores, las raíces y los carnívoros (Oliva et al. 2010a). A los fines de evaluar la incidencia del agua en la formación del sitio, Oliva et al. (2010a) también consideraron la orientación de los huesos en planta y la representación de las partes esqueletarias correspondientes a guanaco en relación con los grupos de probabilidad de transporte hídrico, propuestos por Voorhies (1969), postulando que el conjunto arqueológico procedente del sitio San Martín 1 puede ser tentativamente asignado a lo que Hanson (1980) considera un conjunto tipo $1 \mathrm{~B}$, es decir, una acumulación formada fundamentalmente in situ, donde se encuentran representados preferentemente aquellos elementos con menor potencial de transporte hídrico, pero donde la exposición a ocasionales escorrentías superficiales habría generado una reducción en la representación de aquellos elementos con mayor potencial de transporte y la consecuente acumulación de los elementos óseos remanentes en trampas sedimentarias (i.e. zonas encharcadas de baja energía relativa, laterales al cauce 
del arroyo). Consideran a su vez, que la baja meteorización de la muestra sumada a la ausencia de elementos con meteorización diferencial, sería indicador de que el conjunto no estuvo expuesto durante un tiempo prolongado a condiciones atmosféricas, por lo que este proceso pudo haberse producido en un tiempo cercano al abandono del sitio (Oliva et al. 2010a).

\subsubsection{Investigaciones realizadas en la cuenca Inferior}

En el sector inferior de la cuenca del arroyo Chasicó, los antecedentes son muy escasos, limitándose a una prospección realizada por F. Oliva y G. Martínez a principios de la década de 1990, en la que describen la presencia conjuntos de rodados tehuelches de pequeñas dimensiones sobre la costa de la laguna Chasicó y de materiales arqueológicos en una isla localizada en esta laguna (Martínez 1990; Oliva 1996). 


\section{I Características Ambientales del Área de Estudio}

En este capítulo se presentan las características ambientales generales del sector centro-oriental de la República Argentina, localizado entre $36^{\circ}$ y $42^{\circ}$ de lat. Sur y $57^{\circ}$ y $68^{\circ}$ de long. Oeste, dentro del cual se encuentran comprendidas el sur de la Región Pampeana y el NE de la Región Patagónica, para luego describir las características ambientales del área de Ventania y, particularmente, de la cuenca del arroyo Chasicó.

\subsection{Caracterización ambiental del sur de la Región Pampeana y NE de Patagonia}

La Región Pampeana es una amplia llanura que se extiende en la zona centro-este de la República Argentina. Posee un clima templado-cálido, con una estación calurosa entre los meses de diciembre y marzo y un período más frío que abarca julio y agosto. La continentalidad aumenta de este a oeste, en tanto las temperaturas promedio y las precipitaciones disminuyen en este mismo sentido y de norte a sur, con temperaturas promedio que oscilan entre $24^{\circ} \mathrm{C}$ en enero y $10^{\circ} \mathrm{C}$ en julio en el noreste y entre $20^{\circ} \mathrm{C}$ y $7^{\circ} \mathrm{C}$ para iguales meses en el suroeste (Burgos 1968) y precipitaciones promedio de $1000 \mathrm{~mm} /$ año en el este y $400 \mathrm{~mm} /$ año en el oeste. La isohieta de los $600 \mathrm{~mm} /$ año establece la división convencional entre Pampa Húmeda al este y Pampa Seca al oeste, estableciendo también diferencias fito y zoogeográficas entre una y otra subregión (Burgos 1968; Cabrera y Willink 1980).

La subregión Pampa Húmeda fue subdividida sobre la base de rasgos fisiográficos y, complementariamente, arqueológicos, en siete áreas: Sur, Ventania, Interserrana, Tandilia, Oeste, Depresión del Salado, Norte y Delta (Politis 1984; Berón y Politis 1997). En esta tesis y para el desarrollo de la mayor parte de los análisis, se consideraron las seis primeras, introduciéndose una modificación. Por las particularidades de localización del área de estudio, que comprende parte de las áreas Ventania y Sur, estas fueron unificadas como una misma área definida al sur por los bajos de Chasicó, al oeste por la costa atlántica y la divisoria de aguas entre las cuencas del arroyo Napostá Chico y el río Sauce Grande, al noreste por los límites del afloramiento serrano de Ventania y por una línea imaginaria que se extiende desde los últimos afloramientos rocosos, en la laguna de Puán, hasta las Salinas Grandes.

El NE patagónico, por otra parte, se extiende al sur de los bajos de Chasicó, comprendiendo un área de relieves mesetiformes interrumpidos por las cuencas de los ríos Negro y Colorado, donde se encuentran zonas de bajos sin salida, salares y salitrales (Cabrera 1971; Gonzalez Uriarte et al. 1987; Ringuelet 1955; Schäbitz 1994). Esta subregión presenta un clima templado y seco, con temperaturas máximas medias anuales que oscilan entre 21,1 y $23,7^{\circ} \mathrm{C}$ y temperaturas mínimas con una media de 
entre 6.8 y $9,9^{\circ} \mathrm{C}$, con precipitaciones medias de entre $560 \mathrm{~mm} /$ año y $420 \mathrm{~mm} / \mathrm{año}$, que disminuyen en sentido noreste-sudoeste (García y García 1964).

El área de estudio, conformada por la cuenca del arroyo Chasicó, se ubica en el sudeste de la Región Pampeana, limitando al sur con el NE patagónico, al oeste con la subregión Pampa seca y al norte con el área interserrana. Está incluida parcialmente dentro de lo que ha sido denominado como un área ecotonal entre la Pampa Húmeda y la Pampa Seca (AEHSP sensu Oliva 2006) y entre las regiones Pampeana y Patagónica (Martínez 2010) (Figura 4.1), lo cual posibilita la presencia de recursos propios de las tres áreas. Este límite no debe ser visto como algo estático, sino como una zona de transición fluctuante, donde las variaciones climáticas ocurridas durante el Holoceno, y particularmente durante los últimos 4000 años, habrían generado oscilaciones en la distribución de los organismos en relación con las condiciones ambientales de cada momento particular.

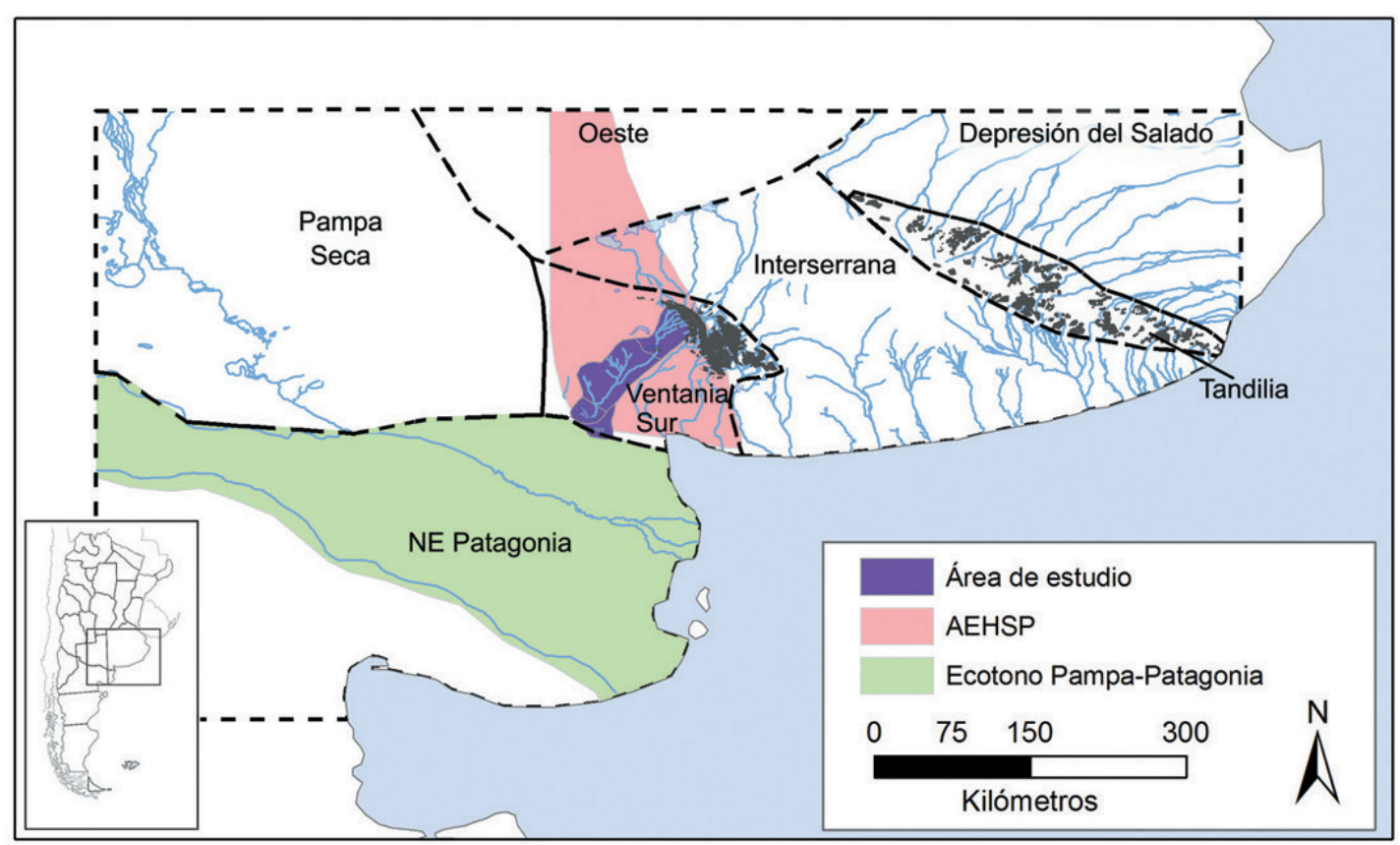

Figura 4.1. Sector centro-oriental de la República Argentina.

\subsubsection{Fitogeografía}

Fitogeográficamente, el sector centro-oriental de la República Argentina corresponde al Dominio Chaqueño de la Región Neotropical (Cabrera 1971; Cabrera y Willink 1980), encontrándose representadas tres provincias fitogeográficas (Figura 4.2):

a) Provincia Pampeana al este, extendiéndose sobre las llanuras y las sierras de Tandilia y Ventania en la provincia de Buenos Aires, con una vegetación predominante de estepa o pseudoestepa de gramíneas. Se encuentran también comunidades edáficas, estepas halófilas, bosques marginales en las orillas de los ríos y bosques xerófilos sobre las barrancas y bancos de conchilla. Esta provincia fue subdividida en tres distritos diferenciados por las proporciones 
de los diferentes géneros de gramíneas: el Distrito Uruguayense desde el sur de Brasil hasta Santa Fe; el Distrito Pampeano Oriental en el norte y este de la provincia de Buenos Aires hasta las serranías de Tandil; el Distrito Pampeano Occidental en el sur de Córdoba, noreste de La Pampa y noroeste de Buenos Aires; y el Distrito Pampeano Austral, en el sur de Buenos Aires, hasta cerca de Bahía Blanca (Cabrera 1971; Cabrera y Willink 1980).

b) Provincia del Espinal, rodea a la provincia Pampeana, formando un arco irregular que cubre llanuras, serranías de poca altura y medanales con vegetación predominante de bosque xerófilo bajo que se prolongan hacia el este, el oeste y el sur por las depresiones y sobre la barrancas de los ríos. Esta provincia ha sido subdividida en tres distritos en función de la especie de Prosopis dominante: Distrito del Ñandubay, en las provincias de Corrientes y Entre Ríos, con predominio de Prosopis algarrobilla (ñandubay) y Prosopis nigra (algarrobo); Distrito del Algarrobo, en el centro de Santa Fe y Córdoba donde predomina Prosopis nigra y Prosopis alba; Distrito del Caldén, en el centro y sur de San Luis, centro de La Pampa y sur de Buenos Aires, donde predomina Prosopis caldenia (caldén) (Cabrera 1971; Cabrera y Willink 1980).

c) Provincia del Monte, localizada al sur sud-oeste de la provincia del espinal, formando con ella amplios ecotonos. Se desarrolla a través de llanuras arenosas, bolsones, meseta y laderas bajas en lo que se considera como región nordpatagónica, con vegetación predominante de matorral o estepa arbustiva xerófila, psamófila o halófila, a veces muy abierta, donde predominan zigofiláceas de los géneros Larrea, Bulnesia y Plectocarpa, bosques marginales de algarrobo, chañar y sauce y abundantes cactáceas en el sector septentrional (Cabrera 1971; Cabrera y Willink 1980).

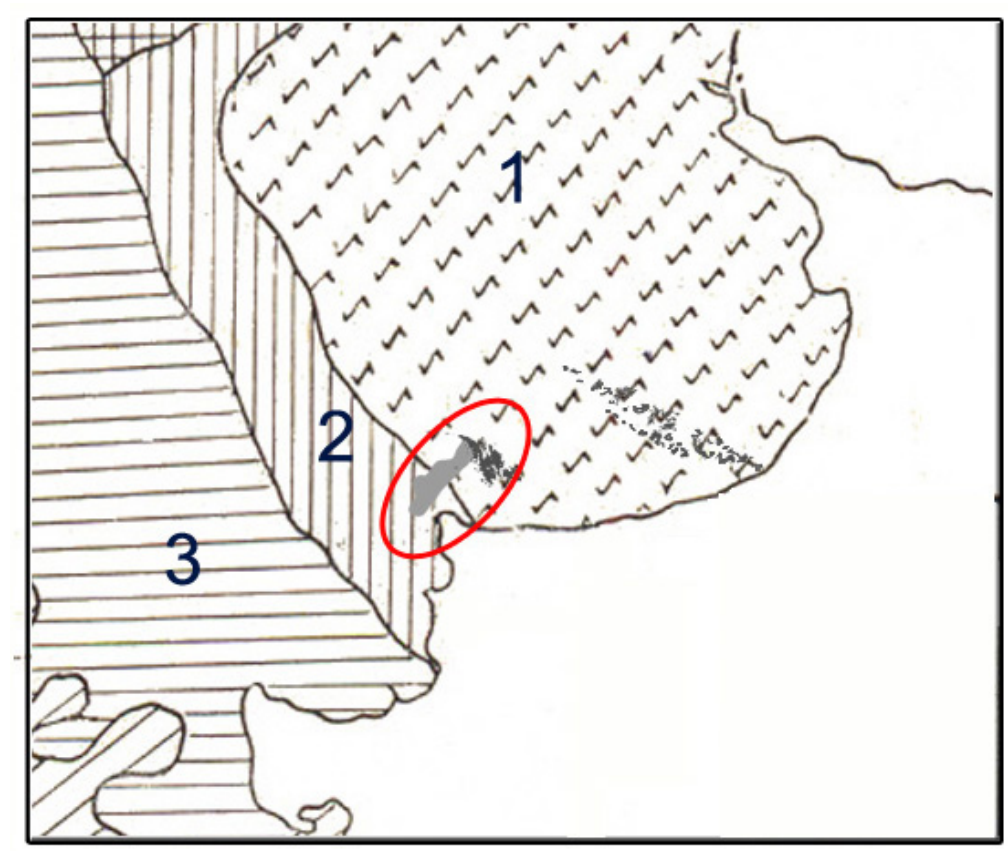

Figura 4.2. Fitogeografía del sector central de la República Argentina, modificado de Cabrera (1971). 1- Dominio Chaqueño, Provincia Pampeana; 2. Dominio Chaqueño, Provincia del Espinal; 3. Dominio Chaqueño, Provincia del Monte. El círculo rojo señala la cuenca del arroyo Chasicó. 


\subsubsection{Zoogeografía}

En cuanto a sus características zoogeográficas, el área de interés abarca, en su sector noreste, al Dominio Pampásico de la sub-región Guayano-Brasileña y, en el sector sudoeste, a los Dominios Central o Subandino y Patagónico de la sub-región Andino-patagónica (Figura 4.3; Ringuelet 1955). El Dominio Pampásico, representado en la mayor parte de la provincia de Buenos Aires, se caracteriza por la presencia de fauna de tipo brasileña, producto de una retracción de la fauna subtropical en general y chaqueña en particular, como consecuencia de cambios en las condiciones ecológicas desde mediados o fines del Cuaternario, pero donde se observa también una fuerte influencia patagónica, especialmente en el límite sur. Algunas de las especies características de este dominio son el ciervo de los pantanos (Blastocerus dichotomus) en las zonas ribereñas del norte, el venado de las pampas (Ozotocerus bezoarticus), el coipo (Myocastor coipus) la vizcacha (Lagostomus maximus), algunos marsupiales como la comadreja (Didelphys azarae), carnívoros, entre los que se pueden mencionar zorrinos (Conepatus), zorro pampeano (Dusicyon gymnocercus) y gato montés (Felis geoffroyi). Numerosos roedores como la mara (Dolichotis australis), tuco-tucos (Ctenomys), cuises (Cavia, Microcavia) además de varias ratas, ratones y lauchas, aves acuáticas y arborícolas y algunos peces (Cabrera y Willink 1980).

El Dominio central o subandino se encuentra interpuesto entre el pampásico y el patagónico, abarcando el Sistema de Ventania y el área que se extiende al sur hasta el río Colorado. Su fauna es fundamentalmente brasílica, de filiación subtropical y chaqueña, pero seleccionada en relación con condiciones ecológicas rigurosas y con una marcada influencia del Dominio Patagónico. Finalmente, este último dominio coincide con la Patagonia extraandina, encontrándose su límite septentrional ubicado en el río colorado (Ringuelet 1961). En este pueden encontrarse mamíferos como el guanaco (Lama guanicoe), zorros (Dusicyon), hurones (Lyncodon y Galictis), zorrinos (Conepatus), gato de los pajonales (Felis colocolo), el puma (Puma concolor) y otros felinos. Se encuentran también numerosos roedores entre los que se ecuentran la mara (Dolichotis patagonum), cuises (Microcavia) y tuco-tucos (Ctenomys), armadillos (Chaetophractus), algunos marsupiales como la comadreja (Didelphys azarae) y aves como perdices (Nothoprocta cinerascens y Nothura darwini) y martinetas (Eudromia elegans) (Cabrera y Willink 1980).

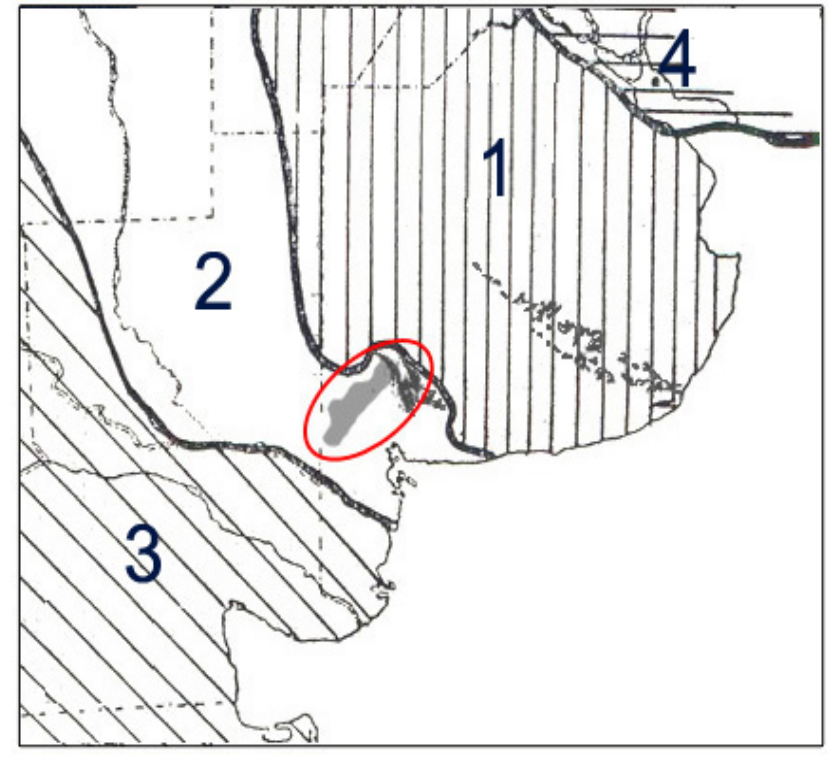

Figura 4.3. Zoogeografía del sector central de la República Argentina, modificado de Ringuelet (1960). 1- Dominio Pampásico; 2- Dominio Central o Subandino; 3- Dominio Patagónico; 4- Dominio Subtropical. El círculo rojo señala la cuenca del arroyo Chasicó 
Los mamíferos de mayor porte, como el venado de las pampas y el guanaco, se encuentran actualmente retraídos a sectores puntuales del área de estudio, como reservas naturales (e.g. Parque Provincial Ernesto Tornquist) y tierras no aptas para el cultivo. Sin embargo, en el pasado habrían tenido una amplia distribución en las regiones pampeana y nordpatagónica. En tal sentido, Politis et al. (2011b) recientemente propusieron mapas predictivos acerca de su localización probable durante el Holoceno tardio, sobre la base de variables ecológicas y de datos de avistamiento (Figura 4.4).

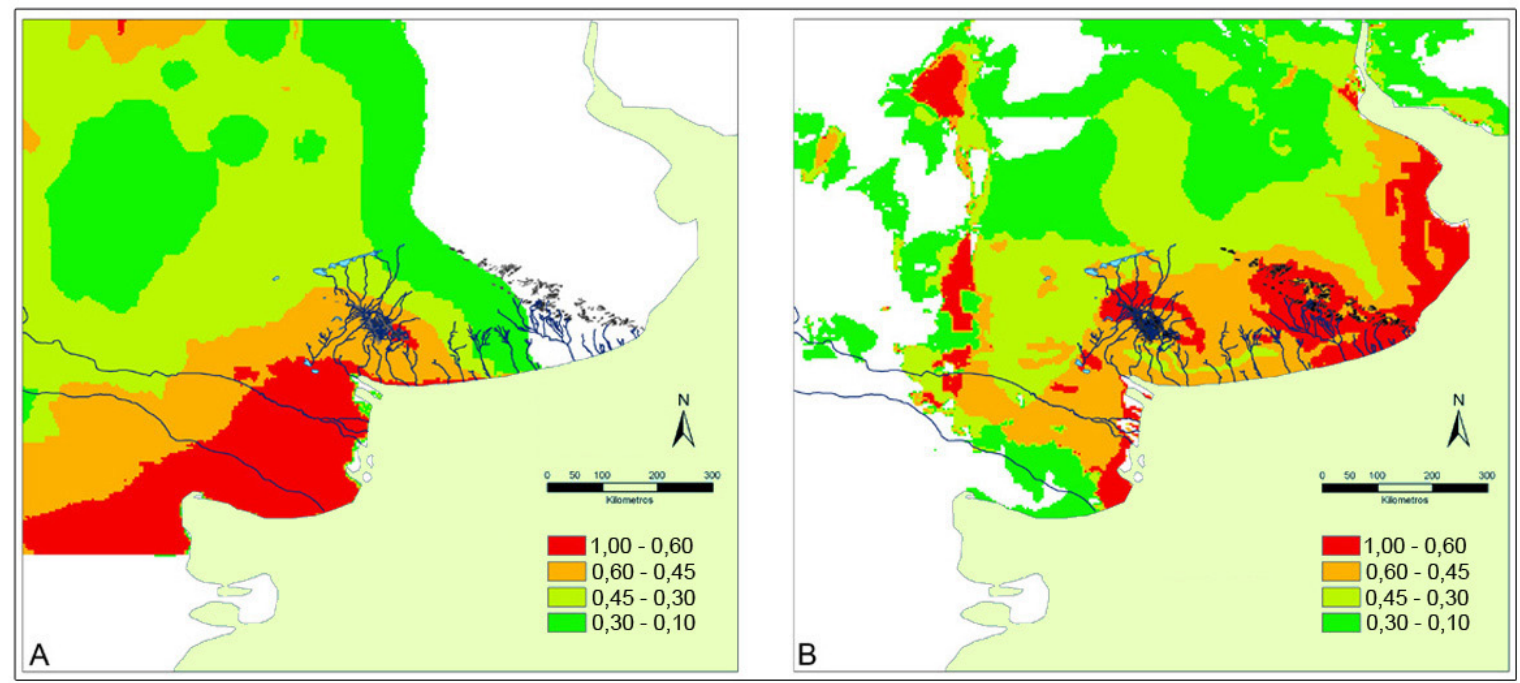

Figura 4.4. Distribución potencial, durante el Holoceno tardío, de: A) Lama guanicoe y B) Ozotoceros bezoarticus. Los intervalos de valores representados por cada color expresan probabilidad. Modificado de Politis et al. (2011b).

\subsubsection{Características geológicas}

El sector correspondiente a la subregión Pampa Húmeda se caracteriza por extensas llanuras, donde predominan los depósitos de loess y limos de edad cuaternaria, sólo interrumpidos por los dos principales afloramientos rocosos de la región: Tandilia al norte y Ventania al sur, y algunos afloramientos menores en el área Interserrana y en la llanura adyacente al sudoeste de Ventania. El Sistema Serrano de Tandilia (Nágera 1940) o Sierras Septentrionales de la provincia de Buenos Aires (Harrington 1956), representa un cordón discontinuo de sierras y lomadas suaves, bajas y dispersas, con alturas máximas cercanas a los $500 \mathrm{msnm}$ y que no sobrepasan los 250 metros sobre la llanura circundante. Se extienden desde la costa atlántica, en la zona de Mar del Plata, hasta las lomadas de Quillalauquén, distantes aproximadamente $300 \mathrm{~km}$ al noroeste de dicha ciudad, con su ancho máximo representado en inmediaciones de la ciudad de Tandil, donde alcanza los 60 km (Teruggi y Kilmurray 1980). Este sistema orográfico está compuesto por un basamento cristalino formado por rocas ígneo-metamórficas, denominado Complejo Buenos Aires, que se encuentra parcialmente cubierto por sedimentitas (Dalla Salda 1999; Dalla Salda et al. 2006; Di Paola y Marchese 1974; Iñiguez Rodríguez 1999). La cobertura sedimentaria, por otra parte, está conformada por dos formaciones mayores, el Grupo Sierras Bayas y la Formación Balcarce conformadas por rocas esencialmente silicoclásticas, a las que se agregan otras formaciones de distribución más localizada, como la Formación Cerro Negro, la Formación Las Águilas y las metapelitas Punta Mogotes. (Iñiguez et al. 1989; Manassero 1986). 
El Grupo Sierras Bayas, de edad Precámbrico superior, se encuentra conformado por una serie de unidades litoestratigráficas compuestas por rocas sedimentarias silicoclásticas y carbonáticas, entre las que se encuentran conglomerados, brechas, arenitas y vaques cuarzosas, cuarcitas, areniscas galuconíticas, fangolitas, limolitas, arcilitas, lutitas, ferrilitas, mudstones, grainstones, boundstones dolomíticos-estromatolíticos y ftanitas. Apoyando indistintamente sobre el basamento cristalino o sobre el Grupo Sierras Bayas, se encuentran sedimentitas silicoclásticas paleozoicas que conforman las formaciones Cerro Negro y Balcarce. La primera compuesta por pelitas rojas asociadas a "bochones de ftanita”, en tanto la segunda, aflorante fundamentalmente en el sector oriental de Tandilia, se compone de arenitas y sabulitas cuarzosas, con intercalaciones pelíticas subordinadas (Dalla Salda et al. 2006). Estas rocas, si bien han sufrido transformaciones relacionadas con procesos de diagénesis/metamorfismo de muy bajo grado, mantienen sus características originales de fábrica, textura y composición mineralógica (Bayón et al. 1999).

En el área interserrana se encuentran, en inmediaciones de las localidades de González Chaves, Lumb, De la Gama y Mariano Roldán, algunos afloramientos de areniscas, bajos y de dimensiones reducidas, que por sus características han sido relacionadas con las formaciones del Grupo Pillahuincó, aflorante en el sector oriental de las Sierras de Ventania (Andreis y Torres Ribeiro 2003; Kostadinoff 2007). Este último sistema serrano, debido a que forma parte de la cuenca del arroyo Chasicó, será tratado en un próximo apartado, cuando se desarrollen las características particulares del área de estudio (Figura 4.5).

Hacia el oeste, en la provincia de La Pampa, las rocas metamorficas y eruptivas representan casi el 90\% de los afloramientos rocosos. En este sector de la Región Pampeana se continúa el paisaje de llanura, encontrándose muy pocas elevaciones, entre las cuales el rasgo orográfico más importante lo constituyen las sierras de Lihué Calel, conformadas principalmente por riolitas, cuya altura máxima es de $590 \mathrm{msnm}$. Se hallan a su vez numerosos afloramientos aislados de reducido tamaño, entre los cuales los de mayor significación son las sierras de Lonco Vaca y el cerro Los Viejos (Linares et al. 1980). Las rocas metamórficas y eruptivas (esquistos micáceos, gneises, granitos, anfibolitas, pegmatitas, etc.) se encuentran, principalmente, formando una faja de rumbo N-S que ocupa la parte central de la provincia de La Pampa, desde el límite con la provincia de Córdoba hasta el río Colorado. Los granitos también afloran en el Valle de Daza, junto con rocas esquistosas, en el centro y bordes de los salitrales. Las riolitas de diversas texturas y tonalidades son otra roca muy abundante en la subregión Pampa Seca, afloran en Lihué Calel (Grupo Sierra Pintada) asociadas con dacitas y riodacitas, en Puelén, Curacó, Utracán, y en forma de rodados en el cerro Las Piletas, Estancia La Candelaria y Puesto Córdoba (Berón 2006; Linares et al. 1980).

En cercanías de la desembocadura del río Salado o Curacó y sobre el río Colorado se intercalan, con rocas eruptivas, formaciones sedimentarias de calizas con nódulos de ftanita y venillas de sílice criptocristalina (formación San Jorge) y reducidos afloramientos de grauvacas y lutitas. Estas últimas, en algunos sectores se encuentran completamente silicificadas (formación Carapacha) e intruídas en algunos casos por riolitas y, en otros, por dacitas. Hacia el oeste, en los cerros Guanaco, Poleo y Bayo, afloran ortocuarcitas blancas. En mucha menor proporción se encuentran también psamitas y conglomerados oligomícticos con clastos de cuarcita y ftanita, intruidas en muchos casos por riolitas. En el sector sudoccidental se encuentran rocas calcáreas, psamíticas y pelíticas con sus capas superiores calcáreas fuertemente silicificadas. Presentan intercalaciones de yeso que, en el borde sur de la Salina 
Grande, se intercalan con bancos de dolomía blanca. Hacia el oeste se encuentran coladas de basaltos de 8-12m de espesor y afloramientos de chert localizados en la Meseta del Fresco. Esta última roca también ha sido en depósitos y afloramientos de tosca, a modo de vetas en la zona de El Carancho (Berón 2006). En el sur de la provincia, en inmediaciones del río Colorado y en la zona de Curacó, se encuentran afloramientos del Manto Tehuelche (Berón 2006; Linares et al. 1980; Martínez, Rabassa y Coronato 2009; Figura 4.5).

En el NE de Patagonia los afloramientos rocosos son escasos, encontrándose representadas básicamente dos formaciones geológicas, La Formación Río Negro y el Manto de Rodados Tehuelches o Patagónicos (Figura 4.5). La primera consiste en areniscas grises de edad Terciaria, en algunos casos cementadas por carbonato de calcio o procesos diagenéticos, con estratificación entrecruzada e intercalaciones de capas arcillosas y lentes de calizas. Aflora en los bordes de los relieves mesetiformes localizados entre los ríos Negro y Colorado con su límite norte definido por las barrancas australes de la depresión Chasicó-Salinas Chicas (De Ferraris 1979; Garcia y García 1964).

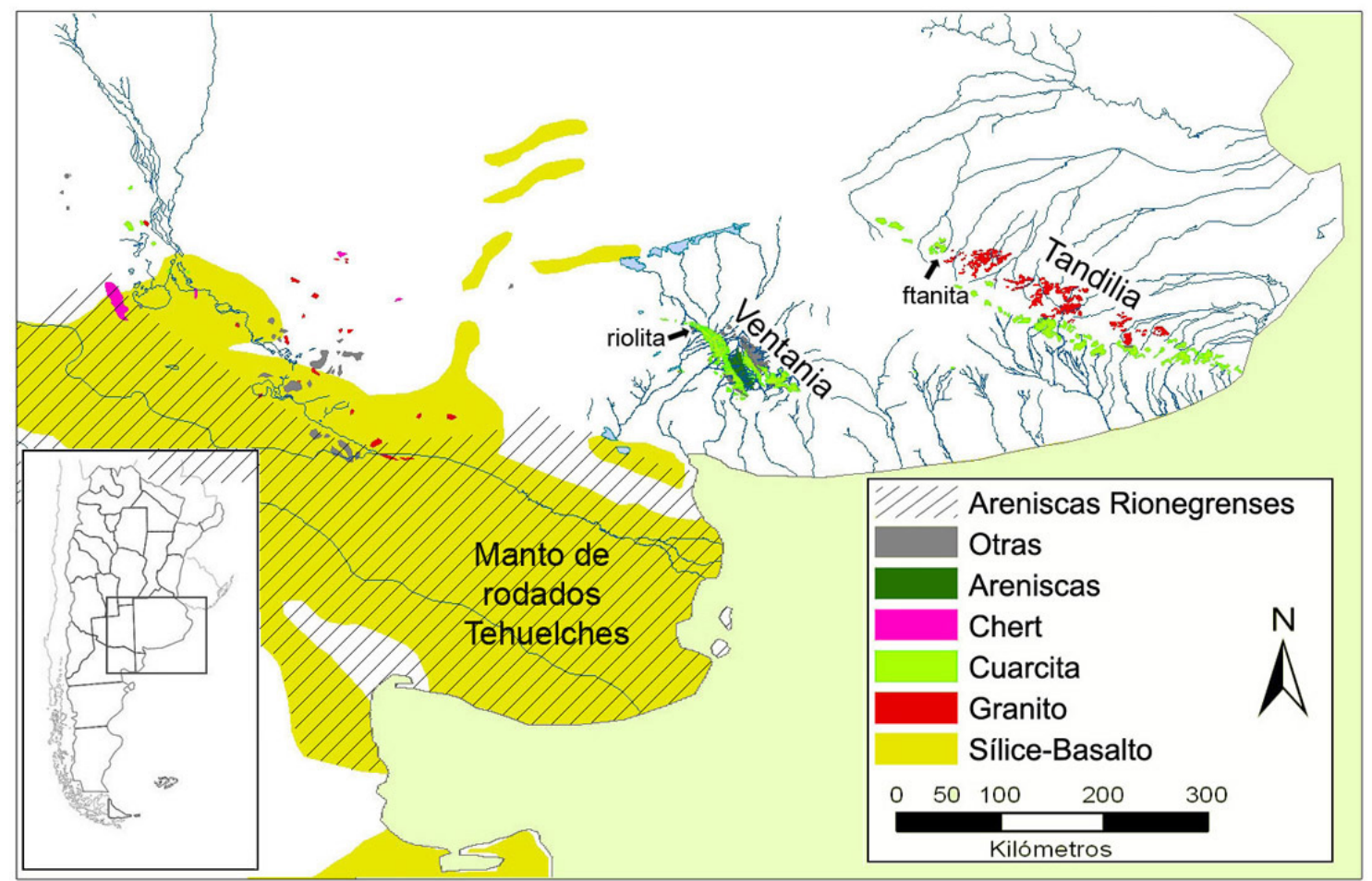

Figura 4.5. Distribución de las principales rocas en el centro-este de Argentina.

El Manto de Rodados Patagónicos o Tehuelches es un depósito de clastos gravosos, sustancialmente rodados, contenidos o recubiertos por una capa calcárea cementada, aunque en algunas ocasiones pueden encontrarse sueltos. Este manto corona, en diferentes niveles, a las mesetas, cubriendo a las areniscas rionegrenses. Esta formación ha sido objeto de múltiples estudios desde mediados del siglo XIX, proponiéndose diferentes denominaciones, edades, orígenes y ambientes de depositación (ver discusión en Martínez, Rabassa y Coronato 2009). Se trata de depósitos con una alta variación litológica, pero con cierto predominio de rocas volcánicas y plutónicas básicas y mesosiliceas y una menor proporción de calcedonias, cuarcitas, xilópalos, esquistos, cuarzos y otras rocas (Martínez, Rabassa y Coronato 2009). Estos depósitos forman mantos horizontales a subhorizontales de extensión y grosor variables, 
generalmente superior a los $20 \mathrm{~m}$, que disminuyen en espesor hacia el norte y el este, encontrándose los últimos remanentes en la depresión Chasicó-Salinas Chicas, en la provincia de Buenos Aires. El tamaño de los rodados también disminuye en este mismo sentido, pudiéndose encontrar en la zona de San Blas rodados con el tamaño de un huevo de avestruz (Bórmida 1962; Witte 1916), en tanto que en cercanías de la depresión Chasicó-Salinas Chicas no superan los $5 \mathrm{~cm}$ de diámetro. Fidalgo y Riggi $(1965,1970)$ clasifican a estos rodados en dos grandes grupos: aquellos con origen fluvial y de piedemonte (Rodados Patagónicos propiamente dichos), más antiguos y ubicados cubriendo las mesetas y piedemontes; y aquellos de menor edad, localizados dentro de valles o depresiones rodeando a las mesetas. Esta distinción es retomada por Bonomo y Prates (2009), quienes distinguen entre Rodados Patagónicos propiamente dichos y rodados fluviales, presentando los primeros dimensiones mayores. Particularmente en el valle del río Colorado, los depósitos de rodados son producto de la acción fluvial, localizándose en relación con paleocauces y zanjones (Martínez 2010).

\subsection{Las características ambientales de la cuenca del arroyo Chasicó y el área de Ventania}

El área de estudio propiamente dicha comprende la cuenca del arroyo Chasicó, un sistema endorreico que abarca una superficie total de $3764 \mathrm{~km}^{2}$, situado en los partidos bonaerenses de Saavedra, Puan, Tornquist y Villarino. Su desarrollo es NE-SO y sus límites hidrológicos son la cuenca del río Sauce Chico al este, la cuenca del arroyo Pigué al norte y una zona sin drenaje superficial al oeste y sur (Bonorino et al. 1989: 10). Sus nacientes se localizan en el Sistema Serrano de Ventania, en tanto que su desembocadura se ubica $120 \mathrm{~km}$ al sur de estas sierras, en la laguna Chasicó (Bonorino et al. 1989). Sobre la base de características hidrológicas, la cuenca puede segmentarse en tres porciones: la subcuenca superior, que comprende las nacientes hasta la laguna Los Chilenos; la subcuenca media, que abarca el sector de llanura desde la laguna Los Chilenos hasta la confluencia entre los arroyos Chasicó y Sanquilcó Grande, y la subcuenca inferior, que incluye el último tramo del arroyo Chasicó hasta la laguna Chasicó (Bonorino et al. 1989; Figura 4.6).

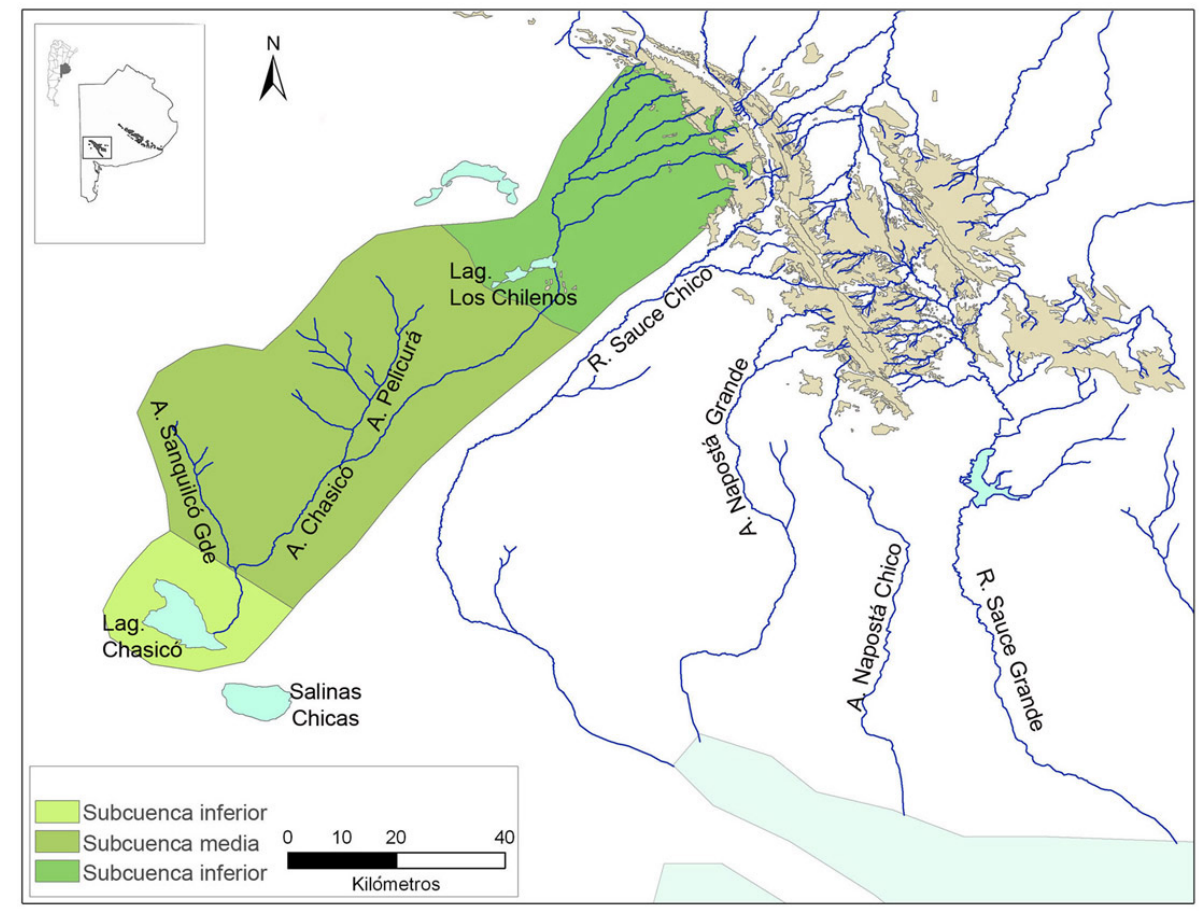

Figura 4.6. Área de estudio. Delimitación de la cuenca del arroyo Chasicó y sus subcuencas, modificado de Bonorino et al. (1989) 


\subsubsection{Clima}

La cuenca del arroyo Chació presenta un clima templado casi seco, con vientos predominantes del noroeste, norte y noreste, una temperatura máxima media que oscila entre $21.1^{\circ} \mathrm{C}$ y $23.7^{\circ} \mathrm{C}$ y temperaturas máximas absolutas que se encuentran entre $42,8^{\circ} \mathrm{C}$ y $44,7^{\circ} \mathrm{C}$. Las temperaturas mínimas medias oscilan entre 6.8 y $9.9^{\circ} \mathrm{C}$, en tanto las mínimas absolutas alcanzan $\operatorname{los}-6,6^{\circ} \mathrm{C}$ y $-7,8^{\circ} \mathrm{C}$. Las lluvias son escasas, entre 751.8 y $331 \mathrm{~mm} /$ año, disminuyendo gradualmente hacia el oeste y el sur, y distribuyéndose en un semestre lluvioso -octubre a marzo- y otro de pocas precipitaciones -abril a septiembre- (Bonorino et al. 1989; García y García 1964). Particularmente en la cuenca del arroyo Chasicó, la precipitación disminuye desde las cabeceras, con $800 \mathrm{~mm}$ anuales en la sierra de Curamalal, hacia la subcuenca inferior con $570 \mathrm{~mm}$ anuales en la laguna Chasicó (Bonorino et al. 1989). En la subcuenca superior, el clima es sub-húmedo con nula deficiencia de agua y un $45 \%$ de evapotranspiración anual concentrada en verano. Las lluvias más bajas se registran en los meses invernales, en tanto que durante los meses de enero, marzo y septiembre, los valores de precipitación son elevados. En la subcuenca inferior, por otra parte, el clima es sub-húmedo seco con nulo exceso de agua y un $46 \%$ de la evapotranspiración anual concentrada en la estación estival, con diferencias en precipitación entre la estación invernal y el resto del año menos evidentes que en la subcuenca superior (Bonorino et al. 1989; García y García 1964).

\subsubsection{Hidrografía}

La cuenca del arroyo Chasicó consiste en un área sin desagüe atlántico, cuyo nivel de base se encuentra a unos -20 msnm en la laguna de Chasicó, donde desaguan la zona sudoeste de la sierra de Curamalal y parte del flanco noreste de la misma y noroeste de la sierra de Bravard (Bonorino et al. 1989; Harrington 1947). En la porción superior de la cuenca del arroyo Chasicó, el drenaje se encauza a través de dos colectores principales: los arroyos Cochenleufú Grande y Chico. Este último recibe, además, los aportes de los arroyos Alfalfa y Agua Blanca; encontrándose a su vez, entre los arroyos Cochenleufú Chico y Agua Blanca, el arroyo Saudades, un pequeño curso que se pierde en la llanura por infiltración y evaporación. Los dos colectores principales confluyen para desembocar como un curso único en la laguna Los Chilenos (Figura 4.7). En esta laguna nace el arroyo Chasicó, que recibe en el sector medio de la cuenca, sobre su margen derecha, primero la afluencia del arroyo Pelicurá que cuenta con el aporte de otros dos cursos intermitentes y $15 \mathrm{~km}$ aproximadamente aguas arriba de su desembocadura en la laguna Chasicó, el aporte del arroyo Sanquilcó Grande, un curso con bajo caudal de agua (Figura 4.8) (Bonorino et al. 1989; García y García 1967). Estos arroyos han labrado sus cauces en sedimentos terciarios correspondientes a la formación Chasicó y puede observarse la presencia de pequeñas cascadas, principalmente en el cauce medio, e indicios de antiguas lagunas a veces anteriores a la formación del cauce (García y García 1967). 


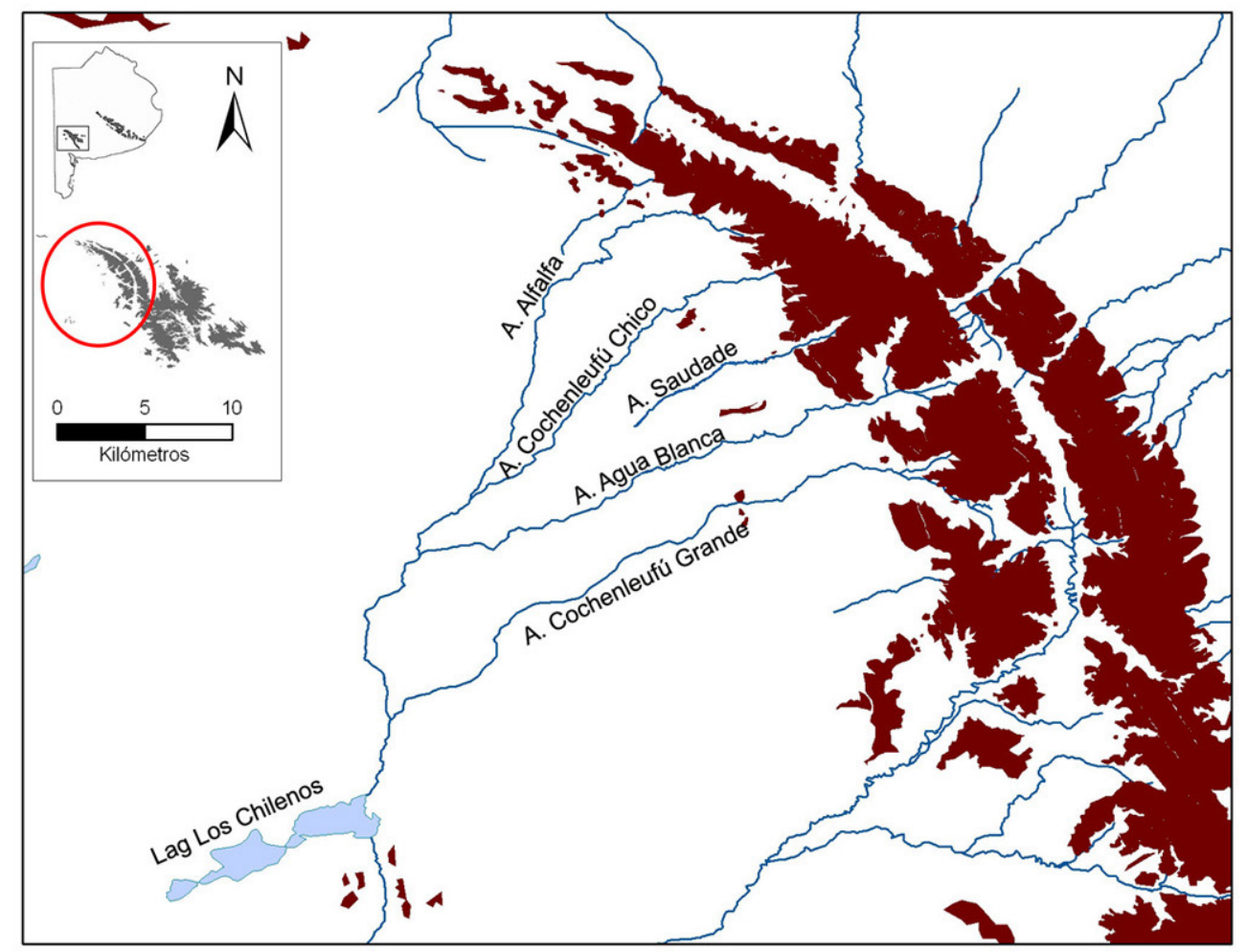

Figura 4.7. Hidrografía de la cuenca superior del arroyo Chasicó.

La laguna Chasicó se localiza unos $120 \mathrm{~km}$ al sur del Sistema Serrano de Ventania, dentro de una depresión alargada y de fondo plano que se extiende desde la provincia de La Pampa hasta la costa Atlántica, con un nivel de base de $-20 \mathrm{msnm}$ que permite la captación del escurrimiento superficial circundante (García y García 1967). Esta laguna se diferencia de las demás lagunas pampeanas por su origen geomorfológico combinado tectónico-eólico, una profundidad mayor que la media de otras lagunas y la ausencia de macrófitas (plantas acuáticas) producto de su alta salinidad (Volpedo y Cirelli 2013). Por otro lado, la laguna Chasicó se ha visto afectada por grandes variaciones en su superficie, la que aumentó desde $31 \mathrm{~km}^{2}$ en la década de 1960, momento en que presentaba condiciones de salina, a $85 \mathrm{~km}^{2}$ entre 2003-2004, disminuyendo en la actualidad a 50,3 $\mathrm{km}^{2}$, consecuencia de períodos de inundación y sequía (Remes Lenicov y Colautti 2003; Volpedo y Cirelli 2013). A menos de $15 \mathrm{~km}$ al oeste de esta laguna, y compartiendo la misma depresión estructural, se encuentran las Salinas Chicas, actualmente explotadas para la obtención de cloruro de sodio. Estas presentan una cota de $-42 \mathrm{msnm}$ y una superficie de $36 \mathrm{~km}^{2}$. Se trata de salinas de cosecha en las que la sal se encuentra disponible, principalmente, durante la estación estival, cuando la costra temporaria que constituye la capa explotable tiene un espesor variable de 1 a $3 \mathrm{~cm}$. En los meses invernales, en cambio, la superficie se cubre con 20 a $30 \mathrm{~cm}$ de salmuera color rosado (Mogni 1991; Schalamuk et al. 1999).

Bonorino et al. (1989) diferencian dos estadios en el comportamiento hidrológico de la cuenca, uno cuando el sistema se encuentra totalmente integrado, lo que posibilita que los excedentes hídricos de la subcuenca superior sean transferidos, a través del arroyo Chasicó, hacia la laguna homónima. El segundo estadio se inicia cuando la laguna Los Chilenos adquiere capacidad de almacenamiento y actúa 
como un embalse natural, por lo que el caudal con que el arroyo ingresa a la laguna Chasicó resulta de la suma del aporte de sus afluentes y de la descarga subterránea que recibe a lo largo de su trayecto. En años húmedos o secos uno de los estadios predominará sobre el otro. Durante el primero de los estadios el principal aporte lo constituye el escurrimiento superficial (50\% del total frente al $33 \%$ que provino de la precipitación directa sobre la laguna y $17 \%$ del escurrimiento subterráneo local). En el segundo estadio el principal ingreso de agua a la laguna se dio por precipitación directa $(50 \%$, en tanto el escurrimiento superficial representa $26 \%$ y el subterráneo $24 \%$ ).

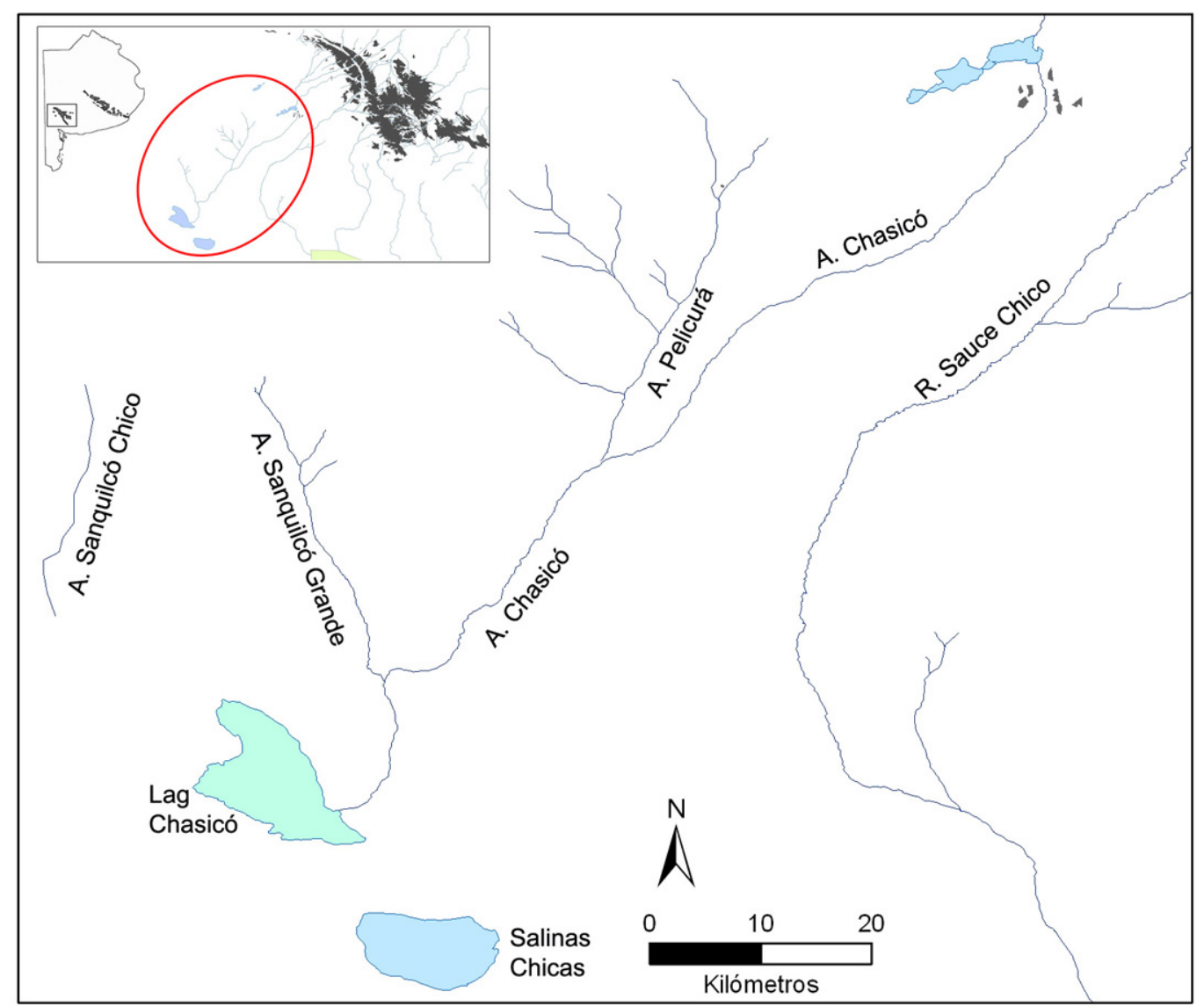

Figura 4.8. Hidrografía de las cuencas media e inferior del arroyo Chasicó.

\subsubsection{Geomorfología y estratigrafia}

La cuenca del arroyo Chasicó se desarrolla en un área con marcadas diferencias topográficas. Considerando estas variaciones y sobre la base de la caracterización regional de González Uriarte (1984), Bonorino et al. (1989) distinguen tres grandes unidades (Figura 4.9):

A- Dominio del positivo de Ventania: comprende la sierra de Curamalal, cuyas alturas máximas constituyen una divisoria de aguas superficiales que da origen a una serie de arroyos que fluyen hacia la laguna Los Chilenos.

B- Nivel de planación general: se extiende con pendiente regional hacia el sur, desde el pie de la sierra hasta la escarpa de erosión. Se reconocen dos unidades subordinadas: 1- El piedemonte, demarcado a partir del cambio de gradiente topográfico y la pérdida por infiltración de algunos 
cursos de agua (e.g. arroyo Saudade) a unos $8 \mathrm{~km}$ de Ventania. Se ubica aproximadamente entre los 350 y $400 \mathrm{msnm}$; 2- La llanura periserrana, caracterizada por la presencia de una capa de tosca rematando los sedimentos pampeanos.

C- Paleovalle poligénico: depresión que forma parte de un gran alineamiento regional con orientación ESE-ONO.

Las diferentes subcuencas y unidades topográficas mencionadas, no sólo presentan variaciones en cuanto a sus características topográficas, sino también una distribución heterogénea de los recursos bióticos y en cuanto a la disponibilidad y calidad de los recursos líticos, ya que si bien estos últimos se encuentran presentes a lo largo de toda la cuenca, la abundancia, predictibilidad y variabilidad de materias primas líticas es diferente en los distintos sectores.

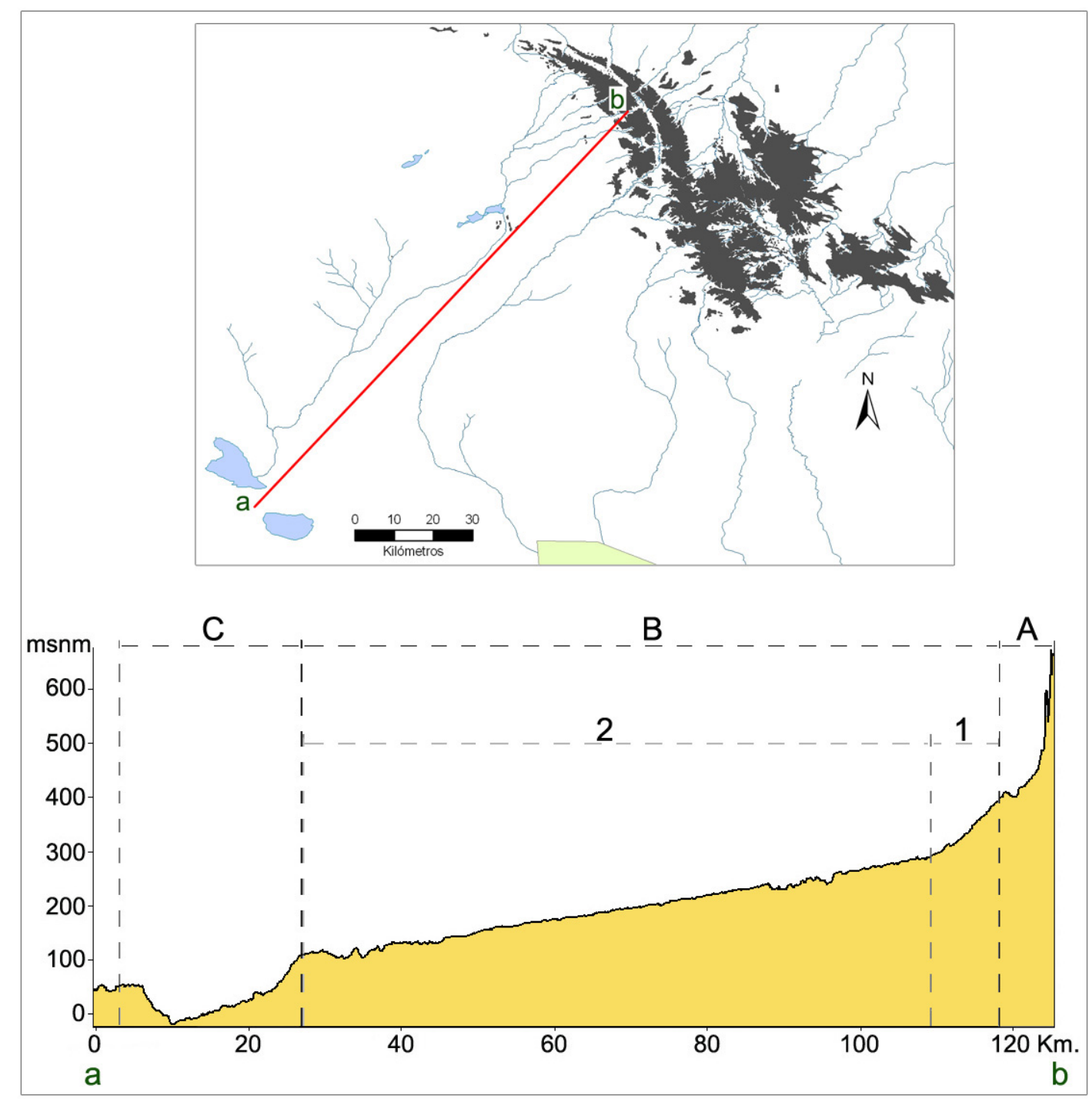

Figura 4.9. Perfil longitudinal de la cuenca del arroyo Chasicó con la demarcación de las subunidades determinadas por Bonorino et al. (1989). Las letras a y b del perfil se corresponden con las letras a y b en el mapa, indicando los puntos extremos de la transecta representada. Las letras mayúsculas y los números corresponden a los indicados en el texto. 


\subsubsection{Las Sierras de Ventania y el piedemonte}

El Sistema Serrano de Ventania forma un conjunto de elevaciones alargado en sentido NO-SE, cuyo núcleo central comprende unos $180 \mathrm{~km}$ de longitud por un ancho máximo de $60 \mathrm{~km}$, encontrándose a su vez afloramientos aislados en la llanura adyacente al sudoeste del mismo. Sus alturas sobrepasan los $1000 \mathrm{msnm}$ en el sector occidental y son drenadas por múltiples ríos y arroyos que presentan, en su lecho, numerosos rodados principalmente cuarcíticos. Pueden distinguirse dos sectores diferenciados morfológica, estratigráfica y tectónicamente: el oriental, con un relieve suave y redondeado formado por las sierras de Las Tunas y Pillahuincó (Harrington 1947, 1972); y el occidental, caracterizado por cordones bien definidos con laderas empinadas surcadas por profundos y angostos valles transversales, el cual comprende las sierras de Puan, Curamalal, Bravard y la Ventana. El relieve en los cerros de los cordones Bravard y Curamalal se caracteriza por presentar pendientes occidentales siempre algo más abruptas que las orientales, como consecuencia de un drenaje predominantemente lineal en oposición al dendrítico característico de estas últimas (Harrington 1947).

Petrológicamente, el Sistema de Ventania consiste en una cuenca sedimentaria rellenada entre el Paleozoico inferior y superior y deformada en condiciones de moderada presión y temperatura, cuya intensidad decrece de oeste a este (Sellés-Martínez 2001). Se encuentra formado principalmente por rocas sedimentarias paleozoicas, entre las cuales las más abundantes son las cuarciticas de diferentes granulometrías, las areniscas y las limolitas. También se encuentran algunos granitos y pórfidos cuarcíferos (riolitas) que corresponderían al Precámbrico, en el pie occidental de las sierras (Harrington 1947, 1972; Schiller 1930; Suero 1972). Las rocas paleozoicas han sido descriptas por Harrington (1947, 1970, 1972) y posteriormente por Suero (1972) como conformadas por tres grupos geológicos: Curamalal, Ventana y Pillahuincó, cada uno compuesto por cuatro formaciones geológicas (Figura 4.10):

a) Grupo Curamalal: abarca los cerros de Puan, Gran Chaco y sierra de Curamalal, entre otros. Se encuentra conformado por:

-Formación La Lola: Conglomerado de metacuarcitas en tonos rosa a rojizo junto a otras rocas como pizarras y riolitas.

-Formación Mascota: Areniscas cuarcíticas u ortocuarcitas de grano fino a muy fino muy homogéneas, color flor de durazno hasta blanquecino o amarillo con brillo vítreo. Presentan a menudo fractura concoidal.

-Formación Trocadero: Areniscas cuarcíticas u ortocuarcitas de grano fino a medio, cemento silíceo parcialmente ferruginoso y brillo vítreo. Colores gris y rosado hasta lila, en algunas ocasiones rojizas o amarillentas.

-Formación Hinojo: Areniscas cuarcíticas u ortocuarcitas de grano fino a medio, de color gris oscuro, plomizo o levemente morado, con las que se asocian bancos de color amarillento claro y rosado rojizo.

b) Grupo Ventana: Superior al Curamalal, forma la sierra de Bravard, de la Ventana y elevaciones menores hasta el río Sauce Grande.

-Formación Bravard: Areniscas de grano grueso a conglomerádico de color rojo ladrillo, rosado y amarillento. 
-Formación Napostá: Areniscas cuarcíticas u ortocuarcitas de grano fino a muy fino, color blanco lechoso hasta rosado, brillo vítreo y fractura subconcoidal.

-Formación Providencia: Ortocuarcitas de grano fino, color originario gris blanquecino pero pigmentadas por óxido de hierro con tonalidades desde el rojo ladrillo intenso hasta el rosado.

-Formación Lolén: areniscas micáceas esquistosas de color pardo amarillento a verdoso.

c) Grupo Pillahuincó: Sierras de Las Tunas y Pillahuincó

-Formación Sauce Grande: Gruesos conglomerados con intercalaciones espesas de ortocuarcitas idénticas a las de la Formación Bonete.

-Formación Piedra Azul: Pizarras azul negruzcas y areniscas de grano grueso sobrepuestas por sedimentos arcilloso arenosos gris azulados oscuros.

-Formación Bonete: areniscas cuarcíticas u ortocuarcitas verdosas y azuladas moteadas de blanco junto a sedimentos arenoso-arcillosos de colores oscuros.

-Formación Tunas: areniscas de grano grueso color pardo claro hasta limolitas moradas con manchas verdes o verdes con manchas moradas, pasando por limolitas tenaces y macizas con fractura concoidal de color verde nilo.

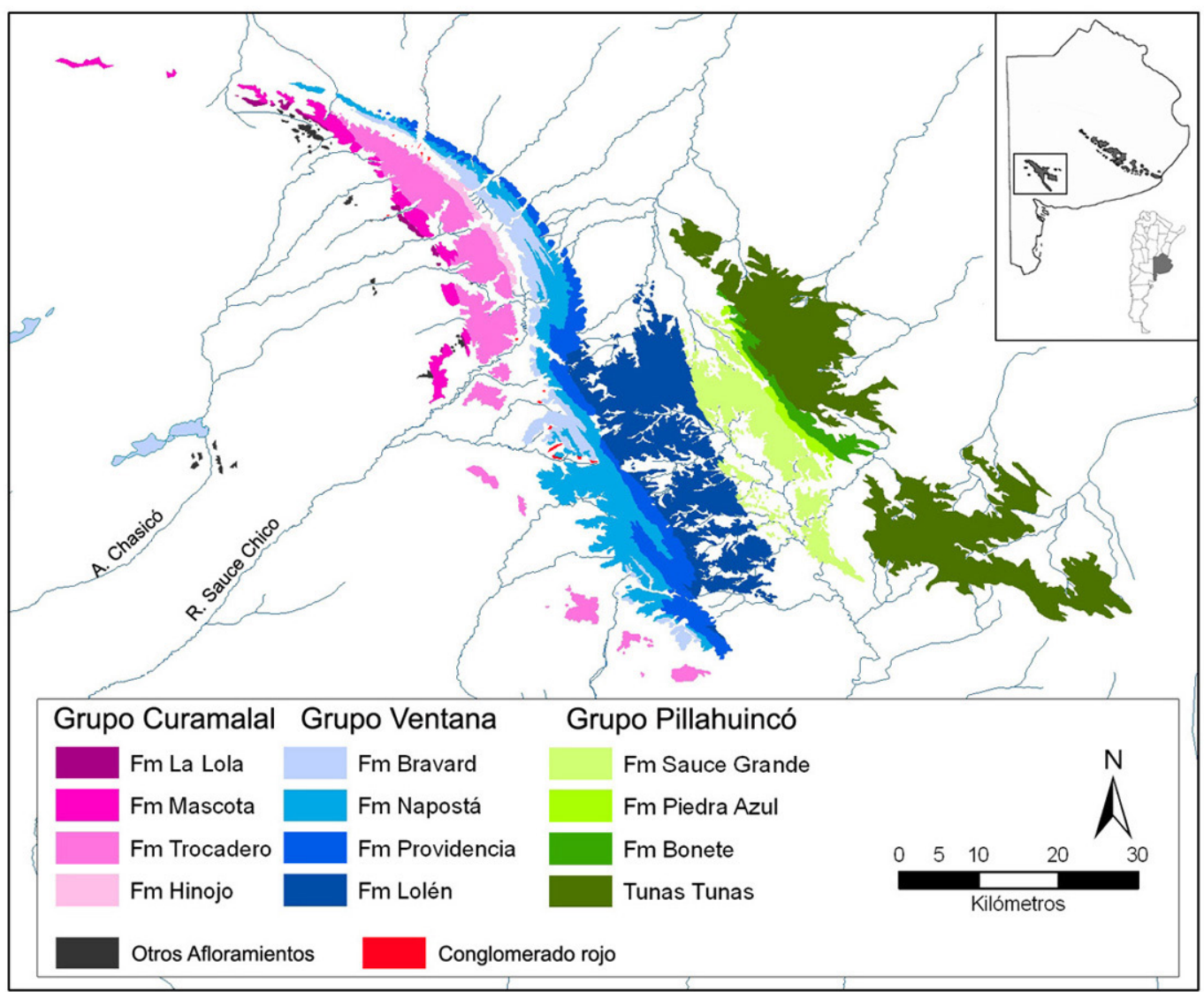

Figura 4.10. Formaciones geológicas del Sistema Serrano de Ventania, modificado de Harrington (1947) y Suero (1972). Se presentan en detalle únicamente aquellas de origen sedimentario. 
En el sector suroccidental de la sierra de Curamalal se encuentran 12 afloramientos de pórfidos cuarcíferos (Harrington 1947) o rocas riolíticas (Cingolani y Varela 1973), distribuidos en un área de $45 \mathrm{~km}^{2}$. Éstos componen dos grupos de afloramientos, el primero en la zona de La Mascota, en inmediaciones del abra de Saavedra y el segundo en el cerro La Ermita, a unos $6 \mathrm{~km}$ al este de la localidad de Saavedra (Figura 4.11). Se trata de rocas de textura porfírica, con escasos fenocristales de cuarzo y feldespato en una pasta afanítica rojiza, en partes amarillenta incluyendo tonalidades violáceas y con bandas casi negras (Harrington 1947; Kilmurray 1968; Oliva y Moirano 1997). En este sector afloran, también, granitos de color rosado hasta rojizo y de grano mediano a grueso, en las lomas de la cantera Aguas Blancas, entre el arroyo Cochenleufú Grande y la localidad de Dufaur, y en el pie occidental del cerro del Chaco (Figura 4.11) (Harrington 1947).

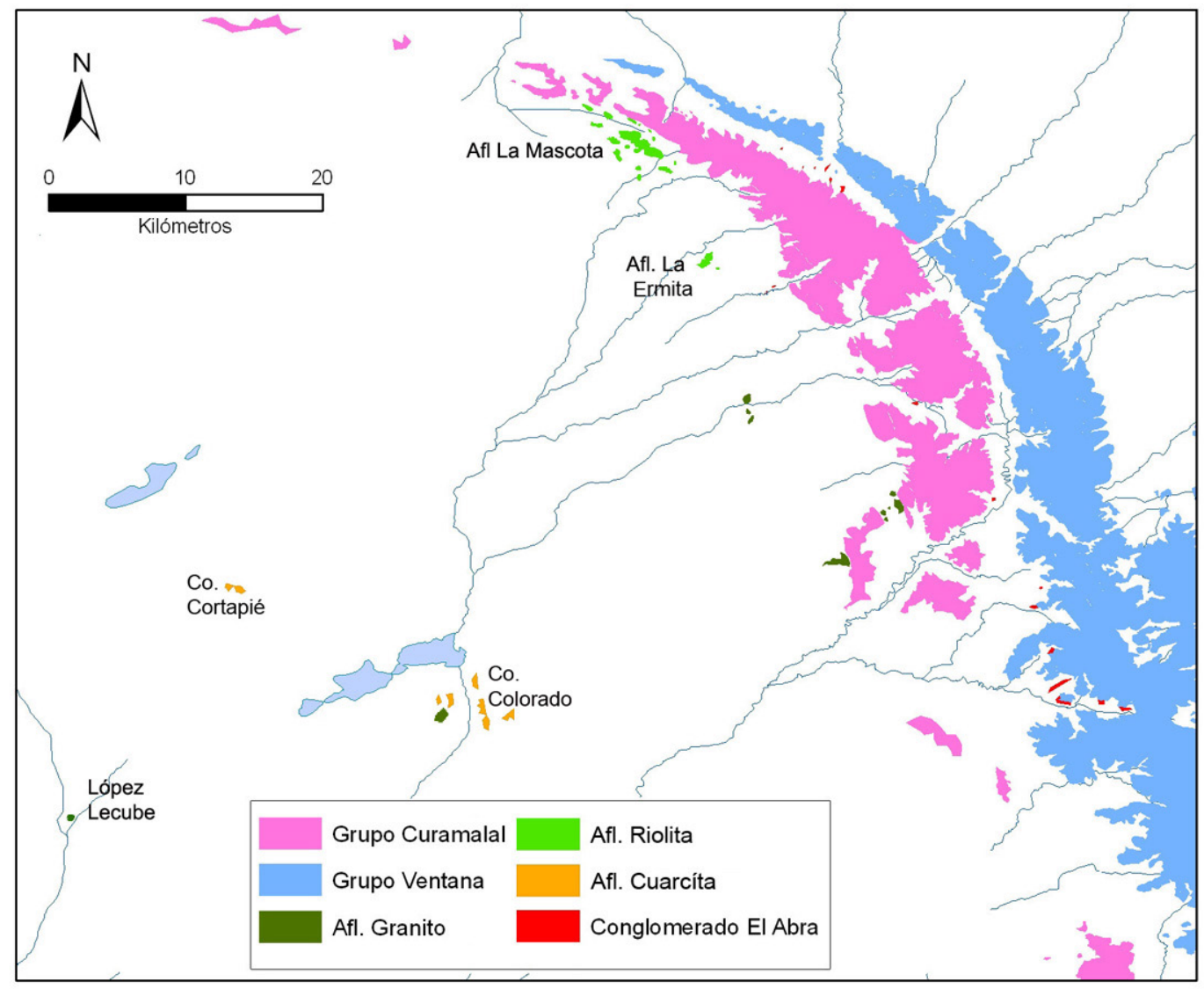

Figura 4.11. Formaciones geológicas del sector occidental del Sistema Serrano de Ventania, modificado de Harrington (1947) y Suero (1972).

En el sector de piedemonte se encuentran depósitos sedimentarios relictuales, consistentes en brechas y conglomerados correspondientes a lo que ha sido denominado como "Conglomerado rojo" (Harrington 1936, 1947; Keidel 1916; Schiller 1930), "Conglomerado El Abra" (Harrington 1980) o "Brecha Cerro Colorado" (Andreis et al. 1971). Se trata de pequeños restos de un depósito grueso, de hasta $35 \mathrm{~m}$ de espesor, que a menudo tiene estructura de brecha, pero también a veces de conglomerado, de color rojo ladrillo o rojo pardo y, en algunos casos, gris rosado y gris amarillento. La forma y tamaño de los bloques, cantos rodados y trozos angulosos de acarreo que incluye el conglomerado, varían entre los distintos remanentes y también en los diferentes bancos de un mismo afloramiento. Generalmente 
son clastos angulosos o subangulosos, con tamaños que oscilan entre partículas pequeñas de unos pocos centímetros, hasta bloques de dos y tres metros, pero donde el tamaño dominante se encuentra entre los 40 centímetros y 1,60 metros. Estos clastos están compuestos por rocas que se encuentran en los alrededores, mayormente cuarcitas provenientes de los grupos Curamalal o Ventana., envueltas en una matriz arenosa gruesa por lo general cementada con ópalo y sesquióxidos de hierro, lo que le da una gran dureza y una coloración rojiza. Los remanentes del conglomerado se hallan dispersos en diferentes lugares de las faldas de las sierras más elevadas, flancos de las sierras de Curamalal, Bravard, Chaco y Ventana, en asociación estrecha con la superficie de $450 \mathrm{~m}$ (Zárate et al. 1995), pero estando ausentes en las sierras de las Tunas y Pillahuincó. Generalmente se localizan en el frente de pequeños valles que drenan las sierras y consisten en abanicos o depósitos de pendiente, cuya edad fue considerada tradicionalmente miocénica y, más recientemente, reinterpretada como cretácica (Harrington 1936; Zárate et al. 1995, 1998).

\subsubsection{La llanura y los bajos de Chasicó}

Hacia el sudoeste de la sierra se extiende una llanura interrumpida bruscamente por una depresión alargada y de fondo plano que se extiende desde los $64^{\circ} 29^{\circ}$ de longitud Oeste (Provincia de La Pampa) hasta la costa atlántica (García y García 1964). Esta zona comprende el ambiente de llanura adyacente, caracterizado por presentar un relieve suavemente ondulado en algunos lugares y casi horizontal en otros, cubierto de mantos medanosos que se encuentran interrumpidos únicamente por pequeños afloramientos aislados, con alturas que no superan los $50 \mathrm{~m}$ con respecto a la llanura circundante, conformados por rocas cuarcíticas -cerro Cortapié y Chasicó-, y por rocas graníticas de características similares a los que afloran en cercanía de las sierras -cerros Colorado y López Lecube-. En este sector el arroyo Chasicó recibe, sobre su margen derecha la afluencia del arroyo Pelicurá y $15 \mathrm{~km}$ aguas arriba de su desembocadura, en la laguna homónima, del arroyo Sanquilcó Grande.

En las cabeceras de los ríos y arroyos que drenan el Sistema Serrano de Ventania y en gran parte de la llanura adyacente, se han descripto depósitos conglomerádicos y arenosos finos. Sobre el sustrato paleozoico. Furque (1973) reconoce las formaciones Saldungaray y La Toma, correspondientes al Plioceno y Pleistoceno respectivamente, sobre las cuales se desarrolla el relieve actual siguiendo, en término generales, el paisaje elaborado a partir del Pleistoceno superior. Durante el Pleistoceno y Holoceno, se depositan, en las divisorias de aguas, sedimentos principalmente eólicos, confacies de remoción en masa y, en los valles fluviales, sedimentos aluviales y coluviales. En las divisorias, la secuencia se inicia con la depositación de la formación Saavedra, compuesta por un miembro Inferior conformado por arenas finas castaño claro que pasan lateralmente a limos arenosos castaños sin estratificación, y un miembro Medio, compuesto por arenas finas a limos arenosos castaño claro a castaño rojizo de origen eólico, sin estratificación. Ambos miembros corresponden al Pleistoceno superior. Sobre éstos se depositan las arenas finas y limos arenosos castaño claro a castaño amarillento, masivos y de origen eólico del miembro Superior de la formación Saavedra, asignado al Holoceno temprano. Asimismo, se encuentran las arenas finas y limos arenosos, grises y castaños, masivos y de origen eólico, que conforman la formación Matadero Saldungaray, depositados durante el Holoceno tardío (Rabassa 1989). 
Por otra parte, en los valles fluviales, la columna estratigráfica comienza con la depositación de los sedimentos arenosos limosos, de la Formación Agua Blanca. Esta formación fue subdividida en: 1- Miembro Psefítico inferior, compuesto por conglomerados arenosos a arenas gruesas castaño rojizas, bien estratificados con guijarros bien redondeados de rocas paleozoicas, depositados durante el Pleistoceno superior; 2- Miembro Arenoso Medio, comparable al miembro Guerrero de la Formación Lujan, conformado por arena fina a limo pardo rojizo de aspecto masivo, que culmina, en el arroyo Napostá Grande, con un paleosuelo correlacionable con el suelo Puesto Callejón Viejo; 3- Miembro Limo Arenoso Superior, compuesto de sedimentos limo-arcillosos gris claro con laminación, bioturbación y gran cantidad de gasterópodos (Littoridona, Biomphalaria, Lymnaea, Chilina) que se correlaciona con el Miembro Rio Salado de la Formación Lujan. La base se asigna de este miembro fue asignada al Holoceno temprano, y sobre esta se depositan los sedimentos arenosos muy finos pardo-grisáceos, del Miembro Superior de la Formación Saavedra, de origen eólico y en el que se encuentra la mayor diversidad de especies de la secuencia (Lestodelphys halli, Holochilus brasilensis, Ozotoceros bezoarticus, Lama guanicoe, Lycalopex gymnocercus) (Deschamps y Tonni 1992; Rabassa 1989).

Finalmente se depositan los limos de planicie de inundación de la Formación Chacra La Blanqueada, de color pardo claro a pardo grisáceo y los sedimentos eólicos de la Formación Matadero Saldungaray (De Francesco 1970; Deschamps y Tonni 1992; Quattrocchio et al. 1988; Rabassa 1989). Zárate y Blasi (1993) consideran que dado el tamaño de las partículas que conforman los depósitos eólicos de la secuencia sedimentaria Pleistoceno-Holoceno del sudeste de la Provincia de Buenos Aires, éstas no podrían haber sido transportadas por distancias mayores a los $200 \mathrm{~km}$. Por tal motivo, proponen que se habría dado un transporte fluvial, a través de los ríos Negro y Colorado, de material vulcanoclástico desde el piedemonte de los andes y el norte de la Patagonia extraandina, su depositación en las planicies de inundación distales de estos ríos y su posterior transporte eólico por suspensión corta y saltación desde las planicies de inundación hacia la provincia de Buenos Aires. A este transporte indirecto a través de tormentas de polvo, se le agrega el aporte directo de cenizas volcánicas transportadas por suspensión (Zárate y Blasi 1993).

En el curso inferior de los arroyos Chasicó y en el Sanquilcó Grande, se encuentra representada la formación Chasicó, asignada al Plioceno inferior. Se trata de limos arenosos o arenas limosas de color castaño rojizo a castaño amarillento de aspecto masivo, carente de estratificación que afloran en la zona de influencia del cauce inferior del arroyo Chasicó, la laguna homónima y las Salinas Chicas, con espesor de 3 o $4 \mathrm{~m}$ que a veces alcanza los $6 \mathrm{~m}$. A veces presenta concentraciones psefíticas intercaladas con clastos mayores muy angulosos que escasamente superan los 2 o $3 \mathrm{~cm}$ de diámetro, al norte y este de cuarcitas blancas y rosadas de Ventania, y al Oeste y sur de rocas volcánicas. Subdividen esta formación en: 1Miembro Vivero, en el sector inferior de la formación, conformado por limos con cantidades subordinadas de arena y arcilla; 2- Miembro Las Barrancas, por sobre el primero, conformado por una fracción arena con menor frecuencia de limo y arcilla. En discordancia de erosión se deposita la Formación Los Salitrales y la Formación Río Negro, la primera conformada por sedimentos limo-arcillosos principalmente lacustres, de edad Plioceno, muy bien estratificados a masivos de color amarillento verdoso a castaño que en oportunidades se intercala con sedimentos de la formación Río Negro, conformada por areniscas y arenas grises y azules, poco compactadas y a veces cementadas parcialmente por carbonato de calcio, sobre todo en los niveles más superficiales (Fidalgo et al. 1978, 1987). 
Durante el Pleistoceno se produce la depositación de la formación Salinas Chicas, conformada por gravas arenosas con fuerte impregnación de carbonato de calcio, que quizá constituyen remanentes septentrionales de los rodados Tehuelches, integrados por rocas volcánicas, esencialmente basaltos y tobas. Durante el Pleistoceno también se depositan, al norte de la laguna Chasicó, el Conglomerado Bajada de los Toros, compuesto por gravas arenosas algo cementadas, donde los clastos mayores corresponden a cuarcitas procedentes de Ventania, que se habrían depositado en condiciones topográficas similares a las actuales. Posteriormente se habría depositado la Grava Arenosa y Limo Sanquilcó, consistentes en sedimentos fluviales de distinta granulometría en los valles actuales y sedimentos finos (arenas, limos y arcillas) en las depresiones mayores. En parte contemporáneamente, habría comenzado la depositación de sedimentos eólicos denominados como Formación Estancia La Aurora, los que continuaron depositándose casi hasta la actualidad (Fidalgo et al. 1978, 1987).

En el sector inferior, el cauce del arroyo se convierte en un valle encajonado, en el que se encuentran, frecuentemente, saltos o cascadas que raramente sobrepasan el metro de altura. El arroyo desemboca en la laguna Chasicó, localizada en una depresión regional (o valle pampeano-bonaerense sensu Melo et al. 2003) de relieve suave delimitada por alturas que apenas superan los $100 \mathrm{msnm}$ y cuya cota mínima es de -40 msnm en las Salinas Chicas. Esta depresión posee rumbo noroeste sureste, con un ancho superficial promedio que oscila entre 6 y $10 \mathrm{~km}$ y un ancho máximo que alcanza los $20 \mathrm{~km}$ en el límite Buenos Aires La Pampa, nace en inmediaciones de las sierras de Lihué Calel, encontrándose como accidentes más notables, de oeste a este, la laguna Colorada Grande, la laguna Chasicó, las Salinas Chicas, y el Salitral de la Vidriera. Dentro de la depresión de encuentran dos fajas medanosas principales conectadas entre si, la primera se extiende desde la estancia Dos Chañares (La Pampa) hasta la localidad de Ombucta (Buenos Aires), está limitada al norte por la estepa graminosa del oeste de la provincia de Buenos Aires y sudeste de La Pampa y en el sur por los relieves mesetiformes. Esta faja en la zona limítrofe La Pampa-Buenos Aires se divide en dos ramas que bordean la meseta que separa la laguna Colorada Grande de la laguna Blanca Grande. La segunda faja de médanos se extiende desde el sur de Salinas Grandes, de Gaviotas hasta la zona costera. El ancho medio es de $10 \mathrm{~km}$. En esta faja se pueden distinguir médanos vivos, médanos semifijos y médanos fijos (García y García 1964; Melo et al. 2003). Hacia el sur de esta depresión o valle se encuentran otros dos grupo de valles pampeano-bonaerenses con una distribución paralela a subparalela y separados entre sí por cerros mesa con alturas máximas de $150 \mathrm{~m}$. El primero de estos grupo se origina en la confluencia de los ríos Colorado y Salado, conectando el salitral Negro, y la laguna Callaquéo, finalizando en la depresión Chasicó-Salinas Chicas, en tanto el segundo grupo se encuentra un poco más al sur, vinculado directamente con el río Colorado (Melo et al. 2003)

\subsubsection{Fitogeografia}

En el sur de la Región Pampeana y norte de Patagonia, la distribución de la vegetación está principalmente relacionada con el gradiente de precipitación y particularmente con el balance hídrico. La transición entre la estepa pampeana y el bosque xerófilo del espinal, con árboles de Prosopis y cobertura graminosa, se desarrolla al sudoeste de Bahía Blanca hasta el río Colorado, en tanto los matorrales xerofíticos del Monte, dominados por arbustos del género Larrea, se extienden en las tierras áridas del NE de Patagonia y forman una transición con el Espinal entre los ríos Colorado y Negro. En este 
marco, la cuenca del arroyo Chasicó comprende la actual transición entre las provincias fitogeográficas Pampeana y del Espinal (figuras 4.12 y 4.13 ).

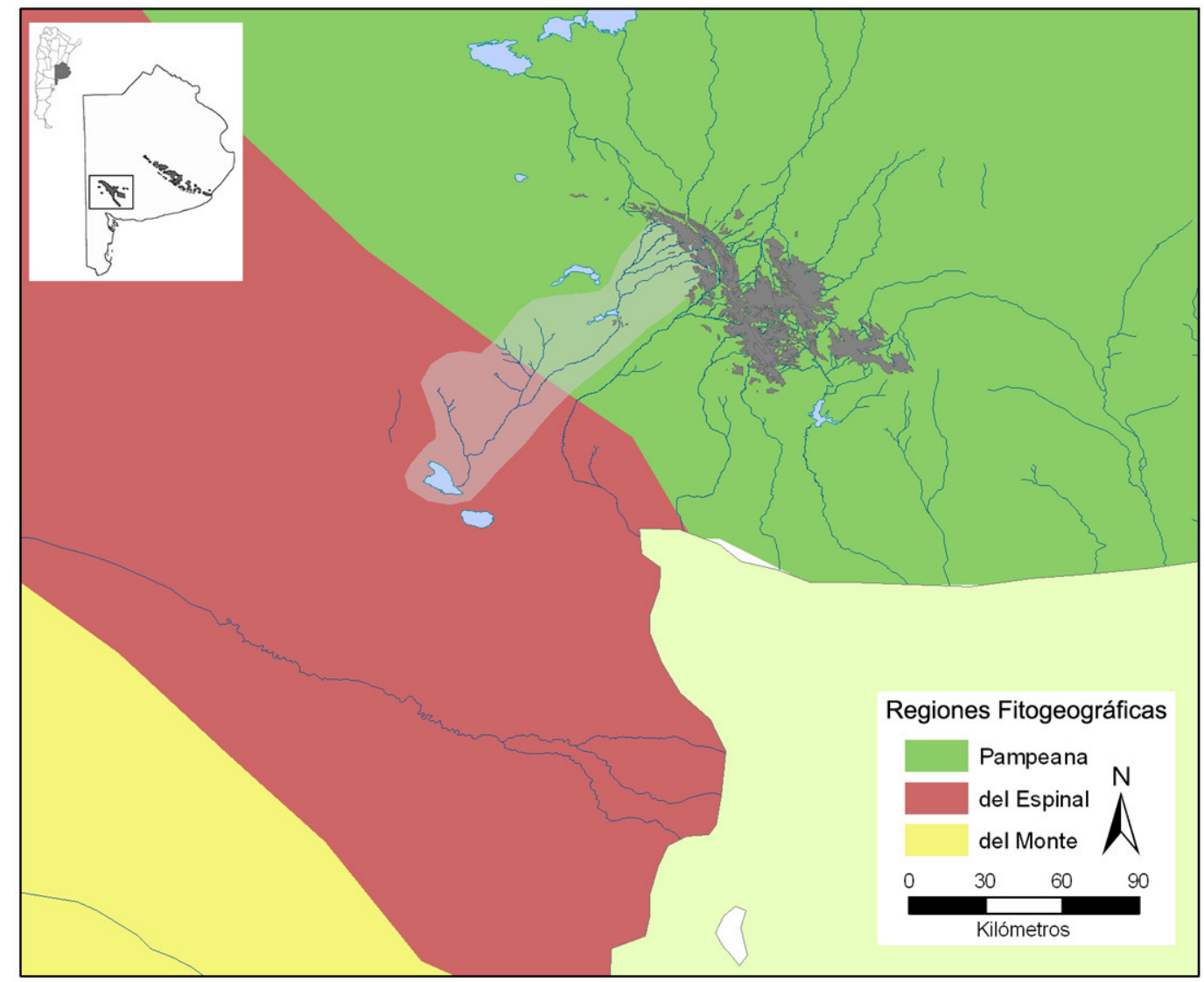

Figura 4.12. Distribución de las regiones fitogeográficas en el sudeste de la región Pampeana y Noreste de la región Patagónica. Modificado de Cabrera (1971).

La vegetación dominante en el Sistema Serrano de Ventania es la de la Provincia Pampeana, Distrito Pampeano Austral, que se extiende desde las sierras de Tandilia hasta cerca de Bahía Blanca, siendo el distrito más frío y seco de la Provincia Pampeana. Consiste en una estepa de gramíneas cespitosas, donde la comunidad climax es el flechillar constituido por numerosas especies de Stipa y Piptochaetium (e.g. Stipa clarazzi, Stipa Trichotoma, Stipa tenuis, Piptochaetium napostaense, Piptochaetium lejopodum y Poa ligularis), y arbustos y subarbustos como la brusquilla (Discaria longispina), ojo de perdiz (Margyricarpus pinnatus) y yerba de la oveja (Baccharis ulicina), sin árboles nativos, aunque se hallan en las orillas de ríos y arroyos de las inmediaciones de Ventania ejemplares de Salix Humboldiana (Cabrera 1971). Se encuentran, a su vez, estepas de paja vizcachera (Stipa caudata), pajonales de paja colorada (Papalum quadrifarium) en suelos mas húmedos y, en las sierras, matorrales de curro (Colletia paradoxa), de chilca (Dodonaea viscosa), de Baccharis tandilensis y de brusquilla (Discaria longispina), así como algunos elementos andino-patagónicos (Mulinum spinosum) e incluso especies de la Provincia Subantártica (Gaultheria phylariaefolia y Gavilea adoratissima). Particularmente en Sierra de la Ventana, se encuentran endemismos como Plantago bismarkii (pinito plateado), arbusto leñoso 
en forma de bola, Senecio ventanensis (senecio de las sierras) arbusto alto con tallos erectos, Grindelia ventanensis, (margarita de la cumbre) subarbusto bajo y Festuca ventanicola (pasto de la sierras) hierba perenne de bajo porte (Burkart 1952, Cabrera 1971; Frangi y Barrera 1996).

\begin{tabular}{|c|c|c|c|c|}
\hline $\begin{array}{l}\text { Nombre } \\
\text { científico }\end{array}$ & $\begin{array}{l}\text { Nombre } \\
\text { vulgar }\end{array}$ & Distribución & $\begin{array}{c}\text { Parte } \\
\text { utilizada }\end{array}$ & Usos \\
\hline $\begin{array}{l}\text { Geoffrea } \\
\text { decorticans }\end{array}$ & Chañar & $\mathrm{s} / \mathrm{d}$ & $\begin{array}{l}\text { Corteza Frutos } \\
\text { Madera hojas }\end{array}$ & $\begin{array}{l}\text { Medicinales, comestible, } \\
\text { elaboración de bebidas alcohólicas, } \\
\text { utilitario, forraje, melífera }\end{array}$ \\
\hline Prosopis nigra & $\mathrm{s} / \mathrm{d}$ & $\mathrm{s} / \mathrm{d}$ & $\mathrm{s} / \mathrm{d}$ & $\begin{array}{l}\text { Medicinales, leña y madera, } \\
\text { forraje, comestible }\end{array}$ \\
\hline $\begin{array}{l}\text { Prosopis } \\
\text { caldenia }\end{array}$ & $\mathrm{s} / \mathrm{d}$ & $\begin{array}{l}\text { La Pampa, San Luis, } \\
\text { sudoeste de Buenos Aires, } \\
\text { (Adolfo Alsina, Puan, Bahia } \\
\text { Blanca, Tornquist, Villarino) }\end{array}$ & $\begin{array}{l}\text { Tronco, hojas y } \\
\text { fruto }\end{array}$ & Leña, utilitario, forraje \\
\hline $\begin{array}{l}\text { Prosopis } \\
\text { riscifolia }\end{array}$ & $\mathrm{s} / \mathrm{d}$ & $\mathrm{s} / \mathrm{d}$ & $\mathrm{s} / \mathrm{d}$ & Medicinales, leña y madera, forraje \\
\hline $\begin{array}{l}\text { Prosopis } \\
\text { strombulifera }\end{array}$ & \begin{tabular}{|l|} 
Retortuño, \\
retortón, \\
mastuerzo, \\
pata de loro \\
\end{tabular} & $\begin{array}{l}\text { En el oeste de la provincia de } \\
\text { Buenos Aires, desde Puan a } \\
\text { Patagones }\end{array}$ & Frutos & $\begin{array}{l}\text { Aplicaciones medicinales, leña y } \\
\text { madera, forrajeros su decocción es } \\
\text { un remedio contra la disentería }\end{array}$ \\
\hline $\begin{array}{l}\text { Prosopis } \\
\text { alpataco }\end{array}$ & Alpataco & $\begin{array}{l}\text { Mendoza, La Pampa, Río } \\
\text { Negro y extremo sudoeste } \\
\text { de la pcia de Buenos Aires } \\
\text { (Bahía Blanca, Villarino, } \\
\text { Patagones) }\end{array}$ & Frutos & Forrajeros \\
\hline $\begin{array}{l}\text { Prosopis } \\
\text { flexuosa }\end{array}$ & Algarrobo & $\begin{array}{l}\text { De Catamarca hasta Río } \\
\text { Negro, oeste y sudoeste de } \\
\text { la Pcia de Buenos Aires } \\
\text { (Guaminí, Carhué, Adolfo } \\
\text { Alsina, Villarino). }\end{array}$ & $\mathrm{s} / \mathrm{d}$ & $\mathrm{s} / \mathrm{d}$ \\
\hline
\end{tabular}

Tabla 4.1. Distribución y usos de las principales especies presentes en la provincia fitogeográfica del Espinal. Datos tomados de Burkart (1952), Cabrera (1971).

Hacia el sur, la vegetación propia del Sistema de Ventania comienza a ser reemplazada, a medida que el clima se vuelve más árido, por especies características de la Provincia del Espinal distrito del Caldén (Figura 4.13). Este distrito, el más seco de la provincia del Espinal, conforma un bosque xerófilo, en el que son muy abundantes las leguminosas, acompañado por estepas graminosas y matorrales de arbustos, muchas de estas especies utilizables con fines alimenticios, medicinales, utilitarios y para leña (Tabla 4.1). La estructura original del caldenal corresponde a la de un bosque semicerrado a abierto con la presencia de un estrato arbustivo escaso o ausente y pastizales densos compuestos fundamentalmente por gramíneas perennes mixtas (figuras 4.13 y 4.14) (Bogino 2006). La comunidad clímax es el bosque de Caldén (Prosopis caldenia), árbol endémico de este distrito, el cual crece aislado o asociado a árboles secundarios como algarrobo (Prosopis nigra, Prosopis flexuosa), isletas de chañar (Geoffroea decorticans), sombra de toro (Jodina rhombifolia), incienso (Schinus fasciculatus) y pata (Ximenia americana), y ocasionalmente constituye bosques puros (Figura 4.14). El caldén es un árbol de 4 a 10 $\mathrm{m}$ de altura característico de clima semiárido, templado con estación seca y precipitación media anual no superior a los $545 \mathrm{~mm}$. Se encuentra en terrenos bajos y deprimidos con suelos arenosos y franco arenosos muy jóvenes, con horizontes débilmente desarrollados, con baja estabilidad estructural y escaso 
contenido de materia orgánica, por lo que son muy vulnerables a los procesos erosivos cuando están desprovistos de cubierta vegetal. Este árbol prospera en sectores que presentan algunas condiciones que limitan el crecimiento de otras especies arbóreas, como son las precipitaciones reducidas, grandes amplitudes térmicas estacionales, elevado déficit hídrico y suelos pobres y muy vulnerables a los procesos erosivos (Bogino 2006; Gómez et al. 2006).
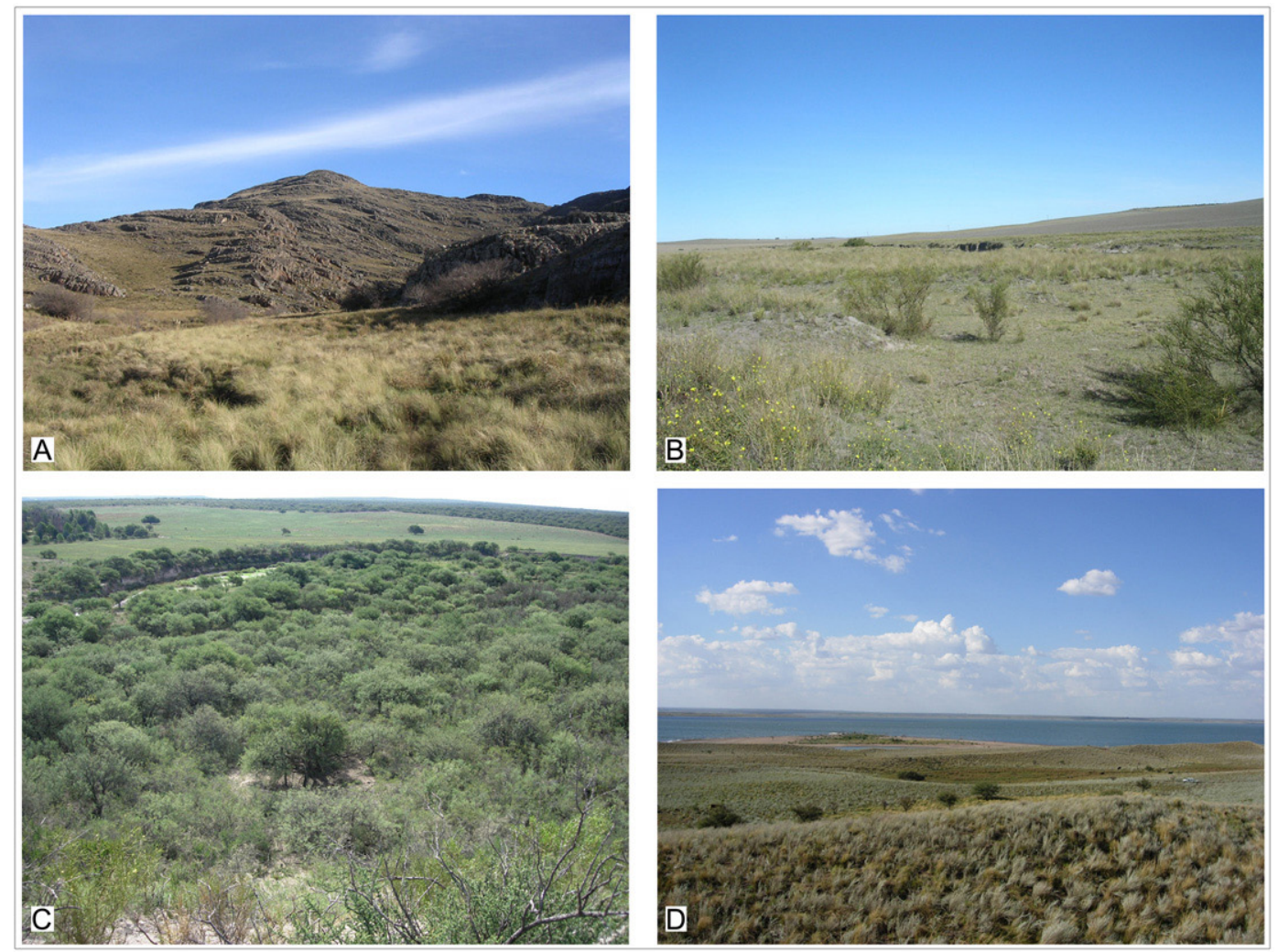

Figura 4.13. Vegetación presente en los distintos sectores de la cuenca del arroyo Chasicó: A- estepa con árboles dispersos en el Sistema Serrano de Ventania, B- estepa arbustiva en la cuenca media, $5 \mathrm{~km}$ aguas arriba de la confluencia con el arroyo Pelicurá, C- Bosque de Caldén en la cuenca media inferior en inmediaciones de la confluencia con el arroyo Sanquilcó Grande; D- estepa y caldenes dispersos en la laguna Chasicó.

Entre los arbustos propios del distrito del Caldén pueden mencionarse el piquillín (Condalia microphylla), el atamisque (Atamisquea emarginata), el alpataco (Prosopis alpataco), la pichana (Cassia aphylla), el manca caballo (Prosopidastrum globosum) y la jarilla (Larrea divaricata, Lycium chilense, Ephedra triandra, Ephedra ochreata y otras). Se encuentran a su vez estepas de flechillas (Stipa tenuis, Stipa clarazii, Piptochaetium napostaense) en zonas medanosas; estepas de junquillo (Sporobolus rigens) y tupe (Panicum urvilleanum) como comunidades edáficas sobre médanos vivos, a veces acompañadas por el olivillo (Hyalis argentea); matorrales de matorro o palo azul (Cyclolepis genistoides) en suelos muy alcalinos y quenopodiáceas crasas como Suaeda divaricata (jume) Allenrolfea patagónica y Heterostachys olivascens en los suelos salobres. (Cabrera 1971; Cabrera y Willink 1980). 

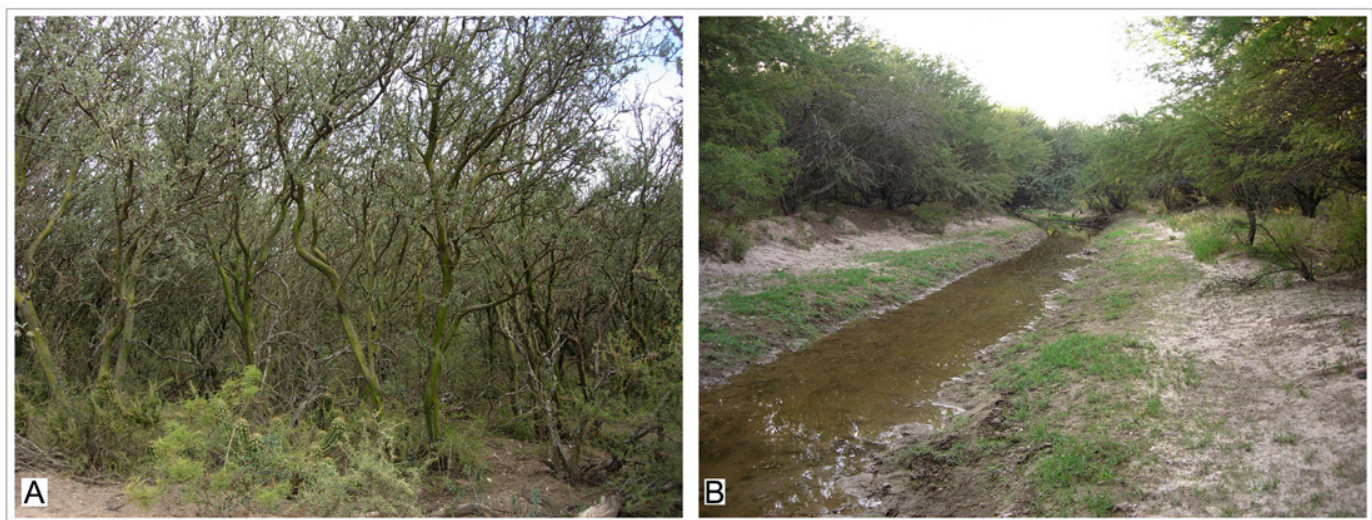

Figura 4.14. Vegetación en la cuenca inferior (provincia del Espinal). A- Bosque de Geoffrea decorticans (chañar); B- Bosque conformado predominantemente por Prosopis caldenia (caldén) en el arroyo Sanquilcó.

La desembocadura del arroyo en la laguna Chasicó, se ubica en plena provincia del Espinal, a menos de $100 \mathrm{~km}$ al norte de la actual Provincia del Monte, con la que forma amplios ecotonos, La provincia del Monte ocupa una gran extensión de las regiones más áridas de la argentina, desde el paralelo $-27^{\circ}$ al $-44^{\circ}$ aproximadamente, encontrándose, en el extremo noreste de Patagonia en la región entre el rio Negro y el sur de los pastizales pampeanos, muchos de sus elementos mezclados con los del espinal. La formación dominante del Monte es la de matorral, a veces muy abierto, donde predominan zigofiláceas de los géneros Larrea, Bulnesia y Plectocarpa como las jarillas (Larrea divaricata, Larrea cuneifolia y Larrea nítida), la rodajilla (Plectrocarpa rougessi) y asociadas a estas, otras especies como la matasebo (Monttea aphylla), el alpataco (Prosopis alpataco), comunidades edáficas de bosquecillos de algarrobos (Prosopis flexuosa, Prosopis chilensis) en las orillas de los ríos y en las depresiones de capa freática poco profunda $\mathrm{y}$, en la parte septentrional de la provincia, las cactáceas de manera muy abundante (Cabrera 1971; Cabrera y Willink 1980).

\subsubsection{Zoogeografia}

En cuanto a la fauna, y considerando que los territorios zoogeográficos no están divorciados de los territorios fitogeográficos, el sector de la Pampa que comprende el Sistema Serrano de Ventania y las llanuras ubicadas al sur de este, hasta el río Colorado, comprende también características transicionales. Este sector de la provincia de Buenos Aires presenta una marcada influencia patagónica, encontrándose dentro de lo que Ringuelet $(1955,1961)$ ha caracterizado como subregión Andino-patagónica, Dominio Central o Subandino, distrito sud-oriental. Este se encuentra interpuesto entre el dominio Pampásico con fauna fundamentalmente brasílica, de filiación subtropical y chaqueña, seleccionada en relación con condiciones ecológicas rigurosas, cuya influencia llega hasta la zona de Bahía Blanca (pudiendo su límite austral máximo haberse encontrado en el río Colorado o en el río Negro), y el dominio Patagónico, plenamente desarrollado al sur del río Colorado (Ringuelet 1955, 1961). Particularmente, desde el río Colorado hasta Bahía Blanca, e incluyendo a las sierras de Ventania a modo de isla, los 
caracteres patagónicos se diluyen en una fauna vinculada a la del monte y a la de las áreas serranas centrales difiriendo menos de estas que de la fauna pampásica (Ringuelet 1955). Es decir que la cuenca del arroyo Chasicó comprendería el dominio Central en sus cabeceras y cuenca media inferior hasta su desembocadura, con influencias del el dominio pampásico particuarmente en el sector de llanura adyacente a Ventania (cuenca media superior). Las aves tienen fuerte influencia patagónica hasta más allá de Bahía Blanca, en tanto los caracoles muestran relaciones con los de la provincia de La Pampa y los peces parenenses y los decápodos dulciacuícolas tienen en Ventana su límite extremo.

Entre algunas de las especies representadas se encuentran el guanaco (Lama guanicoe), actualmente presente en el Sistema Serrano de Ventania (Figura 4.15), el peludo (Chaetophractus villosus), el piche (Zaedyus pichiy), la comadreja overa (Didelphis albiventris) y la colorada (Lutreolina crassicaudata), la mara (Dolichotis patagonum), la vizcacha (Lagostomus maximus), el zorrinito (Conepatus castaneus), el ñandú (Rhea americana) (Cabrera y Yepes 1960).

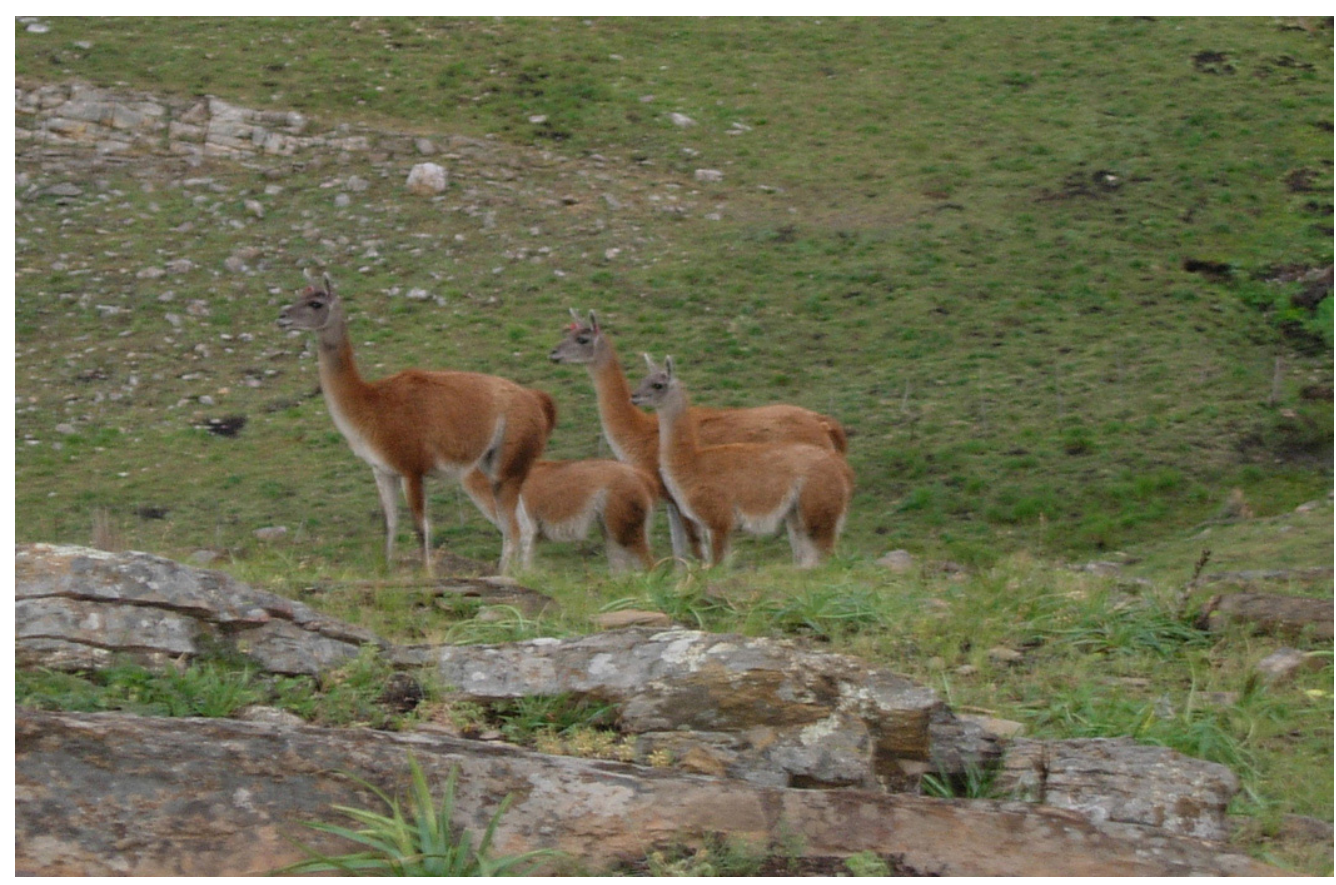

Figura 4.15. Guanacos en el Parque Provincial Ernesto Tornquist (Sierra de la Ventana).

Como se desprende de lo descripto, el área entre el Sistema Serrano de Ventania y el río Negro se distingue por presentar características transicionales, donde la provincia fitogeográfica del Espinal forma amplios ecotonos tantos con la provincia Pampeana como con la del Monte. En este sentido, la transición entre la estepa pampeana y el bosque xerófilo del espinal, con árboles de Prosopis y densa cobertura graminosa se desarrolla al sudoeste de Bahía Blanca hasta el río Colorado, en tanto los matorrales xeríticos del Monte, forman una transición con el Espinal entre los ríos Colorado y Negro (Schäbitz 2003). La fauna representada en este sector es también difícil de definir, pudiendo considerársela como una zona de transición, al norte con la provincia Chaqueña y al oeste y sur con la del Monte, debido a que se encuentran presentes muchas especies de ambas provincias (Cabrera y Willink 1980). 


\subsection{Características paleoambientales}

La información disponible acerca de las condiciones paleoambientales en el área de estudio corresponde a datos generados, por investigadores procedentes de variadas disciplinas, a partir del estudio de secuencias polínicas, de microfósiles (diatomeas-ostrácodos), estratigráficas y bioestratigrágicas (representación de fauna vertebrada) realizadas en los perfiles de los arroyos Chasicó y Napostá Grande, de los ríos Sauce Chico y Sauce Grande y de las salinas Chicas, Anzoategui, Inglés, Piedra y Espuma, correlacionándose, a su vez, dicha información con aquella obtenida para otras áreas de las regiones Pampeana y Patagónica (e.g. Deschamps y Tonni 1992; Prieto 1996; Quattrocchio et al. 1988, 1993, 1998; Zavala y Quattrocchio 2001; Schäbitz 2003; Tonni et al. 1999). Los indicadores utilizados poseen un grado variable de resolución y responden diferencialmente a las variaciones ambientales, por lo que en algunos casos las interpretaciones llevan a reconstrucciones paleoambientales que tienden a diferir fuertemente. En líneas generales, los estudios paleoclimático coinciden en que, durante el Holoceno temprano se habría dado un proceso de mejoramiento de las condiciones ambientales, dado por el aumento en temperatura y humedad. Durante el Holoceno medio en cambio, si bien la mayor parte de los indicadores señalan la presencia de condiciones cálidas, estos divergen en cuanto a las condiciones de humedad, que pudieron ser húmedas o bien alternantes húmedas y secas dependiendo del proxie considerado. Tampoco se observa acuerdo en relación con la duración de estas condiciones, pero promediando la información brindada por los diferentes indicadores, los cambios se habrían producido entre $c a$. 4000-3500 años cal AP, momento en que las condiciones se vuelven más frías y áridas (Iriondo 1999; Tonni et al. 1999; Figura 4.16).

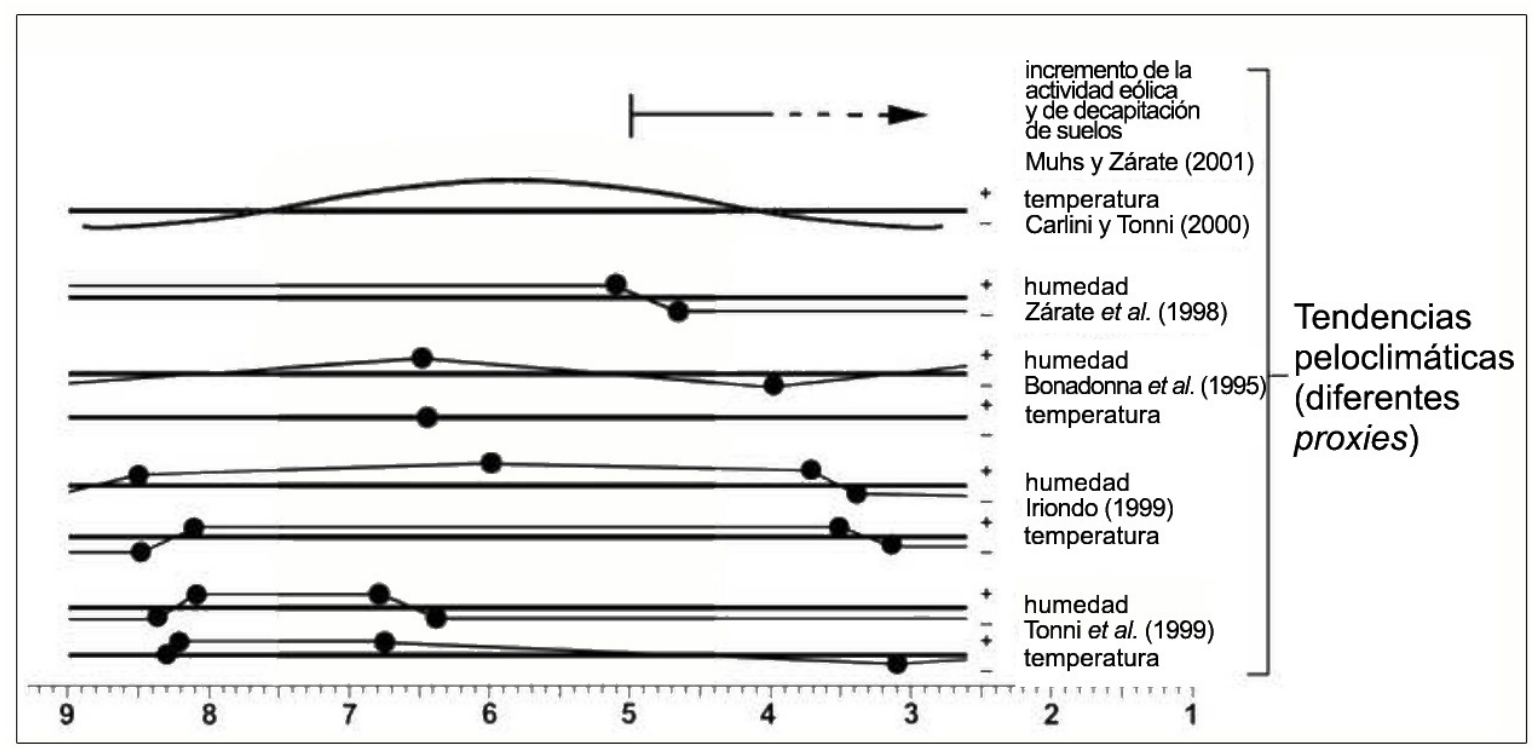

Figura 4.16. Tendencias paleoclimáticas en la Región Pampeana según diferentes proxies de temperatura y humedad. Modificado de Barrientos y Masse (2012).

En el área de Ventania, los diferentes indicadores concuerdan en que la transición PleistocenoHoloceno se habría caracterizadas por condiciones fías y áridas. En este sentido, los perfiles polínicos analizados por Quatrocchio y otros investigadores en la cuenca media del arroyo Napostá Grande, se caracterizan por el predominio de Chenopodiaceae y la ausencia de Graminae, indicadores de condiciones áridas a semiáridas, con una precipitación media de entre 400 y $600 \mathrm{~mm}$, con vegetación 
de estepa halófila y herbácea psamófila con representantes del bosque arbustivo xérico (Quattrocchio et al. 1988, 1993 y 1998; Zavala y Quattrocchio 2001). Zech et al. (2009) describen condiciones similares a partir del análisis de susceptibilidad magnética y materia orgánica $(C, N$ y S) presente en un perfil de la cuenca media del arroyo Chasicó. Para estos autores las condiciones habrían sido demasiado frías y al menos estacionalmente demasiado secas como para permitir la producción o preservación significativa de biomasa, encontrándose representados sólo algunos arbustos tolerantes a la sequía. Concordantemente, los estudios desarrollados sobre fauna vertebrada, la caracterizan como propia de áreas abiertas de estepa de pastos de condiciones áridas a semiáridas y frías (Deschamps y Tonni 1992). En los depósitos fluviales, Zavala y Quatrocchio (2001) describen acumulaciones fluviales efímeras y eólicas en depresiones geomorfológicas relacionadas a valles fluviales inactivos en los que el aporte fluvial habría sido temporario y no provendría de la cuenca de drenaje principal, con cabeceras en las Sierras Australes, sino de redes de drenaje secundarias, más pequeñas, localizadas en las divisorias, con una orientación perpendicular respecto a la del curso principal.

Los diferentes estudios concuerdan en que $c a .10000$ años AP las condiciones ambientales habrían comenzado a mejorar. Para este momento Borel et al. (2001) registra la formación de un suelo en el cauce del arroyo Chasicó y, en los estudios palinológicos, se observa el cambio de una estepa halófila y psamófila con elementos arbustivos a una pradera húmeda (Quattrocchio et al. 1998; Prieto 1996), con desarrollo de vegetación de lagunas y planicies de inundación indicadoras de condiciones de humedad más elevadas hasta ca 8000 años AP (Prieto 1996). En la cuenca del arroyo Chasicó, Zech et al (2009) observan la presencia de una secuencia de sedimentos húmicos, es los que analizan la susceptibilidad magnética, la granulometría del sedimento e isótopos $\delta^{13} \mathrm{C}$ del componente orgánico. Considerando estos datos proponen, para este momento, un aumento en la temperatura $\mathrm{y}$, probablemente, humedad que habrían producido un cambio en la composición vegetal, producto de la expansión de pastos y hierbas con el consecuente incremento en la biomasa. Los estudios isotópicos $\delta^{13} \mathrm{C}$ también reflejan el predominio de vegetación arbustiva $\mathrm{C}_{3}$ durante el Pleistoceno tardío, que es reemplazada durante el Holoceno temprano por pastos $\mathrm{C}_{4}$ (Zech et al 2009). Melo et al. (2003) proponen que, durante los momentos de mayor temperatura y humedad producido con posterioridad al Último Máximo Glacial, la depresión ocupada actualmente por la laguna Chasicó y las Salinas Chicas habría captado una porción del drenaje del sector noreste de las sierras de Lihué Calel y del río Colorado que, al colmatar la depresión, habría continuado hacia el actual salitral de la Vidriera, desembocando en inmediaciones de la actual ciudad de Bahía Blanca.

Los datos disponibles para el Holoceno medio, son un poco menos coherentes, evidenciándose algunas contradicciones entre los diferentes indicadores considerados. Entre 6200-5300 años AP se encuentra evidencia, en los perfiles del río Sauce Grande y el arroyo Napostá Grande, de la presencia de vegetación de estepa graminosa, que estaría reflejando un mejoramiento climático con respecto a las condiciones imperantes durante el Pleistoceno, que podría relacionarse con el llamado Óptimo Climático del Holoceno medio o Hypsitermal. El miembro limo-arenoso superior de la formación Agua Blanca presenta, entre ca 5000 y 3000 años AP, elevada bioturbación y polen predominantemente acuático y de elementos que se encuentran en inmediaciones de los cuerpos de agua (Juncaeae, Potamogetonaceae) o a lo largo de cursos de agua (Potamogetonaceae, Alismataceae, Hydrocotyle, Cyperaceae). Esto sugiere la existencia de cuerpos lagunares de aguas tranquilas y dulces que podrían estar relacionados con encharcamientos dentro del valle fluvial producto del ascenso del nivel freático por sobre la superficie 
del fondo del valle. Dichos encharcamientos habrían originado una serie de lagunas en rosario a lo largo de los valles fluviales, las que habrían sido progresivamente capturadas por erosión retrocedente a medida que se configuraba la red fluvial actual durante el Holoceno medio-tardío (Zavala y Quattrocchio 2001). Los ostrácodos presentes en los sedimentos también indican la existencia de cuerpos pandos de escasa energía, baja salinidad y vegetación densa, con una asociación fósil que actualmente se encuentra presente en ambientes del sur de Brasil (Quattrocchio et al. 1993). A su vez, Gil et al. (2008) observan, en el Abra de la Ventana, la presencia de conglomerados de cuarcita con cemento ferruginoso que evidenciarían condiciones de mayor humedad y temperatura y que serían producto de sistemas de dispersión clástica de alta eficiencia que permitieron la buena selección y la cementación por hierro de estos conglomerados durante el Holoceno medio (Gil et al. 2008). Por otra parte, en el arroyo Chasicó, Zech et al. (2009) describen condiciones más áridas durante el Holoceno medio (ca. 7900-3000 años cal. AP), con una vegetación mezclada $\mathrm{C} 3 / \mathrm{C} 4$ con predominio de arbustos resistentes a la sequía.

Asociado al Hypsitermal se produjo un aumento en el nivel del mar de 2,2 a 2,5m sobre el nivel actual que dejó como evidencia las fases transgresivas de la Formación Las Escobas, representada en las zonas de costa baja y en las desembocaduras de los arroyos (Isla 1989; Aguirre y Whatley 1995; Isla y Espinosa 1995). La ubicación cronológica de este evento puede ubicarse entre 8000 y 5000 años AP, si bien los diferentes investigadores difieren en el momento de inicio y fin del mismo. En este sentido, en tanto Aguirre y Whatley (1995) lo ubican entre 8000 y 6000 años AP, Isla (1989) lo localiza entre 6000 y 7000 años AP, en tanto Bonadonna et al. (1995) y Zárate y Flegenheimer (1991) lo sitúan entre 6000 y 5000 años AP. En la desembocadura del arroyo Napostá Grande, Quattrocchio et al. (2008) observan ca. 5500 años AP, la presencia de un ambiente marino infralitoral, cuyas características indican una transgresión marina correspondiente a un momento de nivel máximo relativo del mar. Por las características palinológicas de la muestra, relaciona este momento con condiciones climáticas más cálidas y, probablemente, más húmedas Este evento se asocia a su vez con la expansión de pastizales tierra adentro, reflejando condiciones más templadas y húmedas, evidenciado por la presencia de la estepa graminosa en la cuenca media del arroyo Napostá y el río Sauce Grande (Borromei 1995; Quattrocchio et al. 2008).

Para el lapso comprendido entre 5000 y 4500 años AP varios autores proponen un periodo de regresión marina coincidente con el retorno a condiciones climáticas subhúmedas áridas (Aguirre y Whatley 1995; Isla 1989). En la desembocadura del arroyo Napostá Grande, Quattrocchio et al (2008) encuentran evidencias del paso gradual, $c a$. 3800 años AP, desde un ambiente marino hacia un ambiente transicional marino litoral-estuárico, polihalino, que culmina con la introducción de taxa no marinos hacia ca 3000 años AP, cuando se estabiliza la línea de costa en toda la provincia de Buenos Aires (Isla 1989; Isla y Espinosa 1995). Melo et al. (2003) consideran que bajo estas condiciones climáticas templado-árido, los aportes hídricos del río Colorado y las sierras de Lihué Calel a la depresión ChasicóSalinas Chicas se transforman en transitorios hasta desaparecer o transformarse en salinas, y se conforma el paisaje geomorfológico actual (Melo et al. 2003).

Durante Holoceno tardío, los registros de polen, geológicos y paleontológicos reflejan una variabilidad ambiental mayor con cortos episodios semiáridos a húmedos y cálidos, en donde el clima habría tenido un comportamiento oscilatorio (Markgraf 1991; Quattrocchio et al. 2008). Esta variabilidad climática habría sido mayor entre 3100 y 1500 años AP, volviéndose más estables durante los últimos 
1500 años AP (Zech et al. 2009). Hacia ca 3500 años AP, se habría iniciado una fase más árida y fría que se prolonga hasta ca 1000 años AP (Isla 1989; Isla y Espinosa 1995). A partir de ca. 2600 años AP y asociado con la formación Chacra La Blanqueada, se identifica en el arroyo Napostá Grande, evidencias de una estepa herbácea con representantes del bosque arbustivo (arbustos y arbustos espinosos como Geoffrea decorticans, Prosopidastrum globosum, Duscaria longispina, Condalia microphylla y Ephedra triandra) que sugiere un cambio climático hacia condiciones más secas, de tipo áridas a semiárida (Quattocchio et al. 1993, 1998; Zavala y Quattrocchio 2001; Rabassa 1989). Condiciones similares son registradas por Borromei (1995) en el valle medio del Sauce Grande, donde observa vegetación de estepa herbácea psamófila con escasos elementos del bosque de arbustos fechada en ca. 2800 años AP.

Hacia ca 2000 años AP, Quattrocchio et al. (1988, 1993, 1998, 2008) observan, en la cuenca media del arroyo Napostá Grande, un aumento en el polen de gramíneas, indicador de la presencia en el área de la estepa graminosa actual, y de comunidades hidrófilas probablemente asociadas a un cuerpo lagunar, asociadas con fauna vertebrada brasilica y/o acuática, a partir de lo que infieren un pulso de alta humedad con un aumento relativo en la temperatura. Sin embargo, Quattrocchio et al. (1998) llaman la atención sobre el hecho de que la mencionada fauna de tipo brasílica, se encuentra en simpatría con elementos patagónicos (Lestodelphys halli y Lama guanicoe). Esto es interpretado por los autores como producto de condiciones áridas a semiáridas previas y un momento de cambio hacia condiciones más húmedas y probablemente más cálidas, donde los cuerpos de agua vegetados habrían modificado localmente las condiciones regionales proveyendo parches para el avance de los elementos brasílicos (Quattrocchio et al. 1998). Hacia los niveles superiores de los perfiles del arroyo Napostá Grande, se infiere, a partir de la disminución de Cytheridell salebrosa y el registro de Cytheridella ilosvavi, un descenso en la salinidad consecuencia de un aumento de las precipitaciones. Este aumento en la humedad también queda evidenciado por el desarrollo de paleosuelos correlacionables con el suelo Puesto Berrondo (Fidalgo 1992; Fidalgo et al. 1973; Quattrocchio et al. 1998). Piovano et al. (2009) sugieren la presencia de condiciones húmedas y cálidas, similares a las actuales, para las planicies pampeanas entre $c a 1400$ y 1800 AP, con un importante desarrollo de suelos y formación de encharcamientos en las depresiones. Este momento de mayor humedad, habría sido interrumpido por fases frías y secas, principalmente entre 1475 y 1060 años AP. Algunos investigadores han propuesto que los cambios ambientales producidos por el Máximo Climático Medieval entre ca 800-1200 AD habrían producido la retracción del guanaco hacia el oeste y hacia el sur, que abandona las subregiones Interserrana, Norte y Depresión del Salado (Politis y Pedrota 2006; Politis et al. 2011b). Sin embargo, la presencia de restos óseos de esta especie en sitios del nordeste han sido interpretados como producto de la caza y, por lo tanto, como indicadores de su presencia en esos ambiente hasta momentos tardíos (Loponte 2007).

Hacia 1000 años AP, Borromei (1995) describe la presencia en el valle medio del río Sauce Grande, de vegetación de estepa herbácea psamófila con escasos elementos del bosque de arbustos. Si bien se encuentran evidencias de mayor aridez para este momento, también persiste la fauna vertebrada con elementos brasílicos, reflejada en el registro de Dasypus hybridus en el sitio La Toma, que estaría indicando condiciones cálidas probablemente coincidentes con el Óptimo Climático Medieval s. XIIXIII (Madrid y Politis 1991; Quattrocchio et al. 2008; Salemme 1987; Tonni et al 1999). Este aumento en las condiciones de temperatura y humedad, también es observado en sitios arqueológicos del curso medio del río Negro y del curso inferior del río Colorado, donde se registra, entre ca. 1.000-400 años AP, la presencia de Holochilus brasiliensis y del género Ceratophrys, escuerzo cuyo registro actual más 
austral se encuentra en la localidad de Necochea (Stoessel et al. 2008). Como resultado de estos cambios ambientales producidos durante el Óptimo Climático Medieval, algunos autores han propuesto que el guanaco habría sufrido una retracción hacia el oeste entre $c a$. 1200-800 años AP (Politis y Pedrotta 2006; Politis et al. 2011b; Tonni y Politis 1980).

Posteriormente, ya en tiempos históricos y con el advenimiento de las condiciones de la Pequeña Edad del Hielo, se habría producido una aridización regional, que se registra en la porción superior del río Sauce Grande y arroyo Napostá Grande, por la presencia de vegetación de estepa halófila asociada a ambientes eólicos que indican condiciones ambientales semiáridas (Quattrocchio et al. 2008). Piovano et al. (2009) describe para este momento, al norte de la Diagonal Árida, dos pulsos fríos y áridos, interrumpidos por una fase más cálida y húmeda. El primer pulso frío, entre las primeras décadas del siglo XV y el final del siglo XVI, produjo condiciones de sequía severa, frecuentes tormentas de polvo, reactivación de las dunas de arena, desecación de las lagunas y mortalidad del ganado. Entre el final del siglo XVI y los inicios del siglo XVII se produce la expansión de las lagunas, que vuelven a retraerse a inicios del siglo XVIII como consecuencia del segundo pulso frío, y seco, que se continúa hasta fines del siglo XIX. Evidencias basadas en mamíferos sugieren tendencias secas y áridas para los 440 años AP (Tonni et al. 1999) pero algo más benignas para los 300 años AP (Pardiñas y Tonni 2000). Los relatos de los primeros viajeros y explotadores también mencionan condiciones más áridas y secas que las actuales, evidenciadas por la presencia en Sierra de la Ventana de bosquecillos espinosos, densos, representados por chañares (Geoffroea decorticans) en las barrancas de los arroyos permanentes (D`Orbigny 1999).

Por otra parte, a partir de los estudios polínicos realizados en perfiles ubicados en el nordeste de Patagonia, entre el río Negro y el sur de la estepa pampeana, Schâbitz (2003) observa una marcada tendencia hacia el incremento de los valores de precipitación desde el Holoceno medio (entre 7000-5000 años AP), cuando los valores se habrían encontrado entre 210-290mm anuales, hasta la actualidad, con valores de 260 y 380mm anuales y de 466 mm en el río Colorado (Sánchez et al. 1998; Schâbitz 2003). Durante el Holoceno medio, se habrían dado condiciones de alta temperatura y baja precipitación como consecuencia del predominio de los vientos del oeste que impidieron el ingreso al continente del aire húmedo del atlántico, generándose así un escenario árido, con disminución en el tamaño de las salinas y re-movilización de arenas y dunas sobre las playas. Con posterioridad a 5000 años AP y hasta 3000 años AP el clima habría cambiado hacia condiciones semiáridas incrementándose la precipitación a valores de entre 240-320 mm anuales, lo que generó a su vez el desarrollo de capaz salinas en los bajos, lo cual indicaría una precipitación más estacional, probablemente causada por la deriva estacional de los vientos del oeste y el ingreso del aire húmedo del Atlántico. Durante los últimos 3000 años estas condiciones comenzaron a manifestarse más regularmente, incrementándose la precipitación hasta alcanzar los valores actuales a los valores actuales de entre (Schâbitz 2003).

Resumiendo, durante el Pleistoceno tardío y hasta el Holoceno medio, la fauna representada en el área interserrana y las sierras de Ventania habría sido la misma, indicando condiciones paleoambientales similares, áridas a semiáridas. Hacia $c a .4000$ años AP, se inicia, un período de mayor variabilidad climática, donde los registros de polen, geológicos y paleontológicos reflejan un comportamiento de tipo oscilatorio, con cortos y alternantes episodios semiáridos y húmedos - cálidos (Quattrocchio et al. 2008). Durante este momento, Deschamps y Tonni (1992) observan que comienzan a encontrarse 
diferencias entre las especies representadas en el Sistema Serrano de Ventania y aquellas presentes en el área interserrana. Ciertas especies como Lestodelphys halli, por ejemplo, que durante el Holoceno temprano se registra en el área interserrana, hacia el Holoceno tardío se retrae y desaparece del registro debido a un mejoramiento de las condiciones climáticas por aumento de humedad y temperatura coincidente con el ingreso de la fauna brasílica. A su vez, la simpatría en algunos contextos de Vetania, de Lestodelphys halli con Holochilus brasiliensis y Cavia aperea es interpretado como posible indicador de la presencia de cuerpos de agua con vegetación que modificaron localmente las condiciones áridas y semiáridas regionales, constituyendo vías de penetración de los elementos brasílicos (Deschamps y Tonni 1992). Las mencionadas variaciones ambientales generaron a su vez, cambios hidrológicos y geomorfológicos en el área de estudio, que habría alcanzado las características actuales $c a .3000$ años AP. (Melo et al. 2003). 


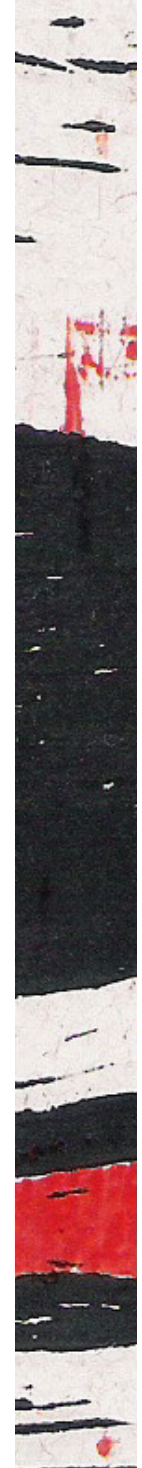

GENERACIÓN DE MODELOS DESCRIPTIVOS 


\section{I Derivación de Expectativas Arqueológicas para la Cuenca del Arroyo Chasicó sobre la Base del Análisis e Integración de Información Preexistente}

\subsection{Los datos secundarios: sus potencialidades y limitaciones}

El objetivo de este capítulo es formular expectativas precisas acerca del contenido y distribución de aspectos relevantes del registro arqueológico de la cuenca del arroyo Chasicó -y de sus mecanismos de formación-, sobre la base del análisis e integración de información preexistente (i.e. datos secundarios).

El análisis de datos secundarios implica, típicamente, el estudio de información recolectada en forma primaria (i.e. original) por uno o varios investigadores a lo largo del tiempo y que se organiza en bases, especialmente creadas con la finalidad de responder a interrogantes bien definidos que, generalmente, son diferentes de aquellos que inicialmente motivaron su obtención (Andrews et al. 2012; Devine 2003; Fielding 2004). En la actualidad, el análisis de datos secundarios representa una valiosa herramienta, que ha sido utilizada arqueológicamente, por ejemplo, en el estudio de grandes cantidades de fechados radiocarbónicos como datos para inferir -a través del análisis de su distribución temporal- patrones de ocupación y sesgos tafonómicos en espacios definidos a diferentes escalas, que van desde la regional (mesoescala) a la continental (megaescala) (v.g. Rick 1987; Riede 2009; Steele 2010; Surovell y Brantingham 2007; para ejemplos locales, ver Barrientos 1997; Barrientos y Masse 2012; Barrientos y Pérez 2005).

Entre las ventajas del análisis de datos secundarios, puede mencionarse que: a) constituye un modo efectivo de estudiar datos cuando hay dificultades para acceder a ciertas muestras, cuando se trabaja con problemas particularmente sensibles, o con poblaciones pequeñas y/o fenómenos raros; b) conforma un modo eficiente de conducir una investigación, particularmente de gran escala, al permitir minimizar el gasto de recursos (i.e. dinero, tiempo, personal) vinculado con la recolección primaria de datos (Andrews et al. 2012; Corti 2008; Heaton 1998; Trochim 2006). A pesar de los aspectos positivos mencionados, el análisis de datos secundarios ha sido objeto de críticas por parte de algunos investigadores, que señalan las siguientes desventajas: a) ausencia de control sobre la generación de los datos; b) descontextualización de la información (Bishop 2007; Brewer 2006; Szabo y Strang 1997). Sin embargo, cabe consignar que durante la tarea de elaboración de las bases de datos, la aplicación de múltiples criterios de filtrado de la información permite, en numerosas ocasiones, mejorar la performance de los datos originales, al ponerlos en un contexto comparativo más amplio y eliminar posibles ruidos o distorsiones inadvertidas por el generador primario de los mismos.

\subsection{Modelos descriptivos}

Sobre la base del uso de datos secundarios de distinta naturaleza, en esta sección se describirá la metodología empleada para la construcción de modelos estadísticos, espaciales y cronológicos que permitan derivar expectativas específicas aplicables a nuestro caso de estudio, acerca de: 1) los factores involucrados, directa e indirectamente, en la generación del registro (i.e. factores ambientales 
y socioecológicos tales como la estructura regional de los recursos, el tamaño probable de los grupos humanos implicados, las pautas de movilidad a escala grupal y la composición de la dieta y 2) patrones distribucionales (espaciales y temporales) de diferentes aspectos del registro arqueológico del sur de la Región Pampeano y NE de Patagonia (i.e. fechados radiocarbónicos, materias primas, clases artefactuales, restos humanos, valores de isótopos estables del C y $\mathrm{N}$ en muestras humanas y faunísticas).

\subsubsection{Factores directa o indirectamente involucrados en la generación del registro}

A partir de información ambiental/paleoambiental y etnográfica, se construyeron modelos espaciales y estadísticos acerca de aspectos de interés para la derivación de expectativas arqueológicas específicas para la cuenca del arroyo Chasicó. Los modelos espaciales se elaboraron mediante el manejo de información georeferenciada, administrada y analizada con sistemas de información geográfica (SIG), mientras que los estadísticos a través del uso de estadísticas descriptivas, aplicadas a la distribución de valores cuantitativos de diferentes variables. En esta sección se describe la metodología empleada y los resultados obtenidos en cada una de las diferentes instancias.

\subsubsection{Modelo acerca de la estructura regional de los recursos}

Con el fin de poder derivar expectativas acerca del uso diferencial de los principales recursos en función de su distribución espacial, se construyó un modelo de disponibilidad que combina información referida a recursos vegetales, faunísticos y líticos. Para ello, se generaron y combinaron, mediante el uso de SIG, mapas distribucionales de recursos animales, vegetales y líticos -sobre la base de distintas fuentes de información-.

\subsection{Mapeo de recursos vegetales}

Como ya ha sido mencionado, en el área de estudio se encuentran representadas actualmente las provincias fitogeográficas Pampeana y del Espinal, cuya extensión relativa fluctuó durante el Holoceno tardío. Estas fluctuaciones se relacionan con los cambios ambientales ocurridos en el período, siendo probablemente la humedad el principal factor determinante del avance y retroceso de estas provincias fitogeográficas. Las especies del Espinal son principalmente xerófilas, por lo que necesitan un clima caluroso y seco para desarrollar una buena floración y fructificación y suelen verse perjudicadas por la competencia con las gramíneas, características de las pampas húmedas (Burkart 1952). En tiempos recientes, el avance de la agricultura y de la ganadería, y el consecuente desmonte para generar campos aptos para el manejo agropecuario, así como el aprovechamiento forestal de las especies leñosas, fueron también factores importantes en la retracción de las especies arbóreas autóctonas. Esto produjo cambios en el paisaje, que dejaron a los bosques del Espinal inmersos en un mosaico formado por cultivos, tierras ganaderas y áreas urbanas (Arturi 2005).

Probablemente, las especies propias de la Provincia Fitogeográfica del Espinal (Distrito del Caldén) son las que tuvieron la mayor importancia en la economía prehistórica de las sociedades que ocuparon el área de estudio, dada la abundancia de especies leñosas (Capítulo 4), factibles de ser utilizadas como combustible, como materia prima para la elaboración de utensilios y como fuente de extracción de 
nutrientes a través de la recolección, procesamiento y consumo de sus partes comestibles (v.g. vainas de leguminosas; Burkart 1952). A los fines de realizar una primera aproximación a las probables variaciones que se habrían generado en la distribución espacial de esta provincia fitogeográfica, se recopilaron sus mapas de distribución publicados entre 1941 y 2004, los cuales fueron georreferenciados, agregados como capas de información y reclasificados, utilizando el paquete de SIG ArcGis 9.3, para obtener coberturas raster con dos valores (i.e. presencia o ausencia de especies arbóreas), según la información proporcionada por cada uno de los autores. De esta manera se obtuvieron 5 mapas, que representan las diferentes propuestas acerca de la distribución espacial de la provincia fitogeográfica del Espinal. Estas 5 capas fueron procesadas mediante operaciones de adición (operador And de la herramienta Raster Calculator, disponible en el módulo Spatial Analyst de ArcGis 9.3) y reclasificación, que permitieron determinar zonas de mayor y de menor superposición, las cuales fueron interpretadas como zonas de mayor y menor probabilidad, respectivamente, de distribución de las especies arbóreas del Espinal. De este modo, el área en la que las 5 capas se encuentran superpuestas fue considerada como una zona donde el Espinal se habría encontrado de manera más permanente, con poca o nula influencia de las fluctuaciones climáticas, conformando un área nuclear estable. Aquella zona sin superposición, donde solo una capa indica su presencia, típicamente situada en los márgenes, constituyen sectores caracterizados por una distribución, en época actual o subactual, de pequeños relictos del bosque del Espinal (principalmente de ejemplares de Prosopis y Geoffroea; Frenguelli 1941; Parodi 1940; Oliva com. pers. 2007; Politis 1984), representando remanentes aislados resultantes del avance de esta provincia sobre áreas ocupadas por el pastizal pampeano, bajo condiciones de menor disponibilidad de agua. Entre la primera y la última se encontraría una franja transicional, más inestable en cuanto a disponibilidad y densidad de las especies arbóreas típicas del Espinal, caracterizada también por la presencia actual de formaciones relictuales (Figura 5.1).

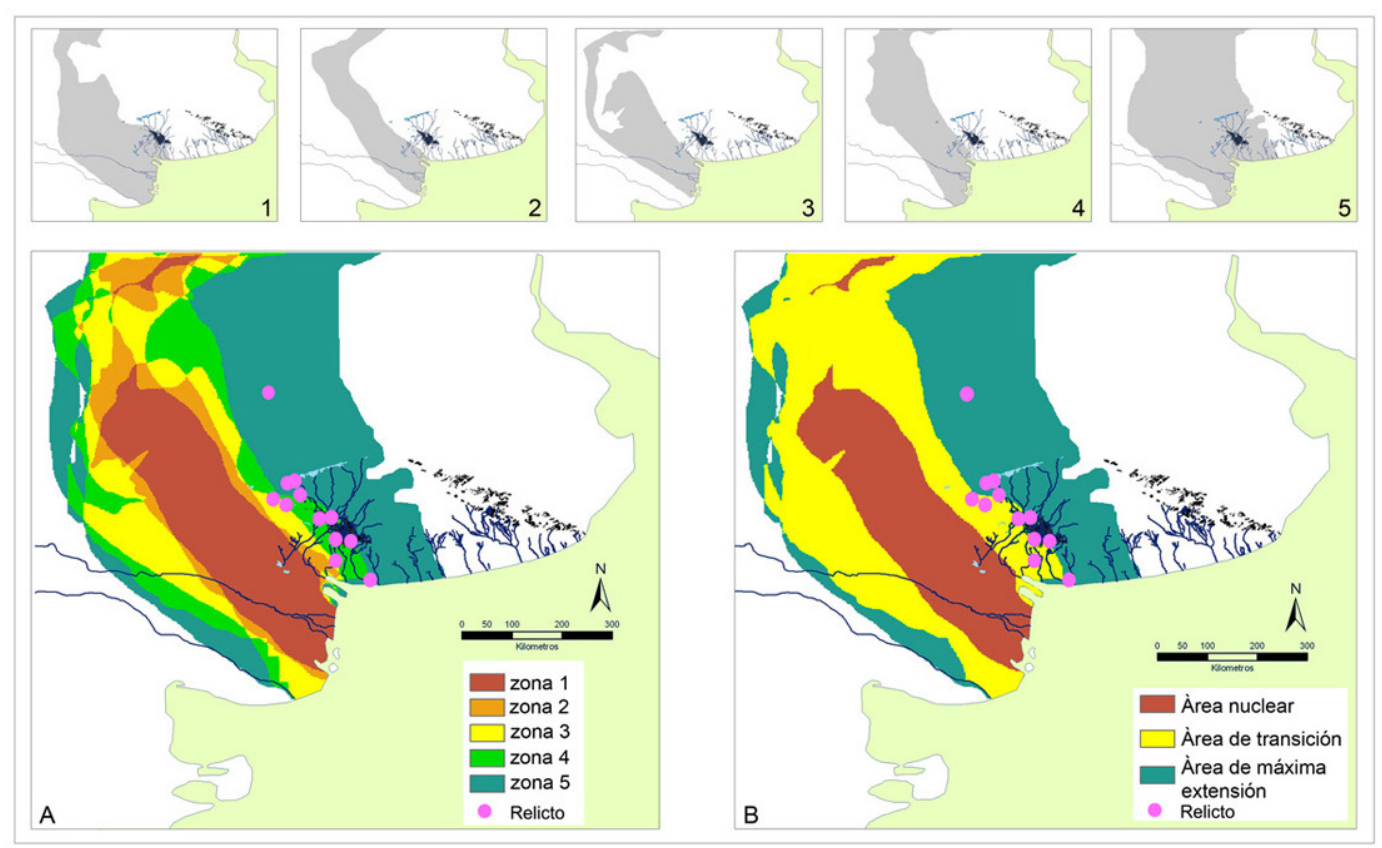

Figura 5.1. Distribución de la provincia fitogeográfica del Espinal. Arriba relevamientos del Espinal realizados por diferentes investigadores (1- Frenguelli 1941; 2- Cabrera 1971; 3- Prieto 1996; 4- Burkart et al. 1999; 5- Josse et al. 2003). Abajo superposición de los 5 mapas de distribución. A- mapa donde se muestran 5 zonas resultantes de la superposición de capas en número decreciente. B- Mapa simplificado a partir de A, donde se han generado 3 áreas: Nuclear aquella en que todos los autores coinciden en la distribución del Espinal; Transición: entre dos y cuatro autores describen la presencia del espinal; Área de máxima extensión: sólo autor describe su presencia. 
La cuenca del arroyo Chasicó correspondería, entre su cabecera y aproximadamente la confluencia de los arroyos Pelicurá y Chasicó, a la zona transicional, mientras que la parte distal situada entre dicha confluencia y la laguna Chasicó, correspondería a la zona nuclear.

\subsection{Mapeo de recursos animales}

Si bien la fauna del área de estudio y de las regiones naturales en las cuales ésta se encuentra es variada (Capítulo 4), para el modelado de la distribución de los recursos faunísticos se consideraron sólo dos especies que, dada su biomasa, tamaño corporal y otros atributos fenotípicos, habrían tenido un rol central en la subsistencia de las sociedades que habitaron el sur de la Región Pampeana y de NE de Patagonia: guanaco (Lama guanicoe) y venado de las pampas (Ozotoceros bezoarticus). A los fines de estimar su distribución combinada, se utilizaron los mapas de probabilidad de distribución potencial para el Holoceno tardío de ambas especies, publicados por Politis et al. (2011b). Estos mapas, construidos mediante el uso del programa MaxEnt, combinan información histórica, museística, arqueológica, climática, fisiográfica y ecológica, con el fin de predecir áreas de probabilidad diferencial de aparición de cada especie (Figura 5.2). A los fines de este trabajo, las imágenes de ambos mapas fueron georreferenciadas, y reclasificadas, obteniéndose una nueva cobertura raster (formato GRID) para su posterior tratamiento mediante SIG.

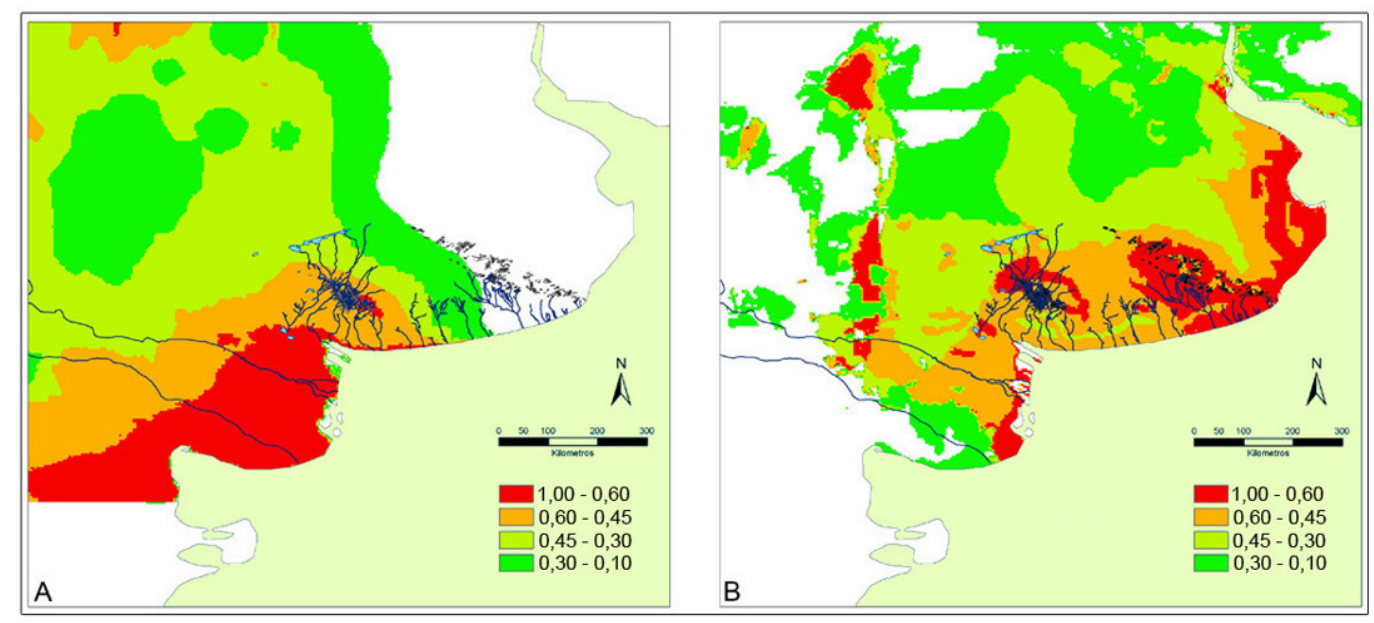

Figura 5.2. Mapas modificados a partir de Politis et al. (2011b), en los que se expresan zonas de distribución potencial moderna, expresadas como probabilidad, de. A- Lama guanicoe; B- Ozotoceros bezoarticus.

\subsection{Mapeo de recursos líticos}

La disponibilidad de recursos líticos fue establecida a partir de datos extraídos de la literatura especializada y de las hojas geológicas publicadas para el sur de la Región Pampeana y NE de Patagonia. Sobre la base de este material, se construyó una cobertura vectorial con la distribución de todos los afloramientos primarios y mantos secundarios descriptos, en la que se incluyó información acerca de sus principales características (tipo de roca, tamaño de grano, tipo de fractura, entre otras). En el caso 
de los mantos secundarios, rodados tehuelches y rodados fluviales que afloran en los cortes naturales constituidos por los ríos y arroyos cuyas nacientes se encuentran en Ventania, no se consideraron los lugares puntuales en los que actualmente se encuentran disponibles, sino el área potencial de distribución de los mismos, ya que su distribución y exposición puede fluctuar a través del tiempo por procesos de transporte, cobertura sedimentaria y/o erosión.

Sobre la base de las características de la roca y del tipo de instrumentos arqueológicos confeccionados con ellas, se realizó una clasificación en función de la utilidad potencial de las rocas en: rocas aptas para la confección de instrumentos tallados, rocas aptas para la elaboración de artefactos formatizados por picado, abrasión y/o pulido, o bien, rocas aptas para elaborar ambos tipos de artefactos (Figura 5.3). A partir de esta cobertura vectorial clasificada según la potencial funcionalidad de las rocas, se generó una nueva cobertura raster (formato GRID), en la que, indistintamente del tipo de roca disponible, la información se clasificó según su potencial uso, considerando que las sociedades cazadoras-recolectoras del Holoceno tardío habrían necesitado confeccionar tanto instrumentos para cortar, perforar y raspar, confeccionados predominantemente por talla como instrumentos para machacar, moler y pulverizar, elaborados predominantemente por picado, abrasión y/o pulido.

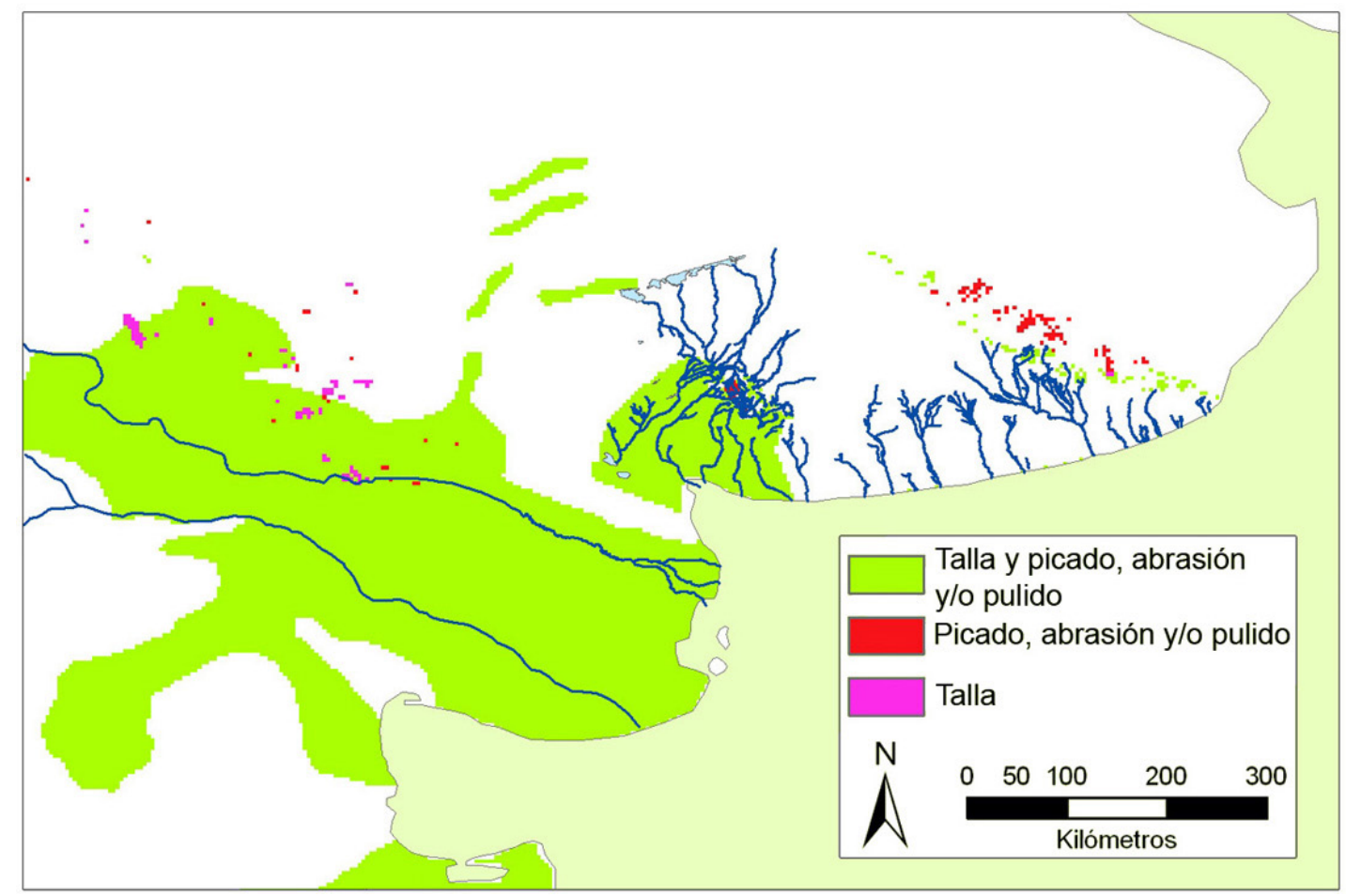

Figura 5.3. Distribución de materias primas líticas clasificadas según su aptitud para la confección de instrumentos por técnica de talla, de picado, abrasión y/o pulido o de ambas. 


\subsection{Adición de capas de información y generación de un mapa predictivo combinado}

Una vez generadas todas las superficies de distribución de recursos, se utilizó el paquete de SIG ArcGis 9.3 para realizar operaciones de adición entre capas y, de esta manera, generar nuevas superficies raster representando las zonas de superposición de los recursos en sus distintas probabilidades de aparición (procedimiento descripto en el apartado 5.2.1.1.1), a los fines de jerarquizar los ambientes en función de la densidad y variabilidad de recursos disponibles. En todas las operaciones se incluyó la capa de materias primas aptas para la confección de instrumentos por talla y por picado, abrasión y pulido. Esta capa fue combinada con la de Lama guanicoe y la de Ozotoceros bezoarticus en sus tres probabilidades más elevadas, excluyéndose de las operaciones la probabilidad más baja de aparición $(0,30-0,10)$. Dado que el guanaco es, de estas dos especies, aquella de mayor importancia económica, la clasificación de los ambientes fue realizada considerando, en primer lugar, la probabilidad de aparición de esta especie y, en segundo lugar, la de Ozotoceros bezoarticus. Esto permitió identificar aquellas zonas de mayor y menor variedad y, probablemente, mayor y menor abundancia de recursos, generándose así lo que puede caracterizarse como un ranking de zonas $(\mathrm{n}=3)$, representativo de la oferta ambiental de recursos (Figura 5.4).

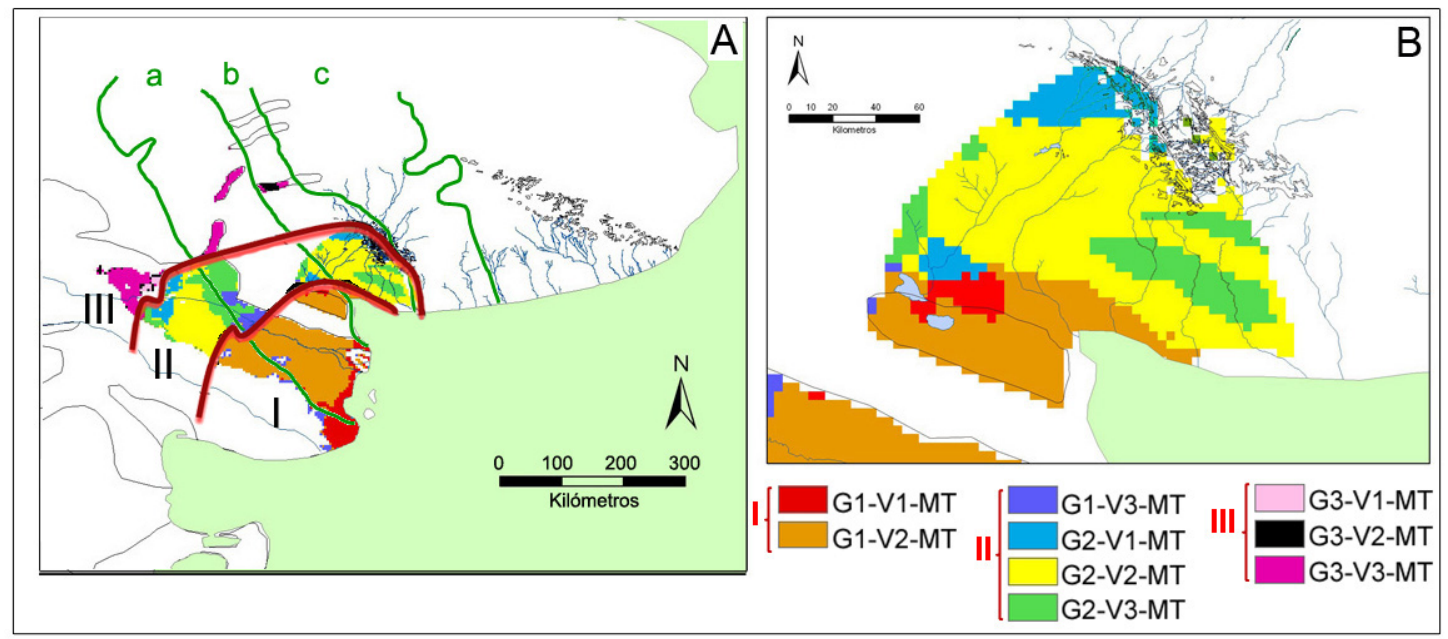

Figura 5.4. Mapa representando las áreas con mayor abundancia de recursos (líticos, animales y vegetales). A- Región Pampeana y NE de Patagonia; B- Acercamiento al área de estudio. Los diferentes colores representan sectores del Espinal con disponibilidad de rocas aptas para la confección de instrumento tanto por técnica de talla como por picado, abrasión y/o pulido en relación con las zonas de distribución potencial de Lama guanicoe (G.) y Ozotoceros bezoarticus (V), materias primas líticas aptas para la confección de artefactos por talla y por picado, abrasión y/pulido (MT), los números que acompañan las siglas corresponden al grado de probabilidad presentado en la Figura $5.2(1=1,00-0,60 ; 2=0,60-0,45$; $3=0,45-0,30)$. a- área nuclear del espinal; b- área de transición del espinal.; c-área de máxima extensión probable del espinal. Zonas I, II y III señalan áreas de disponibilidad decreciente en recursos.

La zona I, incluye ambientes dentro del área nuclear del Espinal en los cuales se encuentra disponibilidad de rocas para la confección de artefactos por talla y por abrasión, picado y/o pulido, la mayor probabilidad de aparición de guanaco y hasta 0,45 de probabilidad de aparición de venado; cabe consignar que, en el área costera de esta zona, hay también disponibilidad de recursos marinos, lo cual aumenta la cantidad y la calidad de la oferta ambiental. La zona II incluye ambientes del área nuclear 
del Espinal y de las áreas denominadas como transicionales, situadas al NE y SO del área nuclear, en los cuales hay disponibilidad de rocas para la confección de artefactos por talla y por abrasión, picado y/o pulido, al tiempo que existen combinaciones de probabilidades altas a medias de guanaco y diferentes probabilidades de aparición de venado. Finalmente, la zona III incluye ambientes de las áreas nuclear y transicional del Espinal, mayormente desprovistos de rocas aptas para la confección de artefactos por talla y abrasión, picado y pulido, con muy bajas probabilidades de ocurrencia de guanacos y probabilidades variadas de aparición de venados.

Considerando esta clasificación ambiental, el sector distal de la cuenca del arroyo Chasicó y sus inmediaciones (i.e. valle inferior, laguna Chasicó, Salinas Chicas y Salitral de la Vidriera) pertenece a la zona I, mientras que la parte media de la cuenca y sus cabeceras, ocupa ambientes de la zona II (Figura $5.4)$.

\subsubsection{Modelo socioecológico}

Para realizar una estimación del tamaño probable de los grupos humanos que habitaron la cuenca del arroyo Chasicó durante el Holoceno tardío, así como su densidad, patrones de movilidad y composición de la dieta, se consideraron datos cuantitativos procedentes de fuentes etnográficas, sistematizados por Binford (2001). De las 339 sociedades cazadoras-recolectoras consideradas por este autor, se seleccionaron aquellos casos correspondientes a grupos localizados entre los $36^{\circ}$ y $40^{\circ}$ de latitud, un rango que comprende al SE de la Región Pampeana y al NE de Patagonia. La selección de los grupos en función de su posición respecto del ecuador obedece al hecho de que es esperable que, en latitudes equivalentes, se encuentren características climáticas similares las que, en interacción con el relieve, las rocas del soporte, el agua, el suelo y los seres vivos que habitan esos entornos, constituyen sistemas naturales o "geosistemas" análogos (Morello 2002). Como resultado del proceso de selección efectuado en la muestra total sobre la base del criterio explicitado, se conformó una submuestra constituida por 40 grupos que habitan, o habitaron en el pasado reciente, el oeste de Estados Unidos (California, Gran Cuenca y Grandes Llanuras; Figura 5.5) y dos grupos localizados en el sudeste de Australia (Victoria). De esta submuestra se excluyeron, en primer lugar, aquellas sociedades $(n=5)$ que utilizaban caballos en forma habitual (i.e. cazadores ecuestres) al momento de ser observados por los autores de los informes revisados por Binford (2001) ya que, en estos grupos, los valores de las distintas variables de interés se desvían significativamente de los de aquellas sociedades en las que el caballo o bien no fue utilizado, o bien no tuvo un impacto significativo en diferentes esferas de su organización (v.g. social, económica, política, simbólica). En segundo lugar, se excluyeron los grupos etnográficos que habitan o habitaron zonas montañosas o con cobertura boscosa de clima templado (norte de California y SE de Australia), por tratarse de ambientes muy diferentes de aquellos comprendidos por la cuenca del arroyo Chasicó. 


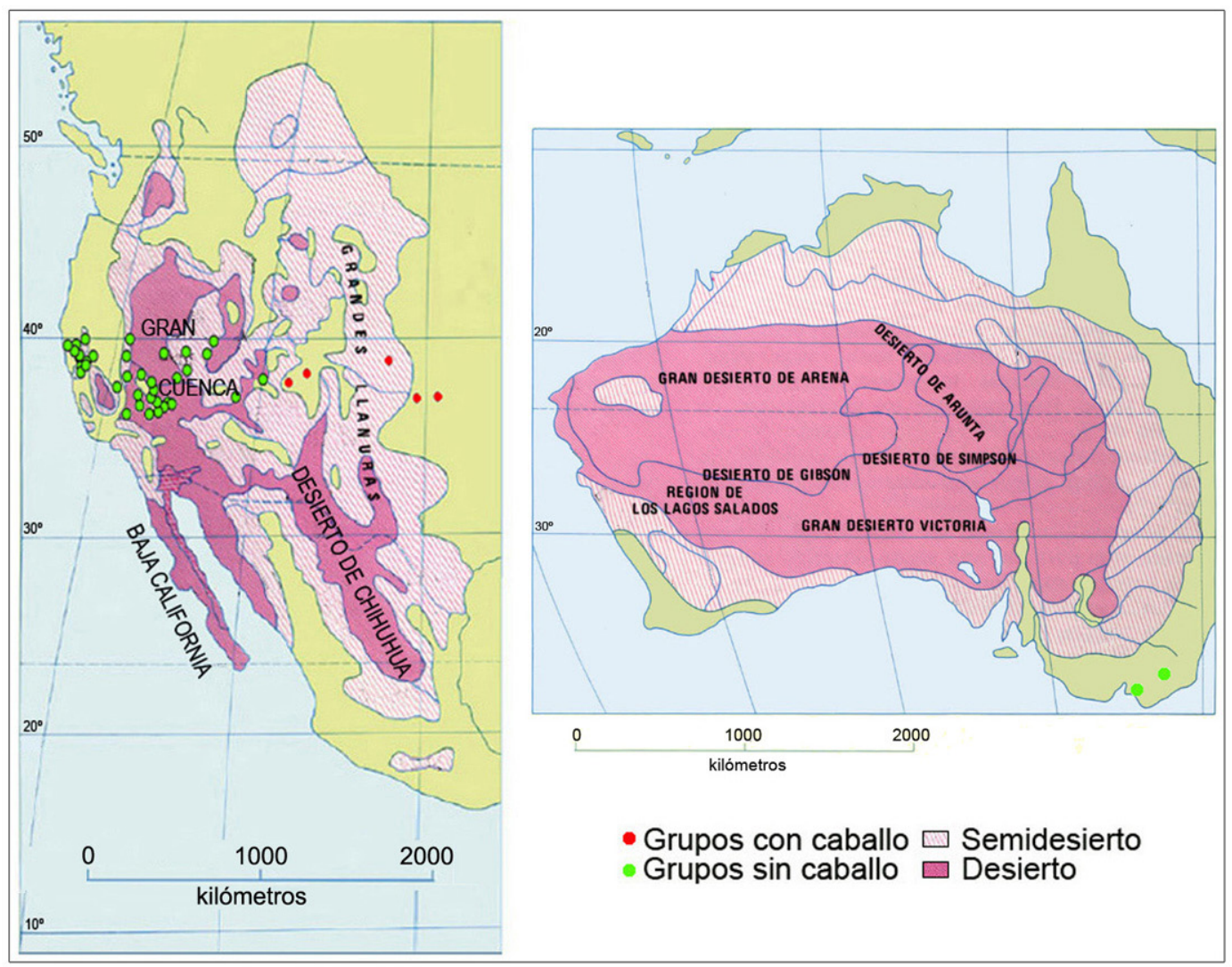

Figura 5.5. Localización de los grupos cazadores-recolectores de Australia y Norteamérica que integran la muestra inicial -seleccionada a partir de Binford (2001)- a partir de la cual se seleccionó la submuestra utilizada para la generación de un modelo socioecológico aplicable al caso de estudio. Se indican aquellos grupos que utilizaban caballos en forma habitual y aquellos que no lo hacían (mapas de base tomados de Morello 2002).

La submuestra resultante quedó constituida por 25 sociedades de Norteamérica, 7 de ellas ubicadas en el oeste de California y las 18 restantes en la Gran Cuenca, en ambientes predominantemente áridossemiáridos. Tales entornos han sido descriptos por Morello (2002) como similares en clima, relieve, roca madre y - debido a un proceso de convergencia ambiental — en el tipo de vegetación dominante y combinación de formas biológicas, a los ambientes de desierto y semidesierto, correspondientes, en Argentina, a las provincias fitogeográficas del Monte y del Espinal respectivamente (Figura 5.6).

Si bien en la actualidad una porción importante del área de estudio se encuentra fuera de la zona dominada por especies del Espinal, en diferentes momentos del Holoceno tardío ésta habría estado incluida dentro de dicha provincia fitogeográfica en su totalidad (ver apartado 5.2.1.1.1). En virtud de la similitud ambiental defendida por Morello (2002), se considera que las sociedades de la Gran Cuenca y del O. de California representan análogos adecuados para extraer generalizaciones empíricas que permitan modelar aspectos clave de la socioecología de las poblaciones del Holoceno tardío de la cuenca del arroyo Chasicó y de las áreas circundantes. 


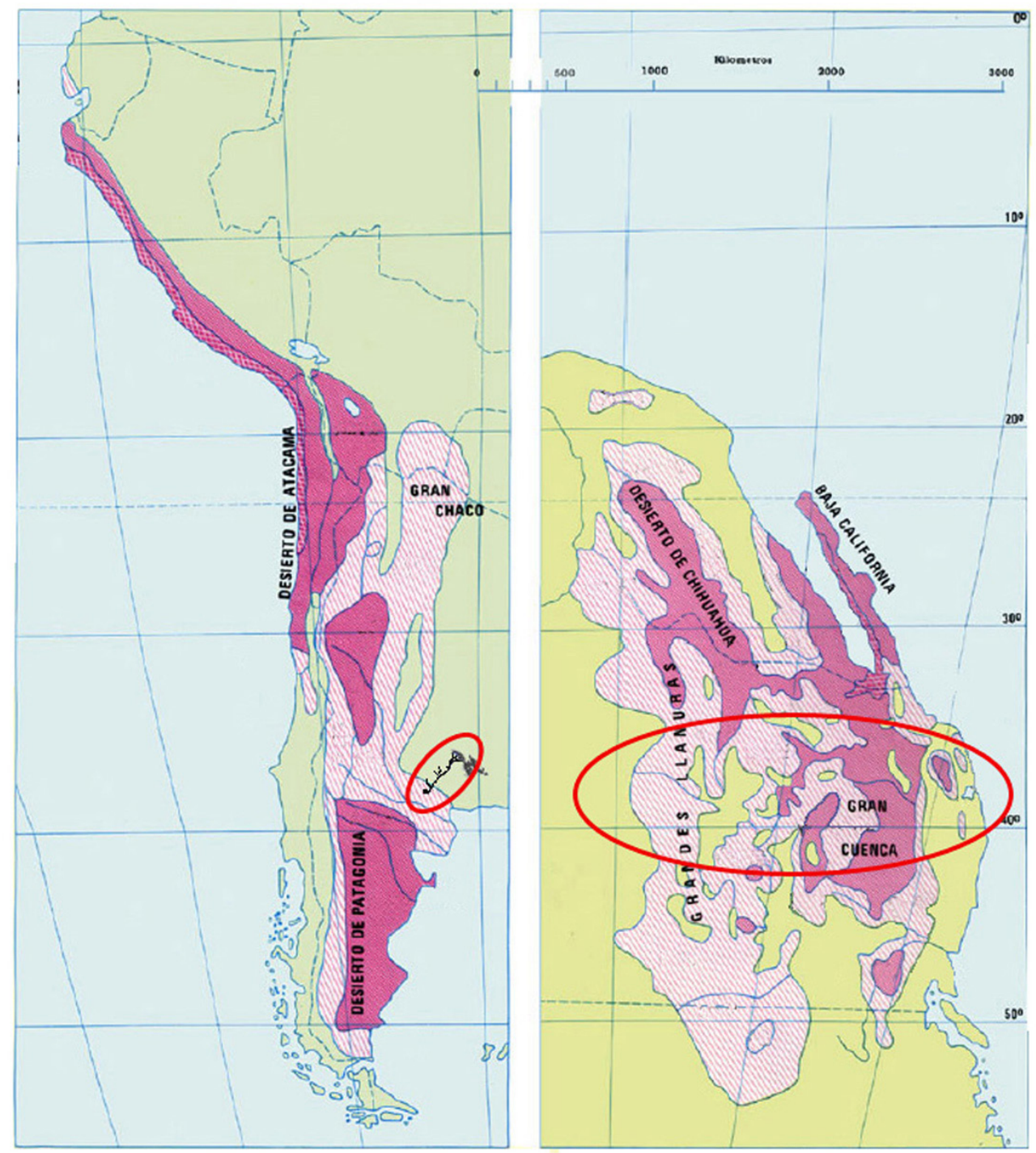

Figura 5.6. Mapa modificado a partir de Morello (2002), donde se realiza una comparación entre los ambientes de América del Sur y América del Norte. Las áreas señaladas en rojo muestran los ambientes de interés, a la izquierda el área de estudio y a la derecha aquella ocupada por los grupos descriptos por Binford (2001).

Las sociedades seleccionadas se dividen en dos grupos (códigos 1 y 2 de la variable GRPPAT; Binford 2001: 117): I) las que son móviles y que, en cada movimiento residencial, la totalidad del grupo se desplaza de un sitio a otro $(n=21 ; 84 \%)$ y II) las que son completamente sedentarias o mantienen un lugar central por períodos superiores a un año $(n=4 ; 16 \%)$. En las tablas 5.1 y 5.2 se resumen, para cada uno de estos grupos, las estadísticas descriptivas para diferentes variables cuantitativas, relevadas a partir de Binford (2001). Como la mayoría de las distribuciones de valores no son normales, se prefirió utilizar la mediana y el rango intercuartil como los principales estadísticos para caracterizar, en tales distribuciones, a la tendencia central y a la dispersión, respectivamente. Las variables pueden agruparse en: a) climática (temperatura efectiva en ${ }^{\circ} \mathrm{C}$ ), b) demográficas (Grupo I: tamaño total del grupo; tamaño medio de la unidad de consumo móvil que acampa junta durante la fase anual de mayor dispersión o 
GROUP1; tamaño medio de la unidad de consumo móvil que acampa junta durante la fase anual de mayor agregación o GROUP2; tamaño medio de los grupos agregacionales que se reúnen periódicamente o GROUP3; área total, en $\mathrm{km}^{2}$, ocupada por cada sociedad; densidad poblacional, medida en hab./100 km²; Grupo II: las mismas que en el grupo I, con excepción de las variables GROUP1 y GROUP2 que, en este caso, representan respectivamente el tamaño del grupo de tareas móvil que opera fuera de un asentamiento relativamente permanente y el tamaño medio de las aldeas que un grupo mantiene por dos o más años), c) de subsistencia (\% de caza, pesca y recolección respecto del total de las actividades de subsistencia) y d) de movilidad (cantidad media de movimientos residenciales anuales o NOMOV; cantidad media total de $\mathrm{km}$ recorridos en un año a través de los movimientos residenciales o DISMOV).

En términos del clima, las sociedades etnográficas muestreadas habitan climas de latitudes medias entre frescos y moderados, con una tendencia central hacia moderados (Bailey 1960: 8). La mediana de $14{ }^{\circ} \mathrm{C}$, con un rango intercuartil de $2{ }^{\circ} \mathrm{C}$ de temperatura efectiva (calculado para el total de la muestra, con independencia del grupo al que pertenecen los casos), concuerda con los valores estimados por

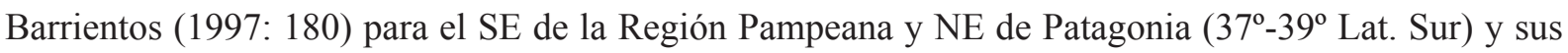
probables variaciones durante el Holoceno $\left(13-14,5^{\circ} \mathrm{C}\right)$.

En relación con la demografía, las sociedades del Grupo I difieren significativamente, en todas las variables, respecto de las del Grupo II. Los valores de la mediana para los tamaños totales son de 250 personas (rango intercuartil= 290) para el Grupo I y 3435 personas (rango intercuartil= 3979) para el Grupo II, mientras que el área total ocupada es de $3270 \mathrm{~km}^{2}$ en el primer caso y de $8760 \mathrm{~km}^{2}$ en el segundo. Esto conduce a que las sociedades más móviles vivan bajo condiciones de mucha menor densidad poblacional (4 hab./100 km²) que las menos móviles o sedentarias (38 hab./100 km²).

\begin{tabular}{|l|r|r|r|r|r|r|r|}
\hline \multicolumn{1}{|c|}{ Variable } & Mediana & Mín. & Máx. & $\begin{array}{c}\text { Cuartil } \\
\text { Inf. }\end{array}$ & $\begin{array}{c}\text { Cuartil } \\
\text { Sup. }\end{array}$ & $\begin{array}{c}\text { Rango } \\
\text { Inter- }\end{array}$ & Sesgo \\
cuartil & \\
\hline Temperatura Efectiva $\left({ }^{\circ} \mathrm{C}\right)$ & 14 & 12 & 17 & 13 & 15 & 2 & 0,657 \\
\hline Tamaño Total del Grupo & 250 & 23 & 1877 & 100 & 390 & 290 & 2,826 \\
\hline GROUP1 & 10 & 0 & 16 & 8 & 11 & 4 & $-0,791$ \\
\hline GROUP2 & 27 & 0 & 55 & 23 & 32 & 10 & $-0,286$ \\
\hline GROUP3 & 70 & 0 & 350 & 0 & 110 & 110 & 1,753 \\
\hline Área Ocupada $\left(\mathrm{km}^{2}\right)$ & 3270 & 380 & 25970 & 2400 & 6260 & 3860 & 2,030 \\
\hline Densidad $\left(\mathrm{hab}^{2} / 100 \mathrm{~km}^{2}\right)$ & 4 & 1 & 38 & 2 & 16 & 14 & 1,478 \\
\hline \% Caza & 40 & 25 & 55 & 35 & 45 & 10 & 0,068 \\
\hline \% Recolección & 50 & 40 & 75 & 48 & 55 & 7 & 1,150 \\
\hline \% Pesca & 7 & 0 & 25 & 0 & 15 & 15 & 0,373 \\
\hline NOMOV & 9 & 0 & 14 & 7 & 11 & 4 & $-0,829$ \\
\hline DISMOV & 195 & 0 & 270 & 90 & 220 & 130 & $-0,635$ \\
\hline
\end{tabular}

Tabla 5.1. Estadísticas descriptivas para diferentes variables cuantitativas relevadas a partir de Binford (2001), correspondientes a 21 sociedades etnográficas norteamericanas móviles del O. de California y de la Gran Cuenca (Grupo I). 


\begin{tabular}{|l|r|r|r|r|r|r|r|}
\hline \multirow{2}{*}{ Variable } & Mediana & Mín. & Máx. & $\begin{array}{c}\text { Cuartil } \\
\text { Inf. }\end{array}$ & $\begin{array}{c}\text { Cuartil } \\
\text { Sup. }\end{array}$ & $\begin{array}{c}\text { Rango } \\
\text { Inter- }\end{array}$ & \multirow{2}{*}{ Sesgo } \\
cuartil & \\
\hline Temperatura Efectiva $\left({ }^{\circ} \mathrm{C}\right)$ & 14 & 14 & 15 & 14 & 15 & 1 & 1,026 \\
\hline Tamaño Total del Grupo & 3435 & 1212 & 6500 & 1656 & 5635 & 3979 & 0,305 \\
\hline GROUP1 & 12 & 0 & 19 & 6 & 16 & 11 & $-0,894$ \\
\hline GROUP2 & 55 & 45 & 92 & 45 & 78 & 33 & 1,168 \\
\hline GROUP3 & 208 & 150 & 300 & 158 & 275 & 118 & 0,372 \\
\hline Área Ocupada $\left(\mathrm{km}^{2}\right)$ & 8760 & 4950 & 17070 & 5235 & 14535 & 9300 & 0,618 \\
\hline Densidad (hab./100 $\left.\mathrm{km}^{2}\right)$ & 38 & 25 & 40 & 31 & 39 & 8 & $-1,923$ \\
\hline \% Caza & 30 & 20 & 35 & 25 & 33 & 8 & $-1,129$ \\
\hline \% Recolección & 53 & 50 & 65 & 50 & 60 & 10 & 1,414 \\
\hline \% Pesca & 15 & 5 & 30 & 8 & 25 & 18 & 0,482 \\
\hline NOMOV & 2 & 1 & 4 & 1 & 3 & 2 & 1,414 \\
\hline DISMOV & 11 & 4 & 32 & 5 & 25 & 20 & 1,002 \\
\hline
\end{tabular}

Tabla 5.2. Estadísticas descriptivas para diferentes variables cuantitativas relevadas a partir de Binford (2001), correspondientes a 4 sociedades etnográficas norteamericanas sedentarias o semisedentarias del O. de California y de la Gran Cuenca (Grupo II).

En cuanto a la subsistencia, la dispersión de los valores porcentuales de caza, recolección y pesca, así como los valores de tendencia central, indican que las sociedades etnográficas consideradas poseen una dieta mayoritariamente basada en el consumo de recursos vegetales ( $\geq 40 \%$; tablas 5.1-5.2 y Figura 5.7). Las sociedades del Grupo I tienden a complementar la dieta con recursos animales procurados mediante la caza y, sólo marginalmente, a través de la pesca. Las del Grupo II -que presentan mayores porcentajes de recolección respecto de los del Grupo I- incluyen, en sus dietas, una mayor cantidad de recursos provenientes de la pesca, lo que sugiere que poseen una dieta de espectro más amplio, acorde con sus mayores valores de densidad poblacional.

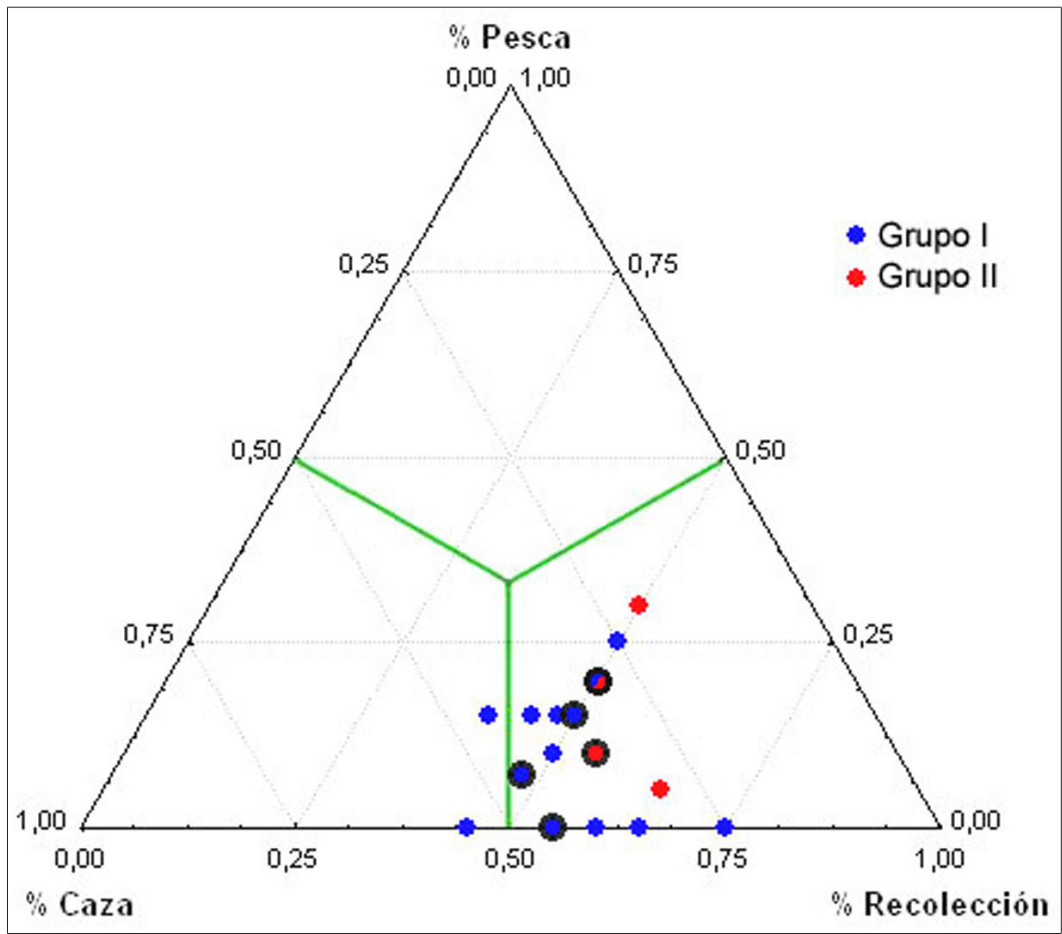

Figura 5.7. Gráfico ternario que muestra la dispersión de los valores porcentuales de caza, recolección y pesca correspondientes a las 25 sociedades muestreadas a partir de Binford (2001), discriminadas por su patrón de asentamiento (Grupo I y Grupo II). Los casos enmarcados en color negro son aquellos cuya latitud coincide con la de la cuenca del arroyo Chasicó $\left(37^{\circ}-38^{\circ}\right)$. 
Finalmente, respecto de los patrones de movilidad residencial, las sociedades del Grupo I son lógicamente más móviles que las del Grupo II, tanto en términos de la cantidad media de movimientos residenciales anuales como de la distancia total recorrida en un año en vinculación con tales desplazamientos.

Si consideramos que, entre cazadores-recolectores, las estrategias de asentamiento y de organización de la subsistencia constituyen un continuum, y que, en ambientes similares y cercanos, pueden existir marcadas diferencias en cuanto a demografía y patrones de movilidad, resulta posible unificar -en un segundo paso- la muestra y recalcular las estadísticas descriptivas de algunas de las variables de interés (tabla 5.3).

\begin{tabular}{|l|r|r|r|r|r|r|r|}
\hline \multicolumn{1}{|c|}{ Variable } & Mediana & Mín. & Máx. & $\begin{array}{c}\text { Cuartil } \\
\text { Inf. }\end{array}$ & $\begin{array}{c}\text { Cuartil } \\
\text { Sup. }\end{array}$ & $\begin{array}{c}\text { Rango } \\
\text { Inter- } \\
\text { cuartil }\end{array}$ & Sesgo \\
\hline Tamaño Total del Grupo & 378 & 23 & 6500 & 105 & 500 & 395 & 2,848 \\
\hline Área Ocupada $\left(\mathrm{km}^{2}\right)$ & 5300 & 400 & 26000 & 2600 & 6800 & 4200 & 1,705 \\
\hline Densidad (hab./100 $\left.\mathrm{km}^{2}\right)$ & 6 & 1 & 40 & 3 & 24 & 21 & 0,885 \\
\hline \% Caza & 40 & 20 & 55 & 30 & 45 & 15 & 0,065 \\
\hline \% Recolección & 50 & 40 & 75 & 48 & 55 & 7 & 1,043 \\
\hline \% Pesca & 10 & 0 & 30 & 0 & 15 & 15 & 0,456 \\
\hline NOMOV & 8 & 0 & 14 & 5 & 11 & 6 & $-0,369$ \\
\hline DISMOV & 150 & 0 & 270 & 50 & 215 & 165 & $-0,231$ \\
\hline
\end{tabular}

Tabla 5.3. Estadísticas descriptivas para diferentes variables cuantitativas relevadas a partir de Binford (2001), correspondientes a 25 sociedades etnográficas norteamericanas móviles, sedentarias o semisedentarias del O. de California y de la Gran Cuenca (Grupos I y II).

A partir de la muestra total, pueden investigarse las relaciones existentes entre demografía, subsistencia y movilidad. Para ello, se analizará la distribución de los valores individuales de: a) la densidad poblacional -una medida sintética que relaciona el tamaño del grupo y el área total ocupada por el mismo-, b) el porcentaje de recursos alimenticios provistos por la caza, la recolección y la pesca, c) la cantidad media de movimientos residenciales anuales, una medida de movilidad altamente correlacionada con la distancia recorrida en un año (Rho de Spearman= 0,$88 ; p<0,001)$.

La Figura 5.8 muestra la relación existente entre densidad poblacional y la contribución porcentual de las actividades de caza, recolección y pesca a la dieta, mientras que la Figura 5.9 expresa esta misma relación sólo para el porcentaje de recolección -actividad de subsistencia principal en estas sociedadesen vinculación con la movilidad residencial. 


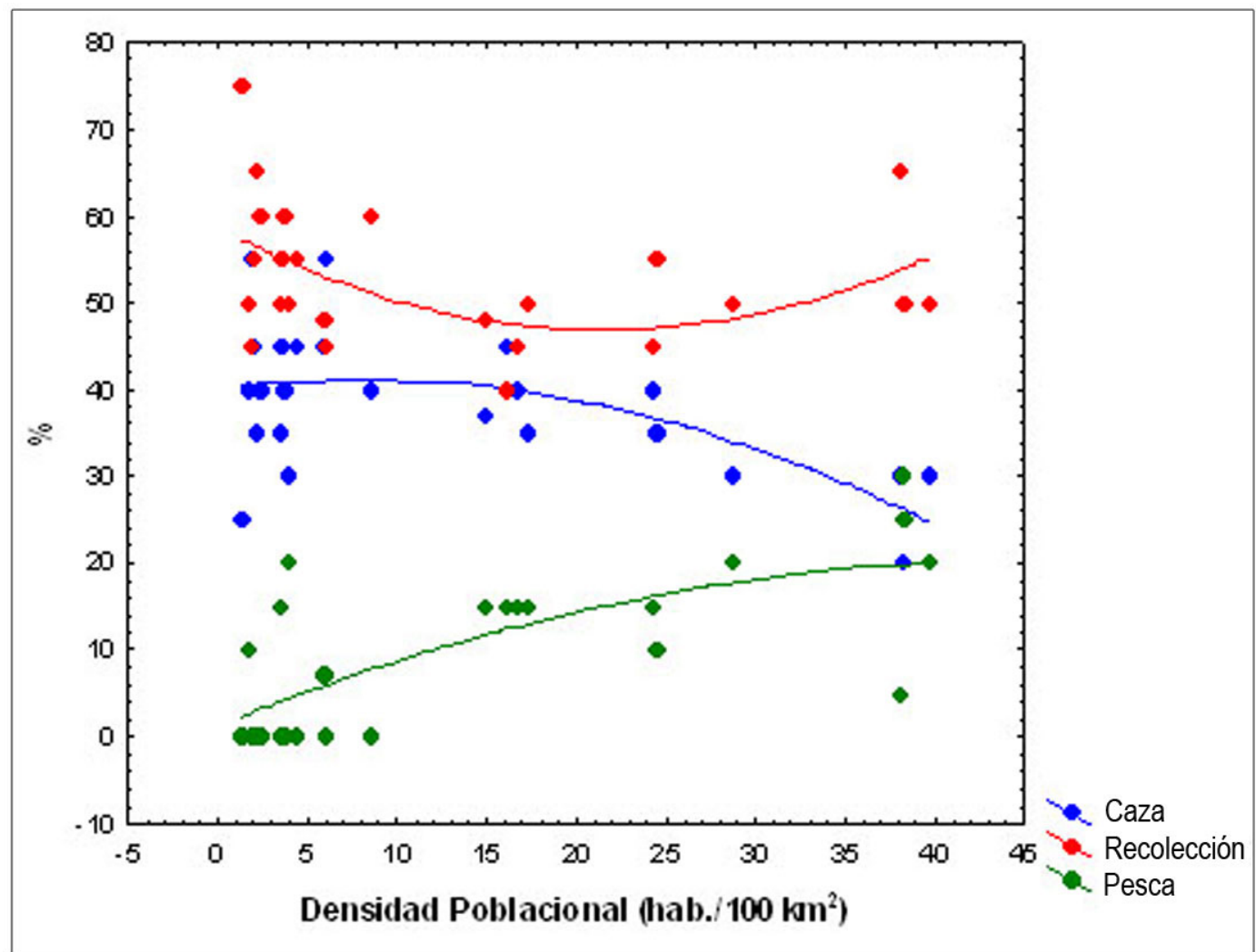

Figura 5.8. Diagrama de dispersión múltiple (ajuste exponencial negativo ponderado), que muestra la relación entre densidad poblacional y composición de la dieta para la muestra total $(n=25)$.

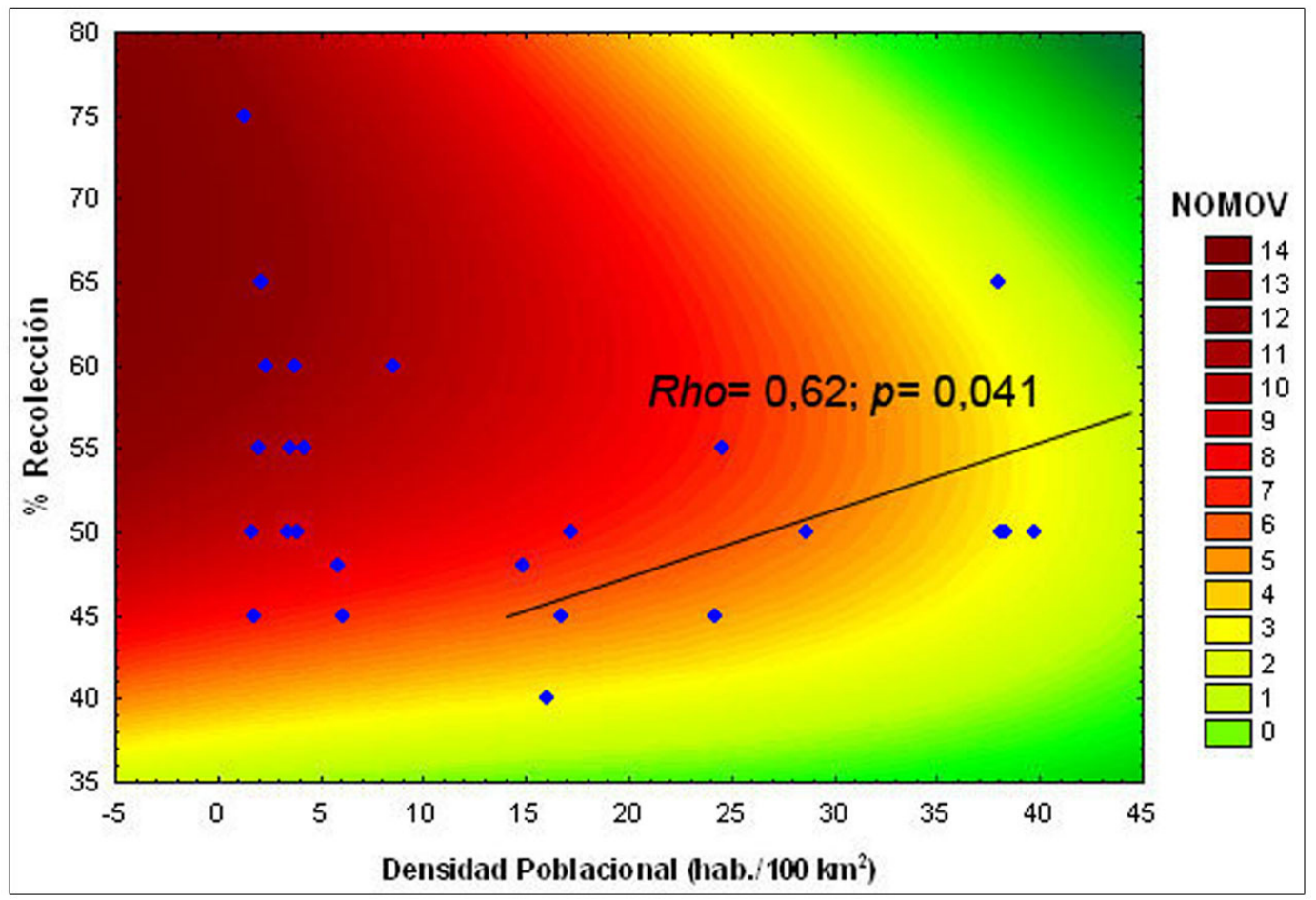

Figura 5.9. Diagrama de contorno 3D (ajuste exponencial negativo ponderado; rigidez=0,5), que muestra la relación entre densidad poblacional, porcentaje de recolección y movilidad para la muestra total $(n=25)$. La recta de ajuste sólo fue calculada para los casos $(n=11)$ cuyo valor de densidad era superior a $10 \mathrm{hab} . / 100 \mathrm{~km}^{2}$. 
En relación con la densidad, ninguna actividad de subsistencia posee, globalmente, un comportamiento lineal. En general se observa que, para valores de densidad inferiores a 10 hab./100 km², la contribución de cada actividad al total de la dieta es muy variable. Sin embargo, a medida que la densidad aumenta más allá de ese valor, las relaciones se tornan lineales: positivas en el caso de la recolección y de la pesca y negativa en el caso de la caza. Estos resultados sugieren que, bajo condiciones de baja densidad poblacional, no existe ningún factor que determine la composición de la dieta más allá de la oferta ambiental de recursos mientras que, a medida que la densidad aumenta y, consecuentemente, aumenta la presión de la población sobre los recursos disponibles, principalmente los de mayor valor nutricional y social (v.g. recursos faunísticos terrestres), se incrementa una tendencia a la diversificación de la dieta mediante la incorporación de recursos vegetales (i.e. con mayor diversidad específica y/o con un uso más intensivo de ciertas especies) y de pequeños vertebrados, como roedores y peces (Bettinger 1991; Broughton 1994; Kelly 1995). El incremento de la pesca podría ser interpretado como el resultado, en determinados ambientes, de una tendencia a mantener más o menos estables los valores de proteínas de alto valor biológico en la dieta, ante la disminución en el acceso a grandes vertebrados terrestres. Como es de esperarse, la movilidad residencial y la densidad poblacional varían en forma inversa (Rho de Spearman= -0,70; $p<0,001$; Figura 5.9), lo cual está de acuerdo con la noción de que una de las principales causas que conducen a un creciente desequilibrio entre población y recursos es la disminución de las opciones de movilidad, resultante de una mayor fragmentación de los hábitats o de una saturación de los espacios más requeridos.

A modo de síntesis puede decirse que el registro etnográfico del Oeste de California y de la Gran Cuenca, que por diferentes razones puede ser considerado como un análogo adecuado para modelar aspectos de la demografía, la subsistencia y la movilidad de las poblaciones tardías del área de estudio, muestra que:

a) existe una cierta variación en los parámetros de subsistencia analizados que sólo parcialmente puede ser explicada por diferencias en los patrones de asentamiento (i.e. Grupos I y II), ya que algunos de los grupos más móviles (Grupo I) se comportan, en términos de ciertas variables, como los correspondientes al Grupo II (v.g. figuras 5.7 y 5.9); esto refuerza la idea acerca de la existencia de un continuum entre ambas estrategias;

b) la distinción fundamental entre las sociedades consideradas se establece en relación con la densidad: cuando ésta es menor a $10 \mathrm{hab} . / 100 \mathrm{~km}^{2}$, tiende a ocurrir una mayor amplitud en los valores porcentuales de caza, recolección y pesca, que varían en forma independiente de la densidad; cuando la densidad poblacional es mayor a 10 hab./100 km², los valores porcentuales de caza, recolección y pesca tienden a variar linealmente (ya sea en forma positiva o negativa) con la densidad;

c) la densidad de población y la movilidad residencial tienden a variar en forma inversa, siendo probablemente -en la mayoría de los casos- la disminución de la segunda a causa del aumento de la primera.

En el apartado 5.2.1.1.4 se propuso una estratificación del SE de la Región Pampeana y el NE de Patagonia, a partir de la cual se generaron tres zonas diferenciadas por la disponibilidad de recursos. Cada una de estas zonas pudo haber posibilitado densidades demográficas diferentes y, en consecuencia, 
variables estrategias de movilidad y uso de los recursos a lo largo del Holoceno tardío. La mayor parte de los espacios categorizados como Zona I en la Figura 5.4 coinciden con el cauce inferior de los ríos Negro y Colorado, áreas para las que se ha propuesto que, a partir de los 1000 años AP, se habrían producido cambios en la organización de las sociedades, que involucraron mayor densidad poblacional, una mayor estabilidad y duración de las ocupaciones, reocupación de lugares específicos del paisaje, implementación de estrategias de diversificación económica y de movilidad logísticas y un complejo tratamiento de los muertos relacionado con un fuerte sentido territorial (Barrientos y Pérez 2004; Martínez 2010). En este contexto, podría hipotetizarse que los espacios de la Zona I habrían sido los más requeridos y aquellos en los que, bajo determinadas circunstancias (ver Barrientos 1997; Barrientos y Pérez 2004), se habría llegado a ciertos niveles de saturación demográfica (Borrero 1994-1995, 2001b) que podrían haber sentado las bases de los mencionados cambios en diferentes esferas de la organización de las sociedades implicadas. En los espacios de las Zonas II y III, en cambio, la disponibilidad ambiental de recursos es menor, por lo que este tipo de procesos pudo haberse desarrollado de manera marginal y, en consecuencia, con una intensidad menor. De este modo, los grupos pudieron presentar características más afines a las de aquellos de menor densidad poblacional y mayor movilidad residencial aquí descriptos, entre los cuales se esperaría una variación en la contribución de la caza, la recolección y la pesca -aunque con un marcado énfasis en la recolección- dependiente sobre todo de la oferta ambiental de recursos. En este sentido, serían esperables diferencias en determinados parámetros arqueológicos, vinculados con las variables consideradas en este apartado, entre la parte distal de la cuenca del arroyo Chasicó, correspondiente a la Zona I, y la parte media y proximal de la cuenca, incluidas dentro de la Zona II. Estas expectativas serían válidas para el Holoceno tardío, antes de la incorporación del caballo por parte de las sociedades aborígenes de la región.

\subsubsection{Patrones distribucionales (espaciales y temporales) de diferentes aspectos del registro arqueológico del sur de la Región Pampeana y NE de Patagonia}

Con el fin de modelar la estructura regional del registro arqueológico y poder así generar expectativas precisas para la cuenca del arroyo Chasicó, en esta sección se presentará y discutirá un conjunto de datos acerca de los patrones distribucionales, tanto temporales como espaciales, de diferentes ítems arqueológicos en el centro-este de Argentina (entre $36^{\circ}$ y $42^{\circ}$ de latitud sur y entre $57^{\circ}$ y $68^{\circ}$ de longitud oeste), área que incluye el sur de la Región Pampeana (Pampa Húmeda y Pampa Seca) y el NE de Patagonia. Se revisará la distribución de los fechados radiocarbónicos, de las principales materias primas líticas representadas en forma de artefactos en los sitios arqueológicos (cuarcita, rocas silíceas opacas -RSO- y calcedonia), de los artefactos de molienda, de la cerámica y de los valores de $\delta^{13} \mathrm{C}$ y $\delta^{15} \mathrm{~N}$ de muestras humanas y faunísticas. En todos los casos, se exceptúan los datos previamente disponibles para la cuenca del arroyo Chasicó, ya que estos serán presentados y discutidos en conjunto con la nueva información obtenida, en los capítulos 6 a 11.

Para la formulación de los modelos cronológicos y espaciales, se elaboraron bases de datos georreferenciados -a partir de un exhaustivo relevamiento de la literatura- para su posterior tratamiento estadístico y geoestadístico. La distribución temporal de los fechados radiocarbónicos calibrados fue analizada mediante la generación de curvas de probabilidades sumadas, mientras que los datos georreferenciados, referidos a distintos aspectos del registro, fueron utilizados como base para la 
producción de modelos espaciales continuos. Los mismos fueron realizados utilizando el método de interpolación kriging (ordinary kriging, prediction map, spherical semivariogram), incluyendo entre 5 y 8 puntos y realizándose correcciones para anisotropía y tendencia (Márquez Pérez 2012) cuando los datos así lo requirieron. El kringing es un método de interpolación geoestadística que, basándose en el principio de autocorrelación espacial (que establece que la información de una determinada variable procedente de puntos cercanos en el espacio presentará mayores semejanzas que aquella procedente de localizaciones más distantes), permite modelar superficies continuas a partir de datos discretos ya existente (Lloyd y Atkinson 2004). En arqueología, la autocorrelación es una asunción razonable para una gran cantidad de ítems (Conolly y Lake 2006), por lo que la producción de mapas distribucionales continuos en formato raster representa una importante herramienta que permite visualizar claramente las tendencias espaciales en los datos, al tiempo que proporciona nuevas formas de análisis cuantitativo de la información.

\subsubsection{Modelo cronológico}

La generación de esta clase de modelo se realizó a los fines de construir un marco temporal en el cual poner en perspectiva la información arqueológica generada durante el desarrollo de esta investigación y presentada en el capítulo 7. Para la selección de los fechados a ser incluidos en la base de datos, se siguieron los criterios utilizados por Barrientos y Masse (2012), consistentes en: a) no incorporar aquellos fechados que, teniendo en cuenta el contexto, los autores de los correspondientes informes han considerado problemáticos o dudosos; b) en aquellos casos en los que se realizó más de una medición sobre la misma muestra, tomar sólo la fecha más antigua; c) excluir los fechados que no se relacionan directamente con conjuntos arqueológicos (v.g. muestras sedimentarias) y c) eliminar los fechados con un error de medición ( $\sigma$ o sigma) mayor a 300 años ${ }^{14} \mathrm{C}$. De esta manera se obtuvo una base de datos conformada por 300 fechados procedentes de 107 sitios arqueológicos (Figura 5.10).

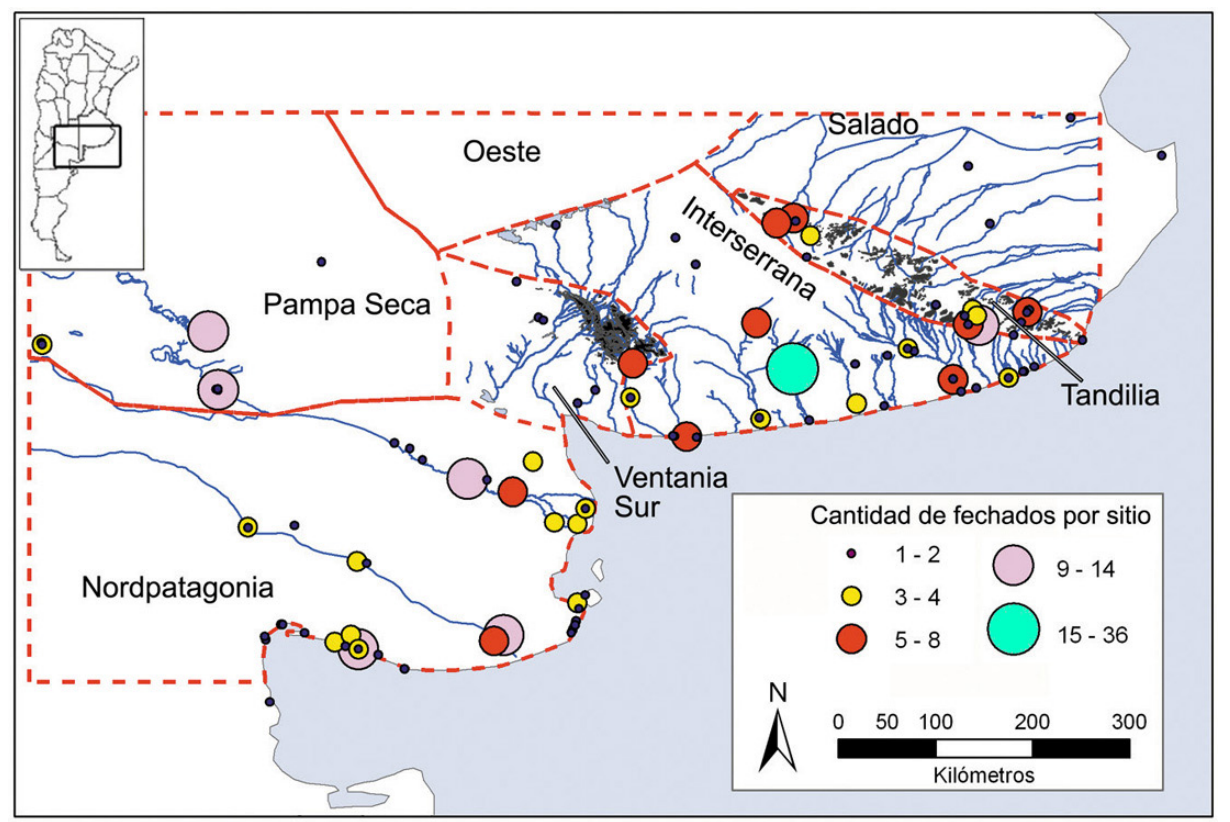

Figura 5.10. Distribución espacial de los fechados considerados para generar el modelo cronológico del sur de la Región Pampeana y NE de Patagonia. 
En los casos en que fue necesario, los fechados obtenidos por conteo beta sobre colágeno (muestras faunísticas y humanas) fueron corregidos por fraccionamiento isotópico mediante el uso de la fórmula disponible en el sitio http://calib.qub.ac.uk/calib/fractionation.html. Los valores de $\delta^{13} \mathrm{C}$ requeridos para realizar la corrección procedieron de dos clases de fuentes: local y regional. En el primer caso, se utilizaron los valores individuales o promediados correspondientes a muestras del mismo sitio y especie disponibles, ya sea por estar asociados a fechados radiocarbónicos con AMS o por la realización de estudios específicos de isótopos estables del C. En el segundo caso, ante la ausencia de información local se utilizaron, para cada especie, los valores de $\delta^{13} \mathrm{C}$ promediados correspondientes a diferentes contextos arquelógicos de la respectiva área o región (Interserrana, Ventania, Tandilia, Pampa Seca y NE de Patagonia Costa y NE de Patagonia Interior). En los casos en los que el material datado correspondía a elementos de origen marino, se realizó la corrección por efecto reservorio, para lo cual se utilizó el valor de -266 años para el caso de muestras procedentes del NE de Patagonia (Favier Dubois 2009) y de $-138,3$ para las muestras al norte de Bahía Blanca, considerando los valores publicados en la base de datos para corrección por efecto reservorio disponible en http://calib.qub.ac.uk/marine/.

Una vez obtenidas las edades radiocarbónicas convencionales (i.e. corregidas por fraccionamiento isotópico), los fechados fueron calibrados mediante el uso del paquete informático CalPal-2007 (Weninger et al. 2012), un software que permite el procesamiento simultáneo de grandes conjuntos de datos y su comparación, en tiempo real, con diversos proxies plaeoclimáticos. La curva utilizada fue Calpal-2007-Hulu (Weninger y Jöris 2007), que produce resultados comparables —en función de los propósitos y de la escala de análisis de este estudio- a INTCAL09 (Bradtmöller et al. 2012). Las posibles diferencias con los resultados derivados del uso de la curva SHCal04 recomendada para el Hemisferio Sur (McCormac et al. 2004), se consideran poco importantes frente a las ventajas derivadas de la aplicación del paquete CalPal-2007. Para el conjunto de fechados calibrados diferenciados por zona o región (i.e. Interserrana, Ventania, Tandilia, Pampa Seca y NE de Patagonia), se obtuvo la curva de probabilidades sumadas, un recurso ampliamente utilizado para evaluar las diferencias temporales en la intensidad de la "señal arqueológica" e identificar sus posibles fuentes de ruido y distorsión (Barrientos y Masse 2012: 55), entre los que se encuentran los llamados sesgos tafonómicos y de investigación (Surovell y Brantingham 2007; Surovell et al. 2009).

Los resultados obtenidos indican que la señal arqueológica de las distintas áreas es muy dispar, lo que puede estar en relación con los efectos de tres causas combinadas: 1) el patrón de ocupación humana prehistórico, 2) los sesgos derivados de los procesos que destruyen o enmascaran el registro y 3) los sesgos de muestreo. Cuando se consideran períodos largos de tiempo, como el segmento temporal constituido por el Pleistoceno final y Holoceno, el patrón de distribución de frecuencias esperable es el curvilíneo, en el cual el número de fechas aumenta desde el pasado más distante hasta el presente (Surovell y Brantingham 2007; Surovell et al. 2009). Esto se debe a que la acción de fuerzas destructivas con efectos acumulativos a través del tiempo (v.g. erosión, diagénesis, meteorización), hace más probable el hallazgo y la datación de los correlatos materiales de los eventos temporalmente más próximos a nosotros que de los más lejanos. En la muestra considerada, sólo las distribuciones de Pampa Seca y del NE de Patagonia se ajustan a este patrón, mientras que las de las áreas Interserrana y Tandilia manifiestan diferentes desviaciones respecto del mismo, sugiriendo la existencia de otros factores causales. Ventania se encuentra representada por una cantidad pequeña de casos, lo que dificulta la interpretación de la distribución encontrada. 


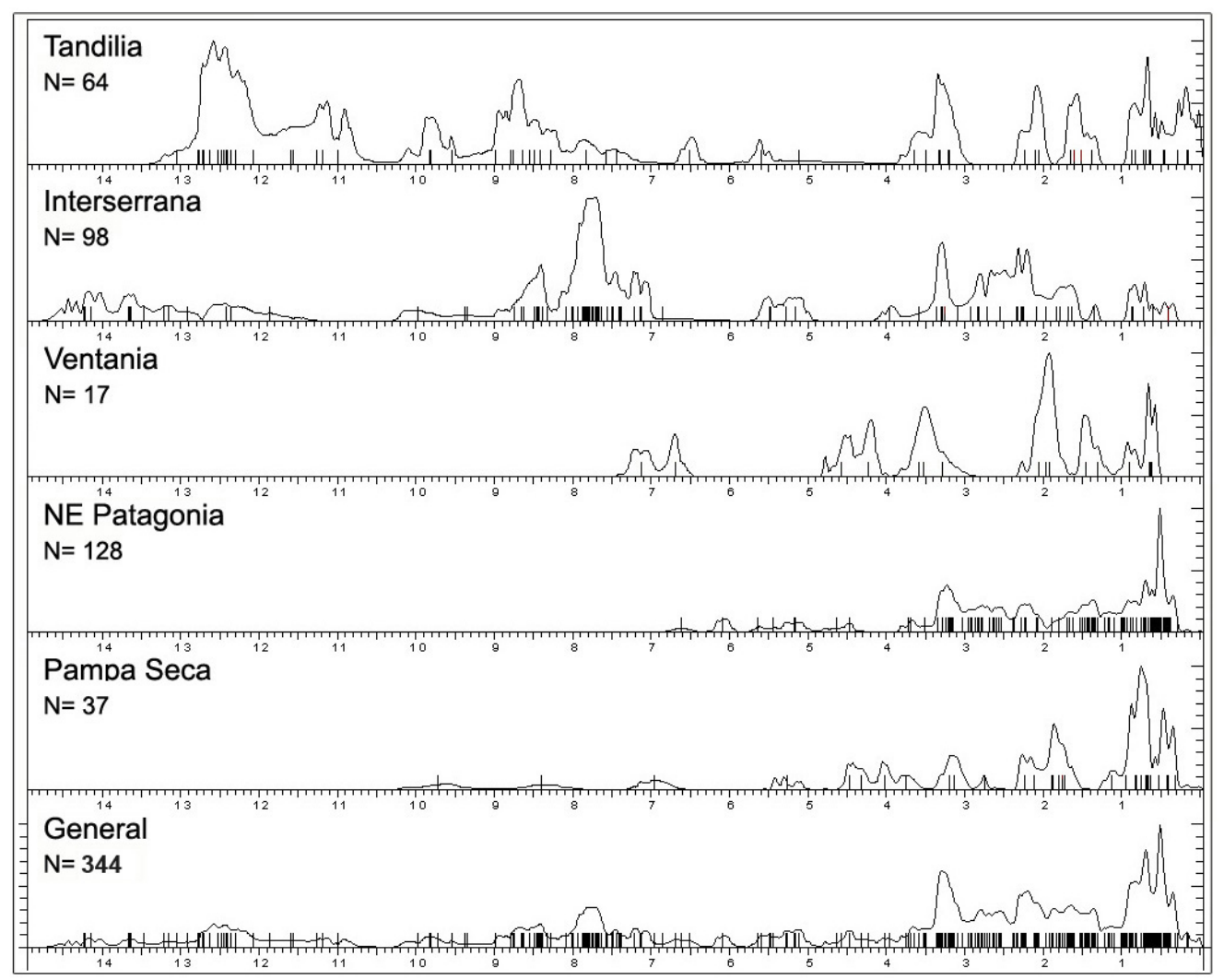

Figura 5.11. Curvas de probabilidades sumadas de los fechados radiocarbónicos calibrados para las diferentes áreas consideradas y para la muestra total $(\mathrm{n}=344)$.

En el caso de Tandilia, se hallan sobrerrepresentados el Pleistoceno final y el Holoceno temprano, mientras que en el área Interserrana, tal sobrerrepresentación se localiza a inicios del Holoceno medio. En ambos casos, las causas de los patrones distribucionales encontrados son múltiples, siendo las más probables el patrón de ocupación regional, problemas de conservación diferencial del registro y, sobre todo, sesgos de muestreo derivados de la búsqueda, localización y datación preferencial de ocupaciones tempranas en el caso de Tandilia y de la intensidad de la investigación de un sitio emblemático como Arroyo Seco 2, en el área Interserrana. La curva general, que describe las tendencias del total de la muestra, exhibe el característico patrón curvilíneo, con dos zonas temporales que muestran una muy débil intensidad de la señal arqueológica: el Holoceno temprano ( $c a$. 11.000-9000 años cal. AP) y el Holoceno medio (ca.7000-4000 años cal. AP). La baja intensidad de la señal arqueológica en estos períodos, e incluso su ausencia (i.e. discontinuidades en la secuencia de fechados) han sido interpretadas como resultado de problemas de muestreo, una disminución en la demografía, aumento en la movilidad y/o cambios en el uso del espacio (Barrientos 1997, 2009; Barrientos y Masse 2012; Barrientos y Perez 2005; Barrientos et al. 2005; Bonomo y León 2010; Martinez 2002; Politis 1984).

A partir de la información disponible, se puede construir el marco cronológico para el área de estudio considerando los conceptos de "cuenta larga" y de "cuenta corta" (Borrero et al. 1992). La cuenta larga, definida como la máxima esperable, está dada por los fechados más antiguos registrados para el centro-oeste de Argentina, (ca. 14.000 años cal. AP; Steele y Politis 2009). La cuenta corta por otra parte, se define como la profundidad temporal defendible, por medio de fechados radiocarbónicos, para el área de estudio y sus inmediaciones, en este caso el área de Ventania, definida a los fines de esta 
tesis como el Sistema Serrano de Ventania y la llanura localizada al sudoeste del mismo (ubicada entre la divisoria de aguas de las cuencas del arroyo Napostá Chico y el río Sauce Grande, el límite entre las provincias de Buenos Aires y La Pampa y los bajos ocupados por la laguna Chasicó), donde la secuencia se inicia $c a .7500$ años cal. AP, (Caverna El Abra; Castro 1983). Sin embargo, la tendencia general del área de estudio, considerando las dataciones más tempranas registradas en cada sitio o localidad (Figura 5.12), indica que el registro adquiere mayor visibilidad a partir de la primera fase del Holoceno tardío (de aquí en más Holoceno tardío inicial, ca. 4000-2000 años cal. AP), un rasgo compartido con Pampa Seca y parte del NE de Patagonia. En tal sentido, para la cuenca del arroyo Chasicó, será esperable la presencia de materiales arqueológicos correspondientes a momentos posteriores a los 4000 años cal $\mathrm{AP}$, principalmente en la cuenca inferior, donde habrían actuado procesos geomorfológicos similares a los actuantes en el NE de Patagonia. En la cuenca media y, principalmente, superior, podrá esperarse la presencia de registro arqueológico de mayor antigüedad.

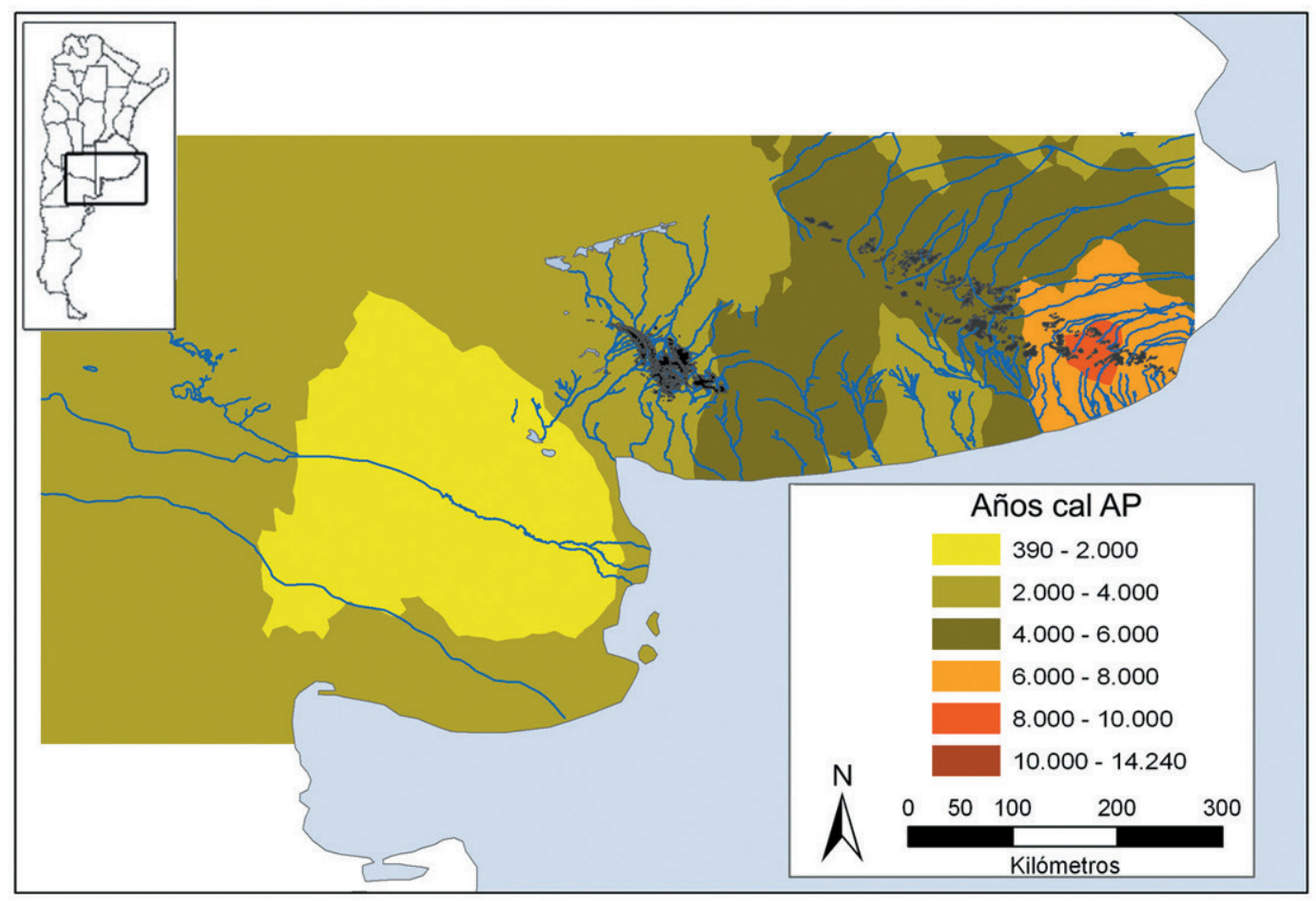

Figura 5.12. Distribución espacial de los fechados más tempranos registrados en cada sitio o localidad arqueológica $(\mathrm{n}=117)$.

\subsubsection{Modelos distribucionales de la variación tecnológica}

\subsection{Tecnología lítica}

\subsection{Materias primas representadas en artefactos}

La distribución en el espacio de las materias primas bajo la forma de artefactos, se encuentra estrechamente relacionada tanto con la ubicación y características de las fuentes, como con las estrategias de movilidad y los rangos de acción de las poblaciones que las utilizaron (Amick 1999; Binford 1980; Browne y Wilson 2011; Gould y Saggers 1985). En tal sentido, la distribución de materias primas en el espacio, particularmente de aquellas de las que se conoce su probable lugar de procedencia, puede ser 
un indicador, al menos parcial, del rango de movilidad de las poblaciones y del modo en que el recurso lítico es utilizado (ver discusión en el capítulo 10).

La Región Pampeana y el NE de Patagonia se diferencian, entre otras cosas, en su disponibilidad de rocas. En la región Pampeana, particularmente en la Pampa Húmeda, la materia prima más abundante es la cuarcita, que está presente en los dos sistemas serranos y en algunos afloramientos menores, así como en bancos de rodados localizados en el cauce de muchos arroyos y en paleocauces enterrados que, en ciertos lugares, afloran por la erosión (Catella et al. 2013). Las rocas microcristalinas (v.g. calcedonias o ftanitas, sílices opacas) en cambio, se encuentran restringidas a algunos afloramientos puntuales de Tandilia y a los rodados costeros distribuidos actualmente, con mayor continuidad y abundancia, al sur del cabo Corrientes y hasta el río Quequén Salado (Bonomo 2004; Bonomo y Prates 2009). En el NE de Patagonia y el sur de la Pampa Seca en cambio, la principal fuente de materias primas es el manto de rodados tehuelches, conformado predominantemente por rocas silíceas opacas (RSO) y, en menor proporción, por basaltos y otras rocas ígneas, encontrándose las cuarcitas representadas sólo por algunos rodados aislados presentes en este mismo manto (Linares et al. 1980; Martínez, Rabassa y Coronato 2009). Estas materias primas (cuarcitas y calcedonias en Pampa Húmeda y RSO en el NE de Patagonia y Pampa Seca), son las principales rocas representadas artefactualmente en la mayor parte de los conjuntos líticos definidos a nivel de sitio.

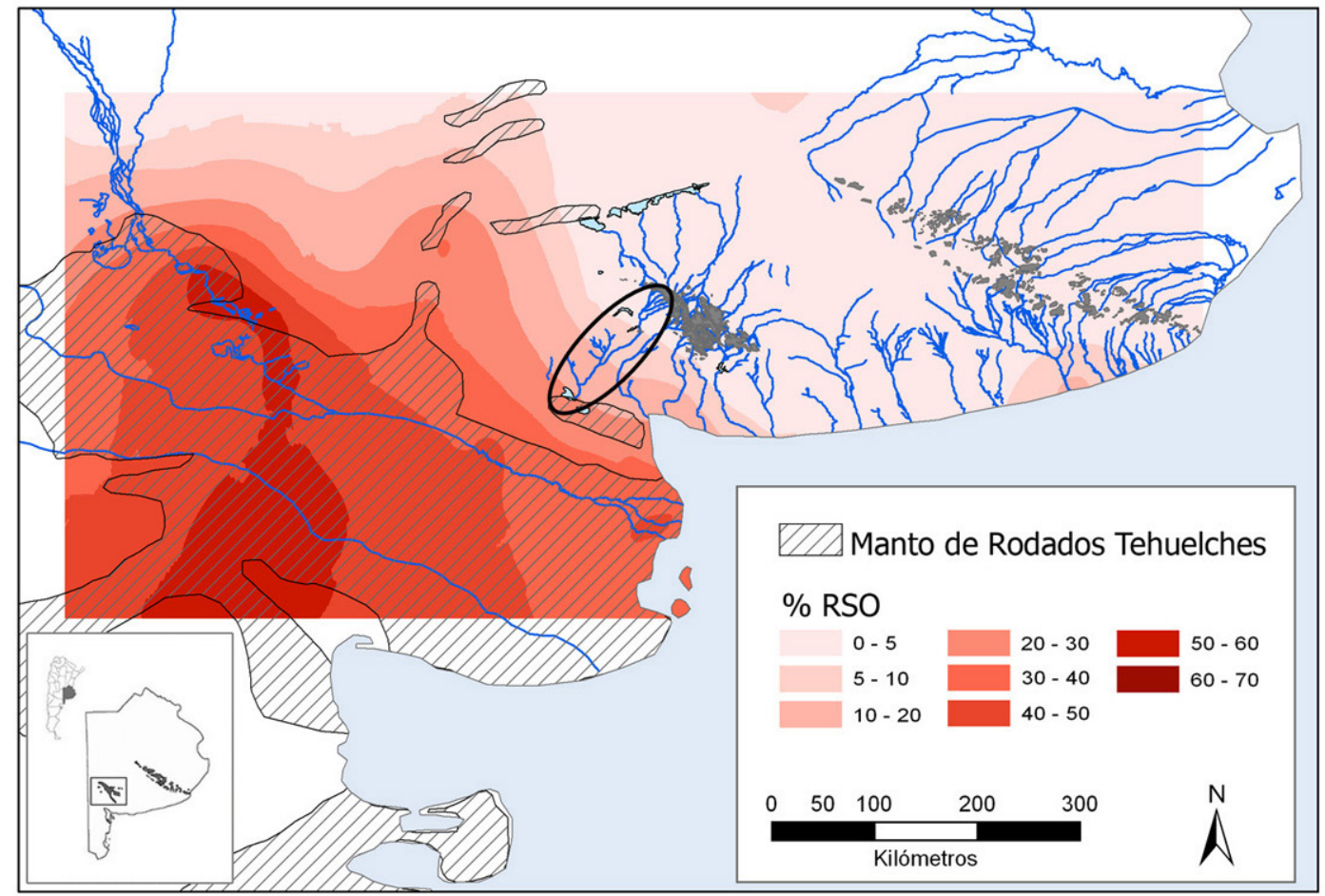

Figura 5.13. Modelo espacial continuo de la distribución de frecuencias relativas de RSO en la forma de artefactos. El círculo señala la cuenca del arroyo Chasicó, excluida en esta instancia de la interpolación $(\mathrm{n}=110)$. 
Considerando el predominio de estas tres rocas en los sitios arqueológicos y el hecho de que se conoce con bastante precisión sus potenciales fuentes de abastecimiento, se modeló su distribución espacial utilizando el método de interpolación kriging previamente descripto (apartado 5.2.2). Los mapas distribucionales fueron realizados sobre la base de valores porcentuales de las materias primas representadas como artefactos en 110 sitios y/o localidades arqueológicas localizados entre los $36^{\circ}$ y los $42^{\circ}$ de latitud sur y entre la costa atlántica y los $68^{\circ}$ de longitud oeste excluyéndose, en todos los casos, los sitios de la cuenca del arroyo Chasicó (los que son incorporados y discutidos en el Capítulo 10). Sólo se consideraron los conjuntos con un $n \geq 25$ artefactos, debido a que valores menores dificultan la estimación de los porcentajes. Para evitar una concentración exagerada de puntos en ciertos sectores del espacio, aquellos sitios separados por distancias lineales inferiores a $1 \mathrm{~km}$ fueron considerados en conjunto, calculándose un valor porcentual promediado para cada tipo de roca.

La Figura 5.13 muestra que los mayores porcentajes de RSO se encuentran en aquellos sitios arqueológicos localizados dentro del área de distribución del Manto de Rodados Tehuelche (sensu Martínez, Rabassa y Coronato 2009), disminuyendo rápidamente su representación en aquellos sitios que no se encuentran localizados en las inmediaciones de esta fuente. La mayor parte del área Interserrana, Tandilia y la Depresión del Salado presentan valores entre 5\% y 0\%, con excepción del sector costero y parte del interior localizado alrededor de la parte inferior de la cuenca del río Quequén Grande, coincidiendo tal dispersión con la presencia de RSO en los depósitos litorales de rodados del área. El modelo predice, para la cuenca del arroyo Chasicó, valores decrecientes desde la parte distal a las cabeceras, con un gradiente que va del $30 \%$ a menos del $5 \%$.

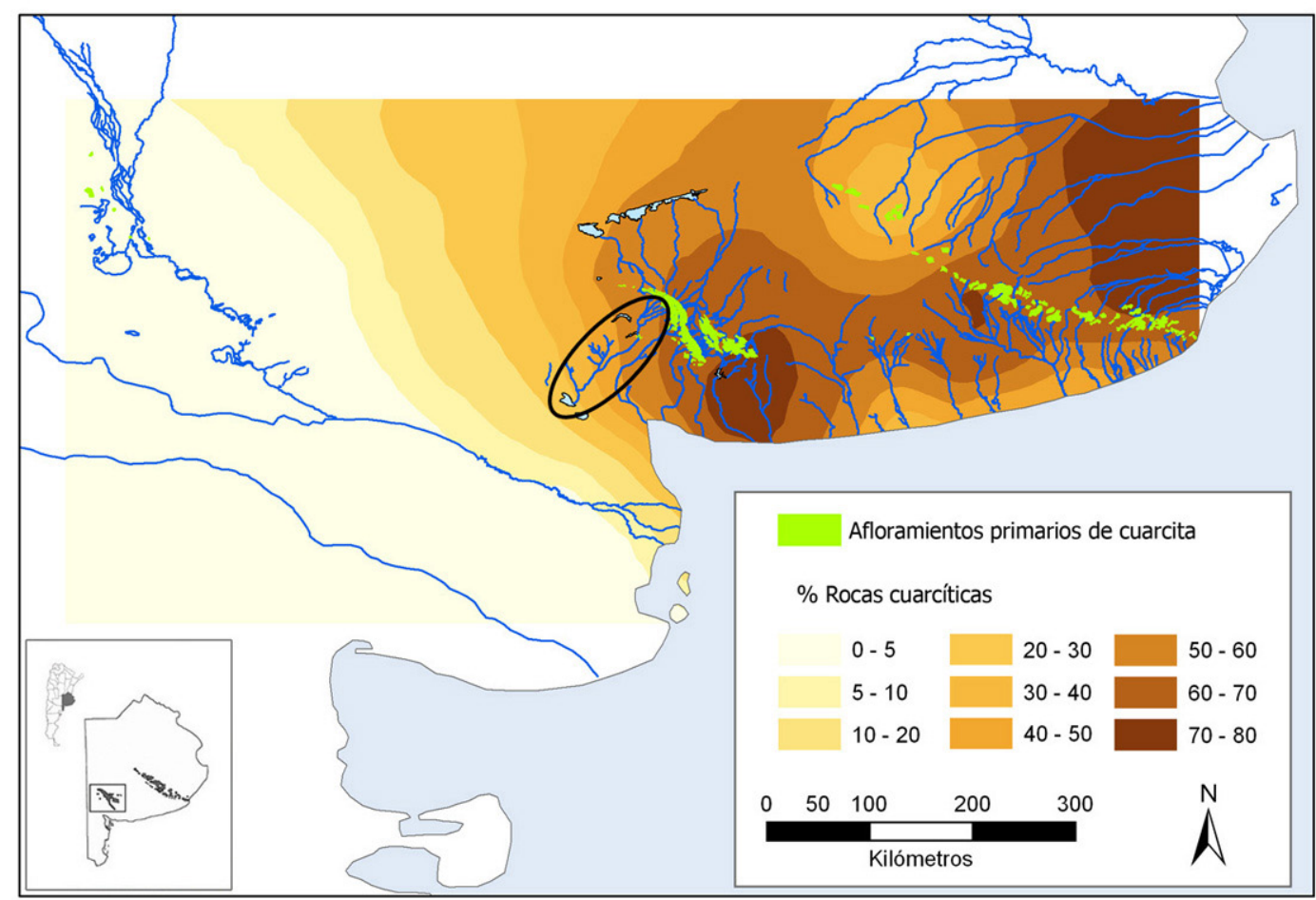

Figura 5.14. Modelo espacial continuo de la distribución de frecuencias relativas de cuarcitas en la forma de artefactos. El círculo señala la cuenca del arroyo Chasicó, excluida en esta instancia de la interpolación $(\mathrm{n}=110)$. 
En relación con las cuarcítas, la Figura 5.14 muestra que el mayor predominio de éstas se da en inmediaciones de los dos principales afloramientos primarios de dicha materias prima (sistemas serrano de Tandilia y Ventania), extendiéndose hacia el área Interserrana y la llanura ubicada al NE de Tandilia. $\mathrm{Su}$ representación en los sitios arqueológicos disminuye rápidamente hacia el SO de Ventania y NO de Tandilia, así como en el sector central de la costa atlántica bonaerense. Esta situación probablemente responde a la presencia de otras fuentes de materias primas inmediatamente disponibles, como es el caso de las RSO y los basaltos presentes en forma de rodados en la costa atlántica y en el manto de rodados tehuelches más al sur, o bien la presencia de afloramientos primarios de calcedonia en el noroeste de Tandilia. Para la cuenca del arroyo Chasicó, el modelo predice un gradiente decreciente, desde las cabeceras a la parte distal, que va del $80 \%$ en la zona serrana hasta el $20 \%$ en la laguna Chasicó.

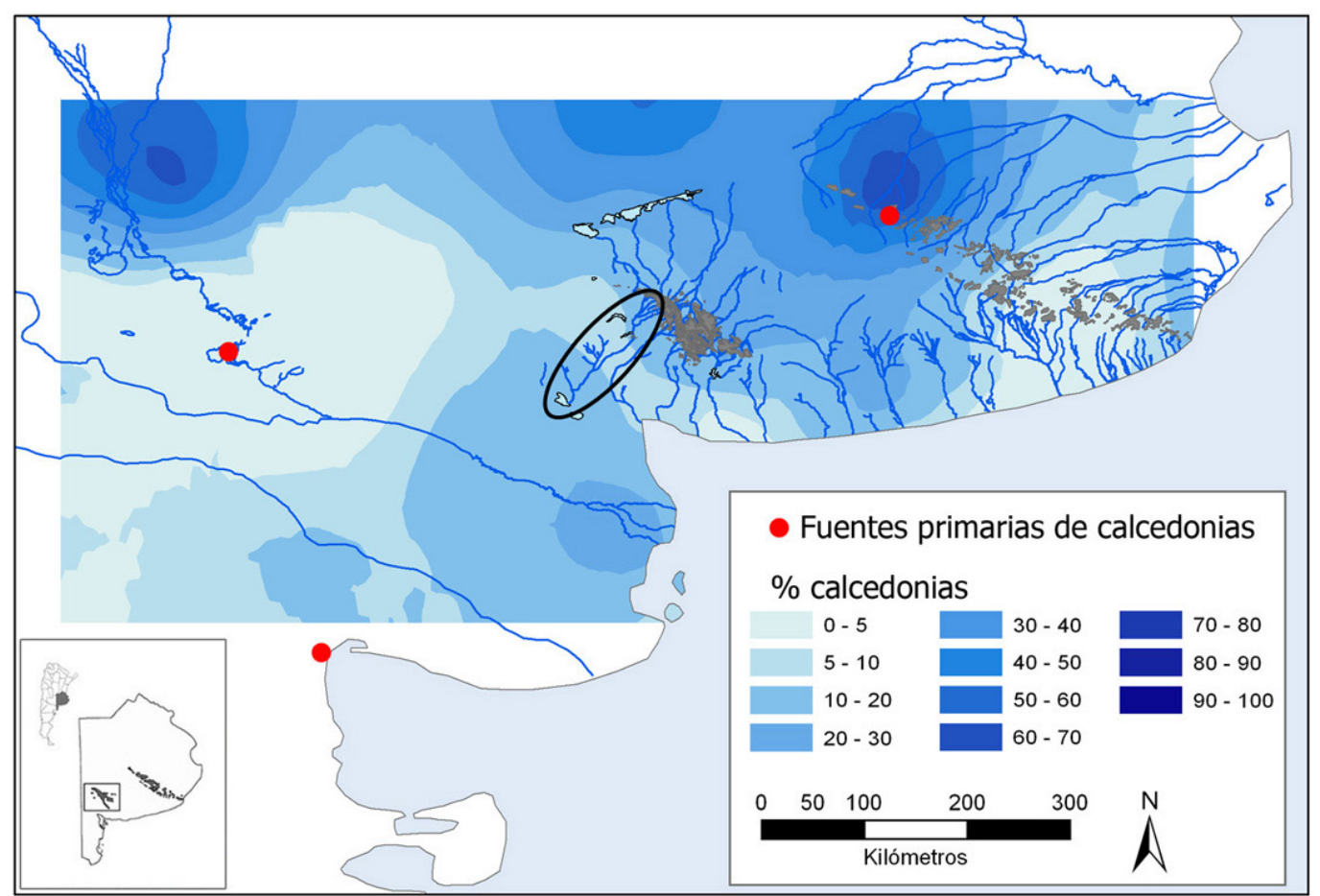

Figura 5.15. Modelo espacial continuo de la distribución de frecuencias relativas de calcedonias en la forma de artefactos. El círculo señala la cuenca del arroyo Chasicó, excluida en esta instancia de la interpolación $(\mathrm{n}=110)$.

La distribución de calcedonias en los sitios arqueológicos estaría indicando la presencia de entre dos y tres potenciales fuentes de obtención de esta materia prima, evidenciadas por picos que muestran áreas con una mayor representación de esta roca en los sitios arqueológicos (Figura 5.15). El primero y más evidente, se encuentra en el noroeste de las sierras de Tandilia, coincidiendo con los afloramientos de calcedonias Sierras Bayas, Olavarría (Barros y Messineo 2004; Lozano 1991; Messineo 2008). Un segundo pico, más débil, se ubica en el sur de la provincia de Buenos Aires, y podría vincularse con su presencia, aunque en un bajo porcentaje, en el manto de rodados tehuelches, así como a la localización de nódulos tabulares en la costa oeste y norte del Golfo de San Matías (Cardillo y Scartascini 2011). Finalmente, el tercero de estos picos se localiza en el noroeste de la provincia de La Pampa, pudiendo vincularse con fuentes no desciptas o con aquellas presentes en el sur de Mendoza, en el área El Payén (Salgán y Pérez Winter 2008-2009). En la cuenca del arroyo Chasicó, los valores esperables de calcedonia, en función de la proyección, serían relativamente bajos, siendo levemente superiores en la cuenca inferior 
y superior, con porcentajes entre 10 y $20 \%$. En la cuenca media en cambio, estos no superarían el 10\%.

La visualización de todas las materias primas en conjunto muestra que la mayor parte de la cuenca del arroyo Chasicó, se encuentra comprendida dentro del área caracterizada por cuarcitas y otras materias primas presentes en porcentajes superiores al 20\%, en tanto calcedonias y RSO no superarían dicho porcentaje. La laguna Chasicó es el único sector de la cuenca localizado en el área donde, además de las cuarcitas y de otras rocas, también se encuentran presentes RSO con porcentajes superiores al $20 \%$. Es decir que, sería esperable que las principales materias primas representadas a lo largo del curso del arroyo Chasicó y sus afluentes fuesen la cuarcita junto con otras rocas (v.g. riolitas) variando en el porcentaje de representación pero siempre por sobre el 20\%. En la laguna Chasicó en cambio, las RSO también alcanzarían porcentajes superiores a 20\% (Figura 5.16).

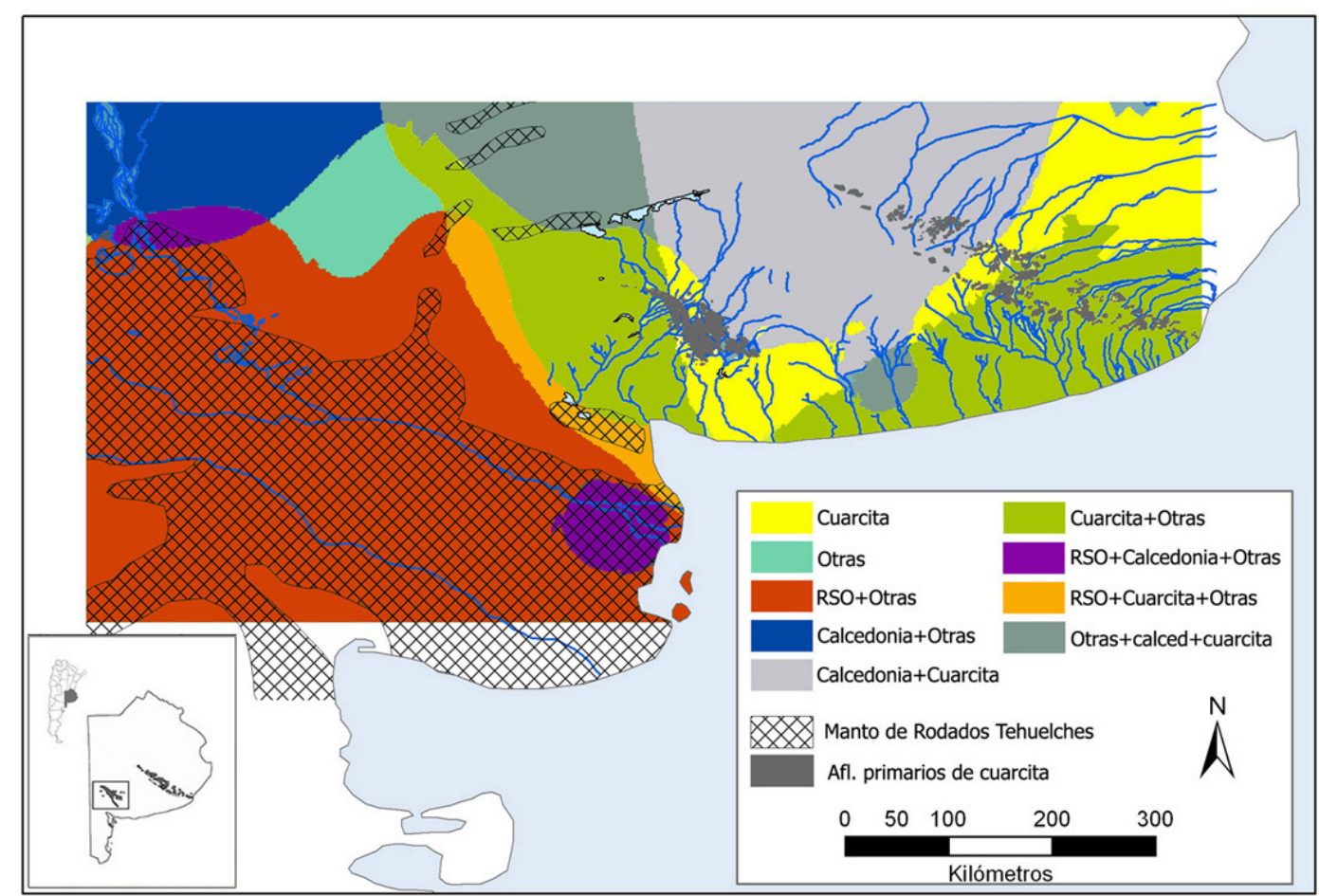

Figura 5.16. Modelo generado a partir de datos extraídos de las figuras 5.13 a 5.15 en el que se representa la distribución espacial de materias primas representadas con valores superiores al 20\%.

\subsection{Artefactos de molienda}

La presencia de artefactos de molienda permite inferir, aunque de manera indirecta, la utilización de especies vegetales para el consumo a través del procesamiento de sus semillas. En el caso de la región Pampeana y el NE de Patagonia, la mayor concentración de especies con semillas factibles de ser utilizadas se encuentran formando parte de la provincia fitogeográfica del Espinal, por lo que sería esperable que la mayor proporción de estos artefactos se encuentre en coincidencia con aquellos sectores del paisaje donde más frecuentemente se ha encontrado representada la asociación florística que caracteriza al Espinal. Sin embargo, la presencia en grandes cantidades de este tipo de artefactos, también ha sido mencionada para gran parte de la región pampeana, incluyendo el área Interserrana (Bonomo y Matarrese 2012; Martínez 1999; Matarrese 2007). En tal sentido, y a los fines de evaluar la relación entre la distribución de los artefactos de molienda y la provincia fitogeográfica del Espinal, se relevó la presencia de estos artefactos en los sitios y colecciones arqueológicas. A los fines de estandarizar la 
proporción de artefactos de molienda en los distintos sitios y resolver así el problema de las diferencias en el $n$ total de las muestras, se calculó un índice que relaciona el $n$ de artefactos de molienda y el $n$ de artefactos de filo representados en cada sitio (como artefactos de filo se incluyeron los instrumentos tallados y las lascas con rastros complementarios) (i.e. $\mathrm{n}_{\text {mol }} / \mathrm{n}_{\text {fil }}$ ). Los instrumentos tallados y las lascas con rastros complementarios se encontrarían vinculados con la realización de actividades vinculadas al corte y raspado, por lo que una relación cuantitativa con aquellos utilizados en actividades de molienda puede dar una idea de la importancia relativa de uno y otro tipo de actividad (corte y raspado vs. molienda).

Para la elaboración del mapa de distribución de artefactos de molienda se incluyeron 114 sitios arqueológicos, localizados entre $\operatorname{los} 35,98^{\circ}$ y $40,71^{\circ}$ de latitud sur y $\operatorname{los} 56,87^{\circ}$ y $67,19^{\circ}$ de longitud oeste, para los que se localizó información édita referida al tipo y número de artefactos líticos manufacturados por talla y manufacturados por picado, abrasión y pulido.

El modelo generado (Figura 5.17) muestra que la proporción de los artefactos de molienda, en relación con los artefactos de filo, es considerablemente mayor en el área incluida dentro de la zona nuclear del Espinal (zona de mayor abundancia y estabilidad de estos vegetales, tal como se modeló en el apartado 5.2.1.1.1). Para el caso de la cuenca del arroyo Chasicó, sería esperable una alta proporción de artefactos de molienda en el sector inferior y medio inferior, y medios y bajos en los sectores medio superior y superior respectivamente.

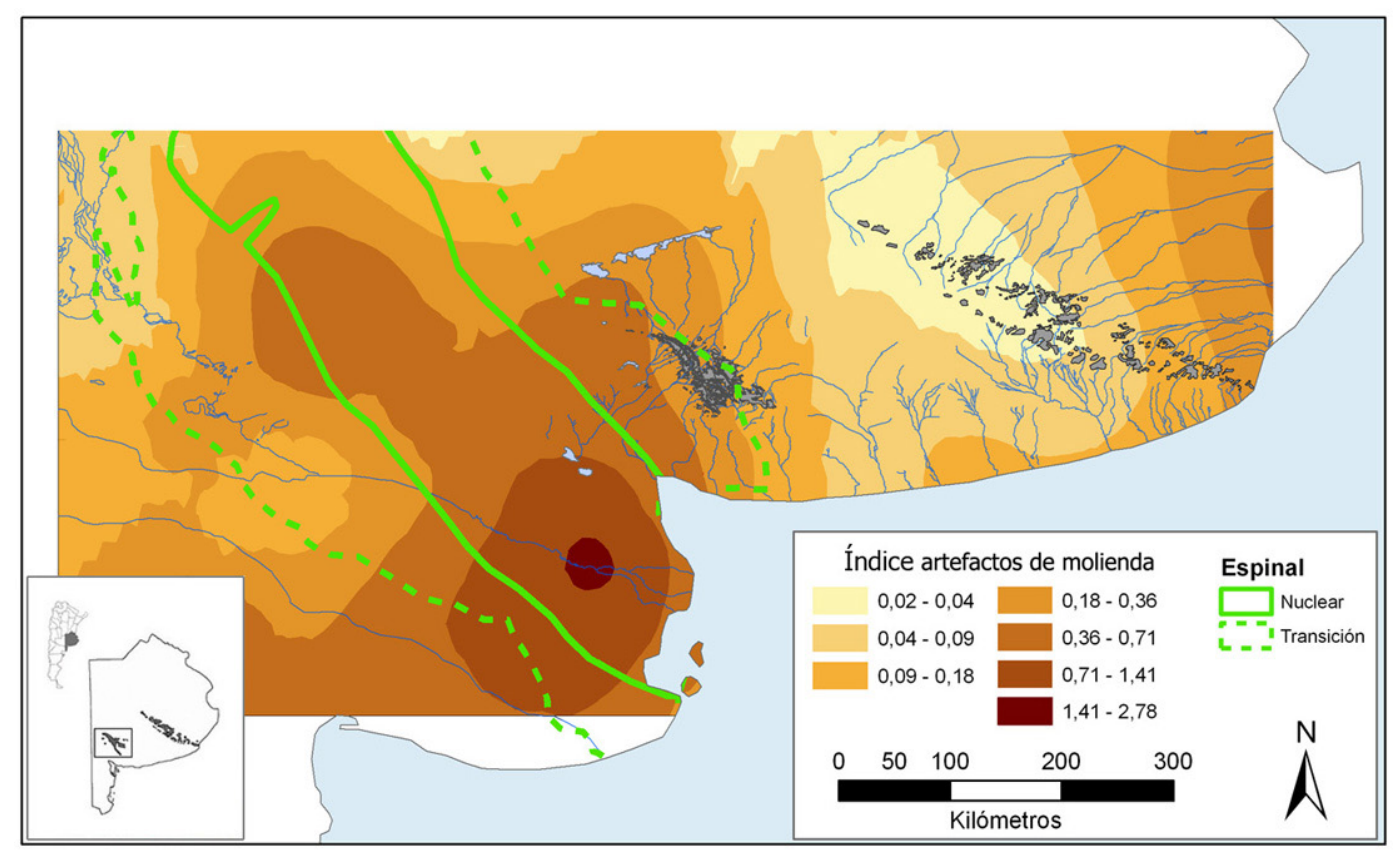

Figura 5.17. Distribución de los artefactos de molienda en relación con los artefactos de filo clasificadas por quiebres naturales (natural breaks) $(\mathrm{n}=114)$.

\subsection{Tecnología cerámica}

Las características de los conjuntos cerámicos aportan importante información acerca tanto del tipo de recursos utilizados, como de las estrategias de movilidad implementadas para su explotación. En el primer caso, la impregnación de ácidos grasos en las paredes de los contenedores permite inferir el tipo de recursos procesados -cocidos y/o almacenados- (González de Bonaveri y Frére 2004; Rice 1996). A partir de las características de la pasta (los tipos de arcilla y antiplástios) pueden realizarse inferencias 
acerca del lugar de obtención de la materia prima y propiedades buscadas en ellas y, en relación con esto, establecer posibles centros de producción, circuitos de circulación y funciones desarrolladas (Orton et al. 1997; Tite 1999). Por último, diversos autores han discutido también acerca del modo en que las características tecnológicas, morfológicas y la frecuencia de estos materiales, se relacionan con las estrategias de movilidad implementadas (Bright y Ugan 1999; Eerkens 2003; Eerkens et al. 2002; Rice 1987; Simms et al. 1997; Skibo et al. 1989). En tal sentido, Arnold (1985) propuso que la movilidad es un factor limitante al momento de incorporar la tecnología cerámica y, por lo tanto, las sociedades con una alta movilidad residencial no utilizarán esta tecnología o lo harán en baja frecuencia (para una discusión más profunda de este aspecto, ver el Capítulo 9).

Dado que la frecuencia es una variable que puede ser relevada a escala macro-regional, se indagó acerca de su distribución para la generación de modelos espaciales. Se realizaron cuatro modelos representativos de la frecuencia absoluta y relativa (por medio de un índice dado por el total de fragmentos cerámicos / el total de artefactos líticos de un sitio) de los tiestos cerámicos. Estos modelos fueron generados mediante dos técnicas de interpolación diferentes: IDW y kriging. La incorporación de IDW se debe a que, en el caso de la cerámica, algunos sitios localizados a corta distancia muestran importantes variaciones en sus frecuencias, es decir, escasa autocorrelación espacial, una de las presuposiciones de las técnicas geoestadísticas como el kriging. El método IDW refleja mejor las variaciones puntuales (Márquez Pérez 2012), razón por la que se consideró importante analizar las variaciones entre uno y otro modelo. Para la cuenca del arroyo Chasicó, los modelos planteados indican que es esperable observar frecuencias cerámicas, tanto relativas como absolutas, similares a las observadas para la cuenca inferior de los ríos Negro y Colorado o levemente inferiores a las del río Colorado. En relación con el área Interserrana, en cambio, las frecuencias cerámicas serían levemente superiores en la mencionada cuenca (Figura 5.18).
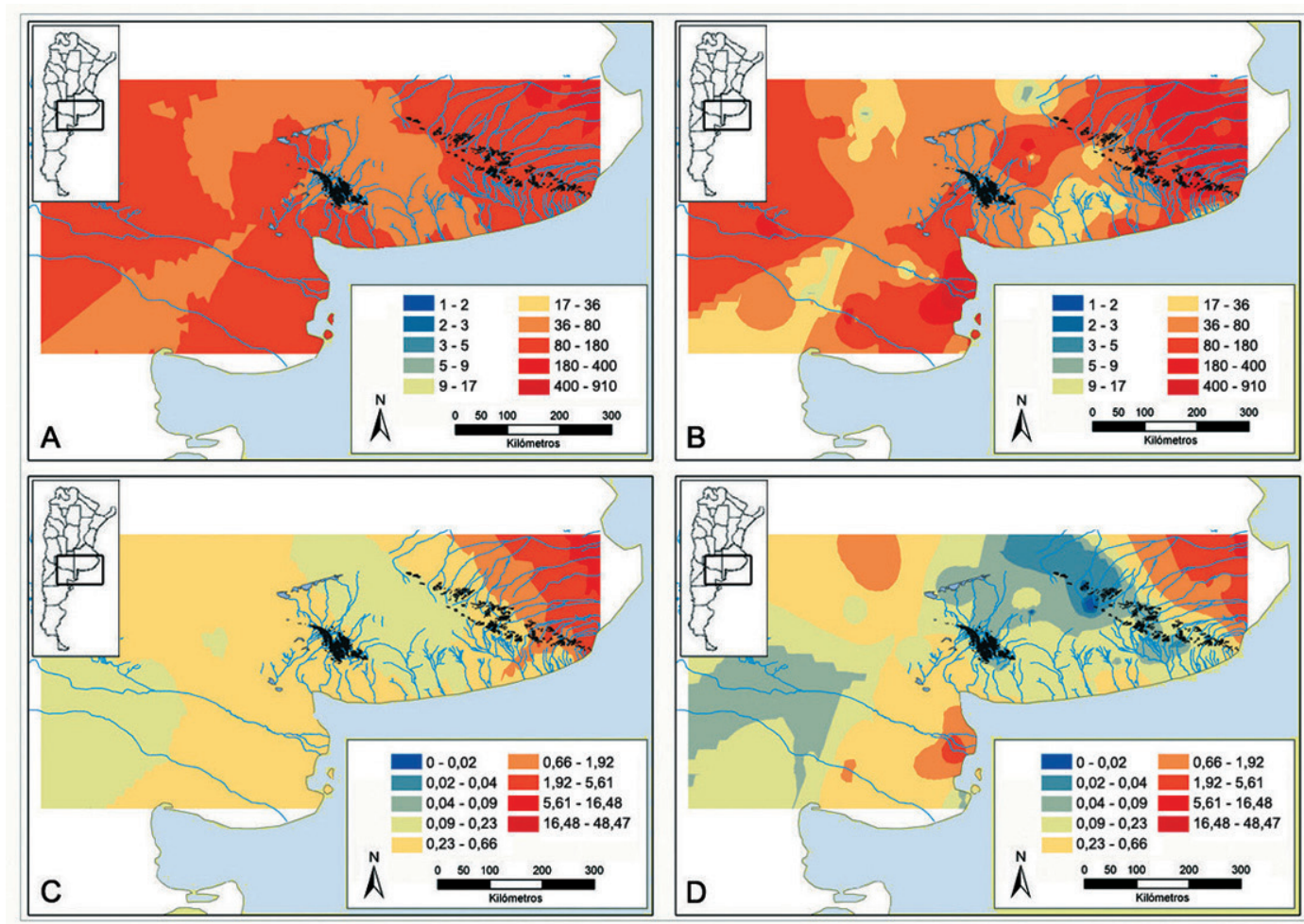

Figura 5.18. Modelado de la frecuencia de aparición de material cerámico utilizando las técnicas de interpolación kriging y IDW. A- Interpolación de frecuencias absolutas utilizando el método kriging; B- Interpolación de frecuencias absolutas utilizando el método IDW; C- Interpolación de frecuencias relativas utilizando método kriging; D- Interpolación de frecuencias relativas utilizando el método $I D W$. 


\subsubsection{Modelos distribucionales acerca de la dieta (isótopos estables del C y N)}

El análisis de los valores de isótopos estables del $\mathrm{C}$ y del $\mathrm{N}\left(\delta^{13} \mathrm{C}\right.$ y $\left.\delta^{15} \mathrm{~N}\right)$ permite realizar reconstrucciones acerca de la composición de la dieta de un individuo durante los últimos años de su vida, entre 10 y 20 años en el caso de los elementos óseos, o durante su infancia, en el caso de los dientes que luego no continúan regenerándose. Esto se debe a que los valores isotópicos de los animales (y por lo tanto también del ser humano) se encuentran positivamente correlacionados con el tipo de recursos consumidos (Kellner y Schoeninger 2007; Schoeninger y Moore 1992). A su vez, los valores de $\delta^{13} \mathrm{C}$ difieren entre las plantas con patrón fotosintético $\mathrm{C}_{3}$ y $\mathrm{C}_{4}$, por lo que, al analizar el valor $\delta^{13} \mathrm{C}$ de un consumidor de éstas, puede inferirse el grado de dependencia relativa de unas y otras. Las plantas con patrón fotosintético $\mathrm{C}_{3}$, entre las que se incluyen todos los árboles, la mayor parte de los arbustos y los pastos de climas templados y fríos, presentan valores de $\delta^{13} \mathrm{C}$ entre $-20 \%$ y $-34 \%$, en tanto aquellas plantas con patrón fotosintético $\mathrm{C}_{4}$, entre las que se encuentran cultivos como el maíz, el mijo y el sorgo y hierbas de ambientes tropicales, presentan valores de $\delta^{13} \mathrm{C}$ entre $-9 \%$ y $-16 \%$. Los valores isotópicos también permiten inferir el grado de consumo de recursos marinos, pero en este caso, no se diferencian por los valores de $\delta^{13} \mathrm{C}$, los que son similares a aquellos presentes en vegetales $\mathrm{C}_{4}$, sino por presentar valores más enriquecidos $\delta^{15} \mathrm{~N}$, que suelen oscilar entre 5,7 $\pm 2,2 \%$ para mamíferos terrestres y 15,6 \pm 2,2\%o para mamíferos marinos. En tal sentido, las inferencias acerca de las paleodietas humanas deberán realizarse considerando estos dos isótopos. Por otra parte, tanto los valores de carbono como los de nitrógeno se ven modificados por el nivel trófico, produciéndose un incremento entre distintos niveles del orden del 1\%o en el carbono y del 3\%o en el nitrógeno (Kellner y Schoeninger 2007; Schoeninger y Moore 1992). En algunos casos los isótopos del carbono también podrán aportar información acerca del grado de dependencia en recursos marinos, pero dado que los valores de carbono de vegetales $\mathrm{C}_{4}$ y recursos marinos se superponen, en aquellos casos en que ambos tipos de recursos hayan podido ser consumidos, su discriminación deberá realizarse a partir del análisis de los valores de $\delta^{15} \mathrm{~N}$, los cuales, como fue mencionado, si bien presentan una amplia variabilidad, siempre son más enriquecidos en los recursos marinos y por lo tanto, aquellas dietas con un consumo intensivo de estos presentarán valores más positivos que las centradas en recursos terrestres (Kellner y Schoeninger 2007; Schoeninger y Moore 1992).

Las simulaciones realizadas por Barrientos (2010) considerando datos isotópicos publicados para el sur de Sudamérica, indican, en líneas generales, que dietas basadas en el consumo de vegetales $\mathrm{C}_{3}$ y/o herbívoros consumidores de estos vegetales, tendrán valores medios de entre -20,5\% (en el caso de dietas basadas exclusivamente en vegetales), y -17,5\% (para dietas exclusivamente carnívoras), siendo esperables valores cercanos a los $-19 \%$ en dietas omnívoras (Barrientos 2010). En el caso de dietas en las que predomine el consumo de vegetales $\mathrm{C}_{4}$, entre las que se encuentran hierbas de climas tropicales cálidos y secos y algunos arbustos de las familias Euphorbiacea y Chenopodiaceae, los valores $\delta 1{ }^{13} \mathrm{C}$ se verán enriquecidos con respecto a las primeras (Kellner y Schoeninger 2007; Schoeninger y Moore 1992).

Los valores isotópicos mencionados, sin embargo, también pueden ser modificados por variaciones en la salinidad y compactación de los suelos y por las condiciones climáticas y/o de stress, como aquellas generadas por los climas áridos. En este tipo de ambientes se han observado valores ligeramente más elevados de $\delta 1{ }^{13} \mathrm{C}$, así como una diferencia mayor a la esperada entre la abundancia de $\delta^{15} \mathrm{~N}$ en los distintos niveles tróficos, por ejemplo, en áreas con precipitaciones menores a los $400 \mathrm{~mm}$ anuales se 
han planteado valores más elevados de lo esperado para herbívoros (Barberena 2002 y bibliografía allí citada). Es por esto que, para que los valores isotópicos tengan significado, deben ser interpretados en el marco de una ecología isotópica local, es decir, considerando los rangos de valores de los alimentos potencialmente consumidos.

La visualización de la distribución espacial de los valores isotópicos ( $\mathrm{N}$ y C) registrados en restos humanos del sur de la Región Pampeana y NE de Patagonia puede aportar información en relación con la variabilidad regional de recursos consumidos y, complementariamente, sobre posibles rangos de movilidad, por medio de la identificación del consumo de determinados recursos y su relación con sus potenciales lugares de explotación, como es el caso de los recursos marinos. Esta visualización se realizó a través de la construcción de mapas de distribución de los valores isotópicos $\left(\delta^{13} \mathrm{C} \mathrm{y} \delta^{15} \mathrm{~N}\right)$, para lo cual se siguieron los procedimientos de interpolación descriptos más arriba. Para el $\delta^{13} \mathrm{C}$ se consideraron 141 datos correspondientes a 52 sitios o colecciones distribuidas entre $\operatorname{los} 41,45^{\circ}$ y $34,39^{\circ}$ de latitud Sur y $\operatorname{los} 67,62^{\circ}$ y $57,37^{\circ}$ de longitud Oeste. Para los valores $\delta^{15} \mathrm{~N}$, debido a que es menor la disponibilidad de datos en este caso (sólo 52 datos correspondientes a 19 sitios o colecciones arqueológicas), se realizó una estimación de los mismos por medio de la generación de un valor aleatorio ubicado dentro de un rango dado por el valor $\delta^{15} \mathrm{~N}$ mínimo y máximo probable para un valor $\delta^{13} \mathrm{C}$ dado. Para esto se verificó, a partir de un diagrama de dispersión, la dependencia lineal entre valores $\delta^{13} \mathrm{C}$ y $\delta^{15} \mathrm{~N}$, así como la dispersión alrededor de la recta de ajuste. Se establecieron las bandas de predicción, las que fueron consideradas como el valor $\delta^{15} \mathrm{~N}$ mínimo y máximo probable para un valor $\delta^{13} \mathrm{C}$, a partir de los cuales, se calculó, mediante el generador de números aleatorios disponible en www.random.org un valor probable de $\delta^{15} \mathrm{~N}$. Se considera a esta metodología más apropiada que otros medio de imputación de los datos perdidos $\delta^{15} \mathrm{~N}$ a partir de datos $\delta^{13} \mathrm{C}$, como el uso de las medias o el programa NORM 2.03, debido a que existe correlación entre los valores $\delta^{15} \mathrm{~N}$ a partir de datos $\delta^{13} \mathrm{C}$. Por otra parte, la realización simplemente de una correlación, habría generado una gran cantidad de datos localizados sobre la recta de regresión.

Los valores $\delta^{13} \mathrm{C}$ publicados para el sur de la Región Pampeana y NE de Patagonia se encuentran predominantemente por debajo de $-17,8 \%$, lo que ha sido interpretado como un indicador del predominio de dietas relacionadas principalmente con el consumo de vegetales $\mathrm{C}_{3} \mathrm{y} / \mathrm{o}$ de herbívoros consumidores de vegetales $\mathrm{C}_{3}$, para aquellas con valores más negativos, y dietas mixtas con la incorporación en diferentes proporciones de recursos marinos, para el caso de los valores más enriquecidos, vinculadas principalmente a ambiente costeros (Barrientos 1997, 1999; Berón 2004; Bonomo et al. 2013; Borella 2007; Favier Dubois et al 2007; Flegenheimer et al 2002; Martínez, Zangrando y Prates 2009; Murgo y Aldazabal 2007; Politis et al. 2009; Scabuzzo y González de Bonaveri 2007). Para el caso de la cuenca del arroyo Chasicó, la proyección indica valores isotópicos entre -21,2 y -17,8\%, en la cuenca inferior, y entre $-16,8$ y $-13 \%$ en la cuenca superior. A su vez, los valores isotópicos publicados para la vegetación $\mathrm{C}_{3}$ del $\mathrm{NE}$ de Patagonia presentan una media de -23\%o, en tanto aquellos correspondientes a los principales herbívoros (Lama guanicoe, Ozotocaros bezoarticus y Rhea americana) oscilan entre -21,08\% y -22,12\% (Barberena et al. 2009; Martínez, Zangrando y Prates 2009). Considerando la ecología isotópica desarrollada para el NE de Patagonia los valores de la cuenca del arroyo Chasicó se corresponden con dietas mixtas basadas principalmente en el consumo de plantas $\mathrm{C}_{3} \mathrm{y} / \mathrm{o}$ de herbívoros consumidores de $\mathrm{C}_{3}$ así como la incorporación en pequeñas cantidades de vegetales del tipo $\mathrm{C}_{4} \mathrm{y} / \mathrm{o}$ recursos marinos (Figura 5.19). 


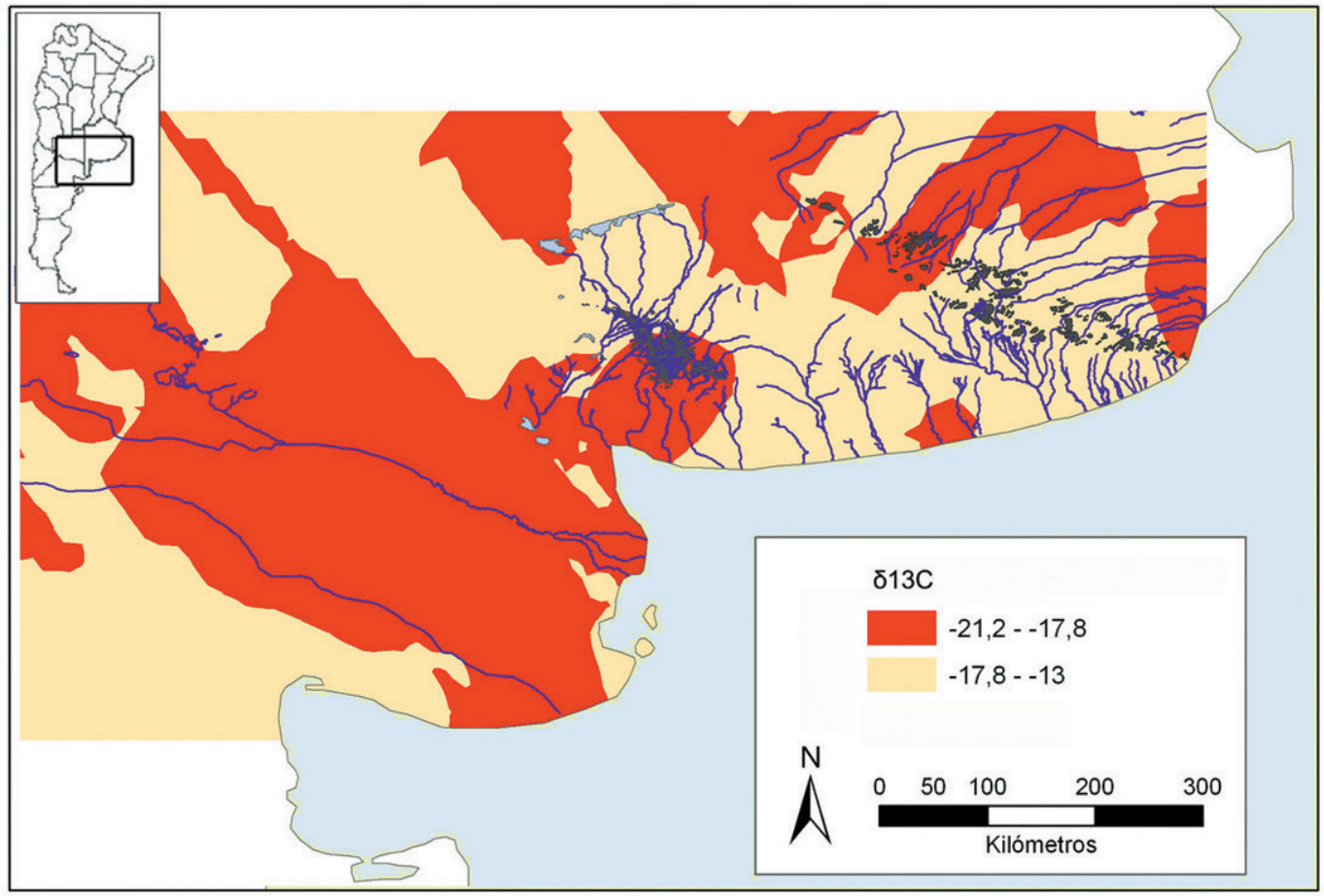

Figura 5.19. Distribución de valores isotópicos $\delta^{13} \mathrm{C}$ en muestras humanas, clasificados de manera manual considerando rangos de valor dietario (Pate 1995). El color rojo indica dietas compuestas por más de un $80 \%$ de recursos C3 y el color salmón claro dietas mixtas en las que la proporción de recursos C3 es inferior al $80 \%$.

En el caso de los valores $\delta^{15} \mathrm{~N}$, estos muestran una mayor dispersión, lo que ha sido interpretado como producto del consumo, en distintas cantidades, de proteína de origen marino (Berón et al. 2009; Martínez, Zangrando y Prates 2009; Politis et al. 2009) incluso en zonas alejadas de la costa, como la Pampa Seca, donde si bien no se descarta un enriquecimiento producto de la aridez, también se considera plausible que algunos individuos estuviesen involucrados en un uso más o menos sistemático de los recursos marinos (Berón et al. 2009). Para el caso de la cuenca del arroyo Chasicó, la proyección indica valores de entre 12 y 17,4\%o, para la cuenca inferior, y entre 8 y 12\%o, en la cuenca superior. En el caso de los valores de la cuenca inferior, estos se corresponderían con dietas que pudieron haber incorporado recursos marinos, si bien no de manera intensiva. Valores semejantes se presentan en la zona interior del río Colorado y han sido interpretados como producto de la ingesta variable de recursos terrestres y acuáticos -tanto marinos como fluviales- (Figura 5.20).

A los fines de proponer las dietas esperables para la cuenca del arroyo Chasicó, en función de los datos disponibles para otras áreas, se combinaron los modelos de $\delta^{13} \mathrm{C}$ y $\delta^{15} \mathrm{~N}$, por medio de su reclasificación y sumatoria (Figura 5.21). En este caso, para la cuenca del arroyo Chasicó, las expectativas son de encontrar tres clases diferentes de dietas. En la cuenca inferior estas se caracterizarían por un aporte mayor al $80 \%$ de vegetales $\mathrm{C}_{3}$, o herbívoros consumidores de vegetales $\mathrm{C}_{3}$, y un porcentaje inferior al $20 \%$ compuesto por probables recursos marinos. En la cuenca media será esperable encontrar dietas conformadas por más de un $80 \%$ de recursos vegetales $\mathrm{C}_{3}$, o herbívoros consumidores de vegetales $\mathrm{C}_{3}, \mathrm{y}$ un porcentaje inferior al $20 \%$ de vegetales $\mathrm{C}_{4}$, o herbívoros consumidores de vegetales $\mathrm{C}_{4}$. Por último, en la cuenca inferior las expectativas indican dietas mixtas, con proporciones similares de recursos $\mathrm{C}_{3} \mathrm{y} \mathrm{C}_{4}$ 


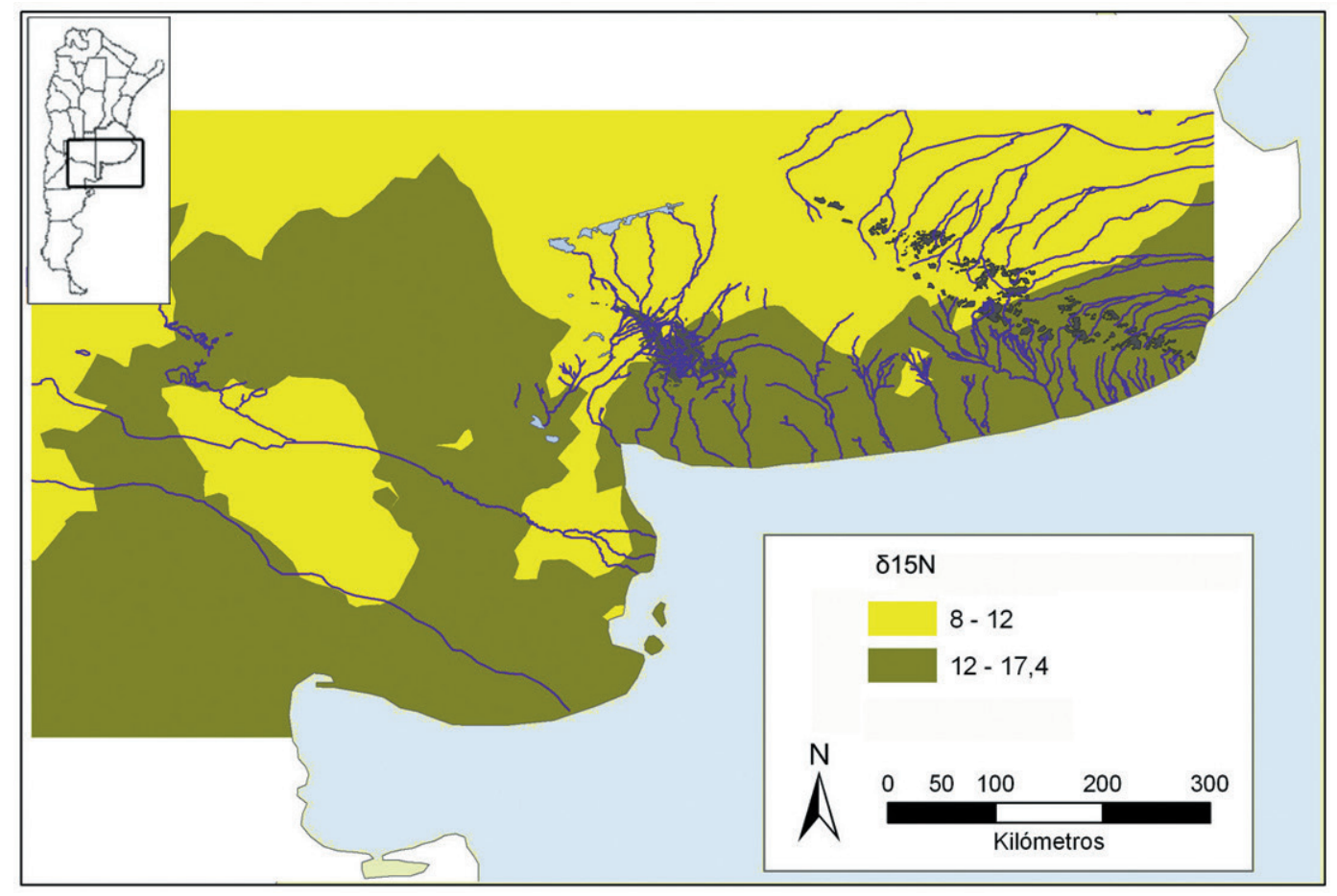

Figura 5.20. Distribución de valores isotópicos $\delta^{15} \mathrm{~N}$ en muestras humanas, clasificados de manera manual considerando rangos nivel trófico (Barrientos 2010).

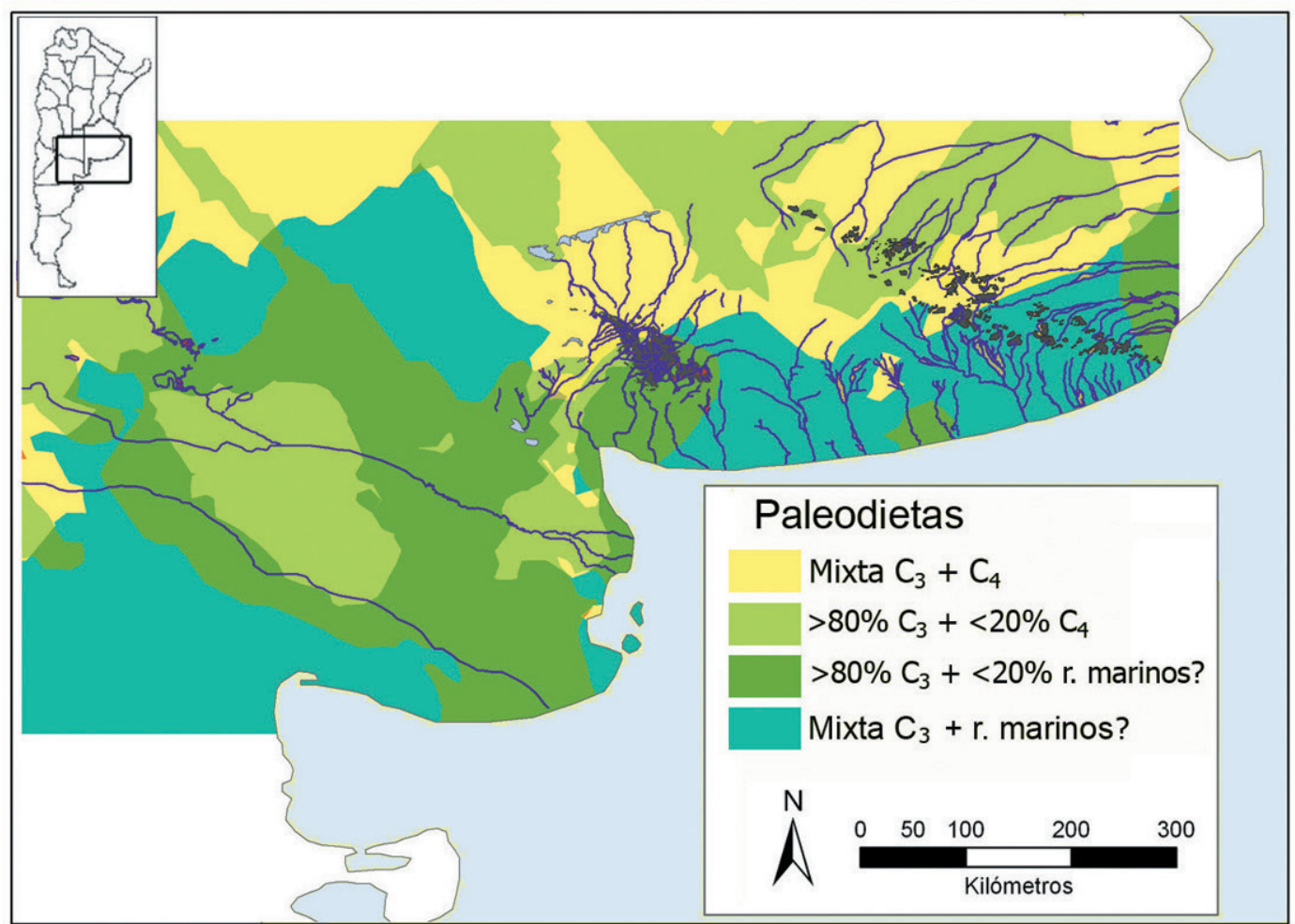

Figura 5.21. Distribución de paleodietas humanas obtenidas a partir de la reclasificación y sumatoria de las superficies obtenidas por interpolación para $\delta^{13} \mathrm{C}$ (ver Figura 5.19) y para $\delta^{15} \mathrm{~N}$ (ver Figura 5.20). 


\subsection{Discusión}

A partir de los datos expuestos se puede delinear un modelo tentativo, acerca de, por un lado, las características ambientales y sus posibles variaciones a través del tiempo y por otro, las estrategias puestas en práctica por las sociedades cazadora-recolectoras para utilizar estos ambientes. De esta manera, se buscó generar expectativas sobre las estrategias de movilidad y uso de los recursos, que puedan ser puestas a prueba con el registro arqueológico de la cuenca del arroyo Chasicó.

La configuración ambiental del área de estudio, en relación con la distribución de los recursos animales, vegetales y líticos más frecuentemente utilizados, muestra al menos dos sectores diferenciables por la diversidad, disponibilidad y estabilidad de los recursos representados. El sector inferior, con una mayor densidad y estabilidad de las especies del Espinal, animales de gran porte y materias primas líticas, presenta las mejores condiciones ambientales, en relación con otros sectores vecinos. Es esperable que esto se traduzca en una mayor atracción ejercida sobre las poblaciones que habrían utilizado más intensivamente este sector, generando un registro arqueológico más denso que el de los sectores medio y superior, caracterizadas como zonas sub-óptimas en función de los recursos.

Considerando el aporte de los datos etnográficos, las poblaciones cazadoras-recolectoras que ocuparon la cuenca del arroyo Chasicó durante el Holoceno tardío, y previo a la incorporación del caballo a su sistema cultural, habrían tenido rangos de acción del orden de los pocos miles de kilómetros cuadrados, rondando entre los $400 \mathrm{~km}^{2}$ y $26000 \mathrm{~km}^{2}$. Esto implicaría la utilización predominante de los recursos presentes en un área más o menos acotada, que no se extendería mucho más lejos del Sistema Serrano de Ventania, la costa atlántica y/o el río Colorado, con una dieta en la que la recolección de recursos habría tenido mayor importancia que la caza, y donde la pesca, en caso de haber estado presente, habría ocupado un lugar marginal en el aporte de nutrientes. De manera coincidente, el modelo generado a partir de los valores isotópicos publicados indica, para el área de Chasicó y en relación con la ecología isotópica de la región, el predominio de una dieta mixta, con una ingesta predominante de vegetales $\mathrm{C}_{3}$ y/o herbívoros terrestres consumidores de vegetales $\mathrm{C}_{3}$ así como la incorporación en pequeñas cantidades de vegetales del tipo $\mathrm{C}_{4} \mathrm{y}$ recursos marinos. El aumento en la densidad relativa de artefactos de molienda en el sector con mayor densidad de especies del espinal, también estaría apoyando la importancia en la dieta de los elementos recolectados, particularmente durante el Holoceno tardío, momento para el que se ha propuesto una mayor densidad poblacional y estrategias de intensificación en el manejo de recursos (Barrientos 1997).

Considerando los datos publicados para el área sobre las características del registro arqueológico, se observa que el sector localizado entre las sierras de Ventania y el río Colorado, donde se encuentra la cuenca del arroyo Chasicó, presenta características que, en algunos casos, se asemejan a las del área Interserrana y serrana de Tandilia y en otros se relaciona con el NE patagónico, presentando generalmente una gradación en franjas desde las cabeceras hasta la desembocadura. La representación mayoritaria de las materias primas disponibles localmente, con predominio de artefactos confeccionados sobre rocas cuarcíticas en los contextos arqueológicos cercanos a la sierra, cuya utilización disminuye paulatinamente en relación con la distancia, a la vez que son reemplazadas por las RSO y otras materias primas en sectores cercanos a los afloramientos del manto de rodados Tehuelches. Para el caso de las calcedonias en cambio, no se observan mayores variaciones, encontrándose esta representada en porcentajes medios a bajos a lo largo de toda la cuenca. 
Cronológicamente los momentos con mayor densidad de fechados en el área de Ventania, son coincidentes con momentos de mayor densidad de fechados en el área Interserrana y serrana de Tandilia, lo que podría estar evidenciando momentos de mayor intensidad de ocupación en todo este sector y menor impacto de los sesgos tafonómicos. Por otra parte, la ausencia de fechados tempranos en el NE de Patagonia podría responder a factores de transformación del paisaje, vinculados con modificaciones en el cauce del río Colorado (Martínez et al. 2013; Melo et al. 2003). Estos procesos de formación pudieron haber afectado a la cuenca inferior del arroyo Chasicó, por lo que en este sector sería esperable obtener fechados comprendidos dentro de rangos similares a los esperables para el NE patagónico, en tanto en los sectores medio y superior podrían ser esperables fechados más tempranos. 


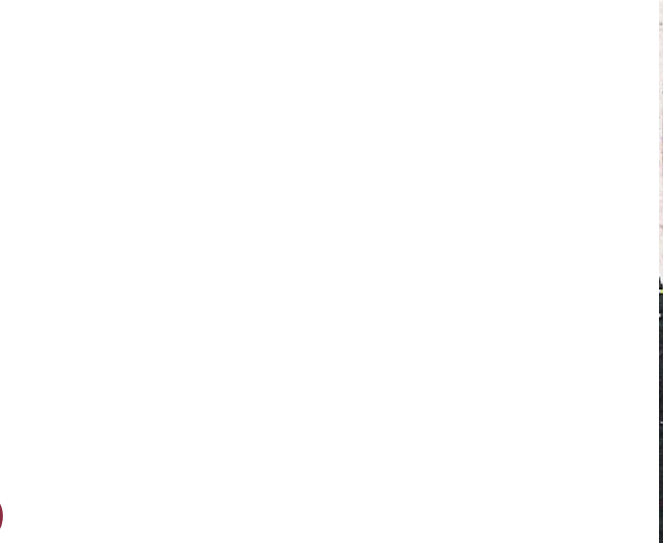

RESULTADOS 


\section{I Prospecciones, Sondeos y Excavaciones Arqueológicas}

La información primaria analizada y discutida en esta tesis consiste en datos ambientales y arqueológicos obtenidos por medio de la realización de prospecciones, recolecciones superficiales y sondeos. También se re-estudiaron, en relación con preguntas particulares, los materiales recuperados en excavaciones extensivas realizadas como parte de los estudios desarrollados con anterioridad por Oliva (2014) y se analizaron las colecciones de pobladores locales. En este capítulo se presenta la metodología empleada y los resultados obtenidos a partir de la realización de las tareas de campo (prospecciones, recolecciones superficiales y sondeos), se expone brevemente la metodología empleada por F. Oliva en la excavación de los sitios así como sus principales características (Oliva 2014) y se detallan las colecciones de museos y de pobladores locales analizadas.

Las prospecciones estuvieron enfocadas en, por un lado, adquirir información sobre la estructura del registro arqueológico (densidad, distribución, tipo de artefactos representados) y, por otro, obtener una muestra representativa de la diversidad de ambientes y recursos. En este último caso, se orientaron a controlar, a escala arqueológica, la variabilidad, calidad y disponibilidad de rocas factibles de ser utilizadas en la confección de artefactos, tanto por técnica de talla como por picado abrasión y/o pulido. Durante las prospecciones, también se buscó relevar las características topográficas del terreno y los factores que inciden en la formación y visibilidad del registro arqueológico en los distintos microambientes: los procesos de erosión y depositación, la cobertura vegetal y el tipo de suelo.

\subsection{Metodología}

Dado que el área de estudio posee una gran extensión, aproximadamente $3800 \mathrm{~km}^{2}$, y que la información disponible previamente era escasa y dispar, la metodología general aplicada durante las prospecciones fue de índole exploratoria, a los fines de obtener conocimiento extensivo de las características ambientales y arqueológicas de los diferentes sectores de la cuenca del arroyo Chasicó. Las prospecciones, sin embargo, tuvieron un mayor desarrollo en los sectores superior e inferior. En el sector superior, esto se debió a que uno de los objetivos fue aumentar la información sobre la disponibilidad de materias primas, particularmente acerca de la variabilidad de rocas cuarcíticas disponibles en las sierras de Ventania y la homogeneidad o heterogeneidad con que estas se distribuyen en el espacio, para, de esta manera, poder realizar interpretaciones más precisas acerca del registro arqueológico lítico. En el sector inferior, la intensificación de las prospecciones se debió, por una parte, a que no se contaba con información previa acerca de las características de su registro arqueológico y por otra, a que los trabajos geológicos relevados (De Ferraris 1979; Fidalgo et al. 1987; García y García 1964; Martínez, Rabassa y Coronato 2009) indicaron la presencia de rocas diferentes a las del sector superior, como mantos de 
rodados patagónicos y areniscas rionegrenses, sobre las cuales no se contaba con información acerca de su variabilidad, abundancia y distribución en una escala arqueológica. En el sector medio, en cambio, la variabilidad de rocas es menor y relacionada con aquellas presentes en la cuenca superior (Oliva et al. 2006), a la vez que, arqueológicamente, se contaba con información previa obtenida por Oliva (Oliva 1996, 2014; Oliva et al. 1991b). Complementariamente se relevaron las cabeceras del río Sauce Grande y el arroyo Napostá (Catella et al. 2010), las Salinas Chicas, el área entre las salinas Chicas y la laguna Chasicó y el salitral de la Vidriera (Figura 6.1).

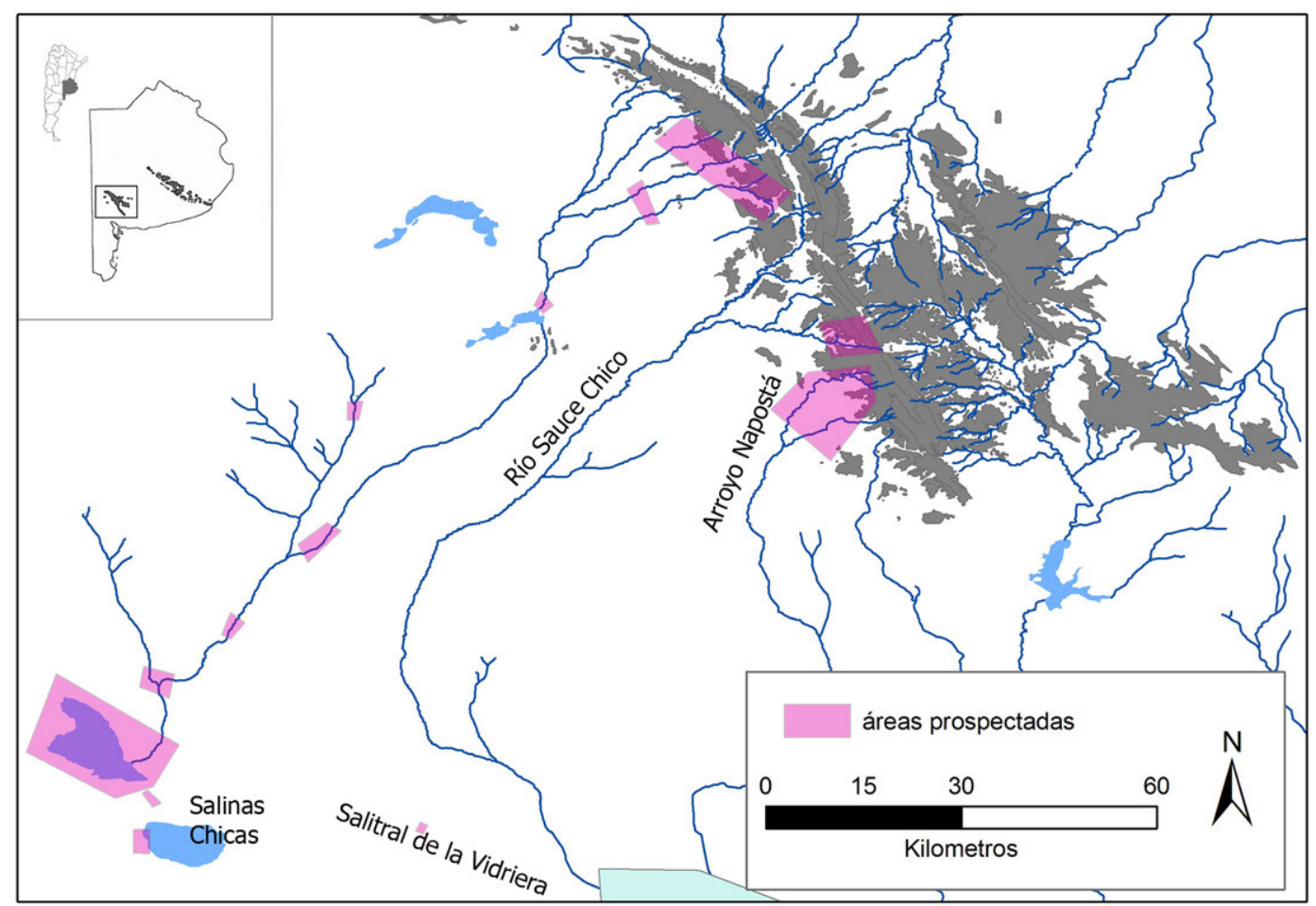

Figura 6.1 Áreas donde se llevaron a cabo las prospecciones.

La metodología implementada durante las prospecciones fue uniforme en cuanto al tipo de planillas utilizadas y, como consecuencia, la clase de datos relevados, pero variable en cuanto al área cubierta y diseño de las transectas. Esto, como fue mencionado, se debió a la variabilidad en la información previa y las características ambientales de cada sector. Las prospecciones fueron realizadas por dos/tres personas separadas entre sí por aproximadamente 10 metros. Durante el desarrollo de estas actividades se posicionaron mediante GPS los puntos inicial y final de los sectores prospectados y, en cada uno de ellos, se relevó la presencia o ausencia y las dimensiones de la playa, las terrazas y la barranca. A partir de las variaciones en las características de estos rasgos, se delimitaron, en el terreno, unidades del paisaje, cuyos puntos inicial y final también fueron tomados con GPS, y dentro de las cuales se relevó, diferenciando por sector de arroyo o laguna, playa y terrazas, el tipo de vegetación (pastos, arbustos o árboles), la abundancia relativa de la misma y como se distribuye (de manera dispersa, continua o en islotes), las características de los rodados y la presencia de materiales arqueológicos. 


\subsubsection{Relevamiento de la disponibilidad de materias primas líticas}

En relación con los rodados, se registró si estos se encontraban distribuidos de manera dispersa, continua o agrupados en bancos. Cuando los rodados se encontraron distribuidos en bancos, se consignó su cantidad en cada sector prospectado, el largo y ancho de los mismos, y su localización (en el cauce del arroyo, sobre la playa o en la/s terraza/s). Se plantearon a su vez unidades de muestreo, consistentes en sectores más acotados, de entre 10 y 20 m de extensión dependiendo el caso, donde se relevó la diversidad y disponibilidad de rocas factibles de ser utilizadas en la confección de artefactos, tanto por técnica de talla como por picado abrasión y/o pulido. Se realizaron tres tipos de muestreos (Figura 6.2): 1- orientados a identificar la variabilidad de rocas presentes en el cauce de los arroyos, en los que se seleccionaron sectores del cauce donde los rodados estuviesen concentrados y se obtuvieron cortes frescos de varios de ellos, para luego seleccionar 10 representativos de la diversidad de cuarcitas encontradas en el sector. A estos rodados se les midió en el campo su longitud, ancho y espesor, se determinó su materia prima, considerando color, fractura y tamaño de grano y su forma geométrica en relación con la angulosidad de sus aristas. Se obtuvieron muestras de todos ellos (mediante la extracción de lascas por percusión) que fueron transportadas al laboratorio para su análisis microscópico y para la conformación de una litoteca de rocas de Ventania; 2- orientados a obtener información acerca de la densidad de rocas cuarcíticas de muy buena calidad para la talla, en este caso, se siguió en líneas generales, la metodología propuesta por Franco y Borrero (1999), consistente en muestrear los rodados durante 10 minutos, recolectándose, para su posterior análisis en laboratorio, aquellas cuarcitas de mejor calidad para la talla; 3- toma de muestras de materias primas de buena calidad para la talla o factibles de ser utilizadas en la confección de artefactos por picado abrasión y/o pulido, en estos casos fueron localizadas mediante GPS, fotografiadas y relevadas sus características principales (tipo de roca, calidad densidad y tamaño de la forma base disponible).

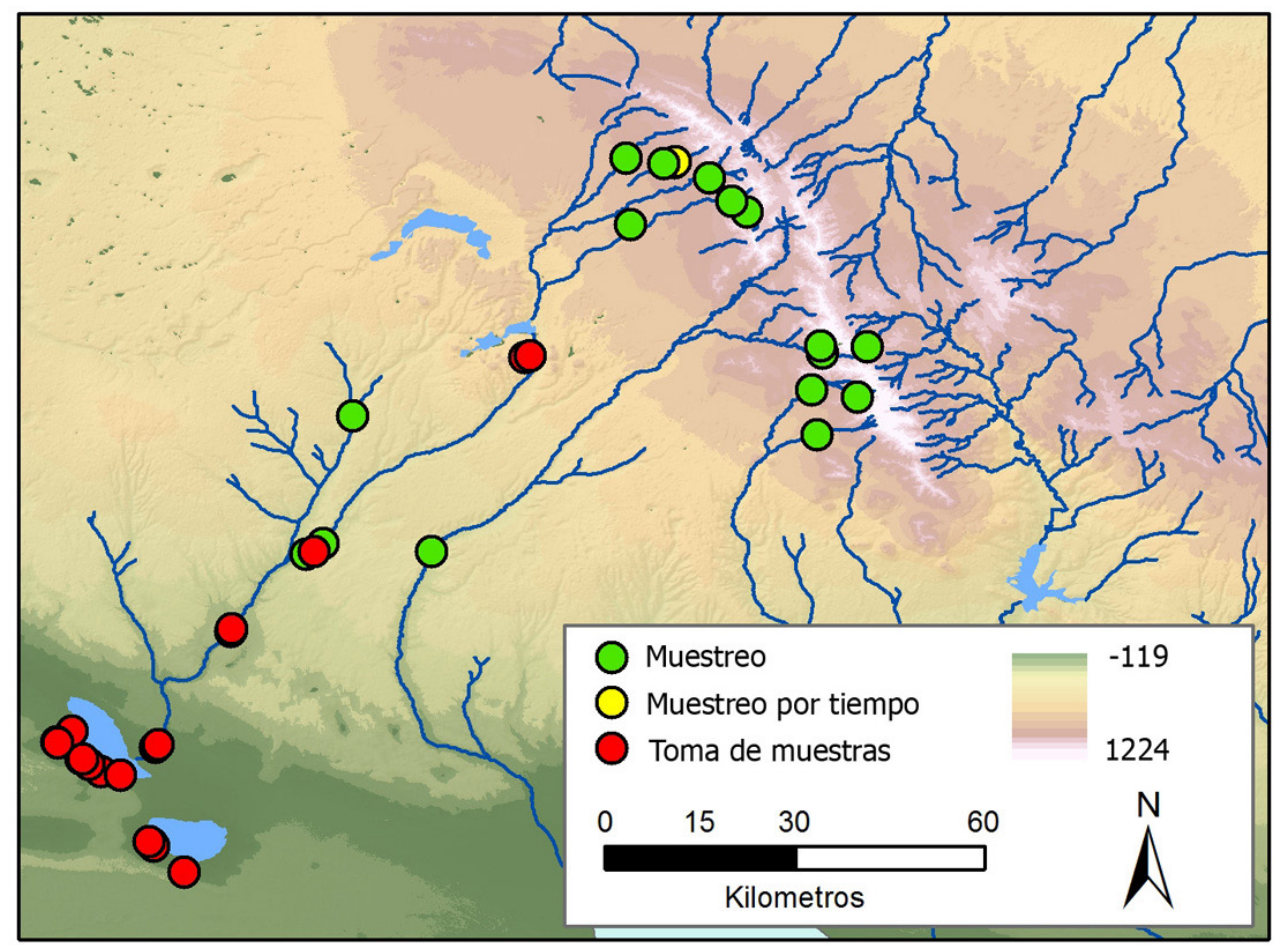

Figura 6.2. Muestreos realizados en la cuenca del arroyo Chasicó y áreas vecinas. 


\subsubsection{Relevamiento de la distribución del registro arqueológico}

Todos los materiales arqueológicos identificados durante las prospecciones, desde las concentraciones de mayor densidad hasta los hallazgos aislados, fueron posicionados con GPS y se relevaron sus dimensiones, unidad geomorfológica de localización y si se lo observa en superficie o en el perfil de una barranca, así como el tipo de materiales arqueológicos observados. Dependiendo de razones de tiempo y capacidad para transportar los materiales, estos en algunos casos fueron recolectados, en tanto en otros se relevó su densidad y principales características (materia prima, dimensiones, grupo tipológico) y se los dejó en el lugar. En el caso de agregaciones, se midió el largo y ancho de la misma y su densidad aproximada, considerándose como sitio cuando el número de artefactos fue mayor a 24 en un diámetro de aproximadamente 20m (Borrero et al. 1992; Magnín 2010). En aquellas agregaciones en las que, dependiendo principalmente de la disponibilidad de tiempo y capacidad de carga de los materiales, se realizaron recolecciones, se llevó a cabo un mapeo general del área y se plantearon unidades de recolección y/o transectas, dependiendo de las características del sitio, dentro de las cuales se recolectaron todos los materiales presentes. Cabe señalar que en algunos sectores del paisaje se practicaron recolecciones en más de una ocasión, en tales casos, para evaluar la densidad de hallazgos por $\mathrm{m}^{2}$ se consideró únicamente el material correspondiente a la recolección en la que se obtuvo mayor densidad de hallazgos, en tanto los restantes materiales arqueológicos fueron utilizados en la realización de otro tipo de análisis como la diversidad de instrumentos y materias primas. En la cuenca inferior, por último, se llevaron a cabo sondeos en algunos de los sectores con mayor densidad de hallazgos, a los fines de evaluar la presencia de materiales arqueológicos en estratigrafía. La metodología utilizada en estos se describe más adelante.

\subsection{3 Áreas prospectadas}

En la cuenca superior, el diseño de prospección y muestreo se realizó sobre la base de la cartografía y bibliografía geológica disponible, obteniendo así una primera aproximación a la diversidad ambiental y litológica en los diferentes sectores de la cuenca, lo que permitió programar un diseño de prospección orientado a evaluar esta variabilidad en términos arqueológicos. Dado que el Sistema de Ventania se caracteriza por un relieve abrupto con laderas empinadas, las prospecciones siguieron el cauce de los arroyos, ya que se considera que en estos se encontrará una muestra de la diversidad litológica del área, permitiendo obtener una primera aproximación a la variabilidad de rocas disponibles. De esta manera, se buscó obtener información acerca de la diversidad de rocas disponibles dentro de cada una de las formaciones descriptas en los trabajos geológicos (ver Capítulo 4 para un detalle de las mismas). Además, la abundancia de rodados en los arroyos y el fácil acceso a los mismos debieron haber favorecido su utilización como fuentes de abastecimiento secundarias.

En el sector de piedemonte se prospectaron los arroyos Saudade, Agua Blanca y Cochenleufú Chico en tanto el arroyo Cochenleufú Grande fue prospectado en el sector serrano y en la zona de llanura, inmediatamente antes de su desembocadura en la laguna Los Chilenos (Figura 6.3). Se incorporó a su vez, el sector suroccidental del Sistema de Ventania (localizado al este de la cuenca del arroyo Chasicó), 
donde se relevaron los cauces de los arroyos Ventana, Napostá Grande, del Águila y el río Sauce Grande (Figura 6.3), pudiendo evaluarse de esta manera la variabilidad en la disponibilidad de materias primas,

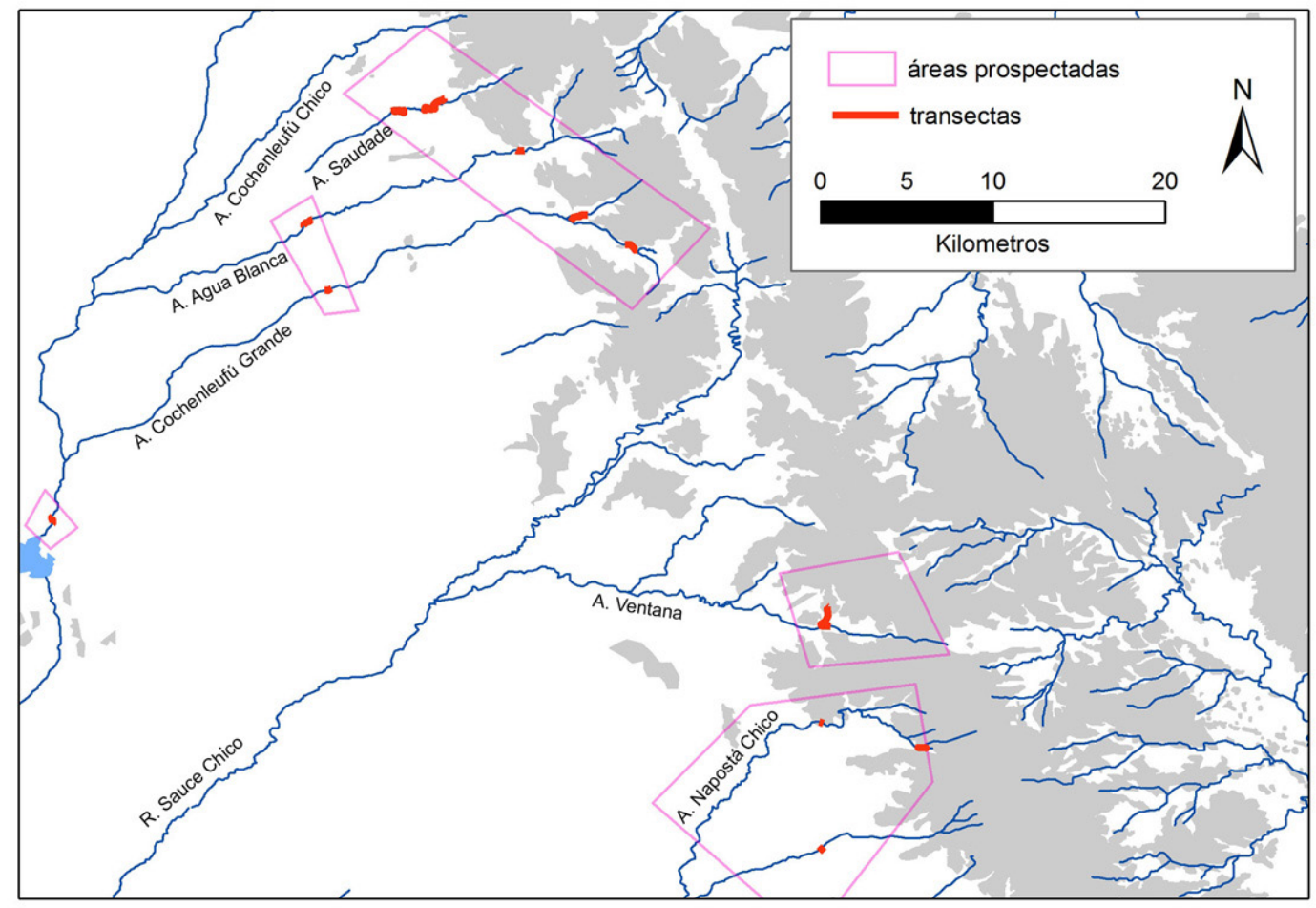

Figura 6.3. Transectas realizadas en la cuenca superior del arroyo Chasicó y áreas adyacentes (cabecaras del río Sauce Chico y arroyo Napostá).

particularmente cuarcitas, en los diferentes sectores de este sistema serrano (Catella et al. 2010, 2013).

En la cuenca media se prospectaron las márgenes del arroyo Chasicó y de sus tributarios los arroyos Pelicurá y Sanquilcó Grande. En el arroyo Chasicó se realizaron tres transectas, la primera de ellas, de 3 km de largo, aguas arriba de la confluencia con el arroyo Pelicurá, la segunda, de 1 km de extensión entre las desembocaduras de los arroyos Pelicurá y Sanquilcó Grande y la tercera en el sector inmediatamente aguas arriba de la desembacadura del Sanquilcó grande, de 1,6 km de largo. Por otra parte, el arroyo Pelicurá fue prospectado en inmediaciones de la localidad López Lecube, en un área de $900 \mathrm{~m}$, en tanto el Sanquilcó Grande se prospectó en inmediaciones de su desembocadura en el Chasicó, en una extensión de 1,7 km. En el sector inferior de la cuenca se prospectó casi la totalidad del perímetro de la laguna Chasicó y el 50\% del tramo del arroyo. En este sector las transectas se realizaron sobre las márgenes de la laguna y el arroyo y también de manera perpendicular a estos. Complementariamente, y considerando la distribución de las áreas con mayor disponibilidad de recursos (ver Capítulo 5), se realizaron prospecciones en las salinas chicas, en un sector entre las salinas y la laguna Chasicó y en el salitral de la Vidriera a los fines de evaluar las características del registro arqueológico en estos sectores (Figura 6.4). 


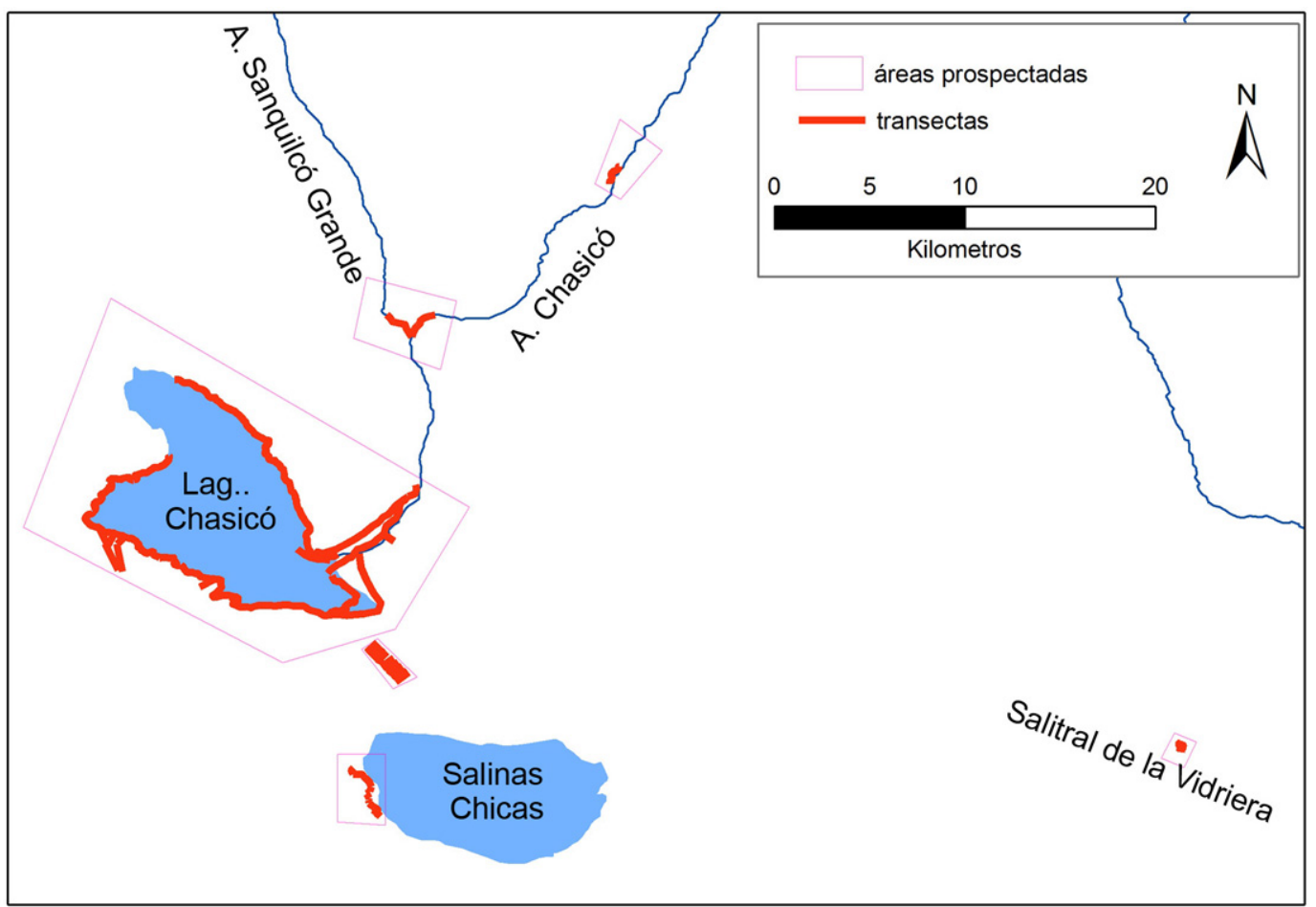

Figura 6.4. Transectas realizadas en la cuenca inferior, sector inferior de la cuenca media y las áreas adyacentes de las salinas Chicas y el salitral de la Vidriera.

\subsection{Resultados de las prospecciones}

\subsubsection{Características ambientales}

\subsubsection{Variaciones geomorfológicas y ecológicas}

Las prospecciones permitieron relevar variaciones en las características ambientales y geomorfológicas presentes a lo largo de la cuenca. Estas variaciones se correlacionan con diferencias en el tipo e intensidad de los procesos y agentes que afectan la formación y visibilidad del registro arqueológico y, como consecuencia, en su estructura observable. El sector superior se caracteriza por barrancas bajas y playas angostas (de no más de $2 \mathrm{~m}$.) o inexistentes, cubiertas por sedimento limoso a limoso arcilloso y abundante vegetación. La visibilidad es generalmente muy mala, debido a la presencia de esta densa cobertura vegetal, conformada por pastos, que en ocasiones superan el metro de altura, arbustos y algunos árboles. Esta cubierta se extiende sobre las terrazas y, en ocasiones, cubre también las barrancas y planicie de inundación. Las mejores condiciones de visibilidad fueron observadas en afloramientos rocosos con escasa depositación de sedimento sobre ellos, caminos y campos arados, donde esta es de regular a buena (Figura 6.5).

En el sector medio se desarrollan altas barrancas de entre 1 y 5 metros y sectores con dos y hasta tres terrazas, playas angostas y a veces inexistentes. Las condiciones ambientales son más secas y como consecuencia disminuye la cobertura vegetal, la que está conformada por pastos, que no superan los $30 \mathrm{~cm}$ de alto, y arbustos localizados en forma de "manchones" sobre las terrazas. En las inmediaciones del arroyo, el suelo es arcilloso con un alto porcentaje de carbonatos, encontrándose sectores erosionados por acción hídrica y/o eólica, donde en algunos casos se observan materiales arqueológicos. Tanto el 
arroyo Pelicurá como el sector medio superior del arroyo Chasicó presentan condiciones similares, pero con barrancas más bajas de entre $50 \mathrm{~cm}$ y $1,50 \mathrm{~m}$ en el primero. Hacia el sector medio inferior, en inmediaciones de la confluencia con el arroyo Sanquilcó Grande, las barrancas del arroyo Chasicó se hacen más altas, superando los $5 \mathrm{~m}$ de altura, la vegetación en este sector es de bosque cerrado, compuesto por especies de la provincia del espinal (principalmente chañar y caldén), por lo que no sólo la visibilidad es muy mala, sino que transitar a través de ella es muy difícil, debiendo realizarse los movimientos a través de caminos abiertos por el ganado o por la playa del arroyo, cuando esta existe. Esta vegetación se extiende sobre el arroyo Sanquilcó Grande, con la diferencia de que en este las barrancas son casi inexistentes, por lo que resulta sencillo transitar por sus playas, donde este tipo de vegetación es reemplazada por pastos (Figura 6.5).

El sector inferior de la cuenca está conformado por un tramo del arroyo Chasicó, desde la confluencia con el Sanquilcó Grande hasta su desembocadura en la laguna Chasicó y por esta última laguna. En el arroyo, las barrancas aumentan aun más su altura superando los $10 \mathrm{~m}$ de alto en algunas ocasiones, generalmente se encuentra una o dos terrazas y una amplia playa. El sedimento es predominantemente arenoso, con excepción del cauce del arroyo donde los sedimentos son en general limosos y arcillosos. Continúa la vegetación propia de la provincia del espinal, con montes cerrados de caldén y chañar, separados por zonas donde estos están ausentes, siendo reemplazados por pastos característicos de los arenales. Si bien la visibilidad es mayor, dada la menor cobertura vegetal y la presencia de "ventanas de visibilidad", como hoyadas de deflación y caminos de ganado, el predominio de suelos arenosos favorece el enterramiento y disminuye las posibilidades de hallazgo (Figura 6.5).
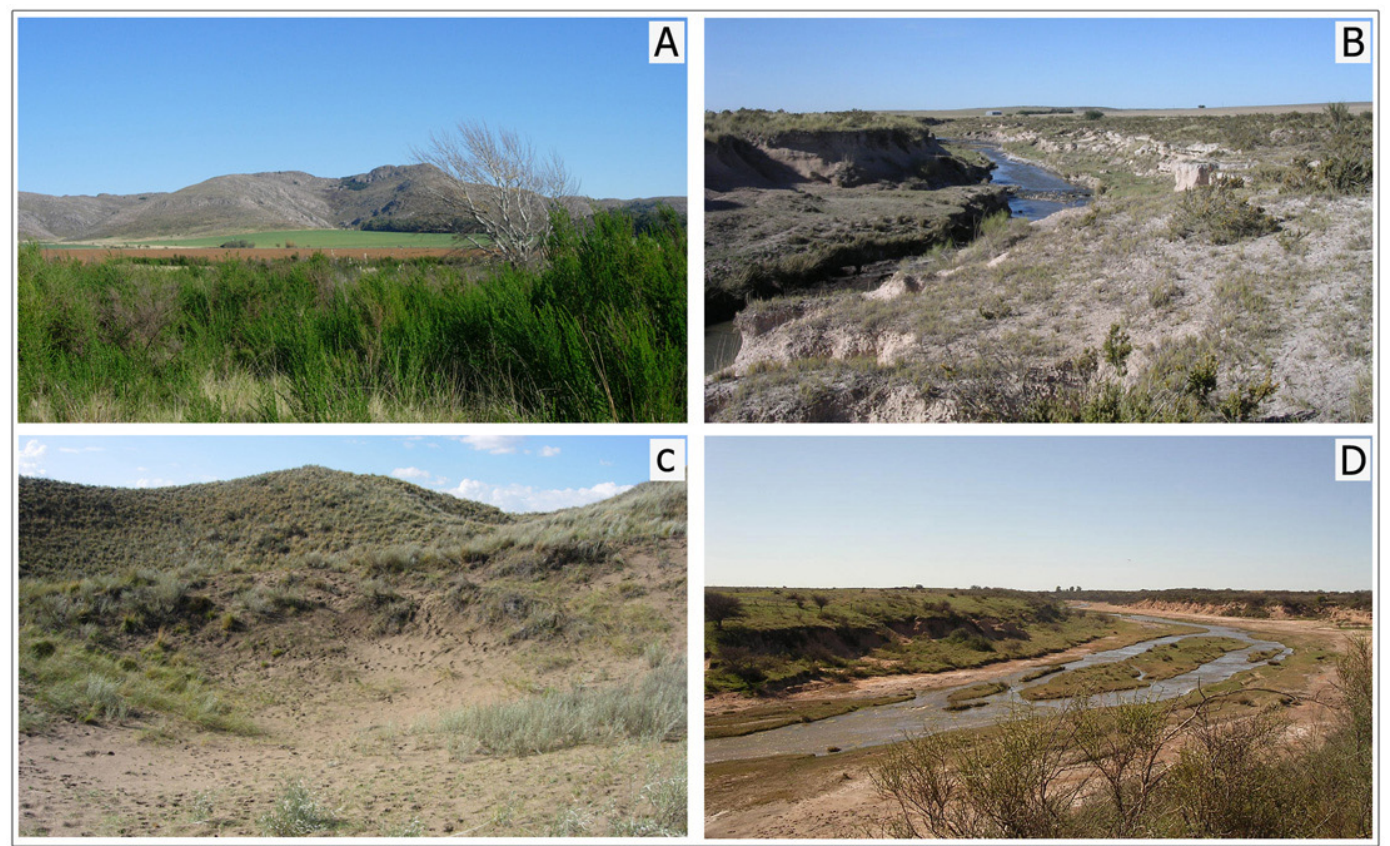

Figura 6.5. Variabilidad en la visibilidad en los distintos sectores de la cuenca A- sector superior, B- cuenca media, C- Médanos en las inmediaciones de la laguna Chasicó, D- cuenca inferior del arroyo. 
En la laguna Chasicó predominan las costas bajas arenosas y médanos con alturas que, en algunos casos, superan los $5 \mathrm{~m}$ de alto. La visibilidad es muy variable tanto temporal como espacialmente, sobre los médanos esta es de regular a mala, dependiendo del grado de cobertura de los pastos. Las zonas de mayor visibilidad se limitan a las hoyadas de deflación, pero en este caso, el enterramiento y depositación de arenas eólicas puede ocultar rápidamente los materiales. En el caso de la costa de la laguna, la visibilidad es de buena a regular, en relación con las fluctuaciones en su caudal de agua y los procesos de depositación eólica y enterramiento. En los alrededores de esta laguna la vegetación cerrada del espinal se encuentra limitada a sectores acotados del paisaje, por lo que no es difícil transitar en sus alrededores.

\subsubsection{Disponibilidad de materias primas líticas}

La materia prima lítica se encuentra disponible, aunque en cantidades y variedades diferentes, a lo largo de toda la cuenca, tanto en afloramientos primarios como secundarios. En el sector superior dominan los afloramientos que componen el Sistema Serrano de Ventania, conformado principalmente por rocas cuarcíticas y afloramientos puntuales de riolitas y granitos (ver capítulo 4 para una mayor descripción). A partir de las prospecciones, se evaluó el modo en que los rodados se localizan en el espacio (sectores del paisaje en que se encuentran, homogeneidad o heterogeneidad en su distribución), en tanto los muestreos brindaron datos acerca de la variabilidad de rocas y dimensiones y forma de los rodados.

En la cuenca superior, los rodados no presentan una distribución homogénea, encontrándose diferencias en su cantidad y tamaño. En el sector serrano son muy abundantes, presentes de manera continua en el cauce de los arroyos, en sus playas y, en algunos casos, sobre la primera terraza (Figura 6.6). También se encuentran depósitos conglomerádicos enterrados que son observables en las barrancas del arroyo, conformados por grandes bloques de más de $1 \mathrm{~m}$ de diámetro y rodados de menores dimensiones, que oscilan entre $20 \mathrm{~cm}$ y $30 \mathrm{~cm}$ en su eje máximo. En el sector de piedemonte los rodados se hacen menos abundantes, encontrándose generalmente en forma de bancos depositados en el cauce y playa del arroyo. Las dimensiones de los rodados también disminuyen, no encontrándose grandes bloques y predominando rodados con un eje máximo de entre $15 \mathrm{~cm}$ y $20 \mathrm{~cm}$. También se observó la presencia, sobre el arroyo Saudade (Figura 6.6), de sectores donde afloran brechas y conglomerados cementados, conformados por rodados de cuarcitas, y en menor proporción, riolitas, granitoides y rocas metamórficas (Catella et al. 2013), que se corresponden con el llamado "Conglomerado Rojo" (Harrington 1936, 1947; Keidel 1916; Schiller 1930;) o "Conglomerado Abra" (Harrington 1980), uno de estos afloramientos presenta evidencias de extracción y será tratado más adelante. La roca predominante en los rodados de todos los arroyos prospectados es la cuarcita, encontrándose en menores proporciones cuarzo y, en algunos arroyos, rodados aislados riolíticos (arroyos Cochenleufú Grande y Saudade) y rocas silíceas traslúcidas color verde amarillento (arroyo Saudade). F. Oliva también observó la presencia de rodados riolíticos en el arroyo Cochenleufú Chico, en proximidades de uno de los afloramientos de riolita de La Mascota, y en el arroyo Cochenleufú Grande, entre la confluencia con el arroyo Cochenleufú Chico y su desembocadura en la laguna Chasicó (Oliva 1996, 2014). Finalmente, en el área denominada por Bonorino et al. (1989) como de llanura periserrana, desde aproximadamente $11 \mathrm{~km}$ de la sierra y hasta la laguna Los Chilenos, los rodados son muy escasos y de tamaño pequeño, con un largo máximo que 
en muy pocos casos supera los $9 \mathrm{~cm}$, presentes sólo de manera dispersa o concentrados en pequeños bancos (Figura 6.6).

En el sector medio del cauce del arroyo Chasicó, la disponibilidad de rocas se limita a un

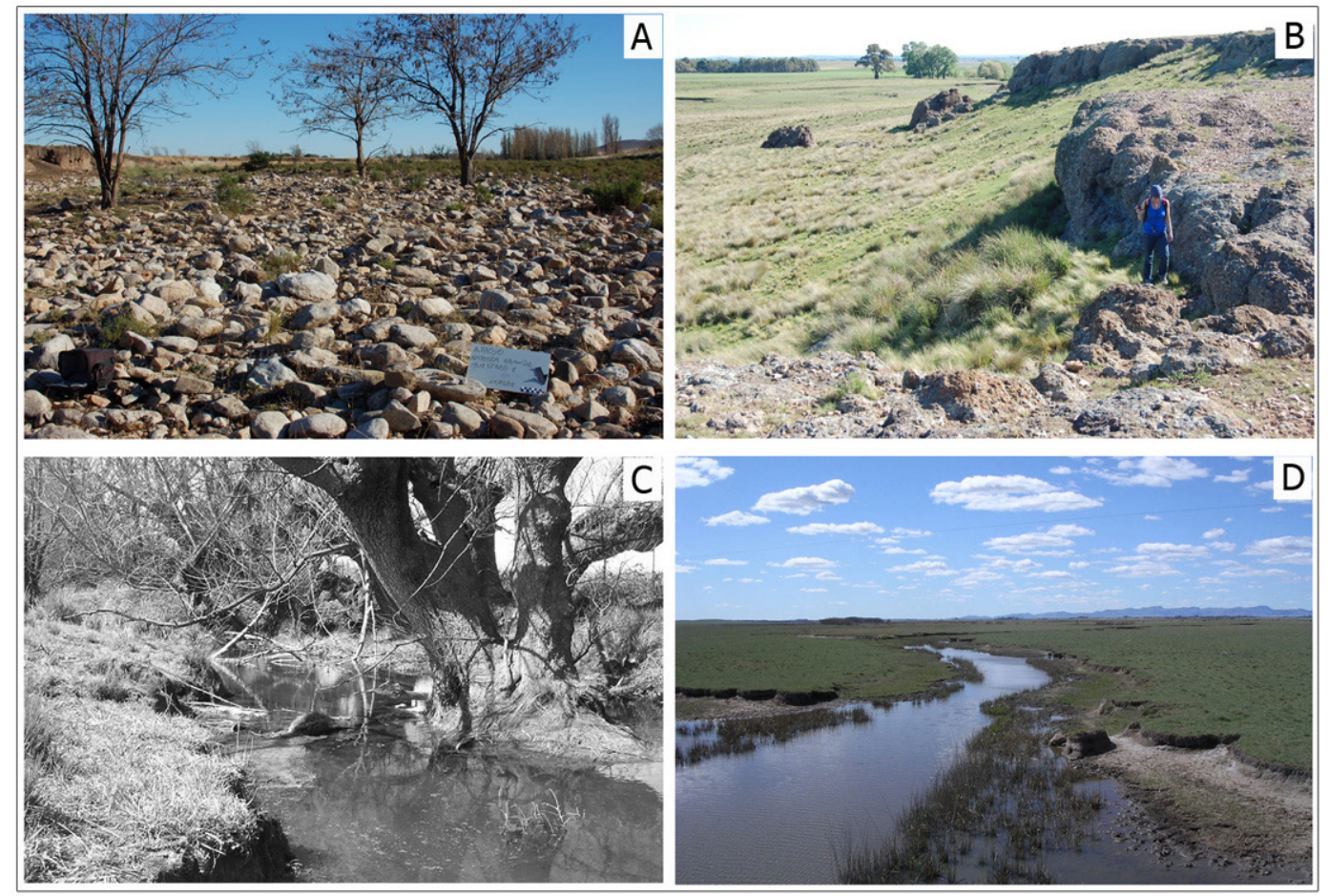

Figura 6.6. Distribución de rodados en los diferentes sectores de la cuenca superior A- área inmediatamente adyacente a las sierras, B- conglomerados El Abra en el sector periserrano, C- área sin rodados a aproximadamente $12 \mathrm{~km}$ de las sierras, D. Arroyo Cochenleufú Grande en inmediaciones de su desembocadura en la laguna Los Chilenos, sobre la derecha pueden observarse algunos rodados de pequeño tamaño.

afloramiento primario de granito de pequeñas dimensiones y a la presencia de rodados, principalmente cuarcíticos, que se distribuyen de manera dispersa sobre las terrazas y cauce, o bien conformando bancos cuyas dimensiones promedio rondan los $9 \mathrm{~m}$ de largo y $5 \mathrm{~m}$ de ancho. Su frecuencia y tamaño aumentan en relación con el sector periserrano, presentando dimensiones máximas que, en algunos casos, superan los $20 \mathrm{~cm}$ de largo y cuyo promedio es cercano a los $10 \mathrm{~cm}$ de largo y $7 \mathrm{~cm}$ de ancho (figuras 6.7 y 6.8). Estas dimensiones los vuelven potencialmente utilizables, ya sea como elementos de molienda, principalmente manos, como percutores y/o yunques y como nódulos para la obtención de lascas. Además de la cuarcita, que en los casos muestreado presentó una calidad para la talla de mediana a mala, se encuentran algunos rodados de riolita y cuarzo (dos de riolita y uno de cuarzo sobre 26 rodados muestreados). Finalmente, cabe destacar que en algunas porciones del sector medio, las barrancas superan los $3 \mathrm{~m}$ de altura y las playas angostas o inexistentes lo que dificulta el acceso a los rodados localizados en el cauce del arroyo.

En el sector inferior, el tamaño de los rodados solo disminuye levemente con respecto al cauce medio (Figura 6.8), pero su frecuencia es menor, distribuyéndose de manera dispersa a lo largo de la playa y el cauce del arroyo. En este sector, también se encuentran conglomerados conformados principalmente 

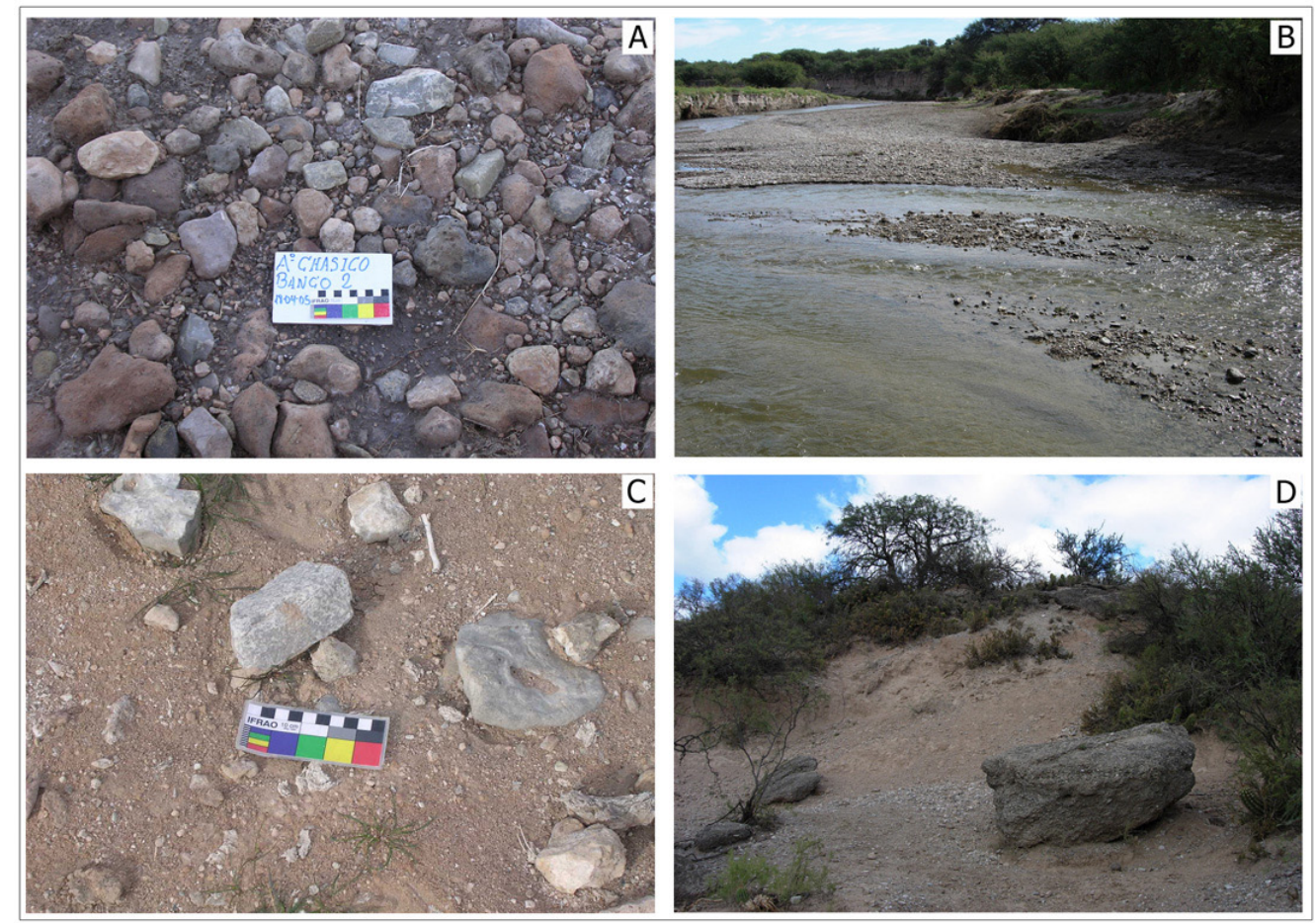

Figura 6.7. Rodados cuarcíticos en la cuenca media e inferior del arroyo Chasicó. A- Banco de rodados en la cuenca media, B- Rodados sobre el cauce del arroyo en la cuenca media, en inmediaciones de la confluencia con el arroyo Sanquilcó Grande, C- Rodados dispersos en la cuenca inferior, Conglomerado en inmediaciones de la desembocadura en la laguna Chasicó.

por rodados cuarcíticos fuertemente cementados, que pueden observarse en las barrancas, denominados formación "Bajada de los Toros" (Figura 6.7) (Fidalgo et al. 1978, 1987). Si bien las barrancas son altas, las playas suelen ser muy amplias, permitiendo la circulación sobre ellas y facilitando el acceso a los rodados. A diferencia de lo que ocurre en el arroyo Chasicó, en el cauce de los arroyos Pelicurá y Sanquilcó Grande, tributarios del Chasicó en su tramo medio, no se registraron rodados cuarcíticos, pero si, en el caso del arroyo Pelicurá, clastos graníticos angulosos, de entre 7 y veinte $\mathrm{cm}$ aproximadamente, probablemente relacionados con la presencia en las inmediaciones de una cantera moderna de granito, actualmente sin explotación.

En el área ocupada por la laguna Chasicó, la disponibilidad de rocas factibles de ser utilizadas en la confección de artefactos, ya sea mediante talla o por picado, abrasión y/o pulido se vincula con la presencia de remanentes de los llamados Rodados Tehuelches, en el primer caso, y con afloramientos de la formación Río Negro, en el segundo (Figura 6.9). En el caso de los Rodados Tehuelches, se los encuentra dispersos o en pequeños bancos presentes sobre la playa de la costa oeste y sudoeste de la laguna, en las Salinas Chicas y en las hoyadas de deflación de algunos médanos localizados al sur de la laguna. También se detectó un conglomerado fuertemente cementado en el sector de costa adyacente al balneario Chapalcó, el que dependiendo de la dinámica de erosión y depositación de arenas de la laguna, en algunas ocasiones queda expuesto en tanto en otras es cubierto por la arena. En el caso de los rodados disgregados se muestrearon aquellos presentes en inmediaciones de los sitios 2 y 3 (sitios que serán descriptos más adelante) los que presentan diámetros máximos de $3 \mathrm{~cm}$ y formas redondeadas a subredondeadas. 


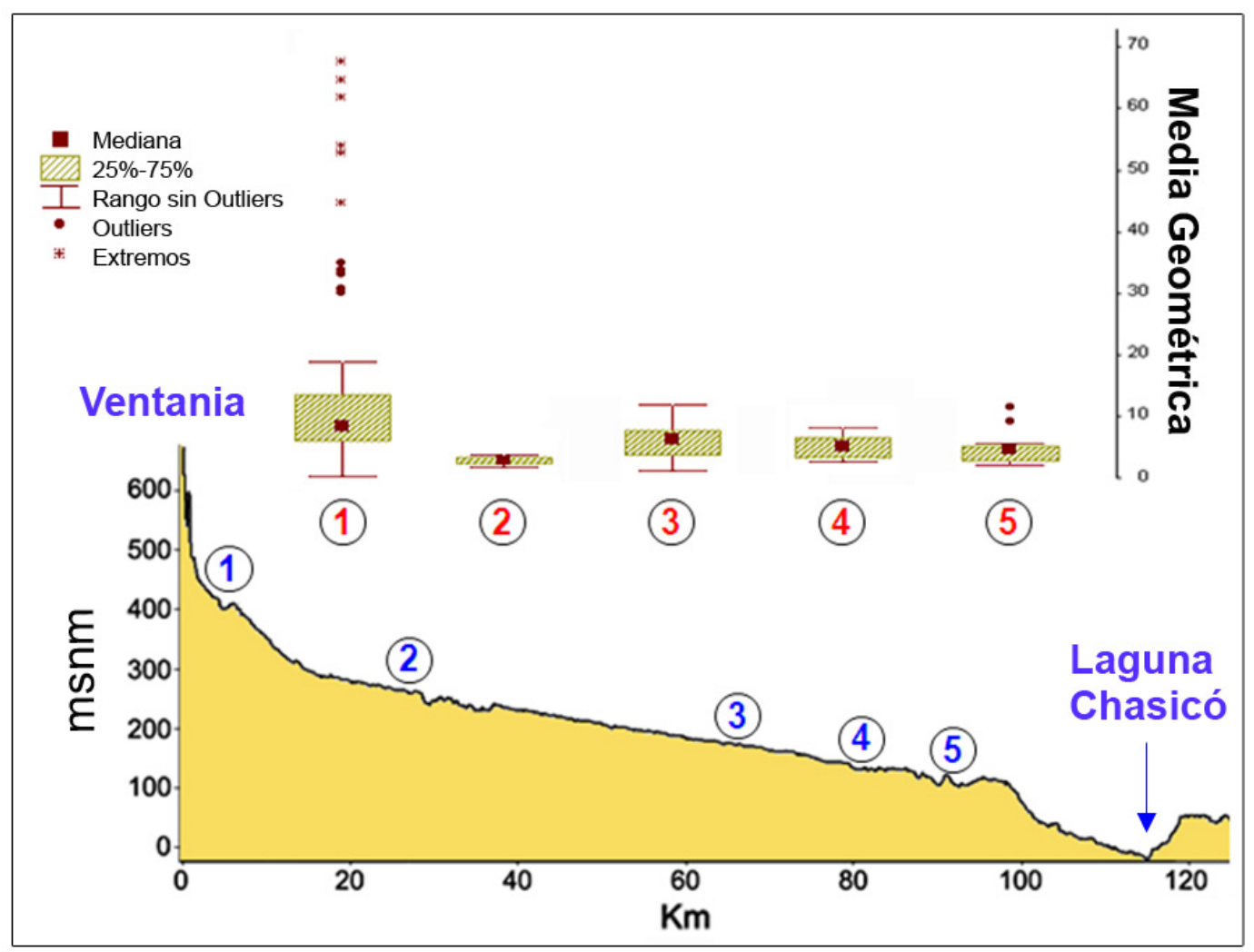

Figura 6.8. Perfil topográfico de la cuenca del arroyo Chasicó y boxplot representando la media geométrica de los rodados cuarcíticos. Los números señalan los sectores en donde se llevaron a cabo muestreos.

Por otro lado, y en relación con las materias primas factibles de ser utilizadas en la elaboración de artefactos por picado, abrasión y/o pulido, se identificó la presencia de la formación Río Negro, o areniscas rionegrenses, la cual, al igual que los rodados tehuelches, sólo se encuentra presente en la costa oeste y sudoeste de la laguna Chasicó. Esta aflora en lugares acotados del paisaje, que no siempre se encuentran expuestos, sino que, en muchas ocasiones, son cubiertas por el agua, la arena, o ambas (Figura 6.9). Se registraron seis afloramientos puntuales de areniscas, las que presentan una importante variabilidad en cementación, desde apenas consolidadas hasta fuertemente cementadas. También se registró su presencia en las Salinas Chicas y al sur de estas, en la zona del Decauville (Fidalgo et al. 1978, 1987).
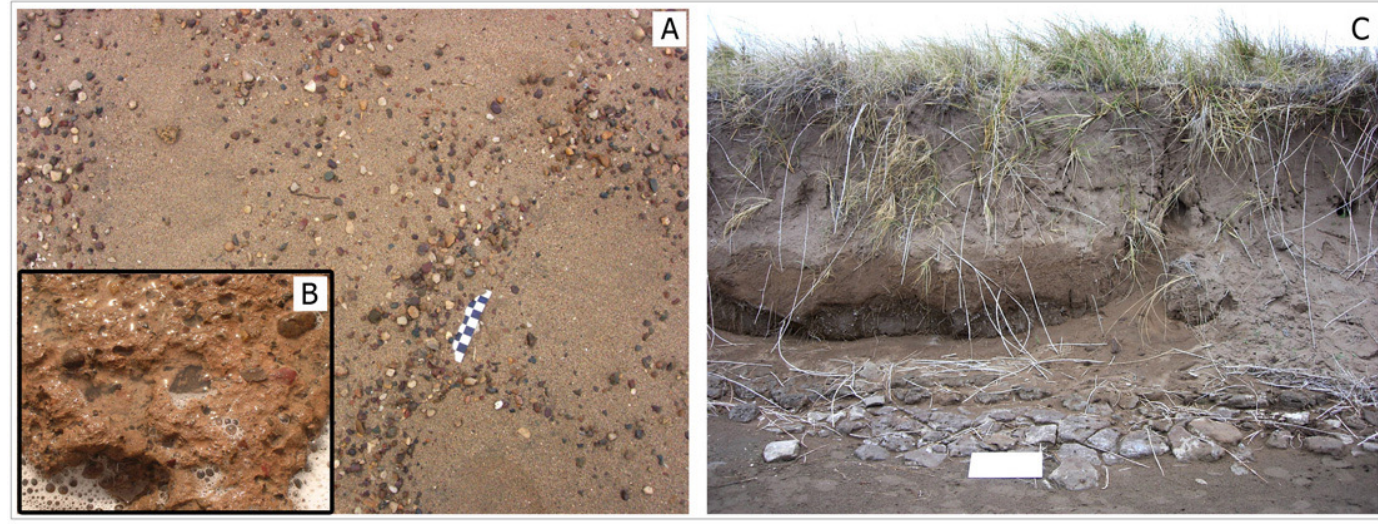

Figura 6.9. Materias primas disponibles en la laguna Chasicó. A- Manto de Rodados Tehuelches disgregado sobre la playa, B- Manto de Rodados Tehuelches cementados aflorando en la línea de costa, C- Areniscas rionegrenses expuestas en la base del médanos al bajar el nivel de la laguna. 


\subsubsection{Distribuciones arqueológicas}

Como ha sido mencionado previamente, los materiales arqueológicos registrados fueron recolectados cuando las condiciones materiales lo permitieron, aplicando en cada caso metodologías acordes a la situación particular. A continuación se presenta el tipo de información arqueológica obtenida en cada sector y el modo en que esta fue adquirida.

\subsubsection{Sector superior}

La información arqueológica de la cuenca superior, analizada en los capítulos subsecuentes, procede tanto de investigaciones realizadas por F. Oliva desde mediados de las década de 1980 (Barrientos et al. 1997, 2002; Oliva 1996, 2000, 2014; Oliva y Moirano 1997, 2001; Oliva et al. 2000), como de recolecciones superficiales llevadas a cabo durante el desarrollo de esta tesis. Entre las primeras se encuentran las investigaciones desarrolladas, en las cabeceras de la cuenca, en los sitios 2, 4 y 5 de La Sofía y en el sitio 1 de La Montaña y, en el área de llanura, en los sitios 1 y 2 de Los Chilenos (Figura 6.10) (Barrientos et al. 1997, 2002). Entre las segundas se encuentra la localidad Arroyo Saudade ubicada en el piedemonte serrano (Figura 6.10) (Catella et al. 2013).

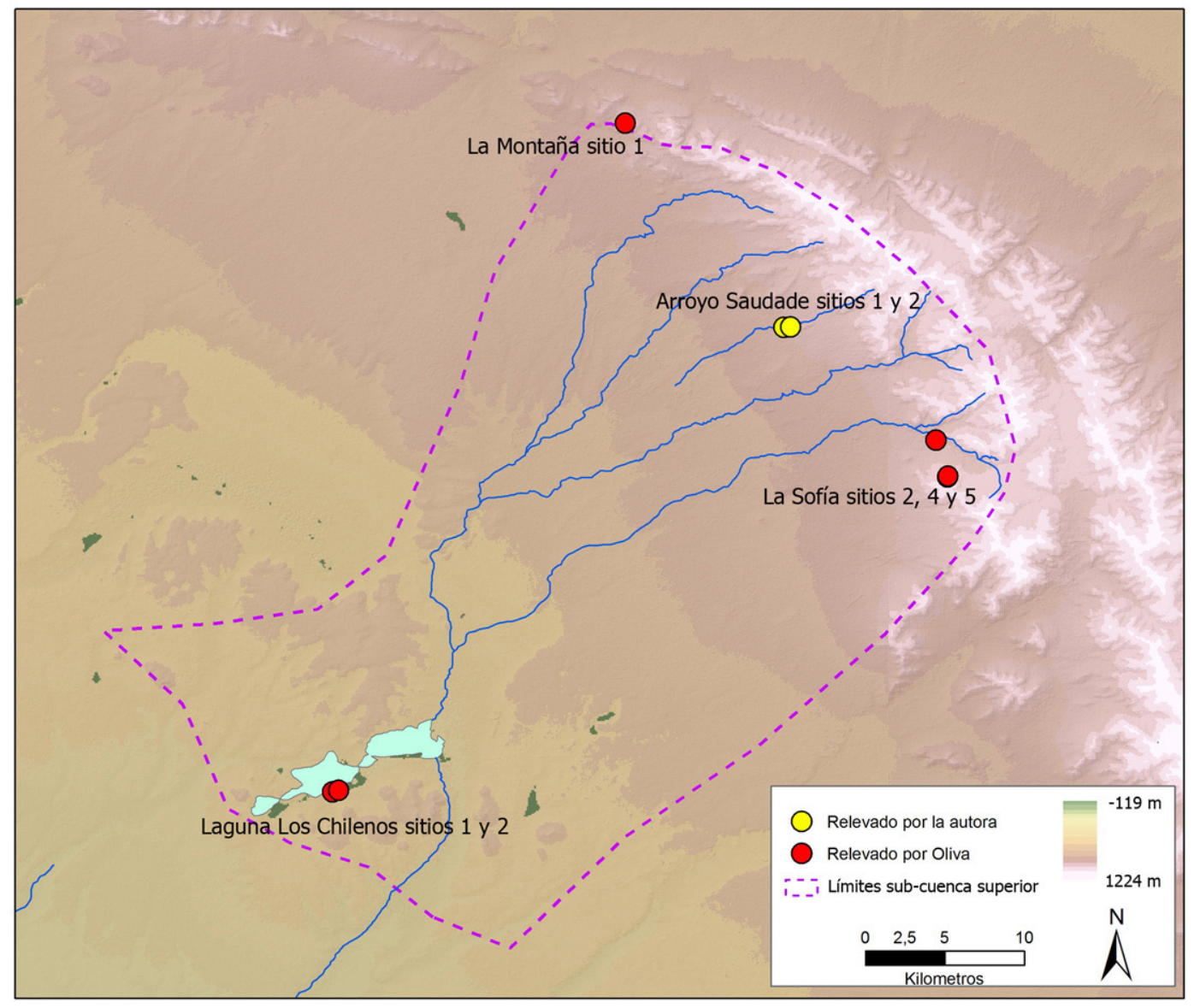

Figura 6.10. Cuenca superior: localización de los sitios estudiados en esta tesis. 


\subsection{Localidad La Sofía}

La localidad La Sofía se encuentra conformada por 7 sitios arqueológicos, entre los que se encuentran seis abrigos rocosos con representaciones rupestres en sus superficies y un sitio a cielo abierto (ver Capítulo 3). Para el desarrollo de esta tesis se re-estudiaron los materiales líticos de esta localidad, los cuales fueron recuperados en los sitios 2, 4 y 5. Dos de estos sitios consisten en abrigos rocosos (sitios 2 y 4), localizados sobre la margen izquierda de una de las nacientes del arroyo Cochenleufú Grande, a $150 \mathrm{~m}$ uno del otro, en tanto el tercero se encuentra a cielo abierto (sitio 5). En el sitio 2 los propietarios del establecimiento recolectaron algunos materiales líticos y F. Oliva realizó dos sondeos de $70 \mathrm{~cm}$ de lado, en los que sólo se recuperó material óseo indeterminable y algunos artefactos líticos (Oliva 2014). Los materiales arqueológicos del sitio 4 proceden de un sondeo de un metro cuadrado realizado en el sector central del abrigo rocoso. Este fue excavado hasta una profundidad de $40 \mathrm{~cm}$, recuperándose 4 artefactos líticos y restos óseos de Lama guanicoe (Oliva 2000, 2014). Por último, en el sitio 5, localizado en el valle del abra, sobre la margen izquierda de una de las nacientes del arroyo Cochenleufu Grande y a $2300 \mathrm{~m}$ en dirección noroeste de los sitio 2 y 4, F. Oliva realizó recolecciones superficiales sistemáticas (Figura 6.11; Oliva 2014).

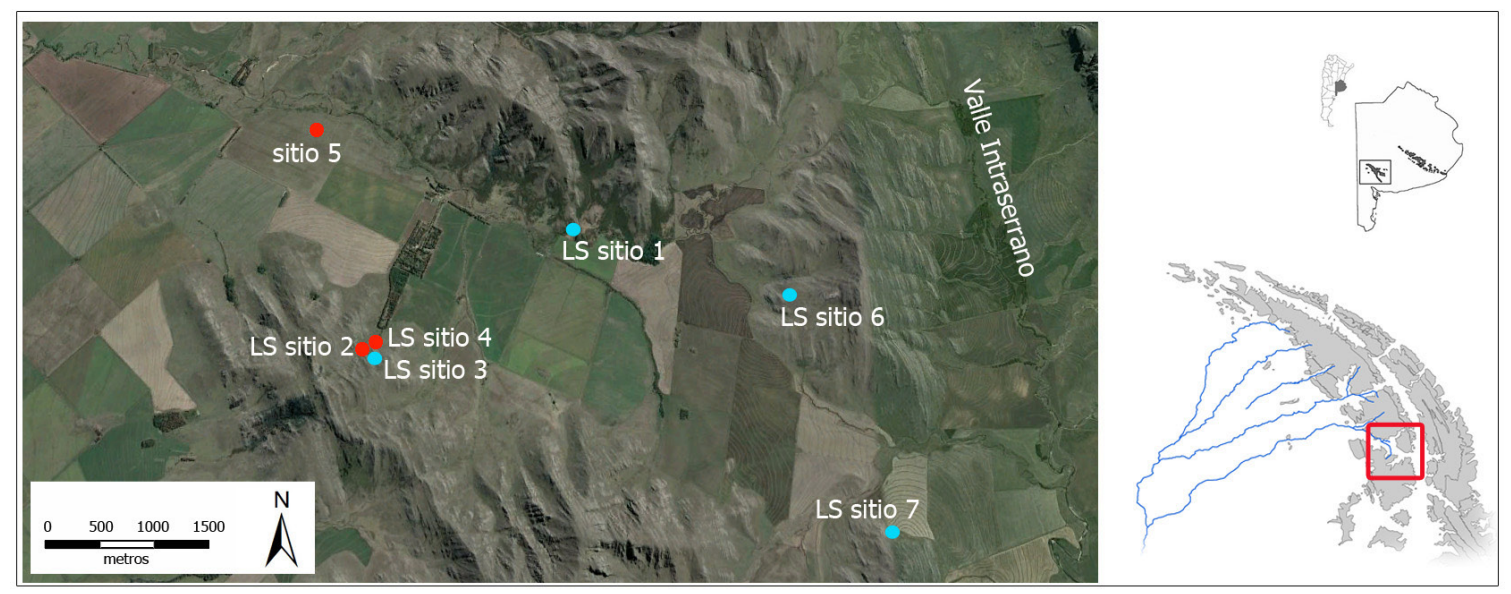

Figura 6.11. Localización de los sitios que conforman la localidad arqueológica La Sofía (Oliva 2013 com. pers.). En rojo se señalan los sitios de los que provienen los materiales analizados en esta tesis.

\subsection{La Montaña sitio 1}

En el sitio 1 de la localidad arqueológica de La Montaña (ver Capítulo 3 para un mayor detalle de las investigaciones realizadas en otros sitios de la localidad), se localiza a a 10 metros del lugar donde los propietarios del establecimiento llevaron a cabo las recolecciones de los materiales que hoy conforman las colecciones del museo Coyug Curá. La excavación fue realizada en inmediaciones de un pequeño arroyo, en un sector donde, si bien se desarrollaron actividades de arado, estas fueron menos intensivas que en otras áreas cercanas. F. Oliva planteó 5 cuadrículas localizadas, 4 de ellas al sudeste de un pequeño arroyo intermitente y la quinta al noroeste del mismo (Figura 6.12; Oliva 2014; Oliva et al. 2000). La superficie total excavada fue de $15 \mathrm{~m}^{2}$, mediante niveles artificiales de $5 \mathrm{~cm}$, hasta alcanzar una profundidad de $80 \mathrm{~cm}$ desde el nivel 0 (el que se localizó aproximadamente $30 \mathrm{~cm}$ sobre el nivel de superficie; Oliva 2014). A partir de las excavaciones se recuperó, inmediatamente por debajo de la línea de arado, material lítico, fragmentos cerámicos y elementos óseos asignables a Lama guanicoe y Ozotoceros bezoarticus. La mayor densidad de estos materiales se registró en las cuadrículas 1 a 4, con 
picos de concentración entre los niveles 7 y 11 en asociación con la UEB. La cuadrícula 5 en cambio, mostró una muy baja densidad de materiales en todos sus niveles, siendo levemente mayor entre los niveles 8 y 10 (Oliva 1996, 2014). Para el desarrollo de la presente tesis se re-analizaron los materiales líticos, cerámicos y óseos provenientes de las cinco cuadrículas mencionadas.

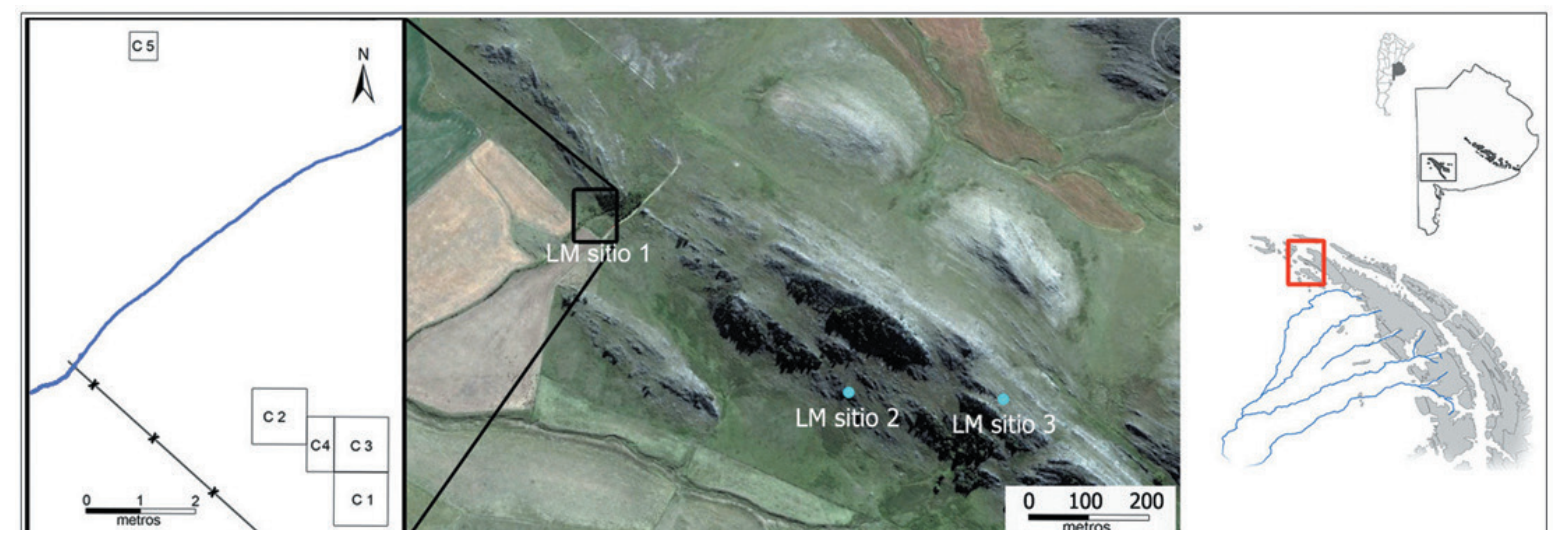

Figura 6.12. Planta del sitio La Montaña 1 y localización espacial de los tres sitios que conforman la localidad (Dibujo de planta F. Oliva).

\subsection{Localidad Arqueológica Arroyo Saudade}

Sobre las márgenes del arroyo Saudade en su recorrido por el ambiente periserrano, se registró un área de aproximadamente $600 \mathrm{~m}$ de largo, donde se presentan materiales arqueológicos con una densidad variable, a la que se denominó localidad arqueológica Arroyo Saudade. Esta localidad arqueológica se encuentra asociada a cuatro sectores donde afloran brechas y conglomerados cementados, conformados por rodados de cuarcitas, y en menor proporción, riolitas, granitoides y rocas metamórficas que corresponderían a lo que ha sido llamado como "Conglomerado rojo" o "el Abra"(Harrington 1936, 1947; Keidel 1916; Schiller 1930). Estos conglomerados están conformados por rodados cementados, localizados a diferentes alturas con respecto al cauce del arroyo, en un área con características estructurales o geotectónicas que generan resaltos en el terreno, exponiendo los depósitos fluviales conglomerádicos del Terciario (Cretácico?) en los bordes de los meandros actuales del arroyo

El primero de estos afloramientos (afl.1) se localiza a 2,5 $\mathrm{km}$ de la sierra, sobre el cauce del arroyo, con una cota de $407 \mathrm{msnm}$. El segundo (afl 2), se ubica también sobre el cauce del arroyo, a 2,45 km de las sierras y con una cota de $409 \mathrm{msnm}$. Este presenta rodados y bloques de gran tamaño, cuyos diámetros superan en muchos casos los $30 \mathrm{~cm}$, y es el único con evidencias de explotación intensiva. A 2,20 km de la sierra se identificó el tercer afloramiento (afl.3), conformado por rodados con diámetros inferiores a los $8 \mathrm{~cm}$, que se localiza a alrededor de $40 \mathrm{~m}$ del cauce del arroyo y unos $2 \mathrm{~m}$ sobre el nivel de base de éste, con una cota de 416 msnm. Finalmente, el cuarto de los afloramientos (afl.4), está conformado por rodados que no superan los $6 \mathrm{~cm}$ de diámetro. Se encuentra a 1,65 km de la sierra, a 80 $\mathrm{m}$ del cauce del arroyo y $3 \mathrm{~m}$ sobre el nivel de base de éste, con una cota de $425 \mathrm{msnm}$ (Figura 6.13).

Los materiales arqueológicos se concentran mayoritariamente en dos áreas, alrededor de las cuales se encuentran artefactos líticos dispersos, la primera, a la que se denominó Arroyo Saudade sitio 1 (ASS1), consiste en una cárcava de erosión hídrica, en tanto la segunda concentración se localiza 300 $\mathrm{m}$ aguas arriba de ASS1, sobre el afloramiento 2 -afl.2-. Este afloramiento presenta una superficie 
expuesta reducida de aproximadamente $147 \mathrm{~m}^{2}$, en la que se observaron evidencias de explotación del conglomerado. Los rodados y bloques que lo conforman se caracterizan por poseer colores rosado, bordó y amarillo-ocre y tamaños de entre algunos centímetros y más de un metro de diámetro. En las inmediaciones de los sitios, sobre una superficie de alrededor de $65.000 \mathrm{~m}^{2}$ (Figura 6.14), se encuentran materiales líticos en menor densidad, sin embargo, las variaciones en densidad entre los sitios y el área circundante podría relacionarse con la mala a regular visibilidad, que sólo es buena en lugares acotados del espacio donde la erosión es mayor y no se desarrolla cubierta vegetal, como es el caso de la cárcava de erosión y el conglomerado aflorante.

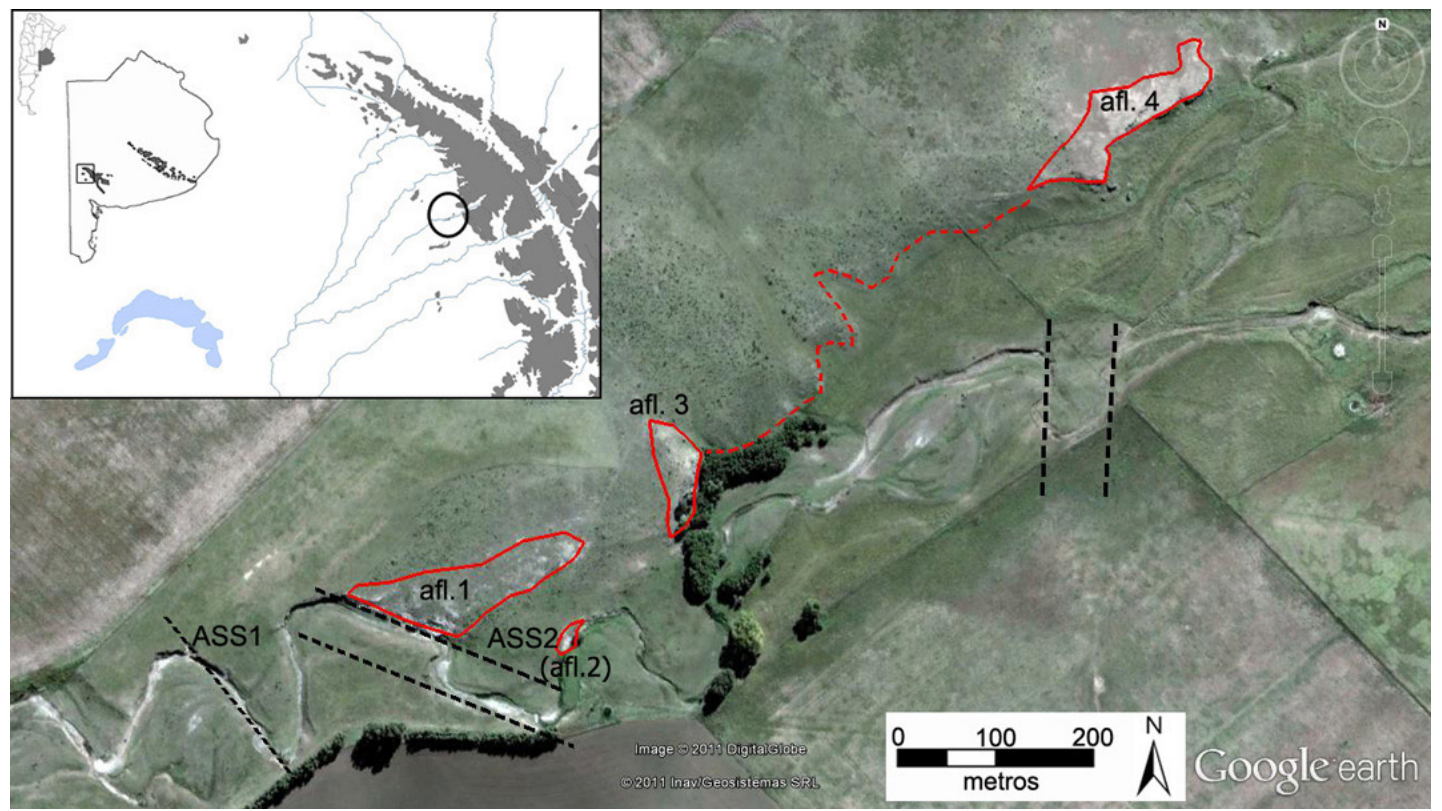

Figura 6.13. Localización de los sitios que conforman la localidad Arroyo Saudades, . ASS1 = Arroyo Saudade sitio 1; ASS2 = Arroyo Saudade sitio 2, y de los afloramientos del "Conglomerado Rojo", delimitados en color rojo. Las líneas punteadas negras marcan posibles fallas en el terreno que controlan los principales resaltos y el diseño de los meandros, favoreciendo las exposiciones de los conglomerados.

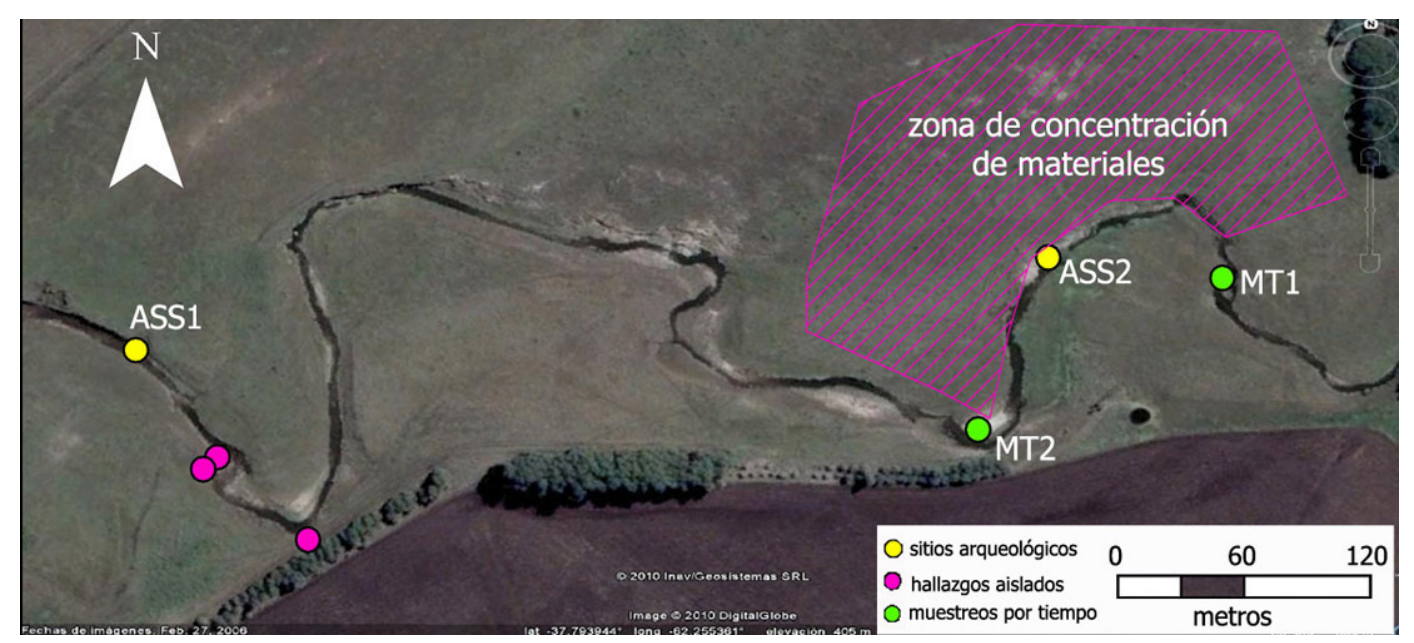

Figura 6.14. Imagen satelital Google Earth mostrando la ubicación de los sitios estudiados, muestreos de los bancos de rodados y localización de los hallazgos aislados recolectados y de la zona, fuera del sitios 2, con mayor concentración de materiales en superficie. 
La metodología implementada en el relevamiento de los sitios estuvo orientada a obtener una primera aproximación al tipo de materiales representados y, complementariamente, la densidad de los mismos en los diferentes sectores. El sitio ASS1 fue subdividido en dos sectores: el Sector A comprende materiales expuestos sobre una cárcava de erosión y en sus inmediaciones, en tanto el Sector B se localiza $15 \mathrm{~m}$ aguas abajo y presenta materiales en algunos sectores del perfil. En ambos se realizaron mapeos y recolecciones superficiales diferenciándose por sector. En el sitio ASS2 también se llevó a cabo el mapeo de todo el afloramiento y se plantearon dos unidades de recolección de $50 \mathrm{~cm}$ x $50 \mathrm{~cm}$ (UR1 y UR2), una al sur y otra al norte del afloramiento, dentro de las cuales fueron recolectados todos los materiales observados (Figura 6.15).

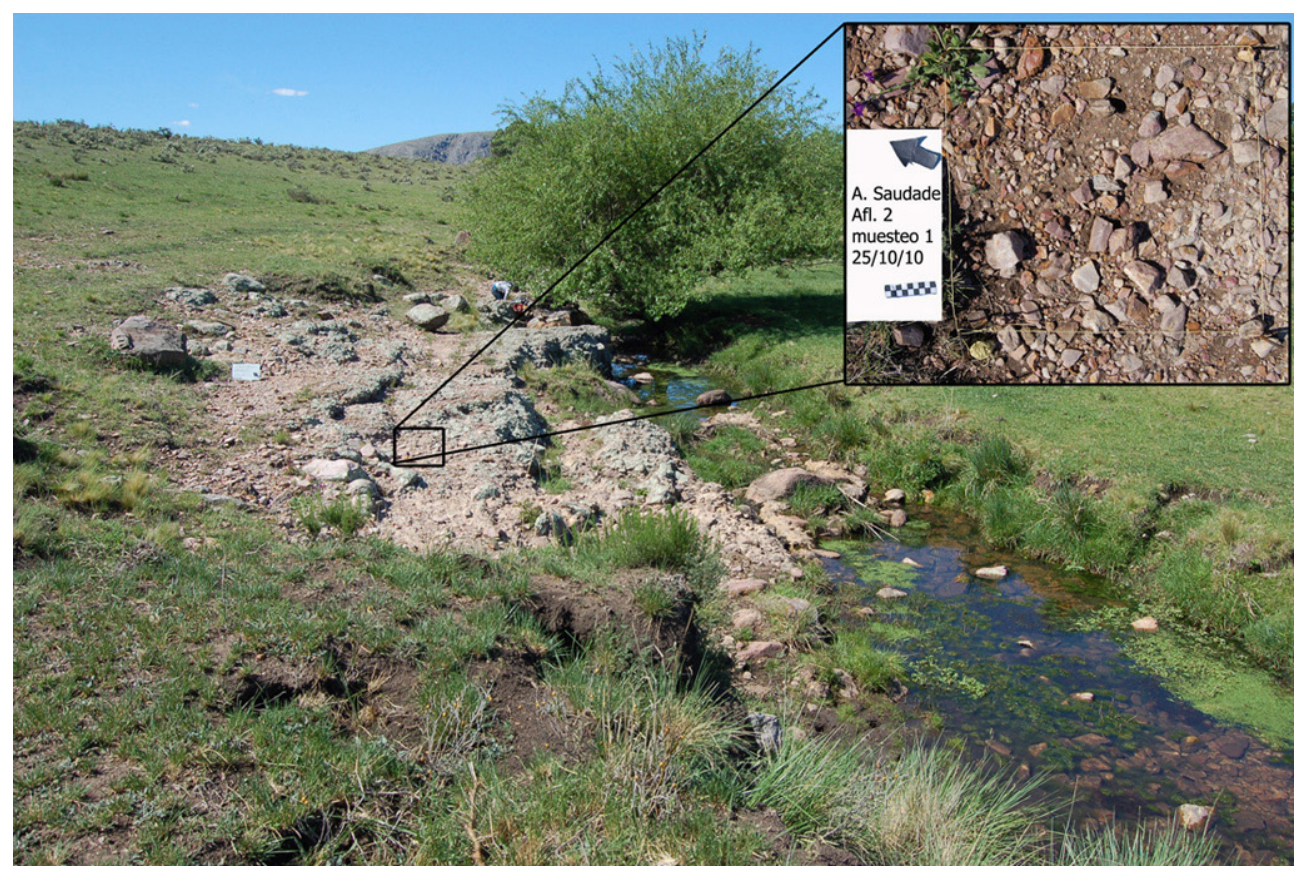

Figura 6.15. Vista del sitio 2 y detalle de uno de los muestreos realizados.

A su vez, entre ASS1 y ASS2 se realizó una prospección asistemática siguiendo el cauce del arroyo, donde se registró la presencia de bancos y rodados aislados de cuarcita de buena y muy buena calidad, algunos con lascados de extracción. Estos últimos fueron fotografiados, referenciados mediante GPS y recolectados como hallazgos aislados en aquellos casos en que su tamaño lo permitió, cuando esto no fue así, se relevaron sus dimensiones in situ. Por otra parte, y a los fines de evaluar la disponibilidad en el cauce del arroyo de rodados de buena calidad para la talla, se realizaron dos muestreos por tiempo, uno en el banco localizado $50 \mathrm{~m}$ aguas arriba de ASS2 (MT1) y otro en el banco localizado $60 \mathrm{~m}$ aguas abajo (MT2). Los materiales líticos localizados en las inmediaciones de este afloramiento, incluido el sitio 1 (ASS1), parecen ser producto de la explotación del mencionado afloramiento, por lo que se ha considerado a la localidad como un área cantera-taller de rocas cuarcíticas de muy buena calidad para la talla (Catella et al. 2013)

Finalmente, en el afloramiento 1 se realizó, en colaboración con el Dr. M. Manassero, el relevamiento del perfil expuesto en la barranca del arroyo, observándose que el depósito se encuentra compuesto por niveles conglomerádicos sub-redondeados, matriz y clasto sostén, con tamaños máximos que llegan a los $15 \mathrm{~cm}$, presentando una gran variedad composicional con clastos de cuarcitas $\mathrm{y}$, en menor 
proporción, riolitas, granitoides y rocas metamórficas pertenecientes a las rocas del basamento y de la cobertura sedimentaria paleozoica aflorantes en el cordón serrano de Ventania. En este se pueden apreciar al menos cuatro paleocauces fluviales superpuestos, que marcan la presencia de un valle inciso desarrollado en forma perpendicular al cordón serrano. Hacia el techo, los depósitos sedimentarios se hacen más arenosos marcando una disminución en la paleopendiente regional reflejada en esta disminución de la granulometría. Las paleocorrientes medidas por la imbricación de los clastos (Figura 6.16) y por el desarrollo de las capas entrecruzadas en los niveles superiores del depósito, marcan un sentido predominante desde el norte y desde el nordeste (Catella et al. 2013).
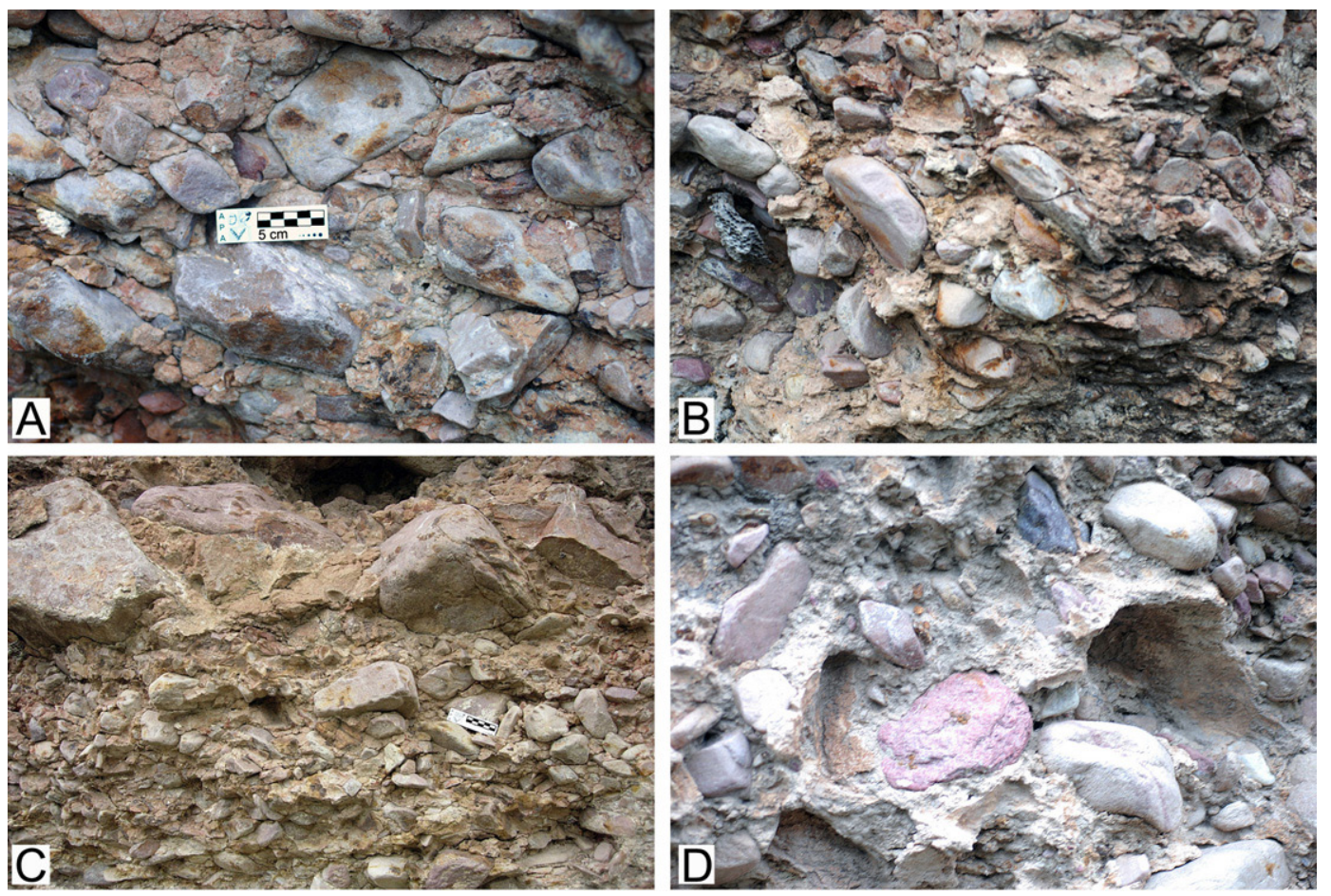

Figura 6.16. Afloramiento 1. A- Ortoconglomerado polimíctico con clastos sub-angulosos de hasta 20 $\mathrm{cm}$ de diámetro en matriz arenosa; B- Idem anterior pero aquí se puede apreciar una imbricación de clastos que indica una paleocorriente desde el noreste al sudoeste; C- Estratificación gradada y clastos orientados dentro del ortoconglomerado; D- Clastos de diversa composición (cuarcitas, riolitas) con coloraciones distintivas.

\subsection{Localidad arqueológica Laguna Los Chilenos}

Los sitios 1 y 2 de Los Chilenos, excavados y analizados por F. Oliva y G. Barrientos durante la década de 1990, se localizan en la laguna Los Chilenos, en el límite entre las cuencas superior y media del arroyo Chasicó (Barrientos et al. 1997, 2002; Oliva 1996, 2014). El sitio 1 fue identificado a partir de la presencia, en la playa y barranca, de restos óseos humanos expuestos por la acción erosiva de la laguna y que fueron detectados por pobladores locales. En este sector se excavó un área total de $21 \mathrm{~m}^{2}$, donde se reconocieron 10 unidades estratigráficas (UE A - I y UE N). A partir de estas excavaciones se recuperaron tres entierros, dos primarios y uno secundario, numerosos elementos óseos humanos dispersos, escasos artefactos y ecofactos y elementos óseos correspondientes a Ovis aries (en las unidades superiores), Ctenomys sp. y Dasipodidae sp. La totalidad de los materiales arqueológicos se localizó en las UE F, G H y N (Figura 6.17) (Barrientos et al. 1997, 2002). 


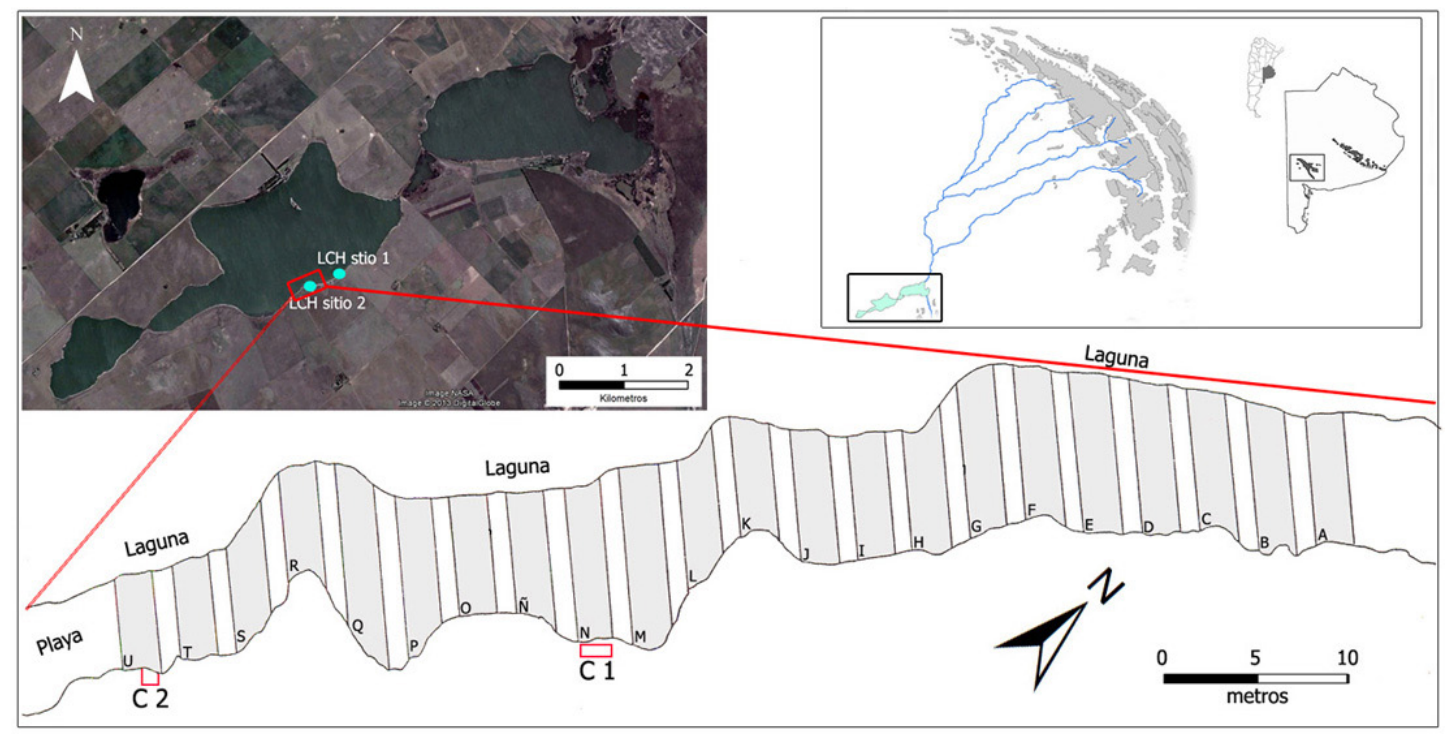

Figura 6.17. Imagen satelital mostrando la ubicación de los sitios 1 y 2 y detalle de las actividades desarrolladas en el sitio 2. En gris se marcan la recolección superficial y en rojo los dos sondeos realizados en el sitio 2 (Dibujo de planta F. Oliva).

En el sitio 2, F. Oliva, G. Barrientos realizaron recolecciones superficiales de los materiales depositados sobre la playa, planteando 23 unidades de recolección (UR A - U) de $2 \mathrm{~m}$ de ancho, desde la línea de barranca hasta la línea de costa, con un espaciamiento lateral de $1 \mathrm{~m}$, en las que recuperaron artefactos, ecofactos y restos óseos de guanaco, venado y vaca y algunos restos humanos. Sobre la barranca, coincidentemente con las zonas de mayor concentración de materiales, se excavaron dos pozos de sondeo $\left(3 \mathrm{~m}^{2}\right)$, en los que se identificaron siete unidades estratigráficas correlacionables, de la UE. E a la UE. H, con las del sitio 1 (Barrientos et al. 2002; Oliva 2014). Los materiales arqueológicos fueron recuperados principalmente en la base de la UE. E y parte superior de la UE. F. Para el desarrollo de esta tesis, fueron re-analizados los artefactos líticos, cerámicos y arqueofaunísticos recuperados en las excavaciones realizadas en los sitios 1 y 2 y en las recolecciones llevadas a cabo en las unidades $\mathrm{N}$, Q, U y R.

\subsubsection{El sector medio}

\subsection{Colección San Martín (Museo Regional Chasicó)}

La mayor parte de la información obtenida para la cuenca media proviene del sitio arqueológico San Martín 1 y sus inmediaciones. Este se encuentra en el partido de Puán, unos 70 km. al sur del Sistema Serrano de Ventania. En este sector, la Prof. N. Cinquini recolectó numerosos materiales arqueológicos que actualmente forman parte de las colecciones del Museo Regional Chasicó. Estos proceden de las terrazas del arroyo y de un sector de campo localizado a aproximadamente $600 \mathrm{~m}$ del arroyo. Sobre las terrazas Cinquini identificó 5 concentraciones de materiales a las que denominó colección San Martín (1 a 5), conformadas por un posible cache, artefactos líticos tallados y formatizados por picado, abrasión y/o molienda y fragmentos cerámicos. En el sector de campo, al que denominó colección Bastán, los hallazgos consistieron en material lítico tallado expuestos en superficie luego que el campo fuese arado 
(Figura 6.18). Estas colecciones poseen un registro detallado sobre la procedencia de sus materiales y se encuentran conformadas por diversidad de tamaños, inclusive aquellos más pequeños, así como por artefactos poco atractivos como los desechos de talla, por lo que pueden ser consideradas como “confiables", es decir, que se habría recolectado todo lo que se encontraba en el campo y no sólo aquellos artefactos más grandes o más vistosos, como sucede con algunas de las colecciones de particulares (Moirano 1999).

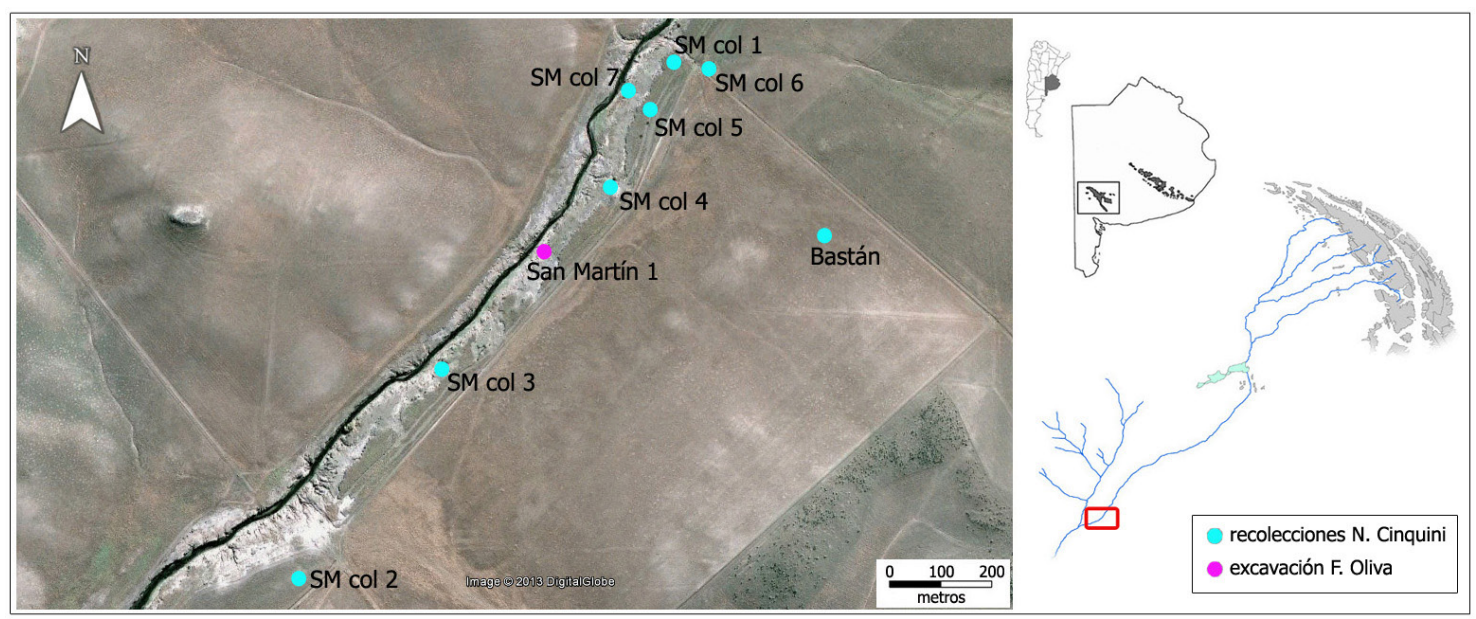

Figura 6.18. Localización del sitio San Martín 1 y de las recolecciones realizadas por N. Cinquini en sus inmediaciones.

\subsection{San Martín sitio 1}

A partir del año 1988, F. Oliva excavó, en tres etapas, un área a la que denominó San Martín sitio 1 y realizó recolecciones superficiales aguas abajo de este sitio, en el área a la que llamó sitio 2 y que coincide aproximadamente con la colección denominada San Martín 3 por N. Cinquini. Posteriormente, durante los años 2003 y 2005 y en el marco de esta tesis, se realizaron relevamientos y recolecciones superficiales en las inmediaciones del sitio 1 (Oliva et al. 2006). Dicho sitio se localiza sobre la margen izquierda del arroyo Chasicó, en la segunda terraza de un conjunto de tres, las cuales en la actualidad están siendo surcadas por cárcavas producto de la erosión hídrica. Estas cárcavas nacen en la segunda y tercer terrazas, desembocando en el arroyo en ángulo aproximado de $40^{\circ}$ y con dirección este-oeste.

El área excavada consistió en 11 cuadrículas que abarcaron una superficie de $38 \mathrm{~m}^{2}$, en las que se reconocieron cinco unidades estratigráficas -A, B, C, D y E- (Oliva 1996; Oliva et al. 1991b; 2010a). La excavación se dividió en dos sectores, uno de $29 \mathrm{~m}^{2}$ (cuadrículas 1 a 8) y otro de $9 \mathrm{~m}^{2}$ (cuadrículas 9 a 11), distantes uno del otro $4 \mathrm{~m}$, y separados por una de las cárcavas arriba mencionadas (Figura 6.19). En el sitio se recuperaron, elementos óseos y malacológicos, artefactos líticos, fragmentos de pigmento mineral y cuentas de collar confeccionadas sobre mica y valva. La mayor densidad de materiales se encuentra en el sector sur de las cuadrículas, entre los niveles 7 y 15 y en asociación con la UE. B., la que aparece en forma de lentes de un sedimento de color marrón oscuro, arcilloso y blando, con pequeñas incrustaciones de carbonato y mayor densidad de caracoles de las especies Biomphalaria sp., Austroborus sp., Heleobia sp. -anteriormente llamada Littoridina- y Succinea sp. (Oliva 2014; Oliva et al. 1991b). 


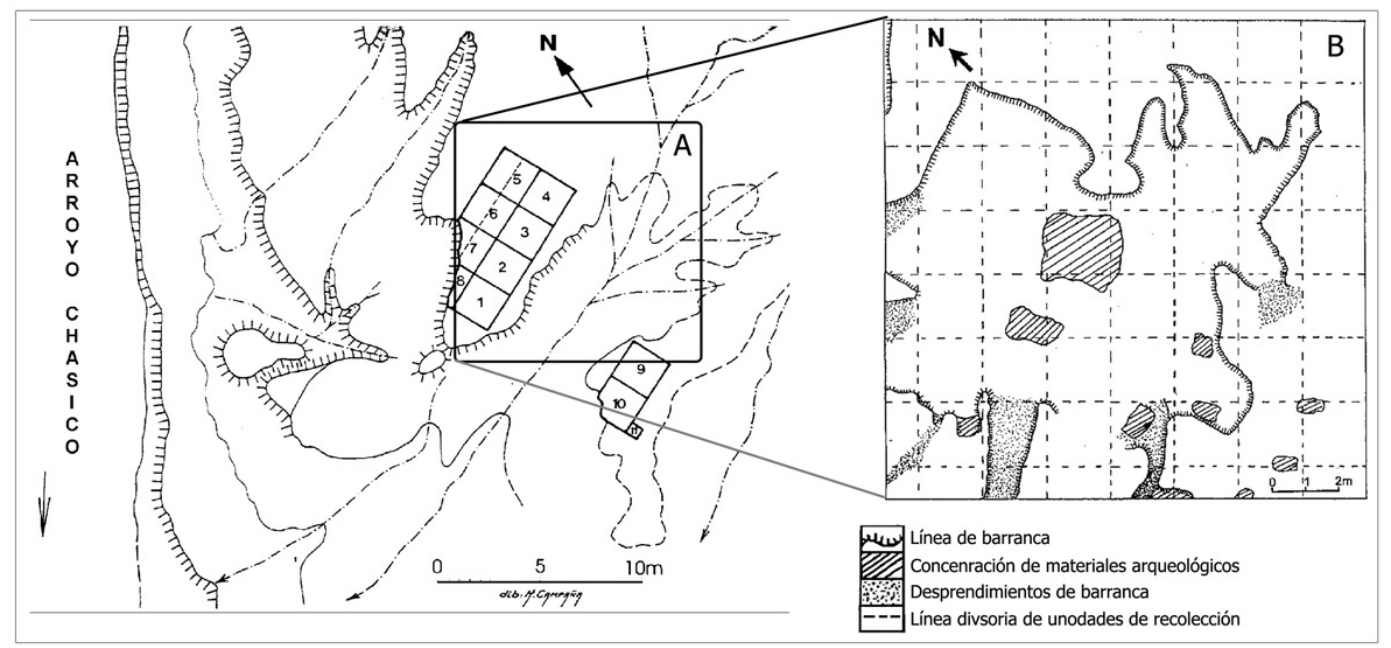

Figura 6.19. Plantas del sitio San Martín 1. A- excavaciones realizadas entre 1988 y 1992 (Oliva et al. 2010; Oliva 2014), B- relevamiento y recolecciones superficiales realizadas en el período 2003-2005 (Oliva et al. 2006).

Durante los relevamientos realizados en los años 2003 y 2005, se observó abundante cantidad de material arqueológico expuesto en superficie, producto de la erosión de los perfiles de las cuadrículas excavadas en la década del '90. Dada esta situación se trazó un cuadriculado de $225 \mathrm{~m}^{2}$ dividido en 64 unidades (Figura 6.19), sobre el cual se efectuó una recolección superficial en la que se recuperaron cáscaras de huevo de Rhea americana y placas de Dasipodidae (con evidencias de combustión en muchas de ellas), restos óseos faunísticos muy fragmentados, restos de valva de la especie Adelomelon brasiliana y artefactos líticos (Oliva et al. 2006).

También se continuaron las prospecciones aguas abajo de este sitio, observándose, en un área de $2000 \mathrm{~m}$ de largo, un total de 7 concentraciones de materiales líticos expuestos en superficie, consistentes en instrumentos tallados, desechos de talla y artefactos confeccionados por picado, abrasión y pulido, entre estos una boleadora y una base de molino. Las mayores densidades de materiales se localizan en cercanías del sitio San Martín 1, disminuyendo al alejarse de este, aguas abajo. Estos materiales fueron referenciados con GPS y fotografiados, pero por cuestiones de tiempo y movilidad no se los recolectó.

\subsubsection{El sector inferior}

Los antecedentes arqueológicos para esta área al momento de iniciar las investigaciones eran prácticamente inexistentes. Estos se limitaban al relevamiento expeditivo de un sitio arqueológico localizado sobre las playas de la laguna y a la mención de la presencia de rodados del Manto Tehuelche en sus inmediaciones (ver Capítulo 3). Por tal motivo, las prospecciones desarrolladas en este sector fueron de tipo intensivo, orientadas a obtener información relevante acerca de las características del registro arqueológico y de los procesos actuantes en su formación. Dado que, como se mencionó previamente, la cuenca inferior y, especialmente la laguna Chasicó, constituye un ambiente de gran dinamismo, se realizó al menos una prospección anual en el área, a los fines de relevar las variaciones en el paisaje y su relación con la distribución de materiales arqueológicos y disponibilidad de materias primas. La mayor cantidad de materiales arqueológicos fue registrada en los alrededores de la laguna Chasicó, donde se identificó una importante cantidad de hallazgos aislados y sitios arqueológicos, siendo escasos los 
materiales observados en el arroyo. Estas diferencias en la densidad artefactual entre el arroyo y la laguna pueden deberse, al menos en parte, a la menor estabilidad de los ambiente que circundan la laguna, ya que este espejo de agua a experimentado importantes variaciones en su nivel de base. Las oscilaciones en dicho nivel, producen la erosión hídrica de los médanos circundantes, exponiendo y re-depositando, sobre las playas de la laguna, los materiales arqueológicos contenidos en estos. La magnitud de este proceso puede observarse en la Figura 6.20 donde se representa la línea de costa en el año 1963 (carta topográfica IGM 3963-9-4) y en el año 1993-1996 (carta de imagen satelitaria IGM 3963-I).

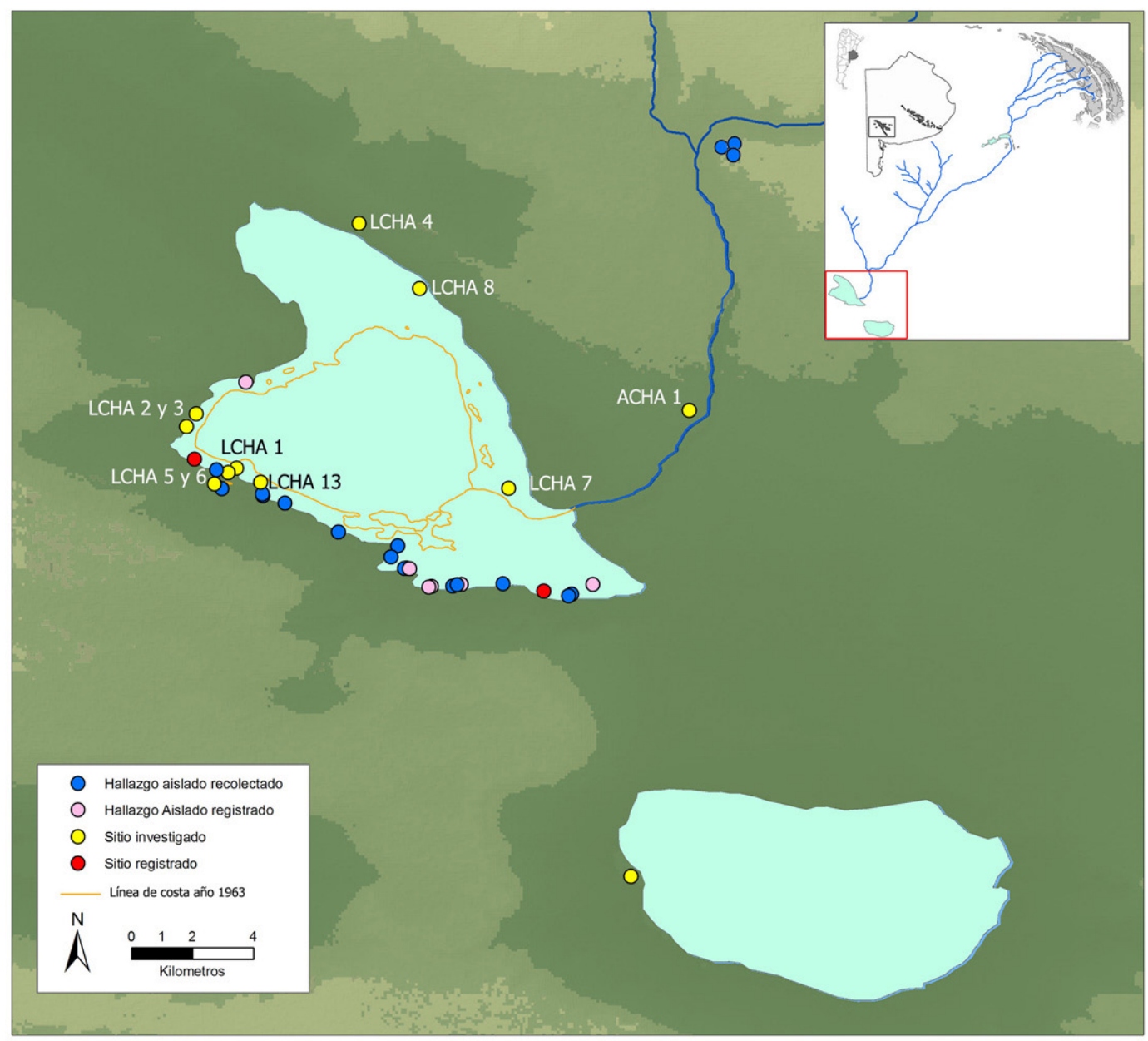

Figura 6.20. Distribución de materiales arqueológicos (sitios y hallazgos aislados) en la cuenca inferior. Se diferencia entre aquellos que sólo fueron posicionados mediante GPS (registrados) y los que fueron recolectados y mapeados (recolectado/investigado). Puede observarse también la comparación con la línea de costa de la laguna en el año 1963, tal como fue registrada en la carta IGM 3963-9-4.

\subsection{Arroyo Chasicó}

En el cauce del arroyo, a pesar de haber sido prospectado en reiteradas oportunidades, de forma paralela y transversal al cauce, los materiales arqueológicos identificados fueron muy escasos. Estos consiste en seis hallazgos aislados localizados en las inmediaciones de la confluencia del arroyo Sanquilcó Grande con el Chasicó, sobre una meseta con una altura de aproximadamente $30 \mathrm{~m}$ sobre el cauce del arroyo y rodeada de bosque del espinal, y un sitio arqueológico y algunos materiales dispersos, aproximadamente $4000 \mathrm{~m}$ antes de la desemboadura en la laguna Chasicó (Figura 6.20). 


\subsection{Arroyo Chasicó sitio 1}

A partir de las prospecciones se detectó un área, localizada sobre la margen derecha del arroyo, aproximadamente 4000 metros aguas arriba de su desembocadura en la laguna homónima, en la que se observó un sitio arqueológico, ubicado en una hoyada de deflación, y algunos artefactos líticos dispersos en sus inmediaciones. Este sitio fue denominado Arroyo Chasicó sitio 1, está localizado a unos 50 metros de altura en relación al curso de agua y a 200 metros aproximadamente de la costa del arroyo. Se presenta sobre un médano erosionado de forma circular con una extensión aproximada de 20 metros de diámetro. Fue visitado por primera vez en el año 2003, cuando se hizo un primer relevamiento consistente en referenciarlo mediante GPS y fotografiarlo (Oliva et al. 2006), posteriormente, en el año 2004, se realizó el mapeo del mismo y se planteó una recolección superficial consistente en 16 UR de 5 $\mathrm{m}$ de lado $\left(400 \mathrm{~m}^{2}\right)$ que cubrieron la totalidad del área erosionada y en la que se recuperaron artefactos líticos confeccionados por talla y por picado, abrasión y/o pulido (Figura 6.21). Posteriormente, en el año 2005 se re-visitó el sitio, observando la presencia de nuevo material lítico en superficie (un fragmento de arenisca, una lasca de riolita y lascas de cuarcita) que no fue recolectado.

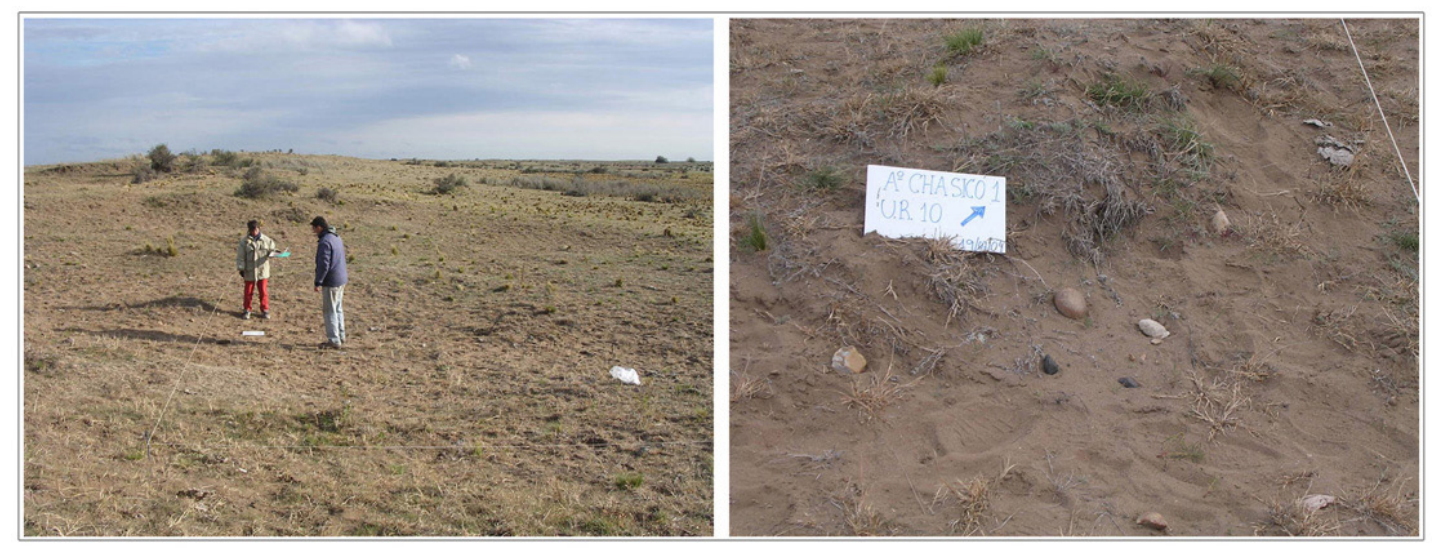

Figura 6.21. Arroyo Chasicó sitio 1, a la izquierda vista general de la hollada y a la derecha detalle de los materiales.

\subsection{Laguna Chasicó}

En la laguna Chasicó se prospectó aproximadamente el 90\% de la costa, no pudiéndose relevar el sector noroeste debido a que es la zona más baja y por consiguiente más inundada. Dado que la laguna Chasicó fue recorrida en diferentes años, pudieron registrarse fluctuaciones en su línea de costa, consecuencia de variaciones en su nivel de base. A partir del año 1976, la laguna de Chasicó, al igual que muchas de las lagunas del sudoeste de la provincia de Buenos Aires, experimentó un aumento en su caudal de agua, produciendo la inundación de las áreas circundantes (Zinger et al. 1997). Los puntos donde es más notoria esta situación, la desembocadura del arroyo y los sectores noroeste y sudoeste paralelos a la dirección de la depresión en que se encuentra la laguna. Este proceso también puede ser observado claramente en la localidad de Chapalcó, la que quedó casi por completo cubierta por el agua (Figura 6.22). Durante los trabajos de campo, el punto máximo en su nivel de base fue observado en el año 2005, momento en que los sectores de playa presentaban dimensiones mínimas (alrededor de un metro de ancho) o eran inexistentes. Luego de este momento, la laguna comenzó un paulatino y constante descenso, que expuso materiales arqueológicos en los distintos sectores de su 
playa. Durante el desarrollo de esta tesis se registraron 11 sitios arqueológicos, de los cuales 9 fueron relevados mediante mapeos, recolecciones sistemáticas y en algunos casos sondeos, y 22 hallazgos aislados, de los cuales 15 fueron recolectados y analizados. En el caso de los materiales que solo fueron registrados (tanto hallazgos aislados como concentraciones), se midió su posición mediante GPS, se relevaron expeditivamente sus características y se los dejó en el terreno.

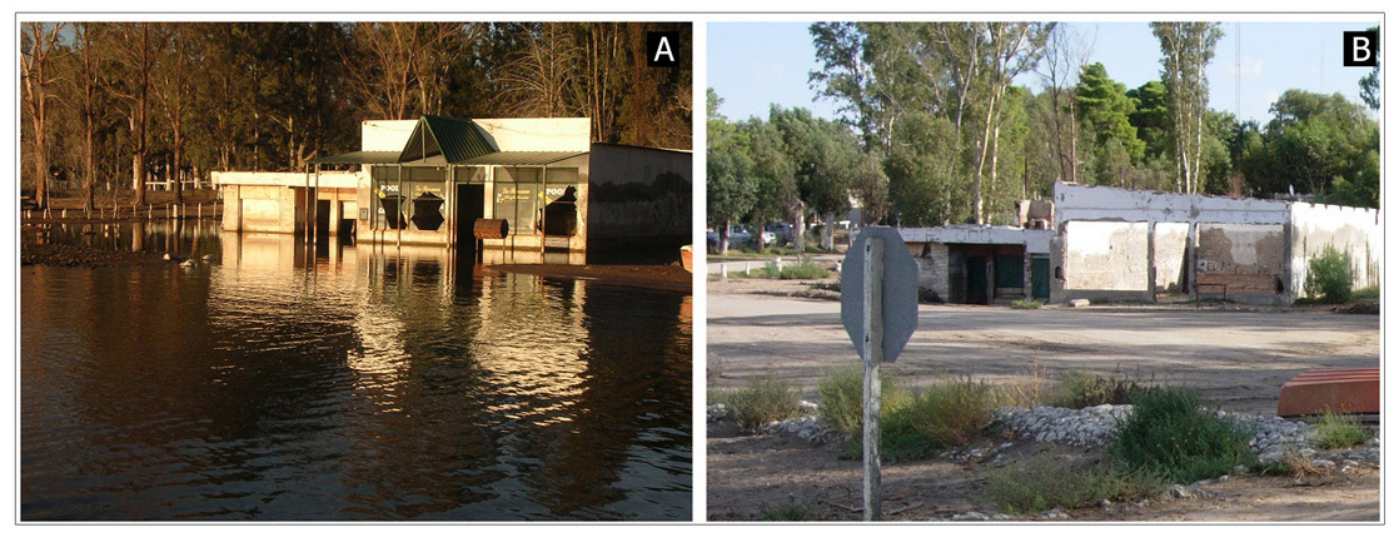

Figura 6.22. Variaciones en el nivel de base de la laguna Chasicó. A- localidad de Chapalcó en el año 2004, B- mismo lugar en el año 2009.

\subsection{Laguna Chasicó sitio 1}

El sitio 1 se encuentra en la costa SE de la laguna, sobre una pequeña isla formada por médanos que fueron parte de una península hasta fines de la década de 1970. En esta península se encontraba el puesto de una estancia y posteriormente funcionó también como lugar donde se celebraban fiestas, como correlato de lo cual actualmente pueden observarse restos de baldoses y ladrillos en distintos sectores. Actualmente sólo se puede llegar en embarcación o nadando y si bien no se permite el acceso a la misma, muchos pescadores la utilizan para obtener leña o inclusive para realizar pesca de costa.

Este sitio fue relevado por primera vez por F. Oliva a principios de la década de 1990, quien describe la presencia de médanos erosionados en la línea de costa y materiales arqueológicos sobre aproximadamente $500 \mathrm{~m}$ de playa (Oliva 1996). Entre los años 2003 y 2011 se realizaron varias visitas al sitio durante las cuales se mapeó la isla, se registraron las variaciones en la línea de costa y se llevaron a cabo recolecciones superficiales y sondeos. La primer recolección se realizó en el año 2004, momento en que el agua cubría gran parte de la isla, aflorando únicamente dos pequeños islotes (uno al norte y otro al sur). Debido a la poca extensión de la playa expuesta y la escasez de materiales en superficie, mayormente dispersos, se realizó, solo en la isla norte, una recolección expeditiva subdividiendo esta en dos sectores.

En el año 2007, el descenso en el caudal de agua de la laguna dejó expuestos numerosos materiales arqueológicos, entre los que se destaca una gran cantidad de artefactos confeccionados por picado, abrasión y/o pulido, artefactos tallados y, en menor proporción, fragmentos cerámicos, caracoles marinos y restos óseos faunísticos y humanos. Los materiales se encontraban distribuidos sobre un amplio espacio de playa, con picos de concentración en cuatro sectores ( A, B, C y D) y parcialmente cubiertos por el agua (Figura 6.23). Dada esta situación y que muchos de ellos resultaban llamativos, 
especialmente por su tamaño, y por lo tanto expuestos a ser recolectados por visitantes ocasionales, se planteo la realización de recolecciones del material siguiendo dos metodologías. Por un lado, se trazaron 34 unidades de recolección, distribuidas entre las concentraciones A y B, dentro de las cuales se recuperaron todos los materiales presentes. Por otra parte, se referenciaron con GPS y levantaron aquellos materiales más llamativos. Las recolecciones se realizaron, principalmente, en las concentraciones A, B y C, debido a que en la concentración D la mayor parte de los materiales corresponde a desechos de talla de pequeñas dimensiones, probablemente producto de re-depósito, en esta concentración sólo se recolectaron algunos restos óseos faunísticos muy mineralizados y restos óseos humanos desarticulados que fueron referenciados mediante GPS.

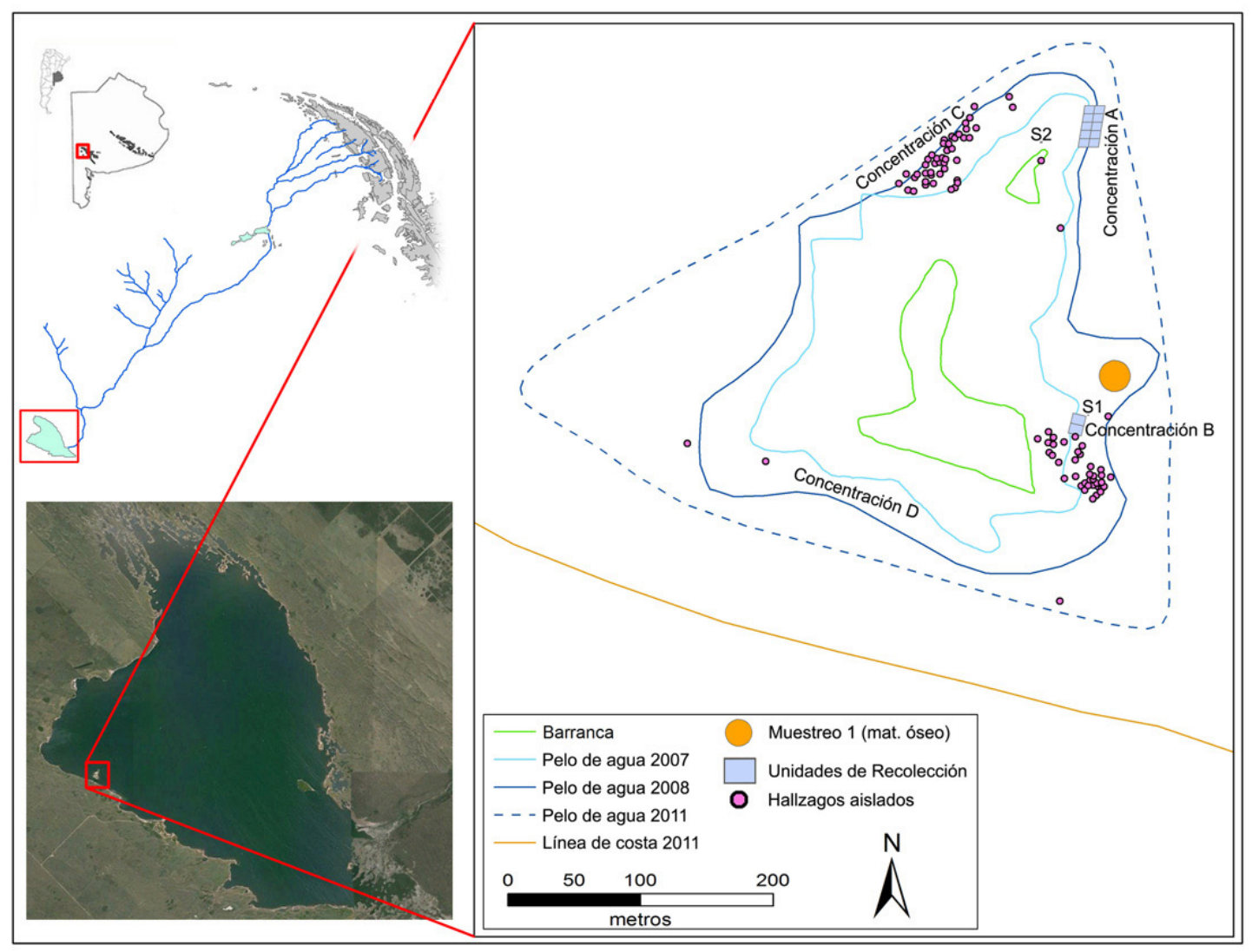

Figura 6.23. Laguna Chasicó sitio 1. Planta de la isla donde se detalla la evolucion de la línea de costa y las áreas donde se desarrollaron las recolección y sondeos. $\mathrm{S}=$ sondeo.

En la concentración A se recolectaron algunos materiales con GPS y se plantearon 10 UR de $5 \mathrm{~m}$ x $6 \mathrm{~m}$ localizadas, 5 en el sector de playa y 5 adyacentes a las primeras pero en el área cubierta por el agua. En la concentración B, se plantearon dos unidades de recolección de $6 \mathrm{~m}$ x $8 \mathrm{~m}$ sobre un sector con mayor densidad de materiales (UR 1 al norte y UR 2 al sur) y se tomaron un total de 38 puntos con GPS que en algunos casos corresponde a un solo material y en otros corresponde a varios materiales próximos unos a otros, en este caso se aclaró el radio de dispersión (Figura 6.23). Posteriormente, en el año 2009 y luego de que la laguna retrocediese aún más, se trazó una transecta paralela a la línea de costa que fue subdividida en 24 unidades de recolección de 2,5 m de lado, a los fines de realizar una recolección intensiva que permitiese complementar la información obtenida anteriormente. En las concentraciones C y D, la totalidad de los materiales fue recolectada utilizando GPS, debido a la gran 
dispersión que presentaban estos. Por último, se realizó un muestreo de material óseo (muestreo 1), para lo cual se trazó un círculo de aproximadamente $10 \mathrm{~m}$ de diámetro dentro del que se recolectó la totalidad del material óseo presente a los fines de analizar variabilidad en mineralización y meteorización.

Se realizaron tres sondeos a los fines de evaluar la presencia de materiales en estratigrafía. Uno localizado en inmediaciones de la concentración A (Sondeo 1), de $1 \mathrm{~m}$ de lado y otros dos en la concentración B (Sondeos 2 y 3) de $50 \mathrm{~cm}$ de lado, los dos primeros excavados hasta el nivel de agua, 60 $\mathrm{cm}$ y $45 \mathrm{~cm}$ respectivamente, y el tercero hasta los $45 \mathrm{~cm}$ de profundidad. En el sondeo 1 se recuperaron sólo lascas y microlascas, asociadas a un sedimento arenoso y oscuro, casi negro, en tanto en los otros dos sondeos no se recuperó material arqueológico. En todos los sondeos se tomaron muestras de sedimento.

\subsection{Laguna Chasicó sitio 2}

El sitio 2 se localiza sobre la costa oeste de la laguna, en terrenos del pesquero "Los Rastros", en un área que actualmente se utiliza para realizar pesca de costa. En este sector, el paisaje está conformado por extensos médanos sobre los que se extiende una cubierta de gramíneas, montes de chañar y caldenes aislados. El aumento en el nivel de la laguna ha erosionado los médanos generando una barranca cuya altura oscila entre $30 \mathrm{~cm}$ y $4 \mathrm{~m}$ de altura siendo inexistente en algunos sectores. Sobre la playa y con una extensión de aproximadamente $300 \mathrm{~m}$ se extienden de forma irregular materiales arqueológicos conformados por artefactos líticos, cerámicos y, en menor proporción, restos óseos faunísticos.

El sitio fue relevado por primera vez en el año 2003, cuando se lo referenció mediante GPS y se realizaron algunas observaciones sobre la distribución de los materiales, y el ancho de la playa (inexistente en algunos sectores, alcanzando un ancho máximo de $11 \mathrm{~m}$ ), sin llevar a cabo recolecciones. En el año 2004, se revisitó el sitio observándose un descenso en el nivel de la laguna, se realizó el relevamiento topográfico y se plantearon 78 UR con una extensión de $5 \mathrm{~m}$ cada una por el ancho de la playa, dentro de las cuales se recolectaron todos los materiales observados. En este sitio también se realizó, a los fines de evaluar la presencia de materiales arqueológicos en estratigrafía, un sondeo de 50 $\mathrm{cm}$ de lado. Este se planteó sobre la playa de la UR 64, en uno de los sectores con mayor concentración de materiales pero no se recuperaron materiales arqueológicos en estratigrafía (Figura 6.24).

En el año 2005, momento de máxima crecida de la laguna, el agua cubrió completamente el sitio y, consecuencia de la erosión hídrica de los médanos y el sedimento de la playa, dejó al descubierto un afloramiento de areniscas rionegrenses bien consolidadas de características similares a las utilizadas en la confección de los artefactos confeccionados por picado, abrasión y/o pulido (Figura 6.24). Este afloramiento fue mapeado y muestreado y se realizaron algunas recolecciones midiendo la localización de los materiales con GPS. En posteriores visitas al sitio se observó un importante descenso de la laguna, la que dejó al descubierto amplias extensiones de playa, de más de $50 \mathrm{~m}$ en algunos sectores. Los materiales arqueológicos, sin embargo, aparecen concentrados en una franja de entre 1.30 y $2 \mathrm{~m}$ de ancho que se ubica a un metro de la barranca, no encontrándose materiales demasiado cerca de la barranca ni del pelo de agua. El material se encontraba muy mezclado con elementos actuales y en algunos casos se había encendido fuego sobre ellos, lo que muestra el alto grado de perturbación que sufren los materiales una vez expuestos por la acción erosiva. 


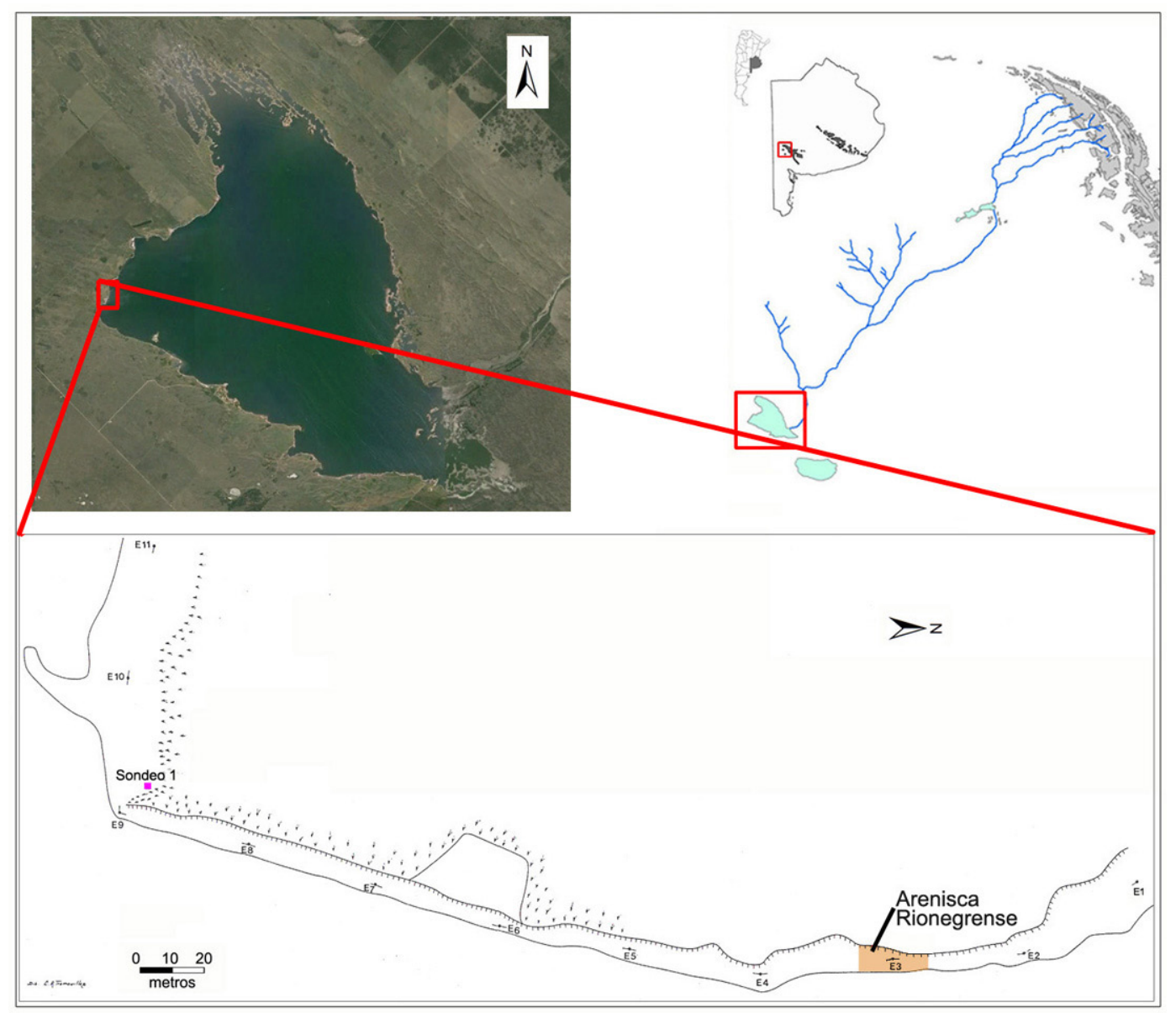

Figura 6.24. Laguna Chasicó sitio 2. Planta del área de costa donde se desarrollaron las recolección y localización de los sondeos realizados y del afloramiento de areniscas rionegrenses detectado.

\subsection{Laguna Chasicó sitio 3}

El sitio 3 fue identificado en el año 2004 debido a que, durante las prospecciones de 2003, se encontraba cubierto por el agua. Se localiza sobre la costa de la laguna, unos $400 \mathrm{~m}$ en línea recta al norte del sitio 2. Al igual que este último, presenta una barranca conformada por un médano seccionado por la acción erosiva del agua, que alcanza una altura máxima de $3 \mathrm{~m}$ aproximadamente. Los materiales arqueológicos se encuentran dispersos a lo largo de una angosta playa de $200 \mathrm{~m}$ de largo, que fue mapeada y dividida en 30 UR de $10 \mathrm{~m}$ de largo por el ancho de la playa, en las que se recuperaron artefactos líticos, confeccionados por talla y por técnicas de picado, abrasión y/o pulido y, en menor proporción, material cerámico y óseo (Figura 6.25). Estas recolecciones fueron realizadas en dos momentos diferentes pero respetando las mismas unidades de recolección. También se llevaron a cabo dos sondeos de $50 \mathrm{~cm}$ de lado, el primero, localizado sobre la barranca, se excavó hasta una profundidad de $120 \mathrm{~cm}$, no encontrándose materiales arqueológicos en el mismo. El segundo sondeo se realizó sobre la playa, en un sector donde aparecía mayor densidad de artefactos y tampoco arrojó materiales. 


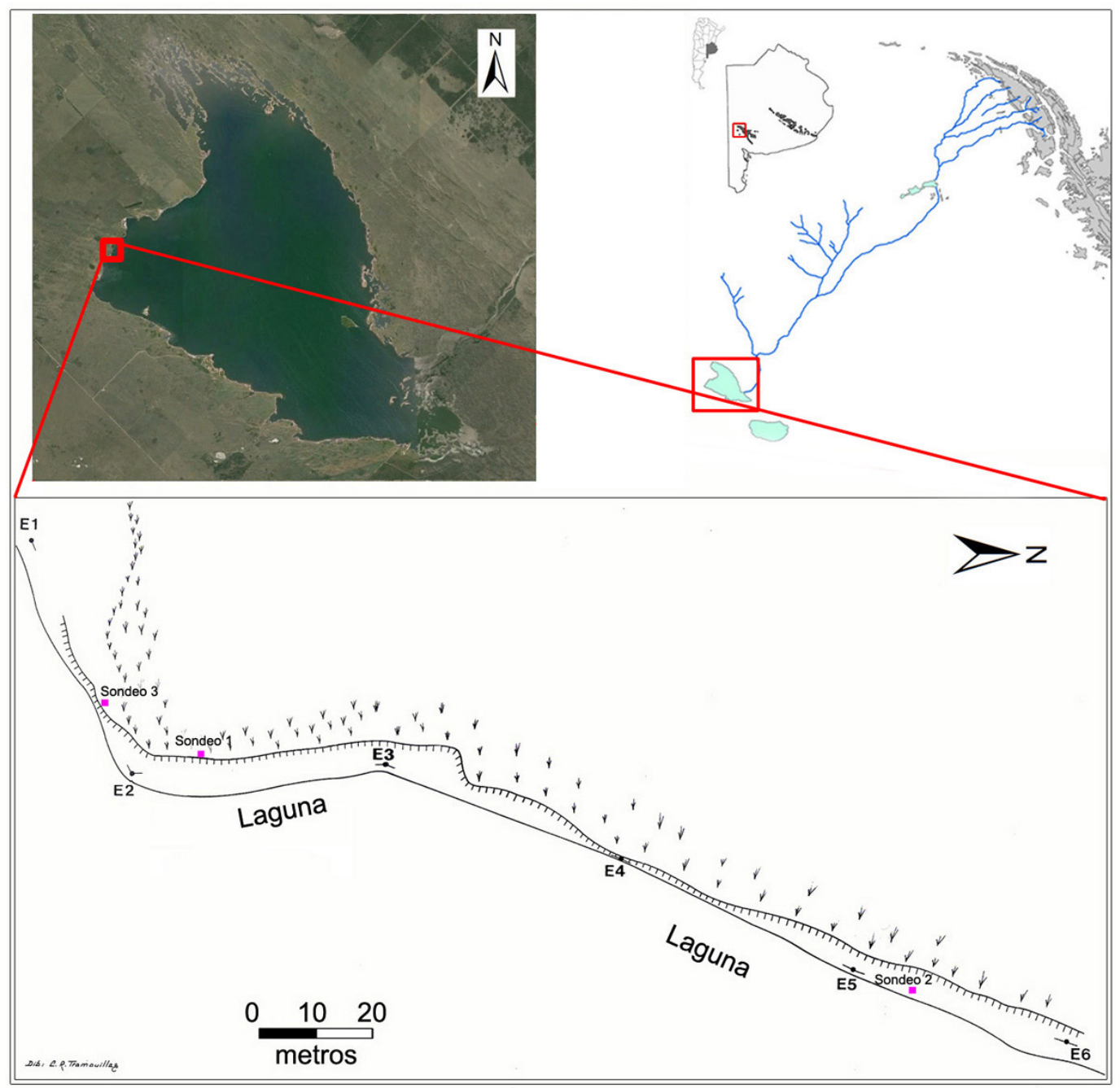

Figura 6.25. Laguna Chasicó sitio 3. Planta del área de costa donde se desarrollaron las recolección y localización de los sondeos realizados.

\subsection{Laguna Chasicó sitio 4}

El sitio 4 se encuentra ubicado en el sector NE de la laguna, en una zona de costas bajas que han sido invadidas por el agua en los últimos 20 años. Se haya a unos $500 \mathrm{~m}$ de la actual línea de costa, sobre un médano erosionado, de forma elipsoidal. Fue visitado en el año 2003 debido a que los guardaparques de la laguna recolectaron, en este, una punta de proyectil y una lasca. En ese primer momento el sitio no presentaba material en superficie, posteriormente, en el año 2005, se realizó una nueva visita al sitio, en la que se observó la presencia de artefactos confeccionados por talla y por abrasión, picado y/o pulido, así como algunos restos óseos faunísticos. En esta ocasión se realizó el relevamiento topográfico del sitio y una recolección superficial, para lo cual se plantearon 4 UR perpendiculares al largo máximo del sector erosionado, de $20 \mathrm{~m}$ de largo por el ancho de la hoyada (Figura 6.26). En las posteriores visitas al sitio no se volvieron a observar materiales en superficie. 


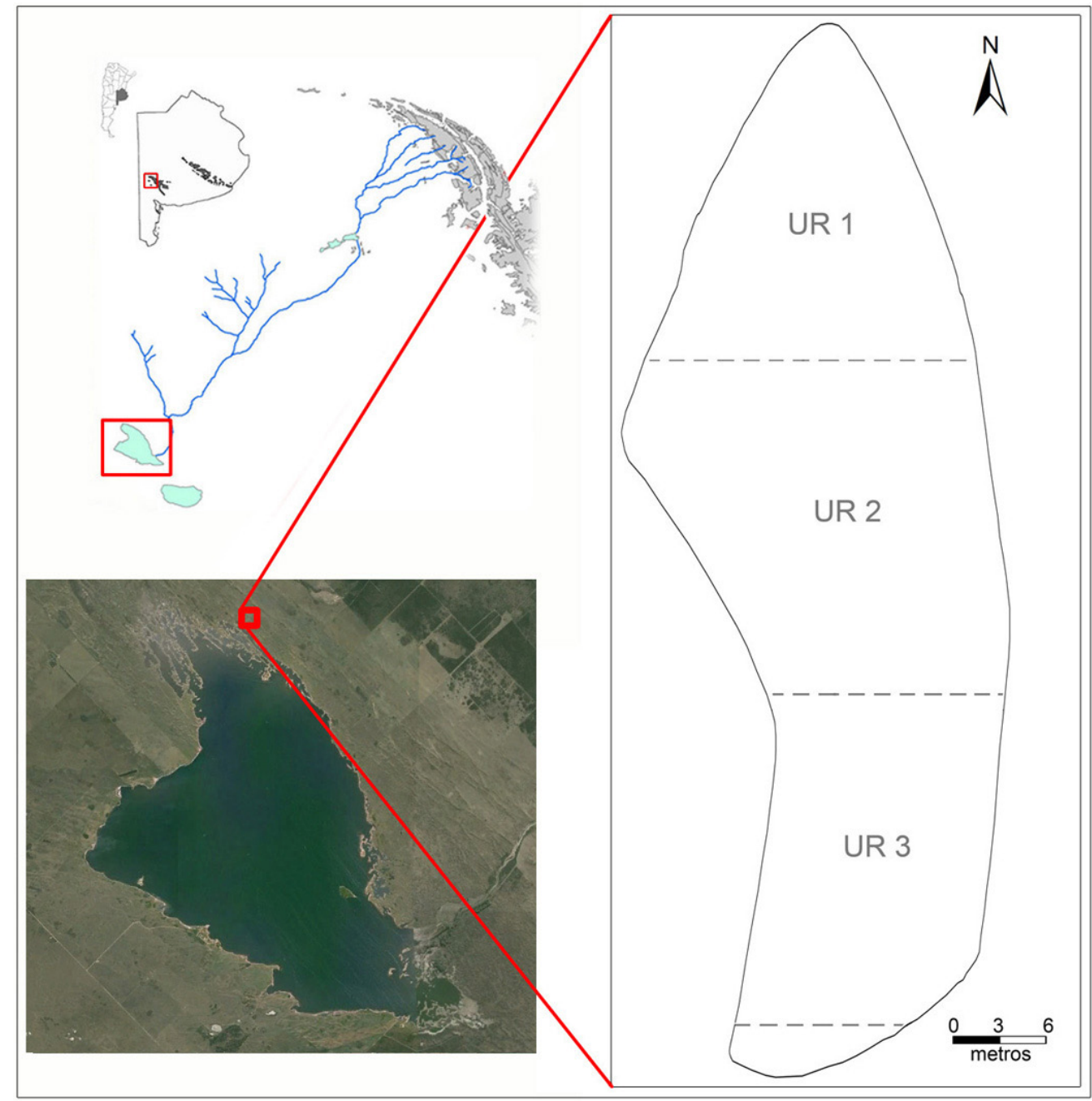

Figura 6.26. Laguna Chasicó sitio 4. Planta del voladero donde se desarrollaron las recolección.

\subsection{Laguna Chasicó sitios 5, 6 y 13}

En el sector noroeste de la laguna Chasicó se localizaron tres pequeñas concentraciones de materiales arqueológicos. El primero, denominados sitio 5 se encuentra sobre la playa de la laguna, en este se recuperaron, en sucesivos momentos, artefactos líticos tallados, entre ellos dos puntas de proyectil, y formatizados por picado, abrasión y o pulido. El segundo, denominado sitio 6 se localiza sobre un médano erosionado que se encuentra frente a un ojo de agua. En este se planteó una pequeña recolección a partir de la cual se recuperaron artefactos líticos. Por último, el sitio 13 consiste en materiales líticos.

\subsection{Laguna Chasicó sitio 7}

Este sitio fue relevado en abril de 2008, luego que, al descender el nivel de la laguna, los guardaparques observasen la presencia de materiales arqueológicos en superficie. En prospecciones anteriores no se observaron materiales arqueológicos debido a que la laguna cubría el área, inundando la zona de médanos. El sitio se localiza en la costa este de la laguna, cerca de la desembocadura del arroyo, en campos de la Universidad Nacional del Sur, donde no está permitido realizar pesca de costa. Los materiales se extienden de manera dispersa sobre una superficie de aproximadamente $700 \mathrm{~m}$ de largo por $200 \mathrm{~m}$ de ancho, dentro de la cual se mapeo un sector de $320 \mathrm{~m}$ de largo, localizado hacia el 
centro del sitio, donde la concentración de materiales es mayor. Se plantearon un total de 32 unidades de recolección de $20 \mathrm{~m}$ de largo, distribuidas de a pares entre la barranca y el pelo de agua. Posteriormente, entre los años 2009 y 2011, se re-visitó el sitio y, dada la presencia de materiales en superficie, se realizaron nuevas recolecciones. Para esto se midió con GPS la ubicación de los hallazgos dispersos y se trazó una nueva unidad de recolección de 8 m x 10 m (UR 33) en el área de mayor densidad de materiales (Figura 6.27).

A partir de estas tareas se recuperaron materiales líticos confeccionados por talla y por picado abrasión y/o pulido y escasos elementos óseos, entre los que se destaca un molar humanos que fue datado por AMS (ver capítulo 7) y un punzón realizado sobre un metapodio de Ozotoceros bezoarticus (ver capítulo 8), pero en ninguna ocasión se registró la presencia de cerámica. También se observaron algunos rodados de cuarcita sin evidencias de talla, que probablemente se vinculen con las formaciones Bajada de los Toros o bien sean producto del acarreo del arroyo.

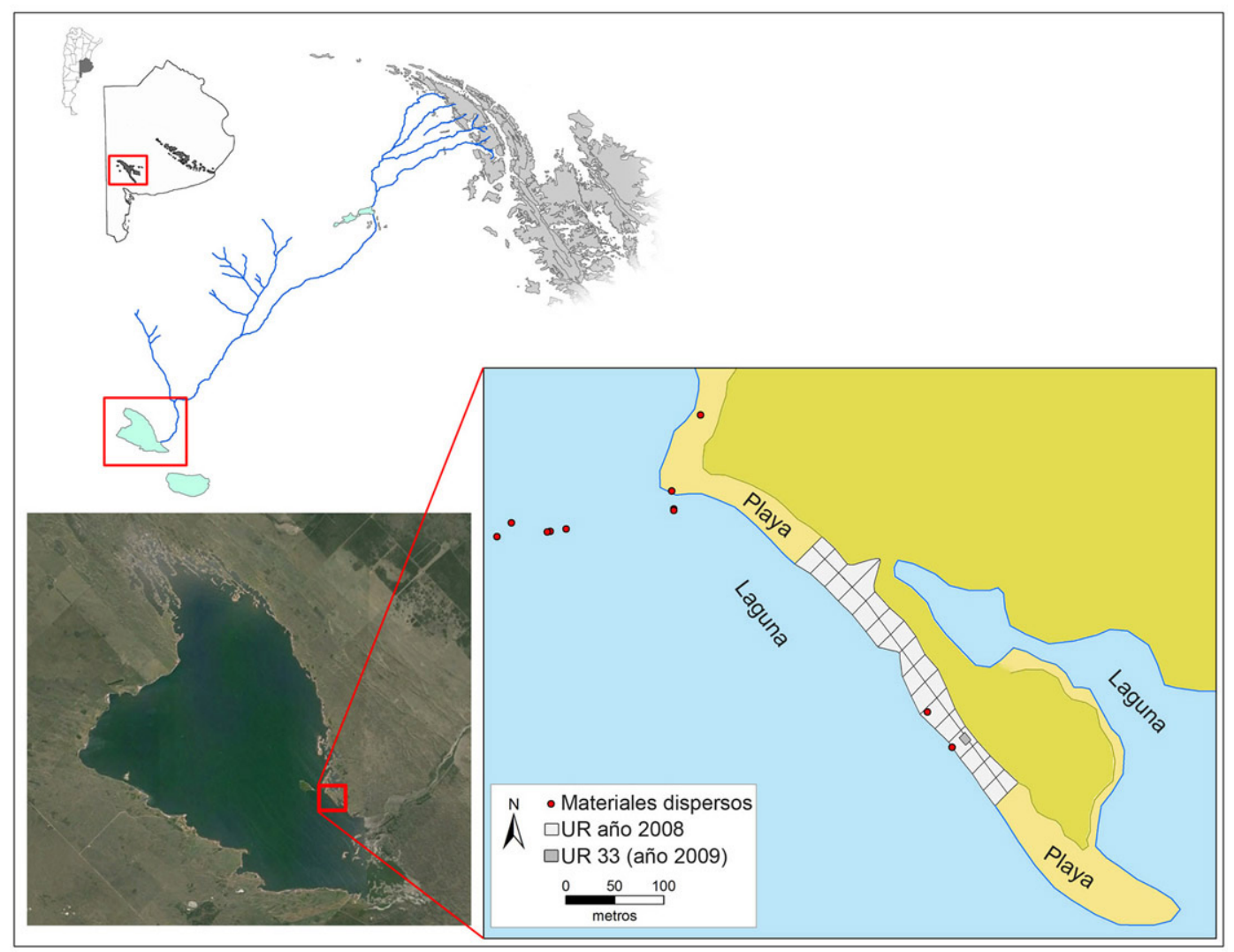

Figura 6.27. Laguna Chasicó sitio 7. Planta del sector de playa donde se desarrollaron las recolecciones durante los años 2008, 2009 y 2011.

\subsection{Laguna Chasicó sitio 8}

El sitio se ubica en el noreste de la laguna, dentro del campo de Los Rastros pero limitando con los terrenos del Pesquero "Médanos". Al igual que el sitio 7, se encuentra sobre un sector de playas que se encontraba inundado al momento de realizar las prospecciones en la costa noreste de la laguna, por lo que fue localizado por el guardaparque de la reserva a comienzos del año 2009. En abril de ese mismo año se visitó el sitio, se midió su posición con GPS y se realizó un mapeo y recolección. Para esto se trazaron tres transectas de $4 \mathrm{~m}$ de ancho y $100 \mathrm{~m}$ de largo, localizadas dos de ellas de manera adyacente, 
en el área de mayor densidad de materiales y la tercera separada de estas por $20 \mathrm{~m}$. Cada transecta fue subdividida en 10 unidades de recolección de $10 \mathrm{~m}$ de largo (Figura 6.28). Los materiales recuperados consistieron casi exclusivamente en artefactos tallados (instrumentos y productos de su fabricación y/o mantenimiento).

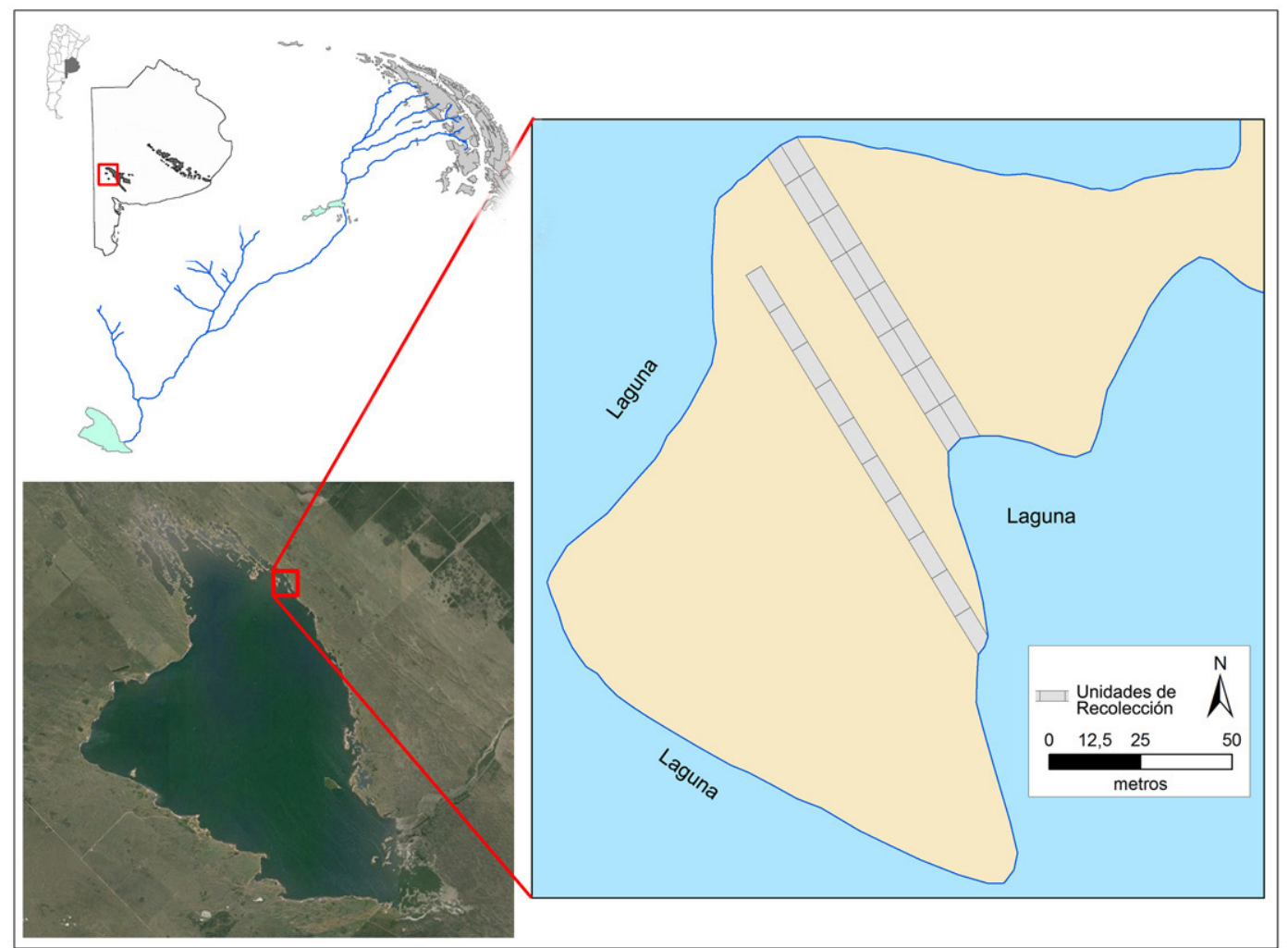

Figura 6.28. Laguna Chasicó sitio 8. Planta del sector de playa (pequeña península producto de la bajante de la laguna) donde se desarrollaron las recolección.

\subsection{Laguna Chasicó sitios 9 y 10}

Estos dos sitios se localizan sobre la playa de la costa sudoeste de la laguna, el primero en el extremo norte, entre los sitios 1 y 2 y el segundo en el extremo sur, en inmediaciones del Pesquero "lo de Guette". En ninguno de ellos se realizaron recolecciones, únicamente se los referenció mediante GPS y se realizó un relevamiento expeditivo in situ, observándose la presencia de productos de talla de pequeño tamaño sobre RSO, cuarcita y otras materias primas.

\subsection{Hallazgos aislados}

Entre los hallazgos aislados se incluyeron tanto materiales registrados durante las prospecciones, como artefactos recolectados por pobladores locales o guardaparques, de los que se tenían datos precisos de su localización. Estos fueron registrados principalmente en la costa sur, donde si bien no se registraron sitios arqueológicos, es frecuente el hallazgo de materiales aislados, principalmente de artefactos de molienda. También se los encuentra en la costa oeste, estando ausentes en el área norte de la laguna, probablemente en relación con su mayor distancia al poblado, y por lo tanto menor tránsito, y debido a que este sector no fue prospectado sistemáticamente en el momento de mayor bajada de la laguna. 
Se registraron un total de 22 hallazgos aislados (algunos consisten en un solo artefactos en tanto otros comprenden pequeños conjuntos) de los cuales 15 fueron recolectados, en tanto los siete restantes se referenciaron y dejaron en el terreno.

\subsubsection{3 Áreas adyacentes a la cuenca inferior}

En el sector inferior de la cuenca del arroyo Chasicó, se prospectaron también otras áreas cercanas que, si bien no se encuentran comprendidas dentro de sus límites, presentan estrechas vinculaciones espaciales con la laguna Chasicó. En el Capítulo 5 se presentaron las áreas con mayor concentración de recursos teórica (animales, vegetales y líticos), en las que, en principio, sería esperable observar una mayor intensidad de uso y, como correlato, una mayor densidad de materiales arqueológicos. Estas comprenden el área que abarca la costa sur de la laguna Chasicó y el oeste de las salinas Chicas y el salitral de la Vidriera. A los fines de evaluar la presencia de materiales arqueológicos en ellas, se seleccionaron tres sectores del paisaje en los que llevar a cabo prospecciones.

Una de las áreas prospectadas, considerando a su vez la importancia que la sal pudo haber tenido en la conservación y preparación de alimentos (Musters [1871] 1997), fueron las salinas Chicas. Aquí se prospectó, en dos oportunidades, un total de $3,4 \mathrm{~km}$ de su borde oeste, sector donde la visibilidad es mayor, ya que más allá de este borde se encuentra un denso monte nativo difícil de transitar. Durante la realización de las prospecciones los materiales arqueológicos y rodados de mayor tamaño fueron referenciados con GPS y recolectados, encontrándose la mayor densidad en un sector restringido de $600 \mathrm{~m}$, donde se registró la casi totalidad de los hallazgos, consistentes únicamente en artefactos líticos tallados. También se relevó un cuadro arado localizado entre las Salinas Chicas y la laguna Chasicó, de $2 \mathrm{~km}$ de largo por $700 \mathrm{~m}$ de ancho, sobre la que se trazaron 31 transectas transversales al eje máximo. En esta área se registró la presencia de remanentes del Manto de Rodados Tehuelches, de tamaño similar a los registrados en la laguna Chasicó, pero no se identificó material arqueológico. Por último, se llevaron a cabo dos transectas en el área circundante al salitral de la Vidriera, donde tampoco fueron registrados materiales arqueológicos.

\subsection{Discusión}

La cuenca del arroyo Chasicó muestra, actualmente, variaciones en el tipo y densidad de los recursos bióticos (principalmente de los vegetales), dada por la gradual transición desde los ambientes más húmedos de las cabeceras con una densa cobertura de gramíneas, hacia los más áridos de la desembocadura, donde estas disminuyen su representación, siendo reemplazadas por las especies del Espinal. Los recursos líticos también muestran variaciones, pero en este estas son abruptas, dadas por la amplia distribución de cuarcitas al norte de la laguna Chasicó y la presencia de materias primas silíceas al sur de ella. Es decir, que al norte de la laguna Chasicó predominan las rocas con características "pampeanas" (básicamente cuarcitas) mientras al sur de dicha laguna, las rocas disponibles pueden ser caracterizadas como "patagónicas" (rocas silíceas y areniscas rionegrenses). Más adelante se analizará si esta estructura de los recursos líticos incide a su vez en las características de los conjuntos líticos.

La mayor concentración de recursos en algunos sectores de la cuenca inferior y sus inmediaciones, no parece correlacionarse con una mayor intensidad en el uso de estos espacios, lo que puede relacionarse 
con la escasez de agua en algunos de ellos. Por otra parte, la visibilidad, topografía y geomorfología tampoco se muestran homogéneas, lo que incide en la probabilidad de localizar materiales arqueológicos. En este caso, sin embargo, las variaciones no siguen un eje longitudinal, sino que varían dentro de cada sector, en función de procesos locales de erosión - depositación y de las variaciones en la cobertura vegetal. En tal sentido, la mayor concentración de materiales arqueológicos en el este sudoeste de la laguna, de manera coincidente con una mayor disponibilidad de recursos líticos, puede deberse a una selección de estos lugares para el aprovechamiento del recurso lítico, o bien a que este sector ha sido más afectado por el aumento en el caudal de agua de la laguna. 


\section{I Marco Cronológico}

En este capítulo se presenta la información cronológica obtenida para la cuenca del arroyo Chasicó y se la discute en relación con la cronología del área de Ventania así como con aquella disponible para el NE de Patagonia, Pampa Seca, el área Interserrana y las sierras de Tandilia, presentada en el Capítulo 5. A los fines de organizar esta información en categorías amplias, se utilizó la subdivisión del Holoceno realizada por Walker et al. (2012), quienes considerando diferentes indicadores paleoambientales señalan como límite entre el Holoceno temprano y el medio los 8200 años cal AP, en tanto localizan el límite entre el Holoceno medio y el tardío en 4200 años cal AP.

En el marco de las investigaciones desarrolladas previamente por F. Oliva, se realizaron fechados sobre materiales arqueológicos recuperados en La Montaña 1, La Sofía 1 (Oliva 2000), Los Chilenos sitio 1 (Barrientos et al. 2002) y San Martín sitio 1 (Oliva y Lisboa 2006). Estos permiten ubicar a las ocupaciones de la cuenca del arroyo Chasicó entre inicios del Holoceno tardío y momentos inmediatamente previos al contacto con la sociedad europea (Barrientos et al. 2002; Oliva 2013; Oliva y Lisboa 2006). Durante el desarrollo de esta tesis y a los fines de complementar la información pre-existente, se realizaron 4 nuevos fechados radiocarbónicos. De este modo se obtuvo información cronológica para sitios que carecían de ella (sitios Los Chilenos 2 y Laguna Chasicó 7) y se complementó la ya existente para el caso de los sitios La Montaña 1 y San Martín 1 (ver detalle en la Tabla 7.1).

\subsection{Marco cronológica de la cuenca del arroyo Chasicó}

En La Montaña sitio 1 se procesó un fragmento distal de tibia de guanaco procedente del sector que arrojó la mayor densidad artefactual durante las excavaciones -cuadrícula 3, nivel 8-. En el sitio 2 de Laguna Los Chilenos, para el que no se contaba con información cronológica previa, el fechado se realizó sobre un molar de guanaco, seleccionado también del sector de mayor densidad de materiales arqueológicos -nivel 16 de la cuadrícula 1-. A su vez, se llevó a cabo una nueva corrección del fechado obtenido por conteo beta para el sitio 1 , considerando, en esta ocasión, valor $\delta^{13} \mathrm{C}$ de $-16,7 \%$, obtenido a partir de análisis isotópicos realizados en el INGEIS sobre material óseo del mismo individuo datado (ver Capítulo 10). El valor obtenido a partir de esta nueva corrección difiere del publicado por Barrientos et al (2002), debido a que en aquella ocasión no se disponía del valor isotópico $\delta^{13} \mathrm{C}$ y, por lo tanto, se utilizó un valor $\delta^{13} \mathrm{C}$ de $-18.2 \%$ resultado del promedio de las muestras las humanas del área. En el caso de San Martín sitio 1, se seleccionó un molar, recuperado en el nivel 12 de la cuadrícula 3, dentro de la UE B, donde se concentra la mayor parte de los materiales óseos. La información cronológica previa para este sitio, consiste en un fechado radiocarbónico realizado sobre material malacológico presente en el sedimento (Austroborus sp. y Succinea sp.; Oliva y Lisboa 2006). El procesamiento de este tipo de materiales se debe a que las muestras óseas procesadas, tanto por conteo beta como por AMS, no poseían el colágeno suficiente (Oliva et al. 2010a). Por tal motivo, el fechado aquí presentado constituye 
la primera información cronológica directa del sitio (i.e. obtenida a partir de materiales arqueológicos). Por último, en la laguna Chasicó -cuenca inferior- se seleccionó un molar humano obtenido en superficie en el sitio 7 espacialmente asociado a un instrumento confeccionado sobre un metacarpo de Ozotoceros beazoarticus y a numeroso material lítico (ver detalle en capítulos 8 y 10).

En el caso de la cuenca inferior, resultó difícil recuperar muestras que pudiesen ser enviadas a fechar debido a que el material orgánico es muy escaso en este sector de la cuenca y, cuando se lo encuentra, suele estar altamente mineralizado. Esto puede deberse a varias razones, desarrolladas en mayor extensión en el capítulo 8, entre las que se encuentran el aumento en el nivel de la laguna, y la consecuente erosión de las costas, y el alto contenido de sales disueltas en las aguas superficiales, subterráneas y en algunos sectores del suelo (Bonorino et al. 1989; INTA 2009). En tal sentido, la erosión hídrica de las costas, producto del aumento producido en el nivel de la laguna, expone en superficie, y consecuentemente a condiciones aéreas, a los materiales arqueológicos, entre ellos los orgánicos, produciéndose su degradación por factores meteóricos, principalmente por la alternancia de ciclos húmedos y secos, fríos y cálidos, pisoteo, rodamiento, etc. (Behrensmeyer 1978; Lyman 1994). La alternancia entre condiciones húmedas y secas, sumado a la alta disponibilidad ambiental de sales higroscópicas, también habría favorecido la fragmentación. Esto se produce debido a que, las sales infiltran el hueso cuando se encuentran disuelta y luego, al cambiar las condiciones, cristalizan dentro de este, expandiéndose y fracturándolo por acción mecánica (Hamilton 1997). Finalmente, la alta mineralización de algunos de los elementos óseos puede haberse producido como consecuencia de situaciones en que los materiales se mantuvieron durante un tiempo prolongado en un ambiente estable pero saturado en sales disueltas, produciéndose, de esta manera, la infiltración de sales a través de los poros del hueso y la alteración de la composición química y estructural original (Lyman 1994).

\begin{tabular}{|c|c|c|c|c|c|c|c|}
\hline Sitio arqueológico & $\begin{array}{c}\text { Edad } \\
{ }^{14} \mathrm{C} \\
\end{array}$ & $\begin{array}{c} \pm \\
\text { DS } \\
\end{array}$ & $\delta^{13} \mathrm{C}$ & Edad cal 2o & $\begin{array}{c}\text { Material } \\
\text { datado }\end{array}$ & Código & Cita \\
\hline La Montaña S1 & 700 & 43 & $-19,5$ & 556-669 años cal. AP & $\begin{array}{r}\text { óseo } L . \\
\text { guanicoe }\end{array}$ & AA95515 & Esta tesis \\
\hline La Montaña S1 & 385 & 70 & $-18,8$ & 285-515 años cal. AP & $\begin{array}{c}\text { óseo } L . \\
\text { guanicoe }\end{array}$ & AA19298 & Oliva 2000 \\
\hline La Sofía S1 & 1595 & 70 & $-22,7$ & 1301-1564 años cal. AP & $\begin{array}{l}\text { óseo } L . \\
\text { guanicoe }\end{array}$ & AA19290 & Oliva 2000 \\
\hline $\begin{array}{l}\text { Laguna Los } \\
\text { Chilenos S1 }\end{array}$ & $606^{*}$ & 40 & $-16,7$ & 512-643 años cal. AP & óseo humano & LP501 & $\begin{array}{l}\text { Barrientos et } \\
\text { al. } 2002\end{array}$ \\
\hline $\begin{array}{l}\text { Laguna Los } \\
\text { Chilenos S2 }\end{array}$ & 2323 & 48 & $-18,8$ & 2151-2352 años cal. AP & $\begin{array}{l}\text { molar } L . \\
\text { guanicoe }\end{array}$ & AA95518 & Esta tesis \\
\hline San Martin S1 & 2890 & 80 & $\mathrm{~s} / \mathrm{d}$ & 2770-3206 años cal. AP & caracol & LP624 & $\begin{array}{l}\text { Oliva y } \\
\text { Lisboa } 2006\end{array}$ \\
\hline San Martin S1 & 2526 & 49 & $-18,4$ & 2362-2714 años cal. AP & $\begin{array}{l}\text { molar } L . \\
\text { guanicoe }\end{array}$ & AA95513 & Esta tesis \\
\hline Laguna Chasico S7 & 3925 & 54 & $-17,5$ & 4093-4429 años cal. AP & molar humano & AA95517 & Esta tesis \\
\hline
\end{tabular}

Tabla 7.1. Detalle de las dataciones radiocarbónicas efectuadas en la cuenca del arroyo Chasicó. *Datación corregida por fraccionamiento isotópico.

Las nuevas dataciones son congruentes, en algunos casos, con aquellas obtenidas previamente, pero presentan ciertas discrepancias con lo esperado, en otras. En el caso del sitio 1 de La Montaña, el nuevo fechado es más temprano que el anteriormente obtenido y, utilizando el software Calib Rev.6.1.0 (Stuiver et al. 2005) se determinó que ambos son significativamente diferentes a un nivel de confianza del 95\% 
(test de $\mathrm{T}=14,7 ; \mathrm{Xi}^{2}(.05)=3,84$; grados de libertad $=1$ ), de cualquier manera, la nueva información continúa apoyando la asignación del sitio como correspondiente a momentos finales del Holoceno tardío. El sitio 1 de La Montaña se encuentra localizado en inmediaciones de estructuras de piedra y de un abrigo rocoso con representaciones rupestres, formando parte de una extensa área con alta densidad de materiales, entre los que se encuentran instrumentos de molienda, al menos un núcleo de gran tamaño y un conjunto de artefactos de riolita que por sus características (artefactos bifaciales grandes encontrados a corta distancia unos de otros) pueden ser considerado un cache. Todos estos artefactos que pueden ser considerados como elementos que aprovisionan sitios (site furniture en el sentido de Binford 1979) parecen indicar la reocupación del área durante un lapso más o menos prolongado de tiempo. En este contexto, la variación cronológica entre las dos muestras procesadas puede estar indicando el lapso de tiempo mínimo durante el cual el área fue utilizada.

En el caso del sitio 2 de Los Chilenos, la datación obtenida arrojó una edad considerablemente más antigua que la esperada. Inicialmente, en función de las características estratigráficas, sedimentos similares a los del sitio 1, y del tipo de materiales recuperados, como la presencia de una placa grabada y de un fragmento de placa, se asignó este sitio a momentos finales del Holoceno tardío, atribuyéndosele una cronología similar a la del sitio 1 (Barrientos et al. 1997, 2002). El nuevo fechado le asigna una antigüedad $c a$. 1700 años radiocarbónicos mayor que la obtenida para el sitio 1, por lo que, al menos en principio, estos dos sitios no pueden considerarse como contemporáneos. Otras explicaciones posibles para esta discordancia cronológica son la contaminación del material datado o bien que el área haya sido recurrentemente ocupada durante los últimos 2000 años, lo que junto a procesos de erosión, depositación y re-depositación habría generado un palimpsesto conformado por materiales acumulados a través del tiempo. Esta última interpretación es concordante con lo propuesto por Barrientos et al. (1997), quienes consideraron que "...la distribución de items arqueológicos... caracterizada por la presencia de concentraciones relativamente densas de artefactos y ecofactos vinculadas con áreas de menor densidad, podría ser ... explicada como el resultado de una secuencia ocupacional con un grado moderado de congruencia espacial, operando conjuntamente con la acción de diversos agentes postdepositacionales. De ello se desprende que lo que observamos hoy, tanto en estratigrafía como en superficie, es en gran medida un palimpsesto de restos producidos por ocupaciones sucesivas, que se superpusieron en diversos sectores del espacio..." (Barrientos et al. 1997: 121).

Los sitios arqueológicos localizados sobre las márgenes de la laguna Los Chilenos, se encuentran en un ambiente que actualmente presenta un alto dinamismo dado tanto por el tipo de sedimentos y cubierta vegetal como por la acción de agentes erosivos como el viento y el agua. Los materiales arqueológicos se encuentran contenidos dentro de sedimentos arenosos que conforman mantos y médanos total o parcialmente edafizados con suelos poco desarrollados que, al disminuir (inclusive por lapsos breves de algunos años) el promedio de precipitaciones, pierden fácilmente la cubierta vegetal y consecuentemente son erosionados, transportados y re-depositados por la acción del viento. Por otra parte, los cambios en el nivel de la laguna generan la erosión hídrica de las barrancas, re-depositando los sedimentos y, cuando están presentes, materiales arqueológicos sobre las costas. Este dinamismo pudo haber generado diferentes modificaciones de los conjuntos arqueológicos, que deberán ser evaluadas a través de estudios geoarqueológicos y tafonómicos y de la realización de nuevos fechados provenientes de niveles inferiores y superiores al actual así como de materiales procedentes de la cuadrícula 2. 
El nuevo fechado realizado para el sitio 1 de San Martín es congruente con la asignación cronológica previamente realizada ya que, si bien las dos fechas obtenidas son significativamente diferentes a un nivel de significación del 05\% (Calib rev 6.1.0 test $\mathrm{T}=15,05 ; \mathrm{Xi}^{2}(.05)=3,84$; grados de libertad=1), esta diferencia puede deberse al tipo de muestras procesadas. En este sentido, el fechado realizado sobre valvas de caracoles dulciacuícolas, arrojó una edad ca 400 años más antigua que la obtenida para el material óseo, lo que podría deberse a un envejecimiento de la primera por efecto de carbonatos disueltos en al agua, si bien no se cuenta con información suficiente como para evaluarlo. Finalmente, el fechado obtenido para la laguna Chasicó aporta un dato novedoso, ya que no se contaba con información cronológica para este sector de la cuenca. La edad de $3925 \pm 54$ años ${ }^{14} \mathrm{C}$ AP es la más antigua registrada para la llanura localizada al sudoeste de las sierras de Ventania y más antigua también que la mayor parte de los registros reportados para el curso inferior del río Colorado (Martínez et al. 2013), por lo que deberá ser corroborada con la realización de nuevas dataciones. Por otra parte, no debe olvidarse que el material datado corresponde a un molar aislado recuperado en superficie, por lo que la edad obtenida puede ser considerada como una edad máxima de ocupación del área.

\subsection{La cronología de la cuenca del arroyo Chasicó en relación con las áreas vecinas}

La cronología obtenida para la cuenca del arroyo Chasicó corresponde a fines del Holoceno medio y al Holoceno tardío, con edades entre $c a .4400$ y 280 años cal AP. Este lapso temporal se encuentra comprendido dentro de la cuenta corta propuesta para el área de Ventania, la cual abarca desde aproximadamente 7000 años cal AP (Castro 1983) hasta momentos del contacto hispano-indígena (Oliva et al. 2007) (ver Capítulo 5). Las primeras evidencias de ocupación, corresponden a un fechado realizado en cueva El Abra, un abrigo rocoso situado en el sector serrano (Castro 1983) y ocupaciones registradas en la cuenca media del río Sauce Grande (Bayón et al: 2010). Estas coinciden con el final de un momento de mayor evidencia cronológica en el área Interserrana, que comprende el lapso entre $c a$. 7000 y 9000 años cal AP, y para el que se registran ocupaciones arqueológicas en áreas muy cercanas a Ventania, como el cauce medio y la desembocadura del río Sauce Grande en el océano Atlántico (Bayón et al. 2012; Blasi et al. 2013; Politis et al. 2009). Con excepción de esta primer evidencia temprana, los restantes fechados del área de Ventania, se localizan desde $c a .5000$ años cal AP., con una mayor frecuencia a partir de los 4000 años cal AP. Es con este momento con el que se corresponde la información cronológica obtenida para la cuenca del arroyo Chasicó (Figura 7.1).

En relación con la información regional presentada, la cronología obtenida para la cuenca del arroyo Chasicó es concordante con lo esperable para la llanura adyacente al sudoeste de Ventania y NE de Patagonia, donde los fechados registrados son, mayormente, posteriores a ca. 3500 años cal AP (Favier Dubois 2013; Martínez et al. 2013; Oliva et al. 1991a; Oliva y Lisboa 2006). El fechado de 4360 años cal AP en la laguna Chasicó, se corresponde con las fechas más tempranas registradas, comprendidas entre $c a .4500$ años cal AP en el río Sauce Grande (Bayón et al. 2010), ca. 5000 años cal AP en la cuenca inferior del río Colorado (Martínez et al. 2013) y ca. 6000 años cal AP en el Golfo de San Matías (Favier Dubois 2013) e inmediaciones de Bahía San Blas (Eugenio y Aldazabal 2004). Estos primeros fechados del área, son seguidos por un lapso de 1500 años en que no se registran fechados en Ventania o sus proximidades y son escasos en toda las áreas analizadas (Pampa Seca, NE Patagonia, Interserrana, Tandilia; Figura 7.2) (Martínez et al. 2013; Berón 1995, 2004; Barrientos y Masse 2012). Dicha menor frecuencia en los fechados, que puede ser producto de una disminución en la evidencia arqueológica 
o, al menos, de su visibilidad (ver discusión en el Capítulo 5), ha sido interpretada, en otras áreas de la Región Pampeana, como consecuencia de un aumento en la movilidad residencial, un descenso en la densidad demográfica de las poblaciones, sesgos de muestreo, variación en la ubicación de los sitios, problemas de preservación de los contextos costeros o bien a una conjunción de estos diversos procesos (Barrientos 1997; 2001, 2009; Barrientos y Pérez 2005; Bonomo y León 2010; Martínez 2002; Politis 1984). Con posterioridad a 3500 años cal AP. se produce un aumento en las frecuencias de fechados en todas las áreas, momento con el que coincide la mayor parte de las ocupaciones registradas en la cuenca. Este aumento en la frecuencia de fechados hacia momentos tardíos, puede responder procesos destructivos dependientes del tiempo (Barrientos y Masse 2012; Surovell y Brantingham 2007), a una ocupación efectiva del área y mayor densidad demográfica (Barrientos 2009; Martínez 2002), o bien a una conjunción de ambos procesos.

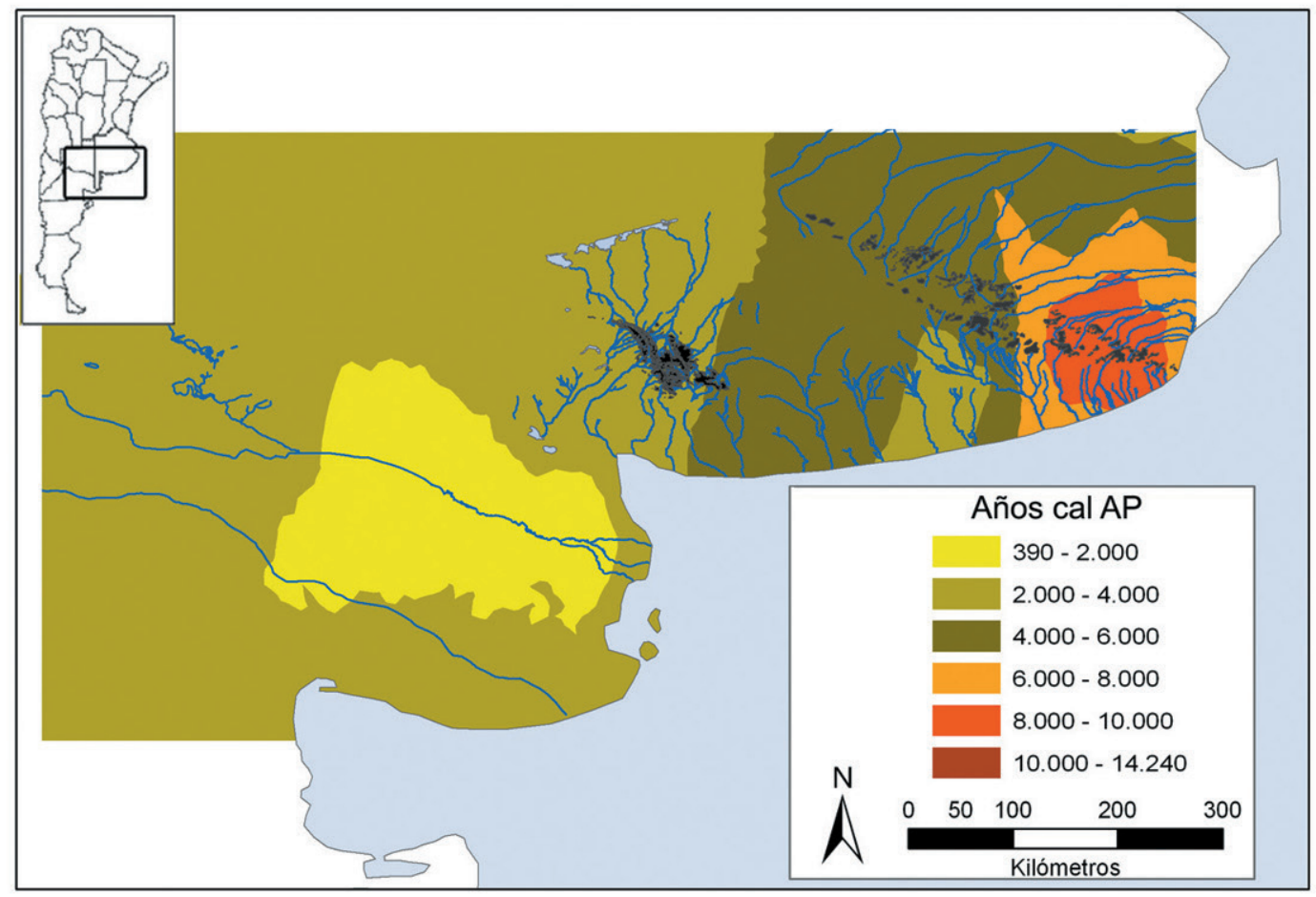

Figura 7.1. Distribución de los fechados más tempranos. La metodología utilizada en la generación del modelo fue descripta en el capítulo $5(\mathrm{n}=124)$.

Para la cuenca del arroyo Chasicó en particular, así como para el NE de Patagonia y la llanura adyacente al sudoeste de Ventania, los factores geomorfológico parecen tener mayor importancia en la explicación de la ausencia de fechados anteriores al 3500-4000 años cal AP, en relación con modificaciones del paisaje producidas ca. 3000-4000 años AP (Melo et al. 2003; Quatrocchio et al. 2008; Zavala y Quattrocchio 2001). En tal sentido, Zavala y Quattrocchio (2001) consideran que la actual red fluvial del área se configuró durante la transición Holoceno medio-tardío y Melo et al. (2003) postulan que hacia los 3000 años AP se habrían producido importantes modificaciones en la geomorfología de la llanura adyacente al sur y sudoeste de Ventania. Hasta $c a .3000$ años AP. la depresión ocupada por la laguna Chasicó y las salinas Chicas (que se continúa hacia las lagunas Colorada Chica, Colorada Grande, Callaqueo y Blanca Grande), habría funcionado como parte de la red de drenaje del noreste de las sierras de Lihue Calel, recibiendo también aportes hídricos desde la confluencia de los actuales 
ríos Salado-Chadileuvú y Colorado y transportando aguas hacia la actual área de Bahía Blanca a través del Salitral de la Vidriera (Melo et al. 2003). El aporte hídrico de estos cursos habría comenzado a disminuir a partir de los 4500 años AP, desapareciendo finalmente, hacia los 3000 años AP. Para este momento, como consecuencia de cambios isostáticos y de la invasión de la llanura por campos de arena, también se habrían producido modificaciones en el cauce de los ríos y arroyos que drenan las sierras de Ventania, generándose modificaciones de los cursos del Napostá Chico, el Sauce Grande, el Sauce Chico y el Chasicó (Melo et al. 2003). Estos procesos pudieron haber afectado la visibilidad del registro arqueológico, ocultando o destruyendo la evidencia de ocupaciones tempranas en el área.

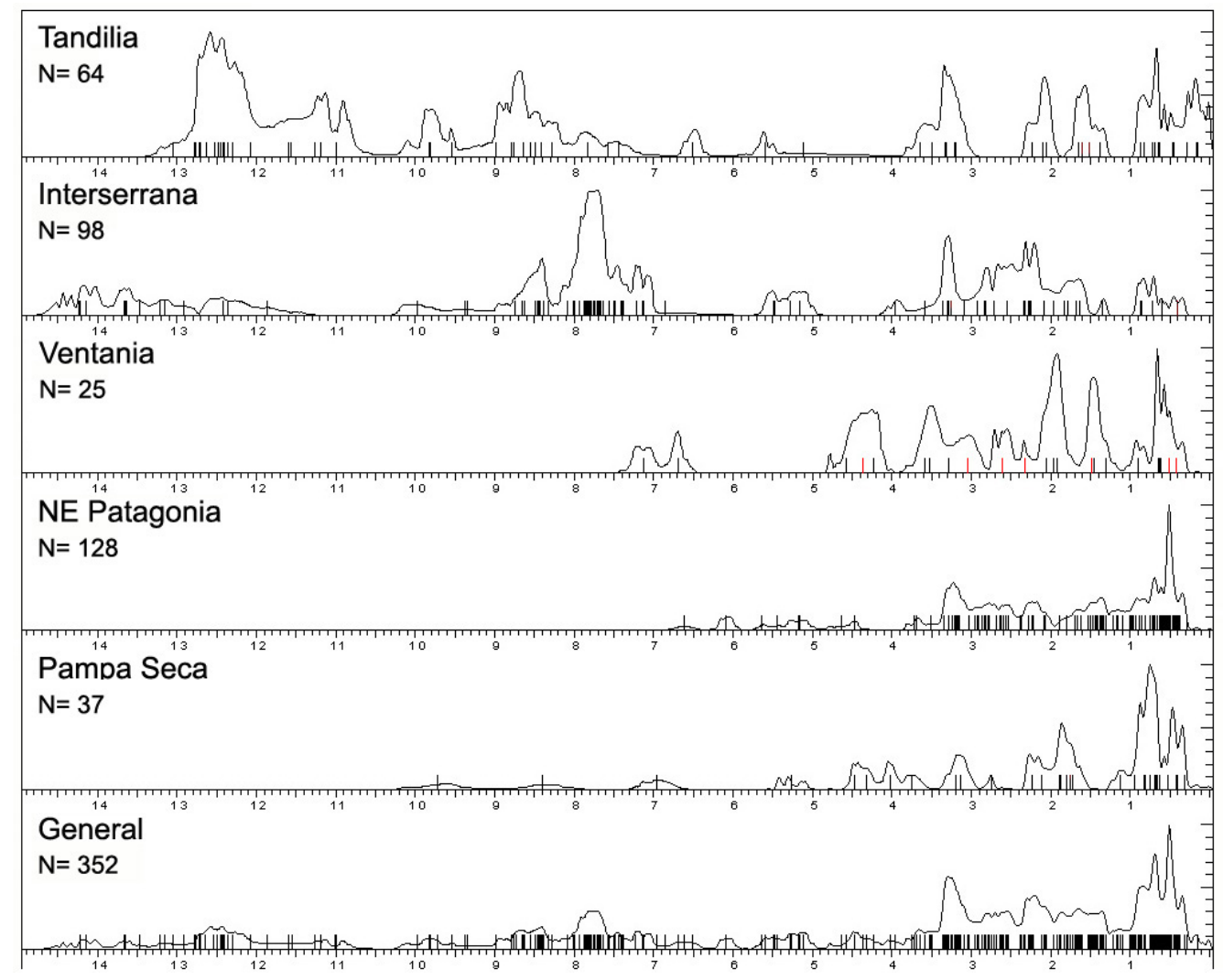

Figura 7.2 Distribución de los fechados en el conjunto de las áreas consideradas y en cada una de las áreas que la componen. El espacio comprendido por cada una de las áreas ha sido explicada en el capítulo 5. En la distribución de Ventania se señalan en rojo los fechados correspondientes a la cuenca del arroyo Chasicó. Las curvas utilizadas para la calibración corresponden a los datos de temperatura VOSTOK y Sajama 1997.

Considerando la distribución de fechados y las variaciones paleambientales propuestas para el área (ver un mayor desarrollo en el Capítulo 4), los fechados fueron agrupados en dos grandes bloques temporales, a partir de los cuales se estructura la información obtenida: 1) Holoceno tardío inicial, desde ca. 4000 años cal AP, momento en que comienzan a producirse las modificaciones en las condiciones ambientales imperantes durante el Holoceno medio, y que finalmente configurarán el paisaje actual, hasta ca. 2000 años cal AP., cuando los diversos registros paleoambientales del área señalan un cambio hacia condiciones más húmedas y cálidas (Melo et al. 2003; Quattrocchio et al 2008; Zavala y Quattrocchio 2001). 2) Holoceno tardío final, que comprende el lapso ca 2000 cal años AP hasta el contacto hispanoindígena, período en el que las condiciones ambientales se habrían vuelto más estables (Quattrocchio et al. 1998, 2008) y durante el cual se ha propuesto el desarrollo, en el sur de la Región Pampeana y NE de 
Patagónica, de un proceso de aumento demográfico, ocupación efectiva del espacio e intensificación y/o diversificación económica (Barrientos 2009; Martínez 2002, 2010; Politis et al. 2001).

\subsection{Discusión}

Las secuencias regionales de fechados pueden ser utilizadas, considerando las limitaciones discutidas en el capítulo 5, como indicadoras de la intensidad de la "señal arqueológica (Barrientos y Masse 2012). Si bien en algunas de las áreas, inclusive en el área de Ventania, las ocupaciones se inician tempranamente (ca. 13500 y 7000 años cal AP respectivamente), las primeras evidencias de ocupación en la cuenca del arroyo Chasicó, se registran recién a partir de 4500 años cal AP y con mayor intensidad luego de los 3500 años cal AP. Esto puede responder a diversas causas como: 1) que el área haya sido ocupada tardíamente, debido a condiciones ambientales locales desfavorables, que impidieron o dificultaron su ocupación efectiva, volviéndola una zona marginal con respecto a otras áreas más tempranamente ocupadas; 2) que la evidencia haya sido destruída por procesos tafonómicos y/o geológicos 3) una menor visibilidad de las ocupaciones, consecuencia de una alta movilidad residencial y baja densidad demográfica; 4) problemas de muestreo (i.e. investigaciones centradas en los actuales cursos fluviales y cuerpos lacustres).

Si bien en el estado actual del conocimiento no es posible decidir por una de estas posibilidades, la comparación de la secuencia con la distribución temporal de los fechados en el NE de Patagonia (Martínez et al. 2013), sumado a lo estudios que indican modificaciones en el paisaje con anterioridad a 3000 años AP, llevan a suponer que la ausencia de evidencias tempranas en la cuenca del arroyo Chasicó, podría responder, con mayor probabilidad, a tres factores; 1) problemas de muestreo; 2) una menor densidad de población y/o patrones de movilidad que habrían dejado como correlato una evidencia más efímera y 3) procesos de formación y transformación del paisaje que pudieron actuar destruyendo y/o enmascarando la evidencia. Independientemente de cuál sea la razón por la que no se cuenta con ocupaciones tempranas en el área, la secuencia cronológica registrada para la cuenca del arroyo Chasicó, así como las áreas cercanas, estaría indicando una ocupación del área a partir de $c a .4000$ años AP, motivo por el cual, esta tesis se centra en las estrategias de movilidad y uso del ambiente, implementadas por poblaciones cazadoras-recolectoras durante el Holoceno tardío. 


\section{I El Registro Arqueofaunístico}

En este capítulo se presentan los análisis realizados sobre materiales arqueofaunísticos recuperados en los distintos sectores de la cuenca del arroyo Chasicó. Dichos análisis tuvieron como objetivo último aportar información sobre el modo en que los recursos animales fueron utilizados por parte de las sociedades cazadoras-recolectoras que ocuparon la cuenca durante el Holoceno tardío. Sin embargo, tanto las especies como las unidades anatómicas representadas en un conjunto óseo y su grado de fragmentación, responden tanto a la actividad antrópica (i.e. selección de presas y partes de estas presas, transporte diferencial, intensidad de aprovechamiento), como a factores no antrópicos, relacionados con los procesos que afectan a los conjuntos luego de su depositación, entre los que pueden mencionarse el tiempo transcurrido antes del enterramiento, la re-exposición de los materiales, la química del sedimento y la fauna y la flora del lugar (Behrensmeyer 1978; Gutiérrez 2004; Lyman 1994). Por tal motivo, se analizaron también, los posibles factores que pudieron haber afectado la estructura de este tipo particular de registro.

Como fue desarrollado en el Capítulo 4, el área de estudio abarca ambientes de variadas condiciones, que incluyen diversas geoformas, suelos con características variables en cuanto a su composición y granulometría, diferencias en las especies vegetales representadas y variaciones en la temperatura y humedad ambiental. Dadas estas características, es esperable que no sólo el aprovechamiento humano de estos ambientes haya sido diferente, sino que las condiciones de depositación y preservación de los restos óseos sean, también, espacialmente variables. Considerando esta situación, los análisis se orientaron, en primera instancia, a la identificación de los principales agentes y procesos tafonómicos actuantes en el área de estudio y su relación con la preservación diferencial del registro óseo para, posteriormente, aportar información sobre la subsistencia de aquellas sociedades.

Los estudios llevados a cabo en relación con los conjuntos faunísticos tuvieron los siguientes objetivos particulares:

- Identificar los principales agentes y procesos post-depositacionales actuantes sobre el registro óseo faunístico y determinar su distribución espacial.

- Caracterizar unidades del paisaje en función de los agentes y procesos post-depositacionales actuantes en los diferentes sectores.

- Evaluar en qué medida las diferencias entre conjuntos óseos responden a factores no antrópicos que afectan a los depósitos arqueológicos.

- Aportar información sobre los modos en que los grupos cazadores-recolectores aprovecharon los recursos faunísticos disponibles en el área. 
8.1 Algunos conceptos teóricos sobre el registro arqueofaunistico y los procesos post-depositacionales que lo afectan

El estudio del registro zooarqueológico, su distribución espacial y temporal, así como las modificaciones que presenta permiten obtener información acerca de la interacción entre las poblaciones humanas y su ambiente, particularmente con su componente animal, pudiéndose conocer, entre otros aspectos, cuáles fueron las presas más seleccionadas para su consumo y el modo e intensidad con que fueron procesadas (Johnson 1985; Lyman 1994; Shipman 1981). Cambios en estas estrategias, podrán estar reflejando a su vez, variaciones en diversas esferas de las sociedades, como su economía, el modo en que utilizaron el espacio y su organización social, entre otros aspectos (Bettinger 2001; Bousman 1993, 2005; Broughton 1994; Cashdan 1985; Veth 2005).

Desde la ecología evolutiva se han postulado varios modelos tendientes a evaluar el modo en que los recursos, en este caso los faunísticos, son incorporados a la dieta y la relación entre esto y las características ambientales generales (i.e. la disponibilidad de recursos en relación con las necesidades de una población). Entre dichos modelos, los de amplitud de dieta y elección de parches, resumidos en el capítulo 2, son los que han sido más utilizados en los análisis arqueofaunísticos (Bettinger 2009; Bird et al. 2009; Lupo 2007), ya que permiten evaluar bajo qué condiciones la incorporación de ciertos recursos aumenta la adaptabilidad (Bettinger 1991). El modelo de amplitud de dieta predice que: 1- los recursos de alto valor, que generalmente se corresponden con aquellos animales de mayor tamaño, serán incorporados siempre que éstos sean encontrados; 2- La incorporación de recursos de menor jerarquía, los cuales implican mayores costos de procesamiento, se realizará en función de la abundancia de los recursos de mayor retorno y 3- la tasa de retorno relativa de cada recurso (su valor energético menos el gasto de búsqueda y procesamiento) permite predecir el orden en que estos serán incorporados a la dieta (Broughton 1994; Janetski 1997; Lupo 2006). El modelo de selección de parches, de un modo similar, ordena los parches en función de su retorno energético por unidad temporal pero, en este caso, considerando también el tiempo invertido en la búsqueda de un parche (Kelly 1995).

En el marco de los modelos descriptos, se ha propuesto que la incorporación de recursos de menor ranking implica menor eficiencia de forrajeamiento, es decir, una disminución en la tasa neta de retorno obtenida, que es esperable como respuesta ante una situación de riesgo generada por un aumento en la densidad poblacional y/o una disminución en los recursos disponibles (Broughton 1994; Cashdan 1985; Bousman 1993, 2005; Veth 2005). Este proceso de incorporación de nuevos recursos ha sido llamado de intensificación (Bousman 1993, 2005; Broughton 1994; Cashdan 1985; Veth 2005) o también de diversificación, por autores como Hasltead y Shea (1989), debido a que a partir del mismo se amplía la base del sistema de subsistencia. Una dieta que incorpora un espectro más amplio de recursos, donde se incorporan aquellos de bajo ranking, implica que, si bien los individuos deben gastar más energía por unidad de tiempo en las tareas de procesamiento, la energía final obtenida aumenta debido a que estos nuevos recursos incorporados son muy abundantes, incrementándose así la capacidad de sustentación por unidad de área (Bettinger 2001; Broughton 1994). La intensificación también puede consistir (ver capítulo 9) en un proceso en el que se incrementa la producción a partir de un aumento en la eficiencia de explotación de un recurso por incorporación de nuevas estrategias de procesamiento y/o nuevas tecnologías (Bettinger et al. 2006; Bousman 1993; Ugan et al. 2003) 
En el registro arqueofaunístico, un proceso de intensificación se verá evidenciado por un incremento relativo en el NISP de animales de pequeño porte como aves y roedores en detrimento de aquellos animales de mayor tamaño como el guanaco y el venado (Broughton 1994; Bettinger 2001; Hasltead y O'Shea 1989). Estos últimos, a su vez, pueden presentar una declinación en la edad media de los individuos cazados y un mayor grado de procesamiento, que podrá verse reflejado en la utilización de elementos de bajo ranking y en un mayor aprovechamiento de la grasa contenida en los huesos, ya sea en forma de médula ósea o en la micro estructura del tejido trabecular, lo cual redundará en un alto grado de fragmentación de los conjuntos, en general, y de aquellos elementos con mayor cantidad de grasa, en particular (Broughton 2002; Burger et al. 2005; Otaola 2012; Veth 2005). Particularmente para la Región Pampeana, se ha propuesto que durante el Holoceno tardío se habrían desarrollado procesos de características similares a los arriba descriptos, incorporándose, producto de una modificación en las estrategias socioeconómicas, presas de menor ranking que el guanaco (Barrientos 2001; Martínez 2002; Politis et al. 2001). En tal sentido, Martínez y Gutiérrez (2004) proponen que alrededor del 1000 años AP se habría dado un proceso de diversificación e intensificación de las economías areales, caracterizado por la incorporación a la dieta de mamíferos medianos y pequeños y algunos reptiles, que podría ser consecuencia de una retracción de L. guanicoe hacia el sur y el oeste de la Región Pampeana (Politis 2008; Politis y Pedrotta 2006; Politis et al. 2011b; Tonni y Politis 1980). En la cuenca inferior del río Colorado también se propone un proceso de intensificación en el uso de los recursos faunísticos a partir de $c a .1000$ años AP, cuando se observa un uso más intensivo del guanaco y la incorporación a la dieta de recursos marinos y taxa de menor tamaño como peces, en proximidades de los paleocauces del rio Colorado (Stoessel 2012a, 2012b). De manera similar, en el curso medio del río Negro se describe una dieta diversa para momentos tardíos, pero en este caso, no se cuenta con secuencias más tempranas, que den sustento a la existencia de un proceso de intensificación (Fernandez et al. 2011; Prates 2008).

En otro orden, algunos elementos correspondientes al mundo animal recuperados en la Región Pampeana, generalmente recursos exóticos o presentes en baja frecuencia, como los caracoles marinos, huesos mineralizados y dientes -generalmente de carnívoros- (Bonomo 2006; Oliva 2006; Politis y Madrid 2001) han sido utilizados como bienes de intercambio o materias primas para la confección de elementos de prestigio u ornamentales, que pueden circular por largas distancia y largos periodos de tiempo (Trubitt 2003), convirtiéndose en correlatos de redes sociales y circuitos de intercambio de información y bienes, que funcionan como redes de seguridad ante situaciones de escasez de los recursos (Bettinger 2001; Fitzhugh et al. 2011; Lovis y Donahue 2011; Whallon 2006, 2011).

Hasta aquí se ha hecho referencia al tipo de información que el registro faunístico puede brindar en relación con aspectos económicos y sociales, pero no se han mencionado sus sesgos y limitaciones al momento de realizar las interpretaciones. Diversos agentes y procesos actúan sobre el registro arqueológico desde que este abandona el contexto sistémico hasta que es recuperado por el arqueólogo (Binford 1981; Schiffer 1972, 1987), generando modificaciones que afectan en distinto grado a sus componentes y producen su conservación diferencial. El análisis de los procesos tafonómicos puede realizarse a diferentes escalas, a nivel del sitio, los estudios apuntan a establecer relaciones entre una traza, atributo visible que se manifiesta en un hueso, su agente causal, causa física inmediata de una traza, el efector, material que realiza la modificación sobre el hueso, y el actor, fuente de la energía que produjo la traza (Gifford-González 1991 en Marean 1995), pudiéndose establecer estas relaciones a partir 
de información obtenida por estudios experimentales o comparativos (i.e. generando modelos a partir del estudio de trazas sin que la relación entre actor, agente causal y traza sea observada directamente). A nivel regional, el foco estará en identificar y comprender los procesos que potencialmente pueden afectar al registro arqueológico, analizando su distribución natural y grado de incidencia en una escala regional (Borrero 1988, 2001a). Los paisajes son complejos mosaicos en cuya formación intervienen factores físicos, biológicos y humanos, tanto presentes como pasados (Burger et al. 2008). La utilización de una escala espacial amplia, permite la identificación de patrones que no son observables en escalas menores, de este modo, la tafonomía regional complementa el sitio, como unidad de análisis, con la región tafonómica, analizando la variación de procesos ocurridos entre conjuntos y la identificación de áreas en las que se espera que actúen ciertos procesos particulares, enfatizando en la preservación diferencial de los conjuntos óseos (Borrero 1988, 2001a).

De esta manera, idealmente, pueden generarse mapas de zonas con posibilidades similares de depositación, enterramiento y preservación de huesos (Borrero 1988, 2001a), a partir de las cuales establecer relaciones entre la composición diferencial de las muestras de restos óseos recuperados por área y la posible distribución e impacto diferencial de distintos agentes tafonómicos, tales como mamíferos cavadores, erosión, composición química de los suelos, etc. (Barrientos 1997). En este punto cabe destacar que, si bien estos mapas son principalmente aplicables a los restos óseos, debido a que las variables fueron seleccionadas en función de su acción sobre este tipo de materiales, muchas de sus implicancias son también relevantes para otro tipo de registros como el cerámico o el lítico que, en grado variable, son también afectados por los diversos procesos de modificación.

\subsection{Metodología}

\subsubsection{Estrategia metodológica general}

Siguiendo los lineamientos arriba planteados, y en concordancia con los objetivos generales de esta tesis, durante la realización de los análisis arqueofaunísticos se trabajó en dos escalas. En la escala regional, resultó operativa la noción de tafonomía regional planteada por Borrero (1988, 2001a), la cual permite analizar los procesos de formación del registro arqueológico en grandes espacios, generando herramientas para estimar las probabilidades de conservación del registro óseo y de mezcla entre materiales arqueológicos y elementos depositados por otros procesos (Borrero 1988). En este sentido, se generó, a nivel de la cuenca, un modelo de agentes y procesos post-depositacionales, a partir del cual se identificaron unidades del paisaje caracterizadas por la similitud en el tipo y la intensidad de los agentes que afectan a la preservación del material óseo. De esta manera, se generaron expectativas sobre las condiciones de conservación del material óseo y se detectaron unidades del paisaje con posibilidades diferenciales de preservación de este tipo de registro, a partir de las cuales realizar interpretaciones con un mayor grado de confianza.

A nivel del sitio, se analizaron los conjuntos óseos evaluando su grado de preservación e integridad a partir de variables como meteorización, abrasión, tipo de marcas presentes en los elementos y grado de fragmentación del conjunto. Esta información junto con las expectativas sobre preservación diferencial derivadas del modelo regional de agentes y procesos post-depositacionales, fue utilizada para evaluar en qué grado pueden ser comparables los conjuntos procedentes de ambientes diferentes. 
8.2.1.1 Generación de un modelo regional de agentes y procesos post-depositacionales: identificación de áreas con expectativas diferenciales de preservación del registro óseo

Un primer acercamiento a los procesos post-depositacionales actuantes se realizó a través de la generación de mapas ambientales en los que quedasen representadas áreas con expectativas de preservación del registro óseo similares. De esta manera, se buscó predecir, en algún grado, las características que sería esperable encontrar en los conjuntos óseos ubicados en diferentes ambientes de la cuenca. Para su generación se utilizó la información sobre suelos publicada por el INTA (2009), la información sobre composición del agua publicada por Bonorino et al. (1989) y datos relevados en los sitios arqueológicos de la cueca. Esta información fue administrada mediante el uso de Sistemas de Información Geográfica (SIG), particularmente del sofware ArcGis $9.3\left(\right.$ Esri $\left.^{\circledR}\right)$. Las variables seleccionadas fueron:

- Salinidad del suelo y el agua subterránea;

- Susceptibilidad de erosión, diferenciando por agente;

- Composición textural predominante de los suelos;

- Probabilidad de desarrollo de cobertura de pastos;

- $\mathrm{PH}$ de los depósitos sedimentarios.

La información obtenida del INTA", forma parte del proyecto "Monitoreo de la cobertura y uso del suelo a partir de sensores remotos" (2009), consistente en cartografía vectorial digital de la República Argentina, relativa a la ocupación de las tierras (i.e. tipo de cubierta biofísica observada en superficie) y uso actual de los suelos (i.e. actividades que la sociedad realiza en determinadas coberturas para producir, cambiar o conservar su estado) a escala 1:500.000, realizada mediante el sistema de clasificación de ocupación de tierras "Land Cover Classification System LCCS" propuesto por Di Gregorio y Jansen (1998), utilizando como fuente primaria de información imágenes de los satélites Landsat y Terra y datos de campo y antecedentes cartográficos (INTA 2009).

En el caso de la composición del agua, se utilizaron mapas impresos a escala 1:500.000 (Bonorino et al. 1989), los que fueron escaneados para su digitalización y luego georreferenciados y vectorizados utilizando ArcGis $9.3\left(\right.$ Esri $\left.^{\circledR}\right)$. La información vectorial fue transformada en raster (utilizando dentro de "Conversion tools" la herramienta "Feature to raster"). Finalmente, aquellos datos obtenidos como mediciones realizadas en los sitios a (i.e. valores de $\mathrm{pH}$ ), fueron ingresados a la base de datos como puntos y transformados en una capa raster a través de la realización de una interpolación realizada con el método kriging. La elección de trabajar con imágenes raster se debió a que, si bien las coberturas vectoriales poseen mayor precisión, las imágenes raster permiten realizar combinaciones y manipulaciones matemáticas con mayor facilidad y rapidez que las vectoriales (Conolly y Lake 2006; Wheatley y Gillings 2002).

Una vez obtenidas todas las imágenes raster estas fueron reclasificadas (utilizando el módulo spatial analyst) a los fines de obtener imágenes simplificadas que permitiesen realizar operaciones algebraicas

1 La cartografía puede ser descargada de la página web del INTA http://inta.gob.ar/documentos/cobertura-delsuelo-de-la-republica-argentina.-ano-2006-2007-lccs-fao/ 
con facilidad. El paso siguiente fue la realización de operaciones de adición entre capas (utilizando la herramienta raster calculator incluida en el módulo spatial analyst) a los fines de generar nuevas coberturas raster en las que quedasen representadas aquellas áreas donde los agentes agresivos para con el registro óseo, presentan mayor intensidad.

A continuación se describen las razones por las que se seleccionó cada una de las variables consideradas y la metodología particular empleada en el tratamiento de la información para su incorporación al modelo regional.

\subsection{Salinidad}

Los minerales disueltos en agua pueden afectar a los restos óseos de dos maneras principales, A- a través del reemplazo de las partes duras originales por otros minerales, mediante un proceso de mineralización o B- por su infiltración y depositación dentro de los poros del tejido esqueletal (Lyman 1994). En el primer caso, la morfología del hueso no se ve afectada, pero si su composición y estructura microscópica, dificultando la posibilidad de realizar análisis químicos en relación con, por ejemplo, su composición isotópica (Gutiérrez 2007; Hedges et al. 1995; Lyman 1994). En el segundo caso, la acción sobre el material óseo dependerá del tipo de minerales que se infiltre, cuando precipitan minerales como silicatos o carbonatos, se produce un proceso de permineralización o petrificación que favorece la conservación de las formas, si bien puede alterar al componente orgánico (Lyman 1994), en cambio, cuando se infiltran sales higroscópicas, estas podrán producir daños físicos en los materiales óseos (Hamilton 1997). Los huesos presentes en ambientes salados absorben las sales solubles, las que, cuando el objeto se seca, cristalizan produciendo la descamación y fractura mecánica de los huesos. Este proceso puede ocurrir repetidamente, ya que con los aumentos y descensos de la humedad ambiental las sales se disuelven y cristalizan una y otra vez, pudiendo producir la destrucción completa del espécimen (Hamilton 1997).

Para estimar la salinidad se utilizó, por un lado, la cobertura vectorial del INTA (2009), en la que se detallan aquellos sectores donde la salinidad es considerada una limitante, ya sea primaria, secundaria o terciaria, para el uso del suelo o bien sectores en los que se describe la presencia de suelos sódicos o con leve grado de salinidad (si bien no llega a ser una limitante importante para el cultivo). A partir de esta información, se realizó una reclasificación en suelos con alta concentración de sales y suelos con baja concentración de sales, que fue luego convertida a formato raster (Figura 8.1).

Por otra parte, se utilizó la información sobre concentración de cloruros disueltos en las aguas subterráneas, publicada por Bonorino et al. (1989). En este caso se trataba de mapas impresos en papel, por lo que estos fueron digitalizados, georreferenciados y transformados en una capa de puntos a partir de la cual se realizó una interpolación (mediante método kriging) obteniéndose una superficie raster, representativa de los valores estimados de concentración de cloruros disueltos en las aguas subterráneas. Dicha cobertura fue reclasificada a los fines de obtener una nueva superficie en la que sólo quedasen representados sectores con alta concentración de cloruros y sectores con baja concentración de cloruros, como valor crítico entre ambas se consideró, arbitrariamente, una concentración de 700 mg/l (Figura 8.2). 


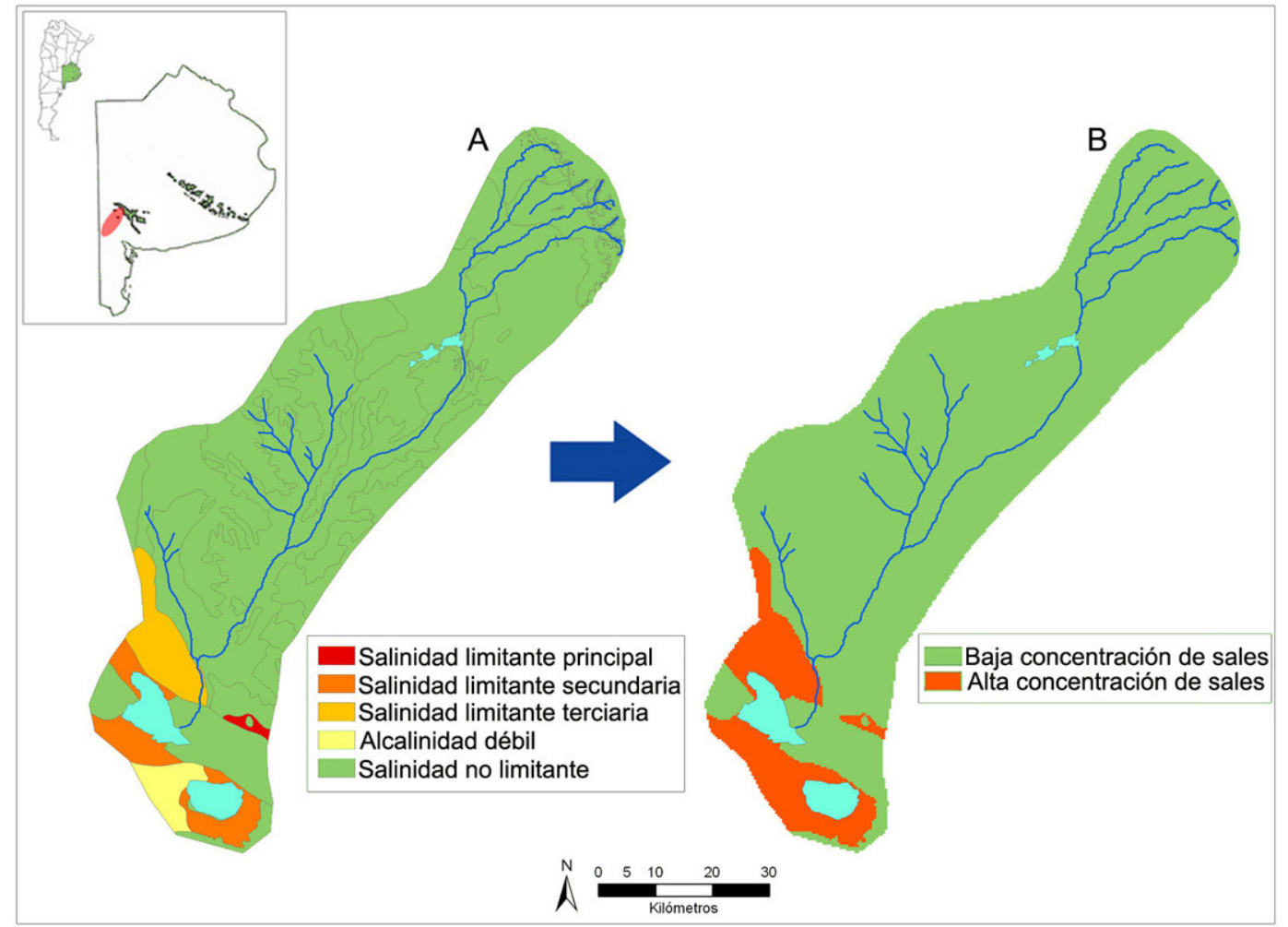

Figura 8.1. Suelos con mayor concentración de sales. A- Clasificación de la cobertura vectorial INTA (2009) en función de la limitación para el cultivo, principal, secundaria o terciaria, derivada de la presencia de sales en los suelos. B- Reclasificación de dicha capa vectorial en áreas de baja concentración de sales, donde estas no actúan como limitante para el cultivo, y áreas de alta concentración, en las que la presencia de sal es una limitante.

Estas dos coberturas raster, fueron combinadas (mediante el operador Or), a los fines de obtener una tercer capa representativa de la salinidad general del ambiente, donde se distingue entre ambientes con alta concentración de sales (aquellos sectores en que la salinidad es una limitante para el uso de los suelos o bien sectores en los que las aguas subterráneas tienen una concentración de cloruros superior a los $700 \mathrm{mg} /$ litro) y ambientes con baja concentración de sales, los restantes (Figura 8.3). 


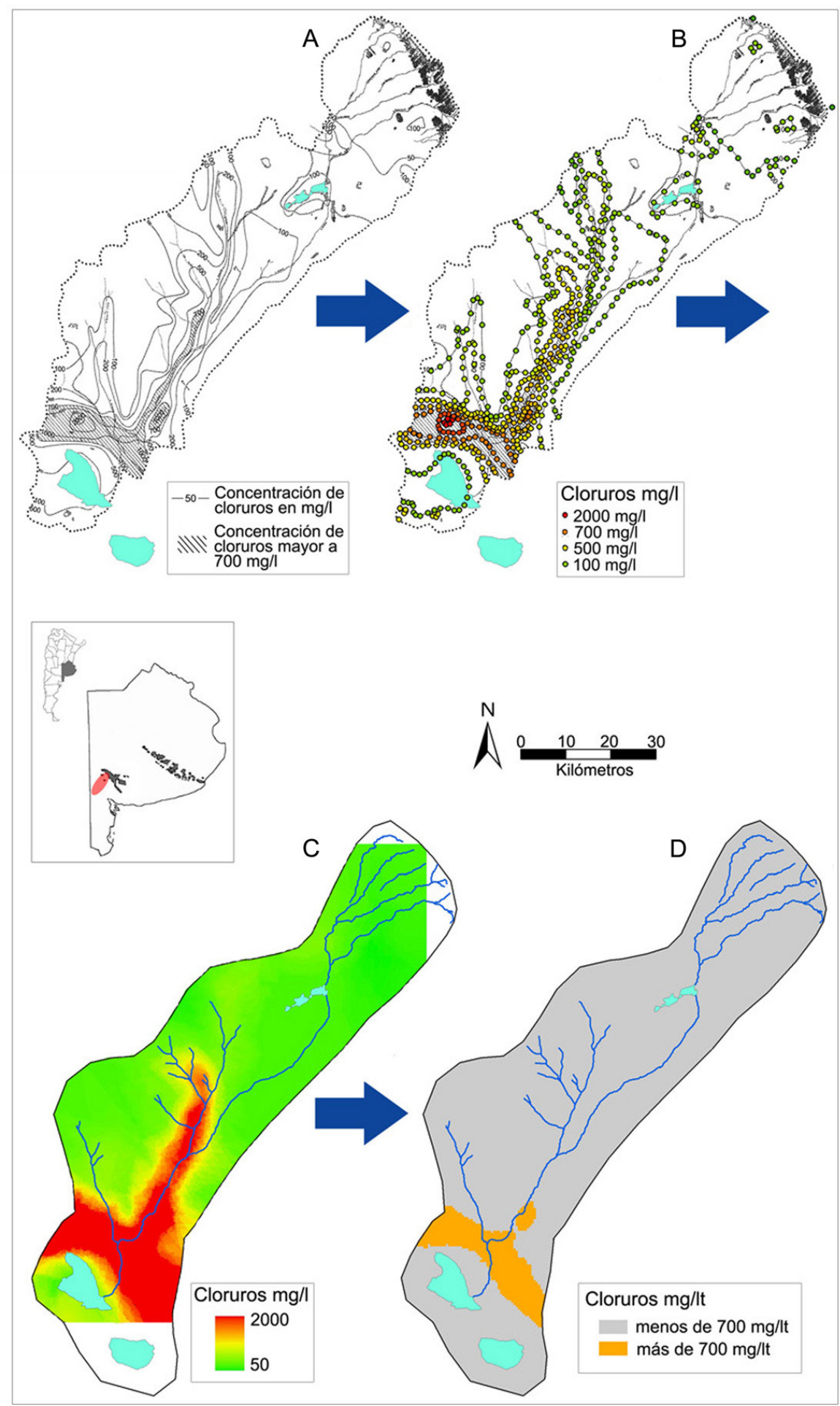

Figura 8.2. Concentración de cloruros en las aguas subterráneas. A- Mapa publicado por Bonorino et al. (1989), en el que se indican isolíneas de concentración de cloruros. B- Vectorización, en ArcGis 9.1, de dicho mapa, por medio de la generación de una capa de puntos. C-Cobertura raster generada a partir de la interpolación de la capa vectorial de puntos. D- Cobertura raster re-clasificada considerando como valor umbral los $700 \mathrm{mg} / \mathrm{lt}$. 


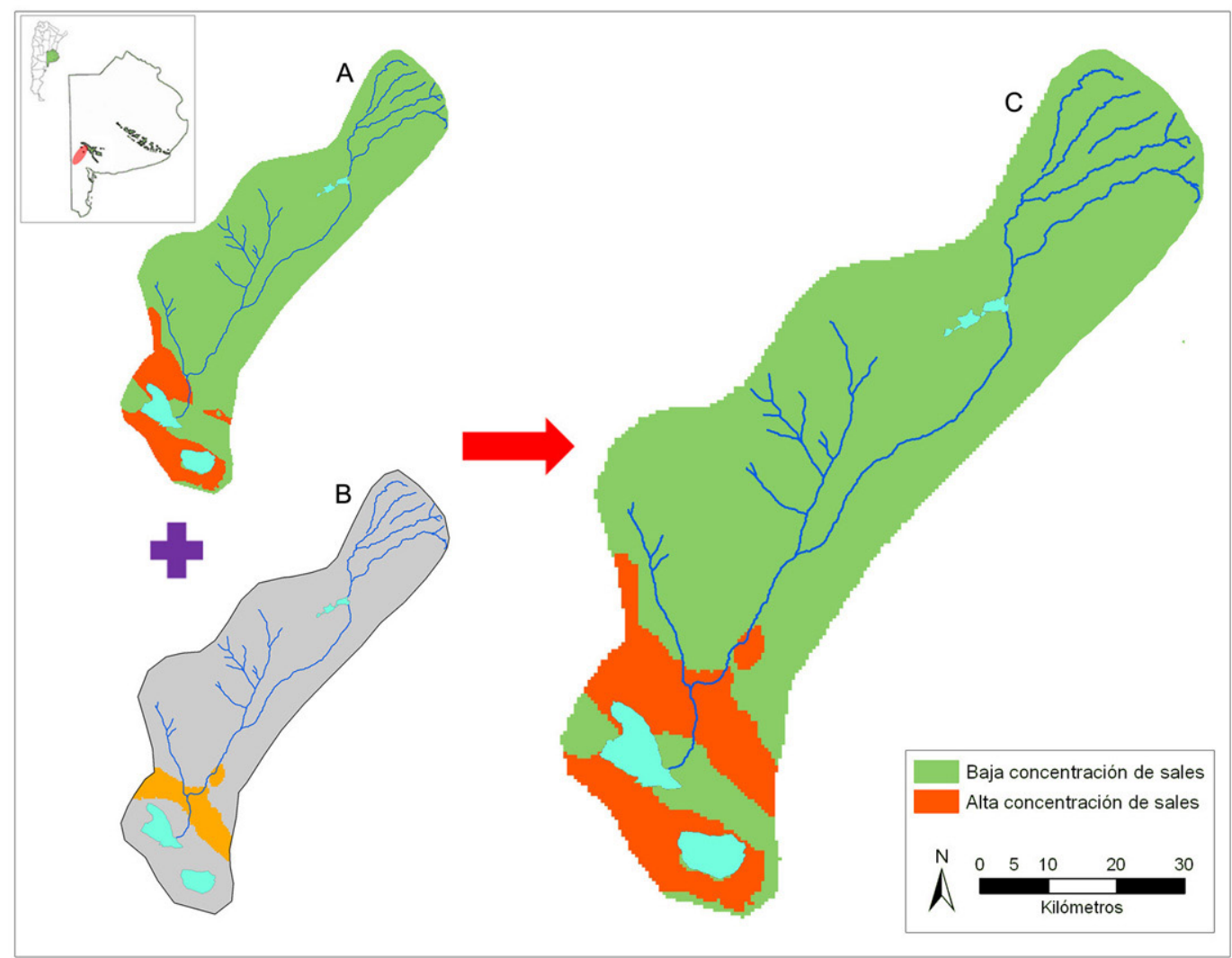

Figura 8.3. Generación de la cobertura de concentración de sales (C) a partir de la combinación de las capas obtenidas en función de la información sobre salinidad de los suelos (A) y de las aguas subterráneas $(\mathrm{B})$.

\subsection{Erosión}

La erosión, ya sea esta hídrica o eólica, puede producir la re-exposición de los materiales arqueológicos, generando de esta manera la mezcla entre materiales arqueológicos correspondientes a diferentes momentos y entre materiales arqueológicos y no arqueológicos. Por otra parte, los materiales expuestos en superficie son más susceptibles de ser afectados por diferentes agentes y procesos que afectan a su conservación (i.e. pisoteo, rodamiento, alternancia entre momentos húmedos y secos, cálidos y fríos), aumentando así su fragmentación y meteorización (Behrensmeyer 1978; Lyman 1994). La identificación de aquellos sectores en los que los procesos erosivos tienen mayor incidencia, se realizó a partir de la cobertura vectorial del INTA (2009), donde se detallan las áreas en las que la erosión hídrica o eólica es una limitante para el uso del suelo. Esta capa fue reclasificada en suelos con baja erosión, con erosión hídrica y con erosión eólica y transformada a raster (Figura 8.4). 


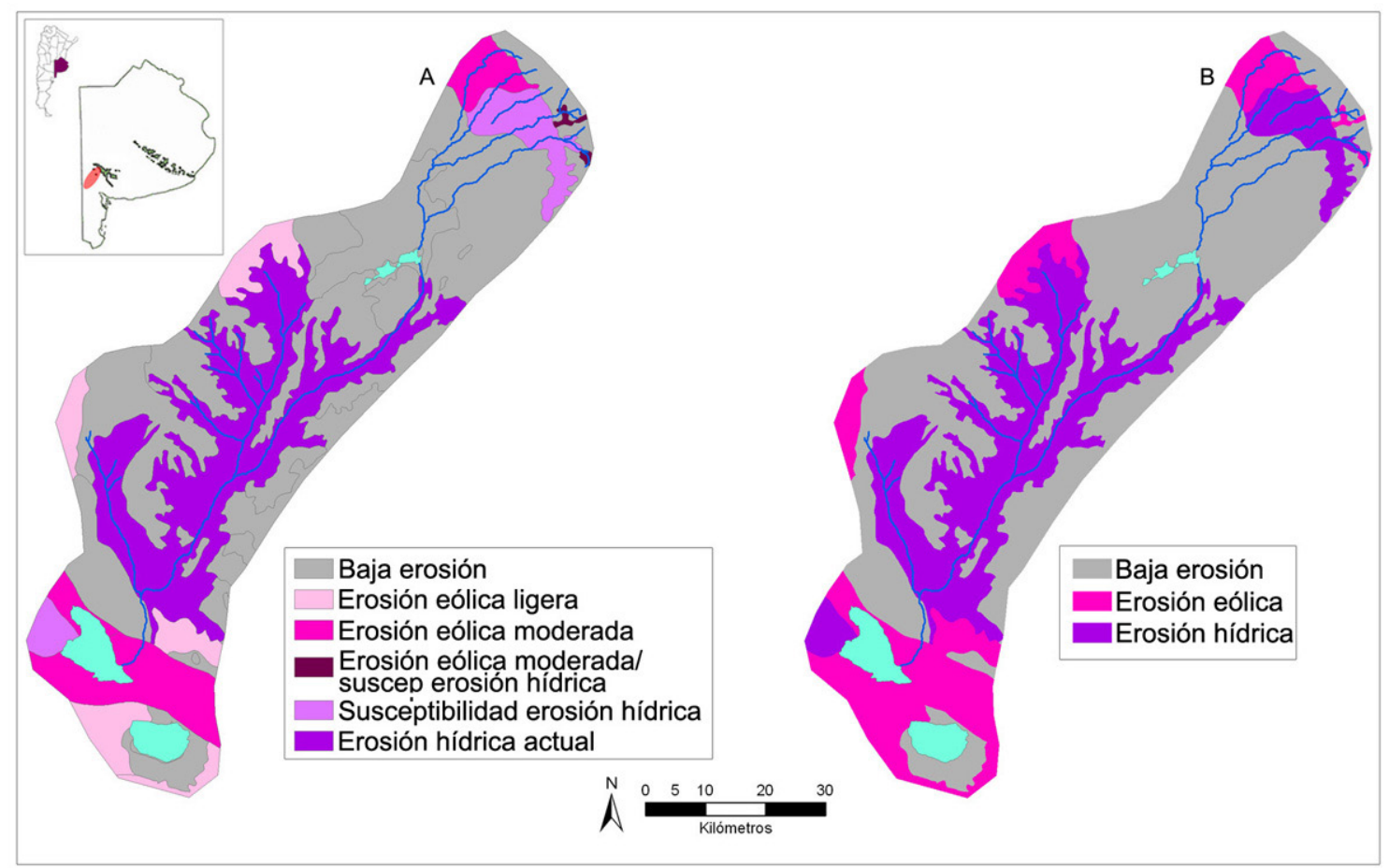

Figura 8.4. Áreas con mayor susceptibilidad a la erosión. A- Clasificación de la cobertura vectorial INTA (2009) en función de la incidencia de la erosión, eólica o hídrica, sobre los suelos. B- Reclasificación de dicha capa vectorial en áreas de baja erosión y áreas actualmente erosionados, o susceptibles de serlo, por la acción de agentes eólicos o hídricos.

\subsection{Composición predominante de los suelos}

La fracción predominante en la composición del suelo (limo, arena o arcilla), es otra de las variables que influyen en la preservación del registro óseo. En tal sentido, en condiciones sub-ácueas, los suelos arcillosos y limosos, son los que generan mayor abrasión y, consecuentemente, redondeamiento, en los huesos que se encuentran meteorizados o fosilizados (Fernández-Jalvo 2003), en tanto los suelos arenosos, principalmente las arenas más finas, producirán un mayor grado de abrasión en los huesos frescos, generando su redondeamiento y dificultando, de esta manera, la identificación de rasgos diagnósticos. A su vez, este tipo de sedimentos, permiten un mayor flujo de agua a través de ellos, acelerando los procesos diagenéticos relacionados con el movimiento de solutos hacia o desde el hueso (Grupe 1995; Hedges y Millard 1995). Por tal motivo, se consideró a los suelos arenosos como aquellos más agresivos para con el registro óseo.

La caracterización de la fracción dominante en la composición de los suelos presentes en la cuenca se realizó también, a partir de la información sobre textura superficial del "suelo principal” publicada en formato vectorial por el INTA (2009). En función de dicha variable, la cobertura fue reclasificada considerando tres categorías: suelos predominantemente limosos, suelos predominantemente arcillosos y suelos predominantemente arenosos, para luego ser transformada a formato raster (Figura 8.5). 


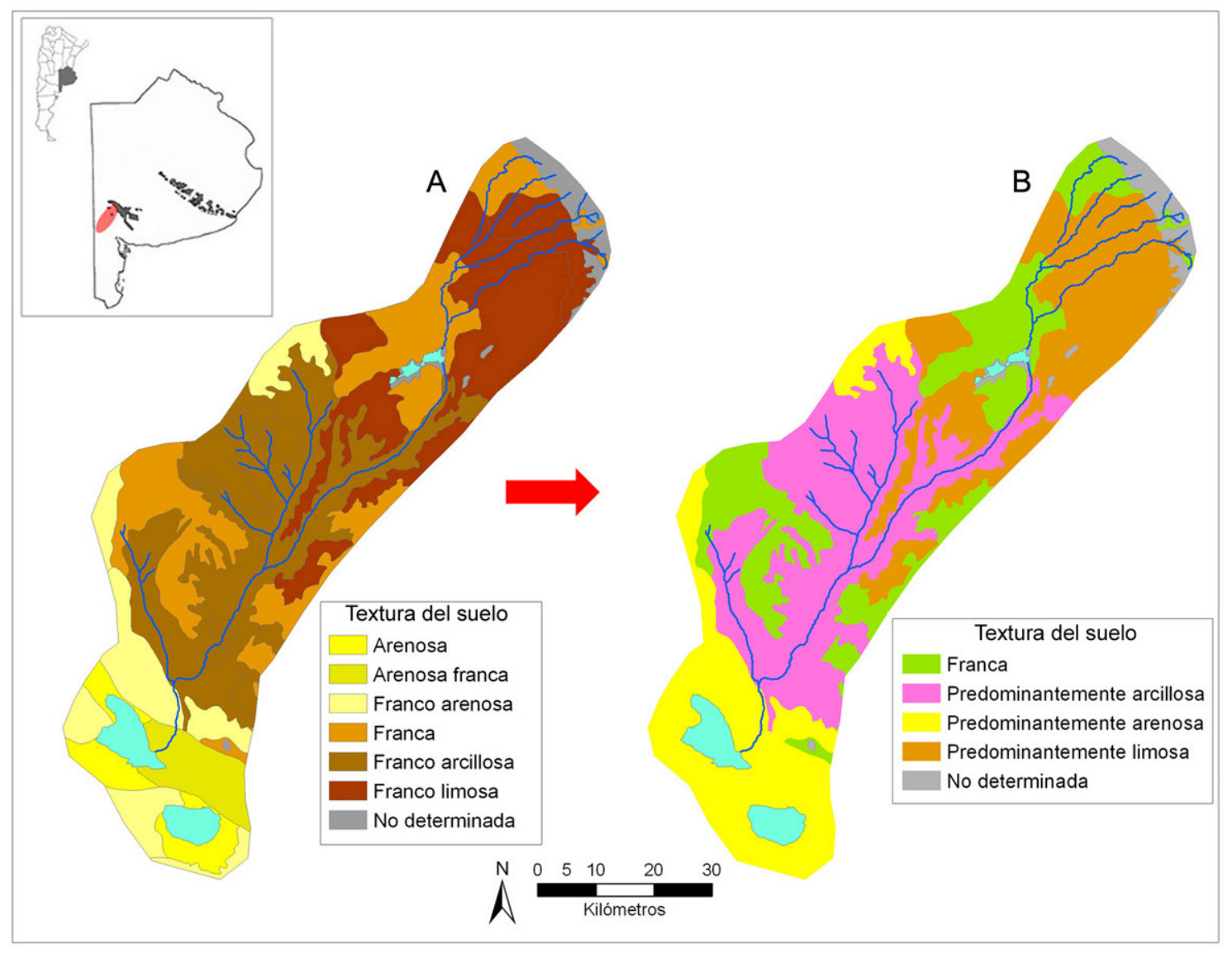

Figura 8.5. Textura predominante de los suelos. A- Clasificación de la cobertura vectorial INTA (2009) en función de la textura del suelo principal. B- Reclasificación de dicha capa vectorial en áreas donde predomina la fracción arcilla, limo o arena.

\subsection{Probabilidad de desarrollo de cubierta vegetal}

El tipo y densidad de la vegetación puede afectar al registro arqueológico a través de las raíces que estas desarrollan. Por una parte, las raíces, pueden producir el desplazamiento vertical y/o horizontal de los materiales, entre ellos los restos óseos (Behrensmeyer 1978; Gutiérrez 2004). Por otro lado, la acidez secretada por las raíces de la mayor parte de la vegetación produce, al entrar en contacto con la superficie cortical de los huesos, marcas dendríticas poco profundas que, cuando se extienden sobre la superficie del hueso, pueden enmascarar otras marcas previas, como aquellas producto de las actividades de fileteado y/o de despostamiento, impidiendo completamente o volviendo difícil su identificación (Gutiérrez 2004; Lyman 1994; Mengoni Goñalons 1999). Finalmente, cuando las raíces penetran en el interior de los huesos, principalmente del tejido esponjoso, pueden llegar a producir su destrucción por acción mecánica (Micozzi 1991).

Como indicador del probable desarrollo de cobertura vegetal, particularmente de pastos, se consideraron los órdenes y sub-órdenes (USDA 1999) del "suelo principal" descriptos por el INTA (2009). Los suelos descriptos para la cuenca del Chasicó son Molisol, en los sectores medio 
y superior, y Entisol, en el sector inferior. El primero de estos se caracteriza por suelos oscuros, ricos y minerales con desarrollo de uno o más horizontes formados típicamente bajo cobertura de pastos perennes. Dentro del orden Molisol, se encuentran representados en la cuenca los sub-órdenes Udol, desarrollado en climas húmedos y en el que dominan los pastos altos, y Ustol, propio de climas subhúmedos a semiáridos, con sequías frecuentes que pueden limitar el crecimiento de los cultivos y en consecuencia, también de la vegetación de pastos. Finalmente, en el sector inferior de la cuenca se encuentra representado el orden Entisol, caracterizado por poca o ninguna evidencia de horizontes pedogénicos (USDA 1999), consecuencia de una mayor erosión y menor desarrollo de la cobertura vegetal. Considerando la información mencionada, se reclasificó la capa vectorial INTA en probabilidad alta (sub-orden Udol), media (sub-orden Udol) y baja (orden Entisol, sub-ordenes fluvent, orlent y psament) de desarrollo de pastos, para luego transformarla a formato raster (Figura 8.6).

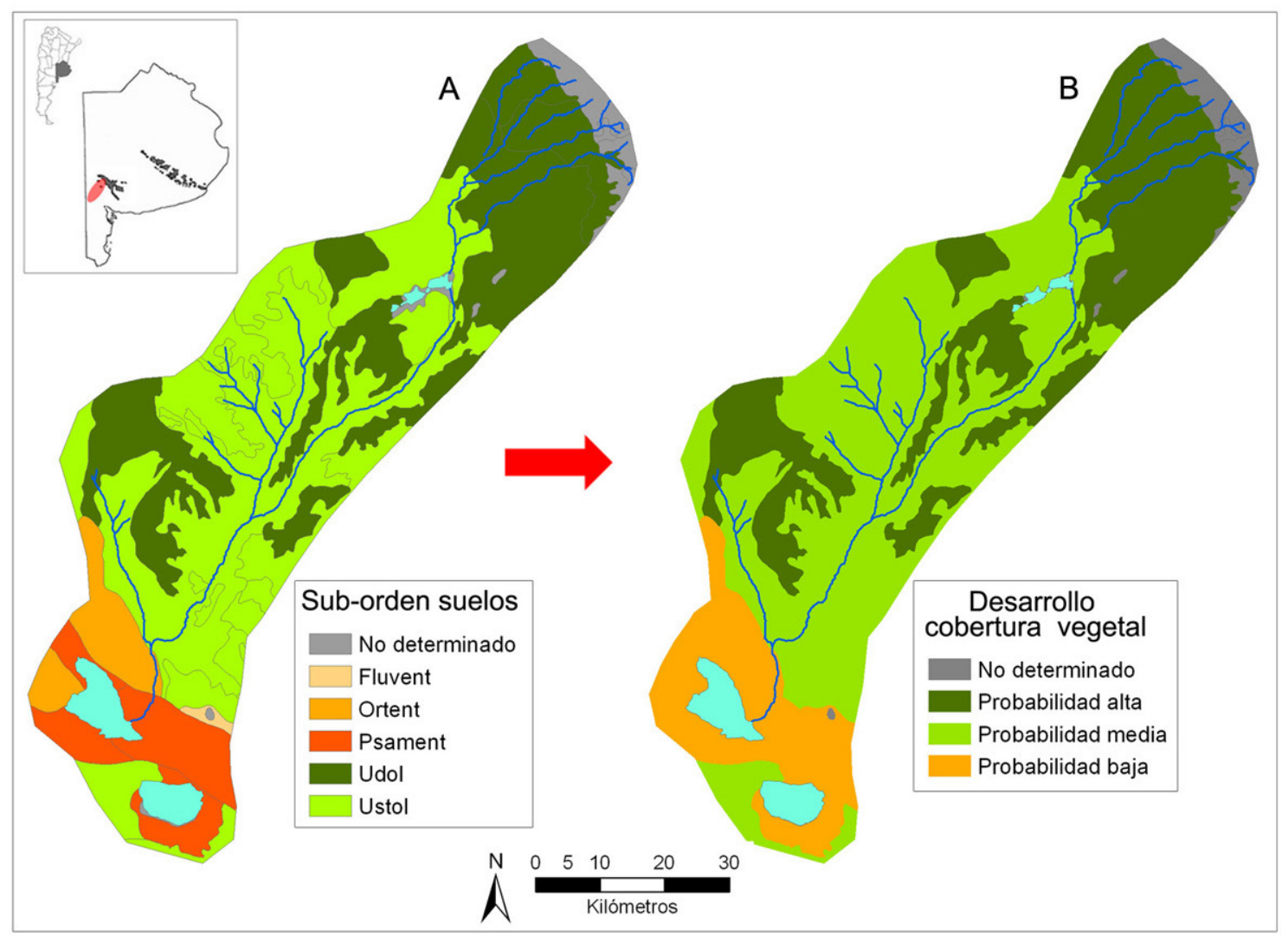

Figura 8.6. Probabilidad de desarrollo de cubierta vegetal de pastos. A- Clasificación de la cobertura vectorial INTA (2009) en función del sub-orden del suelo principal. B- Reclasificación de dicha capa vectorial considerando la relación entre el sub-orden del suelo y el desarrollo de una cobertura de pastos. 


\subsubsection{5 pH promedio de los depósitos sedimentarios}

Si bien algunos estudios han señalado que el $\mathrm{pH}$ del suelo, considerado aisladamente, no es el mayor determinante en la conservación de los huesos (Nicholson 1996), los estudios realizados coinciden en que este factor incide de diversas maneras en su preservación (Gordon y Buikstra 1981; Lyman 1994; Nicholson 1996; Watson 1967), habiéndose observado, en algunos casos, la existencia de una correlación negativa significativa entre el $\mathrm{pH}$ del suelo y el grado de destrucción de los huesos, el cual aumenta a medida que el pH decrece (Gordon y Buikstra 1981). Esto se debe a que, el valor de $\mathrm{pH}$ influye en el rango y tipos de micro-organismos disponibles en el ambiente. Las condiciones ácidas pueden favorecer la acción de hongos y los suelos con $\mathrm{pH}$ entre 6 y 7,5 permiten el desarrollo de numerosos organismos intolerantes a suelos muy ácidos (Lyman 1994; Nicholson 1996; Nielsen Marsh et al. 2007). Por otra parte, el pH del suelo puede jugar un rol importante en la disolución y esculpido de los huesos, debido a que las condiciones ácidas producen la disolución de la fracción mineral del hueso exponiendo la fracción orgánica, lo que favorece a su vez, la acción de hongos y otros organismos microbianos (Lyman 1994; Nicholson 1996; Stiner et al. 2001).

La determinación del valor de $\mathrm{pH}$ se realizó en el laboratorio, a partir de muestras de sedimento de las distintas unidades estratigráficas observadas en los sitios arqueológicos excavados (ya sea por medio de excavaciones extensivas o sondeos). La medición fue realizada en una suspensión conformada por una proporción sedimento-agua destilada de 1:4, utilizando un $\mathrm{pH}$-metro portable con una precisión de \pm 0.1 (Tabla 8.1).

Una vez obtenidos los valores de las distintas unidades estratigráficas se obtuvo un valor promedio para cada sitio, a partir de los cuales se generó por interpolación utilizando el método kriging, una cobertura raster representativa de los posibles valores de $\mathrm{pH}$ para los distintos sectores de la cuenca. En este caso no se realizó la capa de cálculo del error estándard, debido a que el número de puntos muestreados es muy escaso y por lo tanto la superficie obtenida es sólo indicadora de la tendencia general observada en la cuenca (Figura 8.7). 


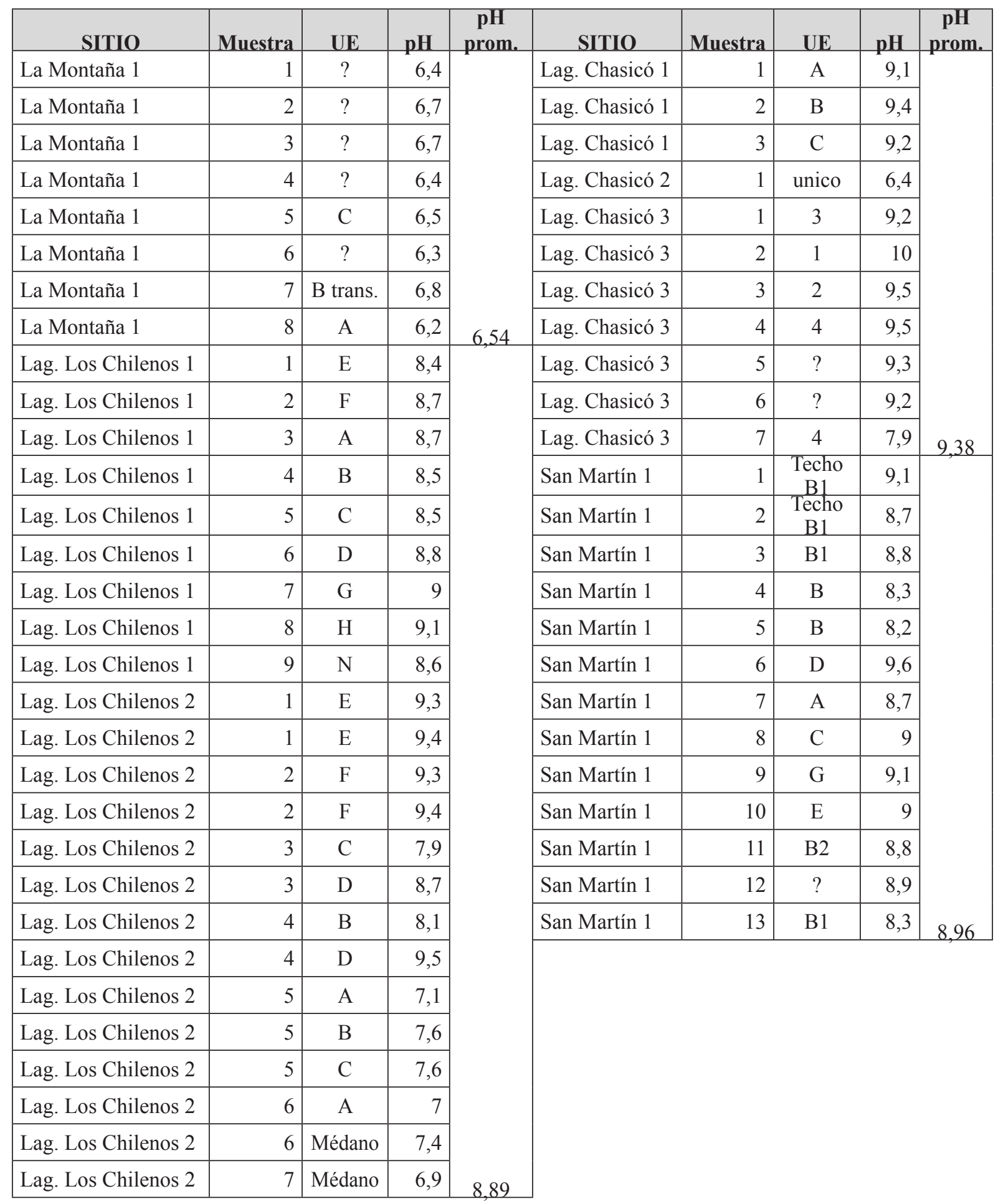

Tabla 8.1. Medición del pH de las muestras de sedimento tomadas en las distintas unidades estratigráficas de los sitios y cálculo del pH promedio de cada uno de ellos 


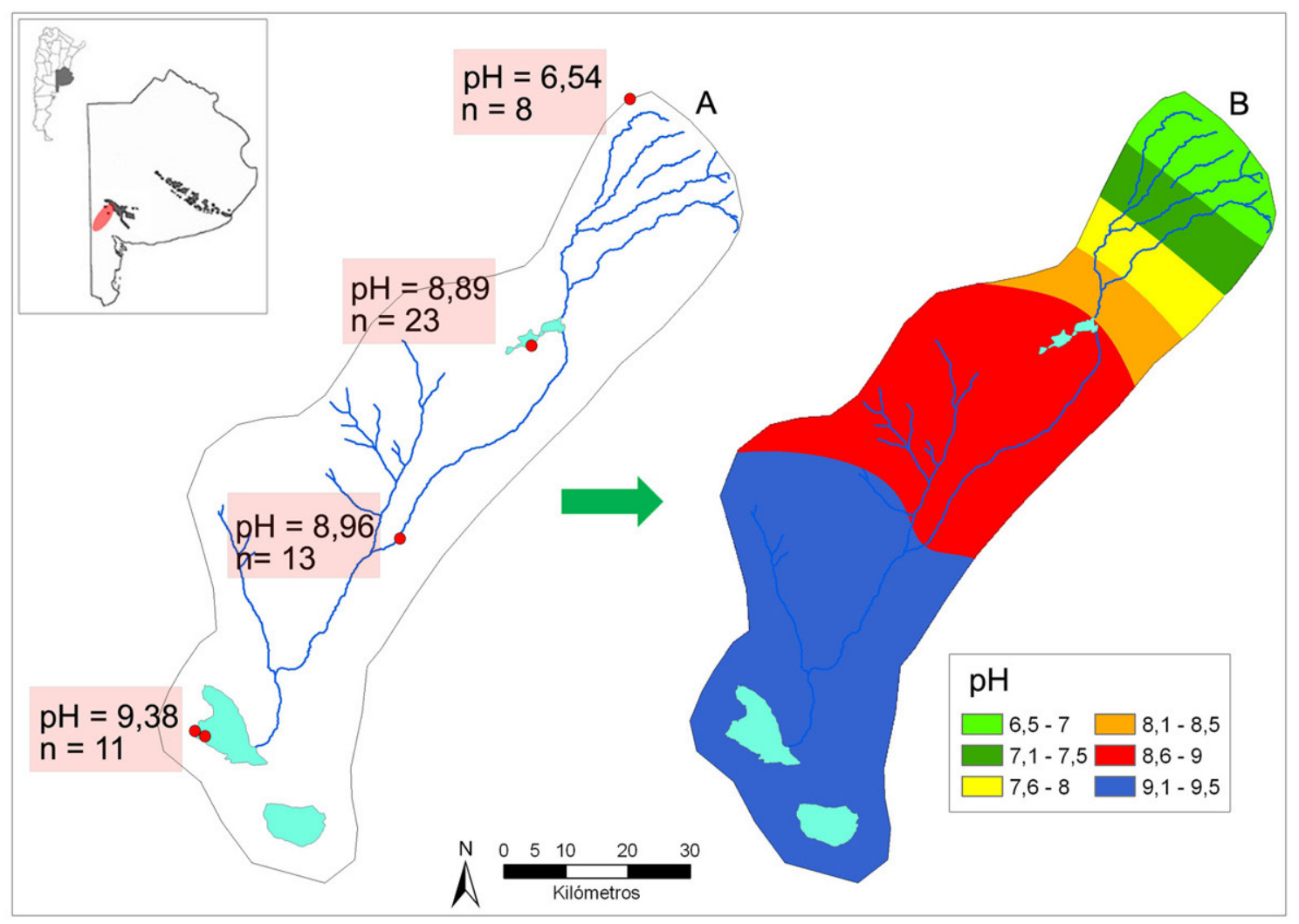

Figura 8.7. pH promedio estimado de los suelos. A- Generación de una capa vectorial de puntos en la que se incluyeron los valores de $\mathrm{pH}$ promedio de los sitios considerados. B- Generación por interpolación, a partir de la capa vectorial mencionada, de una cobertura raster representativa de los valores de $\mathrm{pH}$ promedio estimados para la cuenca.

\subsection{Modelo regional de agentes y procesos post-depositacionales}

Una vez obtenidas las cinco coberturas representativas de la distribución de los principales agentes que afectan al registro óseo en la región, se procedió a evaluar el modo en que estas se combinan, a través de la realización de operaciones de adición entre capas, realizadas con la herramienta raster calculator (operadores And y $O r$ ). De esta manera se obtuvo una nueva cobertura donde, los diferentes sectores, se encuentran caracterizados en función de la cantidad de factores agresivos para con el registro óseo y la intensidad con que estos actúan (Figura 8.8).

Esta cobertura fue luego simplificada considerando del número de agentes actuantes con mayor intensidad, a los fines de generar un mapa ilustrativo de sectores de preservación diferencial del registro óseo. Este último mapa indica que en la cuenca pueden distinguirse al menos tres sectores, dos sectores, cabecera y cuenca inferior, en los que la intensidad con la que actúan los agentes y procesos agresivos para con el registro es mayor y, por lo tanto, las expectativas de recuperar materiales óseos son menores. Un tercer sector, que comprende la cuenca media y el sector inferior de la cuenca superior, donde la intensidad de dichos agentes y procesos es menor y, en consecuencia, es esperable que el registro óseo se encuentre mejor preservado (Figura 8.9). 


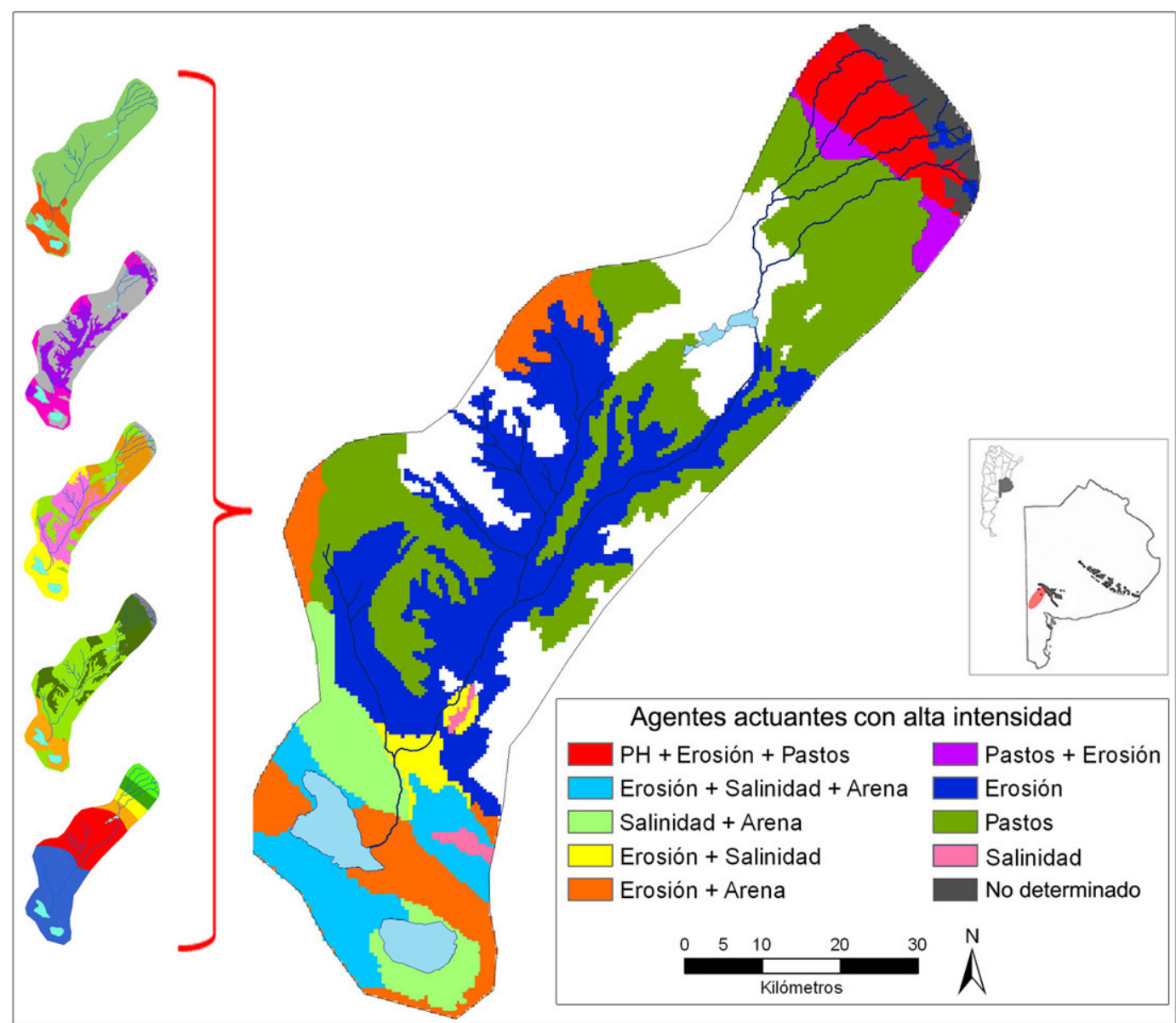

Figura 8.8. Generación, a partir de la adición de las coberturas de salinidad, erosión, textura del suelo, cobertura de pastos y $\mathrm{pH}$, de una cobertura en la que se sectoriza la cuenca en función de los agentes y procesos post-depositacionales actuantes sobre el registro óseo.

Finalmente, cabe aclarar que, debido a la escala de estos mapas, sólo se representan aquellos factores que actúan sobre espacios amplios, generándose expectativas para esta misma escala. Dentro de cada una de estas unidades, podrán encontrarse variaciones locales que deberán ser evaluadas en cada caso en particular. Un ejemplo de esto son los bordes de laguna, los cuales puede presentar un mayor grado de pisoteo por parte de animales que concurren a abrevar, además de mayores posibilidades de enterramiento o erosión, dependiendo el caso (Borrero et al. 1993). 


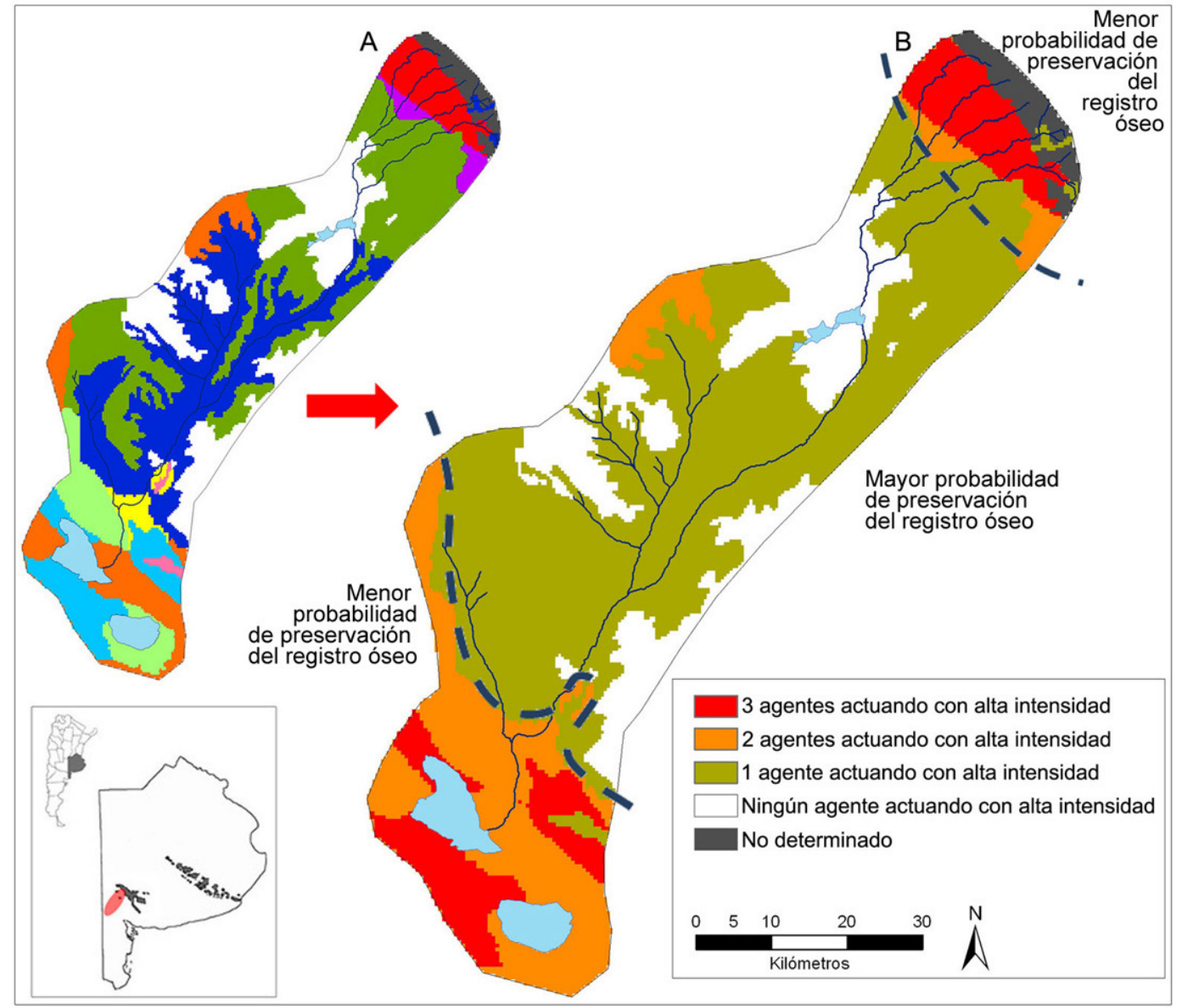

Figura 8.9. Reclasificación de la cobertura raster de agentes y procesos (A) en función de la cantidad de ellos que actúan en un mismo sector. De esta manera se obtiene una nueva cobertura (B) en la que se discrimina entre áreas de menor probabilidad de preservación del registro óseo y un área de mayor probabilidad de preservación del mismo. La línea punteada separa unas de otra.

\subsubsection{Metodología empleada en el análisis de los elementos arqueofainístios}

Los elementos faunísticos estudiados fueron recuperados a partir de recolecciones superficiales sistemáticas realizadas por la autora en la cuenca inferior, particularmente en sitios localizados sobre las márgenes de la laguna Chasicó. A los fines de evaluar las variaciones de este tipo de registro a lo largo de la cuenca, se incorporaron materiales obtenidos por F. Oliva mediante excavaciones sistemáticas, realizadas en los sitios La Montaña 1, Los Chilenos 2 y San Martín 1, y recolecciones superficiales, llevadas a cabo en inmediaciones del sitio Los Chilenos 2 (Oliva 2014).

El análisis de los materiales óseos se realizó a nivel macroscópico y con una lupa binocular Hokenn de 40X, considerando variables orientadas a la identificación de los procesos y agentes post-depositacionales actuantes sobre los conjuntos y a la evaluación del modo en que las sociedades cazadoras-recolectoras utilizaron los recursos faunísticos. Los conjuntos fueron analizados cuantitativamente calculándose como medidas de abundancia taxonómica, el Número de Especímenes Identificados por taxón (NISP) y el Número Mínimo de Individuos (NMI) y, como medidas de abundancia anatómica el Número Mínimo de Elementos (NME). El cálculo, utilidad y limitaciones de cada una de las mencionadas medidas ha sido descripto en detalle por diversos investigadores por lo que no me extenderé en estos aspectos (Binford 1981; Gutiérrez 2004; Lyman 1994; Mengoni Goñalons 1988, 1999). Cabe destacar que el 
análisis de los conjuntos se realizó de manera exploratoria, a los fines de comenzar a evaluar similitudes y diferencias entre conjuntos y, principalmente, detectar generalidades en sus historias tafonómicas que permitan indagar acerca de su comparabilidad. Por tal motivo, los cálculos de NMI y NME son estimativos, en el primer casos se consideraron criterios de lateralidad y edad, en tanto en el segundo se consideró la lateralidad, porcentaje representado y parte representada.

La identificación taxonómica y anatómica del material faunístico se llevó a cabo comparativamente, sobre la base de rasgos morfológicos y métricos, utilizando como colecciones de referencia aquellas existentes en la División Arqueología y en la sala de vertebrados del Museo de La Plata y empleando, complementariamente, los atlas osteológicos de aves (Gilbert et al. 1981) de Blastoceros dichotomus (Loponte 2004), de camélidos sudamericanos (Pacheco Torres et al. 1979) y de cérvidos andinos (Altamirano Enciso 1983). La identificación taxonómica se realizó a nivel de especie, cuando esto fue posible de manera confiable, en tanto en aquellos casos en que los elementos, o fragmentos de elementos, no fueron lo suficientemente diagnósticos, la identificación se realizó a niveles taxonómicos más generales (género, familia, orden o clase). En mamíferos se identificó también, siempre que fue posible, su edad de muerte a partir del estadio de fusión de los elementos óseos, principalmente huesos largos y vértebras (Kauffman 2009). Posteriormente, y a los fines de facilitar la comparación entre conjuntos con historias tafonómicas muy diversas y variados niveles de profundidad de análisis, se utilizaron las categorías taxonómicas amplias de aves, mamífero mediano/grande (i.e. Ozotoceros bezoarticus y Lama guanicoe) y mamífero pequeño (i.e. roedores, Lagostomus maximus, Chaetophractus villosus).

A los fines de establecer la identidad y cantidad de agentes participantes en la formación de los conjuntos, se analizaron a ojo desnudo las modificaciones presentes en las superficies de los restos óseos y en aquellos casos en que se identificaron rasgos llamativos se utilizó una lupa binocular Hokenn de 10X a 40X. Esto permitió realizar inferencias acerca del agente efector de las marcas (antrópico, raíces, roedores, carnívoros), a partir de la forma de las modificaciones óseas, su ubicación, orientación y agrupamiento (Binford 1981; Lyman 1994; Mengoni Goñalons 1988). Para evaluar la acción del agua sobre el conjunto, se analizó el grado de abrasión del material óseo siguiendo la propuesta de FernándezJalvo y Andrews (2003), quienes proponen cuatro estadios en función del redondeamiento de los bordes y del estado de las superficies.

Se determinó a su vez el grado de alteración estructural de los elementos óseos, considerando cuatro niveles de alteración, no alterados, alteración baja, media y alta. La elección de esta variable por sobre la meteorización (Behrensmeyer 1978), se debe a que los huesos se deterioran a través de una secuencia continua, que comienza en la superficie y subsuperficie y persiste bajo condiciones de enterramiento, resultando en muchos casos difícil distinguir los rasgos diagnósticos de una y otra, dado que no se ha desarrollado aún una metodología adecuada. (Barrientos y Gutierrez 1996; Barrientos 2000; Lyman y Fox 1989; Todd y Frison 1986; Todd et al. 1987). La densidad estructural y/o la porosidad de los elementos óseos influyen en la velocidad con la que estos se alteran, por lo que esta variable es dependiente del taxón y el elemento esqueletario afectado (Behrensmeyer 1978; Gifford 1981; Lyman y Fox 1989; Todd et al. 1987). Tanto la alteración estructural como la abrasión y la mineralización, fueron medidas únicamente en aquellos elementos óseos mayor a $4 \mathrm{~cm}^{2}$. Esta variables no fueron analizadas en el caso de dientes y molares, placas de dasipódidos y otros elementos no óseos, con excepción de la mineralización, que fue cuantificada también en este tipo de elementos faunísticos. 
La mineralización fue evaluada macroscópicamente, por lo que no se distinguió entre mineralización (reemplazo de partes duras originales por otras minerales) y petrificación (infiltración de minerales en los poros del tejido esqueletal), sino que se distinguió entre huesos mineralizados y no mineralizados (Lyman 1994). Se realizó a su vez, la identificación macroscópica de las depositaciones químicas, como el carbonato de calcio, evidenciado por la presencia de una cubierta blanquecina y dura, y precipitaciones de óxido de manganeso, en la forma de manchas negras aisladas o agrupadas. Finalmente, se calculó el grado de fragmentación del conjunto considerando la relación, expresada como el valor de la razón, entre el número total de especímenes presentes en la muestra (NSP) y el número de especímenes identificables (NISP), la que será indicadora de la extensión de la fragmentación, es decir, de cuan fragmentada se encuentra (Otaola 2012).

\subsection{Resultados}

\subsubsection{Localidad La Montaña}

\subsubsection{La Montaña sitio 1}

La muestra consiste en 1528 especímenes óseos, 2 placas dérmicas de dasipodido y 22 fragmentos de diente o molar, los que fueron analizados en conjunto con F. Oliva y N. Morales en el marco de los respectivos proyectos de tesis doctorales (Morales et al. 2012; Oliva 2014). La mayor densidad de especímenes se encuentra en las cuadrículas 1 a 3, entre los niveles 7 y 15 . Las cuadrículas 1 y 3 presentan una distribución bimodal de los especímenes, que responde, al menos principalmente, a una mayor fragmentación de la muestra en los niveles inferiores (Figura 8.10).

Del total de especímenes óseos, 402 pudieron ser identificados a algún nivel anatómico y/o taxonómico, en tanto los 1026 restantes, debido a su tamaño y/o grado de alteración estructural, no pudieron ser determinados. Las especies representadas son Lama guanicoe, con un NMI de 2, y Ozotoceros bezoarticus con un NMI de 1, en ambos casos calculado a partir de astrágalos derechos. Con excepción de dos placas de dasipodido, no se encuentran representados animales de menor porte como aves o mamíferos pequeños, sino que todos aquellos especímenes que no fueron identificados a nivel específico corresponden o bien a Artiodactyla, o bien a mamíferos medianos o mediano/grandes. A su vez, todas las unidades anatómicas observadas en el sitio, tanto las que fueron identificadas a niveles específicos como las que lo fueron a niveles más generales, corresponden a las extremidades, por lo que, en los casos no determinados específicamente (la mayor parte corresponden a fragmentos de diáfisis), probablemente se trate también de restos correspondientes a guanaco o venado de las pampas, que por su grado de fragmentación, no pudieron ser determinados (Tabla 8.2). 


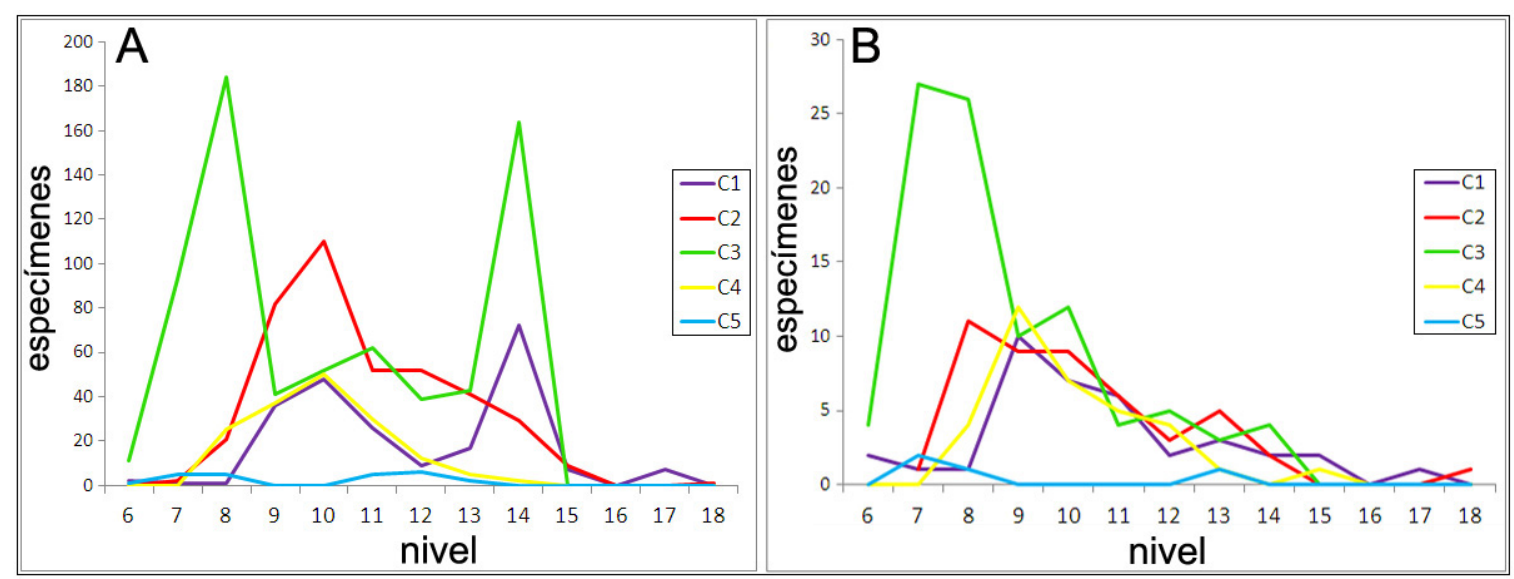

Figura 8.10. Cantidad de especímenes óseos por nivel estratigráfico en el sitio La Montaña 1. A- Densidades de especímenes determinables e indeterminables (NSP); B- Densidades, únicamente, de aquellos especímenes determinables (NISP).

\begin{tabular}{|l|r|r|r|r|r|r|r|r|r|r|}
\hline \multicolumn{2}{|r|}{ Taxón } & L. guanicoe & \multicolumn{2}{c|}{$\begin{array}{c}\text { O. } \\
\text { bezoarticus }\end{array}$} & $\begin{array}{c}\text { M. mediano } \\
\text { grande }\end{array}$ & \multicolumn{2}{c|}{ M. chico } & \multicolumn{2}{c|}{ Indet. } \\
\hline Elemento & NME & nisp & NME & nisp & NME & nisp & NME & nisp & NME & nisp \\
\hline diente/molar & & & & & 1 & 16 & & & 0 & 6 \\
\hline vertebra & & & & & & & & & 1 & 1 \\
\hline húmero epífisis distal & 1 & 1 & & & & & & & & \\
\hline tibia porción distal & 1 & 4 & & & & & & & & \\
\hline hueso largo & & & & & & 303 & & & & 94 \\
\hline astrágalo & 3 & 4 & 1 & 2 & 1 & 1 & & & & \\
\hline hueso del tarso o carpo & 7 & 8 & & & 2 & 2 & & & & \\
\hline falange 1 & 1 & 2 & & & 1 & 9 & & & & \\
\hline indeterminado & & & & & 3 & 50 & & & 122 & 1047 \\
\hline placas & & & & & & & & 2 & & \\
\hline
\end{tabular}

Tabla 8.2. Diversidad taxonómica representada en el sitio La Montaña 1

La muestra presenta un alto grado de fragmentación, con 34 especímenes identificables de un total de 1528, lo que da una razón NSP:NISP de 44,94. El grado de alteración estructural general de la muestra es elevado, el 4\% de los especímenes presentan alteración alta, 16\% media y sólo el 2\% tiene una baja alteración, en el 78\% restante la alteración no pudo ser determinada debido al alto grado de fragmentación (fragmentos menores a $4 \mathrm{~cm}^{2}$ ), lo que podría ser también consecuencia de grados elevados de alteración, es decir, que el grado más elevado de alteración podría estar sub-representado debido a que en este, los huesos se fragmentan dificultando su determinación. Los elementos óseos presentan pocas evidencias de abrasión hídrica, encontrándose solo dos elementos altamente abradidos (estadio 3), 40 con abrasión media (estadio 2) y 264, con abrasión leve. En este caso también, dado el grado de fragmentación, la abrasión no pudo determinarse en más del 79\% de la muestra. Finalmente, no se registró mineralización en el conjunto, con excepción de cuatro fragmentos que mostraron mineralización leve, ni precipitaciones de carbonato de calcio y/o manganeso (Figura 8.11).

Se identificaron marcas en 131 especímenes, entre éstas las más abundantes son las marcas de raíz, presentes sobre las superficies de 122 fragmentos óseos. Los restantes agentes se encuentran poco 
representados, probablemente por la alta incidencia de las raíces por un lado y la alta fragmentación de la muestra por otro, que dificultan su identificación. En tal sentido, se observó una sola marca producida por un carnívoro, una que no pudo ser determinada y siete especímenes con huellas antrópicas, seis en fragmentos de diáfisis y una sobre un hueso del tarso o carpo probablemente de guanaco, que no pudo ser determinado con precisión debido al mal estado de conservación del mismo. En 904 especímenes no pudo evaluarse la presencia de marcas debido al grado de fragmentación de la muestra (fragmentos menores al 5\%) o el grado de alteración estructural de los materiales (Figura 8.12).

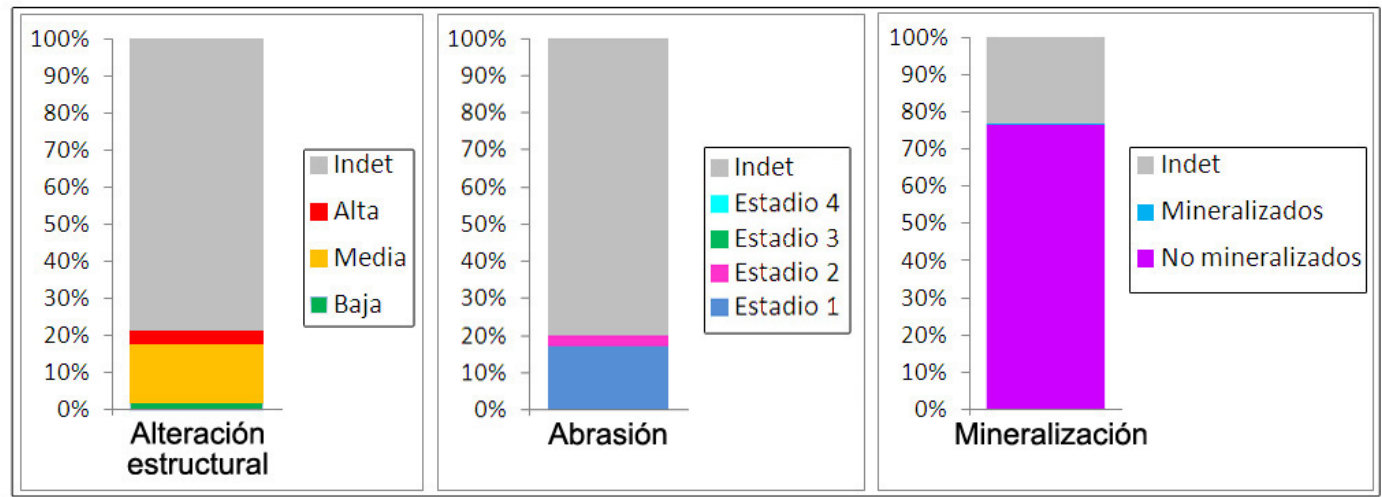

Figura 8.11. Principales modificaciones producto de la acción de agentes y procesos postdepositacionales, representadas en los especímenes óseos procedentes del sitio La Montaña 1.
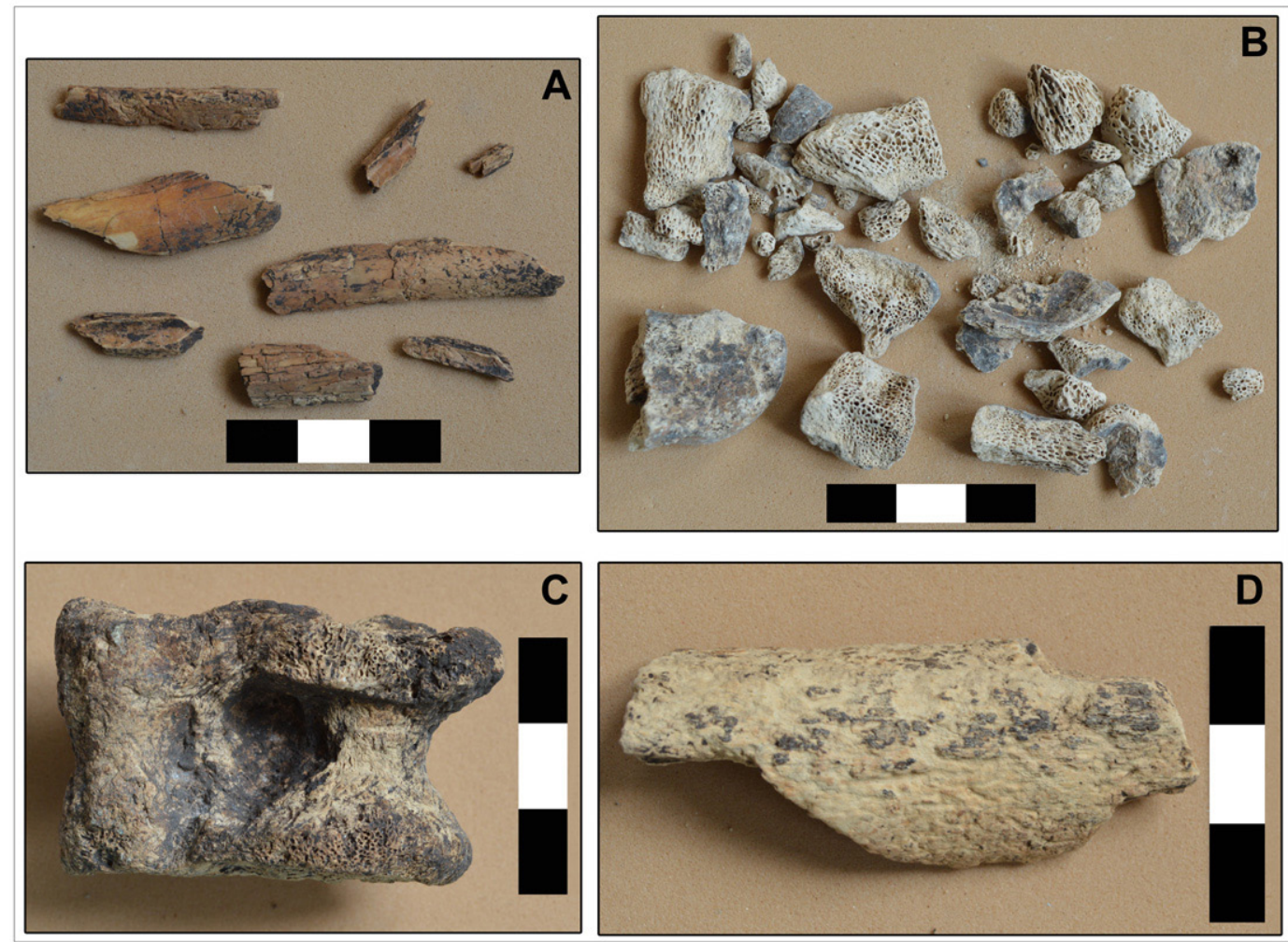

Figura 8.12. Estado de conservación de la muestra ósea procedente del sitio La Montaña 1. A- Fragmentos indeterminables con alteración estructural media; B- Fragmentos indeterminables con alteración estructural alta; C- Astrágalo con alteración estructural alta y marcas de raíz y roedor; D Fragmentos de diáfisis con alteración estructural alta y marcas de raíz. 


\subsubsection{Laguna Los Chilenos}

\subsubsection{Los Chilenos sitio 2}

Los materiales óseos faunísticos analizados proceden de las excavaciones realizadas en el sitio 2 y de recolecciones superficiales llevadas a cabo en sus inmediaciones, los que fueron analizados en conjunto con F. Oliva y N. Morales en el marco de los respectivos proyectos de tesis doctorales (Morales et al. 2012; Oliva 2014). Los materiales recuperados en estratigrafía consisten en 1941 fragmentos óseos, 156 fragmentos de diente y nueve placas de dasipódidos, recuperados la mayor densidad en la cuadrícula 1 , entre los niveles 14 y 19 y, en la cuadrícula 2 en los niveles 17 a 21 (Figura 8.13).

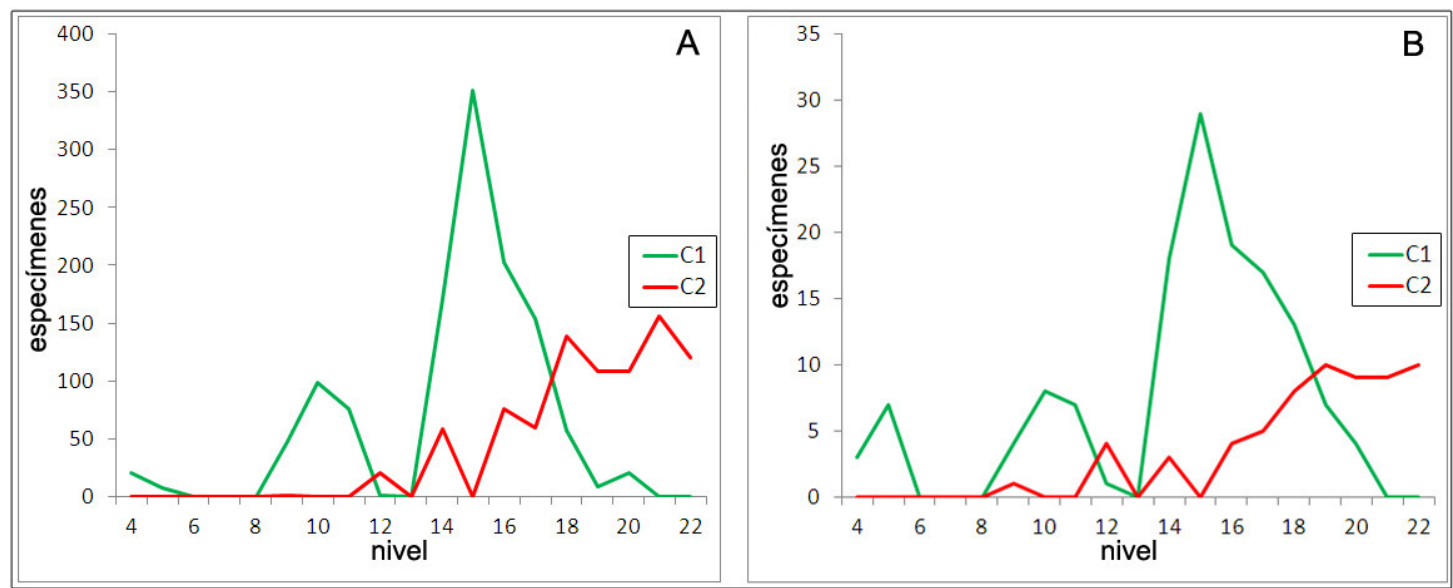

Figura 8.13. Cantidad de especímenes óseos por nivel estratigráfico en el sitio Los Chilenos 2 estratigrafía. A- Densidades de especímenes determinables e indeterminables (NSP); B- Densidades, únicamente, de aquellos especímenes determinables (NISP).

De entre los 1941 restos óseos, 108 especímenes pudieron ser asignados a algún nivel anatómico y/o taxonómico, en tanto los restantes fragmentos, dada su alta fragmentación, no pudieron ser identificados. La especie Lama guanicoe se encuentra representada por al menos un individuo con un NISP de 41, del que se encuentran presentes casi de manera exclusiva elementos correspondientes a las extremidades. También se encuentran varios fragmentos de diáfisis de hueso largo y un fragmento de vértebra que, si bien no pudieron ser determinados a nivel específico por la ausencia de rasgos diagnósticos, asignándolos a mamífero mediano a grande, probablemente correspondan también a Lama guanicoe. Las especies de menor porte se hallan poco representadas, encontrándose solo elementos asignables a roedor y placas de dasipódido, estas últimas en bajo número (Tabla 8.3). 


\begin{tabular}{|c|c|c|c|c|c|c|c|c|c|c|}
\hline Taxón & L gua & nicoe & Artiod & actylia & $\begin{array}{c}\text { mam } \\
\text { med }\end{array}$ & $\begin{array}{l}\text { ífero } \\
\text { iano } \\
\text { nde }\end{array}$ & $\begin{array}{r}\text { Mam } \\
\text { pequ }\end{array}$ & $\begin{array}{l}\text { ífero } \\
\text { leño }\end{array}$ & & et. \\
\hline Elemento & NME & NISP & NME & NISP & NME & NISP & NME & NISP & NME & NISP \\
\hline diente/molar & & & 2 & 16 & & & 3 & 31 & & 137 \\
\hline hemandíbula & & & & & & & 2 & 10 & & \\
\hline atlas & & & & & & & 1 & 1 & & \\
\hline vértebra & 2 & 3 & & & 1 & 1 & 2 & 2 & & \\
\hline húmero & 1 & 1 & & & & & 1 & 1 & & \\
\hline radio-cúbito & 1 & 1 & & & & & & & & \\
\hline fémur & 1 & 1 & & & & & 1 & 1 & & \\
\hline tibia & 1 & 2 & & & & & & & & \\
\hline metatarso & 1 & 5 & & & & & & & & \\
\hline metapodio & 1 & 18 & & & & & & & & \\
\hline calcáneo & 1 & 2 & & & & & & & & \\
\hline falange & 2 & 3 & & & & & & & & \\
\hline hueso largo & 1 & 5 & & & 2 & 50 & & & & 14 \\
\hline placa & & & & & & & & 9 & & \\
\hline indeterminado & & & & & & 1 & & & & 1819 \\
\hline total general & 12 & 41 & 2 & 16 & 3 & 52 & 10 & 55 & & 1970 \\
\hline
\end{tabular}

Tabla 8.3. Diversidad taxonómica representada en el sitio Los Chilenos 2.

La fragmentación presenta un índice NSP:NISP de 35,94, dado por 54 especímenes identificables sobre un total de 1941 especímenes. La alteración estructural de la muestra es baja en la mayor parte de los especímenes $(n=237)$, encontrándose solo 30 especímenes con alteración media, en tanto en los 1674 fragmentos restantes, esta no pudo determinarse debido al pequeño tamaño de los fragmentos. La abrasión es baja en la mayor parte de los especímenes en los que pudo ser medida $(n=208)$, con estadios medios y altos de abrasión en solo 7 y 11 especímenes respectivamente, en tanto en 1715 no fue medida por su tamaño. Por último, 10 especímenes presentan precipitaciones de carbonato de calcio en menos del $25 \%$ de su superficie y 186 se encuentran mineralizados, en tanto 144 no presentan evidencias de mineralización y en 1804 fragmentos, esta no pudo ser medida (figuras 8.14 y 8.15).

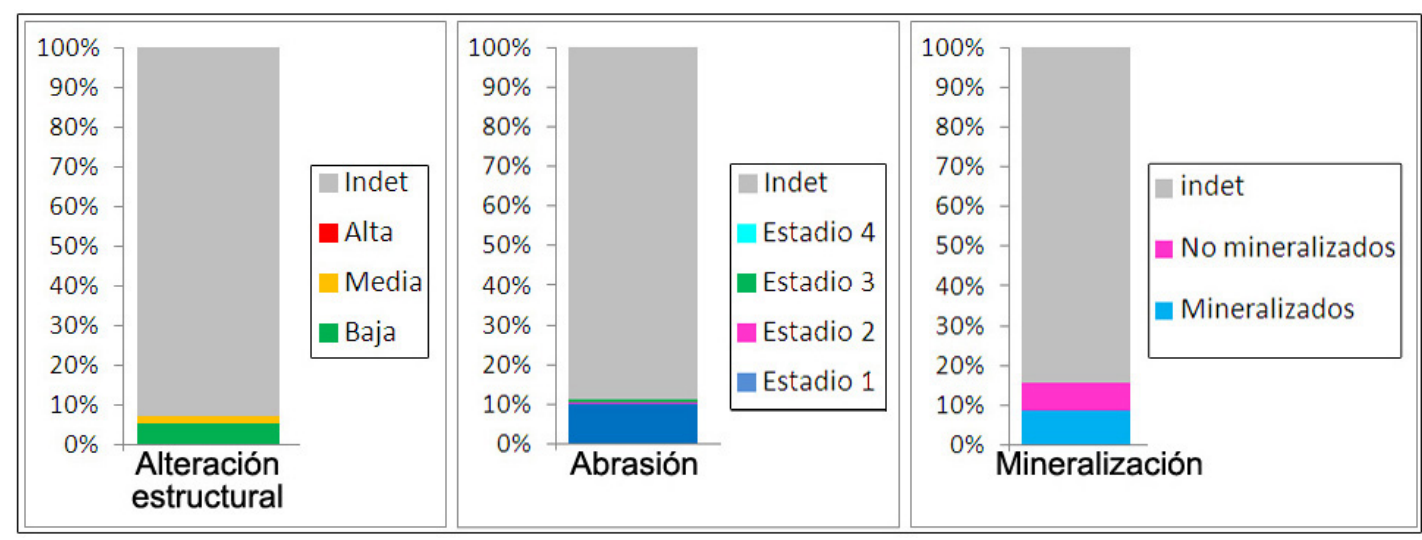

Figura 8.14. Principales modificaciones producto de la acción de agentes y procesos postdepositacionales, representadas en los especímenes óseos procedentes del sitio Los Chilenos 2 estratigrafía. 
En relación con las marcas representadas en la muestra, únicamente aquellos elementos determinados como L. guanicoe o mamífero mediano/grande presentan marcas antrópicas, a los que se suman especímenes que por su tamaño no pudieron ser determinados, no encontrándose este tipo de marcas en los elementos correspondientes a las especies de menor porte. También se pudo identificar la presencia de marcas producto de la acción de las raíces en 19 especímenes y correspondientes a carnívoro y roedor en 16 especímenes en cada caso, a los que se suman tres fragmentos con marcas cuyo agente no pudo ser identificado. (Figura 8.15).

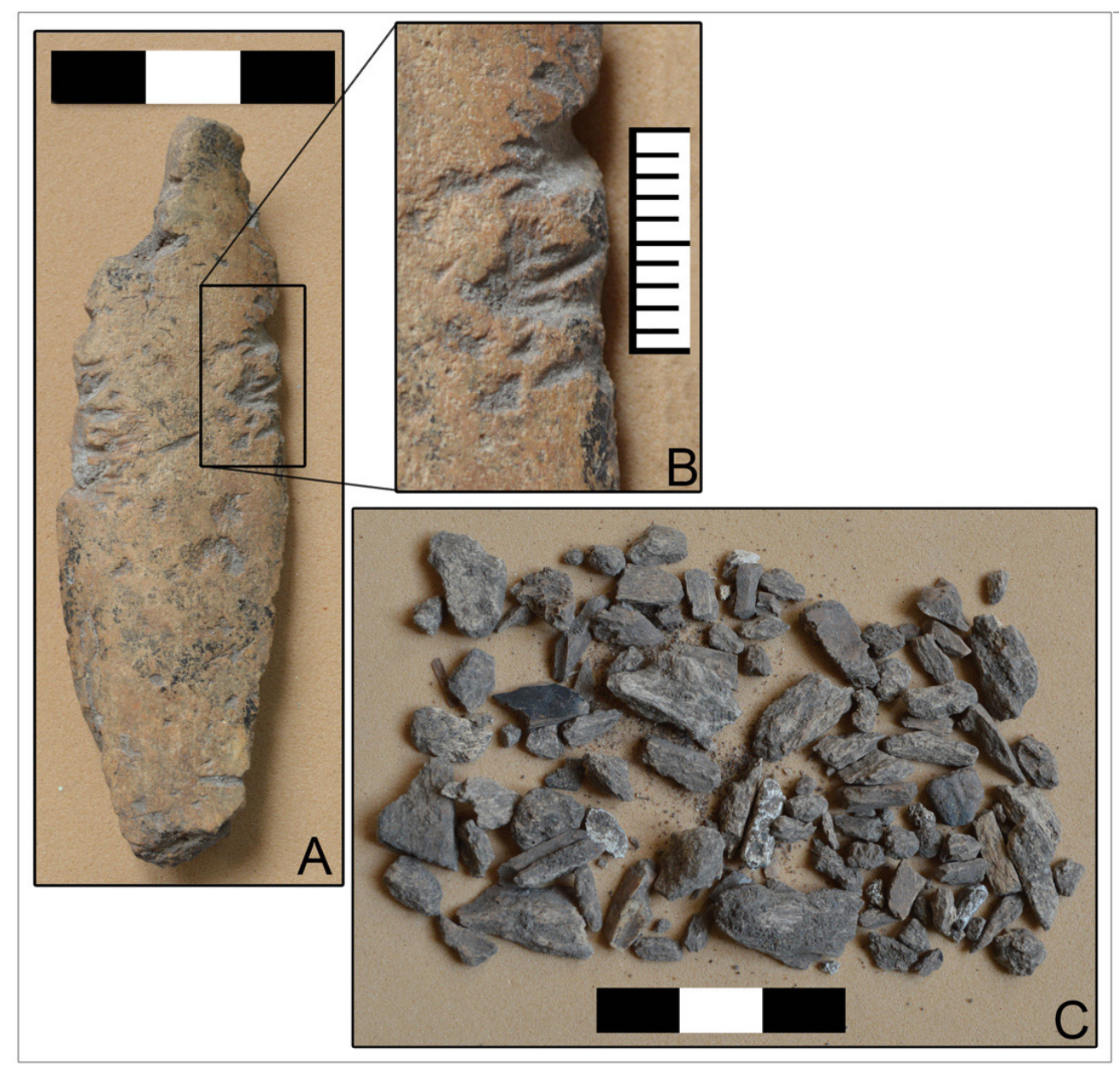

Figura 8.15. Estado de conservación de la muestra ósea procedente del sitio Los Chilenos 2 estratigrafía. A. Fragmento de diáfisis con alteración estructural baja y marcas de roedor; BDetalle de las marcas de roedor; C- Especímenes altamente fragmentados.

En superficie, por otra parte, se analizaron 61 fragmentos óseos y 7 fragmentos de diente y/o molar, procedentes de las unidades de recolección $\mathrm{M}$ a U. La mayor densidad de materiales se encuentra en las unidades $\mathrm{N}, \mathrm{R}$ y O (con cantidades decrecientes), en tanto en las unidades $\mathrm{P}$ y S y no registró la presencia de material óseo. En esta muestra todos los especímenes identificados corresponden a Lama guanicoe ( $\mathrm{n}=11)$ o mamífero mediano/grande $(\mathrm{n}=25)$, con excepción de una diáfisis de hueso largo de ave. Se encuentran marcas de corte en 16 fragmentos óseos, identificados como L. guanicoe $(\mathrm{n}=1)$, mamífero mediano/grande $(n=12)$ y mamífero indet $(n=3)$. Las marcas de raíz se encuentran poco representadas $(n=6)$ así como las de carnívoro y roedor (2 especímenes en cada caso). 


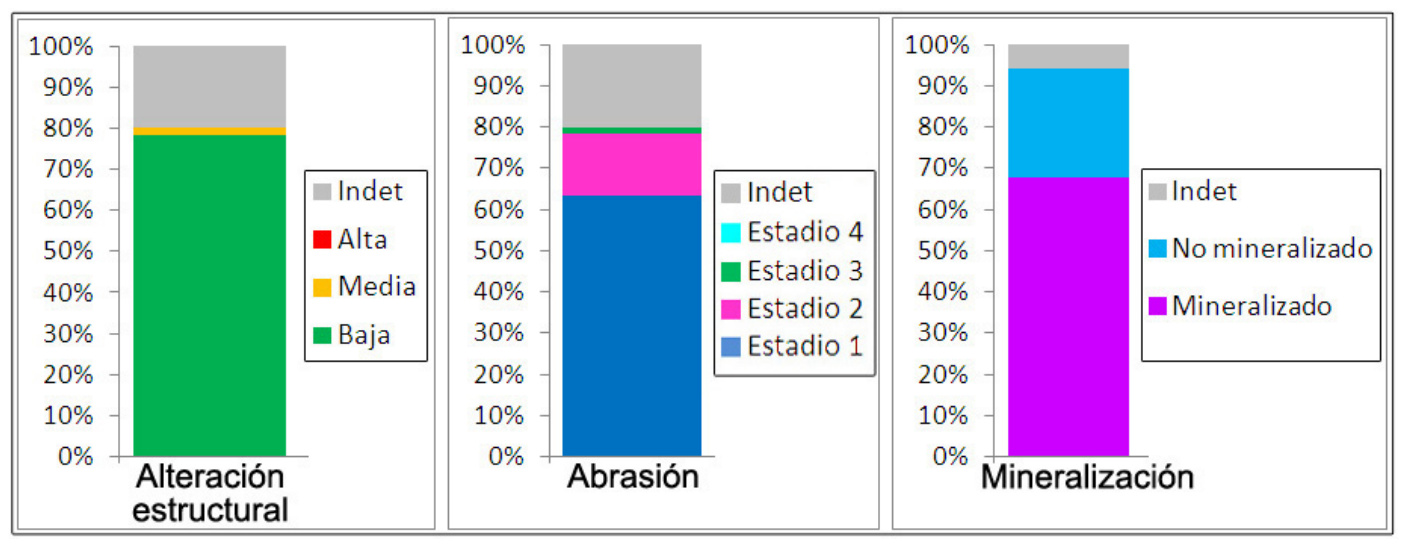

Figura 8.16. Principales modificaciones producto de la acción de agentes y procesos postdepositacionales, representadas en los especímenes óseos procedentes del sitio Los Chilenos 2 superficie.

Debido a que se trata de una muestra de superficie, son escasos los fragmentos indeterminables de pequeño tamaño, observándose una relación NSP:NISP de 4,46. La alteración estructural, también en este caso es baja $(n=47)$, con solo un especímen con grado medio y ninguno con un alto grado. A pesar de tratarse de un conjunto recuperado en superficie, sobre las costas de una laguna, la mayor parte de los materiales presenta un bajo grado de abrasión (estadio 1=38), encontrándose los estadios 2 y 3 escasamente representados ( $n=9$ y 1 respectivamente) (figuras 8.16 y 8.17). En relación con la mineralización, el 67\% de la muestra presenta evidencias de mineralización, el 26\% no está mineralizada y en el $6 \%$ restante no fue medida por el tamaño de los fragmentos (Figura 8.16). Ningún fragmento presenta precipitación de carbonato de calcio o manganeso.

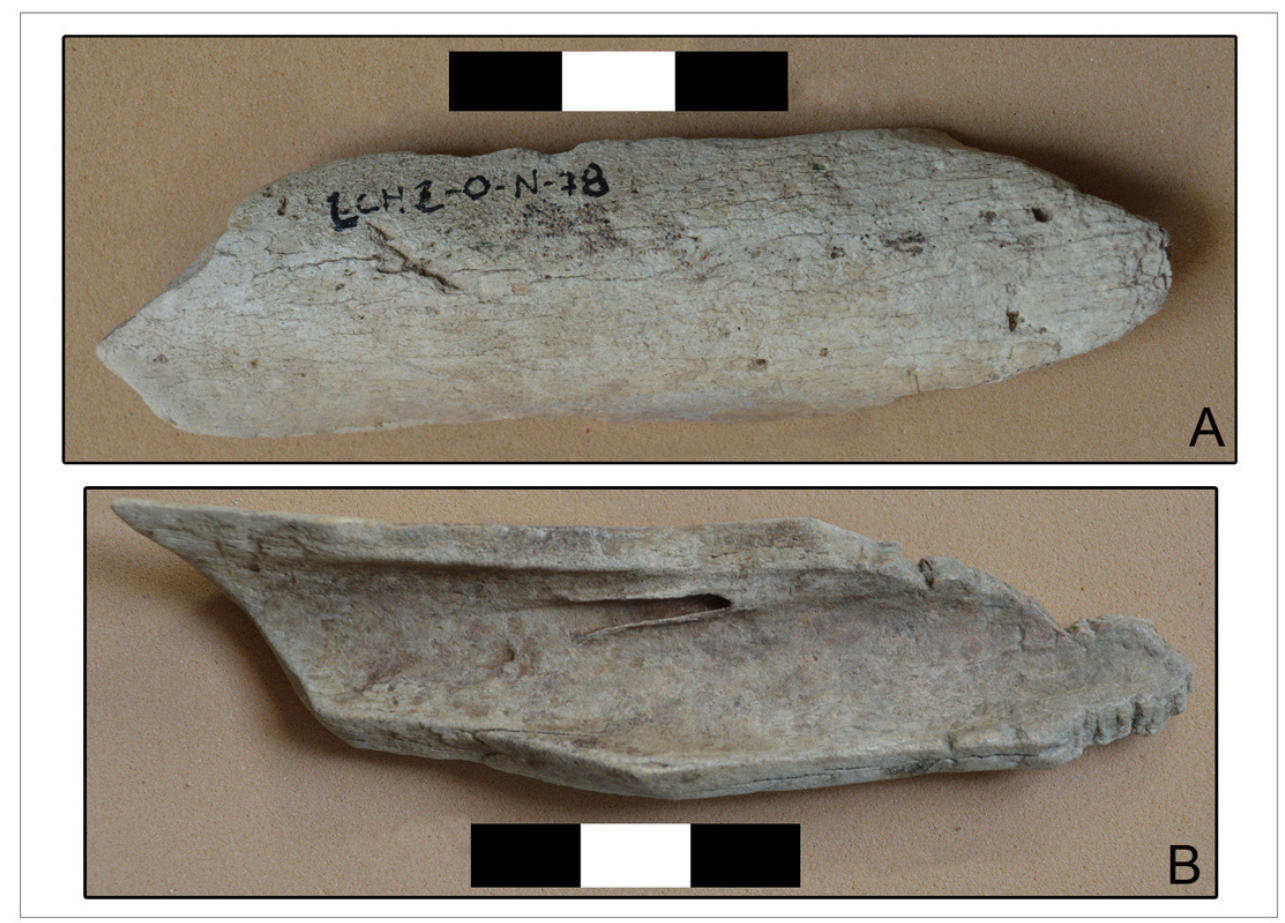

Figura 8.17. Estado de conservación de la muestra ósea procedente del sitio Los Chilenos 2 superficie. Fragmentos de diáfisis con alteración y abrasión media. En el extremo derecho de B se observan a su vez marcas de roedor. 


\subsubsection{Localidad San Martín}

\subsubsection{San Martín sitio 1}

En este caso también, los materiales fueron analizados en conjunto con F. Oliva y N. Morales en el marco de los respectivos proyectos de tesis doctorales (Morales et al. 2012; Oliva 2014). El registro arqueofaunístico de este sitio se encuentra compuesto por 8801 fragmentos óseos y 201 fragmentos de diente y/o molar, a los que se suman placas de dasipódidos, cáscaras de huevo de ñandú y cuatro caracoles marinos Voluta sp. y Adelomelon brasiliana (recuperados tres en estratigrafía y uno en superficie). La mayor densidad de los materiales faunísticos se encuentra entre los niveles 7 y 15, hallándose el pico de máxima densidad entre los niveles 8 y 10 (35 a $50 \mathrm{~cm}$ de profundidad). Horizontalmente, los materiales tampoco presentan una distribución homogénea, encontrándose la mayor concentración en las cuadrículas 1 a 4 y 9 a $11(92 \%)$ y dentro de estas, en el sector sur, coincidentemente con la distribución de la unidad estratigráfica $\mathrm{B}$, con la que se asocia el $81 \%$ de aquellos restos óseos a los cuales se les asignó unidad estratigráfica. Las cuadrículas 5 a 8 por otra parte, no sólo presentan menor densidad de materiales por $\mathrm{m}^{3}$ sino que el grado de fragmentación también es mayor (Figura 8.18; Oliva et al. 2010a).

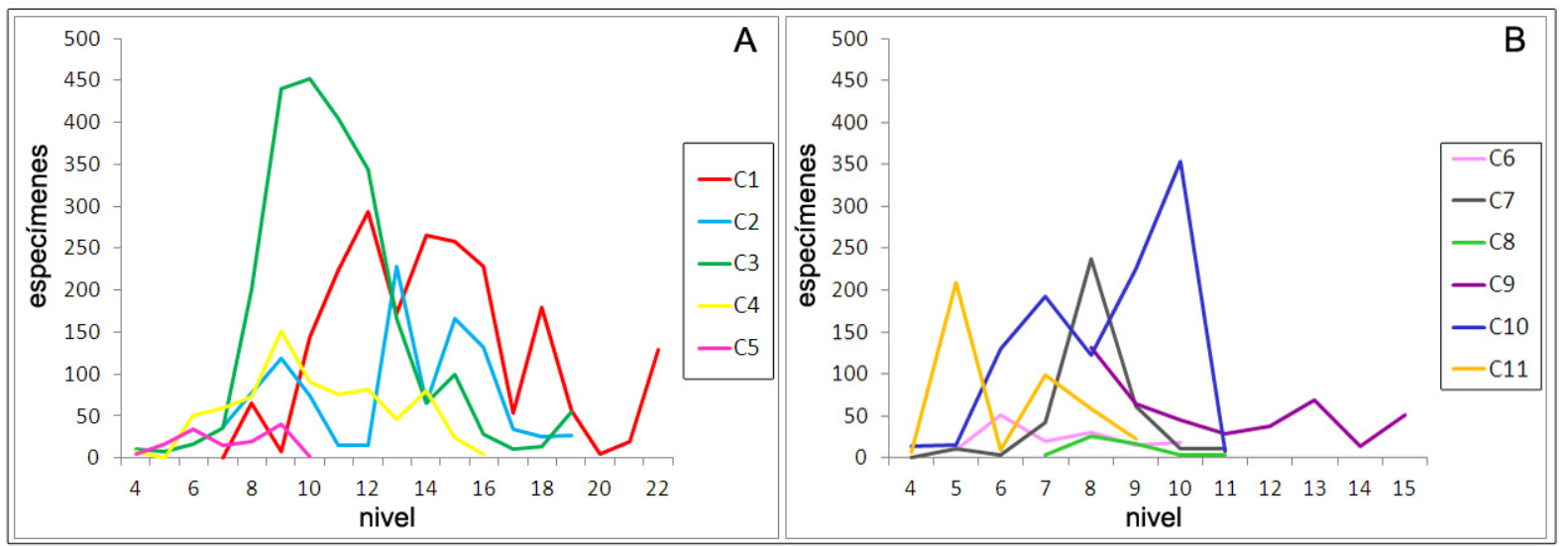

Figura 8.18. Cantidad de especímenes óseos (determinables e indeterminables) por nivel estratigráfico en el sitio San Martín 1. A- cuadrículas 1 a 5; B- cuadrículas 6 a 11.

El material faunístico fue identificado a algún nivel anatómico o taxonómico en el 25\% de los casos, en tanto el 75\% de los especímenes no pudo ser determinado por tratarse de fragmentos no diagnósticos. Entre los taxa identificados se encuentran Lama guanicoe, con un NMI de 5, calculado sobre la base de escápulas derechas correspondientes a tres individuos adultos y dos juveniles, Ozotoceros bezoarticus, con un NMI de 2 calculado a partir de astrágalos y calcáneos derechos, Rhea americana con un NMI de 1 y entre las especies de menor porte Lagostomus maximus y Dolichotis patagonum, todas con huellas de origen antrópico, a los que se suman algunos elementos asignables a carnívoro (Lycalopex gymnocercus y elementos correspondientes a carnívoro indeterminado), dasipódidos (Chaetophractus villosus, Dasypus hybridus), una hemimandíbula de Lestodelphys halli y un grupo numeroso identificado como 
roedores, los cuales aún no han sido determinados a nivel específico (Tabla 8.4; Oliva et al. 1991b; Oliva et al. 2010a; Oliva 2014). Entre las marcas representadas, además de las huellas de origen antrópico mencionadas, presentes en un total de 57 especímenes correspondientes, en mayor proporción, a $L$. guanicoe, se encuentran también marcas de raíces, roedor, carnívoro y algunas a las que no se les pudo asignar un origen específico (Tabla 8.5; Figura 8.19).

\begin{tabular}{|c|c|c|c|c|c|c|c|c|c|c|c|c|c|c|c|c|}
\hline \multirow{2}{*}{$\begin{array}{l}\text { Taxón } \\
\text { Elemento } \\
\end{array}$} & \multicolumn{2}{|c|}{ L. guanicoe } & \multicolumn{2}{|c|}{$\begin{array}{c}o . \\
\text { bezoarticus }\end{array}$} & \multicolumn{2}{|c|}{$\begin{array}{c}\text { M. } \\
\text { mediano } \\
\text { grande }\end{array}$} & \multicolumn{2}{|c|}{$\begin{array}{c}\text { M. } \\
\text { mediano } \\
\text { pequeño }\end{array}$} & \multicolumn{2}{|c|}{$\begin{array}{c}\text { M. } \\
\text { pequeño }\end{array}$} & \multicolumn{2}{|c|}{ M. indet } & \multicolumn{2}{|c|}{ Aves } & \multicolumn{2}{|c|}{$\begin{array}{c}\text { Anura } \\
\text { indet }\end{array}$} \\
\hline & NME & NISP & NME & NISP & NME & NISP & NME & NISP & NME & NISP & NME & NISP & NME & NISP & NME & NISP \\
\hline cráneo frag & 1 & 1 & & & & 16 & & & & & & 6 & & & & \\
\hline hemimandíbula & & & & & & & 6 & 9 & 23 & 77 & & 5 & & & & \\
\hline bula auditiva & 2 & 12 & & & 3 & 3 & & & 1 & 1 & & & & & & \\
\hline diente & 1 & 3 & & & 3 & 13 & 1 & 1 & 35 & 98 & & 15 & & & & \\
\hline molar & 4 & 9 & & & 3 & 33 & 3 & 7 & 1 & 4 & 1 & 3 & & & & \\
\hline atlas & 1 & 1 & & & 1 & 1 & 2 & 4 & & & & & & & & \\
\hline axis & 1 & 1 & & & & & & & & & 1 & 2 & & & & \\
\hline vertebras & 14 & 27 & 2 & 2 & 5 & 50 & 4 & 4 & 10 & 12 & 1 & 10 & 2 & 3 & & \\
\hline escápula & 7 & 92 & 2 & 2 & 2 & 25 & & & 2 & 5 & & 1 & 1 & 1 & & \\
\hline coracoides & & & & & & & & & & & & & 2 & 2 & & \\
\hline costilla & 17 & 69 & & & 12 & 212 & 1 & 3 & 1 & 3 & 2 & 21 & & & & \\
\hline esternon & & & & & 1 & 3 & & & & & & & 1 & 200 & & \\
\hline esternebra & 2 & 2 & & & 3 & 3 & & & & & & & & & & \\
\hline Húmero & 2 & 2 & & & 1 & 3 & 2 & 2 & 6 & 16 & & & & & 1 & 1 \\
\hline radiocúbito & 2 & 3 & & & & & 1 & $2 *$ & 2 & $4^{*}$ & & & 2 & $8^{*}$ & & \\
\hline carpos & 13 & 13 & 3 & 3 & & & & & 1 & 1 & & & & & & \\
\hline metacarpo & 1 & 1 & 1 & 1 & & & & & & & & & & & & \\
\hline pelvis fr & 1 & 2 & & & 1 & 1 & & & & & & & & & & \\
\hline fémur & 2 & 5 & & & 1 & 45 & 2 & 3 & 20 & 35 & 2 & 2 & & & 1 & 3 \\
\hline rótula o patella & 1 & 1 & & & & & 1 & 1 & & & & & & & & \\
\hline tibia & 4 & 7 & 1 & 1 & 2 & 3 & 5 & 7 & 10 & 17 & & & & & & \\
\hline astrágalo & 2 & 2 & 2 & 2 & & & & & 1 & 1 & & & & & & \\
\hline calcáneo & 4 & 5 & 2 & 2 & 1 & 1 & 1 & 1 & 1 & 1 & & & & & & \\
\hline tarsos & 11 & 12 & 7 & 7 & & & & & & & & & & & & \\
\hline metatarso & 3 & 3 & 2 & 5 & & & 2 & 3 & & & & & & & & \\
\hline falange & 12 & 15 & 9 & 9 & 3 & 5 & 3 & 3 & 21 & 22 & 1 & 1 & & & & \\
\hline metapodio & 8 & 47 & 1 & 1 & 1 & 1 & 1 & 1 & 2 & 4 & & & & & & \\
\hline hueso largo df & & & 1 & 1 & 10 & 260 & 1 & 6 & 3 & 71 & & 101 & & 9 & & \\
\hline Indeterminado & & & & & & 50 & & 14 & & 108 & & \begin{tabular}{|l|l|}
6836 \\
\end{tabular} & & & & \\
\hline
\end{tabular}

Tabla 8.4. Diversidad taxonómica representada en el sitio San Martín 1. * radio.

\begin{tabular}{|l|r|r|r|r|r|}
\hline Taxón & Antrópicas & Raíz & Carnívoro & Roedor & Indet. \\
\hline Lama guanicoe & 32 & 8 & 1 & 1 & 6 \\
\hline Ozotoceros bezoarticus & 5 & 7 & & & 1 \\
\hline Mamífero mediano / grande & 9 & 11 & & 1 & 3 \\
\hline Mamífero mediano / pequeño & 2 & 2 & & 1 & \\
\hline Mamífero pequeño & & 1 & & & \\
\hline Aves & 2 & 2 & & & \\
\hline Indeterminado & 7 & 5 & & & \\
\hline
\end{tabular}

Tabla 8.5. Modificaciones de las superficies óseas presentes en el sitio San Martín 1 diferenciadas por agente efector y por taxón en que se encuentran. 


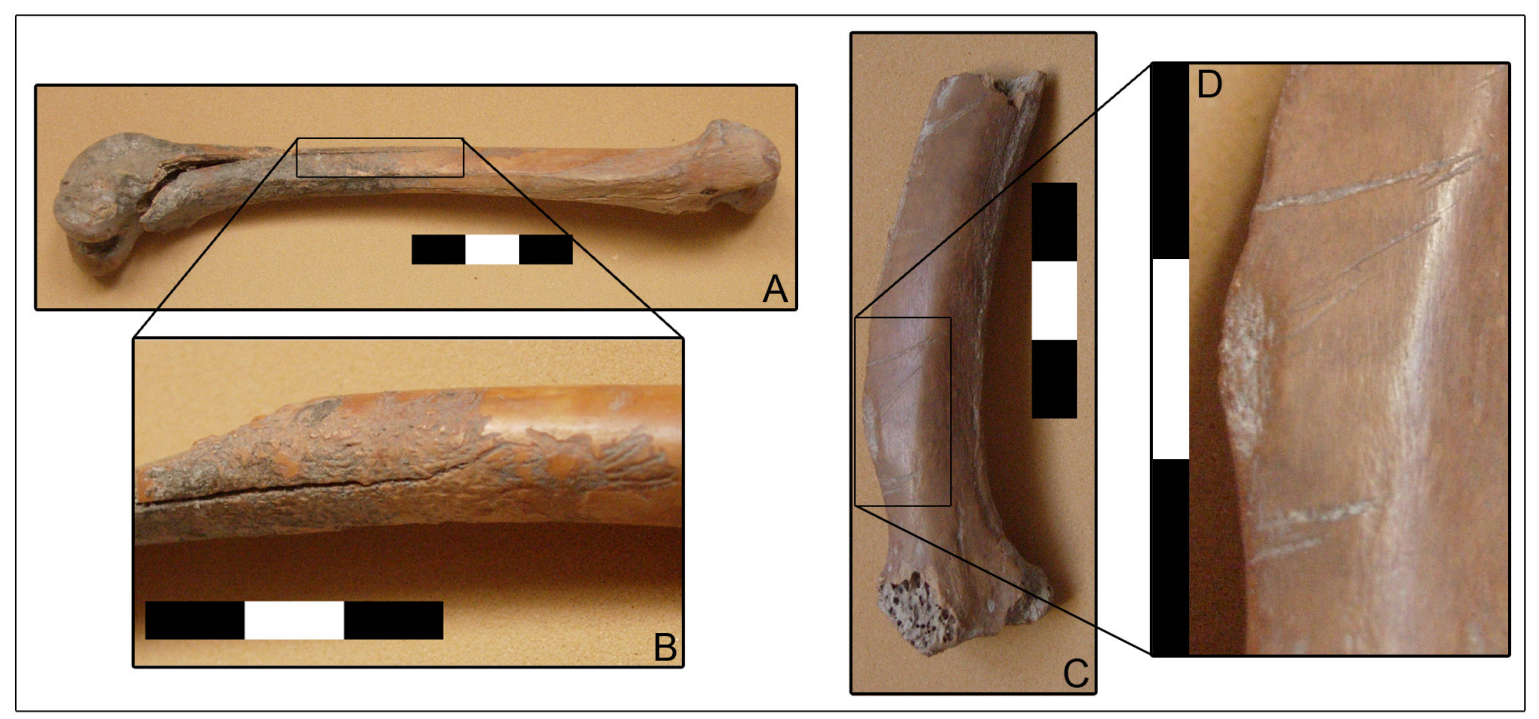

Figura 8.19. Marcas presentes sobre las superficies óseas de los conjuntos del sitio San Martín 1. A y B- Marcas de raíz; C y D- Marcas de corte. Fotos: J. Moirano.

La muestra presenta, comparativamente, un bajo grado de fragmentación, con 1187 especímenes determinables del total de 8801 fragmentos óseos, obteniéndose una razón NSP:NISP de 7,41. La alteración estructural fue determinada en el $25 \%$ de la muestra, donde predomina el grado bajo ( $\mathrm{n}=$ $1704)$, seguido por el medio $(n=437)$ y alto $(n=12)$. La abrasión producto de la acción hídrica también es baja, predominando el estadio $1(\mathrm{n}=1293)$ y en menor número los estadios 2 y 3 , con un $\mathrm{n}$ de 39 y 48 respectivamente (figuras 8.20 y 8.21). La mineralización es muy baja, solo el 1,5\% de la muestra presenta evidencias de mineralización, en tanto el 71\% no muestra signos de mineralización (Figura 8.20). Las precipitaciones de carbonato de calcio sobre los huesos son escasas, presentes solo en el $4 \%$ de la muestra y cubriendo, en la mayor parte de los casos, menos del $25 \%$ de la superficie total del especímen. Solo se registraron manchas de manganeso en un especímen.
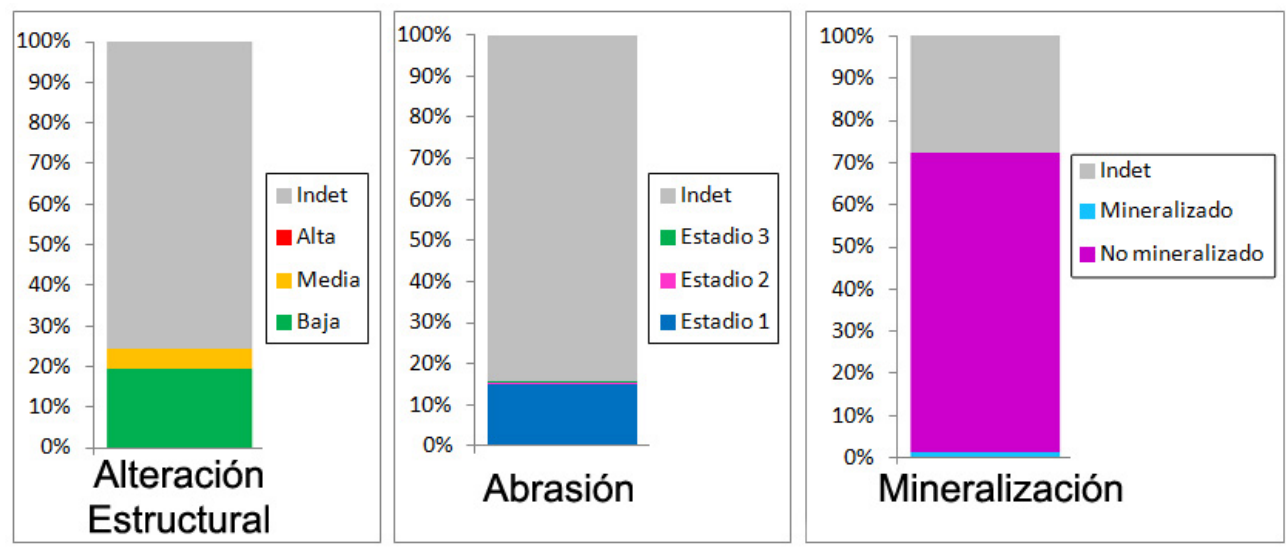

Figura 8.20. Principales modificaciones producto de la acción de agentes y procesos postdepositacionales, representadas en los especímenes óseos procedentes del sitio San Martín 1. 


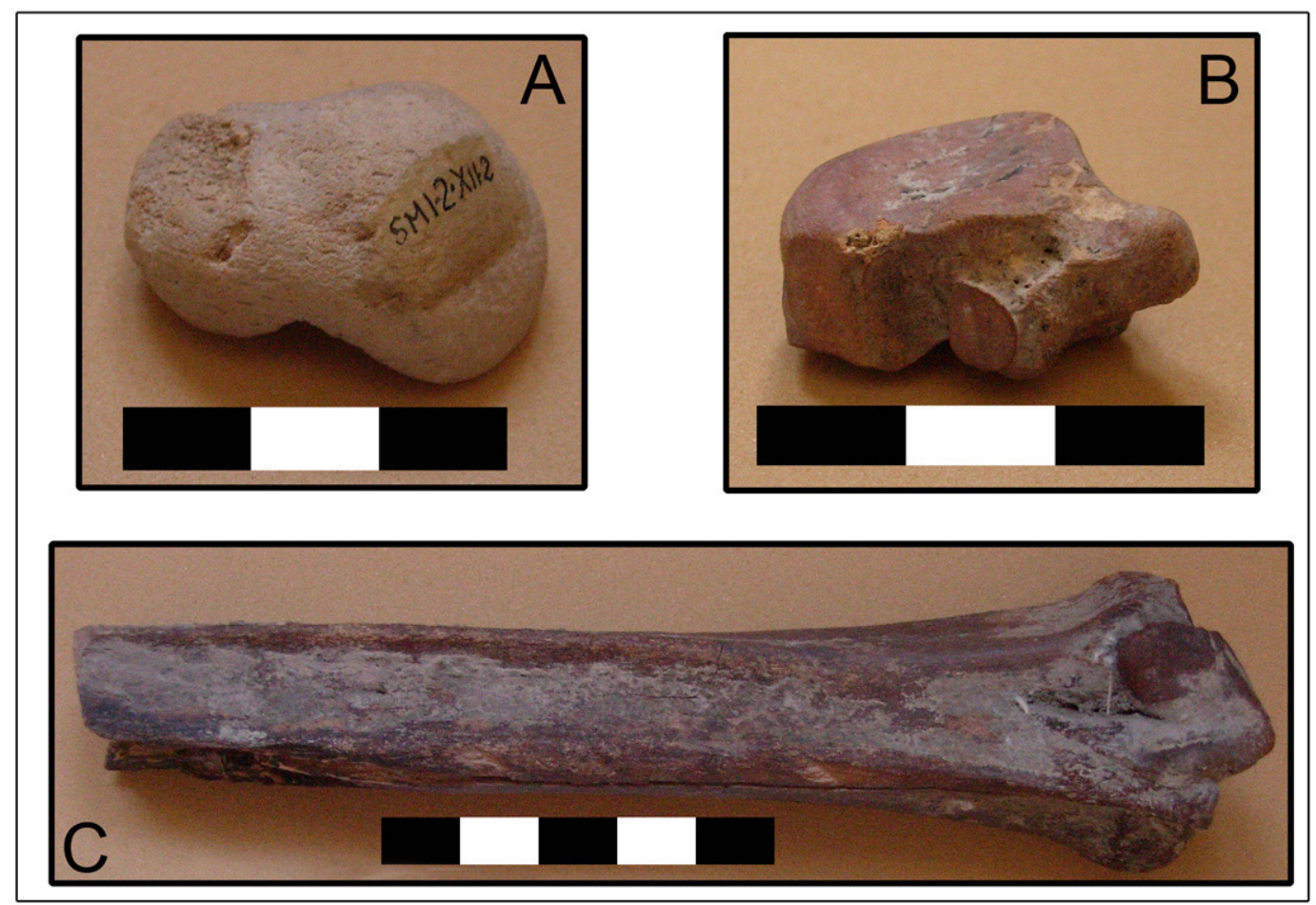

Figura 8.21. Estado de conservación de la muestra ósea procedente del sitio. A- Alteración estructural alta y abrasión alta; B- Alteración estructural baja; C- Alteración estructural baja y precipitación de carbonato de calcio. Fotos: J. Moirano.

\subsubsection{Laguna Chasicó}

\subsubsection{Laguna Chasicó sitio 1}

Los materiales óseos faunísticos provenientes de este sitio consisten en 137 especímenes óseos y seis fragmentos de diente y/o molar, que fueron recolectados en diferentes ocasiones y empleando diversas metodologías, las que fueron detalladas en el capítulo 6. Algunos $(n=8)$ fueron recolectados por los guardaparques de la reserva, por lo que solo se tiene una ubicación aproximada de ellos. Los restantes especímenes fueron obtenidos por medio de recolecciones sistemáticas desarrolladas por la autora, cuatro de ellos fueron hallados en asociación con otros materiales arqueológicos o aislados, posicionados con GPS y levantados, 34 especímenes se recuperaron dentro de las transectas y/o unidades de recolección y los restantes 95 especímenes corresponden al muestreo 1 (ver Capítulo 6 para un mayor detalle).

Entre las especies representadas se encuentran Lama guanicoe, Bos taurus, Rhea sp, y especímenes no determinados a nivel específico, que fueron clasificados como carnívoro, roedores chicos, medianos y grandes, mamífero chico, mamífero mediano/grande, ave indeterminada y pez indeterminado (tanto para Bos taurus como para los peces se infiere una cronología moderna debido a su estado de conservación, la presencia de marcas de sierra en el caso de B. taurus, y el contexto de asociación). Este conjunto está conformado por un total de 81 especímenes identificables a algún nivel anatómico y/o taxonómico, lo que da una razón NSP:NISP de 1,76. En el mismo se identificaron tres fragmentos correspondientes a mamífero mediano/grande y uno indeterminado con marcas de corte, a los que se suma una diáfisis de hueso largo cortada con sierra eléctrica. Las marcas de raíces se encuentran sobre las superficies 
de 16 especímenes y las de roedor en tres, no observándose marcas de carnívoro pero registrándose 4 marcas cuyo agente efector no pudo ser determinado (Tabla 8.6). En este sitio se recuperaron además, cuatro caracoles marinos -tres voluta y un bivalvo- y tres fragmentos de caracol marino, dos de ellos correspondientes a voluta y uno indeterminado.

\begin{tabular}{|c|c|c|c|c|c|c|c|c|c|c|c|c|c|c|c|c|}
\hline Taxón & $\begin{array}{r}B \\
\text { tau }\end{array}$ & $\begin{array}{l}\text { os } \\
\text { rus }\end{array}$ & $\underset{\text { guan }}{\text { La }}$ & $\begin{array}{l}\text { ma } \\
\text { icoe }\end{array}$ & $\begin{array}{r}N \\
\text { med } \\
\text { gra }\end{array}$ & $\begin{array}{l}\text { I. } \\
\text { lano } \\
\text { nde }\end{array}$ & $\begin{array}{r}\mathrm{M} \\
\text { med } \\
\text { chi }\end{array}$ & $\begin{array}{l}\text { I. } \\
\text { iano } \\
\text { ico }\end{array}$ & M. c & hico & Av & & p & $\mathbf{Z}$ & & det. \\
\hline Elemento & MNE & NISP & MNE & NISP & MNE & NISP & MNE & NISP & MNE & NISP & MNE & NISP & MNE & NISP & MNE & NISP \\
\hline diente/molar & & & & & 1 & 3 & 1 & 3 & & & & & & & & \\
\hline hemimandíbula & & & & & & & 3 & 3 & 1 & 1 & & & & & & \\
\hline coracoides & & & & & & & & & & & 1 & 1 & & & & \\
\hline vertebra & & & & & 1 & 1 & & & & & & & 3 & 32 & & 2 \\
\hline costilla & 1 & 8 & & & 1 & 8 & & & & & & & & & & \\
\hline fémur & & & & & 2 & 3 & & & 2 & 4 & & & & & & \\
\hline tibia & & & & & 2 & 2 & & & & & & & & & & \\
\hline metapodio & & & 1 & 1 & 1 & 1 & 1 & 1 & & & 1 & 1 & & & & \\
\hline hueso largo & & & & & & 19 & & & & & & 1 & & & & 14 \\
\hline indeterminado & & & & & & 1 & & & & 1 & & 1 & 1 & 7 & & 25 \\
\hline
\end{tabular}

Tabla 8.6. Diversidad taxonómica representada en el sitio Laguna Chasicó 1.

La alteración estructural fue medida en 105 especímenes, de los cuales 91 presentan alteración estructural baja y 14 alteración estructural media. En cuanto a la abrasión, de los 67 especímenes en los que fue medida, 98 presentan estadio 1 y uno estadio 2. Predominan a su vez, los fragmentos no mineralizados $(n=83)$ por sobre los mineralizados $(n=41)$, con un total de 19 especímenes en los que ésta no pudo ser determinada (Figura 8.22). A su vez, se encuentran tres fragmentos con precipitación de carbonato en menos del $25 \%$ de su superficie y tres en los que la precipitación ocupa entre el 50 y el $75 \%$ de la superficie, así como 10 especímenes con manchas producidas por óxido de manganeso.

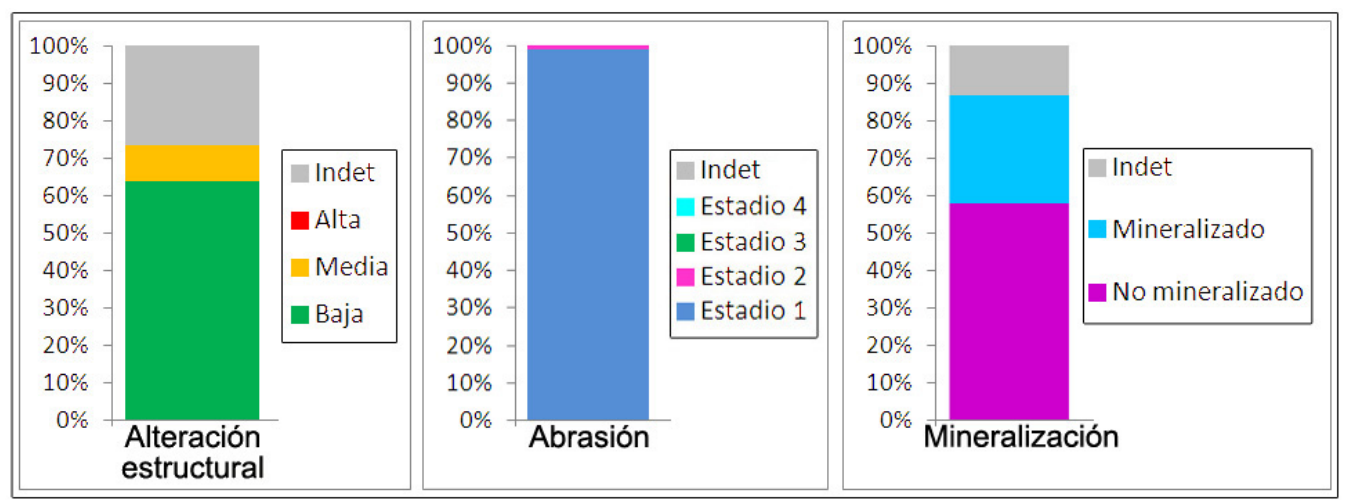

Figura 8.22. Principales modificaciones producto de la acción de agentes y procesos postdepositacionales, representadas en los especímenes óseos procedentes del sitio Laguna Chasicó 1. 


\subsubsection{Laguna Chasicó sitio 2}

Los materiales óseos recolectados en este sitio consisten en 105 especímenes óseos, cuatro fragmentos de diente y 11 placas dérmicas de dasipodido, encontrándose las mayores densidades en las UR 27, 50 y 64 a 67, de los cuales 16 pudieron ser identificados a algún nivel anatómico y/o taxonómico (Tabla 8.7). Entre estos se encuentran 4 fragmentos asignados a L. guanicoe y 12 correspondientes a mamífero mediano/grande, a los que se agregan un diente y un fémur de roedor y tres especímenes de pez que, si bien son actuales, también fueron recolectados como muestra del tipo de materiales hallados. Los restantes 69 especímenes corresponden a fragmentos de hueso largo o indeterminados que no pudieron ser diferenciados taxonómicamente. Las marcas más abundantes son las producidas por efecto de las raíces presentes sobre las superficies de 23 especímenes, también se registraron marcas de roedor $(\mathrm{n}=2)$ y dos marcas de origen antrópico, una producto del uso actual de sierra de carnicero.

\begin{tabular}{|c|c|c|c|c|c|c|c|c|}
\hline Taxón & L. gu & anicoe & $\begin{array}{l}\text { M. me } \\
\text { / gra }\end{array}$ & $\begin{array}{l}\text { diano } \\
\text { inde }\end{array}$ & M. pe & queño & & ez \\
\hline Elemento & MNE & NISP & MNE & NISP & MNE & NISP & MNE & NISP \\
\hline diente & & & 1 & 3 & 1 & 1 & & \\
\hline bula auditiva & & & 2 & 2 & & & & \\
\hline maxilar superior & & & 1 & 1 & & & & \\
\hline hemimandíbula & & & & & & & 1 & 1 \\
\hline escápula & 1 & 1 & 1 & 3 & & & & \\
\hline vértebra & & & & & & & 1 & 1 \\
\hline costilla & & & 1 & 1 & & & & \\
\hline fémur & & & & & 1 & 1 & & \\
\hline metatarso & & & 1 & 1 & & & & \\
\hline metapodio & 1 & 2 & & & & & & \\
\hline tarsos & 1 & 1 & & & & & & \\
\hline falange 2 & & & 1 & 1 & & & & \\
\hline hueso largo & & & 1 & 19 & & 32 & & \\
\hline indeterminado & & & & & & 37 & & \\
\hline placa & & & & & & 11 & & \\
\hline articular? & & & & & & & 1 & 1 \\
\hline
\end{tabular}

Tabla 8.7. Diversidad taxonómica representada en el sitio Laguna Chasicó 2.

Debido a que se trata de una colección de superficie, el número de especímenes determinables (n $=21$ ) en relación con los indeterminables es relativamente alto, lo que da como resultado un índice NSP:NISP de 5,71. La alteración estructural es predominantemente baja $(n=59)$, con solo 3 fragmentos con alteración media. La abrasión también es baja, con 77 fragmentos con estadio 1 de abrasión y solo un fragmento con estadio 2. La mineralización en cambio es elevada, con casi el $40 \%$ de la muestra con evidencias de mineralización ( $n=47)$ y solo el $23 \%$ no mineralizados $(n=28)$, no pudiendo determinarse en los 45 casos restantes dado su pequeño tamaño (Figura 8.23). A su vez cabe destacar que inclusive materiales relativamente modernos, como el fragmento cortado con sierra eléctrica, muestran signos de mineralización, lo que evidencia la rapidez con la que se da este proceso. Cuatro especímenes presentan precipitaciones de carbonato (entre 25 y 75\%), no observándose en ningún caso manchas de manganeso. 


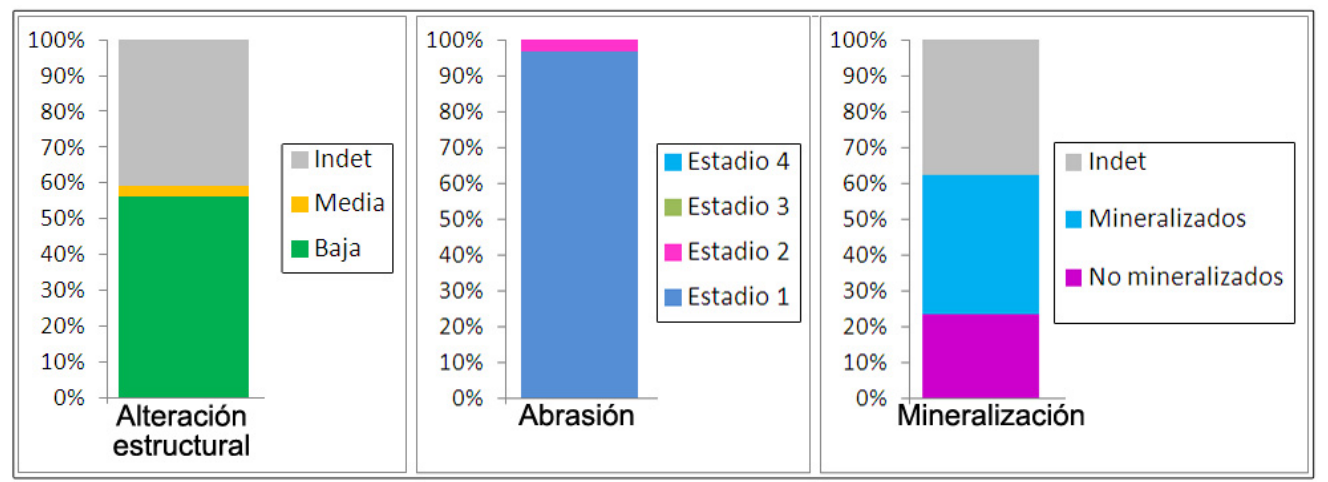

Figura 8.23. Principales modificaciones producto de la acción de agentes y procesos postdepositacionales, representadas en los especímenes óseos procedentes del sitio Laguna Chasicó 2.

\subsubsection{Laguna Chasicó sitio 3}

En este caso, se trata de una muestra ósea pequeña $(n=38)$ a la que se suman tres fragmentos de cáscara de huevo de Rheidos. La mayor parte proviene de las UR 16, 6, 9 y 19 (n 19, 4 y 3 respectivamente), y se encuentra conformada por elementos asignados a Bos taurus y mamífero mediano/grande, con 14 especímenes óseos determinables, lo que da una razón NSP:NISP de 2,71 (Tabla 8.8).

\begin{tabular}{|l|r|r|r|r|r|r|r|r|}
\hline Taxón & \multicolumn{2}{|c|}{ Bos taurus } & \multicolumn{2}{c|}{ M. grande } & \multicolumn{2}{c|}{$\begin{array}{c}\text { M. mediano } \\
\text { /grande }\end{array}$} & \multicolumn{2}{r|}{ M. indet } \\
\hline Elemento & MNE & NISP & MNE & NISP & MNE & NISP & MNE & NISP \\
\hline costilla & 1 & 4 & & 2 & & 0 & & \\
\hline fémur & & & & & 1 & 1 & & \\
\hline hueso largo & & & 1 & 6 & & 0 & & 21 \\
\hline indeterminado & & & & & & & & 4 \\
\hline
\end{tabular}

Tabla 8.8. Diversidad taxonómica representada en el sitio Laguna Chasicó 3.

Se observaron marcas en 9 fragmentos, seis de ellos con marcas antrópicas actuales (cinco producto de sierra eléctrica y uno de cuchillo metálico), a las que se suman dos marcas de raíz y una de carnívoro. La alteración estructural es baja en todos los casos en que se pudo determinar ( $\mathrm{n}=35$ ), lo mismo que la abrasión, la que, con excepción de un fragmento asignado al estadio 2, se encuentra representada únicamente en el estadio 1. La mineralización por su parte, también es relativamente alta, encontrándose 15 fragmentos mineralizados y 21 no mineralizados (en 2 casos no pudo ser determinada), no habiéndose registrado depositaciones de carbonato o manganeso en ninguno de ellos (Figura 8.24).

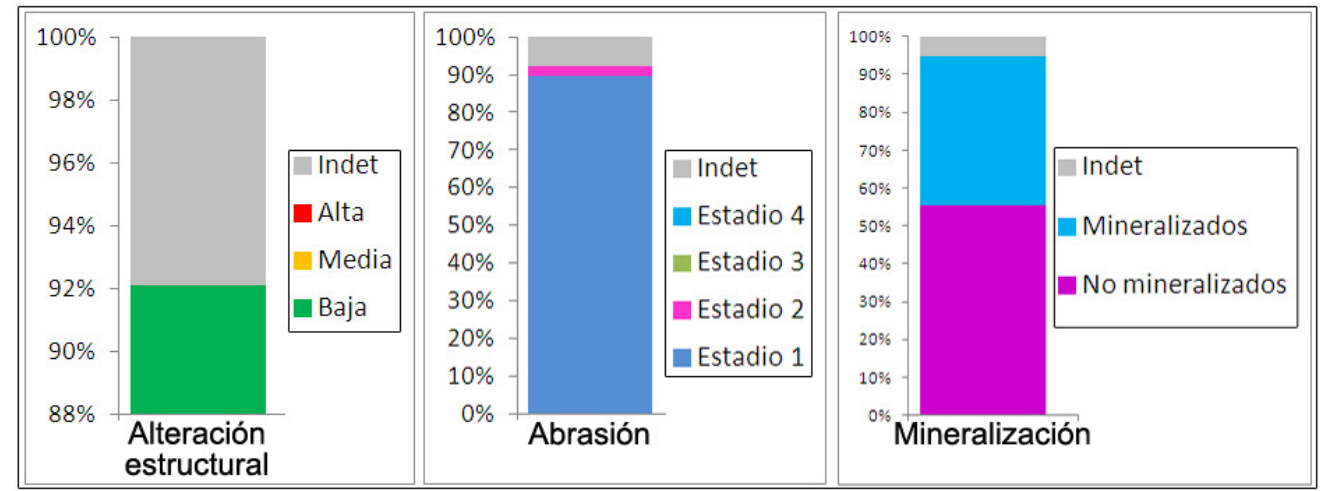

Figura 8.24. Principales modificaciones producto de la acción de agentes y procesos postdepositacionales, representadas en los especímenes óseos procedentes del sitio Laguna Chasicó 3. 


\subsubsection{Laguna Chasicó sitio 4}

En este sitio se recuperaron únicamente 19 fragmentos óseos, la mayor cantidad de los cuales ( $\mathrm{n}=$ 13) corresponde a la UR 3. Entre los taxa identificados se encuentran Bos taurus, Ozotoceros bezoarticus y algunos elementos de mamífero chico y mediano que aún no han sido determinados, a lo que se suma un total de 11 fragmentos indeterminables, dando una relación NSP:NISP de 2,37 (Tabla 8.9).

\begin{tabular}{|c|c|c|c|c|c|c|c|c|c|c|}
\hline Taxón & \multicolumn{2}{|c|}{ Bos taurus } & \multicolumn{2}{|c|}{ O. Bezoarticus } & \multicolumn{2}{|c|}{$\begin{array}{l}\text { M. mediano / } \\
\text { grande }\end{array}$} & \multicolumn{2}{|c|}{ M. chico } & \multicolumn{2}{|c|}{ Indet. } \\
\hline Elemento & MNE & NISP & MNE & NISP & MNE & NISP & MNE & NISP & MNE & NISP \\
\hline calcáneo & & & & & & & 1 & 1 & & \\
\hline cuneiforme & 1 & 1 & & & & & & & & \\
\hline escafoide & 1 & 1 & & & & & & & & \\
\hline falange 2 & & & 1 & 1 & & & & & & \\
\hline fémur & & & & & 1 & 1 & & & & \\
\hline tarso / carpo & 2 & 2 & & & & & & & & \\
\hline hueso largo & & & & & & & & 2 & & \\
\hline indeterminado & & & & & & & & & & 9 \\
\hline pelvis & & & & & 1 & 1 & & & & \\
\hline
\end{tabular}

Tabla 8.9. Diversidad taxonómica representada en el sitio Laguna Chasicó 4.

En ninguno de ellos se observo la presencia de marcas sobre su superficie, la alteración estructural pudo ser determinada en 10 fragmentos, predominando el grado bajo $(n=8)$, con sólo dos fragmentos con alteración media. La abrasión por su parte, también es baja (estadio 1) en todos los casos y la mineralización se encuentra presente en cinco fragmentos, no pudiendo ser determinada en 4 casos (Figura 8.25). Ninguno de los fragmentos muestra depositaciones de carbonato y/o manganeso.

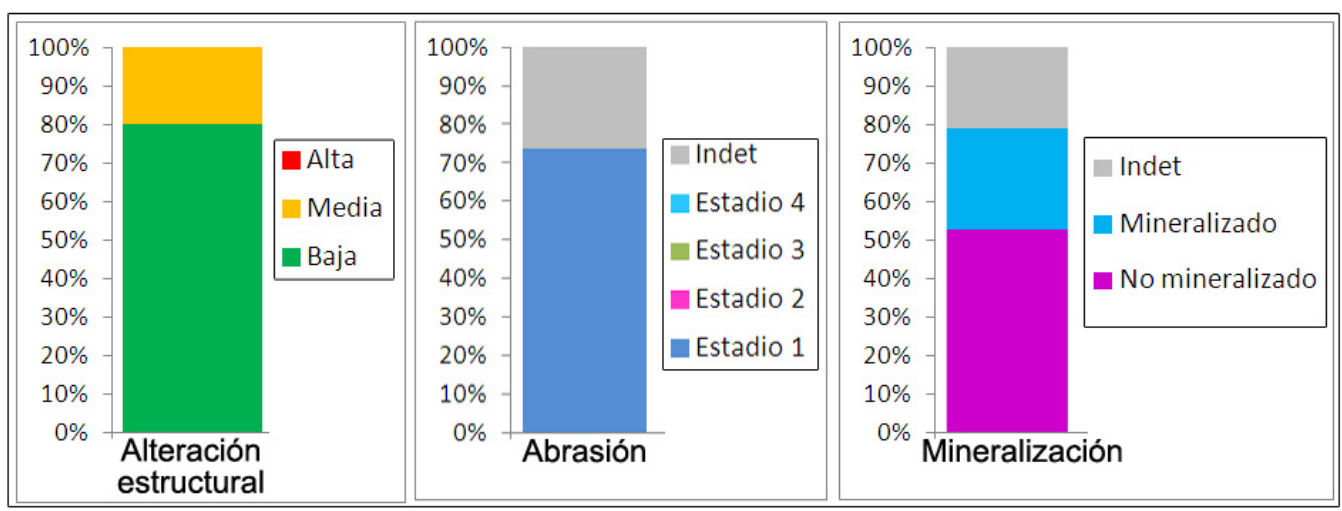

Figura 8.25. Principales modificaciones producto de la acción de agentes y procesos postdepositacionales, representadas en los especímenes óseos procedentes del sitio Laguna Chasicó 4.

\subsubsection{Laguna Chasicó sitio 7}

Los materiales óseos proceden, principalmente, de la UR 33, donde se recuperaron un total de 49 fragmentos óseos, y en menor proporción de las unidades 3, 11, 13, 15, 17, 23, 25, 29 y 31. Entre estos materiales, 20 son determinables, asignados a Ozotoceros bezoarticus, rodentia y mamífero mediano/ grande y chico, con una razón NSP:NISP de 4,9 (Tabla 8.10). Las marcas son escasas, presentes sólo 
en tres fragmentos, en los que el agente efector son las raíces. A ello se suma la presencia de un punzón confeccionado sobre la porción distal de un metapodio de $O$. bezoarticus, en el que se observaron algunas marcas de formatización y/o uso (Figura 8.26).

\begin{tabular}{|c|c|c|c|c|c|c|c|c|c|c|c|c|}
\hline Taxón & B. tal & urus & $\begin{array}{r}O \\
\text { bezoa }\end{array}$ & rticus & $\begin{array}{r}\text { M. me } \\
\text { gra }\end{array}$ & $\begin{array}{l}\text { diano } \\
\text { nde }\end{array}$ & M. c & hico & Av & $\mathbf{e}$ & & \\
\hline Elemento & MNE & NISP & MNE & NISP & MNE & NISP & MNE & NISP & MNE & NISP & MNE & NISP \\
\hline cráneo & & & & & & & & & & 1 & & \\
\hline maxilar sup & & & & & 1 & 1 & & & & & & \\
\hline hemimandíbula & & & & & & & 7 & 10 & & & & \\
\hline diente/molar & & & & & & & 1 & 1 & & & & 1 \\
\hline vértebra & & 2 & & & & & & & & & & \\
\hline escápula & & & & & & & 1 & 1 & & & & \\
\hline costilla & & 10 & & & & & & & & & & \\
\hline húmero & & 1 & & & & & & & & & & \\
\hline radiocubito & 1 & 3 & & & & & & & & & & \\
\hline hueso largo & & & & & 1 & 9 & 2 & 2 & & & & 9 \\
\hline metapodio & 1 & 1 & 1 & 1 & & & & & & & & \\
\hline carpo/tarso & 1 & 1 & & & & & & & & & & \\
\hline fíbula & & & & & & & & & 1 & 1 & & \\
\hline indeterminado & & 10 & & & & 2 & & 1 & & & & 22 \\
\hline cáscara huevo & & & & & & & & & & 23 & & \\
\hline placa & & & & & & & & 1 & & & & \\
\hline
\end{tabular}

Tabla 8.10. Diversidad taxonómica representada en el sitio Laguna Chasicó 7.

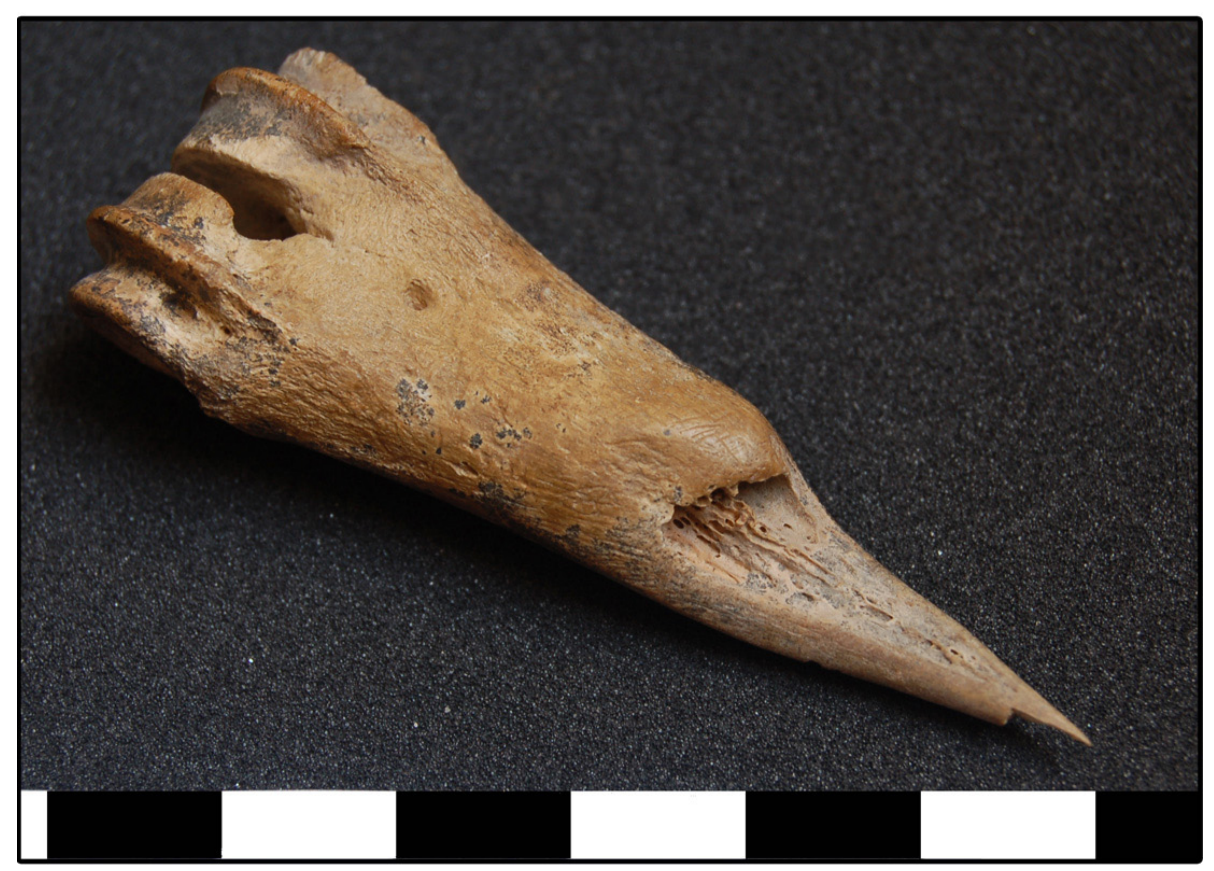

Figura 8.26. Instrumento óseo (punzón) manufacturado sobre el extremo distal de un metapodio de $O$. bezoarticus, recuperado en el sitio Laguna Chasicó 7. Foto: J. Moirano. 
La alteración estructural es baja en todos los casos en que pudo ser determinada ( $\mathrm{n}=22)$, lo mismo que la abrasión, con 27 fragmentos con estadio 1 y uno solo con estadio 2. En relación con la mineralización, solo dos especímenes se encuentran mineralizados, 21 no muestran signos de mineralización, en tanto en los 26 restantes ésta no pudo ser medida dado su tamaño (Figura 8.27). No se registró precipitación de carbonato, encontrándose manchas de manganeso únicamente sobre la superficie del instrumento óseo.

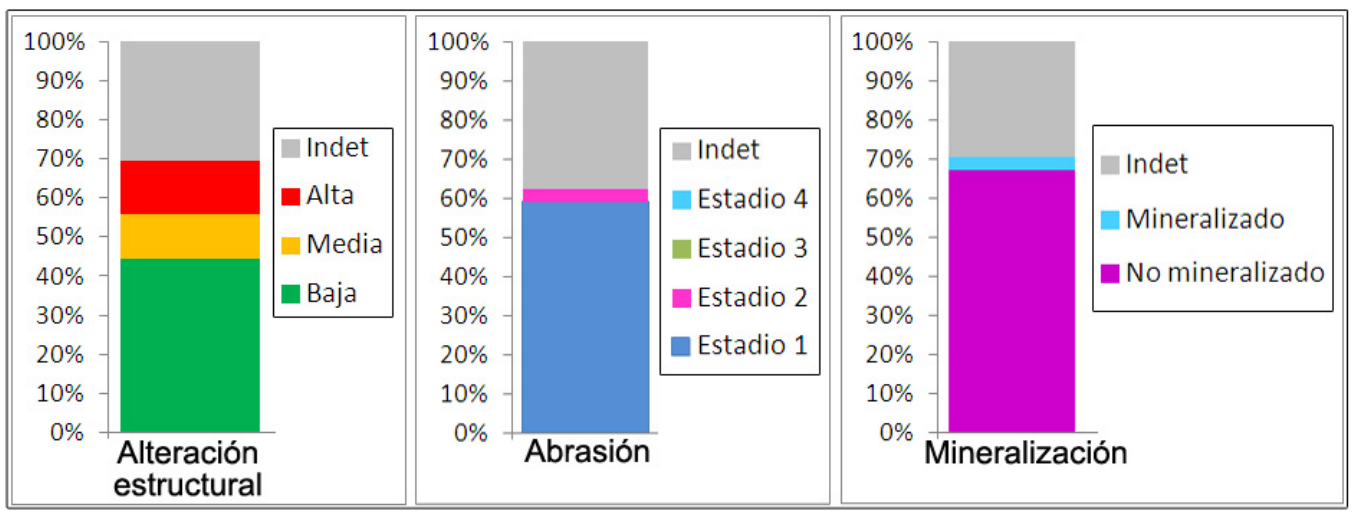

Figura 8.27. Principales modificaciones producto de la acción de agentes y procesos postdepositacionales, representadas en los especímenes óseos procedentes del sitio Laguna Chasicó 7.

\subsubsection{Laguna Chasicó sitio 8}

En este sitio se recolectaron un total de 98 especímenes óseos y 5 fragmentos de diente y/o molar. Estos materiales proceden en mayor proporción de la transecta 1 UR 4 y 7 y de la transecta 3, UR 8 a 10. En la transecta 2 se obtuvieron solo 10 fragmentos distribuidos entre las UR 8 y 9. Entre los especímenes óseos, 53 son determinables a algún nivel anatómico y/o taxonómico, lo que da una razón NSP:NISP de 1,94. Entre las especies identificadas se encuentran Bos taurus, Ozotoceros bezoarticus y especímenes no determinados a nivel específico, que corresponden a Artiodactyla, dasipódidos, roedores, mamífero mediano/grande y mamífero chico y aves, entre estos últimos, uno presenta marcas de origen antrópico (Tabla 8.11). Las marcas son muy escasas, encontrándose, además de la marca de origen antrópico mencionada, sólo un fragmento con marcas de raíces sobre sus superficies. 


\begin{tabular}{|c|c|c|c|c|c|c|c|c|c|c|c|c|}
\hline \multirow{2}{*}{\begin{tabular}{|l|} 
Taxón \\
Elemento
\end{tabular}} & \multicolumn{2}{|c|}{ Bos taurus } & \multicolumn{2}{|c|}{$\begin{array}{l}\text { Ozotoceros } \\
\text { bezoarticus }\end{array}$} & \multicolumn{2}{|c|}{$\begin{array}{c}\text { M. mediano } \\
\text { / grande }\end{array}$} & \multicolumn{2}{|c|}{ M. chico } & \multicolumn{2}{|c|}{ Aves } & \multicolumn{2}{|c|}{ Indet. } \\
\hline & MNE & NISP & MNE & NISP & MNE & NISP & MNE & NISP & MNE & NISP & MNE & NISP \\
\hline cráneo & & & & & & & 1 & 1 & & & & \\
\hline mandibula & & & & & & & 4 & 5 & & & & \\
\hline diente/molar & & & & & 1 & 2 & 1 & 2 & & & nd & 1 \\
\hline costilla & 1 & 6 & & & 1 & 2 & & & & & & \\
\hline disco vertebral & & & & & 2 & 3 & & & & & & \\
\hline vértebra & & & & & 10 & 11 & 2 & 6 & & & 1 & 1 \\
\hline escápula & & & & & 1 & 1 & & & & & & \\
\hline húmero & & & & & 1 & 1 & & & 1 & 1 & & \\
\hline radio & & & & & 1 & 1 & & & & & & \\
\hline isquion & & & & & 1 & 1 & & & & & & \\
\hline fémur & & & & & 1 & 1 & & & & & & \\
\hline tibia (epífisis) & & & & & 2 & 2 & & & & & & \\
\hline tibiatarso & & & & & & & & & 1 & 1 & & \\
\hline hueso largo & & & & & 2 & 3 & 2 & 2 & 3 & 6 & & 3 \\
\hline tarso / carpo & & & & & 1 & 1 & & & & & & \\
\hline falange 2 & & & 1 & 1 & & & & & & & & \\
\hline indeterminado & & & & & & 1 & & 9 & & 1 & & 25 \\
\hline placa & & & & & & & 2 & 2 & & & & \\
\hline
\end{tabular}

Tabla 8.11. Diversidad taxonómica representada en el sitio Laguna Chasicó 8.

La alteración estructural es baja en el 63,54\% de la muestra, media en el 7,29\% y alta en el 2,08\%, en tanto en el 27,08\% restante no pudo ser determinada. La abrasión es baja en la mayor parte de la muestra, encontrándose 72 especímenes con un estadio 1 de abrasión, 5 con estadio 2 y 19 fragmentos en los que no pudo ser medida. La mineralización también es baja, con solo nueve fragmentos mineralizados y 70 no mineralizados (Figura 8.28). Un solo fragmento presenta manchas de manganeso y no se registraron evidencias de depositación de carbonato.

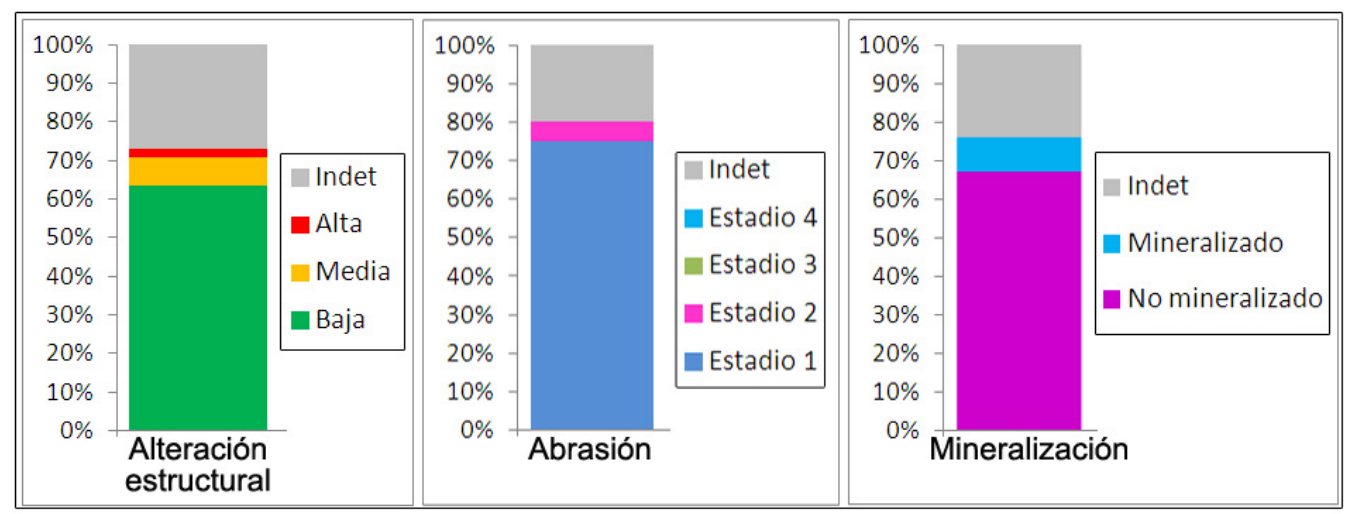

Figura 8.28. Principales modificaciones producto de la acción de agentes y procesos postdepositacionales, representadas en los especímenes óseos procedentes del sitio Laguna Chasicó 8. 


\subsection{El registro arqueofaunistico en la cuenca del arroyo Chasicó}

En todos los sitios de la cuenca del arroyo Chasicó, el guanaco y, secundariamente, el venado de las pampas, son las principales especies consumidas. En el sitio La Montaña 1, éstas parecen ser las únicas especies que ingresaron al sitio como consecuencia de la actividad humana. De manera similar, en Los Chilenos, estratigrafía y superficie, la especie más abundante es L. guanicoe y elementos asignables a mamíferos que, por su tamaño, se corresponderían con guanaco o venado de las pampas. Entre las especies de menor porte sólo se encuentran roedores y dasipodidos sin evidencias de haber sido consumidos. También en los sitios localizados sobre las márgenes de la laguna Chasicó, en la cuenca inferior, las únicas especies con claras evidencias de haber sido utilizadas por las sociedades cazadorasrecolectoras son $L$. guanicoe y $O$. bezoarticus. En este sector, si bien fueron recolectados elementos correspondientes a una mayor diversidad de especies, por tratarse de materiales de superficie, la mayor parte de estos son modernos, consecuencia o bien de la depositación natural o bien de la actividad antrópica actual vinculada con las actividades de pesca que se realizan en esta laguna (Figura 8.29).

La identificación de un punzón elaborado sobre un metapodio de $O$. bezoarticus, corrobora el uso de los elementos óseos en la confección de instrumentos. Este tipo de artefactos son muy escasos en el área, Oliva et al. (1991b) registró su presencia en bajo número en el sitio San Martín y también se los encuentran presentes, siempre en bajo número en algunas de las colecciones de museos locales (colección Ybarra del Museo Regional Chasicó y colección del Museo de la localidad de Puán). Su baja frecuencia puede responder a la amplia disponibilidad de recursos líticos y vegetales en el área que llevaría a emplear los elementos óseos para el desarrollo de tareas específicas. Por otra parte, los factores tafonómicos, pueden enmascarar los rasgos tecnológicos distintivos, volviendo difícil su identificación. Posteriores estudios deberán orientarse a evaluar el tipo de actividades desarrolladas con ellos, la tecnología puesta en juego durante su formatización y los factores que inciden en su baja representación.

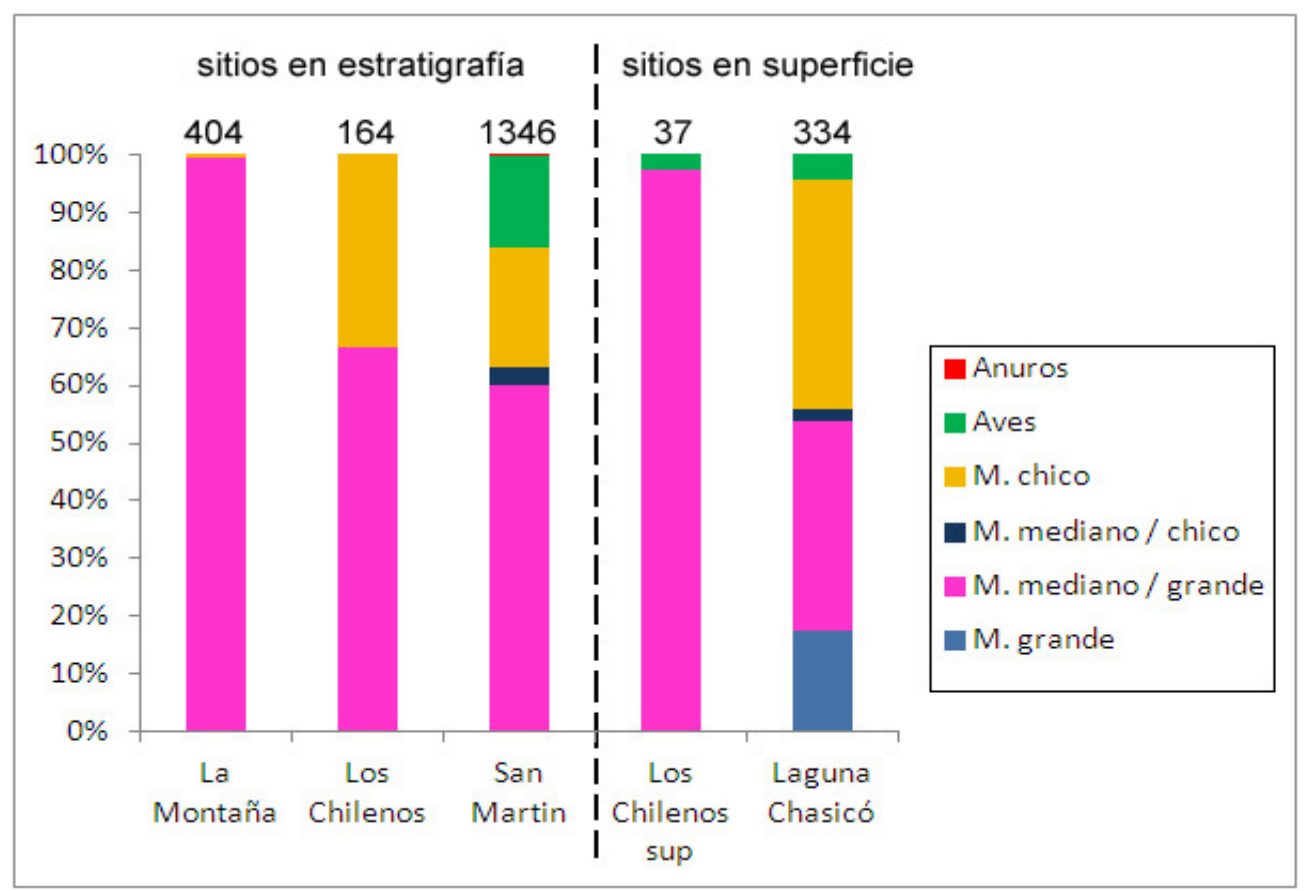

Figura 8.29. Diversidad taxonómica representada en los sitios arqueológicos, expresada en porcentajes. Los números sobre las barras indican el n de la muestra. La línea punteada separa los sitios en estratigrafía de aquellos en superficie. 
El sitio San Martin 1, ubicado en la cuenca media y asignado a momentos iniciales del Holoceno tardío, es el único en el que se encuentran representadas especies de menor porte con claras evidencias de haber sido consumidas. En tal sentido, si bien el guanaco es la especie más representada, seguida por el venado de las pampas, también se encuentran elementos asignados a Rhea sp. y a mamíferos de pequeño tamaño como Lagostomus maximus y Dolichotis patagonum, todas ellas con marcas de corte, a los que se agregan gran cantidad de elementos, principalmente placas, correspondientes a dasipódidos y algunos elementos aislados asignados a aves, al menos un carnívoro y el marsupial Lestodelphys halli, estos últimos sin evidencias de haber ingresado al sitio como producto del consumo humano.

Uno de los factores que puede afectar a la identificabilidad anatómica y taxonómica es el grado de fragmentación. Este disminuye desde la cuenca superior hacia la inferior, observándose que, en los sitios en estratigrafía, las mayores tasas de fragmentación se encuentran en el sitio La Montaña 1, donde a su vez se registra la menor densidad de especímenes óseos por metro cúbico. En Los Chilenos 2 por otra parte, la densidad de especímenes óseos por metro cúbico es la más alta de los tres conjuntos de estratigrafía, y su grado de fragmentación es intermedio entre San Martín 1, con menor fragmentación, y La Montaña 1, donde ésta es mayor. En los sitios en superficie, los materiales recuperados en las recolecciones realizadas en la laguna Los Chilenos, localizada en la cuenca media, presentan un mayor grado de fragmentación y mayor densidad por $\mathrm{m}^{2}$ que aquellos procedentes de la laguna Chasicó (Figura 8.30).

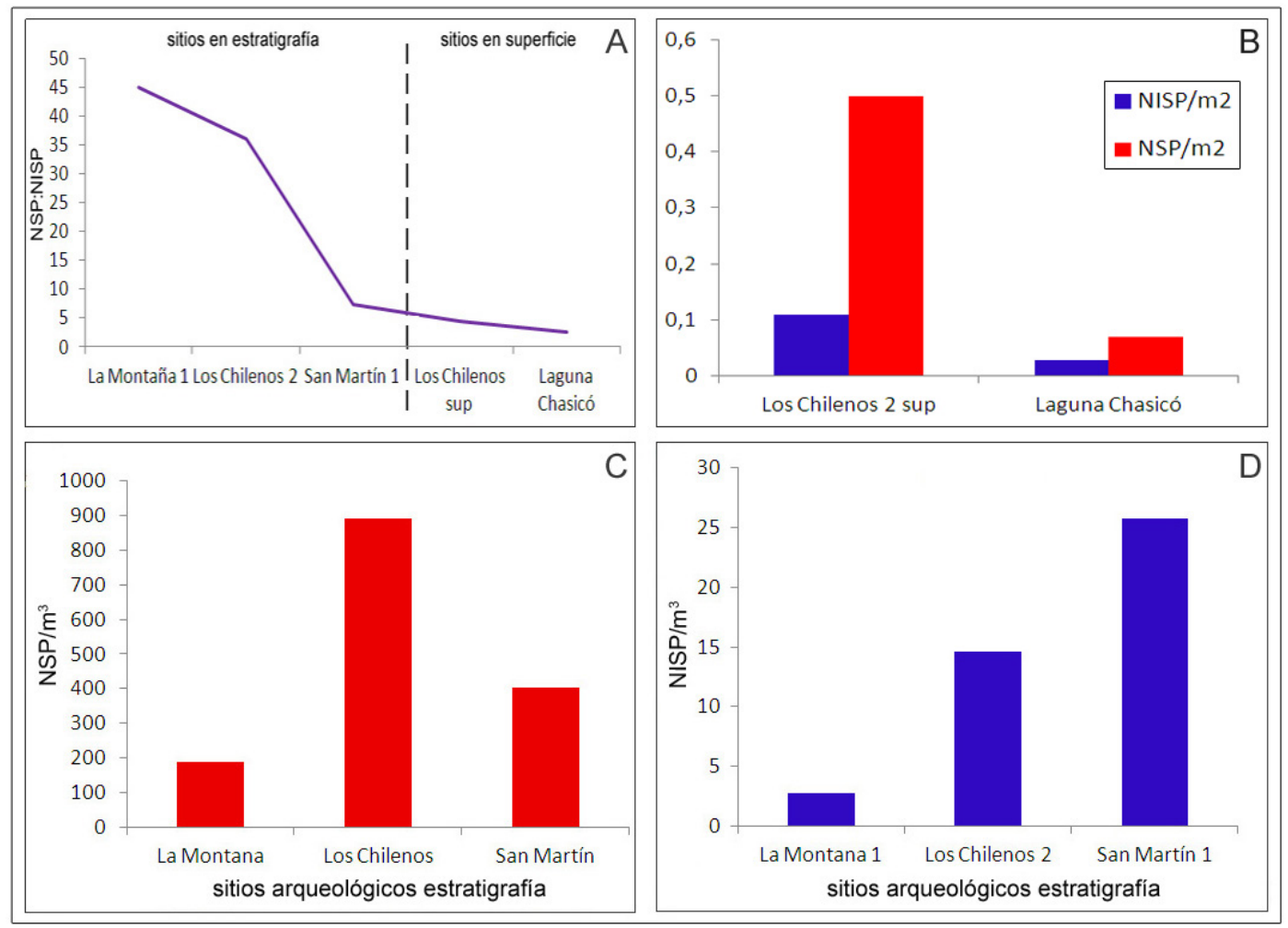

Figura 8.30. Grado de fragmentación y densidad de los especímenes óseos faunísticos. A- grado de fragmentación calculado a partir de la razón entre especímenes determinables y no determinables, la línea punteada separa los sitios en estratigrafía y los en superficie; B- densidad de especímenes determinables y no determinables por metro cuadrado; C- densidad de especímenes determinables por metro cúbico; D- densidad de especímenes (determinables e indeterminables) por metro cúbico. 
La variación observada en la diversidad de especies representadas, en la fragmentación de los conjuntos y en la densidad de materiales óseos, puede responder a 1) factores antrópicos, relacionados con cuáles fueron las especies predominantemente seleccionadas y la intensidad con que fueron procesadas, 2) factores tafonómicos que inciden en la conservación de este tipo de materiales, especialmente aquellos más fácilmente degradables, como es el caso de los elementos óseos correspondientes a aves y animales pequeños, o bien 3) una conjunción de ambas posibilidades. Como fue mencionado previamente, el modelo general de agentes y procesos post-depositacionales generado indica que, en los distintos sectores de la cuenca, los factores que afectan a la preservación del registro arqueofaunístico actúan con variada intensidad. De esta manera, las diferencias observadas entre los conjuntos presentados podrían estar respondiendo a esta situación. En tal sentido, los grados más elevados de alteración estructural fueron observados en el sitio La Montaña 1 y en la localidad laguna Chasicó, ambos localizados en los sectores donde inciden con alta intensidad un mayor número de agentes y procesos. La acción de las raíces sobre la superficie de los huesos también es concordante con el modelo propuesto, encontrándose las mayores proporciones de este tipo de marcas en La Montaña 1, localizado en el área en la que es esperable un mayor desarrollo de pastos. Cabe aclarar que las raíces no solo modifican la superficie de los huesos, sino que, como fue mencionado anteriormente, también pueden contribuir a su fragmentación (Figura 8.31).
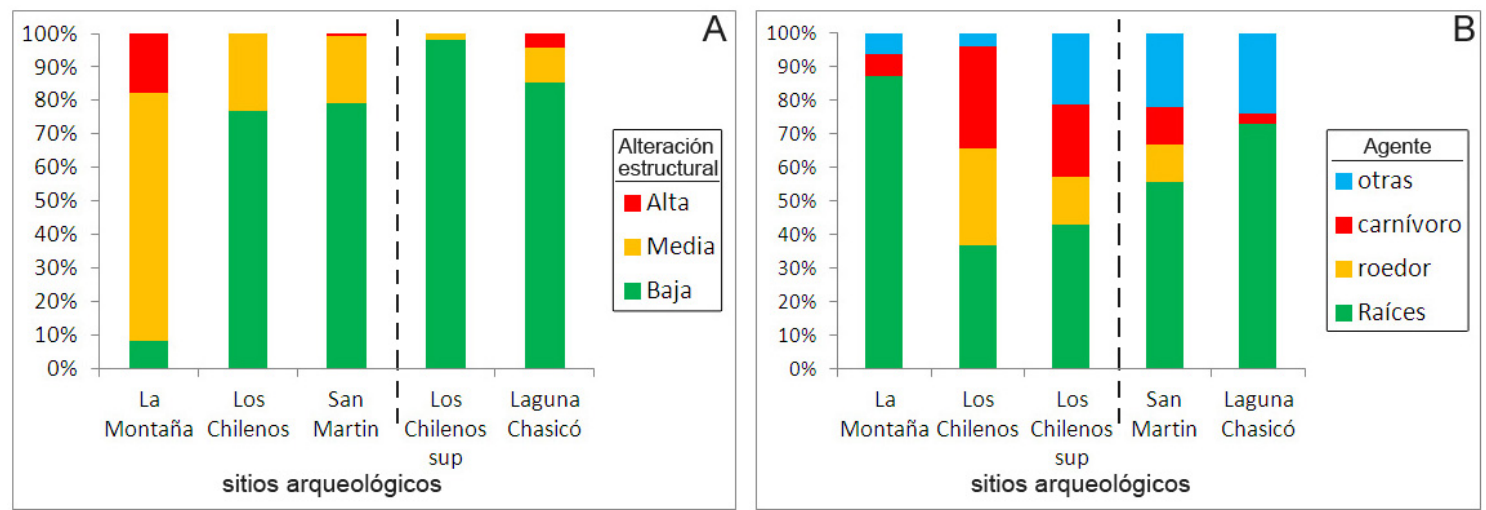

Figura 8.31. Estado de los conjuntos óseos faunísticos. A- alteración estructural; B- marcas

En el caso de la abrasión, esta es baja en todos los sitios, encontrándose los grados más altos en aquellos vinculados a ambientes ácueos, independientemente del tipo de sedimento en que se encuentren. Una excepción a esto lo constituyen los materiales recuperados en la laguna Chasicó, donde los elementos óseos muestran bajos grados de abrasión. Finalmente, en el caso de la mineralización, esta se encuentra representada en mayor proporción en aquellos sitios que han permanecido en condiciones sub-ácueas por algún período de tiempo (Figura 8.32). Esto es particularmente notorio en la laguna Chasicó, donde aquellos sitios localizados en el sector sudoeste, con claras evidencias de haber permanecido sumergidos por algún período de tiempo (presencia de musgos y precipitación de sales como carbonato de calcio), muestran una mayor proporción de elementos mineralizados en relación con aquellos situados en la costa norte . 


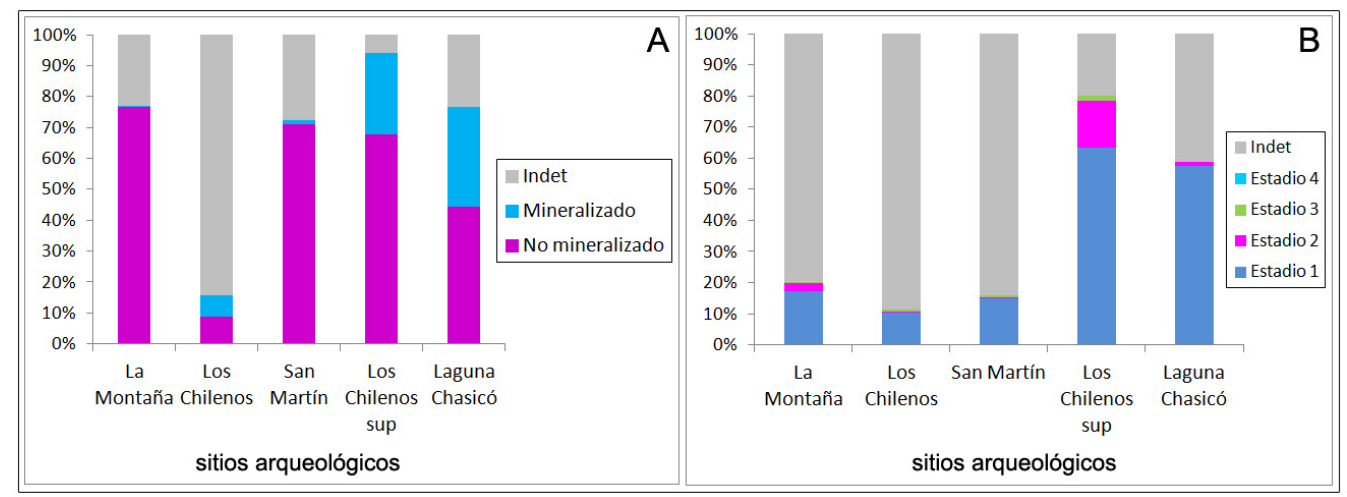

Figura 8.32. Estado de los conjuntos óseos faunísticos. A- mineralización; B- abrasión.

El análisis de las variables tafonómicas muestra diversidad en el estado de preservación de los materiales óseos y, por lo tanto, en el grado en que los procesos y agentes post-depositacionales afectaron a los conjuntos, observándose correspondencia con lo esperado en función del modelo de agentes y procesos post-depositacionales propuesto. En tal sentido, algunos procesos han afectado fuertemente a las muestras, particularmente en los sectores superior e inferior, donde una mayor cantidad de estos actúa con alta intensidad, generando condiciones más agresivas para con el registro óseo. Esto se ve evidenciado en mayores tasas de alteración estructural en el sitio La Montaña 1, en la cuenca superior. También puede responder a esta situación la menor densidad de materiales óseos en los sitios ubicados sobre la laguna Chasicó, donde la exposición como consecuencia de la erosión hídrica y eólica, el alto contenido de sales en el ambiente y los suelos arenosos actúan degradando rápidamente este tipo de materiales (Figura 8.33). Por tal motivo, si bien el registro faunístico de la cuenca del arroyo Chasicó muestra una dieta basada, predominantemente, en el consumo de guanaco y, secundariamente, venado de las pampas que, en algunos casos, se vio complementada por la incorporación de presas de menor porte, no se puede descartar que, la menor diversidad taxonómica evidenciada en algunos de los sitios, dada por la ausencia de especies de menor porte, responda a factores puramente tafonómicos. Por otra parte, el alto grado de fragmentación observado en La Montaña 1 también podría ser consecuencia de un caso de equifinalidad, relacionada con la intensidad de los procesos tafonómicos actuantes o bien con una mayor intensidad de procesamiento de las carcasas, a los fines de aprovechar la grasa contenida en los huesos, ya sea en la forma de médula o de grasa ósea contenida en el tejido esponjoso (Otaola 2012).

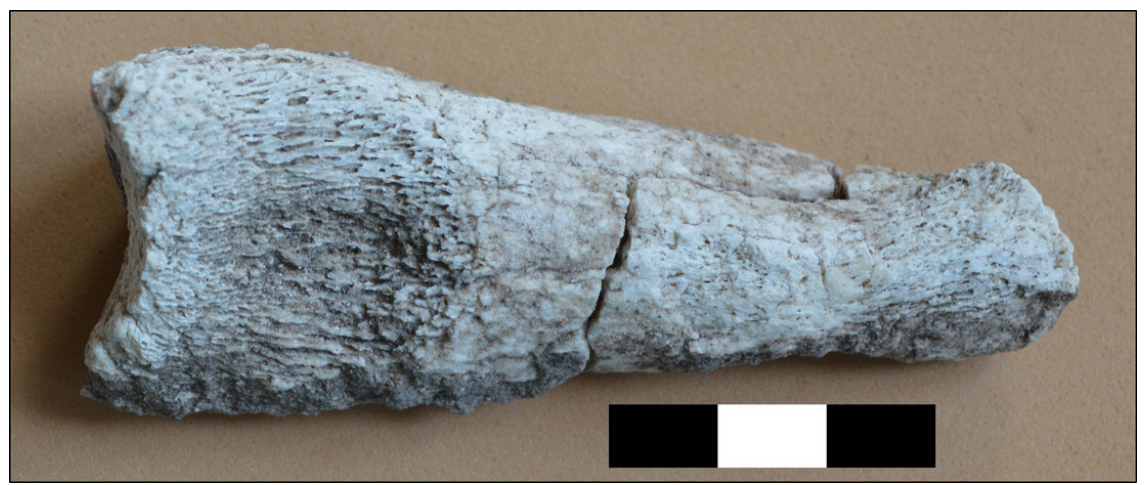

Figura 8.33. Falange recuperada en superficie en las Salinas Chicas, altamente degradada como consecuencia de la exposición al ambiente salino. 
Por último, cabe aclarar, que el objetivo del modelo de agentes y procesos post-depositacionales propuesto, no es predecir las características que poseerá cada uno de los conjuntos arqueológicos. Esto sería desconocer la variabilidad existente a escalas espaciales menores, inclusive dentro de un mismo sitio, en relación con factores físicos y biológicos locales (actuantes desde el momento de depositación hasta el de recuperación), las características culturales intervinientes en su formación (el tipo de actividades desarrolladas en el sitio, la duración y frecuencia de ocupación, la cantidad, etc) y la metodología empleada en la recuperación del conjunto. Por el contrario, un modelo tafonómico regional tiene por objetivo identificar tendencias en unidades de paisaje amplias que actúen como marco de referencia de análisis específicos realizados en escalas menores y permita una mejor comparación entre conjuntos recuperados en ambientes variables (Borrero 1988, 2001a; Burger et al. 2008). De este modo, se busca poner en relación los factores y procesos actuantes a diferentes escalas espaciales de análisis.

\subsection{Discusión}

Concordantemente con lo propuesto para otras áreas de la Región Pampeana y el NE de Patagonia, la información zooarqueológica presentada muestra una dieta basada predominantemente en el consumo del guanaco y, secundariamente, venado de las pampas, ñandú y mamíferos de menor porte (v.g. armadillos, mara). También se encuentran evidencias de la utilización de los huesos de algunos de estos animales como materia prima para la fabricación de instrumentos, lo que se ve evidenciado a partir del hallazgo de un punzón fabricado sobre un metapodio de O. bezoarticus y de "algunos fragmentos de diáfisis que poseen extremos retocados con algunas modificaciones de origen antrópico" en el sitio San Martín 1 (Oliva et al. 1991b: 137). Este tipo de tecnología ha sido descripta, aunque en bajo número, tanto para el SE de la Región Pampeana como para el NE de Patagonia (Borella y Buc 2009; Martínez 2010), particularmente en relación con la formatización de retocadores para la manufactura de instrumentos líticos. Particularmente en el caso de los punzones, su uso ha sido relacionado, más probablemente con la perforación de pieles (Borella y Buc 2009).

Para varias de las áreas comprendidas dentro de estas regiones, se ha descripto, para fines del Holoceno tardío, la existencia de una dieta diversa que, dependiendo del ambiente, incluyó mamíferos pequeños, aves, moluscos, reptiles y peces de agua dulce y salada (entre otros Fernández et al. 2011; Mazzanti y Quintana 2001; Messineo 2008; Prates 2008; Quintana 2005; Quintana et al., 2002). Esta mayor diversidad taxonómica en algunos de los sitios posteriores a los 1000 años AP, ha sido interpretada en ciertas áreas, como consecuencia del desarrollo de un proceso de diversificación y/o intensificación en la explotación de la fauna, que se vería evidenciado también por un aprovechamiento más intensivo del guanaco y la consecuente mayor fragmentación de sus huesos (Martínez y Gutiérrez 2004; Martínez 2008-2009; Quintana et al. 2002; Stoessel 2010, 2012b). Sin embargo, aún resta desarrollar mayor cantidad de estudios tendientes a evaluar este aumento en la diversidad taxonómica y su relación con otros indicadores como, por ejemplo, el índice de fragmentación y la acción de procesos tafonómicos.

Este proceso, sin embargo, no parece ser claro en el área de estudio, donde el guanaco es la principal especie representada y no se registran evidencias, en los sitios más tardíos, de un aumento en la frecuencia de especies de menor porte. Por el contrario, la mayor diversidad taxonómica se da en el sitio San Martín 1, asignado a comienzos del Holoceno tardío, donde además de la presencia de guanaco se registran, en menor número, venado de las pampas, ñandú y animales de pequeño porte (v.g. armadillos, mara). 
Varios factores pueden incidir en esta situación, por una parte, las condiciones ambientales y sociales pudieron no haber favorecido el desarrollo de este tipo de procesos de diversificación e intensificación, por ejemplo por la permanencia del guanaco en el área durante todo el Holoceno tardío (Politis y Pedrotta 2006; Tonni y Politis 1980) o bien por una menor densidad demográfica que la presente en áreas vecinas, como la desembocadura del río Colorado, donde la mayor disponibilidad de recursos, dada por la confluencia de ambientes marinos, fluviales y terrestres, pudo haber posibilitado un mayor aumento poblacional (ver Capítulo 5; Martínez 2010). Por otra parte, los sitios de la cuenca correspondientes a momentos ptardíos, se encuentran localizados en sectores donde las condiciones ambientales son más agresivas para con el registro óseo, lo que podría estar enmascarando algunas de estas evidencias, ya que tanto los huesos correspondientes a animales de pequeño tamaño, como aquellos muy fragmentados tendrían menores probabilidades de preservarse y, por lo tanto, de ser recuperados.

En relación con la mayor diversidad taxonómica representada en San Martín 1, esta puede responder a aspectos tafonómicos y/o conductuales locales. Por una parte, las características de San Martín 1 parecen indicar que este sitio se habría formado como consecuencia del entrampamiento de los materiales en holladas del terreno, lo que aumentaría las posibilidades de preservación y posterior recuperación de una mayor diversidad de especies. Por otra parte, y dado que se trata de un solo sitio, esta diversidad podría responder también a particularidades relacionadas con la funcionalidad del sitio o su estación de ocupación en el año (Oliva et al. 1991b, 2010a).

El grado de fragmentación puede ser otro indicador de la intensidad en la explotación de los recursos faunísticos, ya que ésta se relaciona con el aprovechamiento de la grasa ósea mediante la fractura para el aprovechamiento de la médula o por el triturado y hervido del tejido esponjoso. Este tipo de procesos ha sido propuesto para el sur de Mendoza, donde se observa una mayor intensidad y extensión de la fragmentación para momentos en los que se ha planteado la existencia de un proceso de intensificación de la economía (Otaola 2012). En el área de estudio, la fragmentación, en algunos casos como el de La Montaña, puede responder principalmente a factores tafonómicos, dado que se encuentra en una zona donde los procesos postdepositacionales actúan con mayor intensidad. Por otra parte, la presencia de elevados niveles de fragmentación en Los Chilenos, localizado en un sector donde los procesos tafonómicos actúan con menor intensidad, podría estar respondiendo a factores antrópicos vinculados con el aprovechamiento de la grasa ósea. Estas son líneas de evidencia que deberán continuar analizándose.

Considerando la variabilidad en el tipo y la intensidad de los agentes y procesos tafonómicos que afectan al registro óseo a lo largo de la cuenca, así como la escasez del mismo en algunos de los sectores, es difícil llegar a conclusiones acerca del modo en que los distintos recursos fueron explotados y sus probables variaciones a través del tiempo, debiendo profundizarse en los estudios tafonómicos, locales y regionales, que permitan evaluar con mayor precisión la relación entre las especies y partes esqueletales representadas y su fragmentación con factores económicos y sociales de aquellas sociedades. 


\section{I Tecnología Cerámica}

En este capítulo se presentan los análisis realizados sobre el material cerámico recuperado a partir de investigaciones sistemáticas llevadas a cabo en distintos sectores de la cuenca del arroyo Chasicó, así como sobre aquellos materiales depositados en colecciones particulares y en museos regionales. $\mathrm{Si}$ bien la evidencia de esta tecnología, en el área de estudio, es escasa y fragmentaria, presenta ciertas características particulares, dadas por el tipo de artefactos confeccionados, la materia prima utilizada y los pasos seguidos para su manufactura, que la distinguen de otros registros, pudiendo, de esta manera, aportar información complementaria relacionada con la movilidad de aquellas poblaciones y con el uso de ciertos recursos.

\subsection{Algunos conceptos teóricos sobre la tecnología cerámica}

En el caso de sociedades cazadoras-recolectoras, la tecnología cerámica se utiliza, principalmente, para la elaboración de contenedores utilizados para hervir alimentos y para re-hidratar y/o ablandar carne o semillas (Dean and Heath 1990; Hill 2006; Linton 1944; Reid 1989). La producción de los contenedores cerámicos involucra una serie de pasos que incluyen la elección de arcillas y antiplásticos, su procesamiento y su mezcla, en relación con propiedades particulares vinculadas tanto con la elaboración de la pieza, modelado (incluyendo tratamiento de las superficies y decoración), secado y cocción, como con su posterior funcionalidad (Orton et al. 1997; Rice 1987; 1996). Las elecciones realizadas durante este proceso estarán, a su vez, estrechamente relacionadas con la tecnología y el tiempo disponible durante la producción y uso de las mismas. En este sentido, su manufactura implica que el ceramista permanezca en un mismo lugar por al menos dos a cuatro días en la estación seca ${ }^{1}$ ( ambientales de abundante humedad y, por otra parte, si su elaboración se realiza preferentemente durante el verano, estación seca y/o de mayor radiación solar, también puede competir temporalmente con la recolección de semillas. Posteriormente, el peso, volumen y fragilidad de este tipo de utensilios también puede dificultar su traslado, volviéndolos, para las sociedades con alta movilidad residencial, menos eficaces que otro tipo de contenedores, como los realizados a partir de materiales orgánicos (Arnold 1985; Simms et al. 1997; Skibo et al. 1989).

Algunos autores han considerado la posibilidad de que las características mencionadas (la fragilidad de las vasijas cerámicas, su peso y el tiempo necesario para su confección), puedan ser limitantes al momento de su incorporación por parte de las sociedades móviles (Arnold 1985). Otros investigadores en cambio, sostienen que la movilidad no sería un impedimento para su incorporación, si bien impondría ciertas restricciones, influyendo en los modos de fabricación y uso de estos instrumentos, así como en

1 Actualmente, en la localidad de Villa Gesell, costa atlántica de la provincia de Buenos Aires, la ceramista Gabriela Zavalia, durante el verano, deja secar durante todo un día las vasijas y al siguiente las cocina. 
su tamaño y peso, que tenderían a disminuir al aumentar la movilidad residencial (Bright y Ugan 1999; Eerkens 2003; Eerkens et al. 2002; Rice 1987; Skibo et al. 1989; Simms et al. 1997). En este sentido, Simms et al. (1997) postularon que la inversión de tiempo y energía realizada en la elaboración de contenedores cerámicos, está condicionada por el tiempo de uso de estos y, por lo tanto, se verá afectada por el grado de movilidad residencial, la redundancia ocupacional y la presencia o no de un sistema logístico de uso del espacio. Estos autores proponen que en aquellas sociedades con menor movilidad residencial o bien con alta redundancia ocupacional, donde las vasijas pueden ser guardadas en el sitio para futuras visitas (en la forma de caches), el tiempo de uso de la cerámica aumentará y por lo tanto será esperable una mayor inversión en su fabricación, observable en paredes de espesor fino, una buena selección del tamaño de los antiplásticos -expresado en pastas finas y homogéneas- y superficies mejor terminadas (Simms et al. 1997).

Eerkens (2003), en cambio, expresa que en aquellas sociedades con mayor movilidad residencial, las vasijas tenderán a ser morfológicamente menos variables, con bocas más angostas, paredes un poco más finas, superficies externas rugosas y antiplásticos más pequeños que en sociedades con campamentos residenciales más estables. Estas últimas tres características, espesor de las paredes, rugosidad de la superficie y tamaño de las inclusiones, se relacionan a su vez, con un mejor aprovechamiento calórico y la consecuente disminución en el consumo de combustible, importante cuando la leña es escasa (Eerkens 2003). Por otra parte, una disminución en el espesor de las paredes disminuiría el tiempo de secado y el peso de la vasija y se puede correlacionar, a su vez, con una disminución en el tamaño de las vasijas, todas estas, variables que facilitan el transporte de las vasijas y, por lo tanto, interfieren en menor grado con la movilidad del grupo (Eerkens et al. 2002; Rice 1987; Simms et al. 1997; Skibo et al. 1989; Sugrañes 2011). Si se relaciona la tecnología cerámica con las características ambientales, será esperable un mayor grado de sedentarismo y, consecuentemente, una mayor inversión en la tecnología cerámica en aquellos lugares en los que la estructura de los recursos favorece la permanencia por períodos más largos, en tanto la inversión en la manufactura cerámica será menor en ambientes con mayor variación estacional (Bright y Ugan 1999). Si bien no es posible inferir estrategias de movilidad y uso del espacio únicamente a partir de características tecnológicas, debido a que muchos factores pueden influir en la elección de uno u otro rasgo, estos estudios aportan a la discusión acerca de la presencia de características distintivas en vasijas utilizadas por poblaciones móviles. Trabajos en esta línea, están siendo desarrollados en el sur de Mendoza, a los fines de explorar las posibles relaciones entre la movilidad y diferentes variables de la tecnología cerámica (Franchetti y Sugrañes 2012; Sugrañes 2011)

Finalmente, un rasgo distintivo de este tipo de tecnología, consiste en la posibilidad de decorar fácilmente sus superficies con técnicas y motivos muy variables, lo que agrega una dimensión relacionada con la posibilidad de indagar en las redes de interacción y circulación de información y los códigos e identidades compartidos, a través del análisis de los motivos decorativos, su distribución espacial y su relación con los motivos presentes en otro tipo de soportes, particularmente desde estudios vinculados con la semiótica (Rice 1987, 1996).

Considerando los conceptos arriba enunciados, los análisis sobre tecnología cerámica se llevaron a cabo a los fines de aportar información complementaria a la obtenida a partir del estudio de otro tipo de materiales como los artefactos líticos. En este sentido, los análisis se orientaron a caracterizar tecnológica, morfológica y estilísticamente a los materiales cerámicos, a los fines de evaluar las posibles 
estrategias de producción y uso y aportar datos que complementen la información obtenida a través de otras líneas de investigación.

\subsection{Metodología}

Los materiales cerámicos fueron analizados tanto a ojo desnudo como con una lupa binocular Hokenn con aumentos de entre 10X y 40X, teniendo en cuenta aspectos tecnológicos, morfológicos y estilísticos, analizándose complementariamente, categorías que aportan información acerca de los procesos de formación del registro. Para esto se siguieron los lineamientos propuestos, entre otros, por Shepard (1956), Rice (1987), Rye (1994), P.C.R.G (1995), Orton et al. (1997) y la Primera Convención Nacional de Antropología (1966).

Se consignaron las dimensiones de los fragmentos y se analizaron aspectos tecnológicos, morfológicos y decorativos, realizándose remontajes en todos aquellos casos en que fue posible. Se midieron, con calibre de corredera, el largo y ancho máximo de los fragmentos, así como el espesor en 4 sectores. En relación con aspectos tecnológicos como la composición de la pasta, temperatura y condiciones de cocción, se analizó la regularidad o irregularidad de la fractura fresca, se determinó la dureza, medida en ambas superficies mediante la utilización de la escala de dureza relativa de Mohs (Orton et al. 1997), y se consignó el color en fractura fresca en núcleo márgenes y superficies, utilizando la propuesta del P.C.R.G (1995), consistente en utilizar cuatro categorías basadas en espectros cromáticos: espectro 1: naranja-marrón-rojo; espectro 2: rosa claro-amarillo-blanco; espectro 3: blanco; espectro 4: gris-negro.

Las técnicas de manufactura fueron identificadas, en aquellos casos en que se observó algún rasgo que permitiera inferirlas, como por ejemplo la presencia de ondulaciones en la superficie o de puntos débiles (Orton et al. 1997). Se analizó también el tratamiento de la superficie, características y localización de la decoración y se estimó, en aquellos casos en que el tamaño de los fragmentos lo posibilitaron, la forma y altura de la vasija, así como el diámetro, espesor, tipo y porcentaje del borde y/o base, y el tipo de labio.

Las características de la pasta fueron estudiadas en las superficies y en fractura fresca, mediante la utilización de lupa binocular. Para esto se consideraron las siguientes variables:

- Densidad de las inclusiones en función de 5 categorías basadas en los gráficos de estimación de porcentaje de las inclusiones de Mathew, et. al. (1991) y tomando a todas las inclusiones en conjunto, sin discriminarlas por tipo.

- Selección de las inclusiones, considerándose 5 categorías caracterizadas sobre la base de la homogeneidad en el tamaño de las partículas presentes: muy escasa, escasa, moderada, buena, muy buena.

- Forma de las inclusiones, en relación con el grado de angulosidad o redondez de las partículas. 
- Tipo de inclusiones, en aquellos casos en que, por su tamaño, fue posible identificarlas con lupa binocular.

- Distribución de las inclusiones, consignándose la regularidad o irregularidad en su distribución.

- Tamaño máximo de las inclusiones.

El estado de conservación de la muestra se evaluó consignándose, en cada tiesto, la depositación de sales, el grado de erosión y el grado de rodamiento. La erosión y el rodamiento fueron evaluados considerando 5 estadios definidos, en el primer caso, por el porcentaje de la superficie con evidencias de exfoliación, y, en el segundo, por el redondeamiento de los bordes (Catella y Saghessi 2004). También se evaluó el grado de fragmentación de la muestra en función del tamaño de los tiestos que la conforman.

\subsection{Resultados}

\subsubsection{Localidad La Montaña}

\subsubsection{La Montaña sitio 1}

La colección cerámica del sitio 1 de la localidad arqueológica La Montaña, consiste en 30 fragmentos recuperados entre los niveles 6 y 11 de las cuadrículas 1, 2 y 3. La muestra no presenta depositación de sales, pero su grado de fragmentación es alto, estando conformada por tiestos que no superan los 18 $\mathrm{cm}^{2}$ de superficie, con más de la mitad de los fragmentos presentando dimensiones de entre $0,6 \mathrm{~cm}^{2}$ y 4 $\mathrm{cm}^{2}$. A pesar de esta situación, o como consecuencia de la misma, los bordes de los tiestos se encuentran sólo levemente redondeados y sus superficies sin evidencias de erosión o descascaramiento, con excepción de tres fragmentos recuperados en la cuadrícula 1, en los que se observa una erosión de grado 3.

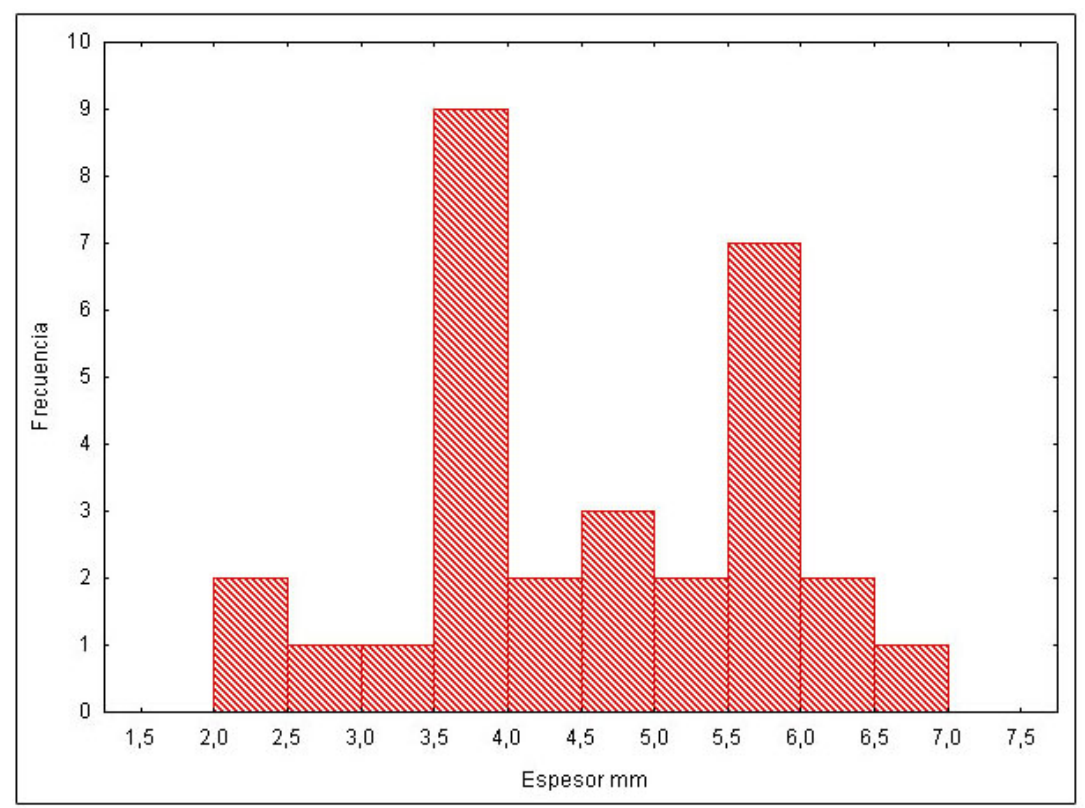

Figura 9.1 Histograma de los valores de espesor de los fragmentos cerámicos procedentes de La Montaña sitio 1. 
El espesor promedio de los tiestos oscila entre 2,25 $\mathrm{mm}$ y $6,75 \mathrm{~mm}$, con una mediana de 4,68 $\mathrm{mm}$ y una distribución claramente bimodal (Figura 9.1). La fractura es, en todos los casos, irregular y las pastas son blandas, con dureza en la escala de Mohs de entre 3 y 4, en proporciones similares. Esto indica, si bien no de manera directa ya que tanto fractura como dureza dependen de diversos factores, una cocción a bajas temperaturas. A su vez, la mayor parte de los fragmentos presentan, colores dentro del espectro 2 (rosa claro-amarillo-blanco), ya sea en toda la sección $(n=9)$ o bien en la sección externa $(n=9)$, con la superficie y margen internos en color negro-gris (espectro 4). El resto de la muestra está conformada por fragmentos con colores del espectro 4 (gris-negro) en toda la sección, y sólo 3 tiestos con colores naranja-marrón-rojo en alguna sección y gris-negra en las restantes (Catella 2004) (Figura 9.2). Esta distribución de colores indicaría el predominio de condiciones de cocción en atmósfera oxidante incompleta, tanto de pastas con bajo contenido de hierro, en el caso de las pastas con colores del espectro 2, como de pastas, aunque minoritarias, con mayor porcentaje de este mineral. La presencia de fragmentos negros en toda la sección puede ser indicador, o bien de su cocción en una atmósfera reductora o transformada en reductora en momentos finales de la cocción por medio del agregado de, por ejemplo, leña verde o estiércol, o bien una cocción breve que no fue suficiente para producir la oxidación de la pasta (Orton et al. 1997; P.C.R.G 1995;).

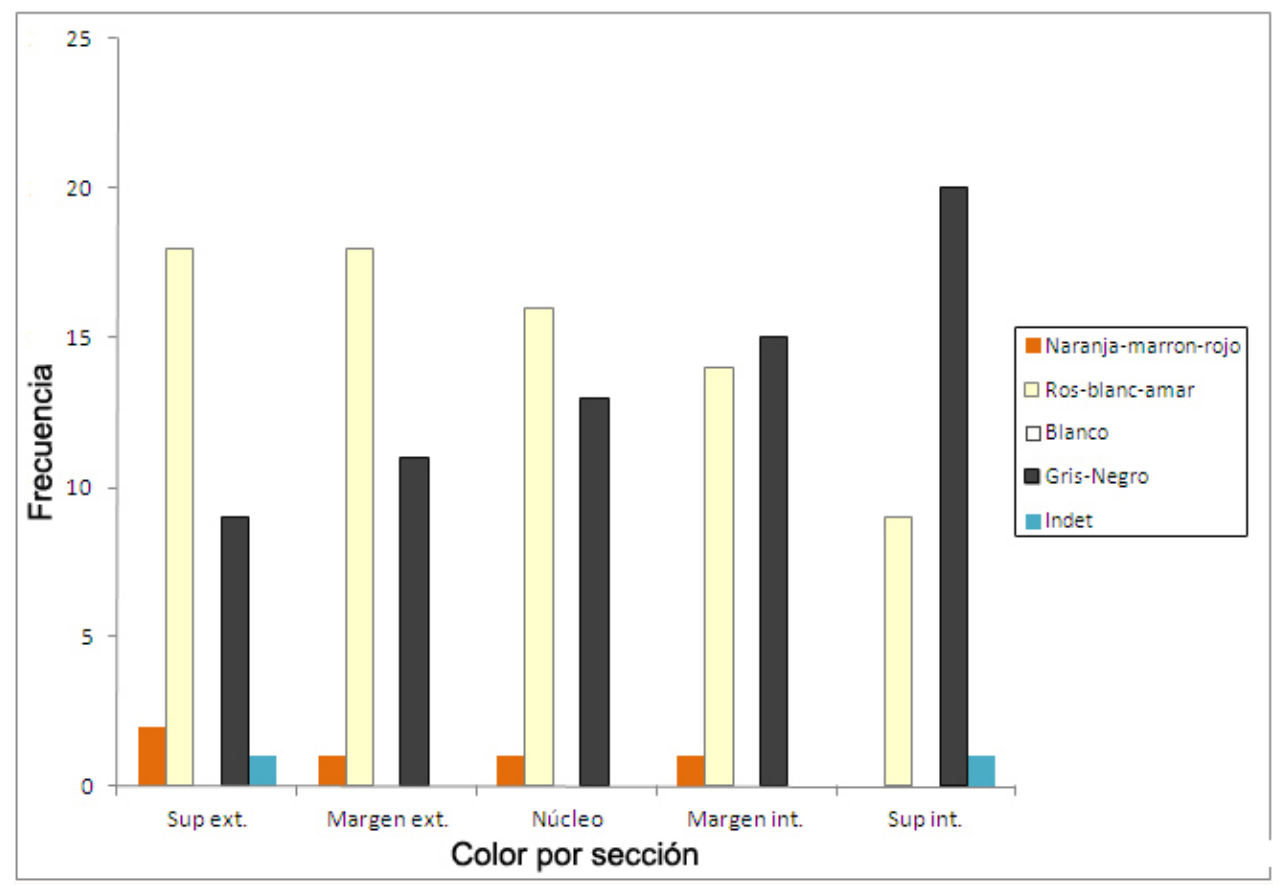

Figura 9.2. La Montaña sitio 1. Distribución de colores en corte fresco.

Las pastas observadas en lupa binocular presentan entre 4 y $20 \%$ de inclusiones, encontrándose un solo fragmento con $20-30 \%$ de inclusiones, su distribución es regular y la selección es predominantemente moderada $(n=11)$ y en menor proporción escasa $(n=8)$ y buena $(n=8)$, con un solo fragmento en el que la selección es muy escasa. Las inclusiones son predominantemente sub-redondeadas y en un porcentaje menor de fragmentos se encuentran también inclusiones sub-angulares $(68 \%)$ y redondeadas (24\%). Aquellas que pudieron ser identificadas consisten, según su abundancia, en cuarzo, mica y rocas negras, blancas y marrones indeterminadas y un fragmento con tiesto molido. 


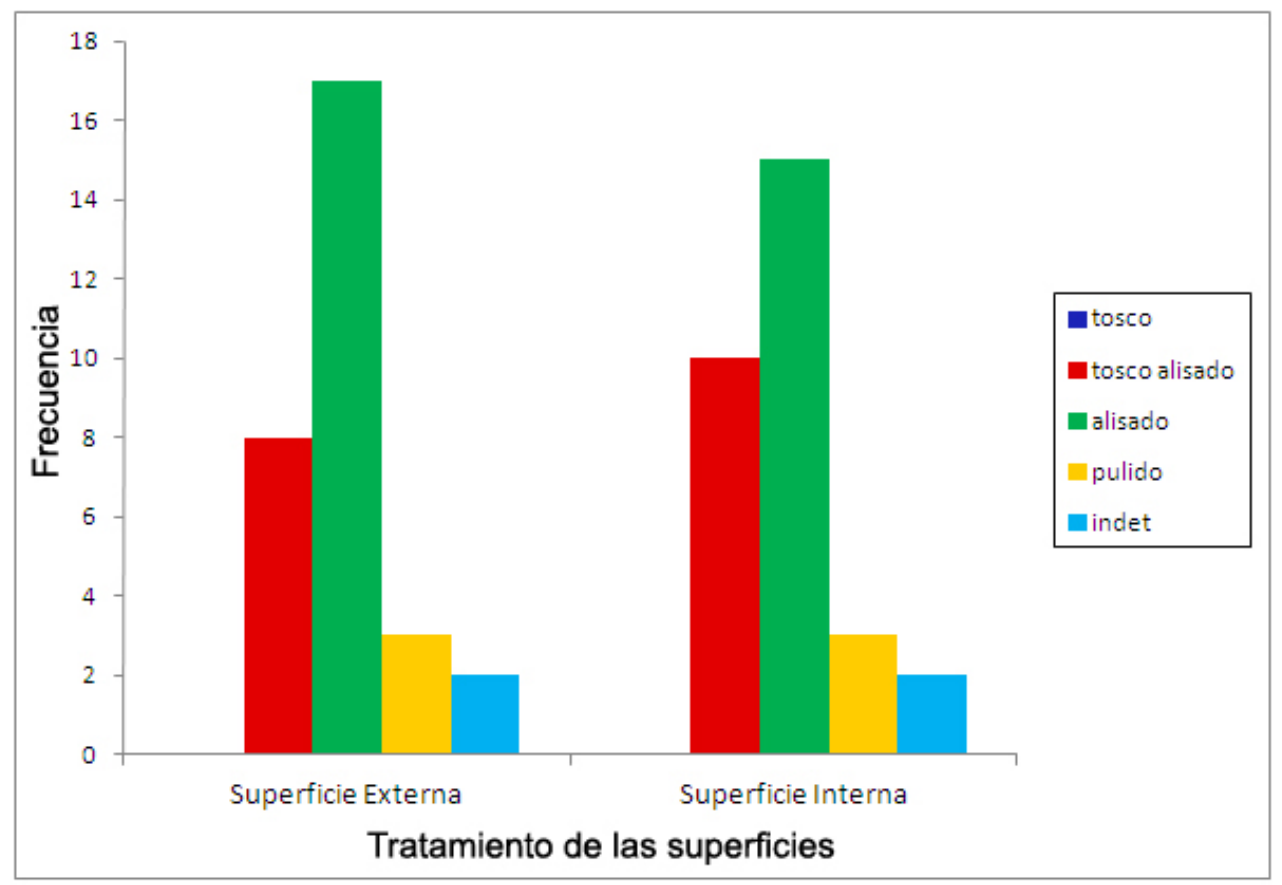

Figura 9.3. Tratamiento de las superficies interna y externa de los fragmentos cerámicos recuperados en La Montaña sitio 1.

En relación con el tratamiento de las superficies, predominan el alisado y tosco alisado en ambas caras, encontrándose sólo tres fragmentos pulidos y dos toscos (Catella 2004) (Figura 9.3). Dada la fragmentación de la muestra, no fue posible reconstruir formas completas, pero se recuperaron un total de cinco fragmentos de borde correspondientes, en función del color y selección, densidad y tamaño de las inclusiones, a por lo menos dos vasijas diferentes, lo que también es coincidente con la distribución bimodal de los espesores. Dado el pequeño tamaño de ellos y que no fue posible realizar remontajes, no pudo determinarse el diámetro de las mismas. Se trata, en todos los casos, de labios convexos y bordes directos, con espesores que oscilan entre $3 \mathrm{~mm}$ y $5 \mathrm{~mm}$. Once fragmentos presentan decoración incisa en su superficie externa, consistiendo ésta en líneas finas conformando motivos geométricos (Figura 9.4). En dos de estos fragmentos se encuentran restos de pintura roja en la superficie interna y en cuatro en la superficie externa, conservada dentro de los poros y de las líneas de incisión.

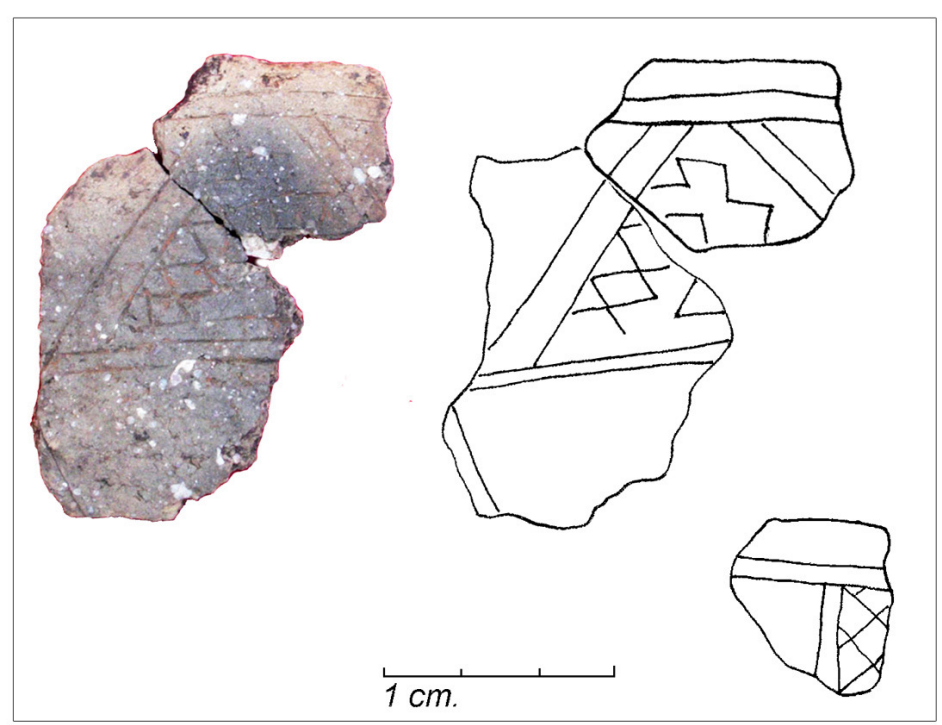

Figura 9.4 Diseños decorativos presentes en la cerámica del sitio La Montaña 1. 


\subsubsection{Laguna Los Chilenos}

En la localidad Laguna Los Chilenos se recuperaron un total de 14 fragmentos cerámicos, 6 procedentes de las cuadrículas 2 y 5 del sitio 1, uno del sitio 2, cuadrícula 2. Los cuatro restantes fueron recolectados en superficie, sobre las márgenes de la laguna, en el sector de playa ubicado entre los dos sitios mencionados. Todos los fragmentos recuperados en estratigrafía presentan un bajo grado de rodamiento y erosión (grado 1), pero un alto nivel de fragmentación, evidenciado en que sólo el fragmento recuperado en el sitio 2 supera $\operatorname{los} 3 \mathrm{~cm}^{2}$. Los tiestos recuperados en superficie también presentan un alto grado de fragmentación (tiestos con tamaños de entre 2 y $4 \mathrm{~cm}^{2}$ ), a lo que se suma mayor rodamiento de los bordes (grado $2 \mathrm{n}=2$ ) y alta erosión de las superficies (grado $4 \mathrm{n}=1$, grado $2 \mathrm{n}=2$ ).

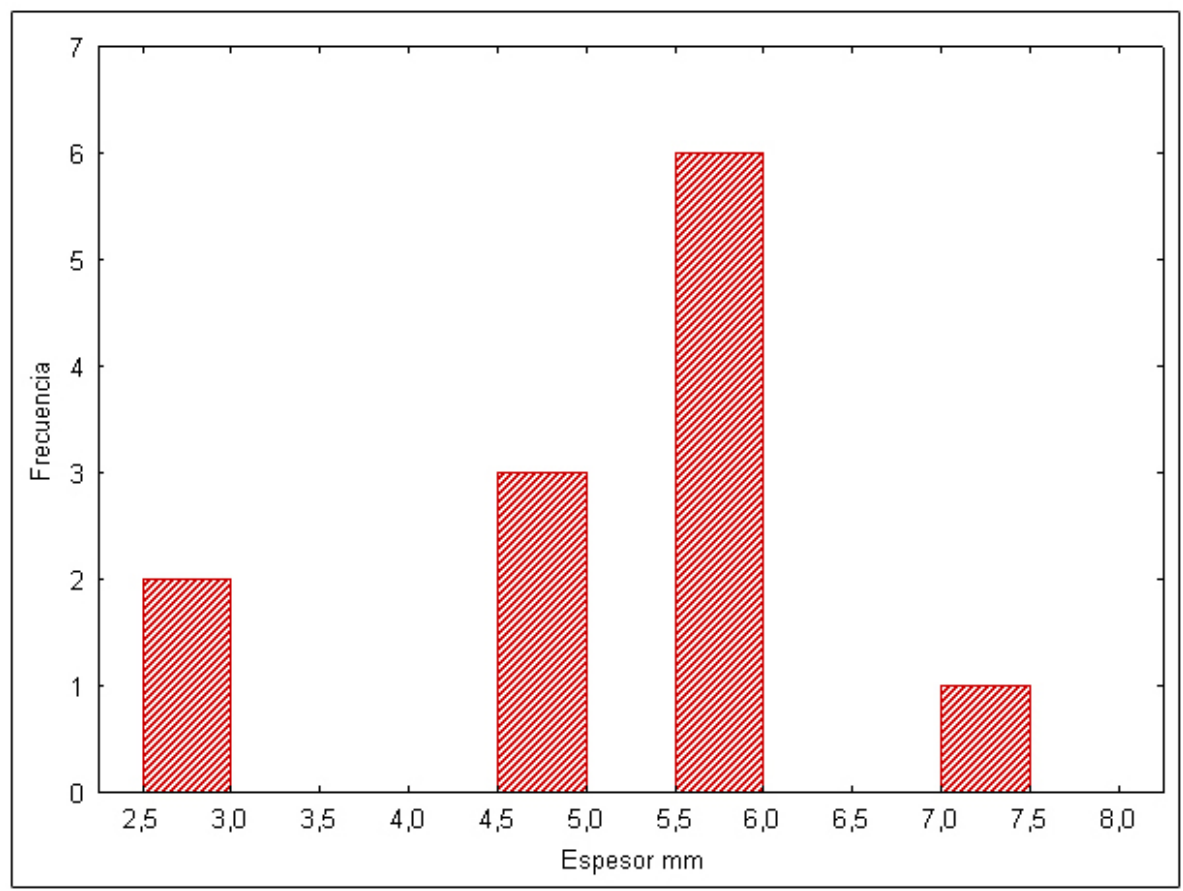

Figura 9.5. Histograma de los valores de espesor de los fragmentos cerámicos procedentes de Los Chilenos.

Dada la poca cantidad de tiestos recuperados en esta localidad, el análisis de los mismos será presentado en conjunto. El espesor oscila entre $3 \mathrm{~mm}$ y $7 \mathrm{~mm}$ con una moda y una mediana de $6 \mathrm{~mm}$ (Figura 9.5). La dureza oscila entre 3 y 4 y la fractura es en la mayor parte de los casos irregular $(n=10)$ y regular en dos fragmentos, en tanto en los restantes casos no pudo determinarse por el pequeño tamaño de los fragmentos. Tanto la baja dureza como la fractura irregular predominante estarían indicando la cocción de las vasijas cerámicas a bajas temperaturas (Orton et al. 1997). Seis fragmentos presentan color negrogris en toda su sección, lo que puede relacionarse con un tiempo de cocción corto o con la generación de atmósfera reductora, en tanto en los restantes casos $(n=8)$ se observaron colores negro-gris en la sección interior y naranja-marrón-rojo en la exterior (Catella 2004) (Figura 9.6), indicadores de condiciones de cocción incompleta en atmósfera oxidante (P.C.R.G 1995). 


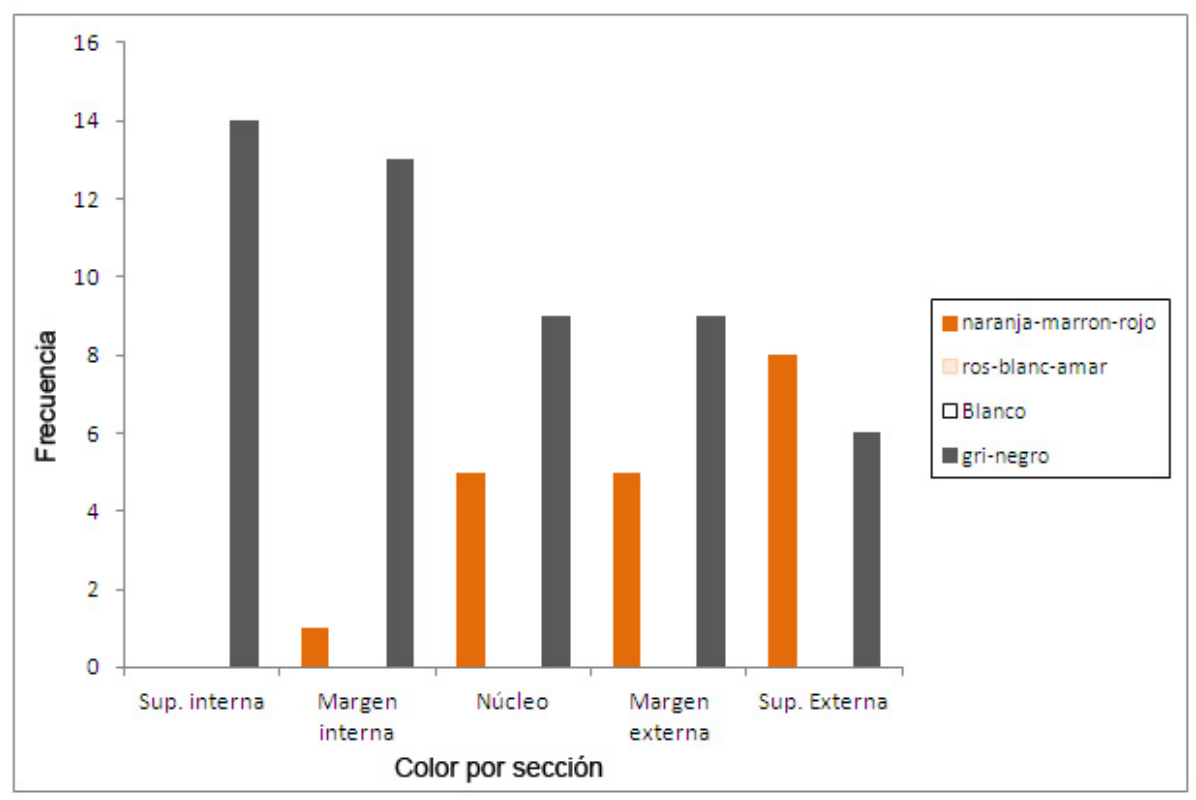

Figura 9.6. Distribución de colores en corte fresco de los fragmentos cerámicos de la localidad arqueológica Los Chilenos.

Las pastas observadas con lupa binocular presentan entre $2 \%$ y $30 \%$ de inclusiones, de las cuales la mitad presentan menos de $10 \%$, el $43 \%$ posee entre $10 \%$ y $20 \%$ y sólo en el $7 \%$ se encuentran entre $20 \%$ y $30 \%$ de inclusiones. Las partículas se encuentran distribuidas predominantemente de manera regular (en sólo 4 casos de forma irregular) y con una selección entre buena y muy buena, donde ninguna inclusión supera los 0,5 $\mathrm{mm}$ de diámetro. Las formas son sub-redondeadas y en, menor proporción, redondeadas y sub-angulares. Entre los antiplásticos que pudieron ser identificados se encuentran cuarzo (en todas las pastas) y tiesto molido $(\mathrm{n}=3$ ), a las que se suman rocas negras, marrones y blancas indeterminadas (Catella 2004).

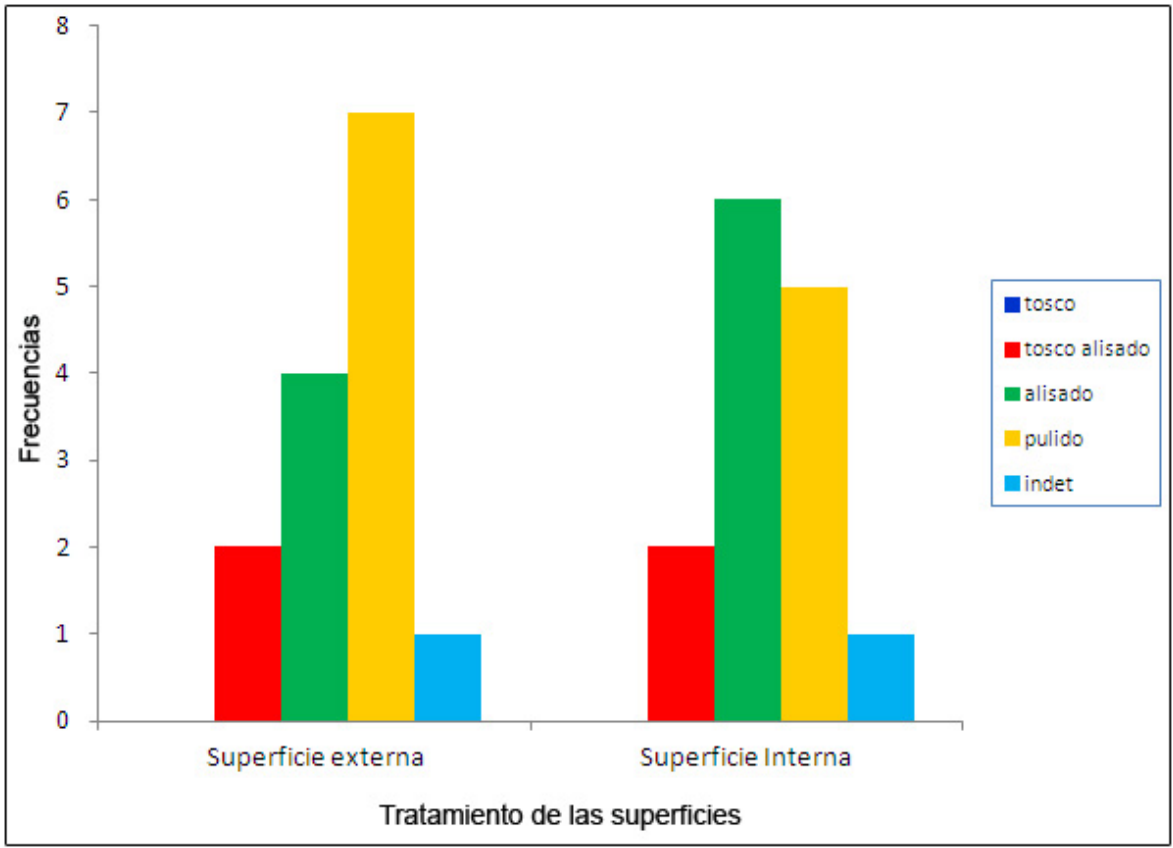

Figura 9.7. Tratamiento de las superficies interna y externa de los fragmentos cerámicos recuperados en la localidad arqueológica Los Chilenos. 
En relación con el tratamiento de la superficie, predominan los tiestos pulidos en la cara externa que presentan a su vez engobe rojo $(n=7)$ y, en menor proporción, alisados $(n=4)$ y tosco alisados $(n=2)$. En la superficie interna, en cambio, se encuentra un mayor número de tiestos alisados $(n=6)$, seguidos por pulidos ( $\mathrm{n}=5$ ) y tosco alisados ( $\mathrm{n}=2$ ), ninguno de ellos con evidencias de engobe (Figura 9.7). Se recuperó un solo fragmento de borde de $4 \mathrm{~mm}$ de espesor, de tipo evertido, con labio convexo e incisiones rectas paralelas sobre éste, a partir del cual se estimó que la vasija correspondiente tendría un diámetro de entre $12 \mathrm{~cm}$ y $24 \mathrm{~cm}$ (Catella 2004).

\subsubsection{Localidad San Martín}

\subsubsection{Colección San Martín}

Esta colección se encuentra conformada por 9 fragmentos recolectados por la Prof. Nora Cinquini, en inmediaciones del sitio 1 de San Martín. Por tratarse de colecciones analizadas en el mismo museo en que se encuentran depositadas, donde no se cuenta con una lupa binocular para hacer las observaciones de pastas, las características de las inclusiones no fueron analizadas en este caso. El espesor de los tiestos oscila entre 4,5 $\mathrm{mm}$ y 7,2 $\mathrm{mm}$, con una mediana de $6 \mathrm{~mm}$. Sus pastas son blandas (dureza 3 en todos los casos) y con fractura irregular. Los colores representados corresponden al espectro negro-gris y naranjamarrón-rojo, encontrándose cuatro fragmentos de color-negro en toda la sección, uno de color naranja y los restantes con variaciones de estos dos espectros cromáticos en su sección. Estas características, también en este caso, estarían indicando su cocción en una atmósfera oxidante incompleta, a baja temperatura (Figura 9.8).

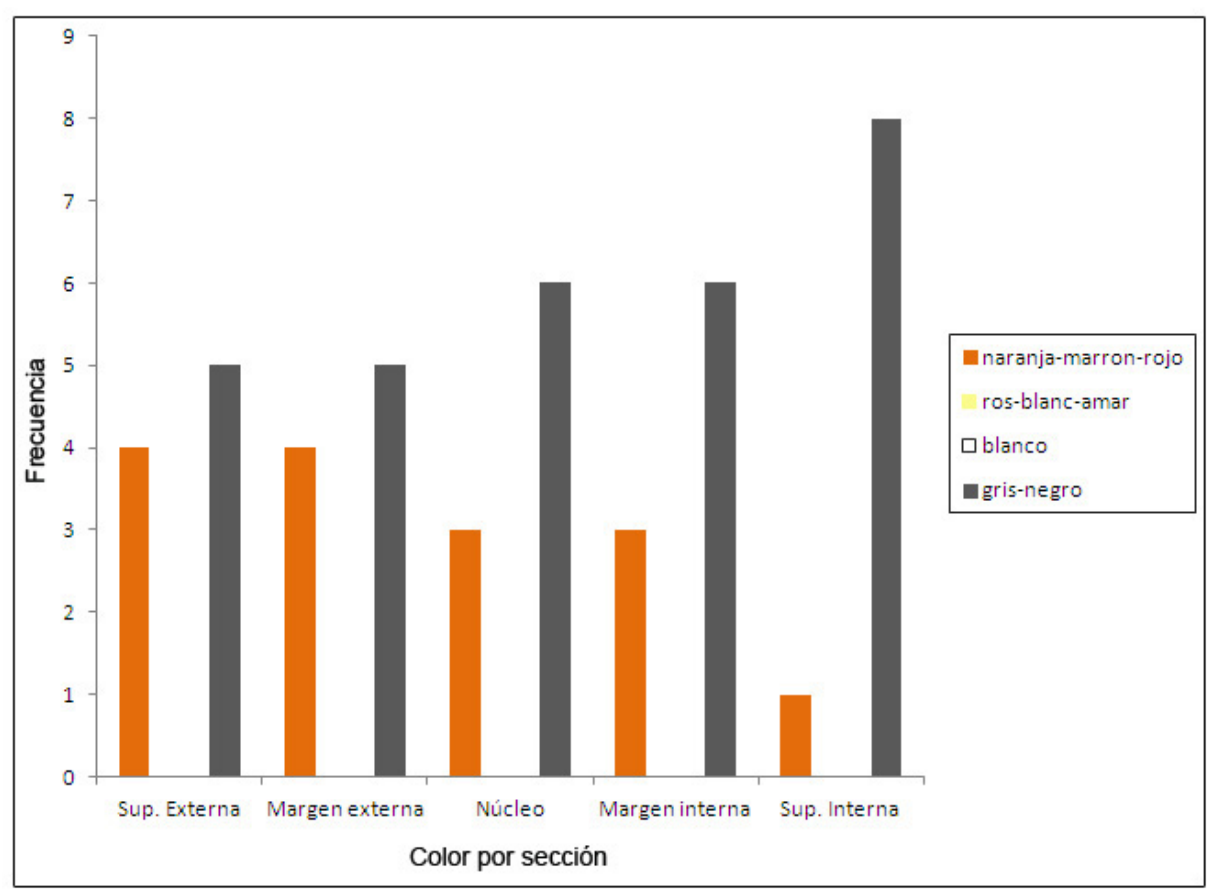

Figura 9.8. Distribución de colores en corte fresco de los fragmentos cerámicos de la colección San Martín. 
En cuanto al tratamiento de las superficies, predomina el alisado en la cara externa $(n=6)$, seguido por el tosco $(n=2) y$, por último, el tosco alisado $(n=1)$. En la superficie interna, la mayor parte de las piezas se encuentra toscamente alisadas $(n=6)$ y, en menor proporción, alisadas $(n=3)$ (Figura 9.9). Los tiestos no se encuentran decorados, con excepción de un fragmento que presenta decoración incisa. Finalmente, 7 de los fragmentos corresponden a bordes de tipo recto y con labio convexo, a partir de los cuales se proyectó un diámetro de boca de entre $6 \mathrm{~cm}$ y $8 \mathrm{~cm}$ en un caso y mayor a $15 \mathrm{~cm}$ en otros 4 fragmentos.

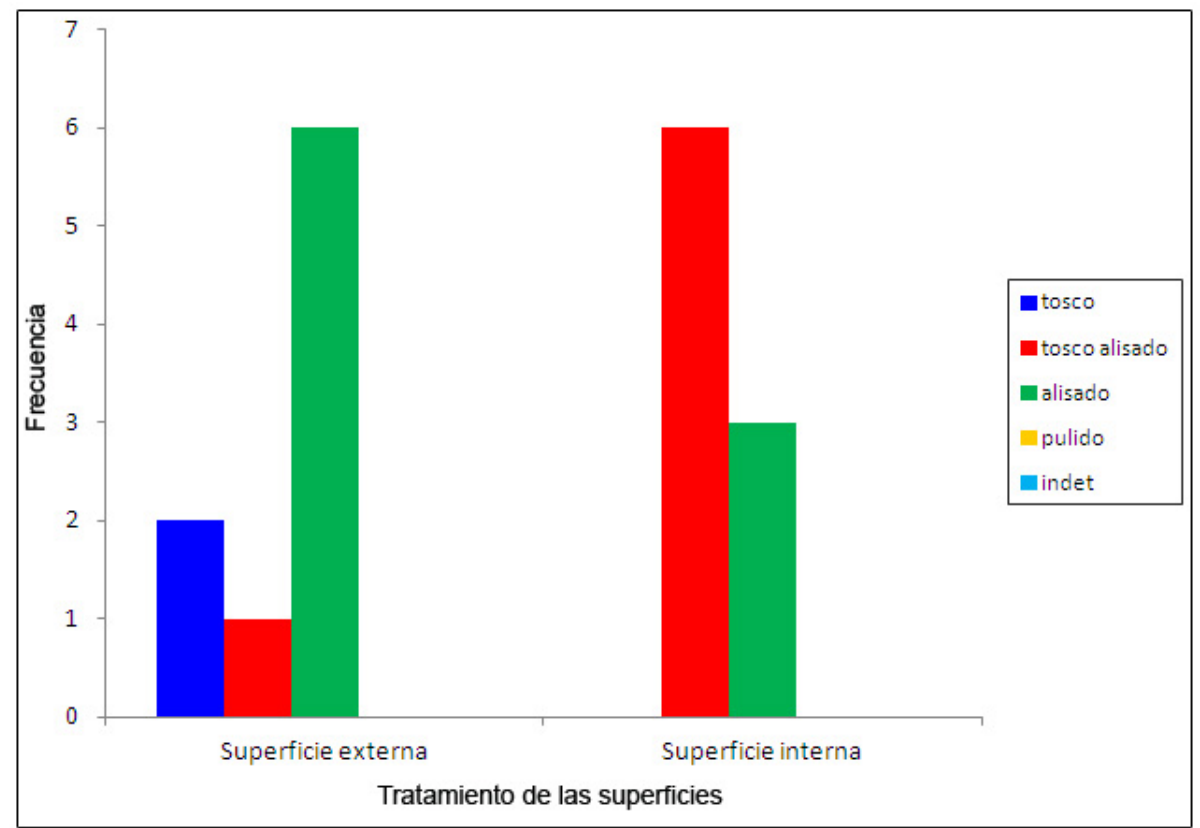

Figura 9.9. Tratamiento de las superficies interna y externa de los fragmentos cerámicos de la colección San Martín.

\subsubsection{Laguna Chasicó}

La muestra cerámica proveniente de la laguna Chasicó está conformada por 35 tiestos, dos de ellos fueron recuperados por el Sr Peluso (habitante de la localidad de Chapalcó) en inmediaciones de los sitios 2 y 3 y los restante 33 provienen de recolecciones superficiales sistemáticas llevadas a cabo en el sitio 1 (cuatro fragmentos), el sitio 2 (19 fragmentos) y el sitio 3 (diez fragmentos). Dada la escasa cantidad del registro cerámico y la similitud de los fragmentos recuperados, la información será presentada en conjunto, realizando las distinciones que sean necesarias. La muestra presenta un estado de conservación variable, con depositación de sales en la mayor parte de los tiestos $(n=25)$ y predominio, a pesar de tratarse de una colección de superficie, de los fragmentos con rodamiento y erosión leve ( $\mathrm{n}=$ 22). No se registró ningún fragmento con alto grado de rodamiento, observándose sólo 2 con alto grado de erosión: Los tiestos restantes presentan un grado medio de rodamiento $(n=3)$ y erosión $(n=11)$, lo cual indicaría un tiempo de exposición corto y un bajo grado de transporte hídrico. El espesor presenta una mayor dispersión que en otros sitios, oscilando entre $3,87 \mathrm{~mm}$ y $10,7 \mathrm{~mm}$, con una moda de $5 \mathrm{~mm}$ y una mediana de 5,87 mm, encontrándose las piezas más espesas en el sitio 2 y el sitio 3 (Figura 9.10). 


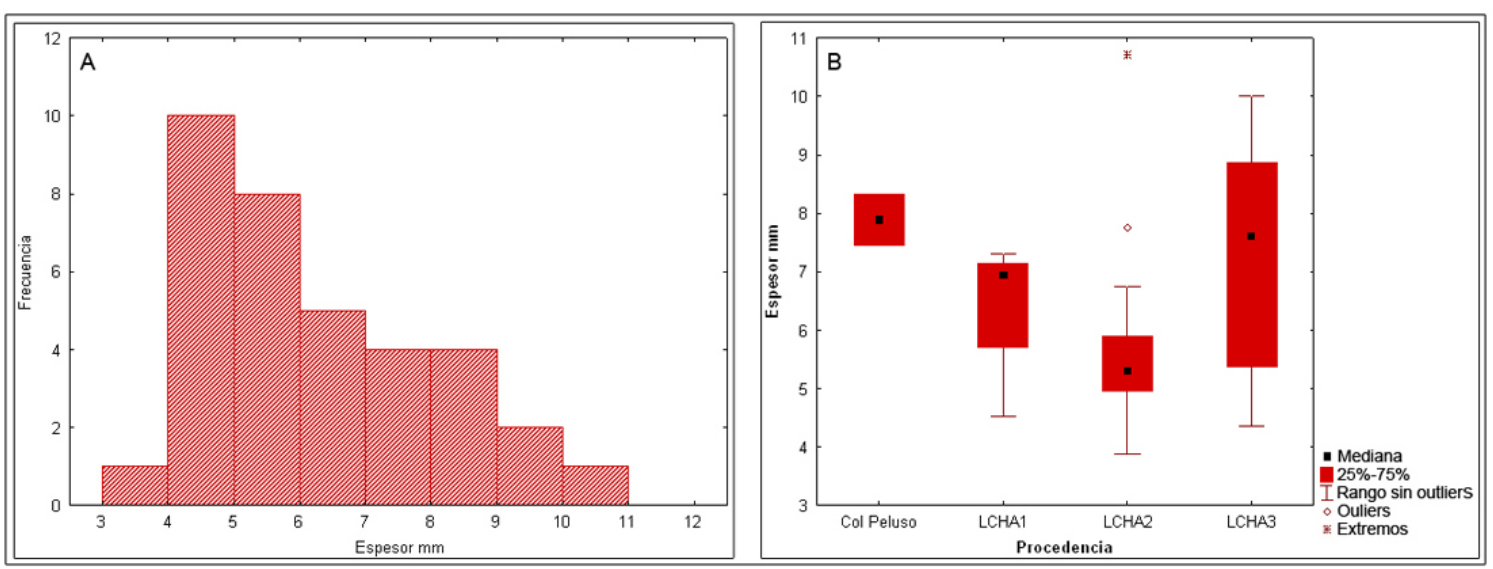

Figura 9.10. Espesor de los fragmentos cerámicos procedentes de la laguna Chasicó. A-histograma sin distinguir sitio de procedencia. B- Box Plot distinguiendo sitio de procedencia.

En relación con las variables tecnológicas, indicadoras del modo de manufactura, predominan aquellos fragmentos con dureza $3(n=25)$ y, en menor proporción, dureza $2(n=7)$ y dureza $4(n=$ 1). Son mayoritarios los tiestos con fractura irregular $(n=29)$, observándose fractura regular en 6 casos, correspondientes a los sitios 2 y 3 . Los colores de pasta presentes en la muestra son aquellos correspondientes al espectro naranja-marrón-rojo y gris-negro que, en la mayor parte de los casos $(n=29)$, se alternan en las distintas secciones del perfil, predominando los colores del espectro 1 en las secciones exteriores y los del espectro 4 en las interiores (Figura 9.11). Se encuentran sólo ocho fragmentos en los que el color es homogéneo en toda la sección, cinco dentro del espectro gris-negro y tres en el espectro naranja-marrón-rojo. En este caso también, las características de la fractura y la dureza estarían indicando una cocción a baja temperatura, en tanto el color de la pasta es indicadora de que ésta ocurrió en una atmósfera oxidante que, en la mayor parte de los casos, habría resultado incompleta. La técnica de manufactura pudo ser inferida, por la presencia de grietas, surcos y/o costuras, en 10 fragmentos y en dos casos pudo establecerse que los rollos utilizados tendrían, aproximadamente, entre $17 \mathrm{~mm}$ y $18 \mathrm{~mm}$ de ancho.

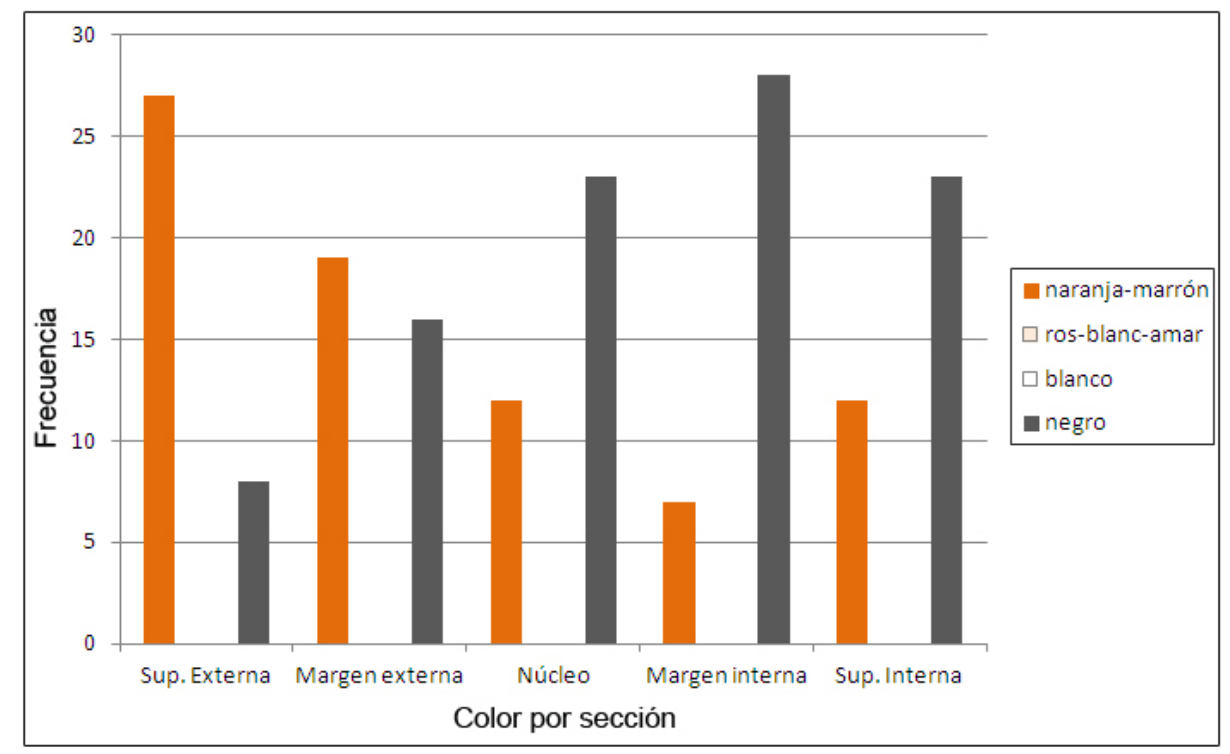

Figura 9.11. Distribución de colores en corte fresco de los fragmentos cerámicos de laguna Chasicó. 
Observados en lupa binocular, los cortes frescos presentan pastas con entre 5 y $40 \%$ de inclusiones, predominando las compuestas por entre un 20 y $30 \%(n=19)$, seguidas por aquellas con entre 10 y $20 \%$ de inclusiones $(n=6)$ y en menor proporción aquellas con menos del $10 \%$ de inclusiones $(n=4)$ o entre 30 y $40 \%(n=3)$. La porción no plástica tiene una distribución regular y una selección entre moderada $(n=13)$ y buena $(n=15)$, con algunos pocos fragmentos en los que la selección es escasa $(n=3)$ o muy buena ( $n=1)$, lo que se correlaciona con el pequeño tamaño de las inclusiones, que sólo en seis tiestos superan el milímetro de diámetro. Las formas de las inclusiones más representadas son la sub-redondeada, presente en 29 tiestos, la angular en 9 tiestos y la redondeada y sub-angular en cinco y cuatro fragmentos respectivamente. Entre las inclusiones que pudieron ser determinadas se encuentran el cuarzo, presente en todas las pastas, cuarcita en cuatro, mica en tres tiestos y tiesto molido en dos. Otras rocas de colores marrón, negro y blanco, no pudieron determinarse debido a los bajos aumentos empleados.

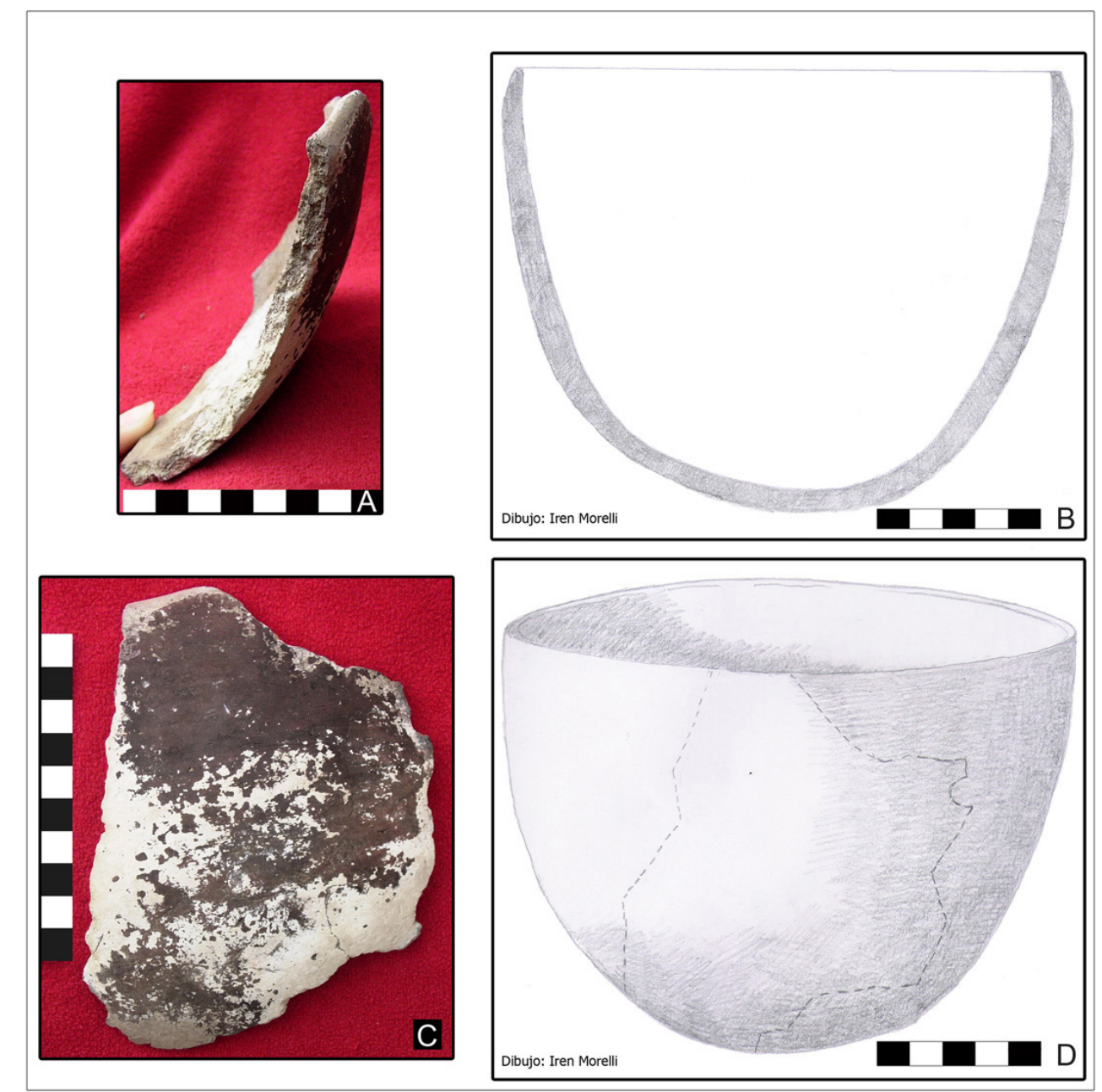

Figura 9.12. Reconstrucción de la forma de una vasija a partir de un fragmento procedente de laguna Chasicó que comprende un sector de borde, un porcentaje del cuerpo y se extiende hasta el inicio de la base. A- perfil del fragmento; B- reconstrucción del perfil de la vasija; C- vista de la superficie externa del fragmento; D- reconstrucción de la forma de la vasija. 
En relación con la forma que pudieron tener las vasijas, se recuperaron un total de siete fragmentos de borde, uno recolectado por el Sr. Peluso y los otros seis recuperados por la autora en Laguna Chasicó sitio $1(n=1)$, Laguna Chasicó sitio $2(n=4)$ y Laguna Chasicó sitio $3(n=1)$. Se trata de bordes rectos o levemente evertidos, con labios convexos y espesores entre $3,5 \mathrm{~mm}$ y $6 \mathrm{~mm}$, la proyección de las bocas de las vasijas a partir de estos fragmentos indica diámetros entre $15 \mathrm{~cm}$ y $25 \mathrm{~cm}$. Un fragmento presenta un agujero de suspensión de $6,2 \mathrm{~mm}$ de diámetro en la superficie externa y $4 \mathrm{~mm}$ en la interna, localizado a $25 \mathrm{~mm}$ del borde. En un caso, debido al tamaño del fragmento, el que comprende un sector de borde, un porcentaje del cuerpo y se extiende hasta el inicio de la base, se pudo realizar una reconstrucción de la forma de la vasija, la cual consiste en un cuenco abierto de contorno simple, con un diámetro de boca de entre $17 \mathrm{~cm}$ y $18 \mathrm{~cm}$ de diámetro y una altura de $13 \mathrm{~cm}$ aproximadamente, con un agujero de suspensión, o remiendo, de sección bicónica, localizado a $5 \mathrm{~cm}$ del borde, cuyo diámetro no pudo ser estimado, por estar ubicado en el borde de fractura (Figura 9.12). Ambas superficies se encuentran toscamente alisadas, observándose en la superficie externa algunos posibles restos de pintura roja o engobe. También pudieron observarse en este fragmento variaciones de color en los distintos sectores de la vasija, siendo éste marrón homogéneo en cercanías del borde, y negro en el núcleo y margen interna y marrón en margen externa, en el sector de cuerpo y base.

Los tiestos cerámicos recuperados en la laguna Chasicó no presentan decoración, con excepción del pigmento rojo observado en la vasija arriba descripta y de los tres fragmentos recolectados por el Sr. Peluso. Estos últimos corresponden a un fragmento de cuerpo y dos fragmentos, uno de borde y uno de cuerpo, que remontan entre sí. Los tres presentan engobe rojo en la superficie externa y han sido decorados con motivos geométricos realizados mediante incisión e impresión. El primero de los fragmentos presenta decoración incisa realizada por surco rítmico en la superficie externa, en tanto en los otros dos fragmentos se utilizó tanto surco rítmico como impresión con un elemento circular hueco (caña o vértebra de pez). En este último caso, la decoración más elaborada se encuentra en la superficie externa, pero también se registró un arreglo lineal de impresiones circulares sobre la cara interna, cerca del borde, e incisiones lineales sobre el labio (Figura 9.13).

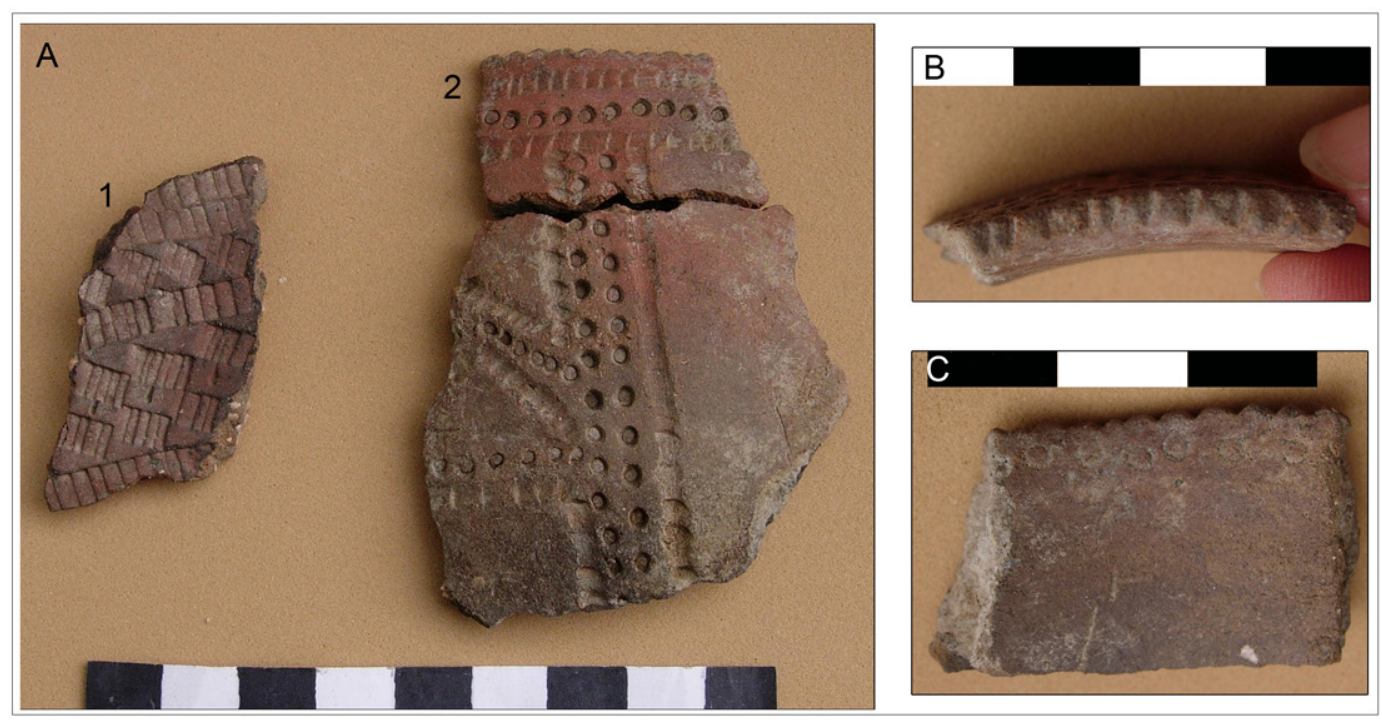

Figura 9.13. Cerámica decorada recolectada por el Sr. Peluso en la laguna Chasicó. A- decoración sobre la superficie externa; B decoración sobre la porción de borde del fragmento 2; C- decoración en superficie interna adyacente al borde del fragmento 2 . 


\subsection{La tecnología cerámica en la cuenca del arroyo Chasicó}

En el área de estudio, la tecnología cerámica se caracteriza por encontrarse representada en muy baja frecuencia, tanto si se la cuantifica de manera absoluta como si se la relaciona con otros materiales como los artefactos líticos, y, generalmente, con un alto grado de fragmentación. Si bien la muestra es muy chica, presenta la particularidad de estar compuesta por algunos fragmentos de mayor tamaño, que permitieron realizar inferencias acerca de la forma y dimensiones de la vasija, rasgos para los que aún se cuenta con poca información en el SE de la Región Pampeana y NE de Patagonia.

En relación con las características de este tipo de contenedores y sus condiciones de fabricación, los estudios realizados permiten proponer que: a) se confeccionaron formas globulares abiertas, de tamaño pequeño a mediano (diámetros estimados no mayores a $24 \mathrm{~cm}$ ), sin asas aunque, en algunos casos, presentan orificios que pudieron ser utilizados para su suspensión; b) sus paredes muestran espesores que varían entre $2,25 \mathrm{~mm}$ y $10,72 \mathrm{~mm}$, con el $50 \%$ de la muestra comprendido entre los valores 4,52 mm y 6,25 mm (primer y tercer cuartil), encontrándose los espesores más gruesos representados en la cuenca inferior del arroyo, aunque las medianas no presentan variación entre los sectores medio e inferior de la cuenca (Figura 9.14). El aumento en el espesor de los contenedores hacia la cuenca inferior podría responder a: a) utilización de la cerámica en actividades que requirieron de contenedores de mayor tamaño, b) menor inversión de tiempo y esfuerzo en su fabricación consecuencia de una mayor movilidad residencial (Simms et al. 1997), c) menor necesidad de optimizar el aprovechamiento calórico consecuencia de la alta disponibilidad de leña en la zona (Eerkens 2003), d) problemas de muestreo, relacionados con la representación diferencial de las distintas partes de una vasija (bases que suelen ser más gruesas que los bordes). Lamentablemente, dado el pequeño tamaño de la muestra, no es posible determinar cuál de estas opciones es más factible.

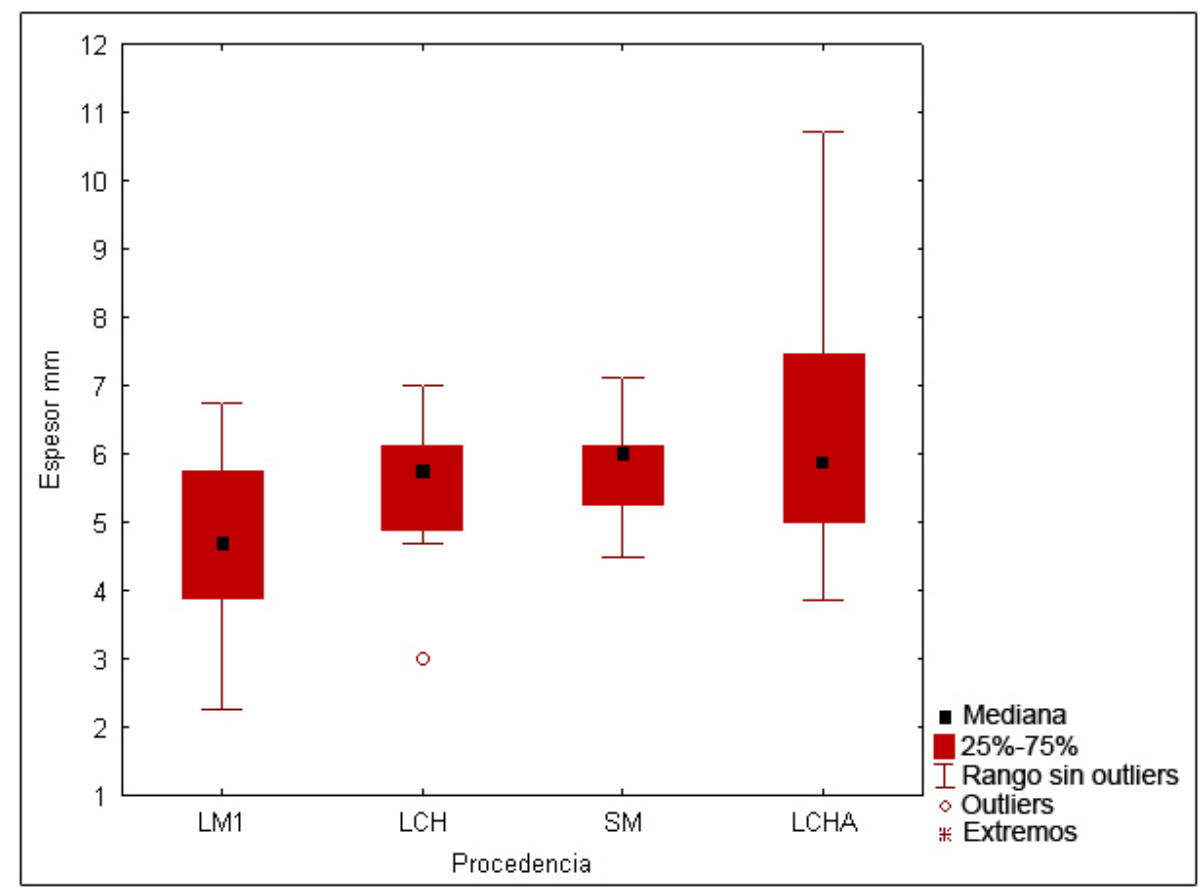

Figura 9.14. Box plot representando la dispersión en espesores en las localidades arqueológicas de la cuenca del arroyo Chasicó. LM1= La Montaña 1 (cuenca superior) LCH= Laguna Los Chilenos (cuenca superio/media) SM= San Martín (cuenca media) LCHA= Laguna Chasicó (cuenca inferior). 
Los colores de pasta representados indican la utilización de arcillas con porcentajes más o menos elevados de hierro, con excepción de aquellas presentes en el sitio La Montaña 1, donde la presencia de colores correspondientes al espectro 2 (rosa claro-amarillo-blanco) se relacionan con el empleo de arcillas con bajo contenido de este mineral. Las pastas, en general, se encuentran de bien a moderadamente seleccionadas $\mathrm{y}$, en algunos fragmentos, escasamente seleccionadas con antiplásticos de formas predominantemente sub-redondeadas y sub-angulares de cuarzo y en menor proporción mica y tiesto molido, junto a otras rocas negras, blancas y marrones que no pudieron ser determinadas. El predominio de inclusiones redondeadas, estaría indicando que no hubo un procesamiento de materiales, mediante por ejemplo molienda, para su posterior incorporación a la pasta, sino que, más probablemente, las arcillas fueron utilizadas sin mayor procesamiento, fueron limpiadas para eliminar aquellas inclusiones de mayor tamaño o bien se incluyeron partículas disponibles, sin un procesamiento previo.

El predominio de fractura irregular y pastas blandas permiten inferir, si bien no de manera inequívoca, la cocción a bajas temperaturas. La gama de colores representada en la muestra (diferentes tonos de marrón, gris y negro) y las variaciones de color en un mismo fragmento (piezas con manchas y cambios del marrón al gris en la sección), indican que el proceso de cocción se habría dado de manera incompleta en atmósfera oxidante o bien bajo condiciones de cocción variables. Sin embargo, no puede descartarse tampoco que los colores negros respondan a la absorción de materia orgánica por el uso de la pieza sobre el fuego (Orton et al. 1997; Skibo 1992).

En cuanto a la terminación de las vasijas, éstas se encuentran alisadas o toscamente alisadas, siendo escasas las superficies pulidas. En los pocos casos de tiestos pulidos, este ha sido realizado de modo expeditivo, obteniéndose una superficie brillante y menos permeable, pero irregular. A su vez, la proporción de tiestos decorados es baja, cuando esta se encuentra presente se ubica en el sector adyacente al borde y consiste en incisión o incisión más pintura roja. También se encuentran fragmentos en los que se aplicó un baño o engobe, que si bien puede haber tenido una función decorativa, también cumple con la función de impermeabilizar.

En líneas generales, la cerámica presente en la cuenca del arroyo Chasicó muestra una baja inversión de tiempo y energía en la preparación de las pastas y terminación de las vasijas, lo que a su vez es acompañado por una escasa estandarización, tanto en el tipo de tratamiento de las superficies como en el espesor de las paredes y las inclusiones representadas en la pasta. Estas características pueden relacionarse con su fabricación en contextos de movilidad residencial relativamente altos (Simms et al. 1997; Eerkens 2003). Excepciones a esto lo constituyen los fragmentos decorados de la Montaña sitio 1 y de de la laguna Chasicó (colección Peluso). En el caso de La Montaña sitio 1, los fragmentos decorados presentan espesores menores a $5 \mathrm{~mm}$ e inclusiones que, en algunos casos, superan los 4 $\mathrm{mm}$ La presencia de estos antiplásticos tan grandes hace más trabajoso el modelado o decoración de la vasija, por lo que la decisión de mantenerlos implica un aumento en el trabajo invertido, que puede estar relacionado con la búsqueda de ciertas propiedades particulares con fines, por ejemplo, decorativos (B. Balesta com. pers. 2009). Estas pastas se diferencian también del resto de las vasijas por su color, el que denota baja proporción de hierro en la arcilla. Los fragmentos de la colección Peluso también muestran mayor inversión de trabajo en su manufactura, en este caso dado por la representación de complejos motivos decorativos, engobe y superficies bien alisadas y pulidas. 


\subsection{La tecnología cerámica en el contexto del sur de la Región Pampeana y el NE de Patagonia}

En los apartados precedentes se desarrollaron las características de los contenedores cerámicos recuperados en la cuenca del arroyo Chasicó, ahora bien, ¿qué similitudes o diferencias pueden establecerse entre estos materiales y aquellos procedentes de otras áreas de las Región Pampeana y el NE de Patagonia? ¿Qué información pueden ofrecernos en relación con las estrategias de movilidad y uso del espacio y los recursos?

La alfarería de la Región Pampeana y del NE de Patagonia ha sido caracterizada como una cerámica cocida a bajas temperaturas, en atmósfera oxidante, generalmente de colores rojizo, marrón y gris y con manchas de cocción. Las formas (para momentos pre-hispánicos), aunque pocas veces pueden ser reconstruidas, son globulares y sin asas, algunas con agujeros de suspensión. La manufactura se realiza por enrollamiento o, en el caso de las vasijas más pequeñas, por modelado y las superficies se terminan mediante alisado o pulido, sobre el que, en ocasiones, se aplica engobe y/o se realiza una decoración incisa geométrica (Aldazabal 1991; Bórmida 1962; Di Prado 2013; Eugenio y Aldazabal 2004; González 2005; Pérez Meroni y Blasi 1997; Politis et al. 2001; Prates 2004; Prates et al. 2010). A pesar de estas semejanzas, dadas por la similitud en las formas y los motivos decorativos, existen algunas variaciones areales, encontrándose al norte del río Salado mayor abundancia de material cerámico, evidencias de manufactura local y mayor diversidad en cuanto a sus formas y diseños decorativos (Aldazábal 1991; González de Bonaveri et al. 2000; Politis et al. 2001; González 2005). Al sur del río Salado en cambio, el material cerámico es escaso y con un alto grado de fragmentación (Bórmida 1962; Catella y Saghessi 2007; Eugenio y Aldazábal 2004; Madrid 1997; Prates 2004; Outes 1908; Vignati 1931).

Las diferencias en la frecuencia y variabilidad de los materiales cerámicos al sur y al norte del río Salado, sumado a las similitudes tecnológicas y decorativas entre ambas subregiones y a la ausencia de evidencia de fabricación al sur de dicho río, llevaron a indagar acerca de los contextos de producción y circulación de los contenedores cerámicos. Eugenio et al. (1987-1988) consideraron que la falta de leña en muchos sectores de la provincia de Buenos Aires pudo haber incidido en la baja frecuencia de los materiales cerámicos, ya que las zonas aptas para su producción se limitarían a los ambientes con abundancia de combustible, como las selvas mixtas o marginales, el distrito del Tala y los sectores de Tandilia en los que abunda el curro (Colletia cruciata). En cambio, Politis y Madrid (2001) -si bien consideraron que la leña no habría sido un recurso determinante debido a que las bajas temperaturas a las que se coció la cerámica pueden ser alcanzadas mediante la utilización de arbustos-, no descartaron que la cerámica haya sido producida en el noreste y Depresión del Salado y desde allí haya circulado en redes de intercambio vinculadas con la ampliación de las redes sociales y de alianzas, durante el Holoceno tardío. Por otra parte, la diferencia en la abundancia relativa de alfarería en una y otra región también ha sido interpretada como consecuencia de diferentes estrategias de movilidad. En el sector norte, la presencia de sitios con todas las etapas de manufactura cerámica representadas, sustentarían la idea de una menor movilidad de los grupos y mayor inversión de tiempo en la manufactura y diseño de las vasijas (Frère et al. 2004). Por otra parte, al sur del Salado, la escasez de alfarería respondería a un menor tiempo de ocupación de los sitios, por lo que la cerámica sería fabricada para ser utilizada de manera ocasional o bien tendría un carácter altamente conservado (Aldazabal 1991; Politis et al. 2001).

El incremento en los estudios sobre las características de las pastas con las que se confeccionaron los contenedores cerámicos, permitió observar recurrencias, pero también variaciones, en la frecuencia con 
que se encuentran representados los tipos de antiplástico, sus tamaños y asociaciones (Di Prado 2013; Madrid 1997; Madrid y Di Prado 2008; Gonzalez et al. 2000; Mazzanti y Porto López 2007). Sobre la base de estas características, Mazzanti y Porto López (2007) plantearon que previo a la conquista, en Tandilia la producción de alfarería se habría realizado a baja escala y supeditada a los requerimientos del grupo doméstico, en tanto las redes de larga distancia pudieron funcionar como un mecanismo más para su circulación. Esta diferencia en las frecuencias también ha sido observada en relación con la Pampa Seca, donde la densidad de fragmentos es mayor, observándose a su vez ciertas diferencias en las características de las pastas y en los tratamientos de superficie (Berón 2004).

La Figura 9.15 muestra la distribución, en el sur de la Región Pampeana y NE de Patagonia, de la frecuencia de fragmentos cerámicos en términos absolutos y en relación con los artefactos líticos, utilizándose también las técnicas de interpolación kriging e $I D W$ (ver Capítulo 5 para un detalle del procedimiento y los motivos de elección de ambas técnicas). Las frecuencias cerámicas en los sitios del sur de la Región Pampeana y NE de Patagonia son muy variables, independientemente de la distancia a la que estos se encuentren unos de otros. Dado que los métodos de interpolación trabajan sobre el supuesto de autocorrelación, su ausencia genera variaciones más o menos importantes en los resultados, como consecuencia de la utilización de una u otra técnica. De cualquier modo, los modelos aquí presentados permiten observar algunas tendencias que, aunque muy generales, muestran las variaciones espaciales en la densidad de los materiales cerámicos. De manera concordante con lo expuesto previamente,

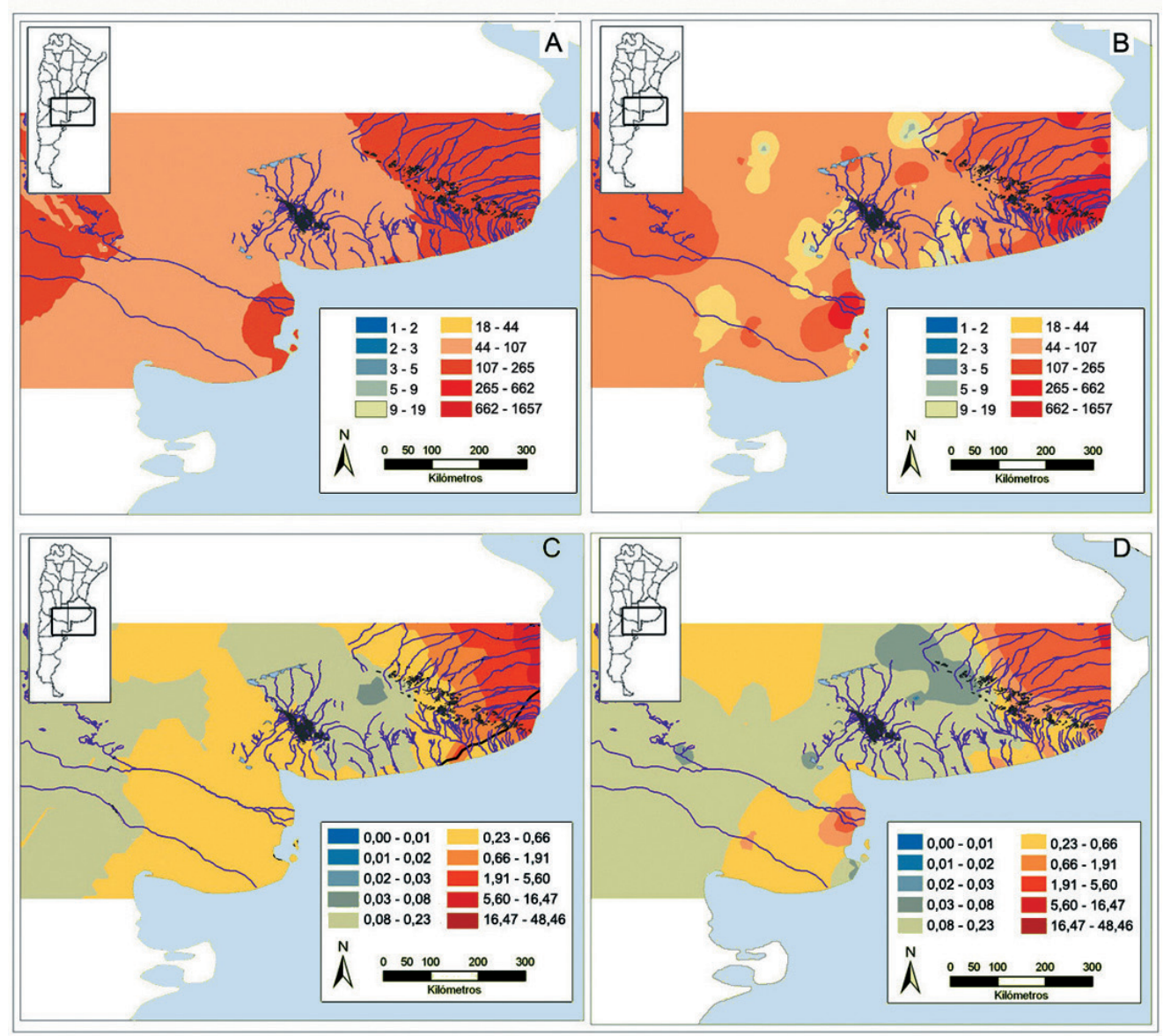

Figura 9.15. Modelado de la frecuencia de aparición de material cerámico utilizando las técnicas de interpolación kriging y IDW. A- Interpolación de frecuencias absolutas utilizando el método kriging; B- Interpolación de frecuencias absolutas utilizando el método IDW; C- Interpolación de frecuencias relativas utilizando método kriging; D- Interpolación de frecuencias relativas utilizando el método $I D W$. 
las mayores densidades, tanto absolutas como relativas, se encuentran en al noreste de las sierras de Tandilia, en tanto las restante áreas se caracterizan por la baja densidad de este tipo de materiales. La única excepción a esto la constituye la desembocadura del río Colorado, donde se observa un leve aumento en las frecuencias relativas y absolutas.

Por otra parte, se vincularon algunas de las características tecnológicas de la cerámica de la cuenca del arroyo Chasicó con aquellas descriptas para las sierras de Tandilia (Mazzanti y Porto López 2007), el área interserrana (Madrid 1997), Ventania (Madrid 1997 y datos presentados en esta tesis) y Sur (datos presentados en esta tesis). Dado que la información es diversa, se consideraron sólo aquellas variables para las que se contaba con información en todas las áreas. Las variables empleadas fueron; a) espesor de los fragmentos, b) porcentaje de inclusiones y c) textura. En todos los casos, se obtuvo el valor de la mediana de cada distribución, a partir del cual se realizó un análisis de cluster, utilizando el método Ward`s con distancias euclideanas (Statistica 8). Los resultados obtenidos reflejan una mayor semejanza entre las muestras de las áreas Interserrana y Tandilia por un lado y Sur y Ventania por otro. Es decir que, tecnológicamente, y en función de las variables consideradas, las cerámicas procedente de las áreas Ventania y Sur presentan mayor similitud entre sí y se diferencian de aquellas recuperadas en el sistema serrano de Tandilia y en el área Interserrana (Figura 9.16).

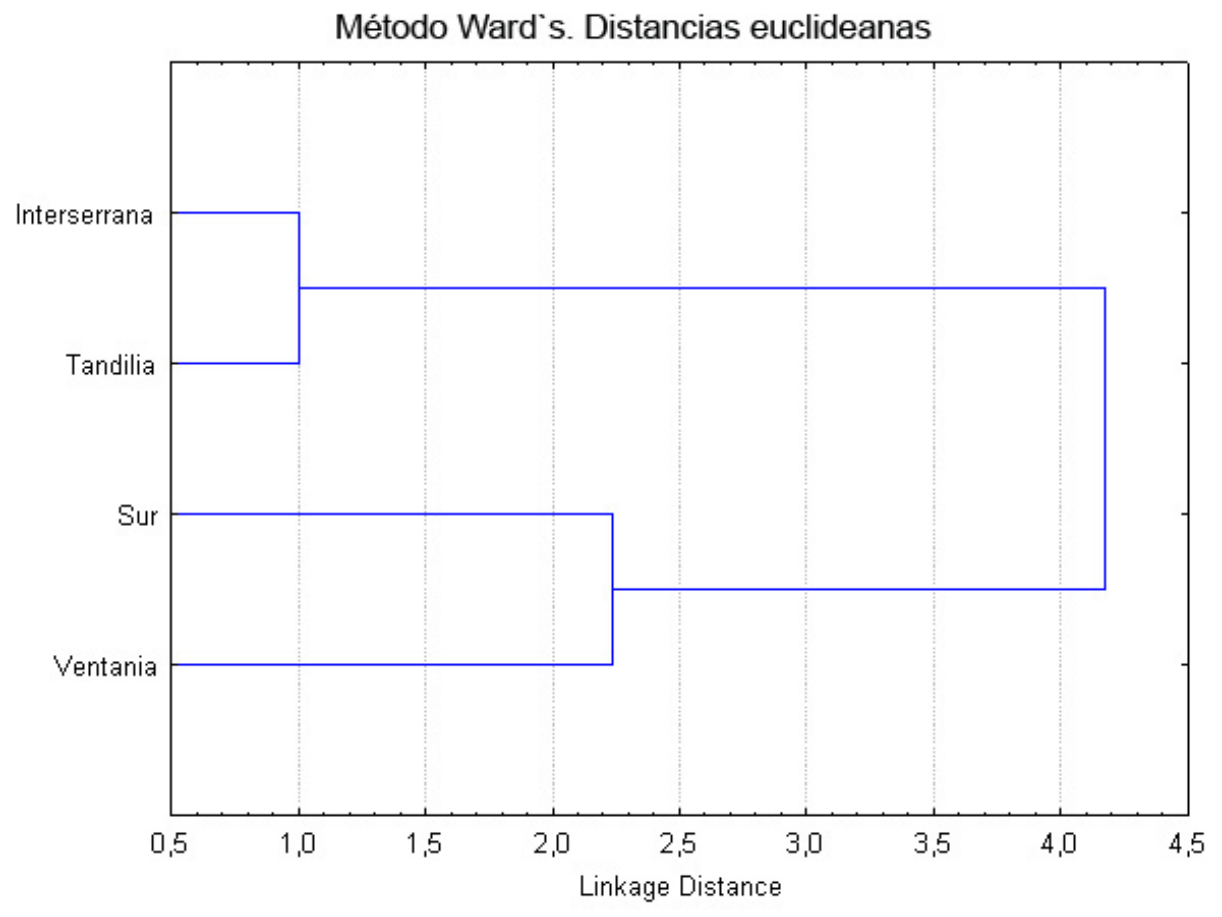

\begin{tabular}{|l|c|c|c|}
\hline Área & $\begin{array}{c}\text { Espesor } \\
(\mathrm{mm})\end{array}$ & Textura & $\%$ inclusiones \\
\hline Interserrana & 6,96 & 1 & 6 \\
\hline Salado & 7,7 & 2 & 3 \\
\hline Sur & 5,6 & 1 & 4 \\
\hline Tandilia & 6 & 1 & 6 \\
\hline Ventania & 5,25 & 3 & 3 \\
\hline
\end{tabular}

Figura 9.16.Análisis cluster entre muestras procedentes de las áreas Interserrana, Tandilia, Sur y Ventania. En la tabla se muestran los valores considerados para generarlo. Textura: 1- fina, 2- media, 3gruesa; \% inclusiones: 1- 15\%-20\%, 2- 20\%-25\%, 3- 25\%-30\%, 4- 30\%-35\%, 5- 35-40\%, 6- 40\%-45\%. 


\subsection{Discusión}

La mayor similitud entre las pastas procedentes de las áreas Ventania y Sur con respecto a las procedentes de Tandilia e Interserrana, pareciera dar sustento a la hipótesis de una manufactura local, supeditada a las necesidades del grupo, lo que deberá explorarse posteriormente por medio de estudios petrográficos y análisis de potenciales fuentes de arcilla en Ventania y la llanura adyacente al sudoeste de dicho sistema serrano. Sin embargo, también se encuentran algunos fragmentos (aquellos correspondientes a la colección Peluso), cuyos motivos decorativos -impresiones circulares, surco rítmico formando rectángulos y líneas incisas sobre el labio- muestran similitudes con la decoración descripta para otras área de la región Pampeana y NE de Patagonia (Di Prado 2013; González y Frère 2010; Prates et. al. 2010). Estos fragmentos, mejor terminados y decorados, pudieron corresponder a vasijas que formaran parte de amplias redes sociales de seguridad e intercambio de información (Bamforth 2009; Binford 1983; Whallon 2006, 2011), si bien dada su baja frecuencia ésta no habría sido la principal manera de acceder a los contenedores cerámicos.

La baja representación de la tecnología cerámica en el área de estudio, tanto si se la considera de manera absoluta, como si se mide en relación con otros materiales arqueológicos como los artefactos líticos, puede estar respondiendo tanto a factores ambientales y/o sociales que limitaron o desmotivaron su uso como a procesos post-depositacionales que afectaron a su conservación. El hecho de que las muestras cerámicas procedan de contextos y ambientes diferentes (estratigrafía, superficie, ambientes lagunares, ambientes fluviales) y hayan sido recolectados tanto por investigadores como por coleccionistas locales (quienes tienen mayores probabilidades de hallar registros poco frecuentes), vuelve menos probable la hipótesis de la acción de agentes postdepositacionales como principal causa de la baja frecuencia absoluta y relativa de este tipo de material.

En relación con los factores ambientales, en el área de estudio se encuentran de manera abundante arcillas y especies leñosas como Prosopis sp y Condalia sp que dan brasa buena y durable y por lo tanto pueden ser usados para la cocción de los contenedores cerámicos (Marconetto 1999), por lo que los factores ambientales no parecen haber funcionado como limitantes en el uso de la tecnología cerámica. Entre los factores culturales, la baja frecuencia podría relacionarse con una mayor movilidad residencial, consecuencia de la cual el uso de los contenedores cerámicos se habría restringido a llevar a cabo actividades específicas (Eerkens 2008; Hill 2006) desarrolladas en ciertos lugares del paisaje (e.g. procesamiento y/o almacenamiento de determinados recursos puntuales, momentos de agregación social, etc.) lo que, a su vez, explicaría la variación en frecuencia entre sitios cercanos y su mayor frecuencia en la desembocadura del los ríos Negro y Colorado, donde la mayor concentración de recursos pudo haber favorecido una menor movilidad residencial.

Por último, la incorporación de contenedores cerámicos en grandes cantidades, suele estar asociada a procesos de intensificación, en los que se implementan nuevas técnicas en el procesamiento de los recursos, a los fines de obtener mayor cantidad de nutrientes (i.e. hervido). En este contexto, su uso se ha relacionado, especialmente, con un aumento en la proporción e intensidad de las semillas procesadas y con la recuperación de la grasa animal y otros nutrientes, mediante el hervidos de los alimentos (Arnold 1985; Church y Lyman 2003; Eerkens 2004; Wolverton et al. 2008). Esta tecnología también permite ampliar el rango de alimentos incorporados, facilitando su detoxificación y/o aumentando la palatabilidad, así como obtener aceites y bebidas fermentadas (Arnold 1985; Braun 1983; Hayden 
1990, 1995; Hoopes 1995). Si bien para otras áreas se ha propuesto un aumento en la intensidad de procesamiento de los recursos faunísticos y una mayor amplitud de la dieta (Barrientos 2001; Martínez 2002, 2010; Politis et al. 2001) durante el Holoceno tardío, las evidencias de este proceso en el área de estudio aún no son claras.

La información actualmente disponible sobre este tipo de materiales es insuficiente para alcanzar resultados concluyentes, pero permite modelar tendencias que plantean nuevas preguntas y vías de análisis en relación con el rol jugado por esta tecnología en las sociedades cazadoras-recolectoras del sur de la Región Pampeana y NE de Patagonia, que deberán ser consideradas con mayor detalle en el futuro. 


\section{I Tecnología Lítica}

En el presente capítulo se exponen los estudios realizados sobre los artefactos líticos, producidos tanto a partir de actividades de talla como por picado, abrasión y/o pulido, recuperados a través de tareas sistemáticas desarrolladas en el marco de este trabajo y de investigaciones previas llevadas a cabo por $\mathrm{F}$. Oliva (Oliva 2014). Se incluyen también, análisis realizados sobre materiales de colecciones privadas, generadas a partir de recolecciones realizadas por aficionados locales.

Los artefactos líticos son los materiales más abundantes en la mayor parte de los sitios arqueológicos de la Región Pampeana en general y de la cuenca del arroyo Chasicó, en particular. Su abundancia, sumada a ciertas particularidades, como la posibilidad de identificar los afloramientos líticos de los que proceden las materias primas empleadas y la versatilidad de sus diseños -que pueden modificarse como respuesta a situaciones particulares planteadas por el ambiente (entendido este como el medio social y natural que lo rodea)- los convierten en una de las principales vías a través de las cuales proponer y poner a prueba hipótesis y modelos acerca de las estrategias de movilidad y uso del espacio y los recursos implementadas por sociedades cazadoras-recolectoras (Bamforth 1986; Barrientos et al. 2014; Binford 1979; Jones et al. 2003; Sellet 2006; Shackely 1985). En tal sentido, los análisis realizados sobre los conjuntos líticos se desarrollaron en relación con cuatro objetivos principales:

1- Evaluar la disponibilidad local de rocas factibles de ser utilizadas para la elaboración de artefactos líticos.

2- Identificar, lo más precisamente posible, los lugares de procedencia de las rocas representadas en los conjuntos, estableciendo criterios de selección de materias primas y formas base, así como el área de dispersión (mediante acciones de traslado) de las mismas;

3- Analizar las estrategias empleadas en el uso de las diferentes materias primas, considerando las características de sus fuentes y de los artefactos presentes en los sitios arqueológicos.

4- Analizar la distribución arqueológica de materias primas de la cuenca del arroyo Chasicó, en relación con la información disponible sobre la estructura de los paisajes líticos (sensu Barrientos et al. 2014) en el sur de la Región Pampeana y NE de Patagonia.

\subsection{Algunos conceptos teóricos sobre la tecnología lítica y su relación con la movilidad y el uso de} los recursos: los artefactos tallados y los confeccionados por picado, abrasión y/o pulido

Entre los factores que pueden influir en la composición de los conjuntos líticos, se encuentran características ambientales generales (predictibilidad y composición del hábitat) y de los recursos líticos en particular (distribución de las rocas en el espacio y su grado de congruencia con otros recursos, calidad en relación con la tarea para la que será utilizada, disponibilidad, accesibilidad y abundancia). A las propiedades ambientales se agregan, a su vez, las estrategias de movilidad y de aprovisionamiento y 
uso de los artefactos líticos, vinculadas con los conocimientos y la tecnología disponibles y con aspectos particulares tales como las preferencias de los individuos, vínculos sociales, entre otros (Andrefsky 1994, 2009; Binford 1979; Gould y Saggers 1985; Hiscock 1994, 1996, 2009; Khun 1994; Nelson 1991; Torrence 1989).

La representación de materias primas en los conjuntos artefactuales ha sido uno de los aspectos más abordados, considerando que su variedad es, generalmente, una representación de la escala de movilidad de los grupos (Amick 1999; Shackley 1985). Por otra parte, ciertos rasgos del diseño de los artefactos (i.e. dimensiones, modo en que fueron reducidos, grado de mantenimiento, versatilidad), han sido relacionados, entre otros factores, con el tipo de acceso a las materias primas líticas (i.e. directo o indirecto; Meltzer 1989) y el modo en que las sociedades circulan a través del paisaje, es decir, con la frecuencia y distancia recorrida en los movimientos, principalmente, residenciales (Beck et al. 2002; Eerkens et al. 2007; Holdaway et al. 2004, 2010; MacDonald 2007; Nelson 1991; Nelson y Lippmeier 1993).

Si bien las rocas pueden ser obtenidas por intercambio o a través de viajes especiales, es esperable que, en ambientes con una distribución más o menos abundante y homogénea de recursos líticos, la mayor proporción de estos se recolecte durante la realización de otras actividades cotidianas (relacionadas o no con la subsistencia), disminuyendo de esta manera su costo de aprovisionamiento, en lo que Binford llamó embeddedness (Binford 1979; Duke y Steele 2010; Gould y Saggers 1985; Jeske 1989). Siguiendo a estos autores, la variabilidad en la proporción de materias primas encontradas en un sitio, si bien no es indicadora directa del tamaño del rango de acción de un grupo, se encuentra en estrecha relación con el hábitat explotado por éste (Ingbar 1994). En otras palabras, los cazadores-recolectores con rangos de acción amplios, tendrán acceso a una mayor diversidad de fuentes de materia prima, generando conjuntos con proporciones altas de rocas no locales que son transportadas en forma de herramientas personales (Eerkens et al. 2007; Holdaway et al. 2004; Mullet 2009; Shackley 1985).

Otros autores han planteado que las distintas fuentes de aprovisionamiento, pueden ejercer una atracción diferencial sobre las poblaciones cazadoras-recolectoras, dependiendo de aspectos tales como la calidad para la talla, el tamaño de la fuente, su accesibilidad, el tipo de formas base disponibles y el esfuerzo requerido para su extracción (Browne y Wilson 2011; Wilson 2007), pudiendo influir, de esta manera, sobre los movimientos efectuados en el espacio (Bamforth 2006). En este sentido, y a diferencia del concepto de estrategia embbedded propuesta por Binford (1979), Bamforth (2006) considera que el aprovisionamiento de materias primas líticas no necesariamente se realiza sin costo alguno sino que, dependiendo de su distribución, la necesidad de acceso a este recurso puede afectar el modo en que las sociedades humanas hacen uso del espacio en general y de los recursos líticos en particular.

En el largo plazo, el transporte de las rocas a través del espacio, ya sea en la forma de artefactos o de fragmentos sin modificar (i.e. ecofactos, manuports), genera un área de dispersión cuya principal característica es su gradiente, producido por variaciones en la frecuencia, tamaño y/o peso de los ecofactos o artefactos transportados. Este gradiente, también llamado curva de fall-off o distance-decay, usualmente decrece de manera monotónica (Renfrew 1975, 1977) desde la fuente hacia los límites exteriores del área de dispersión, con una pendiente variable en función de factores tales como el riesgo ambiental, los patrones de movilidad, la calidad de la materia prima, el acceso a la fuente (i.e. directo, por intercambio, por comercio) y la proximidad de otras áreas de abastecimiento alternativas (Brantingham 
2006; Elston 1992; Ericson 1977; Hodder y Orton 1976; Kooyman 2000; Reid 1986; Torrence 1986; Wilson 2007; ver discusión en Barrientos et al. 2014). En áreas sin materias primas naturalmente disponibles, también modificarán la forma de esta curva las acumulaciones antrópicas realizadas con la intención de aprovisionar lugares mediante el almacenamiento de artefactos de molienda y grandes nódulos, núcleos e instrumentos (generalmente bifaciales) debido a una "litificación" de estos espacios (Martínez 1999; Webb 1993).

En una escala espacial amplia, las distribuciones artefactuales presentarán patrones producto de comportamientos relacionados con su producción, transporte, uso y descarte, que pueden ser analizados a partir del concepto de paisaje lítico (Barrientos et al. 2014). Un paisaje lítico es una construcción teórica definida como la co-ocurrencia espacial de diferentes unidades estructurales, cada una de ellas compuesta por dos elementos principales: una fuente de materias primas (sea primaria o secundaria) y un área circundante de dispersión de los artefactos (i.e. núcleos, instrumentos, desechos) y de los ecofactos (o manuports) producidos con rocas provenientes de dicha fuente (Barrientos et al. 2014) (Figura 10.1).

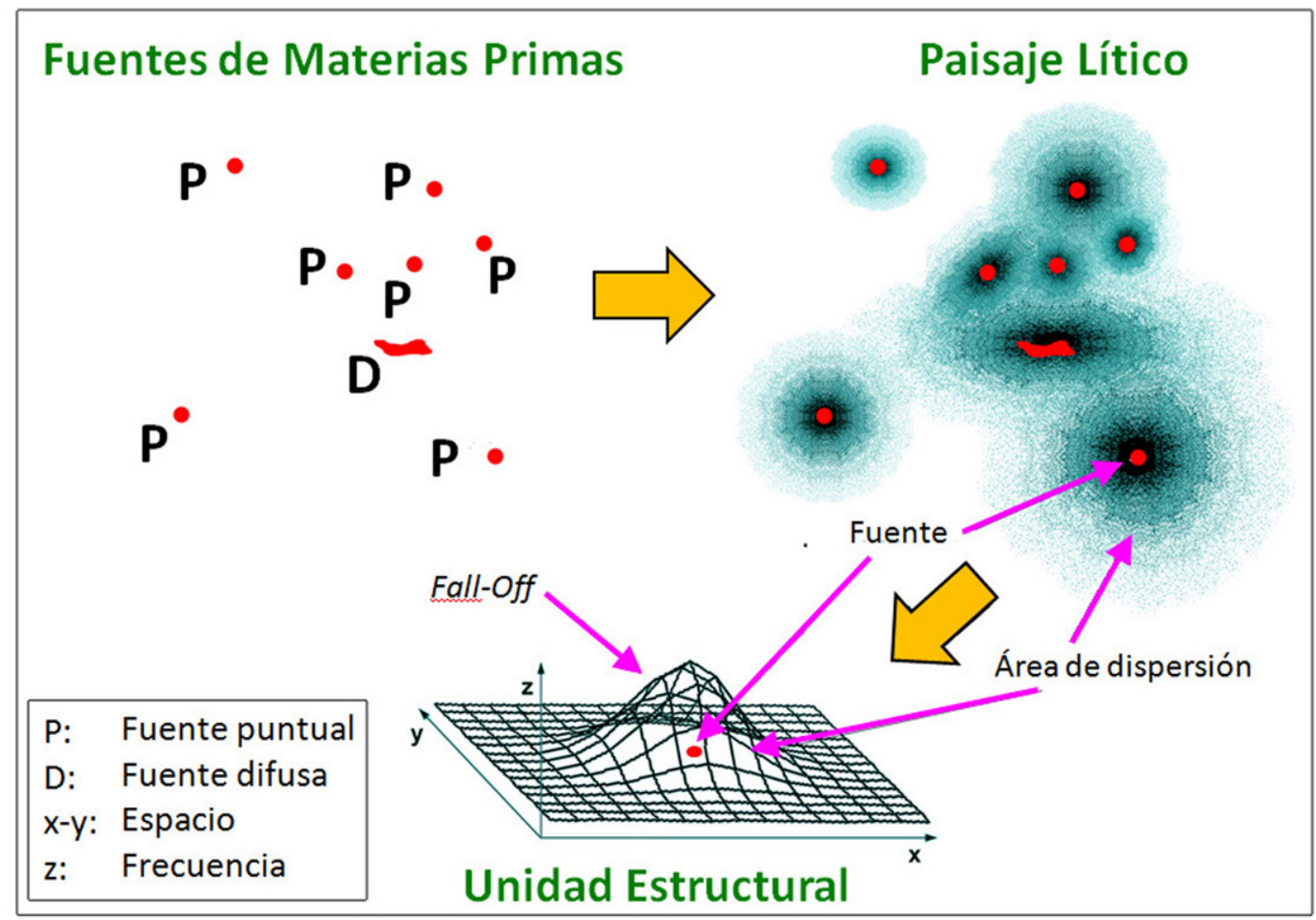

Figura 10.1. Representación esquemática de la estructura de un paisaje lítico; modificado de Barrientos et al. (2014).

El patrón observable en un paisaje arqueológico, en este caso lítico, puede ser generado por una multiplicidad de mecanismos combinados de variadas maneras (Hodder y Orton 1976; Renfrew 1977; Stark y Garraty 2010; Turchin 2003), por lo que es difícil realizar inferencias acerca de los procesos conductuales que les dieron origen. Sin embargo, el análisis de la distribución en el espacio de los ítems o rasgos arqueológicos y de sus curvas de frecuencia en relación con la distribución de los afloramientos líticos permite formular hipótesis acerca de los lugares en los que se llevó a cabo el aprovisionamiento y la extensión de las áreas de transporte de las rocas. A partir de la comparación entre curvas de materias primas diferentes se puede analizar la "competencia" entre distintas fuentes 
y, considerando las características de ellas, postular hipótesis acerca de cuáles son las variables que tuvieron mayor incidencia en la selección de rocas para la elaboración de artefactos (Barrientos et al. 2014). La forma de la curva también podrá dar información, siguiendo a algunos autores, acerca del modo en que circularon los bienes, considerando la cantidad -y extensión- de los movimientos involucrados en la dispersión, el grado de interacción y la existencia de barreras o límites más o menos definidos (Ortega et al. 2014; Renfrew 1975, 1977; Soja 1971). Renfrew $(1975,1977)$ propuso que las curvas de fall-off poco pronunciadas, con colas largas serán consecuencia de un mayor número de eventos de intercambio, en tanto Ortega et al (2014), por medio de simulaciones, sugieren que este tipo de curvas son mejor explicadas por interacciones aleatorias entre agentes distantes y no necesariamente por un aumento en el número de intercambios entre agentes cercanos. Por otra parte, Soja (1971) sugiere que el comportamiento territorial se evidenciará por curvas que evidencien mesetas e inflexiones o caídas abruptas en el patrón de actividad, en tanto Hodder y Orton (1976) observan que la existencia de una barrera sólo producirá diferencias cuando el limite se encuentra cerca de la fuente y se producen varios eventos de intercambio, siendo muy leves las modificaciones a la curva en otros casos.

De lo expuesto hasta aquí se desprende que la estructura y predictibilidad de los recursos, junto con la información disponible y el consecuente grado de planificación de las actividades, influirán sobre las características de los conjuntos. En tal sentido, si se entiende a la tecnología como una serie de comportamientos que contribuyen a la adaptación humana, solucionando los problemas que surgen de la interacción entre el hombre y su entorno (Jochim 1981; Nelson 1991), la composición de los conjuntos líticos puede brindar información acerca de este tipo de relaciones. Nelson (1991) propone que el ambiente es aprovechado a través de dos tipos de estrategias tecnológicas: conservadas y expeditivas, que no son necesariamente excluyentes y que implican planes sobre cómo será utilizado el ambiente. A estas dos estrategias se agrega el comportamiento oportunístico (opportunistic technological behaviour), diferenciándolo de una estrategia expeditiva debido a que comprende acciones no planificadas, que se realizan como respuesta a condiciones inmediatas y no previstas. Una tecnología conservada (curated technology) se orienta a disminuir la incoherencia entre la disponibilidad de utensilios y/o materias primas y el lugar en que se desarrollan las actividades que los emplean. Una tecnología expeditiva (expedient technology) en cambio, implica poco esfuerzo tecnológico en la elaboración artefactual, que tiende a darse bajo condiciones en las que el tiempo y la materia prima están disponibles en cantidades suficientes al momento de uso. Estas estrategias producirán, como correlato, distintos diseños artefactuales, clasificables en: 1) confiables, aquellos que priorizan la seguridad mediante el sobre-diseño, refuerzo y robustez; 2) mantenibles, cuando permiten trabajar con facilidad en diversas circunstancias por medio de diseños seriados o modulares; 3 ) flexibles, que pueden ser reconfigurados con facilidad para satisfacer necesidades diversas; 4) versátiles, con una forma generalizada para satisfacer diversas necesidades; 5) transportables, en los que se prioriza el bajo peso y pequeño tamaño para que no intervengan con los movimientos y el transporte de otros recursos.

En grupos con alta movilidad residencial, es esperable que se prioricen los diseños transportables incluyéndose artefactos flexibles o versátiles, pequeños y livianos que tenderán a ser conservados, con poco desperdicio de materia prima. Este tipo de instrumentos son útiles en situaciones donde el momento de uso y/o el tipo de actividad a desarrollar no es predecible, simplificando además los conjuntos y disminuyendo así la cantidad de utensilios a transportar (Nelson 1991). De esta forma se busca minimizar los costos de transporte, a la vez que se maximiza la durabilidad y versatilidad de los 
artefactos (Khun 1994). Para este autor, será esperable que las sociedades con alta movilidad residencial prioricen el transporte de lascas e instrumentos entre 1,5 y 3 veces el tamaño mínimo utilizable, ya que el transporte de éstos es más eficiente que el de núcleos de masa equivalente (Khun 1994).

Las características de los conjuntos, sin embargo, también se verán modificadas en función de la disponibilidad local y regional de materias primas, pudiendo presentarse estrategias tendientes a maximizar el rendimiento de los artefactos en situaciones de escasez de rocas (Franco 2002, 2004). En este sentido, Bamforth (1986) propone que el grado de mantenimiento y reciclaje de los artefactos se encontrarán relacionados, principalmente, con la disponibilidad de materias primas. Dado que la movilidad incide en el acceso que un grupo tiene a las fuentes de abastecimiento lítico, las modificaciones en los patrones de movilidad (v.g. grado de reocupación y permanencia en un sitio) podrán redundar en variaciones en el diseño y grado de reactivación de los artefactos, aumentando - al disminuir la movilidad-, la intensidad de uso (i.e. mayor mantenimiento, reciclaje, re-utilización, reclamación) de las materias primas alóctonas (Adams 1996; Babot 2004, 2014; Hiscock y Clarkson 2005; Shackley 1985). En aquellas sociedades menos móviles, con ocupaciones residenciales más prolongadas, las oportunidades para acceder a rocas de fuentes distantes serán menores, siendo mayor la utilización de materias primas locales, independientemente de su calidad para la talla (Eerkens et al. 2008; Holdaway et al. 2004, 2010). Se generarán a su vez conjuntos con artefactos de mayor tamaño y peso, dado que deja de ser importante priorizar la transportabilidad de los mismos (Khun 1994; Nelson 1991).

Los artefactos líticos también pueden aportar información acerca de la variedad de recursos procesados y de la intensidad con que fueron empleados. Particularmente en el caso de la molienda, cuando este tipo de tareas insumen una gran cantidad de tiempo, la tecnología se tornará más elaborada a los fines de incrementar su eficiencia. Los artefactos se vuelven más grandes y pesados, para permitir moler mayor cantidad de granos por unidad de tiempo, y adquieren superficies que facilitan la prensión, generando así artefactos más cómodos y más factibles de ser usados e largas jornadas de trabajo (Adams 1996; Babot 2004).

La incorporación de las tareas vinculadas con la molienda genera, en las poblaciones con grados moderados a altos de movilidad residencial, problemas logísticos relacionados con los requerimientos de tamaño y peso de este tipo de artefactos, que pueden entrar en conflicto con las necesidades de movilidad. Soluciones a esto pueden incluir la utilización de artefactos livianos y portátiles, que sean transportados de campamento en campamento, el uso expeditivo de rocas cercanas para su confección, o el almacenamiento de artefactos pesados y fijos en sitios residenciales o cerca de las zonas de concentración de los recursos a procesar (Wright 1994). En este último caso, se verán modificadas las estrategias de movilidad, aumentando su componente logístico y el grado de reocupación de ciertos espacios, y, consecuentemente, las características de los conjuntos (Wright 1994). En aquellos sectores recurrentemente ocupados, será esperable una mayor inversión en la manufactura de los artefactos de molienda y la selección de materias primas de buena calidad, a los fines de aumentar su vida útil y su eficiencia, siendo utilizados hasta su agotamiento (Nelson y Lippmeier 1993; Babot 2014). Bajo estas condiciones, se buscará obtener morfologías eficientes (superficies activas grandes en relación con el tamaño y artefactos superiores cómodos y pesados, siempre dentro de la capacidad de asimiento humana; Babot 2004, 2014), que permitan procesar una mayor cantidad de sustancias en menos tiempo, minimizando así el esfuerzo. Además, una mayor duración y regularidad de ocupación, producirá 
un conjunto donde los artefactos presentan diferencias en sus remanentes de vida útil, evidencias de abundante mantenimiento (cambios en la forma pero no en la función) y técnicas de administración del desgaste (generación de nuevas superficies de molienda o rotación de la pieza horizontal o verticalmente a los fines de conservar las formas confortables) y una elevada proporción de artefactos agotados y/o rotos (Adams 1996; Babot 2004, 2014).

\subsection{Metodología de análisis}

\subsubsection{Estrategia metodológica general}

En primer lugar se estableció la estructura regional de recursos líticos (Ericson 1984) a partir de la información édita, geológica y arqueológica (resumida en los capítulos 3 y 4) y de aquella obtenida por medio de prospecciones sistemáticas llevadas a cabo en los diferentes sectores de la cuenca (presentada en el Capítulo 6). Se tuvieron en cuenta criterios de calidad, tanto para la confección de artefactos por técnica de talla (fractura concoidea) como para la elaboración de artefactos por picado, abrasión y/o pulido (abrasividad y resistencia al desgaste durante el uso), evaluando, en los diferentes casos, el tamaño y morfología de las formas base disponibles, su localización, posible costo de extracción (abundancia, densidad y facilidad de extracción de la roca) y distancia a los sitios de uso (Browne y Wilson 2011; Wilson 2011). Si bien las categorías de recurso local y exótico pueden variar en relación con las estrategias de movilidad de un grupo (Ambrose 2006; Gamble 1992), aquí se consideraron las categorías propuestas por Meltzer (1989): inmediatamente disponibles (menos de $5 \mathrm{~km}$ ), local cercano (5-30 km), local lejano (30-40 km) y no local (más $40 \mathrm{~km}$ ) (ver modificaciones en Civalero y Franco 2003; Salgán 2013).

Por otra parte, los estudios se enfocaron en el análisis de la composición de los conjuntos artefactuales, evaluando la frecuencia de aparición de las distintas materias primas en el registro arqueológico, a los fines de establecer criterios de selección, así como el área de traslado de las mismas (Ericson 1984; Jones et al. 2003). Para poder evaluar la representatividad de las diferentes materias primas, las proporciones se presentan tanto en relación con el número total de piezas, como con el peso total de material lítico presente en el sitio, considerando al peso como una función simple del volumen (Kuhn 1994). Los análisis estuvieron centrados en evaluar la intensidad de utilización de las diversas materias primas, a través de la variedad de estadios de la secuencia de reducción representados y de la inversión de trabajo puesta en su manufactura. De esta manera, se buscó generar información sobre la toma de decisiones en el uso del espacio y las vinculaciones existentes con los recursos presentes en los diferentes ambientes representados. Para facilitar la comparación entre sitios y entre ambientes, se calcularon índices que permiten poner en relación las variables analizadas (Barrientos y Catella 2011; Ericson 1984; Salgán 2013), los que se detallan más adelante.

A los fines de analizar los patrones en la distribución de artefactos y rasgos artefactuales (i.e. materias primas) emergentes en escalas amplias (i.e. mesoescala y macroescala), se generaron, por medio del uso de herramientas SIG, modelos espaciales de superficies continuas. Para ello se efectuaron interpolaciones geoestadística a partir de datos puntuales de sitios arqueológicos. Para la formulación de los modelos de mayor amplitud espacial y a los fines de analizar la distribución de materias primas en la cuenca del arroyo Chasicó en relación con su comportamiento en una escala espacial amplia, se incorporó también la información édita sobre materias primas del sur de la Región Pampeana y NE 
de Patagonia, particularmente aquella correspondiente a las rocas con mayor representación regional: calcedonia, rocas silíceas opacas (desde ahora RSO) y cuarcitas (para un detalle del procedimiento ver Capítulo 5). Los modelos espaciales fueron analizados mediante la realización de re-clasificaciones y combinaciones de superfcies, así como mediante transectas virtuales trazadas a través de los paisajes líticos por medio del módulo ArcGIS 3D Analyst, lo que permite una mejor visualización de las curvas de fall-off, de sus pendientes y de sus formas, evidenciando la presencia de picos y valles y posibilitando su vinculación con otros rasgos del paisaje (e.g. afloramientos rocosos, cursos fluviales).

\subsubsection{Metodología empleada en el análisis de los materiales confeccionados por técnica de talla}

Para el análisis de los artefactos confeccionados por técnica de talla se siguieron los criterios propuestos por Aschero $(1975,1983)$. Se seleccionaron variables que permitiesen realizar una caracterización general de los conjuntos recuperados y llevar a cabo comparaciones entre los distintos sectores de la cuenca (superior, medio e inferior), así como entre unidades más pequeñas del paisaje localizadas dentro de estos tres sectores. Se consideraron, particularmente, aquellas variables que aportan información acerca del modo en que los artefactos ingresaron a los sitios y la intensidad de aprovechamiento de las distintas materias primas. A nivel de todo el conjunto, se analizó: 1) el tipo materia prima (variable utilizada para estratificar todas las muestras) y su calidad para la talla (regular, buena, muy buena, según características macroscópicas que incluyen su textura, fractura y presencia de inclusiones y heterogeneidades; Aragón y Franco 1997; Nami 1992); 2) clases artefactuales representadas (núcleos, productos de talla, artefactos no formatizados con rastros complementarios, instrumentos -artefactos formatizados- ecofactos; Aschero y Hocsman 2004); 3) dimensiones (tamaño, peso); 4) presencia de técnica bipolar y 5) porcentaje de corteza, en caso se calculó el índice de corteza o IC (total de piezas con remanente de corteza / total de piezas) este fue modificado de Ericson (1984), incluyéndose en este caso todas las clases artefactuales.

Se diferenció entre distintas clases y grupos artefactuales representados, utilizando la clasificación morfológico-funcional de Aschero $(1975,1983)$. En el caso de los instrumentos, ésta fue utilizada de modo descriptivo como una forma de sintetizar la información, sin que implique una asignación funcional (Charlin 2007; Salgán 2013). En instrumentos (o artefactos formatizados), se analizaron las siguientes variables: 1) clase técnica fue empleada como indicador del trabajo invertido en la manufactura de los artefactos, considerando tres grandes categorías con inversión decreciente: adelgazamiento, reducción y trabajo marginal (Aschero y Hocsman 2004; Hocsman 2006); 2) situación de los lascados, a partir de lo cual se calculó el índice de bifacialidad o IB (filos bifaciales / total de filos formatizados; modificado de Ericson 1984), en este caso se consideraron los filos en lugar de los instrumentos debido a que en algunos casos, un mismo artefactos presentaba filos unifaciales y bifaciles; Por último, se relacionó la cantidad de instrumentos completos en relación con el total de productos de talla completos, para la obtención del índice de producción o IP (desechos de talla / instrumentos; Ericson 1984). En núcleos se consideró el peso promedio por materia prima, su morfología, el estado de la plataforma (activa, parcialmente agotada o agotada). 
10.2.1.2 Metodología empleada en el análisis de los artefactos modificados por uso o por picado, abrasión y/o pulido

Debido a sus requerimientos similares en cuanto a tamaño, peso y tipos de materias primas, al momento de la presentación de los datos se incluyeron, en una misma categoría, tanto artefactos modificados por uso -percutores, yunques, abradidores y/o sobadores- como formatizados mediante picado, abrasión y/o pulido. Entre estos últimos se incluyeron a los relacionados con actividades de molienda (molinos, morteros y sus manos) y a las bolas de boleadoras. Se enfatizó en el análisis de variables que brindan información sobre el grado de formatizaión (e.g. técnica de manufactura, presencia de rasgos complementarios) y de utilización (e.g. $\mathrm{n}^{\mathrm{o}}$ de superficies activas, evidencias de mantenimiento / reciclaje) siguiéndose, en líneas generales, algunos de los criterios tecno-morfológicos y morfológico funcionales propuestos por Adams (1996) y Babot (2004).

Se analizó la composición de los conjuntos artefactuales considerando materia prima, peso, tipos morfológicos, estado de fragmentación (diferenciando entre artefactos completos o casi completos, cuyo grado de fragmentación no impide estimar su morfología y dimensiones, y artefactos fracturados), evidencias de reciclaje y/o usos secundarios. En los artefactos completos o casi completos modificados por picado, abrasión y/o pulido se evaluó la inversión de trabajo puesta en su formatización, considerando la presencia de rasgos morfológicos complementarios y los criterios de modalidad de manufactura propuestos por Babot (2004): 1) sin manufactura pero con rastros complementarios, 2) con manufactura en alguna de sus partes, 3) importante inversión de trabajo, con la aplicación de dos o más técnicas de manufactura y/o confección de rasgos morfológicos complementarios (Babot 2004).

Para el caso de artefactos vinculados con actividades de molienda se consideraron, además de las variables previamente mencionadas, la cantidad de superficies activas por artefacto y la presencia de mantenimiento, ya sea evidenciada por el repicado de las superficies activas o por la administración del desgaste del artefacto, a través de su rotación horizontal y/o vertical (Babot 2004). La información obtenida fue complementada con aquella generada por Ávila (2009) para el Sistema Serrano de Ventania y la llanura adyacente al sudoeste, a los fines de evaluar tendencias regionales en las estrategias de diseño y uso. Finalmente se generó un índice de molienda o IM (total de artefactos de molienda completos o casi completos / total de artefactos formatizados por talla completos o casi completos), a los fines de cuantificar la importancia de este tipo de actividades en los diferentes sectores de la cuenca en particular y de la macro-área en general.

\subsubsection{Identificación de materias primas}

La determinación de las rocas utilizadas se realizó a nivel macroscópico, a ojo desnudo, y en aquellos casos en los que se consideró pertinente, particularmente para la diferenciación de las rocas cuarcíticas, se llevaron a cabo estudios petrográficos. Los análisis petrográficos se realizaron mediante cortes delgados de $30 \mu \mathrm{m}$ de espesor, que fueron analizados por el Dr. Marcelo Manassero en el Centro de Investigaciones Geológicas (CONICET-UNLP). Para esto se utilizó un microscopio petrográfico con y sin nicoles cruzados y tablas texturales comparativas para la determinación de composición y tamaño, selección y redondez de los granos. 


\subsection{Criterios empleados en la clasificación de las materias primas}

Como fue presentado en el Capítulo 6, las principales rocas disponibles en la cuenca del arroyo Chasicó consisten en cuarcitas, areniscas, riolitas, granitos, rocas silíceas y basaltos, todas ellas presentes en el registro arqueológico del área. A continuación se detallan brevemente los posibles lugares de afloramiento y características de aquellas más representadas en el registro arqueológicos del área, así como la terminología y criterios de clasificación empleados en el desarrollo de este estudio.

Las riolitas presentan una distribución acotada en el paisaje, aflorando en la forma de pequeños cerros (ver capítulos 3 y 4) que pueden ser caracterizadas como fuentes puntuales en el sentido de Wilson (2007). Si bien también se encuentran rocas riolíticas entre aquellas que conforman el manto tehuelche y en afloramientos primarios localizados en la provincia de La Pampa, a los fines de esta tesis el término riolita se reservó, exclusivamente, para aquellas rocas cuyas características macroscópicas permiten relacionarlas con los afloramientos del Abra de Saavedra y La Ermita, incluyéndose las restantes como “otras rocas" o "rodado patagónico indet.", debido a su baja proporción en el registro arqueológico local.

A las rocas siliceas se las encuentra casi de manera exclusiva en la cuenca inferior, habiéndose registrado solo dos rodados aislados de una roca silícea verde traslúcida en el cauce del arroyo Saudade (cuenca superior). Este tipo de rocas fueron clasificadas, macroscópicamente, en cherts, calcedonias y RSO. Entre las primeras se incluyeron todas aquellas rocas opacas o traslúcidas, de colores variados que van del blanco al beige claro, ocre y anaranjado, cuya característica distintiva es la presencia de impurezas y orificios y un aspecto "craquelado". Se trata de rocas sedimentarias de origen químico (J. San Cristóbal com. pers. 2012; Teruggi 1984) con características similares a aquellas descriptas en la Meseta del Fresco y en la zona de El Carancho, en la Provincia de La Pampa (Berón 2006; Charlin 2002). Este tipo de rocas también fueron identificada por J. San Cristóbal en inmediaciones de la localidad de Chapalcó -en la barranca del camino de acceso- y en el Salitral Negro -sobre una de sus márgenes y en el corte de la ruta 154- (Figura 10.2). Como calcedonias fueron clasificadas todas aquellas rocas traslúcidas homogéneas, predominantemente de colores gris o blanco. Entre sus potenciales fuentes de aprovisionamiento se encuentran el Manto de Rodados Tehuelches y afloramientos primarios aislados localizados en las sierras de Tandilia (Barros y Messineo 2004), en la provincia de La Pampa, entre el parque Lihué Calel y la localidad de Puelches (Berón 2006) y en la provincia de Río Negro, en el golfo de San Matías. Por último, la categoría de RSO fue utilizada para hacer referencia a aquellas rocas opacas, sin impurezas, de colores variados pero con predominio del rojo, amarillo, blanco y negro, cuya fuente de aprovisionamiento más probable habría sido el Manto de Rodados Tehuelches (ver capítulos 2, 3 y 6).
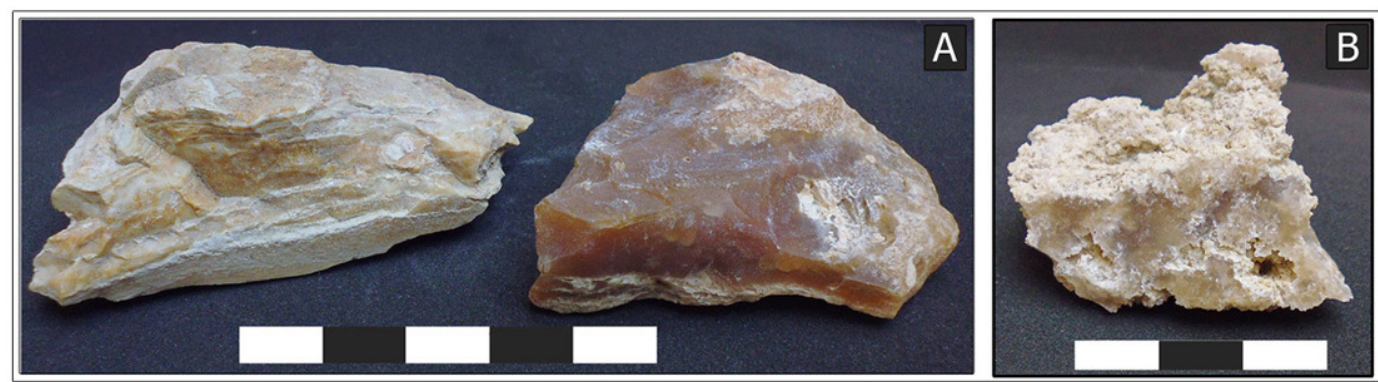

Figura 10.2. Muestras de chert tomadas por Jorge San Cristóbal en A- inmediaciones de la localidad de Chapalcó, laguna Chasicó y B- Salitral Negro, departamente de Caleu Caleu, provincia de La Pampa. 
La limolita silicificada es otra de las rocas que merece aclaración, ya que, en este caso, se incluyó dentro de esta categoría únicamente a aquellas de color verde y buena fractura concoidea. Si bien no se han identificado los afloramientos de esta roca, puede inferirse, a partir de las descripciones geológicas de Ventania, que se corresponden con el grupo Pillahuincó, formación Tunas, aflorante en el sector oriental de las sierras de Ventania (Harrington 1947; Suero 1972).

Para el caso de las areniscas, se diferenció entre areniscas rionegrenses, correspondientes a la formación Río Negro del norte de Patagonia (ver capítulos 4 y 6; De Ferraris 1979; García y García 1964), y areniscas micáceas. A partir de cortes petrográficos, las primeras fueron descriptas como conformadas por arena de tamaño mediano, moderadamente seleccionada, compuesta por fragmentos líticos andesíticos, plagioclasas de tipo oligoclasa y cuarzo monocristalino, con cemento calcáreo en porcentajes siempre inferiores al $40 \%$, por lo que, en los casos donde su proporción es menor, son muy friables. Las areniscas micáceas por otra parte, corresponden a una arenisca consolidada con granos de cuarzo monocristalino subangulosos, feldespato y muscovita, de buena selección y de granulometría correspondiente a arena mediana a gruesa (Ávila y Catella 2005; M. Manassero 2005 com. pers.). De estas últimas, si bien no se conoce con certeza su lugar de procedencia se considera como el área de afloramiento más cercana a las Sierras de Ventania.

Por último, la cuarcita es la única materia prima disponible en todos los sectores de la cuenca. Se la encuentra en la forma de afloramientos primarios, conformando la mayor parte de las sierras de Ventania y cerros aislados de la llanura adyacente, y como depósitos secundarios de rodados en los cauces que drenan este sistema serrano (ver Capítulo 6). Dada su amplia disponibilidad ambiental y representación arqueológica, no solo en el área de estudio, sino en gran parte de la Región Pampeana, se enfatizó, durante el desarrollo de esta tesis, en la caracterización de la variabilidad de este tipo de rocas (Catella et al. 2010, 2013). A partir de las prospecciones y muestreos presentados en el Capítulo 6, se tomaron muestras para la realización de cortes delgados y su análisis mediante microscopio petrográfico. De esta manera se pudieron distinguir al menos tres variedades de cuarcitas claramente diferenciables por sus propiedades para la talla y por sus características microscópicas y macroscópicas (Tabla 10.1). En un trabajo anterior (Catella et al. 2010), la variabilidad de cuarcitas registradas en Ventania fue clasificada en 5 grupos sin embargo, en este caso, considerando los estudios posteriores desarrollados en la cantera Arroyo Saudade sitio 2 (ver Capítulo 6 y apartado 10.3.2.1.1 en este mismo capítulo) y dado que ciertas variedades presentan una muy amplia distribución, esa primer clasificación fue re-organizada en función de sus características macroscópicas y de su calidad para la talla en tres grupos claramente diferenciables y un cuarto en el que se incluyeron otras cuarcitas de fractura subconcoidea a irregular con distribución espacial amplia. Estos son:

- Grupo 1 (G1) (o Napostá): Cuarzo-metareniscas (o metacuarcitas) de grano muy fino a fino (entre 0,88 y $0,250 \mathrm{~mm}$ de diámetro), color bordó o gris a blanco, algunas levemente traslúcidas, brillo vítreo o sin brillo y fractura concoidea. Microscópicamente los granos presentan laminación y contactos crenulares. Su distribución espacial comprende el sector suroccidental, habiendo sido muestreada en los arroyos Napostá Grande, Ventana, del Águila y río Sauce Grande.

- Grupo 2 (G2) (otras): color blanco, violáceo, rosado o amarillento, algunas levemente traslúcidas, brillo vítreo y fractura subconcoidea a irregular. No tienen una distribución espacial acotada, sino que se las encuentra de manera continua en todos los arroyos muestreados. 
- Grupo 3 (G3) (o Saudade): color amarillo y/o rosado, brillo vítreo y fractura concoidea. Tienen una distribución muy restringida, habiendo sido relevado únicamente entre los rodados que conforman uno de los conglomerados El Abra del arroyo Saudade y de manera dispersa en el cauce de este mismo arroyo.

- Grupo 6 (G6): color generalmente blanco, algunas con vetas amarillentas, brillo vítreo y fractura concoidea. Si bien no se han identificado su potenciales fuentes de abastecimiento, este grupo presenta similitudes con las cuarcitas correspondientes al grupo Sierras Bayas del Sistema de Tandilia descriptas por Bayón et al. (1999).

A partir de lo expuesto, pueden realizarse dos consideraciones a tener en cuenta al momento de evaluar la representación de materias primas en los sitios de la cuenca. La primera consiste en que las cuarcitas de mejor calidad para la talla disponibles en el Sistema de Ventania (G1 y G3) presentan una distribución y disponibilidad heterogéneas. Las cuarcitas G1 sólo se encuentra representadas en el sector sudoccidental de las sierras, encontrándose de manera continua en los arroyos Ventana, Napostá Grande y del Águila. Es así como este sector puede caracterizarse como de elevada disponibilidad de cuarcitas de buena calidad para la talla. Por otra parte las cuarcitas G3, de mejor calidad para la talla que las cuarcitas G1, sólo fueron identificadas en el sector noroccidental en un afloramiento del conglomerado El Abra expuesto en el cauce del arroyo Saudade y en la forma de rodados muy dispersos distribuidos en el cauce del mismo arroyo. Dada esta situación, puede inferirse que, aunque esta roca aflore en otros sectores del área, su disponibilidad estaría restringida a sectores muy puntuales del paisaje.

El segundo aspecto a considerar es la variabilidad en las características de las fuentes de aprovisionamiento (potenciales y reales) disponibles dentro de los límites de la cuenca (Figura 10.3). En este sentido, las cuarcitas G2 se encuentran formando parte de fuentes difusas (es decir, extensas y difíciles de delimitar) primarias y secundarias en la cuenca superior y fuentes difusas secundarias en la cuenca media e inferior, en tanto las cuarcitas G3 se presentan como fuentes puntuales primarias y, con menor frecuencia, secundarias en la cuenca superior. Las riolitas por su parte, sólo se encuentran como fuentes primarias puntuales en la cuenca superior, nódulos dispersos alrededor de estos, que conforman fuentes secundarias de muy poca dispersión. Por último las RSO conforman fuentes difusas primarias (rodados contenidos dentro de una matriz) y secundarias (rodados disgregados) localizados en la laguna Chasicó y al sur de ella. Es esperable que esta variabilidad en la extensión de la fuente y la facilidad de obtención de formas base (recolección de rodados $v s$ canteo de afloramientos primarios), haya influido de variadas maneras en la atracción ejercida por cada una de ellas (Browne y Wilson 2011; Wilson 2007) $\mathrm{y}$, por lo tanto, en las estrategias de aprovisionamiento y transporte de las rocas, implementadas por las sociedades cazadoras-recolectoras. 

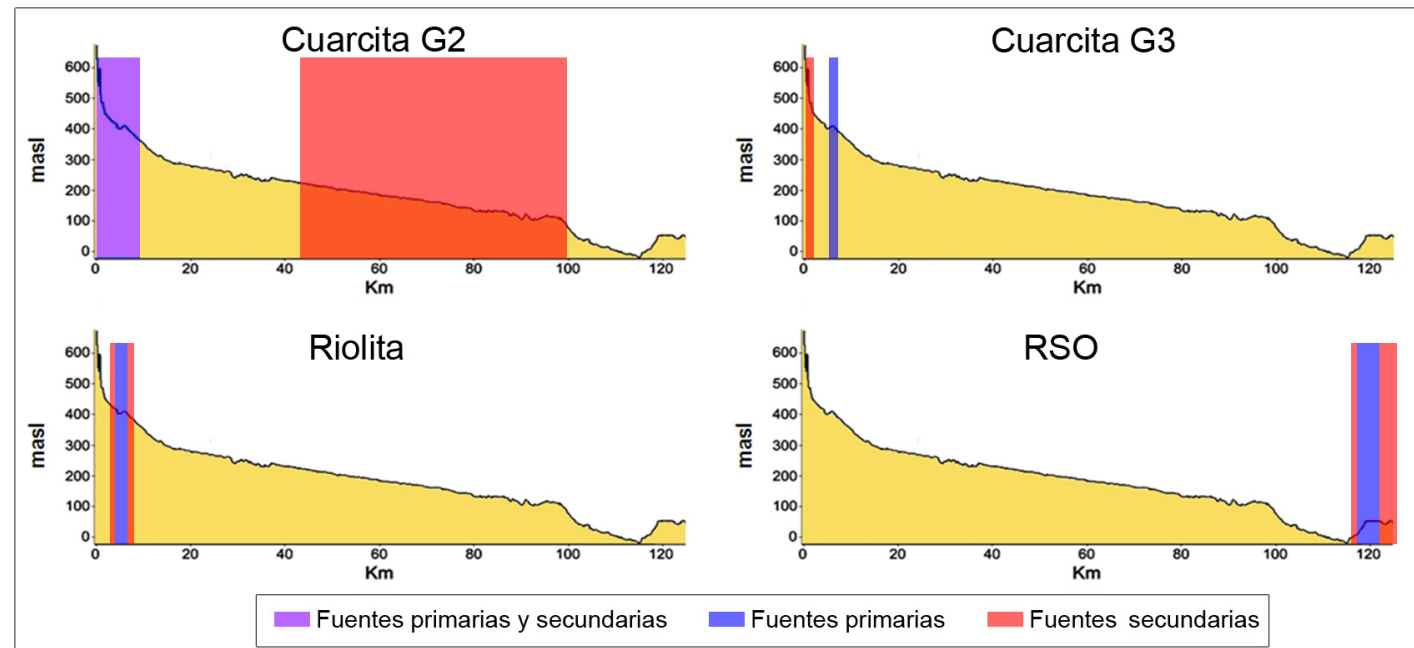

Figura 10.3. Caracterización de la disponibilidad de materias primas líticas en la cuenca del arroyo Chasicó.

\subsection{Resultados}

\subsubsection{Análisis Microscópico}

Los análisis microscópicos se realizaron tanto sobre muestras geológicas de rocas cuarcíticas recolectadas, principalmente, en las Sierras de Ventania y sus adyacencias, así como de materiales arqueológicos, también en cuarcita, procedentes de los diferentes sectores de la cuenca. De esta manera se buscó obtener información acerca de la variabilidad de cuarcitas disponibles en el ambiente y en los sitios arqueológicos, así como establecer vinculaciones que permitan identificar probables áreas de abastecimiento.

\subsubsection{Análisis petrográfico sobre muestras geológicas}

Considerando la clasificación macroscópica en tres grupos, de las cuarcitas muestreadas en los arroyos, se llevaron a cabo análisis con microscopio electrónico en cortes realizados a muestras de cada uno de ellos (Tabla 10.1). También se analizó una muestra de ortocuarcita del Grupo Sierras Bayas, a los fines de contar con material de referencia de fuentes más lejanas pero que potencialmente pudieron ser utilizadas. Los cuatro grupos formulados fueron caracterizados como sigue:

- Grupo 1 (G1) (o Napostá): Cuarzo-metareniscas (o metacuarcitas) de grano muy fino a fino (entre $0,88 \mathrm{~mm}$ y $0,250 \mathrm{~mm}$ de diámetro), microscópicamente los granos presentan laminación y contactos crenulares (Figura 10.4).

- Grupo 2 (G2) (otras): Cuarzo-metareniscas (o metacuarcitas) de grano fino a medio, el diámetro de los granos oscila entre $0,177 \mathrm{~mm}$ y $0,350 \mathrm{~mm}$, presentan laminación y/o contactos crenulados.

- Grupo 3 (G3) (o Saudade): Arenita cuarzosa y ortocuarcitas de grano medio (entre 0,125 mm y $0,350 \mathrm{~mm}$ de diámetro), los granos presentan crecimiento secundario, puntos triples y en algunos casos laminación, Entre ellos se encuentra una matriz característica, conformada por arcillas, mica, feldespato, hematita, etc., cuya presencia evidencia un muy bajo grado de metamorfismo (Figura 10.4). 
- Grupo 6 (G6): Ortocuarcitas de grano mediano (entre 0,177 mm y 0,350 mm de diámetro), sus granos muestran morfología ecuante, crecimientos secundarios y/o puntos triples de contacto. En este caso el corte se realizó sobre un fragmento de cuarcita del Grupo Sierras Bayas de muy buena calidad para la talla ${ }^{1}$.

\begin{tabular}{|c|l|l|l|l|l|l|l|}
\hline M & Procedencia & Gr. & Clasificación & Granulometría & Redondez & Selección & $\begin{array}{l}\text { Otras caract. } \\
\text { microscopicas }\end{array}$ \\
\hline 1 & A. Ventana & 1 & $\begin{array}{l}\text { Qz } \\
\text { metarenisca }\end{array}$ & muy fina & SR & Moderada & $\begin{array}{l}\text { Laminación, } \\
\text { contactos } \\
\text { crenulado }\end{array}$ \\
\hline 2 & $\begin{array}{l}\text { A. Naposta } \\
\text { Chico }\end{array}$ & 1 & $\begin{array}{l}\text { Qz } \\
\text { metarenisca }\end{array}$ & muy fina & SA & Buena & $\begin{array}{l}\text { Laminación, } \\
\text { contactos } \\
\text { crenulado }\end{array}$ \\
\hline 4 & $\begin{array}{l}\text { A. Napostá } \\
\text { Grande }\end{array}$ & 1 & $\begin{array}{l}\text { Qz } \\
\text { metarenisca }\end{array}$ & fina & SA & Buena & $\begin{array}{l}\text { Laminación, } \\
\text { contactos } \\
\text { crenulado }\end{array}$ \\
\hline 5 & A. Ventana & 2 & $\begin{array}{l}\text { Qz } \\
\text { metarenisca }\end{array}$ & muy fina & SR & $\begin{array}{l}\text { Muy } \\
\text { Buena }\end{array}$ & $\begin{array}{l}\text { Paminación, } \\
\text { mica }\end{array}$ \\
\hline 18 & A. Saudade & 3 & $\begin{array}{l}\text { arenita } \\
\text { cuarzosa }\end{array}$ & mediana & SR & Buena & $\begin{array}{l}\text { Laminación, } \\
\text { contactos } \\
\text { crenulado, } \\
\text { mineral lábil } \\
\text { alterado a mica }\end{array}$ \\
\hline 19 & A. Chasicó & 2 & ortocuarcita & fina & SA & Buena & $\begin{array}{l}\text { Contactos } \\
\text { crenulados, } \\
\text { mica }\end{array}$ \\
\hline 17 & Sierras Bayas & 6 & ortocuacita & mediana & SR & MB & $\begin{array}{l}\text { Puntos triples } \\
\text { Contactos } \\
\text { crenulados }\end{array}$ \\
\hline
\end{tabular}

Tabla 10.1. Características petrográficas de muestras de rodados obtenidas en el cauce superior de los principales cursos fluviales que drenan el sector sud-occidental de las sierras de Ventania. Crec sec= crecimiento secundario; $\mathrm{SR}=$ sub-redondeado; $\mathrm{SA}=$ sub-angular; $\mathrm{MB}=$ muy buena; $\mathrm{B}=$ buena.
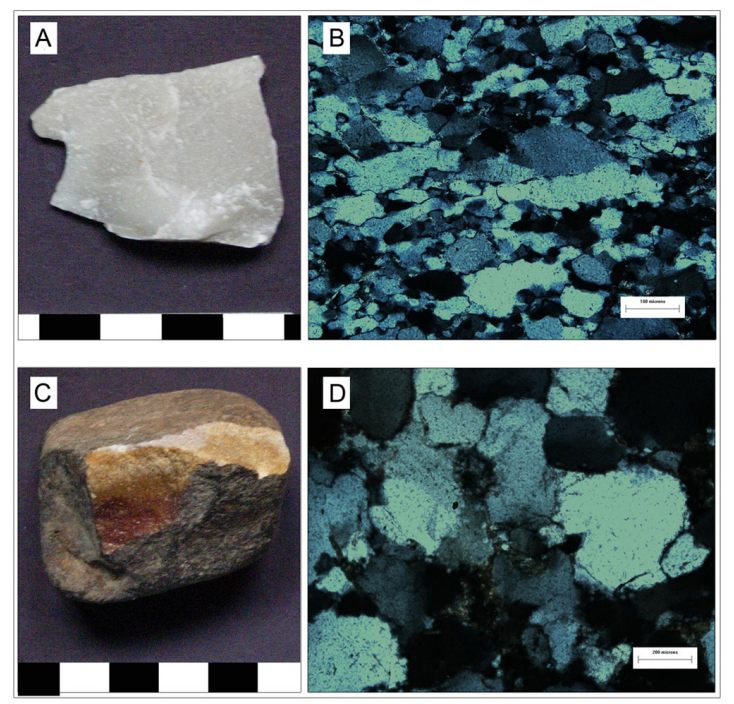

Figura 10.4. Rodados procedentes de los arroyos que drenan las sierras de Ventania. A y B- cuarcita G1, muestra 1: A- muestra de mano; B- imágenes de microscopio petrográfico con nicoles cruzados (200x de aumento); C y D- cuarcita G3, muestra 4: C- muestra de mano; D- imágenes de microscopio petrográfico con nicoles cruzados (100x de aumento).

1 Nódulo utilizado por J. Moirano durante la realización del taller de talla experimental dictado por $\mathrm{N}$. Flegenheimer, C. Bayón y P. Escola en el año 1997 
A partir de los análisis microscópicos realizados sobre las cuarcitas disponibles en Ventania, se observa que éstas no pueden ser definidas homogéneamente como metacuarcitas (Bayón et al. 1999; cf. Catella et al. 2013). Si bien las rocas afectadas por un alto grado de metamorfismo dinámico son las más abundantes en todos los sectores relevados, también se encuentran cuarcitas en las que las evidencias de metamorfismo se encuentran presentes sólo en bajo grado. Estas fueron definidas por M. Manassero como a) arenita cuarzosa, aquellas en las que se observa una matriz entre los granos, conformada por hematita, mica, sericita y arcilla y b) ortocuarcitas, en los casos en que esta matriz es muy escasa, encontrándose todos los granos en contacto unos con otros (ver siguiente apartado).

\subsubsection{Análisis petrográfico sobre muestras arqueológicas}

En el caso de los artefactos arqueológicos, se enfatizó el análisis de aquellos procedentes de la localidad Arroyo Saudade. Esto se debió a que dicho sitio es la única cantera-taller de cuarcitas de buena y muy buena calidad para la talla identificada hasta el momento en las sierras de Ventania A su vez, estas cuarcitas presentan características macroscópicas similares a las descriptas para las cuarcitas Grupo Sierras Bayas (sierras de Tandilia), por lo que se consideró central ampliar su caracterización microscópica, a los fines de identificar rasgos diagnóstico que permitan diferenciarlas de aquellas descriptas para el Grupo Sierras Bayas

A partir de los análisis petrográficos, las muestras procedentes de la localidad arqueológica Arroyo Saudade fueron caracterizadas como rocas sedimentarias con evidencias leves de metamorfismo dinámico y/o soterramiento profundo. Se trata de arenitas cuarzosas y ortocuarcitas conformadas por clastos de cuarzo policristalino poco compactados y con presencia de matriz entre ellos. Los clastos presentan formas predominantemente subredondeadas a subangulares, tamaños en su mayoría medianos a gruesos y buena a muy buena selección. En algunos casos se observó la presencia de crecimiento secundario y puntos triples (indicadores de soterramiento profundo), encontrándose en otros casos matriz entre los clastos. Esta matriz se encuentra conformada por mica, arcillas y hematita (en ocasiones envolviendo los clastos en forma de coating) que le confieren las tonalidades amarillo-ocre y rosadobordó características (Tabla 10.2; Catella et al. 2013).

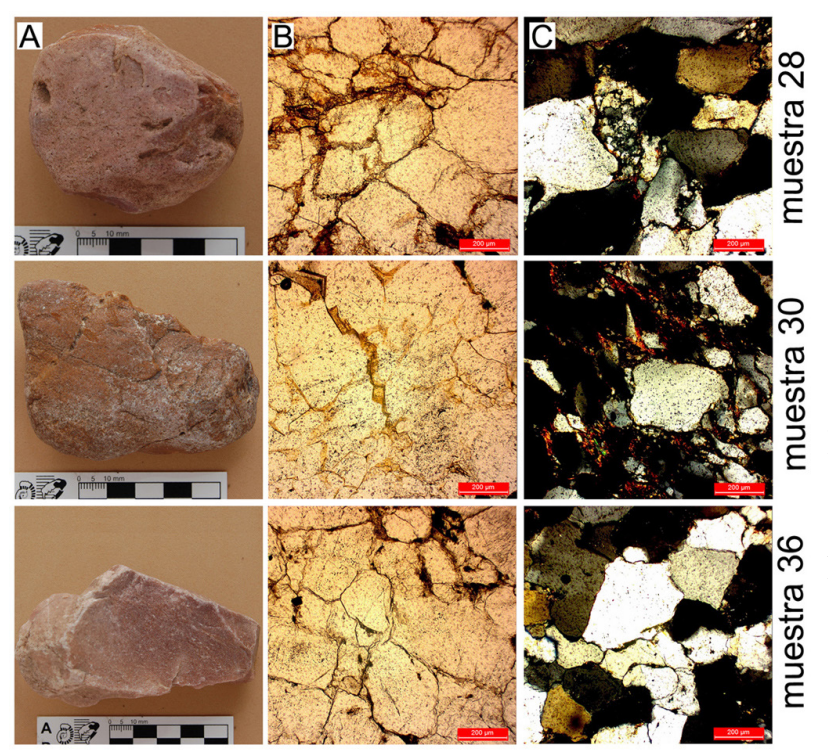

Figura 10.5. Cuarcitas G3 A- muestra de mano; Bimágenes de microscopio petrográfico sin nicoles cruzados, en las que se observa la presencia de hematita intersticial como cemento; C- imágenes de microscopio petrográfico con nicoles cruzados, donde se observa crecimiento secundario (muestra 28 y 36) y mica intersticial (muestra 30) (Catella et al. 2013). 
La distinción presentada entre arenitas cuarzosas y ortocuarcitas se realizó considerando el grado de compactación de los granos. De esta manera se llamó arenitas cuarzosas a aquéllas que presentaron menor compactación y mayor cantidad de matriz, y ortocuarcitas a aquéllas que debido a su escasa matriz presentan contactos entre los clastos, ya sea en forma de puntos triples o de contactos crenulados (Figura 10.5; Catella et al. 2013). Si bien la mayor parte de las muestras observadas al microscopio presentan matriz entre los granos y poca compactación, lo que podría volver menos predecible la fractura, no se observó relación entre la presencia de matriz y una menor calidad para la talla, siendo que todas las muestras exhiben buena fractura concoidea. En tal sentido, las características que estarían favoreciendo a su calidad para la talla -por mejorar la fractura concoidea- son el crecimiento secundario y el cemento silíceo -que en conjunto conforman la silicificación de la roca-, a lo que se agrega en este caso el cemento hematítico.

\begin{tabular}{|c|c|c|c|c|c|c|c|}
\hline $\mathbf{M}$ & Sitio & Grupo & Clasificación & Granulometría & Selección & Redondez & Otras \\
\hline 26 & $\mathrm{AS}$ & 3 & ortocuarcita & mediana & $\mathrm{B}$ & SR & crecimiento secundario \\
\hline 27 & AS & 3 & arenita cuarzosa & gruesa & $\mathrm{MB}$ & SA & mica \\
\hline 28 & AS & 3 & arenita cuarzosa & gruesa & MB & SR & \\
\hline 29 & AS & 3 & arenita cuarzosa & fina & MB & SR & mica \\
\hline 30 & AS & 3 & arenita cuarzosa & gruesa & $\mathrm{M}$ & SR & mica \\
\hline 31 & AS & $6 ?$ & arenita cuarzosa & gruesa & $\mathrm{B}$ & SR & contactos crenulados \\
\hline 32 & AS & 2 & arenita cuarzosa & muy gruesa & $\mathrm{B}$ & SR & mica \\
\hline 33 & AS & 3 & arenita cuarzosa & gruesa & $\mathrm{M}$ & SR & \\
\hline 34 & AS & 3 & arenita cuarzosa & gruesa & $\mathrm{B}$ & SR & \\
\hline 35 & AS & 3 & arenita cuarzosa & gruesa & $\mathrm{B}$ & SA & \\
\hline 36 & AS & 3 & ortocuarcita & gruesa & $\mathrm{B}$ & SA & contactos crenulados \\
\hline 37 & AS & 3 & arenita cuarzosa & muy gruesa & $\mathrm{B}$ & SA & mica \\
\hline 38 & AS & 3 & arenita cuarzosa & gruesa & $\mathrm{B}$ & SA & mica \\
\hline 13 & LM & 3 & arenita cuarzosa & fina & $\mathrm{M}$ & SA & mica; laminación \\
\hline 14 & LM & 6 & ortocuarcita & gruesa & $\mathrm{MB}$ & SA & crecimiento secundario \\
\hline 20 & LM & 3 & ortocuarcita & fina & $\mathrm{MB}$ & SR & mica \\
\hline 22 & LM & 3 & ortocuarcita & mediana & MB & SR & contactos crenulados \\
\hline 24 & LM & 3 & ortocuarcita & mediana & $\mathrm{MB}$ & SR & contactos crenulados \\
\hline 11 & $\mathrm{LCH}$ & $3 ?$ & Qz metarenisca & fina & $\mathrm{M}$ & SA & contactos crenulados \\
\hline 12 & $\mathrm{LCH}$ & 6 & ortocuarcita & mediana & MB & SR & crecimiento secundario \\
\hline 10 & SM & 6 & ortocuarcita & fina & MB & SR & crecimiento secundario \\
\hline 15 & SM & 6 & ortocuarcita & fina & MB & SA & crecimiento secundario \\
\hline 16 & SM & 3 & ortocuarcita & fina & $\mathrm{M}$ & SR & laminación \\
\hline 6 & LCHA2 & $3 ?$ & ortocuarcita & fina & $\mathrm{B}$ & $\mathrm{R}$ & puntos triples \\
\hline 7 & LCHA3 & 1 & Qz metarenisca & muy fina & $\mathrm{B}$ & SA & contactos crenulados \\
\hline 9 & LCHA4 & 1 & Qz metarenisca & fina & $\mathrm{B}$ & SA & contactos crenulados \\
\hline 21 & LCHA8 & 3 & arenita cuarzosa & mediana & MB & SA & \\
\hline
\end{tabular}

Tabla 10.2. Características petrográficas de muestras de cuarcitas procedentes de la localidad Arroyo Saudades. Crec sec= crecimiento secundario; $\mathrm{SR}=$ sub-redondeado; $\mathrm{SA}=$ sub-angular; $\mathrm{MB}=$ muy buena; $\mathrm{B}=$ buena, $\mathrm{M}=$ mala.

En los restantes sitios arqueológicos se priorizó el análisis de aquellas cuarcitas de mejor calidad para la talla, a los fines de evaluar el grado de semejanza con las muestras obtenidas en los arroyos locales. Cabe recordar que las rocas de regular calidad para la talla fueron agrupadas en un mismo grupo heterogéneo (cuarcitas G2) de amplia distribución espacial, por lo que su identificación en los sitios arqueológicos es poco diagnóstica sobre su probable área de procedencia. Estos análisis indican que las cuarcitas de mejor calidad para la talla presentes en los sitios arqueológicos de la cuenca muestran 
características petrográficas similares a las que presentan los rodados correspondientes a cuarcitas G1 y cuarcitas G3, recuperados en los arroyos locales. Es decir, se corresponden con la variabilidad petrográfica descripta en el apartado anterior para las sierras de Ventania. Algunos de estos artefactos sin embargo, presentan también características que se corresponden con las descriptas para el Grupo Sierras Bayas, en las sierras de Tandilia -como la presencia de puntos triples, crecimientos secundarios, granos ecuantes y ausencia de matriz entre los clastos- (Bayón et al. 1999; Colombo 2013).

En el sitio La Montaña 1, se analizaron cinco de los artefactos recuperados. Tres de ellos fueron descriptos como ortocuarcitas de granos sub-redondeados muy bien seleccionados, una de ellas de granulometría fina y laminación leve y las otras dos de granulometría media y contactos crenulados. Los dos restantes corresponden a cuarzo areniscas de granos sub-angulares, uno de ellos con evidencias de laminación, granulometría fina y mala selección, en tanto en el segundo la granulometría es gruesa, con muy buena selección y evidencias de crecimiento secundario. Esta última muestra con algunas características que la diferencian en mayor grado de las descriptas para las cuarcitas G3 (Tabla 10.2; Catella et al. 2010). Para el sitio Los Chilenos 2, se analizaron cortes delgados de dos artefactos recuperados en estratigrafía. Uno de ellos descrito como cuarzo meta-arenisca fina de granos subangulares mal seleccionados, con presencia de contactos crenulados, de color amarillo, corresponde a una cuarcita G2. La segunda muestra consiste en una ortocuarcita de color blanco, con granos de tamaño medio, sub-redondeados y muy bien seleccionados, en los que se observan crecimiento secundarios, todas estas características que la asemejan a las cuarcitas G6 (Catella et al. 2010). Los tres artefactos correspondientes al sitio San Martín 1 fueron descriptos como cuarzo areniscas finas, dos de ellas con muy buena selección de sus granos, evidencias de crecimiento secundario y granos de morfología sub-angular (en un caso) y sub-redondeada (en el segundo), características estas que las asemejan a las cuarcitas G6. En la tercer muestra en cambio, se observan claras evidencias de laminación, mala selección y granos de morfología sub-redondeada, pudiendo ser relacionada con las cuarcitas G3 (Catella et al. 2010). Por último, en los sitios localizados sobre las márgenes de la laguna Chasicó, las muestras corresponden a dos cuarzo metareniscas con granos finos a muy finos, sub-angulares y bien seleccionados, con contactos crenulados entre ellos, asignables a las cuarcitas G1. Las dos muestras restantes corresponden a una cuarzo arenisca fina, con granos redondeados y bien seleccionados y a una arenita cuarzosa mediana con granos sub-angulares muy bien seleccionados (Tabla 10.2).
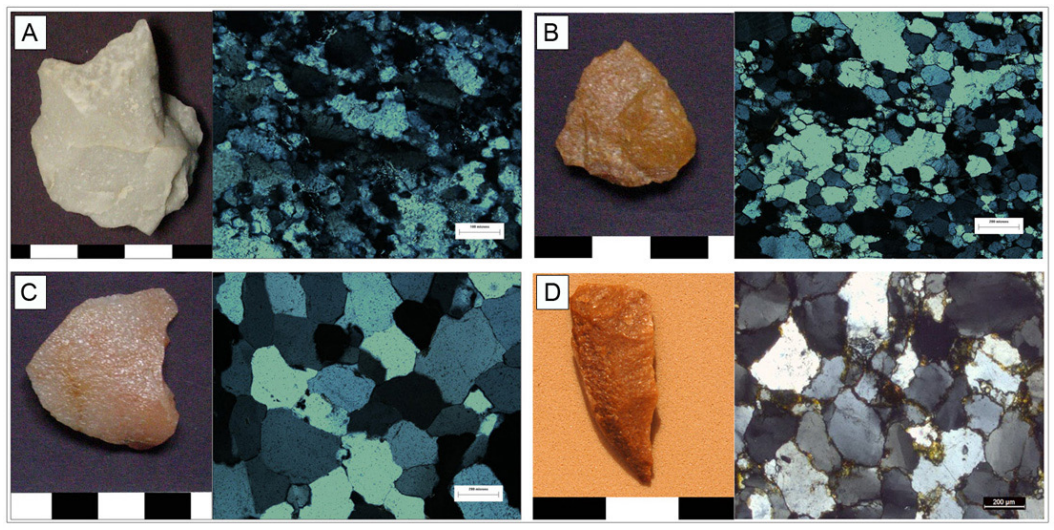

Figura 10.6 Cuarcitas representadas en artefactos de los sitios arqueológicos de la cuenca del arroyo Chasicó A- Cuarcita G1 (metacuarcita), muestra de mano y vista en microscopio petrográfico con 200X de aumento; B- Cuarcita G3 (ortocuarcita) muestra de mano y vista en microscopio petrográfico con 100X de aumento; C- Cuarcita G6 (ortouarcita) muestra de mano y vista en microscopio petrográfico con 100X de aumento; DCuarcita G3 (arenita cuarzosa) muestra de mano y vista en microscopio petrográfico con 100X de aumento. 


\subsubsection{Análisis Macroscópico}

\subsubsection{Cuenca superior}

\subsection{Localidad arqueológica Arroyo Saudade (AS)}

Esta localidad fue identificada durante las prospecciones y, como se expuso en el Capítulo 6, se llevaron a cabo recolecciones de materiales arqueológicos en superficie y el muestreo de las rocas cuarcíticas disponibles en el cauce del arroyo. A partir de estas actividades se recuperaron 20 rodados de cuarcita de buena y muy buena calidad para la talla sin evidencias de utilización, 75 productos de talla, tres lascas en las que se observó un filo natural con rastros complementarios, ocho artefactos formatizados y 22 núcleos y/o nucleiformes. En ninguno de estos artefactos se registró la presencia de técnica bipolar, a excepción de una posible lasca extraída con esta técnica de reducción. La mayor parte de los materiales fueron recuperados en los sitios ASS1 y ASS2, encontrándose una mayor densidad en el último de ellos. En los muestreos por tiempo se obtuvieron principalmente rodados de materia prima de muy buena calidad, algunos núcleos y nucleiformes y muy pocos artefactos formatizados, con una mayor densidad en el MT2, ubicado aguas abajo del sitio 2 (Tabla 10.3) (Catella et al. 2013).

\begin{tabular}{|l|r|r|r|r|r|r|}
\hline \multicolumn{1}{|c|}{ G. subgrupo } & $\begin{array}{c}\text { Hallazgo } \\
\text { aislado }\end{array}$ & MT1 & MT2 & ASS1 & ASS2 & $\begin{array}{c}\text { Total } \\
\text { general }\end{array}$ \\
\hline rodados sin evidencias de talla & 1 & 2 & 2 & 13 & 2 & 20 \\
\hline lascas & & & & 9 & 15 & 24 \\
\hline lascas fragmentadas & & & & 1 & 2 & 3 \\
\hline desechos no clasificable & & & 2 & 12 & 34 & 48 \\
\hline filo natural c/rastros complem. & & & & & 3 & 3 \\
\hline muesca retocada & & & & & 2 & 2 \\
\hline muesca lateral + raspador & & & & & 1 & 1 \\
\hline punta entre muescas lateral & & & & 1 & 1 & 2 \\
\hline artef. format. sum. frag. no dif & & & & & 1 & 1 \\
\hline artef formatizado frag. no dif. & & & 1 & & 1 & 2 \\
\hline núcleos / Nucleiformea & 1 & & 8 & 9 & 4 & 22 \\
\hline
\end{tabular}

Tabla 10.3. Tipos de materiales recuperados en los diferentes sectores muestreados. MT= muestreo por tiempo; $\mathrm{AS}=$ Arroyo Saudade; filo natural c/rastros complem= filo natural con rastros complementarios; artef. format. sum. frag. no dif= fragmento no diferenciado de artefacto de formatización sumaria.

La única materia prima recuperada, tanto en los sitios arqueológicos como en los muestreos, fue cuarcita G2 (44\%) y cuarcita G3 (56\%), cuyas proporciones se invierten si se considera el peso total de cada una de estas materias primas. Estas rocas presentan colores principalmente amarillo-ocre, bordó y diferentes tonos de rosa, de fractura concoidea y calidad para la talla entre regular y muy buena. Esto no significa que en el cauce del arroyo y en algunos conglomerados no se encuentren otras materias primas (en un muestreo anterior realizado aguas abajo se recuperó un rodado de cuarzo y uno de sílice indeterminado) pero éstas, o bien son muy escasas, o bien no presentan buena calidad para la talla (Figura 10.7). 


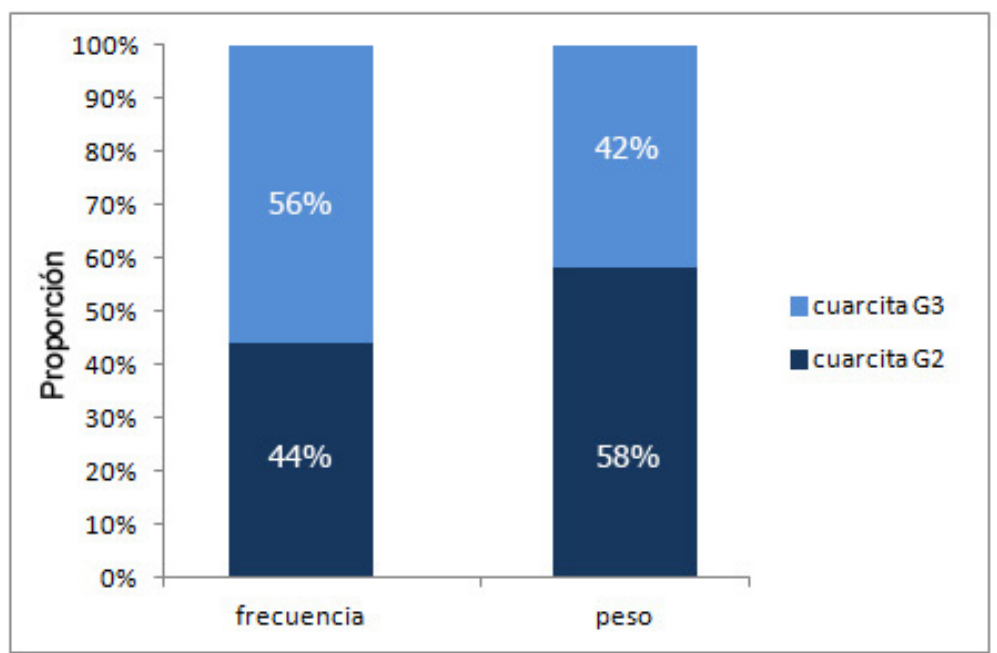

Figura 10.7. Proporción de materias primas presentes en los artefactos de la localidad arqueológica Arroyo Saudades, considerando su peso y frecuencia.

En ambos tipos de cuarcitas, los tamaños predominantes son el pequeño, mediano pequeño, grande y muy grande, los dos primeros en productos de talla e instrumentos y los últimos en núcleos y nucleiformes, aunque en estas dos últimas categorías también se encuentra una importante cantidad de productos de talla y algunos instrumentos (Tabla 10.4). Sin embargo las cuarcitas G2 muestran largos con una media levemente superior y mayor dispersión en los artefactos. Más del 60\% de los artefactos muestran remanente de corteza en alguna proporción. Ésta cubre, en la mayor parte de los casos, entre el $1 \%$ y el 50\% de la superficie de las piezas (Tabla 10.5), siendo levemente mayor la cantidad de artefactos con remanente de corteza entre las cuarcitas G2.

\begin{tabular}{|l|r|r|r|r|r|r|r|}
\hline $\begin{array}{c}\text { Tamaño } \\
\text { Materia prima }\end{array}$ & $\begin{array}{c}\text { Muy } \\
\text { pequeño }\end{array}$ & Pequeño & $\begin{array}{c}\text { Mediano } \\
\text { pequeño }\end{array}$ & $\begin{array}{c}\text { Mediano } \\
\text { grande }\end{array}$ & Grande & $\begin{array}{c}\text { Muy } \\
\text { grande }\end{array}$ & $\begin{array}{c}\text { Súper } \\
\text { grande }\end{array}$ \\
\hline cuarcita G2 & 1 & 9 & 8 & 4 & 14 & 7 & 4 \\
\hline cuarcita G3 & 2 & 15 & 18 & 5 & 12 & 8 & 1 \\
\hline
\end{tabular}

Tabla 10.4. Tamaño en las diferentes materias primas representadas en artefactos de la localidad Arroyo Saudade. Las materias primas se encuentran organizadas en función de la distancia a la que se encuentra su probable fuente de aprovisionamiento más cercana.

\begin{tabular}{|l|r|r|r|r|r|c|}
\hline Corteza & \multicolumn{1}{c|}{$\begin{array}{c}\text { Sin } \\
\text { corteza }\end{array}$} & $\mathbf{1 \%} \mathbf{- 2 5 \%}$ & $\mathbf{2 5 \%}-\mathbf{5 0 \%}$ & $\mathbf{5 0 \%}-\mathbf{7 5 \%}$ & $\mathbf{7 5 \%} \mathbf{- 1 0 0 \%}$ & IC \\
\hline cuarcita G2 & 13 & 13 & 10 & 9 & 2 & 0,72 \\
\hline cuarcita G3 & 21 & 19 & 11 & 9 & 1 & 0,65 \\
\hline
\end{tabular}

Tabla 10.5. Remanente de corteza en las diferentes materias primas representadas en artefactos de la localidad Arroyo Saudade. Las materias primas se encuentran organizadas en función de la distancia a la que se encuentra su probable fuente de aprovisionamiento más cercana.

En el sitio no se registraron evidencias de talla por técnica bipolar, con excepción de una lasca posiblemente obtenida de este modo. Las lascas completas son más abundantes entre las cuarcitas G3, las cuales muestran un IP menor que las cuarcita G2, lo que puede estar relacionado con la manufactura de instrumentos o formas base sobre esta materia prima para su posterior traslado. Los instrumentos, 
principalmente muescas y un raspador, muestran un bajo grado de formatización, que se ve reflejado en la ausencia de formas estandarizadas y en el escaso trabajo invertido en la formatización de los filos. Estos, en todos los casos, fueron realizados por medio de trabajo marginal unifacial (Tabla 10.6).

\begin{tabular}{|c|c|c|c|c|c|c|c|c|c|c|}
\hline \multirow[b]{2}{*}{$\begin{array}{c}\text { Materia } \\
\text { prima }\end{array}$} & \multicolumn{4}{|c|}{ Filos } & \multicolumn{3}{|c|}{ Artefactos } & \multirow[b]{2}{*}{$\begin{array}{l}\text { Lascas / } \\
\text { LF }\end{array}$} & \multirow[b]{2}{*}{ Instrumentos } & \multirow[b]{2}{*}{ IP } \\
\hline & $\begin{array}{c}\text { Unifacial } \\
\text { directo }\end{array}$ & \begin{tabular}{|c|c|}
$\begin{array}{c}\text { Unifacial } \\
\text { inverso }\end{array}$ \\
\end{tabular} & Bifacial & IB & TM & $\mathbf{R}$ & A & & & \\
\hline cuarcita G2 & 1 & & 0 & 0,00 & 1 & 0 & 0 & 7 & 1 & 7,00 \\
\hline cuarcita G3 & 3 & 1 & 0 & 0,00 & 4 & 0 & 0 & 20 & 4 & 5,00 \\
\hline
\end{tabular}

Tabla 10.6. Principales características de los artefactos formatizados por talla. $\mathrm{IB}=$ índice bifacial; $\mathrm{TM}=$ trabajo marginal; $\mathrm{R}=$ reducción; $\mathrm{A}=$ adelgazamiento; $\mathrm{IP}=$ índice de producción. $\mathrm{LF}=$ fragmento proximal de lasca.

En cuanto a los núcleos, se recuperaron 15 núcleos y 7 nucleiformes, cuyo largo morfológico oscila entre $38 \mathrm{~mm}$ y $118 \mathrm{~mm}$, con una mediana de $75 \mathrm{~mm}$, y su peso se encuentra entre 35,5 gr y 730 gr, con una mediana de $167,5 \mathrm{gr}$, valores muy similares a los registrados para los rodados sin evidencias de talla muestreados en los bancos del cauce del arroyo (si bien en el conglomerado se encuentran algunos de mayor tamaño). Se registraron núcleos discoidales irregulares o parciales $(n=9)$, globulosos $(n=5)$, con lascados aislados $(\mathrm{n}=6)$, de morfología indeterminada $(\mathrm{n}=1)$ y uno poliédrico. Se trata en todos los casos de núcleos de lascas, entre los que predominan claramente los núcleos de tamaño muy grande $(n=12)$ seguidos por los grandes y súper grandes $(n=5)$. Solo tres, de menor tamaño, se encuentran agotados, en tanto los restante aún son completamente activos $(n=11)$ o sólo parcialmente agotados $(n=8)$. Los pesos promedio son superiores en las cuarcitas G2, las cuales muestran también una mayor dispersión (Tabla 10.7).

\begin{tabular}{|l|r|r|r|r|r|}
\cline { 4 - 6 } \multicolumn{2}{c|}{} & \multicolumn{2}{c|}{ Estado } \\
\hline Materia prima & N & Peso medio & Error estándar & No agotado & Agotado \\
\hline cuarcita G2 & 10 & 234.20 & 73.90 & 8 & 0 \\
\hline
\end{tabular}

Tabla 10.7. Principales características de los núcleos recuperados en la localidad arqueológica Arroyo Saudade.

\subsection{La Montaña sitio 1(LM1)}

A partir de las excavaciones realizadas en el sitio 1 de la localidad La Montaña, se recuperaron un total de 80 fragmentos de pigmento, siete ecofactos y 645 artefactos líticos entre los que se encuentran 9 manufacturados por picado, abrasión y/o pulido, 32 instrumentos tallados (incluyendo ocho artefactos de formatización sumaria), 597 productos de talla, de los cuales 27 muestran rastros complementarios en alguno de sus filos, seis núcleos y un percutor. Estos materiales fueron analizados en conjunto con Oliva (2014) en relación con preguntas particulares derivadas de las respectivas tesis doctorales. Entre los artefactos, la materia prima más representada es la cuarcita (40\%), seguida por riolita (26\%), limolita silicificada (9\%) y, en menores porcentajes calcedonia, chert y RSO. Si se considera el peso total con el que se encuentran representadas cada una de estas rocas, esta tendencia se mantiene, aunque con 
mayor representación de cuarcitas, principalmente de aquellas correspondientes al grupo 2, que de esta manera alcanzan el 72\%. En este caso aumenta también la proporción de cuarcitas G1, disminuyendo

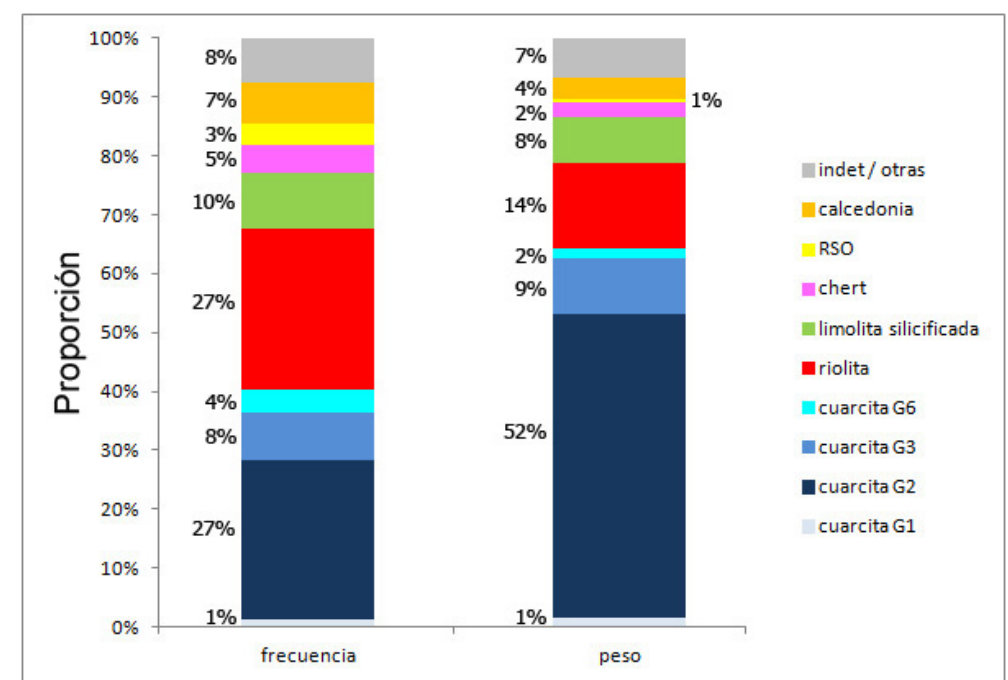

Figura 10.8. Proporción de materias primas presentes en los artefactos del sitio La Montaña 1, considerando su peso y frecuencia.

las cuarcitas G3 3 y G6, este último con menos del 1\% del peso total de materias primas (Figura 10.8).

Predominan los tamaños muy pequeño y pequeño en todas las materias primas, con excepción de las cuarcitas G1, donde el primero de estos no se encuentra representado. Los mayores tamaños solo se encuentran presentes entre las riolitas, las cuarcitas G 2, granito y arenisca micácea (incluidas como otras rocas), a las que se agregan 2 artefactos (un sobador y una lasca) elaborados sobre limolita silicificada. Entre las RSO, solo se encuentran artefactos muy pequeños o pequeños, en tanto entre los chert, calcedonias y cuarcitas G6, si bien predominan los tamaños más pequeños se encuentran también algunos artefactos medianos (Tabla 10.8).

\begin{tabular}{|l|r|r|r|r|r|r|r|}
\hline Materia prima & $\begin{array}{c}\text { Muy } \\
\text { pequeño }\end{array}$ & Pequeño & $\begin{array}{c}\text { Mediano } \\
\text { pequeño }\end{array}$ & $\begin{array}{c}\text { Mediano } \\
\text { grande }\end{array}$ & Grande & $\begin{array}{c}\text { Muy } \\
\text { grande }\end{array}$ & $\begin{array}{c}\text { Súper } \\
\text { grande }\end{array}$ \\
\hline cuarcita G2 & 112 & 43 & 8 & 4 & 4 & 3 & 3 \\
\hline riolita & 47 & 63 & 35 & 14 & 10 & 2 & \\
\hline cuarcita G3 & 11 & 23 & 14 & 3 & & & \\
\hline cuarcita G1 & & 5 & 2 & 1 & & & \\
\hline limolita silicificada & 21 & 34 & 5 & & 2 & & \\
\hline calcedonia & 15 & 24 & 4 & 1 & & & \\
\hline chert & 13 & 13 & 3 & & & & \\
\hline RSO & 18 & 5 & & & & & \\
\hline
\end{tabular}

Tabla 10.8. Tamaño en las diferentes materias primas representadas en artefactos del sitio La Montaña 1. Las materias primas se encuentran organizadas en función de la distancia a la que se encuentra su probable fuente de aprovisionamiento más cercana. 


\begin{tabular}{|l|r|r|r|r|r|r|r|}
\hline cuarcita G6 & 6 & 15 & 2 & 1 & & & \\
\hline indet/otras & 13 & 8 & 2 & 2 & 1 & 1 & 1 \\
\hline
\end{tabular}

En relación con la reserva de corteza presente en los artefactos, predominan aquellos sin corteza o con menos del 25\% de corteza. Los artefactos con mayor remanente de corteza se encuentran entre las cuarcita G2 y limolita silicificada, en tanto el índice de corteza más elevado se encuentra entre las cuarcitas G3. La riolita, si bien con un índice de corteza bajo, presenta algunos artefactos cuyas superficies se encuentran cubiertas por corteza en más del 50\%. El chert también presenta un IC elevado, con varios artefactos con hasta un 50\% de corteza, en tanto entre las cuarcitas G1 y las calcedonias, ningún artefactos presenta más del 25\% de corteza. Las RSO y las cuarcitas G6 no presentan corteza, con excepción de una lasca en esta última materia prima (Tabla 10.9).

\begin{tabular}{|l|r|r|r|r|r|c|}
\hline \multicolumn{1}{|c|}{ Corteza } & $\begin{array}{c}\text { sin } \\
\text { corteza }\end{array}$ & $\mathbf{1 - 2 5 \%}$ & $\mathbf{2 5 - \mathbf { 5 0 } \%}$ & $\mathbf{5 0 - 7 5 \%}$ & $\mathbf{7 5 - 1 0 0 \%}$ & IC \\
\hline cuarcita G2 & 125 & 21 & 18 & 7 & 6 & 0,29 \\
\hline riolita & 137 & 23 & 8 & 2 & & 0,19 \\
\hline cuarcita G3 & 28 & 14 & 7 & 2 & & 0,45 \\
\hline cuarcita G1 & 6 & 2 & & & & 0,25 \\
\hline limolita silicificada & 37 & 15 & 8 & 1 & 1 & 0,40 \\
\hline calcedon & 37 & 7 & & & & 0,16 \\
\hline chert & 20 & 5 & 4 & & & 0,31 \\
\hline RSO & 23 & & & & & 0,00 \\
\hline cuarcita G6 & 23 & & 1 & & & 0,04 \\
\hline indet/otras & 16 & 8 & 3 & 1 & 1 & 0,81 \\
\hline
\end{tabular}

Tabla 10.9. Remanente de corteza en las diferentes materias primas representadas en artefactos del sitio La Montaña 1. Las materias primas se encuentran organizadas en función de la distancia a la que se encuentra su probable fuente de aprovisionamiento más cercana.

La técnica bipolar se encuentra poco representada, habiéndose registrado sólo tres lascas de limolita silicificada y un artefacto de formatización sumaria elaborado sobre una lasca bipolar de cuarcita. Se encuentran a su vez, otras siete posibles lascas bipolares, en las que los rasgos diagnóstico no se observan tan claramente, dos de ellas sobre cuarcita G2, dos sobre riolita y tres sobre limolita silicificada.

Entre los productos de talla predominan las cuarcitas G 2 y riolitas y en menor proporción limolita silicificada, cuarcita G3, calcedonia, chert, RSO y cuarcitas G6 y G1. Entre los instrumentos también predominan las cuarcitas G2 y riolitas, pero con una mayor representación de materias primas de muy buena calidad, encontrándose los menores IP en RSO, chert y cuarcitas G1. Aquellos con mayor grado de formatización consisten en dos puntas apedunculadas elaboradas sobre calcedonia y cuarcita G6, mediante adelgazamiento bifacial. También se recuraron una raedera, un raspador y un fragmento 
trabajado por reducción, en tanto el resto de los instrumentos muestran trabajo marginal. La mayor proporción de bordes bifaciales se encuentran en calcedonia y cuarcita grupo 6, con IB de 0,5 en ambos casos (Tabla 10.10).

\begin{tabular}{|c|c|c|c|c|c|c|c|c|c|c|c|}
\hline \multirow[b]{2}{*}{$\begin{array}{l}\text { Materia } \\
\text { Prima }\end{array}$} & \multicolumn{5}{|c|}{ Filos } & \multicolumn{3}{|c|}{ Artefactos } & \multirow[b]{2}{*}{ Lascas } & \multirow[b]{2}{*}{ Instrum } & \multirow[b]{2}{*}{ IP } \\
\hline & $\begin{array}{l}\text { Unifaial } \\
\text { directo }\end{array}$ & $\begin{array}{l}\text { Unifaial } \\
\text { inverso }\end{array}$ & $\begin{array}{c}\text { Unifacial } \\
\text { indet }\end{array}$ & Bifacial & IB & TM & $\mathbf{R}$ & $\mathbf{A}$ & & & \\
\hline cuarcita G2 & 3 & 1 & & & 0,00 & 2 & 1 & & 33 & 4 & 8,25 \\
\hline cuarcita G3 & 1 & & 2 & 1 & 0,25 & 2 & 1 & & 22 & 4 & 5,50 \\
\hline cuarcita G1 & 3 & & & & 0,00 & 1 & & & 4 & 1 & 4,00 \\
\hline cuarcita G6 & & 3 & & 3 & 0,50 & 1 & & 1 & 12 & 2 & 6,00 \\
\hline riolita & 3 & 2 & 4 & & 0,00 & 7 & & & 42 & 7 & 6,00 \\
\hline lim sil & 1 & & & & 0,00 & 2 & & & 9 & 1 & 9,00 \\
\hline chert & 1 & & 1 & & 0,00 & 2 & & & 11 & 2 & 5,50 \\
\hline RSO & & & 4 & 2 & 0,33 & 1 & 1 & & 10 & 3 & 3,33 \\
\hline calcedonia & 2 & & 1 & 3 & 0,50 & 2 & & 1 & 23 & 3 & 7,67 \\
\hline
\end{tabular}

Tabla 10.10. Principales características de los artefactos formatizados por talla del sitio La Montaña 1 . IB= índice bifacial; $\mathrm{TM}=$ trabajo marginal; $\mathrm{R}=$ reducción; $\mathrm{A}=$ adelgazamiento; $\mathrm{IP}=$ índice de producción; Lim sil= limolita silicificada.

Por último, se recuperó un total de siete núcleos de lascas, uno de chert agotado y reciclado como muesca, cinco de limolita silicificada, también agotados, y el último de cuarcita G2, este último el único que no se encuentra agotado. Sólo el núcleo de cuarcita supera los 200 gr, encontrándose los restantes con pesos inferiores a los 20 gr (Tabla 10.11).

\begin{tabular}{|l|r|r|r|r|r|}
\cline { 5 - 6 } \multicolumn{2}{c}{} & \multicolumn{2}{c|}{ Estado } \\
\hline Materia prima & N & Peso medio & Error estándar & No agotado & Agotado \\
\hline cuarcita G2 & 1 & 222,00 & $\mathrm{np}$ & 1 & \\
\hline limolita silicificada & 5 & 6,50 & 3,33 & & 5 \\
\hline chert & 1 & 8,00 & $\mathrm{np}$ & & 1 \\
\hline
\end{tabular}

Tabla 10.11. Principales características de los núcleos recuperados en el sitio La Montaña $1, \mathrm{np}=$ no pertinente.

Entre los artefactos modificados por uso o por picado, abrasión y/o pulido, se encuentran cuarcitas de grano medio a grueso y, en bajo porcentaje, limolita y basalto, a los que se agregan fragmentos de arenisca micácea, granito y una roca ígnea indeterminada. Todas ellas se encuentran disponibles a una distancia no mayor a $20 \mathrm{~km}$ para las primeras y $50 \mathrm{~km}$ para las últimas. Estos artefactos consisten en dos 
manos de molino, siete alisadores y/o sobadores, uno -en cuarcita- con evidencias de haber sido utilizado también como percutor, con pesos de entre 100 gr y 900 gr. Ninguno muestra evidencias de mantenimiento o manufactura, ya sea en las superficie activas como en las áreas de prensión (Tabla 10.12).

\begin{tabular}{|c|c|c|c|c|c|c|}
\hline & \multicolumn{5}{|c|}{ Tipo de artefacto } & \multirow{2}{*}{$\begin{array}{c}\begin{array}{c}\text { Otras } \\
\text { características }\end{array} \\
\text { Uso } \\
\begin{array}{c}\text { alternativo } \\
\text { percutor }\end{array}\end{array}$} \\
\hline Materia prima & $\begin{array}{c}\text { Alisador / } \\
\text { sobador }\end{array}$ & Percutor & $\begin{array}{l}\text { Mano } \\
\text { molino }\end{array}$ & $\begin{array}{l}\text { Mano } \\
\text { frag. }\end{array}$ & $\begin{array}{c}\text { Fragmento } \\
\text { indet }\end{array}$ & \\
\hline cuarcita & 4 & 1 & 1 & 1 & & 1 \\
\hline limolita & 2 & & & & & \\
\hline basalto & 1 & & & & & \\
\hline arenisca micácea & & & & & 3 & \\
\hline roca ígnea indet & & & & & 1 & \\
\hline granito & & & & & 1 & \\
\hline
\end{tabular}

Tabla 10.12. Principales características de los artefactos modificados por uso y formatizados por picado, abrasión y/o pulido del sitio La Montaña 1 . Indet= indeterminado.

\subsection{Localidad arqueológica La Sofía (LS)}

Las tareas de campo desarrolladas en la Localidad La Sofía, fueron dirigidas por F. Oliva, en el marco de su tesis doctoral (Oliva 2014) y los materiales recuperados en estas fueron estudiados en conjunto con dicho autor en relación con preguntas particulares derivadas de las respectivas tesis doctorales (Oliva 2014). Se recuperó un total de 63 artefactos líticos, de los cuales 28 fueron recuperados en el sitio LS2, (19 en dos sondeos y cuatro recolectados en superficie por la familia Moro en distintas oportunidades). Cuatro artefactos proceden de un sondeo realizado en el sitio LS4, 30 fueron recolectados en superficie en el sitio LS 5 y uno en el sitio LS 6. Debido al escaso número de materiales recuperados en esta localidad, el análisis será presentado en su conjunto, sin realizar diferenciaciones por sitio. Dicho conjunto de materiales líticos está conformado por 35 productos de talla, uno de ellos con rastros complementarios en uno de sus filos, 11 instrumentos entre los que se encuentran cuatro artefactos de formatización sumaria, seis núcleos de lascas, cuatro artefactos manufacturados por picado, abrasión y/o pulido, tres ecofactos y tres fragmentos de pigmento (Oliva 2014).

Entre los artefactos, la materia prima con mayor representación es la cuarcita, principalmente las cuarcitas G2 (56 \%) y en menor proporción cuarcitas G3 (14\%) y cuarcitas G1 (11\%). También se encuentran riolitas, limolitas silicificadas, basaltos y, con menor representación, calcedonias y RSO. Si se considera el peso total de estas rocas, la tendencia se mantiene pero aumenta levemente la representación de las cuarcitas G2, G3 y limolitas silicificadas (Figura 10.9). 


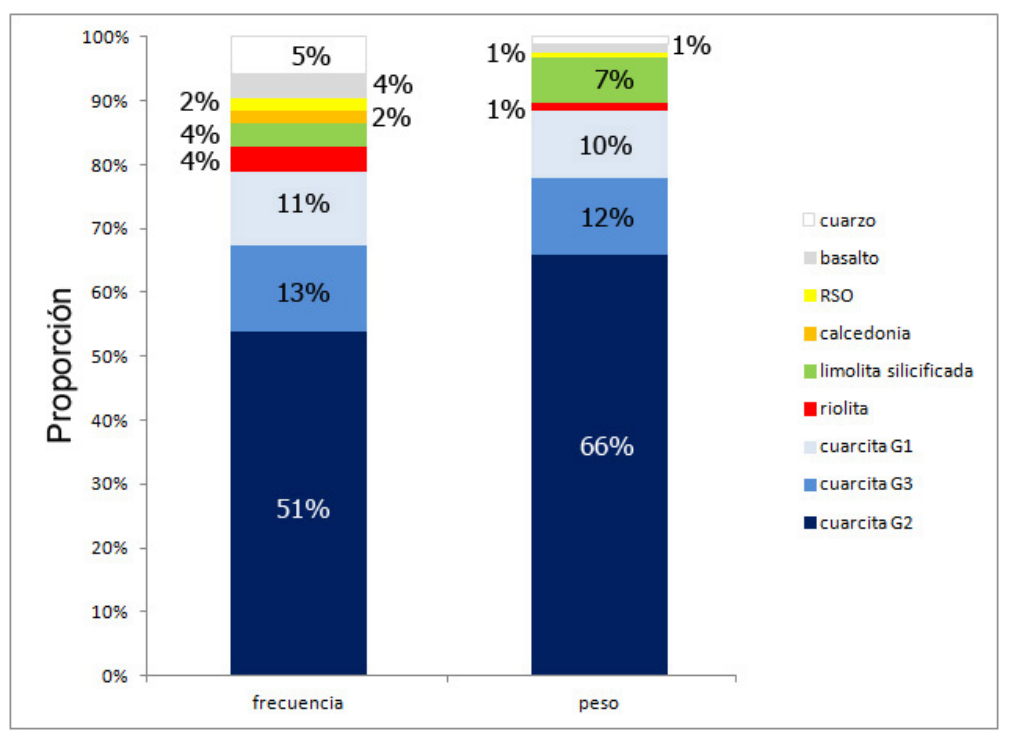

Figura 10.9. Proporción de materias primas presentes en los artefactos de la localidad La Sofía, considerando su peso y frecuencia.

Todos los tamaños se encuentran representados, predominando aquellos correspondientes a los tamaños pequeño, mediano-pequeño y grande. Los tamaños más grandes (muy grande y súper grande, sólo se encuentran presentes en las materias primas disponibles inmediatamente o a una media distancia (entre $12 \mathrm{~km}$ en el caso de la cuarcita G3 y $25 \mathrm{~km}$ para las riolitas, limolitas silicificadas y cuarcita G1). La calcedonia, cuyas fuentes se encuentran a no menos de $100 \mathrm{~km}$ sólo está representada por el tamaño muy pequeño, en tanto otras materias primas exóticas, como el basalto y las RSO, se las encuentra en baja frecuencia pero en tamaños mediano-grande y grande (Tabla 10.13).

\begin{tabular}{|c|c|c|c|c|c|c|c|}
\hline $\begin{array}{l}\text { Tamaño } \\
\text { Materia prima }\end{array}$ & $\begin{array}{c}\text { Muy } \\
\text { pequeño }\end{array}$ & Pequeño & $\begin{array}{c}\text { Mediano } \\
\text { pequeño }\end{array}$ & $\begin{array}{c}\text { Mediano } \\
\text { grande }\end{array}$ & Grande & $\begin{array}{c}\text { Muy } \\
\text { grande }\end{array}$ & $\begin{array}{c}\text { Súper } \\
\text { grande }\end{array}$ \\
\hline cuarcita G2 & 3 & 9 & 5 & 1 & 7 & 3 & 3 \\
\hline cuarcita G3 & & 1 & 4 & 1 & & 1 & 1 \\
\hline cuarcita G1 & & & 1 & & 3 & 2 & \\
\hline riolita & & & 1 & & 1 & & \\
\hline limolita silicificada & & & & & & 2 & \\
\hline basalto & & & & 1 & 1 & & \\
\hline calcedonia & 1 & & & & & & \\
\hline cuarzo & & 2 & & 1 & & & \\
\hline $\mathrm{RSO}$ & & & & 1 & & & \\
\hline
\end{tabular}

Tabla 10.13. Tamaño en las diferentes materias primas representadas en artefactos de la localidad La Sofía. Las materias primas se encuentran organizadas en función de la distancia a la que se encuentra su probable fuente de aprovisionamiento más cercana.

Dominan la muestra los artefactos sin corteza o con menos del $25 \%$ de su superficie cubierta, en tanto los mayores porcentajes de corteza se encuentran en las cuarcitas G2 y, en menor medida, cuarcitas G3 y limolita silicificada (Tabla 10.14). Esto se ve reflejado en su IC cercano a 1 en el primer caso. Otras materias primas como limolitas silicificadas y RSO presentan también IC altos, pero su n es demasiado bajo. 


\begin{tabular}{|l|r|r|r|r|r|r|r|}
\hline $\begin{array}{c}\text { Corteza } \\
\text { Materia prima }\end{array}$ & $\begin{array}{c}\text { Sin } \\
\text { corteza }\end{array}$ & $\mathbf{1 \% - 2 5 \%}$ & $\mathbf{2 5 \%}-\mathbf{5 0 \%}$ & $\mathbf{5 0 \%}-\mathbf{7 5 \%}$ & $\mathbf{7 5 \%}-\mathbf{1 0 0} \%$ & $\begin{array}{c}\text { No } \\
\text { pertinente }\end{array}$ & IC \\
\hline cuarcita G2 & 10 & 7 & 7 & 4 & 1 & 2 & 0,68 \\
\hline cuarcita G3 & 6 & & & 1 & & 1 & 0,25 \\
\hline cuarcita G1 & 5 & 1 & & & & & 0,17 \\
\hline riolita & 2 & & & & & & 0,00 \\
\hline limolita silicificada & & & 2 & & & & 1,00 \\
\hline basalto & 2 & & & & & & 0,00 \\
\hline calcedonia & 1 & & & & & & 0,00 \\
\hline cuarzo & 2 & 1 & & & & & 0,33 \\
\hline RSO & & 1 & & & & & 1,00 \\
\hline
\end{tabular}

Tabla 10.14. Remanente de corteza en las diferentes materias primas representadas en artefactos de la localidad La Sofía. Las materias primas se encuentran organizadas en función de la distancia a la que se encuentra su probable fuente de aprovisionamiento más cercana. $\mathrm{IC}=$ índice de corteza.

La técnica bipolar no se encuentra representada en ninguna de las materias primas. Los productos de talla se encuentran ampliamente representados entre las cuarcitas G2, siendo escasos en las restantes materias primas. Los instrumentos se encuentran en alto número, principalmente entre las cuarcitas. Todos los instrumentos muestran poca inversión de trabajo en su manufactura, aquellos con mayor grado de formatización consisten en un cuchillo y dos raederas, trabajados mediante reducción, en tanto los restantes instrumentos presentan trabajo marginal, en tres casos, en todos los casos por retoque unifacial directo (Tabla 10.15).

\begin{tabular}{|l|r|r|r|r|r|r|r|r|r|r|}
\cline { 2 - 9 } \multicolumn{4}{c|}{} & \multicolumn{3}{c|}{ Filos } & \multicolumn{3}{c|}{ Artefactos } & \multicolumn{2}{c|}{} \\
\hline $\begin{array}{l}\text { Materia } \\
\text { prima }\end{array}$ & $\begin{array}{c}\text { Unifacial } \\
\text { directo }\end{array}$ & $\begin{array}{c}\text { Unifacial } \\
\text { indet }\end{array}$ & Bifacial & IB & TM & R & A & Lascas & Instrumentos & IP \\
\hline cuarcita G2 & 2 & 1 & & 0,00 & 1 & 1 & 7 & 2 & 2,33 \\
\hline cuarcita G3 & 1 & & & 0,00 & 1 & & 0 & 1 & 0,00 \\
\hline riolita & & 1 & & 0,0 & 1 & & 0 & 1 & 0,00 \\
cuarcita G1 & 2 & 2 & 1 & 0,20 & 2 & 2 & & 0 & 4 & 0,00 \\
lim sil & 1 & & & 0,00 & & 1 & & 0 & 1 & 0,00 \\
\hline
\end{tabular}

Tabla 10.15. Principales características de los artefactos formatizados por talla. $\mathrm{IB}=$ índice bifacial; $\mathrm{TM}=$ trabajo marginal; $\mathrm{R}=$ reducción; $\mathrm{A}=$ adelgazamiento; $\mathrm{IP}=$ índice de producción; lim sil= limolita silicificada

Finalmente, entre los núcleos se encuentran uno sobre limolita silicificada de morfología discoidal irregular, dos en cuarcita G1 -uno discoidal irregular y el otro bifacial-, dos en cuarcita G2, ambos con lascados aislados y uno en cuarcita G3 discoidal irregular, todos aún completamente activos. Sus pesos oscilan entre 82 gr y 418 gr, encontrándose los núcleos más livianos sobre cuarcita G1 y limolita silicificada (Tabla 10.16). 


\begin{tabular}{|c|c|c|c|c|c|}
\hline \multirow[b]{2}{*}{ Materia prima } & \multirow[b]{2}{*}{$\mathbf{N}$} & \multirow[b]{2}{*}{ Peso medio } & \multirow[b]{2}{*}{\begin{tabular}{|l} 
Desvío \\
estándar
\end{tabular}} & \multicolumn{2}{|l|}{ Estado } \\
\hline & & & & No agotado & Agotado \\
\hline cuarcita G2 & 2 & 366,50 & 72,83 & 2 & \\
\hline limolita silicificada & 1 & 168 & $\mathrm{np}$ & 1 & \\
\hline cuarcita G3 & 1 & 336 & $\mathrm{np}$ & 1 & \\
\hline cuarcita G1 & 2 & 89,50 & 10,60 & 2 & \\
\hline
\end{tabular}

Tabla 10.16. Principales características de los núcleos recuperados en la localidad La Sofía.

Los artefactos modificados por uso y/o confeccionados por picado, abrasión y/o pulido no muestran inversión en su formatización. Consisten en cuatro rodados de cuarcitas, que en un solo caso superan el medio kilo de peso (664 gr), encontrándose los restantes con pesos que oscilan entre 108 gr y 314 gr. En todos los casos se trata de artefactos activos, entre los que se encuentran un sobador y tres manos de molino con una única superficie activa, una de ellas fragmentada.

\subsection{Los Chilenos sitio 2 (LCH2)}

Los materiales líticos fueron analizados en conjunto con Oliva (2014) en relación con preguntas particulares derivadas de las respectivas tesis doctorales. Estos consisten en 473 artefactos entre los cuales 351 proceden de las excavaciones realizadas sobre la barranca de la laguna ( 278 recuperados en la cuadrícula 1 y 73 en la cuadrícula 2) y 122 artefactos fueron obtenidos por medio de recolecciones sistemáticas realizadas sobre la playa, en inmediaciones de estas dos cuadrículas.

Entre los materiales recuperados en estratigrafía se encuentran 322 productos de talla, 12 de ellos con rastros complementarios en alguno de sus filos, siete instrumentos, dos núcleos, siete fragmentos de pigmento y un posible fragmento de placa grabada de pequeñas dimensiones. Entre los artefactos tallados predomina la cuarcita G2, seguida por cuarcitas G3 y cuarcitas G1. En menor proporción se encuentran las cuarcitas G6 (9\%), calcedonias (8\%) y riolitas (7\%), encontrándose en porcentajes muy bajos RSO, chert y limolita silicificada. Considerando el peso total de cada una de estas rocas, la tendencia general se mantiene, pero aumenta la representatividad de las cuarcitas G2 y G1 y de las rocas indeterminadas, en detrimento de las restantes materias primas, encontrándose la mayor disminución en las cuarcitas G6 (Figura 10.10).

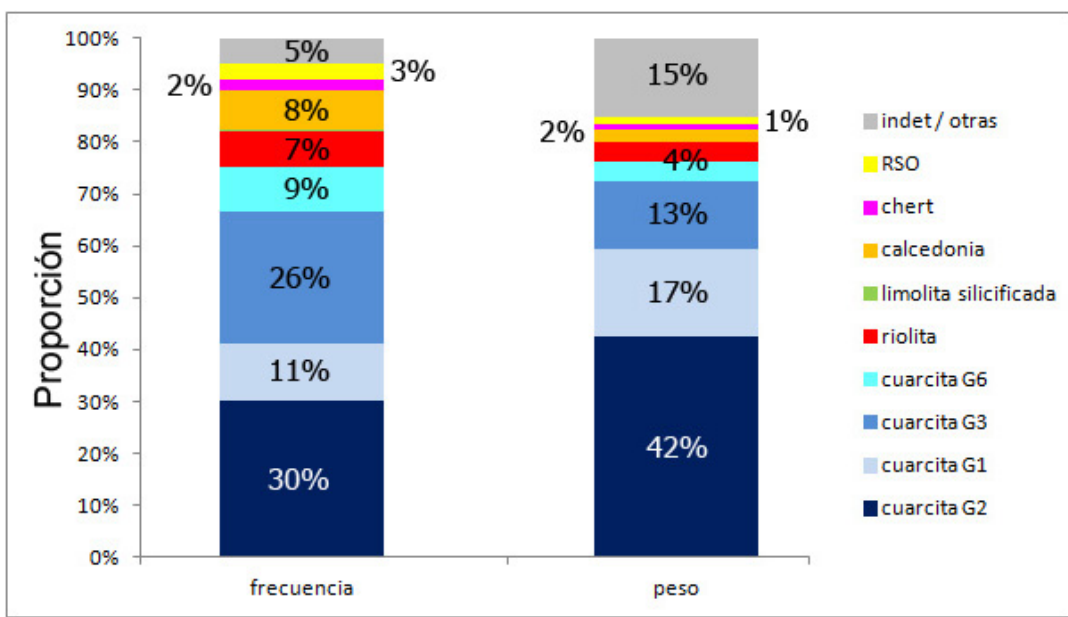

Figura 10.10. Proporción de materias primas presentes en los artefactos del sitio Los Chilenos 2 estratigrafía, considerando su peso $\mathrm{y}$ frecuencia. 
En todas las materias primas predominan los tamaños muy pequeño y pequeño, con excepción del basalto, representado únicamente por una pieza mediano-pequeña. Los artefactos de mayor tamaño sólo se encuentran representados en cuarcitas G1, cuarcitas G2 y cuarcitas G3, en tanto las restantes materias primas se encuentran casi exclusivamente en tamaño muy pequeño o pequeño, con algunos pocos artefactos de cuarcita G6, RSO, riolita y basalto en tamaño mediano pequeño (Tabla 10.17).

\begin{tabular}{|l|r|r|r|r|r|r|}
\hline \multicolumn{1}{|c|}{ Tamaño } & $\begin{array}{c}\text { Muy } \\
\text { pequeño }\end{array}$ & Pequeño & $\begin{array}{c}\text { Mediano } \\
\text { pequeño }\end{array}$ & $\begin{array}{c}\text { Mediano } \\
\text { grande }\end{array}$ & Grande & $\begin{array}{c}\text { Muy } \\
\text { grande }\end{array}$ \\
\hline Materia prima & 49 & 37 & 9 & 8 & 1 & \\
\hline cuarcita G2 & 17 & 12 & 2 & 5 & & 1 \\
\hline cuarcita G1 & 45 & 34 & 8 & 1 & & \\
\hline cuarcita G3 & 9 & 11 & 3 & & & \\
\hline riolita & 1 & & & & & \\
\hline limolita silicificada & 2 & 5 & & & & \\
\hline chert & 19 & 8 & & & & \\
\hline calcedonia & & & 1 & & & \\
\hline basalto & 4 & 5 & 1 & & & \\
\hline RSO & 20 & 8 & 2 & & & \\
\hline cuarcita G6 & 5 & 5 & 5 & & & \\
\hline indet/otras & & & & & & \\
\hline
\end{tabular}

Tabla 10.17. Tamaño en las diferentes materias primas representadas en artefactos del sitio Los Chilenos 2 estratigrafía. Las materias primas se encuentran organizadas en función de la distancia a la que se encuentra su probable fuente de aprovisionamiento más cercana.

El 86\% de los artefactos no presenta remanentes de corteza sobre sus superficies. Las materias primas entre las que se encuentra la mayor cobertura de corteza las cuarcitas G1, cuarcitas G2 y cuarcitas G3, sobre las que se encuentran algunos artefactos con más del 50\% de reserva de corteza, y chert y RSO, en las que se registró un artefactos en cada una con un remanente de corteza de entre $25 \%$ y $50 \%$. De manera concordante, el IC presenta los valores más altos en cuarcita G2 y chert. En cuarcita G6, si bien el número de artefactos es alto, ninguno de ellos muestra remanente de corteza (Tabla 10.18).

\begin{tabular}{|c|c|c|c|c|c|c|c|}
\hline $\begin{array}{l}\text { Corteza } \\
\text { Materia prima }\end{array}$ & $\begin{array}{c}\text { Sin } \\
\text { corteza }\end{array}$ & $1 \%-25 \%$ & $25 \%-50 \%$ & $50 \%-75 \%$ & $75 \%-100 \%$ & Total & IC \\
\hline cuarcita G2 & 76 & 19 & 8 & 1 & & 104 & 0,37 \\
\hline cuarcita G1 & 35 & & & 2 & & 37 & 0,10 \\
\hline cuarcita G3 & 84 & 3 & & & 1 & 88 & 0,04 \\
\hline riolita & 22 & 1 & & & & 23 & 0,07 \\
\hline limolita silicificada & 1 & & & & & 1 & 0,00 \\
\hline chert & 5 & 1 & 1 & & & 7 & 0,29 \\
\hline calcedonia & 24 & 3 & & & & 27 & 0,09 \\
\hline basalto & 1 & & & & & 1 & 0,00 \\
\hline $\mathrm{RSO}$ & 6 & 3 & 1 & & & 10 & 0,50 \\
\hline cuarcita G6 & 30 & & & & & 30 & 0,00 \\
\hline indet/otras & 14 & & 2 & & & 16 & 0.13 \\
\hline
\end{tabular}

Tabla 10.18. Remanente de corteza en las diferentes materias primas representadas en artefactos del sitio Los Chilenos 2 estratigrafía. Las materias primas se encuentran organizadas en función de la distancia a la que se encuentra su probable fuente de aprovisionamiento más cercana. 
Solo tres artefactos muestran evidencias de haber sido reducidos mediante técnica bipolar, dos de ellos confeccionados en cuarcita G3 y el tercero en cuarcita G1. La mayor parte de la muestra se encuentra conformada por productos de talla, entre los cuales 11 presentan rastros complementarios en alguno de sus filos, la mayor cantidad en calcedonia y cuarcita G1. Los artefactos formatizados por talla son escasos, presentes únicamente entre las cuarcitas G1y cuarcitas G2, riolita, calcedonia y una roca indeterminada. Entre estos, aquel con mayor inversión en su elaboración consiste en una raedera formatizada mediante reducción unifacial. En los restantes filos se utilizó el trabajo marginal, sumario en algunos casos (Tabla 10.19). No se registraron artefactos manufacturados por picado, abrasión y/o pulido.

\begin{tabular}{|c|c|c|c|c|c|c|c|c|c|c|c|}
\hline & \multicolumn{5}{|c|}{ Filos } & \multicolumn{3}{|c|}{ Artefactos } & \multirow[b]{2}{*}{ Lascas } & \multirow[b]{2}{*}{ Instrum. } & \multirow[b]{2}{*}{ IP } \\
\hline $\begin{array}{c}\text { Materia } \\
\text { prima }\end{array}$ & $\begin{array}{c}\text { Unifacial } \\
\text { directo }\end{array}$ & \begin{tabular}{|c|} 
Unifacial \\
inverso
\end{tabular} & \begin{tabular}{|c|} 
Unifacial \\
indet.
\end{tabular} & Bifacial & IB & TM & $\mathbf{R}$ & $\mathbf{A}$ & & & \\
\hline calcedonia & 1 & & & & 0,00 & 1 & & & 10 & 1 & 10,00 \\
\hline chert & & & & & 0,00 & & & & 3 & & \\
\hline cuarcita G1 & 3 & 2 & 1 & & 0,00 & 2 & 1 & & 17 & 3 & 5,67 \\
\hline cuarcita G2 & & & 1 & & 0,00 & & & & 25 & 1 & 25,00 \\
\hline cuarcita G3 & & & & & 0,00 & & & & 39 & & \\
\hline cuarcita G6 & & & & & 0,00 & & & & 9 & & \\
\hline riolita & & 1 & & & 0,00 & 1 & & & 11 & 1 & 11,00 \\
\hline $\mathrm{RSO}$ & & & & & 0,00 & & & & 2 & & \\
\hline indet / otras & & & 1 & & 0,00 & 1 & & & 1 & 1 & 0,00 \\
\hline
\end{tabular}

Tabla 10.19. Principales características de los artefactos formatizados por talla del sitio Los Chilenos 2 estratigrafía. $\mathrm{IB}=$ índice bifacial; $\mathrm{TM}=$ trabajo marginal; $\mathrm{R}=$ reducción; $\mathrm{A}=$ adelgazamiento; $\mathrm{IP}=$ índice de producción. Las materias primas se encuentran organizadas en función de la distancia a la que se encuentra su probable fuente de aprovisionamiento más cercana.

Solo fueron recuperados tres núcleos agotados con peso inferior a los 10 gr. Uno de ellos en calcedonia, otro en cuarcita G6 y el tercero un núcleo bipolar sobre un rodado de RSO (Tabla 10.20).

\begin{tabular}{|l|r|r|r|r|}
\cline { 4 - 5 } \multicolumn{2}{c|}{} & \multicolumn{2}{c|}{ Estado } \\
\hline Materia prima & N & Peso (gr.) & No agotado & Agotado \\
\hline calcedonia & 1 & 3,50 & & 1 \\
\hline cuarcita G6 & 1 & 7,00 & & 1 \\
\hline RSO & 1 & 2,00 & & \\
\hline
\end{tabular}

Tabla 10.20. Principales características de los núcleos recuperados en el sitio Los Chilenos 2 estratigrafía.

Entre los materiales recuperados en superficie, la materia prima más representada es la cuarcita G2 (46\%), seguida por la cuarcita G3 (21\%) y la cuarcita G1 (10\%). En menor proporción se encuentran riolita, calcedonia, cuarcitas G6 y RSO. Al considerar la representación de las distintas materias primas en relación con su peso, las cuarcitas G2 aumentan casi en un 20\% su representación y las indeterminadas y otras (areniscas, cuarzo) en casi un 10\%, en tanto las restantes rocas disminuyen, siendo esto más acentuado en las cuarcitas G3, cuarcitas G6, calcedonia y RSO (Figura 10.11). 


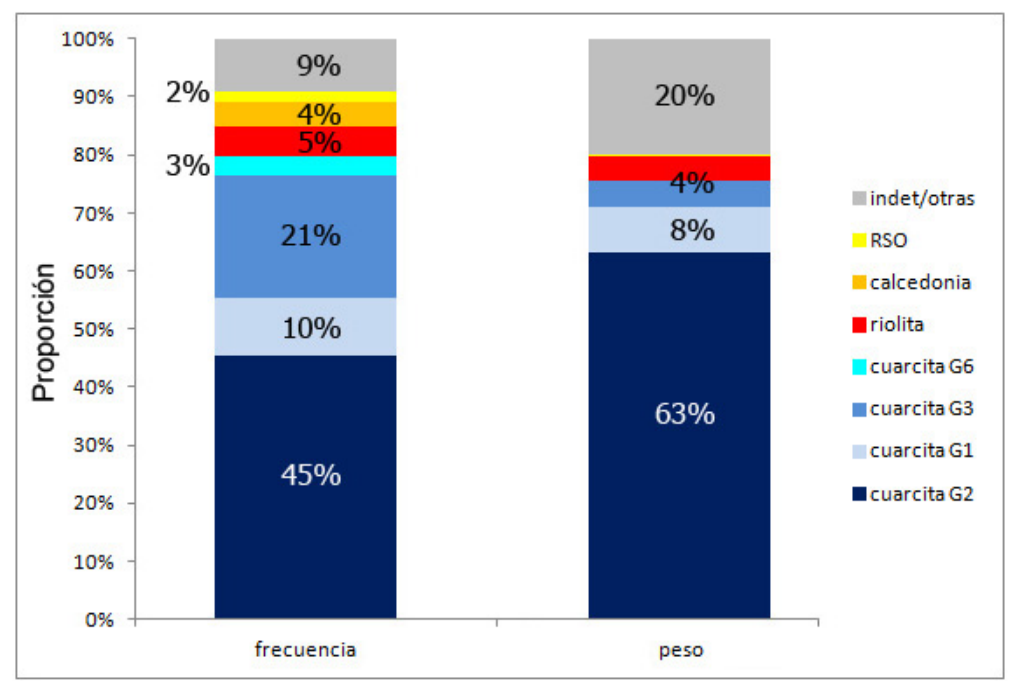

Figura 10.11. Proporción de materias primas presentes en los artefactos del sitio Los Chilenos 2 superficie, considerando su peso y frecuencia.

Entre los tamaños representados predominan aquellos comprendidos entre pequeño y grande, encontrándose en muy bajo número aquellos muy pequeños, probablemente por tratarse de una colección de superficie. Los tamaños mayores solo se encuentran presentes entre las cuarcitas G1, cuarcitas G2, cuarcitas G3 y la riolita, en tanto sobre calcedonia, RSO y cuarcita G6, sólo se observan tamaños pequeño y mediano pequeño. El tamaño súper grande, por último, solo se encuentra presente entre las cuarcitas G2 (Tabla 10.21).

\begin{tabular}{|c|c|c|c|c|c|c|c|}
\hline $\begin{array}{r}\text { Tamaño } \\
\text { Materia prima }\end{array}$ & \begin{tabular}{|c|} 
Muy \\
pequeño
\end{tabular} & Pequeño & $\begin{array}{l}\text { Mediano } \\
\text { pequeño }\end{array}$ & $\begin{array}{l}\text { Mediano } \\
\text { grande }\end{array}$ & Grande & $\begin{array}{c}\text { Muy } \\
\text { grande }\end{array}$ & $\begin{array}{l}\text { Súper } \\
\text { grande }\end{array}$ \\
\hline cuarcita G2 & 3 & 15 & 6 & 11 & 13 & 5 & 1 \\
\hline cuarcita G1 & & 3 & 4 & 2 & 2 & 1 & \\
\hline cuarcita G3 & 1 & 16 & 6 & 1 & & 1 & \\
\hline riolita & & 3 & 1 & & 1 & 1 & \\
\hline calcedonia & & 3 & 2 & & & & \\
\hline RSO & & 1 & 1 & & & & \\
\hline cuarcita G6 & & 2 & 2 & & & & \\
\hline indet/otras & 1 & 2 & 1 & 2 & 3 & & 1 \\
\hline Total & 5 & 45 & 23 & 16 & 19 & 8 & 2 \\
\hline
\end{tabular}

Tabla 10.21. Tamaño en las diferentes materias primas representadas en artefactos de Los Chilenos 2 superficie. Las materias primas se encuentran organizadas en función de la distancia a la que se encuentra su probable fuente de aprovisionamiento más cercana.

Las únicas rocas en las que se registran porcentajes de corteza superiores al 25\% son RSO y cuarcita G1 y cuarcita G2, esta última con la mayor cantidad de artefactos con altos porcentajes de corteza, evidenciado también en su alto IC. Las restantes materias primas no registran evidencias de corteza en ninguno de los artefactos, salvo la riolita, con un IC levemente superior a 0 (Tabla 10.22). 


\begin{tabular}{|l|r|r|r|r|r|c|}
\hline \multicolumn{1}{|c|}{ Corteza } & Sin corteza & $\mathbf{1 \% - 2 5 \%}$ & $\mathbf{2 5 \% - 5 0 \%}$ & $\mathbf{5 0 \% - 7 5 \%}$ & $\mathbf{7 5 \% - 1 0 0 \%}$ & IC \\
\hline Materia prima & 23 & 15 & 8 & 4 & 4 & 0,57 \\
\hline cuarcita G2 & 9 & 1 & 1 & 1 & & 0,25 \\
\hline cuarcita G1 & 25 & & & & & 0,00 \\
\hline cuarcita G3 & 5 & 1 & & & & 0,17 \\
\hline riolita & 5 & & & & & 0,00 \\
\hline calcedonia & & & 1 & 1 & & 1,00 \\
\hline RSO & 4 & & & & & 0,00 \\
\hline cuarcita G6 & 8 & & & & & 0,00 \\
\hline indet & & & & & \\
\hline
\end{tabular}

Tabla 10.22. Tamaño en las diferentes materias primas representadas en artefactos del sitio Los Chilenos 2 superficie. Las materias primas se encuentran organizadas en función de la distancia a la que se encuentra su probable fuente de aprovisionamiento más cercana.

La tecnología bipolar se encuentra representada únicamente por una lasca de calcedonia y otras tres lascas en las que los rasgos distintivos de bipolaridad son menos claros, una en cuarcita G3, una en calcedonia y una en cuarcita G2. Los productos de talla son abundantes entre todas las materias primas y, particularmente, entre las cuarcitas. Los instrumentos se encuentran representados, aunque con bajo número, en todas las materias primas con excepción de la cuarcita G6, con índices de producción más bajos en calcedonia y RSO. Los instrumentos con mayor inversión de trabajo han sido formatizados mediante reducción, principalmente unifacial, pero también bifacial o en combinaciones entre un filo unifacial y otro bifacial. Los demás instrumentos fueron formatizados mediante trabajo marginal (Tabla $10.23)$.

\begin{tabular}{|c|c|c|c|c|c|c|c|c|c|c|c|}
\hline \multirow[b]{2}{*}{$\begin{array}{c}\text { Materia } \\
\text { prima }\end{array}$} & \multicolumn{5}{|c|}{ Filos } & \multicolumn{3}{|c|}{ Artefactos } & \multirow[b]{2}{*}{ Lascas } & \multirow[b]{2}{*}{ Instrumentos } & \multirow[b]{2}{*}{ IP } \\
\hline & \begin{tabular}{|c|} 
Unifacial \\
directo
\end{tabular} & \begin{tabular}{|c|} 
Unifacial \\
inverso
\end{tabular} & $\begin{array}{c}\text { Unifacial } \\
\text { indet. }\end{array}$ & Bifacial & IB & TM & $\mathbf{R}$ & A & & & \\
\hline calcedonia & & & 1 & & 0,00 & 1 & & & 1 & 1 & 1,00 \\
\hline cuarcita G1 & & & 1 & 1 & 0,50 & & 1 & & 4 & 1 & 4,00 \\
\hline cuarcita G2 & 6 & & 3 & 1 & 0,10 & 4 & 3 & & 12 & 7 & 1,71 \\
\hline cuarcita G3 & & & 1 & & 0,00 & 1 & & & 6 & 1 & 6,00 \\
\hline cuarcita G6 & & & & & & & & & 1 & & \\
\hline riolita & 1 & & & 1 & 0,50 & & 2 & & 4 & 1 & 4,00 \\
\hline RSO & 1 & & & & 0,00 & 1 & & & 0 & 1 & 0,00 \\
\hline
\end{tabular}

Tabla 10.23. Principales características de los artefactos formatizados por talla del sitio Los Chilenos 2 superficie. $\mathrm{TM}=$ trabajo marginal; $\mathrm{R}=$ reducción; $\mathrm{A}=$ adelgazamiento;

Por último, los núcleos únicamente se encuentran presentes, entre las cuarcitas G1, cuarcitas G2 y cuarcitas G3. Únicamente un núcleo en cuarcita G3 se encuentra completamente agotado, en tanto los restante aún se encuentran activos. De ellos, los presentes entre las cuarcitas G2 consisten en algunos nódulos con lascados aislados (Tabla 10.24).

\begin{tabular}{|l|r|r|r|l|l|}
\cline { 5 - 6 } \multicolumn{4}{c|}{} & \multicolumn{3}{c|}{ Estado } \\
\hline Materia prima & N & Peso medio & Error estándar & No agotado & Agotado \\
\hline Cuarcita G1 & 1 & 59,00 & $\mathrm{np}$ & 1 & \\
\hline Cuarcita G2 & 6 & 160,00 & 48,74 & 6 & \\
\hline
\end{tabular}

Tabla 10.24. Principales características de los núcleos recuperados en el sitio Los Chilenos 2 superficie, $\mathrm{np}=$ no pertinente. 
En la muestra de superficie analizada se encuentra sólo un artefacto confeccionado por picado, abrasión y/o pulido, consistente en una base de molino en arenisca micácea de $360 \mathrm{gr}$ de peso, con dos superficies activas, una de ellas plana y la segunda cóncava atenuada. También se registraron, en esta misma materia prima, seis fragmentos que, si bien no remontan con la base podrían corresponder a la misma pieza, y un artefacto indeterminado

\subsubsection{Cuenca media}

\subsection{Localidad Arqueológica San Martín (SM)}

En la localidad arqueológica San Martín la Prof. Nora Cinquini, llevó a cabo recolecciones de materiales, que actualmente forman parte de las colecciones depositadas en el Museo Regional Chasicó, y, desde inicios de la década de 1990, F. Oliva dirigió actividades de excavación y recolección superficial (ver Capítulo 6). Para el desarrollo de esta tesis se re-analizó, una muestra de los materiales líticos recuperados en las excavaciones realizadas en el sitio $1(n=380)$ así como los procedentes de recolecciones superficiales llevadas a cabo por la autora en inmediaciones del mismo sitio $(n=124)$. Finalmente, a los fines de complementar la información obtenida, se analizó una muestra de aquellos materiales depositados en el Museo Regional Chasicó ( $\mathrm{n}=318$ ). Estas últimas colecciones fueron estudiadas, por razones de tiempo, de un modo más expeditivo que les obtenidas en investigaciones sistemáticas.

La muestra obtenida en estratigrafía fue estudiada en conjunto con F. Oliva, en relación con preguntas particulares derivadas de las respectivas tesis doctorales (Oliva 2014). Esta se encuentra conformada por seis fragmentos de pigmento, 349 productos de talla, de los cuales 15 presentan rastros complementarios en alguno de sus filos, 12 instrumentos formatizados por talla, tres núcleos y/o nucleiformes, cuatro artefactos manufacturados por picado, abrasión y/o pulido y seis posibles percutores. Predomina ampliamente la cuarcita, encontrándose un 35\% de cuarcitas G2, 25\% de cuarcitas G6 y 10\% de cuarcitas G1 y cuarcitas G3. Otras materias primas como la riolita, limolita silicificada, RSO calcedonia y chert se encuentran presentes porcentajes inferiores al $5 \%$. Si se considera el peso total de cada una de estas rocas, aumenta notablemente la representatividad de las cuarcitas G2, disminuyendo las restantes materias primas (Figura 10.12).

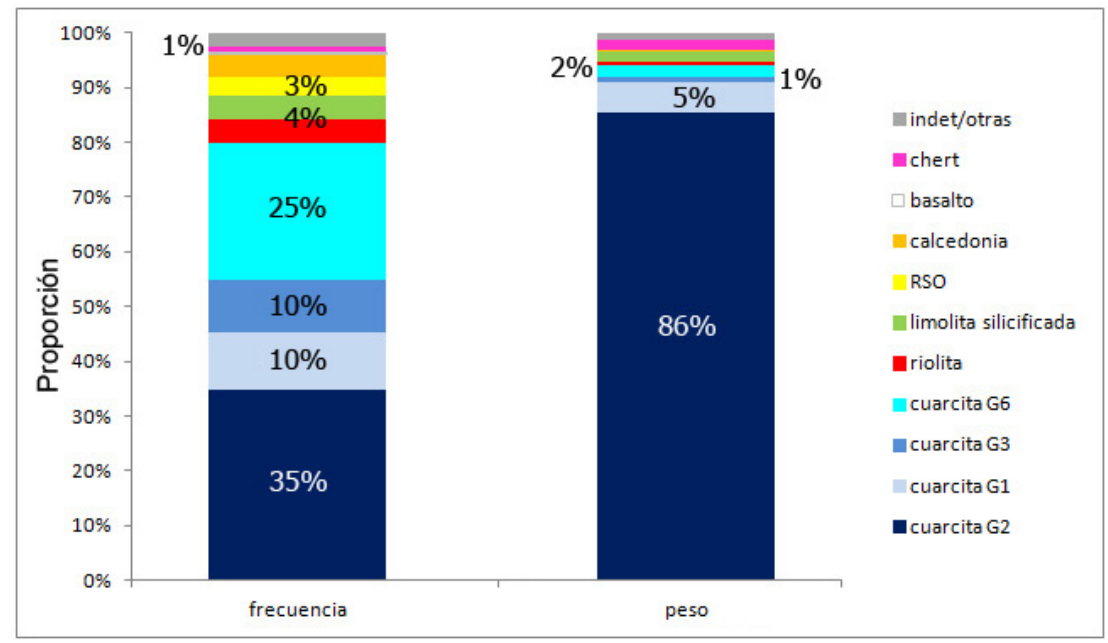

Figura 10.12. Proporción de materias primas presentes en los artefactos del sitio San Martín 1 estratigrafía, considerando su peso y frecuencia. 
Solo las cuarcitas G2 se presentan en todos los tamaños, incluido el súper grande. Entre las restantes materias primas, los tamaños grande y muy grande se encuentran únicamente entre las cuarcitas G1, la limolita silicificada y el chert en muy bajo número. En el caso de la cuarcita G3, riolita, calcedonia y cuarcita G6, muestran solo artefactos de tamaños pequeños y medianos, en tanto el basalto y las RSO presentan sólo tamaños menores (Tabla 10.25).

\begin{tabular}{|l|r|r|r|r|r|r|r|}
\hline Tamaño & $\begin{array}{c}\text { Muy } \\
\text { pequeño }\end{array}$ & Pequeño & $\begin{array}{c}\text { Mediano } \\
\text { pequeño }\end{array}$ & $\begin{array}{c}\text { Mediano } \\
\text { grande }\end{array}$ & Grande & $\begin{array}{c}\text { Muy } \\
\text { grande }\end{array}$ & $\begin{array}{c}\text { Súper } \\
\text { grande }\end{array}$ \\
\hline Materia prima & 76 & 27 & 6 & 8 & 7 & 5 & 1 \\
\hline cuarcita G2 & 16 & 10 & 9 & 3 & & 1 & \\
\hline cuarcita G1 & 24 & 9 & 2 & 1 & & & \\
\hline riolita & 9 & 3 & 3 & 1 & & & \\
\hline limolita silicificada & 11 & 4 & & & 1 & & \\
\hline RSO & 11 & 2 & & & & & \\
\hline calcedonia & 8 & 4 & 2 & 1 & & & \\
\hline basalto & 1 & 1 & & & & & \\
\hline chert & 3 & & & & & & \\
\hline cuarcita G6 & 54 & 34 & 6 & & & & \\
\hline indet & 6 & 1 & 1 & & 1 & & \\
\hline Total & 219 & 95 & 29 & 14 & 10 & 6 & 1 \\
\hline
\end{tabular}

Tabla 10.25. Tamaño en las diferentes materias primas representadas en artefactos del sitio San Martín 1 estratigrafía. Las materias primas se encuentran organizadas en función de la distancia a la que se encuentra su probable fuente de aprovisionamiento más cercana.

Los mayores porcentajes de corteza, superiores al 50\%, sólo se encuentran presentes en las cuarcitas G2 y en un artefacto en cuarcita G1. En cuarcitas G3, riolita, calcedonia, chert y cuarcita G6, si bien predominan los artefactos sin corteza, se encuentran algunos pocos artefactos con hasta un $50 \%$ de corteza. Por último, entre las limolitas silicificadas y el RSO, el mayor porcentaje observado es del 25\%. E1 IC más alto de encuentra en las cuarcitas G2, en tanto el más bajo lo muestran las cuarcitas G3 y cuarcitas G6 (Tabla 10.26).

\begin{tabular}{|l|r|r|r|r|r|l|}
\hline \multicolumn{1}{|c|}{ Corteza } & Sin corteza & $\mathbf{1 \% - 2 5 \%}$ & $\mathbf{2 5 \% - 5 0 \%}$ & $\mathbf{5 0 \% - 7 5 \%}$ & $\mathbf{7 5 \% - 1 0 0 \%}$ & IC \\
\hline Materia prima & 86 & 14 & 14 & 9 & 7 & 0,34 \\
\hline cuarcita G2 & 33 & 5 & & & & 0,15 \\
\hline cuarcita G1 & 34 & 1 & 1 & & & 0,06 \\
\hline cuarcita G3 & 14 & & 2 & & & 0,13 \\
\hline riolita & 15 & 1 & & & & 0,06 \\
\hline limolita silicificada & 11 & 2 & & & & 0,15 \\
\hline RSO & 12 & 2 & 1 & & & 0,20 \\
\hline calcedonia & 2 & & & & & 0,00 \\
\hline basalto & 2 & & 2 & & & 0,50 \\
\hline chert & 91 & 2 & 1 & & & 0,03 \\
\hline cuarcita G6 & 6 & 1 & 2 & & & 1,50 \\
\hline indeterminada & & 2 & & & \\
\hline
\end{tabular}

Tabla 10.26. Remanente de corteza en las diferentes materias primas representadas en artefactos del sitio San Martín 1 estratigrafía. Las materias primas se encuentran organizadas en función de la distancia a la que se encuentra su probable fuente de aprovisionamiento más cercana. 
La reducción por técnica bipolar pudo ser identificada claramente en siete artefactos, a los que se suman otros tres en los que estos rasgos no son tan claramente observables. Estos están confeccionados en cuarcita G1, cuarcita G2 y cuarcita G6, RSO y calcedonia. Dominan la muestra- los productos de talla, de los cuales un alto número presenta rastros complementarios en alguno de sus filos, particularmente en calcedonias y cuarcitas G6. No se registraron instrumentos en RSO, basalto y chert, siendo escasos en las restantes materias primas. Entre aquellos con mayor inversión en su manufactura, se encuentran un fragmento adelgazado bifacialmente y una raedera y un raspador tallados por reducción unifacial, en tanto los restantes instrumentos consisten en filos formatizados mediante trabajo marginal unifacial (Tabla 10.27).

\begin{tabular}{|c|c|c|c|c|c|c|c|c|c|c|c|}
\hline \multirow[b]{2}{*}{ Materia prima } & \multicolumn{5}{|c|}{ Filos } & \multicolumn{3}{|c|}{ Artefactos } & \multirow[b]{2}{*}{ Lascas } & \multirow[b]{2}{*}{ Instrum } & \multirow[b]{2}{*}{ IP } \\
\hline & $\begin{array}{c}\text { Unifacial } \\
\text { directo }\end{array}$ & $\begin{array}{c}\text { Unifacial } \\
\text { inverso }\end{array}$ & Unifacial & Bifacial & IB & TM & $\mathbf{R}$ & $\mathbf{A}$ & & & \\
\hline calcedon & & & 1 & & 0,00 & 1 & & & 7 & 1 & 7,00 \\
\hline cuarcita G1 & & 2 & & & 0,00 & 1 & & & 15 & 1 & 15,00 \\
\hline cuarcita G2 & 1 & & 1 & & 0,00 & 2 & & & 11 & 2 & 5,50 \\
\hline cuarcita G3 & 1 & & & & 0,00 & 1 & & & 13 & 1 & 13,00 \\
\hline cuarcita G6 & 5 & & & 2 & 0,29 & 1 & 1 & 1 & 37 & 3 & 12,33 \\
\hline limolita silicificada & 2 & & & & 0,00 & & 1 & & 4 & 1 & 4,00 \\
\hline riolita & & & 2 & & 0,00 & & 1 & & 7 & 1 & 7,00 \\
\hline
\end{tabular}

Tabla 10.27. Principales características de los artefactos formatizados por talla. $\mathrm{IB}=$ índice bifacial; $\mathrm{TM}=$ trabajo marginal; $\mathrm{R}=$ reducción; $\mathrm{A}=$ adelgazamiento; $\mathrm{IP}=$ índice de producción.

Los núcleos también son escasos, se recuperaron dos nucleiformes, uno en cuarcita grupo 2 y el segundo en chert, ambos de regular a buena calidad para la talla, con un peso de 320 gr y 64 gr respectivamente, y un núcleo de lascas bifacial en cuarcita G1, con un peso de 120 gr completamente activo.

Finalmente, se recuperaron cuatro artefactos manufacturados por picado, abrasión y/o pulido, entre los que se encuentran una hemibola, dos artefactos de molienda superiores (manos) en cuarcita G2 y un fragmento de artefacto de molienda en arenisca micácea. El peso de las manos se encuentra comprendido entre 111 gr y 272 gr no encontrándose evidencias de mantenimiento ni rasgos complementarios relacionados con la prensión en ninguno de los casos.

Entre los materiales de superficie las proporciones de las diferentes rocas son similares a las observadas en el conjunto recuperado en estratigrafía, con altos porcentajes de cuarcitas G2, cuarcitas G3 y cuarcitas G6. Cabe resaltar que se registró una lasca de obsidiana con rastros complementarios en uno de sus filos. Al considerar el peso de las materias primas, la cuarcita G2 supera el 75\%, el conjunto formado por indeterminadas y otras materias primas representa el $17 \%$, en tanto las restantes rocas quedan representadas por menos del 5\% (Figura 10.13). 


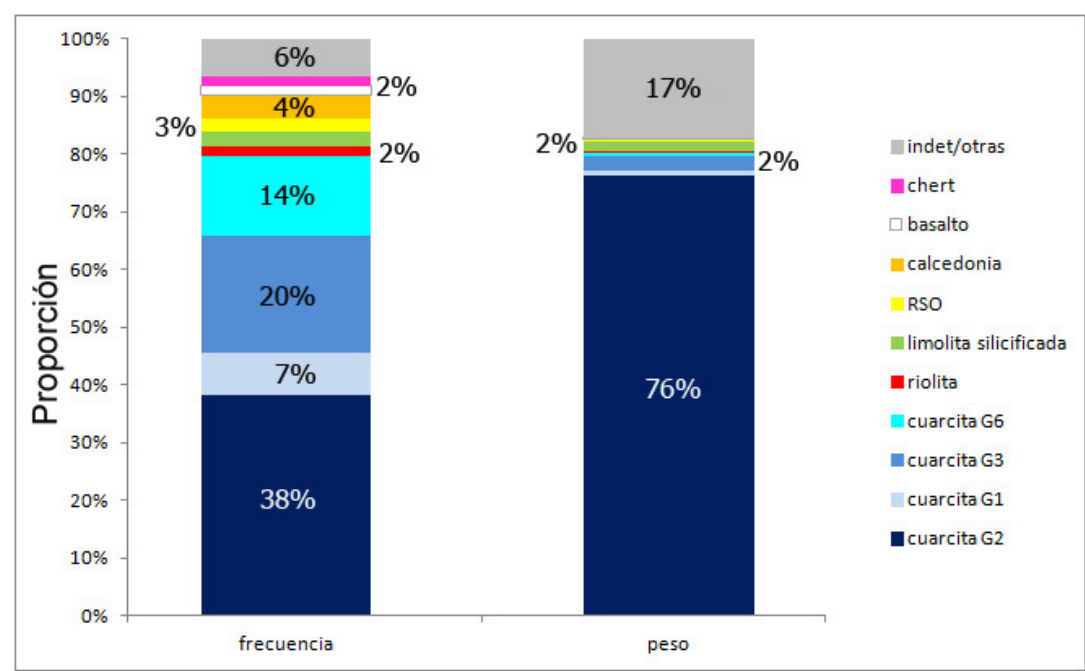

Figura 10.13. Proporción de materias primas presentes en los artefactos del sitio San Martín 1 superficie, considerando su peso y frecuencia.

Los artefactos de mayor tamaño se encuentran en cuarcita G2 y en menor medida en cuarcita G3, limolita silicificada y un artefacto en granito (en la tabla como otras). En los tamaños medianos se agregan, a las materias primas mencionadas, las cuarcitas G6 y la riolita. Por último, las RSO, calcedonia, basalto y chert solo se encuentran representadas por artefactos pequeños o muy pequeños (Tabla 10.28).

\begin{tabular}{|c|c|c|c|c|c|c|c|}
\hline $\begin{array}{l}\text { Tamaño } \\
\text { Materia prima }\end{array}$ & \begin{tabular}{|c|} 
Muy \\
pequeño
\end{tabular} & Pequeño & $\begin{array}{l}\text { Mediano } \\
\text { pequeño }\end{array}$ & $\begin{array}{l}\text { Mediano } \\
\text { grande }\end{array}$ & Grande & \begin{tabular}{|c|} 
Muy \\
grande
\end{tabular} & \begin{tabular}{|c|} 
Súper \\
grande
\end{tabular} \\
\hline cuarcita G2 & 15 & 14 & 8 & 4 & 2 & 3 & 1 \\
\hline cuarcita G1 & 1 & 4 & 4 & & & & \\
\hline cuarcita G3 & 12 & 8 & 2 & 2 & 1 & & \\
\hline riolita & & 1 & 1 & & & & \\
\hline limolita silicificada & & 1 & 1 & & & 1 & \\
\hline $\mathrm{RSO}$ & 1 & 2 & & & & & \\
\hline calcedonia & 2 & 3 & & & & & \\
\hline basalto & 1 & 1 & & & & & \\
\hline chert & & 2 & & & & & \\
\hline cuarcita G6 & 7 & 7 & 3 & & & & \\
\hline obsidiana & & 1 & & & & & \\
\hline indet/otras & 1 & 2 & 1 & 1 & 1 & & 1 \\
\hline
\end{tabular}

Tabla 10.28. Tamaño en las diferentes materias primas representadas en artefactos del sitio San Martín 1 superficie. Las materias primas se encuentran organizadas en función de la distancia a la que se encuentra su probable fuente de aprovisionamiento más cercana.

Las materias primas entre las que se encuentran mayores porcentajes de corteza corresponden a cuarcitas G2, cuarcitas G3 y RSO (entre 50\% y 75\% de corteza por artefacto). En las restantes materias primas, la corteza se encuentra totalmente ausente, o bien se la registra en porcentajes menores al 25\% y en un bajo número de artefactos en calcedonia y cuarcita G6. En este caso también, el mayor IC se encuentra en cuarcitas G2 y el menor, sin considerar las rocas presentes en muy baja frecuencia, en cuarcita G6 (Tabla 10.29). 


\begin{tabular}{|l|r|r|r|r|r|c|}
\hline \multicolumn{1}{|c|}{ Corteza } & Sin corteza & $\mathbf{1 \% - 2 5 \%}$ & $\mathbf{2 5 \% - 5 0 \%}$ & $\mathbf{5 0 \% - 7 5 \%}$ & $\mathbf{7 5 \% - 1 0 0 \%}$ & IC \\
\hline Materia prima & 29 & 6 & 5 & 7 & & 0,38 \\
\hline cuarcita G2 & 8 & 1 & & & & 0,11 \\
\hline cuarcita G1 & 20 & 1 & 2 & 2 & & 0,20 \\
\hline cuarcita G3 & 2 & & & & & 0,00 \\
\hline riolita & 3 & & & & & 0,00 \\
\hline limolita silicificada & 2 & & & & 1 & 0,33 \\
\hline RSO & 3 & 2 & & & & 0,40 \\
\hline calcedonia & 2 & & & & & 0,00 \\
\hline basalto & 2 & & & & & 0,00 \\
\hline chert & 16 & 1 & & & & 0,06 \\
\hline cuarcita G6 & 1 & & & & & 0,00 \\
\hline obsidiana & 4 & 1 & & & & 0,42 \\
\hline indet/otras & & & & & & \\
\hline
\end{tabular}

Tabla 10.29. Remanente de corteza en las diferentes materias primas representadas en artefactos del sitio San Martín 1 superficie. Las materias primas se encuentran organizadas en función de la distancia a la que se encuentra su probable fuente de aprovisionamiento más cercana.

La técnica bipolar fue observada únicamente en dos artefactos, uno en calcedonia y el segundo en RSO. La muestra se encuentra conformada por 99 productos de talla, de los cuales seis, en cuarcita G1, cuarcita G3, cuarcita G6, riolita, calcedonia y obsidiana, presentan rastros complementarios en alguno de sus filos. Los instrumentos en cambio, se encuentran principalmente en cuarcitas G3 y cuarcitas G6. Aquellos con mayor inversión en tiempo y esfuerzo consisten en un fragmento de punta de proyectil adelgazada bifacialmente y un raspador y una raedera, en cuarcita G3 y calcedonia respectivamente, trabajados por reducción unifacial directa. Los restantes instrumentos consisten en raspadores y artefactos sumarios, todos formatizados mediante trabajo marginal (Tabla 10.30).

\begin{tabular}{|c|c|c|c|c|c|c|c|c|c|c|c|}
\hline & \multicolumn{5}{|c|}{ Filos } & \multicolumn{3}{|c|}{ Instrumentos } & \multirow[b]{2}{*}{ Lascas } & \multirow[b]{2}{*}{ Instrumentos } & \multirow[b]{2}{*}{ IP } \\
\hline $\begin{array}{l}\text { Materia } \\
\text { prima }\end{array}$ & $\begin{array}{c}\text { Unifacial } \\
\text { directo }\end{array}$ & $\begin{array}{c}\text { Unifacial } \\
\text { inverso }\end{array}$ & Unifacial & Bifacial & IB & $\mathbf{T M}$ & $\mathbf{R}$ & A & & & \\
\hline calcedonia & 1 & & & & 0,00 & & 1 & & 1 & 1 & 1,00 \\
\hline cuarcita G3 & 4 & 1 & & 2 & 0,29 & 1 & 1 & 1 & 7 & 4 & 1,75 \\
\hline cuarcita G6 & 2 & & & & 0,00 & 4 & & & 6 & 3 & 2,00 \\
\hline lim sil & & & 3 & & 0,00 & 1 & & & 2 & 1 & 2,00 \\
\hline
\end{tabular}

Tabla 10.30. Principales características de los artefactos formatizados por talla. $\mathrm{IB}=$ índice bifacial; $\mathrm{TM}=$ trabajo marginal; $\mathrm{R}=$ reducción; $\mathrm{A}=$ adelgazamiento; $\mathrm{IP}=$ índice de producción. Lim sil= limolita silicificada.

Los núcleos se encuentran poco representados y ninguno muestra formas estandarizadas. Entre ellos se encuentra un núcleo bipolar sobre RSO, un núcleo de lascas en cuarcita G2, con lascados unifaciales unilaterales de 251 gr y seis nucleiformes consistentes en rodados, con pesos de entre 14 y $318 \mathrm{gr}$, de los que se han extraído algunas lascas aisladas (Tabla 10.31). 


\begin{tabular}{|l|r|r|l|l|r|}
\cline { 4 - 6 } Materia prima & N & Peso medio & $\begin{array}{l}\text { Desvío } \\
\text { estándar }\end{array}$ & No agotado & Agotado \\
\hline Cuarcita G2 & 7 & 148,92 & 136,18 & 7 & \\
\hline RSO & 1 & 3,00 & $\mathrm{np}$ & & 1 \\
\hline
\end{tabular}

Tabla 10.31. Principales características de los núcleos recuperados en superficie en el sitio San Martín 1 superficie, $\mathrm{np}=$ no pertinente.

\subsection{Colecciones Museo Regional Chasicó}

A los fines de complementar la información obtenida a partir de investigaciones sistemáticas, se analizaron los materiales líticos correspondientes a seis colecciones procedentes de inmediaciones del arroyo Chasicó, distribuidas sobre una superficie aproximada de poco menos de $1 \mathrm{~km}^{2}$. Cinco de estas colecciones denominadas San Martín 1 (n=9), San Martín 2 ( $n=61)$, San Martín 3 (n=13), San Martín $4(n=62)$ y San Martín $5(n=33)$ fueron recolectadas sobre la terraza fluvial, en tanto la sexta colección denominada Bastan $(n=145)$, procede de un cuadro arado localizado a unos $800 \mathrm{~m}$ del arroyo (ver Capítulo 6).

Entre los materiales recuperados sobre las terrazas del arroyo, predominan las cuarcitas, representadas por poco más del 50\%, seguidas por RSO y calcedonias (13\% y $12 \%$ respectivamente) y, en menor proporción, chert, riolita y limolita silicificada. Mientras que si se considera el peso total de la roca la limolita silicificada representa el 50\% de la muestra en tanto las rocas silíceas disminuyen a menos del 1\%). Concordantemente con el peso, los mayores tamaños se encuentran entre las limolitas silicificadas, materia prima que también muestra la mayor dispersión en el largo morfológico, con valores mínimos de 12,5 mm y máximos de $177 \mathrm{~mm}$. Esto se debe a que en la colección se encuentran ocho artefactos de tamaño grande a súper grande, todos confeccionados en limolita silicificada, que fueron encontrados juntos, formando parte de la colección San Martín 1. Se trata de un núcleo de lascas, cinco artefactos bifaciales con diverso grado de formatización y dos lascas grandes, una de ellas con rastros complementarios en uno de sus filos. Dado su tamaño y sus características de formatización, (presencia de un núcleo y artefactos bifaciales que pueden también ser utilizados como núcleos; Beck et al. 2002) este conjunto podría haber conformado un cache o escondrijo de materia prima (para otros hallazgos similares en la Región Pampeana, ver Oliva y Pérez 2008).

\begin{tabular}{|l|r|r|r|r|r|r|r|}
\hline \multicolumn{1}{|c|}{ Tamaño } & $\begin{array}{c}\text { Muy } \\
\text { pequeño }\end{array}$ & Pequeño & $\begin{array}{c}\text { Mediano } \\
\text { pequeño }\end{array}$ & $\begin{array}{c}\text { Mediano } \\
\text { grande }\end{array}$ & Grande & $\begin{array}{c}\text { Muy } \\
\text { grande }\end{array}$ & $\begin{array}{c}\text { Súper } \\
\text { grande }\end{array}$ \\
\hline cuarcita & 2 & 15 & 28 & 24 & 17 & 2 & \\
\hline riolita & & 1 & 3 & 4 & 4 & & \\
\hline limolita silicificada & & 1 & 2 & & 2 & 2 & 4 \\
\hline RSO & & 21 & 2 & & & & \\
\hline calcedonia & 1 & 18 & 2 & & & & \\
\hline chert & 1 & 11 & 4 & & & & \\
\hline arenisca & & & & & & & \\
\hline
\end{tabular}

Tabla 10.32. Tamaño en las diferentes materias primas representadas en artefactos de las colecciones San Martín (Museo Regional Chasicó). Las materias primas se encuentran organizadas en función de la distancia a la que se encuentra su probable fuente de aprovisionamiento más cercana. 
Entre los restantes materiales, los mayores tamaños se encuentran en los artefactos elaborados sobre cuarcita, los que a su vez muestran la mayor dispersión en su largo, con un valor mínimo de 6,5 mm y máximo de $68 \mathrm{~mm}$. La riolita es otra de las materias primas entre las que se encuentran artefactos de mayor tamaño, predominando los tamaños mediano-grande y grande, con un largo medio de 40,5 mm, inclusive mayor que el de las cuarcitas, debido a una menor representación de los tamaños más pequeños. Las RSO, calcedonias y cherts por otra parte, se diferencian claramente en tamaño de las limolitas silicificadas, cuarcitas y riolitas, mostrando tamaños no mayores al mediano-pequeño y rangos de dispersión similares en el largo morfológico de los artefactos, el que se encuentra comprendido entre $11 \mathrm{~mm}$ y $32 \mathrm{~mm}$, con medias que rondan los $18 \mathrm{~mm}$ (Tabla 10.32).

Los mayores porcentajes en el remanente de corteza se encuentran entre las cuarcitas y riolitas y, en menor medida, en RSO y cherts, que en algunos casos muestran hasta un 50\% de reserva de corteza. Los artefactos elaborados sobre limolitas silicificadas y calcedonias, no mostraron corteza en ninguno de los casos (Tabla 10.33).

\begin{tabular}{|l|c|c|c|c|c|c|c|}
\hline \multicolumn{1}{|r|}{$\begin{array}{l}\text { Corteza } \\
\text { Materia prima }\end{array}$} & $\begin{array}{c}\text { Sin } \\
\text { corteza }\end{array}$ & $\mathbf{1 \% - 2 5 \%}$ & $\mathbf{2 5 \% - 5 0 \%}$ & $\mathbf{5 0 \% - 7 5 \%}$ & $\mathbf{7 5 \% - 1 0 0 \%}$ & Indet & IC \\
\hline cuarcita & 46 & 21 & 12 & 2 & 7 & & 0,48 \\
\hline riolita & 7 & 3 & & & 1 & 1 & 0,33 \\
\hline limolita silicificada & 11 & & & & & & 0,00 \\
\hline RSO & 16 & 4 & 3 & & & & 0,30 \\
\hline calcedonia & 21 & & & & & & 0,00 \\
\hline chert & 13 & 2 & 1 & & & & 0,19 \\
\hline arenisca & & & & & & 2 & $\mathrm{np}$ \\
\hline
\end{tabular}

Tabla 10.33. Remanente de corteza en las diferentes materias primas representadas en artefactos de las colecciones San Martín (Museo Regional Chasicó). Las materias primas se encuentran organizadas en función de la distancia a la que se encuentra su probable fuente de aprovisionamiento más cercana, np= no pertinente.

Entre los instrumentos con mayor grado de inversión en su formatización se encuentran ocho raspadores, seis raederas, un cuchillo, un denticulado y un conjunto de cuatro preformas y 32 puntas de proyectil apedunculadas, estás últimas correspondientes todas al sector, denominado por N. Cinquini como San Martín 2.

La colección Bastán, recolectada a unos $800 \mathrm{~m}$ del cauce del arroyo, se encuentra conformada principalmente por rocas síliceas. Dominan la muestra las RSO (30\%), los cherts (23\%) y, en tercer lugar, las cuarcitas (18\%) seguidas por las calcedonias (16\%), encontrándose las limolitas y riolitas en bajo porcentaje ( $6 \%$ y $2 \%$ respectivamente). Las que mantienen proporciones similar al considerar el peso de cada categoría. Todas las materias primas se encuentran representadas únicamente por tamaños entre pequeño y mediano pequeño, encontrándose una mayor representación de este último entre las limolitas silicificadas (Tabla 10.34). 


\begin{tabular}{|c|c|c|c|}
\hline $\begin{array}{ll}\text { Materia prima } & \text { Tamaño } \\
\end{array}$ & Pequeño & Mediano pequeño & Mediano grande \\
\hline cuarcita & 13 & 9 & 1 \\
\hline riolita & 1 & 1 & \\
\hline limolita silicificada & 2 & 3 & 3 \\
\hline $\mathrm{RSO}$ & 29 & 8 & 2 \\
\hline calcedonia & 16 & 2 & 2 \\
\hline chert & 25 & 5 & \\
\hline arenisca & 2 & 3 & 1 \\
\hline
\end{tabular}

Tabla 10.34. Tamaño en las diferentes materias primas representadas en artefactos de la colección Bastán (Museo Regional Chasicó). Las materias primas se encuentran organizadas en función de la distancia a la que se encuentra su probable fuente de aprovisionamiento más cercana.

Predominan los artefactos sin corteza o con un remanente inferior al $25 \%$, encontrándose los mayores porcentajes de corteza entre las RSO, chert y, en menor cantidad, cuarcitas, materias primas en las que la corteza cubre hasta el $75 \%$ de algunas piezas (Tabla 10.35). Los artefactos que componen esta colección muestran escasa inversión en su formatización, encontrándose únicamente un raspador elaborado en RSO y siete artefactos de formatización sumaria elaborados en chert ( $n=2), \operatorname{RSO}(n=3)$, calcedonia y cuarcita $(n=1)$.

\begin{tabular}{|l|r|r|r|r|r|c|}
\hline \multicolumn{1}{|c|}{$\begin{array}{c}\text { Corteza } \\
\text { Materia prima }\end{array}$} & \multicolumn{1}{c|}{$\begin{array}{c}\text { Sin } \\
\text { corteza }\end{array}$} & $\mathbf{1 \% - 2 5 \%}$ & $\mathbf{2 5 \% - 5 0 \%}$ & $\mathbf{5 0 \% - 7 5 \%}$ & \multicolumn{1}{c|}{$\begin{array}{c}\text { No } \\
\text { pertinente }\end{array}$} & IC \\
\hline cuarcita & 16 & 1 & 3 & 2 & & 0,27 \\
\hline riolita & 2 & & & & & 0,00 \\
\hline limolita silicificada & 7 & 1 & & & & 0,13 \\
\hline RSO & 12 & 8 & 9 & 9 & 1 & 0,67 \\
\hline calcedonia & 11 & 7 & 2 & & & 0,45 \\
\hline chert & 5 & 11 & 5 & 5 & 4 & 0,80 \\
\hline arenisca & & & & & & $\mathrm{np}$ \\
\hline
\end{tabular}

Tabla 10.35. Remanente de corteza en las diferentes materias primas representadas en artefactos de la colección Bastán (Museo Regional Chasicó). Las materias primas se encuentran organizadas en función de la distancia a la que se encuentra su probable fuente de aprovisionamiento más cercana. IC =índice de corteza, $\mathrm{np}=$ no pertinente.

\subsubsection{Cuenca inferior}

\subsection{Curso del arroyo Chasicó}

\subsection{Hallazgos aislados sobre el Arroyo Chasicó}

El sector inferior del arroyo Chasicó, abarca el área comprendida entre la confluencia del arroyo Sanquilcó Grande con el Chasicó y la desembocadura de este último en la laguna Chasicó. Los materiales arqueológicos corresponden a una serie de hallazgos aislados, localizados unos 400m aguas arriba de la confluencia entre los dos arroyos, y una concentración denominada Arroyo Chasicó sitio 1, situada sobre el arroyo Chasicó aproximadamente $4000 \mathrm{~m}$ antes de su desembocadura en la laguna.

Los hallazgos aislados fueron recolectados sobre una meseta a unos $30 \mathrm{~m}$ de altura sobre el curso del arroyo. Consisten en tres lascas y tres artefactos formatizados. Dos de las lascas, son de cuarcita G2, una pequeña y una mediano-pequeña. La tercera es una lasca bipolar en RSO, de tamaño mediano-pequeño, 
todas ellas con menos del 50\% de corteza. Los artefactos formatizados consisten en una preforma de punta de proyectil apedunculada y tres fragmentos de artefactos formatizados. La punta es triangular alargada, elaborada en chert mediante reducción bifacial, con menos de un $25 \%$ de corteza y tamaño mediano pequeño. Uno de los fragmentos fue manufacturado en calcedonia mediante reducción bifacial que deja un pequeño remanente de corteza, menor al 25\%. El segundo, sin corteza, fue elaborado en cuarcita G3 mediante trabajo marginal unifacial directo.

\subsection{Arroyo Chasicó sitio 1 (ACHA1)}

Como producto de las recolecciones superficiales realizadas en el sitio Arroyo Chasicó 1, se recuperaron un total de 50 artefactos líticos, entre los que se encuentran cuatro manufacturados por picado, abrasión y/o pulido, tres de ellos fragmentos, 37 productos de talla, cinco artefactos de formatización sumaria, dos núcleos y un ecofacto. Dominan la muestra las cuarcitas G2 con el 48\% y en segundo lugar cuarcitas G1, RSO, chert y riolita (10\%), en tanto las cuarcitas G3 se encuentran representadas sólo por el 4\%. Al considerar el peso total, las cuarcitas G2 aumentan aún más su representación, disminuyendo las restantes, aunque con menor intensidad las riolitas y cuarcita G1 (Figura 10.14).

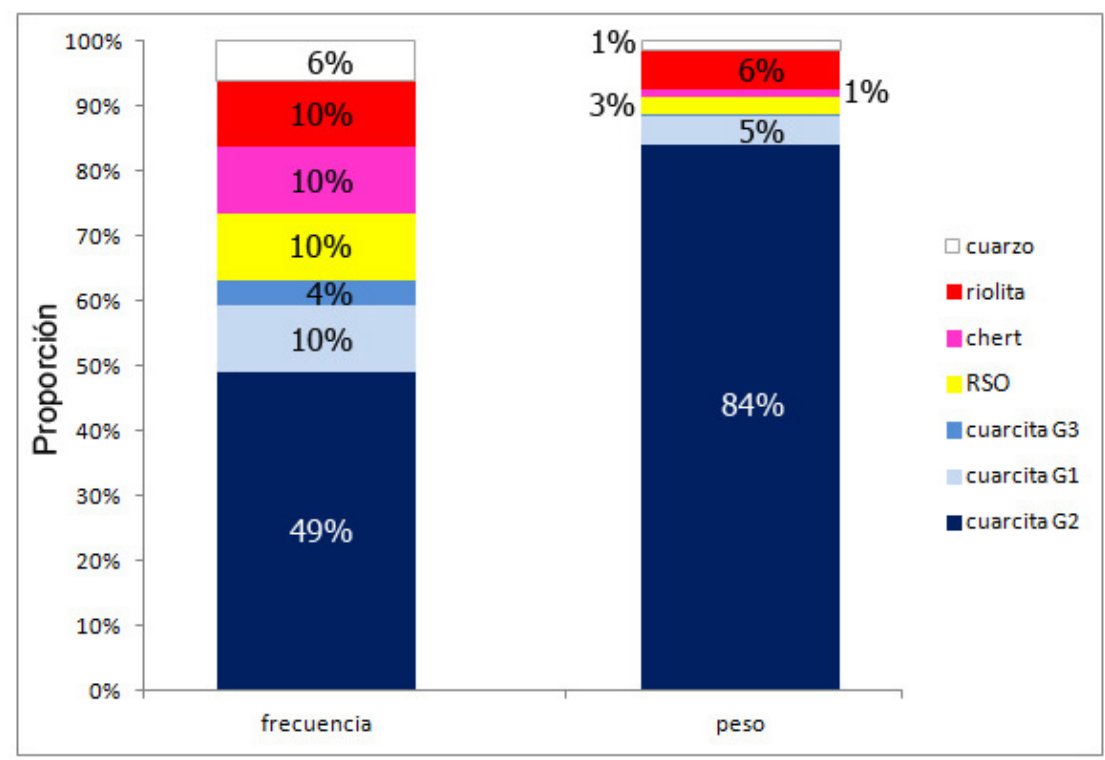

Figura 10.14. Proporción de materias primas presentes en los artefactos del sitio Arroyo Chasicó 1, considerando su peso y frecuencia.

Las piezas de mayor tamaño corresponden a las cuarcitas G2 y a un artefacto de riolita, en tanto en tamaño mediano-grande se encuentran también cuarzo, cuarcita G1 y RSO. El chert y la cuarcita G3, en cambio, solo se encuentra presentes en tamaños mediano-pequeño o inferiores (Tabla 10.36). 


\begin{tabular}{|l|r|r|r|r|r|r|}
\hline \multicolumn{1}{|c|}{ Tamaño } & \multicolumn{1}{c|}{$\begin{array}{c}\text { Muy } \\
\text { pequeño }\end{array}$} & Pequeño & $\begin{array}{c}\text { Mediano } \\
\text { pequeño }\end{array}$ & $\begin{array}{c}\text { Mediano } \\
\text { grande }\end{array}$ & grande & $\begin{array}{c}\text { Muy } \\
\text { grande }\end{array}$ \\
\hline cuarcita Grima & & 4 & 7 & 2 & 8 & 3 \\
\hline RSO & 2 & 2 & & 1 & & \\
\hline chert & & 4 & 1 & & & \\
\hline cuarcita G1 & 1 & 2 & 1 & 1 & & \\
\hline cuarcita G3 & & 1 & 1 & & & \\
\hline riolita & 1 & 2 & & 1 & 1 & \\
\hline cuarzo & & 1 & 1 & 1 & & \\
\hline arenisca & & 1 & & & & \\
\hline
\end{tabular}

Tabla 10.36. Tamaño en las diferentes materias primas representadas en artefactos del sitio Arroyo Chasicó 1. Las materias primas se encuentran organizadas en función de la distancia a la que se encuentra su probable fuente de aprovisionamiento más cercana.

Son abundantes los artefactos en los que puede observarse corteza en algún porcentaje. La cuarcita G2 y el chert son las materias primas con mayor cantidad de artefactos con remanente de corteza (IC= $0,8)$ y con mayor proporción de su superficie cubierta. Otras materias primas como la riolita, presentan pocos artefactos con corteza $(\mathrm{IC}=0,2)$ pero la proporción cubierta en estos es superior al $50 \%$ (Tabla 10.37). La técnica bipolar se encuentra presente únicamente en dos artefactos, una lasca y un artefacto de formatización sumaria, obtenidos a partir de la reducción de rodados de RSO.

\begin{tabular}{|l|r|r|r|r|r|r|c|}
\hline \multicolumn{1}{|c|}{ Corteza } & $\begin{array}{c}\text { Sin } \\
\text { corteza }\end{array}$ & $\mathbf{1 \% - 2 5 \%}$ & $\mathbf{2 5 \% - 5 0 \%}$ & $\begin{array}{c}\mathbf{5 0 \% -} \\
\mathbf{7 5 \%}\end{array}$ & $\mathbf{7 5 \% - 1 0 0 \%}$ & $\begin{array}{c}\text { No } \\
\text { pertinente }\end{array}$ & IC \\
\hline cuarcita G2 & 5 & 9 & 4 & 1 & 2 & 4 & 0,80 \\
\hline RSO & 1 & 1 & 1 & 1 & & & 0,75 \\
\hline chert & 1 & & 2 & 1 & & 0,80 \\
\hline cuarcita G1 & 2 & 2 & 1 & & & & 0,60 \\
\hline cuarcita G3 & 1 & 1 & & & & & 0,50 \\
\hline riolita & 4 & & & & 1 & & 0,20 \\
\hline cuarzo & 1 & 1 & & 1 & & & 0,67 \\
\hline arenisca & & & 1 & & & & 1,00 \\
\hline
\end{tabular}

Tabla 10.37. Remanente de corteza en las diferentes materias primas representadas en artefactos del sitio Arroyo Chasicó 1. Las materias primas se encuentran organizadas en función de la distancia a la que se encuentra su probable fuente de aprovisionamiento más cercana.

Se registraron un total de 9 lascas completas y 5 instrumentos, con los menores IP en RSO y chert. Los instrumentos muestran poca inversión de trabajo en su manufactura, se trata de artefactos de formatización sumaria con lascados unifaciales marginales. A estos se agrega un último artefacto, en RSO con lascados sumarios bifaciales también marginales (Tabla 10.38). Se recuperaron también un núcleo de lascas de riolita agotado, con un peso de 19 gr y un nucleiforme de cuarcita G2 no agotado, con un peso de $375 \mathrm{gr}$. 


\begin{tabular}{|c|c|c|c|c|c|c|c|c|c|}
\hline \multirow[b]{2}{*}{ Materia prima } & \multicolumn{3}{|c|}{ Filos } & \multicolumn{3}{|c|}{ Artefactos } & \multirow[b]{2}{*}{ lascas } & \multirow[b]{2}{*}{ instrumentos } & \multirow[b]{2}{*}{ IP } \\
\hline & $\begin{array}{c}\text { unifacial } \\
\text { indeterminado }\end{array}$ & bifacial & IB & TM & $\mathbf{R}$ & $\mathbf{A}$ & & & \\
\hline chert & 1 & & 0,00 & 1 & & & 1 & 1 & 1,00 \\
\hline cuarcita G1 & 1 & & 0,00 & 1 & & & 2 & 1 & 2,00 \\
\hline cuarcita G2 & 2 & & 0,00 & 2 & & & 6 & 2 & 3,00 \\
\hline $\mathrm{RSO}$ & & 1 & 1,00 & 1 & & & 0 & 1 & 0,00 \\
\hline
\end{tabular}

Tabla 10.38. Principales características de los artefactos formatizados por talla. $\mathrm{IB}=$ índice bifacial; $\mathrm{TM}=$ trabajo marginal; $\mathrm{R}=$ reducción; $\mathrm{A}=$ adelgazamiento; $\mathrm{IP}=$ índice de producción.

Se encuentra a su vez, un sobador o abradidor, elaborado sobre un rodado de cuarcita de forma circular y 340 gr de peso. Este presenta dos superficies activas angostas (de $60 \mathrm{~mm}$ de largo y $50 \mathrm{~mm}$ de ancho) y en posición oblicua con respecto al largo máximo de la pieza. A este instrumento entero, se agregan dos fragmentos de artefactos posiblemente relacionados con actividades de molienda. Uno de ellos corresponde a una cuarcita G2, que aún conserva parte de la superficie activa, probablemente correspondiente a una mano de molino, en tanto el segundo corresponde a un fragmento indeterminado de arenisca micácea. Ninguno muestra rasgos complementarios que faciliten su prensión ni evidencias de mantenimiento, uso alternativo y/o reciclaje.

\subsection{Laguna Chasicó (LCHA)}

\subsection{Sector Oeste}

\subsection{1 Laguna Chasicó sitio 1 (LCHA1)}

A partir de las recolecciones superficiales realizadas en los diferentes sectores de Laguna Chasicó sitio 1 , se recuperaron un total de 17 fragmentos de pigmento, 178 productos de talla, de los cuales siete muestran rastros complementarios en alguno de sus filos, 33 instrumentos manufacturados por talla, 54 núcleos y/o nucleiformes y dos nódulos de materia prima de buena calidad para la talla. A los que se agregan 72 artefactos manufacturados por picado, abrasión y/o pulido enteros, seis artefactos modificados por uso, 73 fragmentos de artefactos formatizados por picado abrasión y/o pulido o modificados por uso y dos ecofactos. Entre los artefactos producto de actividades de talla dominan la muestra las cuarcitas G2 (23\%), chert (21\%) y RSO (20\%), encontrándose también, aunque en menor proporción, cuarcitas G3 $(9 \%)$, calcedonia $(6 \%)$ y, con porcentajes inferiores cuarcita G1, riolita, limolita silicificada y otras materias primas indeterminadas, entre ellas un fragmento de vidrio con un borde formatizado por lascados unifaciales. Al considerar el peso total con que estas rocas se encuentran en el sitio, la proporción de cuarcitas G2 aumenta hasta el 53\% y la de RSO disminuye a 5\%. También disminuyen su representación las cuarcitas G3 y las calcedonias, ahora con el 5\% y 1\% respectivamente (Figura 10.15). 


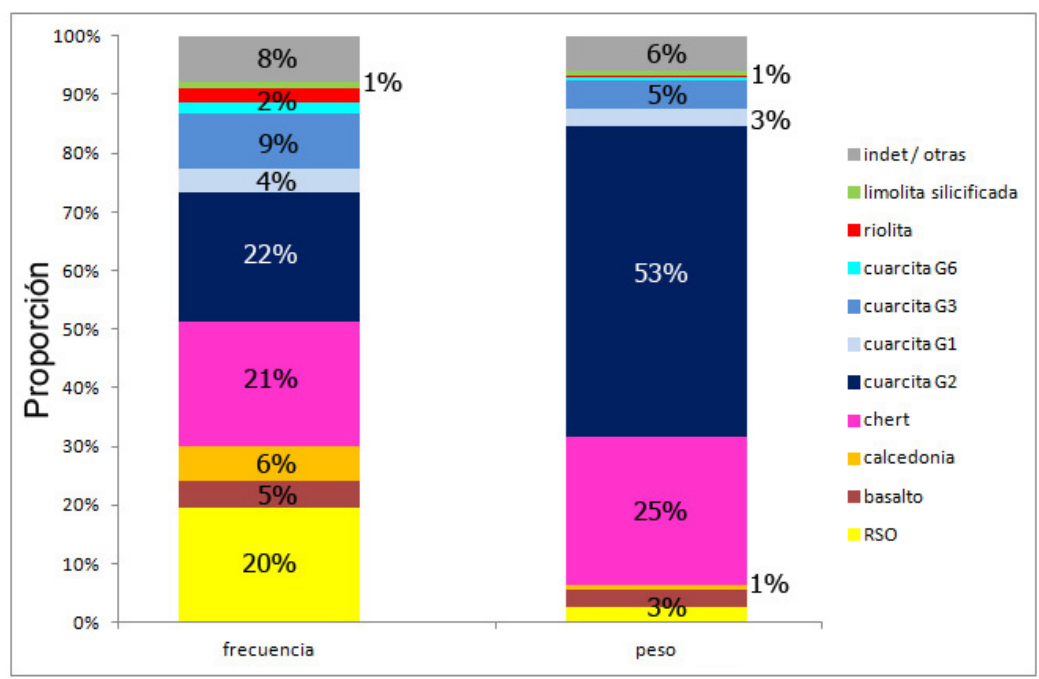

Figura 10.15. Proporción de materias primas presentes en los artefactos del sitio Laguna Chasicó 1, considerando su peso y frecuencia.

El tamaño más representado, entre los artefactos de talla, es el pequeño y, en menor proporción, mediano-pequeño, grande y mediano-grande. Las cuarcitas G2 se encuentran presentes en todos los tamaños, lo mismo que el chert y los rodados patagónicos indeterminados. Las riolita, cuarcitas G1 y cuarcitas G6 también presentan una amplia variedad de tamaños, pero en este caso con ausencia o muy baja representación aquellos muy pequeños o mayores a grande. Las RSO y las calcedonias por otra parte, muestran la menor variabilidad en sus tamaños, que no superan el mediano-grande en el primer caso y el mediano-pequeño en el segundo (Tabla 10.39).

\begin{tabular}{|l|r|r|r|r|r|r|r|}
\hline Mamaño & $\begin{array}{c}\text { Muy } \\
\text { pequeño }\end{array}$ & Pequeño & $\begin{array}{c}\text { Mediano } \\
\text { pequeño }\end{array}$ & $\begin{array}{c}\text { Mediano } \\
\text { grande }\end{array}$ & Grande & $\begin{array}{c}\text { Muy } \\
\text { grande }\end{array}$ & $\begin{array}{c}\text { Súper } \\
\text { grande }\end{array}$ \\
\hline RSO & 2 & 30 & 17 & 1 & & & \\
\hline basalto & & 3 & 4 & 4 & 1 & & \\
\hline rod_pat_indet & & 1 & 2 & 1 & 2 & & 1 \\
\hline calcedonia & 2 & 9 & 4 & & & & \\
\hline chert & & 19 & 10 & 8 & 11 & 4 & 2 \\
\hline cuarcita G1 & & 2 & 1 & 3 & 4 & & \\
\hline cuarcita G2 & 2 & 11 & 3 & 7 & 27 & 4 & 3 \\
\hline cuarcita G3 & & 7 & 4 & 10 & 2 & 1 & \\
\hline cuarcita G6 & & 3 & & 1 & 1 & & \\
\hline limolita silicificada & & 1 & 1 & & 1 & & \\
\hline riolita & 1 & 2 & 1 & 1 & 1 & & \\
\hline indet/otras & & 5 & 2 & 5 & & & \\
\hline
\end{tabular}

Tabla 10.39. Tamaño en las diferentes materias primas representadas en artefactos de sitio Laguna Chasicó 1. Las materias primas se encuentran organizadas en función de la distancia a la que se encuentra su probable fuente de aprovisionamiento más cercana.

En cuanto a la reserva de corteza, las únicas materias primas en las que ésta no fue registrada son riolita y cuarcita G6. Las restantes rocas presentan al menos algunos artefactos con remanente de corteza, si bien entre las limolitas predominan los artefactos sin corteza. Por otra parte, los artefactos con remanente de corteza superior al 50\% de la pieza se encuentran presentes entre RSO, basaltos y otros rodados patagónicos, cherts, cuarcitas G2 y, en muy baja frecuencia, calcedonias (Tabla 10.40). 


\begin{tabular}{|l|r|r|r|r|r|r|r|r|}
\hline \multicolumn{1}{|c|}{ Corteza } & Sin corteza & $\mathbf{1 \% - 2 5 \%}$ & $\mathbf{2 5 \% - 5 0 \%}$ & $\mathbf{5 0 \% - 7 5 \%}$ & $\mathbf{7 5 \% - 1 0 0 \%}$ & Indet & Total & IC \\
\hline Materia prima & 11 & 13 & 10 & 12 & 3 & 1 & 49 & 0,78 \\
\hline RSO & 1 & 4 & 1 & 5 & 1 & & 12 & 0,92 \\
\hline basalto & & & 2 & 3 & 2 & & 7 & 1,00 \\
\hline rod_pat_indet & 2 & 6 & 6 & & 1 & & 15 & 0,87 \\
\hline calcedonia & 8 & 9 & 11 & 9 & 13 & 4 & 50 & 0,84 \\
\hline chert & 8 & 13 & 23 & 10 & 3 & & 57 & 0,86 \\
\hline cuarcita G2 & 4 & 4 & & 2 & & & 10 & 0,60 \\
\hline cuarcita G1 & 12 & 10 & 2 & & & & 24 & 0,50 \\
\hline cuarcita G3 & 5 & & & & & & 5 & 0,00 \\
\hline cuarcita G6 & 2 & & 1 & & & & 3 & 0,33 \\
\hline limolita silicificada & 5 & & & & & & 5 & 0,00 \\
\hline riolita & 8 & 2 & & 1 & & 1 & 11 & 0,27 \\
\hline indet/otras & & & & & & & & \\
\hline
\end{tabular}

Tabla 10.40. Remanente de corteza en las diferentes materias primas representadas en artefactos del sitio Laguna Chasicó 1. Las materias primas se encuentran organizadas en función de la distancia a la que se encuentra su probable fuente de aprovisionamiento más cercana.

Se registró la utilización de técnica bipolar para la reducción de 36 artefactos cinco en basalto (tres núcleos bipolares y dos lascas), seis en calcedonia (un núcleo y cinco lascas), dos en cuarcita G2 (un núcleo y una lasca), dos núcleos bipolares en rodados patagónicos indeterminados, 21 en RSO (cuatro núcleos y 17 lascas bipolares).

Se recuperaron 88 lascas enteras, con mayor frecuencia en cuarcitas G2 y RSO. Por otra parte, las mayores proporciones de artefactos formatizados, en relación con la de productos de talla completos o casi completos se encuentra en chert, con un IP de 0,625 , seguido por cuarcitas G3, limolitas silicificadas y cuarcitas G6. Calcedonias, cuarcitas G2 y RSO por último presentan los más altos IP (Tabla 10.41). Los artefactos con mayor inversión de tiempo y esfuerzo consisten en cuatro puntas de proyectil apedunculadas, tres en chert y una en cuarcita G1, formatizadas por reducción bifacial, y una raedera doble convergente formatizada por reducción unifacial directa. Los restantes artefactos presentan los bordes con trabajo marginal que, en 17 artefactos se realizó bifacialmente y en 12 de manera unifacial. El mayor IB se encuentra entre los cherts, seguido por las RSO, las calcedonias y, por último cuarcitas G1 y cuarcitas G3.

\begin{tabular}{|c|c|c|c|c|c|c|c|c|c|c|}
\hline & \multicolumn{5}{|c|}{ Filos } & \multicolumn{2}{|c|}{ Artefactos } & \multirow[b]{2}{*}{ Lascas } & \multirow[b]{2}{*}{ Instrumentos } & \multirow[b]{2}{*}{ IP } \\
\hline $\begin{array}{l}\text { Materia } \\
\text { prima }\end{array}$ & Unifacial & $\begin{array}{c}\text { Unifacial } \\
\text { directo }\end{array}$ & $\begin{array}{c}\text { Unifacial } \\
\text { inverso }\end{array}$ & Bifacial & IB & $\mathbf{T M}$ & $\mathbf{R}$ & & & \\
\hline cuarcita G6 & & 2 & & & 0,00 & & 1 & 3 & 1 & 3,00 \\
\hline limolita sil. & 2 & & & & 0,00 & 1 & & 2 & 1 & 2,00 \\
\hline vidrio & 2 & & & & 0,00 & 1 & & 0 & 1 & 0,00 \\
\hline cuarcita G2 & 3 & & 1 & 3 & 0,43 & 3 & & 17 & 3 & 5,67 \\
\hline cuarcita G3 & 2 & 1 & & 1 & 0,25 & 3 & & 7 & 4 & 1,75 \\
\hline calcedonia & & 1 & & 3 & 0,75 & 2 & & 7 & 2 & 3,50 \\
\hline $\mathrm{RSO}$ & 2 & & & 4 & 0,66 & 3 & & 29 & 4 & 7,25 \\
\hline chert & 2 & 1 & & 23 & 0,88 & 12 & 3 & 10 & 16 & 0,63 \\
\hline cuarcita G1 & 0 & & & 3 & 1,00 & & 1 & 4 & 1 & 4,00 \\
\hline
\end{tabular}

Tabla 10.41. Principales características de los artefactos formatizados por talla del sitio Laguna Chasicó 1 . IB= índice bifacial; $\mathrm{TM}=$ trabajo marginal; $\mathrm{R}=$ reducción; $\mathrm{A}=$ adelgazamiento; $\mathrm{IP}=$ índice de producción. 
Los núcleos y nucleiformes están ampliamente representados en la muestra, en especial entre las cherts y las cuarcitas, si bien también se los encuentra, aunque en menor número, en RSO y otros rodados patagónicos, en estos últimos casos principalmente como núcleos bipolares. El peso medio más alto se encuentra en siete núcleos de lascas y cinco nucleiformes de cuarcita G2, en su mayoría rodados con pesos de hasta $790 \mathrm{gr}$, que no se encuentran agotados. En el caso de los cherts, 12 de ellos corresponden a nódulos de forma tabular, 11 con lascados aislados y uno sin evidencias de talla, que fueron hallados juntos, conformando un probable escondrijo o cache (Tabla 10.42).

\begin{tabular}{|c|c|c|c|c|c|}
\hline \multirow[b]{2}{*}{ Materia prima } & \multirow[b]{2}{*}{$\mathbf{N}$} & \multirow[b]{2}{*}{ Peso medio } & \multirow[b]{2}{*}{ Desvío Standard } & \multicolumn{2}{|c|}{ Estado } \\
\hline & & & & No agotado & Agotado \\
\hline basalto & 5 & 51,80 & 43,30 & 1 & 1 \\
\hline calcedonia & 1 & 28,00 & $\mathrm{np}$ & 1 & \\
\hline chert & $\begin{array}{r}14 \\
(2)\end{array}$ & 132,37 & 128,75 & 3 & \\
\hline cuarcita G1 & 4 & 62,50 & 31,38 & 1 & \\
\hline cuarcita G2 & 12 & 294,67 & 251,70 & 8 & 1 \\
\hline cuarcita G3 & 4 & 32,25 & 14,66 & & 3 \\
\hline rodado patagónico & 5 & 40,80 & 46,25 & 1 & 1 \\
\hline RSO & 4 & 22,75 & 20,21 & 2 & 2 \\
\hline
\end{tabular}

Tabla 10.42. Principales características de los núcleos recuperados en el sitio Laguna Chasicó 1. Los números entre paréntesis representan nódulos sin evidencias de talla, $n p=$ no pertinente.

Entre los artefactos modificados por uso o por picado, abrasión y/o pulido, que no se relacionan con actividades de molienda, se recuperaron tres rodados tehuelches utilizados como sobadores y un rodado de cuarcita utilizado como yunque. También se registraron dos percutores y cuatro fragmentos de percutor, todos sobre cuarcita que, en tres casos, corresponden a rodados y muestran evidencias de haber sido utilizados alternativamente como yunques. A estos se agregan dos boleadoras, una realizada sobre granito y la segunda en metal. Esta última también con rastros de haber sido utilizada como yunque y sobador, ya que presenta piqueteado, estrías y restos de pigmento rojo.

Entre aquellos vinculados con actividades de molienda, se recuperaron un total de 69 artefactos enteros, 53 superiores y 16 inferiores. Prevalecen, a su vez, los molino y sus manos por sobre los morteros y sus manos. Las materias primas utilizadas son las cuarcitas y las areniscas rionegrenses, las primeras utilizadas principalmente como manos, en tanto las segundas empleadas en proporciones similares en artefactos superiores e inferiores. En menor número se usó también arenisca micácea, tanto para la elaboración de manos como de bases de molino, limolita, en la elaboración de un mortero, y cuarzo, granito, riolita ignimbrítica y un rodado patagónico para manos.

Con excepción del cuarzo, la riolita ignimbrítaca y el rodado tehuelche, todas las restantes materias primas muestran rasgos complementarios y/o evidencias de mantenimiento y/o usos alternativos. Entre los artefactos elaborados en cuarcita, 12 fueron utilizados también como yunques, mostrando piqueteados en alguna de sus superficies y 19 muestran evidencias de mantenimiento (reactivación y/o economía del desgaste). Entre las areniscas rionegrenses y micáceas también se observan evidencias de mantenimiento (en el $17 \%$ y $20 \%$ respectivamente), rasgos complementarios vinculados con la prensión ( $6 \%$ y $20 \%$ respectivamente) y uso alternativo de la pieza, en este caso, vinculado con funciones de abradidor. En los artefactos de granito se observaron rasgos complementarios y evidencias de mantenimiento, en 
tanto el mortero de limolita y otros artefactos en materia prima indeterminada muestran solo evidencias de mantenimiento. Por último, 16 de estos artefactos presentan restos de pigmento rojo en alguna de sus superficies. En este tipo de artefactos, las materias primas que muestran mayor inversión en su formatización consisten en granitos, arenisca micácea y cuarcitas, dada por la presencia de rasgos complementarios, formas simétricas y/o superficies activas formatizadas (Tabla 10.43).

\begin{tabular}{|c|c|c|c|c|c|c|c|c|c|c|}
\hline \multirow[b]{2}{*}{ Materia prima } & \multicolumn{5}{|c|}{ Tipo de artefacto } & \multicolumn{5}{|c|}{ Otras características } \\
\hline & $\begin{array}{c}\text { mano } \\
\text { molino }\end{array}$ & $\begin{array}{c}\text { mano } \\
\text { mortero }\end{array}$ & $\begin{array}{l}\text { mano } \\
\text { indet }\end{array}$ & molino & mortero & $\begin{array}{c}\text { UA } \\
\text { yunque }\end{array}$ & $\begin{array}{c}\text { U A } \\
\text { abradidor }\end{array}$ & Mant. & $\mathbf{R C}$ & pigm. \\
\hline a. rionegrense & 10 & & 1 & 7 & & & 1 & 3 & 1 & 3 \\
\hline a. micácea & 2 & & & 3 & & & 1 & 1 & 1 & 1 \\
\hline cuarcita & 25 & 4 & 2 & 2 & 2 & 12 & & 19 & 9 & 10 \\
\hline cuarzo & 1 & & & & & & & & & \\
\hline granito & 2 & & & & & & & 1 & 1 & 1 \\
\hline limolita sil. & & & & & 1 & & & 1 & & \\
\hline $\begin{array}{l}\text { riolita } \\
\text { ignimbrítica }\end{array}$ & 1 & & & & & & & & & \\
\hline rodado tehuelche & 1 & & & & & & & & & \\
\hline indet & 3 & 1 & & & 1 & 1 & & 3 & 3 & 1 \\
\hline
\end{tabular}

Tabla 10.43. Principales características de los artefactos modificados por uso y formatizados por picado, abrasión $\mathrm{y} / \mathrm{o}$ pulido en el sitio Laguna Chasicó 1 . Indet= indetreminado; $\mathrm{RC}=$ rasgos complementarios; $\mathrm{U} \mathrm{A}=$ uso alternaivo; Mant $=$ mantenimiento; pigm $=$ pigmento.

\subsection{2 Laguna Chasicó sitio 2 (LCHA2)}

Las recolecciones llevadas a cabo en el sitio Laguna Chasicó 2 permitieron recuperar 22 fragmentos de pigmento, 196 productos de talla, de los cuales 3 muestran rastros complementarios en alguno de sus filos, 42 artefactos con filos formatizados, incluyendo aquellos en los que esto fue realizado de manera sumaria, siete núcleos o nucleiformes y 10 nódulos sin evidencias de talla. A estos se agregan tres artefactos modificados por uso (un yunque y dos posibles percutores), 21 artefactos manufacturados por picados, abrasión y/o pulido completos o con más del 50\% y 10 fragmentos de ellos.

Entre los artefactos generados por talla, la materia prima predominante son las RSO (43\%), seguidas por el chert (19\%), la calcedonia (8\%) y las cuarcitas. Entre estas últimas las más representadas corresponden cuarcitas G2 y cuarcitas G3 (7\%), en tanto las cuarcitas G6 y cuarcitas G1 se encuentran en bajo porcentaje ( $4 \%$ y $2 \%$ respectivamente). Con baja representación se encuentran también riolitas, limolita silicificada, basalto y otras rocas indeterminadas. Si se considera el peso, aumenta considerablemente la representación de las cuarcitas, que ahora ocupan el $26 \%$, y disminuye levemente la proporción de RSO y chert (Figura 10.16). 


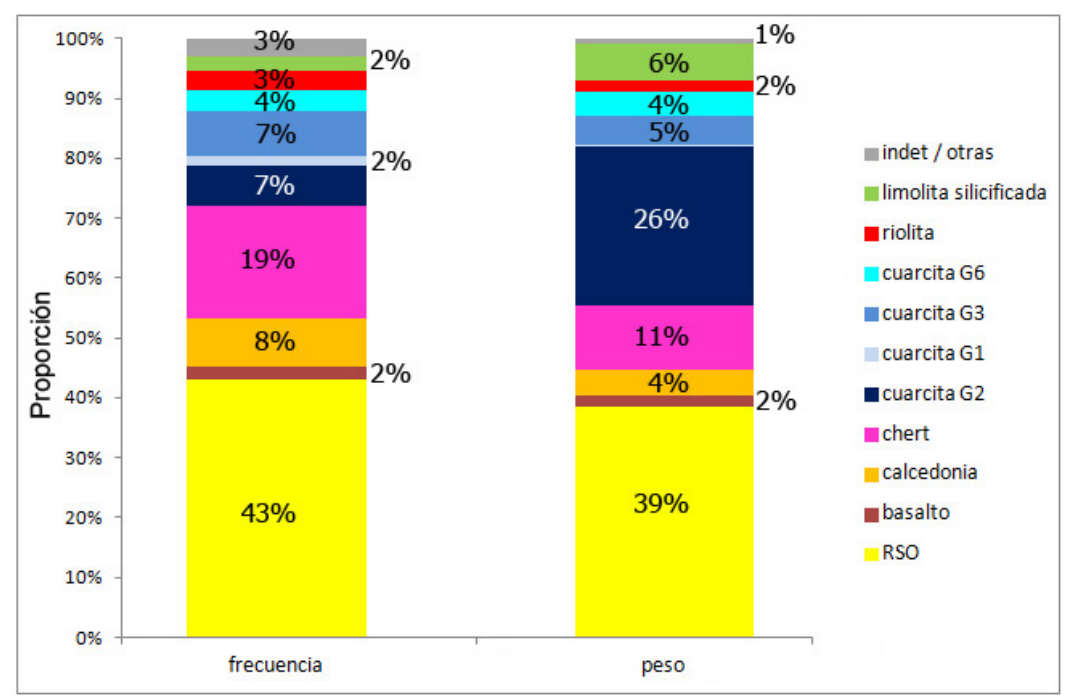

Figura 10.16. Proporción de materias primas presentes en los artefactos del sitio Laguna Chasicó 2, considerando su peso y frecuencia.

Predominan, en la mayor parte de las materias primas, los tamaños muy pequeño a mediano-pequeño. Los artefactos de tamaño mediano grande y grande sólo se encuentran presentes en bajo número en RSO, calcedonia, cuarcitas G2, cuarcitas G6 y limolita silicificada (Tabla 10.44). Los artefactos con tamaños mayores a la categoría grande sólo se encuentran representados entre los artefactos manufacturados por picado, abrasión y/ o pulido o modificados por uso, estando ausentes entre los elaborados por talla.

\begin{tabular}{|l|r|r|r|r|r|}
\hline \multicolumn{1}{|r|}{ Tamaño } & $\begin{array}{c}\text { Muy } \\
\text { pequeño }\end{array}$ & Pequeño & $\begin{array}{c}\text { Mediano } \\
\text { pequeño }\end{array}$ & $\begin{array}{c}\text { Mediano } \\
\text { grande }\end{array}$ & Grande \\
\hline RSO & 18 & 70 & 20 & 1 & 1 \\
\hline chert & 4 & 30 & 14 & & \\
\hline calcedonia & 4 & 13 & 3 & 1 & \\
\hline basalto & 1 & 1 & 3 & & \\
\hline cuarcita G2 & 4 & 7 & 1 & 2 & 3 \\
\hline cuarcita G1 & 1 & 2 & 1 & & \\
\hline cuarcita G3 & 3 & 11 & 5 & & \\
\hline cuarcita G6 & 4 & 2 & 2 & & 1 \\
\hline riolita & 1 & 6 & 1 & & \\
\hline limolita silicificada & 1 & 1 & 1 & & 1 \\
\hline cuarzo & 3 & 1 & & & \\
\hline indet & 1 & 3 & & & \\
\hline
\end{tabular}

Tabla 10.44. Tamaño en las diferentes materias primas representadas en artefactos de talla del sitio Laguna Chasicó 2. Las materias primas se encuentran organizadas en función de la distancia a la que se encuentra su probable fuente de aprovisionamiento más cercana.

Predominan los artefactos sin reserva de corteza, encontrándose en RSO y cherts tanto porcentajes de superficie cubierta mayores como frecuencia de artefactos con corteza más altas. Calcedonia, cuarcita G3, riolita y limolita silicificada, presentan proporciones medias de corteza, en tanto esta no se encuentra presente entre las cuarcitas G6 y cuarcitas G1 (Tabla 10.45). 


\begin{tabular}{|l|r|r|r|r|r|l|}
\hline \multicolumn{1}{|c|}{$\begin{array}{c}\text { Corteza } \\
\text { Materia prima }\end{array}$} & $\begin{array}{c}\text { Sin } \\
\text { corteza }\end{array}$ & $\mathbf{1 \% - 2 5 \%}$ & $\mathbf{2 5 \% - 5 0 \%}$ & $\mathbf{5 0 \% - 7 5 \%}$ & $\mathbf{7 5 \% - 1 0 0 \%}$ & IC \\
\hline RSO & 30 & 23 & 21 & 35 & 1 & 0,72 \\
\hline chert & 11 & 13 & 8 & 4 & 4 & 0,73 \\
\hline calcedonia & 16 & 4 & 1 & & & 0,24 \\
\hline basalto & 2 & 3 & & & & 0,60 \\
\hline cuarcita G2 & 10 & 3 & 3 & 1 & & 0,41 \\
\hline cuarcita G1 & 4 & & & & & 0,00 \\
\hline cuarcita G3 & 14 & 1 & 4 & & & 0,26 \\
\hline riolita & 7 & & 1 & & & 0,13 \\
\hline limolita silicificada & 4 & 2 & & & & 0,33 \\
\hline cuarzo & 1 & & 1 & 2 & & 0,75 \\
\hline cuarcita G6 & 9 & & & & & 0,00 \\
\hline indet & 2 & & 1 & 1 & & 0,50 \\
\hline
\end{tabular}

Tabla 10.45. Remanente de corteza en las diferentes materias primas representadas en artefactos de talla del sitio Laguna Chasicó 2. Las materias primas se encuentran organizadas en función de la distancia a la que se encuentra su probable fuente de aprovisionamiento más cercana.

Se identificó el uso de técnica bipolar en 23 artefactos, 19 de ellos consisten en rodados tehuelches de pequeño tamaño reducidos mediante este técnica y los cuatro restantes corresponden a lascas bipolares de chert, cuarzo y una roca indeterminada. Sobre dos de estas lascas bipolares se manufacturaron raspadores mediante retoque marginal. En todas las materias primas utilizadas para talla predominan las lascas y desechos, con excepción de la limolita silicificada en la que son más abundantes los instrumentos. Los instrumentos son muy abundantes entre las distintas variedades de sílice (RSO, chert y calcedonia, materias primas que habrían estado disponibles localmente) y, aunque en menor cantidad, también en limolitas silicificadas, cuarcitas G6 y cuarcitas G3. Si se evalúa su representación en relación con la de las lascas, las mayores frecuencias relativas se dan entre limolitas silicificadas, chert, cuarcita G6 y calcedonia (IP entre 0,00 y 1,43), en tanto la frecuencia relativa menor corresponde a cuarcitas G3 y RSO (IP entre 9,00 y 4,44 respectivamente; Tabla 10.46).

\begin{tabular}{|c|c|c|c|c|c|c|c|c|c|c|c|}
\hline \multirow[b]{2}{*}{$\begin{array}{l}\text { Materia } \\
\text { prima }\end{array}$} & \multicolumn{5}{|c|}{ Filos } & \multicolumn{3}{|c|}{ Artefactos } & \multirow[b]{2}{*}{ Lascas } & \multirow[b]{2}{*}{ instrumentos } & \multirow[b]{2}{*}{ IP } \\
\hline & $\begin{array}{c}\text { unifacial } \\
\text { indet }\end{array}$ & $\begin{array}{c}\text { unifacial } \\
\text { directo }\end{array}$ & $\begin{array}{c}\text { unifacial } \\
\text { inverso }\end{array}$ & bifacial & IB & TM & $\mathbf{R}$ & $\mathbf{A}$ & & & \\
\hline basalto & & & & 1 & 1,00 & 1 & & & 3 & 1 & 3,00 \\
\hline calcedonia & 1 & 5 & 1 & & 0,00 & 6 & 1 & & 10 & 7 & 1,42 \\
\hline chert & 6 & 2 & & 20 & 0,71 & 11 & 5 & & 8 & 16 & 0,50 \\
\hline cuarcita G3 & & 1 & & & 0,00 & 1 & & & 9 & 1 & 9,00 \\
\hline cuarcita G6 & & 6 & & 4 & 0,40 & 1 & 2 & & 4 & 3 & 1,33 \\
\hline limolita sil & 1 & 4 & 1 & & 0,00 & 5 & & & 0 & 5 & 0,00 \\
\hline RSO & & 6 & & 9 & 0,60 & 8 & & 1 & 40 & 9 & 4,44 \\
\hline
\end{tabular}

Tabla 10.46. Principales características de los artefactos formatizados por talla. $\mathrm{IB}=$ índice bifacial; $\mathrm{TM}=$ trabajo marginal; $\mathrm{R}=$ reducción; $\mathrm{A}=$ adelgazamiento; $\mathrm{IP}=$ índice de producción. 
Aquellos con mayor inversión de trabajo consisten en cuatro puntas apedunculadas (dos de ellas fragmentadas) una adelgazada bifacialmente y las restantes formatizadas mediante reducción bifacial. A estas se agregan, dos cuchillos y un fragmento de instrumento, trabajados también mediante reducción bifacial, y dos raspadores formatizados por reducción unifacial directa. Los restantes 34 instrumentos fueron formatizados mediante trabajo marginal, bifacial en ocho casos, unifacial en 23 (directo e inverso) y combinaciones de filos unifaciales y bifaciales en los dos restantes. Es entre los cherts y basalto donde se encuentra el mayor IB, seguido por las RSO y, por último las cuarcitas G6, no encontrándose instrumentos bifaciales entre las restantes materias primas (Tabla 10.46).

Los núcleos son muy escasos, la totalidad se encuentran entre las RSO, correspondiendo uno de ellos a un núcleo bipolar agotado, otro a un núcleo activo con lascados unifaciales aislados y, los restantes, a rodados de RSO de pequeño tamaño, con lascados aislados clasificados como posibles nucleiformes. A estos se agrega un total de 10 nódulos de chert de entre $15 \mathrm{~mm}$ y $35 \mathrm{~mm}$ de largo y entre $4 \mathrm{~mm}$ y $11 \mathrm{~mm}$ de espesor que, si bien no presentan evidencias de talla, se trata de una materia prima altamente representada en el conjunto, que habría ingresado como consecuencia del transporte antrópico (Tabla 10.47).

\begin{tabular}{|l|r|r|r|r|r|}
\cline { 5 - 7 } Materia prima & N & Peso medio & $\begin{array}{c}\text { Desvío } \\
\text { Standard }\end{array}$ & No agotado & Agotado \\
\hline chert (nódulos) & 10 & 2,01 & 1,99 & - & - \\
\hline RSO & 7 & 15,00 & 28,80 & 1 & 1 \\
\hline
\end{tabular}

Tabla 10.47. Principales características de los núcleos, nucleiformes y nódulos recuperados en el sitio Laguna Chasicó 2.

Entre los artefactos modificados por uso o por picado abrasión y/o pulido se recuperaron cuatro rodados de cuarcita, dos como percutores, uno como yunque y un sobador, dos bolas de boleadora, 16 artefactos de molienda y 22 fragmentos de pequeño tamaños, que por la presencia de alguna superficie alisada o por las características de la materia prima podrían corresponder a artefactos manufacturados por picado, abrasión y/o pulido. La materia prima más utilizada es la cuarcita, seguida por los granitos, arenisca rionegrense y arenisca micácea. También se encuentran dos artefactos elaborados sobre rodados del Manto Tehuelche y dos sobre una arenisca indeterminada.

Entre aquellos artefactos vinculados con actividades de molienda, se recuperaron 13 artefactos completos o casi completos. Predominan los artefactos activos, y entre estos las manos de molino, por sobre los pasivos, representados únicamente por molinos. Para la elaboración de las primeras se seleccionaron arenisca rionegrense, cuarcita, granito y un rodado tehuelche, en tanto que en los artefactos pasivos se utilizó arenisca micácea y cuarcita. A estos artefactos se agrega un posible preforma de hacha, elaborada sobre un rodado tehuelche, con evidencias de haber sido utilizada también como mano de molino, ya que presenta una de sus caras plana, con estrías paralelas y restos de pigmento rojo. Solo se registró el uso alternativo como yunque en un artefacto de arenisca rionegrense, en tanto la presencia de rasgos complementarios únicamente fue identificada en la preforma de hacha, la que a su vez representa el único artefactos en el que se invirtió mayor tiempo y esfuerzo en su manufactura, a través de la búsqueda de una morfología específica y de la generación de rasgos que faciliten la prensión y/o el enmangue (Tabla 10.48). 


\begin{tabular}{|c|c|c|c|c|c|c|c|c|}
\hline \multirow[b]{2}{*}{ Materia prima } & \multicolumn{5}{|c|}{ Tipo de artefacto } & \multicolumn{3}{|c|}{ Otras características } \\
\hline & $\begin{array}{l}\text { Mano } \\
\text { molino }\end{array}$ & $\begin{array}{c}\text { Mano } \\
\text { mortero }\end{array}$ & \begin{tabular}{|l|} 
Mano + \\
preforma \\
de acha
\end{tabular} & Molino & \begin{tabular}{|l|} 
Artefacto \\
de molienda \\
indet.
\end{tabular} & \begin{tabular}{|l|} 
uso \\
alternativo \\
yunque \\
\end{tabular} & $\begin{array}{l}\text { rasgos } \\
\text { complem. }\end{array}$ & pigmento \\
\hline a rionegrense & 3 & & & & & 1 & & 1 \\
\hline arenisca micácea & & & & $7(2)$ & & 0 & & 2 \\
\hline rodado tehuelche & 1 & & 1 & & & 0 & 1 & 2 \\
\hline cuarcita & 2 & 1 & & 2 & 1 & 0 & & \\
\hline granito & 2 & & & & 1 & 0 & & \\
\hline
\end{tabular}

Tabla 10.48. Principales características de los artefactos modificados por uso y formatizados por picado, abrasión y/o pulido. Indet= indetreminado. Entre paréntesis se indica el número mínimo estimado.

\subsection{3 Laguna Chasicó sitio 3 (LCHA3)}

Las recolecciones realizadas en este sitio llevaron a recuperar 10 fragmentos de pigmento, 6 nódulos de materia prima de buena calidad para la talla y 142 artefactos, entre los que se encuentran 73 productos de talla, dos de ellos con rastros complementarios en alguno de sus filos, 18 instrumentos manufacturados por talla, ocho núcleos o nucleiformes, un artefactos modificado por uso y 32 artefactos modificados por picado, abrasión y/o pulidos, de los cuáles 11 se encuentran completos o casi completos y 21 consisten en fragmentos de pequeño tamaño. Entre los artefactos producto de la técnica de talla, las materias primas más representadas son las RSO (37\%) seguidas por los cherts (16\%), las cuarcitas G2 (13\%) y las calcedonias (10\%). Se encuentran también presentes, aunque en una proporción menor, cuarcitas G6, cuarcitas G3, limolita silicificada y riolita. Si se tiene en cuenta el peso con que estas rocas están presentes, las cuarcitas G2 y la limolita silicificada toman mayor importancia, disminuyendo la representación de las restantes materias primas (Figura 10.17).

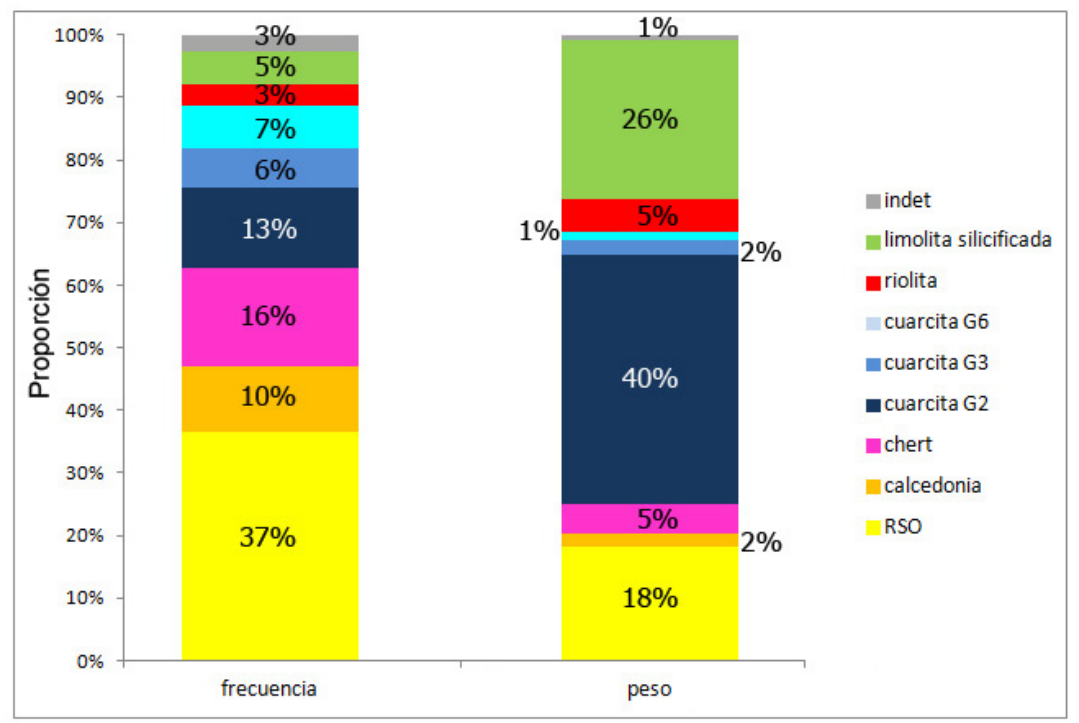

Figura 10.17. Proporción de materias primas presentes en los artefactos del sitio Laguna Chasicó 3, considerando su peso y frecuencia. 
En relación con los tamaños de los artefactos, predominan los pequeños y mediano-pequeños, principalmente entre calcedonia, RSO, cuarcitas y limolita silicificada. En el caso de la riolita, los tamaños más representados son el grande y mediano grande. Por otra parte, los mayores tamaños (muy grande y súper grande), solo se encuentran presentes en bajo porcentaje entre las cuarcitas G2 y la limolita silicificada (Tabla 10.49).

\begin{tabular}{|l|r|r|r|r|r|r|r|}
\hline Tamaño & $\begin{array}{c}\text { Muy } \\
\text { pequeño }\end{array}$ & Pequeño & $\begin{array}{c}\text { Mediano } \\
\text { pequeño }\end{array}$ & $\begin{array}{c}\text { Mediano } \\
\text { grande }\end{array}$ & Grande & $\begin{array}{c}\text { Muy } \\
\text { grande }\end{array}$ & $\begin{array}{c}\text { Súper } \\
\text { grande }\end{array}$ \\
\hline Materia prima & 2 & 20 & 15 & 4 & 1 & & \\
\hline RSO & & 7 & 4 & 1 & & & \\
\hline calcedonia & & 7 & 7 & 4 & & & \\
\hline chert & 2 & 2 & 4 & 2 & 3 & 2 & \\
\hline cuarcita G2 & & & 5 & 1 & 1 & & \\
\hline cuarcita G3 & & 3 & 5 & & & & \\
\hline cuarcita G6 & & 1 & & 1 & 2 & & \\
\hline riolita & & 1 & 3 & & & & \\
\hline limolita silicificada & & & 2 & 1 & & & \\
\hline indet & & & & & & & \\
\hline
\end{tabular}

Tabla 10.49. Tamaño en las diferentes materias primas representadas en artefactos del sitio Laguna Chasicó 3. Las materias primas se encuentran organizadas en función de la distancia a la que se encuentra su probable fuente de aprovisionamiento más cercana.

En cuanto al remanente de corteza presente en los artefactos, los mayores porcentajes se encuentran en las RSO y cherts, con una alta proporción de piezas con corteza, que en algunos casos cubre más del 50\% del artefacto. Las cuarcitas G2 también presentan una alta proporción de piezas con corteza, aunque esta cubre una menor superficie de las mismas, en tanto las restantes materias primas presentan escasas piezas con reserva de corteza sobre sus superficie, la cual se encuentra completamente ausente entre las cuarcitas G6, donde ningún artefacto muestra corteza (Tabla 10.50).

\begin{tabular}{|l|r|r|r|r|r|c|}
\hline \multicolumn{1}{|r|}{ Corteza } & $\begin{array}{c}\text { Sin } \\
\text { corteza }\end{array}$ & $\mathbf{1 \% - 2 5 \%}$ & $\mathbf{2 5 \% - 5 0 \%}$ & $\mathbf{5 0 \% - 7 5 \%}$ & $\mathbf{7 5 \% - 1 0 0 \%}$ & IC \\
\hline Materia prima & 6 & 13 & 7 & 13 & 3 & 0,86 \\
\hline RSO & 11 & 1 & & & & 0,08 \\
\hline calcedonia & & 8 & 2 & 4 & 4 & 1,00 \\
\hline chert & 4 & 6 & 5 & & & 0,73 \\
\hline cuarcita G2 & 5 & 2 & & & & 0,29 \\
\hline cuarcita G3 & 8 & & & & & 0,00 \\
\hline cuarcita G6 & 2 & 1 & 1 & & & 0,50 \\
\hline riolita & 5 & & 1 & & & 0,17 \\
\hline limolita sil. & 1 & 1 & & & & 0,67 \\
\hline indet & & & & & 1 & \\
\hline
\end{tabular}

Tabla 10.50. Remanente de corteza en las diferentes materias primas representadas en artefactos del sitio La Montaña 1. Las materias primas se encuentran organizadas en función de la distancia a la que se encuentra su probable fuente de aprovisionamiento más cercana.

La técnica bipolar se encuentra presente en siete artefactos en RSO y uno de cuarcita G6. Estos consisten en dos núcleos bipolares, tres lascas y tres instrumentos confeccionados sobre lascas bipolares. La mayor frecuencia de instrumentos en relación con lascas completas, se encuentra entre las calcedonias y riolitas, con IP cercanos a cero, en tanto la menor frecuencia se observa en las cuarcitas 
G2, con un IP de 7. Los instrumentos muestran, en todos los casos, una baja inversión en su manufactura, habiéndose utilizado en todos los casos el trabajo marginal para la formatización de los bordes. Entre estos dominan los bordes unifaciales, particularmente los unifaciales directos, encontrándose bordes bifaciales únicamente entre los cherts, riolita y RSO, las primeras con un índice mayor (Tabla 10.51).

\begin{tabular}{|c|c|c|c|c|c|c|c|c|c|c|c|}
\hline & \multicolumn{5}{|c|}{ Filos } & \multicolumn{3}{|c|}{ Artefactos } & \multirow[b]{2}{*}{ Lascas } & \multirow[b]{2}{*}{ Instrumentos } & \multirow[b]{2}{*}{ IP } \\
\hline $\begin{array}{l}\text { Materia } \\
\text { prima }\end{array}$ & Unifacial & $\begin{array}{c}\text { Unifacial } \\
\text { directo }\end{array}$ & $\begin{array}{c}\text { Unifacial } \\
\text { inverso }\end{array}$ & Bifacial & IB & $\mathbf{T M}$ & $\mathbf{R}$ & $\mathbf{A}$ & & & \\
\hline calcedonia & 6 & 1 & 1 & 0 & 0,00 & 6 & & & 2 & 6 & 0,33 \\
\hline chert & 0 & & & 5 & 1,00 & 3 & & & 2 & 3 & 0,67 \\
\hline cuarcita G2 & 1 & & & 0 & 0,00 & 2 & & & 7 & 1 & 7,00 \\
\hline cuarcita G3 & 5 & & & 0 & 0,00 & 3 & & & 2 & 3 & 0,67 \\
\hline cuarcita G6 & 5 & & & 0 & 0,00 & 3 & & & 3 & 3 & 1,00 \\
\hline riolita & 2 & & & 1 & 0,33 & 1 & & & 0 & 3 & 0,00 \\
\hline limolita sil & & & & & & & & & 4 & & \\
\hline $\mathrm{RSO}$ & 7 & 1 & & 2 & 0,20 & 8 & & & 13 & 9 & 1,44 \\
\hline
\end{tabular}

Tabla 10.51. Principales características de los artefactos formatizados por talla. $\mathrm{IB}=$ índice bifacial; $\mathrm{TM}=$ trabajo marginal; $\mathrm{R}=$ reducción; $\mathrm{A}=$ adelgazamiento.

Se registraron núcleos entre las RSO, cuarcitas G2, limolita silicifiada y chert. Entre las primera, estos consisten en tres rodados, dos de ellos tallados bipolarmente y agotados, y el tercero con evidencias de extracción de algunas lascas aisladas por talla no bipolar. Su peso promedio es de 47,76 gr, con una dispersión amplia dada por la diferencia de peso entre los bipolares (entre 11 gr y 12 gr) y el no bipolar (120 gr). Entre las cuarcitas G2 los núcleos muestran plataformas activas y pesos de entre 72 gr y 309 gr con una media de 164, 7 gr. Por último se registraron otros dos núcleos, uno en chert y otro en limolita silicificada, ambos aun activos, y 7 nódulos de chert sin evidencias de talla, con espesores de entre $4 \mathrm{~mm}$ y $9 \mathrm{~mm}$ y pesos de entre 2 gr y 10 gr (Tabla 10.52).

\begin{tabular}{|c|c|c|c|c|c|}
\hline \multirow[b]{2}{*}{ Materia prima } & \multirow[b]{2}{*}{$\mathbf{N}$} & \multirow[b]{2}{*}{ Peso medio } & \multirow[b]{2}{*}{$\begin{array}{c}\text { Desvío } \\
\text { estándar }\end{array}$} & \multicolumn{2}{|l|}{ Estado } \\
\hline & & & & No agotado & Agotado \\
\hline cuarcita G2 & 3 & 164,67 & 126,67 & 3 & \\
\hline limolita silicificada & 1 & 371,00 & $\mathrm{np}$ & 1 & \\
\hline $\mathrm{RSO}$ & 3 & 47,76 & 62,64 & 1 & 2 \\
\hline chert & 1 & 16,00 & $\mathrm{np}$ & 1 & \\
\hline
\end{tabular}

Tabla 10.52. Principales características de los núcleos recuperados en el sitio Laguna Chasicó $3, \mathrm{np}=$ no pertinente.

Entre los artefactos modificados por uso o por picado, abrasión y/o pulido, se recuperaron un alisador en arenisca rionegrense, dos bolas de boleadora partidas, ambas confeccionadas sobre granito, ocho artefactos de molienda enteros, 12 fragmentados y 14 fragmentos en los que no se observaron rasgos diagnósticos, pero que por las características de las materias primas podrían corresponder a este tipo de artefactos. Entre estos artefactos, solo las bolas de boleadora muestran evidencias de reciclaje 
y/o uso alternativo, en ambos casos como yunque y una de ellas, además, como sobador. Entre los artefactos vinculados con actividades de molienda, se encuentran representados en igual cantidad manos de molino, una en arenisca rionegrense y tres en cuarcita, y molinos, dos en arenisca micácea y dos en cuarcita (Tabla 10.53).

\begin{tabular}{|c|c|c|c|c|c|c|c|c|c|c|}
\hline & \multicolumn{7}{|c|}{ Tipo de artefacto } & \multicolumn{3}{|c|}{ Otras características } \\
\hline $\begin{array}{l}\text { Materia } \\
\text { prima }\end{array}$ & Alisador & $\begin{array}{l}\text { BB } \\
\text { frag. }\end{array}$ & $\begin{array}{l}\text { Mano } \\
\text { molino }\end{array}$ & \begin{tabular}{|l|} 
Mano \\
molino \\
frag. \\
\end{tabular} & Molino & $\begin{array}{l}\text { Molino } \\
\text { frag. }\end{array}$ & $\begin{array}{l}\text { Frag. } \\
\text { indet }\end{array}$ & $\begin{array}{l}\text { U A } \\
\text { yunque }\end{array}$ & $\begin{array}{l}\text { U A } \\
\text { sobador }\end{array}$ & Pigmento \\
\hline $\begin{array}{l}\text { arenisca } \\
\text { rionegrense }\end{array}$ & 1 & & 1 & & & & & & & \\
\hline $\begin{array}{l}\text { arenisca } \\
\text { micácea }\end{array}$ & & & & & 2 & 9 & 9 & & & 6 \\
\hline cuarcita & & & 3 & 2 & 2 & 1 & 3 & & & 1 \\
\hline granito & & 2 & & & & & 2 & 2 & 1 & 1 \\
\hline
\end{tabular}

Tabla 10.53. Principales características de los artefactos modificados por uso y formatizados por picado, abrasión y/o pulido en el sitio Laguna Chasicó 3 . Indet= indetreminado; $\mathrm{BB}=$ bola de boleadora; $\mathrm{U} A=$ uso alternativo.

El granito es la materia prima en la que se ha invertido mayor tiempo y esfuerzo para su formatización y mantenimiento, seguida por la arenisca rionegrense y la cuarcita. Dos molinos -uno en arenisca micácea y otro en cuarcita- y varios pequeños fragmentos, muestran restos de pigmento rojo sobre sus superficies activas.

\subsection{4 Hallazgos aislados y pequeñas concentraciones del Sector Oeste}

Aquí se incluyeron los hallazgos aislados y pequeñas concentraciones localizadas entre el balneario Chapalcó y el pesquero Los Rastros (Laguna Chasicó sitios 5, 6, y 13; Hallazgos Aislados 1, 4, 5, 7 y 13). Entre estos se encuentran un fragmento de pigmento, 31 productos de talla, de los cuales 2 presentan rastros complementarios en alguno de sus filos, nueve instrumentos formatizados por talla, siete núcleos y/o nucleiformes y tres artefactos manufacturados por picado, abrasión y/o pulido enteros más un fragmento que, por su materia prima, probablemente haya correspondido también a este tipo de artefactos.

Entre las materias primas utilizadas en actividades de talla se encuentran en primer lugar las cuarcitas G6 y las calcedonias (21\%), seguidas por las RSO y cuarcitas G2 (17\% y 15\% respectivamente), encontrándose en proporciones menores al 10\% chert, cuarcita G1, cuarcita G3, limolita silicificada, basalto y cuarzo. Si se tiene en cuenta el peso con que ellas están presentes, la representación de las cuarcitas G6 y cuarcitas G2 aumenta considerablemente. Las restantes materias primas, en cambio, disminuyen su representación a menos del $10 \%$ (Figura 10.18). 


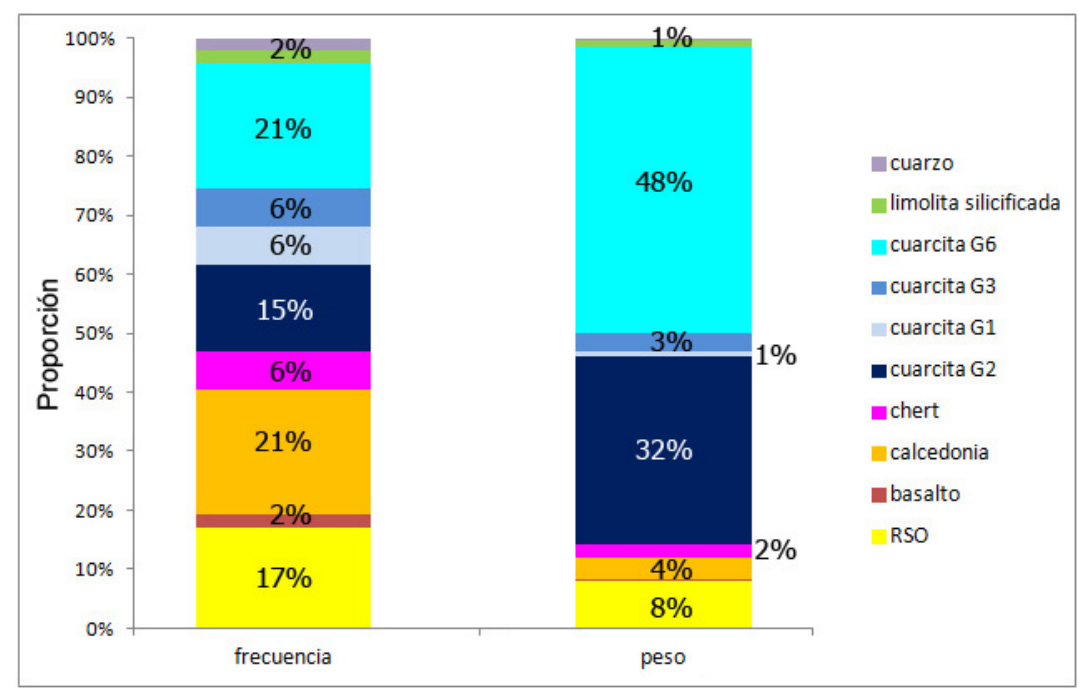

Figura 10.18. Proporción de materias primas presentes en los artefactos del sector oeste de la laguna Chasicó, considerando su peso y frecuencia.

Los tamaños más representados en esta muestra son el pequeño y mediano-pequeño. RSO, calcedonias y cuarcitas G1 solo se encuentran representadas por artefactos de tamaño mediano pequeño o menor, en tanto a los tamaños muy grande y súper grande se los encuentra, en bajo número, únicamente en cuarcitas G2 y cuarcitas G6 (Tabla 10.54).

\begin{tabular}{|l|r|r|r|r|r|r|r|}
\hline Materia prima & $\begin{array}{c}\text { Muy } \\
\text { pequeño }\end{array}$ & Pequeño & $\begin{array}{c}\text { Mediano } \\
\text { pequeño }\end{array}$ & $\begin{array}{c}\text { Mediano } \\
\text { grande }\end{array}$ & Grande & $\begin{array}{c}\text { Muy } \\
\text { grande }\end{array}$ & $\begin{array}{c}\text { Súper } \\
\text { grande }\end{array}$ \\
\hline RSO & 2 & 2 & 4 & & & & \\
\hline basalto & & 1 & & & & & \\
\hline calcedonia & 1 & 6 & 3 & & & & \\
\hline chert & & 1 & 1 & 1 & & & \\
\hline cuarcita G2 & & 2 & 3 & & 1 & 1 & \\
\hline cuarcita G1 & & 3 & & & & & \\
\hline cuarcita G3 & & 1 & 1 & 1 & & & \\
\hline cuarcita G6 & & 6 & 3 & & & & 1 \\
\hline limolita silicificada & & & & & & & \\
\hline cuarzo & & 1 & & & & & \\
\hline
\end{tabular}

Tabla 10.54. Tamaño en las diferentes materias primas representadas en artefactos del sector oeste de la laguna Chasicó. Las materias primas se encuentran organizadas en función de la distancia a la que se encuentra su probable fuente de aprovisionamiento más cercana.

Poco más de la mitad de la muestra corresponde a artefactos que no presentan reserva de corteza en sus superficies. Entre aquellos que sí poseen corteza, predominan aquellos con menos del $50 \%$ de su superficie con corteza, encontrándose únicamente entre las cuarcitas G2 y las RSO algunos artefactos con más del $50 \%$ del artefacto cubierto por corteza. En estas rocas se encuentra, a su vez, la mayor frecuencia de artefactos con corteza (IC de 0,71 y 0,88 respectivamente) (Tabla 10.55). 


\begin{tabular}{|l|r|r|r|r|r|r|}
\hline \multicolumn{1}{|c|}{$\begin{array}{c}\text { Corteza } \\
\text { Materia prima }\end{array}$} & $\begin{array}{c}\text { Sin } \\
\text { corteza }\end{array}$ & $\mathbf{1 \% - 2 5 \%}$ & $\mathbf{2 5 \% - 5 0 \%}$ & $\mathbf{5 0 \% - 7 5 \%}$ & $\mathbf{7 5 \% - 1 0 0 \%}$ & \multicolumn{1}{c|}{ IC } \\
\hline RSO & 1 & 1 & 3 & 2 & 1 & 0,88 \\
\hline basalto & 1 & & & & & 0,00 \\
\hline calcedonia & 6 & 4 & & & & 0,40 \\
\hline chert & 2 & 1 & & & & 0,33 \\
\hline cuarcita G2 & 2 & 1 & 1 & 3 & & 0,71 \\
\hline cuarcita G1 & 2 & & 1 & & & 0,33 \\
\hline cuarcita G3 & 2 & & 1 & & & 0,33 \\
\hline cuarcita G6 & 8 & & 2 & & & 0,20 \\
\hline limolita silicificada & 1 & & & & & 0,00 \\
\hline cuarzo & & & 1 & & & 1,00 \\
\hline
\end{tabular}

Tabla 10.55. Remanente de corteza en las diferentes materias primas representadas en artefactos del sector oeste de la laguna Chasicó. Las materias primas se encuentran organizadas en función de la distancia a la que se encuentra su probable fuente de aprovisionamiento más cercana.

La técnica bipolar fue registrada en ocho artefactos, cuatro núcleos bipolares y una lasca en RSO y dos núcleos bipolares y una lasca en basalto. Se registraron un total de 15 lascas completas la mayor cantidad de ellas en calcedonia y cuarcita G6. La proporción de artefactos formatizados es alta, encontrándose las mayores frecuencias entre los cherts. Aquellos instrumentos con mayor inversión en su manufactura consisten en tres puntas de proyectil bifaciales, manufacturadas en chert, una de ellas mediante adelgazamiento y las otras dos por reducción. A estas se agregan una raedera en limolita silicificada, formatizada por reducción (bifacial en un filo y unifacial directo en el segundo) y un fragmento de artefacto con reducción unifacial en cuarcita G1. En los restantes cuatro instrumentos se utilizó el trabajo marginal unifacial (Tabla 10.56).

\begin{tabular}{|c|c|c|c|c|c|c|c|c|c|c|}
\hline & \multicolumn{4}{|c|}{ Filos } & \multicolumn{3}{|c|}{ Artefactos } & \multirow[b]{2}{*}{ Lascas } & \multirow[b]{2}{*}{ instrumentos } & \multirow[b]{2}{*}{ IP } \\
\hline $\begin{array}{l}\text { Materia } \\
\text { prima }\end{array}$ & $\begin{array}{c}\text { Unifaciales } \\
\text { indet }\end{array}$ & $\begin{array}{c}\text { Unifacial } \\
\text { directo }\end{array}$ & Bifacial & IB & $\mathbf{T M}$ & $\mathbf{R}$ & $\mathbf{A}$ & & & \\
\hline calcedonia & & 2 & & 0,00 & 1 & & & 1 & 1 & 1,00 \\
\hline Chert & & & 8 & 1,00 & & 2 & 1 & & 3 & 0,00 \\
\hline cuarcita G2 & & 2 & & 0,00 & 1 & & & 1 & 1 & 1,00 \\
\hline cuarcita G1 & 1 & & & 0,00 & & 1 & & & 1 & 0,00 \\
\hline cuarcita G3 & & 2 & & 0,00 & 1 & & & 1 & 1 & 1,00 \\
\hline cuarcita G6 & 2 & & & 0,00 & 1 & & & 1 & 1 & 1,00 \\
\hline limolita sil & & 1 & 1 & 0,50 & & 1 & & & 1 & 0,00 \\
\hline
\end{tabular}

Tabla 10.56. Principales características de los artefactos formatizados por talla. $\mathrm{IB}=$ índice bifacial; $\mathrm{TM}=$ trabajo marginal; $\mathrm{R}=$ reducción; $\mathrm{A}=$ adelgazamiento; $\mathrm{IP}=$ índice de producción.

Se registraron siete núcleos, cuatro de RSO, tres de ellos bipolares agotados y el cuarto un nucleiforme con algunos lascados aislados. Dos núcleos bipolares agotados en calcedonia y un núcleo de lascas, activo, en cuarcita G6. Este último presenta lascados perimetrales unifaciales y un peso mayor a 200 gr (Tabla 10.57). 


\begin{tabular}{|l|r|r|r|r|r|}
\cline { 5 - 6 } \multicolumn{2}{c|}{} & \multicolumn{2}{c|}{ Estado } \\
\hline Materia prima & N & Peso medio & Desvío estándar & No agotado & Agotado \\
\hline calcedonia & 4 & 7,62 & 5,06 & 1 & 3 \\
\hline cuarcita G6 & 2 & 3,15 & 2,62 & & 2 \\
\hline
\end{tabular}

Tabla 10.57. Principales características de los núcleos recuperados en el sector oeste de la laguna Chasicó.

Por último, entre los artefactos vinculados con las actividades de molienda, se recuperaron manos de molino y molinos formatizados sobre arenisca rionegrense y cuarcitas, a los que se suman un fragmento de arenisca micácea de pequeñas dimensiones que probablemente haya correspondido a un artefacto de molienda. Entre las areniscas rionegrenses se encuentran una mano, con dos superficies activas y un peso de $797 \mathrm{gr}$, dos bases de molino, con una superficie activa cada una, pesos de entre 6250 gr y 7500 gr y largo de entre $250 \mathrm{~mm}$ y $390 \mathrm{~mm}$ y una posible base de molino en la que, debido a que se desgrana fácilmente, es difícil observar rastros de uso. Por último, se recuperó una mano de molino sobre un rodado de cuarcita, con un peso de 750 gr. Estos artefactos muestran poco inversión en su formatización, no encontrándose tampoco evidencias de mantenimiento, uso alternativo y/o reciclaje.

\subsection{2 sector Sur}

Se agruparon como sector sur todos aquellos hallazgos aislados y concentraciones de baja densidad localizados entre el balneario Chapalcó y las inmediaciones del vivero (Laguna Chasicó sitio 10; Hallazgos Aislados 2, 3, 6, 8, 9, 10, 11, 15). En este sector se recuperó un fragmento de pigmento, 12 productos de talla, de los cuales uno presenta rastros complementarios en uno de sus filos, un núcleo, cuatro instrumentos manufacturados por talla y cinco formatizados por picado, abrasión y/o pulido, uno de ellos fragmentado.

Entre los artefactos producto de actividades de talla, las materias primas dominantes son las RSO (26\%), seguidas por cuarcitas G6, riolita y limolita silicificada (16\%), encontrándose en menor porcentaje los chert (11\%) y cuarcitas G2 y cuarcitas G3 (5\%). En cambio, si consideramos el peso con que estas se encuentran presentes, las cuarcitas G6 ocupan casi el 50\% de la muestra y disminuye considerablemente la representación de las riolitas y de las RSO, en tanto las restantes rocas mantienen porcentajes similares (Figura 10.19). 


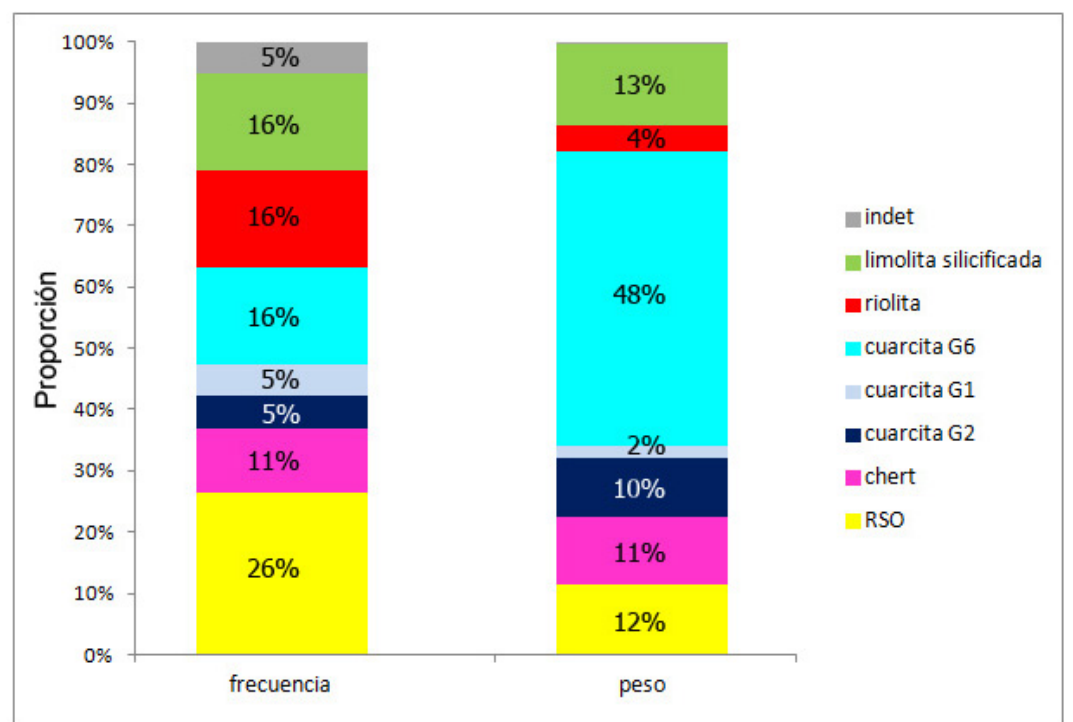

Figura 10.19. Proporción de materias primas presentes en los artefactos del sector sur de la laguna Chasicó, considerando su peso y frecuencia.

Los tamaños pequeño y mediano pequeño se presentan en la mayor parte de las materias primas, con excepción del chert y la cuarcita G2, siendo los únicos tamaños representados entre las RSO, riolita y cuarcita G1. Los tamaños mayores, por otra parte, se encuentran en los cherts, cuarcita G2, limolita silicificada y cuarcita G6, en esta última materia prima, también se observó la presencia de un artefacto de tamaño muy grande (Tabla 10.58).

\begin{tabular}{|c|c|c|c|c|c|}
\hline $\begin{array}{l}\text { Tamaño } \\
\text { Materia Prima }\end{array}$ & Pequeño & Mediano pequeño & Mediano grande & Grande & Muy grande \\
\hline RSO & 4 & 1 & & & \\
\hline chert & & & 1 & 1 & \\
\hline cuarcita G2 & & & 1 & & \\
\hline cuarcita G1 & 1 & & & & \\
\hline cuarcita G6 & 1 & & & 1 & 1 \\
\hline riolita & 1 & 2 & & & \\
\hline limolita silicificada & 1 & & 2 & & \\
\hline indet & 1 & & & & \\
\hline
\end{tabular}

Tabla 10.58. Tamaño en las diferentes materias primas representadas en artefactos del sector sur de la laguna Chasicó. Las materias primas se encuentran organizadas en función de la distancia a la que se encuentra su probable fuente de aprovisionamiento más cercana.

Con respecto a la corteza, las RSO son las únicas rocas entre las que los artefactos presentan más del 50\% de sus superficies con corteza, siendo en esta materia prima, a su vez, donde se encuentra la mayor frecuencia de artefactos con corteza. La limolita silicificada y la cuarcita G2 también presentan artefactos con remanentes de corteza, pero tanto su frecuencia como la superficie cubierta son menores (Tabla 10.59). 


\begin{tabular}{|l|r|r|r|r|r|r|r|}
\hline \multicolumn{1}{|c|}{ Corteza } & Sin corteza & $\mathbf{1 \% - 2 5 \%}$ & $\mathbf{2 5 \% - 5 0 \%}$ & $\mathbf{5 0 \% - 7 5 \%}$ & $\mathbf{7 5 \% - 1 0 0 \%}$ & $\begin{array}{c}\text { No } \\
\text { pertinente }\end{array}$ & IC \\
\hline RSO & 2 & & 2 & 1 & 1,00 \\
\hline chert & 1 & & & & & & 0,00 \\
\hline cuarcita G2 & 1 & & & & & & 1,00 \\
\hline cuarcita G1 & 3 & & & & & & 0,00 \\
\hline cuarcita G6 & 3 & & & & & & 0,00 \\
\hline riolita & 2 & & 1 & & & & 0,00 \\
\hline limolita silicificada & 1 & & & & & & 0,33 \\
\hline indet & & & & & & 0,00 \\
\hline
\end{tabular}

Tabla 10.59. Remanente de corteza en las diferentes materias primas representadas en artefactos del sector sur de la Laguna Chasicó. Las materias primas se encuentran organizadas en función de la distancia a la que se encuentra su probable fuente de aprovisionamiento más cercana.

La técnica bipolar fue registrada en cuatro artefactos elaborados sobre RSO y en uno sobre riolita. La clase artefactual más abundante es la de los instrumentos, presentes en chert, cuarcita G2, cuarcita G6 y limolita silicificada. Estos muestran una baja inversión en su manufactura, habiendo sido modificados los bordes, en casi todos los casos, mediante trabajo marginal unifacial directo. La única excepción a esto es una punta de proyectil sobre chert que fue trabajada mediante reducción bifacial (Tabla 10.60). No se registraron núcleos, con excepción del bipolar agotado de RSO mencionado más arriba, con un peso de 12 gr.

\begin{tabular}{|c|c|c|c|c|c|c|c|c|c|c|}
\hline & \multicolumn{4}{|c|}{ Filos } & \multicolumn{3}{|c|}{ Artefactos } & \multirow[b]{2}{*}{ lascas } & \multirow[b]{2}{*}{ instrumentos } & \multirow[b]{2}{*}{ IP } \\
\hline Materia prima & $\begin{array}{c}\text { unifacial } \\
\text { directo }\end{array}$ & alterno & bifacial & IB & TM & $\mathbf{R}$ & $\mathbf{A}$ & & & \\
\hline chert & & & 3 & 1,00 & & 1 & & 1 & 1 & 1,00 \\
\hline cuarcita G2 & 2 & & & 0,00 & 1 & & & & 1 & 0,00 \\
\hline cuarcita G6 & 3 & 1 & & 0,00 & 3 & & & & 3 & 0,00 \\
\hline limolita silicificada & 1 & & & 0,00 & 1 & & & & 1 & 0,00 \\
\hline
\end{tabular}

Tabla 10.60. Principales características de los artefactos formatizados por talla del sector sur de la Laguna Chasicó. $\mathrm{IB}=$ índice bifacial; $\mathrm{TM}=$ trabajo marginal; $\mathrm{R}=$ reducción; $\mathrm{A}=$ adelgazamiento; $\mathrm{IP}=$ índice de producción.

En este sector fueron recolectados siete artefactos modificados por picado, abrasión y/o pulido y un fragmento de arenisca micácea, que probablemente haya correspondido a un artefacto de este tipo. Estos consisten en una bola de boleadora en arenisca rionegrense y seis artefactos vinculados con actividades de molienda. En estos último se emplearon arenisca micácea, en la confección de una mano de molino y un molino, cuarcita para la elaboración de dos molino y riolita ignimbrítica, utilizada en la formatización de un mortero y una mano de mortero. Ningún artefacto muestra evidencias de reciclaje o uso alternativo, pero sí de mantenimiento, presente este en una mano de molino de arenisca micácea y en el mortero. Estos dos artefactos muestran a su vez rasgos complementarios relacionados con la prensión, en el caso de la mano, y con la decoración en el mortero. Este último, confeccionado sobre una riolita ignimbrítica, ha sido decorado mediante motivos geométricos (líneas en zig-zag, líneas paralelas y tridígitos) grabados sobre su borde y un surco perimetral de $11 \mathrm{~mm}$ de espesor y aproximadamente 2 $\mathrm{mm}$ de profundidad (Tabla 10.61; Figura 10.20). 


\begin{tabular}{|c|c|c|c|c|c|c|c|c|c|}
\hline & \multicolumn{6}{|c|}{ Tipo de artefacto } & \multicolumn{3}{|c|}{ Otras características } \\
\hline $\begin{array}{l}\text { Materia } \\
\text { prima }\end{array}$ & $\begin{array}{l}\text { Frag. } \\
\text { indet }\end{array}$ & \begin{tabular}{|c|} 
Bola de \\
boleadora
\end{tabular} & $\begin{array}{c}\text { Mano } \\
\text { molino }\end{array}$ & $\begin{array}{c}\text { Mano } \\
\text { mortero }\end{array}$ & Molino & Mortero & Mant. & $\begin{array}{c}\text { Rasgos } \\
\text { complem. }\end{array}$ & Pigmento \\
\hline $\begin{array}{l}\text { arenisca } \\
\text { micácea }\end{array}$ & 1 & & 1 & & 1 & & 1 & 1 & 1 \\
\hline $\begin{array}{l}\text { arenisca } \\
\text { rionegrense }\end{array}$ & & 1 & & & & & & & \\
\hline cuarcita & & & & & 2 & & & & \\
\hline $\begin{array}{l}\text { riolita } \\
\text { jonimbrítica }\end{array}$ & & & & 1 & & 1 & 1 & 1 & \\
\hline
\end{tabular}

Tabla 10.61. Principales características de los artefactos modificados por uso y formatizados por picado, abrasión y/o pulido del sector sur de la Laguna Chasicó. Frag indet= fragmento indetreminado. Mant= mantenimiento.

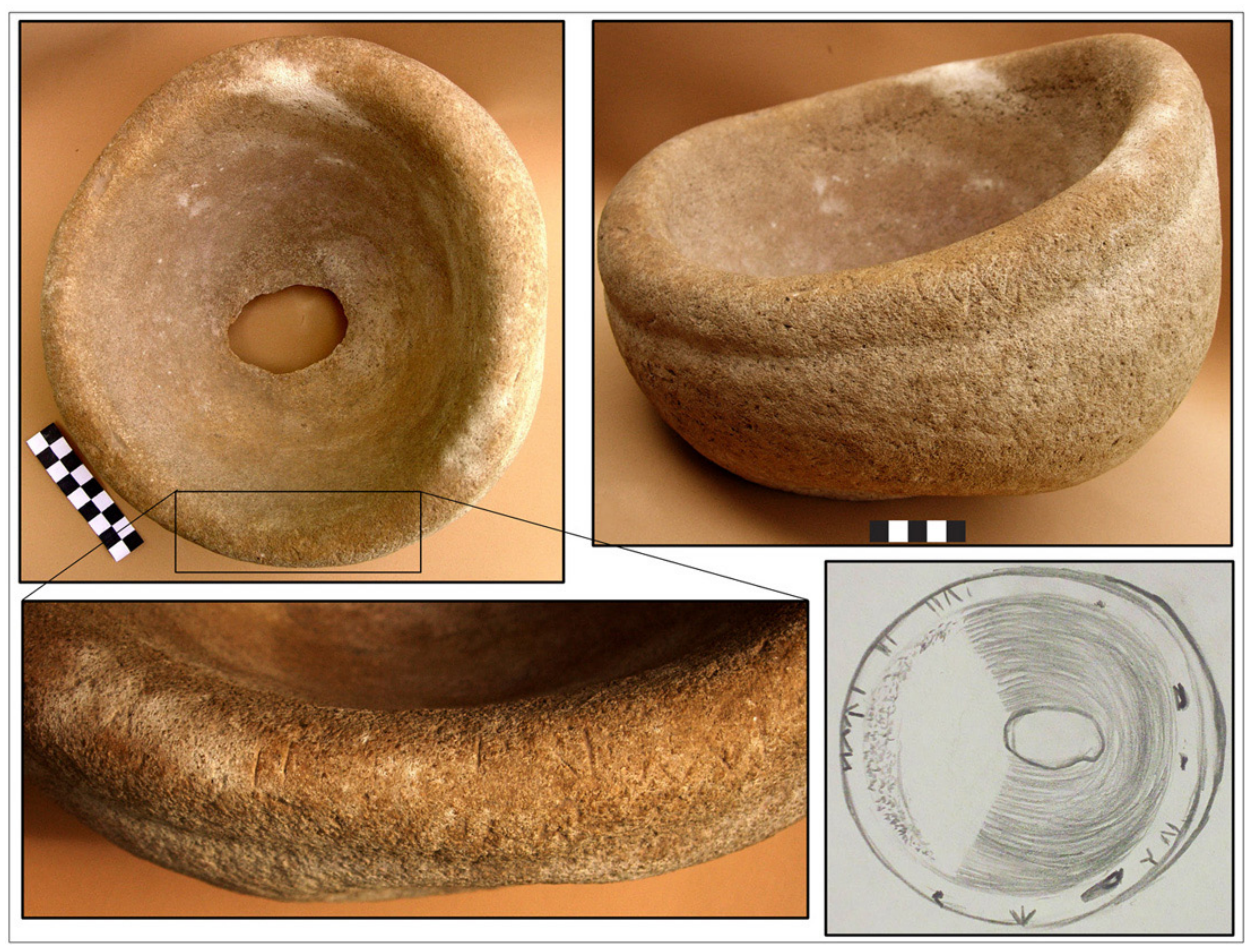

Figura 10.20. Mortero con decoración incisa geométrica en su borde, elaborado en una riolita ignimbrítica. Fue recolectado por el Sr. Peluso en el sector sur de la laguna Chasicó. En el recuadro inferior derecho un dibujo a mano alzada realizado por Gustavo Barrientos, en el que se pueden observar los motivos decorativos.

\subsection{Sector Este}

\subsection{1 Laguna Chasicó sitio 7 (LCHA7)}

En el sitio 7, las recolecciones superficiales permitieron recuperar nueve fragmentos de pigmento, 142 productos de talla -de los cuales dos muestran rastros complementarios en alguno de sus filos-, 15 instrumentos formatizados por talla, nueve núcleos y/o nucleiformes, 13 artefactos manufacturados por picado abrasión y/o pulido, tres fragmentos de este mismo tipo de artefactos y siete ecofactos. Entre las materias primas utilizadas en artefactos de talla, predominan las cuarcitas G2 (39\%), seguidas por las RSO (12\%) y las cuarcitas G1 (10\%). Chert, calcedonia y otras rocas disponibles localmente (si bien no de manera inmediata), se encuentran en porcentajes inferiores al 7\%, en tanto las riolitas, cuarcitas 
G6 y limolitas silicificadas, de origen no local, no superan el 3\%. Si tomamos en cuenta el peso con que estas diversas rocas se encuentran presentes, las cuarcitas G2 alcanzan el 61\%, en tanto las RSO, chert y calcedonia disminuyen al 2\% o inclusive menos (Figura 10.21).

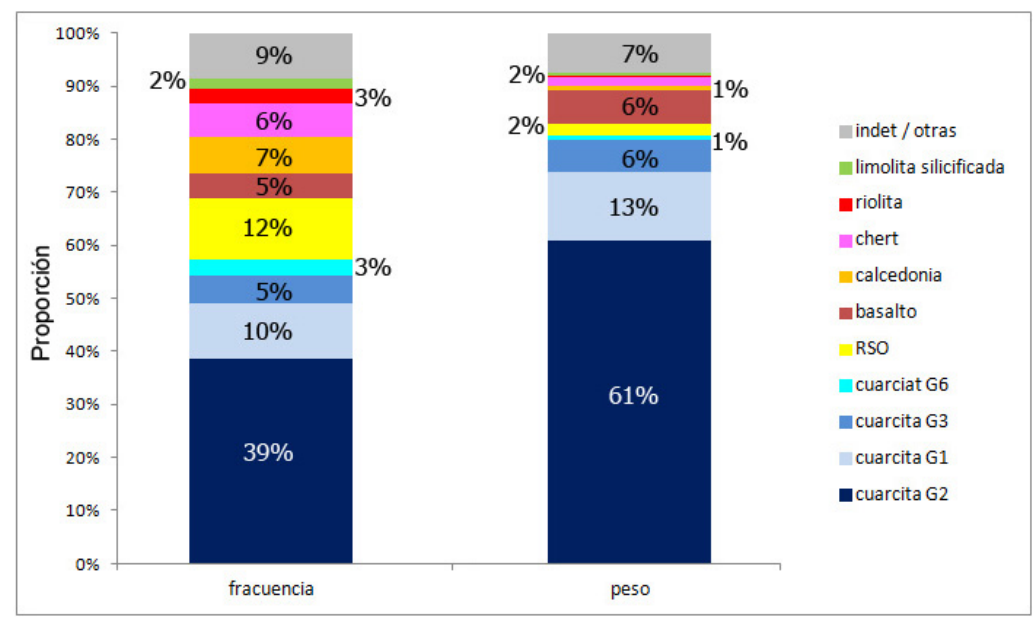

Figura 10.21. Proporción de materias primas presentes en los artefactos del sitio Laguna Chasicó 7, considerando su peso y frecuencia.

Los tamaños más representados en el conjunto son el pequeño y mediano-pequeño, principalmente en riolita, limolita silicificada y calcedonia. Los tamaños mayores (grande, muy grande y súper grande) se encuentran en basalto y en todas las variedades de cuarcita, chert y RSO (Tabla 10.62).

\begin{tabular}{|l|r|r|r|r|r|r|r|}
\hline \multicolumn{1}{|r|}{ Tamaño } & $\begin{array}{c}\text { Muy } \\
\text { pequeño }\end{array}$ & Pequeño & $\begin{array}{c}\text { Mediano } \\
\text { pequeño }\end{array}$ & $\begin{array}{c}\text { Mediano } \\
\text { grande }\end{array}$ & Grande & $\begin{array}{c}\text { Muy } \\
\text { grande }\end{array}$ & $\begin{array}{c}\text { Súper } \\
\text { grande }\end{array}$ \\
\cline { 1 - 6 } cuarcita G2 Prima & & 19 & 15 & 16 & 13 & 3 & 1 \\
\hline RSO & 2 & 8 & 13 & 3 & 1 & & \\
\hline basalto & & 2 & 4 & & & 1 & \\
\hline calcedonia & 1 & 8 & 2 & 1 & & & \\
\hline chert & & 5 & 2 & 2 & 2 & & \\
\hline cuarcita G1 & & 6 & 6 & 4 & & 2 & \\
\hline cuarcita G3 & 1 & 4 & 2 & 1 & & 1 & \\
\hline cuarciat G6 & & 2 & 2 & & & & \\
\hline riolita & & 1 & 4 & & & & \\
\hline limolita silicificada & & 2 & & 1 & & & \\
\hline indet / otras & 2 & 5 & 1 & & 2 & \\
\hline
\end{tabular}

Tabla 10.62. Tamaño en las diferentes materias primas representadas en artefactos del sitio Laguna Chasicó 7. Las materias primas se encuentran organizadas en función de la distancia a la que se encuentra su probable fuente de aprovisionamiento más cercana.

Las mayores proporciones de reserva de corteza se encuentran entre las RSO y basaltos, las que también presentan una alta frecuencia de artefactos con corteza. También muestran abundante corteza (superior al 50\%), aunque en un bajo número de artefactos, las cuarcitas G2, las cuarcitas G1, los chert y las calcedonias. Por otra parte, la mayor proporción de artefactos sin corteza o con menos del $25 \%$ se encuentran entre riolitas, limolitas silicificadas, cuarcitas G6 y cuarcitas G3 (Tabla 10.63). 


\begin{tabular}{|l|r|r|r|r|r|r|r|}
\hline Materia prima & $\begin{array}{c}\text { Sin } \\
\text { corteza }\end{array}$ & $\mathbf{1 \% - 2 5 \%}$ & $\mathbf{2 5 \% 5 0 \%}$ & $\mathbf{5 0 \% - 7 5 \%}$ & $\mathbf{7 5 \% - 1 0 0 \%}$ & $\begin{array}{c}\text { No } \\
\text { pertinente }\end{array}$ & IC \\
\hline RSO & 4 & 7 & 5 & 5 & 5 & 1 & 0,85 \\
\hline basalto & 1 & 2 & 3 & 1 & 1 & & 0,88 \\
\hline calcedonia & 5 & 2 & 4 & 1 & & & 0,58 \\
\hline chert & 3 & 4 & 3 & 1 & & & 0,73 \\
\hline cuarcita G2 & 13 & 19 & 24 & 8 & 1 & 2 & 0,81 \\
\hline cuarcita G1 & 5 & 5 & 6 & 1 & 1 & & 0,72 \\
\hline cuarcita G3 & 6 & 2 & 1 & & & & 0,33 \\
\hline riolita & 5 & & & & & & 0,00 \\
\hline limolita silicificada & 3 & & & & & & 0,00 \\
\hline cuarciat G6 & 4 & 1 & & & & & 0,20 \\
\hline cuarzo & 2 & & 2 & & & & 0,50 \\
\hline indet & 1 & & 1 & & & 2 & 0,75 \\
\hline
\end{tabular}

Tabla 10.63. Remanente de corteza en las diferentes materias primas representadas en artefactos del sitio Laguna Chasicó 7. Las materias primas se encuentran organizadas en función de la distancia a la que se encuentra su probable fuente de aprovisionamiento más cercana.

La técnica bipolar fue utilizada para la reducción de 20 artefactos, entre los que se encuentran nueve en RSO (siete lascas, un núcleo y un cuchillo), cuatro lascas de basalto, tres de calcedonia, una de chert y posibles lascas bipolares en cuarcita G1, cuarcita G2 y cuarcita G6. Los instrumentos manufacturados por talla se encuentran en un alto número, principalmente entre los cherts. Esto se ve reflejado a su vez en su menor IP, seguida por la limolita silicificada y cuarcita G6. Otras materias primas como calcedonia y RSO presentan una baja proporción de instrumentos, en tanto estos no fueron registrados entre las riolitas y cuarcitas G1. Aquellos con mayor inversión de trabajo consisten en dos puntas de proyectil en RSO y cuatro puntas o pre-puntas de proyectil formatizadas en chert mediante reducción bifacial. Los restantes instrumentos fueron confeccionados mediante trabajo marginal unifacial directo $(\mathrm{n}=5) \mathrm{o}$ inverso $(\mathrm{n}=2)$ (Tabla 10.64).

\begin{tabular}{|c|c|c|c|c|c|c|c|c|c|c|c|}
\hline \multirow{3}{*}{$\begin{array}{l}\text { Materia } \\
\text { prima } \\
\text { basalto }\end{array}$} & \multicolumn{5}{|c|}{ Filos } & \multicolumn{3}{|c|}{ Artefactos } & \multirow[b]{2}{*}{ Lascas } & \multirow[b]{2}{*}{ Instrumentos } & \multirow[b]{2}{*}{ IP } \\
\hline & $\begin{array}{c}\text { Unifacial } \\
\text { indet }\end{array}$ & $\begin{array}{c}\text { Unifacial } \\
\text { directo }\end{array}$ & $\begin{array}{c}\text { Unifacial } \\
\text { inverso }\end{array}$ & Bifacial & IB & TM & $\mathbf{R}$ & A & & & \\
\hline & 1 & & & 2 & 0,67 & 1 & 1 & & 5 & 2 & 2,50 \\
\hline calcedonia & & & 1 & & 0,00 & 1 & & & 7 & 1 & 7,00 \\
\hline chert & & & & 8 & 1,00 & & 4 & & 1 & 4 & 0,25 \\
\hline cuarciat G6 & & 2 & & & 0,00 & 1 & & & 2 & 1 & 2,00 \\
\hline cuarcita G1 & & & & & & & & & 6 & & \\
\hline cuarcita G2 & & 2 & & & 0,00 & 1 & & & 19 & 1 & 19,00 \\
\hline cuarcita G3 & & 4 & 1 & & 0,00 & 2 & & & 5 & 2 & 2,50 \\
\hline cuarzo & & & & & & & & & 1 & & \\
\hline limolita sil & & 2 & & & 0,00 & 1 & & & 1 & 1 & 1,00 \\
\hline riolita & & & & & & & & & 3 & & \\
\hline RSO & & 1 & & 4 & 0,80 & 2 & 1 & & 9 & 3 & 3,00 \\
\hline
\end{tabular}

Tabla 10.64. Principales características de los artefactos formatizados por talla del sitio Laguna Chasicó 7. IB= índice bifacial; $\mathrm{TM}=$ trabajo marginal; $\mathrm{R}=$ reducción; $\mathrm{A}=$ adelgazamiento; $\mathrm{IP}=$ índice de producción. 
Se recuperaron un total de nueve núcleos y/o nucleiformes sobre diversas materias primas, todos ellos todavía activos. En el caso de las RSO y chert, su peso oscila entre 14 gr y 21 gr, en tanto en aquellos realizados sobre basalto, cuarcitas G1, cuarcitas G2 y cuarcitas G3 el peso se encuentra entre 200 gr y 300 gr (Tabla 10.65).

\begin{tabular}{|c|c|c|c|c|c|}
\hline \multirow{2}{*}{ Materia prima } & \multirow[b]{2}{*}{$\mathbf{N}$} & \multirow[b]{2}{*}{ Peso medio } & \multirow[b]{2}{*}{ Desvío estándar } & \multicolumn{2}{|c|}{ Estado } \\
\hline & & & & No agotado & Agotado \\
\hline basalto & 1 & 207,00 & np & 1 & \\
\hline chert & 1 & 21,00 & $\mathrm{np}$ & 1 & \\
\hline cuarcita G1 & 2 & 231,50 & 27,60 & 2 & \\
\hline cuarcita G2 & 3 & 301,30 & 176,70 & 3 & \\
\hline cuarcita G3 & 1 & 229,00 & $\mathrm{np}$ & 1 & \\
\hline $\mathrm{RSO}$ & 1 & 14,00 & $\mathrm{np}$ & 1 & \\
\hline
\end{tabular}

Tabla 10.65. Principales características de los núcleos recuperados en el sitio Laguna Chasicó $7, \mathrm{np}=$ no pertinente.

Entre los artefactos modificados por uso y/o por picado abrasión y/o pulido, se encuentran dos yunques, dos bolas de boleadora, siete artefactos completos vinculados con actividades de molienda y 11 fragmentos, de los cuales un fragmento de molino fue reciclado en yunque y uno de arenisca rionegrense en abradidor. Entre los artefactos completos, dos manos de molino, una en cuarcitas y otra en arenisca micácea, muestran evidencias de mantenimiento (economía del desgaste y repiqueteo de la superficie activa). El artefacto en arenisca micácea presenta además, rasgos complementarios vinculados con el mejoramiento de su prensión. El único artefacto que muestra una alta inversión de trabajo en su manufactura es una mano de mortero elaborada sobre riolita ignimbrítica (E. Llambías y A. M. Sato 2013 com. pers.) (Tabla 10.66).

\begin{tabular}{|c|c|c|c|c|c|c|c|c|c|c|c|c|}
\hline & \multicolumn{8}{|c|}{ Tipo de artefacto } & \multicolumn{4}{|c|}{ Otras características } \\
\hline $\begin{array}{c}\text { Materia } \\
\text { prima }\end{array}$ & Yunque & BB & $\begin{array}{c}\text { Mano } \\
\text { molino }\end{array}$ & $\begin{array}{c}\text { Mano } \\
\text { mortero }\end{array}$ & Molino & $\begin{array}{c}\text { Mano } \\
\text { frag }\end{array}$ & $\begin{array}{c}\text { Molino } \\
\text { frag }\end{array}$ & $\begin{array}{l}\text { Frag } \\
\text { indet }\end{array}$ & $\begin{array}{l}\text { Uso } \\
\text { sec }\end{array}$ & Manten & $\mathbf{R C}$ & Pigm. \\
\hline $\begin{array}{l}\text { arenisca } \\
\text { rionegrense }\end{array}$ & & & 1 & & & & & 2 & 1 & & & \\
\hline $\begin{array}{l}\text { arenisca } \\
\text { micácea }\end{array}$ & & & 1 & & & & & 2 & & 1 & 1 & \\
\hline cuarcita & 2 & & 3 & & 1 & 1 & 2 & 1 & 1 & 1 & & 1 \\
\hline granito & & 1 & & & & & & & & & & \\
\hline indet & & 1 & & & & & & 1 & & & & \\
\hline limolita & & & & & & & & 2 & & & & \\
\hline $\begin{array}{l}\text { riolita } \\
\text { ignimbritica }\end{array}$ & & & & 1 & & & & & & & & \\
\hline
\end{tabular}

Tabla 10.66. Principales características de los artefactos modificados por uso y formatizados por picado, abrasión $\mathrm{y} / \mathrm{o}$ pulido en el sitio Laguna Chasicó 7 . Indet= indetreminado; $\mathrm{RC}=$ rasgos complementarios; $\mathrm{BB}=\mathrm{bola}$ de boleadora; Frag= fragmento 


\subsection{Sector Norte}

\subsection{1 Laguna Chasicó 4 (LCHA4)}

En este sitio se recolectaron en superficie cuatro fragmentos de pigmento, 21 productos de talla, de los cuales uno muestra rastros complementarios en uno de sus filos, cinco instrumentos manufacturados por talla y tres fragmentos de artefactos modificados por picado, abrasión y/o pulido, pertenecientes, probablemente, todos al mismo elemento. También se recuperó un ecofacto de granito, materia prima que no se haya disponible en las inmediaciones del sitio. Entre los artefactos manufacturados por talla, predominan las calcedonias (37\%), seguidas por las cuarcitas G2, chert (15\% cada una) y, en menor frecuencia, cuarcitas G1 (11\%), riolitas (8\%) y limolitas silicificadas, RSO, basalto y cuarcita G6 (4\% cada una). Si se tiene en cuenta el peso, la representatividad de las calcedonias y las cuarcitas G2 aumenta aún más, alcanzando el 53\% y 23\% respectivamente, mientras disminuye la proporción de las restantes materias primas (Figura 10.22).

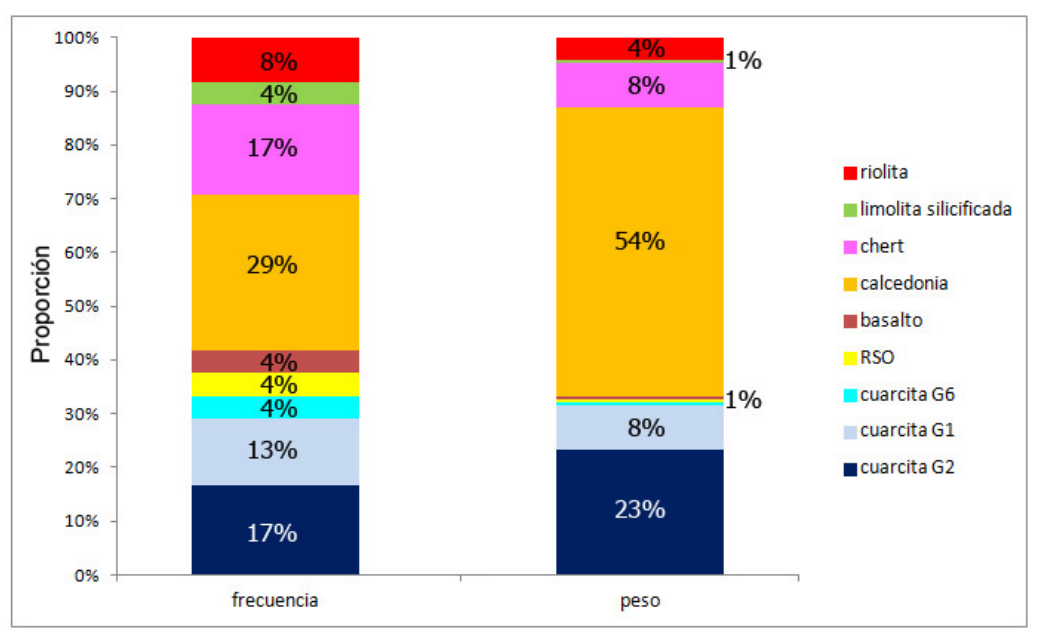

Figura 10.22. Proporción de materias primas presentes en los artefactos del sitio Laguna Chasicó 4, considerando su peso y frecuencia.

Los tamaños más representados son el pequeño y el mediano pequeño, presentes en todas las materias primas con excepción de las cuarcitas G6. La calcedonia es la única materia prima presente en todos los tamaños, con excepción del súper grande, ausente en el sitio. La cuarcita G2 y el chert también presentan algunos artefactos de mayor tamaños (mediano grande y grande) (Tabla 10.67).

\begin{tabular}{|l|r|r|r|r|r|r|}
\hline Materia prima & $\begin{array}{c}\text { Muy } \\
\text { pequeño }\end{array}$ & Pequeño & $\begin{array}{c}\text { Mediano } \\
\text { pequeño }\end{array}$ & $\begin{array}{c}\text { Mediano } \\
\text { grande }\end{array}$ & Grande & $\begin{array}{c}\text { Súper } \\
\text { grande }\end{array}$ \\
\hline RSO & & 1 & & & & \\
\hline basalto & & 1 & & & & \\
\hline calcedonia & 1 & 2 & 2 & 1 & 1 & \\
\hline chert & & 2 & 1 & 1 & & \\
\hline cuarcita G1 & & 1 & 2 & & & \\
\hline cuarcita G2 & 1 & & 2 & & 1 & \\
\hline cuarcita G6 & & 1 & 1 & & & \\
\hline riolita & & 1 & & & & \\
\hline limolita sil. & & & 1 & & & \\
\hline granito & 1 & 1 & & & & \\
\hline cuarzo & & & & & & \\
\hline
\end{tabular}

Tabla 10.67. Tamaño en las diferentes materias primas representadas en artefactos del sitio Laguna Chasicó 4. Las materias primas se encuentran organizadas en función de la distancia a la que se encuentra su probable fuente de aprovisionamiento más cercana. 
La muestra en general presenta bajas proporciones de corteza, encontrándose solo un artefacto, en cuarcita G2, con más del 50\% de la pieza cubierta. Un artefacto en basalto y uno en cuarcita G2 con entre el $25 \%$ y el $50 \%$ de corteza, en tanto los restantes no muestran evidencias o esta se encuentra presente en un sector inferior al $25 \%$ de la pieza. La calcedonia es la materia prima con menor proporción de corteza entre sus artefactos, siendo que en seis de los siete artefactos esta se encuentra ausente, en tanto en el séptimo solo representa menos del $25 \%$ de la pieza (Tabla 10.68).

\begin{tabular}{|c|c|c|c|c|c|}
\hline Materia prima & $\begin{array}{c}\text { Sin } \\
\text { corteza }\end{array}$ & $1 \%-25 \%$ & $25 \%-50 \%$ & $50 \%-75 \%$ & IC \\
\hline RSO & & 1 & & & 1,00 \\
\hline basalto & & & 1 & & 1,00 \\
\hline calcedonia & 6 & 1 & & & 0,14 \\
\hline chert & 2 & 2 & & & 0,50 \\
\hline cuarcita G1 & 2 & & & 1 & 0,33 \\
\hline cuarcita G2 & & 3 & 1 & & 1,00 \\
\hline cuarcita G6 & 1 & & & & 0,00 \\
\hline riolita & 1 & 1 & & & 0,50 \\
\hline limolita silicificada & & 1 & & & 1,00 \\
\hline granito & & & & & 0,00 \\
\hline cuarzo & 1 & 1 & & & 0,50 \\
\hline
\end{tabular}

Tabla 10.68. Remanente de corteza en las diferentes materias primas representadas en artefactos del sitio Laguna Chasicó 4. Las materias primas se encuentran organizadas en función de la distancia a la que se encuentra su probable fuente de aprovisionamiento más cercana.

Ninguno de los artefactos muestra evidencias que indiquen que fue reducido mediante técnica bipolar. Los instrumentos formatizados por talla son escasos, encontrándose la mayor proporción en calcedonia, con un IP de 1.5, seguida por chert y cuarcita G2, ambas con IP de 0,5, en tanto en las restantes materias primas no se registraron instrumentos. Entre los instrumentos, la mayor inversión de tiempo y esfuerzo se encuentra en una punta de proyectil fracturada, fomatizada en chert mediante reducción bifacial y en una raedera doble-convergente de calcedonia, formatizada también por reducción pero en este caso unifacial directa. En los restante instrumentos, los filos fueron formatizados mediante trabajo marginal unifacial (Tabla 10.69).

\begin{tabular}{|c|c|c|c|c|c|c|c|c|c|c|c|}
\hline & \multicolumn{5}{|c|}{ Filos } & \multicolumn{3}{|c|}{ Artefactos } & \multirow[b]{2}{*}{ Lascas } & \multirow[b]{2}{*}{ Instrumentos } & \multirow[b]{2}{*}{ IP } \\
\hline $\begin{array}{l}\text { Materia } \\
\text { prima }\end{array}$ & \begin{tabular}{c|}
$\begin{array}{c}\text { Unifacial } \\
\text { indet. }\end{array}$ \\
\end{tabular} & $\begin{array}{c}\text { Unifacial } \\
\text { directo }\end{array}$ & \begin{tabular}{|c|} 
Unifacial \\
inverso
\end{tabular} & Bbifacial & IB & TM & $\mathbf{R}$ & $\mathbf{A}$ & & & \\
\hline calcedonia & & 7 & 2 & 0 & 0,00 & 2 & 1 & & 2 & 3 & 0,67 \\
\hline chert & & & & 2 & 1,00 & & 1 & & 2 & 1 & 2,00 \\
\hline cuarcita G2 & 1 & & & 0 & 0,00 & 1 & & & 2 & 1 & 2,00 \\
\hline
\end{tabular}

Tabla 10.69. Principales características de los artefactos formatizados por talla del sitio Laguna Chasicó 4 . IB= índice bifacial; $\mathrm{TM}=$ trabajo marginal; $\mathrm{R}=$ reducción; $\mathrm{A}=$ adelgazamiento; $\mathrm{IP}=$ índice de producción.

Entre los artefactos manufacturados por picado, abrasión y/o pulido, se registraron tres fragmentos de arenisca micácea, correspondientes, probablemente, todos al mismo artefactos, consistente en una base de molino con una superficie activa cóncava atenuada, cuyas dimensiones estimadas son $260 \mathrm{~mm}$ de largo y $140 \mathrm{~mm}$ de ancho y $7 \mathrm{~mm}$ de profundidad. No se identificaron evidencias de reciclaje o uso secundario, así como tampoco la presencia de rasgos secundarios. 


\subsection{2 Laguna Chasicó sitio 8 (LCHA8)}

A partir de las recolecciones superficiales realizadas en el sitio 8, se recuperaron 13 fragmentos de pigmento, 200 productos de talla, de los cuales 23 muestran rastros complementarios en alguno de sus filos, nueve instrumentos y cinco fragmentos que, por su materia prima -una arenisca micácea-, probablemente correspondan a artefactos manufacturados por picado abrasión y/o pulido. Entre aquellos artefactos producto de actividades de talla, las materias primas con mayor representación son las cuarcitas, entre estas las correspondientes al grupo 6 (39\%), ocupan el primer lugar, seguida por las cuarcitas G2, cuarcitas G3 y cuarcitas G1 (18\%, 17\% y 8\% respectivamente). Las restantes materias primas, entre las que se encuentran RSO, basaltos, riolitas, limolitas silicificadas y chert, se presentan en porcentajes de entre $1 \%$ y $3 \%$. Al tomar en cuenta el peso con que las distintas materias primas se encuentran en el sitio, la cuarcita G6 disminuye su representación, en tanto aumenta la de la cuarcita G2 (Figura 10.23).

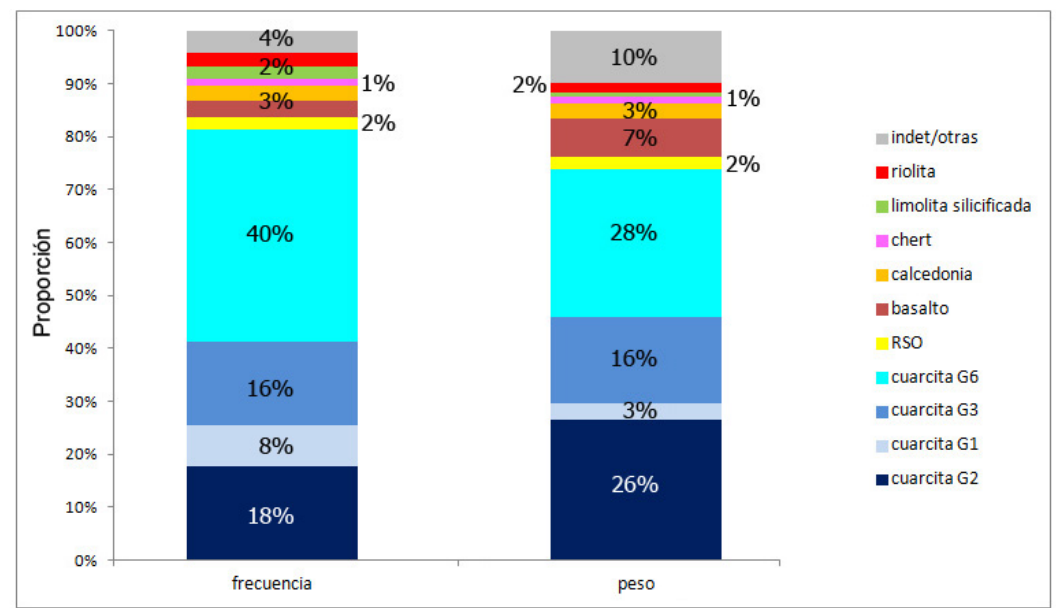

Figura 10.23. Proporción de materias primas presentes en los artefactos del sitio Laguna Chasicó 8, considerando su peso y frecuencia.

Predominan los tamaños pequeño y muy pequeño, este último presente en todas las materias primas, encontrándose ausentes los tamaños mayores a mediano-grande. La cuarcita G6, si bien es la roca más abúndate, se la encuentra casi de manera exclusiva en tamaños pequeño y muy pequeño, con solo seis artefactos mediano-pequeño y ninguno de mayor tamaño (Tabla 10.70).

\begin{tabular}{|l|r|r|r|r|}
\hline $\begin{array}{c}\text { Tamaño } \\
\text { Materia prima }\end{array}$ & $\begin{array}{c}\text { Muy } \\
\text { pequeño }\end{array}$ & Pequeño & $\begin{array}{c}\text { Mediano } \\
\text { pequeño }\end{array}$ & Mediano grande \\
\hline cuarcita G2 & 8 & 22 & 7 & \\
\hline RSO & & 4 & 1 & \\
\hline basalto & 1 & 2 & 4 & \\
\hline calcedonia & 1 & 4 & 1 & \\
\hline chert & & 2 & 1 & \\
\hline cuarcita G1 & 8 & 9 & & \\
\hline cuarcita G3 & 5 & 20 & 10 & \\
\hline limolita silicificada & 3 & 2 & & \\
\hline riolita & & 6 & & \\
\hline cuarcita G6 & 34 & 47 & 8 & \\
\hline indet / otras & 1 & 3 & 4 & \\
\hline
\end{tabular}

Tabla 10.70. Tamaño en las diferentes materias primas representadas en artefactos del sitio Laguna Chasicó 8. Las materias primas se encuentran organizadas en función de la distancia a la que se encuentra su probable fuente de aprovisionamiento más cercana. 
La presencia de corteza es escasa en toda la muestra, especialmente en RSO, limolita silicificada y riolita en las que esta no supera el $25 \%$ en ningún artefacto. Las materias primas en las que se encuentran artefactos con mayor remanente de corteza sobre sus superficies (más del 25\%) son basalto, cuarcitas G2 y cuarcitas G3, calcedonia y chert (Tabla 10.71).

\begin{tabular}{|l|r|r|r|r|r|c|}
\hline \multicolumn{1}{|c|}{$\begin{array}{c}\text { Corteza } \\
\text { Materia prima }\end{array}$} & $\begin{array}{c}\text { Sin } \\
\text { corteza }\end{array}$ & $\mathbf{1 \%} \mathbf{- 2 5} \%$ & $\mathbf{2 5 \% - 5 0 \%}$ & $\mathbf{5 0 \% - 7 5 \%}$ & $\mathbf{7 5 \% - 1 0 0 \%}$ & IC \\
\hline cuarcita G2 & 25 & 11 & 7 & & & 0,42 \\
\hline cuarcita G1 & 18 & 1 & & 1 & & 0,10 \\
\hline cuarcita G3 & 29 & 5 & 1 & & & 0,17 \\
\hline cuarcita G6 & 87 & 2 & & & & 0,02 \\
\hline RSO & 5 & 1 & & & & 0,17 \\
\hline basalto & 3 & 3 & 1 & & 0,62 \\
\hline calcedonia & 10 & 2 & 1 & & & 0,23 \\
\hline chert & 4 & 2 & 1 & & & 0,43 \\
\hline limolita silicificada & 5 & 1 & & & & 0,17 \\
\hline riolita & 7 & 1 & & & & 0,13 \\
\hline indet & 3 & & & & & 0,25 \\
\hline
\end{tabular}

Tabla 10.71. Remanente de corteza en las diferentes materias primas representadas en artefactos del sitio Laguna Chasicó 8. Las materias primas se encuentran organizadas en función de la distancia a la que se encuentra su probable fuente de aprovisionamiento más cercana.

Se registraron evidencias de talla bipolar en 7 lascas, dos en RSO, una de basalto, dos de calcedonia, una de ellas con un filo en raspador y dos de cuarcita G6. La frecuencia de instrumentos en la muestra es escasa, encontrándose únicamente presentes y cuarcitas G6, calcedonias y basalto. La inversión de trabajo en estos instrumentos es muy escasa, dos artefactos fueron formatizados mediante reducción unifacial, ambos en cuarcita G6, en tanto en los restantes casos solo se formatizaron los bordes mediante trabajo marginal (Tabla 10.72). Los filos naturales con rastros complementarios, en cambio, son muy abundantes, principalmente entre las cuarcitas G6, en las que alcanzan un n de 16.

\begin{tabular}{|c|c|c|c|c|c|c|c|c|c|c|c|}
\hline \multirow[b]{2}{*}{$\begin{array}{l}\text { Materia } \\
\text { prima }\end{array}$} & \multicolumn{5}{|c|}{ Filos } & \multicolumn{3}{|c|}{ Artefactos } & \multirow[b]{2}{*}{ Lascas } & \multirow[b]{2}{*}{ Instrumentos } & \multirow[b]{2}{*}{ IP } \\
\hline & $\begin{array}{c}\text { Unifacial } \\
\text { indet }\end{array}$ & $\begin{array}{c}\text { Unifacial } \\
\text { directo }\end{array}$ & $\begin{array}{c}\text { Unifacial } \\
\text { inverso }\end{array}$ & Bifacial & IB & TM & $\mathbf{R}$ & $\mathbf{A}$ & & & \\
\hline basalto & & & 1 & & 0,00 & 1 & & & 4 & 1 & 4,00 \\
\hline calcedonia & 1 & 1 & & & 0,00 & 2 & & & 1 & 2 & 0,50 \\
\hline cuarcita G6 & & 8 & & 3 & 0,27 & 3 & 2 & & 42 & 5 & 8,40 \\
\hline
\end{tabular}

Tabla 10.72. Principales características de los artefactos formatizados por talla del sitio Laguna Chasicó 8 . $\mathrm{IB}=$ índice bifacial; $\mathrm{TM}=$ trabajo marginal; $\mathrm{R}=$ reducción; $\mathrm{A}=$ adelgazamiento; $\mathrm{IP}=$ índice de producción.

\subsection{Salinas Chicas (SCH)}

En las Salinas Chicas se recuperaron un total de 21 productos de talla, cuatro instrumentos, un nucleiforme y un ecofacto. Las materias primas más representadas son las RSO y basalto, que ocupan el $24 \%$ y $17 \%$ de la muestra respectivamente, seguidas por calcedonia, chert, riolita (con el 10\%) y, en menor proporción, cuarcitas G6, cuarcitas G1 y Cuarcitas G2. Si se considera el peso de los artefactos, la proporción de basalto y chert aumenta hasta el $36 \%$ y $14 \%$ respectivamente, en tanto calcedonia y cuarcitas, particularmente cuarcitas G6, disminuyen su representación (Figura 10.24). 


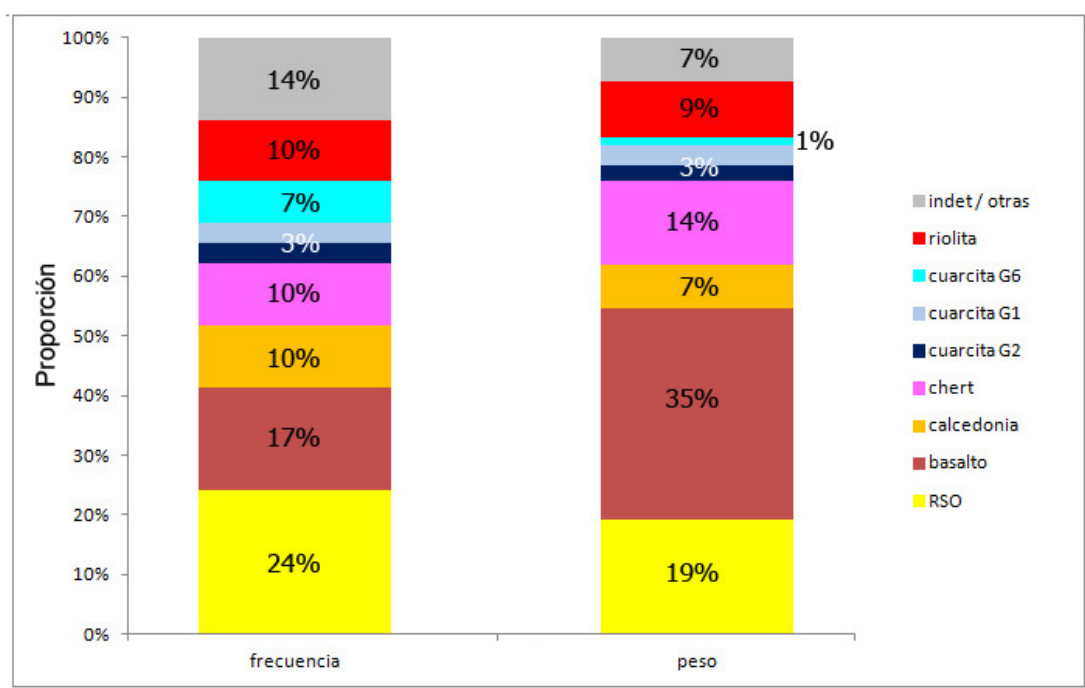

Figura 10.24. Proporción de materias primas presentes en los artefactos de Salinas Chicas, considerando su peso y frecuencia.

Los tamaños se encuentran entre pequeño y mediano grande, este último únicamente en piezas en basalto y RSO. Cuarcitas G6 y riolitas, por otra parte, sólo se encuentran representadas por artefactos de tamaño pequeño (Tabla 10.73).

\begin{tabular}{|l|r|r|r|}
\hline \multicolumn{1}{|r|}{ Tamaño } & Pequeño & Mediano pequeño & Mediano grande \\
\hline Materia prima & 3 & 3 & 1 \\
\hline baso & & 4 & 1 \\
\hline calcedonia & 1 & 3 & \\
\hline chert & & 2 & 1 \\
\hline cuarcita G2 & & 1 & \\
\hline cuarcita G1 & 2 & 1 & \\
\hline cuarcita G6 & 2 & & \\
\hline riolita & 3 & & \\
\hline cuarzo & & & \\
\hline indet & & 1 & \\
\hline
\end{tabular}

Tabla 10.73. Tamaño en las diferentes materias primas representadas en artefactos de Salinas Chicas. Las materias primas se encuentran organizadas en función de la distancia a la que se encuentra su probable fuente de aprovisionamiento más cercana.

Las mayores proporciones de corteza se registraron entre las RSO y basaltos, materias primas en las que se encuentran piezas con más del $75 \%$ de corteza. También presentan altos porcentajes de corteza las riolitas y cherts, en tanto no se registró corteza en cuarcitas G6 y cuarcitas G1 (Tabla 10.74). 


\begin{tabular}{|l|r|r|r|r|r|c|}
\hline Materia prima & \multicolumn{1}{c|}{$\begin{array}{c}\text { Sin } \\
\text { corteza }\end{array}$} & $\mathbf{1 \% - 2 5 \%}$ & $\mathbf{2 5 \% - 5 0 \%}$ & $\mathbf{5 0 \% - 7 5 \%}$ & $\mathbf{7 5 \% - 1 0 0 \%}$ & IC \\
\hline RSO & 3 & 1 & 1 & & 2 & 0,57 \\
\hline basalto & & 2 & 2 & & 1,00 \\
\hline calcedonia & 2 & & 1 & & & 0,33 \\
\hline chert & 1 & & & 2 & & 0,67 \\
\hline cuarcita G2 & 1 & & & & & 1,00 \\
\hline cuarcita G1 & 2 & & & & & 0,00 \\
\hline cuarcita G6 & 1 & & & & & 0,00 \\
\hline riolita & 1 & & & 1 & & 0,67 \\
\hline cuarzo & & & & 1 & & 0,67 \\
\hline indet & & & & & 1,00 \\
\hline
\end{tabular}

Tabla 10.74. Remanente de corteza en las diferentes materias primas representadas en artefactos de Salinas Chicas. Las materias primas se encuentran organizadas en función de la distancia a la que se encuentra su probable fuente de aprovisionamiento más cercana.

Se identificaron evidencias de talla bipolar en10 artefactos, tres en basalto, dos en RSO, dos en riolita y los restantes en otras materias primas. A estos se agregan otros cuatro posibles artefactos bipolares, en basalto, chert, RSO y cuarzo. Se trata en todos los casos de lascas, con la excepción de un raspador y un núcleo bipolar. En cuanto a los instrumentos, se registraron dos en calcedonia, uno en RSO y uno en cuarcita G1 y en ningún caso se registraron filos con rastros complementarios. Estos muestran una baja inversión de trabajo, siendo que todos fueron formatizados mediante trabajo unifacial marginal (Tabla 10.75).

\begin{tabular}{|c|c|c|c|c|c|c|c|c|c|}
\hline \multirow[b]{2}{*}{$\begin{array}{l}\text { Materia } \\
\text { prima }\end{array}$} & \multicolumn{3}{|c|}{ Filos } & \multicolumn{3}{|c|}{ Artefactos } & \multirow[b]{2}{*}{ Lascas } & \multirow[b]{2}{*}{ Instrumentos } & \multirow[b]{2}{*}{ IP } \\
\hline & Unifacial directo & Bifacial & IB & $\mathbf{T M}$ & $\mathbf{R}$ & $\mathbf{A}$ & & & \\
\hline calcedonia & 2 & 0 & 0,00 & 2 & 0 & 0 & 1 & 2 & 0,50 \\
\hline RSO & 1 & 0 & 0,00 & 1 & 0 & 0 & 5 & 1 & 5,00 \\
\hline cuarcita G1 & 1 & 0 & 0,00 & 1 & 0 & 0 & 0 & 1 & 0,00 \\
\hline
\end{tabular}

Tabla 10.75. Principales características de los artefactos formatizados por talla. $\mathrm{IB}=$ índice bifacial; $\mathrm{TM}=$ trabajo marginal; $\mathrm{R}=$ reducción; $\mathrm{A}=$ adelgazamiento.

\subsection{La tecnología lítica en la cuenca del arroyo Chasicó: aprovisionamiento y circulación de rocas}

Las rocas disponibles en el área comprendida por la cuenca del arroyo Chasicó y sus inmediaciones, muestran una amplia variabilidad en cuanto a su distribución, abundancia, accesibilidad, facilidad de extracción y tamaño de las formas base obtenibles. Estas características debieron posibilitar diferentes estrategias para su aprovisionamiento, uso y transporte, redundando en variaciones en el modo en que estas rocas llegaron a formar parte de los conjuntos arqueológicos. Los estudios aquí expuestos, se orientaron a evaluar dichas características, a los fines de alcanzar una primera aproximación a las estrategias de obtención, utilización y transporte de las rocas con mayor representación en los sitios arqueológicos del área.

La cuarcita, con independencia de los grupos identificados, es la roca más utilizada, con frecuencias que en todos los sitios superan el 25\%. Su representación, sin embargo, se incrementa a más del 50\% si se considera el volumen de roca total (i.e. el peso total por materia prima). Los porcentajes más 
bajos de esta materia prima se observan en aquellos sitios en los que se encuentra disponible, en sus inmediaciones, otra roca factible de ser utilizada para la talla de artefactos, como es el caso de las riolitas en el sitio La Montaña y de las RSO en algunos de los sitios de la laguna Chasicó. Dentro de esta amplia categoría de "cuarcita", se observaron variaciones en relación con cada uno de los cuatro grupos descriptos.

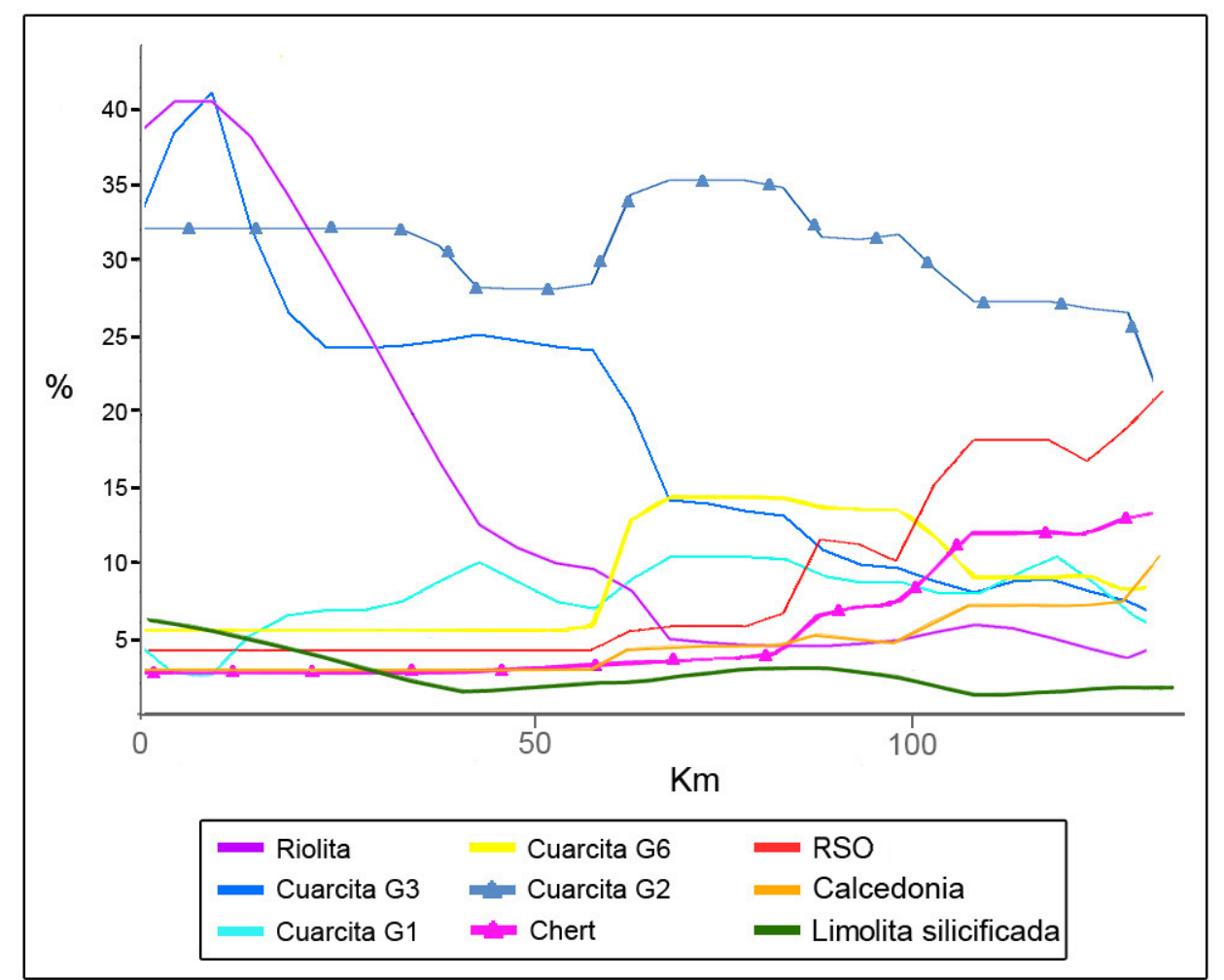

Figura 10.25. Curvas de frecuencia relativa de las materias primas más representadas en los sitios de la cuenca del arroyo Chasicó. El punto $0 \mathrm{~km}$ representa las sierras de Ventania y el extremo opuesto los bajos de Chasicó. Las curvas fueron obtenidas mediante la herramienta interpolate line sobre superficies raster generadas por ordinary kriging - circular semivariogram.

Las cuarcitas G2, son las únicas rocas que se encuentran disponibles, ya sea como afloramientos primarios o secundarios, en las cabeceras y a lo largo de todo el curso del arroyo Chasicó. Esta roca muestra, en todos los sectores de la cuenca, las mayores frecuencias relativas, con su pico máximo en el sector medio (Figura 10.25), así como elevados IC, que inclusive aumentan hacia la cuenca inferior (Figura 10.26). En la mayor parte de los sitios sus tamaños se encuentran entre los más grandes de la muestra. Sin embargo, su presencia disminuye rápidamente cuando no se la encuentra inmediatamente disponible, como es el caso de los sitios localizados en la margen sudoeste de la laguna Chasicó. Sobre esta materia prima se encuentra una proporción relativamente baja de instrumentos (IP altos en todos los sitios), que disminuye hacia la cuenca inferior. Los núcleos son relativamente abundantes, sin formas definidas y con escasos lascados, aumentando su frecuencia hacia la cuenca media e inferior. Las características mencionadas indican que estas rocas fueron obtenidas, prioritariamente, a partir de los rodados disponibles en las inmediaciones de los sitios, para ser utilizadas de manera expeditiva, sin mayor inversión de tiempo y/o esfuerzo en su formatización. En muchos casos, los rodados sin formatización fueron trasladados a los sitios cercanos para ser utilizados como núcleos, percutores, artefactos de molienda y/o yunques, pero su transporte parece limitarse a algunos pocos kilómetros de las fuentes. 


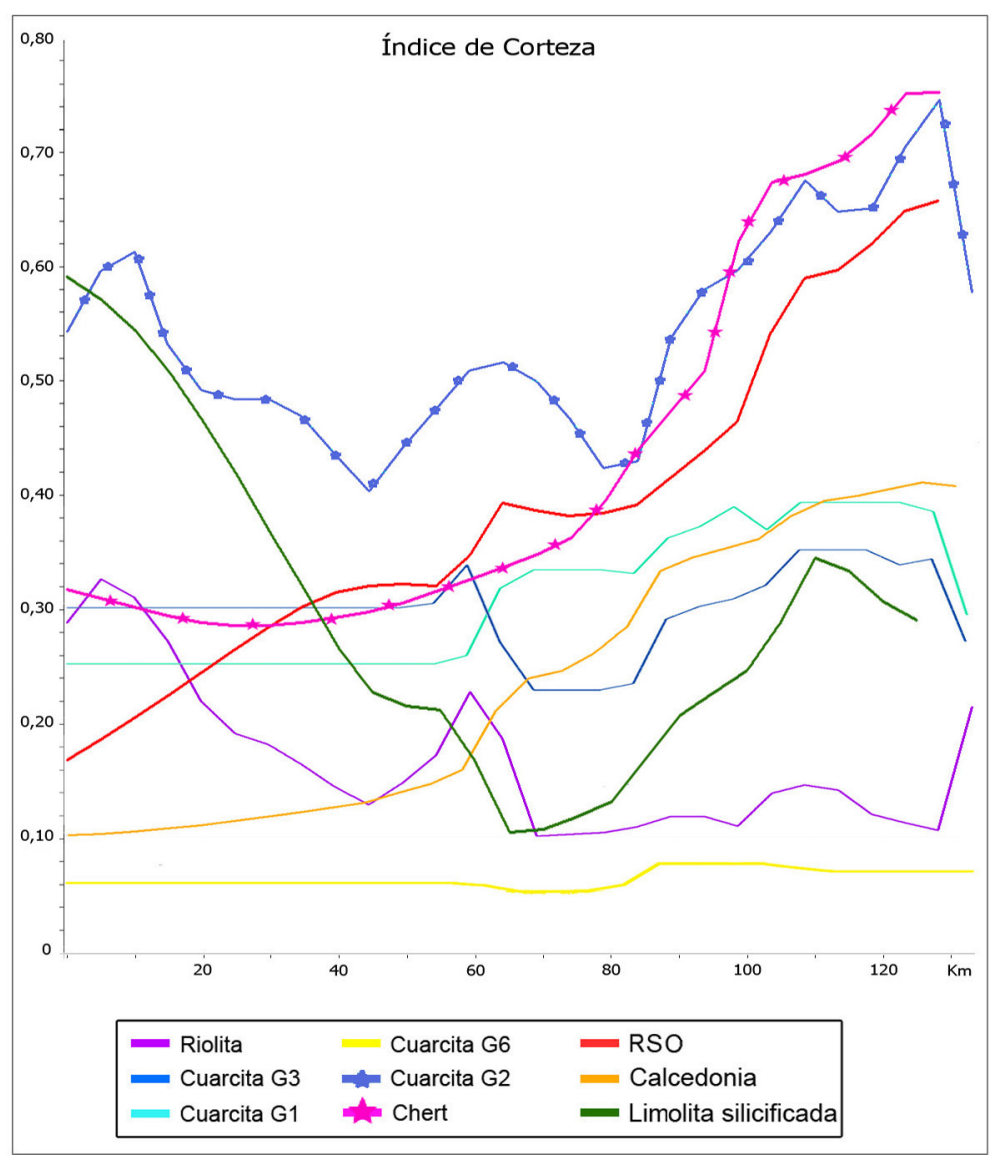

Figura 10.26. Curvas del IC de las materias primas más representadas en los sitios de la cuenca del arroyo Chasicó. El punto $0 \mathrm{~km}$ representa las sierras de Ventania y el extremo opuesto los bajos de Chasicó. Las curvas fueron obtenidas mediante la herramienta interpolate line sobre superficies raster generadas por ordinary kriging circular semivariogram.

Los afloramientos de cuarcita G3 sólo fueron identificados en un sector muy acotado del piedemonte de las sierras de Ventania, en la forma de conglomerados con claras evidencias de explotación antrópica (Arroyo Saudade sitio 2). Los rodados de esta roca se encuentran presentes inmediatamente aguas abajo del conglomerado, siendo observados hasta una distancia de $2 \mathrm{~km}$ del afloramiento más allá de la cual no se los registró durante los muestreos. En los sitios arqueológicos esta materia prima muestra una acentuada disminución en su frecuencia relativa en los primeros kilómetros de distancia a la fuente. Sin embargo, a partir de aproximadamente $20 \mathrm{~km}$ de distancia, la pendiente de su curva de fall-off se vuelve considerablemente más atenuada. El IC muestra valores medios, con pocas variaciones a lo largo de toda la cuenca (Figura 10.26). Esta materia prima se encuentra predominantemente en tamaños pequeños a medianos en la mayor parte de los sitios, con algunos artefactos de tamaños mayores, aunque en bajo número. Los núcleos se presentan con una frecuencia media, en relación con otras materias primas y, de manera similar, el IP tiene también valores medios. Dado el pequeño tamaño de la única fuente identificada y la alta proporción que esta roca presenta en la mayor parte de los sitios, el aprovisionamiento debió involucrar otras fuentes primarias y/o secundarias. En este sentido, la poca variación en el IC y la alta proporción de esta roca, principalmente en los conjuntos de la cuenca media, estarían indicando un aprovisionamiento parcial a través de rodados, a partir de los cuales se obtuvieron formas base de manera expeditiva e instrumentos escasamente formatizados.

Las cuarcitas G1, en cambio, se encuentran representadas siempre en baja frecuencia y con índices de corteza medios, ambos en aumento hacia la cuenca media (figuras 10.25 y 10.26). Los núcleos se hallan presentes en todos los sectores de la cuenca, con frecuencias medias a bajas en relación con otras 
materias primas, pero altas en función de la representación de esta roca en los sitios, el IP en cambio, es alto en la cuenca superior pero disminuye hacia los sectores medio e inferior. Estas características, particularmente las variaciones en su frecuencia e IC, con aumentos hacia la cuenca media, pueden relacionarse con un aprovisionamiento a partir de rodados presentes en el cauce medio del río Sauce Chico (distante de la cuenca del arroyo Chasicó poco más de $10 \mathrm{~km}$ en su sector medio), los que parecen haber sido transportados tanto en la forma de núcleos como de instrumentos formatizados.

Las cuarcitas G6, por otra parte, muestran un comportamiento algo diferente al de las otras variedades de esa roca. En los sitios localizados en las sierras se las encuentra en proporciones muy bajas, aumentando su frecuencia hacia los sectores medio e inferior de la cuenca, donde alcanza valores promedio cercanos al 15\% (Figura 10.25). Su volumen relativo, en cambio, se mantiene en valores cercanos al 1\%, con la única excepción de un sitio en la laguna Chasicó. Es decir que, si bien la frecuencia de esta roca aumenta hacia la cuenca inferior, el tamaño de los artefactos es siempre predominantemente pequeño. Por otra parte, el IC se mantiene muy bajo, siendo siempre la roca con menor remanente de corteza en sus artefactos (Figura 10.26). Estas características son concordantes con un aprovisionamiento a partir de fuentes, al menos predominantemente, primarias que no se encuentran en las inmediaciones de los sitios analizados y que, probablemente, se localicen fuera de los límites de la cuenca. Sus características son similares a aquellas descriptas para la formación Sierras Bayas en las sierras de Tandilia, pero macroscópicamente también se asemejan a algunas de las descriptas en los afloramientos del arroyo Saudade, difiriendo de estas, principalmente, por el color. Las cuarcitas G6 pudieron haber sido obtenidas en los afloramientos primarios de Tandilia, en los depósitos antrópicos secundarios del área Interserrana, en afloramientos puntuales de las sierras de Ventania o bien en una conjunción de estos lugares. Las implicancias sobre las estrategias de movilidad y uso del ambiente, en cada caso, son muy diferentes, siendo indispensable aumentar los estudios tendientes a caracterizar con mayor precisión la variabilidad de rocas cuarcíticas presentes en Ventania que, como se ha expuesto, es más amplia de lo previamente supuesto. El IP en las cuarcitas G6 es medio, similar al de las cuarcitas G3, en tanto los núcleos son muy escasos, lo que lleva a proponer que esta roca habría circulado predominantemente como lascas y artefactos formatizados.

La riolita muestra una rápida y constante disminución -en su frecuencia y volumen- en función de la distancia a la fuente, hasta alcanzar valores cercanos al 5\%, con los que se mantiene en la mayor parte de los sitios localizados a una distancia superior a los $60 \mathrm{~km}$ (Figura 10.25). Su representación también disminuye rápidamente cuando otras materias primas se encuentran presentes en las inmediaciones del sitio, cómo es el caso de aquellos ubicados en las sierras, sobre afloramientos primarios de cuarcitas, donde la riolita se encuentra en proporciones inferiores a lo esperado únicamente en función de la distancia. Su patrón de disminución en la frecuencia, así como los IC, mayormente bajos en todos los sitios con excepción de aquellos más cercanos a las fuentes (Figura 10.26), son concordantes con lo esperado para un aprovisionamiento a partir de fuentes primarias y espacialmente acotadas (i.e. puntuales). Esto es coherente también con la escasa representación de rodados de riolita observada en las prospecciones realizadas en el cauce de los arroyos y en los conglomerados rojos (ver Capítulo 6; Oliva 1996). El IP es relativamente bajo en todos los sectores y particularmente en la cuenca media e inferior, no habiéndose registrado núcleos en ninguno de los sitios analizados, con excepción de uno de pequeño tamaño recuperado en la cuenca inferior del arroyo Chasicó. Considerando estas características, puede proponerse que esta materia prima habría circulado, principalmente, en forma de lascas y/o artefactos formatizados. 
La limolita silicificada presenta frecuencias muy bajas, de alrededor del 5\%, en todos los sitios de la cuenca, con valores levemente más altos en las cabeceras (Figura 10.25). Sus volúmenes son también muy bajos, en tanto el IC muestra los valores más elevados en las cabeceras y en la cuenca inferior (Figura 10.26). Los núcleos son muy escasos, pequeños y generalmente agotados -presentes mayoritariamente en la cuenca superior- en tanto el IC es medio, con valores máximos en la cuenca inferior. Si bien los valores de corteza muestran un patrón menos interpretable que en otras materias primas, las restantes características de estos conjuntos (e.g. frecuencia, tamaños, clases artefactuales) pueden ser relacionadas con un aprovisionamiento a partir de fuentes primarias o secundarias puntuales localizadas fuera de los límites de la cuenca, que circularon a través del traslado de lascas y artefactos formatizados y, en menor proporción, el transporte de núcleos, principalmente en la zona de las cabeceras.

Las curvas de las RSO y la de los cherts muestran un patrón similar, con valores levemente superiores para las primeras, en el que las mayores frecuencias relativas se encuentran en la cuenca inferior, coincidentemente con la presencia de potenciales fuentes de aprovisionamiento, disminuyendo progresivamente al aumentar la distancia a estas (Figura 10.25). Dichas rocas presentan frecuencias iniciales inferiores a las observadas para las riolitas, cuarcitas G2 y cuarcitas G3, pero IC elevados, que descienden rápidamente hasta alcanzar valores intermedios, levemente menores en las RSO (Figura 10.26). Las RSO muestran, en relación con las restantes materias primas, IP medios, en tanto el chert presenta IP bajos o nulos en el sector medio y superior y muy altos en la cuenca inferior, donde es la materia prima con mayor cantidad de artefactos formatizados. Los núcleos en estas dos materias primas (incluyendo también los nódulos en el caso de los cherts) son muy abundantes en la cuenca inferior, particularmente en la laguna Chasicó, pero muy escasos en los restantes sectores. Todos estos indicadores, junto con la disponibilidad en las cercanías de los sitios tanto de rodados silíceos como de fuentes potenciales de chert, lleva a proponer un aprovisionamiento predominantemente local, donde la menor frecuencia relativa inicial con respecto a las cuarcitas G2 y cuarcitas G3 se debería a la mayor diversidad de rocas accesibles localmente, la disponibilidad más localizada en el caso de los cherts y el pequeño tamaño de los rodados en el caso de las RSO. No se descarta, sin embargo, que algunas de estas rocas hayan sido obtenidas a mayores distancias. En el caso de las RSO, en sectores del Manto Tehuelche localizados al sur y oeste, donde los rodados presentan mayor tamaño, y en el caso de los chert, en afloramientos localizados en el salitral Negro, en el valle Argentino -zona del Carancho- o, inclusive, en la meseta del Fresco (Berón 2006). El transporte de estas rocas se habría dado, principalmente, bajo la forma de nódulos y artefactos formatizados, particularmente en el caso del chert, roca sobre la que no se registraron lascas con filos naturales utilizables o con rastros complementarios. Se lo encuentra casi de manera exclusiva bajo la forma de artefactos formatizados, lascas de pequeño tamaño, núcleos y nódulos naturales.

La calcedonia por último, se encuentra en muy bajos porcentajes en toda la cuenca, pero su frecuencia y su IC aumentan hacia la cuenca inferior (figuras 10.25 y 10.26). Los núcleos son muy escasos, presentes únicamente en la cuenca inferior y media (lagunas de Chasicó y Los Chilenos) y el IP muestra valores medios en comparación con las restantes materias primas. Estas características, junto a los tamaños representados, son concordantes con un abastecimiento que haya incluido, además del Manto 
de Rodados Tehuelche inmediatamente disponible, otras fuentes, primarias y/o secundarias localizadas probablemente hacia el sur y oeste de la laguna Chasicó, en las que se pudiesen obtener formas base de mayor tamaño que fueron trasladadas, principalmente, en la forma de lascas y artefactos formatizados.

A modo de síntesis, puede decirse que el registro lítico de la cuenca del arroyo Chasicó se caracteriza por el predominio de materias primas obtenidas dentro de los límites de la cuenca o en sus cercanías, con un alto aprovechamiento de fuentes secundarias. Las rocas inmediatamente disponibles o locales cercanas (obtenibles hasta $30 \mathrm{~km}$ de distancia) se encuentran representadas en los conjuntos arqueológicos, por porcentajes de entre $40 \%$ y $80 \%$, en tanto las no locales poseen una representación más variable, de entre $4 \%$ y $40 \%$. La mayor proporción de las materias primas no locales proviene de fuentes situadas a una distancia máxima de $130 \mathrm{~km}$ en línea recta a partir de cualquier punto en la cuenca. Todas aquellas rocas con fuentes de aprovisionamiento (utilizadas o potenciales) localizadas dentro de los límites de la cuenca, muestran un rápido descenso en su frecuencia durante los primeros kilómetros, hasta alcanzar valores del orden del 3-5\% con los que se mantienen en la mayor parte de los sitios localizados a distancias superiores a los $30 \mathrm{~km}$ del área de abastecimiento (Figura 10.25).

A partir del análisis de las curvas de fall-off de las cuarcitas G2, cuarcitas G3 y riolitas, materias primas más representadas, pueden plantearse algunas hipótesis acerca de las estrategias de aprovisionamiento empleadas (Figura 10.27). Estas curvas muestran comportamientos claramente diferenciables entre sí. La curva de las cuarcitas G2 exhibe un comportamiento homogéneo, manteniéndose siempre por sobre el 25\%. Esto puede relacionarse con que el curso del arroyo Chasicó consiste en una extensa fuente secundaria difusa de este tipo de cuarcitas. De este modo, la curva solo estaría alejándose de la fuente en el sector inferior, en aquellos sitios localizados sobre las márgenes de la laguna Chasicó. La curva de riolitas, en cambio, muestra un patrón concordante con una disminución de las frecuencias a medida que aumenta la distancia a la fuente. Esto coincide con un aprovisionamiento a partir de los afloramientos puntuales localizados en las nacientes de los arroyos Alfalfa y Cochenleufú Chico, corroborando que esta fue la única fuente de aprovisionamiento de esta roca. Por otra parte, la curva de las cuarcitas G3 presenta un patrón intermedio entre las riolitas y las cuarcitas G2. Su curva decrece hacia la cuenca inferior, con una pendiente más acentuada que la de las riolitas en el sector superior pero que, a partir de los $25 \mathrm{~km}$ aproximadamente, muestra una meseta y luego un descenso más suave, manteniéndose en mayores proporciones que las riolitas. Esto puede relacionarse con un aprovisionamiento que, a diferencia de las riolitas, no se llevó a cabo únicamente a partir de fuentes primarias puntuales localizadas en las cabeceras, sino que consistió en un aprovisionamiento mixto, que pudo haber incluido también el uso de rodados disponibles en el cauce del arroyo. Si bien durante las prospecciones en el cauce de los arroyos esta materia prima mostró una baja frecuencia, la recolección de rodados parece haber jugado un rol importante en el aprovisionamiento de este tipo de roca, aunque esto haya implicado un mayor tiempo de búsqueda. El uso de rodados también parece estar evidenciado por la curva del IC, la cual muestra valores medios, con pocas variaciones a lo largo de toda la cuenca, reflejando que, al menos parte de estas rocas, habrían sido obtenidas en la forma de rodados, principalmente en los sectores medio e inferior (Figura 10.26). 


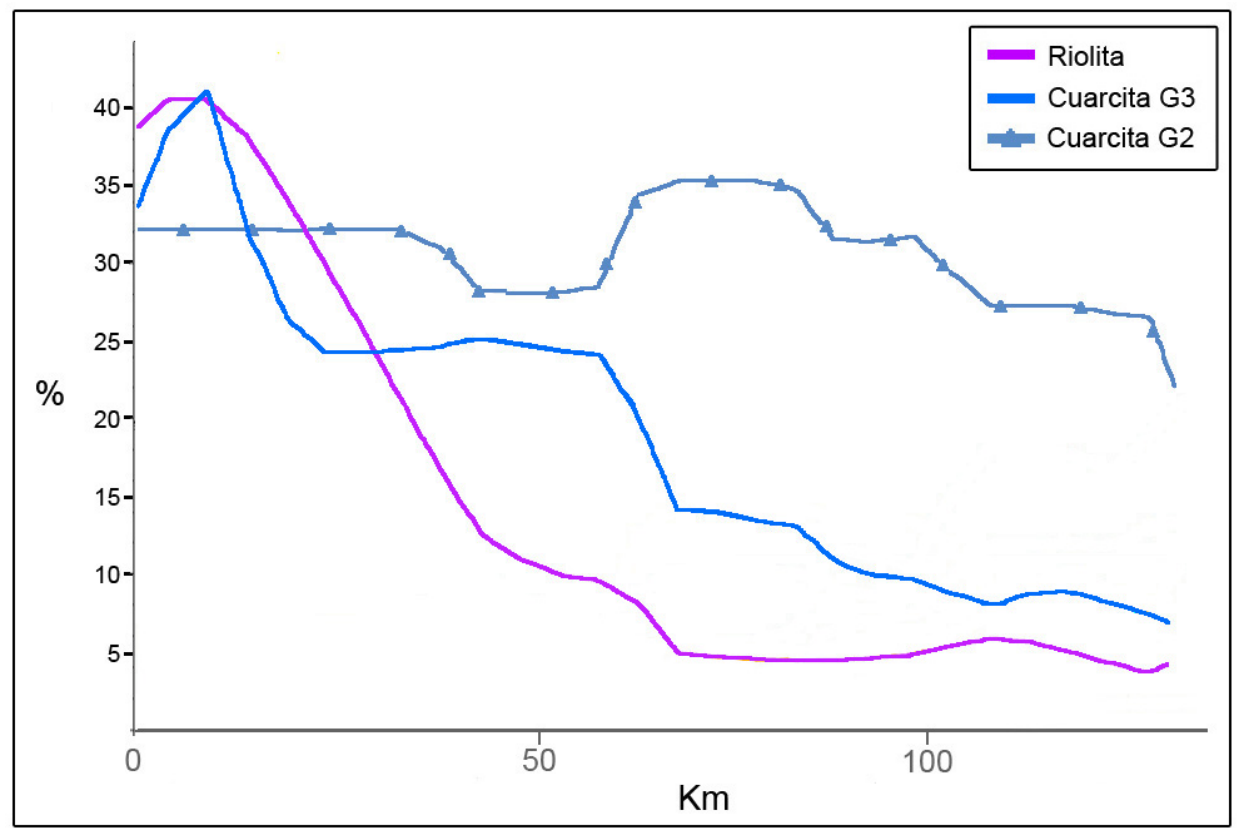

Figura 10.27. Curvas de frecuencia relativa de cuarcita G2, cuarcita G3 y riolita. El punto $0 \mathrm{~km}$ representa las sierras de Ventania y el extremo opuesto los bajos de Chasicó. Las curvas fueron obtenidas mediante la herramienta interpolate line sobre superficies raster generadas por ordinary kriging - circular semivariogram.

En otras palabras, para la cuarcita G2 y la cuarcita G3 puede inferirse un acceso directo a fuentes primarias y secundarias, con un marcado uso de las fuentes secundarias distribuidas a lo largo de la cuenca del arroyo Chasicó, explotadas mediante recolección superficial. Sin embargo, mientras que las cuarcitas G2 parecen haber sido casi enteramente explotadas de esta forma, las cuarcitas G3 exhiben un patrón de aprovisionamiento con un componente mayor de canteo. Las riolitas, en cambio, fueron casi exclusivamente obtenidas por canteo en fuentes primarias puntuales. De este modo, el análisis de las tendencias espaciales a partir de superficies continuas y de la forma de las curvas de fall-off permite maximizar la información arqueológica disponible a los fines de generar expectativas sobre la localización de fuentes y tipos de fuentes permitiendo orientar mejor la prospección. Esto es importante en aéreas grandes, donde la posibilidad de hacer muestreos exhaustivos y detallados, presenta ciertas dificultades.

La representación de cada materia prima en los sitios más cercanos a las fuentes de aprovisionamiento es variable (Figura 10.28), mostrando pendientes suaves en algunos casos y disminuyendo más abruptamente en otros. Esta variación en la proporción con que una materia prima se encuentra presente en los sitios cercanos a la fuente (i.e. localizados a menos de $30 \mathrm{~km}$ ) parece responder principalmente a la disponibilidad local de otras materias primas alternativas, la extensión de la fuente y el tamaño de las formas base disponibles y, de manera secundaria, a la calidad para la talla de la roca. Es decir que, al momento de la selección de una roca se priorizan las características de las fuentes (e.g. extensión, formas base disponibles) por sobre las propiedades de las rocas (e.g. calidad para la función requerida). Las propiedades de las rocas, en cambio, sí estarían relacionadas con el modo en que se formatizaron los instrumentos. Esto puede observarse en el aumento hacia la cuenca inferior del IB, particularmente en los sitios localizados sobre las márgenes de la laguna Chasicó (Figura 10.29). En estos sitios, los valores más altos de bifacilidad se encuentran en RSO y, particularmente, en chert, materia prima utilizada casi de manera exclusiva para la fabricación de instrumentos bifaciales. 


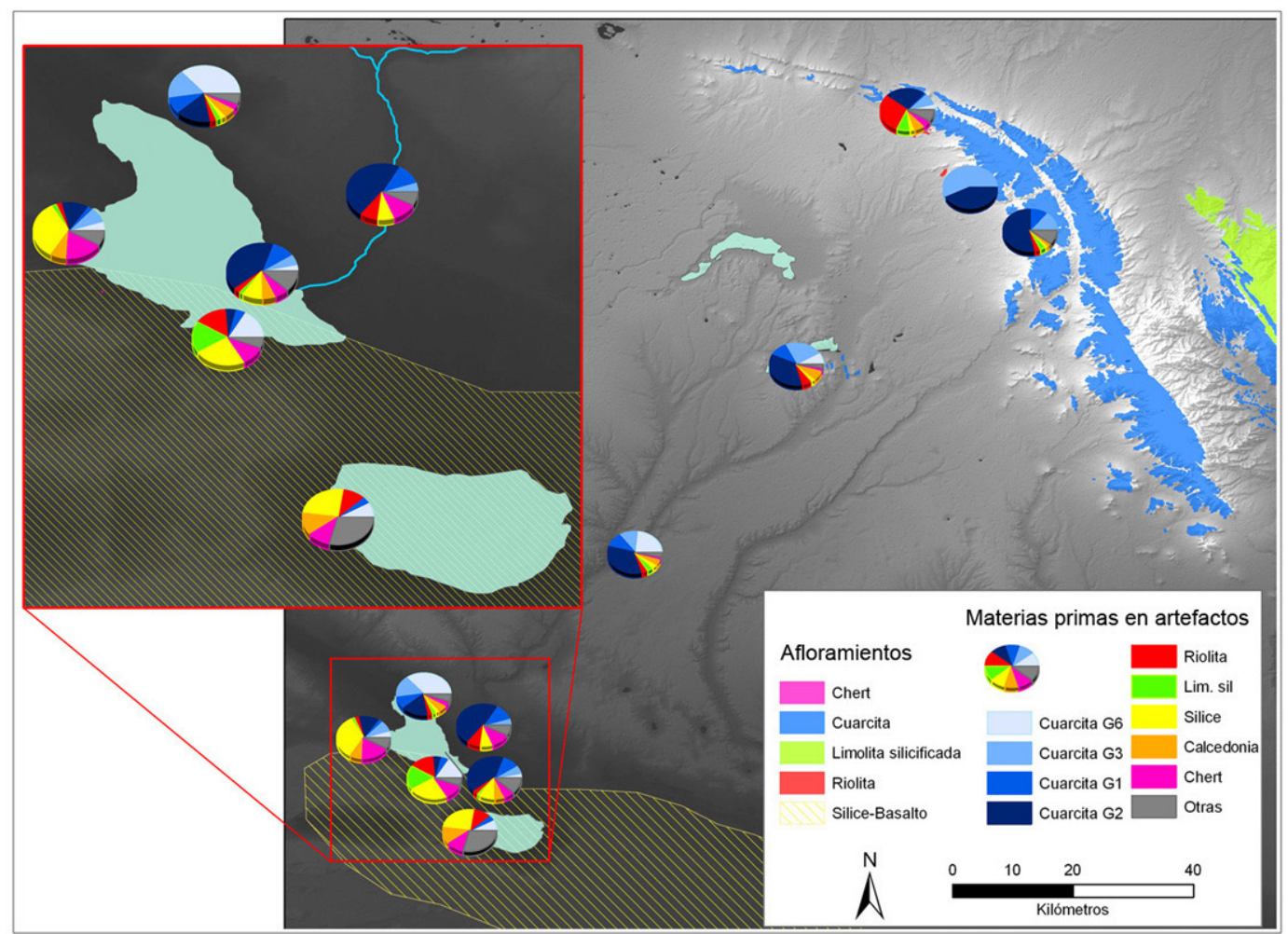

Figura 10.28. Variaciones en las proporciones de materias primas de los sitios arqueológicos de la cuenca del arroyo Chasicó en relación con la disponibilidad local de materias primas líticas.

El mayor números de filos bifaciales en relación con los unifaciales puede responder a diversos factores entre los que se encuentra el predominio, hacia la cuenca inferior, de tecnologías diferentes ya sea como consecuencia de la realización de actividades particulares (para las que fueron preferibles este tipo de filos) o bien producto de tradiciones tecnológicas con mayor proporción de bifacialidad. Esto último ya sea como consecuencia de la incorporación de la laguna dentro de rangos de acción de grupos con tecnologías diferentes (en algún momento del Holoceno tardío) o bien de una mayor vinculación (e.g. a través de redes de intercambio) con poblaciones que utilizaron en mayor proporción la tecnología bifacial (e.g. grupos del NE de Patagonia). Las características de las materias primas disponibles también debieron influir en la decisión acerca de cómo llevar a cabo la formatización. En este sentido, los chert se presentan generalmente con formas tabulares de pequeño espesor y con cortezas craqueladas, por lo que la reducción y el trabajo marginal bifacial debieron resultar los modos óptimos para formatizar los instrumentos en la mayor parte de los casos. Probablemente una conjunción de estos factores (i.e. limitaciones y posibilidades impuestas por las materias primas locales, requerimientos particulares y presencia de artefactos formatizados a partir de tecnologías diferentes a las preponderantes en el sector medio y superior) se encuentran involucrados en la conformación de los conjuntos representados. La importancia de cada uno de estos factores deberá evaluarse por medio de una mejor caracterización de las fuentes locales de aprovisionamiento de rocas silíceas, de la realización de estudios experimentales y de la continuidad en los análisis regionales orientados a responder estos interrogantes.

La clase técnica en cambio, no muestra variaciones en relación con la materia prima, predominando siempre los instrumentos confeccionados mediante trabajo marginal, es decir, con poca inversión en su manufactura. Por último, la baja representación de los núcleos en todos los conjuntos, es concordante con 
estrategias de circulación de rocas a través de lascas e instrumentos y, sólo en menor frecuencia, núcleos. Únicamente en algunos sectores del paisaje, se observan evidencias de estrategias de aprovisionamiento de lugares (sensu Kuhn 1994), como caches de materias primas, grandes núcleos y/o acumulaciones de artefactos de molienda.

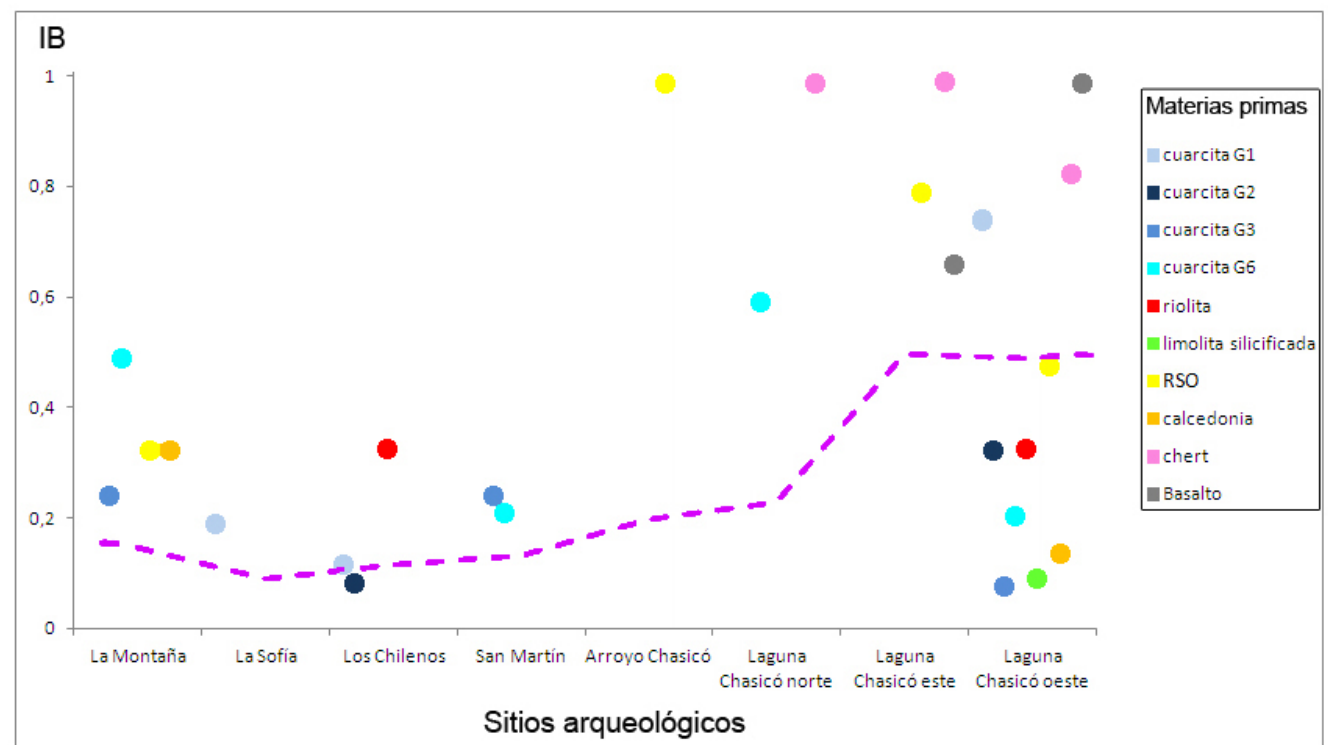

Figura 10.29. Índice de bifacialidad por materia prima en filos. La línea violeta punteada representa la tendencia espacial del índice de bifacialidad por sitio (considerando todas las materias primas en conjunto). El ordenamiento de los sitios sigue el eje de la cuenca, desde las cabeceras (izquierda) hasta su parte distal (derecha).

En cuanto a los artefactos manufacturados por picado, abrasión y/o pulido o modificados por uso, estos corresponden, en mayor proporción, a instrumentos relacionados con actividades de molienda. La mayor cantidad de ellos fue recuperada en la cuenca inferior, concordantemente con lo esperable en relación con el modelo planteado en el Capítulo 5. Estos fueron confeccionados predominantemente (75\% de los artefactos completos recuperados) sobre areniscas rionegrenses y cuarcitas, rocas inmediatamente disponibles. Entre las materias primas alóctonas se encuentran granitos, limolitas, areniscas micáceas y rodados del Manto Tehuelche de más de $10 \mathrm{~cm}$ de diámetro, cuyas probables fuentes de abastecimientos se encuentran, al igual que para el caso de los artefactos confeccionados por talla, a una distancia que no supera los $130 \mathrm{~km}$ lineales.

Los artefactos de molienda superiores (o manos) son más abundantes que los inferiores, en una proporción de 2 a 1, encontrándose a su vez, una mayor frecuencia de artefactos con superficies activas planas o cóncavo/convexo atenuadas, situación que ha sido descripta también para otros sectores cercanos a la cuenca (Ávila 2009). Esos artefactos muestran evidencias de mantenimiento, ya sea por piqueteado de sus superficies o, más comúnmente, mediante rotaciones que administran el desgaste (Babot 2004). Los artefactos superiores son, en la mayor parte de los casos, de pequeño tamaño, generalmente factibles de ser agarrados con una sola mano y, en pocos casos, muestran rasgos complementarios formatizados a los fines de facilitar el agarre. Estas características se corresponden con contextos en los que las tareas de molienda aún no insumen una gran cantidad de tiempo y el volumen de materail procesado es relativamente pequeño. La mayor parte de los artefactos muestra poca inversión en su manufactura, encontrándose sólo algunas piezas con mayor inversión entre las materias primas no locales. En este sentido, pueden mencionarse las riolitas ignimbríticas, materia prima sobre la que se registraron tres 
artefactos con una alta inversión de trabajo en su manufactura, las que pudieron haber formado parte de redes de intercambio de bienes de alto valor. No se descarta que, tratándose de sitios en superficie (al menos en un caso con algunos materiales asignables a momentos de contacto), algunos de estos artefactos de gran tamaño y procedentes de fuentes distante hayan podido ser transportados por medio de la utilización del caballo.

\subsection{El paisaje lítico en el contexto del sur de la Región Pampeana y NE de Patagonia}

Con el objetivo de evaluar los patrones de distribución de materias primas en escalas amplias, se adoptó el concepto de paisaje lítico (definido en Barrientos et al. 2014), entendido como un concepto teórico que permite su modelado por medio de superficies continuas ${ }^{2}$. La generación de modelos sobre la distribución espacial de las principales materias primas líticas permite observar que las RSO muestran una distribución espacial en la que los mayores porcentajes son altamente congruentes con la distribución del Manto de Rodados Tehuelches. Los picos en su frecuencia se encuentran en el valle medio de los ríos Negro y Colorado, en concordancia con el área en que el manto de rodados es más espeso y formado por rodados de mayor tamaño. A su vez, las curvas de fall-off menos abruptas, se asocian con la presencia de depósitos menores de esta formación, que se extienden más allá de los límites del afloramiento principal (Figura 10.30).

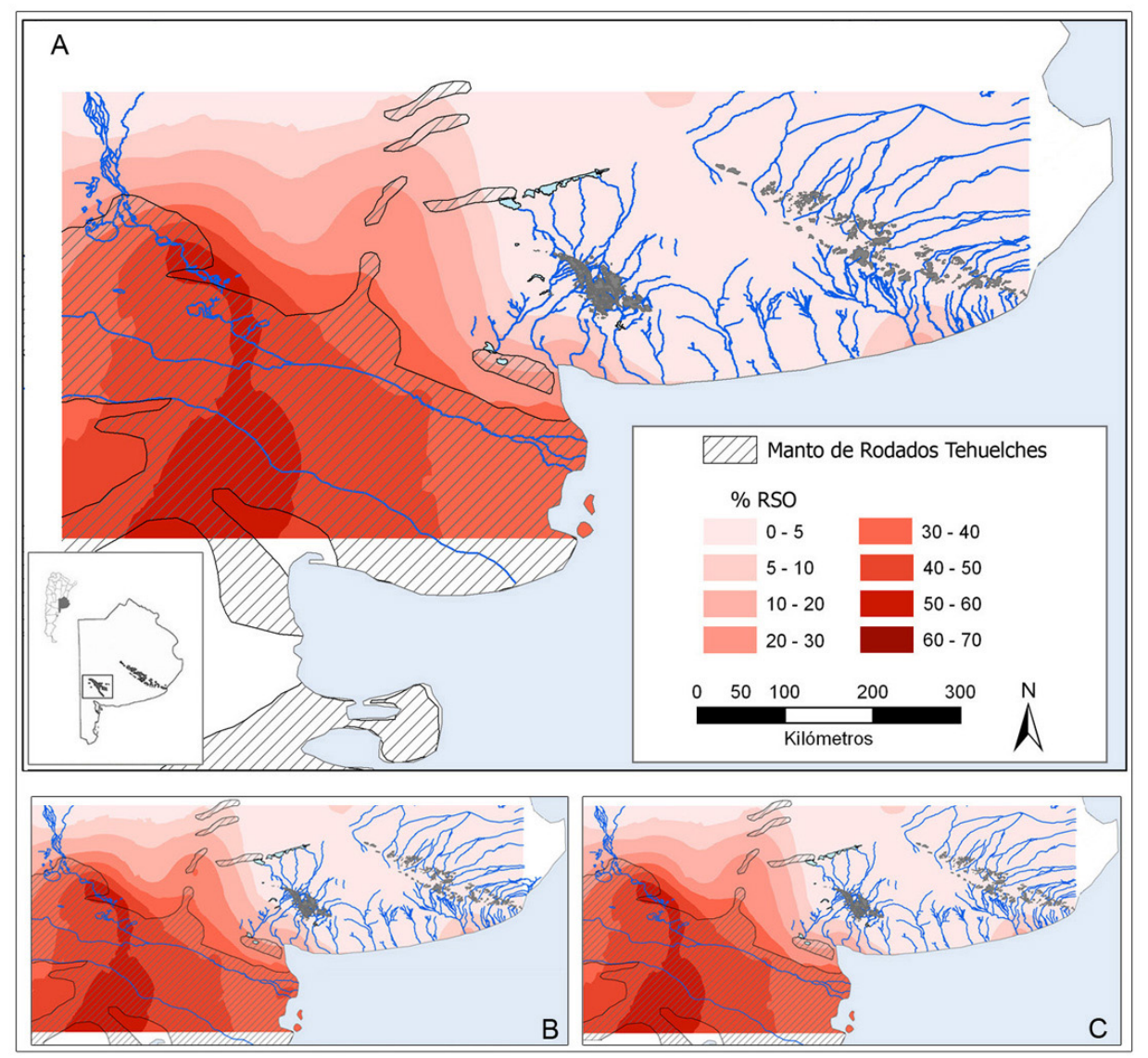

Figura 10.30. A- Modelo espacial continuo de la distribución de frecuencias relativas de RSO en la forma de artefactos en el sur de la Región Pampeana y NE de Patagonia $(n=211)$. B y C comparación entre el modelo espacial generado sin considerar los sitios de la cuenca del arroyo Chasicó, presentado en el Capítulo 5 (B) y el generado considerando los sitios de la cuenca (C).

2 Para un detalle de la metodología utilizada en la generación de estas superficies ver el capítulo 5. 
Las cuarcitas, consideradas globalmente sin discriminar variedades, se encuentran concentradas, principalmente, alrededor de los afloramientos primarios de Tandilia y Ventania y en el sector medio del área interserrana, con la zona de mayor frecuencia en la cuenca del río Sauce Grande. Esta roca muestra curvas de fall-off más suaves hacia el oeste de las sierras de Ventania, donde la disponibilidad de rocas para la talla es menor. Su frecuencia en cambio, disminuye más abruptamente hacia la costa atlántica y el extremo noroccidental de Tandilia (Figura 10.31), en relación con la presencia de otras materias primas disponibles localmente (rodados costeros y calcedonias respectivamente).

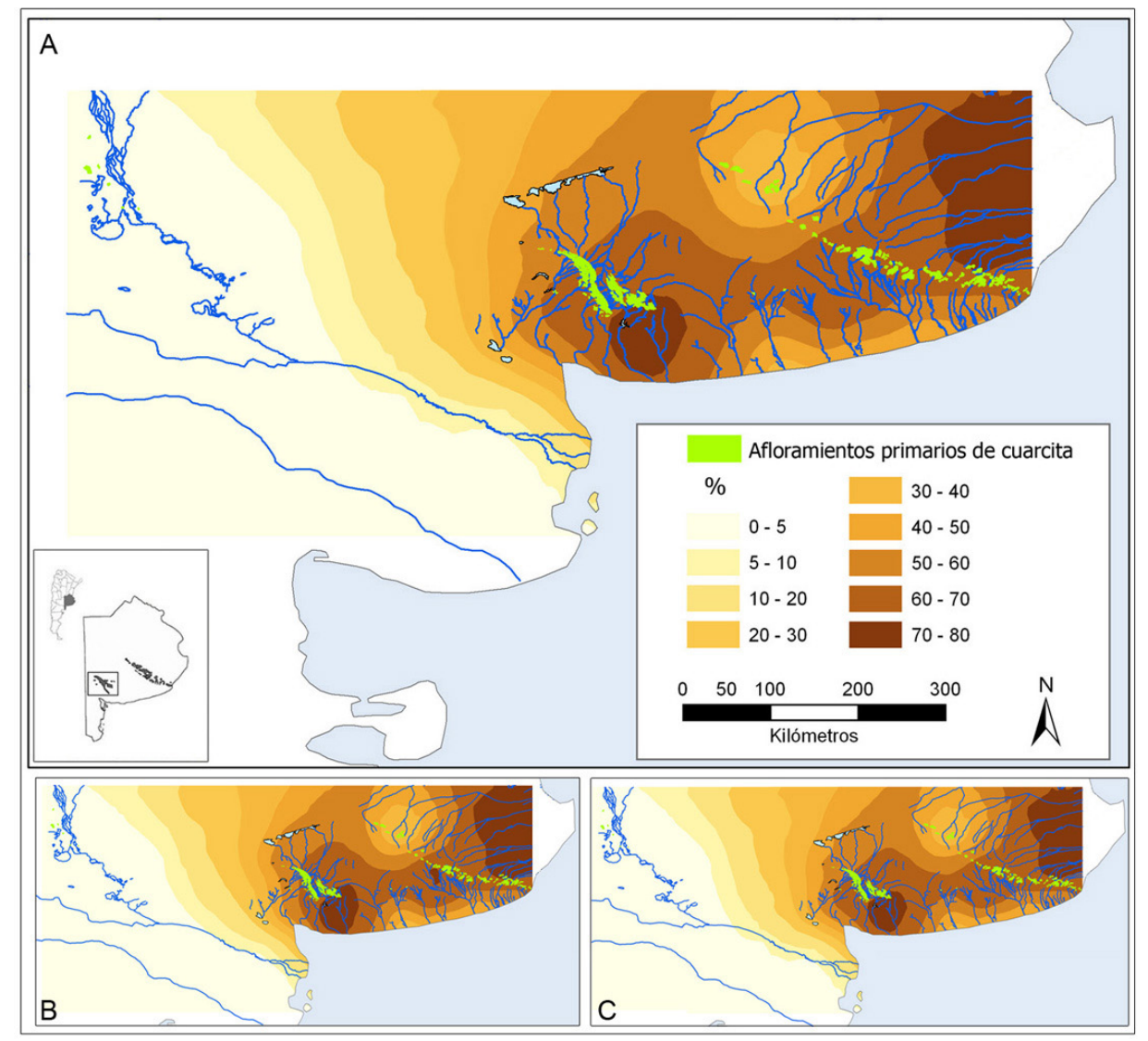

Figura 10.31. A- Modelo espacial continuo de la distribución de frecuencias relativas de rocas cuarcíticas en la forma de artefactos en el sur de la Región Pampeana y NE de Patagonia (n=211). B y C comparación entre el modelo espacial generado sin considerar los sitios de la cuenca del arroyo Chasicó, presentado en el Capítulo 5 (B) y el generado considerando los sitios de la cuenca (C).

Las calcedonias, por último, son las rocas más ubicuas en el paisaje, sugiriendo la presencia de fuentes en diversos puntos. El modelo generado muestra la existencia de al menos dos fuentes con mayor intensidad de uso, una de ellas corresponde a los afloramientos descriptos en el sector noroccidental de las sierras de Tandilia, en tanto la segunda, sugiere la presencia de fuentes no identificadas hasta la fecha en el Oeste de la Región Pampeana, a estas se agregan posibles fuentes menores localizadas hacia el sudeste, en la cuenca inferior del río Colorado. Esta roca muestra una baja representación en el área de estudio, siendo un recurso secundario en la mayor parte de los sitios. Su distribución muestra, que no sería esperable encontrar fuentes de aprovisionamiento de esta materia prima en las sierras de Ventania o bien sus fuentes habrían sido poco explotadas (Figura 10.32). 


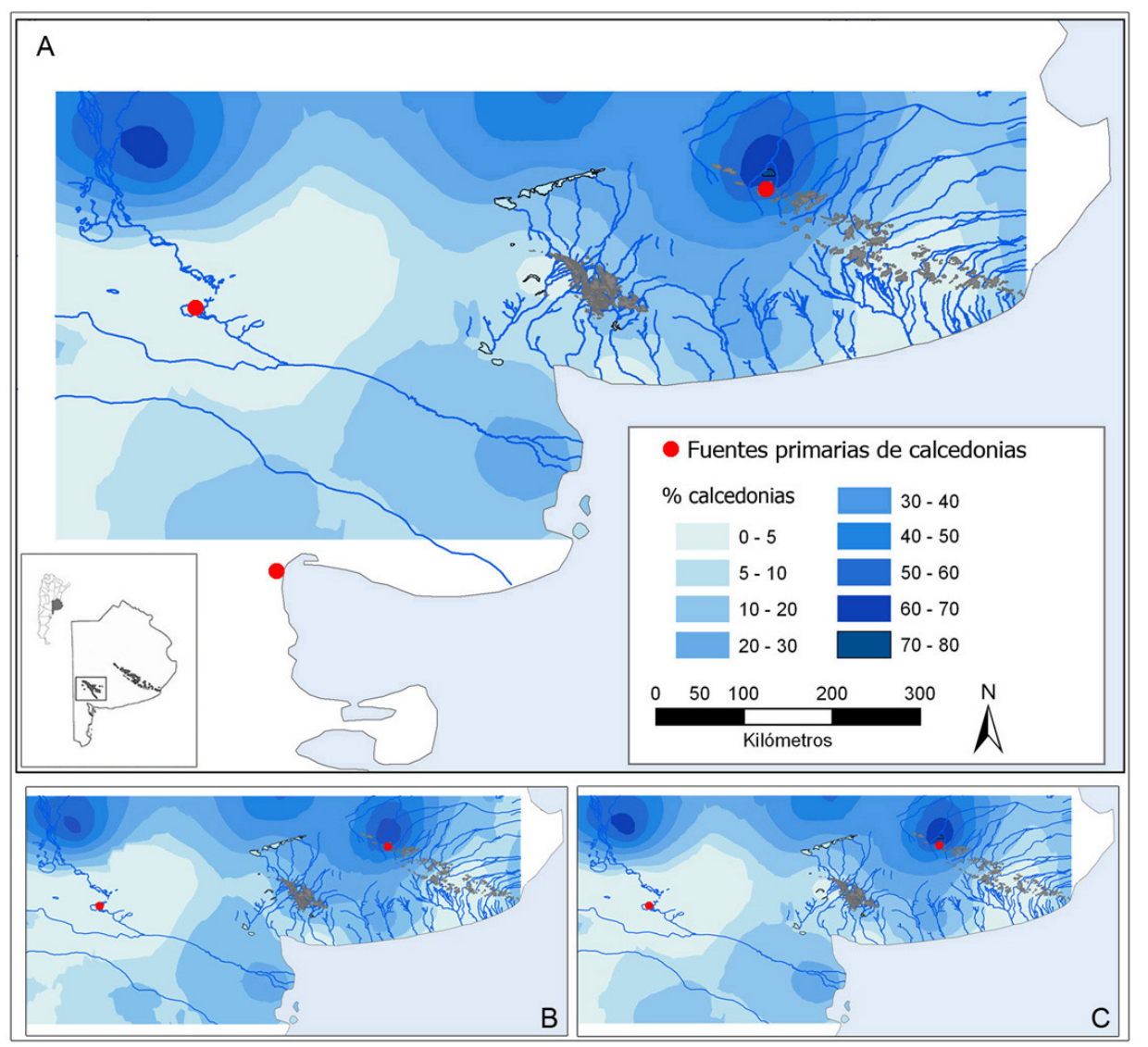

Figura 10.32. A- Modelo espacial continuo de la distribución de frecuencias relativas de calcedonias en la forma de artefactos en el sur de la Región Pampeana y NE de Patagonia $(n=211)$. B y C comparación entre el modelo espacial generado sin considerar los sitios de la cuenca del arroyo Chasicó, presentado en el Capítulo 5 (B) y el generado considerando los sitios de la cuenca (C).

Si se comparan los modelos generados considerando la información obtenida en la cuenca del arroyo Chasicó con aquellos presentados en el Capítulo 5, en los que esta información fue excluida, puede observarse que existe una buena correspondencia entre ambos conjuntos de modelos. Esto implica que la modelización de los paisajes líticos mediante la técnica empleada tiene un fuerte poder descriptivo inclusive para áreas pobremente muestreadas, cuando estas se encuentran rodeadas por sectores suficientemente muestreados. Por otra parte, las variaciones observadas entre unos y otros nos hablan acerca de las particularidades del registro lítico de la cuenca, en relación con la disponibilidad local de rocas y las estrategias empleadas para su obtención. Particularmente, se observa que las cuarcitas se encuentran representadas, en la cuenca, por porcentajes mayores a los esperados, en tanto calcedonias y RSO muestran frecuencias relativas menores a las predichas por los modelos del Capítulo 5. Esto estaría respondiendo a una mayor disponibilidad local de rocas cuarcíticas, dada por su presencia en el cauce del arroyo, inclusive en el sector inferior, con tamaños aptos para su utilización tanto en artefactos manufacturados por talla como en los elaborados por picado, abrasión y/o pulido. 

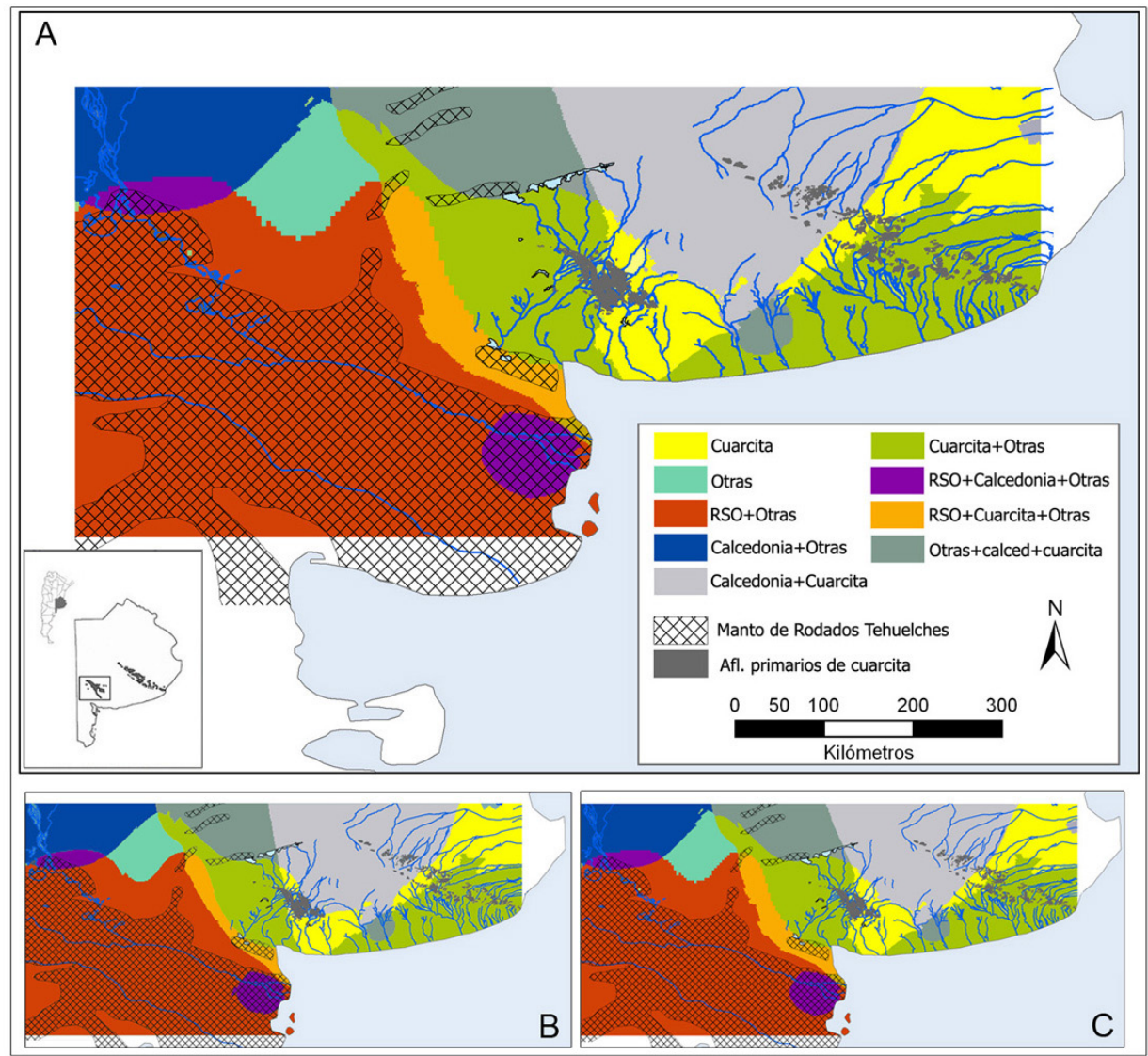

Figura 10.33. A) Modelo generado a partir de datos extraídos de las figuras 10.30 a 10.32 en el que se representa la distribución espacial de materias primas representadas con valores superiores al 20\%. B y C comparación entre el modelo generado sin considerar los sitios de la cuenca del arroyo Chasicó, presentado en el Capítulo 5 (B) y el generado considerando los sitios de la cuenca (C).

La combinación de las distintas superficies generadas (RSO, cuarcitas, calcedonias y otras rocas) muestra que la franja de superposición en cuarcitas y RSO, se extiende por una zona que coincide aproximadamente con el límite entre las regiones Pampeana y Patagónica. En el área de estudio, el límite septentrional del 20\% concuerda con la distribución máxima de la RSO, en tanto el límite meridional de las cuarcitas, se localiza $40 \mathrm{~km}$ más allá de su área máxima de dispersión. Esto estaría evidenciando, al menos en esta zona, un mayor transporte de las rocas cuarcíticas, en relación con las RSO (Figura 10.33). El curso del arroyo se encuentra comprendido en el área dominada por cuarcitas y otras materias primas, en tanto la laguna Chasicó se localiza en la zona donde las materias primas con porcentajes superiores o iguales al 20\% corresponden a cuarcitas, RSO y otras materias primas (Figura 10.33). Dicha franja tiene un ancho uniforme de aproximadamente $40 \mathrm{~km}$, evidenciando un límite difuso entre cuarcitas y RSO y un reemplazo progresivo en el uso de una materia prima por otra. Esto se puede observar más claramente analizando las curvas de las cuarcitas y RSO, materias primas con fuentes de abastecimiento localizadas las primeras en la Región Pampeana y las segundas en Patagonia (Figura 10.34). En este sentido, si bien la forma de la curvas de disminución en la frecuencia puede responder a 
múltiples factores (Brantingham 2006; Hodder y Orton 1976), la presencia de patrones de disminución regulares y estrechamente relacionados con la disponibilidad local de rocas no permite proponer la existencia de barreras o fronteras claramente definidas, sino más bien la existencia de estrategias de uso del espacio continuas (Soja 1971; Barrientos et al. 2014).

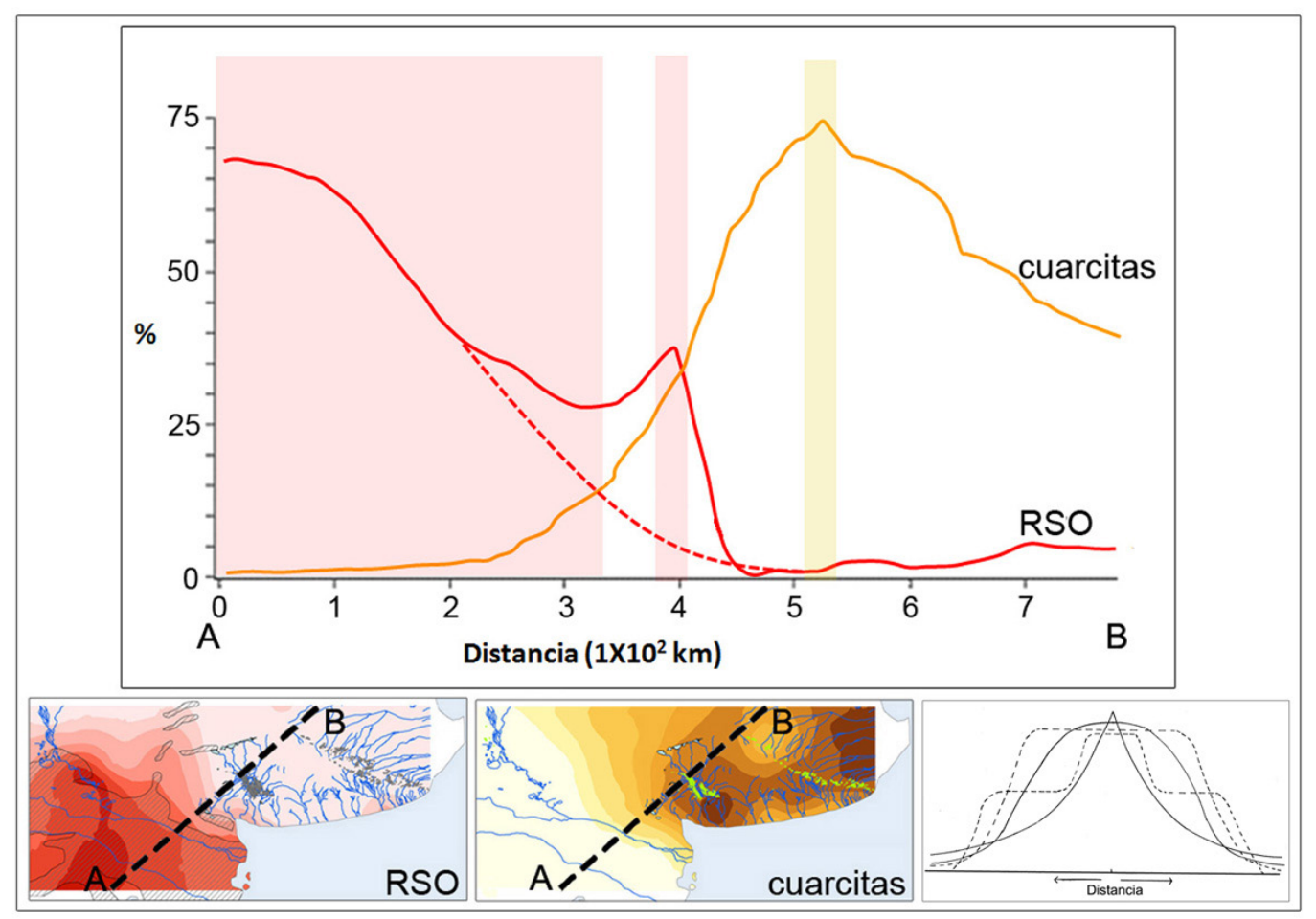

Figura 10.34. Curvas de disminución de las frecuencias de RSO y cuarcitas en el sur de la Región Pampeana y NE de Patagonia. Los rectángulos señalan el sector en que se encuentran disponibles fuentes potenciales de aprovisionamiento de RSO (rosado indicando el Manto Tehuelche) y cuarcitas (amarillo indicando las sierras de Ventania). A y B indican el punto de inicio y finalización de la transecta virtual a partir de la cual se dibujaron las curvas. La línea roja continua señala la curva real en la disminución de la frecuencia relativa de RSO en tanto la línea punteada indica la tendencia proyectada de no encontrarse un segundo afloramiento del Manto Tehuelche. Abajo a la derecha se encuentra el gráfico de Soja (1971: 28) mostrando las distintas formas teóricas que pueden adquirir las curvas en relación con patrones de actividad territorial (líneas punteadas) y no territorial (líneas sólidas).

En cuanto a los artefactos de molienda, en las distintas áreas de la Región Pampeana se ha propuestos que estos incrementan su frecuencia durante el Holoceno tardío. aumentando también su formalidad, tamaño y evidencias de mantenimiento (Ávila 2009; Martínez 2008-2009; Matarrese 2007). Tanto en el área Interserrana como en la cuenca inferior del río Colorado, se observó a su vez, la presencia de conjuntos de artefactos de molienda, considerados producto de eventos de agregación comunal para realizar este tipo de actividades (Bonomo y Matarrese 2012; Martínez 2010; Matarrese 2007). 


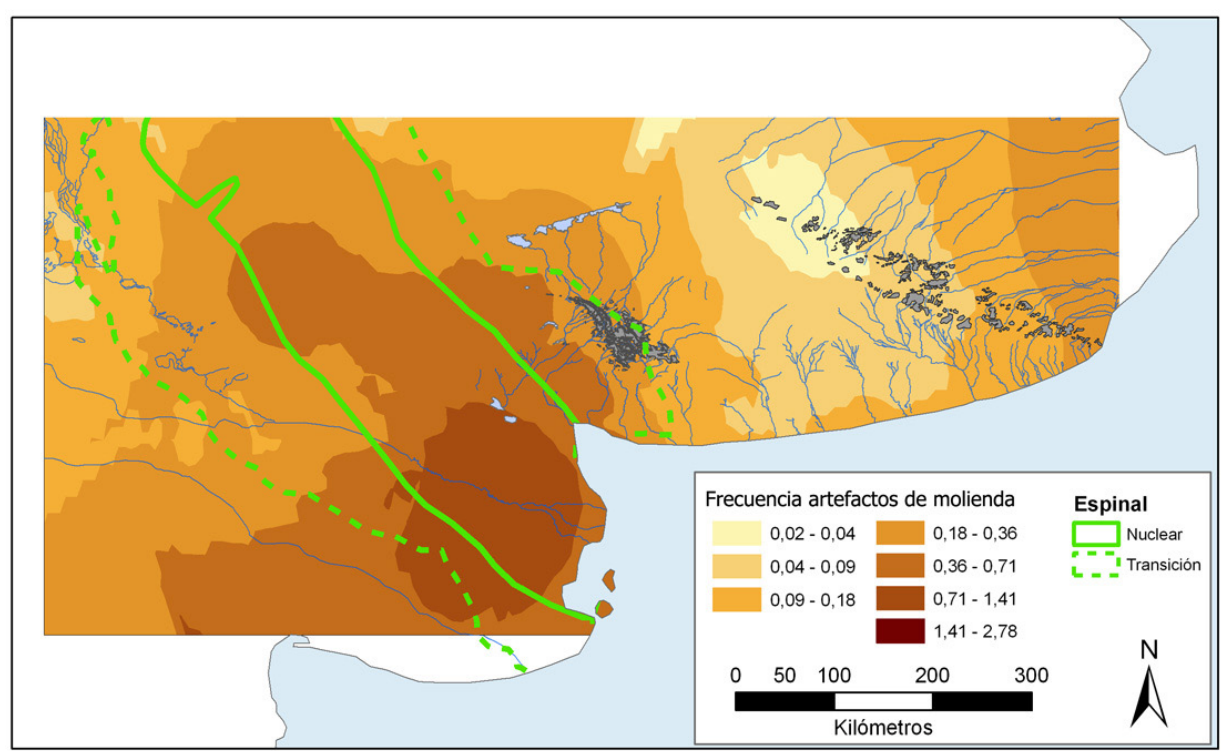

Figura 10.35. Distribución de los artefactos de molienda en relación con los artefactos de filo.

Si bien el aumento en el número y formalización de los artefactos de molienda parece haber sido general de las regiones Pampeana y Patagónica (Matarrese 2007; Politis y Madrid 2001), la Figura 10.35, muestra que su frecuencia relativa no es homogénea en el sur de la Región Pampeana y NE de Patagonia. Esta aumenta hacia el sector inferior de la cuenca del arroyo Chasicó, encontrándose la zona con mayor frecuencia relativa entre los ríos Negro y Colorado, en clara asociación con el área nuclear de la provincia fitogeográfica del Espinal. En tal sentido, si bien su uso pudo haber estado vinculado a una amplia variedad de recursos, entre ellos el procesamiento de pigmentos, su frecuencia relativa apoya la hipótesis de su utilización en la molienda de los recursos vegetales propios de esta provincia del Espinal. En el área Interserrana, por el contrario, los estudios de microfósiles y sustancias adheridas indican su uso en relación, principalmente, con el procesamiento de pigmentos y, en menor medida, de recursos vegetales y posiblemente recursos animales (Bonomo 2004; Bonomo y Matarrese 2012; Crivelli Montero et al. 1987-1988; Martínez 1999).

\subsection{Discusión}

El tamaño del rango de acción, la frecuencia y duración de los movimientos, la disponibilidad de materias primas líticas, la estructura de otros recursos, el grado de planificación de los movimientos y procesos tafonómicos y de muestreo -así como los cambios ocurridos a través del tiempo en tales factores-, son algunas de las variables que afectan a la composición de los conjuntos líticos resultado de procesos acumulativos ocurridos a la escala de los sitios. En tal sentido es necesario considerar la probabilidad de que un único patrón espacial en la distribución de artefactos y rasgos, en este caso un mismo paisaje lítico, pueda responder igualmente a diferentes procesos y/o mecanismos en su generación (Barrientos et al. 2014).

Si se considera a la variedad de materias primas como un indicador de las dimensiones mínimas de un rango de acción (Amick 1999; Shackley 1985), la composición de los conjuntos recuperados en la cuenca del arroyo Chasicó se corresponde con rangos que no debieron extenderse mucho más allá de las áreas abarcadas por las sierras de Ventania y el río Colorado. Dentro de estos, la variedad de materias 
primas representadas puede interpretarse, en principio, como producto de una alta movilidad residencial y/o logística que facilitó el acceso a una amplia variedad de recursos líticos. Las rocas cuyas fuentes de aprovisionamiento se localizan más allá de los $130 \mathrm{~km}$ (como la riolita ignimbrítica o la obsidiana), se limitan a algunos pocos artefactos, los que pudieron haber sido obtenidos a través de otro tipo de estrategias, como redes de intercambio. Las materias primas más representadas muestran un patrón de suave disminución en función de la distancia a la fuente, donde las principales variaciones -evidenciadas por un aumento en la pendiente- se observan en los límites de la distribución natural de cada roca y/o en aquellas zonas en las que se encuentran otras materias primas disponibles localmente. Este patrón de variaciones graduales en las frecuencias de materias primas, no permite proponer la existencia de comportamientos territoriales en los que existiesen barreras -sociales o naturales- limitando, en algún modo, el acceso a las fuentes de aprovisionamiento.

La forma de las curvas de fall off y su relación con las fuentes de aprovisionamiento lítico, así como la composición de los conjuntos y la escasez de sitios cantera de grandes dimensiones, son concordantes con un aprovisionamiento vinculado en mayor grado con estrategias de tipo embedded (Binford 1979), expeditivas y/o oportunistas (Nelson 1991), en un ambiente con amplia disponibilidad de rocas, si bien de variada calidad. Las estrategias conservadas estarían menos representadas, limitadas al traslado de materias primas de buena o muy buena calidad, para su utilización en tareas específicas. La escasez de núcleos, en relación con la frecuencia de lascas e instrumentos, es coincidente con estrategias en las que se priorizó el aprovisionamiento de los individuos por medio de artefactos transportables, principalmente instrumentos terminados y lascas. Algunas excepciones a esto consisten en núcleos de gran tamaño depositados en las colecciones de museos locales y la presencia de caches en lugares puntuales indicadores del retorno periódico a ciertos espacios particulares (Oliva y Pérez 2008; Oliva 2014). La re-ocupación de ciertos lugares también se ve evidenciada por el almacenamiento de artefactos de molienda grandes y pesados en algunos sectores puntuales del paisaje, situación que también fue descripta tanto para el río Colorado como para el área Interserrana (Matarrese 2007; Martínez 1999). De esta manera se ven resueltos los problemas de movilidad que trae aparejada la incorporación de las actividades de molienda.

Por último, cabe destacar que la diversidad observada en las características de las rocas cuarcíticas de Ventania, llama la atención sobre el riesgo de determinar procedencias sobre la base de propiedades macroscópicas o de una única variable como la presencia o ausencia de metamorfismo. Durante el desarrollo de esta tesis se identificaron afloramientos de rocas cuarcíticas macroscópicamente similares a las descriptas para el grupo Sierras Bayas, particularmente aquellas de colores ocre-rosado-rojizo ${ }^{3}$ (N. Flegenheimer 2014 com. pers.). Presuponer que las rocas cuarcíticas de mejor calidad para la talla únicamente pueden ser obtenidas en las sierras de Tandilia, lleva a plantear la existencia de rangos de acción demasiado amplios o bien de redes de intercambio formales (dado el volumen de roca transportada hacia los sitios localizados al sur de Ventania), para lo cual no existe, hasta el presente, suficiente evidencia. Si bien no se descarta que algunas de las ortocuarcitas recuperadas en los sitios al sudoeste de Ventania, especialmente aquellas de color blanco, hayan sido obtenidas en las sierras de Tandilia o en los depósitos antrópicos secundarios del área Interserrana, la mayor proporción de

3 Muestras de las cuarcitas de Arroyo Saudade fueron presentadas en el II Congreso Internacional de Arqueología de la Cuenca del Plata (San José de Mayo, Uruguay, abril de 2014), donde Nora Flegenheimer discutió con la autora y otros colegas, el parecido macroscópìco entre estas rocas y aquellas aflorantes en las sierras de Tandilia. 
éstas, particularmente las coloreadas, pudieron haber sido obtenidas en las sierras de Ventania y/o en los arroyos que las drenan, en un abastecimiento de tipo embedded. Por este motivo, es necesario ampliar los criterios de identificación al momento de realizar inferencias acerca del probable lugar de abastecimiento, incorporando mayor cantidad de variables que, visto el caso de las cuarcitas de arroyo Saudade, podrían ser el color, el tamaño del grano, la compactación de los granos y la presencia de inclusiones como hematita, mica y arcillas.

Los análisis aquí presentados permiten observar algunas tendencias y comenzar a responder preguntas en relación con el modo en que las materias primas circularon a través del paisaje, sin embargo también plantean nuevos interrogantes y señalan temas que deberán ser investigados con mayor intensidad. Uno de estos temas consiste en la identificación y caracterización de fuentes de aprovisionamiento a los fines de generar modelos de gravedad que permitan predecir el área de influencia de cada una de ellas. En relación con esto, deberá continuarse con la caracterización de las materias primas presentes en los sitios arqueológicos, a los fines de establecer con mayor precisión sus áreas de procedencia. La experimentación con distintas materias primas también es un tema prioritario, a los fines de evaluar las posibilidades técnicas cada una de ellas, particularmente de las distintas variedades de cuarcitas. Por razones de tiempo y espacio, a los fines de esta tesis solo se consideraron algunas de las variables tecnotipológicas que pueden aportar información sobre las estrategias de movilidad y circulación de materias primas. En tal sentido, deberá continuar profundizándose los análisis relacionados con el diseño de las distintas clases artefactuales (productos de talla, instrumentos y núcleos) y sus variaciones a través del tiempo. 


\section{IEl Registro Bioarqueológico: Tipos de Entierro e Isótopos Estables}

En relación con los temas que se abordan en esta tesis, el estudio del registro bioarqueológico puede aportar información acerca del uso de los recursos así como de la movilidad, tanto a escala individual y/o grupal como poblacional. Por una parte, la distribución espacial y temporal de los tipos de entierro, de los rasgos morfológicos del esqueleto y de sus modificaciones culturales -como la deformación craneales informativa acerca de las áreas de distribución de una población y su contracción o retracción a través del tiempo (Barrientos 1997, 2001; Barrientos y Pérez 2002). A nivel de la movilidad individual o grupal, pueden aportar información sobre el grado de constreñimiento espacial y de reocupación de determinados sectores del paisaje, tanto el tipo y cantidad de entierros -y la cantidad de individuos por entierro- como la incidencia de patologías infecciosas en el grupo, en este último caso, debido a que al disminuir la movilidad y/o rango de acción aumenta el contacto con fuentes patogénicas $(v . g$. desechos acumulados en áreas de campamento de uso relativamente prolongado) (Barrientos 1997, 2001; Barrientos et al. 1997; Madrid y Barrientos 2000). En relación con el uso de los recursos, los indicadores óseos y dentales del estado de salud, nutrición y dieta permiten evaluar cambios en las condiciones de vida de las poblaciones humanas en relación a la amplitud de la dieta o la intensidad de uso de ciertos recursos (v.g. vegetales ricos en carbohidratos que producen mayor incidencia de caries y patrones de desgaste diferenciables; Barrientos 2001). Finalmente, los isótopos estables aportan información tanto sobre aspectos vinculados con la dieta como con la movilidad de los individuos, grupos y/o poblaciones (ver discusión en capítulos 2 y 5).

Durante el desarrollo de este capítulo se exponen las características del registro bioarqueológico de la cuenca del arroyo Chasicó, se analizan los valores de isótopos estables del carbono y el nitrógeno, en muestras humanas y de Lama guanicoe, como indicadores de movilidad y uso de recursos a escala individual y grupal. Esta información se discute en relación con la información isotópica regional para, de esta manera, analizar variaciones en el tipo de recursos consumidos y evaluar posibles rangos de movilidad. Por último, se presenta la distribución de tipos de entierros humanos y modificaciones óseas (integrando los datos con aquellos disponibles para el sur de la Región Pampeana y NE de Patagonia) como indicadores de movilidad y uso de recursos a escala poblacional. 


\subsection{Metodología}

Los análisis sobre los restos óseos humanos registrados en tareas de campo y el estudio de colecciones de museo llevados a cabo en el marco de la presente investigación, se realizaron con la colaboración de G. Barrientos y M. Delgado Burbano. Estos consistieron, en los casos en que resultó pertinente, en la determinación de las partes esqueletarias representadas, la estimación de sexo y edad de los individuos, el cálculo del NMI y la identificación de pigmento y marcas de corte. Las determinaciones de sexo y edad se realizaron de manera independiente para cada unidad anatómica, siguiendo criterios empleados por Barrientos (1997) y Gordón (2010). Para el cálculo de la edad se consideró, en el caso de huesos largos, la longitud diafisaria -de la que se derivó la edad a partir de curvas de crecimiento desarrolladas por Merchant y Ubelaker (1977)- y el grado de fusión de las epífisis (Brothwell 1987; Ubelaker 1982). En cráneos, por otra parte, se utilizó el grado de desarrollo dentario (Ubelaker 1982) y el cierre de las suturas ectocraneales. En este último caso se realizó una asociación entre la edad cronológica y un puntaje compuesto obtenido a partir de la observación del cierre de las suturas ectocraneales de la región lateroanterior (Meindl y Lovejoy 1985), que permite definir categorías amplias: adultos jóvenes (20-34 años), adultos medios (35-49 años) y Adultos seniles (50 $\geq$ años) (Buikstra y Ubelaker 1994). Finalmente, se consideró el estado de fusión de la sutura esfeno-basilar, considerándose como sub-adultos a aquellos individuos que no presentaban esta sutura fusionada al momento de su muerte (Buikstra y Ubelaker 1994). La determinación sexual se llevó a cabo a partir de observaciones morfológicas, como la forma y extensión de las crestas occipitales y de las líneas temporales, robusticidad de la cresta nucal, tamaño del mastoides, filo del margen supraorbital, prominencia de la glabela y proyección de la eminencia del mentón (Buikstra y Ubelaker 1994), y determinaciones métricas, como el diámetro vertical de la cabeza del húmero y diámetro máximo de la cabeza del fémur (Stewart 1979; Ubelaker 1982). El NMI se calculó - para el caso del entierro secundario múltiple (Saavedra)- siguiendo la metodología utilizada por Barrientos (1997) para el análisis del entierro secundario del sitio 1 de Los Chilenos, en el que consideró criterios de lateralidad (White 1953), edad (Bökönyi 1970) y tamaño (Chaplin 1971).

Para la obtención de valores isotópicos del nitrógeno y el carbono, se procesaron muestras humanas y de Lama guanicoe. La extracción de colágeno se realizó en el INGEIS, siguiendo el protocolo propuesto por Longin (1971) y Tykot (2004) y la medición de $\delta^{13} \mathrm{C}$ y $\delta^{15} \mathrm{~N}$ se llevó a cabo mediante el método EA-IRMS (A. Tessone 2012 com.pers.). También se incorporaron para su estudio aquellos valores $\delta^{13} \mathrm{C}$ obtenidos a partir de fechados AMS realizados sobre muestras humanas, para los que se estimó el valor $\delta^{15} \mathrm{~N}$ a partir de los valores de $\delta^{13} \mathrm{C}$, siguiendo la metodología explicada en el Capítulo 5.

\subsection{Estructura espacial y temporal del registro bioarqueológico de la cuenca del arroyo Chasicó}

Dentro de los límites de la cuenca, la información bioarqueológica proviene de los entierros presentes en el sitio 1 de la laguna Los Chilenos y de restos aislados recuperados en los sitios 1 y 7 de la laguna Chasicó. Complementariamente se analizó también, una colección de elementos óseos del Museo de La Plata, recuperados a principios del siglo XIX en el partido de Saavedra (Figura 11.1). 


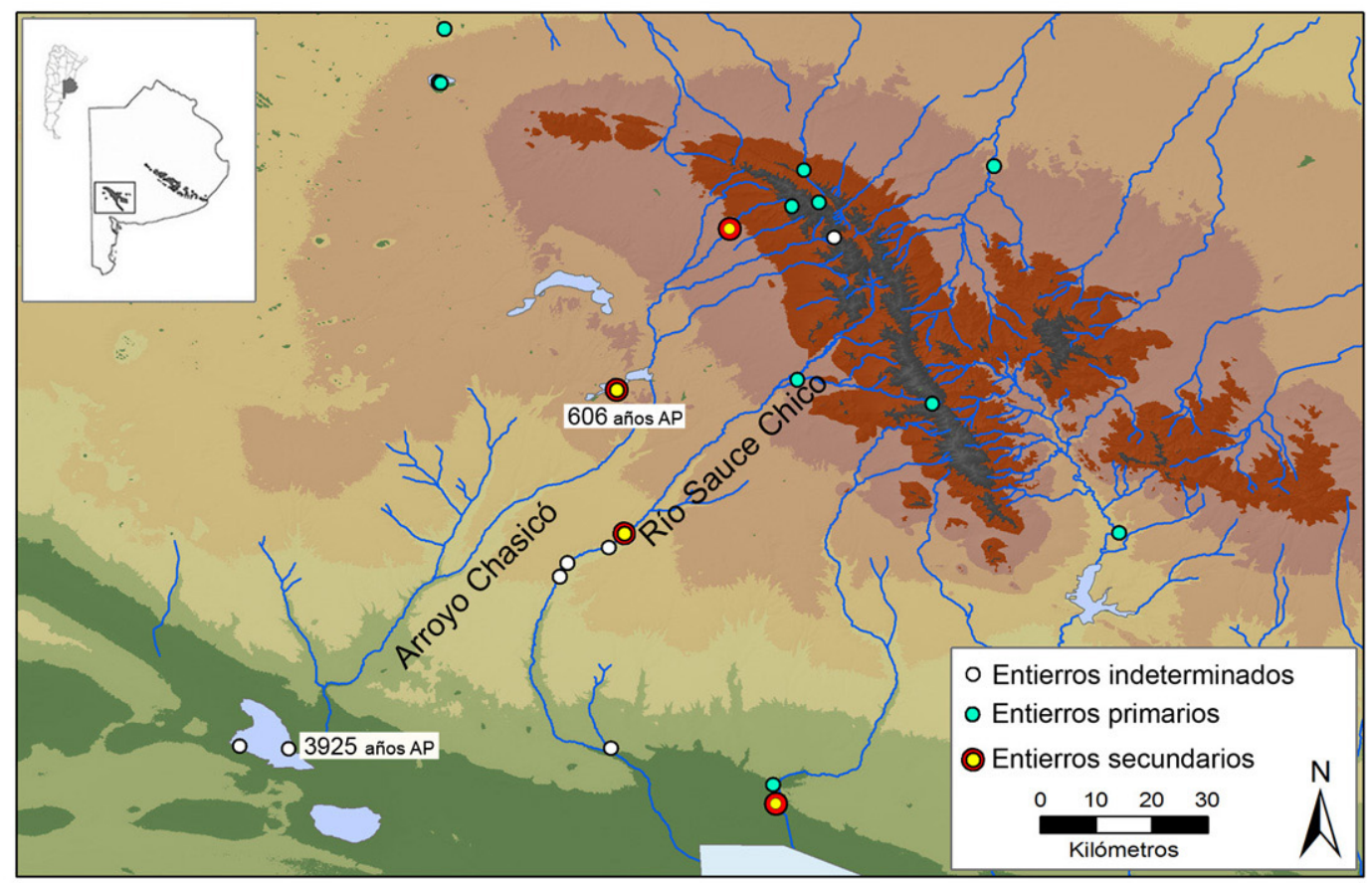

Figura 11.1. Distribución de entierros humanos en la cueca del arroyo Chasicó y sus inmediaciones.

\subsubsection{Laguna Los Chilenos sitio 1}

En la laguna Los Chilenos, F. Oliva y G. Barrientos excavaron, en un área de $21 \mathrm{~m}^{2}$, un entierro secundario y dos entierros primarios individuales y recolectaron en superficie restos dispersos algunos de los cuales pudieron ser relacionados con los entierros excavados. Los materiales óseos humanos fueron analizados por G. Barrientos, quién realizó la determinación de sexo y edad, estimó el número mínimo de individuos (NMI) y la representación de partes esqueletarias en el entierro secundario. También propuso una historia pre y post-depositacional para el sitio en la que los principales agentes involucrados fueron el hombre, para momentos pre-depositacionales, y la acción hídrica y de roedores con posterioridad a su depositación (Barrientos 1997). El entierro secundario se encuentra conformado por elementos óseos, correspondientes a por lo menos 14 individuos ( $\mathrm{NMI}=14$ ), muchos pintados de rojo o amarillo y dispuestos en un paquete de 1,08 $\mathrm{m}$ de largo y 0,63 $\mathrm{m}$ de ancho, asociado a dos toscas dispuestas en el borde noroeste. En este se hallan representados casi la totalidad de los elementos esqueletarios, aunque con frecuencias variables, encontrándose con mayor representación el cráneo, las diáfisis de húmero, radio, fémur, tibia y peroné, las clavículas, el íleon y el isquion (Barrientos 1997). Este entierro está conformado por siete individuos masculinos -uno adulto con deformación tabular erecta, un sub-adulto y 5 infantiles (menores a 8 años)-, tres femeninos -un adulto y dos sub-adultos- y cuatro en los que no se pudo determinar el sexo -dos sub-adultos y dos menores al año de vida- (Barrientos et al. 2002). Algunos de estos elementos presentan marcas poco profundas, producidas mediante el uso de filos cortantes, distribuidas preferencialmente en la parte media de las diáfisis de los huesos largos, dispuestas de manera oblicua o paralela a su eje, y en sus extremos distales y proximales, que fueron interpretadas como producto del descarne. (Barrientos 1997). Uno de los entierros primarios individuales corresponde a un individuo femenino adulto ( $41,1 \pm 10$ años), del cual parte fue recuperado en excavación y parte fue recogido por aficionados (Barrientos 1997; Barrientos et al. 1997, 2002), y el segundo, a un individuo 
probablemente de sexo masculino adulto (41,1 \pm 10 años), que también fue extraído por aficionados, hallándose en excavación únicamente metatarsianos, falanges y fragmentos de costillas (Barrientos et al. 1997, 2002). A estos dos entierros se suman una serie de elementos recuperados sobre la playa y dentro de la laguna que fueron asignados a al menos 7 individuos ( $\mathrm{NMI}=7$ ), cinco adultos (tres masculinos y dos femeninos) y dos subadultos, así como algunos elementos correspondientes al entierros individual excavado (Barrientos 1997).

\subsubsection{Laguna Chasicó}

En la laguna Chasicó se obtuvieron elementos óseos humanos en superficie en los sitios 7 y 1. En el sitio 7 se recolectó un segundo molar superior izquierdo, con un alto grado de desgaste oclusal básicamente plano, característico de los grupos cazadores-recolectores (Smith 1984), pero con un patrón más o menos oblicuo en el hipocono. Su estado de conservación es regular, observándose pérdida del esmalte dental en la superficie mesiolingual de la corona y pigmentaciones oscuras en la superficie bucal de la raíz ajenas al color natural del diente. Presenta a su vez, tres raíces dos bucales y una lingual, con algunas deformaciones y abultaciones que podrían relacionarse con efectos tafonómicos y/o patologías (G. Barrientos M. E. y Delgado Burbano 2011 com. pers.). Por otra parte, en el sitio 1 concentración D, se recuperaron una vértebra lumbar y varios fragmentos de vértebra indeterminable, una rótula derecha y un fragmento de parietal. También en este sitio fue recolectado un parietal derecho, pero para este no se cuenta con información precisa sobre su ubicación exacta, debido a que fue recogido por un aficionado quién se lo entregó al guardaparque de la reserva.

\subsubsection{Colección Saavedra}

Esta colección, depositada en la División Antropología del Museo de La Plata, fue excavada por un técnico del museo a principios del siglo XX. Si bien no se tienen datos precisos sobre su ubicación, fue ingresada como procedente del campo del Sr. Fermín Liceaga, localizado en el partido de Saavedra. Por tal motivo, podría corresponder al sector superior de la cuenca del arroyo Chasicó (ya que aproximadamente el 50\% de dicho municipio se localiza dentro de sus límites) o bien al sector adyacente al norte o noroeste de dicha cuenca. La colección se encuentra conformada, considerando los datos del catálogo, por 133 elementos óseos, de los cuales se analizaron 70, debido a que no pudieron localizarse los restantes (M. Del Papa 2012, com. pers.). Los 133 elementos registrados en el catálogo se encuentran determinados anatómicamente, sin embargo, en el 34\% de los casos analizados ésta no se corresponde con el elemento óseo, razón por la cual, dichas determinaciones no fueron tenidas en cuenta.

A partir de los elementos óseos disponibles, se obtuvo un NMI de 13, de los cuales 10 corresponden a adultos ( 3 femeninos, 7 masculinos), dos a sub-adultos y uno a un niño, este cálculo sin embargo, es una estimación conservadora, realizada considerando el sexo de la unidad anatómica más representada por grupo de edad (adulto, sub-adulto, niño). En el caso de los adultos el cálculo se realizó a partir del húmero, en subadultos a partir del fémur y en el niño se utilizó la clavícula. Si se incluyen las determinaciones de sexo realizadas a partir de elementos del cráneo (i.e. calota, calvaria) el NMI asciende a 15 , debido a que entre estos últimos se identificaron como femeninos 5 elementos, en tanto entre los húmeros solo 3, lo que llevaría el NMI a 15, número máximo para la muestra analizada. Se consideró 
sin embargo, como un NMI más confiable el de 13, debido a que la estimación de sexo a partir de los elementos del cráneo se realizó sobre rasgos cualitativos, los que no siempre pudieron ser observados en su totalidad, siendo por lo tanto, una determinación que puede ser menos confiable que la realizada sobre rasgos métricos del húmero (Ubelaker 1982). De los 70 elementos analizados, 47 presentan pigmento rojo sobre su superficie, no observándose diferencias en el tipo o proporción de elementos pintados, si bien es más frecuente se presencia en cráneos, tibias y fémures. Las marcas de corte, por otra parte, se encuentran presentes en todas las unidades anatómicas, pero con una mayor representación en los huesos largos, principalmente tibia y fémur.

\subsection{Indicadores de movilidad y uso de recursos a escala individual y grupal}

\subsubsection{Información isotópica}

\subsubsection{Variabilidad en la dieta en el sur de Sudamérica}

Debido a que múltiples factores, cómo variaciones ambientales (i.e. salinidad, aridez, características del suelo) pueden incidir en la composición isotópica de un individuo, y considerando que el área de estudio propuesta para el desarrollo de esta tesis es espacialmente acotada, resulta de interés para su mejor comprensión, analizar los valores isotópicos publicados para otras áreas. De esta manera, se podrá evaluar la variabilidad espacial de las dietas en una escala espacial amplia así como su relación con la disponibilidad local de recursos en cada caso.

Análisis realizados por Barrientos (2010) acerca de la distribución espacial de la variación en los valores isotópicos del carbono y el nitrógeno en el sur de Sudamérica, le permitieron plantear ciertas tendencias en el tipo de dietas representadas. G. Barrientos observa el predominio de valores empobrecidos en $\delta^{13} \mathrm{C}$ en el sur de Cuyo, la Región Pampeana, sur de Santa Fe, Entre Ríos y la mayor parte de Patagonia, lo que es relacionable con dietas en las que predomina el consumo de plantas $\mathrm{C}_{3}$ o de animales consumidores de plantas $\mathrm{C}_{3}$, en tanto el norte de Mendoza, San Luis y Córdoba, así como algunos sectores puntuales de Patagonia (península Valdés, y sectores de la costa del extremos sur), presentan valores enriquecidos en $\delta^{13} \mathrm{C}$, relacionables con el consumo de plantas $\mathrm{C}_{4}$ y/o recursos marinos. Los valores de $\delta^{15} \mathrm{~N}$, por otra parte, muestran menor enriquecimiento en las provincias de Neuquén, Mendoza, Córdoba, Santa Fe y San Luis (exceptuando el extremo sur de estas últimas tres provincias), lo que se corresponde con dietas de bajo nivel trófico es decir, con un mayor consumo de vegetales. En la Región Pampeana y gran parte de la Región Patagónica los valores de $\delta^{15} \mathrm{~N}$ son medios, en tanto en península Valdés y sectores costeros del extremo sur son altos, correspondiéndose con dietas de medio y alto valor trófico respectivamente. A partir de estas variaciones, pueden realizarse inferencias acerca de la dieta, donde los valores enriquecidos en $\delta^{13} \mathrm{C}$ y empobrecidos en $\delta^{15} \mathrm{~N}$, observables en el sector noroeste, han sido interpretados como producto de dietas con una alta proporción de vegetales $\mathrm{C}_{4}$, principalmente maíz, en tanto los valores empobrecidos tanto en $\delta^{15} \mathrm{~N}$ como en $\delta^{13} \mathrm{C}$ son interpretados como evidencia de dietas basadas principalmente en el consumo de plantas $\mathrm{C}_{3}$, en este caso particular, los frutos del pehuén. En la Región Pampeana y la mayor parte de la Patagónica, los valores de nitrógeno estarían indicando dietas de valor trófico medio, es decir, basadas principalmente en el consumo de animales consumidores de plantas $\mathrm{C}_{3} \mathrm{y}$ con aportes variables de plantas $\mathrm{C}_{4}$, en tanto en península Valdés y sectores costeros del extremo sur, los altos valores de $\delta^{15} \mathrm{~N}$ y $\delta^{13} \mathrm{C}$ estarían indicando dietas con un 
importante componente marino (Figura 11.2). A modo de síntesis entonces, G. Barrientos propone la existencia de cuatro grandes clases de dietas en el extremo sur sudamericano: 1- aquellas basadas en el consumo de plantas $\mathrm{C}_{4}$, básicamente maíz, en el noroeste; 2- dietas basadas en el consumo de plantas $\mathrm{C}_{3}$, principalmente pehuén, en el centro oeste; 3- dietas basadas en el consumo de herbívoros consumidores de plantas $\mathrm{C}_{3}$, principalmente guanaco, en las regiones pampeana y patagónica; 4- Dietas con un importante componente marino, en algunos sectores costeros de Patagonia y, aunque con señal más débil, Provincia de Buenos Aires (Barrientos 2010).

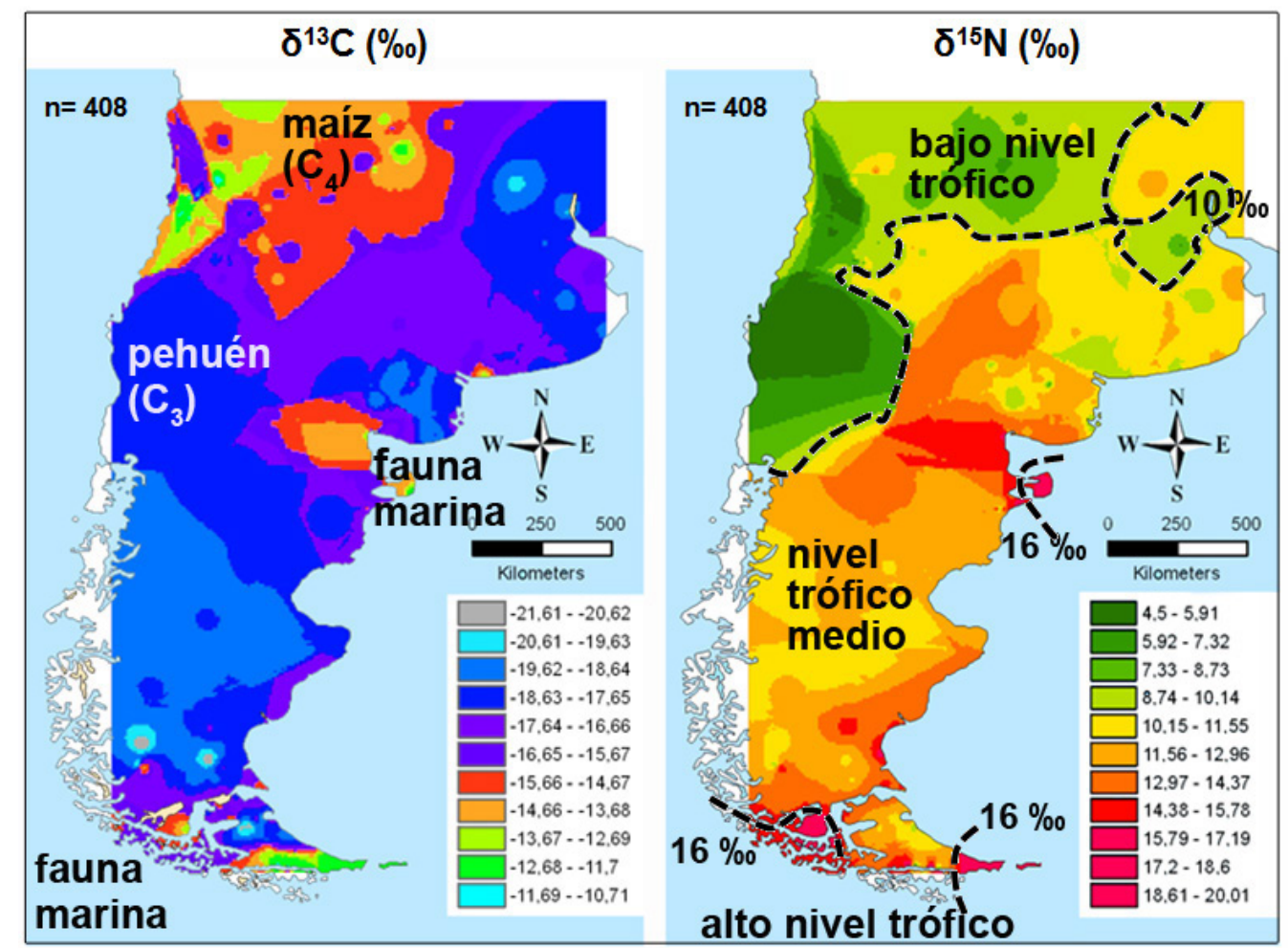

Figura 11.2. Distribución de valores isotópicos de ${ }^{13} \mathrm{C}$ y ${ }^{15} \mathrm{~N}$ en el extremo sur de Sudamérica y su relación con la probable composición de la dieta de las paleo-poblaciones humanas, método de interpolación empleado IDW (Barrientos 2010).

Estas variaciones en la dieta, se relacionan estrechamente con la variabilidad en la disponibilidad de recursos, tanto vegetales como animales. En tal sentido, la Figura 11.3 muestra la disminución de las pasturas, tanto $\mathrm{C}_{3}$ como $\mathrm{C}_{4}$ hacia el sur de la región patagónica, donde en cambio son más abundantes los arbustos propios de la provincia fitogeográfica del Monte (ver Capítulo 4), esta disminución en la proporción de vegetales se vería reflejada en la dieta por un aumento en el componente de la caza, lo cual ya ha sido propuesto por Binford (1991) en su modelos de "dependencia de cazadores-recolectores sobre alimentos recolectados" y discutido por Barrientos (1997) para el sudeste de la Región Pampeana. En tal sentido, sería esperable, y así lo muestran los valores isotópicos, una mayor incorporación de alimentos de origen animal a medida que aumenta la latitud.

La fuerte asociación entre dieta y recursos disponibles también se ve reflejada en la incorporación de alimentos marinos a la dieta. Este tipo de dietas se encuentran asociadas a zonas caracterizadas -biológicamente- por una alta densidad o probabilidad de ocurrencia de especies predadoras de recursos marinos, y por lo tanto donde es esperable que se encuentren altas densidades de las especies consumidas por dichos predadores (Figura 11.4). 


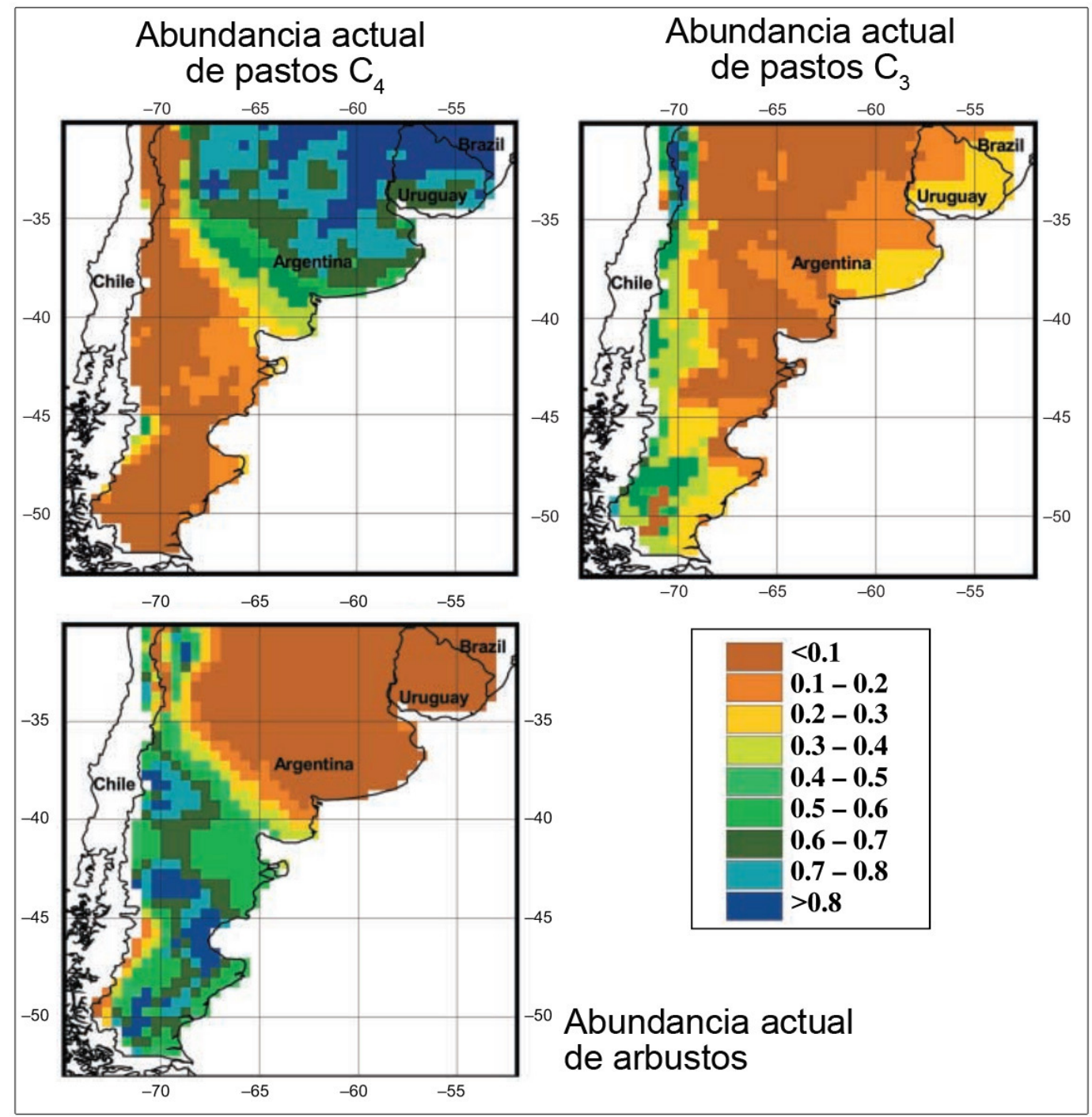

Figura 11.3. Modelos espaciales de abundancia relativa actual de pastos $\mathrm{C}_{3} \mathrm{y} \mathrm{C}_{4} \mathrm{y}$ de arbustos (Epstein et al. 2002).

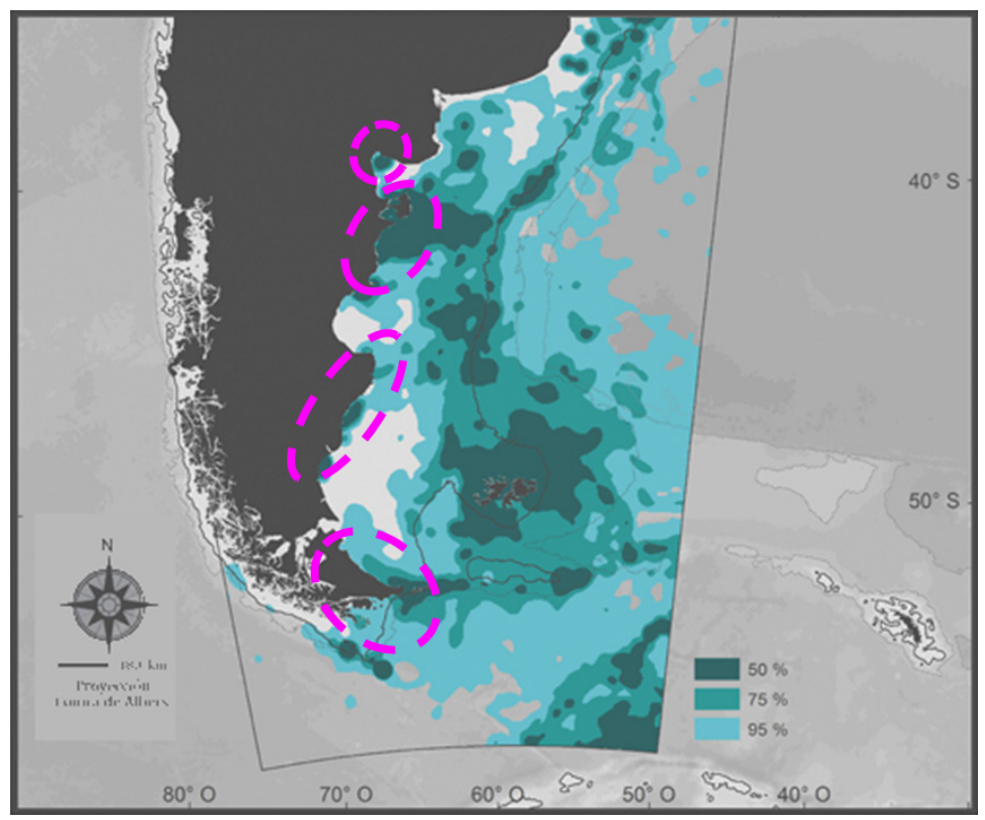

Figura 11.4. Distribución de las áreas utilizadas por las 16 principales especies depredadoras. Las áreas más oscuras, dentro del contorno de $50 \%$, identifican zonas de alta densidad o probabilidad de ocurrencia de estas especies (zonas de uso intenso), en tanto las zonas del $75 \%$ o $95 \%$ identifican el rango de distribución donde la probabilidad de ocurrencia es menor (Falabella et al. 2009, modificado por Barrientos 2012). 


\subsubsection{Isótopos estables en la cuenca del arroyo Chasicó}

En el marco de esta tesis, se obtuvo información isotópica $\delta^{13} \mathrm{C}$ y $\delta^{15} \mathrm{~N}$ a partir del análisis de muestras humanas procedentes de la laguna Chasicó. Esta información fue complementada con aquella disponible para muestras humanas de la laguna Los Chilenos y, fuera de los límites de la cuenca, de la laguna de Puán (Barrientos et al. 2013; Oliva 2014) (Tabla 11.2).

\begin{tabular}{|c|c|c|c|c|c|c|c|}
\hline Muestra & $\begin{array}{l}\text { Tipo de } \\
\text { entierro }\end{array}$ & $\begin{array}{c}\text { Def } \\
\text { craneal }\end{array}$ & $\delta^{13} \mathrm{C}$ & $\delta^{15} \mathrm{~N}$ & Cronología & Cod. Lab & $\begin{array}{c}\text { Cita } \\
\text { bibliográfica }\end{array}$ \\
\hline LCH1-1-M-146 & SMP & TE & $-16,90$ & 11,09 & \multirow{10}{*}{$\begin{array}{c}\text { Holoceno } \\
\text { tardío final }\end{array}$} & AIE28738 & \multirow{10}{*}{$\begin{array}{l}\text { Barrientos et } \\
\text { al. } 2013\end{array}$} \\
\hline $\begin{array}{c}\text { LCH1-1-Sector } \\
\text { C-446 }\end{array}$ & SMP & indet & $-16,60$ & 10,85 & & AIE28739 & \\
\hline LCH1-1-G-H-1632 & SMP & indet & $-16,70$ & 11,65 & & AIE28740 & \\
\hline LCH1-1- G-H-1633 & SMP & indet & $-16,60$ & 10,98 & & AIE28741 & \\
\hline LCH1-1- I-36c & SMP & indet & $-16,70$ & 11,63 & & AIE28743 & \\
\hline LCH1-1- L-555/569 & SMP & indet & $-16,40$ & 10,97 & & AIE28744 & \\
\hline LCH1-2 & PrimS & Sin def & $-17,50$ & 10,94 & & AIE28745 & \\
\hline LCH1-3 & ¿Prim? & Sin def & $-17,70$ & 11,08 & & AIE28746 & \\
\hline LCH2-00-H-31 & Indet & indet & $-17,30$ & 11,43 & & AIE28747 & \\
\hline LCH1-1- F-1028** & SMP & indet & $-15,90$ & 7,58 & & AIE28742 & \\
\hline LCHA1-D-1 & Indet & Indet & $-16,72$ & 11,27 & sd & AIE28823 & \multirow{6}{*}{ Esta tesis } \\
\hline LCHA1-D-2 & Indet & Indet & $-16,92$ & 11,16 & sd & AIE28824 & \\
\hline LCHA1-D-3 & Indet & Indet & $-16,98$ & 11,40 & sd & AIE28825 & \\
\hline LCHA1-D-4 & Indet & Indet & $-16,71$ & 11,32 & sd & AIE28826 & \\
\hline LCHA1-D-5 & Indet & Indet & $-16,91$ & 11,33 & $\mathrm{sd}$ & AIE28827 & \\
\hline LCHA7 & Indet & Indet & $-17,50$ & $11,10^{*}$ & \multirow{2}{*}{$\begin{array}{c}\text { Holoceno } \\
\text { tardío } \\
\text { inicial }\end{array}$} & AA95517 & \\
\hline LP1-1 & PrimS & Circ & -17.90 & 11.10 & & AIE28751 & \multirow{2}{*}{$\begin{array}{c}\text { Barrientos et } \\
\quad \text { al. } 2013\end{array}$} \\
\hline LP6-1 & PrimS & Indet & -17.10 & 10.30 & $\mathrm{sd}$ & AIE28752 & \\
\hline
\end{tabular}

Tabla 11.2. Valores isotópicos obtenidos sobre muestras óseas humanas. Se detalla el tipo de entierro del que procede la muestra, su cronología y si el tipo de deformación craneal. LCH1= Laguna Los Chilenos 1; LCHA 1= Laguna Chasicó 1; LP= Laguna de Puán; $\mathrm{SMP}=$ entierro secundario múltiple pintado; PrimS= primario simple; Prim $=$ primario; $\mathrm{sd}=$ sin datos; Def. $=$ deformación; Indet $=$ indeterminado $;$ Sin def $=$ sin deformación craneal; Circ $=$ circular; Cod- Lab= código de laboratorio. ${ }^{*}$ valor $\boldsymbol{\delta}^{15} \mathrm{~N}$ estimado. ${ }^{* *}$ muestra inhomogénea para la que se obtuvo más de un valor isotópico y que, por lo tanto, no es considerada en los siguientes análisis.

Para poder asignar significado a los datos adquiridos para las muestras humanas, se procesaron también elementos óseos de Lama guanicoe recuperados en los mismos sitios arqueológicos, las que fueron analizadas en el mismo laboratorio y mediante la misma metodología descripta más arriba. Complementariamente se incorporó, también en el caso de los guanacos, la información brindada junto a fechados AMS, pero no se realizaron imputaciones (i.e. procedimiento de reemplazo de valores perdidos) del valor $\delta^{15} \mathrm{~N}$ debido a que la cantidad de datos de nitrógeno para las áreas consideradas es demasiado escasa como para obtener resultados confiables (Tabla 11.3). 


\begin{tabular}{|c|c|c|c|c|c|}
\hline Muestra & $\boldsymbol{\delta}^{\mathbf{1 3}} \mathbf{C}$ & $\boldsymbol{\delta}^{\mathbf{1 5}} \mathbf{N}$ & Cronología & Cod. Lab & Cita bibliográfica \\
\hline LS1 & $-22,70$ & sd & HTf & AA19290 & Barrientos et al. 2013 \\
\hline LM1-3-VIII-3 & $-19,50$ & sd & HTf & AA95515 & Esta tesis \\
\hline LCH2-6/28 & $-18,80$ & 5,28 & HTi & AIE 18967 & Barrientos et al. 2013 \\
\hline LM1 & $-18,80$ & sd & HTf & AA19289 & Oliva 2000 \\
\hline LCH2-1-XVI-16 & $-18,80$ & sd & HTi & AA95518 & Esta tesis \\
\hline LCH1-RecP1 & $-18,40$ & 4,94 & HTf & AIE 18966 & Barrientos et al. 2013 \\
\hline SM1-3-XII-34 & $-18,40$ & sd & HTi & AA95513 & Esta tesis \\
\hline LP1-3-XXX-1 & $-16,60$ & sd & HTi & AA95514 & Oliva 2014 \\
\hline
\end{tabular}

Tabla 11.3 Valores isotópicos obtenidos sobre muestras óseas de Lama guanicoe. HTi= Holoceno tardío inicial; HTf= Holoceno tardío final.

En relación con los valores isotópicos obtenidos para las muestras humanas del área de Ventania y, particularmente, de la cuenca del arroyo Chasicó, la Figura 11.5 muestra poca dispersión, tanto en aquellos correspondientes al carbono como en los del nitrógeno. En el caso del carbono, los valores extremos se encuentran entre $-17,7 \%$ y $-16,4 \%$, con el $50 \%$ de la muestra entre $-17,3 \%$ y $-16,7 \%$. Para el caso del nitrógeno la dispersión también es pequeña, con valores extremos de 10,30\% y 11,65\% y con más del 50\% de la muestra localizada entre los valores 10,97\% y 11,33\%o (Figura 11.5).

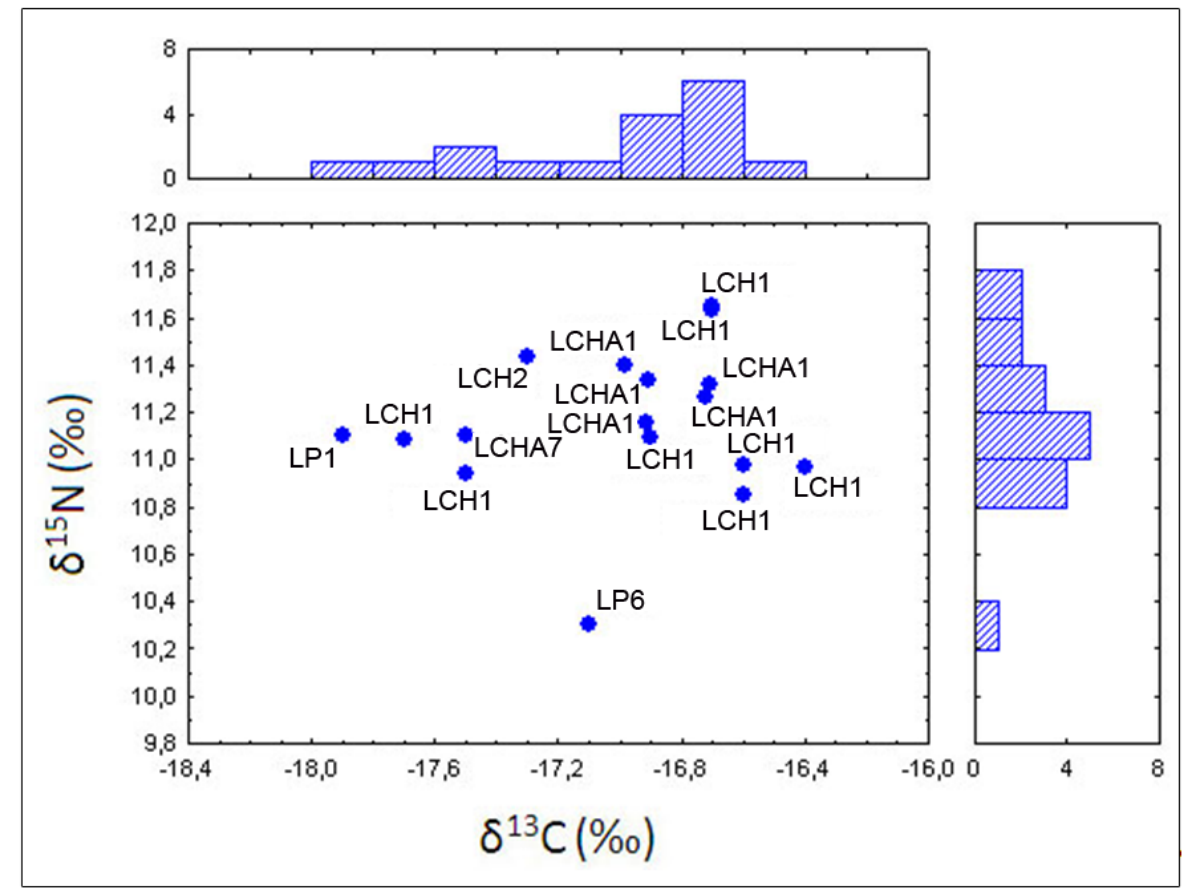

Figura 11.5. Valores isotópicos para nitrógeno y carbono de muestras humanas procedentes del área de Ventania.

La poca dispersión de los valores isotópicos obtenidos para Ventania, puede observarse mejor al compararlos con aquellos disponibles para las otras áreas consideradas (cuencas de los ríos Negro y Colorado, Pampa Seca, golfo de San Matías y llanura Interserrana). En la Figura 11.6 se observa que, para los valores de $\delta^{13} \mathrm{C}$ y $\delta^{15} \mathrm{~N}$, las muestras correspondientes a dichas áreas presentan una dispersión considerablemente mayor que la observada para Ventania y su llanura adyacente al sudoeste. Este mayor rango de dispersión se corresponde con áreas más amplias de procedencia de las muestras, lo que 
evidencia, o bien una mayor variación espacial en la dieta, o bien variaciones espaciales en la ecología isotópica, es decir, diferencias en los valores isotópicos de los recursos, relacionadas, principalmente, con variaciones ambientales locales. El solapamiento en las elipses de las cuatro áreas mencionadas, implica similitudes en sus dietas, que se relacionan con un importante componente continental (mayor al 80\%), donde el principal aporte nutricional estaría dado por el consumo de plantas $\mathrm{C}_{3}$ y animales consumidores de plantas $\mathrm{C}_{3}$, o bien con dietas mixtas, donde al consumo de plantas $\mathrm{C}_{3}$ o consumidores de $\mathrm{C}_{3}$ se agrega el consumo de plantas $\mathrm{C}_{4}$, y/o CAM y/o consumidores de estos vegetales y/o de alimentos marinos. En el caso de las muestras procedentes del Golfo de San Matías, el mayor enriquecimiento en los valores $\delta^{15} \mathrm{~N}$, indica, al menos en el caso de algunos individuos, un mayor aporte a la dieta de nutrientes de origen marino.

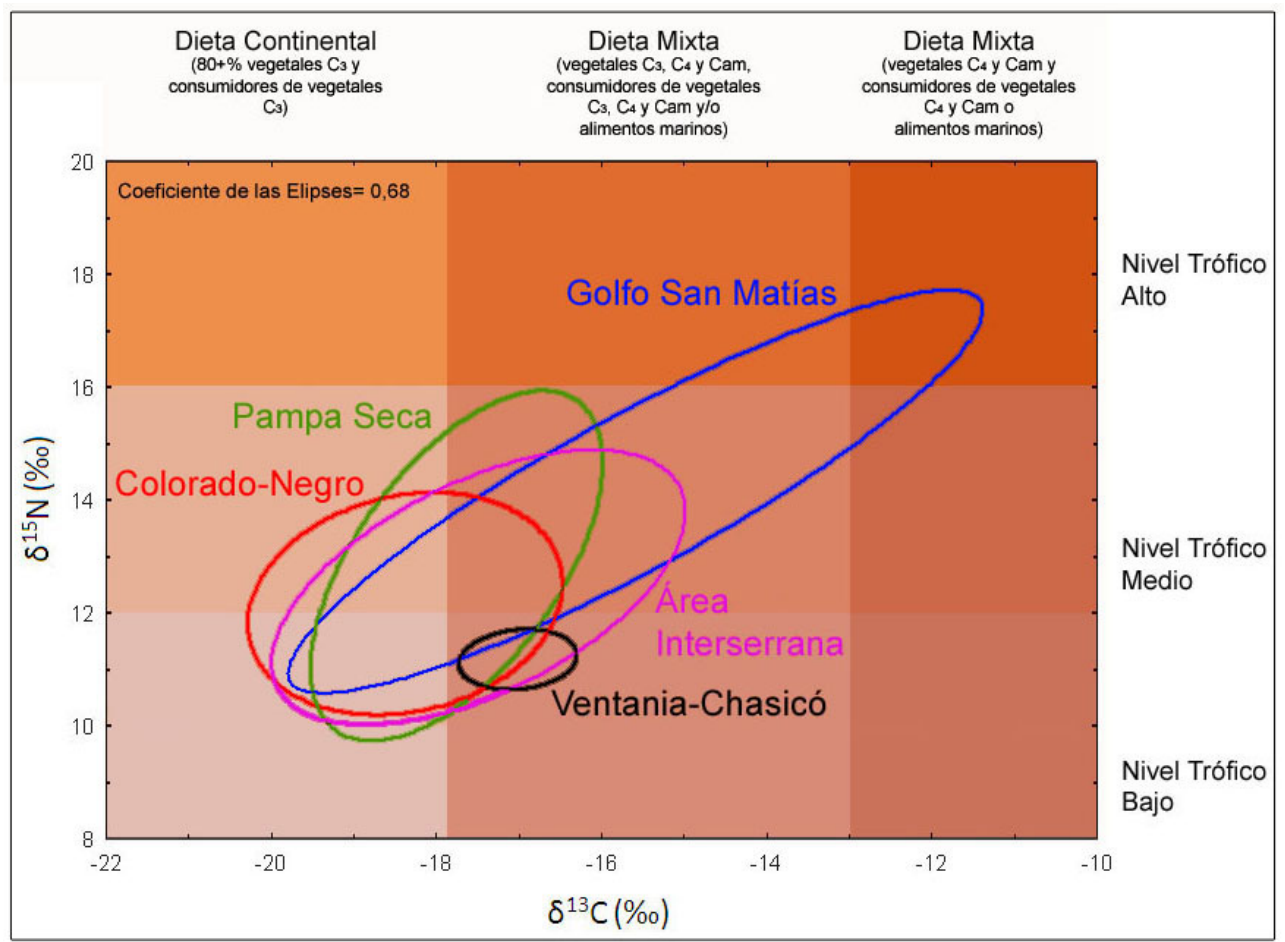

Figura 11.6. Diagrama de dispersión de los valores isotópicos del nitrógeno y el carbono, donde se representan las elipses ajustadas a un coeficientes de 0,68 ajustadas a los datos de cada una de las áreas indicadas en el texto.

Para el caso de Ventania, los valores $\delta^{13} \mathrm{C}$ entre $-18 \%$ y $-16 \%$ reflejan dietas mixtas basadas en el consumo de vegetales $\mathrm{C}_{3}, \mathrm{C}_{4}$ y CAM o consumidores de estos vegetales y/o de alimentos de origen marino (Pate 1995). Sin embargo, los valores $\delta^{15} \mathrm{~N}$ entre $10 \%$ y $12 \%$ corresponden a lo que puede ser clasificado como un nivel trófico medio bajo, que estaría reflejando una mayor influencia del componente vegetal en estas dietas y no así de alimentos de origen marino (Barrientos 2010). En otras palabras, en Ventania se observa una dieta mixta que, en principio, podría incluir el consumo de alimentos marinos, pero que, considerando los valores $\delta^{15} \mathrm{~N}$, se corresponde mejor con el consumo de plantas $\mathrm{C}_{4}$ o CAM o bien consumidores de estos vegetales.

A los fines de complementar la información isotópica obtenida para guanacos del área de Ventania e incorporar datos sobre otros recursos, se recopiló la información publicada sobre algunas de las especies para las cuales existen evidencias, directas o indirectas, que indican su incorporación como parte de 
la dieta de las sociedades cazadoras-recolectoras del pasado (Barberena et al. 2009; Favier Dubois et al. 2009; Martínez et al. 2009; Politis et al. 2004, 2009). Es importante señalar que la información disponible en relación con la ecología isotópica del sur de la Región Pampeana y NE de Patagonia es escasa, especialmente para los recursos de origen vegetal. Esto se debe a la poca diversidad de recursos muestreados y, principalmente, al bajo número de muestras procesadas para cada recurso, lo cual constituye una limitación al momento de interpretar los datos. En la Figura 11.7 se representan aquellas muestras para las que se cuenta con datos isotópicos de nitrógeno y de carbono, pudiéndose observar la dispersión en sus valores, particularmente en las de L. guanicoe, para las que se cuenta con mayor cantidad de información. Esta dispersión en los valores, probablemente este influyendo en la dispersión observada para las muestras humanas provenientes de áreas diferentes.

En tal sentido, la interpretación de los valores isotópicos correspondientes a las muestras humanas de Ventania, en relación con la ecología isotópica regional, indica que estos se corresponden con una dieta basada, principalmente, en el consumo de guanaco y venado de las pampas. En la Figura 11.7, se puede observar que los valores $\delta^{13} \mathrm{C}$ obtenidos para algunos individuos de estas especies son relativamente altos, encontrándose entre $-18 \%$ y $-20 \%$, lo que podría estar influyendo en los valores más enriquecidos de $\delta^{13} \mathrm{C}$ de las muestras humanas de Ventania. Los valores $\delta^{15} \mathrm{~N}$ enriquecidos entre un 3\% y un 7\%o con respecto a los de guanaco también parecen indicar predominantemente su consumo.

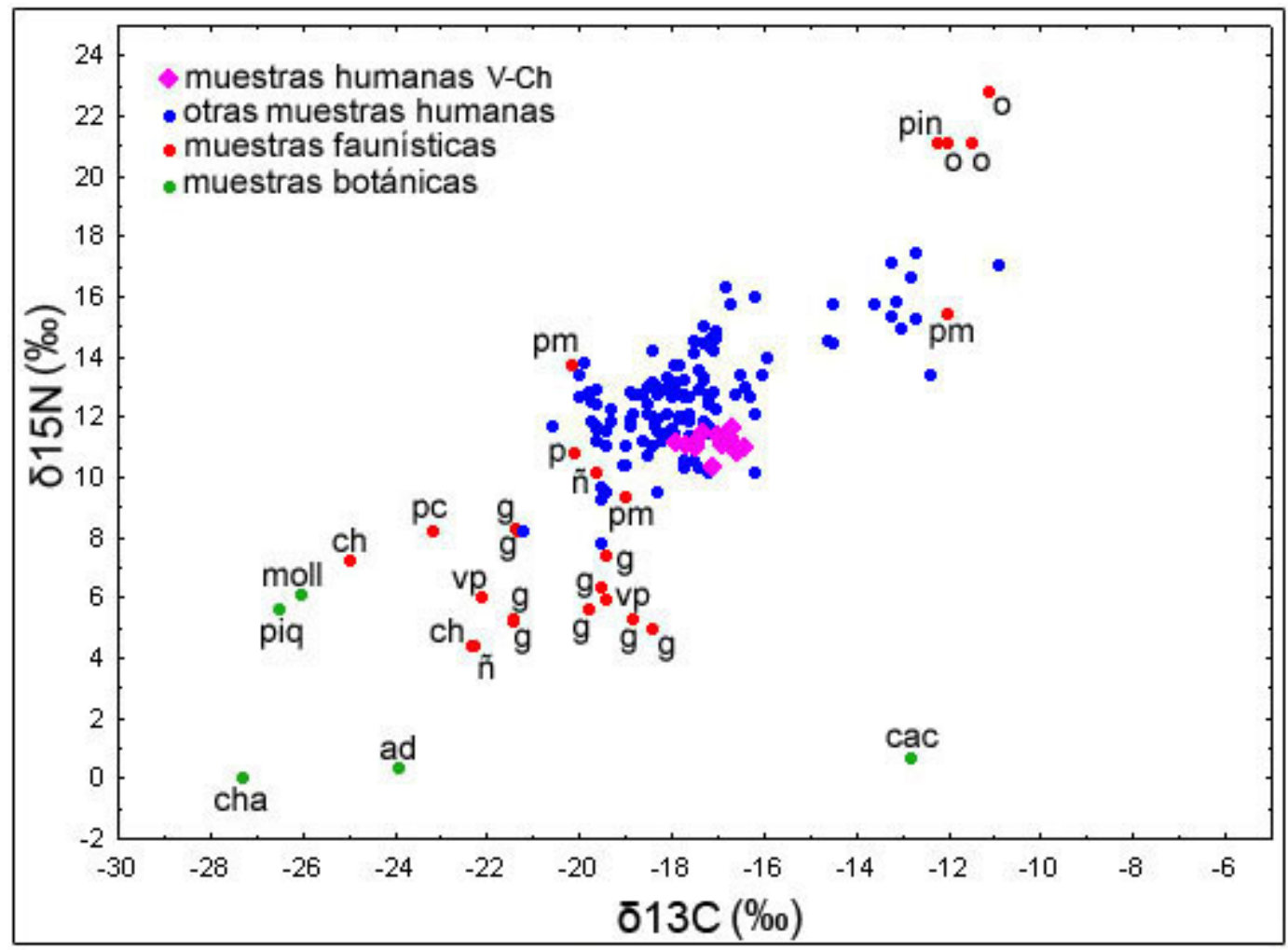

Figura 11.7. Valores $\delta^{13} \mathrm{C}$ y $\delta^{15} \mathrm{~N}$ de muestras humanas y recursos con mayor probabilidad de haber sido consumidos. cha $=$ chañar; piq= piquillín; ad= algarrobo $($ Prosopis flexuos $a)$; moll= molle; cac= cactus; $\tilde{\mathrm{n}}=$ ñandú; $\mathrm{g}=$ guanaco $\mathrm{ch}=$ choique; $\mathrm{pc}=$ pez continental; $\mathrm{vp}=$ venado de las pampas; $\mathrm{pm}=$ pez marino; $\mathrm{pc}=$ piche; $\mathrm{o}=$ otárido; pin= pinnípedo. 
Por otra parte, los valores de $\delta^{13} \mathrm{C}$ de $L$. guanicoe muestran cierta variación en su distribución espacial $^{1}$. En la Figura 11.8 se observa que las muestras procedentes de la llanura localizada al sudoeste de Ventania, presentan valores intermedios entre aquellos más empobrecidos distribuidos en las cuencas de los ríos Negro y Colorado y los más enriquecidos de las sierras de Tandilia y parte de la llanura interserrana. Para el caso de herbívoros, valores inferiores a -20 \% pueden ser interpretados en términos generales, como indicadores de una dieta basada predominantemente en el consumo de plantas $\mathrm{C}_{3}$, en tanto los valores más enriquecidos se corresponden con una incorporación mayor de vegetales $\mathrm{C}_{4}$ o CAM (Schoeninger y Moore 1992). Teniendo en cuenta estos valores, la distribución espacial de aquellos correspondientes a isótopos del carbono indica un mayor porcentaje de vegetales $\mathrm{C}_{4}$ o CAM en la dieta de las comunidades de guanacos que habitaron los espacios localizados al norte del río Colorado y hasta el río Quequén Salado (Figura 11.8).

Los guanacos se comportan como generalistas (i.e. ramoneadores y pacedores) que utilizan los distintos tipos de forraje sin realizar una selección del mismo, sino consumiendo este en proporción directa a su encuentro (Bonino y Pelliza 1991; Puig et al. 2001). Las comunidades de guanacos poseen rangos de movilidad estables en el tiempo y el espacio, que pueden variar entre 2 - $9 \mathrm{~km}^{2}$ (Burgi 2005) y 65 $163 \mathrm{~km}^{2}$ (GECS 2012), dependiendo de la abundancia de animales y la oferta de los recursos (Kaufmann 2009). A su vez, las migraciones son del orden de los 12 km (Ortega y Franklin 1995 en Kaufmann 2009) y con máximos que no superan los $80 \mathrm{~km}$ (GECS 2012), por lo que es esperable que las variaciones mencionadas en sus valores isotópicas se correlacionen con variaciones espaciales en la estructura de las comunidades vegetales. La Figura 11.8, muestra que la señal de los pastos con patrón fotosintético $\mathrm{C}_{4}$, se vuelve notoria en los valores isotópicos de guanaco, cuando superan el $40 \%$ en la composición de la cobertura vegetal. Una excepción a esto se encuentra al noreste del río Quequén Salado y en la sierras de Tandilia, donde las muestras de guanaco presentan valores muy empobrecidos en carbono (inferiores a $-20 \%$ ) en una zona donde los pastos $\mathrm{C}_{4}$ representan entre el $50 \%$ y el $70 \%$ de la cobertura vegetal. Esto sin embargo, puede deberse a condiciones muy locales, vinculadas con microambiente de la costa o las sierras de Tandilia, o bien a variaciones temporales breves que se manifiestan debido a que se cuenta con pocos datos para esa zona, provenientes de un único sitio (Nutria Mansa, donde las muestra presentan valores excepcionalmente bajos, de entre $-25,9 \%$ y -24,6\%; Bonomo 2005). A su vez, los análisis isotópicos realizados por Martínez, Zangrando y Prates (2009) sobre algunos vegetales adaptados a condiciones de aridez y/o salinidad aptos para el consumo humano y/o forrajeo (Portucea, Distichlis scoparia y Opuntia) arrojaron valores $\delta^{13} \mathrm{C}$ de entre -13,3\% y -16,4\%. Este tipo de vegetales, presente en el área de estudio, también estaría influyendo en los valores enriquecidos en $\delta^{13} \mathrm{C}$ que presentan tanto muestra humanas como de guanaco en la cuenca del arroyo Chasicó.

1 El análisis de la estructura espacial de los valores isotópicos se realizó únicamente para los isótopos del carbono de guanaco, debido a que no se cuenta con datos suficientes de isótopos del nitrógeno para esta especie. Tampoco se cuenta aún con la suficiente cantidad de análisis isotópicos de las restantes especies animales y vegetales. 


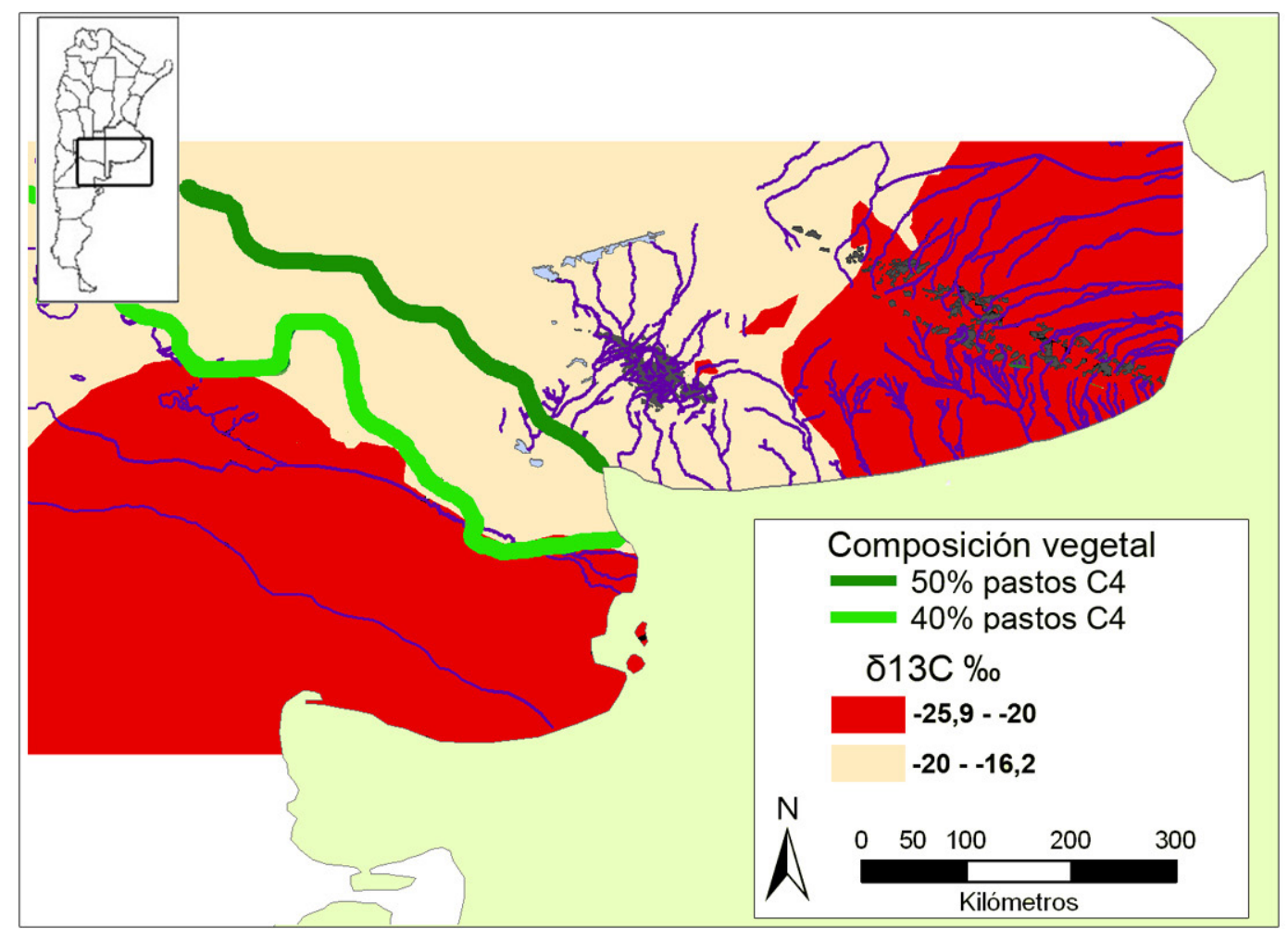

Figura 11.8. Distribución de valores isotópicos $\delta^{13} \mathrm{C}$ en muestras óseas de L. guanicoe, clasificados manualmente considerando rangos de valor dietario (Schoeninger y Moore 1992). Las líneas verdes marcan los límites del área en que los pastos $\mathrm{C}_{4}$ se encuentra representados por entre 40\% y 50\% (Epstein et al. 2002) la figura completa con la distribución de estos puede verse en la Figura 11.3.

En relación con el análisis espacial de la composición isotópica en muestras humanas, se observa un patrón similar al de guanaco, con valores $\delta^{13} \mathrm{C}$ más empobrecidas en la zona comprendida por las cuencas de los ríos Negro y Colorado, indicando paleodietas compuestas predominantemente (más del $80 \%$ ) por alimentos vegetales $\mathrm{C}_{3} \mathrm{o}$ animales consumidores de $\mathrm{C}_{3}$. En el área de Ventania y la llanura interserrana en cambio, la tendencia es hacia la presencia de valores medios, que se corresponden con dietas mixtas conformadas por vegetales $\mathrm{C}_{3} \mathrm{o}$ animales consumidores de $\mathrm{C}_{3}$ y una proporción más importantes de vegetales $\mathrm{C}_{4}$ y/o recursos marinos. Se observan también valores enriquecidos en $\delta^{13} \mathrm{C}$ en algunos sectores puntuales de la costa atlántica, principalmente en el NE de Patagonia. (Figura 11.9). 


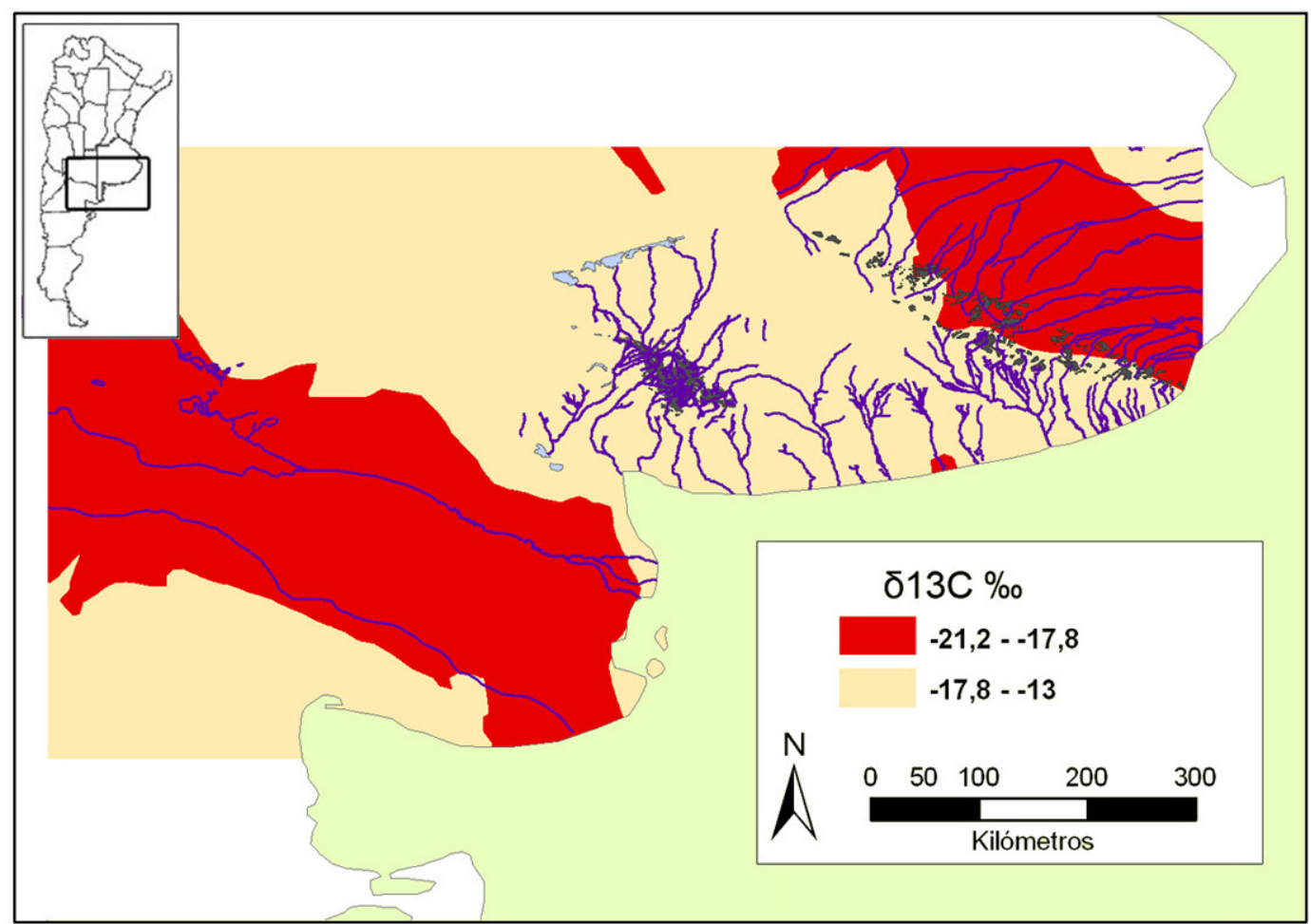

Figura 11.9. Distribución de valores isotópicos $\delta^{13} \mathrm{C}$ en muestras humanas, clasificados de manera manual considerando rangos de valor dietario (Pate 1995). El color rojo indica dietas compuestas por más de un $80 \%$ de recursos $\mathrm{C}_{3} \mathrm{y}$ el color salmón claro dietas mixtas en las que la proporción de recursos $\mathrm{C}_{3}$ es inferior al $80 \%$.

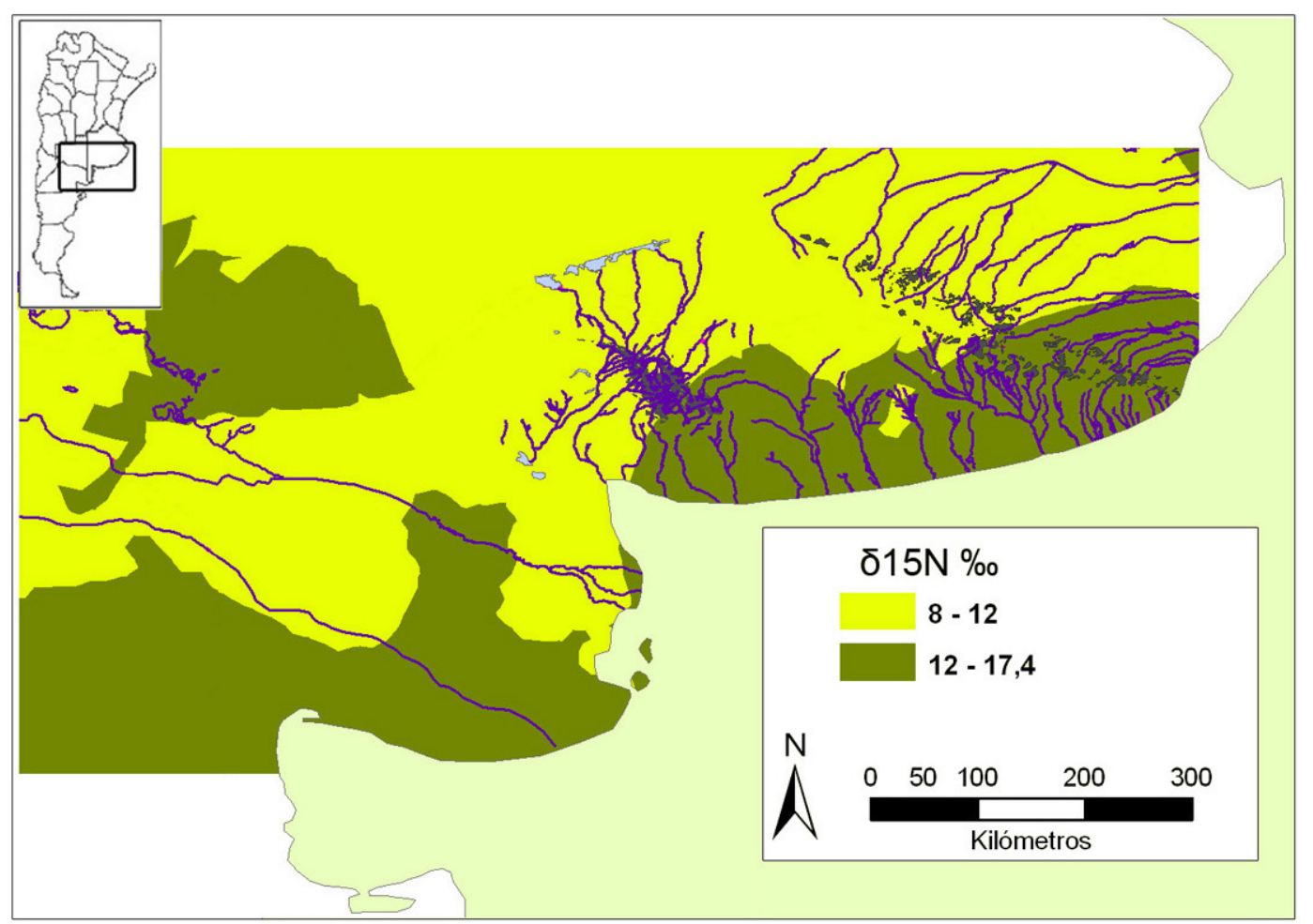

Figura 11.10. Distribución de valores isotópicos $\delta^{15} \mathrm{~N}$ en muestras humanas, clasificados de manera manual considerando rangos de nivel trófico (Barrientos 2010). 
En el caso de la tasa de $\delta^{15} \mathrm{~N}$ la tendencia espacial es hacia valores empobrecidos en $\delta^{15} \mathrm{~N}$, en el área de Ventania, oeste de la llanura interserrana y sectores medios de la cuenca de los ríos Negro y Colorado y valores más enriquecidos en la franja de $100 \mathrm{~km}$ más cercana a la costa de la llanura interserrana y desembocadura de los ríos Colorado y Negro (Figura 11.10), lo que indica un mayor aporte de nutriente de origen marino, en estas últimas zonas (Favier Duboir et al. 2009; Martínez, Zangrando y Prates 2009; Politis et al. 2009).

\subsubsection{Isotopos estables, dieta y movilidad}

A modo de resumen, los valores isotópicos de las muestras procedentes de Ventania indican una dieta mixta, basada en el consumo de plantas $C_{3}$, y/o consumidores de plantas $C_{3}$, y plantas $C_{4}$, y/o consumidores de plantas $\mathrm{C}_{4}$ (Figura 11.11). Este tipo de dieta no parece, al menos en principio, haber presentado cambios de importancia durante el Holoceno tardío, siendo que las muestras procesadas comprenden un lapso temporal de unos 3000 años radiocarbónicos aproximadamente, desde ca. 3300 años AP hasta $c a 500$ años AP. Tampoco se observan variaciones a nivel espacial dentro de los límites de la cuenca, sin embargo sí se evidencian cambios en la dieta cuando se amplía la escala espacial de análisis y se toman en consideración áreas vecinas. Estos cambios espaciales en la dieta estarían respondiendo a una menor proporción de pastos $\mathrm{C}_{4}$ al sur del río Colorado y, en algunos sectores, al uso de recursos marinos (Figura 11.12).

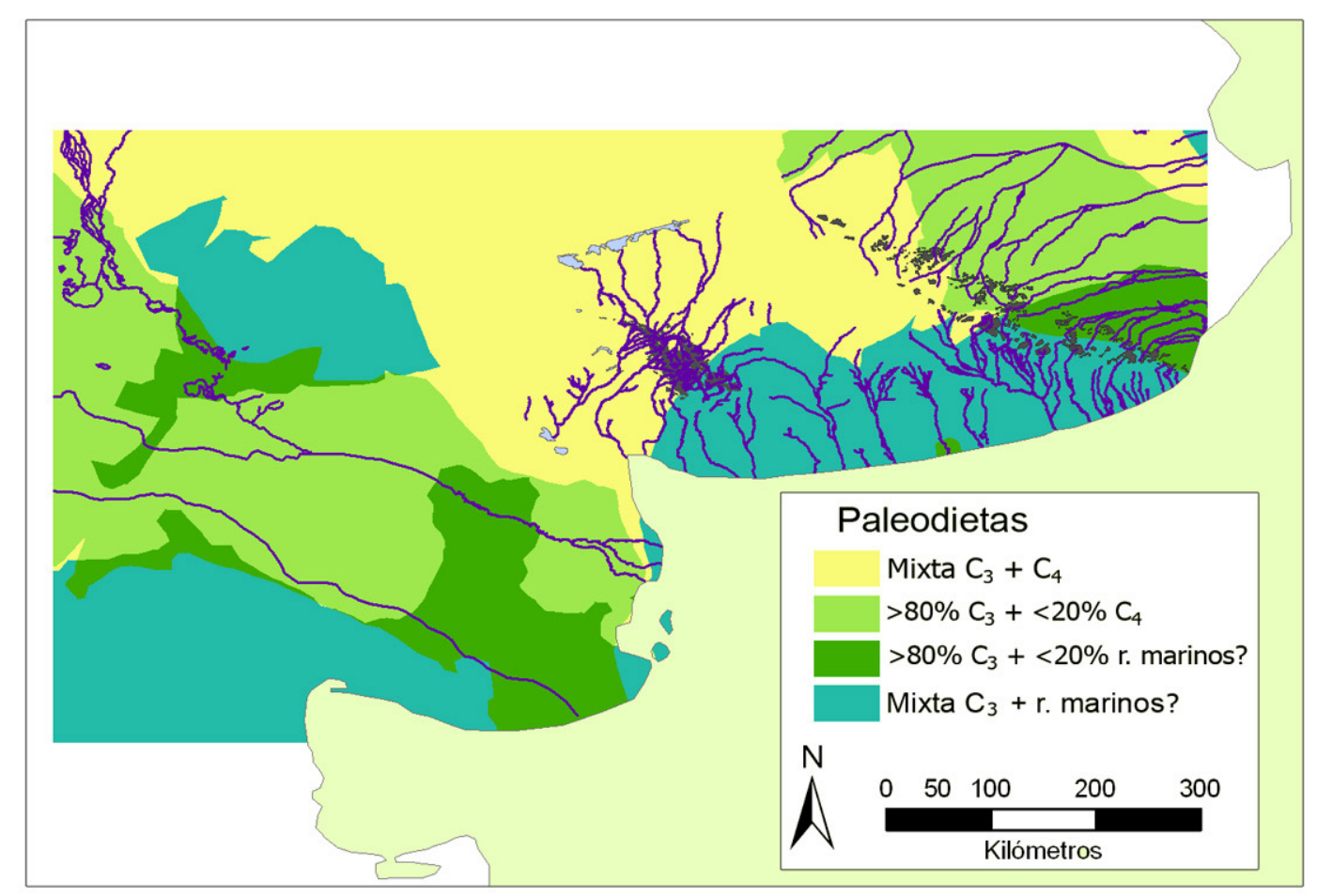

Figura 11.11. Distribución de paleodietas humanas obtenidas a partir de la reclasificación y sumatoria de las superficies obtenidas por interpolación para $\delta^{13} \mathrm{C}$ (ver Figura 11.9) y para $\delta^{15} \mathrm{~N}$ (ver Figura 11.10). 
Para el área de estudio, las variaciones espaciales en los valores isotópicos no parecen responder a cambios en los recursos consumidos por las poblaciones humanas (Figura 11.12), sino a variaciones en la ecología isotópica local. Si se considera, que las poblaciones de guanacos poseen rangos de movilidad más o menos estables y reducidos, es esperable que sus valores isotópicos varíen en función de las modificaciones en la composición de la cubierta vegetal local. Estas variaciones pueden ser útiles al momento de evaluar los rangos de acción de las poblaciones a partir de la composición isotópica de los individuos. La mayor parte de estos estudios se han basado, principalmente, en la proporción de recursos marinos incorporados en la dieta, dado que su consumo es fácilmente identificable a partir de la señal isotópica y, al tener una distribución conocida, es sencillo mapear áreas a partir de las cuales no se registra el consumo de recursos marinos y postular así dimensiones mínimas para los rangos de acción (Barberena 2005). Una situación similar, aunque en principio no tan clara, podría darse en el caso de recursos terrestres cuyas señales isotópicas varían espacialmente en relación con el ambiente en que se encuentran. Este podría ser el caso para Ventania, donde los valores $\delta^{13} \mathrm{C}$ de guanaco parecen diferenciarse de aquellos publicados para áreas vecinas (NE de Patagonia y NE del área Interserrana), mapeando aproximadamente la distribución de pastos $\mathrm{C}_{4}$ con valores superiores al $40 \%$.

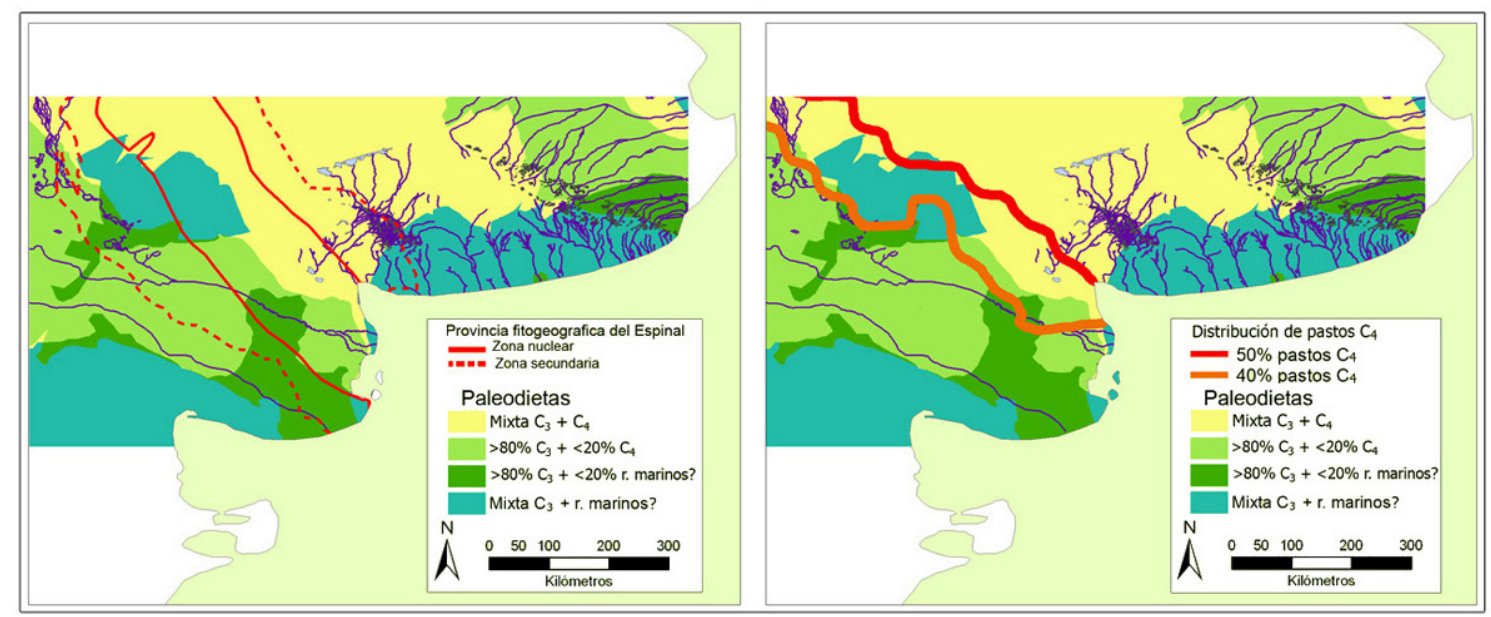

Figura 11.12. Distribución de paleodietas humanas en relación con las características de la estructura vegetal. A- distribución de la provincia fitogeográfica del Espinal y sus posibles variaciones; $\mathrm{B}$ - distribución actual de pastos $\mathrm{C}_{4}$.

La poca dispersión de los valores isotópicos de las muestras humanas de Ventania y la llanura ubicada al sudoeste de este sistema serrano, así como su correspondencia con los recursos locales, diferenciándose tanto de aquellos correspondientes a las cuencas de los ríos Colorado y Negro como a los del sector costero de la llanura Interserrana, parece apoyar la idea de rangos de acción más o menos reducidos, acotados a algunos miles de $\mathrm{km}^{2}$. Esto no significa que se trate de rangos de acción o territorios fijos o estables en el tiempo, ya que, como ha sido ampliamente discutido, el registro arqueológico refleja un promedio, modificado por procesos de formación, de las diferentes configuraciones espaciales adoptadas a lo largo del tiempo (Barberena 2005; Binford 1983; Borrero 2001a). Sin embargo, la correspondencia isotópica entre las muestras humanas de Ventania y las características ambientales locales parece indicar que las áreas regularmente ocupadas por los individuos muestreados, habrían sido espacialmente reducidas, al menos durante los últimos años de vida. Algunos individuos pudieron haber realizado viajes a mayor distancia con cierta frecuencia, por ejemplo en busca de recursos específicos, 
para mantener alianzas, etc, como queda evidenciado por la presencia de elementos exóticos en muchos sitios de la Región Pampeana (Berón 2004; Bonomo 2005; Oliva 2006). Sin embargo, la mayor parte de la población permaneció durante los últimos años de vida, en las inmediaciones de su lugar de entierro final, lo que estaría indicando rangos de acción de tamaños similares a los propuestos en el Capítulo 5 a partir del análisis de información etnográfica.

La presencia de rangos de acción acotados durante el Holoceno tardío, es coherente también con la presencia de áreas formales de entierro, principalmente durante momentos finales, y sitios de actividades múltiples con más de un entierro, que podrían ser correlato de un mayor constreñimiento espacial o de una movilidad grupal más reducida (Barrientos et al.1997; Madrid y Barrientos 2000, ver discusión en Barrientos 2001).

\subsection{Indicadores de movilidad y uso de recursos a escala poblacional}

\subsubsection{Entierros secundarios en el sur de la Región Pampeana y NE de Patagonia}

Para el sur de la Región Pampeana y NE de Patagonia han sido descriptos tanto entierros primarios como secundarios. En tanto entre los primeros existe una amplia variabilidad en cuanto a distribución, temporalidad y característica del entierro (e.g. cantidad de individuos, arreglo del o los cuerpo/s, presencia de deformación craneana), los entierros secundarios muestran, en el SE de la Región Pampeana y NE de Patagonia, ciertas recurrencias que llevaron a G. Barrientos a distinguir entre dos tipos:

"Uno de ellos (Tipo 1), asociado a la práctica de la deformación tabular oblicua, se caracteriza por estar constituido básicamente por el cráneo y los huesos largos, con una muy baja frecuencia de otras partes esqueletarias (Arroyo Seco 2 y Túmulo de Malacara). En el otro tipo (Tipo 2), asociado a la presencia de deformación tabular erecta, se hallan representadas casi la totalidad de las partes esqueletarias, aunque con distinta frecuencia. En la mayoría de los casos registrados (Campo Brochetto, Laguna Los Chilenos 1, Napostá, La Petrona), se verifica la presencia de pigmento rojo, y con menor frecuencia amarillo, sobre algunos de los huesos que integran el entierro. En el primer caso el NMI calculado varía entre 1 y 5, mientras que en el segundo caso, el NMI varía entre 1 y 14" (Barrientos 1997: 167).

La colección Saavedra depositada en el MLP, presenta algunas características, como la presencia de al menos 13 individuos, cráneos con deformación tabular erecta y gran parte de los elementos óseos con pigmento rojo y marcas de corte, que llevan a considerarla como correspondiente a un entierro secundario de tipo 2 (sensu Barrientos 1997, 2001). En cuanto a la representación de partes esqueletarias es difícil establecer la relación debido a que, por un lado se desconoce la metodología con que fue excavado y, por otro, al tratarse de una colección de más de 100 años, muchos de los elementos que la componían no han podido ser localizados, sin embargo la representación en mayor proporción de aquellos elementos más representados en los entierros tipo 2, así como la descripción en el catálogo de otras unidades anatómicas, también indicarían cierta similitud en este aspecto (Figura 11.13). 


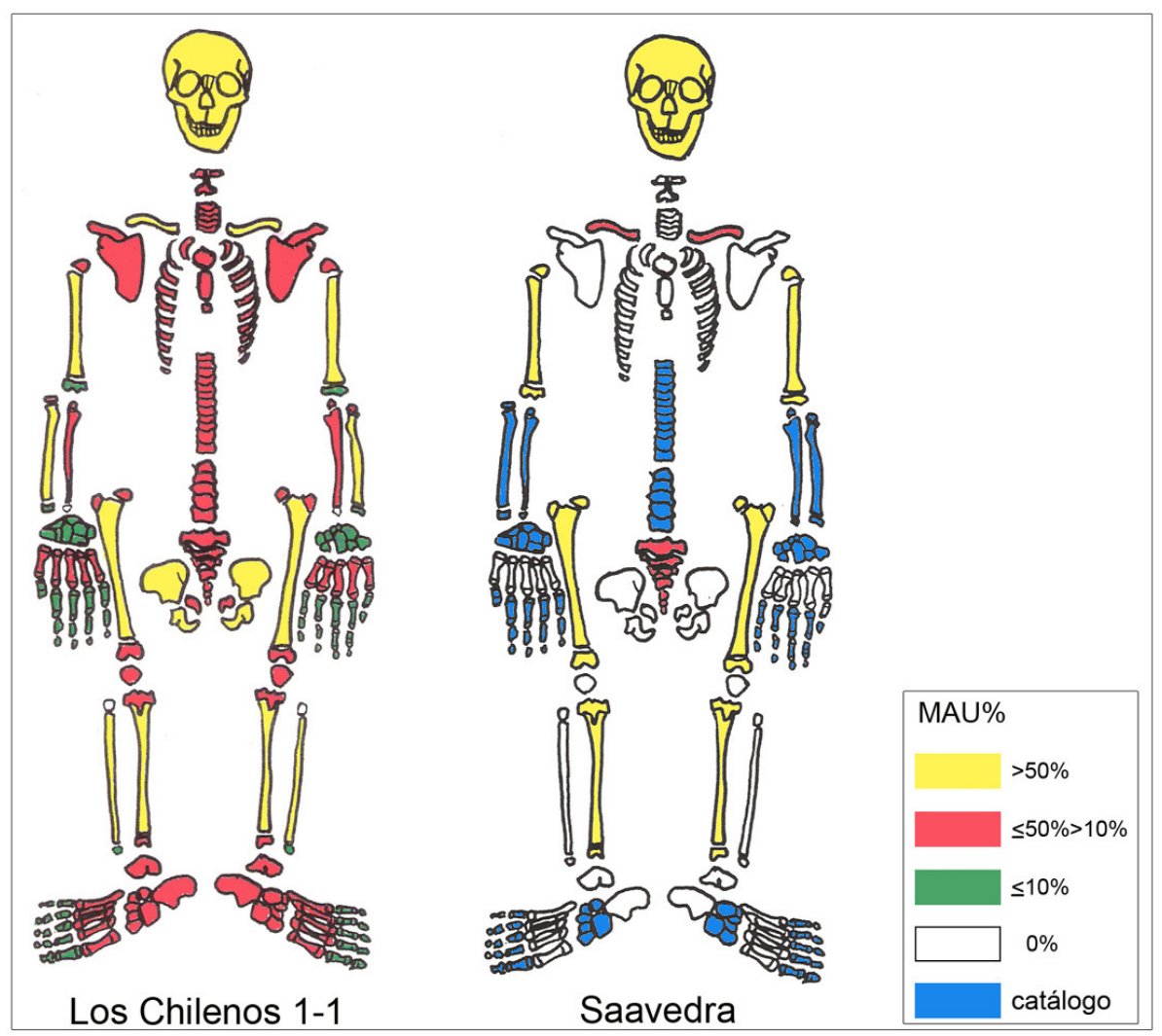

Figura 11.13. Comparación del MAU\% entre el entierro secundario del sitio 1 de Laguna Los Chilenos (Barrientos 1997) y la colección Saavedra. En azul se señalan los elementos mencionados en el catálogo de la colección pero que no pudieron ser localizados para su estudio.

Este tipo de entierros muestra una distribución definida en el tiempo y en el espacio. Se los encuentra en el NE de Patagonia y SE de la Región Pampeana, desde el Golfo de San Matías hasta el área Interserrana (Figura 11.14). Los fechados más tempranos los ubican cronológicamente hacia ca. 1200 años AP en el Golfo de San Matías (sitio Bajo de la Quinta - Cima de los Huesos), en tanto hacia el norte (cuenca del río Colorado y Ventania) presenta fechados más tardíos, que rondan los 500 años AP (sitios Los Chilenos, La Petrona, Paso Alsina). Su densidad también parece ser mayor hacia el sector sur del área donde, a los recientes hallazgos realizados en el curso medio e inferior del río Colorado (Bayón et al. 2004; Martínez et al. 2012) y la costa del Golfo de San Matías (Favier Dubois et al. 2007), se agregan las descripciones de grandes cementerios conteniendo inhumaciones secundarias -constituidas por huesos aglomerados y pintados de rojo, sin ajuar- realizadas a comienzos del siglo XX, para el área comprendida entre los ríos Colorado y Negro (Outes 1926; Vignati 1931). Las descripciones brindadas en todos los casos parecen coincidir en la similitud formal de estos entierros, dada por el arreglo de las piezas en la conformación del fardo funerario (cráneos en los extremos y huesos largos a los lados), la presencia de pigmento, principalmente rojo, la ausencia de ajuar funerario y la asociación con deformación tabular erecta (Barrientos 1997, 2001; Mariano 2008; Martínez 2010). Estos entierros difieren, en cambio, en la composición de los fardos (i.e. representación sexual y etaria y número de individuos), en la cantidad de fardos por sitio y en el color de los pigmentos y los motivos realizados con estos ${ }^{2}$, así como en la asociación o no con entierros primarios y áreas de actividades múltiples (Barrientos 1997, 2001;

2 Esta variabilidad, sin embargo, puede responder a diferencias en las historias tafonómicas de las muestras que redundan en una conservación diferencial de los pigmentos. 
Mariano 2008; Martínez 2010; Scabuzzo 2010). Este tipo de entierros secundarios se diferencia a su vez de aquellos descriptos para la Pampa Seca (sitio Chenque 1), donde los entierros secundarios, parecen ser exclusivos de individuos adultos y presentan un arreglo diferente de las unidades anatómicas, las que a su vez no se encuentran pintadas con ocre (Berón 2004; Luna 2008).

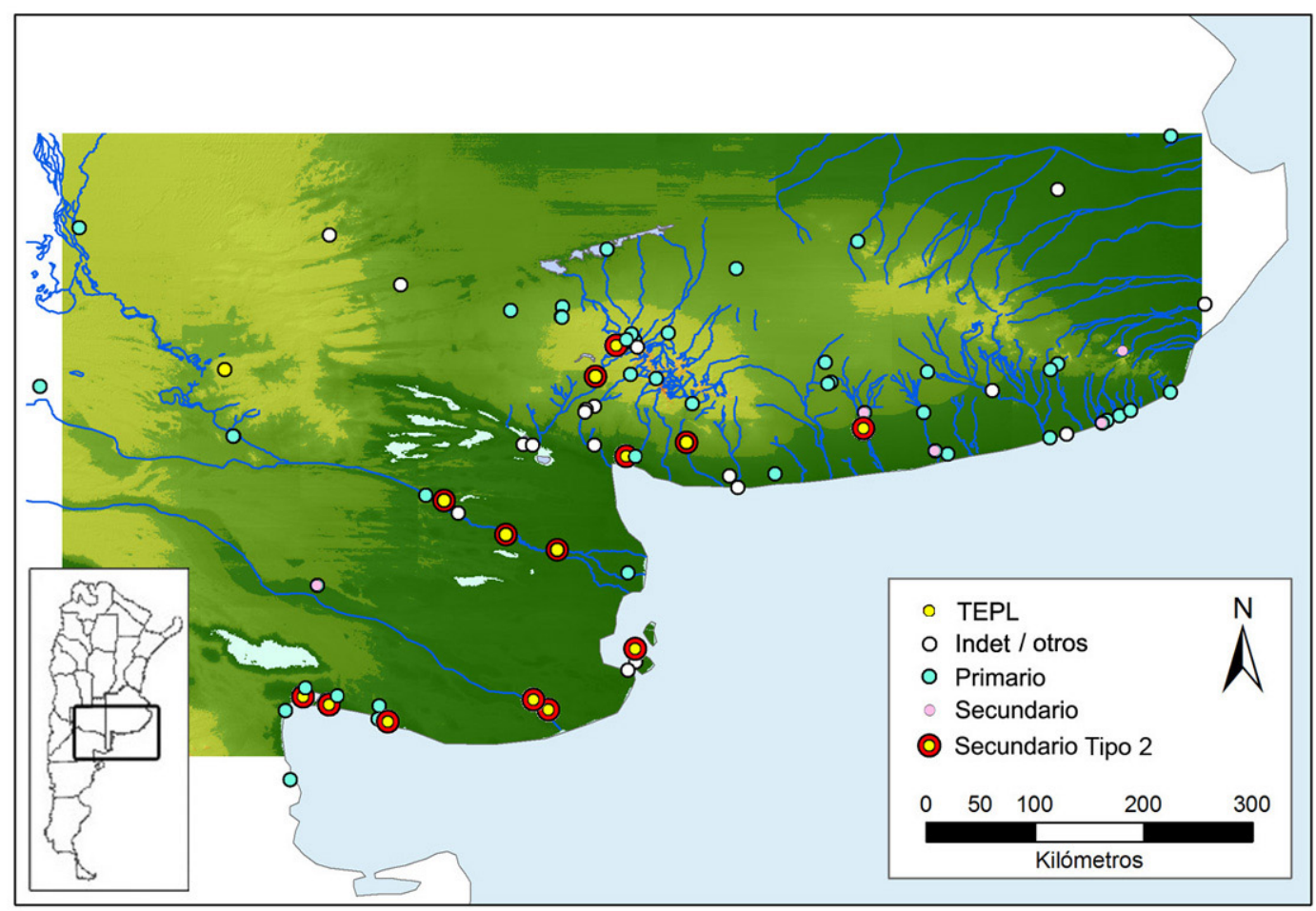

Figura 11.14. Distribución de entierros humanos en NE Patagonia, Pampa Seca, Interserrana, Tandilia y Ventania. TEPL= Deformación tabular erecta plano lambdica. Como entierros secundarios Tipo 2 se consignó tanto aquellos sobre los que se dispone de información contextual y de su disposición en planta como los que presentan algunas características que permite relacionarlo con este tipo de entierros, aunque con menor confiabilidad.

La mencionada distribución espacial y temporal de los entierros secundarios tipo 2 ha sido considerada como evidencia de un proceso de expansión poblacional desde el NE de Patagonia hacia el sudeste de la Región Pampea (Barrientos 1997, 2001; Barrientos y Pérez 2002). En tal sentido, los materiales óseos recuperados en el campo del Sr. Liceaga, en el sector serrano del Partido de Saavedra, aportan nueva información a los fines de evaluar la densidad de estos entierros en las sierras de Ventania y sus inmediaciones, así como sus características particulares y comunes con otros entierros del área de estudio y de otros sectores de la Región Pampeana y el NE de Patagonia (Barrientos 1997; Barrientos et al. 2002; Mariano 2008; Martínez et al. 2012, 2013; Outes 1926; Scabuzzo 2010; Vignati 1931).

\subsection{Discusión}

En este capítulo se ha presentado la información bioarqueológica e isotópica de la cuenca del arroyo Chasicó, analizándosela en relación con la disponible para las áreas vecinas. La identificación de un nuevo entierro, que por sus características parece corresponder a los entierros secundarios tipo 2 definidos por Barrientos (1997), apoya la hipótesis de que hacia momentos finales del Holoceno tardío, se habría producido una reducción en la movilidad, evidenciada, entre otras cosas, por la presencia de sitios con 
gran cantidad de entierros humanos situados a corta distancia unos de otros. La colección Saavedra se agrega a los ya previamente descriptos (Barrientos 2001; Martínez et al. 2012; Scabuzzo 2010). Su presencia es concordante con un aumento estadísticamente significativo en la frecuencia de indicadores vinculados a procesos infecciosos (Barrientos 1997), que probablemente estén evidenciando contactos más frecuentes con fuentes patogénicas, producto de una reducción en la movilidad (i.e. mayor duración de los campamentos y/o mayor redundancia ocupacional) (Barrientos 2001).

Los entierros secundarios tipo 2 han sido utilizados, junto con otras características del registro (i.e. rasgos morfométricos de los individuos, ergologías particulares) como evidencia para proponer una conexión entre el extremo sur de la Región Pampeana y NE de Patagonia. Dada su mayor densidad y aparición más temprana en el NE de Patagonia, se propuso que podrían ser producto de un proceso de expansión de grupos nordpatagónicos hacia territorios ubicados al norte de esta área, en algún momento durante los últimos 1000 años $\mathrm{C}^{14}$ AP (Barrientos 2001). Sin embargo, la poca dispersión de los valores isotópicos $\delta^{13} \mathrm{C}$ y $\delta^{15} \mathrm{~N}$ y su correlación con los recursos locales, estaría indicando la existencia de rangos de acción estrechos. Es decir que, si bien pudo haber existido un proceso de dispersión desde el NE de Patagonia, las nuevas poblaciones llegadas al área de Ventania, se habrían asentado en este sector, permaneciendo en el mismo la mayor parte del tiempo, al menos, durante los últimos 10 años anteriores a su muerte. Esto a su vez, podría explicar la variabilidad registrada entre los entierros secundarios tipo 2, siendo que, las poblaciones que migraron hacia nuevas áreas habrían reformulado, con el paso del tiempo, ciertos rasgos culturales en función de la nueva situación socio-ambiental.

Los estudios paleoambientales indican que durante todo el Holoceno tardío, la proporción de pastos $\mathrm{C}_{4}$ habría sido, en el área de estudio, superior al 40\%. Estos vegetales aumentan en frecuencia hacia fines del Holoceno medio, para luego disminuir durante el Holoceno tardío, hasta alcanzar los valores actuales (Zech et al. 2009), de una cubierta vegetal mixta con plantas $\mathrm{C}_{3}$ y $\mathrm{C}_{4}$ (Epstein et al. 2002). En tal sentido, la poca variación entre las muestras de la cuenca del arroyo Chasicó y sus inmediaciones, independientemente del momento temporal al que correspondan, es concordante con el predominio de pastos $\mathrm{C}_{4}$ durante todo el Holoceno tardío. Esto estaría indicando que, durante el Holoceno tardío, las áreas en las que los individuos obtuvieron los recursos consumidos, se habrían limitado a algunos cientos de kilómetros del lugar final de entierro.

Los valores isotópicos de los individuos analizados no parecen evidenciar cambios importantes en la dieta durante el Holoceno tardío. Sin embargo, la evaluación de otros indicadores, como la frecuencia de caries, muestran cambios significativos hacia momentos finales del Holoceno tardío que podrían reflejar un aumento en el consumo de alimentos ricos en carbohidratos ( v.g. farináceos) (L'Heureux 2000). En tal sentido, la relativa homogeneidad en los valores isotópicos puede responder a que la mayor proporción en hidratos de carbono haya sido obtenida a partir de vegetales localmente disponibles, los cuales son también consumidos por los herbívoros, razón por la cual, es esperable que la señal isotópica sea más débil e identificable, principalmente, en valores $\delta^{15} \mathrm{~N}$ que permiten evaluar el nivel trófico de los individuos (Schoeninger y Moore 1992). En otras palabras, es esperable que la expansión en la dieta o uso más intensivo de ciertos recursos (v.g. vegetales ricos en carbohidratos), propuesta por algunos autores (Barrientos 2001; L’Heureux 2000; Martínez 1999), se evidencie, isotópicamente, por variaciones en el nivel trófico de los individuos.

Si bien los datos isotópicos aquí presentados son preliminares permiten generar hipótesis sobre el 
consumo de recursos y, en relación con esto, la movilidad de las sociedades del pasado, que deberán contrastarse a partir de la realización de un mayor número de análisis isotópicos, principalmente orientados a la construcción de una ecología isotópicas del área Ventania, así como la realización de análisis sobre la fracción inorgánica del hueso que permita estimar mejor la importancia del componente vegetal en la dieta. 


\section{DISCUSIÓN Y CONCLUSIONES}

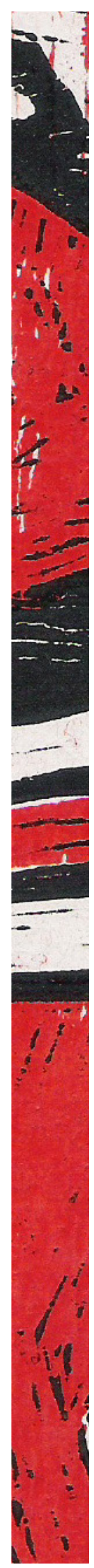




\section{IDiscusión}

La siguiente discusión general se organiza en relación con las preguntas planteadas en el apartado 1.1 de este trabajo, respondiéndose las mismas en función de la información presentada en los capítulos precedentes. En primer lugar, se procederá a discutir las tendencias generales en cuanto a movilidad y uso de recursos en la escala mesoregional (cuenca del arroyo Chasicó) y, en segundo lugar, a analizar desde una perspectiva macrorregional las particularidades del área de estudio en relación con el sur de la Región Pampeana y el NE de Patagonia.

\subsection{Tendencias generales en la cuenca del arroyo Chasicó: movilidad y uso de recursos}

\subsection{1 ¿Cuál es la profundidad temporal de las ocupaciones del área?}

El Holoceno tardío inicial es el momento en que ocurren las primeras evidencias de ocupación en el área de estudio. La secuencia ocupacional se inicia hacia $c a .4000$ años cal AP, incrementándose la intensidad de la señal arqueológica a partir de $c a .3000$ años cal AP, una situación compartida con otras áreas situadas al sur de las sierras de Ventania y hasta la cuenca del río Negro (Favier Dubois 2013; Favier Dubois et al. 2009; Martínez et al. 2013; Prates 2010). Tal patrón temporal, si se descartan sesgos de muestreo, puede responder a múltiples causas de naturaleza geomorfológica, demográfica y organizativa. Entre las primeras se encuentran, en la escala mesorregional, las modificaciones del cauce y capacidad de carga de los ríos y arroyos que drenan las sierras de Ventania. Hacia fines del Holoceno medio e inicios del tardío, los datos paleoambientales indican que se habrían producido importantes procesos geomorfológicos que modificaron el paisaje hasta configurar, a partir de $c a .3000$ años AP. la red fluvial actual (Melo et al. 2003; Zavala y Quattrocchio 2001). La escasez de evidencia arqueológica asignable al período 4000-3000 años cal AP y la ausencia de ésta para momentos anteriores, estaría respondiendo, con mayor probabilidad, a su destrucción o enmascaramiento como consecuencia de los cambios en el paisaje que afectaron el área localizada al sur-suroeste de las sierras de Ventania y, por lo tanto, al registro arqueológico de la cuenca del arroyo Chasicó. En tal sentido, si bien en la cuenca propiamente dicha no se cuenta con fechados más tempranos, éstos sí están presentes en el sector serrano vinculado con la cuenca del río Sauce Grande ( $c a .7000$ años cal AP; Castro 1983) y en la costa Atlántica, en inmediaciones de su desembocadura (ca. 8000 años cal AP; Bayón y Politis 1996; Bayón et al. 2012; Politis et al. 2009). Por otra parte, en la cuenca del río Sauce Chico (inmediatamente al E del arroyo Chasicó) se localizaron dos puntas cola de pescado (Flegenheimer y Bayón 1996; Silveira 1978, citado en Flegenheimer 1980), lo que apoyaría la hipótesis del uso de estos ambientes desde momentos iníciales del poblamiento pampeano, si bien resta aun conocer el modo e intensidad de su uso. 


\subsection{2 ¿Cuáles fueron los recursos aprovechados y qué importancia tuvo cada uno de ellos? ¿Cómo}

fueron utilizados?

En cuanto a las estrategias de subsistencia de carácter alimentario, la información de isótopos estables del $\mathrm{C}$ y $\mathrm{N}$ del colágeno de restos humanos indica la existencia de dietas basadas, fundamentalmente, en el consumo de recursos terrestres, tanto vegetales (mayoritariamente $\mathrm{C}_{3}$ ) como animales (mayoritariamente consumidores de vegetales $\mathrm{C}_{3}$ ). La incorporación de recursos vegetales $\mathrm{C}_{4}$, tanto por vía directa como indirecta, parece haber sido minoritaria, como así también la adquisición de recursos de origen marino, por lo que puede proponerse que los rangos de acción de los individuos que ocuparon la cuenca y fueron enterrados en ella no habrían incluido, en forma sistemática al menos, el litoral atlántico bonaerense.

Entre los recursos animales terrestres, los guanacos y los venados de las pampas parecen haber sido los más explotados, ya que ambas especies o al menos una de ellas (guanacos) se encuentran representadas en todos los conjuntos analizados. La importancia del guanaco en la dieta parece haberse mantenido inclusive en momentos finales del Holoceno tardío, cuando para otras áreas se postula la incorporación de vertebrados de pequeño tamaño, como consecuencia de un proceso de intensificación o diversificación (Martínez y Gutiérrez 2004; Martínez 2008-2009; Quintana et al. 2002; Stoessel 2010, 2012 b. Esto puede explicarse por la persistencia de este animal en el área, inclusive durante los momentos en que esta especie habría experimentado una marcada retracción en otras zonas de la Región Pampeana (Politis et al. 2011b). Si bien como se mencionó en el Capítulo 8, la ausencia de fauna de menor porte en los sitios más tardíos puede deberse a problemas tafonómicos, la poca variación de los valores isotópicos, tanto para $\mathrm{N}$ como para $\mathrm{C}$, también apoya una continuidad en la dieta durante todo el período analizado. A lo largo del tiempo, pues, el guanaco habría sido la principal fuente de proteínas, seguido por venado de las pampas, ñandú y animales menores (v.g. mara, armadillos).

El componente aportado por los recursos vegetales queda evidenciado, de manera indirecta, por el aumento en la densidad de los artefactos de molienda hacia el sector sur de la cuenca, concordante con el aumento en el grado de disponibilidad de las especies del Espinal. Este tipo de artefactos, si bien abundantes en el área de estudio y con evidencias de mantenimiento (e.g. administración del desgaste, mantenimiento de las superficies activas), en general presentan tamaños pequeños, utilizables en la mayor parte de los casos con una sola mano, elaborados sobre materias primas principalmente locales y con baja inversión de trabajo en su formatización. Todo ello indicaría el uso de estos artefactos en actividades de molienda de baja intensidad (Babot 2004, 2014). Los recursos vegetales, y particularmente los del espinal, pudieron ser utilizados a su vez, como alimentos frescos y con fines medicinales y tintóreos, entre otros (ver apartado 4.2.4; Burkart 1952; Prates 2009). Los recursos vegetales leñosos también debieron cumplir un rol de importancia como combustible y como materia prima para la fabricación de instrumentos o partes de instrumentos. Para estos usos no se cuenta con evidencia directa obtenida dentro de los límites de la cuenca, debido a los problemas de conservación que el ambiente pampeano representa para este tipo de materiales, pero diversas fuentes etnohistóricas mencionan su uso con estos fines (ver discusión en Prates 2009). A su vez, las propiedades de muchos de los vegetales del espinal para generar buena brasa, así como la recuperación en sitios de la costa atlántica bonaerense de instrumentos fabricados en madera -al menos uno de ellos en chañar (Geoffrea decorticans)- (Bayón y Politis 2014) permiten proponer que los recursos vegetales del espinal debieron haber sido utilizados, también en el área de estudio, con fines alimenticios, tecnológicos y de combustible. 
En cuanto al uso de los recursos minerales, particularmente las rocas empleadas en la confección de artefactos, su abastecimiento se realizó, principalmente, a partir de fuentes locales e inmediatamente locales. En el caso de las materias primas líticas, su transporte más allá de la zona de abastecimiento local habría sido escaso, limitado al traslado de rocas para ser utilizadas en tareas específicas o hacia aquellos lugares donde éstas no se encuentran inmediatamente disponibles. Las arcillas utilizadas en la elaboración de contenedores cerámicos, también parecen haber sido obtenidas a partir de fuentes locales, si bien la información disponible hasta el presente aún es escasa como para realizar afirmaciones confiables en este sentido. La sal es otro recurso presente en la cuenca y que debió ser de importancia para las sociedades cazadoras-recolectoras. Su empleo fue descripto por diferentes viajeros (Barne [1837] 2007; Musters [1871] 1997; ver también discusión en Prates 2009), quienes mencionan la importancia de su uso en las comidas y especialmente cuando salen a cazar, “...tanto para sazonar la sangre, que rara vez comen sin ella, como también para salar la carne de guanaco o avestruz." (Musters [1871] 1997: 206). El uso de las Salinas Chicas a su vez, queda evidenciado por la presencia de materiales arqueológicos sobre sus márgenes, la densidad de estos, sin embargo, es considerablemente inferior a los observados sobre las márgenes de la laguna Chasicó. Esto puede deberse a la ausencia de fuentes de agua estable en sus inmediaciones, lo que pudo limitar la posibilidad de establecer campamentos por largos períodos de tiempo. En este sentido, el uso de las salinas pudo realizarse de manera logística, desde la laguna Chasicó. Sin embargo, la menor densidad también puede responder a problemas de muestreo dados por una menor intensidad en las prospecciones y/o por una mayor estabilidad del paisaje, donde los procesos erosivos (como la acción del agua) no han actuado exponiendo materiales. Por último, el recurso hídrico se encuentra disponible en toda la cuenca, actuando probablemente con un atractor, dada su escasez en las áreas vecinas (ver apartado 12.1.3)

\subsection{3 ¿Cuáles fueron los recursos con mayor incidencia y de qué manera influyeron en los patrones de} uso del espacio?

Entre los recursos analizados durante esta investigación, algunos presentan una distribución espacial y temporal relativamente homogénea, en tanto otros muestran variaciones en su disponibilidad. Es esperable que estos últimos hayan ejercido mayor influencia en la estructuración de las estrategias de uso del espacio. Entre aquellos recursos con mayor homogeneidad en su distribución se encuentran las materias primas líticas, disponibles a lo largo de toda la cuenca. Si bien su calidad es variable, ésta no parece haber sido determinante en su selección; por el contrario, en el aprovisionamiento lítico predominaron las estrategias de tipo embedded que habrían afectado sólo secundariamente las pautas de movilidad, en relación con la búsqueda de materias primas de mejor calidad para la realización de tareas específicas y con la reocupación de determinados sectores en donde estas fueron acumuladas en la forma de caches o escondrijos de materia prima. Los recursos animales también muestran una distribución homogénea, particularmente en el caso del guanaco. Este recurso habría presentado pocas variaciones en el área de estudio ya que inclusive durante los momentos de mayor retracción su probabilidad de encuentro sería alta (Politis et al. 2011b), por lo que se espera que no haya incidido fuertemente en el modo en que se usó el espacio.

Otros recursos sin embargo, pudieron ejercer mayor influencia sobre las estrategias de movilidad, aunque aún se cuenta con escasa evidencia arqueológica al respecto. Este es el caso de los recursos 
vegetales del Espinal, la sal y el agua. En el Capítulo 5 se propuso un modelo acerca de la extensión que pudo haber tenido la provincia fitogeográfica del Espinal y su estratificación en función de la densidad y grado de estabilidad a través del tiempo (ver apartado 5.2.1.1.1.). Su predictibilidad probablemente también haya sido variable, disminuyendo en las áreas marginales ya que su fructificación puede verse afectada por aumentos en las precipitaciones durante la floración (Burkart 1952). En relación con este modelo, la distribución de las frecuencias relativas de los artefactos de molienda aumenta en el área de mayor concentración actual de recursos del Espinal -área que probablemente haya presentado mayor estabilidad y predictibilidad a través del tiempo- evidenciando, de manera indirecta, su procesamiento. La disponibilidad de sal también pudo influir en el uso del sector inferior de la cuenca. Este recurso se encuentra ausente en la Pampa Húmeda y su obtención se circunscribe, principalmente, a la estación estival (Mogni 1991; Schalamuk et al. 1999; ver apartado 4.2.2.), pudiendo ser también necesario para su procesamiento el uso de artefactos de molienda. Considerando estas características, sería esperable que el modo en que se usó el sector inferior de la cuenca se haya visto influenciado por la distribución, densidad y temporalidad de los mencionados recursos. Estos pudieron incidir en el rango de acción de los grupos (i.e. a los fines de incluir este tipo de recursos), el momento de uso de dicho ambiente (i.e. priorizando el período estival, cuando se produce la fructificación y hay mayores probabilidades de que la sal esté disponible) y/o el grado de permanencia y reocupación de determinados espacios, a los fines de aprovechar los artefactos de molienda acumulados.

En relación con la importancia que la disponibilidad de agua pudo haber tenido en la estructuración de las pautas de uso del ambiente, se observa cierta asociación entre la presencia de registro arqueológico y la disponibilidad inmediatamente local de fuentes de agua. Esto se ve reflejado en la ausencia de registro arqueológico en áreas con una alta concentración de otros recursos pero alejados del curso del arroyo o los cuerpos de agua, situación que se observa, particularmente, en la cuenca inferior (ver apartado 6.2.2.3.3). Si bien las fuentes de agua se encuentran presentes a lo largo de toda la cuenca, son muy escasas en sus inmediaciones, hecho que debió haber dificultado la ocupación de las zonas aledañas. A su vez, en momentos de mayor aridez, cuando la laguna Los Chilenos adquiere capacidad de almacenamiento (Bonorino et al. 1989), este recurso pudo haber estado ausente inclusive en algunos sectores del arroyo, limitando la ocupación del sector medio de la cuenca en los momentos del año con menor disponibilidad hídrica.

Por último, la cuenca del arroyo Chasicó debió funcionar, además, como un nexo entre dos ambientes ricos en recursos: el NE de Patagonia y las sierras de Ventania. En estas últimas, si bien los recursos bióticos de mayor importancia económica (guanaco, venado de las pampas y vegetales propios del Espinal) pudieron tener una menor densidad que en el NE de Patagonia (considerando el modelo presentado en el apartado 5.2.1.1.4.), la presencia de abrigo, amplia variedad y disponibilidad de materias primas líticas y los terrenos escarpados -que pudieron facilitar las estrategias de caza-, habrían jerarquizado el uso de dichas sierras. A esto se agrega su valor simbólico que debió haber ejercido una fuerte atracción sobre los grupos cazadores-recolectores, influyendo en sus estrategias de uso del espacio. La relevancia que tuvo este sistema serrano en la cosmovisión de dichas sociedades queda evidenciado en los más de 30 abrigos rocosos con representaciones pictóricas sobre sus paredes y techo que, a través de algunas de sus características iconográficas, vinculan estas sierras con las de Tandilia, Lihué Calel e incluso el sur de Cuyo y norte de Neuquén (Curtoni 2006; Oliva 2013). Algunas fuentes etnohistóricas también señalan su relevancia, así, Darwin menciona “...Los gauchos piensan que los 
indios consideran al árbol como Dios mismo... un gaucho me refirió que, viajando un día con un indio a algunas millas al norte del rio Colorado, su acompañante se puso a hacer el ruido que hacen todos sus compatriotas en cuanto perciben el famoso árbol; después llevose la mano a la cabeza e indicó la sierra lejana. El gaucho le preguntó la razón de todos esos gestos, y el indio le respondió en su mal español: "Primera vista de la sierra"." (Darwin [1845] 2007: 90). También otras fuentes mencionan el uso de estas sierras, durante los siglos XVIII y XIX, por parte de grupos trasandinos que utilizaron algunas de las cuevas, como la Gruta de los Espíritus, para la realización de rogativas (ver síntesis en Oliva 2013, 2014). Considerando estas evidencias, las sierras pueden ser consideradas como un importante recurso simbólico y estratégico que debió influir sobre las pautas de movilidad.

\subsection{4 ¿Qué amplitud tuvieron los rangos de acción de las poblaciones que habitaron la cuenca del} Arroyo Chasicó?

Durante el lapso comprendido entre $c a .4000$ años cal AP y momentos de contacto hispano-indígena, la distribución de los isótopos estables del $\mathrm{C}$ y $\mathrm{N}$ y de las frecuencias relativas de las materias primas líticas muestran, en el SE de la Región Pampeana y NE de Patagonia, un patrón de distribución que no es uniforme, sino parcelado. Esta heterogeneidad, concordante con la disponibilidad local de recursos, no parece corresponderse con rangos de acción de gran escala, si no con la utilización de áreas relativamente acotadas compatibles, en principio, con las dimensiones de los rangos de acción esperables en función de la latitud, es decir entre ca. $2000 \mathrm{~km}^{2}$ y $12000 \mathrm{~km}^{2}$ según el modelo etnográfico presentado en el Capítulo 5. En tal sentido, los valores isotópicos del carbono y el nitrógeno son congruentes, en la cuenca del arroyo Chasicó, con modificaciones en la frecuencia relativa de vegetales $\mathrm{C}_{4}$ que, al norte del río Colorado, aumentan su representación a valores superiores al 40\%, proporción que habría sido similar o mayor durante todo el Holoceno tardío (Zech et al. 2009). Esta correspondencia entre variaciones en los valores isotópicos y modificaciones en la composición de la vegetación permite proponer que los recursos consumidos por los individuos enterrados en la cuenca del arroyo Chasicó, fueron obtenidos en inmediaciones de dicha cuenca. A su vez, casi la totalidad de las rocas presentes en los sitios de la cuenca del arroyo Chasicó, pueden ser obtenidas a distancias que no superan los $130 \mathrm{~km}$, alejándose de este rango sólo algunas materias primas minoritarias (inferiores al 1\%). Este espacio, en el que fueron obtenidas las rocas, comprende aproximadamente la distancia entre la laguna Chasicó y las sierras de Ventania, coincidiendo a su vez, aproximadamente, con el área comprendida por dietas caracterizadas por un mayor componente de vegetales $\mathrm{C}_{4}$ o consumidores de vegetales $\mathrm{C}_{4}$.

Si bien las diferentes evidencias analizadas son concordantes con rangos de acción relativamente acotados, esto no implica, necesariamente la existencia de límites o territorios claramente definidos. Por el contrario, la información obtenida durante el desarrollo de esta investigación, apoya la hipótesis de patrones de actividad espacialmente continuos, no territoriales, donde las fronteras o límites no habrían estado claramente definidos. En tal sentido, la disminución gradual en la proporción de materias primas en función de la distancia, (Figura 12.1) puede ser interpretada como un posible indicador de la ausencia de límites culturales claramente definidos (Soja 1971). Por otra parte, la similitud en muchos de los motivos empleados en la decoración cerámica, así como la presencia tanto de rasgos artefactuales que se encuentran con alta frecuencia en la Región Pampeana (e.g. altos índices de unifacialidad, raederas doble convergentes, puntas de proyectil apedunculadas) como de otros con mayor frecuencia en 
la Región Patagónica (e.g. aumento del índice de bifacialidad hacia el sector inferior de la cuenca, presencia de una punta pedunculada en este mismo sector) también llevan a inclinarse por un uso del paisaje espacialmente continuo. Esto es coincidente con los estudios realizados por Barrientos y Gordón (2004) y Gordón (2010), quienes observan bajas prevalencias de indicadores de violencia interpersonal en momentos prehispánicos, concordantes con la ausencia de estrategias sistemáticas de defensa de territorios.

\subsection{5 ¿Cuál fue el tipo (residencial o logístico) y el grado (frecuencia de los movimientos) de movilidad predominante de esas poblaciones?}

Si bien es difícil realizar afirmaciones sobre el modo en que las poblaciones del pasado se movieron a través del paisaje, algunos indicadores pueden comenzar a clarificar este aspecto. La baja frecuencia de materiales cerámicos en la cuenca del arroyo Chasicó, tanto absoluta como relativa, puede considerarse un indicador indirecto de una movilidad residencial relativamente alta, dado que el volumen y peso de este tipo de contenedores, puede dificultar su transporte. A esto se agrega el elevado riesgo de fractura de los artefactos y la consecuente pérdida de la eficiencia de la tecnología, sobre todo bajo condiciones que inhiben un reemplazo efectivo de las unidades perdidas, cuando los traslados son frecuentes (Arnold 1985; Simms et al. 1997; Skibo et al. 1989). En el área de estudio, la localización de arcilla y combustible (leña) parece haber sido ubicua, por lo que no constituirían un limitante tecnológico de peso. Sin embargo, la poca utilización de cerámica podría responder a un contexto social en el que la incorporación de esta tecnología para la cocción, procesamiento y/o almacenamiento de recursos no habría sido fundamental, quedando su uso limitado a ciertas situaciones particulares.

En cuanto al registro lítico, se observó el uso predominante de rocas inmediatamente locales y un escaso transporte de éstas, lo que puede responder a varias razones. Por una parte, puede obedecer a una baja movilidad residencial y/o logística y, consecuentemente, a un menor acceso a las fuentes más lejanas, como las localizadas en las sierras de Ventania. Por otra, la baja representación de rocas alóctonas puede ser producto de la alta disponibilidad de materias primas líticas a lo largo de toda la cuenca, donde su transporte habría estado limitado hacia lugares donde éstas no se encuentran inmediatamente disponibles, o bien a aquellas rocas de mejor calidad, que pudieron ser requeridas para llevar a cabo tareas específicas. Por otra parte, la escasez de núcleos, en relación con la frecuencia de lascas e instrumentos, es coincidente con estrategias en las que se priorizó el aprovisionamiento de los individuos por medio de artefactos transportables, principalmente instrumentos terminados y lascas, por sobre el aprovisionamiento de lugares (Khun 1994; Nelson 1991). Este tipo de estrategias puede responder, en este caso también, a una alta movilidad residencial, en la que se privilegió el diseño de instrumentos transportables, o bien, una alta disponibilidad areal de materias primas líticas, entre las cuales no existen grandes diferencias en calidad, pudiendo resolverse la mayor parte de las situaciones mediante el uso de las rocas inmediatamente disponibles, razón por la cual no es necesario desarrollar estrategias de acumulación de grandes cantidades de materias primas en lo que ha sido denominado como procesos de "litificación del paisaje" (Martínez 1999). Esta característica del registro lítico también puede estar respondiendo a una conjunción de ambas situaciones, es decir, una frecuente movilidad residencial en un ambiente con una amplia disponibilidad de rocas. 
Aunque la estrategia priorizada parece haber sido el transporte de rocas en la forma de instrumentos y lascas, en algunos sectores puntuales del paisaje se observan elementos que permiten inferir acciones de aprovisionamiento de lugares, dadas por núcleos de gran tamaño (registrados en algunas colecciones del área; Oliva 2014), caches de materias primas (Oliva 2014; Oliva y Pérez 2008) y depósitos de artefactos de molienda grandes y pesados, en ocasiones con variado grado de desgaste y evidencias de reciclaje y administración del desgaste. Este tipo de artefactos estarían relacionados con la reocupación de sectores particulares del paisaje a los fines de procesar recursos predecibles en el tiempo y el espacio (Smith y Mc Knees 1999), como lo son los productos vegetales del espinal o la sal.

La distribución del registro arqueológico en la forma de concentraciones discretas más o menos extensas (entre 400 y 1000 m de largo en distribuciones con geometría lineal tales como en bordes de lagunas o márgenes de cursos de agua), separadas por áreas sin materiales arqueológicos o con hallazgos aislados dispersos, también estaría indicando patrones de reocupación genérica -i.e. con grado moderado de congruencia espacial entre sucesivas ocupaciones- de ciertos espacios (patrón localizado, sensu Dewar y McBride 1992). En tal sentido, si bien ante la ausencia de estructuras permanentes, es esperable que haya variación en la localización de las sucesivas ocupaciones de un espacio, la generación de ciertos rasgos como la acumulación de artefactos de molienda o el almacenamiento de materias primas, aumentará el atractivo de los sectores previamente ocupados (Smith y Mc Knees 1999). De este modo, las sucesivas ocupaciones podrán tener cierto grado de congruencia, generando así extensas acumulaciones de materiales en lugares particulares del paisaje (Dewar y McBride 1992). Es así como las tensiones entre el uso de artefactos de molienda, necesariamente grandes y pesados, y la movilidad residencial, se reducirán a través de la conservación y almacenamiento de tales artefactos en las inmediaciones de los lugares de procesamiento (Wright 1994). Es decir que, aunque la movilidad residencial pudo haber sido alta, ésta habría incluido la reocupación periódica de determinadas localizaciones, donde se acumularon artefactos con mayor inversión de energía, tanto en su manufactura como en su trasporte. Este tipo de estrategias en el uso del espacio también fue propuesta previamente para las ocupaciones de la laguna Los Chilenos, caracterizada como una distribución localizada, resultado de una secuencia ocupacional con un grado moderado de congruencia espacial (Barrientos et al. 1997). Esta tendencia a la re-ocupación de determinados ambientes se intensifica, al igual que en otras áreas de las regiones pampeana y del NE de Patagonia, durante momentos finales del Holoceno tardío, cuando aumentan las evidencias de reocupación así como la cantidad de sitios de entierro y el número de individuos por entierro (Barrientos 1997; Martínez 2010). Esto se corresponde, en la cuenca del arroyo Chasicó, con los sitios La Montaña 1, Los Chilenos 1 y, probablemente, la colección Saavedra, ubicados cronológicamente en momentos inmediatamente anteriores al contacto hispano-indígena.

En este contexto, ciertos espacios como los grandes cuerpos de agua (para el caso del área de estudio las lagunas de Chasicó y Los Chilenos) donde co-existen varios recursos (i.e. hídricos, vegetales, animales y, en el caso de la laguna Chasicó, sal) pudieron funcionar como lugares de agregación en los que confluyeron grupos diversos. La presencia de caracoles marinos y de algunas rocas cuyas fuentes de aprovisionamiento se localizan más allá de los $130 \mathrm{~km}$ (como la riolita ignimbrítica o la obsidiana), se condice con la existencia de redes sociales amplias que habrían comprendido las distintas subáreas consideradas. La existencia de este tipo de redes también ha sido planteada por otros investigadores, especialmente durante el Holoceno tardío (Berón 2004; Bonomo 2006; Martínez 2010; Politis y Madrid 2001). De esta forma, al menos algunos individuos pudieron haberse trasladado a mayores distancias, 
con el objetivos de adquirir bienes particulares y participar de eventos de agregación en los que se compartiese información de corto y largo plazo y se fortalecieran los lazos sociales necesarios en casos de escasez en la disponibilidad local de recursos (Cashdan 1985; Gamble 1990; Hegmon y Fisher 1991; Mithen 1990; Whallon 2011).

\subsection{La cuenca del arroyo Chasicó en el contexto del sur de la Región Pampeana y el NE de Patagonia}

12.2.1 ¿Pueden identificarse diferencias entre las características (e.g. tecnológicas, morfológicas y/o decorativas) de los conjuntos arqueológicos de la cuenca del arroyo Chasicó y las de áreas vecinas (Ventania, Interserrana, cuenca del rio Colorado, Pampa Seca, Tandilia)?

El registro arqueológico representado en la cuenca del arroyo Chasicó muestra características que no lo diferencian cualitativamente sino cuantitativamente de aquel descripto para el sur de la región Pampeana y NE de Patagonia. Entre ellas se encuentran la presencia de materias primas de origen tanto pampeano (i.e. cuarcitas) como patagónico (i.e. RSO, areniscas rionegrenses), artefactos cuya presencia aumenta hacia la Región Pampeana (e.g. raederas doble convergentes, instrumentos unifaciales) o Patagónica (e.g. puntas pedunculadas, instrumentos bifaciales) y contenedores cerámicos con formas y motivos decorativos similares a los descriptos para el SE de la Región Pampeana y NE de Patagonia, similitud que también se observa para algunos motivos presentes en otros soportes muebles e inmuebles (Fiore y Borella 2010; Oliva 2006, 2013, 2014). Estas similitudes permiten, como se ha venido exponiendo, plantear la existencia de pautas de uso del espacio continuas, sin límites o fronteras claramente definidos y la existencia de redes de intercambio de bienes e información que, a su vez debieron funcionar como herramientas de seguridad ante situaciones de crisis ambiental.

También se observan ciertas similitudes en los patrones de entierro. En este caso, en el área de estudio se recuperaron algunos elementos óseos humanos aislados, un entierro secundario Tipo 2 (Barrientos 1997; Barrientos et al. 1997, 2002) y otro entierro con características similares, depositado actualmente en el Museo de La Plata. Los entierros secundarios caracterizados por Barrientos (1997) como Tipo 2, han sido registrados en un lapso temporal que comprende los últimos 1200 años AP. Espacialmente se los ha registrado desde el NE de Patagonia (costa norte del Golfo de San Matías; Favier Dubois et al. 2007) hasta el arroyo Claromecó en el área Interserrana (Barrientos y Leipus 1997). La cantidad y diversidad de sitios con entierros humanos es mayor al sur del río Colorado (Barrientos y Gordón 2004), aumentando también en esta zona la antigüedad y densidad de los entierros secundarios múltiples con pigmento rojo sobre sus huesos y con un arreglo particular de sus partes (Favier Dubois et al. 2007; Martínez et al. 2012; Outes 1926; Vignati 1931). Al norte del río Colorado en cambio, este tipo de entierros son menos frecuentes, encontrándoselos de manera dispersa (Barrientos 1997; Barrientos et al. 2002; Barrientos y Leipus 1997; Scabuzzo 2010). Considerando la distribución espacial y temporal de estos entierros, la distribución de elementos no utilitarios (e.g. tembetás, placas grabadas) y las características ambientales, se ha propuesto que los ambientes más ricos en recursos (correspondientes a la Zona I en la estratificación presentada en el Capítulo 5), habrían sido los más requeridos. En estos ambientes se habría llegado a niveles de saturación demográfica (Borrero 1994-1995, 2001b) que podrían haber sentado las bases de profundos cambios organizacionales de las sociedades implicadas (v.g. menor movilidad residencial, mayor densidad poblacional, implementación de estrategias de diversificación económica; Barrientos 1997; Barrientos y Pérez 2004). 
En el Capítulo 5 se planteó una estratificación de los ambientes de la cuenca en función de su disponibilidad de recursos, según la cual aquellos localizados en la sub-cuenca inferior presentan características similares (en disponibilidad de recursos terrestres) a los del NE de Patagonia, diferenciándose de los representados en la cuenca media y superior. Estas diferencias, sin embargo, no parecen relacionarse con variaciones en los sistemas de subsistencia, es decir, las variaciones observadas en el registro arqueológico, a lo largo de la cuenca, parecen relacionarse más con la disponibilidad local de recursos que con poblaciones implementando diferentes sistemas de subsistencia. En otras palabras, los procesos de cambio organizativo, para los que existe abundante evidencia en la cuenca inferior de los ríos Negro y Colorado (Barrientos 2009; Martínez 2010; Martínez et al. 2012), no se habrían desarrollado en el área de estudio, al menos no con la misma intensidad. En el estado actual de conocimiento, en el registro zooarquelógico e isotópico de la cuenca del arroyo Chasicó, se observan evidencias de continuidad a través del tiempo, no encontrándose indicadores que puedan ser relacionados con un marcado proceso de intensificación y diversificación económica. Las variaciones en los aspectos tecnológicos por otra parte (e.g. materias primas utilizadas, proporción de artefactos vinculados con actividades de molienda), parecen responder, principalmente, a variaciones espaciales en la disponibilidad local de recursos (v.g. disponibilidad local de rocas, densidad de los recursos del Espinal).

La identificación en la cuenca del arroyo Chasicó, o sus inmediaciones, de un nuevo entierro secundario cuyas características permiten relacionarlo a aquellos definidos por Barrientos (1997) como tipo 2, aumenta a cuatro el número de casos de esta clase de prácticas funerarias localizadas en las llanuras adyacente a las sierras de Ventania, reforzando la hipótesis según la cual, durante momentos finales del Holoceno tardío, la dinámica de poblamiento del SE de la Región Pampeana se habría dado en estrecha vinculación con los desarrollos ocurridos en el NE de Patagonia. Este tipo de rasgos evidencia la existencia de un sustrato simbólico-ideológico compartido por las poblaciones del NE de Patagonia y SE de la Región Pampeana, sin embargo, esto no necesariamente implica la ampliación de los rangos de acción para incorporar las nuevas áreas (rangos de acción que hubiesen incluido desde las sierras de Ventania hasta el río Negro o más allá). Por el contrario, la evidencia registrada hasta el presente se explica mayormente por rangos de movilidad acotados y estables en el tiempo, al menos en una escala temporal corta, los que habrían favorecido el desarrollo de particularidades en este tipo de prácticas. Dicho proceso pudo haberse dado como consecuencia de la expansión de poblaciones desde el NE de Patagonia hacia áreas adyacentes situadas al norte y al oeste de esta región, compitiendo y remplazando a las poblaciones pre-existentes (Barrientos y Pérez 2002), o bien como producto de un proceso que se desarrolló simultáneamente como consecuencia de un escenario de interacción y coexistencia entre los grupos de áreas aledañas (Martínez 2010).

Si bien a partir del desarrollo de esta tesis se han aportado algunos datos acerca de las tendencias temporales observadas en la cuenca del arroyo Chasicó, el foco de las investigaciones estuvo centrado en el análisis de los patrones de variación espacial del registro arqueológico. Por tal motivo, es necesario intensificar los estudios orientados a evaluar las variaciones organizacionales en la escala temporal, a los fines de comprender mejor la dinámica de poblamiento y organización poblacional desarrollados durante el Holoceno tardío en las sierras de Ventania y la llanura localizada al sudoeste de ellas. 


\subsection{3 ¿Cómo varían los patrones observables en el registro arqueológico al aplicar diferentes escalas}

de análisis?

La ventaja de aplicar diferentes escalas de análisis radica en la posibilidad de observar variaciones en los patrones espaciales que de otra manera resultan imperceptibles o poco evidentes. Durante el desarrollo de esta investigación se observó que ciertas distribuciones de rasgos (e.g. valores isotópicos, proporción de artefactos de molienda, proporción de fragmentos cerámicos), cuando se las analiza en la microescala no muestran mayores diferencias en cuanto a lo esperado para el sur de la Región Pampeana, y en cambio, cuando se amplía el espacio en consideración, emergen nuevas tendencias y/o patrones, así como relaciones con variaciones en las características ambientales. Ejemplo de esto es el patrón en parcelas de los valores isotópicos o el aumento en la proporción de artefactos de molienda en concordancia con la densidad de especies propias del Espinal.

Lo expuesto, evidencia también, que la incidencia de los diversos factores planteados en la estructuración de la movilidad y uso de los recursos, es relevante en la escala espacial de la cuenca del arroyo Chasicó. Si se amplía el foco de análisis y se incorporan áreas vecinas, en las que la distribución de estos recursos difiere de la observada para el arroyo Chasicó, es esperable que se observen variaciones en las estrategias empleadas. En este sentido, los modelos sobre distribución de materias primas líticas, por ejemplo, evidencian que las curvas de disminución de la frecuencia en función de la distancia a la fuente en cuarcitas y RSO, presentan pendientes considerablemente más suaves que las observadas en la cuenca del arroyo Chasicó, evidenciando su transporte a través de mayores distancias, en relación con ambiente con menor disponibilidad local de rocas.

Cabe señalar que las interpretaciones aquí propuestas son válidas, principalmente, para el período anterior a la incorporación del caballo ya que, durante momentos del contacto con la sociedad europea (siglos XVI al XIX), el creciente uso por parte de las sociedades indígenas de estos animales, produjo profundas transformaciones en las distintas esferas culturales (Giardina 2010a, 2010b; Mandrini 1993). Esta situación también se observa en las sociedades cazadoras-recolectoras descriptas por Binford (2001), en las que la caza adquiere mayor importancia y los rangos de acción se amplían considerablemente alcanzando dimensiones de $c a .25 .000$ y hasta $57.000 \mathrm{~km}^{2}$. Si bien una parte de los materiales aquí analizados pueden corresponder a momentos posteriores al contacto hispano-indígena -particularmente en el sector distal de la cuenca- se considera que los mismos constituyen una fracción marginal del total de la evidencia recuperada, por lo que los modelos espaciales generados son válidos para los momentos anteriores al contacto. Mediante futuras investigaciones deberá evaluarse de qué modo el contacto con la sociedad europea y, particularmente, la incorporación del caballo, incidieron sobre la conformación y extensión de los rangos de acción, las pautas de movilidad, las estrategias de caza (Giardina 2010a, 2010b), así como sobre las posibilidades de transportar materiales de mayor peso y a mayores distancias. 


\section{IConclusiones y Futuras Líneas de Investigación}

La presente investigación representa un aporte al análisis del uso del espacio y los recursos en el sur de la Región Pampeana, particularmente en la zona transicional con el NE de Patagonia. Durante el desarrollo de estos estudios se generó información arqueológica para un área en la que ésta era muy escasa (i.e. cuenca inferior del arroyo Chasicó). Se avanzó en la contextualización temporal de los materiales y en el análisis de la variabilidad ambiental del registro arqueológico en relación con las variaciones ambientales (i.e. disponibilidad de recursos, procesos y agentes que actúan sobre el registro arqueológico). A su vez, se indagó acerca de la potencialidad de herramientas estadísticas y geoestadísticas para el análisis de los patrones espaciotemporales posibles de ser identificados para diversos indicadores arqueológicos. A partir del uso de tales herramientas, se han podido analizar ciertas tendencias, emergentes a diferentes escalas, lo que ha permitido aportar información necesaria para la realización de inferencias acerca del modo de utilización del espacio y los recursos implementado por las sociedades cazadoras-recolectoras prehispánicas en la cuenca del arroyo Chasicó.

Estos estudios permiten proponer que las características particulares del área de estudio posibilitaron la aplicación de estrategias de movilidad y utilización de recursos que, en algunos casos se asemejan y en otros difieren en variado grado, respecto de aquellas implementadas en áreas vecinas. Los indicadores arqueológicos estudiados para alcanzar los objetivos propuestos, fueron explorados con variado grado de profundidad, dependiendo de las características propias de cada indicador y del estado de avance del conocimiento previo generado para el área de estudio en particular y para el sur de la Región Pampeana y NE de Patagonia en general.

A los fines de contextualizar temporalmente la información generada, se fecharon materiales arqueológicos procedentes de los diferentes sectores de la cuenca. Resta continuar con la construcción de un marco cronológico sólido que permita evaluar con mayor confiabilidad las variaciones temporales en los desarrollos culturales del área. Especialmente, un objetivo a lograr sería la generación de secuencias de fechados procedentes de un mismo sitio, que permitan evaluar mejor la incidencia de procesos tafonómicos, la re-ocupación de determinados espacios y la presencia de cambios y continuidades a través del tiempo.

Una de las líneas de evidencia en las que se centró la investigación fue la composición de los conjuntos líticos, principalmente en términos de las materias primas representadas y de sus probables lugares de procedencia. Sobre estos aspectos se contaba ya con importante información previa (geológica y arqueológica), lo que permitió generar modelos con un mayor grado de especificidad y confiabilidad. Sin embargo, es central continuar profundizando en la identificación y caracterización de fuentes de 
aprovisionamiento de materias primas líticas. Durante el desarrollo de esta tesis, se indagó acerca de algunas de las propiedades -tanto de las rocas como de los afloramientos- que favorecen la selección de determinadas materias primas por sobre otras (e.g. calidad para la talla o molienda, disponibilidad, facilidad de extracción), el incremento de la información en este plano podrá ser utilizado para la construcción de modelos de gravedad (Wilson 2007) que permitan evaluar la "atracción" ejercida por las diversas fuentes de abastecimiento. En relación con esto, la caracterización de un mayor número de las materias primas presentes en los sitios arqueológicos, particularmente en el caso de las calcedonias y cherts, a los fines de establecer con mayor precisión sus áreas de procedencia, permitirá poner a prueba los mencionados modelos de gravedad a los fines de evaluar de qué modo permiten explicar el registro lítico del área. La experimentación con distintas materias primas también es un tema prioritario para poder evaluar las posibilidades técnicas de las rocas, particularmente de las variedades de cuarcitas. Por otra parte, a los fines de esta tesis sólo se presentaron algunas de las variables tecnotipológicas que pueden aportar información sobre las estrategias de movilidad y circulación de materias primas. En tal sentido, deberán profundizarse los análisis tecnológicos sobre las distintas clases artefactuales (i.e. productos de talla, instrumentos y núcleos), en una dimensión tanto espacial como temporal.

El análisis de la tecnología cerámica es otra de las líneas a continuar analizando, principalmente a partir de la realización de estudios petrográficos y de la experimentación con fuentes de arcilla locales. Debido a la escasa frecuencia de aparición de este tipo de materiales en los sitios localizados al sur del río Salado, su estudio sistemático no constituyó, hasta años recientes, un tema de investigación prioritario. La profundización de los estudios orientados a evaluar las características de este tipo de contenedores, que han aumentado su número en los últimos años (Catella 2004; Catella y Saghessi 2007; Di Prado 2013; Eugenio y Aldazabal 2004; Madrid 1997; Madrid y Di Prado 2008; Mazzanti y Porto López 2007; Politis et al. 2001; Prates 2004; Prates et al. 2010), permitirá avanzar en el conocimiento sobre sus áreas de producción, características tecnológicas, funcionalidad y vías de circulación,

Por otra parte, es necesario intensificar los estudios relacionados con la subsistencia de las sociedades cazadoras-recolectoras de la cuenca del arroyo Chasicó y sus posibles variaciones a través del tiempo. Uno de las mayores dificultades para abordar este aspecto radica en los problemas de conservación que muchos de los ambientes pampeanos presentan para los materiales orgánicos, lo que dificulta la recuperación, principalmente, de macrorrestos vegetales y algunos elementos óseos (e.g. aquellos correspondientes a especies de menor porte o que han sido altamente fragmentados). En la presente tesis se ha realizado una primera aproximación a los agentes y procesos tafonómicos que afectan al registro arqueológico, particularmente el óseo, por medio de la generación de un modelo espacial que considera el tipo e intensidad de estos procesos a lo largo de la cuenca. La ampliación de este modelo hacia otros sectores permitirá llevar a cabo el diseño de prospecciones y unidades de observación considerando la variabilidad en el tipo e intensidad de agentes y procesos e intensificar las investigaciones en aquellas áreas en que es mayor la probabilidad de conservación de materiales orgánicos. Esta información será útil también, como marco de referencia a partir del cual desarrollar estudios tafonómicos en una escala espacial menor, que permita evaluar la variabilidad dentro de cada unidad del paisaje y en cada sitio arqueológico particular. 
A partir de los análisis faunísticos realizados durante esta investigación, se propuso que no se observan evidencias que permitan proponer la existencia de un proceso de intensificación o diversificación en el consumo de los recursos faunísticos. Esto requerirá de futuros trabajos orientados a evaluar el grado de fragmentación, así como el análisis de la diversidad de especies representadas en relación con la proporción de los mamíferos de mayor porte y la acción de procesos tafonómicos, ya que las tendencias observadas en la frecuencia de especies de menor porte puede no necesariamente ser indicador de un procesos de diversificación o intensificación, sino responder a otros sesgos (i.e. tafonómicos, de muestreo) (Giardina 2010). El desarrollo de estudios tendientes a identificar el tipo de recursos vegetales incorporados en la dieta y su importancia relativa, es otra de las líneas que deberá implementarse, tanto a través de la identificación de microrrestos presentes en artefactos (e.g. elementos de molienda, contenedores cerámicos) y sedimentos, como a través de la posible recuperación de macrovestigios.

La importancia relativa de los distintos componentes de la dieta, también deberá ser abordada mediante la intensificación de los análisis isotópicos. Este tipo de estudios, ha demostrado gran potencialidad para el análisis, no solo de la subsistencia sino también de las pautas de movilidad. En este trabajo se indagó en la distribución de los valores de isótopos estables del C y N medidos en el colágeno de huesos humanos y animales, distinguiéndose tendencias que permitieron aproximarse a las posibles dimensiones de los rangos de acción. En este sentido, resulta necesario desarrollar en el sur de la Región Pampeana y NE de Patagonia en general y en el área de estudio en particular, proyectos específicos orientados a modelar la ecología isotópica a los fines de analizar, con una mayor cantidad de muestras, si existe correspondencia entre los valores de humanos y los de recursos vegetales y animales y cuál es la variación espacial y temporal que estos presentan. La realización de análisis sobre otros isotopos, como el del oxígeno $\left(\delta^{18} \mathrm{O}\right)$, recientemente llevados a cabo en regiones cercanas (Pampa Seca y Cuyo; Berón et al. 2013; Gil et al. 2011), es otra línea de evidencia que podrá complementar las aquí desarrolladas.

Por último, para el desarrollo de esta tesis se seleccionó un sector del paisaje con características particulares en cuanto a la distribución de los recursos líticos e hídricos. La cuenca del arroyo Chasicó, como ha sido mencionado, se caracteriza por la presencia de estos dos recursos a lo largo de todo su recorrido, si bien con variabilidad en su abundancia y, en el caso de las rocas, su calidad y diversidad. Por lo tanto, las tendencias aquí observadas, son válidas, en principio, únicamente para ambientes con una distribución similar de los recursos. Es necesario evaluar de qué modo, dichas tendencias varían dentro de una misma área (en este caso el área Sur sensu Politis 1986, 2008 o el sector sur del AEHSP sensu Oliva 2006), en función de una estructuración diferencial de los recursos (i.e. de qué modo la disponibilidad de recursos influye en la variación intraareal de los paisajes arqueológicos). Un área donde será esperable observar evidencias de estrategias de movilidad y uso de los recursos (particularmente los líticos) diferentes a las aquí desarrolladas, es la zona sin drenaje localizada al oeste de la cuenca del arroyo Chasicó. En este espacio las rocas están ausentes o limitadas a algunos afloramientos pequeños, por lo que las estrategias de transporte y aprovisionamiento debieron ser diferentes a las aquí presentadas generando variaciones en la estructura del registro arqueológico.

Con el desarrollo de esta tesis, se ha aportado información acerca de las estrategias de movilidad y uso de los recursos, generándose modelos espaciales de escala media, que permitieron integrar información que hasta el presente se encontraba desarticulada y dispersa. De este modo se generó nueva información 
y se exploraron metodologías novedosas para la Región Pampeana y el NE de Patagonia, a partir de las cuales identificar visualmente patrones y tendencias espaciales. En este sentido, la utilización de datos secundarios arqueológicos y etnográficos ha demostrado tener un gran potencial para la generación de modelos descriptivos con cierto valor predictivo. La intensificación de las líneas de investigación aquí comenzadas y la continuación en el desarrollado de vías metodológicas para el análisis de la información en diferentes escalas seguramente permitirá dar respuesta a las nuevas preguntas generadas y continuar evaluando las hipótesis y modelos propuestos para el sur de la Región Pampeana y el NE de Patagonia. 
BIBLIOGRAFÍA

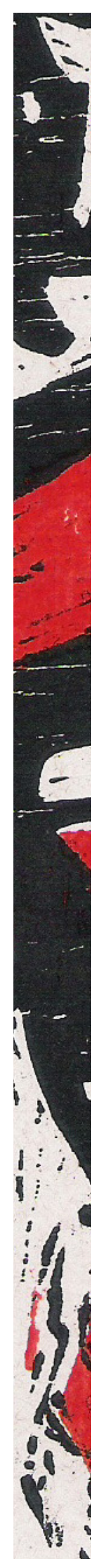




\section{I Bibliografía Citada}

Adams, J. (1996) Manual for a technological approach to ground stone analysis. Center for Desert Archaeology, Tucson.

Aguirre M. y R. Whatley (1995) Late Quaternary marginal marina deposits from north-eastern Buenos Aires province, Argentina: A review. Quaternary Science Review, 14: 223-254.

Aldazabal, V. (1991) Arqueología de la costa central de la Provincia de Buenos Aires. Comparaciones con áreas vecinas. Boletín del Centro, 3: 96-104. Publicación del Centro de Registro del Patrimonio Arqueológico y Paleontológico

Aldazabal, V. (1999) El diseño de la decoración cerámica. Una vía de interpretación. Actas del XII Congreso Nacional de Arqueología Argentina. Facultad de Ciencias Naturales y Museo, UNLP. La Plata. pp 7-15

Aldazabal, V. y E. Eugenio (2006) Informe presentado a la Dirección Provincial de Patrimonio Cultural.

Aldazabal, V., E. Eugenio y M. Silveira (2011) Ocupaciones arqueológicas en el extremo sur de la costa bonaerense. Libro de resúmenes de las VIII jornadas de Arqueología de la Patagonia, p. 8 Malargüe, Mendoza.

Altamirano Enciso, A. J. (1983) Guía osteológica de cérvidos andinos. Serie investigaciones 6. Universidad Nacional Mayor San Marcos, Lima. 58 pp.

Ameghino, F. (1909) Le Diprothomo platensis: un précurseur de l'homme du Pliocéne infèrieur de Buenos Aires. Anales del Museo Nacional de Buenos Aires, 19 (12): 107-209.

Ameghino, F. (1910) Descubrimiento de un esqueleto humano fósil en el pampeano superior del Arroyo Siasgo. Separatas del Congreso Científico Internacional Americano. Buenos Aires, pp. 1-6.

Ameghino, F. (1915) La Antigüedad del Hombre en el Plata. En Obras Completas y Correspondencia Cientifica de Florentino Ameghino, edición dirigida por A. Torcelli, Volumen III. Edición oficial ordenada por el gobierno de la Provincia de Buenos Aires, La Plata.

Amick, D. (1999) Raw Material Variation in Folsom Stone Tool Assemblages and the Division of labor in Hunter-Gatherer Societies. En: D. S. Amick (Ed.) Folsom Lithic Technology. Explorations in Structure and Variation, pp. 169-187. International Monographs in Prehistory, Ann Arbor.

Andrefsky, W. J. (1994) Raw-material availability and the organization of technology. American Antiquity, 59(11): 21-34.

Andrefsky, W. (2009) The analysis of stone tool procurement, production, and maintenance. Journal of Archaeological Research, 17: 65-103.

Andreis, R.R. y M. Torres Ribeiro (2003) Estratigrafía, facies y evolución depositacional de la Formación Sauce Grande (Carbonífero Superior), Cuenca Sauce Grande, Sierras Australes, Buenos Aires, Argentina. Revista de la Asociación Geológica Argentina, 58: 137-165.

Andreis, R. R., L. A. Spaletti y M. M. Mazzoni (1971) Sedimentología de la Brecha Cerro Colorado, Sierras Australes de la provincia de Buenos Aires. Actas de la Reunión sobre Geología de las Sierras Australes Bonaerenses, pp. 65-96, Bahía Blanca. 
Andrews, L., A. Higgins, M. Waring Andrews y J. G. Lalor (2012) Classic grounder theory o analyse secondary data: reality and reflections. Grounded Theory Review, An International Journal, 11 (1) http:// groundedtheoryreview.com/2012/06/01/classic-grounded-theory-to-analyse-secondary-data-realityand-reflections/ visitado el 21/02/2014

Anthony, D. W. (1990) Migration in Archeology: The Baby and the Bathwater. American Anthropologist, 92 (4): 895-914. DOI: 10.1525/aa.1990.92.4.02a00030

Ambrose, S. H. (2006) Howiesons Poort lithic raw material procurement patterns and the evolution of modern human behavior: A response to Minichillo (2006). Journal of Human Evolution, 50: 365-369.

Aragón, E. y N. Franco (1997) Características de rocas para la talla por percusión y propiedades petrográficas. Anales del Instituto de la Patagonia, 25: 187-199.

Armentano, G. (2004a) Observaciones Preliminares acerca de la Organización Tecnológica del valle inferior del río Colorado: Sitio Caldén Guazú-Médano 1-Sector Este. En G. Martínez, M. Gutiérrez, R. Curtoni, M. Berón y P. Madrid (Eds.) Aproximaciones Contemporáneas a la Arqueología Pampeana. Perspectivas Teóricas, Metodológicas, Analíticas y Casos de Estudio, Facultad de Ciencias Sociales de Olavarría. UNCPBA. pp 227-246.

Armentano (2004b) Organización de la tecnología lítica en el valle inferior del río Colorado (Pdos. De Patagones y Villarino, Pcia de Buenos Aires). Tesis de licenciatura inédita. Facultad de Ciencias Sociales, UNICEN. Olavarría.

Arnold, D. E. (1985) Ceramic Theory and Cultural Process. Cambridge University Press, Cambridge.

Arturi, M. (2005) Situación ambiental en la ecorregión espinal. En: A. Brown, U. Martínez Ortíz, M. Acerbi y J. Corcuera (Eds.) La situación ambiental Argentina. Fundación Vida Silvestre.Pp240260. http://www.vidasilvestre.org.ar/sala redaccion/opublicaciones/?2340/ La-Situacin- AmbientalArgentina-2005 visitado el 20/02/2012

Aschero, C. A. (1975) Ensayo para una clasificación morfológica de artefactos líticos aplicada a estudios tipológicos comparativos. Informe presentado al CONICET. MS.

Aschero, C. A. (1983) Ensayo para una clasificación morfológica de artefactos líticos. Revisión. MS.

Aschero, C. A. y S. Hocsman (2004) Revisando cuestiones tipológicas en torno a la clasificación de artefactos bifaciales. En: M. Ramos, A. Acosta y D. Loponte (Comp.) Temas de Arqueología. Análisis Lítico, pp. 7-25. Universidad Nacional de Luján, Luján.

Austral, A. (1965) Investigaciones prehistóricas en el curso inferior del río Sauce Grande. Trabajos de Prehistoria 19: 7-123.

Austral, A. (1966) Noticia sobre un nuevo yacimiento precerámico en el Sur de la Pcia de Buenos Aires. Acta Prehistórica, 5-7 (1961-1963): 193-199. Buenos Aires.

Austral, A. (1967-1968) Los hallazgos arqueológicos de Paso Mayor II, Pdo de Coronel Pringles, Pcia de Buenos Aires. Cuadernos del Sur, 8-9: 1-32. Bahía Blanca.

Austral, A. (1968) Prehistoria de la Región Pampeana Sur. Serie Las Raíces. Universidad Nacional del Sur. Extensión Cultural. Bahía Blanca, 22 pp.

Austral, A. (1971) El yacimiento arqueológico Vallejo en el Noroeste de la Provincia de La Pampa. Contribución a la sistematización de la Prehistoria y Arqueología de la Región Pampeana. Relaciones de la Sociedad Argentina de Antropología (N. S.), 2: 49-70, Buenos Aires.

Austral, A. (1972) El yacimiento de Los Flamencos II. La coexistencia del hombre con fauna extinta en la Región Pampeana. Relaciones de la Sociedad Argentina de Antropología (N. S.), 6: 203-209.

Austral, A. (1987) Hallazgos en capa de un artefacto lítico y fauna extinta en la laguna Las Encadenadas. Provincia de Buenos Aires, República Argentina. En: L. Nuñez y B. Meggers (eds.) Investigaciones paleoindias al Sur de la línea ecuatorial. Estudios Atacameños (número especial), 8: 94-97. 
Austral, A. y J. García Cano (1999) Un caso de Arqueología en lagunas pampeanas, el sitio SA29LE, Las Encadenadas en el partido de Saavedra, provincia de Buenos Aires. Aplicación de técnicas de prospección subacuática. En: C. Diez Marín (Ed.) Actas del XII Congreso Nacional de Arqueología Argentina, 3. 87-94. Universidad Nacional de La Plata. Argentina.

Ávila, J. D. (2003) Investigaciones sobre los materiales líticos manufacturados por técnicas de pulido, abrasión o picado en el sudoeste de la provincia de Buenos Aires. Libro de Resúmenes de las Terceras Jornadas Arqueológicas Regionales. Pigüé, provincia de Buenos Aires. 5 y 6 de abril de 2003. p.1

Ávila, J. D. (2004) Discusión sobre atributos morfológicos para el estudio de artefactos de molienda en el Borde Occidental de la Subregión Pampa Húmeda. Resúmenes del Taller de Morfología macroscópica en la clasificación de artefactos líticos: innovaciones y perspectivas. Instituto de Arqueología y Museo de la Universidad Nacional de Tucumán y Grupo M3.32.99. p. 1. Horco Molle Yerba Buena, Tucumán.

Ávila, J. D. (2009) Estrategias tecnológicas aplicadas en artefactos de molienda en el Sistema Serrano de Ventania y su Llanura Adyacente (Provincia de Buenos Aires). En: A. Austral y M. Tamagnini (comp.) Problemáticas de la Arqueología Contemporánea, 3: 605-618. Universidad Nacional de Río Cuarto. Río Cuarto, Provincia de Córdoba.

Ávila, J. D. y L. Catella (2005) Artefactos de molienda en la cuenca inferior del arroyo Chasicó (Provincia de Buenos Aires). Trabajo presentado al IV Congreso de Arqueología de la Región Pampeana Argentina. Bahía Blanca.

Babot, M. P. (2004) Tecnología y utilización de artefactos de molienda en el Noroeste Prehispánico. Tesis Doctoral inédita. Facultad de Ciencias Naturales e Instituo Miguel Lillo. Universidad Nacional de Tucumán.

Babot, M.P (2014) Movilidad y artefactos de molienda en Antofagasta de la Sierra, Puna Meridional Argentina (ca. 6500-1100 años AP). En: P. Escola y S. Hocsman (Eds.) Artefactos líticos, movilidad y funcionalidad de sitios. British Archaeological Reports (BAR). International series. Oxford.

Babot, M. P., N. Mazzia y C. Bayón (2007) Procesamiento de recursos en la Región Pampeana Bonaerense: aportes del instrumental de molienda de las localidades arqueológicas El Guanaco y cerro La China. En: C. Bayón, A. Pupio, I. González, N. Flegenheimer y M. Frére Arqueología en Las Pampas. Sociedad Argentina de Antropología, pp 635-660.

Bailey, H. (1960) A method of determining the warmth and temperateness of climate. Geografiska Annaler 43: 1-16.

Bamforth, D. (1986) Technological Efficiency and Tool Curation. American Antiquity, 51 (1): 38-50

Bamforth, D. (2006) The windy ridge quartzite quarry: hunter-gatherer mining and hunter-gatherer land use on the North American Continental Divide. World Archaeology, 38:3, 511 - 527

Bamforth, D. (2009) Projectile points, people and plains paleoindian parambulations. Journal of Anthropological Archaeology, 28 (2): 142-157.

Barberena R. (2002) Los límites del mar: Isótopos estables en Patagonia meridional. Sociedad Argentina de Antropología, Colección Tesis de Licenciatura. Buenos Aires, Argentina.

Barberena, R. (2005) Fronteras en tiempo arqueológico. La frontera: realidades y representaciones. CONICET. Instituto Multidisciplinario de Historia y Ciencias Humanas pp. 33-46.

Barberena R, A Zangrando, A Gil, G Martínez, G Politis, L Borrero y G Neme (2009) Guanaco (Lama guanicoe) isotopic ecology in southern South America: Spatial and temporal tendencies, and archaeological implications. Journal of Archaeological Science, 36:2666-2675.

Barne, J. [1837] 2007 Viaje que hizo el San Martín, desde Buenos Aires al puerto de San Julián, el año de 1752. Y del de un indio que desde dicho puerto vino por tierra hasta Buenos Aires. En: P. de Angelis (comp.) Viajes por las Costas de la Patagonia y los Campos de Buenos Aires. Informes, Diarios y Cartas de Viajeros (S. XVIII), pp. 21-46. 
Barrientos G. (1997) Nutrición y dieta de las poblaciones aborígenes prehispánicas del sudeste de la región pampeana. Tesis Doctoral inédita, Facultad de Ciencias Naturales y Museo, UNLP, La Plata. 266pp.

Barrientos, G. (1999) Composición isotópica $\left(\delta^{13} \mathrm{C}\right)$ de muestras de restos óseos humanos del sitio Arroyo Seco 2: inferencias paleodietarias. Relaciones de la Sociedad Argentina de Antropología 24: 81-94.

Barrientos, G. (2000) Los entierros humanos como experimentos tafonómicos naturales: problemas, vías de análisis e interpretación. Resúmenes de II Congreso de Arqueología de la Región Pampeana Argentina, pp.29. Mar del Plata.

Barrientos, G. (2001) Una aproximación bioarqueológica al estudio del poblamiento prehispánico tardío del Sudeste de la Región Pampeana. Intersecciones en Antropología, 2: 3-18.

Barrientos, G. (2009). El estudio arqueológico de la continuidad/discontinuidad biocultural: el caso del sudeste de la Región Pampeana. Perspectivas Actuales en Arqueología Argentina. En: R. Barberena, K. Borrazzo y L. A. Borrero (Eds.), pp: 191-214. Buenos Aires: IMHICIHU

Barrientos, G. (2010) El consumo de guanacos en el extremo sur de Sudamérica (30-56 ${ }^{\circ}$ Lat. Sur): una aproximación isotópica. Congreso Internacional "Culturas Americanas y su Ambiente: Perspectivas desde la Zooarqueología, Paleobotánica y Etnobiología”. Mérida, México.

Barrientos, G. (2011) On the problem of identifying homologies in lithic artifacts. En: H. Muscio y M. Cardillo (Eds.) Darwin's Legacy: The State of Evolutionary Archaeology in Argentina. BAR, Archaeopress, Oxford.

Barrientos, G. (2012) Patterns of Holocene Human Diversification in Fuego-Patagonia. Congreso. $54^{\circ}$ Congreso Internacional de Americanistas. Universidad de Viena, Austria.

Barrientos, G. (2014) On the problem on identifying homologies in lithic artifacts. En: M. Cardillo y H. Muscio (Eds.) Darwin's Legacy: The Status of Evolutionary Archaeology in Argentina. IMHICIHU, CONICET, pp. 44-58.

Barrientos, G. y L. Catella (2010) Explorando la relación entre las áreas transicionales y la distribución de ítems materiales del registro arqueológico tardío del sur de la Región Pampeana y del norte de Patagonia. Trabajo presentado al VI Congreso de Arqueología de la Región Pampeana Argentina. Universidad Nacional de La Plata.

Barrientos, G. y F. Gordón (2004) Explorando la relación entre nucleamiento poblacional y violencia interpersonal durante el Holoceno tardío en el noroeste de Patagonia (Republica Argentina). Magallania, 32: 53-69.

Barrientos, G. y M. A. Gutierrez (1996) Taphonomic and diagenetic processes of human bone remains in the Arroyo Seco 2 site, Pampean Region, Argentina. Trabajo presentado al 61st Annual Meeting, Society for American Archaeology. New Orleans. MS.

Barrientos, G. y M. Leipus (1997) Recientes investigaciones arqueológicas en el sitio Campo Brochetto (Partido de Tres Arroyos Pcia. De Buenos Aires). En: M. Berón y G. Politis (Eds.) Arqueología pampeana en la década de los '90. XI Congreso Nacional de Arqueología Argentina. Mendoza, pp. 35-46.

Barrientos, G. y B. Masse (2012) The archaeology of cosmic impact: lessons from two mid-Holocene argentine case studies. Journal of Archaeological Method and Theory. DOI 10.1007/s10816-012-91490 .

Barrientos G. y S. I. Pérez (2002) La dinámica del poblamiento humano del Sudeste de la Región Pampeana durante el Holoceno. Intersecciones en Antropología, 3: pp. 41-54. 
Barrientos G. y S. I. Pérez (2004) La expansión y dispersión de poblaciones del norte de Patagonia durante el Holoceno Tardío: evidencia arqueológica y modelo explicativo. En: María T. Civalero, Pablo M. Fernández y Ana G. Guráieb (Comp.) Contra viento y marea. Arqueología de Patagonia. Instituto Nacional de Antropología y Pensamiento Latinoamericano, Sociedad Argentina de Antropología. Buenos Aires, pp179-196

Barrientos, G. y S. I. Pérez. (2005) Was there a population replacement during the Late Mid-Holocene in the Southeastern Pampas of Argentina? Archaeological evidence and paleoecological basis. Quaternary International, 132: 95-105.

Barrientos, G., M. Leipus y F. Oliva (1997) Investigaciones arqueológicas en la Laguna Los Chilenos. (Provincia de Buenos Aires). En: M. Berón y G. Politis (Eds.) Arqueología pampeana en la década de los '90. XI Congreso Nacional de Arqueología Argentina. Mendoza, pp. 115-126.

Barrientos, G., F. Oliva y M. del Papa (2002) Historia predepositacional y tafonómica del entierro secundario del sitio Laguna Los Chilenos 1 (Provincia de Buenos Aires). Relaciones de la Sociedad Argentina de Antropología, 27: 303-326.

Barrientos, G., R. Barrientos y L. Menéndez. (2005) Modelos de simulación aplicados al estudio de distribuciones de fechados radiocarbónicos calibrados. Trabajo presentado en el 4to. Congreso de la Región Pampeana Argentina. Bahía Blanca.

Barrientos, G., L. Catella y F. Oliva (2013) Paisajes bioarqueológicos en el centro-este de la República Argentina: Implicancias para el poblamiento de las Sierras Australes de la provincia de Buenos Aires. Trabajo presentado a las XI Jornadas Nacionales de Antropología Biológica, Buenos Aires. MS.

Barrientos, G., L. Catella y F. Oliva (2014) The spatial structure of lithic landscapes: the late Holocene record of east-central Argentina as a case study. Manuscrito enviado a Journal of Archaeological Method and Theory.

Barros, M. P. y P. G. Messineo (2004) Identificación y aprovisionamiento de chert o ftanita en la cuenca superior del Arroyo Tapalqué. Estudios Atacameños 28: 87-103.

Bayón C. y G. Politis (1996) Estado actual de las investigaciones en el sitio Monte Hermoso I. Arqueología, 6:83-115.

Bayón C. y G. Politis (2014) Chapter 7 The inter-tidalzone site of La Olla: early middle Holocene human adaptation on the pampean coast of Argentina. En: Amanda M. Evans, Joseph C. Flatman y Nicholas C. Flemming (Eds.) Prehistoric Archaeology on the continental shelf, pp 115-120. Springer New York.

Bayón, C. y C. Zavala (1997) Coastal sites in southern Buenos Aires: A review of "Piedras Quebradas". Quaternary of South America and Antarctica Peninsula, 10: 229-254.

Bayón, C., N. Flegenheimer y A. Pupio (2006) Planes sociales en el abastecimiento y traslado de roca en la pampa bonaerense en el Holoceno temprano y tardío. Relaciones de la Sociedad Argentina de Antropología, 31:19-45.

Bayón, C. R. Frontini y R. Vecchi (2012) Middle Holocene Settlements on coastal dunes, southwest Buenos Aires Province, Argentina. Quaternary International, 256: 54-61.

Bayón, C., N. Flegenheimer, M. Valente y A. Pupio (1999) Dime cómo eres y te diré de dónde vienes: La procedencia de rocas cuarcíticas en la región pampeana. Relaciones de la Sociedad Argentina de Antropología, 24: 187-235.

Bayón, C., G. Martínez, G. Armentano y C. Scabuzzo (2004) Arqueología del valle inferior del río Colorado. El sitio La Primavera. Intersecciones en Antropología, 5 39-54. Facultad de Ciencias Sociales. UNCPBA.

Bayón, C., A. Pupio, R. Frontini y R. Vecchi, C. Scabuzzo (2010) Localidad arqueológica Paso Mayor: nuevos estudios 40 años después. Intersecciones en Antropología, 11: 115-128. 
Beck, C., A.K. Taylor, G. T. Jones, C.M. Fadem, C. R. Cook y S. A. Millward (2002) Rocks are heavy: transport costs and Paleoarchaic quarry behaviour in the Great Basin. Journal of Anthropological Archaeology, 21: 481-507.

Belardi, J. (2005). Paisajes arqueológicos: un estudio comparativo de diferentes ambientes patagónicos. BAR International Series 1390. Oxford.

Behrensmeyer, A. (1978) Taphonomic and ecologic information from bone weathering. Paleobiology 4(2): 150-162.

Berón, M. (1995) Cronología radiocarbónica de eventos cuturales y algo más... Localidad Tapera Moreira. Área del Curacó, La Pampa. Cuaernos del Instituto Nacional de Antropología, 16: 261-282. Buenos Aires.

Berón, M. (1997) Mobility and subsitence in a semidesert environment. The Curacó River Basin, La Pampa, Argentina. En: Rabassa, J. y M. Salemme (Eds.) Quaternary of South America, 10: 133-164. Rotterdam. Balkema Publishersand Antarctic Peninsula

Berón, M. (2004) Dinámica poblacional y estrategias de subsistencia de poblaciones prehispánicas de la cuenca Atuel-Salado-Chadileuvú-Curacó, Provincia de La Pampa. Tesis Doctoral Inédita. Universidad de Buenos Aires.

Berón, M. (2006) Base regional de recursos minerales en el occidente pampeano. Procedencia y estrategias de aprovisionamiento. Relaciones de la Sociedad Argentina de Antropología, 31: 47-88. Buenos Aires.

Berón, M. (2007) Arqueología de las sociedades prehispánicas de la Provincia de La Pampa. Manejo de recursos culturales y puesta en valor de las historias regionales. Quinto Sol, Revista de Historia Regional, 11: 39-59. Publicación del Instituto de Estudios Sociohistóricos. Facultad de Ciencias Humanas. UNLPam.

Berón, M. y R. Curtoni (2002) Propuestas metodológicas para la caracterización arqueológica de canteras y talleres de la Meseta del Fresco (La Pampa, Argentina). En: Mazzanti, D., M. Berón y F. Oliva (Eds.), Del Mar a los Salitrales. 10.000 de Historia Pampeana en el Umbral del Tercer Milenio, pp. 171-184. Mar del Plata. Facultad de Humanidades. Universidad Nacional de Mar del Plata.

Berón, M. y L. Luna (2011) Isótopos de oxígeno en restos humanos del sitio Chenque 1: primeros resultados sobre dinámica pobalcional y procedencia de los individuos. Libro de resúmenes de las VIII jornadas de Arqueología de la Patagonia, p. 14 Malargüe, Mendoza.

Berón, M. y G. Politis (1997) Arqueología Pampeana en la década de los '90. Estado de las investigaciones y perspectivas. En: M. Berón y G. Politis (comp.) Arqueología Pampeana en la Década de los '90. Museo de Historia Natural de San Rafael (Mendoza). INCUAPA, Facultad de Ciencias Sociales, UNCPBA, pp. 7-32.

Berón, M. L. Migale y R. Curtoni (1995) Hacia la definición de una base regional de recursos líticos en el área Curacó. Una cantera-taller: Puesto Córdoba (La Pampa, Argentina). Relaciones de la Sociedad Argentina de Antropología, 20: 111-128.

Berón M.; L. Luna y R. Barberena. (2009) Isotopic archaeologyin the western Pampas (Argentina): preliminary results and perspectives. International Journal of Osteoarchaeology, 19:250-265.

Berón M.; L. Luna y R. Barberena. (2013) Isótopos de oxígeno en restos humanos del sitio Chenque 1: primeros resultados sobre procedencia geográfica de individuos. En: A. Zangrando, R. Barberena, A. Gil, G. Neme, M. Giardina, L. Luna, C. Otaola, S, Paulides, L. Salgán y A. Tívoli (Comp.) Tendencias Teórico-Metodológicas y Casos de Estudio en la Arqueología de la Patagonia, pp. 27-38. SAA, INAPL, MHNSR. Buenos Aires. 
Berón, M., I. Baffi, R. Molinari, G. Barrientos, C. Aranda y L. Luna. (2000) Estructuras funerarias de momentos tardíos en Pampa- Patagonia. El chenque de Lihue Calel. Desde el país de los gigantes. Perspectivas arqueológicas en Patagonia, 1: 141-160. Universidad Nacional de la Patagonia Austral, Río Gallegos.

Berón, M., I. Baffi, R. Molinari, C. Aranda, L. Luna, A. Cimino (2002) El chenque de Lihue Calel. Una estructura funeraria en las Sierras de la Vida. En: D. Mazzanti, M. Berón y F. Oliva (Eds.) Del Mar a los Salitrales. 10.000 de Historia Pampeana en el Umbral del Tercer Milenio pp. 87-106. Universidad Nacional de Mar del Plata. Facultad de Humanidades. Laboratorio de Arqueología. Mar del Plata.

Bettinger, R. (1987) Archaeological Approaches to Hunter Gatherers. Annual Review of Anthropology, 16: $121-142$.

Bettinger, R. (1991) Hunter-gatherers: Archaeological and Evolutionary Theory. Plenum Press, New York.

Bettinger, R. (2001) Holocene Hunter-Gatherers. En: Feinman, G. y T. Douglas Price (Eds.). Archaeology at the Millennium. Kluwer Academic/Plenum Publishers. New York.

Bettinger, R. (2009) Hunter-Gatherer Foraging: Five Simple Models. Eliot Werner Publications, Clinton Corners, NY.

Bettinger, R. L. y M. A. Baumhoff (1982) The Numic spread: Great Basin cultures in competition. American Antiquity, 47 (3): 485-503.

Bettinger, R. L., B. Winterhalder, R. McElreath (2006) A simple model of technological intensification. Journal of Archaological Science, 33: 538-543.

Binford, L. R. (1979) Organization and formation processes: looking at curated technologies. Journal of Anthopological Research, $35: 255-273$

Binford, L. R. (1980) Humo de sauce y colas de perros: sistemas de asentamiento de los cazadoresrecolectores y la formación de sitios arqueológicos. American Antiquity, 45 (1): 4-20.

Binford, L. R. (1981) Bones: Ancient men and modern myths. Academic Press, New York.

Binford, L. (1982) The Archaeology of Place. Journal of Anthropological Archaeology, 1(1):5-31.

Binford, L. (1983) Long Term Land Use Patterns: Some Implications for Archaeology. En: R. C. Dunnell y D. K. Grayson (Eds.) Lulu Linear Punctated: Essays in Honor of George Irving Quimby, pp. 27-54, Anthropological Papers 72, Museum of Anthropology, University of Michigan, Ann Arbor.

Binford, L. (1991) There is allways more that we need to know. En: T. Dillehay y D. Meltzer (Eds.) The First Americans: Search and Research, CRC Press. Boca Ratón.

Binford, L.R. (2001) Constructing Frames of Reference: An Analytical Method for Archaeological Theory Building Using Ethnographic and Environmental Data Sets. Berkeley: University of California Press.

Bird, D. W. y J. F. O'Connell (2006) Behavioral Ecology and Archaeology. Journal of Archaeological Research, 14 (2): 143-188.

Bird, D., R. Bliege Bird y B. Codding (2009) In Pursuit of mobile prey: Martu hunting strat e g i e s and archaeofaunal interpretation. American Antiquity, 74 (1): 3-29.

Bishop, L. (2007) A reflective account of reusing qualitative data beyond primary/secondary dualism. Sociological Research Online, 12(3)2, doi:10.5153/sro.1553. Acceso 01/12/2013

Blasi, A., G. Politis y C. Bayón (2013) Palaeoenvironmental reconstruction of La Olla, a Holocene archaeological site in the Pampean coast (Argentina). Journal of Archaeological Science, 40 (3): 15541567. 
Bogino, S. (2006) El bosque de caldén en la provincia de San Luis: situación actual y estrategias alternativas de manejo. KAIROS. Revista de Temas Sociales, 17. Universidad Nacional de San Luis. http://www.revistakairos.org

Bökönyi, S. (1970) A new method for the determination of the number of individuals on animal bone material. American Journal of Archaeology, 74: 291-292.

Bogino, S.M. (2006) Revalorizar al caldén: Una especie nativa única de la Argentina y del mundo. SAGPyA Forestal 37, pp. 2-6. www.ulp.edu.ar/ulp/VerCapacitacion.asp?CapacitacionID=8 Acceso $10 / 05 / 2012$

Bonadonna, F., G. Leone y G. Zanchetta (1995) Composición isotópica de los fósiles de gasterópodos continentales de la Provincia de Buenos Aires. Indicaciones Paleoclimáticas. En: M. T. Alberdi, G. Leone y E. Tonni (Eds.) Evolución Biológica y Climática de la Región Pampeana Durante los Últimos Cinco Millones de Años. Un Ensayo de Correlación con el Mediterráneo Occidental, pp.77-104. Monografías Museo Nacional de Ciencias Naturales, CSIC. Madrid.

Bonino, N. y A. Pelliza (1991) Composición botánica de la dieta del guanaco (Lama guanicoe) en dos ambientes contrastantes de Tierra del Fuego, Argentina. Ecología Austral, 1: 97-102.

Bonomo, M. (2002) Distribución espacial y tecnología en el litoral marítimo Bonaerense. En: D. Mazzanti, M. Berón y F. Oliva (Eds.) Del Mar a los Salitrales, Diez Mil Años de Historia Pampeana en el Umbral del Tercer Milenio, pp. 185-204. Facultad de Humanidades. Universidad Nacional de Mar del Plata, Mar del Plata.

Bonomo, M. (2004) Ocupaciones humanas en el litoral marítimo pampeano: un enfoque arqueológico. Tesis Doctoral no publicada. Facultad de Ciencias Naturales y Museo, Universidad Nacional de La Plata, La Plata.

Bonomo, M. (2005) Costeando las llanuras. Arqueología del litoral marítimo pampeano. Sociedad Argentina de Antropología. Buenos Aires. 334 pp.

Bonomo, M. (2006) Un acercamiento a la dimensión simbólica de la cultura material en la región pampeana. Relaciones de la Sociedad Argentina de Antropología, 31: 89-115.

Bonomo, M. (2007) El uso de los moluscos marinos por los cazadores-recolectores pampeanos. Chungara, Revista de Antropología Chilena, 39 (1): 87-102.

Bonomo, M. (2011) The use of the space in the Pampean Atlantic coast and the adjacent plains (Argentina, South America). En: N. F. Bicho, J. A. Haws y L. G. Davis (Eds.) Trekking the Shore. Changing Coastlines and the Antiquity of Coastal Settlement. Sprenger, pp 333. 354.

Bonomo, M. y L. Prates (2009) La explotación de depósitos secundarios de rodados en el curso medio del río Negro y el litoral marítimo pampeano. En: P. Escola y S. Hocsman (Eds.) Artefactos líticos, movilidad y funcionalidad de sitios en Sudamérica. Problemas y perspectivas. BAR International Series, Oxford.

Bonomo, M. y C. Leon (2010) Un contexto arqueológico en posición estratigráfica en los médanos litorales. El sitio Alfar (Pdo. Gral. Pueyrredón, Pcia. Bs. As.). En: M. Berón, L. Luna, M. Bonomo, C. Montalvo, C. Aranda and M. Carrera Aizpitarte (Eds.). Mamül Mapu: pasado y presente desde la arqueología pampeana, pp. 215-231. Libros del Espinillo, Ayacucho.

Bonomo, M. y A. Matarrese (2012) Estado actual de las investigaciones arqueológicas en la localidad Nutria Mansa. Nuevos aportes de los artefactos picados y/o abradidos. Arqueología, 18 https://www. academia.edu/2389905/Estado_actual_de_las_investigaciones_arqueologicas_en_la_localidad Nutria_Mansa._Nuevos_aportes_de_los_artefactos_picados_y_o_abradidos 29/11/2013.

Bonomo, M., C. Scabuzzo y D. C. Leon (2013) Cronología y dieta en la costa atlántica pampeana, Argentina. Intersecciones en Antropología, 14: 123-136. 
Bonorino, A., E. Ruggiero y E. Mariño (1989) Caracterizaciòn hidrològica de la cuenca del arroyo Chasicó. Programa Prioritario de Asesoramiento a Municipalidades. CIC. La Plata. 35 pp.

Borel, C. M., M. V. Bianchinotti, M. E. Quattrocchio (2001) Palinomorfos fúngicos del PleistocenoHolocenoen el valle del arroyo Chasicó, provincia de Buenos Aires, Argentina. Polen, 7: 19-31.

Borella F. (2007) ¿Dónde están los lobos en la costa atlántica de Norpatagonia? Explorando vías para resolver el registro arqueofaunístico. Revista Werken, 9: 97-114.

Borella, F., y N. Buc (2009) Ópticas y Ópticos. Una aproximación a la tecnología ósea en la Bahía de San Antonio (Río Negro), Argentina. Arqueología de Patagonia: una mirada desde el último confín, pp 421-432. Ushuaia

Borgerhoff Mulder, M. y R. Schacht (2012) Human Behavioral Ecology. En: eLS. John Wiley \& Sons, Ltd: Chichester. DOI: 10.1002/9780470015902.a0003671.pub2 acceso 10/05/2014

Bórmida, M. s/f. Prolegomenos para una arqueología de la Pampa Bonaerense. Edición oficial de la Provincia de Buenos Aires. Dirección de Bibliotecas, Museos y Archivos Históricos. La Plata.

Bórmida, M. (1960) Investigaciones paletnológicas en la Región de Bolívar, Provincia de Buenos Aires. Anales de la Comisión de Investigaciones Cientificas de la Provincia de Buenos Aires 1, pp. 190-283. La Plata.

Bórmida, M. (1962) El Jabaliense. Una industria de guijarros de la península de San Blas, Provincia de Buenos Aires (República Argentina). Trabajos de Prehistoria, 6: 1-55.

Bórmida, M. (1964) Arqueología de la costa nordpatagónica. Trabajos de Prehistoria, 14. 1-116. Madrid Bórmida, M. (1969) El Puntarrubiense Trabajos de Prehistoria, 26 (N.S.): 7-112. Ciudad de Madrid

Borrero, L (1988) Tafonomía Regional. En: De procesos, contextos y otros huesos, N. Ratto y A.Haber (Eds.), pp. 9-15. Buenos Aires: ICA y Facultad de Filosofía y Letras (UBA).

Borrero, L. (1989-1990) Evolución cultural divergente en la Patagonia austral. Anales del Instituto de la Patagonia, Serie Ciencias Sociales, 19: 133-139.

Borrero, L. (1994-1995) Arqueología de la Patagonia. Palimpsesto, 4: 9-69. Buenos Aires.

Borrero, L. (2001a) Regional Taphonomy: Backrground Noise and the Integrity of the Archaeological Record. En: Kuznar, L. (Ed.). Ethnoarchaeology in Andean South America: contributions to archaeological method and theory, pp. 243-254. Michigan, International Monographs in Prehistory, University of Michigan Press, Ann Arbor.

Borrero, L. (2001b) Cambios, continuidades, discontinuidades: discusiones sobre arqueología FuegoPatagónica. En: E. Berberían y A. Nielsen (Eds.) Historia Prehispánica Argentina, 2: 815-838. Editorial Brujas, Córdoba.

Borrero L., J. Lanata y P. Cardenas (1991) Reestudiando cuevas: nuevas excavaciones en Última Esperanza, Magallanes. Anales del Instituto de la Patagonia, Serie Ciencias Humanas, 19: 101-110. Punta Arenas.

Borrero, L. A.; J. L. Lanata y B. N. Ventura (1992) Distribuciones de hallazgos aislados en Piedra del Aguila. Análisis espacial en la arqueología patagónica. L. A. Borrero y J. L. Lanata (Eds.), pp. 9-20. Ediciones Ayllu, Buenos Aires.

Borrero, L. A., N. V. Franco, J. L. Lanata y J. B. Belardi (1993) Distribuciones arqueológicas y tafonómicas en la margen Norte del Lago Argentino (Santa Cruz, Argentina). Actas del XII Congreso Nacional de Arqueología Chilena, 1: 23-31.

Borromei, A. M. (1995) Palinología, estratigrafía y paleoambientes del Pleistoceno tardío-Holoceno en el valle del río Sauce Grande, provincia de Buenos Aires. Polen, 9: 5-15. 
Boschín, M. T. (1991-1992) Historia de las investigaciones arqueológicas en Pampa y Patagonia. Runa, 20: 111-144.

Boschín, M. T. y A. Llamazares (1984) La Escuela Histórico-Cultural como factor retardatario del desarrollo científico de la arqueología argentina. Etnia, 32: 101-156. Olavarría.

Bousman, B. (1993) Hunter-gatherer adaptations, economic risk and tool design Lithic Technology, 18 (1 y 2): 59-86

Bousman, B. (2005) Coping with risk: later stone age technological strategies at Blydefontein rock shelder, South Africa. Journal of Anthropological Archaeology 24: 193-226.

Bradtmöller, M., A. Pastoors, B. Weninger y G. C. Weniger (2012) The repeated replacement model -Rapid climate change and population dynamics in Late Pleistocene Europe. Quaternary International, 247: 38-49.

Brantingham, P. J. (2006) Measuring forager mobility. Current Anthropology, 47, 435-459.

Braun, D. (1983) Pots as tools. En: J. A. Moore y A. S. Keene Archaeological hammers and theories, pp. 107-134. Academic Press New York.

Brewer, E.W. (2006) Secondary data analysis. Encyclopaedia of Measurement and Statistics, Sage Publications. http://sage-ereference.com/statistics/Article_n398.html. Acceso 02/12/2013

Bright, I. R. y A. Ugan (1999) Ceramics and Mobility: Assessing the Role of Foraging Behavior and its Implications for Culture-History. Utah Archaeology, 12: 17-29.

Brothwell, D. (1987) Desenterrando Huesos. La Excavación, Tratamiento y Estudio de Restos del Esqueleto Humano. Fondo de Cultura Económica. México.

Broughton, J (1994). Declines in Mammalian Foraging efficiency during the Late Holocene, San Francisco Bay, California. Journal of Anthropological Archaeology 13 :371-401.

Broughton, J. (2002) Prey spatial structure and behavior affect archaeological tests of optimal foraging models: examples from the Emeryville Shellmound vertebrate fauna. World Archaeology, 34 (1): 60-83.

Brown, J. L. (1964) The evolution of diversity in avian territorial systems. The Wilson Bulletin, 76 (2): 160-169.

Browne, C. y L. Wilson (2011) Resource selection of lithic raw materials in the Middle Paleolithic in southern France. Journal of Human Evolution, 61: 597-608.

Buikstra, J. y D. Ubelaker (1994) Standards for data collection from human skeletal remains. Arkansas Archaeological Survey Research Series 44.

Burger, O, M. Hamilton y R. Walker (2005) The prey as patch model. Optimal handling of resources with diminishing returns. Journal of Archaeological Science, 32: 1147-1158.

Burger, O., Todd, L. C. and Burnett, P. (2008). The Behavior of Surface Artifacts: Building a Landscape Taphonomy on the High Plains. In L. L. Scheiber and B. J. Clark (Eds.), Archaeological Landscapes on the High Plains, pp. 203-236. Boulder: University Press of Colorado

Burgi, M.V. (2005) Radio de Acción y Uso de Hábitat en Hembras de Guanaco (Lama guanicoe) en el NE de Chubut. Tesis de Licenciatura en Ciencias Biológicas, Facultad de Ciencias Naturales, Universidad Nacional de la Patagonia.

Burgos, J. J. (1968) El clima de la Provincia de Buenos Aires en relación con la vegetación y el suelo. En: A. L. Cabrera (Ed.) Flora de la Provincia de Buenos Aires. INTA, Buenos Aires, pp. 33-99.

Burkart, A. (1952) Las leguminosas argentinas silvestres y cultivadas. Editorial ACME, Buenos Aires, 569 pp.

Burkart R, N. Bárbaro, R. O. Sánchezy D. A. Gómez (1999) Eco-regiones de la Argentina. Administración de Parques Nacionales. Buenos Aires. Argentina. 43 pp. 
Burmeister, C. (1883-1891) Relación de un viaje a la Gobernación de Chubut. Anales del Museo Nacional de Buenos Aires, 3: 175-238.

Cabanillas, E. y F. Oliva (2004) Análisis de elementos metálicos procedentes del sitio Gascón 1, provincia de Buenos Aires. Libro de Resúmenes XV Congreso Nacional de Arqueología Argentina, Río Cuarto, p. 201.

Cabrera, A. L. (1971) Fitogeografía de la República Argentina. Boletín de la Sociedad Argentina de Botánica, 14 (1-2): 1-42.

Cabrera, A. L. y A, Willink (1980) Biogeografía de América Latina. Monografía OEA, $2^{\circ}$ edición corregida, serie biología, 122p.

Cabrera, A. L. y J. Yepes (1960) Mamíferos Sudamericanos. 2 tomos (2ºdición) Buenos Aires, Ediar S. A.

Carbonari, J., G. Gómez, R. Huarte y A. Figini (1982) Determinación de la edad radiocarbónica de un resto de Megatherium ef americanum (Localidad Arroyo Seco, Pdo de Tres Arroyos, Pcia de Buenos Aires, Argentina). Actas del VII Congreso de Arqueología del Uruguay. Colonia del Sacramento, Uruguay, pp 153-156.

Cardiel, J. (1930) Misión al Río del Sauce. Coni, Buenos Aires.

Cardillo, M. y F. Scartascini (2011). Diversidad artefactual y explotación de materias primas en la costa norpatagónica, golfo San Matías, Río Negro. En: F. Borella y M. Cardillo (Comps.), Arqueología de pescadores y marisqueadores en Nordpatagonia. Descifrando un registro de más de 6.000 años, pp. 6886. Buenos Aires: Editorial Dunken.

Cashdan, E. (1985) Coping with risk: Reciprocity among the Basarwa of Northern Borswana. Man (N.S), 20 (3): 454-474.

Cashdan E. (1992) Spatial Organization and habitat Use. En: E. Smith y B. Winterhalder (Eds.) Evolutionary Ecology and human Behavior, Hawthorne: Aldyne de Gruyter, pp. 237-268.

Castro, A. (1983) Noticia preliminar sobre un yacimiento en la Sierra de la Ventana, Provincia de Buenos Aires. Relaciones de la Sociedad Argentina de Antropología, 15: 91-107.

Castro, A. (1987-1988) Análisis microscópico de huellas de utilización en artefactos líticos de Fortín Necochea. Paleoetnológica, 4: 65-77.

Catella, L. (2004) Análisis tecnológico del material cerámico del Sistema Serrano de Ventania y llanura adyacente (Provincia de Buenos Aires). Miradas. Trabajos de las V Jornadas de Jóvenes nvestigadores en Ciencias Antropológicas, pp. 170-183.

Catella, L. y M. Saghessi (2007) Estudio del material cerámico del área de Las Encadenadas, Partido de Guaminí (Provincia de Buenos Aires). En: F. Oliva, N. de Grandis y J. Rodríguez (comp.) Arqueología Argentina en los Inicios de un Nuevo Siglo. Publicación del XIV Congreso Nacional de Arqueología Argentina.

Catella, L., J. Moirano y F. Oliva (2010) Disponibilidad de materias primas líticas y su importancia para el análisis del uso del espacio y la organización de la tecnología en sociedades cazadoras recolectoras. En: M. Berón, L. Luna, M. Bonomo, C. Montalvo, C. Aranda y M. Carrera Aizpitarte (Eds.) Mamül Mapu: pasado y presente desde la arqueología pampeana, 1: 215-231Editorial libros del Espinillo.

Catella, L., M. Manassero, J. Moirano y F. Oliva (2013) Nuevos aportes al estudio del aprovisionamiento de cuarcita en la Región Pampeana, Argentina Revista Cuadernos del Instituto Nacional de Antropología y Pensamiento Latinoamericano, 1 (2): 200-215, Series Especiales. Buenos Aires. (en línea) http://ppct. caicyt.gov.ar/index.php/cinapl-se/article/view/4002/pdf acceso 10/12/2013

Chaplin, R. (1971) The Study of Animal Bones fron Archaeological Sites. Academic Press. Nueva York. 
Charlin, J. (2002) Aprovisionamiento de materias primas líticas en el NO de la provincia de La Pampa fines del siglo XIX. En: Del mar a los salitrales. Diez mil años de historia pampeana en el umbral del Tercer milenio. D. Mazzanti, M. Beron y F. Oliva (Eds.), pp. 205-218, UNMP, Facultad de Humanidades, Laboratorio de Arqueología.

Charlin, J. (2007) Una perspectiva espacial de la intensidad de uso de las materias primas líticas en el campo volcánico Pali Aike (Prov. Santa Cruz, Argentina). En: F., M. Carballo, A. Martinic, Prieto, y G. Bahamonde (Eds.) Arqueología de Fuego-Patagonia. Levantando piedras, desenterrando huesos ... y develando arcanos, pp.: 129-150. CEQUA. Punta Arenas, Chile.

Charnov, E. (1976) Optimal foraging, the marginal value theorem. Theoretical Population Biology, 9:129 136 .

Church, R. R. y R. L. Lyman (2003) Small fragments make small differences in efficiency when rendering grease from fractured artiodactyl bones by boiling. Journal of Archaeological Science, 30: 1077-1084.

Cingolani, C. A. y R. Varela (1973) Examen geocronológico por el método Rb/Sr de las rocas ígneas de las Sierras Australes bonaerenses. Actas del V Congreso Geológico Argentino, pp, 349-371, Villa Carlos Paz.

Civalero, M. T. y N. Franco (2003) Early Human Occupations in Western Santa Cruz Province, Southernmost South America. Quaternary International, 109-110: 77-86.

Clarkson, C. (2008) Lithics and landscape archaeology. En: B. Davis y J. Thomas (Eds.) Handbook of Landscape Archaeology. World Archaeology Congress, Research Handbooks in Archaeology, 490-501.

Claraz, J. [1865-1866] (1988) Diario de viaje de exploración al Chubut. Marymar, Buenos Aires.

Colombo, M. (2011) El área de abastecimiento de las ortocuarcitas del grupo Sierras Bayas y las posibles técnicas para su obtención entre los cazadores y recolectores pampeanos. Intersecciones en Antropología, 12: 231-243.

Colombo, M. (2013) Los cazadores recolectores pampeanos y sus rocas. La obtención de materias primas líticas vista desde las canteras arqueológicas del centro de Tandilia. Tesis Doctoral Inédita, Facultad de Ciencias Naturales y Museo, Universidad Nacional de La Plata. MS.

Conolly, J. y M. Lake (2006) Geographical Information Systems in Archaeology. Cambridge, University Press.

Consens, M y F. Oliva (1999) Estado de las investigaciones en sitios con representaciones rupestres en la Región Pampeana, República Argentina. Actas del XII Congreso Nacional de Arqueología Argentina. La Plata. pp 119-127.

Corti, L. (2008) Secondary Analysis. Retrieved from The Sage Encyclopaedia of Qualitative Research Methods, Sage Publications. http://sage-ereference.com/research/Article_n415.html. acceso 01/12/2013

Costin, C. (2000) The use of etnoarchaeology for the archaeological study of ceramic production. Journal of archaeological method and theory, 7 (4): 377-403.

Crivelli Montero, E. (1991) Laguna del Trompa (Estancia La Herminia), Laprida, Pcia. de Buenos Aires. Boletín del Centro, 3: 18-29. La Plata.

Crivelli Montero, E., E. Eugenio y M. Silveira (1987-1988) El sitio Fortín Necochea (partido de General La Madrid, provincia de Buenos Aires). El material de superficie. Paleoetnológica, 4:7-37.

Crivelli Montero, E., E. Eugenio, U. Pardiñas y M. Silveira (1997) Archaelogical investigation in the plains of the Providence of Buenos Aires, Llanura Interserrana Bonaerense. Quaternary of South America and Antartic Peninsula, 10 (1994): 197-207.

Curtoni, R. P. (2006) Expresiones simbólicas, cosmovisión y territorialidad en los cazadores-recolectores pampeanos. Relaciones de la Sociedad Argentina de Antropología, 31: 133-160.

D’Orbigny, A. (1999) Viaje por América meridional, 2. Buenos Aires, Emecé. 
Dalla Salda, L. (1999) Cratón del Río de la Plata. El basamento granítico-metamórfico de Tandilia y Martín García.Geología Argentina. Anales, 29, (4): 97-106. Subsecretaría de Minería.

Dalla Salda, L., L. Saplletti, D. Poiré, R. de Barrio, H. Echeveste, y A. Benialgo (2006) Tandilia. Serie Correlación Geológica, 21 (1): 17-46.

Darwin, C. [1845] (2007) Del trópico a la patagonia. Diario de viaje alrededor del mundo a bordo del Beagle 1831-1836. Primera etapa Brasil / las pampas / el plata. Zagier \& Urruty publications. Ushuaia.

De Ferraris, C. (1979) Estudio estratigráfico de la Formación Río Negro de la Provincia de Buenos Aires. Sus relaciones con la Región Nordpatagónica. Anales de la Comisión de Investigaciones Científicas, pp. 85- 166. Buenos Aires.

De Francesco, F. (1970) Geología y estratigrafía del Cenozoico superior pedemontano del flanco occidental de las sierras de Curamalal y Ventana. Relatorio del VI Congreso de Geología Argentina. Bahía Blanca, pp. 103-138.

Dean, P. A y K. Heath (1990) Form and Function: Understanding Gray Pottery in the Northeast Great Basin. En: J. M. Mack (Ed.) Hunter-Gatherer Pottery from the Far West. Anthropological Papers, 32: 19-28. Nevada State Museum. Carson City.

Delcourt, H. y P. Delcourt (1988) Quarternary landscape ecology: relevant scales in space and time. Landscape Ecology, 2, 23-44.

Deschamps, C.M. y E. P. Tonni (1992) Los vertebrados del Pleistoceno tardío-Holoceno del Arroyo Napostá Grande, provincia de Buenos Aires. Aspectos paleoambientales. Ameghiniana, 29: 201-210.

Devine, P. (2003) Secondary data analysis. En: R.L. Miller y J.D. Brewer (Eds.) The A-Z of Social Research, Sage.

Dewar, R. y K. MC Bride (1992) Remnant Settlement patterns. En: J. Rossignol y L. Wandsnider (Eds.) Space, Time and Archaeological Landscapes. Plenum Press. New York. pp. 227-253.

Di Gregorio, A. y L. Jansen (1998) Land Cover Clasification System: Clasification concepts and User Manual. Food and Agriculture Organization of the United Nations, Rome.

Di Paola, E. y Marchese, H.G. (1974) Relación entre la tecto-sedimentación, litología y mineralogía de arcillas del Complejo Buenos Aires y la Formación La Tinta (prov. de Buenos Aires). Revista de la Asociación Argentina de Mineralogía, Petrología y Sedimentología, 5 (3-4): 45-58, Buenos Aires.

Di Prado, V. (2013) Estudio de la alfarería del sitio Calera (partido de Olavarría, provincia de Buenos Aires, Argentina) desde la perspectiva del estilo tecnológico. Revista del Museo de La Plata, Sección Antropología, 13 (87): 279-298.

Dincauze, D. F. (2000) Environmental Archaeology. Principles and Practice. Cambridge University Press, Cambridge.

Duke, C. y J. Steele (2010) Geology and lithic procurement in Upper Paleolithic Europe: a weightsof-evidence based GIS model of lithic resource potential. Journal of Archaeological Science, 37 (4): 813-824.

Dunnell, R. C. y W. Dancey (1983) The siteless survey: A regional scale data collection strategy. En: M. Schiffer (Ed.) Advances in Archaeological Method and Theory, 6:267-287. Academic Press, New York.

Dyson-Hudson, R y E. Smith (1978) Human territoriality: an ecological reassessment. American Anthropologist, 80 (1): 21-41.

Ebert, J. I. (1992) Distributional Archaeology. University of New Mexico Press, New Mexico.

Eerkens, I. W. (2003) Residential Mobility and Pottery Use in the Western Great Basin. Current Anthropology 44 (5): 728-738. 
Eerkens, I. W. (2004) Privatización, small-seed intensification, and the origins of pottery in the western Great Basin. American Antiquity, 69 (4): 653-670.

Eerkens, I. W., H. Neff y M. Glascock (2002) Ceramic production among small-scale and mobile hunters and gatherers: A case study from the Southwestern Great Basin. Journal of Anthropological Archaeology 2: 200-229.

Eerkens, J. W., A M. Spurling y M. A. Gras (2008) Measuring prehistoric mobility strategies based on obsidian geochemical and technological signatures in the Owens Valley, California. Journal of Archaeological Science, 35:668-680.

Eerkens, J. W., M. Mackie y E. J. Bartelink (2013) Brackish water foraging: isotopic landscapes and dietary reconstruction in Suisun Marsh, Central California. Journal of Archaeological Science, 40: 3270-3281.

Eerkens, J. W., J. R. Ferguson, M. D. Glascock, C. E. Skinner y S. A. Waechter (2007) Reduction strategies and geochemical characterization of lithic assemblages: a comparison of three case studies from western North America. American Antiquity, 72 (3): 585-597.

Elkin, D. C. (1995) Volume Density of South American Camelid Skeletal Parts. International Journal of Osteoarchaeology, 5: 29-37.

Elston, R. G. (1992). Archaeological research in the context of cultural resource management: Pushing back in the 1990s. Journal of California and Great Basin Anthropology, 14 (1): $37-$ 48.

Epstein, H. E., R. A. Gill, J. M. Paruelo, W. K. Lauenroth, G. J. Jia y I. C. Burke (2002) The relative abundance of threeplant functional types in temperate grasslands and shrublands of North and South America: effects of projected climate change. Journal of Biogeography, 29: 875-888.

Ericson, J.E. (1977) Egalitarian exchange systems in California: a preliminary view. En: T. K. Earle y J. E. Ericson (Eds.) Exchange Systems in Prehistory, New York Academic Press, pp. 109-126.

Ericson, J.E. (1984) Toward the analysis of lithic reduction systems. En: J. Ericson y B. Purdy (Eds.), Prehistoric Quarries and Lithic Production, Cambridge University Press, Cambridge, pp. 11-22.

Eugenio, E. y A. Aldazabal (2004) Los cazadores recolectores del litoral marítimo del área de Bahía de San Blas, Provincia de Buenos Aires. En: María Teresa Civalero, Pablo Marcelo Fernández y Ana Gabriela Guráieb (comp.) Contra viento y marea. Arqueología de Patagonia. Instituto Nacional de Antropología y Pensamiento latinoamericano, Sociedad Argentina de Antropología.

Eugenio, E y V. Aldazabal (2013) Características petrográficas de la cerámica de litoral de la Bahía San Blas. En: A. Zangrando, R. Barberena, A. Gil G. Neme, M. Giardina, L. Luna, C. Otaola, S. Paulides, L. Salgán y A Tivoli (comp) Tendencias teórico-metodológicas y casos de estudio en la arqueología de la Patagonia. Museo de Historia Natural de San Rafael, Mendoza.pp 81-86.

Eugenio, E; V. Aldazabal, E, Crivelli y M. Silveira (1987-1988) La cerámica del sitio Fortín Necochea; recolección de superficie. Paleoetnologica, 4, 97-103.

Falabella, V., C. Campagna y J. Croxall Eds. (2009) Atlas del Mar Patagónico. Especies y Espacios. Buenos Aires, Wildlife Conservation Society y BirdLife International. http://www.atlas-marpatagonico. org.

Favier Dubois, C. M. (2009) Valores de efecto reservorio marino para los últimos 5.000 años obtenidos en concheros de la costa atlántica norpatagónica (Golfo San Matías, Argentina). Magallania, 37 (2): 139-147. http://dx.doi.org/10.4067/S0718-22442009000200008 acceso 24/09/2012

Favier Dubois, C. M. (2013) Hacia una cronología del uso del espacio en la costa norte del Golfo de San Matías (Río Negro, Argentina): Sesgos geológicos e indicadores temporales. En: A. Zangrando, R. Barberena, A. Gil, G. Neme, M. Giardina, L. Luna, C. Otaola, S, Paulides, L. Salgán y A. Tívoli (Comp.) Tendencias Teórico-Metodológicas y Casos de Estudio en la Arqueología de la Patagonia, pp. 87-96. SAA, INAPL, MHNSR. Buenos Aires. 
Favier Dubois, C. M., F. Borella y R. Tykot (2009) Explorando tendencias en el uso del espacio y los recursos en el litoral rionegrino (Argentina) durante el Holoceno medio y tardío. En: M. Salemme, F. Santiago, M. Alvarez, E. Piana, M. Vázquez y E. Mansur (comp.) Arqueología de Patagonia: una mirada desde el último confin, 2: 985-998. Editorial Utopías. Ushuaia.

Favier Dubois, C., S. García Guraieb, F. Borella, y C. Mariano (2007) Primeros avances acerca del registro bioarqueológico de la costa rionegrina. Resúmenes del XVI Congreso Nacional de Arqueología Argentina, 3: 359-364.

Fernández, F. L. del Papa, G. Moreira, L. Prates y L. De Santis (2011) Small mammal remains recovered from two archaeological sites in the middle and lower Negro River valley (Late Holocene, Argentina): Taphonomic issues and paleoenvironmental implications. Quaternary International en prensa

Fernández-Jalvo, Y. y P. Andrews (2003) Experimental effects of wáter abrasion on bone fragments. Journal of Taphonomy, 1 (3): 147-163.

Fidalgo, F. (1992) Provincia de Buenos Aires continental. En: M. Iriondo (Ed.). El Holoceno en la Argentina. Cadinqua, pp. 23-38. Buenos Aires.

Fidalgo, F. y J. C. Riggi (1965) Los Rodados Patagónicos en la Meseta de Guenguel y alrededores. Revista de la Asociación Geológica Argentina, 20: 273-325.

Fidalgo, F. y J. C. Riggi (1970) Consideraciones geomórficas y sedimentológicas sobre los Rodados Patagónicos. Revista de la Asociación Geológica Argentina, 25: 430-443.

Fidalgo, F., F. O. De Francesco y U. R. Colado (1973) Geología superficial de las hojas Castelli, J. M. Cobo y Monasterio (Provincia de Buenos Aires). V Congreso Geológico Argentino, Córdoba, pp 27-39.

Fidalgo, F., J. Laza; N. Porro y E. Tonni (1978) Algunas características de la Formación Chasicó y sus relaciones. VII Congreso Geológico Argentino, 1: 213-225. Neuquén.

Fidalgo, F, E. Tonni, N. Porro y J. Laza (1987) Geología del área de la laguna Chasicó (Partido de Villarino, Provincia de Buenos Aires) y aspectos bioestratigráficos relacionados. Revista de la Asociación Geológica Argentina, 42 (3-4): 407-416.

Fidalgo F, L. Meo Guzmán, G. Politis, M. Salemme, E. Tonni, J. Carbonari, G. Gómez, R. Huarte y A. Figini (1986) Investigaciones Arqueoloógicas en el Sitio 2 de Arroyo Seco, Partido de Tres Arroyos, Provincia de Buenos Aires, Republica Argentina. En: A. Bryan (Ed.) New Evidence for the Pleistocene Peopling of the Americas. Center for the Study of Early Man: University of Maine at Orono, pp 222-269.

Fielding, N. (2004) Getting the most from archived qualitative data: epistemological, practical and professional obstacles. International Journal of Social Research Methodology, 7 (1): 97-104.

Fiore, D. y F. Borella (2010) Geometrías delicadas. Diseños grabados en cáscaras de huevo de Rheidae recuperados en la costa norte del Golfo San Matías, Río Negro. Intersecciones en Antropología, 11 (2): 277-293.

Fitzhugh W., A. Herzog, S. Perdikaris y B. McLeod (2011) Ship to shore: Inuit, early europeans, and maritime landscapes in the northern gulf of St. Lawrence. En: The Archaeology of Maritime Landscapes: When the Land Meets the Sea. New York: Springer, pp.99-108.

Flegenheimer, N. (1980) Hallazgos de puntas "cola de pescado" en la provincia de Buenos Aires. Relaciones de la Sociedad Argentina de Antropología, 14 (1): 169-176.

Flegenheimer, N. (1988) Producción lítica en el Cerro El Sombrero, Resultados preliminares. Resúmenes de las Ponencias Cientificas presentadas al IX Congreso Nacional de Arqueología Argentina, p. 58, Buenos Aires.

Flegenheimer, N. (1991) La Liebre, un sitio cantera-taller. Boletín del Centro, 2: 58-64.

Flegenheimer, N. y C. Bayón, (1996) Surface Fell's Cave stemmed points in the argentine pampas. Current Research in the Pleistocene, 13: 17-19. 
Flegenheimer, N. y C. Bayón, (1999) Abastecimiento de rocas en sitios pampeanos tempranos: Recolectando colores. En: C. Aschero, A. Korstanje, P. Vuoto (Eds.) En los tres reinos: Prácticas de recolección en el cono sur de América, pp. 95-107. Ediciones Magna Publicaciones, Tucumán.

Flegenheimer, N. y C. Bayón (2002) Cómo, cuándo y dónde? Estrategias de abastecimiento lítico en la pampa bonaerense. En: D. Mazzanti, M. Berón y F. Oliva (Eds.) Del mar a los salitrales. Diez mil años de historia pampeana en el umbral del tercer milenio. Universidad Nacional de Mar del Plata. Sociedad Argentina de Antropología. pp 231-241.

Flegenheimer, N. y C. Bayón (2004) Cambio de planes a través del tiempo para el traslado de roca en la pampa bonaerense. Estudios Atacameños, 28: 59-70.

Flegenheimer, N., R. A. Guichón y C. Scabuzzo (2002) Restos óseos humanos en el sitio El Guanaco, partido de San Cayetano. En: D. L. Mazzanti, M. A. Berón y F. W. Oliva (Eds.) Del Mar a los Salitrales. Diez Mil Años de Historia Pampeana en el Umbral del Tercer Milenio, pp. 121-126. Universidad Nacional de Mar del Plata, Mar del Plata.

Flegenheimer, N., C. Kain, M. Zárate y A. Barna. (1996) Aprovisionamiento de cuarcitas en Tandilia, las canteras de Arroyo Diamante. Arqueología, 6: 117-141.

Foley, R. (1981) Off-Site Archaeology and Human Adaptation in Eastern Africa. An Analysis of Regional Artefact Density in the Amboseli, Southern Kenia. Cambridge Monographs in African Archaeology 3. BAR International Series 97. Oxford.

Franchetti, F. y N. Sugrañes (2012) Ceramic technology, environment \& residential mobility in small scale groups: preliminary trends from north Patagonia, Argentina. Before Farming, 2012 (3), article 2.

Franco, N. (1990) El aprovisionamiento de los recursos líticos por parte de grupos del Área Interserrana Bonaerense. Shincal. X Congreso Nacional de Arqueología Argentina, 2 (3): 39-51. Catamarca.

Franco, N. V. (1994) Maximización en el aprovechamiento de los recursos líticos. Un caso analizado en el área interserrana bonaerense. En: J. Lanata y L. Borrero (Comp.) Arqueología de cazadoresrecolectores. Límites, casos y aperturas. Buenos Aires.

Franco, N. V. (2002) ¿Es posible diferenciar los conjuntos líticos atribuidos a la exploración $\quad$ d e un espacio de los correspondientes a otras etapas del poblamiento? El caso del extremo sur de Patagonia. Werken, 3: 119-132 Santiago de Chile.

Franco, N. V. (2004) La organización tecnológica y el uso de las escalas espaciales amplias. El caso del sur y oeste de Lago Argentino. En: A. Acosta, D. Loponte y M. Ramos (Eds.) Temas de Arqueología, Análisis Lítico, Universidad Nacional de Luján, Luján, pp.:101-144.

Franco, N. V. y L. Borrero (1999) Metodología de análisis de la estructura regional de recursos líticos. En: C. Aschero, A. Korstanje y P. Vuoto (Eds.) En los tres reinos: prácticas de recolección en el cono sur de América, pp. 7-27. Magna, Tucumán.

Frangi, J. L. y M. D. Barrera (1996) Biodiversidad y dinámica de los pastizales en la Sierra de la Ventana, Provincia de Buenos Aires. En: G Sarmiento y M Cabido (Eds.) Biodiversidad y funcionamiento de pastizales y sabanas en América Latina, pp. 134-162 Mérida, Cyted y Cielat.

Frenguelli, J. (1941) Rasgos principales de Fitogeografía Argentina. Revista del Museo de La Plata (Nueva Serie), Botánica, 3: 65-181.

Frère, M., I. González y A. Francese (2004) Experimentación y diseño decorativo: primeros ensayos. En: C. Gradín y F. Oliva (Eds.) La Región Pampeana, su pasado arqueológico. Laborde Editor. Pp. 115-121.

Furque, G. (1973) Descripción geológica de la hoja 34n, Sierra de Pillahuincó. Servicio Nacional de Minería y Geología, 141: 1-70. Buenos Aires. 
Gallego, M y F Oliva (2005) Evaluación de agentes de deterioro biológicos y culturales en los sitios en cuevas y abrigos rocosos del Sistema Serrano de Ventania, Provincia de Buenos Aires. Revista de la Escuela de Antropología, 11: 133-148. Escuela de Antropología, Facultad de Humanidades y Artes, Universidad Nacional de Rosario

Gamble, C. (1990) El Poblamiento Paleolítico de Europa. Ed. Crítica, Barcelona. 519 pp.

Gamble, C. (1992) Exchange, foraging and local hominid networks. En: C. Scarre y F. Healy (Eds.) Trade and exchange in prehistoric Europe. Oxbow Bocks, pp. 35-44.

García, J. y O. M. E. de García (1964) Hidrogeología de la Región de Bahía Blanca (Provincia de Buenos Aires). Boletín del Ministerio de Economía de la Nación, 96: 7-93. Secretaria de Industria y Minería, Subsecretaría de Minería, Dirección Nacional de Geología y Minería. Buenos Aires.

Gat, A. (2000) The human motivational complex: Evolutionary theory and the causes of hunter-gatherer fighting. Anthropological Quarterly, 73: 20-34.

GECS (2012) http://www.camelidosgecs.com.ar/especies_guanacos.html 21/07/2013.

Giardina, M. A. (2010a) El aprovechamiento de la avifauna entre las sociedades cazadoras-recolectoras del sur de Mendoza: un enfoque arqueológico. Tesis Doctoral Inédita. Facultad de Ciencias Naturaes y Museo, Universidad Nacional de la Plata. MS.

Giardina, M. A. (2010b) Registro zooarqueológico en el Alero Puesto Carrasco: un aporte para discutir la explotación de reidos en Nordpatagonia. En: M. De Nigris, P. M. Fernández, M. Giardina, A. F. Gil, M. A. Gutiérrez, A. Izeta, G. Neme y H. D. Yacobaccio (Eds.). Zooarqueología a principios del siglo XXI: aportes teóricos, .metodológicos y casos de estudio. Ediciones del Espinillo, pp 133-144.

Gifford, D (1981) Taphonomy and paleoecology: a critical review of archeology's sister disciplines. En: M. B. Schiffer (Ed.) Advances in Archaeological Method and Theory, 4: 365. New York Academic Press.

Gil, A. (2002) El Registro arqueológico y la ocupación humana de La Payunia. En: A. Gil y G. Neme (Eds.) Entre Montañas y Desiertos: Arqueología del Sur de Mendoza, , pp. 103-118. Sociedad Argentina de Antropología, Buenos Aires.

Gil, V., M. Asensio y A. M. Campo (2008) Registros climáticos en depósitos cuaternarios, Sierras Austrles de la provincia de Buenos Aires. Resúmenes de la XII Reunión Argentina de Sedimentología, Buenos Aires.

Gil, A., G. Neme, A. Ugan y R. Tykot (2011) Oxygen isotopoes and human residential mobility in Central Western Argentina. International Journal of Osteoarchaeology. Article first published online: 2 DEC 2011 DOI: 10.1002/oa.1304

Gilbert, M., L. D. Martin y H. G. Savage (1981) Avian Osteology. B. Miles Gilbert (Ed.), Laramie, Wyoming.

Gómez, M., A. Collado, E. Jobbagy y V. Gómez Hermida (2006) Especies Nativas con Aptitud Forestal, capítulo V. En: J. Echaverría, E. Jobbagy y A. Collado (Eds.) Aptitud forestal de la provincia de San Luis. INTA. Pp 64-73

González, I. (2005) Arqueología de alfareros, cazadores y pescadores pampeanos. Sociedad Argentina de Antropología. 366pp.

González de Bonaveri, M. I. y M. M. Frère (2004) Analysis of Potsherd Residues and Vessel Use in Hunter-Gatherer-Fisher Groups (Pampean Region, Argentina). Acts of the XIVth UISPP Congress, University of Liège, pp 27-35. British Archaeological Reports 1270, Oxford.

González de Bonaveri, M. I. y M. M. Frère (2010) Diseños prehispánicos de la alfareria pampeana. Editorial de la Facultad de Filosofía y Letras (UBA), Buenos Aires. 
González de Bonaveri, M. I., M. M. Frère y P. Solá (2000) Petrografía de cerámicas arqueológicas de la cuenca del río Salado, provincia de Buenos Aires Relaciones de la Sociedad Argentina de Antropología, 25: 207-226.

González Uriarte, M. (1984) Características geomorfológicas de la porción continental que rodea la Bahía Blanca, Provincia de Buenos Aires. Actas del IX Congreso Geológico Argentino, 3: 556-576, Bariloche, Argentina.

González Uriarte, M., F. González Martín, H. Kruger, S. Lamberto, G. Arbanesi y V. G. de Vercesi (1987) Evaluación expeditiva del recurso suelo y uso y cobertura de la tierra en el sur de la Provincia de Buenos Aires. Informe Técnico Nro. 28. Secretaría de Agricultura, Ganadería y Pesca, INTA. Estación Experimental Agropecuaria Hilario Ascasubi

Gordón, F. (2010) Dinámica Poblacional, Conflicto y Violencia en el Norte de Patagonia durante el Holoceno Tardío: un Estudio Arqueológico. Tesis Doctoral, Facultad de Ciencias Naturales y Museo, Universidad Nacional de La Plata, EdULP, La Plata. 329 pp.

Gordon, C y J. Buikstra (1981) Soil pH, bone preservation, and sampling bias at mortuary Sites. American Antiquity, 46:6:566-571.

Gosselain, O. (2000) Materializing Identities: An African Perspective. Journal of Archaeological Method and Theory, 7 (3): 187-217.

Gould, R. y S. Sagers (1985) Lithic procurement in Central Australia: A closer look at Binford's idea of embeddedness in archaeology. American Antiquity, 50:117-136.

Gradín, C. (1975) Contribuciones a la arqueología de La Pampa (Arte Rupestre). Dirección Provincial de Cultura. Manzini Hnos. S.A.I.C Santa Rosa, Provincia de La Pampa.

Gradín, C. (1978) Algunos aspectos del análisis de las manifestaciones rupestres. Revista del Museo Provincial, 2 Neuquén.

Graves, R. (2006) Forager Landscape Use and Residential Organization. En: F. Sellet, R. D. Greaves y P. L. Yu (Eds.) Archaeology and Ethnoarchaeology of Mobility. University Press of Florida, Gainesville. pp. 127-153.

Gremillion, K. J. (2002) Foraging Theory and Hypothesis Testing in Archaeology: An Exploration of Methodological Problems and Solutions. Journal of Anthropological Archaeology, 21 (2): 142-164.

Grove, M. (2009) Hunter-gatherer movement patterns: causes and constraints. Journal of Anthropological Archaeology, 28: 222-233.

Grupe, G. (1995) Preservation of collagen in bone from dry, sandy soil. Journal of Archaeological Science, 22: 193-199.

Gutiérrez, M. (2004) Análisis tafonómicos en el área interserrana (provincia de Buenos Aires). Tesis de Doctorado Inédita, Facultad de Ciencias Naturales y Museo, Universidad Nacional de La Plata, La Plata.

Gutiérrez, M. (2007) Preservación ósea diferencial a través del análisis diagenético: perspectivas, alcances e implicaciones arqueológicas. Cazadores-Recolectores del Cono Sur. Revista de Arqueología 2: $35-66$.

Gutiérrez, M. y G. Martínez (2008) Trends in the faunal human exploitation during the Late Pleistocene and Early Holocene in the Pampean region (Argentina). Quaternary International, 191: 53-68.

Hajduk, A. (1991) Las cuentas vítreas del sitio arqueológico Caepe Malal I (Departamento de Chos Malal, Neuquén) como indicadores temporales. Arqueología y Etnohistoria de la Patagonia Septentrional. Cuadernos de Investigación del IEHS, pp. 36-48, Tandil.

Hajduk, A. y A. Biset (1996) El sitio arqueológico Caepe Malal I (Cuenca del Río Curi Leuvú, Provincia del Neuquén). En: J. Gómez (Ed.) Arqueología Solo Patagonia. Publicación del Centro Nacional Patagónico y Consejo Nacional de Investigaciones Científicas y Técnicas, pp. 77-87. 
Halstead, P. y J. O'Shea (1989) Cultural responses to risk and uncertainty. En: P. Halstead y J. O'Shea (Eds.) Bad year economics, Cambridge University Press; 1-7

Hamilton, D. (1997) Basic method of conserving underwater archaeological material culture. Nautical Archaeology Program, Department of Anthropology, Texas A\&M University. US Department of Defense Legacy Resource Management Program. Washington DC. 154p. http://www.history.navy.mil/branches/ UA_\%20Conserv.pdf acceso 29/11/2012

Hamilton M. J, Milne B. T, Walker R. S. y J. H. Brown (2007) Nonlinear scaling of space use in human hunter-gatherers. Proceedings of the National Academy of Sciences of the United States of America, 104 (11): 4765-4769.

Hanson, B. (1980) Fluvial taphonomic processes: models and experiments. En: A. Behrensmeyer y A. Hill (Eds.) Fossils in the Meking. Vertebrate taphonomy and paleoecology, pp. 156-181. University of Chicago.

Harrington, H. (1936) El conglomerado rojo de las Sierras Australes de Buenos Aires y sus relaciones con el relieve de montaña. Obra del Cincuentenario del Museo de La Plata, 2: 145-184. La Plata.

Harrington, H. J. (1947) Explicación de las Hojas Geológicas 33m y 34m Sierras Australes de Curamalal y de la Ventana, Prov. de Buenos Aires. Boletín de la Dirección de Minas y Geología, 61: 5-43. Secretaría de Industria y Comercio. Buenos Aires.

Harrington, H. J. (1956) Morphostructural Provinces, Argentina, Paraguay and Uruguay. En: W. Jenks, (Ed.) Handbook of South American Geology. Geological Society of America, Memoir 65: 1-378.

Harrington, H. J. (1970) Las Sierras Australes de Buenos Aires, República Argentina. Cadena aulacogénica. Revista de la Asociación Geológica Argentina, 25: 151-181.

Harrington, H. J. (1972) Sierras Australes de Buenos Aires. En: A. F. Leanza (Ed.) Geología Regional Argentina, pp. 395-405. Academia Nacional de Ciencias, Córdoba.

Harrington, H J. (1980) Sierras Australes de la Provincia de Buenos Aires. Segundo Simposio de Geología Regional Argentina, 2: 967-983. Academia Nacional de Ciencias de Córdoba.

Hayden, B. (1990) Nimrods, Piscators, Pluckers, and Planters: The emergence of food production. Journal of Anthropological Archaeology, 9: 31-69.

Hayden, B. (1995) The emergence of prestige technologies and pottery. En: W. K. Barnett y J. W. Hoopes (Eds.) The Emergence of Pottery: Technology and Innovation in Ancient Societies, pp. 257-265. Smithsonian Institution, Washington D.C.

Haynes, K. y S. Fotheringham (1984) Gravity and spatial interaction models. En: K. Haynesy S. Fotheringham (Eds.). Gravity and spatial interaction models Pp 9-13. Beverly Hills Sage.

Heaton, J. (1998) Secondary analysis of qualitative data. Retrieved from Social Research Update, 22. Guildford: Department of Sociology, University of Surrey, Guildford. http://sru.soc.surrey.ac.uk/ SRU22.html acceso 29/11/2012

Hedges, R. y A. Millard (1995) Bones and groundwater: towards the modelling of diagenetic processes. Journal of Archaeological Science, 22:155-64

Hedges, R., A. Millard y A. Pike (1995) Measurements and relationships of diagenetic alteration of bone from three archaeological sites. Journal of Archaeological Science, 22: 201-209.

Hegmon, M. y L. Fisher (1991) Information Strategies in Hunter-Gatherer Societies. En: L. Fisher, P. Miracle, and J. Brown (Eds.) Hunters and Gatherers Past and Present, pp. 127-45. Michigan Discussions in Anthropology 10. University of Michigan, Ann Arbor.

Henrich, J. (2002) Cultural transmission and the diffusion of innovations: adoption dynamics indicate that biased cultural transmission is the predominate force in behavioral change. American Anthropologist, 103 (4): 992-1013. 
Henrich, J., Boyd, R., Bowles,S., Gintis,H., Fehr, E., Camerer, C., McElreath, R., Gurven, M., Hill, K., Barr, A. , Ensminger, J., Tracer, D., Marlow, F., Patton, J., Alvard, M., Gil-White F., and N. Henrich (2005) 'Economic Man' in Cross-Cultural Perspective: Ethnography and Experiments from 15 smallscale societies. Behavioral and Brain Sciences, 28: 795-855.

Hill, D. V. (2006) Theoretical and methodological approaches to the study of the ceramics of protohistoric semi-sedentary hunter-gatherers. Trabajo presentado en Transitions from Prehistory into History in the Mogollon Area: An Emphasis on Mobile Groups, Organized by Deni J. Seymour. The 2006 Mogollon Conference, Tucson, Arizona. https://www.academia.edu/214159/Theoretical_and_Methodological_ Approaches_to_the_Study_of_the_Ceramics_of_Protohistoric_Semi-Sedentary_Hunter-Gatherers. Acceso 10/11/2013

Hiscock, P. (1994) Technological responses to risk in Holocene Australia. Journal of World Prehistory, 8 (3): 267-292.

Hiscock, P. (1996) Mobility and technology in the Kakadu coastal wetlands. Bulletin of the IndoPacific Prehistory Association, 15: 151-157. http://ejournal.anu.edu.au/index.php/bippa/article/ viewFile/412/401 Acceso 10/03/2012

Hiscock, P. (2009) Reduction, recycling, and raw material procurement in Western Arnhem Land, Australia. En: B. Adams y B. Blades (Eds.) Lithic materials and Paleolithic societies. Wiley-Blackwell, pp. 78-93.

Hiscock, P. y C. Clarkson (2005) Experimental evaluation of Kuhn's geometric index of reduction and the flat-flake problem. Journal of Achaeological Science, 32: 1015-1022.

Hocsman, S. (2006) Producción lítica, variabilidad y cambio en Antofagasta de la Sierra (ca. 55002000 AP). Tesis Doctoral inédita. Facultad de Ciencias Naturales y Museo, Universidad Nacional de La Plata, La Plata. MS.

Hodder, I. y C. Orton (1976) Spatial analysis in archaeology. Cambridge: Cambridge University Press.

Holdaway, S. J., J. Shiner y P. Fanning (2004) Hunter gatherers and the archaeology of discard behavior: an analysis of surface stone artifacts from Sturt National Park, western New South Wales, Australia. Asian Perspectives, 43 (1): 34-72.

Holdaway, S. J., W. Wendrich y R. Phillipps (2010) Identifying low-level food producers. Detecting mobility from lithics. Antiquity, 84: 185-194.

Holmberg, E. (1884) La Sierra de Curá-Malal (Currumalan). Informe presentado al excelentísimo señor gobernador de la Provincia de Buenos Aires, Doctor Dardo Rocha. Buenos Aires. 81p

Hoopes, J. W. (1995) Interaction in hunting and gathering societies as a context for the emergence of pottery in the Central American Isthmus. En: W. K. Barnett y J. W. Hoopes (Eds.) The Emergence of Pottery: Technology and Innovation in Ancient Societies, pp. 185-198. Smithsonian Institution, Washington D.C.

Hrdlicka, A. (1912) Early man in South America. Smithsonian institute Bureau of American Etnologyl,. 52. Washington D.C.

Ingbar, E. (1994) Lithic Material Selection and Technological Organization. En: P. Carr (Ed.) The organization of North American prehistoric chipped stone Technologies, pp.: 45-56. International Monographs in Prehistory. Archaeological Series 7. Michigan.

Ingold, T. (1987) Evolution and Social Life. Cambridge University Press

INTA (2009) Monitoreo de la cobertura y el uso del suelo a partir de sensores remotos, resultados 20062009. Informe Técnico Unificado PNECO 1643. INTA, 31pp. 
Iñiguez, A.M., A. Del Valle, D. G. Poirè, L. A. Spalletti, P. E. Zalba (1989) Cuenca PrecámbricaPaleozoica Inferior de Tandilia. Provincia de Buenos Aires. En: G. Chebli, G. y L. A. Spalletti (Eds.) Cuencas Sedimentarias Argentinas. Tucumán, Universidad Nacional de Tucumán. p. 245-263. (Serie Correlación Geológica).

Iñiguez Rodriguez, A. M. (1999) La Cobertura Sedimentaria de Tandilia. En: R. Caminos (Ed.) Geología Argentina., pp.101-106, SEGEMAR, Anales 29, Buenos Aires.

Iriondo, M., (1999) Climatic changes in the South American plains: records of a continental-scale oscilation. Quaternary International 57-58: 93-112.

Isla, F. (1989) Holocene sea level fluctuation in the Southern Hemisphere. Quaternary Science Reviews, 8: 359- 368 .

Isla, F. y M. Espinoza (1995) Coastal environmental changes associated with Holocene sea level fluctuations. Quaternary International, 26: 55-60.

Janetski, J. (1997) Fremont Hunting and Resource Intensification in the Eastern Great Basin. Journal of Archaeological Science, 24: 1075-1088.

Jeske, R. (1989) Economies in raw material use by prehistoric hunter-gatherers. En Time, Energy and Stone Tools, R. Torrence (Ed.)., pp. 34-45. Cambridge University Press. Cambridge.

Jeske, R. (1992) Energetic efficiency and lithic technology: an upper Mississippian example. American Antiquity, 57 (3): 467-481

Johnson, E. (1985) Current developments in bone technology. Advances in Archaeological Method and Theory, 8: 157-235

Jochim, M. (1976) Hunther-gatherer Subsistence and Settlement: a Predictive Model. Academic Press, New York.

Jochim, M (1981) Strategies for survival. Academic Press. New York.

Jones, G., C. Beck, E. Jones y R. Hughes (2003) Lithic source and paleoarchaic foraging territories in the Great Basin. American Antiquity, 68 (1): 5-38.

Josse, C., G. Navarro, P. Comer, R. Evans, D. Faber-Langendoen, M. Fellows, G. Kittel, S. Menard, M. Pyne, M. Reid, K. Schulz, K. Snow, and J. Teague (2003) Ecological Systems of Latin America and the Caribbean: A Working Classification of Terrestrial Systems. NatureServe, Arlington, VA.

Kaufmann, C. (2009) Estructura de sexo y edad en guanaco. Estudios actualísticos y arqueológicos en Pampa y Patagonia. Relaciones de la Sociedad Argentina de Antropología. Buenos Aires.

Keidel, J. (1916) La geología de las sierras de la provincia de .Buenos Aires y sus relaciones con las montañas de Sud África y los Andes. Anales del Ministerio de Agricultura de la Nación, Sección Geología, Mineralogía y Minería, 11(3): 1-78, Buenos Aires.

Kellner, C. M. y M. J. Schoeninger (2007) A simple carbon isotope model for reconstructung prehistoric human diet. American Journal of Physical Anthropology, 133: 1112-1127.

Kelly, R. (1983) Hunter-Gatherer Mobility Strategies. Journal of Anthropological Research, 39 (3): 277-306.

Kelly, R. (1992) Mobility/sedentism concepts: archaeological measures, and effects. Annual Review of Anthropology 21: 43-66.

Kelly, R. (1995) The Foraging Spectrum: Diversity in Hunter-Gatherer Lifeways. Smithsonian Institution Press, Washington D.C.

Kilmurray, J. (1968) Petrología de las rocas ígneas de las Sierras Australes de la Provincia de Buenos Aires. Revista del Museo de La Plata (N.S.) Sección Geología, 6: 155-188. 
Kooyman, B. P. (2000) Understanding stone tools and archaeological sites. Calgary, University of Calgary Press.

Kostadinoff, J. (2007) Evidencia geofísica del umbral de Trenque Lauquen en la extensión norte de la cuenca de Claromecó, provincia de Buenos Aires. Revista de la Asociación Geológica Argentina, 62 (1): $1-10$.

Krebs J. y N. Davies (1993) An Introduction to Behavioral Ecology. Chapter 5. Competing for resources. Oxford Blackwell Scientific Publishing.

Kuhn, S. (1994) A formal approach to the design and assembly of mobile toolkits. American Antiquity, 59: 426-442.

L'Heureux, L. (2000) Estudio comparativo de indicadores de adecuación fisiológica y salud bucal en muestras de restos humanos del Sudeste de la Región Pampeana. Relaciones de la Sociedad Argentina de Antropología, 25: 51-73.

Lahr, M. M. y R. Foley (1994) Multiple dispersals and modern human origins. Evolutionary Anthropology: Issues, News, and Reviews, 3 (2): 48-60.

Layton, R. (1986) Poitical and territorial structure among hunter-gatherers. Man, 21 (1) (NS): 18-33.

Leipus, M. (2006) Análisis de los modos de uso prehispánicos de las materias primas líticas en el Sudeste de la Región Pampeana. Una aproximación funcional. Tesis Doctoral Inédita. La Plata: Facultad de Ciencias Naturales y Museo.

Leipus, M. y F. Oliva (1999) Vías alternativas de estudio aplicadas a reservorios de materias primas líticas: análisis de rastros de uso en artefactos de sitios Laguna de Puan 1. Libro de Resúmenes del XIII Congreso Nacional de Arqueología Argentina. 99. 21-22.

Leipus, M. y A. Mansur (2007) El análisis funcional de base microscópica aplicado a materiales heterogéneos. Perspectivas metodológicas para el estudio de las cuarcitas de la región Pampeana. En: C. Bayón, A. Pupio, I. González, N. Flegenheimer y M. Frére Arqueología en Las Pampas. Sociedad Argentina de Antropología. Pp 179-200.

Linares, E., E. Llambías y C. Latorre (1980) Geología de la Provincia de La Pampa, República Argentina y geocronología de sus rocas metamórficas y eruptivas. Revista de la Asociación Geológica Argentina, 35 (1): $87-146$.

Linton, R. (1944) North American Cooking Pots. American Anthropologist 9(4):369-380.

Lista, R. [1879] (1975) Mis exploraciones y descubrimientos en la Patagonia. Marymar. Buenos Aires.

Lloyd C. D. y P. M. Atkinson (2004) Archaeology and geostatistics. Journal of Archaeological Science, 31: 151-165.

Longin, R. (1971) New method of collagen extraction for radiocarbon dating. Nature, 230: 241-242.

Loponte, D. (2004) Atlas osteológico de Blastocerus dichotomus (ciervo de los pantanos). Editorial Los Argonautas, Buenos Aires.

Loponte, D. (2007) La economía prehitórica del norte bonaerense. Arqueología del humedal del Paraná inferior, Bajíos Ribereños meridionales, Tesis Doctora Indédita. Universidad Nacional de La Plata.

Lovis, W. y R. Donahue (2011) Space, information and knowledge: ethnocartography and north american boreal forest hunter-gatherers. En: R. Whallon, W. Lovis y R. Hitchcock (Eds.) Information and Its Role in Hunter-Gatherer Bands, pp. 59-88. Ideas, Debates, and Perspectives 5. Costen Institute of Archaeology Press, University of California, Los Angeles.

Lozano, P. (1991) Cerro Aguirre: un sitio de aprovisionamiento de materias primas líticas en la localidad de Sierras Bayas (Pcia. de Buenos Aires). Shincal 3 (3): 145-150. 
Luna, L. H. (2008) Estructura demográfica, estilo de vida y relaciones biológicas de cazadoresrecolectores en un ambiente de desierto. Sitio Chenque 1 (Parque Nacional Lihué Calel, provincia de La Pampa, Argentina). BAR. International Series 1886, England.

Lupo, K. (2006) What explains the carcass field processing and transport decisions of contemporary hunter-gatherers? Measures of economic anatomy and zooarchaeological skeletal part representation. Journal of Archaeological Method and Theory, 13(1): 19-66.

Lupo, K. (2007) Evolutionary foraging models in zooarchaeological analysis: recent applications and some future challenges. Journal of Archaeological Research, 15: 143-189.

Lyman, R. (1994). Vertebrate taphonomy. Cambridge University Press, Cambridge.

Lyman, R. y G. Fox (1989) A Critical Evaluation of Bone Weathering as an Indication of Bone Assemblage Formation. Journal of Archaeological Science, 16: 293-317.

MacDonald, D. (2007) The role of lithic raw material availability and quality in determining tool kit size, tool function, and degree of retouch: a case study from Skink Rockshelter (46NI445), West Virginia. http://www.cas.umt.edu/facultydatabase/FILES_Faculty/514/MacDonald-Retouch-Final\%20May\%20 07.pdf Acceso 10/02/2014

MacDonald, D. y B. Hewlett (1999) Reproductive Interests and Forager Mobility. Current Anthropology, 40(4):501-523.

Madrazo, G. (1967) Prospecciones Arqueológicas en Sierra de la Ventana. Etnía 5: 3-5. Olavarría.

Madrazo, G. (1973) Síntesis de arqueología Pampeana. Etnía 17: 13-25.

Madrazo, G. (1979) Los cazadores de larga distancia de la Región Pampeana. Prehistoria Bonaerense pp.13-17. Olavarría.

Madrid, P. (1997) Análisis petrológicos y alfarería pampeana. En: M. Berón y G. Politis (comp) Arqueología Pampeana en la década de los '90. Museo de Historia Natural de San Rafael, XI Congreso Nacional de Arqueología Argentina, INCUAPA - Facultad de Ciencias Sociales (UNCPBA). Pp 61-70.

Madrid, P. y M. Salemme (1991) La ocupación tardía del sitio 1 de la Laguna Tres Reyes, Adolfo Gonzalez Chaves, Provincia de Bs. As. Boletín del Centro, 3: 165-179.

Madrid, P. y G. Politis (1991) Estudios paleoambientales en la región pampeana: un enfoque multidisciplinario. Actas del XI Congreso de Arqueología Chilena, 1: 131-153. Santiago de Chile.

Madrid, P. y F. Oliva (1994) Análisis preliminar de las representaciones rupestres presentes en cuatro sitios del Sistema de Ventania, Provincia de Buenos Aires. Revista del Museo de La Plata, (Nueva Serie), 9:200-223. La Plata.

Madrid, P. y G. Barrientos (2000) La estructura del registro arqueológico del sitio Laguna Tres Reyes 1 (Provincia de Buenos Aires): nuevos datos para la interpretación del poblamiento humano del Sudeste de la Región Pampeana a inicios del Holoceno tardío. Relaciones de la Sociedad Argentina de Antropología (N.S.) 25: 179-206.

Madrid, P. y V. Di Prado (2008) Una caracterización macroscópica y petrográfica de cerámicas arqueológicas del Área Interserrana y Serrana de Tandilia, región pampeana. Trabajo presentado al V. Congreso de Arqueología de la Región Pampeana Argentina.

Magnín, L. (2010) Distribuciones arqueológicas en la meseta central de Santa Cruz. Implicancias para los estudios de uso del espacio y movilidad de sociedades cazadoras-recolectoras. Tesis Doctoral inédita, Facultad de Ciencias Naturales y Museo UNLP, La Plata

Mandrini, R. (1993) Las transformaciones de la economía indígena bonaerense (1600 - 1820). En: R. Mandrini y A. Reguera (Comp.) Huellas en la tierra. Indios, agricultores y hacendados en la pampa bonaerense, Tandil Instituto de Estudios Históricos y Sociales, pp.45-74. 
Manassero, M. J. (1986) Estratigrafía y Estructura en el sector oriental de la localidad de Barker, Provincia de Buenos Aires. Revista de la Asociación Geológica Argentina, 41 (3-4): 375-385.

Matthew, J.A., A.J. Woods and C. Oliver. (1991) Point before eyes. En: A. Middleton e I. Freestone (Eds.) Recent Developments in Ceramic Petrology. Occasional Paper No 81. British Museum.

Marconetto, B. (1999) Las leñas del jagüar. En: C. Aschero, M. Korstanje y P. Vuoto (Eds.) En los Tres Reinos: Prácticas de Recolección en el Cono Sur. Instituto de Arqueología y Museo, Facultad de Ciencias Naturales e Instituto Miguel Lilli, Universidad Nacional de Tucumán, pp 179-186.

Marean, C. W. (1995) Of Taphonomy and Zooarchaeology. Evolutionary Anthropology, 4 (2): 64-72.

Mariano, C. I. (2008) Prácticas Mortuorias y Registro Bioarqueológico en la Costa Rionegrina del Golfo de San Matias. Tesis de Licenciatura. Facultad de Ciencias Sociales, Universidad Nacional del Centro de la Provincia de Buenos Aires. Olavarría.

Markgraf, V. (1991) Late Pleistocene environmental and climatic evolution in southern South America. Bamberguer Geographische Schriften band, 11:271-281.

Márquez Pérez, J. (2012) Modelos de superficies: Generación, análisis y aplicaciones. VIII Curso de Expertos en Sistemas de Información Geográfica. Universidad Internacional de Andalucía. MS. 136 pp.

Martínez, G. (1990) Informe de las tareas de prospección arqueológica realizadas en cercanías de la laguna Chasicó, Partido de Villarino, Provincia de Buenos Aires. Informe inédito. MS.

Martínez, G. (1999) Tecnología, subsistencia y asentamiento en el curso medio del Río Quequén Grande: un enfoquearqueológico. Tesis Doctoral inédita, Facultad de Ciencias Naturales y Museo UNLP, La Plata.

Martínez, G. (2002) Organización y cambio en las estrategias tecnológicas: un caso arqueológico e implicaciones comportamentales para la evolución de las sociedades cazadoras-recolectoras pampeanas. En: G. Martínez y J. Lanata (Eds.) Perspectivas Integradoras entre Arqueología y Evolución. Teoría, Método y Casos de Aplicación. Olavarría, Buenos Aires, pp. 121-156.

Martínez, G (2004) Resultados preliminares de las investigaciones arqueológicas realizadas en el curso inferior del Río Colorado (Partidos de Villarino y Patagones, Provincia de Buenos Aires). En: G. Martínez, M. Gutierrez, R. Curtoni, M. Berón y P. Madrid (Eds.). Aproximaciones Contemporáneas a la Arqueología Pampeana. pp 275-292.

Martínez, G. (2008-2009) Arqueología del curso inferior del río Colorado: estado actual del conocimiento e implicaciones para la dinámica poblacional de cazadores-recolectores pampeanos-patagónicos. Cazadores-Recolectores del Cono Sur. Revista de Arqueología, 3: 73-94. Editorial Universitaria de Mar del Plata, Mar del Plata

Martínez, G. (2010) Arqueología de los grupos cazadores-recolectores del curso inferior del río Colorado (partidos bonaerenses de Villarino y de Patagones)- En: R. Masera (comp.) Los ríos mesetarios norpatagónicos. Aguas generosas del Ande al Atlántico. Gobierno de Río Negro. Ministerio de Producción, pp 167-194

Martínez, G. y M. Figuerero Torres (2000) Sitio arqueológico La Petrona (Pdo. de Villarino, Pcia. de Bs. As.): Análisis de las modalidades de entierro en el área Sur pampeana. Relaciones de la Sociedad Argentina de Antropología, 25: 227-247.

Martínez, G. y Q. Mackie (2003-2004) Late Holocene human occupation of the Quequén Grande river valley bottom: settlement systems and an example of a built environment in the Argentine pampas. Before Farming: the Archaeology of Hunter-Gatherers, 1: 178-202.

Martínez, G. y M. Gutiérrez (2004) Tendencias en la explotación humana de la fauna durante el Pleistoceno final y Holoceno en la Región Pampeana (Argentina). En: G. Mengoni Goñalons (Ed.) Zooarchaeology of South America. Pp 81-98. Archaeopress, 1298. 
Martínez, G. y L. Prates (2007) Adaptaciones ribereñas en ambientes árdos-semiáridos: arqueología de los cursos inferior y medio de los ríos Colorado y Negro (Pcia. De Buenos Aires y Río Negro, Argentina). I Jornadas Nacionales de Arqueología de Cazadores-Recolectores. Libro de resúmenes, p. 17. Santiago de Chile.

Martínez, G., F. Zangrando y L. Stoessel (2005) Sitio el Tigre (Pdo. De Patagones; Pcia de Buenos Aires, Argentina): evidencias sobre la explotación de peces en el curso inferior del río Colorado e implicaciones para los sistemas de subsistencia. Magallania, 33 (2): 127-142. Punta Arenas, Chile.

Martínez, G., F. Zangrando y L. Prates (2009) Isotopic ecology and human palaeodiets in the lower basin of the Colorado Rivier, Buenos Aires Province, Argentina. International Journal of Osteoarchaeology, 19 (2): 281-296.

Martínez, G., Flensborg, G. y P. Bayala (2012) Human corpse manipulation and the body as symbols: A case study from de Eastern Pampa-Patagonia transition (Argentina) during the Final Late Holocene. Journal of Anthropological Archaeology, 31 (2):215-226.

Martínez, G., Flensborg, G. y P. Bayala (2013) Chronology and human settlement in northeastern Patagonia (Argentina): Patterns of site destruction, intensity of archaeological signal, and population dinamics. Quaternary International, 301: 123-134.

Martínez G, P. Bayala, G, Flensborg y R. López (2006) Análisis preliminar de los entierros humanos del sitio Paso Alsina 1 (Pcia. de Buenos Aires). Intersecciones en Antropología, 7: 95-108.

Martínez, G., G. Flensborg, P. Bayala y R. López (2007) Análisis de la composición anatómica, sexo y edad de los entierros secundarios del sitio Paso Alsina 1 (Pdo de Patagones, Pcia de Buenos Aires). En: C. Bayón, A. Puppio, M. González, N. Flegenheimer y M. Freire (Eds.) Arqueología en las Pampas, 1: 41-58. Sociedad Argentina de Antropología. Buenos Aires.

Martínez, O., J. Rabassa y A. Coronato (2009) Charles Darwin and the first scientific observations on the Patagonian shingle formation (Rodados Patagónicos). Revista de la Asociación Geológica Argentina, 64 (1): $90-100$.

Martínez Sarasola, C. (1992) Nuestros Paisanos los Indios. Emecé Editores S.A.

Matarrese, A. (2007) Análisis tecnomorfológico de artefactos de molienda de la localidad arqueológica Zanjón Seco, Área Interserrana Bonaerense. En: C. Bayón, N. Flegenheimer, M. I. González de Bonaveri, A. Pupio y M. Frère (Eds.) Arqueología en las Pampas, pp. 615- 634. Sociedad Argentina de Antropología, Buenos Aires.

Mazzanti, D. (1995-1996) Arqueología del borde oriental de Tandilia: cambios y continuidades en el uso del espacio. Shincal, 5: 7-24.

Mazzanti, D. (1997) Excavaciones arqueológicas en el sitio Cueva Tixi, Buenos Aires, Argentina. Latin American Antiquity 8: 55-62.

Mazzanti, D. (1999) Arqueología de un asentamiento araucanizado postconquista en las serranías orientales de Tandilia, Pcia de Buenos Aires. Soplando en el Viento... Actas de las Terceras Jornadas de Arqueología de la Patagonia, pp. 451-460.

Mazzanti, D. (2006) La constitución de territorios sociales durante el Holoceno tardío el caso de las sierras de Tandilia, Argentina. Relaciones de la Sociedad Argentina de Antropología, 31: 277-300. Buenos Aires.

Mazzanti, D. y J. Porto López (2007) Caracterización petrográfica y estructural de cerámicas arqueológicas de las Sierra de Tandilia. En: M. Cremonte y N. Ratto (Eds.) Cerámicas Arqueológicas. Perspectivas arqueométricas para su análisis e interpretación, Universiad Nacional de Jujuy. Jujuy. Pp $97-122$. 
Mazzanti, D. y C. Quintana (Eds.) (2001) Cueva Tixi: Cazadores y Recolectores de las Sierras de Tandilia Oriental. 1 Geología, Paleontología y Zooarqueología. Publicación especial 1. Universidad Nacional de Mar del Plata, Mar del Plata. 231pp.

Mazzanti, D. y C. Quintana (2010) Estrategias de subsistencia de las jefaturas indigenas del siglo XVIII. Zooarqueologia de la localidad arqueologica Amalia (Tandilia Oriental). Relaciones de la Sociedad Argentina de Antropología, 35: 143-170.

McCormac, F. G., Hogg, A. G., Blackwell, P. G., Buck, C. E., Higham, T. F. G., y Reimer, P. J. (2004). SHCal04 Southern Hemisphere calibration, 0-11.0 cal kyr BP. Radiocarbon, 46(3): 1087-1092.

Meindl, R. y O. Lovejoy. (1985) Ectocranial suture closure: a revised method for the determination of skeletal age at death based on the lateral-anterior sutures. American Journal of Physical Anthropology, 68: 57-66.

Melo, W. D., R. Schillizzi, G. M. E. Perillo y M. C. Piccolo (2003) Influencia del área continental pampeana en la evolución morfológica del estuario de Bahía Blanca. Revista de la Asociación Argentina de Sedimentología, 10 (1): 37-50.

Meltzer, D. (1989) Was Stone Exchange Among Eastern North American Paleoindians? En: C. Ellis y J. Lothrop (Eds.) Eastern Paleoindian lithic resource use, pp.11-39. Westview Press, Boulder.

Menéndez, L., M. Osterrieth, F. Oliva (2009) A phytolith approximation to diet study in the archaeological site Gascón 1, Pampean Region, Republica Argentina. Quaternary International: 204: 84-94.

Menghin, O. F. (1963) Industrias de morfología protolítica en Sudamérica. Anales de la Universidad del Norte, 2: 69-77

Menghín, O. F. y M, Bórmida (1950) Investigaciones prehistóricas en Cuevas de Tandilia (Provincia de Buenos Aires). Runa, 3, parte 1-2. Buenos Aires.

Mengoni Goñalons, G. (1988) Análisis de materiales faunísticos de sitios arqueológicos. Xama, 1: $71-120$.

Mengoni Goñalons, G. (1999) Cazadores de guanacos de la estepa patagónica. Sociedad Argentina de Antropología, Buenos Aires.

Merchant, V. y D. Ubelaker (1977) Skeletal growth of the Protohistoric Aricara. American Journal of Physical Anthropology 46: 61-72.

Messineo, P. (2008) Investigaciones arqueológicas en la Cuenca superior del arroyo Tapalqué (partidos de Olavarría y Benito Juárez, provincia de Buenos Aires). Tesis doctoral, Facultad de Ciencias Naturales y Museo. Universidad Nacional de La Plata. MS.

Messineo, P. y G. Politis (2007) El sitio Calera. Un depósito ritual en las Sierras Bayas (sector noroccidental de Tandilia). En: C. Bayón, A. Pupio, M. I. González, N. Flegenheimer y M. Frère (Eds.) Aqueología en Las Pampas. Sociedad Argentina de Antropología. Pp 697-720.

Messineo, P. G., M. P. Barros, D. Poiré y L. Gómez Peral. (2004). Características litológicas de los niveles de chert o ftanitas en las Sierras Bayas (Pdo. de Olavarría, Pcia. de Buenos Aires). En: G. Martínez, M. Gutiérrez, R. Curtoni, M. Berón y P. Madrid (Eds.) Aproximaciones Contemporáneas a la Arqueología Pampeana. Perspectivas Teóricas, Metodológicas, Analíticas y Casos de Estudio, pp. 307-319. Facultad de Ciencias Sociales, Universidad Nacional del Centro de la Provincia de Buenos. Olavarría.

Micozzi M. (1991) Postmortem change in human and animal remains. A systematic approach. Springfield, Illinois: Charles C. Thomas

Miotti, L.; M. Vázquez y D. Hermo (1999) Piedra Museo un Yamnagoo Pleistocénico en la Colonización de la Meseta de Santa Cruz. El estudio de la Arqueofauna. Soplando en el Viento... Actas de las III Jornadas de Arqueología de Patagonia, pp. 113-136. 
Mithen, S. J. (1989) Modeling hunter-gatherer decision making: Complementing optimal foraging theory. Journal of Human Ecology, 17: 53-89.

Mithen, S. J. (1990) Thoughtful foragers. A Study of Prehistory Decision Making. Cambridge University Press. 289 pp.

Mogni, A. C. (1991) Los cuerpos salinos, un recurso de zonas áridas. Acaecer, 177: 16-18. www. produccion-animal.com.ar acceso 10/07/2013

Moirano, J. (1999) Aprovisionamiento de recursos líticos y variabilidad artefactual en el sur de la Subregión Pampa Húmeda: la revisión de las colecciones particulares. Relaciones de la Sociedad Argentina de Antropología 24: 237-255.

Moirano, J., F. Oliva y R. Ruiz (2007) Análisis de la evolución del uso del espacio en el Sistema de Ventania, Provincia de Buenos Aires, mediante la implementación de un modelo digital del terreno. XVI Congreso Nacional de Arqueología Argentina, 1: Pp 453-455. San Salvador de Jujuy.

Morales, N., L. Catella y F. Oliva (2012) Una primera aproximación a los agentes y procesos postdepositacionales actuantes en los paisajes arqueológicos de la cuenca del arroyo Chasicó, Provincia de Buenos Aires, Argentina. Trabajo presentado al Simposio Paisajes Arqueológicos del Holoceno Tardío, Interaciones entre Seres Humanos y el Ambiente. Rosario.MS.

Morello, J. (2002) Perfil ecológico de Sudamérica. Características estructurales de Sudamérica y su relación con espacios semejantes del planeta. Instituto de Cooperación Sudamericana. http://www. gepama.com.ar/morello/downloads/perfil-ecologico-de-sudamerica.pdf acceso 18/10/2012.

Moreno, F. (1874) Cementerios y paraderos prehistóricos de la Patagonia. Anales Cientificos Argentinos 1: 2-13.

Moreno, F. (1876) Viaje a la Patagonia septentrional. Anales de la Sociedad Cientifica Argentina 1: 129-392.

Morgan, C. (2009) Climate change, uncertainty and prehistoric hunter-gatherer mobility. Journal of Anthropological Archaeology, 28: 382-396.

Mullet, A. (2009) Paleoindian mobility ranges predicted by the distribution of projectile points made of Upper Mercer and Flint Rodge Flint. Thesis submitted to Kent State University. 96pp. Ms. https://etd.ohiolink.edu/ap/0?0:APPLICATION_PROCESS\%3DDOWNLOAD_ETD_SUB_DOC_ ACCNUM:::F1501_ID:kent1253900203\%2Cinline Acceso 10/03/2014

Murdock, G. (1967) Ethnographic atlas: a summary. Ethnology, 6: 109-236

Murgo, A. y V. Aldazabal (2007) Análisis de isótopos estables de carbono y nitrógeno de restos humanos provenientes de sitios del área Pampa Deprimida Centro Oriental. En: F. Oliva, N. de Grandis y J. Rodríguez (Comp.) Arqueología Argentina en los Inicios de un Nuevo Siglo, publicación del XIV Congreso Nacional de Arqueología Argentina, pp. 259-263, Laborde editor, Rosario.

Musters, G. ([1871] 1997) Vida entre los Patagones. Editorial El Elefante Blanco. Buenos Aires.

Musaubach, M. G., G. Erra y M. Osterrieth (2010) Estudios arqueoetnobotánicos en la localidad Tapera Moreira (departamento de Lihué Calel, provincia de La Pampa). Análisis fitolíticos en artefactos de molienda. En: M. Berón, L. Luna, M. Bonomo, C. Montalvo, C. Aranda y M. Carrera Aizpitarte (Eds.) Mamül Mapu: pasado y presente desde la arqueología pampeana, 1: 77-86, Editorial libros del Espinillo.

Musaubach, M. G. (2012) Potencialidad de estudios arqueobotánicos sobre tártaro dental de cazadores recolectores de la provincia de La Pampa, Argentina. Revista Argentina de ntropología Biológica, 14 (NS): 105-113.

Nágera, J. J. (1940) Historia Física de la Provincia de Buenos Aires. Tomo I Tandilia. Biblioteca Humanidades 24. Universidad Nacional de La Plata. 
Nami, H. (1992) El subsistema tecnológico de la confección de instrumentos líticos y la explotación de los recursos del ambiente: una nueva vía de aproximación. Shincal, 2 :33-53.

Nelson, M. (1991) The study of technological organization. Archaeological Method and Theory, 3: pp. 57-100. University of Arizona Press. Tucson.

Nelson, M y H. Lippmeier (1993) Grinding-tool design as conditioned by Land-Usepattern. American Antiquity, 58 (2): 286-305.

Nicholson, R. (1996) Bone degradation, burial medium and species representation: Debunking the myths, an experiment-based approach. Journal of Archaeological Science, 23: 513-533.

Nielsen-Marsh, C.N., C. Smith, M. Jans, A. Nord, H. Kars y M. Collins (2007). Journal of Archaeological Science, 34: 1523- 1531.

Nieto, M. y A. Prieto (1986) Análisis palinológico del Holoceno tardío del sitio Fortín Necochea (Pdo. De Gral La Madrid, Pcia. De Buenos Aires, Argentina). Ameghiniana, 23 (2-3); 271-276.

Odell, G (1996) Economizing behavior and the concept of curation. En: G. Odell (Ed.) Stone Tools. Theoretical insights into human prehistory. Plenum Press. New York and London. pp 51-80

Oliva, F. (1996) Investigaciones arqueológicas en el Sector Occidental de Ventania y la llanura adyacente. Beca Posdoctoral. Informe presentado al CONICET. MS.

Oliva F (2000) Análisis de las localizaciones de los sitios con representaciones rupestres en el sistema de Ventania, Provincia de Buenos Aires. En: M. M Podestá y M. de Hoyos (Eds.). Arte en las Rocas. Sociedad Argentina de Antropología. Buenos Aires, pp. 143-158

Oliva, F. (2006) Uso y contexto de producción de elementos "simbólicos" del sur y oeste de la provincia de Buenos Aires, República Argentina (Área Ecotonal Húmeda Seca Pampeana). Revista de la Escuela de Antropología, 12: 101-116. Rosario.

Oliva, F. (2013) Registro de máscaras en Sierra de la Ventana de la Región Pampeana Argentina. Presentación de explicaciones alternativas. Boletín del Museo Chileno de Arte Precolombino, 18 (2): 89-106.

Oliva, F. (2014) Investigaciones arqueológicas en el sector centro-occidental de la Sierra de la Ventana y la llanura adyacente. Tesis doctoral en preparación. Facultad de Ciencias Naturales y Museo (UNLP). MS.

Oliva, F. y G. Barrientos (1988) Laguna de Puán: un potencial sitio de aprovisionamiento de materia prima lítica. Resúmenes IX Congreso Nacional de Arqueología Argentina: 77. Buenos Aires, Argentina.

Oliva, F y J. Moirano (1997) Primer informe sobre aprovisionamiento primario de riolita en Sierra de La Ventana. En: M. Berón y G. Politis (Eds.). Arqueología pampeana en la década de los '90. XI Congreso Nacional de Arqueología Argentina. San Rafael, Mendoza, pp. 137-146.

Oliva, F. y J. Moirano (2001) Estrategias para el estudio de la utilización de recursos líticos en el sur de la Región Pampena, República Argentina. Arqueología Uruguaya hacia el fin del Milenio, 1: 521-537. Colonia del Sacramento Uruguay.

Oliva, F. y M. Leipus (1999) Vías alternativas de estudio aplicadas a reservorios de materias primas líticas: análisis de rastros de uso en Artefactos de sitios Laguna de Puan 1. Libro de Resúmenes del XIII Congreso Nacional de Arqueología Argentina. Universidad Nacional de Códoba, Córdoba, pp. 22-23

Oliva F. y M. Algrain (2004) Una aproximación cognitiva al estudio de representaciones rupestres del Casuhati (Sistema Serrano de Ventania y llanura adyacente, Provincia de Buenos Aires). En: C. Gradín y F. Oliva (Eds.). La Región Pampeana -su Pasado arqueológico-. Editorial Laborde, Rosario Argentina. pp. 49-60.

Oliva F. y M. Algrain (2005) Simbolismo en las sociedades indígenas en el sur del ecotono húmedo seco pampeano ¿Arte shamánico?. Revista de la Escuela de Antropología de Rosario, 10: 155:168. 
Oliva, F. y L. Lisboa (2006) El estudio de cuentas en diferentes contextos arqueológicos del Sistema de Ventania y su llanura adyacente (Área Ecotonal Húmeda seca Pampeana). Revista de la Escuela de Antropología, 12: 135-148. Rosario.

Oliva F. y S. I Pérez (2008) Análisis cuantitativo de "reservorios" o "caches" de artefactos y materias primas líticas de sitios del borde occidental de la Pampa Húmeda. En: A. Austral y M. Tamagnini (Comp.) Problemáticas de la Arqueología Contemporánea, 2: 345-354.

Oliva, F. y M. C. Panizza (2012) Primera aproximación a la arqueología monumental del Sistema Serrano de Ventania, Provincia de Buenos Aires. Anuario de Arqueología, 4: 161-180. Departamento de Arqueología, Escuela de Antropología, Facultad de Humanidades y Artes, Universidad Nacional de Rosario.

Oliva, F., J. Moirano y M. Saghessi (1991a) Estado de las investigaciones en el sitio Laguna de Puan 1. Boletín del Centro 2. La Plata.

Oliva, F., A. Gil y M. Roa (1991b) Recientes Investigaciones en el Sitio San Martín 1 (BU/PU/S). Partido de Puan, Pcia de Bs As. Shincal. X Congreso Nacional de Arqueología Argentina. 3 (3):135-139

Oliva, F., L. Catella y N. Morales (2010a) Análisis de los procesos de formación actuantes en el sitio San Martín 1, cuenca media del arroyo Chasicó, Provincia de Buenos Aires. Actas del XVII Congreso Nacional de Arqueología Argentina.

Oliva, F., M. C. Panizza y M. Algrain (2010b). Diferentes enfoques en la investigación del Arte Rupestre del Sistema Serrano de Ventania. Comechingonia, Revista de Arqueología 13: 89-107. Universidad Nacional de Córdoba.

Oliva, F., M. C. Panizza y R. Ruíz (2013) Cuencas visuales vinculadas con el estudio del paisaje y del arte rupestre en el Sistema Serrano de Ventania. En: M. Ramos, M. Lanza, V. Helfer, V. Pernicone, F. Bognani, C. Landa, V. Aldazabal y M. Fernández (Eds.) Arqueometría Argentina, Estudios Pluridisciplinarios. Programa de Arqueología Histórica y Estudios Pluridisciplinarios, Departamento de Ciencias Sociales, Universidad Nacional de Luján, pp 99-111.

Oliva, F., E. Levin, J. Moirano y D. Avila. (2000) Investigaciones arqueológicas de momentos tardíos en el Abra de Saavedra, Provincia de Buenos Aires. Trabajo presentado al II Congreso de Arqueología de la Región Pampeana Argentina. MS.

Oliva, F., J. Moirano, R. Ruiz, J. Calamante, y A. Soliz (2004) Aplicación de GIS en las investigaciones arqueológicas del Sistema de Ventania, Provincia de Buenos Aires. En: C. Gradin y F. Oliva (Eds.) La Región Pampeana -su pasado arqueológico-. Ed Laborde. Argentina. pp 91-100.

Oliva, F., J. Avila, M. Ayuso, L. Catella y M. Gallego (2006) Investigaciones arqueológicas en la cuenca del arroyo Chasicó y llanura adyacente, Sudoeste de la Provincia de Buenos Aires. Comechingonia. Revista de Arqueología, 9: 123-139. Universidad Nacional de Córdoba.

Oliva, F., G. L'heureux, H. De Angelis, V. Parmigiani y F. Reyes (2007) Poblaciones indígenas de momentos postcontacto en el borde occidental de la pampa húmeda: Gascón 1, un sitio de entierros humanos. En: F. Oliva, N. de Grandis y J. Rodriguez (Eds.) Arqueología Argentina en los Inicios de un Nuevo Siglo, pp 265-274. Editorial Laborde, Rosario.

Ormazabal, P. (1999) Lumb: Un sitio de aprovisionamiento de materia prima lítica para elementos de molienda. Actas del XII Congreso Nacional de Arqueología Argentina, Tomo III, pp. 156-164. La Plata.

Ortega, D., J. J. Ibañez, L. Khalidi, V. Méndez, D. Campos y L. Teira (2014) Towards a Multi-AgentBased Modelling of Obsidian Exchange in the Neolithic Near East. Journal of Archaeological Method and Thoery, 21: 461-485.

Orton, C., P. Tyers y A. Vince (1997) La cerámica en arqueología. Barcelona, Ed. Crítica.

Otaola, C. (2012) Procesos de intensificación y aprovechamiento de médula y grasa ósea en el sur de Mendoza, Argentina. Archaeofauna, 21: 235-247. 
Outes, F. (1908). Arqueología de San Blas (provincia de Buenos Aires). Anales del Museo Nacional de Buenos Aires 16:249-273.

Outes, F. (1909) Sobre una facies local de los instrumentos neolíticos bonaerenses. Revista del Museo de La Plata 16 (s.3): 319-339.

Outes, F. (1926) Noticias sobre el resultado de mis investigaciones antropológicas en la extremidad sudeste de la provincia de Buenos Aires. Physis 8: 387-390.

Pacheco Torres V., E. Altamirano y G. Porras (1979) Guía Osteológica para Camélidos Sudamericanos. Serie Investigaciones 4. Departamento Académico de Ciencias Histórico-Sociales. Universidad de San Marcos.

Paez, M. y A. Prieto (1993) Paleoenvironmental reconstruction by pollen analysis from loess sequences of the southeast of Buenos Aires (Argentina). Quaternary International, 17:21-26.

Pal, N. M. (2012) Tendencias temporales en las estrategias de explotación y uso de los materiales líticos recuperados en la cuenca superior del arroyo Tapalqué (partidos de Benito Juárez y Olavarría): una perspectiva desde el análisis funcional. Tesis Doctoral Inédita, Facultad de Ciencias Sociales, Universidad Nacional del Centro de la Provincia de Buenos Aires. https://www.academia.edu/3694623/ Tendencias_temporales_en_las_estrategias_de_explotacion_y_uso_de_los_materiales_liticos_de_la cuenca_superior_del_arroyo_Tapalque_Partidos_de_Benito_Juarez_y_Olavarria_Una_perspectiva_ desde_el_Analisis_Funcional acceso 19/05/2014

Panizza, M. C. (2008) Análisis semiótico de algunos motivos presentes en las representaciones rupestres del Sistema Serrano de Ventania, provincia de Buenos Aires. Libro de resúmenes del V Congreso de Arqueología de la Región Pampeana Argentina. Santa Rosa (La Pampa), pp. 92-93.

Panizza, M. C. (2010). Estética y semiótica en el estudio de las representaciones rupestres del Sistema Serrano de Ventania (Provincia de Buenos Aires). En: J. R. Bárcena y H. Chiavazza (Eds.) Arqueología Argentina en el Bicentenario de la Revolución de Mayo. Actas del XVII Congreso Nacional de Arqueología Argentina, 2: 887-890.

Pardiñas, U. F. J. y E. P. Tonni (2000) A giant vampire (Mammalia, Chiroptera) in the Late Holocene from the Argentinean pampas: palaeoenvironmental significance. Palaeogeography, Palaeoclimatology, Palaeoecology, 160: 213-221.

Parodi, L.R. (1940) Los bosques naturales de la Provincia de Buenos Aires. Anales de la Academia Nacional de Ciencias Exactas, Físicas y Naturales, 7: 79-90.

Pate, F. (1995) Stable carbon isotope assessment of hunter-gatherer mobility in prehistory South America. Journal of Archaeological Research, 22: 81-87.

Paulides, L. (2007a). Prepárate, vas a viajar: sobre tendencias productivas en la formatización de núcleos en el complejo de canteras de Arroyo Diamante, partido de Benito Juárez (provincia de Buenos Aires). En: C. Bayón, A. Pupio, M. I. González, N. Flegenheimer y M. Frère (Eds.) Arqueología en las Pampas, 1: 233-249. Sociedad Argentina de Antropología, Buenos Aires.

Paulides, (2007b) Algunos criterios metodológicos para el análisis de las técnicas de abastecimiento y el reconocimiento de fuentes de aprovisionamiento arqueológicas prehispánicas en el complejo de canteras de Arroyo Diamante, Sistema de Tandilia (Pcia. De Buenos Aires - República Argentina). En C. Bayón, A. Pupio, M. I. González, N. Flegenheimer y M. Frère (Eds.) Arqueología en las Pampas, 1: 289-308. Sociedad Argentina de Antropología, Buenos Aires.

P.C.R.G Prehistoric Ceramics Research Group (1995) The study of later prehistoric pottery. General policies and guidelines for analysis and publication. England, The Prehistoric Ceramics Research Group. Occasional Papers N 1 and 2.

Pérez, S. I. 2006 El Poblamiento Holocénico del Sudeste de la Región Pampeana: Un Estudio de Morfometría Geométrica Craneofacial. Tesis doctoral inédita. Facultad de Ciencias Naturales y Museo, Universidad Nacional de La Plata. MS 
Pérez Amat, M., D. Scheines y M. Bayón (1985) Noticia preliminar sobre hallazgos de pinturas rupestres en el establecimiento Santa Marta (Partido de Saavedra). Sapiens, 5: 86-90. Chivilcoy.

Perez Meroni, M. y A. Blasi (1997) Sitio arqueológico El Ancla, Provincia de Buenos Aires. Ensayos y experimentación de sedimentos pelíticos locales para la manufactura cerámica. En: M. Berón y G. Politis (comp) Arqueología Pampeana en la década de los '90. Museo de Historia Natural de San Rafael, XI Congreso Nacional de Arqueología Argentina, INCUAPA - Facultad de Ciencias Sociales (UNCPBA). Pp.175-184

Piovano, E.L., D. Ariztegui, F. Córdoba, M. Cioccale y F. Sylvestre (2009) Hydrological Variability in South America Below the Tropic of Capricorn (Pampas and Patagonia, Argentina) during the Last 13.0 Ka,. En: F. Vimeux, F. Sylvestre y M. Khodri (Eds.) Past Climate Variability in South America and Surrounding Regions, From the Last Glacial Maximum to the Holocene, 14, 323-351. Springer.

Podgorny, I. y G. Politis (1990-1992) Qué sucedió en la historia? Los esqueletos araucanos del Museo de la Plata y la Conquista del Desierto. Arqueología Contemporánea 3: 73-79.

Politis, G. (1984) Arqueología del Área Interserrana Bonaerense. Tesis Doctoral. Facultad de Ciencias Naturales y Museo. UNLP.

Politis, G. (1986) Investigaciones arqueológicas en el Área Interserrana Bonaerense. Etnia, 32: 7-52. Olavarría

Politis, G. (1988) Paradigmas, modelos y métodos en la arqueología de la Pampa Bonaerense. En Arqueología Contemporánea Argentina. Pp. 109-145. Edición Búsqueda, Buenos Aires.

Politis, G. (1998) Arqueología de la Infancia: una perspectiva etnoarqueológica. Trabajos de Prehistoria, 55 (2): 5-19.

Politis, G. (2008) The Pampas and Campos of South America. En: H. Silverman y W. Isbell (Eds.) Handbook of South American Archaeology. Springer. Pp 235-260.

Politis, G. y P. Madrid (1988) Un hueso duro de roer: análisis preliminar de de la tafonomía del sitio Laguna Tres Reyes 1, Pdo. De Adolfo González Cháves, Pcia. de Buenos Aires. En: A. Haber y N. Ratto (Eds.) De procesos, contextos y otros huesos. ICA, UBA, Buenos Aires, pp. 29-44.

Politis G y P. Madrid (2001) Arqueología pampeana: estado actual y perspectivas. En: E. Berberián y A. Nielsen (Eds.) Historia Argentina Prehispánica, 2:737-814. Ed. Brujas. Córdoba.

Politis, G. y V. Pedrotta (2006) Recursos faunísticos y estrategias de subsistencia en el este de la Región Pampeana durante el Holoceno tardío: el caso del guanaco. Revista Relaciones de la Sociedad Argentina de Antropología, 31: 301-336.

Politis, G., G. Martínez y M. Bonomo (2001) Alfarería temprana en sitios de cazadores reclectores de la Región Pampeana (Argentina). Latin American Antiquity, 12 (2): 167-181.

Politis, G., P. Messineo, C. Kaufmann (2004) El poblamiento temprano de las llanuras pampeanas de Argentina y Uruguay. Complutum, 15: 207-224.

Politis, G., C. Scabuzzo y R. H. Tykot (2009) An approach to pre-hispanic diets in the pampas during the early /middle Holocene. International Journal of Osteoarchaeology, 19: 266-280.

Politis, G., G. Barrientos y T. Stafford (2011a) Revisiting Ameghino: New $\delta^{12} \mathrm{C}$ dates from ancient human skeletons from the argentine pampas. En: D. Vialou (Ed.) Peuplements et Préhistoire en Amériques, pp43-53. Comité des Travaux Historiques et Scientifiques, París.

Politis, G; L. Prates, M. Merino y M. Tognelli (2011b). Distribution parameters of guanaco (Lama guanicoe), pampas deer (Ozotoceros bezoarticus) and marsh deer (Blastocerus dichotomus) in Central Argentina: Archaeological and paleoenvironmental implications. Journal of Archaeological Science, 38 (7): 1405-1416. 
Politis, G., P. G. Messineo, C. Kaufmann, M. P. Barros, M. Álvarez, V. DI Prado y R. Scalise. (2005) Persistencia ritual entre cazadores recolectores de la llanura pampeana. En: P. Kaulicke y T. Dillehay (Eds.) Encuentros: Identidad, Poder y Agencia de Espacios Públicos, Boletín de Arqueología PUCP, 9: 67-90.

Prates, L. (2004) Arqueología de la cuenca media del Río Negro (Provincia de Río Negro). Una primera aproximación. Intersecciones en Antropología, 5: 55-69. Olavarría

Prates, L. (2007) Arqueología de los grupos cazadores-recolectores del curso medio del Río Negro (provincia de Rio Negro). Tesis Doctoral inédita, Facultad de Ciencias Naturales y Museo UNLP, La Plata.

Prates, L. (2008) Los indígenas del río Negro, Un enfoque arqueológico. Sociedad Argentina de Antropología, Buenos Aires.

Prates, L. (2009) El uso de recursos por los cazadores-recolectores posthispánicos de patagonia continental y su importancia arqueológica. Relaciones de la Sociedad Argentina de Antropología, 34 : 201-229.

Prates, L. (2010) La ocupación humana pre-hispánica del Calle del río Negro. En: R. Masera (comp.) Los ríos mesetarios norpatagónicos. Aguas generosas del Ande al Atlántico. Gobierno de Río Negro. Ministerio de Producción, pp 341-359.

Prates, L., G. MartíneZ y C. Scabuzzo (2006) Evidencias arqueológicas del Holoceno tardío final en el curso medio del Río Colorado (Provincia de Río Negro): sitio Don Aldo 1. Cazadores-Recolectores del Cono Sur. Revista de Arqueología, 1: 163-178

Prates, L. y C. Acosta Hospitaleche (2010) Las aves de sitios arqueológicos del Holoceno tardío de Norpatagonia, Argentina. Los sitios Negro Muerto y Angostura 1 (Río Negro). Archaeofauna, 19: 7-18.

Prates, L., V. Di Prado, E. Mange y A. Serna. (2010) Sitio Loma de los Muertos. Múltiples ocupaciones sobre un médano del este de Nordpatagonia (Argentina). Magallania, 38: 165-181.

Price, D., J. Wahl y A. Bentley (2006) Isotopic evidence for mobility and group organization among neolithic farmers at talheim, germany, 5000 bc. European Journal of Archaeology, 9 (2/3): 259-284.

Prieto, A.R. (1996) Late Quaternary vegetational and climatic changes in the pampa grassland of Argentina. Quaternary Research, 45:73-88.

Primera Convención Nacional de Antropología (1966) Publicaciones Nueva Serie, 1 (26),Instituto de Antropología, Facultad de Filosofía y Humanidades, Universidad Nacional de Córdoba.

Puig, S., F. Videla, M.I. Cona y S. Monge (2001) Use of food availability by guanacos (Lama guanicoe) and livestock in Northern Patagonia (Mendoza, Argentina). Journal of Arid Environments, 47: 291-308.

Quattrocchio, M. E., S. C. Grill y C. A. Zavala (1998) Chronostratigraphic and palynozone chronosequences charts of Napostá Grande Creek, Southwestern Buenos Aires Province, Argentina. Quaternary of South America and Antarctic Peninsula, 11:111-133.

Quattrocchio, M. E., A. Borromei, C. Deschamps, S. Grill y C. Zavala (2008) Landscape evolution and the climate changes in the Late Pleistocene-Holocene, southern Pampa (Argentina): Evidence from palynology, mammals and sedimentology. Quaternary International, 181: 123-138.

Quattrocchio, M. E., C. Deschamps, D. Martínez, S. Grill y C. Zavala (1988) Caracterización paleontológica y paleoambiental de sedimentos cuaternarios. Arroyo Napostá Grande, provincia de Buenos Aires. Actas de las Segundas Jornadas Geológicas Bonaerenses, pp. 37-46.

Quattrocchio, M. E., C. Deschamps, C. Zavala, A. Borromei, S. Grill y R. Guerstein (1993) Cuaternario del sur de la provincia de Buenos Aires. Estratigrafía e inferencias paleoambientales. En: M. Iriondo (Ed.) El Holoceno en Argentina, 2: 22-34, CADINQUA, Paraná. 
Quintana, C. (2005) Despiece de microroedores en el Holoceno tardío de las sierras de Tandilia (Argentina). Archaeofauna, 217: 227-241.

Quintana, C. y D. Mazzanti (2001) Selección y aprovechamiento de recursos faunísticos. En: D. Mazzanti y C. Quintana (Eds.) Cueva Tixi: cazadores y recolectores de las sierras de Tandilia oriental. I. Geología, Paleontología y Zooarqueología, pp.181-209. Publicación Especial 1. ARBO-UNMDP, Mar del Plata.

Quintana, C., F. Valverde y D. Mazzanti (2002) Roedores y lagartos como emergentes de la diversificación de la subsistencia durante el Holoceno de las sierras de Tandilia, Argentina. Latin American Antiquity, 13(4): 455-473.

Rabassa, J. (1989) Geología de los depósitos del Pleistoceno superior y Holoceno en las cabeceras del Río Sauce Grande, Provincia de Buenos Aires. Actas de las Primeras Jornadas Geológicas Bonaerenses. Pp 765-790. Tandil.

Reid, P. (1986) Models for prehistoric exchange in the Middle Great Lakes' Basin. Ontario Archaeology, 46, 33-44.

Reid, K. C. (1989) A Material Science Perspective on Hunter-Gatherer Pottery, en: G. Bronitsky (Ed.), Pottery Technology: Ideas and Approaches, 167-180, Westview Press, Boulder.

Remes Lenicov M y D. Colautti (2003) Estudio de la laguna Chasicó (Pdo. de Villarino y Puán). Campaña de relevamientos limnológicos e ictiológicos. Subsecretaría de Actividades Pesqueras, MAA Provincia de Buenos Aires, Informe Técnico $\mathrm{n}^{\circ}$ 56: 1-25 http://www.maa.gba.gov.ar/pesca/archivos/ informes_biologicos/continentales/66\%20-\%20Chasico\%2004.pdf Acceso 18/03/2014

Renfrew, C. (1975) Trade as action at a distance: Questions of integration and communication. En: J. A. Sabloff y C. C. Lamberg-Karlovsky (Eds.) Ancient civilization and trade, pp. 3-36. Albuquerque: University of New Mexico Press.

Renfrew, C. (1977) Alternative models for exchange and spatial distribution. En: T. K. Earle $\quad$ y J. E. Ericson (Eds.) Exchange systems in prehistory, pp. 71-90. New York: Academic Press.

Renfrew, C. y P. Bahn (2004) Archaeology : theories, methods and practice. $4^{\circ}$ edición, Thames \& Hudson, Londres.

Rice, P. (1987) Pottery Analysis. A Sourcebook. University of Chicago Press. Chicago.

Rice, P. (1996) Recent ceramic analysis: 1. function, style and origins. Journal of Archaeological Research, 4 (2): 133-163.

Rick, J.W., (1987) Dates as data: an examination of the Peruvian pre-ceramic radio-carbon record. American Antiquity, 52 (1): 55-73.

Riede, F. (2009) Climate and demography in early prehistory: Using calibrated ${ }^{14} \mathrm{C}$ dates as population proxies. Human Biology, 81, 309-337.

Ringuelet, R. A. (1955) Panorama zoogeográfico de la provincia de Buenos Aires. Notas del Museo de La Plata, 18: 1-15.

Ringuelet, R. A. (1961) Rasgos fundamentales de la Zoogeografía de la Argentina. Physis, 22: 151- 170, Buenos Aires.

Rockman, M. y J. Steele (Eds.) (2003) Colonization of Unfamiliar Landscapes: The archaeology of adaptation. Routledge, London y New York.

Rye, O. (1994) Pottery Technology. Manuals on Archaeology 4. Taraxacum. Washington.

Sackett, J. (1985) Style, Ethnicity, and Stone Tools. En: M. Thompson, M. García y F. Kense (Eds.) Status, Structure, and Stratification: Current Archaeological Reconstructions, pp: 277-282. The Archaeological Association, University of Calgary, Calgary. 
Sackett, J. (1990) Style and ethnicity in archaeology: the case for isochrestism. En: M. Conkey y C. Hastorf (Eds.) The uses of style in archaeology, pp. 32-43. Cambridge University Press.

Salemme, M. C. (1987) Paleoetnozoología del sector bonaerense de la región pampeana con especialvatención a los mamíferos. Tesis Doctoral no publicada. Facultad de Ciencias Naturales y Museo, Universidad Nacional de La Plata, La Plata.

Salemme, M. C. (1990) Zooarchaeological studies in the Humid Pampas, Argentina. Quaternary of South America and Antartic Peninsula, 6: 309-335. Rotterdam.

Salgán, M. L. (2013) Organización tecnológica y biogeografía humana en La Payunia, sur de la provincia de Mendoza. Tesis Doctoral inédita, Facultad de Ciencias Naturales y Museo, UNLP, La Plata, 447 pp.

Salgán, M. L. y C. Pérez Winter (2008-09) Fuentes primarias y secundarias en ambientes de altura y áridos del sur demendocino. Anales en Antropología y Etnología, 63-64: 247-275.

Sampson, C.(1988) Stylistic boundaries among mobile hunter-foragers. Washington: Smithsonian Institution Press.

Sánchez, R., N. Pezzola y J. Cepeda (1998) Caracterización edafoclimática del área de influencia del INTA. EEA Hilario Ascasubi. Boletín de Divulgación 18, INTA. Buenos Aires. www.patagones.gov.ar/ descargar/Edafoclima_Inta_Ascasubi.pdffAcceso 10/02/2013

Sanguinetti de Bórmina, A., N. Weiler, H. Nami, D. Curzio y E. Eugenio (1999) Investigaciones prehistóricas en la costa patagónica septentrional. Nota preliminar. Libro de resúmenes del XIII Congreso Nacional de Arqueología Argentina. Córdoba pp. 405-406.

Scabuzzo, C. (2010) Actividades, patologías y nutrición de los cazadores recolectores pampeanos. Tesis Doctoral inédita, Facultad de Ciencias Naturales y Museo, UNLP.

Scabuzzo, C. y M.I. Gonzáles de Bonaveri. (2007) Un acercamiento a la dieta de las poblaciones prehispánicas de la Depresión del Salado durante el Holoceno tardío. En: C. Bayón, N. Flegenheimer, M. I. González de Bonaveri y M. Frere (Eds.) Arqueología en las Pampas, 1: 59-74. EDIUNS. Bahía Blanca.

Schäbitz, F (1994) Holocene climatic variations in northern Patagonia, Argentina. Palaeogeography, paleoclimatology, palaeoecology, 109: 287-294.

Schäbitz, F. (2003) Estudios polínicos del Cuaternario en las regiones áridas del sur de Argentina. Revista del Museo Argentino de Ciencias Naturales, 5 (2): 291-299.

Schalamuk, I. B., M. Del Blanco, D. Marchionni, S. Romero y M. C. Cabana (1999) Salinas y sulfateras de la Región Pampeana, Buenos Aires y La Pampa. En: E. O. Zapettini (Ed.). Recursos Minerales de la República Argentina, Anales, 35:1947-1962. Instituto de Geología y Recursos Minerales SEGEMAR,

Schalenger, S. H. (1992) Recognizing persisten places in Anasazi settlement systems. En: J. Rossignol y L. Wandsnaider (Eds.) Space, Time, and Archaeological Landscapes. Plenum Press, New York and London, pp 91-112.

Schiffer, M. (1972) Archaeological context and systemic context. American Antiquity, 37(2): 156-165.

Schiffer, M. (1987) Formation Processes of the Archaeological Record. University of New Mexico Press, Albuquerque.

Schiller, W. (1930) Investigaciones geológicas en las montañas del sudoeste de la Provincia de Buenos Aires. Anales del Museo de La Plata, 4: 9.101.

Schoeninger, M. J. y K. Moore (1992) Bone stable isotope studies in archaeology. Journal of World Prehistory, 6 (2): 247-296.

Sellés-Martínez, J. (2001) Geología de la Ventania (Provincia de Buenos Aires, Argentina). Journal of Iberian Geology, 27: 43-69. 
Sellet, F. (2006) Two Steps Forward, One Step Back The Inference of Mobility Patterns from Stone Tools. En: F. Sellet, R. D. Greaves y P. L. Yu (Eds.) Archaeology and Ethnoarchaeology of Mobility. University Press of Florida, Gainesville. pp 221-239

Sellet, F., R. D. Greaves y P. L. Yu (2006) Archaeology and Ethnoarchaeology of Mobility. University Press of Florida, Gainesville.

Shackley, S. (1985) Lithic raw material procurement and hunter gatherer mobility, strategies in the southwest archaic. 50 Annual Meeting of the Society for American Archaeology. pp 1-35

Shepard, A. O. (1956) Ceramics for the archaeologist. Publication 609. Carnegie Institution of Washington, Washington D.C.

Shipman, P. (1981) Life History of a Fossil: an Introduction to Taphonomy and Paleoecology. Harvard University Press.

Simms, R.; J. Bright y A. Ugan (1997) Plain-ware ceramics and residential mobility: a case study from the Great Basin. Journal of Archaeological Science, 24: 779-792.

Skibo, J. M. (1992) Pottery function. A use alteration perspective. Plenum Press, Nueva York y Londres.

Skibo, J., M. Schiffer y K. Reid (1989) Organic-tempered pottery: an experimental study. American Antiquity, 54 (1): 122-146

Smith, B. H. (1984) Patterns of molar wear in hunter-gatherers and agriculturalists. American Journal of Physical Anthropology 63:39-56.

Smith, E. A. (1983) Anthropological applications of Optimal Foraging Theory: A critical review. Current Anthropology, 24 (5): 625-651.

Smith, C y L. Mc Knees (1999) Facilities and hunter-gatherer long term land use patterns: an example from southwest wyoming. American Antiquity, 64 (1): 117-136.

Soja, E. (1971) The political organization of space. Association of American Geographers, Resource Paper, 8. Seattle, Northwestern University.

Stark, B. L. y C. P. Garraty (2010). Detecting marketplace exchange in archaeology: A methodological review. En: C. P. Garraty y B. L. Stark (Eds.) Archaeological approaches to market exchange in ancient societies, pp. 33-60. Boulder: University Press of Colorado.

Steele, J. (2010) Radiocarbon dates as data: quantitative strategies for estimating colonisation front speeds and event densities. Journal of Archaeological Science, 37: 2017-2030.

Steele J y G. Politis (2009) AMS 14C dating of early human occupations of southern South America. Journal of Archaeological Science, 36 (2). 419-429.

Stewart, T (1979) Essentials of forensic Anthropology Especially as Developed in the United States. Springfield, III.: Charles Thomas.

Stiner, M., S. Kuhn, T. Surovell, P. Goldberg, L. Meignen, S. Weinner y O. Bar-Yosef (2001) Bone preservation in Hayonim Cave (Israel): a macroscopic and mineralogical study. Journal of Archaeological Science, 28: 643-659.

Stoessel, L. (2007) Análisis arqueofaunístico de los sitios Loma Ruíz 1 y El Tigre (partidos de Villarino y Patagones, provincia de Buenos Aires). Aportes para el conocimiento de la subsistencia en el valle inferior del río Colorado durante el Holoceno tardío. Intersecciones en Antropología, 8: 235-251. Olavarría.

Stoessel, L. (2010) Distribución y consumo diferencial de peces en el valle inferior del río Colorado durante el Holoceno tardío. En M. A. Gutiérrez, M. De Nigris, P. M. Fernández, M. Giardina, A. F. Gil, A. Izeta, G. Neme y H. D. Yacobaccio (Eds.), Zooarqueología a principios del siglo XXI: aportes teóricos, metodológicos y casos de estudio: 333-342. Ayacucho, Buenos Aires, Libros del Espinillo. 
Stoessel, L. (2012a). Consumo de peces en e área ecotonal árida-semiárida del curso inferior del río Colorado (Provncia de Buenos Aires) durante el Holoceno tardío. Relaciones de la Sociedad Argentina de Antropología, 37: 159-182.

Stoessel, L. (2012b) Evaluating intensity in the processing of guanaco (Lama guanicoe) at the lower basin of the Colorado river (Argentina): fragmentation levels, and fracture patterns analysis. International Journal of Osteoachaeology. PublishedonlineinWileyOnlineLibrary DOI:(wileyonlinelibrary. com)10.1002/oa.2225.

Stoessel, L., S. Bogan, G. Martínez, y F. L. Agnolin (2008) Implicaciones paleoambientales de la presencia del género ceratophrys (anura, ceratophryinae) en contextos arqueológicos de la transición pampeano-patagónica en el Holoceno tardío (curso inferior del río Colorado, Argentina). Magallania, 36 (2): 195-203.

Stojanowski, C. M. y K. J. Knudson (2014) Changing patterns of mobility as a response to climatic deterioration and aridification in the middle Holocene southern Sahara. American Journal of Physical Anthropology, 154 (1): 79-93. DOI: 10.1002/ajpa.22474

Strobel, P. (1867) Paradero prehistorici in Patagonia. Atti Della società Italiana de Scienze Naturali 10: 167-171.

Strobel, P. (1868) Materiale di palaetnologia comparata, ricolti in Sud-américa, Parma

Stuiver, M. P. J. Reimer y R. W. Reimer (2005) CALIB 6.1.0 (www.program and documentation).

Suero, T. (1972) Compilación geológica de las Sierras Australes de la provincia de Buenos Aires. En J. Ulibarrena (Ed.) Ministerio de Obras Publicas, Laboratorio de Ensayo de Materiales, 2 (216): 138-147.

Sugrañes, N. (2011) Tecnología cerámica y estrategias de movilidad entre cazadores-recolectores de altura. El caso del sitio Valle Hermoso 1 (Malargüe, Mendoza). Intersecciones en Antropología, 12: 155-166.

Surovell, T. A. y P. J. Brantingham (2007) A note on the use of temporal frequency distributions in studies of prehistoric demography. Journal of Archaeological Science, 34: 1868-1877.

Surovell, T. A., V. T. Holliday, J. A. M. Gingerich, C. Ketron, C. V. Haynes, I. Hilman, D. P. Wagner, E. Johnson y P. Claeys (2009) An independent evaluation of the Younger Dryas extraterrestrial impact hypothesis. Proceedings of the National Academy of Sciences of the United States of America, 106: $18155-18158$.

Szabo, V. y Strang, V.R. (1997) Secondary analysis of qualitative data. Advances in Nursing Science, 20(2), 66-74.

Tainter, J. (1998) Surface Archaeology: Perceptions, Values, and Potencial. En: Surface Archaeology, 3: 169-179. P. Sullivan (Ed.). University of New Mexico Press, Albuquerque.

Tapia, A. y J. Charlín (2004) Actividades de molienda y pulido en las tolderías ranquelinas del caldenar pampeano. En: G. Martínez, M. Gutiérrez, R. Curtoni, M. Berón y P. Madrid (Eds.) Aproximaciones Contemporáneas a la Arqueología Pampeana. Perspectivas teóricas, metodológica, analíticas y casos de estudio. Facultad de Ciencias Sociales. Universidad Nacional del Centro de la Provincia de Buenos Aires. pp. 363-385.

Tassara, C. y M. Osterrieth (2008) Silicofitolitos en artefactos de molienda de sitios arqueológicos del área Interserrana, Buenos Aires. Un estudio preliminar. En: M.A. Korstanje y M del P. Babot (Eds.) Matices interdisciplinarios en estudios fitoliticos y de otros microfósiles. Oxford: British Archaeological Reports International Series. p 163-171.

Teruggi M. (1984) Diccionario Sedimentológico Vol.II. Rocas aclásticas y suelos. Ed. Científica Argentina LIBRAT (ECAL), 236pp. Buenos Aires.

Teruggi, M. E. y J. O. Kilmurray (1980) Sierras Septentrionales de la Provincia de Buenos Aires. En: J. Turner (Ed.) Geología Regional Argentina, 2: 919-956. Academia Nacional de Ciencias, Córdoba 
Thomas, D. (1975) Nonsite Sampling in Archaeology: Up the Creek Without a Site? En: J. W. Mueller (Ed.) Sampling in Archaeology, pp. 61-81. University of Arizona Press. Tucson

Tite, M. (1999)Pottery production, distribution and consumption. The contribution of the physical sciences. Journal or Archaeological Method and Theory, 6 (3): 181-233.

Todd, L. y G. Frison (1986) Taphonomic Study of the Colby Site Mammoth Bones. En: The Colby Mammoth Site. Taphonomy and Archaeology of a Clovis Kill in Northern Wyoming, G. C. Frison y L. C. Todd (Eds.) pp. 27-90. Albuquerque: University of New Mexico Press.

Todd, L., R. Witter y G. Frison (1987) Excavation and Documentation of the Princeton and Smithsonian Horner Site Assemblages. En: The Horner Site: The Type Site of the Cody Cultural Complex, G. C. Frison y L. C. Todd (Eds.), pp. 39-91. Orlando: Academic Press.

Tonni, E. (1985) Mamíferos del holoceno del partido de Lobería, provincia de Buenos Aires. Aspectos paleoambientales y bioestratigraficos del holoceno del sector oriental de Tandilia y área Interserrana. Ameghiniana, 22 (3-4): 283-288

Tonni, E. y G. Politis (1980) La distribución del guanaco (mammalia, camelidae) en la provincia de Buenos Aires durante el Pleistoceno Tardío y Holoceno. Los factores climáticos como causas de su retracción. Ameghiniana, 17 (1): 53-66.

Tonni, E. P., A. Cione y A. Figini (1999) Predominance of arid climates indicated by mammals in the pampas of Argentina during the late Pleistocene and Holocene. Palaeogeography, Palaeoclimatology, Paleoecology, 147: 257-281.

Torrence, R. (1986) Production and exchange of stone tools. Cambridge: Cambridge University Press.

Torrence, R. (1989) Retooling: toward a behavioral theory of stone tools. En: R. Torrence (Ed.) Time, Energy, and Stone Tools, pp. 57-66. Cambridge University Press, Cambridge.

Torres, L. (1922) Arqueología de la Península de San Blas (Provincia de Buenos Aires). Revista del Museo de La Plata, 26: 473-532.

Trochim, W. M.K. (2006) Unobtrusive measures. The Research Methods Knowledge Base, 2nd edn. http://www.socialresearchmethods.net/kb/unobtrus.php. acceso 20/11/2013

Trubitt, M. (2003) The production and exchange of marine shell prestige goods. Journal of Archaeological Research, 11 (3): 243-276.

Turchin, P. (2003) Historical dynamics: Why states rise and fall. Princeton: Princeton University Press.

Tykot, R. H. (2004) Stable isotopes and diet: you are what you eat. En: M. Martini, M. Milazzo y M. Piacentini (Eds.) Physics Methods in Archaeometry. Proceedings of the International School of Physics “Enrico Fermi”, Course CLIV, Societa`Italiana di Fisica: Bologna, Italy, pp. 433-444.

Ubelaker, D. (1982) Human Skeletal Remains. Taraxacum, Washington.

Ugan, A., J. Bright y A. Rogers (2003). When is technology worth the trouble? Journal of Archaeological Science, 30: 1315-1329.

USDA (1999) Soil Taxonomy. A Basic System of Soil Classification for Making and Interpreting Soil Surveys. Second Edition. Agricultural Handbook No 436.

Valverde, F (2002) Variabilidad de recursos líticos en dos sitios paleoindios de las sierras de Tandilia Oriental, Provincia de Buenos Aires. En: D. Mazzanti, M. Berón y F. Oliva (Eds.) Del Mar a los Salitrales. Diez Mil Años de Historia Pampeana en el Umbral del Tercer Milenio, pp 281-287. Facultad de Humanidades UNMdP/SAA. Mar del Plata.

Vecchi, R., R. Frontini y C. Bayón (2013) Paso Vanoli: una instalación del Holoceno tardío en valles fluviales del sudoeste bonaerense. Revista del Museo de La Plata (Sección Antropología), 13 (87): 77-93. http://www.fcnym.unlp.edu.ar/uploads/docs/rmlp_antro_2013_t13_n87_vecchi_etal.pdf acceso $04 / 12 / 2013$ 
Verhagen, P. y T. G. Whitley (2012) Integrating Archaeological Theory and Predictive Modeling: a Live Report from the Scene._Journal of Archaeological Method and Theory, 19 (1): 49-100.

Veth, P. (2005) Cycles of aridity and human mobility. Risk minimization among late Pleistocene foragers of the Western Desert, Australia. En: P. Veth, M. Smith y P. Hiscock (Eds.) Desert Peoples: Archaeological perspectives. Blackwell Publishing. Pp 100-115

Vignati, M. (1931) Investigaciones antropológicas en el litoral marítimo subatlántico bonaerense. Notas Preliminares del Museo de La Plata, 1:19-31.

Vita-Finzi, C, y E. S. Higgs (1970) Prehistoric economy in the Mount Carmel area of Palestine: site catchment analysis. Proceedings of the Prehistoric Society, 36:1-37.

Voglino, D. y U. Pardiñas (2005) Roedores sigmodontinos (Mammalia: Rodentia: Cricetidae) y otros micromamíferos pleistocénicos del norte de la provincia de Buenos Aires (Argentina): reconstrucción paleoambiental para el Ensenadense cuspidal. Ameghiniana, 42 (1): 143-158. Buenos Aires.

Volpedo, A. y A. Fernández Cirelli (2013) El Lago Chasicó: similitudes y diferencias con las lagunas pampásicas. AUGM DOMUS Revista electrónica del Comité de Medio Ambiente, 5: 1-18. http://revistas. unlp.edu.ar/index.php/domus/issue/current/showToc acceso 04/12/2013.

Voorhies, M.R., (1969) Taphonomy and population dynamics of an early Pliocene vertebrate fauna, Knox County, Nebraska. Contributions to Geology (Special Paper), 1: 1-69. University of Wyoming.

Walker, M. J. C., M. Berkelhammer, S. Björck, L. C. Cwynar, D. A. Fisher, A. J. Long, J. J. Lowe, R. M. Newnham, S. O. Rasmussen y H. Weiss (2012) Formal subdivision of the Holocene Series/ Epoch: a Discussion Paper by a Working Group of INTIMATE (Integration of ice-core, marine and terrestrial records) and the Subcommission on Quaternary Stratigraphy (International Commission on Stratigraphy). Journal of Quaternary Science, 27: 649-659.

Wandsnider, L. (1992) Archaeological landscape studies. En: J. Rossignol y L. Wandsnaider (Eds.) Space, Time, and Archaeological Landscapes. Plenum Press, New York and London, pp 285-2292. Plenum Press.

Wandsnider, L (1998) Landscape Element Configuration, Lifespace, and Occupation History: Ethnoarchaeological Observations and Archaeological Applications. En: Surface Archaeology, 3: 2138. P. Sullivan (Eds.). University of New Mexico Press, New York.

Watson, J. P. (1967) A Termite Mound in an Iron Age Burial Ground in Rhodesia. Journal of Ecology, 55(3): 663-669.

Webb, K. (1993) The lithification of a sandy environment. Archaeology in Oceania, 28, 105-111.

Weninger, B. y O. Jöris (2007 in press). Towards an Absolute Chronology at the Middle to Upper Palaeolithic Transition in Western Eurasia: A New Greenland ${ }_{\text {Hulu }}$ Time-scale Based on U/Th Ages. Journal of Human Evolution.

Weninger, B., Jöris, O., Danzeglocke, U., (2012) CalPal-2007. Cologne Radiocarbon Calibration \& Palaeoclimate Research Package. http://www.calpal.de/, Acceso 04/03/2012.

Whallon, R. (2006) Social networks and information: Non-“utilitarian" mobility among hunter-gatherers. Journal of Anthropological Arcaheology, 25: 259-270

Whallon, R. (2011) An introduction to information and its role in hunter-gatherer bands. En: R. Whallon, W. A. Lovis y R. K. Hitchcock (Eds.) Information and its Role in Hunter-Gatherer Bands. Cotsen Institute of Archaeology Press, pp. 1-28.

Wheatley, D. y M. Gillings (2002) Spatial technology and archaeology: the archaeological applications of GIS. Taylor \& Francis Editor. 269pp.

White, T. (1953) Observations on the butchering technique of some aboriginal peoples: 2. American Antiquity 19: 160-164. 
Wiessner, P. (1983) Style and social information in the Kalahari San projectile points. American Antiquity, 48 (2): 253-276.

Wilson, L. (2007) Understanding prehistoric lithic raw material selection: application of a gravity model. Journal of Archaeological Method and Theory, 14: 388-411.

Wilson, L. (2011) The role of geoarchaeology in extending our perspective. Geological S o c i e t y Special Publication, 352, 1-9.

Willis, B. (1912) Notes on Playa and Campo Peralta. En: A. Hrdlièka (Ed.) Early Man in South America, pp. 122-123. Bureau of American Ethnology 52, Smithsonian Institute, Washington.

Winterhalder, B., W. Baillargeon, F. F. Cappelletto, I. R. Daniel y C. (1988) The population ecology of hunter-gatherers and their prey. Journal of Anthropological Archaeology, 7: 289-328.

Witte, L. (1916) Estudios geológicos de la región de San Blas. Revista del Museo de La Plata, 24 (2).

Wolverton, S., L. Nagaoka, J. Densmore y B. Fullerton (2008) White tailed deer Harvest pressure and within-bone nutrient exploitation during the mid to late Holocene in Southeast Texas. Before Farming, 2 article 4 .

Wright, K. (1994) Ground-stone tools and hunter-gatherer subsistence in Southwest Asia: implications for the transition to farming. American Antiquity, 59 (2): 238-263.

Zarate, M. y F. Flegenheimer (1991) Geoarchaeology of Cerro La China Paleoindian locality, Buenos Aires, Argentina. Geoarchaeology, 6(3): 273-294.

Zárate, M.A. y A. Blasi (1993) Late Pleistocene-Holocene deposits of the southern Buenos Aires Province, Argentina: A preliminary model. Quaternary International, 17:15-20.

Zárate, M., J. Rabassa, T. Partridge, R. Maud (1995) La brecha Cerro Colorado (Abra de la Ventana, Buenos Aires): ¿es miocena?. Actas de las Cuartas Jornadas Geologicas y Geofisicas Bonaerenses, 1: 159-167, Junin

Zárate, M., J. Rabassa, R. Maud, T. Partridge (1998) La silicificación de la Brecha Cerro Colorado: clasificación, génesis e implicancias ambientales Actas de las $V$ Jornadas Geológicas y Geofisicas Bonaerenses, pp. 165-173, Mar del Plata.

Zavala, C. y M. Quattrocchio (2001) Estratigrafía y evolución geológica del río Sauce Grande (Cuaternario), provincia de Buenos Aires, Argentina. Revista de la Asociación Geológica Argentina, 56 (1): 25-37.

Zech, W., M. Zech, R. Zech, N. Peinemann, H. J. M. Morrás, L. Moretti, N. Ogle, R. M. Kalim, M. Fuchs, P. Schad, B. Glaser (2009) Late Quaternary palaeosol records from subtropical (38 $\left.{ }^{\circ} \mathrm{S}\right)$ to tropical $\left(16^{\circ} \mathrm{S}\right)$ South America and palaeoclimatic implications. Quaternary International, 196: 107-120.

Zetti, J. y R.M. Casamiquela (1967) Noticia sobre una breve expedición arqueológica a la zona de Lihuel Calel (Provincia de la Pampa) y observaciones complementarias. Cuadernos del Sur. Instituto de Humanidades. Universidad Nacional del Sur.

Zinger, A. S., O. M. del Pozo y M. M. Campos (1997) Reactivación de ecosistemas lagunares alterados a través de la actividad turística. El caso de la laguna Chasicó. Provincia de Buenos Aires. Argentina. Las Actividades Turísticas y el Espacio Geográfico GEO 08. Acceso el 10/10/2013 http://www.naya.org.ar/ congresos/contenido/49CAI/Campos.htm

Zucol, A. F. y M. Bonomo (2008) Estudios arqueobotánicos del sitio Nutria Mansa 1 (Partido de General Alvarado, Provincia de Buenos Aires): En: M.A. Korstanje y M del P. Babot (Eds.) Matices interdisciplinarios en estudios fitolíticos y de otros microfósiles. Oxford: British Archaeological Reports International Series, pp. 173-186. 


\section{ANEXO: Cortes}

\section{Petrográficos}

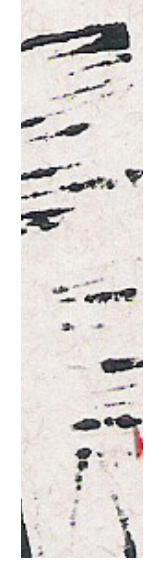




\section{Muestra 1}

Procedencia: Arroyo Ventana Roca: Cuarzo metarenisca Granulometría: muy fina Tamaño de los granos: $0.88-0,125 \mathrm{~mm}$. Forma de los granos: subredondeada Selección de los granos: moderada Composición: cuarzo monocristalino $75 \%$; cuarzo policristalino $20 \%$; feldespato $5 \%$

Observaciones: presencia de laminación y contactos crenulados
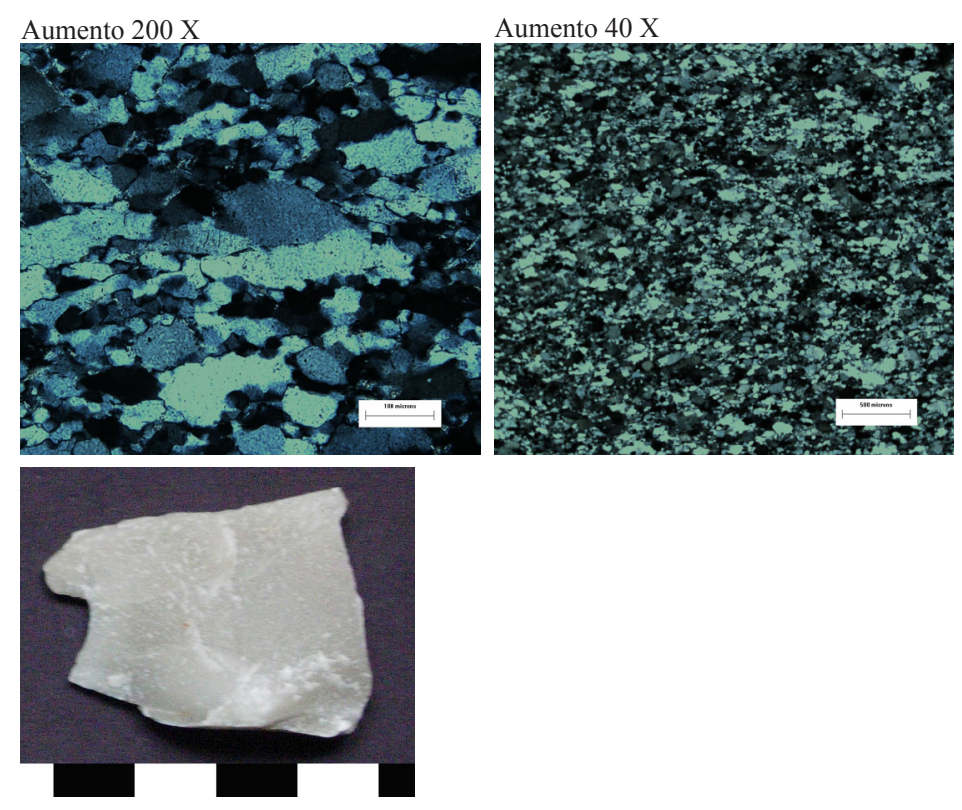

\section{Muestra 2}

Procedencia: arroyo Del Águila

Roca: cuarzo metarenisca

Granulometría: muy fina

Tamaño de los granos: 0,88-0,125 mm

Forma de los granos: subangular

Selección de los granos: buena

Composición: cuarzo monocristalino $90 \%$, cuarzo

policristalino $5 \%$, feldespato $5 \%$

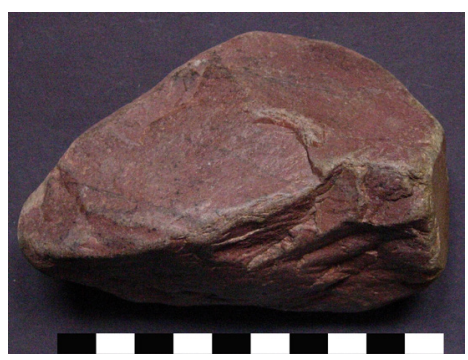

Observaciones: presencia de laminación y contactos

crenulados

\section{Muestra 3}

Procedencia: arroyo Napostá Grande Roca: cuarzo metarenisca

Granulometría: fina

Tamaño de los granos: 0,125-0,177 mm

Forma de los granos: subangular

Selección de los granos: buena

Composición: cuarzo monocristalino 85\%,
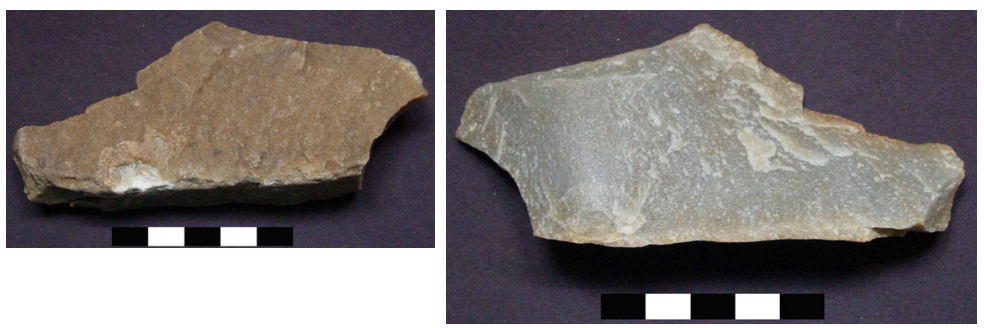

cuarzo policristalino $10 \%$

Observaciones: presencia de laminación y

contactos crenulados 


\section{Muestra 4}

Procedencia: arroyo Saudade Roca: arenita cuarzosa Granulometría: mediana Tamaño de los granos: 0,250$0,350 \mathrm{~mm}$.

Forma de los granos: redondeada Selección de los granos: buena Composición: cuarzo monocristalino $75 \%$, cuarzo policristalino $10 \%$, fesldespato $10 \%$, chert $5 \%$

Observaciones: presencia de puntos triples

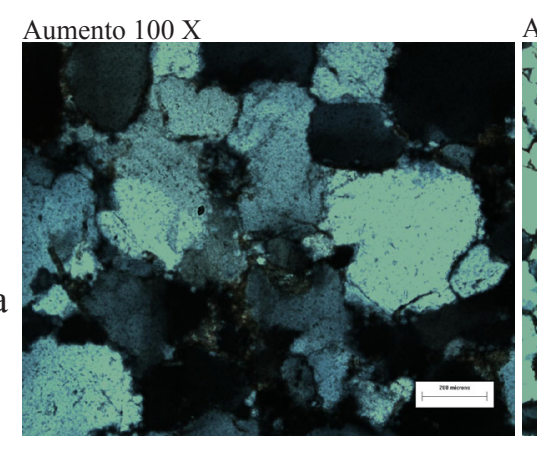
Aumento $40 \mathrm{X}$
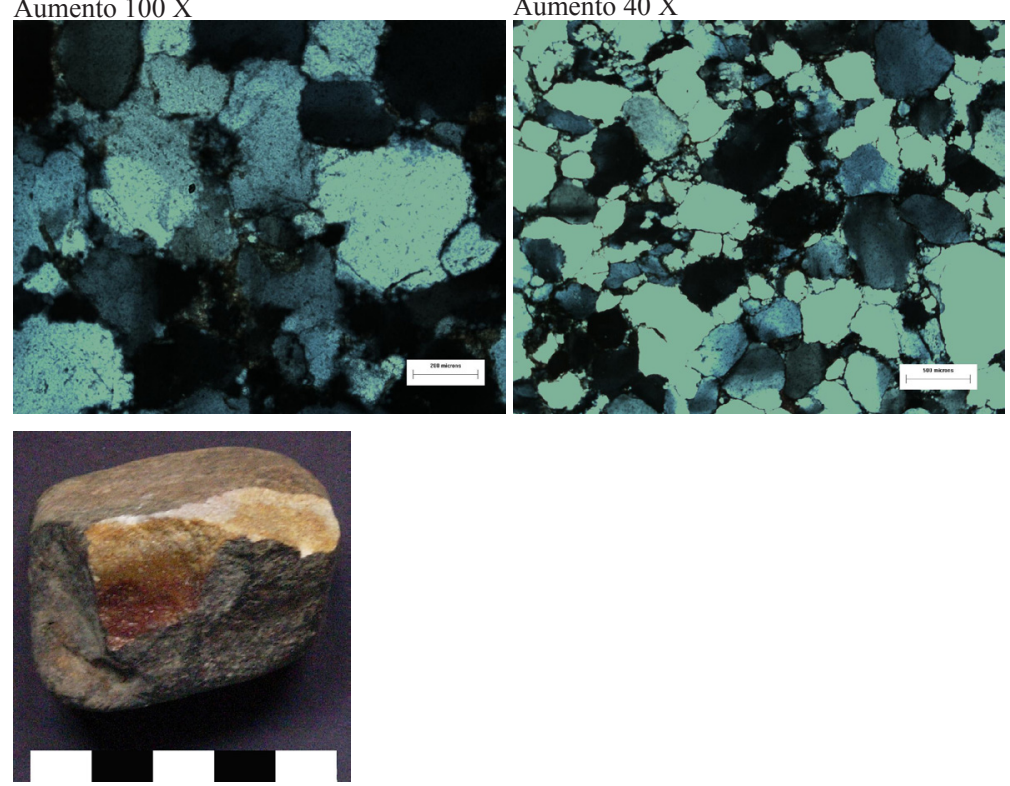

\section{Muestra 5}

Procedencia: arroyo Ventana

Roca: cuarzo metarenisca

Granulometría: muy fina

Tamaño de los granos: 0,88-0,125 mm.

Forma de los granos: subredondeada

Selección de los granos: muy buena

Composición: cuarzo monocristalino $80 \%$, cuarzo policristalino $20 \%$

Observaciones: presencia de laminación y mica

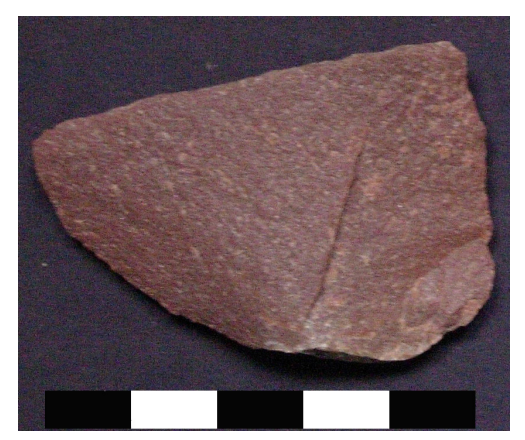

\section{Muestra 6}

Procedencia: Laguna Chasicó Sitio 2

Roca: ortocuarcita

Granulometría: fina

Tamaño de los granos: 0,177-0,250 mm.

Forma de los granos: redondeada

Selección de los granos: buena

Composición: cuarzo monocristalino $85 \%$, cuarzo

policristalino $10 \%$, feldespato $5 \%$

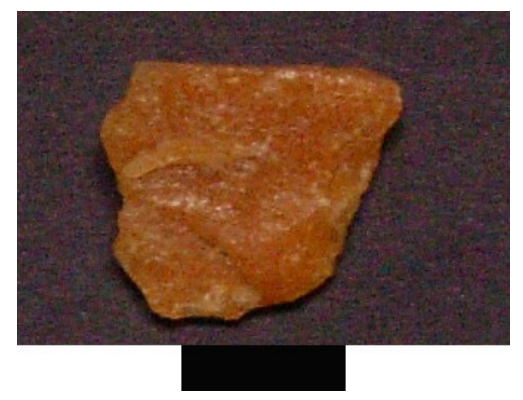

Observaciones: presencia de puntos triples 


\section{Muestra 7}

Procedencia: Laguna Chasicó sitio 3 Roca: cuarzo metarenisca Granulometría: muy fina Tamaño de los granos: 0,62-0,88 mm. Forma de los granos: subangular Selección de los granos: buena Composición: cuarzo monocristalino $85 \%$, cuarzo policristalino $10 \%$, feñdespato $5 \%$

Observaciones: presencia de laminación y contactos crenulados.
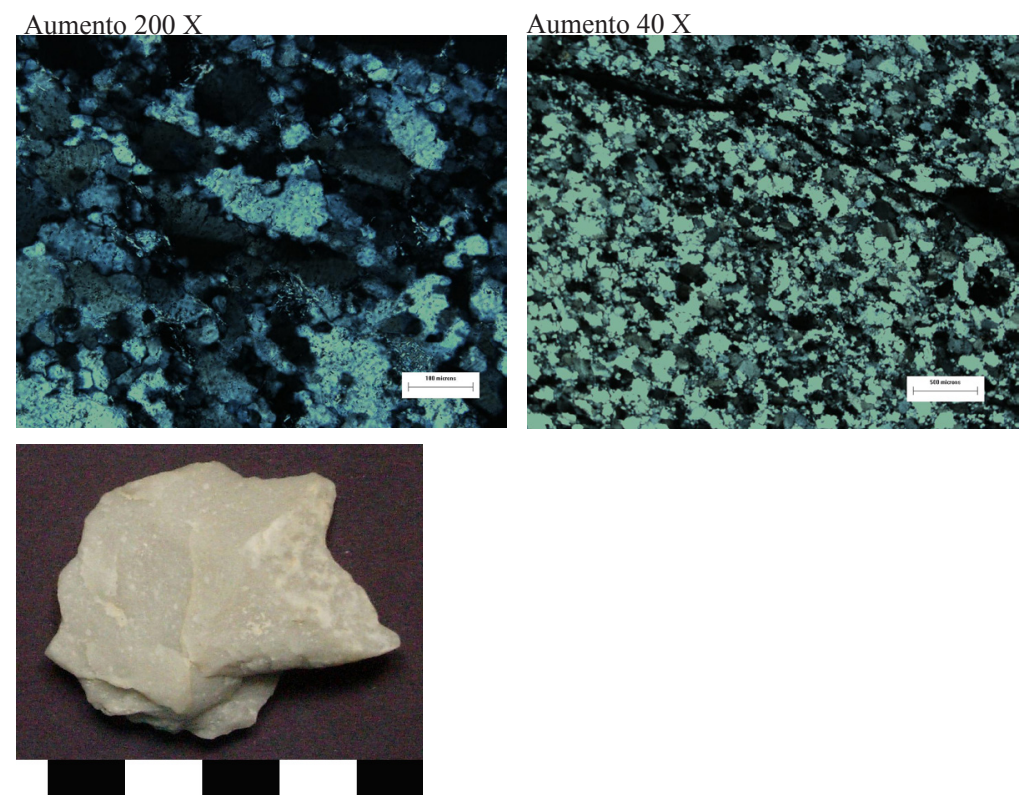

\section{Muestra 8}

Procedencia: Laguna Chasicó sitio 3

Roca: fangolita

Granulometría: muy fina

Tamaño de los granos: menor a $0,88 \mathrm{~mm}$.

Forma de los granos:

Selección de los granos:

Composición:

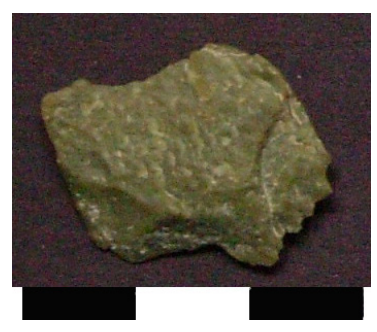

Observaciones: masivo, con pequeños

clastos flotantes de cuarzo.

\section{Muestra 9}

Procedencia: Laguna Chasicó sitio 4 Roca: cuarzo metarenisca

Granulometría: fina

Tamaño de los granos: 0,177-0,250 mm. Forma de los granos: subangular Selección de los granos: buena Composición: cuarzo monocristalino $85 \%$, cuarzo policristalino $10 \%$,

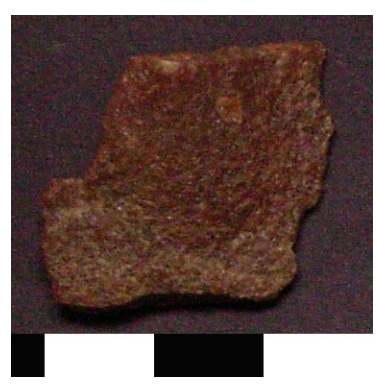

feldespato $5 \%$

Observaciones: presencia de laminación y contactos crenulados 


\section{Muestra 10}

Procedencia: San Martín sitio 1

Roca: ortocuarcita

Granulometría: fina

Tamaño de los granos: 0,177-0,250 mm.

Forma de los granos: subredondeada

Selección de los granos: muy buena

Composición: cuarzo monocristalino 95\%, cuarzo policristalino $5 \%$

Observaciones: presencia de crecimiento secundario.

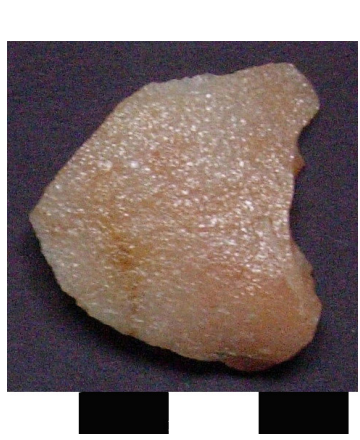

Aumento $40 \mathrm{X}$
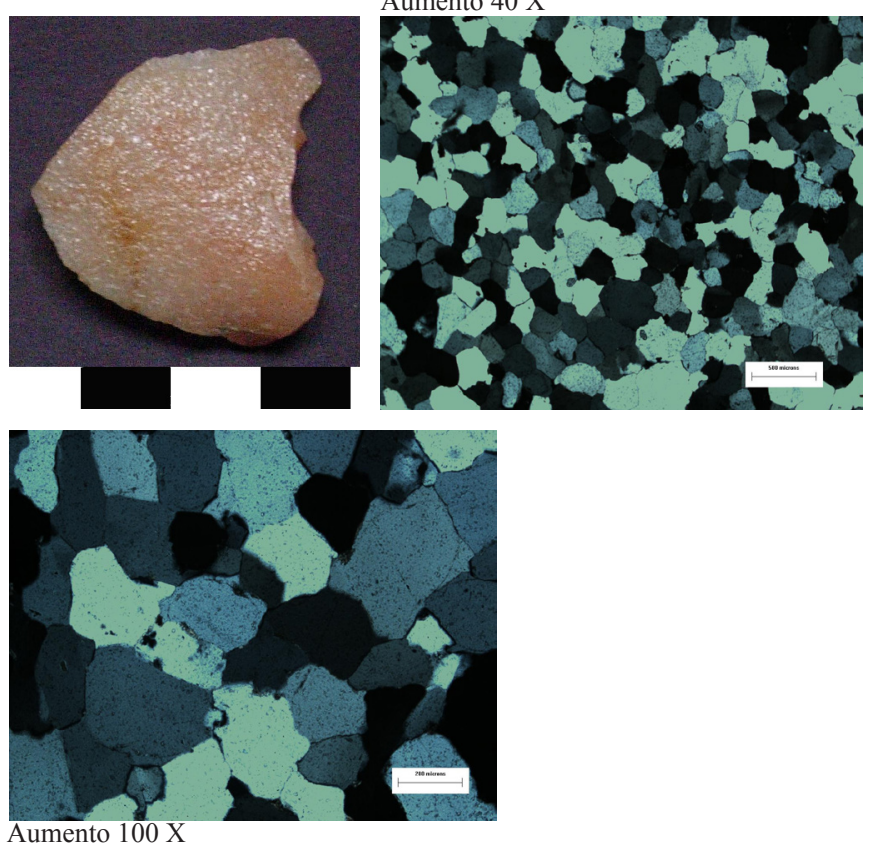

\section{Muestra 11}

Procedencia: Laguna Los Chilenos sitio 2

Roca: cuarzo metarenisca

Granulometría: fina

Tamaño de los granos: 0,177-0,250

Forma de los granos: subangular

Selección de los granos: mala

Composición: cuarzo monocristalino 50\%, cuarzo policristalino $40 \%$, feldespato $10 \%$

Observaciones: presencia de contactos

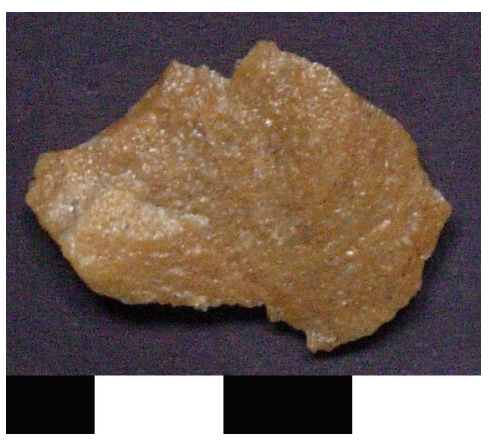

crenulados

\section{Muestra 12}

Procedencia: Laguna Los Chilenos sitio 2

Roca: ortocuarcita

Granulometría: mediana

Tamaño de los granos: 0,250-0,350 mm.

Forma de los granos: subredondeada

Selección de los granos: muy buena

Composición: cuarzo monocristalino 95\%, cuarzo policristalino 5\%

Observaciones: presencia de crecimiento secundario

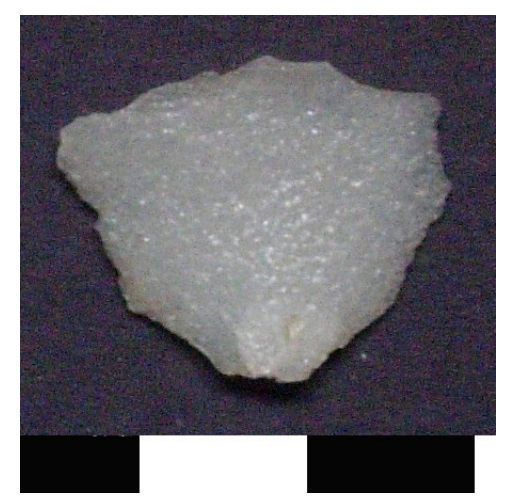




\section{Muestra 13}

Procedencia: La Montaña sitio 1

Roca: arenita cuarzosa

Granulometría: fina

Tamaño de los granos: 0,177-0,250 mm

Forma de los granos: subangular

Selección de los granos: mala

Composición: cuarzo monocristalino 70\%, cuarzo policristalino $20 \%$,

feldespato $5 \%$, chert $5 \%$

Observaciones: presencia de laminación
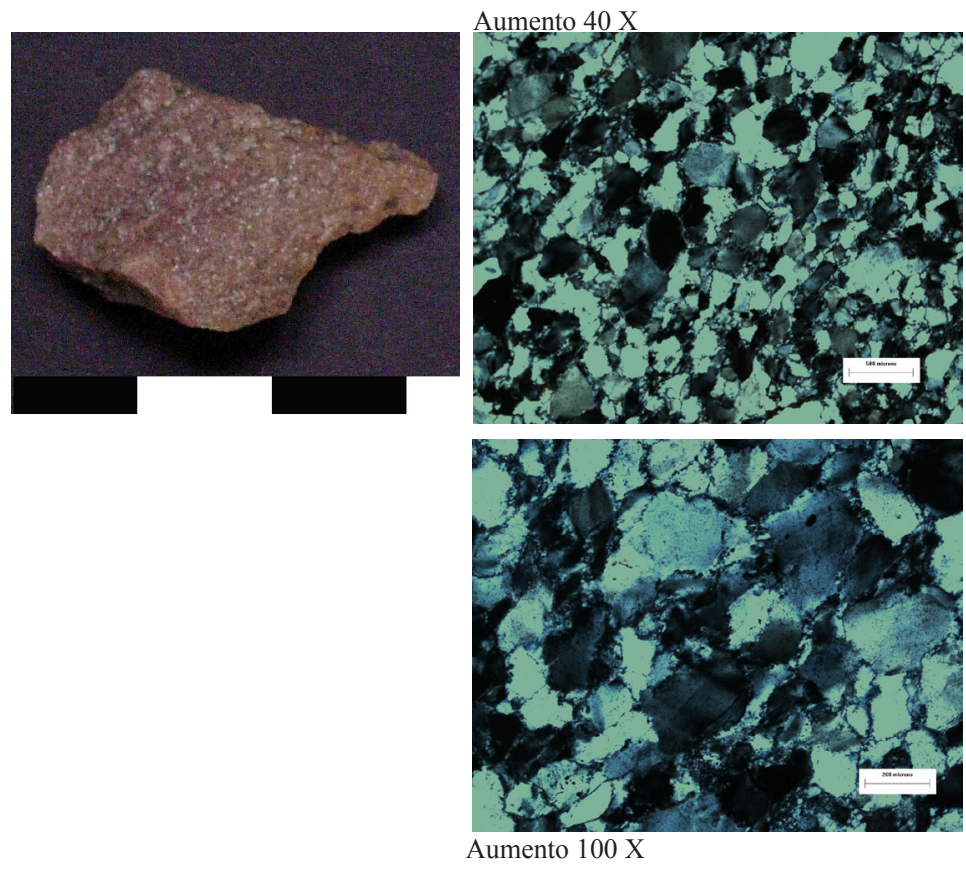

\section{Muestra 14}

Procedencia: La Montaña sitio 1

Roca: ortocuarcita

Granulometría: gruesa

Tamaño de los granos: 0,5-0,710 mm

Forma de los granos: subangular

Selección de los granos: muy buena

Composición: cuarzo monocristalino 95\%,

cuazo policristalino $5 \%$

Observaciones: presencia de crecimiento

secundario
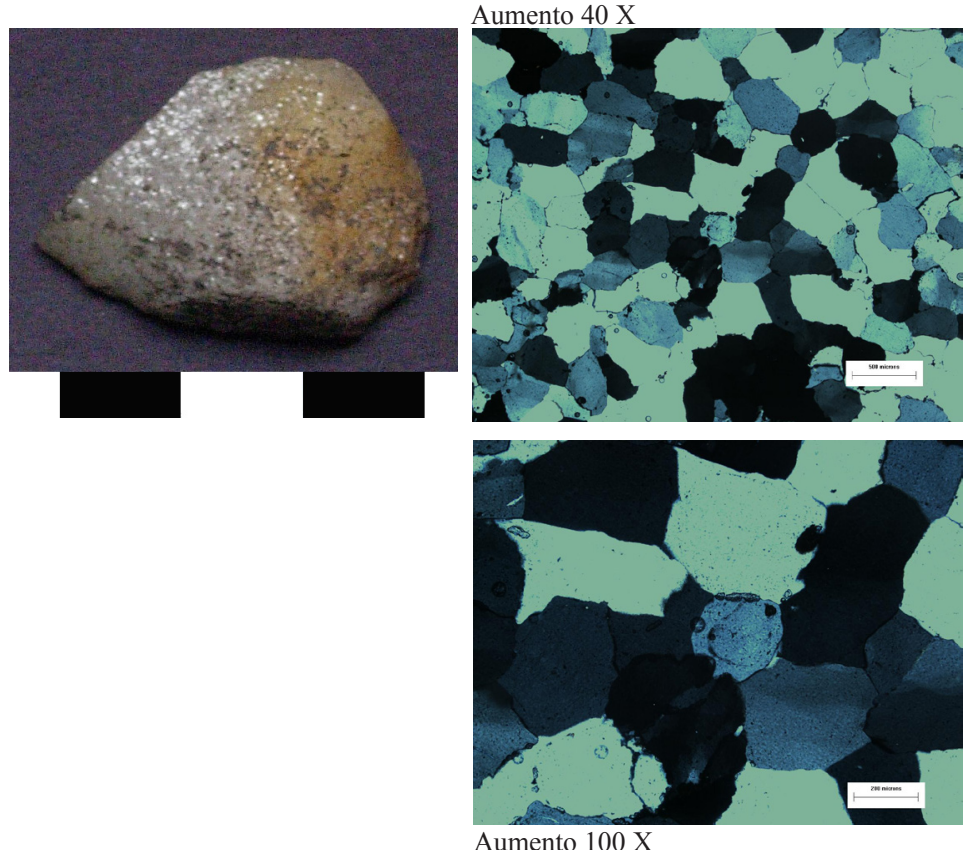

Aumento $100 \mathrm{X}$

\section{Muestra 15}

Procedencia: San Martín sitio 1

Roca: ortocuarcita

Granulometría: fina

Tamaño de los granos: 0,177-0,250 mm.

Forma de los granos: subangular

Selección de los granos: muy buena

Composición: cuarzo monocristalino $95 \%$, cuarzo policristalino 5\%

Observaciones: presencia de crecimiento secundario.

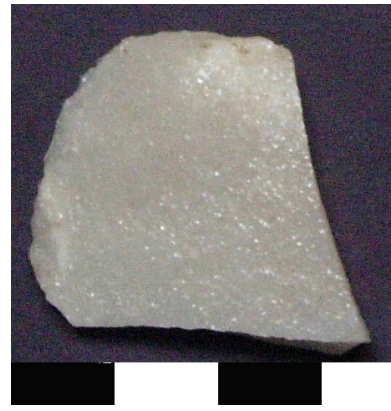




\section{Muestra 16}

Procedencia: San Martín sitio 1 Roca: ortocuarcita

Granulometría: fina

Tamaño de los granos: 0,125$0,177 \mathrm{~mm}$.

Forma de los granos:

subredondeada

Selección de los granos: mala Composición: cuarzo

monocristalino $90 \%$, cuarzo policristalino $10 \%$

Observaciones: presencia de laminación.
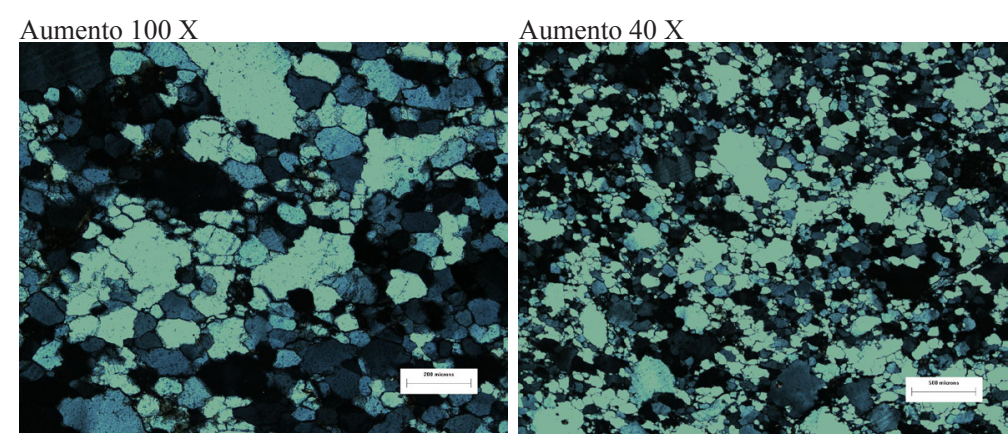

\section{Muestra 17}

Procedencia: Sierras Bayas

Roca: ortocuarcita

Granulometría: mediana

Tamaño de los granos:

Forma de los granos:

subredondeada

Selección de los granos: muy

buena

Composición:

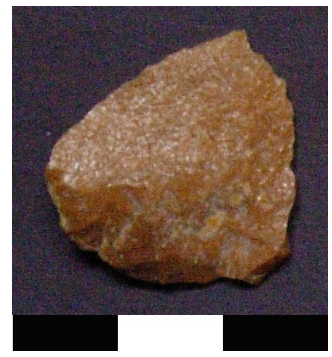

Observaciones: presencia de

puntos triples

\section{Muestra 18}

Procedencia: arroyo Saudade

Roca: arenita cuarzosa

Granulometría: mediana

Tamaño de los granos:

Forma de los granos: subredondeada

Selección de los granos: buena

Composición: presencia de cuarzo

policristalino

Observaciones: presencia de

laminación, contactos crenulados y
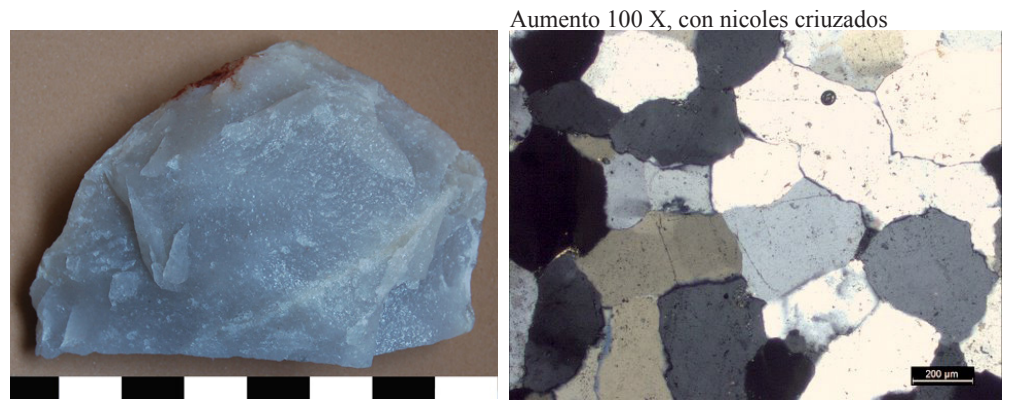

mineral labil alterado a mica 


\section{Muestra 19}

Procedencia: arroyo Chasicó

Roca: ortocuarcita

Granulometría: fina

Tamaño de los granos:

Forma de los granos: subangulare

Selección de los granos: buena

Composición:

Observaciones: presencia de contactos
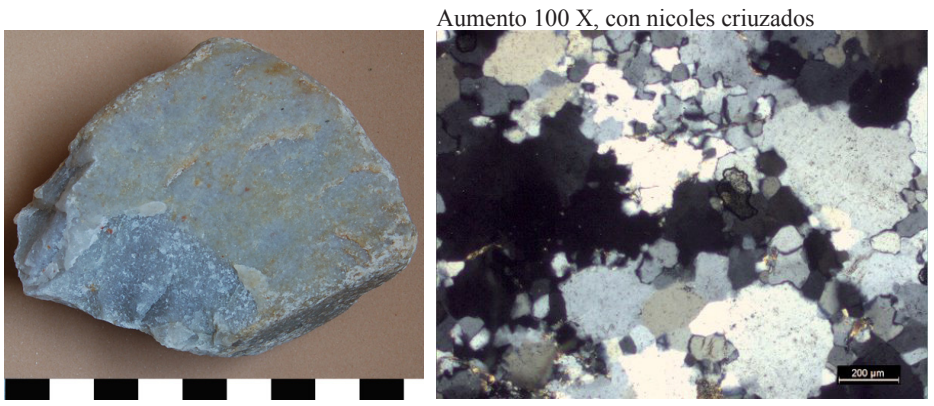

crenulados y mica

\section{Muestra 20}

Procedencia: La Montaña sitio 1

Roca: ortocuarcita

Granulometría: fina

Tamaño de los granos:

Forma de los granos: subredondeada

Selección de los granos: muy buena

Composición:

Observaciones: presencia de
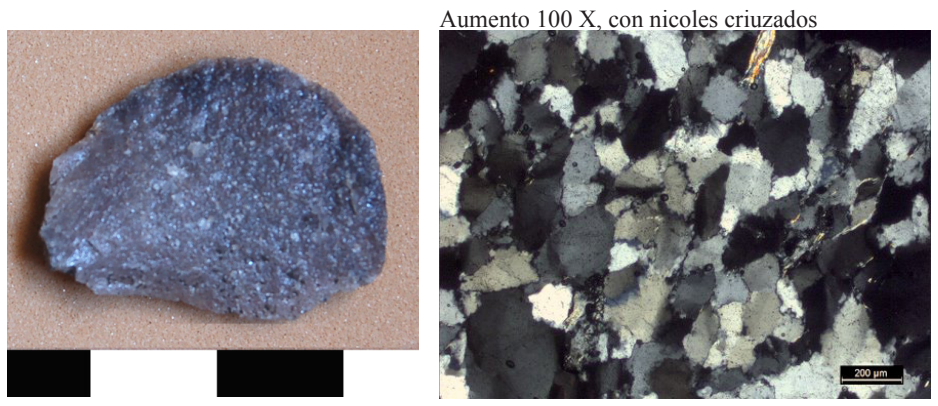

laminación

\section{Muestra 21}

Procedencia: Laguna Chasicó Sitio 8

Roca: arenita cuarzosa

Granulometría: mediana

Tamaño de los granos:

Forma de los granos: subangular

Selección de los granos: muy buena

Composición:

Observaciones: evidencias de foliación
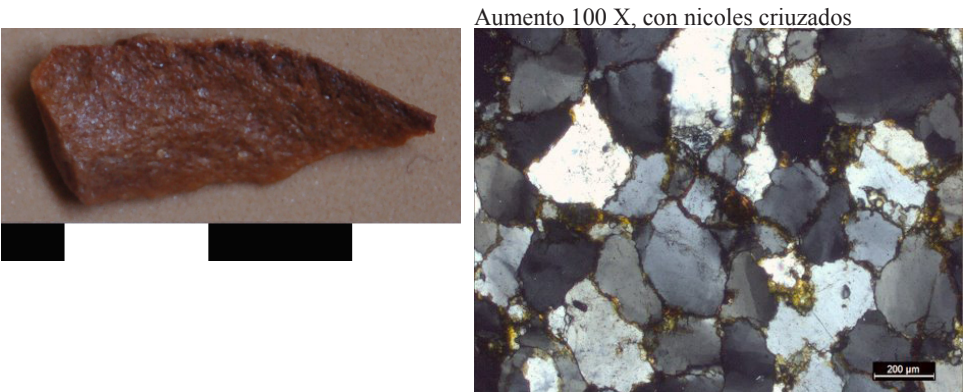

\section{Muestra 22}

Procedencia: La Montaña sitio 1

Roca: ortocuarcita

Granulometría: mediana

Tamaño de los granos:

Forma de los granos: subredondeada

Selección de los granos: muy buena

Composición: presencia de cuarzo

policristalino

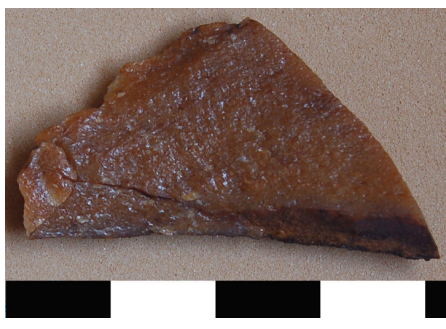

Aumento $100 \mathrm{X}$, con nicoles criuzados

Observaciones: presencia de contactos

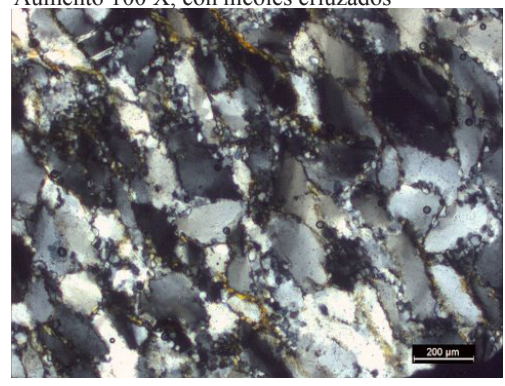

crenulados 


\section{Muestra 23}

Procedencia: arroyo Saudade

Roca: ortocuarcita

Granulometría: gruesa

Tamaño de los granos:

Forma de los granos: subangular

Selección de los granos: muy buena

Composición:

Observaciones: presencia de foliación
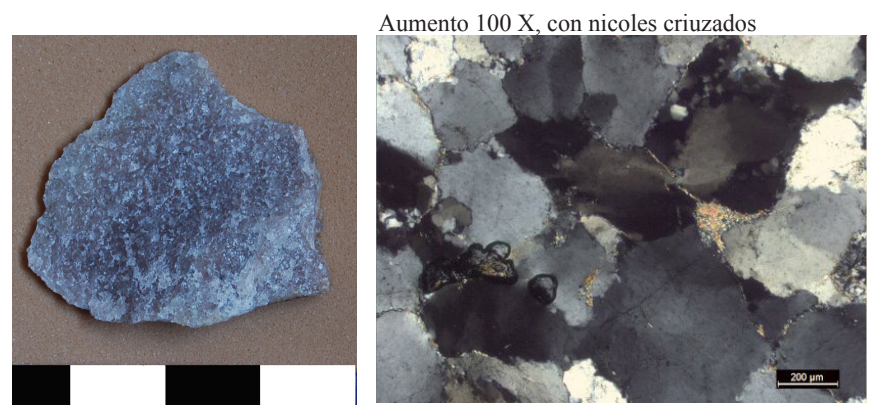

\section{Muestra 24}

Procedencia: La Montaña Sitio 1

Roca: ortocuarcita

Granulometría: mediana

Tamaño de los granos:

Forma de los granos:

subredondeada

Selección de los granos: muy buena

Composición:

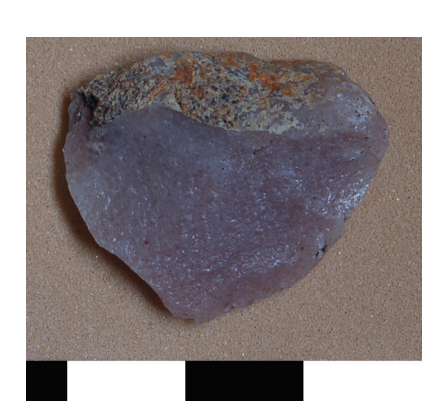

Aumento $100 \mathrm{X}$, con nicoles criuzados

Observaciones: presencia de

contactos crenulados

\section{Muestra 25}

Procedencia: arroyo Chasicó

Roca: ortocuarcita

Granulometría: mediana

Tamaño de los granos:

Forma de los granos: subredondeada

Selección de los granos: buena

Composición:

Observaciones: presencia de contactos
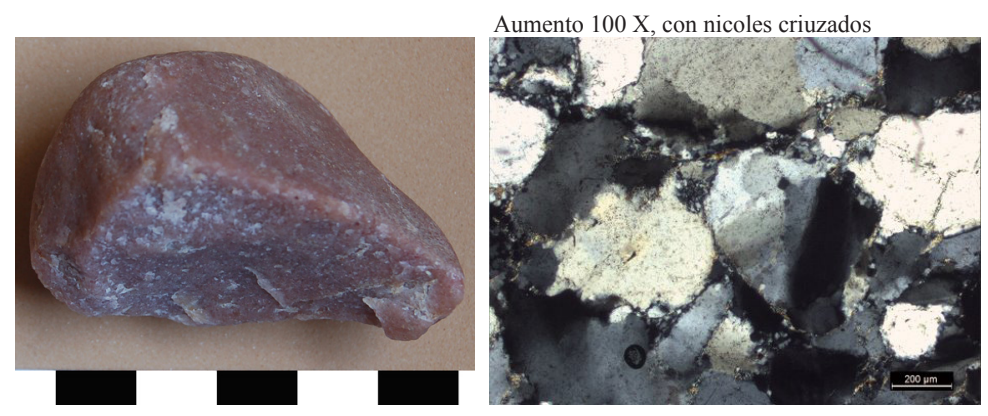

crenulados y mica como coating (i.e.

envolviendo a algunos de los granos)

\section{Muestra 26}

Procedencia: Localidad A. Saudade (HA)

Roca: ortocuarcita

Granulometría: mediana

Tamaño de los granos:

Forma de los granos: subredondeada

Selección de los granos: buena

Composición: presencia de cuarzo

policristalino

Observaciones: presencia de contactos crenulados
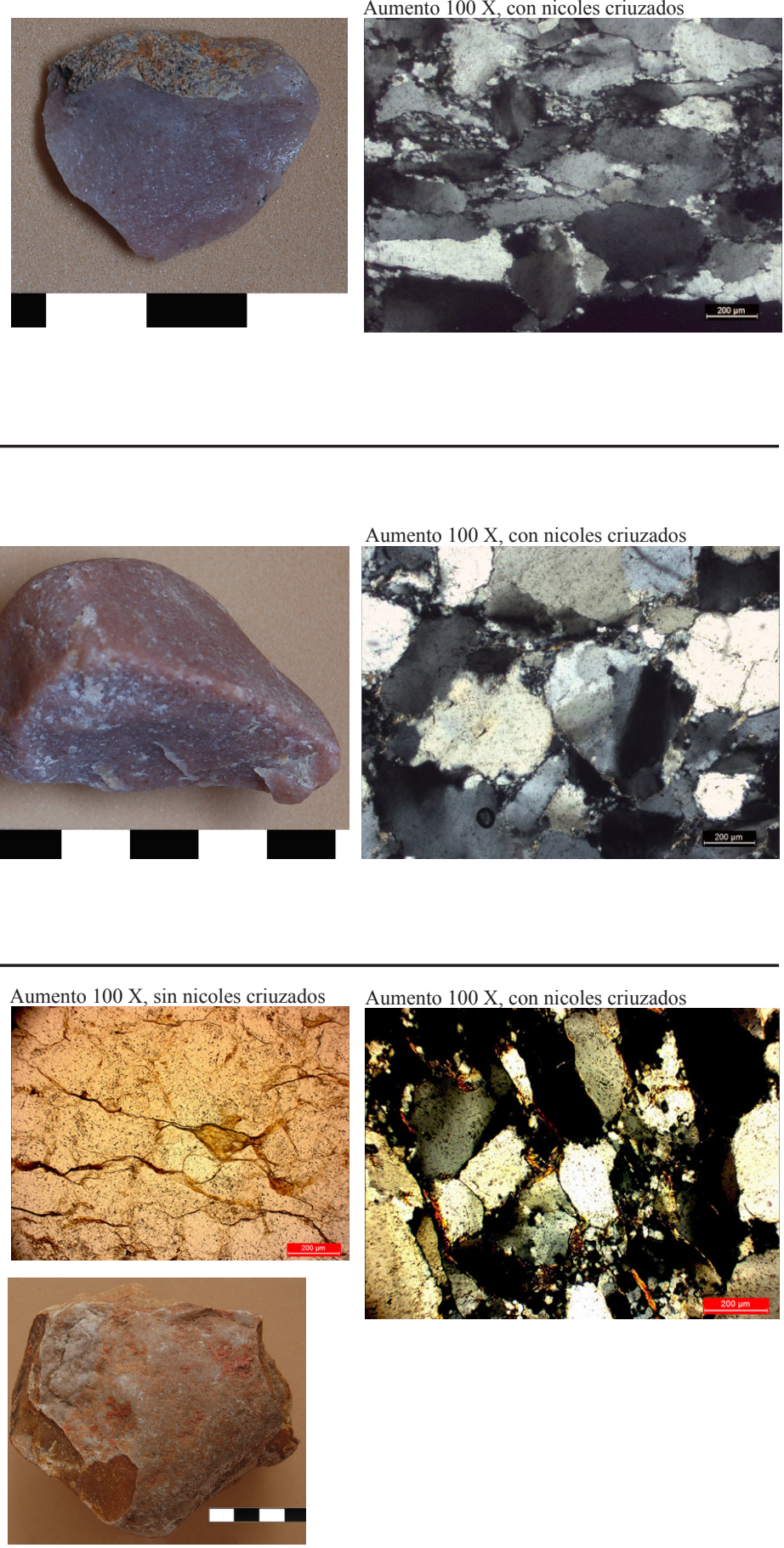


\section{Muestra 27}

Procedencia: arroyo Saudade M 1

Roca: arenita cuarzosa

Granulometría: gruesa

Tamaño de los granos:

Forma de los granos: subangular

Selección de los granos: muy buena

Composición: presencia de cuarzo

policristalino
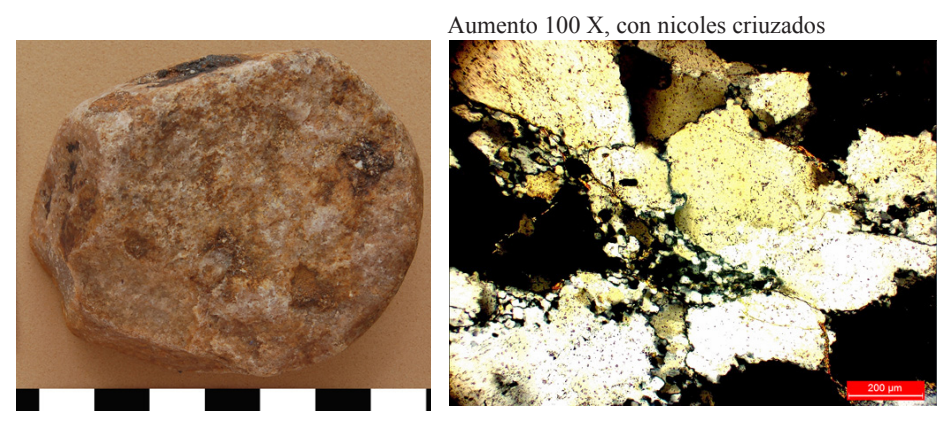

Observaciones: presencia de mica

\section{Muestra 28}

Procedencia: Arroyo Saudade sitio 1

Roca: arenita cuarzosa

Granulometría: gruesa

Tamaño de los granos:

Forma de los granos: subredondeada Selección de los granos: muy buena

Composición: presencia de cuazo policristalino

Observaciones: mucha hematita intersticial como cemento (con luz polarizada sin cruzar nicoles). Con nicoles cruzados se observa crecimiento secundario, producto de temperaturas producidas por un soterramiento importante.
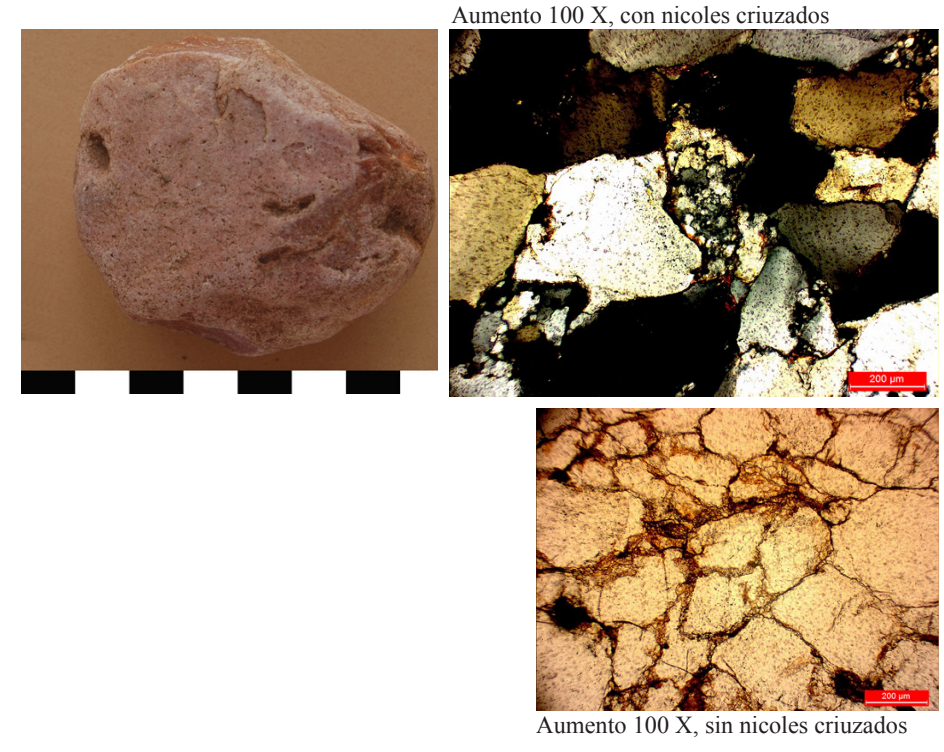

\section{Muestra 29}

Procedencia: Localidad A.

Saudade M 1

Roca: arenita cuarzosa

Granulometría: fina

Tamaño de los granos:

Forma de los granos:

subredondeada

Selección de los granos: muy buena

Composición: presencia de

cuarzo policristalino

Observaciones: presencia

demica, cementación hematítica

que avanza por los planos
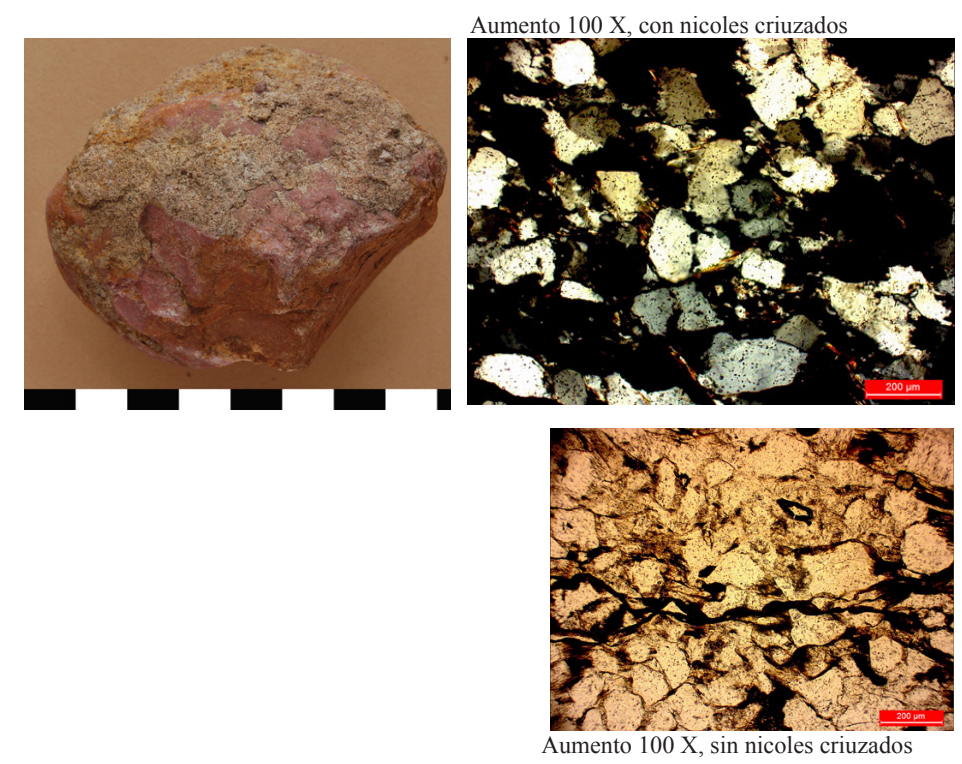


\section{Muestra 30}

Procedencia: Arroyo Saudade sitio 1 Roca: arenita cuarzosa

Granulometría: gruesa

Tamaño de los granos:

Forma de los granos: subredondeada Selección de los granos: mala

Composición:

Observaciones: presencia de mica, poco cemento con mica instersticial,

matrix de arcilla, coating de hematita
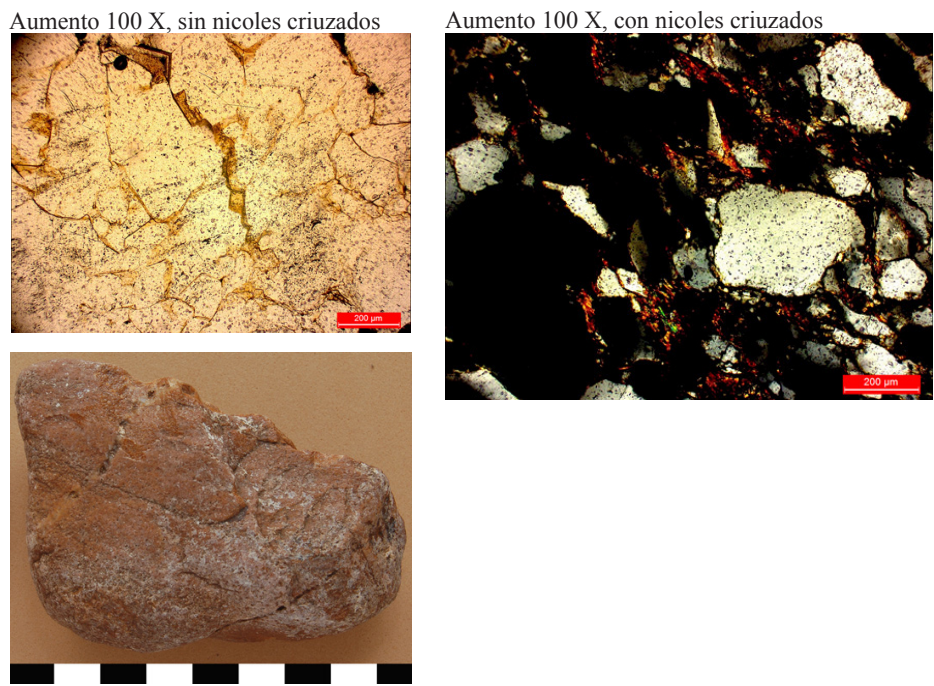

\section{Muestra 31}

Procedencia: Arroyo Saudade sitio 2 Roca: arenita cuarzosa Granulometría: gruesa Tamaño de los granos:

Forma de los granos: subredondeada Selección de los granos: buena Composición: presencia de cuarzo policristalino

Observaciones: opacos intersticiales (hematita o magnetita). Contactos crenulados.
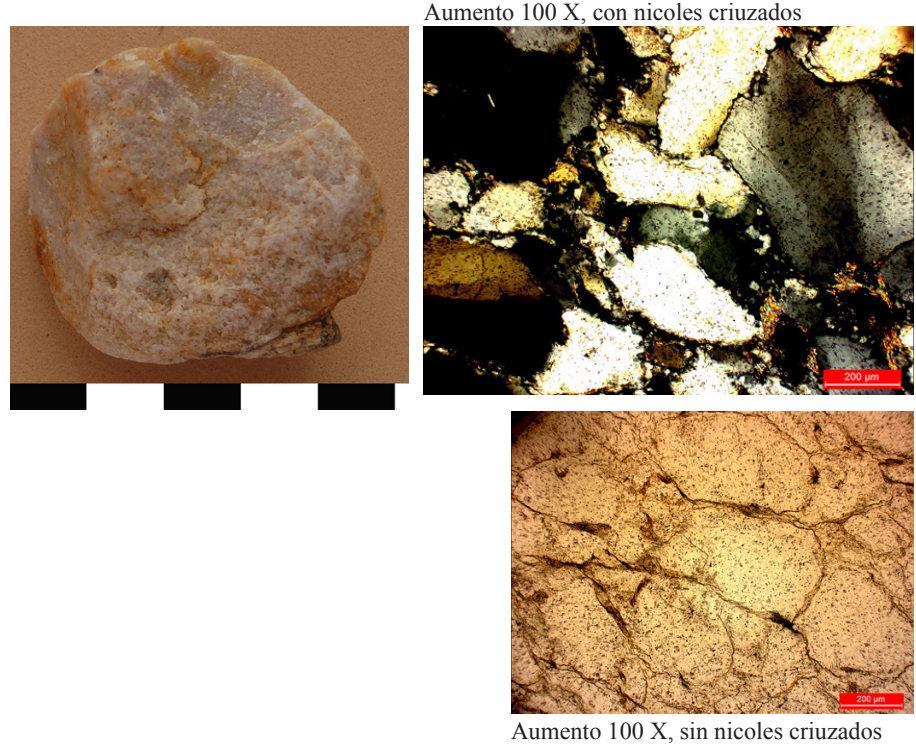

\section{Muestra 32}

Procedencia: Arroyo Saudade Sitio 2 Roca: arenita cuarzosa

Granulometría: muy gruesa

Tamaño de los granos:

Forma de los granos: subredondeada Selección de los granos: buena

Composición: presencia de cuarzo policristalino

Observaciones: presencia de mica, cemento hematitico que se mete por los intersticios.
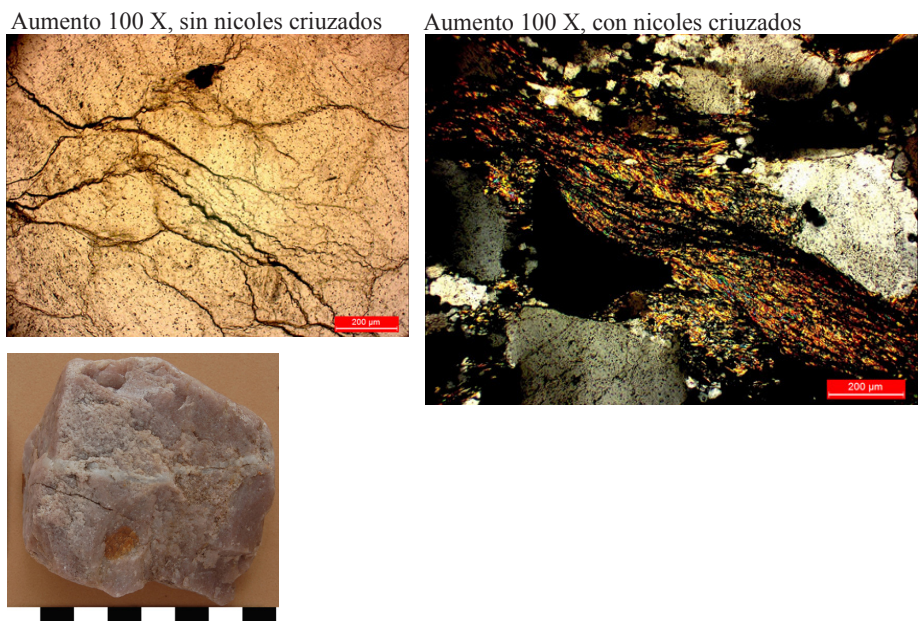


\section{Muestra 33}

Procedencia: Arroyo Saudade Sitio 1 Roca: arenita cuarzosa

Granulometría: gruesa

Tamaño de los granos:

Forma de los granos: subredondeada

Selección de los granos: mala

Composición: presencia de cuarzo

policristalino

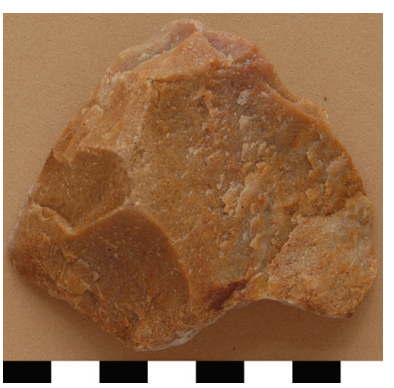

Aumento $100 \mathrm{X}$, con nicoles criuzados

Observaciones: presencia de sericita, clastos con relleno de cemento hematítico.

Clastos deformados, apretados y rotos.
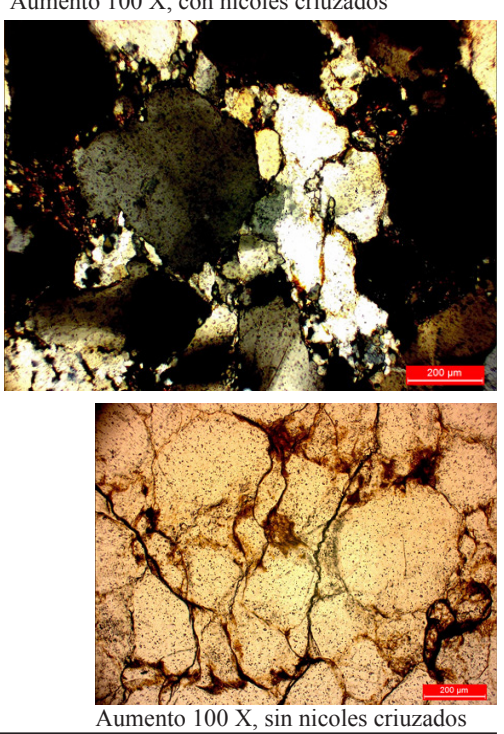

\section{Muestra 34}

Procedencia: Arroyo Saudade Sitio 1 Roca: arenita cuarzosa

Granulometría: gruesa

Tamaño de los granos:

Forma de los granos: subredondeada Selección de los granos: buena

Composición: presencia policristalino Observaciones: clastos deformados con

Aumento $100 \mathrm{X}$, con nicoles criuzados cemento intersticial, presencia de sericita y

mica
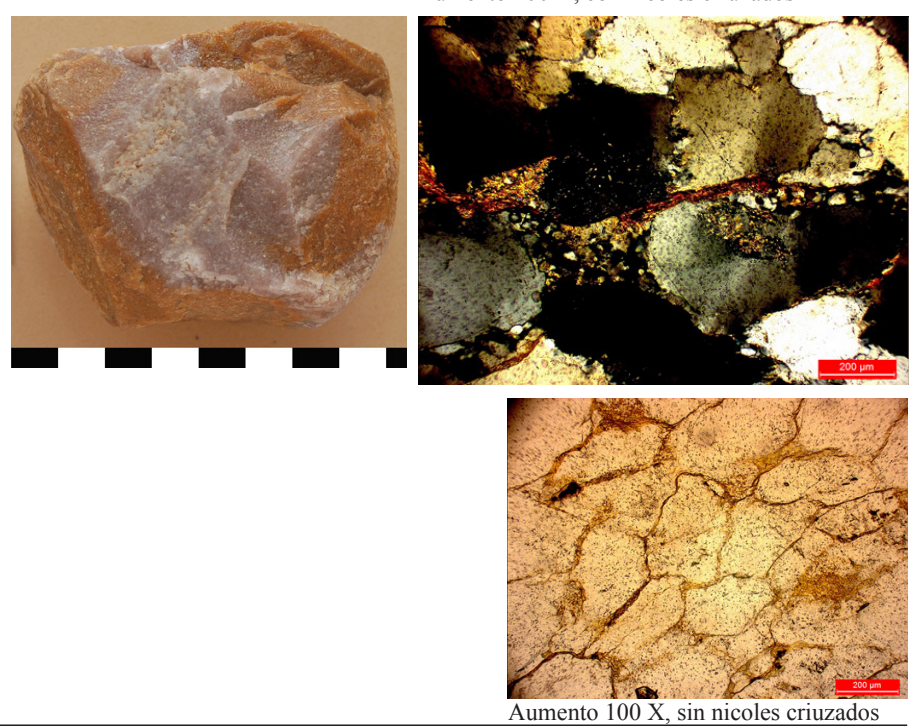

\section{Muestra 35}

Procedencia: Arroyo Saudade Sitio 2 Roca: arenita cuarzosa

Granulometría: gruesa

Tamaño de los granos:

Forma de los granos: subangular

Selección de los granos: buena

Composición: presencia de cuarzo policristalino

Observaciones: Arenita cuarzosa con clastos líticos de otra composición. Presencia secundaria de mica.
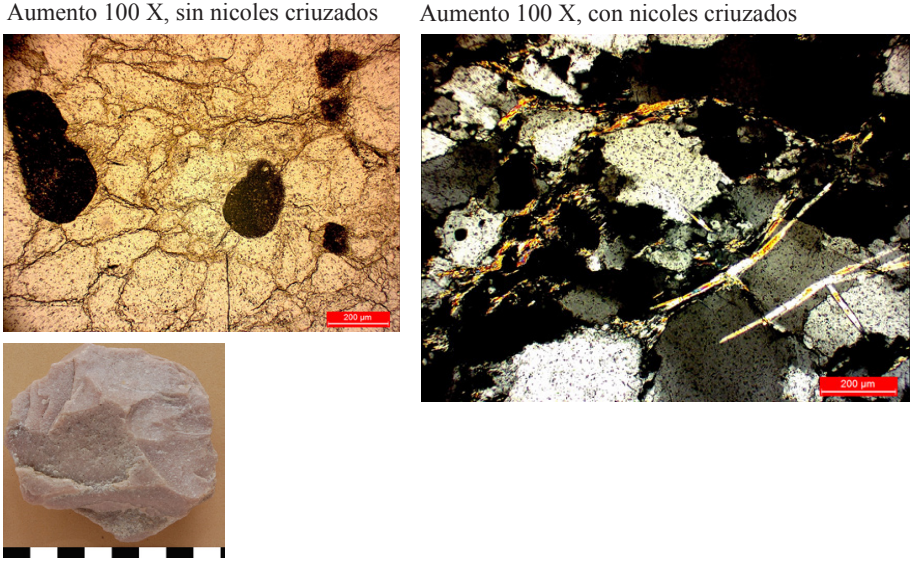


\section{Muestra 36}

Procedencia: Localidad A. Saudade M 2

Roca: ortocuarcita

Granulometría: gruesa

Tamaño de los granos:

Forma de los granos: subangular

Selección de los granos: buena

Composición:

Observaciones: Presencia de contactos crenulados, poco cemento hematitico y crecimiento secundario
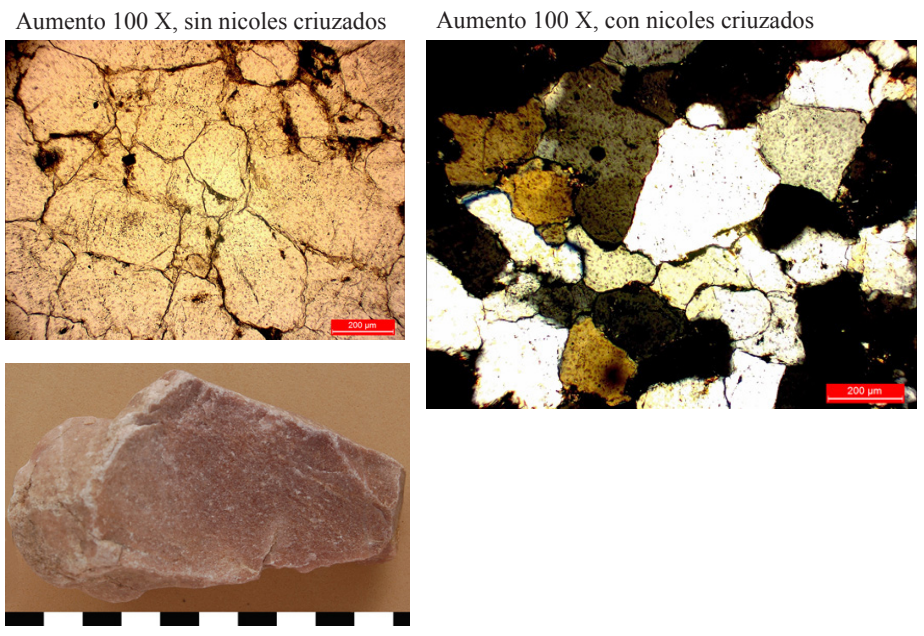

\section{Muestra 37}

Procedencia: Localidad A. Saudade HA

Roca: arenita cuarzosa

Granulometría: muy gruesa

Tamaño de los granos:

Forma de los granos: subangular

Selección de los granos: buena

Composición: presencia de cuarzo

policristalino

Observaciones: presencia de cemento

hematitico y mica intersticial
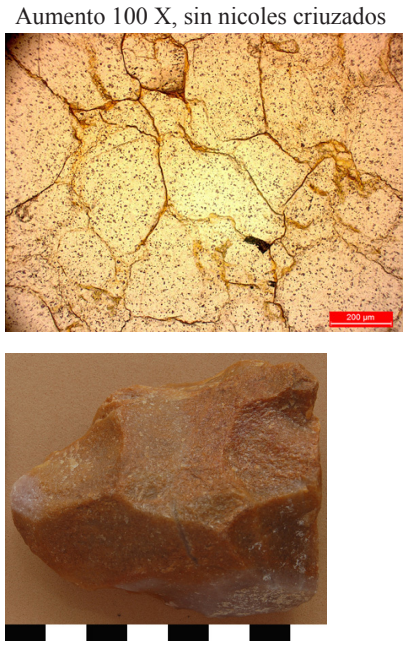

Aumento $100 \mathrm{X}$, con nicoles criuzados

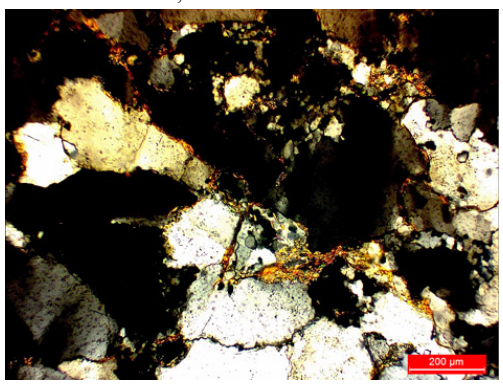

\section{Muestra 38}

Procedencia: Localidad A. Saudade M 2

Roca: arenita cuarzosa

Granulometría: gruesa

Tamaño de los granos:

Forma de los granos: subangular

Selección de los granos: buena

Composición: presencia de cuarzo policristalino

Observaciones: presencia de hierro

intersticial, mica y líticos alterados.
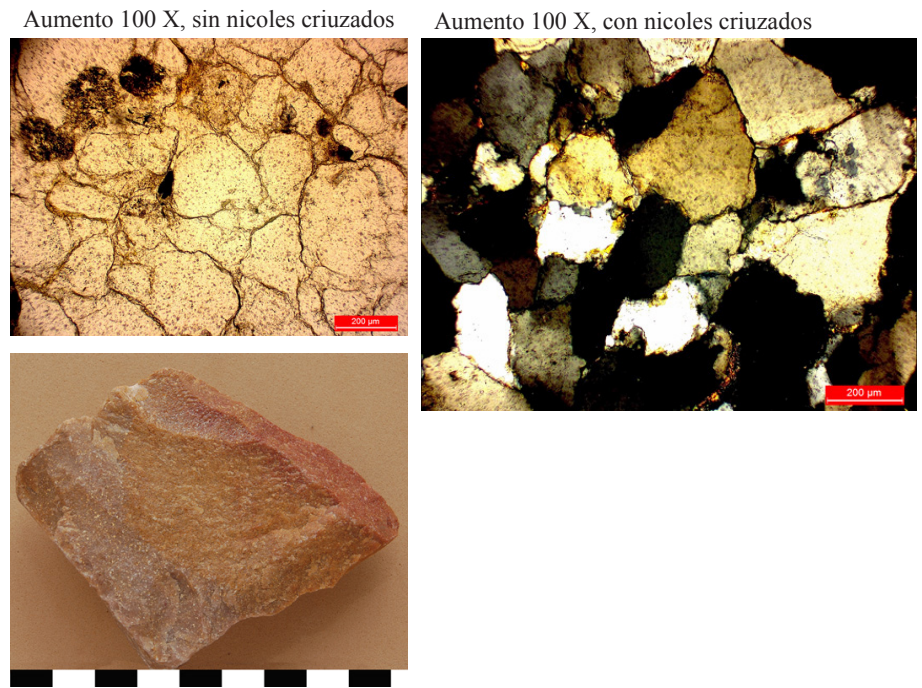
